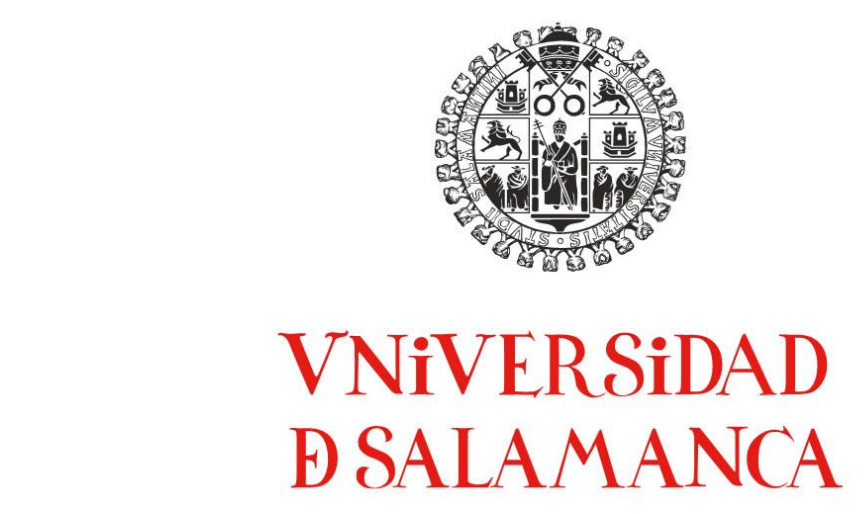

FACULTAD DE EDUCACIÓN

DEPARTAMENTO DE DIDÁCTICA, ORGANIZACIÓN Y MÉTODOS DE INVESTIGACIÓN

Área de Métodos de Investigación y Diagnóstico en Educación

TESIS DOCTORAL

\title{
Evaluación y Formación en Competencias \\ Informacionales en la Educación Secundaria Obligatoria
}

Autor: $\quad$ Fernando Martínez Abad

Directora: María José Rodríguez Conde

Salamanca, 2013 

VNIVERSIDAD

DSALAMANCA

\author{
Departamento de Didáctica, Organización y Métodos de Investigación \\ Área de Métodos de Investigación y Diagnóstico en Educación
}

Dra. Ma José Rodríguez Conde, Profesora Titular de Universidad de Métodos de Investigación y Diagnóstico en Educación, en el Departamento de Didáctica, Organización y Métodos de Investigación de la Universidad de Salamanca, en calidad de directora del trabajo de Tesis Doctoral titulado "Evaluación y Formación en Competencias Informacionales en la Educación Secundaria Obligatoria”, realizado por Fernando Martínez Abad,

HACE CONSTAR que dicho trabajo alcanza, bajo su punto de vista, todos los requisitos científicos y formales para ser presentado y defendido públicamente. La investigación indaga sobre un problema relevante en investigación educativa y presenta un grado alto de innovación. El proceso metodológico seleccionado resulta adecuado a los objetivos e hipótesis planteadas y la discusión es completa y relacionada con una actualizada fundamentación teórica. Presenta una contextualización adecuada, un riguroso procedimiento de obtención y análisis de datos y extracción de conclusiones valiosas para el área de conocimiento en el que está inmerso.

Por todo ello, manifiesto mi acuerdo para que sea autorizada la presentación y defensa del trabajo referido.

En Salamanca, a 01 de febrero de 2012

Dra. Mํㅡ José Rodríguez Conde

Directora de la Tesis 

A Inma, que parece que olvido, pero siempre está en mi cabeza. 



\section{AGRADECIMIENTOS}

Esta Tesis Doctoral sólo ha sido posible gracias al apoyo, en muchos casos incondicional y anónimo, de muchas personas que no me gustaría olvidar. A pesar de que en unas pocas líneas no seré capaz de expresar toda la gratitud que siento, cabe dejar claro que, desde la primera hasta la última persona aquí citada, ha sido valiosa en la consecución del resultado final obtenido. Sin el salvavidas de cada una de ellas este largo periodo, que se inició allá por 2009, hubiera sido más tedioso, lleno de dificultades y, probablemente, insalvable.

En primer lugar, como no puede ser de otra manera, quiero comenzar recordando a Inma, la mujer más importante de mi vida. Sin tu humanidad, generosidad y coraje incalculables no habría sido posible llegar a este punto. Gracias por quererme, acompañarme, entenderme, soportarme y, sobre todo, hacerme Persona.

Quisiera agradecer muy especialmente a mi familia más cercana su interés y cariño. A pesar de que la mayoría ha estado lejos de mí durante esta etapa, he sentido su apoyo a lo largo de todo el camino. En concreto, a mi hermano Mario, que ha estado presente y me ha aguantado en parte del camino; a mi hermano Félix Ángel, que ha sido modelo durante muchos años, y ha estado siempre cuando le he necesitado; y no me puedo olvidar de mi abuelo Teófilo, vigía bondadoso y maestro paciente, perdido en el transcurrir de estos años.

A María José Rodríguez Conde, directora de esta Tesis Doctoral y, más que eso, madre académica desde que comencé mi andadura en la Universidad. Sin tus consejos, capacidad de coordinación, dirección y organización, y orientación distante pero sistemática, no hubiera sido posible que esta empresa hubiera llegado a buen puerto. Gracias por una guía que da pie al trabajo colaborativo pero autónomo, y que me ha posibilitado desarrollarme libremente, aprendiendo de los demás y de los propios errores. Estaré siempre agradecido por haberme dado esta oportunidad, posibilitando un ansiado futuro profesional, y, sobre todo, por haberme acogido no sólo a nivel profesional, sino a todos los niveles posibles.

A Juan Pablo, amigo y acompañante incansable desde el primer día que pisé Salamanca. El destino nos llevó por el mismo camino durante estos años, en los que sus sabios consejos, tanto académicos como personales, han sido vitales en muchas ocasiones. Una vez he llegado a este oasis, en el que él está también a punto de 
recalar, deseo que el destino siga manteniéndonos juntos en el recorrido hasta el próximo del horizonte.

A mis compañeros del Grupo de Evaluación Educativa y Orientación, cuyo apoyo y estima he sentido durante las diversas etapas de realización de la Tesis. En algunos casos, más que compañeros, se pueden considerar amigos: A Susana, por su esfuerzo y dedicación incondicional, su alegría y por hacerme sentir valorado en todo momento. A Juanfran, por su inteligencia emocional en los peores momentos y contagiar una visión positiva de la realidad con su percepción del mundo. A Esperanza, por sus consejos y su generoso esfuerzo, que nos hace más fácil la vida a todos los compañeros.

A todos los Becarios del Departamento de Didáctica, Organización y Métodos de Investigación, por mantener un ambiente cooperativo más que competitivo, a pesar de las difíciles circunstancias laborales. A Jorge Martín Domínguez, por su sinceridad y nobleza, y por luchar día a día por mejorar nuestras condiciones. A Adriana, por su capacidad, alegría, honestidad y generosidad en todos los aspectos, con el deseo de que pueda continuar trabajando con ella en el futuro. A Eva, por su permanente y altruista predisposición para ayudar ante cualquier dificultad. A Carlos, por su optimismo y esfuerzo desinteresado en mantener redes de trabajo colaborativo, compartiendo en todo momento su caudal de ideas desbordante. A Patricia, por su optimismo vital y alegría constante, que hacen más llevadero el día a día. A Vanesa, por escucharme y aguantarme día a día. A Jorge Martín de Arriba porque, aunque pueda no parecerlo, siempre ha estado disponible cuando se le ha necesitado.

A Begoña Orgaz, cuyos consejos desinteresados sobre la aplicación de ciertas técnicas estadísticas han propiciado los resultados obtenidos. Sin su ayuda la Tesis hubiera sido significativamente diferente.

Gracias también a todos los compañeros del Departamento de Didáctica, Organización y Métodos de Investigación de la Universidad de Salamanca, desde la Dirección hasta la Secretaría, porque me han acogido e integrado en la vida del Departamento desde el primer día, permitiéndome aprender con ellos y de ellos. Su apoyo, disposición para ayudarme y aprecio me han facilitado el trabajo durante estos difíciles años. Especialmente quiero acordarme de Javier Tejedor, Ana García-Valcárcel, Ángel Domingo, Anunciación Quintero, Elena Ramírez, María Clemente, Azucena Hernández, Mạ Cruz Sánchez, Teófilo Ausín y Luis González, por su calurosa acogida y apoyo constante. 
Por último, no me puedo olvidar de las Instituciones que, gracias al apoyo prestado, han posibitado la realización de la Tesis Doctoral. En primer lugar, quiero agradecer al Instituto Universitario de Ciencias de la Educación y la Facultad de Educación haberme acogido entre sus históricos muros. Por otro lado, tanto la Consejería de Educación de la Junta de Castilla y León, como el Ministerio de Educación del Gobierno de España han sido esenciales durante esta etapa al financiar sendas becas de investigación para la realización de esta Tesis Doctoral. Por último, mostrar mi agardecimiento a Salamanca y a la Universidad de Salamanca, que me han abierto las puertas y han ido configurando, desde mi llegada, una identidad profesional que promueve una identidad personal plenamente satisfactoria.

A todos y todas mi agradecimiento más sentido.

Fernando Martínez Abad 



\section{Índice de contenidos}

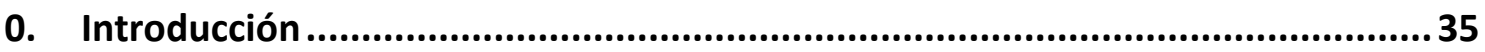

1. De la sociedad de la información a la sociedad del conocimiento ...................... 43

1.1. Origen de una nueva sociedad, la sociedad de la información ................................. 47

1.1.1. La revolución informacional como detonante de la sociedad de la información .. 47

1.1.2. Las TIC: Elemento reactivo de la revolución informacional .................................50

1.2. Pilares e implicaciones de la sociedad de la información ........................................... 53

1.2.1. Características principales de la sociedad de la información .................................54

1.2.2. Problemática de la sociedad de la información......................................................62 62

1.3. Las competencias informacionales como puente entre la sociedad de la información

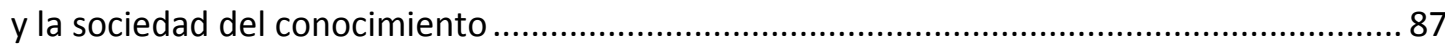

1.4. El aprendizaje en la sociedad de la información: buscando la sociedad del

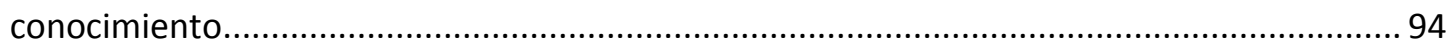

1.4.1. Las TIC como recurso educativo inherente a la sociedad de la información .......... 95

1.4.2. El nuevo rol del profesor y del alumno para una nueva escuela .......................... 100

1.4.3. Competencias clave en la sociedad del conocimiento ........................................ 104

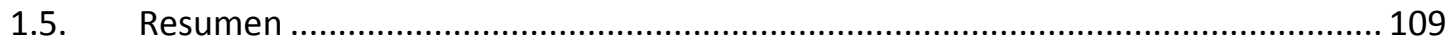

2. La multialfabetización en el desarrollo de competencias informacionales........113

2.1. Influencia de los cambios sociales en el concepto de alfabetización ....................... 114

2.2. Evolución del concepto alfabetización desde su nacimiento hasta la actualidad ... 122

2.3. El concepto de multialfabetización. La multialfabetización como marco integrador

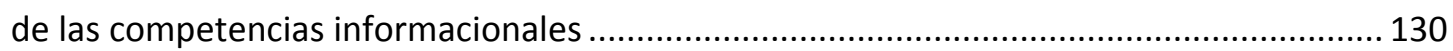

2.4. La formación del profesorado en un contexto multialfabetizado ............................ 137

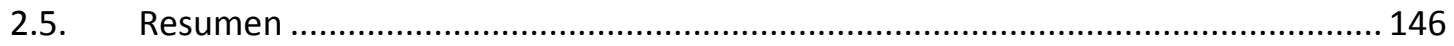

3. La formación basada en competencias: las competencias informacionales ..... 151

3.1. Aspectos básicos sobre las competencias …........................................................ 153

3.1.1. Análisis socio-histórico del concepto competencias .......................................... 154

3.1.2. Aproximación al concepto de competencias: definiciones de competencia........ 159 
3.1.3. Análisis crítico de la formación basada en competencias desde una perspectiva

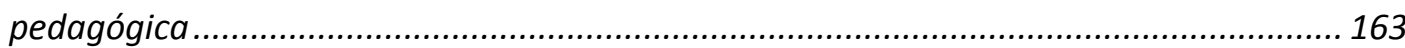

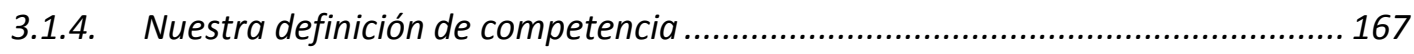

3.2. El modelo de formación basada en competencias .............................................. 171

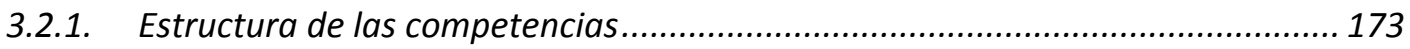

3.2.2. El aprendizaje en un modelo basado en competencias..................................... 183

3.3. Las competencias informacionales. Competencias básicas para la sociedad del conocimiento.

3.3.1. Las competencias informacionales, nuevas competencias en la sociedad contemporánea

3.3.2. Aspectos básicos sobre las competencias informacionales................................ 194

3.3.3. Definición de competencias informacionales .................................................... 198

3.3.4. Organización de las competencias informacionales. Dimensiones, modelos y normas

3.3.4.1 Desempeños específicos inmersos en las competencias informacionales 215

3.3.4.2 Modelo para la enseñanza de las competencias informacionales

3.3.5. La implementación y evaluación de las competencias informacionales en programas educativos

3.4. Resumen

4. ESTUDIO I: Evaluación de las competencias informacionales en estudiantes de educación secundaria (14-16 años) y en futuros profesores de ESO

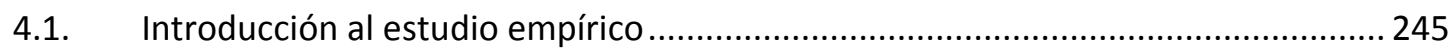

4.2. Metodología de la investigación. Estudio I ................................................................ 251

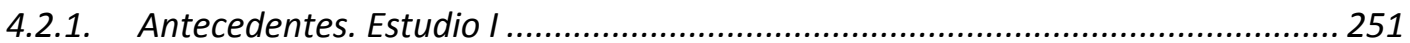

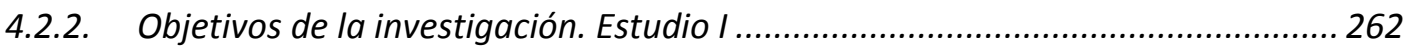

4.2.3. Diseño de la investigación. Estudio I ............................................................. 265

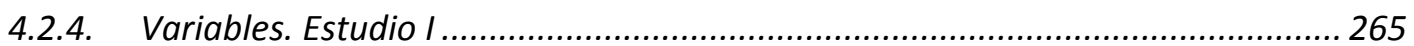

4.2.5. Instrumento: diseño y análisis psicométrico. Estudio I..................................... 271

4.2.5.1 Cuestionario para alumnos de Educación Secundaria Obligatoria............. 272

4.2.5.2 Cuestionario para futuros profesores de Educación Secundaria ................ 296

4.2.6. Población y muestra. Estudio I .......................................................................... 317

4.2.6.1 Muestreo para alumnos de Educación Secundaria ..................................... 318

4.2.6.2 Muestreo para futuros profesores de Educación Secundaria ...................... 321

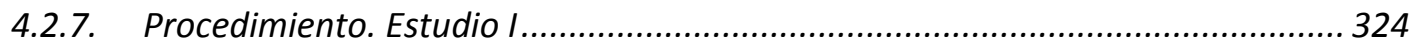

4.2.7.1 Aplicación de la encuesta entre el alumnado de educación secundaria.... 324 
4.2.7.2 Aplicación de la encuesta entre el futuro profesorado de educación secundaria

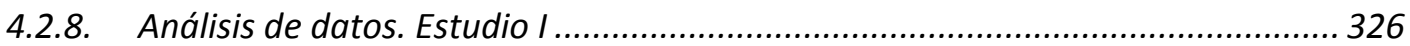

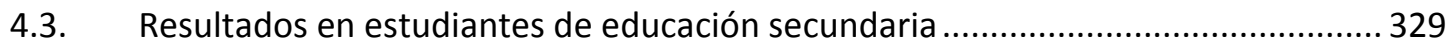

4.3.1. Información demográfica en estudiantes....................................................... 329

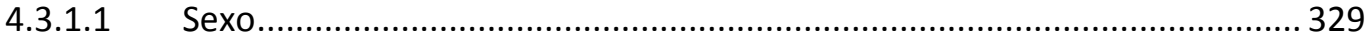

4.3.1.2 Año de nacimiento..................................................................................... 330

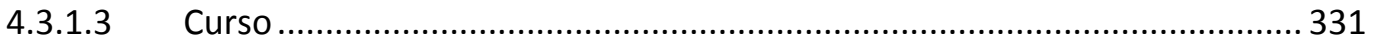

4.3.1.4 Nivel de estudios de los padres .............................................................. 332

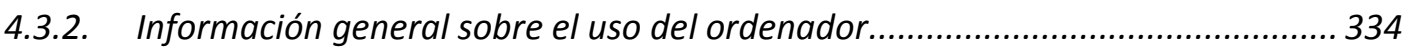

4.3.2.1 Infraestructura: Existencia de ordenadores en el hogar ........................... 334

4.3.2.2 Frecuencia en el manejo general del ordenador ......................................... 336

4.3.3. Empleo de herramientas informáticas en estudiantes .......................................338

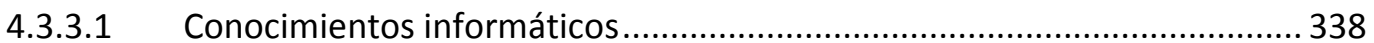

4.3.3.2 Frecuencia en el empleo de herramientas informáticas .............................. 340

4.3.4. Competencias informacionales en estudiantes .................................................. 344

4.3.4.1 Importancia y nivel de conocimientos percibidos sobre las competencias

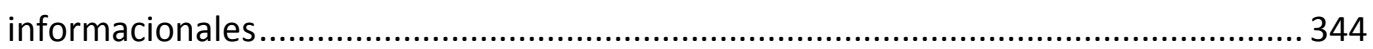

4.3.4.2 Competencias informacionales: análisis de dimensiones .......................... 351

4.3.5. Estudio comparado de competencias informacionales, por grupos principales $\mathbf{3 7 0}$

4.3.5.1 Estudio comparado por sexo …………................................................ 370

4.3.5.2 Estudio comparado por curso ................................................................... 373

4.3.5.3 Estudio comparado por nivel de estudios de los padres .............................. 375

4.3.6. Estudio correlacional y multivariante en estudiantes ........................................ 380

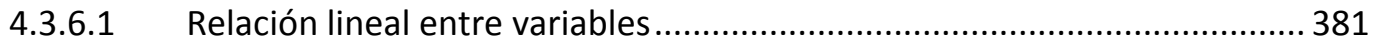

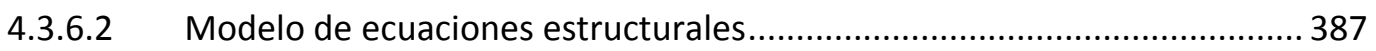

4.3.6.3 Diferencias por grupos principales ....................................................... 393

4.4. Resultados en futuro profesorado de educación secundaria.................................... 401

4.4.1. Información demográfica en futuro profesorado.............................................. 401

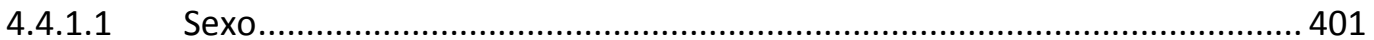

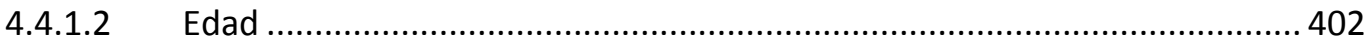

4.4.1.3 Nivel de estudios de los padres ................................................................. 403

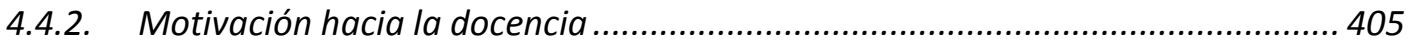

4.4.3. Empleo de herramientas informáticas en futuro profesorado ............................ 405

4.4.3.1 Frecuencia en el manejo general del ordenador ........................................ 406 
4.4.4. Competencias informacionales en futuro profesorado

4.4.4.1 Importancia y nivel de conocimientos percibidos sobre las competencias informacionales.

4.4.4.2 Competencias informacionales: análisis de dimensiones en futuros profesores de Secundaria

4.4.5. Diferencias por grupos principales en futuro profesorado. 436

4.4.5.1 Diferencias localizadas por sexo ................................................... 436

4.4.5.2 Diferencias localizadas por edad .................................................. 438

4.4.5.3 Diferencias localizadas por especialidad .......................................... 441

4.4.6. Estudio correlacional-multivariante: Modelo causal...................................... 443

4.4.6.1 Estructura del modelo teórico .................................................. 444

4.4.6.2 Supuestos previos al análisis .................................................... 445

4.4.6.3 Comprobación del ajuste del modelo............................................. 446

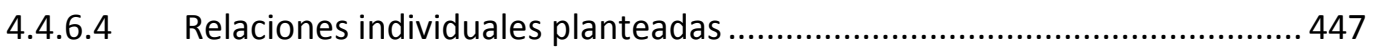

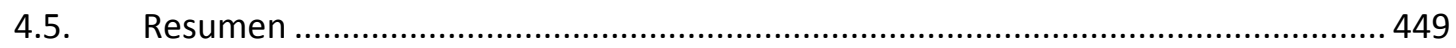

5. ESTUDIO II: Formación en competencias informacionales para el futuro

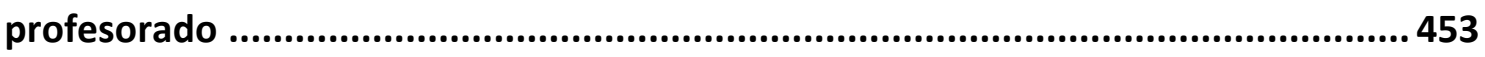

5.1. Metodología de la investigación. Estudio experimental .................................... 454

5.1.1. Antecedentes. Estudio experimental .................................................. 455

5.1.2. Objetivos de la investigación e hipótesis de validación .....................................458

5.1.3. Diseño de la investigación. Estudio experimental ........................................ 460

5.1.4. Descripción del programa formativo......................................................... 460

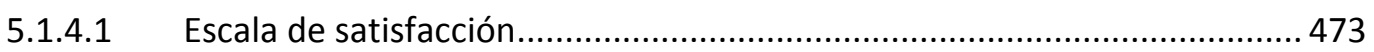

5.1.5. Variables e instrumentos. Estudio experimental.......................................... 474

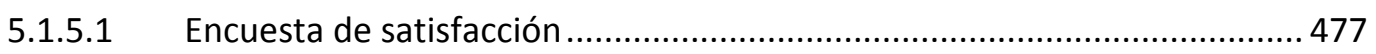

5.1.6. Fiabilidad y validez de los instrumentos del inventario ..................................479

5.1.6.1 Inventario de evaluación de nivel en competencias informacionales .......479

5.1.7. Población y muestra. Estudio experimental ............................................ 499

5.1.8. Procedimiento de aplicación del programa ................................................... 502

5.1.9. Análisis de datos. Estudio experimental ........................................................ 504

5.2. Resultados del estudio experimental ......................................................... 507

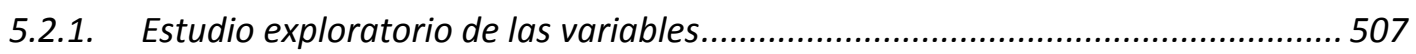

5.2.1.1 Pretest: Análisis gráfico de distribuciones ........................................ 507 
5.2.1.2 Pretest: Análisis estadístico básico y contrastes de normalidad

5.2.1.3 Postest: Análisis gráfico ……………....................................................... 516

5.2.1.4 Postest: Análisis estadístico básico y contrastes de normalidad................. 521

5.2.2. Diferencias pretest-postest. Contraste de hipótesis ........................................... 526

5.2.3. Diferencias pretest-postest. Análisis gráfico .................................................. 529

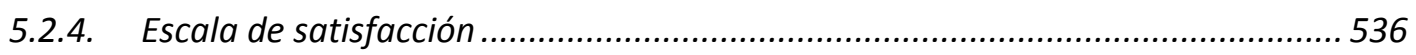

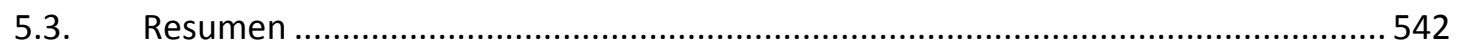

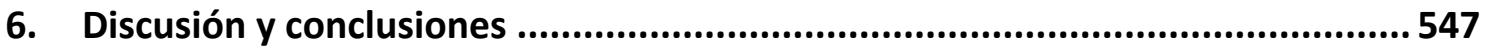

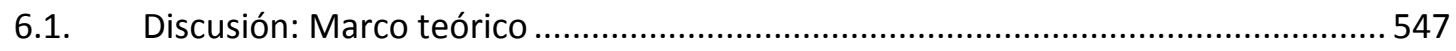

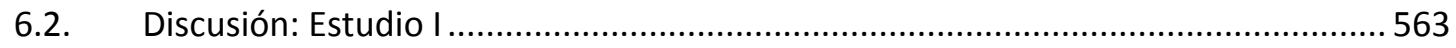

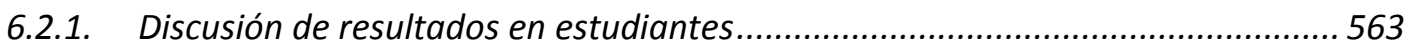

6.2.2. Discusión de resultados en futuro profesorado................................................. 567

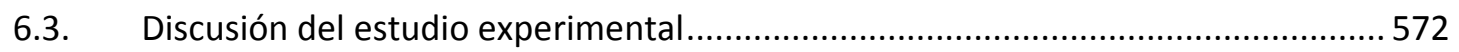

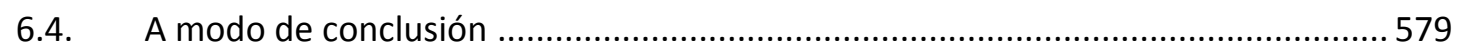

6.4.1. Conclusiones a nivel teórico y empírico ...............................................................5 579

6.4.2. Propuestas de mejora del estudio empírico ....................................................... 584

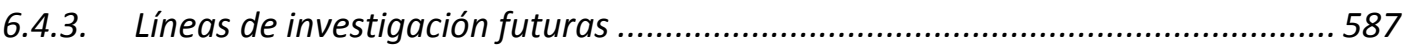

6.5. Publicaciones vinculadas a la Tesis Doctoral .......................................................... 590

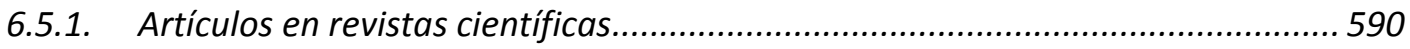

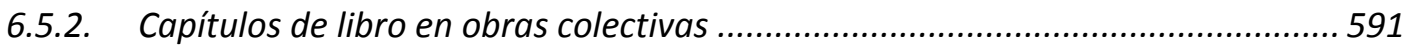

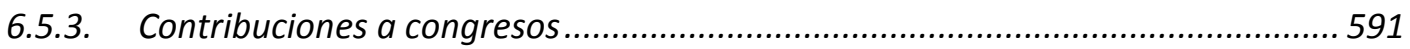

6.5.4. Participación en proyectos de investigación .................................................... 593

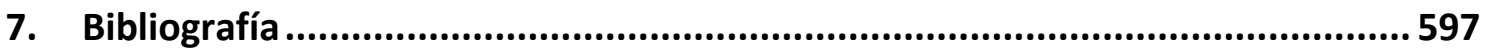

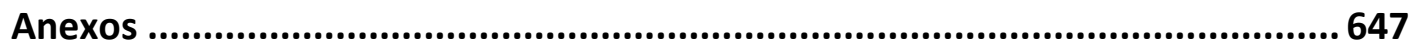




\section{Índice de tablas}

Tabla 1.1 Cantidad de empleo basado en la industria del conocimiento (2005) 61

Tabla 1.2 Negocio de las industrias europeas del conocimiento (2005)

Tabla 2.1 Evolución del concepto de alfabetización 129

Tabla 3.1 Polaridad en la concepción de competencia 162

Tabla 3.2 Dimensiones y componentes de la competencia. 170

Tabla 3.3 Descripción de los componentes de la competencia... 182

Tabla 3.4 Funciones de la evaluación basada en competencias 186

Tabla 3.5 Comparación de los diferentes modelos pedagógicos y normas-estándares de las competencias informacionales 208

Tabla 4.1 Citaciones en revistas JCR a artículos relacionados con competencias informacionales 251

Tabla 4.2 Variables intervinientes en el estudio I 266

Tabla 4.3 Estadísticos total-elemento para estudiantes. Búsqueda de información 279

Tabla 4.4 Estadísticos total-elemento para estudiantes. Evaluación de información 280

Tabla 4.5 Estadísticos total-elemento para estudiantes. Procesamiento de información ........ 280

Tabla 4.6 Estadísticos total-elemento para estudiantes. Comunicación de información 281

Tabla $4.7 \alpha$ de Cronbach para las sub-escalas en alumnos. Competencias informacionales autopercibidas.

Tabla 4.8 Matriz de correlaciones escala búsqueda de información en alumnos 284

Tabla 4.9 Matriz de correlaciones escala evaluación de información en alumnos 285

Tabla 4.10 Matriz de correlaciones escala procesamiento de información en alumnos 285

Tabla 4.11 Matriz de correlaciones escala comunicación de información en alumnos 285 
Tabla 4.12 Test de Barlett y KMO para las cuatro dimensiones teóricas en alumnos 285

Tabla 4.13 Matriz de correlaciones anti-imagen. Búsqueda de información en alumnos ........ 286

Tabla 4.14 Matriz de correlaciones anti-imagen. Evaluación de información en alumnos ....... 286

Tabla 4.15 Matriz de correlaciones anti-imagen. Procesamiento de información en alumnos286 Tabla 4.16 Matriz de correlaciones anti-imagen. Comunicación de información en alumnos 286 Tabla 4.17 Comunalidades. Búsqueda de información. Alumnos 287

Tabla 4.18 Varianza total explicada. Búsqueda de información. Alumnos. 287

Tabla 4.19 Matriz de componentes. Búsqueda de información. Alumnos. 288

Tabla 4.20 Comunalidades. Evaluación de información. Alumnos 288

Tabla 4.21 Varianza total explicada. Evaluación de información. Alumnos 288

Tabla 4.22 Matriz de componentes. Evaluación de información. Alumnos 289

Tabla 4.23 Comunalidades. Procesamiento de información. Alumnos. 289

Tabla 4.24 Varianza total explicada. Procesamiento de información. Alumnos 289

Tabla 4.25 Matriz de componentes. Procesamiento de información. Alumnos 290

Tabla 4.26 Comunalidades. Comunicación de información. Alumnos 290

Tabla 4.27 Varianza total explicada. Comunicación de información. Alumnos 290

Tabla 4.28 Matriz de componentes. Comunicación de información. Alumnos. 291

Tabla 4.29 Índices análisis factorial confirmatorio. Dimensiones teóricas. Alumnos. 291

Tabla 4.30 Matriz de correlaciones escala competencias informacionales. Alumnos 293

Tabla 4.31 Matriz anti-imagen. Competencias informacionales. Alumnos 293

Tabla 4.32 Test de Barlett y KMO. Competencias informacionales. Alumnos 294

Tabla 4.33 Comunalidades. Competencias informacionales. Alumnos. 294

Tabla 4.34 Varianza total explicada. Competencias informacionales. Alumnos 294

Tabla 4.35 Matriz de componentes. Competencias informacionales. Alumnos 294

Tabla 4.36 Índices análisis factorial confirmatorio. Competencias informacionales. Alumnos 295 Tabla 4.37 Estadísticos total-elemento para futuros profesores. Búsqueda de información .. 302 Tabla 4.38 Estadísticos total-elemento para futuros profesores. Evaluación de información. 303 
Tabla 4. 39 Estadísticos total-elemento para futuros profesores. Procesamiento cognitivo ... 304

Tabla 4.40 Estadísticos total-elemento para futuros profesores. Procesamiento informático 304

Tabla 4.41 Estadísticos total-elemento para futuros profesores. Habilidades comunicativas. 305

Tabla 4.42 Estadísticos total-elemento para futuros profesores. Informática para la comunicación.

Tabla 4.43 $\alpha$ de Cronbach para las sub-escalas en profesores. Competencias informacionales autopercibidas. 306

Tabla 4.44 Matriz de correlaciones escala búsqueda de información en profesores .............. 307

Tabla 4.45 Matriz de correlaciones escala evaluación de información en profesores ............. 308

Tabla 4.46 Matriz de correlaciones escala procesamiento de información en profesores ...... 308

Tabla 4.47 Matriz de correlaciones escala comunicación de información en profesores ........ 308

Tabla 4.48 Test de Barlett y KMO para las cuatro dimensiones teóricas en profesores ........... 309

Tabla 4.49 Matriz de correlaciones anti-imagen. Búsqueda de información en profesores ... 309

Tabla 4.50 Matriz de correlaciones anti-imagen. Evaluación de información en profesores .309

Tabla 4.51 Matriz de correlaciones anti-imagen. Procesamiento de información en profesores

Tabla 4.52 Matriz de correlaciones anti-imagen. Comunicación de información en profesores

Tabla 4.53 Comunalidades. Búsqueda de información. Profesores ......................................... 310

Tabla 4.54 Varianza total explicada. Búsqueda de información. Profesores ............................ 311

Tabla 4.55 Matriz de componentes. Búsqueda de información. Profesores ........................... 311

Tabla 4.56 Comunalidades. Evaluación de información. Profesores......................................... 312

Tabla 4.57 Varianza total explicada. Evaluación de información. Profesores ...........................312

Tabla 4.58 Matriz de componentes. Evaluación de información. Profesores ............................ 312

Tabla 4.59 Comunalidades. Procesamiento de información. Profesores ................................. 313

Tabla 4.60 Varianza total explicada. Procesamiento de información. Profesores ..................... 313

Tabla 4.61 Matriz rotada de configuración. Procesamiento de información. Profesores......... 314

Tabla 4.62 Comunalidades. Comunicación de información. Profesores ....................................314

Tabla 4.63 Varianza total explicada. Comunicación de información. Profesores....................... 315 
Tabla 4.64 Matriz rotada de configuración. Comunicación de información. Profesores 315

Tabla 4.65 Índices análisis factorial confirmatorio. Dimensiones teóricas. Profesores

Tabla 4.66 Índices análisis factorial confirmatorio. Competencias informacionales. Profesores

Tabla 4.67 Distribución de centros de Castilla y León 319

Tabla 4.68 Conglomerados/Centros que constituyen el tamaño poblacional 320

Tabla 4.69 Muestra obtenida por centro educativo 321

Tabla 4.70 Encuestas obtenidas en futuro profesorado por especialidad cursada 323

Tabla 4.71 Fechas de encuestación en alumnos por centro educativo. 324

Tabla 4.72 Encuestas obtenidas en futuro profesorado por grupo de docencia 325

Tabla 4.73 Encuestas obtenidas en futuro profesorado por especialidad 325

Tabla 4.74 Distribución de la muestra global de alumnos por sexo...... 329

Tabla 4.75 Distribución de la muestra global de alumnos por año de nacimiento 330

Tabla 4.76 Distribución de la muestra global por curso 331

Tabla 4.77 Distribución de la muestra global por nivel de estudios del padre

Tabla 4.78 Distribución de la muestra global por nivel de estudios de la madre 333

Tabla 4.79 Distribución de la muestra global, por existencia o no de computadora en el hogar

Tabla 4.80 Distribución de la muestra global, por disponibilidad o no de computadora en el hogar

Tabla 4.81 Distribución de la muestra global, por existencia o no de internet en el hogar ...... 335

Tabla 4.82 Tabla de contingencia, porcentaje por disponibilidad de ordenador y de internet.

Tabla 4.83 Descriptivos básicos sobre la experiencia en el manejo del ordenador... 336

Tabla 4.84 Estadísticos básicos sobre la frecuencia en el manejo del ordenador 338

Tabla 4.85 Descriptivos básicos sobre el nivel de conocimientos en aplicaciones para el ordenador

Tabla 4.86 Estadísticos básicos sobre el nivel de manejo de aparatos digitales diferentes del ordenador. 
Tabla 4.87 Estadísticos básicos sobre la frecuencia en el manejo del ordenador dentro del instituto

Tabla 4.88 Estadísticos básicos sobre la frecuencia en el manejo del ordenador fuera del instituto

Tabla 4.89 Intervalos poblacionales para el manejo del ordenador en el aula y en el hogar .. 343

Tabla 4.90 Descriptivos básicos sobre la importancia que conceden los alumnos a las competencias informacionales. Alumnos

Tabla 4.91 Estadísticos básicos sobre el nivel de conocimientos autopercibidos en competencias informacionales. Alumnos

Tabla 4.92 Exploración de las dimensiones de la importancia de las competencias informacionales. Alumnos.

Tabla 4.93 Prueba de normalidad de Kolmogorov-Smirnov para la importancia concedida.

Alumnos

Tabla 4.94 Exploración de las dimensiones del nivel autopercibido en competencias informacionales. Alumnos

Tabla 4.95 Prueba de normalidad de Kolmogorov-Smirnov para el nivel autopercibido.

Alumnos

Tabla 4.96 Estadísticos básicos. Importancia de las competencias informacionales por dimensiones. Alumnos.

Tabla 4.97 Estadísticos básicos sobre el nivel de competencias informacionales por dimensiones. Alumnos.

Tabla 4.98 Prueba de los rangos con signo de Wilcoxon. Importancia y nivel percibidos en competencias informacionales. Alumnos

Tabla 4.99 Estadísticos descriptivos. Importancia por sexo. Alumnos

Tabla 4.100 Prueba Prueba U de Mann-Whitney. Importancia por sexo. Alumnos

Tabla 4.101 Estadísticos descriptivos. Nivel por sexo. Alumnos

Tabla 4.102 Prueba Prueba U de Mann-Whitney. Nivel por sexo. Alumnos

Tabla 4.103 Estadísticos descriptivos. Importancia por curso

Tabla 4.104 Prueba Prueba U de Mann-Whitney. Importancia por curso

Tabla 4.105 Estadísticos descriptivos. Importancia por curso

Tabla 4.106 Prueba Prueba U de Mann-Whitney. Nivel por curso.

Tabla 4.107 Estadísticos descriptivos. Importancia por estudios del padre. 
Tabla 4.108 Prueba Prueba H de Kruskal-Wallis. Importancia por estudios del padre. 376

Tabla 4.109 Estadísticos descriptivos. Nivel por estudios del padre 376

Tabla 4.110 Prueba Prueba H de Kruskal-Wallis. Nivel por estudios del padre 377

Tabla 4.111 Estadísticos descriptivos. Importancia por estudios de la madre. 378

Tabla 4.112 Prueba Prueba H de Kruskal-Wallis. Importancia por estudios de la madre 378

Tabla 4.113 Estadísticos descriptivos. Nivel por estudios de la madre 379

Tabla 4.114 Prueba Prueba H de Kruskal-Wallis. Nivel por estudios de la madre....... 379

Tabla 4.115 Análisis factorial exploratorio para las competencias informáticas. Alumnos ..... 383

Tabla 4.116 Solución rotada AFAC. Competencias informáticas. Alumnos. 384

Tabla 4.117 Matriz de correlaciones frecuencia de empleo y nivel de manejo en herramientas informáticas. Alumnos 386

Tabla 4.118 Correlación competencias y hábitos informáticos con competencias informacionales. Alumnos. 387

Tabla 4.119 Test de normalidad para las variables incluidas en el modelo. Alumnos 390

Tabla 4.120 Indicadores de ajuste del modelo causal. Alumnos. 392

Tabla 4.121 Efectos directos, indirectos y totales estandarizados entre las variables del modelo 393

Tabla 4.122 Indicadores de ajuste del modelo causal por sexo. 394

Tabla 4.123 Contraste de las vías planteadas por sexo....... 395

Tabla 4.124 Indicadores de ajuste del modelo causal por curso. 396

Tabla 4.125 Contraste de las vías planteadas por curso. 396

Tabla 4.126 Indicadores de ajuste del modelo causal por Estudios de la madre. 397

Tabla 4.127 Contraste de las vías planteadas por estudios de la madre. 399

Tabla 4.128 Distribución de la muestra global de futuros profesores por sexo 402

Tabla 4.129 Distribución de la muestra global del futuro profesorado por edad 402

Tabla 4.130 Distribución de la muestra de futuros profesores por nivel de estudios del padre

Tabla 4.131 Distribución de la muestra de futuros profesores por nivel de estudios de la madre 
Tabla 4.132 Distribución de la muestra de futuros profesores por motivación hacia el Máster 405

Tabla 4.133 Frecuencia en manejo general del ordenador en futuro profesorado 406

Tabla 4.134 Descriptivos básicos sobre la frecuencia en el manejo de herramientas informáticas

Tabla 4.135 Descriptivos básicos sobre el nivel en el manejo de herramientas informáticas . 408

Tabla 4.136 Intervalos poblacionales para la frecuencia y el nivel en el manejo de aplicaciones informáticas

Tabla 4.137 Descriptivos básicos sobre la importancia asignada a las competencias informacionales. Futuro profesorado

Tabla 4.138 Estadísticos básicos sobre el nivel de conocimientos autopercibidos en competencias informacionales. Futuro profesorado

Tabla 4.139 Exploración de las dimensiones de la importancia de las competencias informacionales. Futuro profesorado

Tabla 4.140 Exploración de las dimensiones de la importancia de las competencias informacionales. Futuro profesorado

Tabla 4.141 Prueba de normalidad de Kolmogorov-Smirnov para la importancia concedida. Futuro profesorado

Tabla 4.142 Exploración de las dimensiones del nivel autopercibido en competencias informacionales. Futuro profesorado

Tabla 4.143 Prueba de normalidad de Kolmogorov-Smirnov para el nivel autopercibido. Futuro profesorado.

Tabla 4.144 Estadísticos básicos. Importancia de las competencias informacionales por dimensiones. Futuro profesorado.

Tabla 4.145 Estadísticos básicos sobre el nivel de competencias informacionales por dimensiones. Futuro profesorado.

Tabla 4.146 Prueba de los rangos con signo de Wilcoxon. Importancia y nivel percibidos en competencias informacionales. Futuro profesorado.

Tabla 4.147 Estadísticos descriptivos. Importancia por sexo. Futuro profesorado

Tabla 4.148 Prueba Prueba U de Mann-Whitney. Importancia por sexo. Futuro profesorado437

Tabla 4.149 Estadísticos descriptivos. Nivel por sexo. Futuro profesorado 438

Tabla 4.150 Prueba de t para muestras independientes. Nivel por sexo. Futuro profesorado 438

Tabla 4.151 Estadísticos descriptivos. Importancia por edad del futuro profesorado 439 
Tabla 4.152 Prueba Prueba H de Kruskal-Wallis. Importancia por edad del futuro profesorado

Tabla 4.153 Estadísticos descriptivos. Nivel por edad del futuro profesorado 439

Tabla 4.154 Tabla ANOVA. Nivel por edad del futuro profesorado. 440

Tabla 4.155 Estadísticos descriptivos. Importancia por especialidad del futuro profesorado. 441

Tabla 4.156 Prueba H de Kruskal-Wallis. Importancia por especialidad del futuro profesorado

Tabla 4.157 Estadísticos descriptivos. Nivel por especialidad del futuro profesorado 442

Tabla 4.158 Tabla ANOVA. Nivel por especialidad del futuro profesorado 442

Tabla 4.159 Test de normalidad para las variables incluidas en el modelo. Futuro profesorado.

Tabla 4.160 Indicadores de ajuste del modelo causal. Futuro profesorado 447

Tabla 5.1 Estructura de los instrumentos de evaluación 477

Tabla 5.2 Plantilla de puntuaciones escala ordinal. 487

Tabla 5.3 Clasificación dificultad de ítems 487

Tabla 5.4 Índice de dificultad de ítems. Prueba objetiva. 488

Tabla 5.5 Clasificación discriminación de ítems. 489

Tabla 5.6 Índice de discriminación de ítems. Prueba objetiva 490

Tabla 5.7 Índice de fiabilidad de ítems. Prueba objetiva 492

Tabla 5.8 Estadísticos total-elemento búsqueda de información. Escala de actitudes. 493

Tabla 5.9 Estadísticos total-elemento evaluación de información. Escala de actitudes. 493

Tabla 5.10 Estadísticos total-elemento procesamiento de información. Escala de actitudes. 494

Tabla 5.11 Estadísticos total-elemento comunicación y difusión de información. Escala de actitudes. 494

Tabla 5.12 Índice de fiabilidad de ítems. Escala de actitudes. 495

Tabla 5.13 Distribución de la población de alumnos del Máster. 500

Tabla 5.14 Distribución de la muestra de alumnos del Máster 500

Tabla 5.15 Prueba de rachas para las variables del inventario 501 
Tabla 5.16 Pretest. Exploración de estadísticos básicos para las puntuaciones T estandarizadas 513

Tabla 5.17 Test de normalidad de Kolmogorov-Smirnov pretest 515

Tabla 5.18 Postest. Exploración de estadísticos básicos para las puntuaciones T estandarizadas 521

Tabla 5.19 Test de normalidad de Kolmogorov-Smirnov pretest 524

Tabla 5.20 Estadísticos básicos y diferencia de medias pretest-postest 526

Tabla 5.21 Contraste de hipótesis. Diferencia de medias-medianas pretest-postest 527

Tabla 5.22 Descriptivos básicos ítems escala de satisfacción 536

Tabla 5.23 Descriptivos básicos categorías escala de satisfacción . 538 


\section{Índice de gráficos}

Gráfico 4.1 Citaciones a artículos relacionados con competencias informacionales en Revistas de Ciencias de la Educación 253

Gráfico 4.2 Distribución de la muestra global, por edad y por sexo. 331

Gráfico 4.3 Distribución de la muestra global, por estudios del padre y de la madre 333

Gráfico 4.4 Fuente de aprendizaje en el manejo

Gráfico 4.5 Diferencias entre el empleo del ordenador dentro y fuera del aula

Gráfico 4.6 Diferencias en la percepción de la importancia y el nivel de conocimientos de las competencias informacionales. Alumnos

Gráfico 4.7 Función de densidad de la importancia asignada a la búsqueda de información. Alumnos

Gráfico 4.8 Función de densidad de la importancia asignada a la evaluación de información. Alumnos

Gráfico 4.9 Función de densidad de la importancia asignada al procesamiento de información. Alumnos

Gráfico 4.10 Función de densidad de la importancia asignada a la comunicación de información. Alumnos

Gráfico 4.11 Diagramas de cajas importancia percibida sobre competencias informacionales. Alumnos 354

Gráfico 4.12 Q-Q normal para la importancia en la búsqueda de información. Alumnos ........ 356

Gráfico 4.13 Q-Q normal para la importancia en la evaluación de información. Alumnos...... 357

Gráfico 4.14 Q-Q normal para la importancia en el procesamiento de información. Alumnos357

Gráfico 4.15 Q-Q normal para la importancia en la comunicación de información. Alumnos. 358

Gráfico 4.16 Función de densidad del nivel autopercibido en la búsqueda de información.

Alumnos

Gráfico 4.17 Función de densidad del nivel autopercibido en la evaluación de información. Alumnos 
Gráfico 4.18 Función de densidad del nivel autopercibido en el procesamiento de información. Alumnos

Gráfico 4.19 Función de densidad del nivel autopercibido en la comunciación de información.

Alumnos 360

Gráfico 4.20 Diagramas de cajas nivel autopercibido sobre competencias informacionales.

Alumnos

Gráfico 4.21 Q-Q normal para el nivel autopercibido en la búsqueda de información. Alumnos

Gráfico 4.22 Q-Q normal para el nivel autopercibido en la evaluación de información. Alumnos

Gráfico 4.23 Q-Q normal para el nivel autopercibido en el procesamiento de información.

Alumnos

Gráfico 4.24 Q-Q normal para el nivel autopercibido en la comunicación de información.

Alumnos

Gráfico 4.25 Distribución de densidad conjunta para el nivel y la importancia en la búsqueda.

Alumnos 367

Gráfico 4.26 Distribución de densidad conjunta para el nivel y la importancia en la evaluación. Alumnos 368

Gráfico 4.27 Distribución de densidad conjunta para el nivel y la importancia en el procesamiento. Alumnos

Gráfico 4.28 Distribución de densidad conjunta para el nivel y la importancia en la comunicación. Alumnos

Gráfico 4.29 Distribución de la muestra del futuro profesorado por edad

Gráfico 4.30 Distribución de la muestra del futuro profesorado por estudios del padre y de la madre

Gráfico 4.31 Diferencias entre la frecuencia y nivel declarados en el manejo de herramientas

Gráfico 4.32 Diferencias en la percepción de la importancia y el nivel de conocimientos de las competencias informacionales. Futuro profesorado

Gráfico 4.33 Función de densidad de la importancia asignada a la búsqueda de información. Futuro profesorado

Gráfico 4.34 Función de densidad de la importancia asignada a la evaluación de información. Futuro profesorado 
Gráfico 4.35 Función de densidad de la importancia asignada al procesamiento de información. Futuro profesorado

Gráfico 4.36 Función de densidad de la importancia asignada a la comunicación de información. Futuro profesorado

Gráfico 4.37 Diagramas de cajas importancia percibida sobre competencias informacionales.

Futuro profesorado

Gráfico 4.38 Q-Q normal para la importancia en la búsqueda de información. Futuro profesorado

Gráfico 4.39 Q-Q normal para la importancia en la evaluación de información. Futuro profesorado.

Gráfico 4.40 Q-Q normal para la importancia en el procesamiento de información. Futuro profesorado.

Gráfico 4.41 Q-Q normal para la importancia en la comunicación de información. Futuro profesorado

Gráfico 4.42 Función de densidad del nivel autopercibido en la búsqueda de información.

Futuro profesorado

Gráfico 4.43 Función de densidad del nivel autopercibido en la evaluación de información.

Futuro profesorado

Gráfico 4.44 Función de densidad del nivel autopercibido en el procesamiento de información. Futuro profesorado

Gráfico 4.45 Función de densidad del nivel autopercibido en la comunciación de información.

Futuro profesorado

Gráfico 4.46 Diagramas de cajas nivel autopercibido sobre competencias informacionales.

Futuro profesorado

Gráfico 4.47 Q-Q normal para el nivel autopercibido en la búsqueda de información. Futuro profesorado

Gráfico 4.48 Q-Q normal para el nivel autopercibido en la evaluación de información. Futuro profesorado

Gráfico 4.49 Q-Q normal para el nivel autopercibido en el procesamiento de información.

Futuro profesorado

Gráfico 4.50 Q-Q normal para el nivel autopercibido en la comunicación de información. Futuro profesorado

Gráfico 4.51 Distribución de densidad conjunta para el nivel y la importancia en la búsqueda.

Futuro profesorado 
Gráfico 4.52 Distribución de densidad conjunta para el nivel y la importancia en la evaluación. Futuro profesorado

Gráfico 4.53 Distribución de densidad conjunta para el nivel y la importancia en el procesamiento. Futuro profesorado

Gráfico 4.54 Distribución de densidad conjunta para el nivel y la importancia en la comunicación. Futuro profesorado.

Gráfico 5.1 Funciones de densidad pretest. Aspectos básicos 507

Gráfico 5.2 Diagramas de cajas pretest. Aspectos básicos. 507

Gráfico 5.3 Funciones de densidad pretest. Búsqueda de información. 508

Gráfico 5.4 Diagramas de cajas pretest. Búsqueda de información. 508

Gráfico 5.5 Funciones de densidad pretest. Evaluación de información. 509

Gráfico 5.6 Diagramas de cajas pretest. Procesamiento de información. 509

Gráfico 5.7 Funciones de densidad pretest. Procesamiento de información 510

Gráfico 5.8 Diagramas de cajas pretest. Procesamiento de información. 511

Gráfico 5.9 Funciones de densidad pretest. Comunicación de información.

Gráfico 5.10 Diagramas de cajas pretest. Comunicación de información.

Gráfico 5.11 Gráficos Q-Q normales pretest. Aspectos básicos.

Gráfico 5.12 Gráficos Q-Q normales pretest. Búsqueda de información. 514

Gráfico 5.13 Gráficos Q-Q normales pretest. Evaluación de información 514

Gráfico 5.14 Gráficos Q-Q normales pretest. Procesamiento de información. 514

Gráfico 5.15 Gráficos Q-Q normales pretest. Comunicación de información. 515

Gráfico 5.16 Funciones de densidad postest. Aspectos básicos. 516

Gráfico 5.17 Diagramas de cajas postest. Aspectos básicos. 517

Gráfico 5.18 Funciones de densidad postest. Búsqueda de información 517

Gráfico 5.19 Diagramas de cajas postest. Búsqueda de información. 518

Gráfico 5.20 Funciones de densidad postest. Evaluación de información. 518

Gráfico 5.21 Diagramas de cajas postest. Procesamiento de información. 519

Gráfico 5.22 Funciones de densidad postest. Procesamiento de información. 519

Gráfico 5.23 Diagramas de cajas postest. Procesamiento de información. 520 
Gráfico 5.24 Funciones de densidad postest. Comunicación de información

Gráfico 5.25 Diagramas de cajas postest. Comunicación de información

Gráfico 5.26 Gráficos Q-Q normales postest. Aspectos básicos.

Gráfico 5.27 Gráficos Q-Q normales postest. Búsqueda de información. 523

Gráfico 5.28 Gráficos Q-Q normales postest. Evaluación de información. 523

Gráfico 5.29 Gráficos Q-Q normales postest. Procesamiento de información. 523

Gráfico 5.30 Gráficos Q-Q normales postest. Procesamiento de información. 524

Gráfico 5.31 Diagramas de dispersión e histograma variables bidimensionales. Saber 531

Gráfico 5.32 Funciones de densidad conjuntas búsqueda y procesamiento. Saber 532

Gráfico 5.33 Diagramas de dispersión e histograma variables bidimensionales. Saber hacer 533

Gráfico 5.34 Funciones de densidad conjuntas evaluación y tratamiento. Saber hacer..... 534

Gráfico 5.35 Diagramas de dispersión e histograma variables bidimensionales. Saber ser/estar 535

Gráfico 5.36 Funciones de densidad conjuntas evaluación y comunicación. Saber ser/estar . 536 


\section{Índice de figuras}

Figura 1.1 sociedad de la información vs. sociedad del conocimiento........................................ 89

Figura 3.1 Modelo de formación basada en competencias .................................................... 172

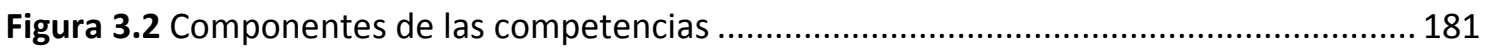

Figura 3.3 Sociedad de la información vs. sociedad del conocimiento ................................... 198

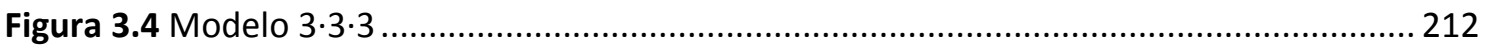

Figura 3.5 Siete pilares de la alfabetización informacional ..................................................... 213

Figura 3.6 Dimensiones globales para la enseñanza de las competencias informacionales .... 215

Figura 3.7 Modelo de formación en competencias informacionales ...................................... 232

Figura 4.1 Evolución de las competencias informacionales en la etapa escolar ...................... 260

Figura 4.2 Esquema general del proceso de investigación. Estudio I .......................................2.264

Figura 4.3 Cuestionario para alumnos de Educación Secundaria I ........................................273

Figura 4.4 Cuestionario para alumnos de Educación Secundaria II ......................................... 274

Figura 4.5 Cuestionario para alumnos de Educación Secundaria III .......................................... 275

Figura 4.6 Cuestionario para alumnos de Educación Secundaria IV .......................................... 276

Figura 4.7 Estructura factorial de la escala de competencias informacionales para alumnado 283

Figura 4.8 Cuestionario para el futuro profesorado de Educación Secundaria I .......................297

Figura 4.9 Cuestionario para el futuro profesorado de Educación Secundaria II .......................298

Figura 4.10 Cuestionario para el futuro profesorado de Educación Secundaria III ...................299

Figura 4.11 Cuestionario para el futuro profesorado de Educación Secundaria VI................... 300

Figura 4.12 Estructura factorial de la escala de competencias informacionales para profesores

Figura 4.13 Diseño del modelo de ecuaciones estructurales teórico. Alumnos 389 
Figura 4.14 Solución estandarizada del modelo planteado. Alumnos

Figura 4.15 Solución estandarizada del modelo por sexo ........................................................ 395

Figura 4.16 Solución estandarizada del modelo por curso ..................................................... 396

Figura 4.17 Solución estandarizada del modelo por estudios de la madre ...............................398

Figura 4.18 Diseño del modelo de ecuaciones estructurales teórico. Futuro profesorado ..... 444

Figura 4.19 Solución estandarizada del modelo planteado. Futuro profesorado ......................447

Figura 5.1 Esquema general del proceso de investigación. Estudio experimental.................. 454

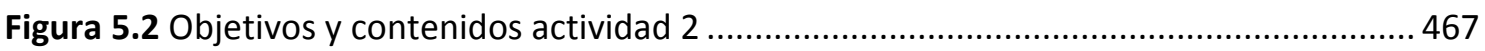

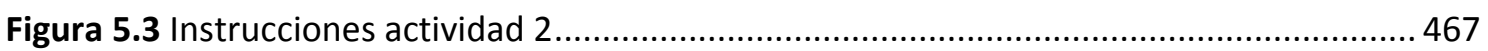

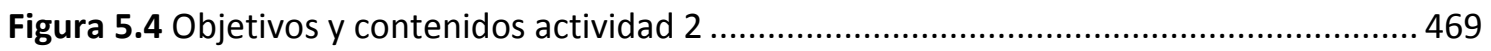

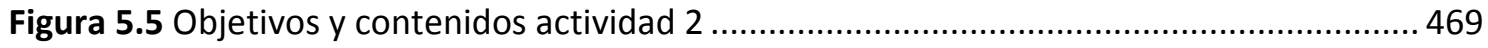

Figura 5.6 Portada espacio Moodle curso competencias informacionales ............................. 471

Figura 5.7 Bloque II espacio Moodle curso competencias informacionales............................ 472

Figura 5.8 Encuesta de satisfacción Moodle curso competencias informacionales.................. 473

Figura 5.9 Evaluación de nivel en competencias informacionales. Identificación .................... 482

Figura 5.10 Evaluación de nivel en competencias informacionales. Prueba objetiva ............... 483

Figura 5.11 Evaluación de nivel en competencias informacionales. Escala ordinal ................. 484

Figura 5.12 Evaluación de nivel en competencias informacionales. Escala de actitudes.......... 485

Figura 5.13 Evaluación de nivel en competencias informacionales. Feedback final ................. 486 

INTRODUCCIÓN 



\section{Introducción}

En un entorno mediado por las tecnologías de la información y la comunicación (TIC), en el que todas las relaciones y sectores sociales están determinados por dichas tecnologías (Castells, 1999a; Valimaa \& Hoffman, 2008), la sociedad actual se encuentra con nuevas necesidades formativas que requieren una renovación de los objetivos, competencias, contenidos, metodologías y evaluación de los procesos de enseñanza-aprendizaje vigentes (Jones \& Goff, 2011).

Así, desde las instituciones responsables en materia de diseño curricular a nivel nacional y autonómico, ya se han comenzado a completar algunos de los pasos previos para adaptar los currículos a la nueva realidad social. Fruto de ello es la renovación de los procesos de enseñanza-aprendizaje, desde enfoques por objetivos, centrados en el objeto a enseñar, a los actuales enfoques de formación por competencias, que apuntan directamente hacia el proceso de aprendizaje que se lleva a cabo (Calvo Bernardino \& Mingorance Arnáiz, 2010; de Miguel Díaz, 2010).

Por otro lado, en cuanto a los contenidos educativos deseables en todo currículo escolar de la etapa de educación primaria y secundaria, tanto en el ámbito nacional como internacional, se ha propuesto la integración como parte de las competencias básicas, ejes transversales de la educación obligatoria, de competencias relacionadas con el manejo eficiente de la información tanto en entornos virtuales como presenciales. Surgen así las denominadas competencias informacionales, como un conjunto de competencias esenciales a desarrollar por todos los ciudadanos de esta sociedad de la información (Weiner, 2010).

Las competencias informacionales se consideran generalmente como un constructo formado por cuatro dimensiones teóricas o sub-competencias. Estas dimensiones se definen como la capacidad de la persona para buscar la información que necesita (dimensión de búsqueda de información); para analizar y seleccionar la información localizada de manera eficiente (dimensión de evaluación de información); para organizar y procesar la información de manera apropiada (dimensión de procesamiento de información); y para utilizar y comunicar la información de modo eficaz, ética y legalmente y con el fin e colaborar en una construcción común del conocimiento (dimensión de comunicación y difusión de información). En todos los casos, estas dimensiones están en función de las necesidades informacionales concretas de la situación en la que está inmerso el sujeto. 
En este contexto concreto surge la presente Tesis Doctoral, inmersa dentro un proyecto nacional $1+D+i^{1}$ financiado por el actual Ministerio de Economía y Competitividad de España. Se pretende, en primer lugar, profundizar en el estudio del estado en el que se encuentra el desarrollo de las competencias informacionales tanto en el alumnado al finalizar la etapa de la educación secundaria, como en el futuro profesorado de esta etapa educativa. En segundo lugar, una vez estudiado el estado de la cuestión, y analizadas las áreas clave en las que los alumnos demandan una mayor formación, y en las que alumnos y futuros profesores poseen una formación más deficitaria, se pretende diseñar un programa educativo para la formación en competencias informacionales del futuro profesorado de educación secundaria.

Para dar respuesta a estos objetivos, el trabajo se estructura en torno a 3 bloques de contenido bien definidos:

- En primer lugar, se procede con el desarrollo del marco teórico, que incluye un estudio profundo y pormenorizado del estado de la cuestión siguiendo una lógica deductiva: Se comienzan analizando todos aquellos hitos generales que están en torno a la emergencia de la sociedad de la información, para ir centrándose poco a poco en las bases epistemológicas que guían los procesos educativos propios de dicha sociedad y a continuación en los pilares pedagógicos que fundamentan el enfoque actual de formación basada en competencias. Todo ello para justificar e ir concentrando la atención en la reciente irrupción de las competencias informacionales como contenido básico transversal en los planes de estudio tanto a nivel nacional como internacional. Se finaliza este marco teórico examinando en profundidad el concepto competencias informacionales y su ámbito de actuación.

- El segundo bloque de este trabajo se refiere al estudio empírico propiamente dicho. Una vez examinado el contexto en el que está inmerso el objeto de nuestro estudio, cabe analizar el conjunto de investigaciones llevadas a cabo al respecto y dar respuesta a las consecuentes cuestiones de investigación emergentes a través de un proceso investigador diseñado e implementado de manera sistemática, controlada, empírica y objetiva. Se

\footnotetext{
${ }^{1}$ Proyecto Nacional I+D+i, convocatoria 2009: Evaluación de Competencias Clave y Formación de Profesorado de Educación Secundaria: TIC, ALFIN Y Convivencia Escolar (EF-TALCO). Ref.: EDU200908753.
} 
pretende como fin último colaborar en la creación y desarrollo del cuerpo de conocimientos sobre la evaluación y desarrollo de competencias informacionales en alumnado y futuro profesorado de educación secundaria. Para dar respuesta a los objetivos propuestos, se verá como se hace necesario el planteamiento de dos estudios diferenciados, el primero de tipo no experimental, de corte descriptivo y correlacional, y el segundo con un mayor nivel de experimentalidad, de tipo eminentemente inferencial.

- Por último, dada la extensión y gran cantidad de información que emerge de la investigación llevada a cabo, se incluye un último bloque de conclusiones, en el que se tratan de sintetizar las principales ideas, logros, líneas de investigación abiertas, problemas,... que surgen a partir del desarrollo de la Tesis Doctoral.

El primer bloque del trabajo se subdivide a su vez en tres capítulos que aportan una estructura lógica a los contenidos tratados a lo largo de todo el marco teórico.

Con el objetivo de estudiar qué sociedad ha florecido a partir de los cambios globales, propiciados en gran parte por el desarrollo tecnológico desmedido surgido desde el último tercio del siglo XX hasta la actualidad, y sus implicaciones en el ámbito educativo, se desarrolla el capítulo primero. Así, se acepta la denominación 'sociedad de la información' para definir la sociedad actual, caracterizada por unas dinámicas muy concretas. En este aspecto, se señalan las TIC como el elemento reactivo principal del surgimiento de esta nueva sociedad. En el intento de definición operativa de la sociedad de la información se exponen sus características propias, que implican unas dificultades globales para los sistemas educativos en general y los procesos de enseñanza-aprendizaje en particular. El estudio de estas dificultades nos indica que su afrontamiento debe hacerse de manera coordinada a todos los niveles educativos, y apunta hacia la aparición de nuevas necesidades educativas para todos los ciudadanos de la sociedad de la información, entre las que se encuentra la inclusión de las competencias informacionales como materia básica de los planes de estudio. Se postula, en este contexto, con la necesidad del desarrollo e implementación efectiva de un nuevo modelo educativo, que incluya la enseñanza de competencias informacionales, para alcanzar el objetivo ideal de la sociedad del conocimiento.

La emergente necesidad de un nuevo modelo educativo tiene mucho que ver con el actual desarrollo de la tecnología, que ha implicado evolucionar desde un entorno 
monomodal y monomedial, a partir del que surge el modelo de escuela que se sigue manteniendo hoy en día, hasta la realidad actual, totalmente multimodo y multimedia. Estos cambios tienen implicaciones importantes que afectan profundamente a una de las principales metas vinculadas al sistema educativo, la alfabetización de los ciudadanos. Mientras que la alfabetización en la sociedad industrial tiene que ver con enseñar a leer y escribir, en el capítulo segundo se analiza cómo en la sociedad de la información el concepto de alfabetización evoluciona hasta alcanzar una gran complejidad. Esta complejidad es tal que, dada la gran variedad de sistemas de representación de la realidad, que se explicitan en múltiples modos y medios de construcción de significados culturales, se hace necesario sustituir la visión tradicional de alfabetización, por enfoques más actuales vinculados a la teoría de la multialfabetización, expuesta en este capítulo. Así, las competencias informacionales se consideran como un grupo de competencias básicas que forman parte del mapa de competencias necesarias para alcanzar la meta de la multialfabetización de los ciudadanos de la sociedad de la información. En este contexto, evidentemente, es necesaria una formación del profesorado acorde y con unos contenidos específicos apropiados, entre los que se incluyan las competencias informacionales.

Las características propias de sociedad de la información, junto con las nuevas necesidades educativas y alfabetizadoras que de la misma emanan, hacen necesaria la configuración e implementación de modelos de enseñanza-aprendizaje que se adapten al nuevo contexto. Así, en el tercer capítulo se procede al estudio y fundamentación de los diseños basados en competencias como modelos de enseñanza-aprendizaje válidos para el desarrollo de procesos formativos en la sociedad de la información, dadas su flexibilidad y particularidades. Se pretende conceptualizar la formación basada en competencias y analizar su pertinencia desde una perspectiva histórica, epistemológica y pedagógica. Debido a la adaptabilidad y variabilidad de los diseños basados en competencias, se procede también a lo largo del capítulo a concretar una definición de competencia y modelo de formación basado en competencias propio, adaptado a los enfoques que se han ido construyendo a lo largo de los capítulos previos.

Una vez que se ha conceptualizado y modelizado en profundidad el proceso de formación basado en competencias, se dedica el resto del tercer capítulo al estudio pormenorizado de las competencias informacionales. Así, se procederá inicialmente a un estudio genérico de estas competencias definiendo claramente lo que se entiende por competencias informacionales, estudiando los aspectos básicos que rodean a este 
constructo, y analizando su estructura y componentes. Después de este análisis global, se procede al estudio específico de cada una de las dimensiones y componentes que dan forma a las competencias informacionales, hasta llegar a la definición de un modelo propio de la formación en competencias informacionales basado en el modelo de formación basado en competencias indicado anteriormente.

Una vez fundamentado y desarrollado el marco teórico, se dispone de una base conceptual suficiente como para proceder a la presentación del estudio empírico, diseñado e implementado para dar respuesta a las cuestiones de investigación planteadas inicialmente. Dada la diversa naturaleza de los objetivos generales propuestos, el estudio empírico se subdivide en dos capítulos, coincidiendo cada uno con uno de los dos estudios desarrollados en el marco de la investigación la Tesis Doctoral.

El estudio del estado de la cuestión muestra cómo no se han llevado a cabo evaluaciones diagnósticas amplias y sistemáticas de los estudiantes de educación secundaria y del futuro profesorado en este mismo nivel educativo sobre los aspectos relacionados con las competencias informacionales. Así, el capítulo cuarto muestra un estudio inicial que evalúa las competencias informacionales en alumnado de educación secundaria (14-16 años) y en futuros profesores, estudiantes del Máster de Formación de Profesorado de Educación Secundaria. Además de un estudio descriptivo que nos aporte un mapa claro de la situación en cuanto al nivel autopercibido en competencias informacionales, se pretende estudiar tanto la importancia de algunas variables de agrupación, como el sexo o el nivel socio-económico, en el desarrollo de las competencias informacionales, como las relaciones existentes entre algunas variables que se pueden considerar a priori explicativas de las competencias informacionales, como el nivel de manejo de algunas herramientas informáticas y la frecuencia de empleo en el aula $y$ en el hogar, y las propias competencias informacionales autopercibidas.

Fruto de los resultados cosechados en este primer estudio, que aportan información acerca del nivel actual y las deficiencias formativas del alumnado y profesorado en cada una de las dimensiones de las competencias informacionales, sobre cómo afecta la pertenencia a determinados grupos en el desarrollo de estas competencias y sobre algunas otras variables importantes en el desarrollo de competencias informacionales, se configura el segundo estudio, expuesto en el quinto capítulo de la Tesis Doctoral. Se elabora aquí un diseño de investigación con un mayor nivel de experimentalidad, en el que se evalúa la efectividad de un programa formativo 
diseñado para la formación en competencias informacionales del futuro profesorado de educación secundaria. Los contenidos del programa formativo se diseñan en función de las áreas prioritarias detectadas a partir de los resultados obtenidos en el primer estudio y de las conclusiones extraídas del estudio teórico y el análisis del estado de la cuestión llevado a cabo. El análisis de datos muestra tanto la efectividad del programa en la formación del profesorado, como su impacto específico en las áreas de formación prioritaria detectadas en el estudio I.

Por último, de cara a compilar y resumir los resultados más valiosos obtenidos a lo largo de todo el proceso investigador, se presenta el capítulo sexto, que incluye una discusión y las principales conclusiones sacadas del estudio. Se incluye una discusión de los resultados obtenidos, tanto relativos al marco teórico, como a cada uno de los estudios descritos. Dichos apartados son los referentes a partir de los que se extraen las conclusiones del trabajo expuestas en este capítulo.

Dada la relevancia de algunos de los hallazgos y logros alcanzados en la presente Tesis Doctoral para el área de conocimiento en el que está inmersa, se considera importante hacer esta síntesis final que pueda facilitar al lector la visión de conjunto de la propia Tesis, y que ayude a todo investigador y persona interesada a comprender en qué aspectos concretos se está contribuyendo al avance de la ciencia dentro del campo en el que estamos inmersos.

Es conveniente señalar, finalmente, que un trabajo de esta naturaleza genera una gran cantidad de materiales que se ponen a disposición del lector en los anexos. Dada la gran cantidad de información dispuesta en los anexos, a pesar de su relevancia para la comprensión de ciertos procedimientos aplicados a lo largo de la tesis, se han incluido en CD-ROM incluido al final de la Tesis Doctoral 


\title{
Capítulo I
}

\author{
DE LA SOCIEDAD DE LA \\ INFORMACIÓN A LA SOCIEDAD \\ DEL CONOCIMIENTO
}




\section{Capítulo I}

De la sociedad de la información a la sociedad del conocimiento
1.1 Origen de una nueva sociedad, la sociedad de la información

1.2 Pilares e implicaciones de la sociedad de la información

1.3 Las competencias informacionales como puente entre la sociedad de la información y la sociedad del conocimiento

1.4 El aprendizaje en la sociedad de la información: buscando la sociedad del conocimiento

1.5 Resumen 


\section{De la sociedad de la información a la sociedad del conocimiento}

«...veamos los siguientes hechos:

- En los últimos 20 años se ha producido más información que en los 500 años anteriores.

- La información se duplica cada 4 años y cada vez con más celeridad. Hasta hace 100 años la información que utilizaba el ser humano en su vida cotidiana permanecía básicamente la misma por varias generaciones.

- La información que ofrece cada día, por ejemplo, el periódico N.Y. Times es mayor que la que una persona podría encontrar en el siglo XVII durante toda su vida.

- El $80 \%$ de los nuevos empleos requiere habilidades sofisticadas de tratamiento de la información.

- Los empleos que implican el uso de Internet se pagan cerca de un 50\% más que los que no lo emplean.

- En los próximos 5 años, el 80\% de los trabajadores estará realizando su trabajo de forma diferente a como lo ha venido desarrollando durante los últimos 50 años, o estará desempeñando otros empleos

Así pues, no parece exagerado afirmar que la supervivencia de los individuos, las organizaciones y las naciones, en la era de la información depende sustancialmente de la adquisición, uso, análisis, creación y comunicación de información. » (Gimeno Sacristán, 2008, p. 61)

Los grandes y apresurados avances científicos relacionados con las Tecnologías de la Información y de la Comunicación (TIC) acontecidos desde mediados del siglo XX, desde que Alan Turing (1912-1954) comenzara a desarrollar sus estudios sobre computación, hasta los albores del siglo XXI, han transformado por completo tanto las vidas cotidianas de los seres humanos, como su relación con el entorno. Nuevos artefactos tecnológicos basados en el manejo eficiente de la información han irrumpido, y se han convertido en uno de los pilares del desarrollo económico, social y cultural de nuestros días (Castells, 1999a).

En paralelo a este proceso, sociólogos y estudiosos de la realidad social comienzan a demandar una nueva denominación de esta "sociedad", más acorde a las nuevas circunstancias que la rodean. Y en este punto, desde que comenzó este debate, seguimos sin llegar a un acuerdo total sobre su denominación (Cassity \& Ang, 2006; Cebrián Herreros, 2009; D. Cohen \& McCuaig, 2008; Sakaiya \& Fields, 1991; Valimaa \& Hoffman, 2008).

Mientras que, para unos, nos encontramos inmersos en la sociedad del conocimiento, para otros, no se podría llegar más allá que a denominarse como 
sociedad de la información. Realmente, no podemos afirmar que la base conceptual que se encuentra debajo de este conflicto sea ligera y sin importancia. De hecho, esta consideración es uno de los puntos clave para el posterior entendimiento e interpretación de todo lo que subyace a esta nueva sociedad.

Los autores que defienden el término sociedad del conocimiento, entienden que el pilar esencial que mueve la nueva sociedad es el manejo, intercambio y generación eficiente del conocimiento. El conocimiento, entendido como el conjunto de informaciones filtradas, procesadas, asimiladas e interiorizadas por una persona $y / 0$ grupo, es el bien que genera riqueza y desarrollo, ya que la información por sí misma no genera nada. De hecho, un amplio porcentaje de trabajadores están empleados hoy en día en industrias y empresas del conocimiento, y están, por tanto, perfectamente preparados para ser unos buenos gestores del conocimiento. Para resumirlo de algún modo, se podría decir que la sociedad está preparada a nivel general para llevar a cabo el manejo, intercambio y la generación del conocimiento.

Por su parte, los autores que definen como más conveniente el término sociedad de la información, señalan que lo que realmente está moviendo la sociedad en el momento actual son los flujos de información. El intercambio y la organización eficiente y óptima de la información, entendida como datos codificados con un patrón determinado, controlado y conocido, es el pilar esencial del desarrollo y la generación de riqueza en la nueva sociedad. De hecho, un amplio porcentaje de trabajadores están empleados hoy en día en industrias y empresas de la información, y son, por tanto, expertos en generar y manejar sistemas y máquinas que traten la información eficazmente. A nivel general, la sociedad no está preparada para manejar, intercambiar y generar conocimientos, ya que la formación recibida por los ciudadanos estaba prevista para el desarrollo en una sociedad industrial, y no para una sociedad en la que la información lo inunda todo.

Como el lector habrá podido observar tanto en la Introducción, como en las implicaciones que conlleva el título general de este apartado, durante todo lo largo y ancho de este trabajo, nos inclinaremos por la denominación general de sociedad de la información para referirnos al contexto social, cultural, económico, etc., en el que nos encontramos envueltos hoy en día. Varias son las razones por las que definirnos por este concepto:

- En primer lugar, esta Tesis Doctoral estudia, y trata de probar teórica y empíricamente, la necesidad de incorporar las competencias informacionales 
de manera definitiva y sistemática en los planes de estudio de la educación formal y en el ámbito de conocimientos de la educación informal. De hecho, se postula con que el nuevo contexto social demanda nuevos escenarios educativos, y entre estas nuevas demandas, las competencias informacionales son esenciales para formar personas capaces de generar conocimiento a través del tratamiento de la información. Bajo este punto de partida tiene sentido pensar que los ciudadanos no están preparados para generar conocimiento, ya que no están formados en el tratamiento eficiente de la información para estos fines.

- Por otro lado, a pesar de que somos conscientes de que el término sociedad de la información es ambiguo e incorrecto para definir la complejidad de la sociedad actual (Cebrián Herreros, 2009), es la denominación más extendida, y por tanto, con la que está más familiarizada la sociedad. De hecho, prestigiosos estudiosos como Daniel Bell, sociólogo y profesor emérito de la Universidad de Harvard, mientras que en sus primeros estudios consideraba a esta sociedad como sociedad del conocimiento, ahora es más propenso a denominarla sociedad de la información (Bell, 1976; D. Cohen \& McCuaig, 2008)

- Por último, creemos en la existencia de una brecha del conocimiento², más profunda y fundamental que la brecha digital, y entendemos que aunque se elimine la brecha digital, la brecha del conocimiento seguirá sin desaparecer (Cebrián Herreros, 2009).

Para ilustrar mejor la postura adoptada, podemos concluir con dos citas: «estamos acostumbrados a pensar que la falta de conocimientos de una persona casi siempre era consecuencia de una falta de información», sin embargo, en el modelo actual, «la

\footnotetext{
${ }^{2}$ El concepto brecha del conocimiento hace referencia a las enormes diferencias que se pueden encontrar entre personas en lo que respecta a las competencias de manejo de la información, entendiendo manejo como las habilidades de búsqueda, evaluación, procesamiento y comunicación de la información (pasos esenciales para generar conocimiento).

De hecho, a lo largo del texto queremos desmarcarnos del concepto brecha digital en favor de brecha del conocimiento, ya que el primero tiene unas implicaciones más comerciales y menos pedagógicas: El remedio a la brecha digital, supone a nivel conceptual que todas las personas aprendan a utilizar (a nivel técnico) las Tecnologías de la Información y la Comunicación. Esto presupone la existencia de estas tecnologías al alcance de las personas.

Mientras, trabajar en solventar la brecha del conocimiento supone formar a todas las personas para que sepan emplear la información que tengan a su alcance en la búsqueda de generar conocimientos útiles para su vida.
} 
falta de conocimientos muchas veces es consecuencia de un exceso de información» (Majó i Cruzate \& Marqués, 2002, p. 66). Por otro lado, podríamos añadir a modo de corolario una cita muy reveladora: la receta de cocina escrita permite llenar parcialmente el vacío dejado por la ausencia de la abuela. Tan sólo parcialmente, porque esa receta es información pura y dura, datos codificados (Goody, 1977).

Es este el principal razonamiento que sirve de apoyo para defender que nos encontramos en una sociedad de la información, y que la educación en información es el principal eje para caminar hacia una sociedad del conocimiento.

Al margen de este conflicto, lo que está claro para ambos bandos, es que la base del desarrollo en esta nueva sociedad es el manejo eficiente de datos convenientemente organizados (ya sean tratados como información o como conocimiento), gracias a la participación de máquinas y personas expertas que optimizan el proceso.

A lo largo de este apartado, por tanto, se estudiará en profundidad todo lo que rodea a la sociedad de la información, desde su origen, hasta su caracterización, implicaciones y problemática asociada. Después de este exhaustivo análisis de la sociedad actual, se estudiará en más profundidad cómo tender puentes entre la sociedad de la información y la sociedad del conocimiento, con el fin de alcanzar esta última. Por último, ya que hemos apuntado que los nuevos entornos socio-culturales deben ir acompañados de nuevos contextos formativos, terminaremos el capítulo haciendo referencia a esta adaptación del mundo educativo, señalando tanto las virtudes y defectos de las nuevas herramientas al servicio del docente, como las nuevas perspectivas metodológicas que surgen con la sociedad de la información. 


\subsection{Origen de una nueva sociedad, la sociedad de la información}

No cabe duda de que la sociedad de la información es un hecho. Todos los ámbitos y todas las esquinas de la sociedad occidental ${ }^{3}$ están inundadas y afectadas por objetos que transmiten, gestionan, intercambian, etc., información. No nos imaginamos ir a un supermercado y que nos hagan la cuenta sumando los precios a mano, o que en un banco soliciten por correo postal una transferencia. Como estos existen millones de ejemplos que alteran el funcionamiento de todas las realidades en las que las personas están inmersas.

\subsubsection{La revolución informacional como detonante de la sociedad de la información}

Este salto de una sociedad industrial a otra informacional se ha producido debido, en gran parte, al desarrollo exponencial de las Tecnologías de la Información y de la Comunicación (TIC), y su gran «capacidad de penetración en todo el ámbito de la actividad humana» (Castells, 1999a, p. 31).

Hablar de "sociedad de la información" no quiere decir que exista una sola sociedad, sino que la definimos así de modo general, al igual que se habló de "sociedad industrial", ya que existen rasgos fundamentales comunes. Todas las sociedades son sociedades informacionales porque «los procesos centrales de generación del conocimiento, la productividad económica, el poder político/militar y los medios de comunicación ya han sido profundamente transformados por el paradigma informacional.» (Castells, 1999a, p. 47)

Son innumerables los autores que hablan de este paradigma informacional y sus tecnologías asociadas como el surgimiento de una revolución informacional que impacta en las estructuras más arraigadas de la sociedad industrial y hace romper sus costuras. Este proceso se denota en muchos casos con el nombre de tercera revolución industrial, o revolución informacional. Podemos destacar, entre la larga lista de autores, algunos que hacen referencia a esta revolución:

\footnotetext{
${ }^{3}$ De aquí en adelante nos referiremos al mundo desarrollado únicamente como sociedad, aun a riesgo de no responder a la precisión terminológica que este texto se merece.
} 
- «Así como hubo una (primera) revolución industrial a fines del siglo XVIII y luego otra a fines del XIX, es útil pensar el período actual como una tercera revolución industrial» (D. Cohen, 2007, p. 25). De hecho, podemos hablar de tres revoluciones dentro de la tercera revolución industrial:

○ Tecnológica

- Social: Organización del trabajo, relaciones sociales, cultural. Se exige concretamente a los trabajadores y asalariados una gran polivalencia y una mayor asunción de responsabilidades (Askenazy, 2002), con lo cual se exigen nuevas competencias al trabajador.

- Financiera: La bolsa se hace con el poder de las empresas.

- «La tecnología de la información es a esta revolución [revolución informacional] lo que las nuevas fuentes de energía fueron a las sucesivas revoluciones industriales» (Castells, 1999a, p. 57)

- Las TIC son la vanguardia de la tercera revolución (Tubella i Casadevall \& Vilaseca i Requena, 2005), en este caso informacional. De hecho, «la novedad de esta tercera revolución industrial no pasa por el hecho de que se fundamenta en nuevos conocimientos e informaciones» sino que debemos de hablar de otra novedad, que no es otra que «la utilización del conocimiento para generar aparatos que incidan directamente en la generación de conocimiento y en la sustitución de habilidades mentales» (Tubella i Casadevall \& Vilaseca i Requena, 2005, pp. 37-38)

- «La humanidad ha pasado por diferentes revoluciones tecnológicas, que a grandes rasgos han ido desde la agrícola y artesanal, a la industrial, postindustrial y de la información o del conocimiento, que es en la que nos encontramos» (Cabero Almenara \& Alonso García, 2007, p. 1)

- «El nuevo modelo social, [...] posee una vigorosa dinámica de cambio y supone en muchos casos una verdadera revolución respecto a las pautas de actuación anteriores» (Majó i Cruzate \& Marqués, 2002, p. 15)

- La sociedad de la información es la «tercera revolución tecnológica de la era capitalista» (Area Moreira, 2001, p. 40). Los actuales cambios tecnológicos «han dado lugar a cambios radicales en la organización el conocimiento, en las 
prácticas y formas de organización social y en la propia cognición humana» (Area Moreira, 2001, p. 101). De hecho, podemos señalar a las TIC también como fruto de la cuarta revolución cultural, o el cuarto cambio radical, que sufre la sociedad:

- El lenguaje oral

- El lenguaje escrito

- La imprenta

- La digitalización y las TIC

Podemos señalar como característica esencial y definitoria de esta revolución, que la diferencia radicalmente de las anteriores, que esta se articula en torno a la irrupción de nuevos artefactos tecnológicos con base física, (hasta aquí nada cambia con respecto a las anteriores revoluciones) pero cuya esencia está en lo inmaterial de su contenido, en la información y el conocimiento intangibles como ejes fundamentales del desarrollo y de la generación de riqueza. Podríamos decir que las instituciones fundamentadas en la era de la información han sustituido la cultura del átomo por la cultura del bit, buscan negocio de un modo substancialmente diferente a las "empresas industriales", ya que generan bienes en la mayoría de los casos intangibles, perceptibles y valorables a nivel abstracto. Su materia prima principal es la información, y la información no tiene importancia solamente a nivel económico, sino que también es transcendente, como veremos más adelante, a nivel social, cultural, etc.

Con esto no queremos decir que solamente los negocios fundamentados en la información forman parte de lo que hemos denominado revolución informacional. De hecho, como ya hemos apuntado, las TIC han penetrado en todos los sectores, y hoy en día no se imagina un campo en el que no hayan impactado y se hayan mantenido como un objeto importante y necesario. Podemos poner como ejemplo claro y revelador el caso de la banca, que ha preferido asumir los elevados costes de prejubilación de personal "irreciclable" para la alfabetización digital, que mantenerlos en plantilla con el consiguiente retraso en la integración de las TIC. Así, mientras que las prejubilaciones durante los años 70 y 80 no significaban una práctica muy extendida, a partir de la década de los 90 y principios del presente siglo se comenzó a dar un vuelco. A partir de aquí ya no son solamente las empresas que se encuentran en crisis las que organizan planes de prejubilación de los empleados, sino que se 
convierte en una práctica muy extendida en empresas en expansión y con importantes beneficios (Traus Boix, 2007). «En los últimos años, como consecuencia de la búsqueda de la competitividad [...] han aumentado de forma significativa las reducciones de plantillas de forma pactada, como las desvinculaciones y las jubilaciones anticipadas, que han llegado a afectar incluso a personas con menos de 50 años» (Velasco Juez, 2006, p. 460).

\subsubsection{Las TIC: Elemento reactivo de la revolución informacional}

Una vez expuesta la argumentación anterior, nos podemos plantear una cuestión fundamental; ¿cómo es posible que una herramienta, o conjunto de herramientas, como las TIC, sean capaces de encabezar un cambio tan profundo y radical como el producido en todos los campos hasta llegar a la sociedad de la información? Se antoja complicado pensar en que las TIC son artefactos con poderes extraordinarios (que casi llegan a ser mágicos), capaces de modificar tanto a las personas como a los contextos a su paso. Expresada de este modo, parece que la hipótesis es presuntuosa y poco sistemática para su análisis crítico. Sin embargo, estudiándola a partir de las ideas que propone McLuhan, no parece tan descabellada. (McLuhan, 1967, 1969, 1987)

En primer lugar, siguiendo la argumentación de McLuhan, podríamos señalar varios conceptos fundamentales:

- El ser humano, como animal que es, tiene una alta capacidad de adaptación a nuevos o diferentes contextos. Busca el equilibrio con el medio, y si hay modificaciones en el entorno que crean desequilibrios, puede modificarse para volver a alcanzar el equilibrio. De hecho, podríamos llegar a decir que nos convertimos en lo que vemos, o que somos lo que nos ha tocado vivir.

- Las herramientas son extensiones de nuestros propios cuerpos, ya que nos permiten ampliar las capacidades físicas, sensoriales y/o mentales de los mismos. Por ejemplo, una rueda es extensión de nuestros pies, o un vestido es extensión de nuestra piel. Por lo tanto, las tecnologías son la extensión de la biología.

- El hombre es capaz de diseñar herramientas de todo tipo y para muy diferentes fines. Partiendo de la idea anterior, podríamos afirmar que primero somos capaces de dar forma a las herramientas, y una vez que las 
herramientas existen, estas nos dan forma a nosotros, nos «afecta(n) profundamente a todo su (nuestro) modo de vida, tanto en el nivel de acción como en el nivel simbólico o de pensamiento» (García Carrasco, 2009, p. 63).

- Los medios no son simples soportes físicos asépticos, contenedores de información, sino que el propio medio es el mensaje (o al menos parte de él). Dado que los medios reconfiguran el mundo del hombre y al propio hombre, estaremos de acuerdo en que el medio transmite información por sí mismo. "Las tecnologías no son neutrales, sino que reflejan las posiciones ideológicas y sociales de la cultura en la cual se desarrollan y potencian» (Cabero Almenara, 2001, p. 65). Esta íntima relación entre pensamiento e instrumento ya la abarcó Vygotsky en sus estudios acerca de la influencia del empleo de instrumentos y símbolos en el desarrollo intelectual (1973, 1979), cuando lanza la siguiente hipótesis: "el momento más significativo en el curso del desarrollo intelectual [...], es cuando el lenguaje y la actividad práctica, dos líneas de desarrollo antes completamente independientes, convergen» (1979, pp. 47-48). Con el término "actividad práctica", Vygotsky se está refiriendo explícitamente al empleo de instrumentos para la solución de problemas. Así, el desarrollo de los procesos de pensamiento, y por ende, de la representación mental del mundo, está íntimamente ligado al empleo de herramientas. Por lo tanto, el contexto tecnológico en el que se desarrollan las personas tiene consecuencias importantes en su estructura de pensamiento.

- Las TIC van más allá del resto de tecnologías, ya que, mientras que las otras tecnologías sólo crean perturbaciones en órganos mecánicos (piernas, brazos, etc.) que conducen a reequilibrios sencillos, estas nuevas tecnologías, por su naturaleza (son una extensión de las capacidades sensoriales, como la vista o el oído/voz, y de las capacidades del sistema nervioso central, como almacenar, organizar, e incluso procesar la información), conducen a desequilibrios muy intensos que requieren de una reestructuración profunda los pensamientos y sentimientos, la forma de pensar y actuar.

Partiendo de estas ideas (McLuhan, 1967, 1969, 1987) sí que podríamos plantear como hipótesis de trabajo que las TIC generan unos cambios tan intensos en el entorno que nos rodea, que obligan a una reestructuración intensa de la psique del hombre. 
Aún a riesgo de adelantarnos a la exposición posterior, es importante señalar en este punto una reflexión sobre la que volveremos más adelante. Estamos acostumbrados a escuchar que la sociedad de la información es una sociedad muy dinámica, cambiante, sin una forma definida estable. Esta incansable metamorfosis no nos debe sorprender, si atendemos al exponencial desarrollo de las tecnologías que están asociadas a la sociedad actual, las TIC. Este desarrollo, que nos obliga a reaprender prácticamente a diario el manejo de miles de herramientas y aplicaciones, es un arma de doble filo: ¿hasta qué punto el ser humano está preparado para ser tan dinámico que no tome formas definidas?, ¿podríamos hablar, llegados a este punto, de personas con una especie de "esquizofrenia adaptativa"?

Ante esta situación, McLuhan apunta indirectamente una solución, que no es otra que educar en entender los lenguajes de los nuevos medios, en comprender que el ambiente es un proceso cambiante, y que las TIC, con sus perturbaciones sobre la mente humana, modifican las relaciones sensoriales y alteran las formas de pensar y actuar. En realidad todo se podría resumir, aplicando términos más actuales, en desarrollar competencias en las personas para que éstas sean capaces de dominar al medio y que hayan interiorizado las habilidades necesarias para aprender a aprehender del medio. Si no primamos esta formación, el hombre se puede ver abocado a navegar a la deriva en un medio "hiperinstrumentalizado", sin controlar su propio desarrollo.

De hecho, este modelo de educación que propone McLuhan, aplicado al empleo de herramientas relacionadas con la gestión de la información, tiene mucho que ver con el concepto de competencias informacionales, que surgen debido al incremento incalculable de la información disponible para las personas gracias a las TIC, y que proponen formar a las personas para que sean capaces de gestionar eficazmente la información que obtienen de estas y otras herramientas. Esta gestión eficaz de la información incluye, por supuesto, entender los lenguajes de los instrumentos de los que se obtiene información y aprender a aprender para ser capaces de adaptarse eficazmente a los entornos volubles presentes y futuros. 


\subsection{Pilares e implicaciones de la sociedad de la información}

Hemos visto cómo nos encontramos en un nuevo contexto en el que surge una nueva sociedad, con nuevas relaciones, nuevas dinámicas y nuevas estructuras. Esta se vino a denominar sociedad de la información. En esta sociedad tienden a perder valor objetos que anteriormente lo tenían en favor de la información como bien de consumo. La información se constituye como un objeto valioso y como un eje principal, vertebrador y definitorio de la sociedad moderna (al menos en los países desarrollados). Ahora los ciudadanos están inmersos en un entorno en el que se encuentran sobresaturados e hiperestimulados con información en todos los formatos posibles. El saber, que desde siempre había sido propiedad de unos pocos, se convierte ahora en un bien social, distribuible y accesible en cualquier rincón del mundo. Y es la rápida expansión de las TIC el elemento que influye con más fuerza en esta distribución imparable y global de la información.

En este sentido, para entender el porqué de la importancia de las TIC, podemos apuntar sus principales características, que adaptaremos de las señaladas muy esquemáticamente por Majó i Cruzate y Marqués (2002):

- Facilitan el acceso a todo tipo de información y en cualquier formato.

- Permiten el procesamiento de datos de todo tipo, de una manera fácil, rápida y fiable.

- Proporcionan canales de comunicación síncrona y asíncrona.

- Permiten la automatización de tareas realizadas hasta ahora por operarios especializados.

- Los sistemas informáticos son interactivos, es decir, nos permiten un diálogo con el sistema en cuestión.

- Gracias al progreso de la informática, hoy en día podemos almacenar inmensas cantidades de información en soportes físicos de un tamaño muy reducido. 
- Homogeneización de los códigos. Con esto nos referimos a que es posible digitalizar, procesar y convertir a un formato estándar cualquier tipo de información.

Como podemos observar en las características descritas, todas hacen referencia a cómo estas tecnologías expanden exponencialmente las capacidades del hombre para el almacenamiento, tratamiento y la comunicación de información en cualquier canal. $Y$ es aquí donde radica la importancia de estos instrumentos.

\subsubsection{Características principales de la sociedad de la información}

Una vez señalados estos puntos introductorios, podemos comenzar a analizar, tomando como principal referencia la obra de Castells (1998, 1999a, 1999b), las características definitorias del paradigma informacional propio de la sociedad de la información:

En primer lugar, como ya hemos señalado a lo largo de la argumentación por su importancia, nos encontramos con una nueva sociedad en la que su materia prima es un bien intangible, no físico, la información. La información es valiosa y se convierte en un bien de consumo.

Por otro lado, es importante señalar la importancia de los efectos de las nuevas tecnologías, como sustancia reactiva que tiene gran capacidad para penetrar en todos los procesos de nuestra existencia individual y colectiva. De hecho, se podría comparar el impacto que ha supuesto el surgimiento de las TIC con el surgimiento de la escritura o la imprenta (Adell, 1997).

Como tercera característica, podemos hablar de la lógica de la interconexión, esto es, el cómo en la sociedad de la información, gracias a las TIC, se genera una red en la que todos los nodos están interconectados, entendiendo por nodo cada uno de los usuarios o grupo de usuarios conectado a una red global mediante la cual se puede intercambiar información: Los nuevos medios tecnológicos han permitido el intercambio de información a tiempo casi real entre cualquier persona en cualquier punto del mundo. Este intercambio permanente y vertiginoso provoca que el ritmo de cambio de la sociedad aumente hasta niveles impensables hace tan sólo cincuenta años. Por primera vez se observa como la economía funciona como una unidad en tiempo real a lo largo de toda la tierra (Area Moreira, 2008). 
Otro factor reseñable en esta sociedad de la información es su flexibilidad, es decir, su gran capacidad de reconfiguración y de permanente cambio. Nos referiremos a esta característica, a la que ya hemos hecho referencia más arriba, con la denominación general de sociedad líquida (Bauman, 2006, 2007), como un pilar definitorio de la sociedad de la información. Parece innegable que en el contexto actual nos movemos en una realidad dinámica e incierta en la que las conductas adaptativas de las personas al entorno deben modificarse a un ritmo tan alto que no llegan ni siquiera a interiorizarse (Bauman, 2006) y en la que la cultura y el conocimiento dejan de ser duraderos, perdiendo el valor irremplazable que tenían en anteriores épocas. Así, las personas deben estar en constante movimiento intelectual, y se las exige una capacidad continua de actualización y de adquisición de nuevas competencias adaptadas al nuevo contexto presente (Markauskaite, 2006; Méndez Paz, 2005; Pesquero Franco et al., 2008). Para conseguir crear estas mentes líquidas, maleables, es necesario formar ciudadanos, tanto preparados para aprender a aprender, como para comprometerse y responsabilizarse de su aprendizaje a lo largo de toda la vida (Organización Internacional del Trabajo, 2003).

La anterior argumentación nos conduce necesariamente a otro de los elementos esenciales que dan forma a la sociedad de la información, la especificidad del mercado de trabajo. El mercado laboral, al igual que toda la sociedad, no es estático. Las condiciones y exigencias de contratación se modifican al mismo ritmo que el resto de los sectores de la sociedad, lo cual exige al trabajador una capacidad de adaptación al mismo. Podemos derivar de este hecho dos consecuencias claras:

- La extensión de la educación a toda la vida de las personas (lifelong learning), para asegurar la actualización personal y la capacidad de adaptación a situaciones socio-laborales en constante cambio (Bauman, 2007; Federighy, 2006; Fernández Ludeña, 2007; Pinto Molina, Sales, \& Osorio, 2008; Sabán Vera \& Monclús Estella, 2008). El desarrollo efectivo de estos procesos de aprendizaje permanente es esencial para asegurar la participación activa y efectiva de las personas en esta sociedad.

- La exigencia de nuevas competencias dentro del perfil personal y/o profesional. Del mismo modo que podemos asegurar la importancia actual del lifelong learning, creemos conveniente señalar que «La cultura popular de hoy es [...] cognitivamente más exigente que la de generaciones anteriores» (Lankshear \& knobel, 2008, p. 245). Esto quiere decir que las personas requieren dominar competencias variadas, más complejas y diferentes de las 
necesarias hace tan solo unos años (Area Moreira, 2010a), y que esas competencias son exigibles no sólo en el entorno laboral, sino también a nivel personal, comunitario o familiar (Castells, 1998; Commission of the European Communities, 2000; Fernández Enguita, Souto González, \& Rodríguez Rávena, 2007; Markauskaite, 2006; Sabán Vera \& Monclús Estella, 2008).

Otra característica esencial propia de la sociedad de la información es la interdisciplinariedad y el trabajo cooperativo en los procesos productivos, sociales y por supuesto educativos (Castells, 1999a; Monereo, 2005). En una sociedad con estructuras construidas en torno a redes de información y a partir de las TIC «la colaboración productiva es pieza clave del conjunto de redes de organizaciones interactivas abiertas al cambio incesante» (Guitert, Romeu, \& Pérez-Mateo, 2007, p. 2).

En penúltimo lugar, es necesario señalar como característica de la sociedad de la información que no se debería obviar, el desarrollo y la imposición de la globalización a todos los niveles, tanto económico y político, como social y cultural. Los fenómenos ya no se producen localmente, y adquieren transcendencia global. Este proceso, que surge en el terreno económico, se extiende al modelo de vida de los ciudadanos de la sociedad de la información, que toma como referencia el modelo norteamericano (Cabero Almenara \& Alonso García, 2007), cuna del neoliberalismo más salvaje.

A pesar de que nace en el terreno económico, es incorrecto decir que la globalización no tiene dimensiones extra-económicas. De hecho, se podría afirmar que el desarrollo se produce de manera intercorrelacionada en todas sus dimensiones (económica, social, cultural, ambiental, físico-territorial,...), que conviven y se mezclan cotidianamente (Franco, 2000; Robertson, 2003). Partiendo de estas premisas, podemos apuntar consecuencias que tiene la globalización en todos estos sectores. Vamos a apuntar las principales a nivel económico, político y cultural:

- A nivel económico:

- Apertura generalizada de los mercados de bienes y capitales con el consiguiente fin de los bloques comerciales, tratados regionales e independencia económica de los países.

- Creciente privatización de los sectores económicos, junto al auge de la empresa multinacional y el decaimiento de empresas nacionales. 
- Aumento de la competencia (económica) que por un lado incrementa la cantidad y calidad de los productos y por otro amenaza las condiciones de trabajo. Así mismo, se corre el riesgo de generar una sobreexplotación del medio ambiente.

- Acceso sin normas de los países a los mercados internacionales, lo que por un lado facilita la venta de sus productos y la adquisición de todo tipo de tecnologías y mercancías y por el otro desprotege los mercados de menor calibre económico y lleva al abandono de intentos organizados de promover progreso y justicia social.

- A nivel político:

- Tendencias políticas globales, internacionalistas y surgimiento de nacionalismos como defensa de lo propio.

- Manejo de las grandes empresas multinacionales sobre algunos aspectos de la política de los países; Los estados-nación pierden soberanía en favor de las empresas y organizaciones internacionales.

- Generalización de la democracia y el estado de derecho como formas de gobierno predominantes a nivel mundial. Como contrapunto, resurgen zonas de profunda inestabilidad política debidas, por un lado, a la pérdida de poder por parte de los gobiernos $y$, por el otro, al rechazo existente hacia las características occidentales de hacer política.

- Disminución progresiva del control de las migraciones, que puede llevar a la pérdida de los sectores más cualificados (fuga de cerebros) y la invasión de elites empresariales internacionales en países pobres.

- A nivel cultural:

- El contacto multicultural y el intercambio que con esto se genera provoca una falsa sensación de amenaza a la integridad de las culturas e identidades culturales de los grupos. Por otro lado, si somos capaces de superar este miedo, se presenta la oportunidad de enriquecernos a todos con un intercambio positivo de costumbres. 
- Se amplía la cantidad de información disponible, pero se mantienen, e incluso aumentan las diferencias fruto del conocimiento previo de cada agente a la hora de enfrentarse a dichas informaciones.

- Proceso de homogeneización, masificación e internacionalización cultural, occidentalizando las culturas globalizadas. «Las expresiones, valores y sistemas culturales de los grupos que tienen el poder, los medios y la capacidad para hacerlo van imponiéndose progresivamente» (Monereo \& Coll, 2008, p. 29).

Por supuesto, estos cambios económicos, políticos y culturales (y los correspondientes al resto de dimensiones) están afectando, y mucho al ámbito educativo. Es evidente que dichos procesos de globalización tienen consecuencias importantes en la transformación de los procesos de enseñanza-aprendizaje, ya que han sido comprendidos hasta ahora en el contexto de prácticas educativas y políticas públicas de carácter meramente nacional (Burbules \& Torres, 2001). En los aspectos económicos, parece claro, que los nuevos entornos de empleo y las nuevas exigencias laborales están reclamando una formación específica diferente a la que se venía impartiendo tradicionalmente. Por otra parte, a las escuelas no les interesa preparar a los estudiantes sólo como productores, sino que existe una preocupación creciente en lo que se refiere a actitudes y prácticas como consumidores y ciudadanos de la sociedad de la información. A nivel político, surge el conflicto de seguir manteniendo, o no, como un objetivo importante del sistema escolar la formación de la conciencia nacional en un contexto en el que el estado-nación ya no tiene el sentido y el poder de antaño. Por último, a nivel cultural surge la preocupación por el mantenimiento de las identidades culturales regionales, con su consecuente inclusión en los currículos escolares.

El último elemento que queremos destacar como una de las principales características de la sociedad de la información, es el surgimiento de la llamada "nueva economía". Éste término, acuñado por gran cantidad de estudiosos de los factores económicos que implica la sociedad de la información (Castells, 1999a; Diario oficial de la Unión Europea, 2006; Majó i Cruzate \& Marqués, 2002; Picardo Joao, 2002; Tubella i Casadevall \& Vilaseca i Requena, 2005), se refiere al movimiento de capitales surgido gracias a la información y el conocimiento como fuente de negocio y beneficio.

Esta nueva economía, surgida en los años 90 al amparo del nacimiento de internet, colisiona con el modelo tradicional de hacer negocio de modo definitivo, ya que ahora 
ninguna empresa puede renunciar a los beneficios de la nueva economía. Manuel Castells (1999a, p. 81) analiza perfectamente este impacto, cuando señala lo siguiente:

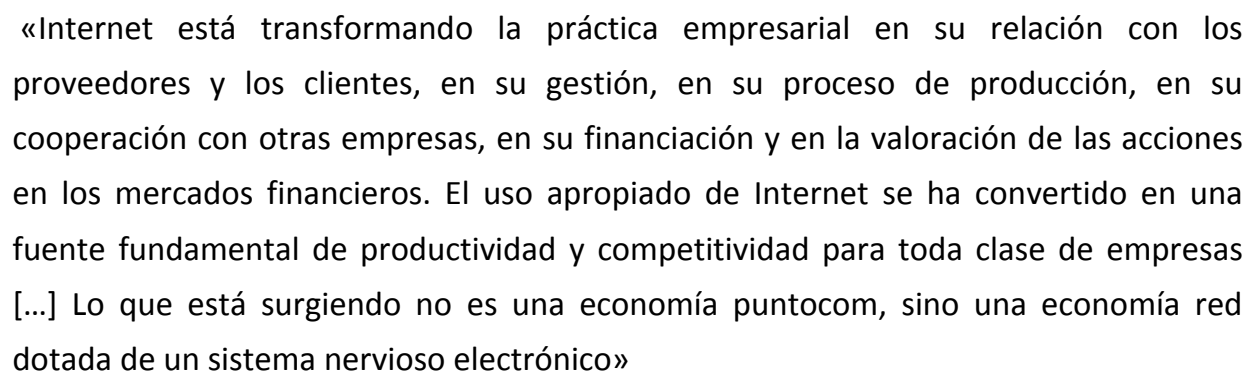

Con esta última frase, Castells quiere dejar claro que la nueva economía no son únicamente aquellas empresas que desarrollan todo su negocio de manera totalmente virtual, sin una representación física; la nueva economía la forman todas las empresas que aprovechan las tecnologías de la información para mejorar la productividad y/o la innovación, bien sea en los procesos productivos, de relación con los clientes, de gestión y administración, de financiación,...

Por tanto, las aportaciones de las TIC al ámbito empresarial parece que son inabarcables. A partir del estudio llevado a cabo a partir de varios autores (Area Moreira, 2005; Castells, 1999a; Franco, 2000; Robertson, 2003), intentaremos especificar y resumir las principales aportaciones de las TIC, señalando las contribuciones específicas de este medio tecnológico al nuevo modelo de empresa:

- Escalabilidad: Con este término nos estamos refiriendo a que a la red no le importa si las operaciones son globales o locales, o dónde estén localizadas, o si las transacciones se retraen o se expanden. A la red esta variabilidad no le supone grandes costes, ya que el sistema de producción puede reprogramarse muy fácilmente. Esta ruptura de las fronteras espaciales supone un ahorro de recursos enorme.

- Glocalización: Íntimamente relacionada con la anterior característica, aparece este término. Analizando bajo una perspectiva cultural el fenómeno de la globalización, se puede caer en la cuenta de una paradoja evidente (Bolívar Botía, 2001): En el contexto en el que nos encontramos, en el cual se está siguiendo un proceso de desterritorialización progresiva (a nivel, sobre todo, económico y político), con una globalización cultural creciente, se ha incrementado la territorialización cultural. En este ambiente existe una 
dualidad aparentemente enfrentada y contrapuesta: lo global y lo local. De este dualismo nace el concepto "Glocalización". El término glocalización procede del vocablo japonés dochakuka (derivada de dochaku, que significa "el que vive en su propia tierra"). Esta palabra hace referencia a una práctica del mundo de la agricultura que consiste en adaptar las técnicas generales agrarias a las condiciones que el propio agricultor posee en su contexto local. Este mismo término también ha sido empleado en el mundo de los negocios en Japón principalmente para referirse a la entidad que está dispuesta a actuar localmente con un pensamiento global, es decir, adaptarse a las condiciones locales tomando como punto de referencia una perspectiva global. Durante los años ochenta el término empezó a cobrar fama en los círculos económicos, pero fue en los noventa cuando se convirtió en una de las ideas y ejes principales del marketing (Robertson, 2003). Hoy en día el término glocalización va un poco más allá: En una sociedad dominada por la inmediatez y la comunicación, en la que el espacio y el tiempo se han reconfigurado, la glocalización supone que los acontecimientos locales se vuelven globales, ya que son modelados por eventos que ocurren a kilómetros de distancia y viceversa. Esto quiere decir que tanto lo local influye en lo global, como lo global influye en lo local. Para entender mejor esta relación entre global y local, podemos pensar en el mundo como una inmensa red (sociedad reticular o sociedad-red), en la que la aldea global se forma fruto de la interconexión de muchas aldeas locales. Estas conexiones están continuamente abiertas y retroalimentándose, generando relaciones de colaboración e influencia mutua. Lo que acaba ocurriendo es que cuando un sujeto o un grupo de sujetos hacen algo en una región (o aldea local), esto afecta tanto a la propia región como al conjunto de regiones (aldea global). Del mismo modo, la actuación del sujeto ha estado influida por otras regiones de la aldea global.

- Interactividad: Interactividad a tiempo real o asíncrono entre clientes, empleados, subcontratas, proveedores.... Esto provoca una mejora en la calidad de los servicios y de la información.

\footnotetext{
${ }^{4}$ Hago referencia a estos dos polos como "aparentemente enfrentados" debido al desacuerdo existente entre los sociólogos en lo que respecta a señalar lo local bien como contrario o bien como complementario a lo global. El término glocalización presenta estos dos términos como inseparables e íntimamente relacionados. Para profundizar sobre este aspecto, recomiendo la consulta del capítulo de Roland Robertson (2003) señalado en la bibliografía.
} 
- Flexibilidad: Las TIC posibilitan que según las características y necesidades de cada proyecto empresarial, el alcance se extienda de un modo predeterminado y la composición se diversifique de manera controlada. Además, estas nuevas tecnologías permiten conservar el control del proyecto empresarial.

- Gestión de la marca: Una de las obsesiones de las empresas de hoy en día es conseguir un valor de marca, es decir, que los clientes y la sociedad en general valoren la marca que representa la empresa de modo positivo. Para conseguir este valor de marca, es muy importante tener un control fuerte de la innovación y de la calidad del producto ofrecido. Las tecnologías asociadas a la era de la información permiten llevar a cabo este control de modo mucho más eficiente, realizando retroalimentación positiva de todos los componentes del proceso de producción, detectando y corrigiendo errores,...

- Personalización: Uno de los ejes fundamentales de la nueva forma de hacer negocios. La personalización es la capacidad de la empresa para adaptarse a las preferencias y necesidades de cada mercado local. Se puede fabricar un producto a gran escala (lo cual es beneficioso para la empresa, ya que reduce costes marginales), pero adaptando el producto final a las necesidades del consumidor individual. Internet es la herramienta que está permitiendo a las empresas ofrecer productos a gusto del consumidor.

Tabla 1.1 Cantidad de empleo basado en la industria del conocimiento (2005)

\begin{tabular}{l|c|c|c}
\hline & MANUFACTURACIÓN & SERVICIOS & TOTAL \\
\hline Suecia & $6.5 \%$ & $47.8 \%$ & $54.3 \%$ \\
\hline Dinamarca & $6.3 \%$ & $42.8 \%$ & $49.1 \%$ \\
\hline UK & $5.6 \%$ & $42.4 \%$ & $48 \%$ \\
\hline Finlandia & $6.8 \%$ & $40.5 \%$ & $47.3 \%$ \\
\hline Holanda & $3.3 \%$ & $41.9 \%$ & $45.2 \%$ \\
\hline Bélgica & $6.5 \%$ & $38.3 \%$ & $44.8 \%$ \\
\hline Alemania & $10.4 \%$ & $33.4 \%$ & $43.8 \%$ \\
\hline Francia & $6.3 \%$ & $36.3 \%$ & $42.6 \%$ \\
\hline Irlanda & $6 \%$ & $33.9 \%$ & $39.9 \%$ \\
\hline Austria & $6.5 \%$ & $31 \%$ & $37.5 \%$ \\
\hline Italia & $7.4 \%$ & $29.8 \%$ & $37.2 \%$ \\
\hline
\end{tabular}




\begin{tabular}{l|c|c|c}
\hline España & $4.7 \%$ & $27 \%$ & $31.7 \%$ \\
\hline Grecia & $2.1 \%$ & $24.5 \%$ & $26.6 \%$ \\
\hline Portugal & $3.3 \%$ & $22.7 \%$ & $26 \%$ \\
\hline EU 15 & $6.7 \%$ & $34.7 \%$ & $41.4 \%$ \\
\hline
\end{tabular}

Una vez analizadas las variables que influyen en el surgimiento y mantenimiento de la nueva economía, es importante aportar algunos datos que validen lo dicho anteriormente. Nos centraremos para ello en el informe de la Work Foundation sobre la economía del conocimiento en Europa (Brinkley \& Lee, 2006). En este informe, se aportan datos acerca del impacto de la industria del conocimiento en Europa. Si observamos las tablas 1.1 y 1.2 podemos observar cómo alrededor del $40 \%$ del total de la industria de la Unión Europea se basa en el conocimiento como fuente de negocio y beneficio.

Tabla 1.2 Negocio de las industrias europeas del conocimiento (2005)

\begin{tabular}{l|c}
\hline \multicolumn{1}{c|}{ EU 15 } & \% del empleo total \\
\hline Manufactuación basada en tecnología & $6.9 \%$ \\
\hline - Alta tecnología & $1.1 \%$ \\
\hline - Media tecnología & $5.8 \%$ \\
\hline Servicios de mercado & $15.3 \%$ \\
\hline - Servicios de alta tecnología & $3.5 \%$ \\
\hline - Servicios financieros & $3.2 \%$ \\
\hline - Negocios/comunicaciones & $8.6 \%$ \\
\hline Salud, Educación, Cultura & $19.4 \%$ \\
\hline TOTAL & $\mathbf{4 1 . 5 \%}$ \\
\hline
\end{tabular}

En las tablas anteriores se muestra, tanto la cantidad de personas con empleos relacionados con la economía del conocimiento (tabla 1.1), como el porcentaje de industrias con una actividad propia de este mismo modelo (tabla 1.2). En ambos casos se puede ver cómo se supera el $40 \%$; y esta tendencia parece que sigue en aumento sin final a la vista. De hecho, cinco años más tarde, según el informe del Euroean Investment Bank (Uppenberg, 2010), alrededor del 70\% del empleo y del valor añadido de la economía europea procede de la industria del conocimiento, principal agente de la nueva economía.

\subsubsection{Problemática de la sociedad de la información}


Al igual que hemos hablado de las principales características de la sociedad de la información, sin implicar un sesgo negativo en el análisis (más bien, al basarnos en la obra de Castells, el sesgo del análisis anterior puede inclinarse hacia el lado positivo), entendemos que es necesario, en pos de tener en cuenta esta realidad a la hora de continuar con el proceso de investigación teórica y en el diseño, implementación y análisis del proceso metodológico, estudiar ciertas especificidades que la sociedad de la información tiene vinculadas, y que pueden tener consecuencias negativas (especialmente a nivel educativo, que es el que nos ocupa) si no se tienen en cuenta.

A lo largo de la literatura analizada relativa al tema que nos ocupa, se han ido localizando ciertas preocupaciones de los estudiosos de la sociedad de la información basadas en datos empíricos en unas ocasiones, en simples elucubraciones teóricas en otras, o en una mezcla de las dos en muchos casos. Sin entrar a valorar si estas inquietudes son más o menos fundadas, consistentes y razonables, lo que sí es verdad es que éstas aparecen de manera sistemática en buena parte de la literatura estudiada, y que, como iremos viendo a continuación, la mayoría de los autores se resisten a obviar esta realidad, considerándola como un elemento importante dentro de cualquier estudio que pueda hacerse de la sociedad de la información.

Para la exposición de dicha problemática hemos tratado de clasificar los principales hitos a los que se refiere la literatura en grupos con características comunes. Los ejes resultantes de dicha clasificación, que se irán desgranando uno a uno, son los siguientes:

- Las brechas de la sociedad de la información

- Inmigrantes y nativos digitales

- La sobrecarga informacional

- Cultura del espectáculo

- Cultura mosaico

- La alfabetización funcional en la sociedad de la información

- La vida líquida

\section{Las brechas de la sociedad de la información}

«El impacto de las TIC en las actividades de la vida diaria, profesional y de ocio del ciudadano, y las carencias formativas que tienen muchas personas junto a la precariedad de medios para acceder a la información en igualdad de condiciones 
ha llevado a los poderes públicos, a la administración y a las bibliotecas a rediseñar su misión, sus metas y sus funciones, incorporando nuevos conocimientos y habilidades que ofrecen la alfabetización informacional, [...] prerrequisito para participar eficazmente en la sociedad de la información» (Pinto Molina \& Uribe Tirado, 2012, p. 149)

Bajo esta denominación se agrupa todo aquello que hace referencia a las desigualdades que auspicia, por sus características estructurales y tecnológicas, la sociedad de la información. Desigualdades centradas principalmente en lo que se refiere a las posibilidades de aprovechamiento de las tecnologías de la sociedad de la información en búsqueda de la construcción de conocimiento para el beneficio personal y social.

El término general más recurrido en la bibliografía que le hace referencia es "brecha digital" (digital divide en inglés). Podemos situar el nacimiento oficial de esta expresión en la primera encuesta del National Telecommunications \& Information Administration (NTIA), que analizaba las diferencias entre los grupos que tenían y no tenían posibilidades de utilizar internet. (Castaño-Muñoz, 2010)

Más recientemente la denominación "brecha digital" se ha discutido, ya que a nivel conceptual no parece tener en cuenta todas las dimensiones que están implicadas en las desigualdades que a partir de ella surgen (Cabero Almenara, 2004; Castaño-Muñoz, 2010; Cebrián Herreros, 2009; Pimienta, 2008). Estos autores señalan que el propio concepto puede tener consecuencias perversas, ya que da a entender que las desigualdades surgen esencialmente por las diferencias de acceso a las TIC $^{5}$, mientras que las investigaciones han demostrado que el simple hecho de que estas tecnologías estén disponibles, no asegura que estas desigualdades tiendan a desaparecer (Cabero Almenara, 2004; Castaño-Muñoz, 2010; Peña-López, 2010a, 2010b; Selwyn, 2010). Podríamos resumir esta postura con las palabras de Peña-López, cuando señala que el modelo de intervenir en infraestructuras para derrotar a la brecha digital "falls short when adding the human factor to the equation: infrastructures do not work on their own, they need to be operated and, indeed, operated in a specific way by a specific person» (2010b, p. 3)

\footnotetext{
${ }^{5}$ Soportar esta postura implica llevar a cabo políticas de provisión de infraestructuras sin más trasfondo que ese, sin tener en cuenta las necesidades contextuales y personales. Se habla de consecuencias perversas porque estas políticas benefician principalmente a las grandes multinacionales que sellan acuerdos con los gobiernos para llenar de aparatos los espacios públicos.
} 
Podemos encontrar en la literatura multitud de estudios sobre la brecha digital que sostienen este concepto: La mayor parte de estos análisis apunta hacia que la vertiente formativa también es importante a la hora de analizar la brecha digital. Sin embargo, a la hora de cuantificarla para observar las diferencias entre las diferentes regiones y los distintos países, se toman únicamente variables cuantitativas. Por ejemplo, Hernández, Blanco y Lera (2003), en su estudio, al tratar de aportar indicadores de la brecha digital, señalan como principales las infraestructuras según zona geográfica y los usos de internet, entendiendo usos no como calidad en el aprovechamiento de los recursos, sino como cantidad, esto es, cuantía de uso de internet en el trabajo y en la escuela, porcentaje de profesores que utilizan internet semanalmente, etc.

Mientras que las personas y estudiosos que trabajan para mitigar los efectos de la brecha digital señalan que esto nunca se conseguirá sin dar el papel capital que se merece a la formación (saber aprovechar lo poco que se tiene es más productivo que invertir grandes esfuerzos en equipamiento de dudosa eficiencia que se queda obsoleto en poco tiempo), las instituciones públicas siguen empeñadas en dar más importancia a llenar de aparatos el entorno con iniciativas al menos de dudosa validez ética.

En este sentido, podemos reseñar las iniciativas del G-8, que constituyó el DOT Force (Digital Opportunity Task Force) con la finalidad de superar la brecha digital a nivel global. En el informe que este grupo emitió (2002), señala como retos para superar la brecha, los siguientes:

- Fortalecimiento del desarrollo digital mediante políticas estratégicas que lo favorezcan.

- Incrementar el acceso y la conectividad mediante proyectos que doten de mayores infraestructuras.

- Desarrollar habilidades para la economía de la información. Desarrollar la alfabetización tecnológica en las personas, especialmente en los estudiantes, entendiendo esta alfabetización como las habilidades para utilizar las tecnologías.

- Fomentar la aplicación de las TIC de manera ajustada al contexto local de cada región. 
Este grupo, fomentado por el G-8, también tiene apoyo de la ONU, que participa en el DOT Force a través del UNICT Task Force. Este grupo, señala entre sus objetivos ${ }^{6}$ mejorar el desarrollo de capacidades que fomenten el uso de las TIC, en términos muy similares a los que apuntábamos en el eje tercero del DOT Force.

A lo largo de los informes que se desprenden de la actividad de estas instituciones, se puede observar cómo el interés que éstas tienen en el desarrollo de competencias tiene como objetivo que las personas usen las tecnologías para beneficio de la economía, no para su beneficio personal o para el comunitario. La formación que tratan de impulsar estas instituciones es meramente técnica, de conocimientos de uso de los aparatos, sin tener en cuenta el para qué su empleo.

No podemos finalizar esta argumentación sin hacer referencia a la "Ley de Pimienta", que resume perfectamente la postura que aquí estamos defendiendo. Esta "ley", ha sido promulgada por Daniel Pimienta, antiguo directivo de empresas informáticas como IBM, y actualmente fundador y director de la ONG FUNREDES, que busca difundir las TIC en los países en desarrollo, particularmente en América Latina y el Caribe (Pimienta, 2008, p. 15):

«La “ley de Pimienta" estipula que:

1) Un proyecto de TICPD [TIC para el desarrollo] cuya proporción de presupuesto de infraestructura pasa del $60 \%$ terminará con toda probabilidad con serios problemas por carencias en otros rumbos.

2) Un proyecto de TICpD cuya proporción de presupuesto de infraestructura pasa del $80 \%$ terminará con toda probabilidad siendo un desastre...

3) Un proyecto de TICPD que recibe cerca del $100 \%$ de su presupuesto para la capa de infraestructura debería ser el objeto de escrutinio de los organismos de detección y prevención de la corrupción... pues lo más probable es que su finalidad es generar comisiones substanciosas en la compra de equipamientos que terminarán en pocos años obsoletos antes de recibir el uso debido.»

El empleo de estos preceptos como plantilla para analizar proyectos lanzados para la integración de las TIC en cualquier ámbito puede ser de gran utilidad. Por ejemplo, si revisamos globalmente el ambicioso proyecto lanzado en España, conocido como "Escuela $2.0^{\prime 7}$, nos percatamos de las deficiencias que dicho programa tiene, ya que no especifica ni las competencias digitales concretas que se incluyen (o deben incluir) en

\footnotetext{
${ }^{6}$ Consultado el 9 de noviembre de 2010 en http://www.unicttf.org/about/planofaction.html

${ }^{7}$ Programa cancelado a principios de 2012 por el Gobierno de España: http://sociedad.elpais.com/sociedad/2012/04/04/actualidad/1333569324_569893.html
} 
la formación, ni hace referencia clara a las nuevas metodologías que surgen con el nuevo paradigma vinculado a las TIC (sólo señala unas indicaciones genéricas sobre la “metodología 2.0"). Parece como si el principal campo de acción en el que se plantea hacer incidencia de manera seria y sistemática es en el nivel de las infraestructuras. De hecho, como se puede consultar en numerosas notas de prensa e informaciones que transmiten los medios de comunicación, la información que llega a la opinión pública sobre la implementación del plan Escuela 2.0 sólo hace referencia a este ámbito: «EI programa Escuela 2.0 dotará de un portátil a 400.000 alumnos y 20.000 profesores y digitalizará 14.400 aulas durante el curso 2009/2010».

Y bien, retomando el debate abierto más arriba, si el término brecha digital no es del todo correcto por sus implicaciones y su falta de generalidad, ¿qué término podríamos emplear que lo sustituya?

En este aspecto, aunque son muchas las propuestas, no existe un consenso generalizado. Nosotros vamos a aportar a partir de nuestra visión de la realidad las que más nos convencen:

Desde nuestro punto de vista, un término que englobe toda la realidad de las brechas de la sociedad de la información debe hacer referencia precisamente a eso, es decir, a las desigualdades en la capacidad que tienen las personas para el acceso, manejo y difusión de la información y la construcción del conocimiento. Partiendo de que el principal valor añadido de la sociedad actual con respecto a las anteriores es la existencia de la información abundante y fácilmente accesible como fuente de riqueza, (revolución informacional), las desigualdades que se puedan derivar de dicha sociedad tendrán que ver con las posibilidades de cada persona o comunidad para poder manejarla y convertirla en un conocimiento beneficioso para uno mismo y/o para el grupo.

Así, la reducción de dichas desigualdades se constituirá en varias dimensiones o ejes ordenados (Selwyn, 2010):

- Acceso formal a la información mediada por las tecnologías. Esto quiere decir que la persona, al menos en teoría, puede tener acceso físico a las tecnologías que le permiten el acceso a la información.

\footnotetext{
${ }^{8}$ Como ejemplo presentamos el titular de una nota de prensa publicada el 04 de septiembre de 2009, obtenida directamente de la web del Ministerio de Educación (www.educacion.es): http://www.educacion.es/horizontales/prensa/notas/2009/09/escuela2p0.html
} 
- Acceso efectivo, es decir, que la persona, además de poder acceder a la información, siente que es capaz de utilizar las tecnologías que le dan acceso a la misma.

- Uso técnico de los recursos. La persona no sólo sabe que puede acceder a la información, sino que usa los recursos que le dan acceso, entendiendo usar como manipular. Ese uso no tiene porqué ser efectivo para los objetivos de la persona.

- Empleo significativo de la tecnología. El uso que se hace de las tecnologías tiene sentido, y se realiza con un aceptable control de la situación por parte del usuario, que está capacitado para acceder a los contenidos que desea. De este modo, el empleo es fructífero, relevante y útil.

- Resultados del empleo. A corto plazo, las consecuencias del manejo de la información.

- Consecuencias actuales y percibidas de la integración de los recursos. Consecuencia a medio/largo plazo en términos de participación en la sociedad, ya sea económica, social, política,...

De este modo, reducir la brecha supone actuar en varios frentes a la vez, siendo casi más importante la formación del usuario en competencias informacionales que le hagan capaz de buscar, seleccionar, procesar y comunicar la información que desea, y con ello transformarla en conocimiento. El que exista una igualdad ante el acceso a la información no presupone directamente, que exista una igualdad ante el acceso al conocimiento.

«La brecha digital es tecnológica, la del conocimiento es vital» (Cebrián Herreros, 2009 , p. 28). Por mucho que eliminemos la brecha digital, entendida como posibilidad de acceso a las TIC y conocimientos técnicos de manejo de las herramientas, no eliminaremos la desigualdad real, la brecha del conocimiento, hasta que no eduquemos a la sociedad en competencias informacionales. Por tanto, el desarrollo de competencias informacionales es necesario para la reducción de la brecha del conocimiento (Cabero Almenara, 2004; Castaño-Muñoz, 2010; Cebrián Herreros, 2009; NCLIS, 2003).

En conclusión, parece claro que es más realista, ético y operativo relacionar las brechas de la sociedad de la información con las posibilidades de acceso al 
conocimiento que con la disponibilidad de equipamiento tecnológico. Por tanto, podemos hablar de la brecha del conocimiento para referirnos a aquellas desigualdades producidas por efecto de la sociedad de la información que tienen que ver con las posibilidades de aprovechamiento de sus tecnologías asociadas para manejar información y construir conocimiento para el beneficio personal y social. De esta manera, para combatir voces discordantes que entonan críticas como que «el aumento de la información, en vez de aproximar, contribuirá a incrementar el distanciamiento en el conocimiento y en, consecuentemente, la aparición de brechas socioculturales» (Aguiar Perera, Farray Cuevas, \& Brito Santana, 2002, p. 23), o que el predominio del informacionalismo actual «va unido al aumento de la desigualdad y la exclusión en todo el mundo» (Castells, 1999b, p. 95) debemos perseguir un cambio de paradigma, desde un enfoque hacia la propia tecnología, hasta un enfoque hacia los contenidos y las aplicaciones, esto es, un enfoque educativo (Pimienta, 2008). Una orientación educativa que prime la formación en competencias informacionales (búsqueda, evaluación, procesamiento y comunicación de información) más allá de las competencias digitales o tecnológicas (Cabero Almenara, 2004; Monereo \& Coll, 2008).

\section{Inmigrantes y nativos digitales}

Esta construcción, que podría considerarse como un aporte conceptual concreto dentro de lo que hemos agrupado como brechas de la sociedad de la información, se ha colocado en un apartado independiente debido a la relevancia que ha tenido en su área de conocimiento y, por ende, al gran número de estudios que la hacen referencia y que realizan investigaciones en torno a su naturaleza desde que Mark Prensky (2001a, 2001b) la desarrollara.

El término nativo digital (del inglés digital native), que tiene un predecesor en el concepto net generation (Tapscott, 1998) que ya apuntaba hacia lo que finalmente Prensky conceptualizó en su estudio, hace referencia a toda persona nacida en el contexto de lo que hemos definido como sociedad de la información, y que se ha desarrollado en entornos ricos en tecnologías propias de dicha sociedad. Este hecho, unido a los modernos descubrimientos procedentes de las neurociencias ${ }^{9}$, que indican

\footnotetext{
${ }^{9}$ Específicamente hacemos referencia a la neuroplasticidad y la maleabilidad cerebral, dos términos muy relacionados que surgen a partir de la explosión de las neurociencias. Para más información al respecto se pueden consultar los siguientes enlaces:

http://memoryzine.com/2010/07/02/introduction-to-neuroplasticity/

http://www.dialogues-cns.org/brochures/21/pdf/21.pdf
} 
que el cerebro es un órgano totalmente dinámico, capaz de reconfigurarse y reestructurarse en función de los estímulos que recibe, lleva a afirmar que "today's students think and process information fundamentally differently from their predecessors». (Prensky, 2001a, p. 1)

Por otro lado, surge necesariamente otro concepto antagónico al anterior, el de inmigrante digital (del inglés digital inmigrant), con el que nos referimos a toda persona nacida en un contexto anterior (históricamente hablando) al de la sociedad de la información, y que se ha tenido que adaptar a los profundos cambios que esta sociedad conlleva, desde una concepción personal de la realidad totalmente diferente.

Para terminar de retratar estos dos conceptos opuestos, creemos conveniente añadir la siguiente cita:

La mayoría de los docentes de la educación obligatoria, nos encontramos descentrados, sin las ideas claras, viviendo entre grandes paradojas que suscitan los actuales cambios sociales, laborales y tecnológicos. Sentimos que tenemos un pie en la sociedad industrial y el otro en la sociedad de la información; comprobamos el desfase generacional entre lo que es importante aprender para nosotros y los intereses y necesidades de niños y jóvenes; y observamos un distanciamiento entre la práctica y la problemática real de los centros educativos de Primaria y Secundaria, y la investigación y las propuestas universitarias (Benito Morales, 2008, p. 149)

A pesar del impacto positivo que tuvo este concepto en el desarrollo de posteriores trabajos, en los últimos años se han desarrollado estudios empíricos críticos con esta construcción que parecen negar la existencia de diferencias tan claras entre los nativos y los inmigrantes digitales. Estos estudios revelan que variables como el género, el nivel educativo, la autonomía personal, o las características socioeconómicas del sujeto, son más explicativas de los diferentes niveles de uso de las tecnologías de la sociedad de la información que la edad de los propios sujetos, que no explica la diversidad sustancial en el uso de estas tecnologías (Hargittai, 2010; Selwyn, 2010; Snyder, 2004).

Estas críticas se pueden complementar con otros estudios que buscan encontrar las principales dificultades que tienen los estudiantes cuando se enfrentan a una tarea de tratamiento de la información. Podríamos hacer una síntesis de estos estudios, señalando las principales conclusiones sobre las competencias informacionales de los alumnos (Gómez Hernández, 2010): 
- No saben identificar sus necesidades reales de información, por lo que desarrollan estrategias de búsqueda poco eficaces, impulsivas y superficiales.

- No evalúan ni contrastan la calidad, pertinencia ni veracidad de la información obtenida, comparando los resultados obtenidos en función de su relevancia.

- No se observa conexión entre los conocimientos previos y la diversidad de fuentes existentes.

- Poca reflexión sobre cómo difundir los resultados en función de la intención y el contexto.

- Desconocimiento y poco respeto por los aspectos éticos implicados en el uso y acceso a la información.

- Los estudiantes parten en su búsqueda de motores generalistas (Google), sin tener en cuenta otras posibilidades, como los portales de las bibliotecas.

Esto quiere decir que los actuales estudiantes (nativos digitales), tienen grandes dificultades para hacer un tratamiento eficaz de la información. Por lo tanto, ser nativo digital no garantiza alcanzar un dominio elevado de las competencias informacionales, y no se puede afirmar, entonces, que existan diferencias entre los nativos y los inmigrantes digitales en este aspecto (favorables a los nativos).

Sin embargo, desde nuestro punto de vista, estos estudios críticos con este concepto no contrastan exactamente lo que Prensky define como variable dependiente: Mientras que las diferencias entre el nativo y el inmigrante digital (variable independiente) están situadas para Prensky en la manera de pensar de unos y otros (variable dependiente), las investigaciones que tratan de contrastar estos conceptos sitúan como variable dependiente el perfil de manejo de las Tecnologías de la Información y la Comunicación. Y perfil de pensamiento (o modo en el que se procesa la información en la mente) poco tiene que ver, a nuestro parecer, con el perfil de manejo de las TIC. Por otro lado, los estudios que demuestran que los nativos digitales tienen grandes dificultades para procesar la información de manera eficiente, no implican que éstos desarrollen procesos de pensamiento similares o diametralmente opuestos a los que despliegan los inmigrantes digitales.

En suma, una vez señalado todo esto, debemos decir que la distinción entre nativos e inmigrantes digitales nos parece un aspecto importante a tener en cuenta a 
la hora de diseñar cualquier proceso formativo. Lo que supone esta distinción es "un modo distinto de pensar el mundo, primordialmente no de manera lineal sino simultánea, no de manera analítica sino sintética, no de manera racional sino intuitiva» (Ferrés i Prats, 2000, p. 56). Existen grandes diferencias entre inmigrantes y nativos, ya que «En oposición a la cultura humanística, sistematizada y jerarquizada [inmigrante digital], hay que hablar de una cultura mosaico, caracterizada por la dispersión y el caos aleatorio [nativo digital]» (Ferrés i Prats, 2000, p. 56). Esta exposición nos vuelve a arrastrar hacia las ideas de McLuhan $(1967,1969,1987)$, señaladas anteriormente, que indican que las tecnologías, una vez diseñadas por el hombre, tienen la capacidad, en cuanto a que son instrumentos, de reconfigurar completamente la mente del ser humano, y afectar así al modo de proceder de todos sus niveles (incluido, por supuesto, el del pensamiento consciente e inconsciente).

De este modo, es lícito que pensemos que una persona que haya desplegado su experiencia vital rodeada por una determinada tecnología, es susceptible de desarrollar una estructura mental y unos procesos de pensamiento dispares a otra persona cuyas experiencias se hayan extendido alrededor de otra tecnología con unas bases conceptuales totalmente diferentes: "We now know that brains that undergo different developmental experiences develop differently, and that people who undergo different inputs from the culture that surrounds them think differently» (Prensky, 2001b, p. 3).

Sin embargo, a pesar del dispar desarrollo de estas facultades mentales, parece también claro que los nativos digitales, por sí solos, no son más competentes en el manejo efectivo de la información a través de los entornos mediados por las TIC. Más bien, como veremos en los siguientes apartados, estos nativos digitales se dejan fascinar por la "cultura del espectáculo" (Ferrés i Prats, 2000), haciendo un uso encapsulado y estático de la información.

\section{La sobrecarga informativa}

Con este concepto, nuclear en todo trabajo que se refiera a la educación en la sociedad de la información (Area Moreira, 2005; Bruce, 1997; Cabero Almenara \& Alonso García, 2007; Cebrián Herreros, 2009; Fernández Enguita et al., 2007; González Mariño, 2008; Majó i Cruzate \& Marqués, 2002; Markauskaite, 2006; Martí Lahera, 2007; Monereo \& Coll, 2008; Pablos Pons, 2010; Scardamalia, 2004; Tubella i Casadevall \& Vilaseca i Requena, 2005), nos queremos referir a la sobresaturación de 
información que recibimos gracias a las Tecnologías asociadas a esta sociedad, y a la multiplicidad de formatos en los que se puede presentar dicha información.

El núcleo del problema no se encuentra en el exceso de información en sí, sino en que gran cantidad de información que nos llega está sin filtrar, es de dudosa calidad, anónima, y aparece en los más diversos soportes (CAUL, 2001, 2002). Una persona sin las herramientas necesarias para hacer frente a este bombardeo de informaciones que pueden ser contradictorias, de diversas calidades, en diversos soportes, de autores anónimos o de dos extremos opuestos del mundo, etc., se puede encontrar desorientada o incluso totalmente perdida en el océano de la información sin ni siquiera ser consciente de ello. En estos casos la información, más que ser un cimiento clarificador que nos facilita la comprensión de la realidad (o de una realidad concreta), se puede convertir en caos y simple ruido que nos desorienta aún más. De hecho, algunos autores comienzan a hablar del information fatigue syndrome (IFS), information overload o infoglut, cuando se refieren a los síntomas que produce la exposición continua al exceso de información (Baker, 2006; Kabachinski, 2004; Thomas, 1998; Zelder, 2009): «Symptoms included paralysis of analytical ability, mounting anxicty and self doubt and an increasing tendency to blame others» (Bundy, 1998). Estos mismos autores señalan la importancia capital de formar en competencias informacionales para prevenir estas consecuencias.

El término con el que nos referiremos a esta realidad es el que emplea Alfons Cornellá $(2003,2009)$ habitualmente en su trabajo: infoxicación.

El concepto infoxicación supone que si no desarrollamos el espíritu crítico y no disponemos de herramientas cognitivas suficientes para detectar la necesidad específica de información, buscarla, evaluarla, procesarla conforme a nuestras necesidades y comunicarla de manera adecuada, nos veremos sobrepasados por las propias TIC, no las dominaremos en busca del beneficio personal y/o social y no seremos capaces de desempeñar un rol activo y relevante en nuestra comunidad y, por ende, en la sociedad de la información (Cabero Almenara \& Alonso García, 2007).

La otra consecuencia de esta infoxicación, íntimamente relacionada con la anterior, es que la persona "infoxicada" no es capaz de transformar la información que recibe en conocimiento, y por tanto, no está aprovechando el valor intrínseco potencial que tiene la información (Area Moreira \& Guarro, 2012). Esta diferenciación entre información y conocimiento es esencial, ya que se plantea como uno del los ejes esenciales de la argumentación que se desarrollará posteriormente: 
"We're drowning in information and starving for knowledge» (C. Campbell, 1985, p. 10)

Esta cita, aunque antigua, es muy reveladora de lo que está ocurriendo en la sociedad de la información. Mientras que nos encontramos en un contexto en el que tenemos literalmente al alcance de nuestras manos todo tipo de información útil, la mayor parte de las personas no somos lo suficientemente competentes en el ámbito informacional para aprovechar dicha información en búsqueda de la promoción del bienestar personal y social, esto es, para llevar a cabo un proceso de tratamiento de la información que la transforme en conocimiento aprovechable en la consecución de nuestros objetivos.

Mientras que la información es simplemente «un conjunto de datos, estructurados $y$ formateados, pero inertes e inactivos hasta que no sean utilizados por los que tienen el conocimiento suficiente para interpretarlos» (David \& Foray, 2002, p. 6), el conocimiento se puede definir como la consecuencia de un conjunto de capacidades cognoscitivas o competencias. La persona que es competente informacionalmente es capaz de transformar uno o varios bloques informativos en conocimiento, seleccionando, sintetizando, agrupando, generalizando, etc. dicha información, en busca del beneficio personal y/o social.

Por lo tanto, podemos afirmar que promocionar un acceso equitativo y universal a la información no presupone al mismo tiempo una igualdad ante el conocimiento, y que el fomento del desarrollo de competencias informacionales a lo largo de todos los niveles formativos vuelve a ser un punto esencial: «accessing information, while a precondition, is not equal to learning or to being able to mobilize knowledge appropriately» (O'Farrill, 2008, p. 157)

Así, en este apartado se vuelve a poner de relieve la importancia capital de las competencias informacionales en la sociedad de la información, y la necesidad de llevar a cabo las acciones necesarias para que su desarrollo ocupe una posición nuclear y se convierta en una de las principales metas de los sistemas educativos actuales. De hecho, este nuevo panorama informacional, implica en el ámbito educativo que la escuela pierde valor como agente informativo, ya que existen otras instituciones más eficientes en la transmisión de la información. Por ende, nos encontramos con que en la escuela adaptada a la sociedad de la información, «más importante que el qué enseñar será el cómo hacerlo». (Cabero Almenara \& Alonso García, 2007, p. 17)

\section{La cultura del espectáculo}


Partiendo de las ya comentadas ideas de McLuhan, se construye esta teoría llamada la "cultura del espectáculo" (Ferrés i Prats, 2000). La cultura del espectáculo nace al considerar que las tecnologías asociadas a la Sociedad de la información, por su estructura y por su relevancia capital, han modificado tanto la realidad física como la realidad de las personas de una manera profunda e impactante. Este cambio radical, producido en unos pocos años, ha provocado que convivan en la sociedad personas pertenecientes a culturas prácticamente opuestas. Los rasgos principales de estos cambios culturales, desde una cultura lineal, sistematizada y jerarquizada, hasta otra del espectáculo, dinámica y circular, los podemos resumir en cinco (Ferrés i Prats, 2000, pp. 25-35):

- Primacía de lo sensorial y concreto sobre lo abstracto y simbólico: En la cultura del espectáculo se transmiten valores materialistas, vinculados con la preponderancia de la imagen sobre los signos abstractos, como la palabra.

- Primacía de lo narrativo sobre lo analítico y estructurado: En la nueva realidad todo es presentado como relato, ya sea el cine, las noticias, la publicidad, etc. Las personas nacidas en la cultura del espectáculo prefieren un relato a una información aséptica y sistemática como la que se puede presentar en un libro de texto.

- Primacía de lo dinámico sobre lo estático: Ahora el conocimiento y el saber no son algo estático, inamovible y cerrado, sino que todo es dinámico, relativo y en constante movimiento.

- Primacía de las emociones sobre el raciocinio: Se prima el placer inmediato que aportan las emociones sobre el placer postergado que otorga, por ejemplo, el texto escrito.

- Primacía del sensacionalismo sobre lo ordinario: Este eje tiene mucho que ver con el anterior. Lo que produce sensaciones inmediatas, emociones, es más buscado que lo ordinario, estático, racional, en una palabra, aburrido.

Así, el mundo de la educación no puede mantenerse impasible ante estos cambios estructurales fundamentales, y debe asumir que los alumnos no son iguales que hace unos años, y que los métodos que funcionaban cuando los profesores eran estudiantes no funcionarán en sus alumnos de hoy en día. (Prensky, 2001a).

Para concluir, en palabras del propio Ferrés i Prats: 
Si los nuevos medios han modificado profundamente la cultura en la que surgieron y si ésta ha modificado a su vez profundamente la manera de ver, de sentir y de pensar la realidad por parte de las nuevas generaciones, es imprescindible que la educación y la cultura sepan modificar también sus propias estructuras, esquemas y criterios para adecuarse a unos sujetos modelados por la sociedad en la que nacieron. (2000, p. 64)

\section{La cultura mosaico}

Esta característica, muy emparentada con el concepto anterior de cultura del espectáculo (incluso el propio Ferrés i Prats emplea este concepto para definir alguna de las características de la nueva cultura), fue desarrollada por Abraham Moles (1975) a lo largo de toda su obra.

El término cultura mosaico hace referencia a «una forma atomizada del bagaje de conocimientos presente en el ser humano y que representa el aspecto extremo de una cultura de la época de las comunicaciones de masas» (Moles, 1975, p. 205). Así, el conjunto de conocimientos e ideas encapsulados y recibidos al azar sirven de base para estructurar el cerebro de los sujetos inmersos en dicha cultura. En contraste con la "cultura clásica", que se proponía ordenar el tejido cerebral como si de una tela de araña se tratara, construyendo la estructura en un primer momento y haciendo la trama cada vez más densa por medio de la educación, la cultura mosaico promueve la construcción de un sistema fibroso, de fieltro, que añade fragmentos azarosamente y sin una estructura formal definida. Sin embargo, al contrario de lo que podríamos pensar, esta estructura puede alcanzar la misma cohesión y densidad (aunque no lógica) que la de tela de araña.

Ciertamente parece que la sociedad de la información y todas las tecnologías que la acompañan fomentan un modelo de información fragmentada y encapsulada, que consiste en acceder a la información a través de gran número de cápsulas informativas concretas, poco extensas e inconexas (Cerezo, 2008), que se conectan y agrupan de manera azarosa «mediante una simple yuxtaposición temporal o por las leyes de frecuencia» (Moles, 1975, p. 565).

Esta especie de zapping informacional que se basa en consumir vertiginosa y superficialmente una gran cantidad de contenidos sin una estrategia definida (Benito Morales, 2008; Ferrés i Prats, 2000), se opone de pleno a los presupuestos de la educación clásica, y por tanto, plantea un reto a las instituciones educativas, en el sentido de que deben aprovechar y prever que los alumnos van a llegar a la escuela con un bagaje muy amplio de información adquirida por diferentes medios. 
Información en forma de puzzle; inconexa, estancada e incluso deformada que nuestros estudiantes deben organizar, integrar y convertir en conocimiento útil a través de estrategias (meta)informacionales (Majó i Cruzate \& Marqués, 2002; Pozo et al., 2006). Siguiendo con la analogía, podríamos definir los pasos siguientes:

1. Realizar agrupaciones de las piezas por similitud cromática (organización previa de la información)

2. Componer cada bloque por separado, encajar las piezas en cada grupo (construir conocimiento)

3. Una vez que se tienen encajadas las piezas por bloques, sólo queda agrupar todos en un puzzle unitario (sintetizar e integrar en un cuerpo de conocimientos lógico y estructurado)

Y, por supuesto, otra vez podemos ver la estrecha relación entre estos pasos descritos y el desarrollo de las competencias informacionales (búsqueda, evaluación, procesamiento y comunicación de información), lo cual nos vuelve a conducir a resaltar el papel nuclear que debe ocupar la formación en estas competencias a lo largo y ancho de los procesos educativos anclados en el contexto de la sociedad de la información.

\section{La alfabetización funcional en la sociedad de la información}

Aunque más adelante dedicaremos un apartado completo al análisis pormenorizado del concepto alfabetización y las variables que le rodean, nos adelantaremos mínimamente a dicho estudio señalando en este punto algunas de las implicaciones básicas de la alfabetización funcional en la sociedad de la información.

En primer lugar definiremos alfabetización funcional: Para entender mejor el término, veremos la evolución que ha sufrido el término alfabetización, hasta llegar a considerarse alfabetización funcional en la documentación oficial de la UNESCO, organismo internacional que desarrolla gran cantidad de proyectos en el ámbito de la alfabetización. Mientras que en 1958 considera alfabetización como: «A person is considered literate if he/she can read and write with understanding a simple statement related to his/her daily life» (UNESCO, 2001, p. 15); alrededor de 30 años más tarde, el concepto de alfabetización, al que ya podríamos denominar alfabetización funcional, es el siguiente: «Está funcionalmente alfabetizada la persona que es capaz de realizar todas las actividades en que la alfabetización es necesaria para la actuación eficaz en su grupo o comunidad y que le permiten seguir valiéndose de la 
lectura, la escritura y la aritmética al servicio de su propio desarrollo y el de la comunidad» (Fernández Ludeña, 2007, p. 27).

Lo que caracteriza a este cambio, como se puede observar, es principalmente la consideración de que la persona alfabetizada es capaz en la nueva definición de algo más que decodificar y dar un sentido global a un conjunto de símbolos (alfabeto). $Y$ este añadido hace referencia a las posibilidades efectivas participación en la comunidad gracias a la alfabetización.

Este cambio de dirección en lo que respecta a la consideración de lo que es una persona alfabetizada tiene que ver esencialmente con la expansión del pensamiento freiriano, que concibe la alfabetización como la capacidad de "leer la palabra y el mundo". Esto supone dar al lenguaje un enfoque contextual, ya que está inscrito en una realidad social determinada y no es aséptico. De este modo, la persona alfabetizada es aquella capaz de participar en contextos socio-culturales específicos que requieren a su vez el dominio de la lecto-escritura (Monereo \& Coll, 2008). Cada práctica de alfabetización y cada contexto exigen el desempeño de un tipo de competencias lectoescritoras diferentes (no es lo mismo leer una revista de divulgación en un viaje en tren, que consultar un manual para aprender a emplear un programa informático delante del ordenador).

Por otro lado, centrándonos más en el contexto escolar, podemos encontrar indicios de que el concepto de alfabetización también se reestructura en este ámbito si lo relacionamos con las tres grandes crisis de la escuela (Ferrés i Prats, 2000):

- Una primera crisis tiene lugar cuando Grecia pasó de una cultura oral a una escrita: En este momento comienzan a surgir escuelas que se preocupan por la educación en el arte de leer y escribir las letras y los números, en una palabra, por alfabetizar. Esta escuela prototípica está reducida a un pequeño estrato de la población, y no parece haber una gran preocupación por extender la alfabetización a todos los ciudadanos.

- La aparición de la imprenta a gran escala y la consecuente diseminación de documentos escritos supone la segunda crisis importante de la escuela: A partir de este momento, debido a que el texto escrito es accesible para un gran porcentaje de población, comienza a surgir una notable preocupación por extender y generalizar la alfabetización a la ciudadanía, y con ello surge una fuerte reestructuración de la escuela y su institucionalización como 
agente que debe asegurar la alfabetización de las personas. El concepto de alfabetización que se maneja en este momento es estático y vinculado con la decodificación e interpretación aséptica de símbolos gráficos.

- Esta escuela se ha mantenido, con mayores o menores cambios (no estructurales), hasta hoy en día, llevando a cabo su labor de manera más o menos eficiente. Sin embargo, el momento actual lo podemos identificar con una tercera crisis de la escuela, como consecuencia de la revolución informacional (Pérez Gómez, 2012): En el ambiente de la sociedad de la información no tiene sentido hablar de alfabetización en términos de interpretación de textos desvinculados de su contexto original, ya que el número de contextos $\mathrm{y}$ formatos comunicativos se ha multiplicado exponencialmente (no nos comunicamos de la misma forma en un chat que en un libro), y por tanto, es necesario que tanto emisor como receptor interpreten debidamente el continente para no "malinterpretar" el contenido ${ }^{10}$. Y, evidentemente, la cantidad de contextos y formatos comunicativos posibles cambian con el paso del tiempo, son dinámicos.

Desde este punto de vista debemos considerar la alfabetización como un proceso inacabado, permanente, hasta el punto de entenderla como aprendizaje a lo largo de toda la vida (Fernández Ludeña, 2007), ya que la evolución social y tecnológica genera nuevas prácticas y nuevos contextos que implican la aparición de nuevas alfabetizaciones. Así, adoptando esta visión socio-cultural de alfabetización, no podemos hablar del término alfabetización en sentido exclusivo, sino que debemos hacer referencia a alfabetizaciones para referirnos a este conjunto de prácticas surgidas por los diferentes contextos y tecnologías (Monereo \& Coll, 2008).

Así, hemos llegado ya al concepto de lo que muchos autores han acabado por denominar "alfabetizaciones múltiples" o "nuevas alfabetizaciones" (Area Moreira, 2008; Cope \& Kalantzis, 2009a; Kellner, 2004; Lankshear \& knobel, 2008; Pozo et al., 2006), nuevas alfabetizaciones propias de la sociedad de la información, surgidas como consecuencia del desarrollo tecnológico en este ámbito de la información y la comunicación.

\footnotetext{
${ }^{10}$ La interpretación de una información cualquiera depende en gran parte de las experiencias previas del sujeto, lo cual determina su estructura mental y de pensamiento. Por eso consideramos que el término malinterpretar no existe en sí mismo para el receptor (que siempre interpreta adecuadamente en función de su visión de la realidad), sino que es una construcción del emisor en función de la diferencia entre lo que quiere transmitir y lo que realmente transmite al receptor
} 
Para terminar esta argumentación, no podemos olvidar la importancia que tiene entender la alfabetización como una puerta de entrada al universo del conocimiento. Las siguientes palabras lo expresan perfectamente:

\footnotetext{
«La alfabetización, más que un objetivo en sí mismo, puede ser entendida como la puerta que permite a los seres humanos acceder a un universo de conocimiento, no el único pero sí el más complejo, que viene vehiculado a través de la cultura escrita teniendo siempre muy en cuenta que el objetivo no es aprender a leer y escribir mecánicamente, sino incorporar la cultura lectora.»
}

De este modo, podemos inferir que la alfabetización funcional tiene mucho que ver con el desarrollo de las competencias informacionales, ya que ambos conceptos hacen referencia a competencias que se deben desarrollar como cimientos sólidos sobre los que construir el bagaje de conocimiento personal. Así, para superar la fase de la sociedad de la información y alcanzar la anhelada sociedad del conocimiento, es necesario desarrollar una ciudadanía funcionalmente alfabetizada, capaz de actuar eficazmente en su grupo o comunidad y que utiliza los distintos modos de representación a su alcance al servicio de su propio desarrollo y el de su comunidad.

En conclusión, parece que en la sociedad de la información tiene más justificación y vigencia que nunca hablar de alfabetizaciones múltiples, y no tiene sentido, por tanto, que las instituciones educativas mantengan la postura de enseñar a leer y escribir como un simple proceso de decodificación e interpretación de símbolos. La alfabetización supone el conocimiento y manejo de los posibles diferentes contextos y formatos alfabetizados, así como el dominio de estrategias que permitan continuar con el proceso de alfabetización de manera continua. Como consecuencia, el desarrollo de competencias informacionales que faculten a la persona para aprender a aprender de manera autónoma a lo largo de toda su vida, parece básico para capacitar a la persona en la búsqueda de la "alfabetización para toda la vida".

\section{La vida líquida}

Ya se han realizado más arriba algunos apuntes descriptivos básicos sobre el término "vida líquida", no obstante, dada su riqueza conceptual como axioma fundamental para la generación de otras teorías, y su potencial conflictivo si se obvia dentro de cualquier actuación educativa en la sociedad de la información, hemos decidido añadir en este apartado una descripción más exacta y pormenorizada del mismo. 
«Frente a la solidez de las certezas de la cultura decimonónica el presente digital nos ha traído un tiempo de relativismo y mutuabilidad del conocimiento, de formas efímeras de las ideas, valores y costumbres, de cambio permanente, de permisividad de las diferencias, de incertidumbre sobre el futuro inmediato. En definitiva, la cultura es más compleja, multivariada y multimodal.» (Area Moreira \& Guarro, 2012, p. 47)

Con este concepto tan visual y revelador, Zygmunt Bauman $(2006,2007)$ se refiere a la vida que tendemos a vivir en una sociedad profundamente dinámica e incierta, en la que "las condiciones de actuación de sus miembros cambian antes de que las formas de actuar se consoliden en unos hábitos y en unas rutinas determinadas [...]. La vida líquida, no puede mantener su forma ni su rumbo durante mucho tiempo». (2006, p. 9)

Al igual que la realidad circundante se reconfigura constantemente, el conocimiento también deja de ser estático, lento y verdadero. Desde diferentes lugares se producen conocimientos que se difunden instantáneamente. Se estima que el conocimiento que posee la humanidad se duplica en la sociedad de la información cada 5 años (Cabero Almenara \& Alonso García, 2007) y, por tanto, el ciclo a través del que se producen conocimientos nuevos quedando obsoletos los anteriores es significativamente más corto que el propio ciclo biológico de la vida activa de las personas (Majó i Cruzate \& Marqués, 2002). De este modo, es lógico pensar que los conocimientos adquiridos durante la infancia y la juventud en las instituciones educativas formales no van a servir para siempre, ya que se quedan obsoletos en poco tiempo (Area Moreira, 2001; Commission of the European Communities, 2000; Pinto Molina et al., 2008), y que la sociedad va a demandar a estas personas una capacidad continua de actualización y de adquisición de nuevas competencias exigibles para cada momento (Markauskaite, 2006; Méndez Paz, 2005; Pesquero Franco et al., 2008). Así, el reto de las sociedades modernas líquidas y sus instituciones y agentes educativos, no es otro que formar ciudadanos con capacidad para desarrollar aprendizajes a lo largo de la vida (lifelong learning) y con las competencias necesarias para aprender a aprender y para hacerse responsables del seguimiento de su propio aprendizaje (Organización Internacional del Trabajo, 2003).

Si aceptamos el postulado de la vida líquida, entonces estaremos de acuerdo con el siguiente corolario: El sistema educativo de nuestros días, basado en formar jóvenes con la idea de que los conocimientos y la información adquiridos les servirán definitivamente para toda su vida, ha quedado obsoleto, y va a ser necesario que las 
personas renueven sus conocimientos a lo largo de su vida, tanto si se mantienen en el mismo puesto de trabajo, como si, como les ocurrirá muy probablemente, cambian de empresa, y hasta de especialización laboral.

Entonces, ¿cómo pensar en la educación en la sociedad líquida? ¿Qué papel deben asumir los sistemas y los agentes educativos en este nuevo entorno poco amigable con lo que entendíamos hasta ahora por formación?

Ante estas preguntas, Bauman $(2006,2007)$, con la facilidad que le caracteriza para la construcción de símiles visuales, ofrece la siguiente reflexión:

Pensemos en la educación de la "edad moderna sólida" (pre-informacional o prelíquida) como un arma balística, cuando se dispara, tanto su dirección como la distancia que recorrerá han sido decididos previamente por la forma y la posición del cañón y por la cantidad de pólvora que contiene la munición. Por tanto, es posible calcular con bastante fiabilidad dónde impactará el proyectil. De hecho, los filósofos de la educación de la era pre-líquida concebían a los profesores como lanzadores de proyectiles balísticos y su misión consistía en instruirles sobre como asegurarse de que sus disparos se mantuvieran con la mayor precisión dentro de la trayectoria preestablecida.

¿Ha cambiado el objetivo en la edad moderna líquida? ¿tenemos ahora un objetivo fijo? Hoy en día se podría decir que los objetivos «además de ser invisibles para el artillero, empiezan a moverse» (Bauman, 2006, p. 155), incluso a mayor velocidad de la que pueden alcanzar los propios proyectiles. Por tanto las armas balísticas no son útiles. En la educación actual se hace necesario un misil inteligente con capacidad para cambiar la dirección en función de los movimientos imprevisibles del objetivo y aprender continuamente de los movimientos del blanco (buscar su secuencia matemática de movimientos) hasta que sea capaz de predecir con la mayor exactitud posible el movimiento del objetivo:

«Los misiles inteligentes, a diferencia de sus anteriores parientes balísticos, aprenden sobre la marcha. Por lo tanto, lo que necesitan que se les suministre al principio es la capacidad de aprender, y de aprender deprisa [...] Lo que nunca debe olvidar el cerebro de los proyectiles inteligentes es que el conocimiento que adquieren es sumamente desechable, válido sólo hasta nuevo aviso y útil sólo de forma temporal, y que para tener garantías de éxito no se puede pasar por alto el momento en el que el conocimiento adquirido deja de ser útil y tiene que ser descartado, olvidado y reemplazado» (Bauman, 2006, pp. 156-157) 
Ni siquiera el conocimiento tiene un valor irremplazable como producto en la vida líquida, ya que es cambiante. El verdadero valor pasa a asignarse ahora a todas aquellas competencias que fomentan la (re)construcción incesante del conocimiento personal y/o social y que promocionan personas en movimiento cognitivo constante.

Así pues, la educación no es un producto acabado, sino que en la sociedad líquida la educación se convierte en un proceso inacabado, dinámico y que se reconstruye y reconfigura continuamente. Mientras que el educador de la vida sólida inyecta directamente en sus alumnos el conocimiento necesario y suficiente para la vida, el educador de la vida líquida transmite herramientas que hacen al alumno capaz de rastrear permanentemente el esquivo e incierto conocimiento (aunque no llegue nunca a alcanzarlo).

Y estas herramientas, evidentemente, están muy vinculadas con las competencias informacionales, ya que estas últimas aportan al alumno una serie de instrumentos cognitivos que le sirven para detectar la necesidad de actualizar el bagaje personal de conocimientos, y llevar a cabo autónomamente y de manera continuada el proceso de manejo de la información (búsqueda, selección, procesamiento y comunicación), y la consecuente construcción de conocimiento.

En suma, para concluir este apartado, podemos resumir que a lo largo de este capítulo hemos tratado de analizar específicamente a través de qué proceso hemos llegado a situarnos en lo que hoy denominamos sociedad de la información, para después hacer una breve exposición sobre las principales características de la sociedad de la información. En relación con las características definidas, hemos llevado a cabo una descripción más pormenorizada de la principal problemática que arrastra la sociedad de la información desde el punto de vista de la cultura y la educación, que es el tema que realmente nos interesa y nos ocupa.

En este aspecto, no nos gustaría terminar sin aportar una reflexión acerca de los verdaderos intereses que parecen guiar la evolución de esta sociedad de la información, a partir de las características descritas a lo largo del apartado. Nos da la sensación de que en la mayor parte de los casos los intereses y excesos económicos y el desinterés y detrimento cultural son los ejes que orientan el camino de la sociedad:

- Hemos señalado que uno de los pilares básicos que configuran la sociedad de la información son las TIC, una tecnología muy potente y numerosa con una industria detrás igual de potente que presiona fuertemente sacando nuevos 
productos que convierten en obsoletos aparatos y aplicaciones que eran perfectamente útiles para el usuario (incluso más eficientes que los nuevos en algunos casos), pero que quedan en desuso y obligan al cambio (uso ilegal del "monopolio", acuerdos entre empresas, avances progresivos, incompatibilidad de formatos, etc.).

- La información es un bien de consumo que genera riqueza. Así, estamos acostumbrados a consumir una abundante cantidad de píldoras informativas $y$, a pesar de la infoxicación que sufrimos, nuestra adicción artificialmente generada al consumo nos empuja a seguir demandando más información.

- La flexibilidad y dinamismo, ejes de la sociedad de la información, lo son también del consumismo irrefrenable y continuado. Generar personas poco apegadas al conocimiento (ya que es voluble y cambiante) conduce, evidentemente, a generar personas poco apegadas a las cosas, ya sean materiales o no materiales. Así, al perder todas las cosas (y digo todas, incluso las propias personas) su valor intrínseco, el único valor es estar a la última, esto es, conseguir todo el elenco de conocimientos y objetos de última generación, sin importar para nada otros valores humanos o sentimentales. Las instituciones educativas, entonces, ¿promocionan bajo este modelo personas críticas que definen su itinerario intelectual continuamente?¿̇o promociona más bien "sujetos veleta", que dan bandazos en medio del caos al ritmo que le marcan los poderes sociales (macro-empresas que controlan los medios de comunicación y que tienen claros intereses estratégicos, políticos, económicos, culturales,...)?

- La inmediatez, o más bien instantaneidad en el acceso a los estímulos deseados y el propio bombardeo de estímulos placenteros puede generar sujetos con una tolerancia ínfima a la espera, adictos al consumo permanente de estímulos externos y por tanto al ruido constante. En esta realidad, ¿̇ónde queda tiempo para la reflexión cognitiva que lleve al desarrollo de una persona crítica que planifica y construye su bagaje de conocimientos en busca del beneficio personal y social?

- Nos hemos referido a la flexibilidad laboral sin aplicar un juicio de valor sobre su bondad o maldad. Pero, ¿no es más exacto hablar de inseguridad laboral? En realidad todo es inseguro en la sociedad de la información. Acordándonos de la expresión latina tempus fugit, nos damos cuenta de que todo cambia y 
se nos escapa, por lo que lo que deberíamos hacer es vivir al día, aprovechando los preceptos del carpe diem, y consumiendo, bajo este criterio y nuestra adicción al consumo, incluso más de lo que nos podemos permitir con nuestros recursos económicos actuales (hasta un simple televisor puede ser financiado para pagarlo en "24 cómodos plazos").

- Cuando hablamos del desarrollo de la globalización en todos los ámbitos, ¿no estamos hablando realmente del avance del mercado global que facilita la inserción de las multinacionales en nuevos mercados y la apertura a nuevos horizontes empresariales? ¿Qué beneficio operativo tiene la globalización entonces para el común de la sociedad?

- A nivel político, ya hemos comentado cómo se observa una pérdida de poder a favor del poder económico. $Y$ en el contexto de la fuerte crisis que nos sacude actualmente (2007-...) se observa mucho mejor, viendo como la sanidad económica (y por ende, social) de los Estados funciona y deja de funcionar a voluntad de los grandes inversores y poderes financieros, que llegan a arruinar países completos en beneficio propio.

- Incluso a nivel de cultura la estandarización cultural tiene efectos perversos beneficiosos para la economía, ya que gracias a la misma se reduce el abanico de posibles productos de consumo, y así se prima la producción en cadena y se reducen los costes empresariales.

- Y acercándonos más al campo educativo, chasta qué punto las políticas que buscan fomentar el lifelong learning obedecen a intereses económicos (Antunes, 2008; Borg, 2005; R. Castro, 2006; Gaio Alves, Neves, \& Gomes, 2010) en vez de buscar encaminarnos hacia una verdadera sociedad del conocimiento?

- Hemos abogado por el empleo del término brecha del conocimiento para hacer una aproximación a las brechas o desigualdades que genera la sociedad de la información más humanista y menos vinculada a los intereses económicos. Sin embargo, de poco nos sirve esta concreción para fomentar una mayor equidad cuando este conjunto de desigualdades «no es otra cosa que el reflejo de la brecha social en el mundo digital» (Pimienta, 2008, p. 11), brecha vinculada y mantenida a y por intereses puramente económicos. 
Entonces, ante la posibilidad de que estemos orientándonos inconscientemente (por inercia) más por los valores que transmite la nueva economía que por los propios valores humanistas y pedagógicos que perseguimos, y que nos estemos moviendo más que en la sociedad de la información, en la economía de la información (Cornellá, 1997), deberíamos ser enormemente cautos a la hora de diseñar e implementar procesos intencionalmente destinados a acercarnos al objetivo de la sociedad del conocimiento, ya que, los hechos nos hacen pensar que lo andado hasta ahora ha sido más hacia atrás que hacia adelante. 


\subsection{Las competencias informacionales como puente entre la sociedad de la información y la sociedad del conocimiento}

Después de todo lo expuesto en el apartado anterior, que nos ha servido en unos casos para comprender mejor la verdadera estructura de lo que consideramos sociedad de la información, y en otros casos para despertarnos si cabe más dudas acerca de sus verdadero funcionamiento, lo que bajo nuestro punto de vista parece evidente es que, como defienden muchos estudiosos del tema, no podemos definir la actual sociedad como del conocimiento: "Vivimos en una sociedad de la información que sólo para unos pocos, los que han podido acceder a las capacidades que permiten desentrañar, poner orden en esa información, se convierte en verdadera sociedad del conocimiento» (Pozo et al., 2006, p. 49).

Otros autores, aludiendo a estas mismas diferencias, prefieren emplear la dicotomía economía de la información-sociedad de la información, argumentando que, una vez analizadas las características de esta nueva sociedad, sus tendencias socioeconómicas invitan a pensar que la revolución informacional es más económica que social, y que hacen falta otro tipo de causalidades para alcanzar la sociedad de la información: «Una cosa es desarrollar una economía de la información, que está más o menos al alcance de cualquier país, y otra muy diferente desarrollar una sociedad de la información [...] Este objetivo puede que dependa más de hasta qué punto exista o no una cultura de la información suficientemente desarrollada en la sociedad» (Cornellá, 1997, p. 10)

En nuestro caso preferimos referirnos a esta dicotomía a través de la terminología sociedad de la información-sociedad del conocimiento, ya que les consideramos términos más reveladores y pertinentes a nivel conceptual para este trabajo y para el área de conocimiento en el que se mueve.

$\mathrm{Y}$, ¿en qué se fundamenta la noción de esta brecha entre sociedad de la información y sociedad del conocimiento? Ya hemos señalado más arriba las profundas diferencias entre lo que entendemos por información y por conocimiento: mientras que información se considera al conjunto de datos presentados en un formato concreto y con un orden determinado, que transmiten un determinado contenido o realidad, conocimiento se refiere al conjunto de informaciones filtradas, 
procesadas, asimiladas e interiorizadas por una persona y/o grupo. De este modo, hablar de un fragmento de información es hablar de un producto acabado, estático, independiente de la persona y hablar de generar conocimiento es hablar de un proceso abierto, dinámico, totalmente dependiente de la cultura de la propia persona o el grupo. Podemos ver en primer lugar, pues, que información y conocimiento son términos íntimamente relacionados pero con una naturaleza totalmente opuesta, y que no tiene por tanto sentido hablar de sociedad de la información y el conocimiento como una sola cosa.

Siguiendo con esta argumentación, también debemos señalar el hecho de que la forma en que se presenta la información hoy en día facilita el acceso a la misma de manera rápida y permanente, ya que las píldoras informativas son de fácil consumo para cualquier persona con unas competencias tecnológicas mínimas. Sin embargo, esta simplicidad en su formato también implica una mayor dificultad para el acceso al conocimiento y a la profundidad de los temas (Cerezo, 2008). Mayor dificultad con respecto a la lógica con la que se presentaba la información antes de la revolución informacional: Mientras que en la era sólida moderna ${ }^{11}$ se propone un modelo jerárquico en el que la estructura lógica de partida y el razonamiento deductivo se convierten en algo esencial en la presentación de la información (Moles, 1975), en la sociedad actual se impone un modelo horizontal, en el que no se intuye una estructura predefinida y que prima el razonamiento inductivo por yuxtaposición de acontecimientos o informaciones sin una necesaria relación entre las mismas. $Y$ convendrán con nosotros cuando afirmamos que en la actualidad nos encontramos en un entorno informacional cognitivamente mucho más complejo y exigente (Lankshear \& knobel, 2008), y que la construcción de conocimiento en este contexto exige destrezas muy diferentes a las que se podrían requerir en las sociedades previas a la revolución informacional.

Parece claro, pues, que al menos a nivel educativo-cultural las diferencias entre sociedad de la información y sociedad del conocimiento son manifiestas y tienen que ver, más que con el desarrollo de nuevas tecnologías, con las propias competencias que desarrollen los ciudadanos de dicha sociedad. Nos queda ahora por definir más específicamente las diferencias entre ambos estados y tender finalmente puentes que

\footnotetext{
${ }^{11}$ Recordamos que de esta manera definía Bauman $(2006,2007)$ a la sociedad previa a la que hoy consideramos de la información.
} 
puedan servir de enlace que promocione el proceso de transformación de la sociedad de la información hacia una verdadera sociedad del conocimiento.

Así, podemos identificar el concepto sociedad de la información con aquella en la que nacen y se diseminan herramientas capaces de generar, almacenar, transmitir y facilitar el acceso a la información, y por ende, en la que la información es la materia prima más preciada (Area Moreira, 2001). Por su parte, el concepto sociedad del conocimiento lo podríamos vincular, en base a la anterior definición, como aquella en la que proliferan modelos educativos que forman ciudadanos capaces de generar, almacenar, transmitir y acceder a la información a través del empleo de las tecnologías disponibles y con las competencias necesarias para generar conocimiento a lo largo de toda la vida en busca del beneficio personal y/o social. Sin embargo, mientras que hoy en día existe disponible una cantidad de información valiosa inimaginable tan sólo hace unos años, «los individuos tenemos prácticamente los mismos recursos biológicos, intelectuales y afectivos para captar, entender y dar sentido a esa información, que quienes nos precedieron hace cincuenta o dos mil años» (Area Moreira, 2001, p. 47).

\title{
SOCIEDAD DE LA INFORMACIÓN
}

SOCIEDAD DEL CONOCIMIENTO

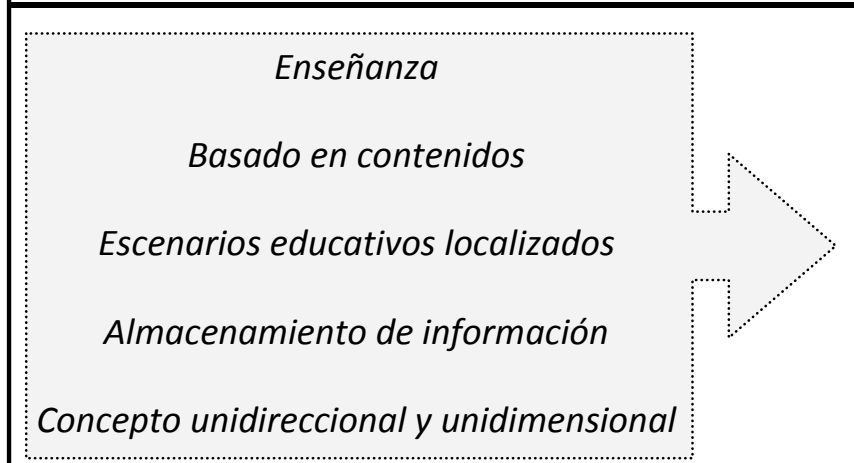

\author{
Aprendizaje \\ Basado en competencias \\ Deslocalización espacio-temporal \\ Gestión y construcción del conocimiento \\ Concepción de red
}

\section{APRENDER A ENSEÑAR}

\section{ENSEÑAR A APRENDER}

\section{Figura 1.1 sociedad de la información vs. sociedad del conocimiento}

Estos recursos biológicos, intelectuales y afectivos a los que se refiere Manuel Area se pueden inferir a partir de lo expuesto en la figura anterior. En la misma podemos encontrar una comparativa entre los procesos educativos que se desarrollan en la actual sociedad de la información como fruto de la aplicación directa de los preceptos de la educación clásica, y los procesos educativos básicos que se persiguen en la nueva sociedad del conocimiento. Así, podemos poner en comparación cada pareja de conceptos para ver qué significa cada cambio: 
- Enseñanza vs aprendizaje: Es decir, desde una perspectiva basada tanto en el que enseña como en lo que se enseña, a una perspectiva que se orienta más hacia el que aprende y lo que se aprende. De este modo, el tradicional rol pasivo del alumno se reconfigura totalmente al igual que el rol del profesor, que pasa de ser un mero almacén de la información que se debe enseñar a los alumnos, a una especie de guía intelectual que acompaña al educando a lo largo de todo su proceso formativo.

- Contenidos vs competencias: Mientras que tradicionalmente el objetivo de la escuela ha sido transmitir contenidos, esto es, enculturar a la persona en un determinado contexto y campo, en la sociedad del conocimiento no tiene sentido esta manera de trabajar. La escuela no puede continuar transmitiendo conocimientos antiguos como si estuviera formando trabajadores de la era industrial. En la actualidad, el contexto emergente demanda el desarrollo de competencias (Cabero Almenara \& Alonso García, 2007). Cualquier persona puede acceder a cualquier contenido que sea de interés académico (o no académico), por lo que lo realmente interesante es que el educando aprenda herramientas y estrategias metainformativas que le permitan acceder a la información que necesite y adquirir con autosuficiencia conocimientos (David \& Foray, 2002). Debemos orientar al estudiante más al proceso que al contenido en sí de la actividad. Lo esencial hoy no es memorizar palabras, frases y textos (eso lo podemos dejar para las máquinas), sino implementar el proceso adecuado para entender la realidad que está detrás del contenido. $\mathrm{Si}$ se dominan estos procesos, se accederá sin duda al contenido (Andretta, 2007).

- Escenarios localizados vs deslocalización temporal y espacial: Aceptando que las tecnologías (especialmente las TIC) aumentan nuestras capacidades en una amplia variedad de tareas físicas y cognitivas (McLuhan, 1969; Prensky, 2009), podemos señalar que una de esas capacidades expandida es la de la deslocalización espacio-temporal. Gracias a la introducción de las TIC como nueva variable en los escenarios educativos, se consigue modificar en buena medida el resto de variables (como los roles de los actores, el formato de interacción o la organización del tiempo el espacio y los recursos específicos) y se logra dilatar el espacio vital del proceso educativo más allá de las paredes del propio centro escolar (Monereo \& Coll, 2008). De este modo, con la integración de las TIC en el contexto educativo se propicia que las fronteras 
educativas se disipen, y se favorece un surgimiento de nuevos entornos educativos, necesarios para afianzar el acceso eficaz a un sistema que promociona y trata de asegurar el aprendizaje a lo largo de toda la vida (Commission of the European Communities, 2000).

- Almacenamiento vs gestión y construcción del conocimiento: Esta comparativa se refiere a cómo se desarrolla el proceso de tratamiento de la información en los procesos de enseñanza-aprendizaje de una y otra Sociedad. Mientras que en la educación tradicional los procesos de búsqueda, evaluación, adecuación al oyente (procesamiento) y comunicación de información corrían a cargo del profesor en todo momento, de manera que el educando no tenía más que memorizar una información bien masticada y preparada, hoy en día no tiene tanto sentido fomentar los conocimientos relativos a los hechos, "al tiempo que va en aumento la necesidad de conocer la manera de acceder, analizar y explotar la información y transformarla en nuevos conocimientos» (Organización Internacional del Trabajo, 2003). Así, los resultados formativos que espera la sociedad del educando se han transformado completamente: no se pretende la reproducción del conocimiento, sino, más bien, la generación del mismo (Marzal García-Quismondo, 2010). No es tan importante la cantidad de información que los sujetos en edad formativa reciben, sino más bien interesa la calidad de la que construyen en los distintos contextos informativos (Pablos Pons, 2010).

- Unidireccionalidad y unidimensionalidad vs estructura en red: Con estos conceptos nos estamos refiriendo más que a diferencias en los procesos educativos, a diferentes maneras de percibir, interpretar y actuar en la realidad. Ante una concepción jerarquizada del mundo, con una estructura vertical que favorece el estatismo y la falta de relación entre las diferentes unidades, nace una visión más reticular, horizontal y que responde a la lógica de la interconexión (Castells, 1999a). Las organizaciones forman una red en la que todos los nodos están interconectados, e intercambian recursos paralela y constantemente. De este modo, en el campo educativo, la multidireccionalidad y multidimensionalidad que permiten la estructura reticular favorecen un aprendizaje menos departamentalizado, más interrelacionado. Se puede entender mucho mejor esta dicotomía relacionándola con la ya clásica diferencia entre Web 1.0 y Web 2.0: En la Web 1.0 (unidireccional y unidimensional) es un grupo de personas afines el 
que construye una información para publicarla en un espacio de manera que lo que allí se refiere es estático, y el usuario se convierte en un receptor pasivo de información más o menos veraz y de mayor o menor calidad. Por su parte, la Web 2.0 (estructura reticular) no es estática, sino que por su lógica permite la construcción compartida de contenidos, de manera que el conocimiento es dinámico. Mientras que la Web 1.0 tiene mucho que ver con la mentalidad del átomo: Productos acabados, preparados para que las personas los consuman, cerrados, que no permiten al usuario controlar sus propios datos; la Web 2.0 se basa en la mentalidad del bit: Se centra en los servicios y en habilitar al usuario y a las comunidades de usuarios para la producción y adquisición de productos comunes compartidos (Lankshear \& knobel, 2008). La Web 2.0 ha cambiado cualitativa y cuantitativamente la estructura de internet, proponiendo una nueva filosofía y promoviendo una manera radicalmente diferente de enfrentarse al conocimiento (Liu, Liu, Bao, Ju, \& Wang, 2010; Rubio, Martín, \& Morán, 2010). Así, hemos pasado de ser entes independientes, lectores del conocimiento escrito y estático (visión unidireccional y unidimensional) a ser nodos conectados en una red cuasiilimitada, tanto lectores como escritores del conocimiento voluble, que fluye y cambia constantemente (concepción de red). Y este nuevo paradigma que surge en la sociedad para enfrentarse al conocimiento se adapta perfectamente al actual contexto líquido, dominado por las TIC y por la lógica de la interconexión.

Las dicotomías presentadas más arriba, que realmente se corresponden con la evolución lógica que pensamos, en base a nuestra investigación, que está sufriendo la educación en el siglo XXI, se pueden considerar como cada uno de los apartados que articula el cambio global en la concepción de la educación al que nos estamos enfrentando. Este cambio conceptual en lo que entendemos por educación se sitúa fundamentalmente en concebir actualmente la educación más como un proceso en el que el educando adquiere las competencias necesarias para ser capaz de aprender y generar conocimiento autónomamente, que como el producto de los conocimientos que el sujeto ha adquirido en su periplo escolar. Es decir, frente a una cultura de "aprender a enseñar", nos encontramos con la necesidad de "enseñar a aprender".

De hecho, la propia terminología empleada en la actualidad nos indica esta evolución; mientras que el concepto "conocimiento" se relaciona con una visión estática, productual, unidimensional, etc., de la realidad, el término "competencia", 
que sustituye hoy en día en la mayoría de documentos de las instituciones educativas a conocimiento, está más ligado al principio de aprender a aprender y al concepto de lifelong learning (Pablos Pons, 2010).

«Enfocar la enseñanza no desde los contenidos sino buscando la formación en competencias, implica un aprendizaje activo que presupone la motivación para aprender, la capacidad para emitir un juicio crítico y la facultad para saber cómo aprender» (Sabán Vera \& Monclús Estella, 2008, p. 171)

Hoy en día, por tanto, más que promover aprender una cultura, las instituciones educativas y la sociedad en general, deben fomentar una cultura del aprendizaje (Pozo et al., 2006) acorde con las características de la propia sociedad de la información y que prepare para la sociedad del conocimiento en la que con casi toda seguridad van a necesitar desenvolverse los ciudadanos: «El objetivo, pues, de construir una economía basada en el conocimiento comporta la puesta en práctica del aprendizaje, tanto en el ámbito individual como en el social, como vía de acceso a la información y al conocimiento» (Pifarré, Sanuy, Vendrell, \& Gòdia, 2009, p. 130). Y esta nueva cultura del aprendizaje está basada en el desarrollo de competencias informacionales que capaciten a la persona para desarrollar las competencias necesarias de manera autónoma y en cualquier momento y lugar y para gestionar eficazmente la información y participar activamente en los procesos de construcción del conocimiento, considerando éste como un proceso permanente e inestable.

De hecho, hay autores que incluso hablan, más que de desarrollar la competencia de aprender a aprender, de la importancia de aprender a desaprender en un contexto en el que el conocimiento queda obsoleto de manera acelerada (Alemany, 2003; Andrade, 2005). 


\subsection{El aprendizaje en la sociedad de la información: buscando la sociedad del conocimiento}

«Durante el siglo XIX y buena parte del siglo XX el sentido social de la educación fue básicamente político. La educación, a través de la creación de los sistemas escolares obligatorios, tuvo la función de formar homogéneamente a los ciudadanos, mientras que los niveles superiores del sistema formaban a las élites dirigentes. Desde la segunda mitad del siglo XX hasta casi su finalización, el sentido de la educación estuvo definido por la economía. La educación fue concebida como la agencia responsable de la formación de los recursos humanos necesarios para el desarrollo económico y social y, en esa medida, las políticas estuvieron definidas en el marco de procesos de planificación. Las últimas décadas, en cambio, se caracterizaron por una suerte de déficit de sentido, por ausencia de perspectivas de mediano y largo plazo, donde la competencia (en el sentido económico y de mercado) privó a la educación de una orientación clara en cuanto a su función social» (Tedesco, 2012, p. 27)

De lo dicho hasta ahora parece claro que, dados los profundos cambios experimentados hasta llegar a la actual sociedad de la información, el mundo de la educación debe replantear sus bases más profundas y arraigadas y adaptarlas al contexto actual para preparar y dirigir el camino hacia la sociedad del conocimiento. Se parte del hecho de que "las sociedades del conocimiento no existen todavía, sólo cabe hablar de economías del conocimiento y de comunidades del conocimiento» (Echeverría, 2012, p. 39).

De hecho, sabemos que una de las funciones básicas de la educación es la transmisión del patrimonio cultural y social, entendiendo cultura como «el conjunto de representaciones, reglas de conducta, ideas, valores, formas de comunicación y pautas de comportamiento adquiridas que caracterizan a un grupo social» (Quintanilla, 1992, p. 2). Como tal, si la cultura y la sociedad cambian de modo significativo, la educación también debe cambiar significativamente:

«No es lo mismo educar a unas personas para que vivan y trabajen durante toda la vida con unos conocimientos relativamente estables que formar a personas para que a lo largo de su vida sepan continuar aprendiendo y cambiando sus conocimientos cuando la cambiante sociedad en la que están inmersas lo exija. Tampoco es lo mismo aprender en una sociedad que ofrece un acceso muy limitado a la información, que aprender inmersos en un enorme mar informativo y 
dotados de poderosos instrumentos para el proceso de la información y la comunicación» (Majó i Cruzate \& Marqués, 2002, p. 107)

A lo largo de este apartado, por tanto, vamos a hablar sobre la educación en la sociedad de la información, los principales factores implicados y hacia dónde se dirigen los procesos de enseñanza-aprendizaje.

\subsubsection{Las TIC como recurso educativo inherente a la sociedad de la información}

No cabe duda de la gran capacidad de penetración de las TIC en todos los sectores de la sociedad (Castells, 1999a), especialmente en el ámbito educativo. Remarcamos su importancia en el mundo educativo, ya que dado su potencial nos inclinamos a pensar que su presencia enriquece los procesos de enseñanza-aprendizaje (Pinto Molina et al., 2008) y es esencial. A pesar de que no se ha demostrado empíricamente que la incorporación de las TIC en los procesos educativos mejore efectivamente los resultados de la formación de las personas, "It is now widely accepted that information and communications technologies lie at the heart of education in the twenty-first century» (Selwyn, 2010, p. 34).

Sin embargo, esta aceptación general de la incorporación de las TIC al ámbito educativo trae consigo muchos riesgos derivados de una integración automática y poco reflexiva de las mismas:

- En primer lugar, debemos tener en cuenta el riesgo de que estas tecnologías se incorporen a los procesos educativos como un objetivo en sí mismo y no como un recurso con potencial educativo. En la medida en la que las TIC, por extraordinarias que sean, se conviertan en algo más que un mero instrumento curricular integrado de manera organizada y coordinada con el resto de componentes del currículo (Aguiar Perera et al., 2002), estaremos fomentando que estas herramientas, más que facilitar y promover la enseñanza y el aprendizaje, entorpezcan el propio proceso.

- Derivado de este riesgo nos encontramos con que, lejos de aprovechar el potencial de las TIC, su integración se limite a ofertar formación en el dominio instrumental del hardware y software asociado a las TIC, reduciendo al ciudadano «a ser un mero consumidor de información y productos digitales [...] Consumir 
información, pero sin criterios intelectuales ni morales conduce, inevitablemente, hacia la alienación cultural y social» (Area Moreira, 2001, p. 87). De este modo, la escuela estaría poniéndose al servicio de los intereses económicos existentes, fomentando ciudadanos que sepan utilizar las TIC para convertirse en potenciales consumidores. Así, la formación estaría sirviendo solamente a los intereses empresariales. Debemos ser conscientes de que, desde un punto de vista pragmático, la importancia de las TIC no es su desarrollo tecnológico (Tubella i Casadevall \& Vilaseca i Requena, 2005), sino su extraordinario potencial para permitir a las personas el acceso al conocimiento.

- Por otro lado, podemos hablar del riesgo que supone para la escuela pensar que debe incorporarse al carro de las últimas tecnologías por el simple hecho de estar a la última. Esta fascinación más por la novedad de la tecnología que por la convicción de su bondad y utilidad (Ferrés i Prats, 2000) está muy extendida y se alimenta de las presiones que las instituciones escolares reciben desde las empresas fabricantes de TIC, familias y la sociedad en general. Así, muchas veces las TIC se han incorporado efectivamente al sistema educativo, pero en muchos casos se han empleado sólo como una forma de atraer la atención de los alumnos, sin planear el currículo, monitorizar el progreso del alumno o aprovechar las posibilidades de retroalimentación que permiten (González Mariño, 2008).

- Por último, debemos cuestionarnos la gran velocidad con la que nacen, se desarrollan y mueren las TIC. En este aspecto, ya hemos visto que la aceleración del cambio es tal que las personas difícilmente son capaces de seguir el ritmo. Esto para los educadores es fatal, ya que muchas veces estamos más preocupados por aprender a utilizar las nuevas herramientas que por llevar a cabo una reflexión sobre las verdaderas fortalezas y debilidades que éstas tienen en nuestra actividad docente (Cabero Almenara \& Alonso García, 2007).

A pesar de todos estos riesgos asociados al uso de las TIC dentro de los procesos de enseñanza-aprendizaje, seguimos considerando capital su incorporación, ya que, al margen de su potencial educativo, las TIC están en la base de la mayor parte de las competencias informacionales, por las cuales estamos abogando a lo largo de esta Tesis Doctoral. Está demostrado que las TIC colaboran en el desarrollo de la capacidad 
de localizar, evaluar, procesar y comunicar la información (Cabero Almenara, 2004), formación fundamental si perseguimos caminar hacia la sociedad del conocimiento:

A la hora de analizar la importancia de las TIC en la educación, la perspectiva de análisis no debe ser tanto comparar la enseñanza basada en TIC con respecto a la enseñanza tradicional, cuanto estudiar cómo integrar las tecnologías disponibles para facilitar el desarrollo en las personas de competencias básicas y esenciales para la sociedad del conocimiento (Monereo \& Coll, 2008; Scardamalia, 2004).

Para ser capaces de incorporar de manera efectiva y eficiente estas tecnologías en el currículum, debemos conocer qué características comunes tienen. Así podemos, partiendo de las ideas de Cabero (2007; 1996, 2001, 2004), apuntar hacia las siguientes características definitorias de las TIC que consideramos de mayor importancia:

- Inmaterialidad: Ya que la materia prima que explotan es la información inmaterial en múltiples códigos.

- Interconexión: Ya que las TIC suelen presentarse de manera integrada, combinándose y ampliando de esta manera las posibilidades expresivas y comunicativas.

- Interactividad: Lo cual diluye la diferenciación clásica entre emisor y receptor y convierte a todos los actores en potenciales emisores y receptores. Gracias a esta posibilidad, podemos hablar de la actual Web 2.0 y la consecuente construcción compartida del conocimiento.

- Redimensionalización del espacio y el tiempo: Las TIC permiten la ruptura casi completa de las barreras espaciales y temporales. Podemos ponernos en contacto instantáneamente con personas muy distanciadas en el espacio, e incluso mantener una conversación asíncrona con cualquier persona o grupo de personas del mundo.

- Aparición de nuevos códigos y lenguajes: Los nuevos sistemas comunicativos multicanal e hipertextuales suponen la aparición de nuevas maneras de comunicarse. Así, surgen en la sociedad de la información nuevos alfabetismos, naciendo el concepto de multialfabetización (Cope \& Kalantzis, 2009a; Kellner, 2004; Lankshear \& knobel, 2008), que analizaremos más detenidamente en el siguiente capítulo de este Trabajo. 
- Flexibilidad: Nos referimos con esta característica a su gran capacidad para adaptarse, introduciendo pequeños cambios, a cualquier entorno y/o persona. Esta característica ha derivado en la existencia de una diversidad muy grande de tecnologías disponibles, que tienen diferentes funciones pero siempre dentro de los parámetros que aquí hemos caracterizado.

Entonces las TIC, por su estructura y por su lógica de funcionamiento, parecen aportar unas posibilidades muy grandes al ámbito educativo. Pero, ¿realmente se está aprovechando este potencial, o en verdad los riesgos a los que hacíamos referencia más arriba son los que están predominando en su empleo?

La multitud de estudios al respecto parecen corroborar que el equipamiento en las aulas tanto en España como en el resto de Europa es bueno (i2010 High Level Group, 2009; INE, 2009; Sigalés, Mominó, Meneses, \& Badia, 2009), dado que el esfuerzo económico llevado a cabo por las instituciones en este aspecto es importante. Sin embargo, según el estudio de Manuel Area, que analiza los resultados de varias investigaciones en el ámbito europeo, «a pesar del incremento de la disponibilidad de recursos tecnológicos en las escuelas, la práctica pedagógica de los docentes en el aula no supone necesariamente una alteración sustantiva del modelo de enseñanza tradicional» $(2008$, p. 3).

De hecho, pensando en la educación de la futura sociedad del conocimiento, es difícil imaginar una escuela menos academicista y con currículos más abiertos, que fomenta el espíritu crítico y el aprendizaje basado en el análisis del discurso, con una organización y arquitectura de naturaleza espacio-temporal libre y abierta e implicada activamente en la realidad y espacio contextual de la ciudad o pueblo de referencia. En realidad, a muchos les viene a la cabeza un escenario muy parecido al actual, como el que propone Martínez Bonafé (2012).

\footnotetext{
«cualquier escenario escolar en el que permanece inalterable el concepto hegemónico de cultura, de conocimiento escolar y de currículo, tal como hoy lo conocemos. En este contexto discursivo, da igual si los materiales curriculares cambian su forma según van incorporándose a las nuevas tecnologías, porque lo esencial permanece inalterable» (p. 102)
}

Así, las metodologías innovadoras vinculadas a la integración de las TIC son prácticamente inexistentes, y la gran mayoría de las veces que se utilizan estas tecnologías en los procesos de enseñanza-aprendizaje se vinculan a metodologías como (Area Moreira, 2008): 
- Apoyar las exposiciones magistrales del profesor en el aula (empleo del PowerPoint, acceso a páginas web con información, etc.)

- Realización por parte del alumno de actividades específicas similares a las de los libros de texto, descontextualizadas en muchos casos y con el añadido del multimedia y el feedback inmediato (Jclic, Hot potatoes, etc.). De este modo, las TIC se convierten en una herramienta puntual no integrada en el proceso.

- Complemento del libro de texto, para buscar información complementaria, o incluso sustitución del libro de texto por libros virtuales, que no son otra cosa que libros de texto digitalizados ofertados por las mismas editoriales.

- Enseñar al alumno competencias tecnológicas en el manejo del software y el hardware sin tener en cuenta las competencias informacionales, que son más necesarias y que los alumnos tienen más dificultades para aprender autodidactamente.

Parece lógico, pues, lanzar la hipótesis de que, o bien no se ha hecho un esfuerzo suficiente por parte de las instituciones en lo que a formación del profesorado en metodologías relacionadas con las TIC respecta, con lo que los profesores se sienten un poco desorientados, o que los propios programas formativos lanzados a gran escala han incidido en aspectos diferentes a las propias metodologías.

Nosotros nos inclinamos hacia esta segunda tesis, y entendemos que los esfuerzos desde las instituciones educativas en materia formativa han sido grandes, pero que han ido destinados más a un dominio técnico del nuevo instrumento que a aprender sobre unas tecnologías que proponen una forma radicalmente diferente de acceso al conocimiento y hacen necesaria una nueva cultura del aprendizaje (Monereo \& Coll, 2008).

De hecho, la mayor parte de los pedagogos estudiosos del tema, coinciden en señalar la necesidad de reformular en el contexto de la sociedad de la información los principios metodológicos que han regido la educación durante prácticamente toda la vida (Area Moreira, 2008, 2010a; Cabero Almenara \& Alonso García, 2007; Gisbert Cervera, 2002; Marzal García-Quismondo, 2010; Pablos Pons, 2010).

Así, tanto los procesos de formación inicial del profesorado, como la formación continua que se les imparte cuando ya son docentes debe repensarse y adquirir una nueva dimensión y perspectiva, basada en una nueva cultura del aprendizaje. Un 
profesor experimentado en los procesos de construcción y gestión del conocimiento a través de las competencias informacionales y que domina y sabe aprovechar tanto las TIC como el resto de recursos a su alcance para desarrollar estos procesos con sus estudiantes.

Por tanto, y para terminar este sub-apartado, creemos necesario destacar que en la sociedad de la información, que como habíamos visto tiene unas características muy específicas y muy diferenciadas de las anteriores, surgen ciertas necesidades educativas hasta ahora obviadas. Estas nuevas necesidades tienen mucho que ver con el nuevo entorno tecnológico que se presenta, dominado por las TIC, y el contexto informacional que les acompaña. Mientras que el papel del profesorado se intuye y se prevé radicalmente diferente, la realidad es que en las escuelas las metodologías que acompañan a los cambios tecnológicos y contextuales no sufren grandes alteraciones. Lo que se hace necesario, en suma, es una formación inicial y permanente del profesorado que asegure esta revolución ${ }^{12}$ metodológica.

En este punto nos surge una cuestión importante que tratará de ser abarcada en el siguiente apartado: ¿cuál es el papel concreto con respecto a sus alumnos que debe cumplir el profesor en este nuevo contexto metodológico dominado por las competencias informacionales, el lifelong learning y el aprendizaje basado en competencias? ¿Qué nuevos roles desempeñará el alumno con la implementación de estas metodologías innovadoras?

\subsubsection{El nuevo rol del profesor y del alumno para una nueva escuela}

Ya hemos visto al principio de este capítulo cómo la adaptación de todas las estructuras de la sociedad a la situación actual dominada por las TIC ha redefinido los procesos laborales y e incluso la propia capacitación de los trabajadores de todos los sectores (Castells, 1999a; Tubella i Casadevall \& Vilaseca i Requena, 2005). Este hecho, junto con la rotación del puesto de trabajo en la vida de las personas por la alta temporalidad en los contratos (Fernández Enguita et al., 2007), implica que los trabajadores de la sociedad de la información deben ser flexibles tanto en lo personal como en lo laboral para adaptarse a condiciones cambiantes.

\footnotetext{
${ }^{12}$ Si hemos aceptado la tesis de la tercera revolución industrial o revolución informacional a nivel social, no es descabellado hablar de revolución metodológica a nivel educativo.
} 
La cultura escolar y la profesión de profesor no pueden mantenerse al margen de los cambios laborales ocurridos en todos los sectores, ya que "es preciso dotar al alumno de herramientas intelectuales con las cuales enfrentarse al mundo de los adultos donde se va a insertar» (Fernández Enguita et al., 2007, p. 84), y eso sólo lo podrá hacer un profesional que haya adquirido esa capacidad para ser flexible.

En cuanto a las escuelas, nos encontramos con un contexto totalmente desalentador.

«No gusta a los alumnos, aunque eso no es ninguna novedad. Tampoco gusta a las familias, pero eso ya no es tan normal. Entre la escuela y la familia, la alianza que antaño se daba por sentada se está transformando en un conflicto cada vez más duro [...] Y lo que es incluso paradógico es que la escuela ni siquiera gusta a los maestros [...] Y por último, la escuela no gusta a nuestra sociedad en general que, por un lado, la acusa de no ser capaz de proporcionar la preparación a los ciudadanos de nuestros días de forma actualizada para las profesiones modernas y, por el otro, de no saber evitar, mediante las oportunas enseñanzas, determinados comportamientos incívicos de jóvenes y adolescentes» (Tonucci, 2012, p. 66)

Y en parte, este disgusto general se debe a cómo ha afrontado y afronta la escuela y el mundo educativo en general la adaptación a la sociedad de la información. En unos casos por culpa de los propios educadores y personas relacionadas directamente con el contexto educativo y en otras muchas por cuestiones más de política.

Como ejemplo, en la escuela nos podemos encontrar con un entorno repleto tanto de tecnologías menos modernas, como de las más actuales. Estos recursos actuales no ayudan al objetivo de crear una escuela de la información (o del conocimiento) cuando, en vez de utilizarlos como herramientas metodológicas de aprendizaje y comunicación, se enseña simplemente a manejarlos (Benito Morales, 2008). Y aquí es donde puede entrar en juego el verdadero papel del profesor en los entornos ricos en información, que más que un transmisor se convierte en un facilitador, entrenador y capacitador del proceso de aprendizaje permanente de los estudiantes (Aguiar Perera et al., 2002; Andretta, 2007; Area Moreira, 2001; Bundy, 2004), que participan activamente en el mismo. Se trata de caminar desde una perspectiva de pasividad, centrada en lo que se enseña a otra bien diferente centrada en lo que la persona aprende y será capaz de aprender para su crecimiento personal (Sabán Vera \& Monclús Estella, 2008). 
Desde el punto de vista del profesional de la educación es claro, por tanto, que es exigible un cambio en las actividades laborales del profesor. Pero, ¿̇y desde el punto de vista del propio estudiante?

Los estudiantes de educación obligatoria han vivido durante toda su vida inmersos en un entorno informacional emergente y rodeados continuamente por instrumentos tecnológicos muy diferentes a los que las personas mayores tenían a su disposición en su infancia. Así, desde los primeros años de su vida se han enfrentado experiencias radicalmente distintas a las que antes se enfrentaban las personas de ese rango de edad. Por tanto, podríamos afirmar que los estudiantes de hoy en día tienen una estructura mental y, por ende, una visión e interpretación del mundo completamente distinta a la de los adultos ${ }^{13}$, y más acomodada al contexto de la sociedad de la información:

"...the brain is now generally understood to be highly plastic, continually adapting to the input it receives, it is possible that the brains of those who interact with technology frequently will be restructured by that interaction» (Prensky, 2009)

En este entorno, nos encontramos con la situación de que, mientras que los alumnos se encuentran de sobra preparados para participar en la "escuela informacional", el profesor no se siente capacitado para adaptarse a los cambios que los propios estudiantes y el nuevo contexto social y escolar le exigen (Alonso García, 2002; González Mariño, 2008). Sin embargo, consideramos que tiene el deber de acomodarse a la nueva situación, ya que el rol tradicional del profesor en un entorno actual pierde fuerza y pertinencia; no tiene sentido ser un simple transmisor de información hoy en día, con la cantidad de comunicadores más atractivos y eficientes a los que nos enfrentamos (la batalla la tenemos casi perdida de antemano).

Y una vez discutidas las razones que nos inclinan hacia estas opiniones, veamos cómo podríamos agrupar estos cambios o nuevos roles exigibles al profesor de la sociedad de la información (Gisbert Cervera, 2002):

- El profesor como consultor experto en el manejo y gestión de la información: Un profesor que busca recursos educativos adecuados, apoya a los alumnos en su correcto tratamiento de la información y es experto en el manejo de herramientas tecnológicas para la búsqueda, evaluación, procesamiento y comunicación de información.

\footnotetext{
${ }^{13}$ Las ideas que expone Marshall McLuhan $(1967,1969,1987)$ al respecto ya las hemos comentado a lo largo de este capítulo, y las hemos aceptado como hipótesis de trabajo.
} 
- Un docente que conoce las estrategias y metodologías implicadas en el aprendizaje colaborativo, y sabe diseñar actividades cooperativas que fomentan la construcción compartida del conocimiento.

- El profesor como facilitador del aprendizaje: El rol del docente no es tanto el de transmisor de información, como el de dinamizador y facilitador de procesos mediante la implementación de recursos y estrategias.

- Un maestro en generar el conocimiento de manera crítica. Se camina hacia la formación de alumnos críticos, que son competentes para trabajar y tomar decisiones autónomamente tanto en lo personal como en lo académico, como en lo profesional.

- Un supervisor académico que acompaña el proceso de aprendizaje de los alumnos, y les devuelve los feedbacks pertinentes, con el objetivo de ayudar a éstos en la elección de la ruta de su carrera académica-profesional.

En cuanto al nuevo papel del alumno, se deriva evidentemente de los roles generales reivindicados para el profesor. Así, un cambio desde una perspectiva centrada en la enseñanza hacia otra más orientada hacia el aprendizaje supone que el alumno se convierta en un elemento activo y dinámico del proceso de aprendizaje, guiado por el desarrollo de habilidades de búsqueda, evaluación, procesamiento y comunicación de información.

Y evidentemente, conseguir que esta situación se invierta de alguna manera, sólo es posible a través de un impulso tanto en la formación inicial como en la permanente de los actuales y futuros profesores.

En suma, desde nuestro punto de vista consideramos necesario un cambio profundo tanto en los roles que están asimilando profesores y estudiantes, más propios de sociedades anteriores, como, por ende, en las metodologías que se emplean a lo largo de los procesos formativos llevados a cabo en las aulas. Sabemos que las metodologías docentes caminan de la mano con el perfil que asuma el profesor. Ahora bien, ¿cuáles son los pilares básicos en los que se sustentan las metodologías educativas en la sociedad del conocimiento? O más bien, ¿sobre qué ejes se sustenta lo que hemos venido a llamar "cultura del aprendizaje"? 


\subsubsection{Competencias clave en la sociedad del conocimiento}

Parece claro que desde un punto de vista social y tecnológico el desarrollo de competencias informacionales adquiere una importancia y dimensión considerables. Bajo esta misma perspectiva hemos señalado la incipiente necesidad de las instituciones educativas de formular cambios, reconsiderando los fundamentos y procesos educativos en su práctica totalidad. Sin embargo, aún no hemos reflexionado desde un punto de vista pedagógico sobre los principios educativos que sirven de cimiento a estas reformas estructurales que se le exige al mundo de la educación.

En el escalafón más básico y profundo de los cambios se encuentra el principio de formación basada en competencias. Si pensamos en el desarrollo de competencias como una estructura jerárquica o por niveles, podríamos considerar este principio como una construcción conceptual que se sitúa en un metanivel. Así, la formación basada en competencias dirige y aporta una forma definida a los distintos niveles en los que se encuadran las competencias. A lo largo del tercer capítulo de este documento se desarrollará de manera más específica y extensa tanto el concepto de formación basada en competencias, como su estructura y sus implicaciones dentro de los procesos de enseñanza-aprendizaje. Por lo tanto, no nos extenderemos más en este concepto a lo largo del presente apartado.

Si la formación basada en competencias es la que aporta sentido conceptual a cada uno de los elementos de esta estructura jerárquica, estos elementos, evidentemente, se van a concretar en competencias y subcompetencias. Así, el primer nivel de ésta escala es el conformado precisamente por los pilares de la educación en la sociedad del conocimiento, esto es, por los principios educativos que sirven de base a la nueva cultura del aprendizaje. $Y$ estos principios se integran en una competencia que está en la base de todas las demás: la competencia para el aprendizaje (Bolívar Botía, 2009).

Por lo tanto, la cultura del aprendizaje se traduce en una competencia para el aprendizaje, y esta a su vez se deriva en una serie de aprendizajes básicos. Parece claro que el principal componente de esta "supracompetencia" es aprender a aprender. Pero para aprender a aprender es necesario desarrollar una serie de aprendizajes básicos transversales comunes a todas las disciplinas escolares y no escolares: 
- lifelong learning: El giro hacia la formación basada en competencias pone en evidencia que el aprendizaje a lo largo de la vida es necesario en la sociedad actual (Martínez Clares \& Echeverría Samanes, 2009). Prueba de ello se obtiene al observar como en los últimos años el aprendizaje permanente se ha convertido en un tema central que dirige los principios y estrategias de las políticas educativas tanto a nivel europeo como en el contexto mundial (Borg, 2005; Commission of the European Communities, 2000; Diario oficial de la Unión Europea, 2006; Gaio Alves et al., 2010; Organización Internacional del Trabajo, 2003; UNESCO, 2009). De hecho, nadie pone en duda que el contexto líquido actual es la clara causa de la incesante búsqueda del lifelong learning por parte de las instituciones públicas y privadas. Así, hoy sabemos que las competencias que va a poder adquirir el sujeto en su periodo de formación básica y superior durante su infancia y juventud no van a ser suficientes, ni mucho menos, para desempeñarse durante toda su vida laboral. De hecho, las personas deben renovarse constantemente, al igual que se renueva constantemente y con una aceleración exponencial el flujo de conocimientos que existe en todas las áreas de conocimiento (Andretta, 2007; Area Moreira, 2005; Bundy, 2004; Gunasekara \& Collins, 2008; Sabán Vera \& Monclús Estella, 2008).

- Aprendizaje autónomo: El impulso de la autonomía personal en el proceso educativo es un elemento básico para el desarrollo de la competencia para el aprendizaje. Ser capaz de llevar a cabo un proceso de aprendizaje autónomo implica tener iniciativa para llevar a cabo proyectos tanto en el ámbito personal como en el laboral, académico o social. Así, podemos encontrar cuatro dimensiones dentro del aprendizaje autónomo (Bolívar Botía, 2009):

- Valores y actitudes personales: conciencia y aplicación.

- Autovaloración y autonomía.

- Proyección y planificación de planes personales.

- Desarrollo y realización de proyectos.

- Aprendizaje activo: Este elemento está íntimamente relacionado con el aprendizaje autónomo, antes expuesto. No sólo es necesario que el alumno sea capaz de implementar proyectos que le ayuden en su desarrollo integral, sino que es esencial que la persona sienta la necesidad imperiosa de participar 
y colaborar en los propios procesos educativos y que se implique efectivamente en los mismos. Sólo con un compromiso sincero y una participación activa en dichos proyectos se va a conseguir alcanzar el objetivo final. Al igual que el aprendizaje significativo y constructivo sólo se alcanza mediante la movilización y activación de los recursos cognitivos de la persona (logrando una implicación activa y positiva), la capacidad para aprender a aprender no se desarrollará sin el dominio consciente de estos recursos (De Miguel Sánchez, 2005; Escalante Estrada, 2006). Y para conseguir este dominio es necesaria la participación directa y continuada en los procesos de enseñanza-aprendizaje.

- Aprendizaje crítico: En esta sociedad tan plural y relativista, es necesario que las personas aprendan a construir de manera crítica y bien fundamentada sus propios puntos de vista y posicionamientos ante las realidades 0 informaciones concretas (Monereo \& Coll, 2008). Vivimos en un entorno incierto y dinámico, en el que el conocimiento también lo es, por lo que el posicionamiento personal es lo único que nos libra de la relatividad. Desarrollar la competencia para el aprendizaje y, por ende, la capacidad de aprender a aprender implica la asunción de un estilo crítico en el que el estudiante, en lugar de ser un mero receptor de contenidos, identifica, interpreta y se enfrenta a problemas importantes a partir de su punto de vista personal (Elborg, 2008). Así, en vez de la concepción de la enseñanza como un banco de conocimientos, esta premisa requiere caminar hacia un aprendizaje que genere conciencia crítica.

- Aprendizaje social: A pesar de la importancia que hemos atribuido al desarrollo del aprendizaje autónomo, cabe decir que el hombre aprende de manera eminentemente social, enmarcado en ciertos contextos organizacionales e institucionales que por supuesto influyen en el desarrollo de los propios aprendizajes. Se podría afirmar que el aprendizaje es fruto de la relación activa con otras personas y con instrumentos y códigos simbólicos propios de la cultura en la que se está inmerso (Pifarré et al., 2009). Así, cada persona participa, dentro de su contexto cultural concreto, de lo que comúnmente se denomina "cerebro social": "learning is a way of being in the world, not just of coming to know about it» (O’Farrill, 2008, p. 158). Así, la competencia para el aprendizaje implica, entre otras cosas, tanto dominar las herramientas que nos permiten participar activamente en este cerebro social 
compartiendo nuestros conocimientos con la comunidad, como aprovechar el conocimiento presente en la sociedad para el enriquecimiento personal.

- Aprendizaje cooperativo: "La cooperación consiste en trabajar juntos para alcanzar objetivos comunes» (Johnson, Johnson, \& Holubec, 1999, p. 14). La sociedad de la información ha generado una red de conexiones con consecuencias importantes en todos los ámbitos de la vida de las personas. Así, dada la organización actual de la sociedad en torno a redes de información interconectadas mediadas por las TIC, el aprendizaje cooperativo se postula como uno de los saberes más importantes para el ciudadano del siglo XXI, y básico para desarrollar la competencia para el aprendizaje. La investigación educativa, además de destacar la importancia de la interacción profesor-alumno en los procesos de aprendizaje, destaca la incidencia positiva de la interacción alumno-alumno en dichos procesos (Pifarré et al., 2009). Consideramos que igual de importante que desarrollar aprendizajes de manera autónoma e individual, es ser capaz de aprender cooperativamente junto a otras personas en grupos reducidos (Johnson et al., 1999), ya sea en ambientes físicos o virtuales.

- Aprendizaje deslocalizado: Tener la posibilidad de aprender a aprender a lo largo de la vida implica una deslocalización y ampliación de los escenarios educativos (Pinto Molina et al., 2008). Ampliación porque la necesidad de reciclaje permanente de las personas exige que puedan formarse en lugares diferentes de las escuelas y deslocalización porque gracias a la expansión de las TIC cualquier contexto físico puede ser adecuado para el aprendizaje. Así, las personas deben ser conscientes de su necesidad de aprender de manera deslocalizada, independientemente del contexto espacio-temporal en el que estén inmersas. De esta manera, con esta ampliación ilimitada de los espacios de aprendizaje, las posibilidades de generación de aprendizajes son mucho mayores (David \& Foray, 2002).

Si la competencia para el aprendizaje y todos los elementos básicos que se derivan de la misma forman parte del primer nivel de las competencias, ¿dónde se sitúan las competencias informacionales? A lo largo de todo este capítulo hemos estado defendiendo la importancia capital del desarrollo de competencias informacionales para los ciudadanos de la sociedad de la información, y por tanto es lógico que nos planteemos esta pregunta. Bajo nuestro punto de vista, y basándonos en los planteamientos que establecen documentos oficiales como el Real Decreto 1632/2006, 
de 29 de diciembre, por el que se establecen las enseñanzas mínimas correspondientes a la Educación Secundaria Obligatoria (a nivel español), o la Recomendación del Parlamento Europeo de 18 de diciembre de 2006 sobre las competencias clave para el aprendizaje permanente (a nivel europeo), las competencias informacionales se encuentran en un segundo nivel de la jerarquía planteada más arriba, dentro de lo que podríamos denominar "competencias básicas" o "competencias clave". Estas competencias básicas incluyen, entre otras, la matemática, la de comunicación lingüística o la social y ciudadana.

Así, desde una perspectiva estrictamente educativa, a pesar de no quedar tan patente la importancia de las competencias informacionales, estas siguen ocupando un lugar privilegiado dentro de los planes de estudio y los currículos oficiales. Otro asunto bien distinto es que esta posición se traduzca en una integración correcta y efectiva dentro de los procesos de enseñanza-aprendizaje cotidianos o en la práctica. 


\subsection{Resumen}

Hemos comenzado el capítulo señalando el nuevo panorama político, económico, social y educativo que surge a nivel mundial a partir de los inicios del desarrollo de la computación y la informática. El primer objeto interés del desarrollo del capítulo, no ha sido otro que el de realizar una precisión conceptual sobre los conceptos que emplearemos para definir esta sociedad en función de nuestras ideas y de las extraídas de la revisión del estado de la cuestión. Así, se emplea generalmente sociedad de la información para definir la sociedad actual, caracterizada por unas estructuras y dinámicas muy concretas.

Más adelante, una vez llevada a cabo la especificación terminológica, se ha comenzado, evidentemente, definiendo la propia sociedad de la información y apuntando hacia las causas que promocionan su surgimiento. Entre otras, se han señalado las TIC como el elemento reactivo principal.

Este desarrollo ha conducido necesariamente a la definición de las principales características de la sociedad de la información. Esta enumeración general, nos ha llevado, por medio de un razonamiento deductivo, a recoger ciertos elementos más concretos característicos de esta sociedad que pueden implicar (e implican efectivamente) dificultades en el contexto educativo general.

Una vez analizada la sociedad de la información tanto desde un punto de vista general más propio de la Sociología como desde una perspectiva más específica centrada en las Ciencias de la Educación, nos hemos planteado cómo se puede hacer frente desde el mundo de la educación a esta situación nueva y totalmente diferente a la que existía cuando se fundaron las bases de la formación escolar. Así, en la búsqueda de soluciones a la crisis del sistema educativo tradicional se ha introducido un concepto relativamente nuevo, competencias informacionales.

Por último, en la búsqueda de situar más concretamente el posicionamiento de las competencias informacionales dentro de los aprendizajes necesarios para el ciudadano del siglo XXI, se ha llevado a cabo un análisis breve de los principios pedagógicos que fundamentan los nuevos planes de estudio de las actuales instituciones educativas y la consecuente reestructuración que "sufren" los procesos de enseñanza-aprendizaje vinculados a las acciones formativas. En este sentido, se ha explorado la labor de las TIC como un recurso educativo integrado dentro de los procesos, se ha analizado el nuevo papel que tienen que asumir tanto docentes como alumnos para aprender 
efectivamente en la sociedad de la información, y se ha apuntado hacia un modelo concreto de formación basada en competencias y una serie de competencias básicas necesarias para cualquier persona inmersa en esta sociedad. 


\section{Capítulo II}

\section{LA MULTIALFABETIZACIÓN EN \\ EL DESARROLLO DE COMPETENCIAS INFORMACIONALES}




\section{Capítulo II}

\section{La multialfabetización en el desarrollo de competencias informacionales}

2.1 Influencia de los cambios sociales en el concepto de alfabetización

2.2 Evolución del concepto alfabetización desde su nacimiento hasta la actualidad

2.3 El concepto de multialfabetización. La multialfabetización como marco integrador de las competencias informacionales

2.4 La formación del profesorado en un contexto multialfabetizado

2.5 Resumen 


\title{
2. La multialfabetización en el desarrollo de competencias informacionales
}

\begin{abstract}
"La imagen del navegante ha sido utilizada a lo largo de los siglos para referirse metafóricamente al viaje de los humanos por el mar proceloso de la existencia. Hoy la metáfora ha pasado a referirse al cada vez más complejo viaje de los internautas por el ciberespacio, convertido no ya en un mar, sino en un océano de informaciones caóticas y dispersas. [...]. Como los navegantes, tampoco los educadores y los hombres de cultura pueden decidir cuáles son los vientos que han de soplar. Lo único que pueden hacer es adaptarse a ellos, sacarles partido. $Y$, para conseguirlo, es imprescindible que se enfrenten a ellos con lucidez, En otras palabras, para que puedan llevar la nave al puerto previsto y no a aquel al que la lleven los vientos es imprescindible que los navegantes tomen conciencia de los vientos que soplan en cada momento, que conozcan su naturaleza, su fuerza y su dirección, y sobre todo que sepan cómo controlarlos y manejarlos» (Ferrés i Prats, 2000, p. 19)
\end{abstract}

En el primer capítulo hemos analizado detenidamente los drásticos cambios que se han producido en la sociedad postmoderna, en la que nos toca desenvolvernos en la actualidad, y qué causas y consecuencias tiene esta profunda revolución en campos tan diversos como la cultura, economía, política, sociedad y sobre todo en el mundo de la educación.

De este modo, hemos señalado como la escuela, como hoy la conocemos, surge en la era industrial, como respuesta a las demandas y necesidades socio-económicas en relación a la alfabetización y adoctrinamiento de las masas. Podemos señalar el surgimiento de la Imprenta, con el consecuente aumento de la facilidad de acceso a las fuentes impresas por parte de las masas y diseminación de una mayor cantidad de información, como uno de los factores principales en el nacimiento de la escuela. Por otro lado, el asentamiento de la organización del mundo en estados-nación es un factor determinante, ya que es necesario crear en el pueblo un sentimiento común de pertenencia a un estado y de identificación con el mismo.

En consecuencia, desde su origen, el objetivo de la escuela es alfabetizar a todos los estudiantes desde una perspectiva homogeneizadora (Fiori, Fiori, \& Freire, 1973) para que sean capaces de aprovechar toda la información impresa que les rodea. De hecho, el gran problema al que nos enfrentamos en la actualidad, y al que dedicamos especial atención en este capítulo, es que esa visión de la realidad sigue aún instaurada hoy en día en nuestros centros educativos. 
«a glaring problem with contemporary educational institutions was that they become fixed in monomodal instruction whith homogenised lesson plans, curricula, examinations, and pedagogy, and neglect to address challenging political, cultural, or ecological problems.» (Kellner, 2004, p. 14)

\subsection{Influencia de los cambios sociales en el concepto de alfabetización}

Como se puede observar en el capítulo previo, se ha postulado que la educación debe virar en el contexto actual desde concepciones más vinculadas a entender el conocimiento como algo estático, objetivo y absoluto, hacia la idea del mundo como un entorno dinámico, relativo y totalmente cambiante. Así, tomando prestadas las ideas de Paulo Freire $(1973 ;$ 1975, 1984), se debe pasar de una "concepción bancaria", de la educación, en la que el proceso educativo es un acto mercantil constante de depositar contenidos en una conciencia vacía y el educando es un ente pasivo que recibe imposiciones de otros, a una concepción humanista y liberadora de la educación, en la que se entiende el mundo como una realidad en permanente cambio y en la que el educando es un ente activo, reflexivo e intencional que posee un pensamiento crítico y una conciencia propias que se van desarrollando a través de las experiencias y praxis personales y sociales. En lo que respecta a la alfabetización, este necesario cambio de perspectiva se hace también patente si tenemos en cuenta la visión clásica, en la que podemos definir la alfabetización como el proceso de codificación y decodificación del lenguaje oral y escrito en el conjunto de símbolos y fonemas que lo forman. $Y$ los numerosos estudios relacionados realizados hasta la fecha, especialmente entre los años 1970 y 1980, indican claramente que «la alfabetización no puede definirse simplemente como la capacidad de escribir y leer» (Gee, 2003, p. 54). La alfabetización es mucho más que eso, como continúa señalando el mismo autor:

\footnotetext{
«la visión tradicional de la alfabetización como la capacidad de leer y escribir arranca la alfabetización de sus contextos socioculturales y la trata como una competencia cognitiva asocial que poco o nada tiene que ver con las relaciones humanas. Encubre las conexiones de la alfabetización con el poder, con la identidad social y con las ideologías, a menudo con el fin de privilegiar ciertos tipos de alfabetizaciones y a ciertas clases de personas.» (Gee, 2003, p. 61)
}

Pero, ¿por qué defendemos junto con otros muchos autores la necesidad de este radical cambio en la educación y en el propio concepto de alfabetización? 
Desde un punto de vista histórico y tecnológico, es evidente que la sociedad industrial poco o nada tiene que ver con la sociedad actual. De hecho, el haber aceptado la tesis de la tercera revolución industrial o revolución informacional para definir los cambios que han llevado a la sociedad actual tiene consecuencias, ya que «una revolución industrial no se basa sólo en la aparición de un nuevo recurso productivo estratégico como explicación del conocimiento y del desarrollo económico, sino que también son necesarias otras transformaciones sociales, culturales, institucionales y políticas» (Tubella i Casadevall \& Vilaseca i Requena, 2005, p. 38). De hecho, si nos centramos más en el tópico principal de este capítulo, podemos considerar la alfabetización como una herramienta para adquirir y participar en el proceso de transformación de la cultura en la que la persona está inmersa (Koltay, 2009; Markauskaite, 2006). Y «dado que el alfabetismo es un fenómeno cultural no es extraño que una definición única del alfabetismo no pueda ser formulada y mantenida de manera permanente» (Wagner, 1998, p. 24). Por tanto, debemos aceptar que profundos cambios en una cultura determinada deberían propiciar modificaciones importantes en el concepto y los modos de alfabetización.

\footnotetext{
«La tecnología siempre ha definido la alfabetización. Antes de la imprenta, lo que definía la alfabetización era la oralidad, la capacidad para transmitir ideas y pensamientos e información, a través de la voz. Hoy día, el concepto vuelve a cambiar en un mundo saturado de medios, donde las TIC son en parte, responsables y protagonistas de la transformación de la sociedad de la información en la que nos hallamos inmersos. Toda nuestra actividad social y cultural está mediatizada por este tipo de tecnologías y los nuevos medios requieren de nuevas alfabetizaciones» (González Fernández-Villavicencio, 2012, p. 18)
}

Ahora bien, ¿qué es lo que ha cambiado concretamente con el surgimiento de la sociedad de la información que provoque la necesidad de este cambio radical en las concepciones más profundas sobre la alfabetización? Veamos los cinco aspectos principales que consideramos que son de vital importancia en este:

En primer lugar, debemos tener en cuenta que la realidad de la sociedad de la información es multidimensional, variada y dinámica. Esto implica que hoy en día, muchos conceptos que se definían desde un punto de vista unidimensional, se reformulan y son sustituidos por conceptos que tienen cuenta un mayor número de perspectivas (Lonsdale \& McCurry, 2004). Así, el estatismo y la visión universal del mundo se modifica radicalmente, existiendo hoy en día una perspectiva sobre la realidad abierta, flexible y cambiante. La alfabetización, por tanto, es también multidimensional, y no tiene sentido definirla y desarrollarla a través de prácticas 
parciales y unidimensionales (Freire, 1989), sino que es necesario interpretarla como una práctica enmarcada en una realidad social e histórica determinada:

«Literacy conceptions today are no longer limited simply to reading and writing. There is a general recognition that changes have so transformed the world in recent years that the concept of literacy needs to encompass a broader range of capabilities than in the past» (Lonsdale \& McCurry, 2004, p. 14)

Por otro lado, en segundo lugar, nos encontramos el contexto laboral, que ha cambiado radicalmente en gran parte debido al surgimiento de lo que hemos denominado nueva economía que, como indica David Cohen, "The new economy [...] designatres a radical modification of the established paradigm of the economy as analyzed by Adam Smith and Karl Marx» (2008, p. 5). Este profundo cambio de paradigma conduce inevitablemente a una reestructuración de las bases del empleo en todos los sectores productivos. Ahora se requiere de empleados con nuevas destrezas principalmente relacionadas con la gestión, el procesamiento de información y las relaciones interpersonales (Castells, 1998). Por tanto, podemos afirmar que la nueva economía y la nueva sociedad propicia que «cada ciudadano requerirá una amplia gama de competencias para adaptarse de modo flexible a un mundo que está cambiando con rapidez y muestra múltiples conexiones» (Diario oficial de la Unión Europea, 2006). En conclusión, parece que en este nuevo entorno, nuestra labor como educadores debe consistir, más que en la transmisión de conocimientos estáticos para su posterior reproducción, en promover la formación de ciudadanos con capacidad crítica y preparados para buscar, evaluar, procesar, comunicar y aportarle sentido al océano de informaciones que les rodean. Todo ello con el objetivo de despejar la infinitud de caminos posibles y que cada persona sea capaz de detectar «las variables sustantivas capaces de generar vías de profundización» (Aguiar Perera et al., 2002, p. 14). De este modo, no podemos apostar por una alfabetización más propia de la era industrial que de los designios que requieren la economía y la sociedad actuales.

El tercer elemento, íntimamente relacionado con el expuesto en segundo lugar, es el referente a las transformaciones en el "perfil del ciudadano" debido al surgimiento $y$ evolución de las TIC. Es evidente que la nueva economía no habría podido surgir sin la inestimable colaboración de las TIC. Sin embargo, consideramos que ambos hechos son diferenciables si los analizamos desde la perspectiva de la alfabetización, ya que el impacto de las TIC tiene, como ya hemos visto, otras muchas consecuencias además del nacimiento de la nueva economía. De hecho, podemos analizar el impacto de las TIC sobre el concepto de alfabetización desde dos perspectivas: 
1. La primera perspectiva tiene que ver de nuevo con el perfil del empleado que surge por las TIC y la nueva economía. Está claro que las tecnologías actuales han provocado cambios en las estructuras de las empresas en todos los ámbitos. Por ejemplo, los nuevos artefactos han permitido una amplia extinción de las tareas repetitivas de rutina, ya que pueden ser codificadas y programadas para ejecutarse por máquinas más eficientes (Castells, 1999a). Por otro lado, las nuevas tecnologías integradas en las empresas han facilitado una evolución de un modelo de producción fordista a un modelo flexible, ya que las máquinas se estructuran en redes de producción fáciles de programar, por lo que se adaptan rápidamente a lo que les piden los mercados (flexibilidad del producto) y a los cambios de los inputs tecnológicos (flexibilidad del proceso) (Castells, 1999a). Esta flexibilidad y dinamismo, por tanto, permite en la empresa una adaptabilidad sin precedentes a condiciones nuevas más o menos adversas. Sin embargo, las consecuencias para el perfil del empleado requerido también han sufrido transformaciones sin precedentes. Mientras que la escuela sigue formando a las personas en una concepción estática y unidimensional del conocimiento y del mundo, la realidad laboral demanda a los ciudadanos habilidades de cooperación, trabajo en equipo, autonomía y responsabilidad personal. Para el aprovechamiento máximo del potencial de las TIC es necesaria «la interacción y el procesamiento de información constantes entre los trabajadores, entre éstos y la dirección, y entre lo humanos y las máquinas» (Castells, 1999a, p. 275).

2. La otra perspectiva que podemos asumir es la relativa a los nuevos modos $y$ medios de representación de la realidad que se forman gracias a las TIC. Con los avances de las TIC, se han generado todo tipo de materiales textuales, visuales, semánticos,... Así, en este contexto están resurgiendo una serie de "alfabetizaciones" hasta ahora prácticamente olvidadas, como la visual (O’Farrill, 2008). Y lo que es más, gracias a las TIC están surgiendo nuevos modos y nuevos medios para transmitir información que «suponen formas nuevas y cambiantes de producir, distribuir, intercambiar y recibir textos por medios electrónicos» (Lankshear \& knobel, 2008, p. 39).

Así, la generalización de las TIC parece un elemento esencial que ha cambiado el concepto de alfabetización, al igual que la extensión de la imprenta modificó radicalmente lo que se entendía por alfabetización hasta entonces. Esta 
argumentación tiene cierta lógica si volvemos a evocar las ideas de McLuhan (1967, 1969, 1987), cuando presentaba su pensamiento indicando que realmente los humanos nos convertimos en lo que vemos y de alguna manera, en un principio, damos forma a las herramientas hasta que estas nos acaban dando forma a nosotros. Las tecnologías, que son artefactos que sirven para extender las habilidades innatas del hombre, son diseñadas por el propio hombre (eso es innegable). Sin embargo, lo paradógico es, según McLuhan, que una vez el hombre emplea cierta herramienta nueva, su manera de representar el mundo se debe reestructurar para adaptarse a una realidad en la que existe dicho instrumento. $Y$ esta reconstrucción será mayor cuanto más grandes sean las posibilidades de la herramienta en cuestión.

Dado el potencial de las TIC, si aplicamos los principios de McLuhan, su empleo debe provocar cambios estructurales profundos en los modos de representar el mundo del hombre. Así, es lógico pensar que el concepto de alfabetización, íntimamente ligado con la cultura y la representación del mundo, se modifique substancialmente.

Como cuarto aspecto a tener en cuenta en nuestro análisis consideramos importante señalar la crisis del modelo de Estado tradicional. Los grandes teóricos sobre la sociedad de la información coinciden al observar cómo los Estados están en plena crisis estructural producida por el avance de los mercados y la globalización, perdiendo de este modo el control sobre muchos de los elementos que hasta ahora eran esenciales en sus políticas, sobre todo económicas (Castells, 1998, 1999a; D. Cohen \& McCuaig, 2008; David \& Foray, 2002).

«la globalización, la reestructuración capitalista, la interconexión organizativa, la cultura de la virtualidad real y la primacía de la tecnología por la tecnología, los rasgos clave de la estructura social de la era de la información, son las fuentes mismas de la crisis del estado y de la sociedad civil tal y como estaban constituidos en la era industrial» (Castells, 1998, p. 397)

En esta situación deja de tener sentido el modelo de escuela como un entorno para enculturizar a los futuros ciudadanos a través de una alfabetización unidimiensional para homogeneizar y primar la cultura dominante.

Para finalizar esta revisión, podemos señalar en quinto lugar el que creemos que es el elemento más importante desde un punto de vista educativo, las necesidades de formación permanente en la sociedad de la información. 
Ya hemos hecho referencia con cierto detenimiento al concepto de aprendizaje permanente o lifelong learning a lo largo del anterior capítulo, por lo que no nos detendremos en demasía en su conceptualización. El hecho es, para explicarlo brevemente, que en una sociedad líquida (Bauman, 2006, 2007), en la que el ritmo de cambio es tan acelerado que las personas deben estar en continuo proceso de readaptación y movilidad, el conocimiento, entre otras cosas, también es tremendamente plástico, modificándose y evolucionando hacia perspectivas inciertas y multidimensionales. Así, la presentación de conocimientos estáticos y cerrados no tiene sentido, ya existen grandes probabilidades de que lo que una persona ha aprendido en un momento determinado de su vida no le sirva en relativamente poco tiempo (Area Moreira, 2010a; Cabero Almenara \& Alonso García, 2007; Monereo \& Coll, 2008) si no ha sido actualizado en un proceso de aprendizaje, reaprendizaje e incluso desaprendizaje.

Sin embargo, pese a esta realidad comúnmente aceptada, la escuela se ha mantenido impasible, dando continuidad a sus estructuras y procedimientos más arcaicos (Pérez Gómez, 2012). Consideramos que la escuela debería desistir en su empeño de mantener un modelo formativo tradicional, basado en la presentación estática y acrítica del mundo, para implementar modelos más coherentes con el mundo que le rodea, que desarrollen competencias realmente básicas en la sociedad de la información como el tratamiento de la información, aprender a aprender, el espíritu crítico y la autonomía personal, el trabajo colaborativo en grupos multidisciplinares, etc.

En relación a esto último, muchos autores han percibido cómo las necesidades de aprendizaje permanente de los ciudadanos en la sociedad de la información, y la falta de previsión de las instituciones públicas y las propias escuelas en este aspecto, ha llevado a un aumento considerable de la oferta privada en formación, y a que las propias empresas destinen unas sumas de dinero cada vez mayores a formar en estas competencias básicas a sus propios empleados (Federighy, 2006). En este nuevo entorno social, económico, cultural y educativo la finalidad última de la educación no puede ser solamente transmitir conocimientos culturales a las nuevas generaciones, sino que se debe encauzar desde el primer momento el proceso de aprendizaje a lo largo de toda la vida. «Si el sistema educativo no da una respuesta a esta necesidad de educación permanente, será el mercado quien lo hará [...] y sin duda esto no contribuirá a la igualdad de oportunidades de todos los ciudadanos ante las necesidades formativas» (Majó i Cruzate \& Marqués, 2002, p. 112). 
En suma, ante el reto que proponen al mundo de la educación estos cinco aspectos fundamentales característicos de la sociedad de la información, hemos visto como la alfabetización tradicional no aporta respuestas convincentes. Es necesario, pues, un nuevo modelo que acoja estas necesidades y reformule profundamente el concepto tradicional de alfabetización: "As scholars from the literacy domain argue, new capabilities are required to exploit the potential of Reading, writing and numeracy in a new environment, and consequently the notions of traditional literacies need to be redefined» (Markauskaite, 2006). El profesor García Carrasco (2009) expresa esta necesidad de manera brillante:

\begin{abstract}
«No podemos comprender las transformaciones culturales en las que nos vemos envueltos, sin tomar en cuenta esta metamorfosis del proceso de alfabetización, ni sin advertir que se trata, con toda propiedad en todos los casos, de un verdadero y auténtico proceso de recrecimiento y evolución de la alfabetización...» (p. 59) «...La alfabetización como proyecto pedagógico sufre una metamorfosis irreversible en la sociedad actual, nunca más podrá entenderse como un proceso de aprender a leer y a escribir, porque ha pasado a la necesidad de ser un proceso de leer para aprender, un proceso de entrenamiento instrumental para deliberar, un proceso básico para aprender a vivir» (p. 72)
\end{abstract}

A pesar de las discrepancias terminológicas que se pueden encontrar en la literatura acerca de la denominación de la nueva alfabetización vinculada a la sociedad del conocimiento, lo que nos ha quedado, a priori, claro es que «estamos asistiendo de nuevo a un cambio en el concepto de alfabetización y de lo que significa estar alfabetizado» (Monereo \& Coll, 2008, p. 333) y que hoy en día estar alfabetizado para ser un buen estudiante en la escuela no garantiza de ninguna manera estar alfabetizado para la vida cotidiana (Ferreiro, 2002).

Desde nuestra perspectiva, nosotros adoptaremos generalmente para referirnos a este nuevo concepto de alfabetización la terminología aplicada y desarrollada por el New London Group (1996), multialfabetización. Así, nos referiremos en el ámbito educativo a la "pedagogía de la multialfabetización" como el cambio que deben experimentar la enseñanza y el aprendizaje de las alfabetizaciones en un mundo en constante transformación, en el que el entorno de las comunicaciones es diverso, flexible y cambiante (Cope \& Kalantzis, 2009a).

Llegados a este punto, vamos a entrar mínimamente a elaborar una definición previa del término multialfabetización para que tengamos un marco teórico definido sobre el que asentar nuestra Tesis, ya que a partir de ahora vamos a hacer referencia 
al mismo con bastante frecuencia. No obstante, en siguientes apartados desarrollaremos con más amplitud este concepto.

Si aceptamos la definición de alfabetización desde una perspectiva sociocrítica como

«un conjunto de prácticas que pueden ser utilizadas tanto para habilitar como para inhabilitar a las personas [...] Es la relación que existe entre los educandos y la realidad, mediada por la transformación de dicha realidad, que se produce en el entorno mismo de aquellos que se mueven» (Freire, 1989, p. 10),

caemos en la cuenta de que en el mundo actual existen una serie de medios relacionados con las TIC que aumentan el alcance original de la alfabetización descrita, y que incluso transforman la propia alfabetización al aplicar nuevos modos con sus convenciones y combinaciones (Levine, 1990). Así nos podemos encontrar que actividades como "bloguear", "photoshopear", utilizar "podcasts", producir "manga", etc. son diferentes medios que desarrollan modos propios de la alfabetización.

De ahí precisamente el término multialfabetización, que da respuesta a los cambios y necesidades propuestos en el contexto de la sociedad de la información:

1. En un mundo totalmente multimodal y multimedio no se puede mantener un concepto de alfabetización unidimensional, sino que se debe definir desde una perspectiva multidimensional (Area Moreira \& Ribeiro-Pessoa, 2012).

2. En el entorno laboral que genera la nueva economía no se puede mantener una educación alfabetizadora estática, propia de la era industrial. La formación de los sujetos debe estar adaptada al perfil de empleo que exigen los puestos de trabajo actuales. Se debe promocionar una alfabetización desde un punto de vista abierto, dinámico y crítico, que promocione la participación responsable y activa de los ciudadanos en la sociedad de hoy en día.

3. En un contexto dominado por las $T I C$, en el que se genera una cultura multimodal, no se puede pretender una educación ajena, que no tenga en cuenta en sus prácticas alfabetizadoras los nuevos modos y medios de representación y construcción de significados que nacen gracias a estas tecnologías (Area Moreira \& Guarro, 2012).

4. En un momento histórico en el que los estados pierden su hegemonía en muchos campos de la sociedad y modifican su papel profundamente, no se 
puede mantener un concepto de escuela vinculada a los ideales y designios del estado-nación, que trata de homogeneizar a las masas desarrollando una alfabetización estándar propia de las clases más favorecidas. La alfabetización recibida en las escuelas, más que para adoctrinar e instigar un modelo de persona, debe promocionar la diversidad, el espíritu crítico y la educación liberadora.

5. En una realidad incierta y en constante transformación, en la que los sujetos tienen la necesidad de actualizar sus conocimientos a lo largo de toda su vida, no tiene sentido un modelo de escuela que presenta el conocimiento como algo absoluto y cerrado, y la alfabetización como la simple decodificación de símbolos en fonemas y viceversa. En realidad, la alfabetización debe servir para que el sujeto sea competente para localizar, seleccionar, analizar, interpretar, procesar y difundir información presentada a través de cualquier modo o constelación de modos y a través de cualquier medio.

\subsection{Evolución del concepto alfabetización desde su nacimiento hasta la actualidad}

De lo señalado hasta este punto, parece aceptable la consideración de que los drásticos cambios sufridos en el actual contexto en el ámbito social y cultural deben traen consigo cambios profundos en el propio concepto de alfabetización y por ende en las prácticas alfabetizadoras de cada entorno. De hecho, es evidente que «el concepto de alfabetización ha evolucionado a lo largo del tiempo, a medida que la sociedad ha experimentado profundas transformaciones» (Fernández Ludeña, 2007, p. 24).

Así, el objeto de este apartado es relatar, desde la visión que nos concede el estudio realizado de las principales fuentes teóricas, cómo ha ido evolucionando el concepto de alfabetización desde lo que hemos venido señalando como "alfabetización tradicional", hasta llegar al actual concepto de "multialfabetización", ya introducido a lo largo de este tema.

En primer lugar, podemos situarnos en el contexto del nacimiento de las primeras civilizaciones con una fuerte cultura lecto-escritora, principalmente, la cultura griega. Si estudiamos estas civilizaciones desde nuestra actual perspectiva, 
«Da la sensación de que la alfabetización liberó a parte de la humanidad de un estado primitivo, de una etapa anterior de evolución humana. Si el lenguaje es lo que nos hace humanos, parece que la alfabetización es lo que nos hace civilizados» (Gee, 2003, p. 41).

De hecho, muchos de los lectores podrán estar de acuerdo con nosotros si afirmamos que la alfabetización conduce al pensamiento lógico, analítico, crítico y racional, que permite el empleo abstracto del lenguaje, el manejo y reconocimiento del tiempo y el espacio, facilita el razonamiento complejo e incluso permite unas mayores tasas de desarrollo social, cultural económico y político.

Esta anterior teoría es comúnmente aceptada. Sin embargo, no existen en la investigación relativa existente evidencias claras que la confirmen sin dar lugar a ningún tipo de dudas. Así, nos encontramos autores que hablan del "mito de la alfabetización" (Gee, 2003; Graff, 1979, 1981).

La primera crítica a este mito de la alfabetización la promulgó Platón en sus escritos (Gee, 2003). Así, el filósofo griego, pensaba que la escritura promociona una visión de la realidad poco ajustada a la verdad, y dificulta el desarrollo de la memoria humana. Por otro lado, el texto escrito facilita la visión de los conceptos que contienen las palabras como algo estático y cerrado. Esto es, prima ver el conocimiento como algo hecho, objetivo y absoluto $y$, por ende, transmite la idea de la concepción bancaria de la educación (Freire, 1989).

Sócrates, por su parte, también criticaba el lenguaje escrito al observar que no cambia, que transmite lo mismo a todas las personas que acuden a él. Para estos filósofos el auténtico conocimiento sólo existe cuando existe un proceso continuo y dinámico de reelaboración del conocimiento. El lenguaje escrito no responde a este precepto, ya que no se va adaptando a las circunstancias contextuales y es fijo. La escritura no permite la reflexión crítica, la pregunta y el diálogo que lleve a la reflexión continua.

\footnotetext{
«si valen todas las interpretaciones, ninguna sirve, pues, en ese caso, el texto dice todo y, por tanto, nada, y si, para interpretarlo, no son precisas disciplina, experiencia o credenciales algunas, parece que todas las interpretaciones valdrán.» (Gee, 2003, p. 46)
}

La perspectiva que se infiere en las reflexiones de Platón y Sócrates, tiene mucho que ver con la concepción tradicional de la alfabetización. Y la alfabetización, desde una postura clásica, «se reduce al acto mecánico de depositar en los analfabetos 
palabras, sílabas y letras» (Fiori et al., 1973, p. 66). Este depósito no es suficiente para que el hombre analfabeto deje de serlo. De hecho esta visión de la alfabetización es ingenua, ya que supone que el hecho de que las personas memoricen símbolos y significados que nada tienen que ver con su experiencia existencial les va a convertir en alfabetizados. "La alfabetización sólo es auténticamente humanista, [...] cuando, sin temer la libertad, se instaura como un proceso de búsqueda de creación, de recuperación de su palabra por el alfabetizado» (Fiori et al., 1973, p. 71).

Esta controversia que supone considerar el lenguaje escrito y la alfabetización como un proceso mecánico que desarrolla el espíritu acrítico más que el reflexivo se mantiene entre los temas de los autores de todas las épocas. Incluso se llega a considerar en muchos casos el proceso de alfabetización como un proceso de modelado de las personas en la cultura burguesa dominante con el fin del asentamiento y preservación de las estructuras y estamentos sociales existentes. Esto es así hasta que aparece un grupo de estudiosos, con Paulo Freire a la cabeza, con sus ideas revolucionarias sobre la alfabetización liberadora desde una postura sociocrítica.

Freire adopta el dilema de Platón, considerando que «la alfabetización sólo potencia a las personas cuando las transforma en cuestionadoras activas de la realidad social que las rodea» (Gee, 2003, p. 52). Ninguna acción humana es neutra, y por lo tanto, ninguna enseñanza lo es. Así, toda acción educativa lleva inherente una ideología política concreta, por lo que además de orientarnos hacia el qué enseñar, Freire y Platón se inclinan hacia pensar en que es muy importante pensar en el cómo enseñar, qué ideología concreta estamos transmitiendo al enseñar (Freire, 1975, 1984, 1989; Gee, 2003; Graff, 1981).

García Carrasco (2009), enumera esta dicotomía, señalando y confrontando las principales características de cada visión:

- Desde una perspectiva tradicional, podemos considerar la alfabetización simplemente como aprender a hablar, leer y escribir. Alfabetizar sería en este caso, como mínimo, «entrenar, habilitar en el manejo de instrumentos humanos, que se aprenden de una vez por todas y no le queda otro progreso, con el tiempo y la práctica que el del acicalamiento: hablar, leer o escribir correctamente» (p. 53). Avanzando un poco más en la definición, podríamos entender alfabetización como «extender el poder de traducción que los seres humanos adquieren al hablar, ampliando su vocabulario de uso, y aplicar esa 
habilidad a la interpretación de los signos gráficos que representan, literalmente, palabras y oraciones que tienen sentido» (p. 53).

- Desde la perspectiva sociocrítica, alfabetizar consiste en comprender, interpretar y aprender al hablar, al leer y al escribir. Tiene más que ver con la alfabetización funcional, esto es, con el entendimiento de alfabetización como la interpretación de los símbolos condicionados por la inmersión en un contexto concreto y por las experiencias previas del intérprete. Esto implica que el receptor debe asignar a cada expresión una intención, intención que ejecuta el emisor, y a la que asigna significado el receptor.

La expansión de la perspectiva sociocrítica se produce a partir de los años 70 gracias principalmente a tres factores:

1. El concepto de Freire de alfabetismo como "leer la palabra y el mundo" implica mucho más que las sencillas ideas de descifrar lo impreso y codificarlo. Este nuevo concepto da un vuelco al enfoque que la educación da a la alfabetización. «En el enfoque de Freire para promover la alfabetización, el proceso de aprender literalmente a leer y a escribir palabras formaba parte del aprendizaje para comprender cómo opera social y culturalmente el mundo para crear oportunidades y resultados desiguales para distintos grupos de personas.» (Lankshear \& knobel, 2008, p. 25)

2. Los gobiernos e instituciones caen en la cuenta de que a pesar de la generalización de la educación y de la alfabetización en los "países desarrollados", se encuentra un numeroso grupo de personas no preparadas para adaptarse a la sociedad postindustrial (analfabetas): «Las escuelas no estaban consiguiendo que todos los aprendices quedaran alfabetizados en la medida requerida para vivir "eficazmente" en las condiciones contemporáneas.» (Lankshear \& knobel, 2008, p. 26)

3. Popularidad creciente de la perspectiva sociocultural en los estudios del lenguaje y en las ciencias sociales. Toda esta investigación científica, llevada a cabo durante las décadas de 1970 y 1980 indica que «lo importante no es la alfabetización en cuanto capacidad descontextualizada de leer o escribir, sino las prácticas sociales que las personas aprenden al formar parte de un grupo social» (Gee, 2003, p. 72). 
Este nuevo concepto de alfabetización implica que el alfabetizando emplea las palabras no como significados objetivos, sino "para decir y escribir su mundo, su pensamiento, para contar su historia» (Fiori et al., 1973, p. 15). Por tanto, la alfabetización no consiste en «repetir palabras ni se restringe a desarrollar la capacidad de pensarlas [...] simplemente coloca al alfabetizando en condiciones de poder reexistenciar críticamente las palabras de su mundo, para, en la oportunidad debida, saber y poder decir su palabra» (Fiori et al., 1973, p. 16). Así, a pesar de que lo que hace el alfabetizando, operativamente hablando, es aprender a leer y escribir, la intención profunda con la que realmente lo hace transciende la mera alfabetización. Alfabetizarse implica adquirir una conciencia reflexiva de la propia cultura, emprender un proceso de reconstrucción crítica del mundo y abrir nuevas posibilidades de evolución y desarrollo personal y social. Desde este punto de vista, por tanto, debemos considerar la alfabetización más que como un acto de transferencia de conocimiento, como un acto de conocimiento en sí mismo.

Dicho en palabras del propio Freire,

«Leer no consiste solamente en decodificar la palabra o el lenguaje escrito; antes bien, es un acto precedido por el conocimiento de la realidad. El lenguaje y la realidad están interconectados dinámicamente. La comprensión que se alcanza a través de la lectura crítica de un texto implica percibir la relación que existe entre el texto y el contexto» (Freire, 1989, p. 51).

Y es por este mismo razonamiento por el que el mismo autor continúa señalando que

«La lectura del mundo precede a la lectura de la palabra, de ahí que la posterior lectura de ésta no pueda prescindir de la continuidad de la lectura de aquél. Lenguaje y realidad se vinculan dinámicamente. La comprensión del texto a ser alcanzada por su lectura crítica implica la percepción de relaciones entre el texto y el contexto.» (Freire, 1984, p. 94).

Desde esta perspectiva desde la que se analiza la alfabetización, no es posible concebir un texto deslocalizado, sin estar enmarcado en un contexto concreto.

Si llegamos un poco más lejos en el análisis de este punto de vista, podemos caer en la cuenta de que en el sentido sociocrítico, la alfabetización es la condición previa para la emancipación social y económica del sujeto (Lonsdale \& McCurry, 2004). Así, las competencias informacionales son una parte de esta condición previa, ya que 
sirven para que la persona sea independiente a la hora de aprender a lo largo de la vida. Esta emancipación requiere la reflexión crítica del sujeto.

La perspectiva sociocrítica tiene una gran influencia en las teorías y concepciones modernas sobre alfabetización. Es a partir de estas ideas desde donde organismos internacionales como la UNESCO comienzan a variar sus puntos de vista y sus políticas sobre alfabetización. Así es como se supera una visión dicotómica, que considera que las personas pueden estar alfabetizadas o ser analfabetas, por una visión de la alfabetización como un continuum de una escala. La alfabetización es un proceso que está formado por gran cantidad de niveles, desde el simple hecho de descifrar símbolos básicos (alfabetización tradicional), hasta el desarrollo del razonamiento lógico y el pensamiento crítico abstracto. Así, se pone de manifiesto la diferencia entre estar alfabetizado en el sentido clásico de la definición y estar alfabetizado en el sentido funcional de la palabra.

Estas nuevas perspectivas más abiertas y multidimensionales surgen al plantearse la siguiente pregunta: ¿cuál es la barrera entre alfabetizado y analfabeto? Realmente, en una sociedad en la que aumentan los niveles de alfabetización general, el límite de lo que se considera alfabetizado o analfabeto también sube (Levine, 1990), por lo que esta barrera no es fija, es variable. Por tanto, no debemos olvidar tratar de ser cautelosos con el empleo acrítico de la dicotomía alfabeto-analfabeto, máxime teniendo en cuenta que este modelo «sirve de poco cuando se trata de dar algo más que simples indicaciones elementales en cuanto a la política a seguir, dadas las múltiples variantes de significación que hay dentro y entre los términos alfabeto y analfabeto» (Wagner, 1998, pp. 84-85).

Entendiendo pues que una sociedad alfabetizada va mucho más allá de una sociedad donde las tasas de alfabetización son altas, el concepto de alfabetización funcional que comienzan a manejar estos organismos, y que hoy en día sigue vigente, es el siguiente:

«está funcionalmente alfabetizada o es analfabeta funcional la persona que, respectivamente, es capaz o incapaz de realizar todas las actividades en que la alfabetización es necesaria para la actuación eficaz en su grupo o comunidad y que le permite seguir valiéndose de la lectura, la escritura y la aritmética al servicio de su propio desarrollo y el de la comunidad» (Fernández Ludeña, 2007, p. 76).

Así, vemos cómo la alfabetización funcional está íntimamente relacionada con las propias competencias informacionales (Koltay, 2009), que abarcamos en este trabajo. 
Esto nos lleva, como veremos más adelante, a considerar la alfabetización como un conjunto de competencias básicas relacionadas con el manejo reflexivo, crítico y orientado al desarrollo personal y social de la lecto-escritura en diferentes contextos, modos y medios.

Y después de este breve repaso histórico, llegando a las perspectivas más actuales, los estudiosos de este ámbito coinciden en señalar que el concepto de alfabetización se ha transformado completamente en el contexto actual de la sociedad de la información (Buschman, 2010; Ferreiro, 1997; Levine, 1990; O’Farrill, 2008; Wagner, 1998).

La extensa proliferación de las tecnologías relacionadas con la información, la comunicación y el desarrollo multimedia han cambiado radicalmente los modos en los que la gente trabaja, se comunica con otras personas y dedica su tiempo de ocio (Kellner, 2004). Como consecuencia,

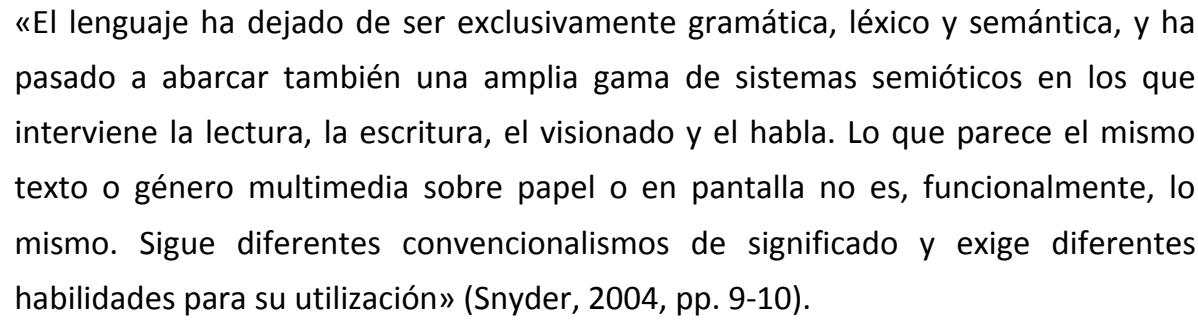

Esta evolución hacia realidades más amplias y multidimensionales ha provocado cierta confusión en lo que respecta a los límites reales de la alfabetización y las llamadas nuevas alfabetizaciones (Lonsdale \& McCurry, 2004). De hecho, muchos autores muestran su preocupación por la extensión del término alfabetismos a casi cualquier cosa (Pasadas Ureña, 2008), mucho más allá del propio concepto de prácticas sociales de representación, ámbito en el que estaba descrito hasta la actualidad, "hasta convertirlo en una metáfora de cualquier tipo de habilidad o competencia» (Pahl \& Rowsell, 2006, p. 7).

A pesar de esta lógica preocupación, lo cierto es que en el actual contexto han surgido gran cantidad de modos y medios de representación y construcción de significados que no están incluidos dentro de un concepto tradicional de alfabetismo. Así, consideramos la propuesta de la "multialfabetización" como el planteamiento más ajustado, completo y holístico que explica lo que significa estar alfabetizado en cualquier contexto concreto tanto a nivel histórico como a nivel geográfico. 
"If literacy is conceptualised as social practice rather than as an individualised, self contained action, and is thus likely to differ from context to context, then it follows thatther can be no such thing as a single, universal literacy but rather multiple literacies that vary with time and place and are embedded in specific cultural practices» (Lonsdale \& McCurry, 2004, p. 26)

Tabla 2.1 Evolución del concepto de alfabetización*

\begin{tabular}{|c|c|c|}
\hline DENOMINACIÓN & $\begin{array}{l}\text { PRINCIPALES } \\
\text { VALEDORES }\end{array}$ & DEFINICIÓN \\
\hline $\begin{array}{l}\text { Alfabetización } \\
\text { básica (modelo } \\
\text { clásico) }\end{array}$ & (UNESCO, 1957) & $\begin{array}{l}\text { Habilidad para leer y escribir. Estar } \\
\text { alfabetizado es una simple competencia } \\
\text { básica. }\end{array}$ \\
\hline $\begin{array}{l}\text { Alfabetización } \\
\text { sociocrítica } \\
\text { (perspectiva } \\
\text { liberadora) }\end{array}$ & $\begin{array}{l}\text { (Fiori et al., } \\
\text { 1973) } \\
\text { (Freire, 1975, } \\
\text { 1984, 1989) }\end{array}$ & $\begin{array}{l}\text { La alfabetización no es otra cosa que la } \\
\text { práctica de la libertad, la persona alfabetizada } \\
\text { es aquella capaz de «aprender a escribir su } \\
\text { vida, como autor y como testigo de la } \\
\text { historia» (Fiori et al., 1973, p. 11). } \\
\text { La alfabetización permite a la persona, } \\
\text { además de leer la palabra, ser capaz de leer el } \\
\text { mundo que le rodea. }\end{array}$ \\
\hline $\begin{array}{l}\text { Alfabetización } \\
\text { como una } \\
\text { tecnología del } \\
\text { intelecto }\end{array}$ & $\begin{array}{l}\text { (Goody, 1963, } \\
\text { 2005) } \\
\text { (Ong, 1982) }\end{array}$ & $\begin{array}{l}\text { La alfabetización es un proceso que } \\
\text { promociona en el individuo capacidades que } \\
\text { no son posibles sin la misma, como el } \\
\text { razonamiento abstracto independiente del } \\
\text { contexto, la capacidad para el pensamiento } \\
\text { deductivo e inductivo, para clasificar, inferir, } \\
\text { etc. }\end{array}$ \\
\hline $\begin{array}{l}\text { Alfabetización } \\
\text { Funcional }\end{array}$ & $\begin{array}{l}\text { (UNESCO, 1976) } \\
\text { (Fernández } \\
\text { Ludeña, 2007) }\end{array}$ & $\begin{array}{l}\text { "Es alfabeto funcional la persona que puede } \\
\text { emprender aquellas actividades en que la } \\
\text { alfabetización es necesaria para la actuación } \\
\text { eficaz en su grupo y comunidad y que le } \\
\text { permitan asimismo seguir valiéndose de la } \\
\text { lectura, la escritura y la aritmetica al servicio } \\
\text { de su propio desarrollo y del desarrollo de la } \\
\text { comunidad» (UNESCO, 1976) }\end{array}$ \\
\hline $\begin{array}{l}\text { Alfabetización } \\
\text { como conjunto de }\end{array}$ & $\begin{array}{l}\text { (O'Farrill, 2008) } \\
\text { (Markauskaite, }\end{array}$ & $\begin{array}{l}\text { «The progressive development of } \\
\text { competences for becoming aware of, }\end{array}$ \\
\hline
\end{tabular}




\begin{tabular}{|c|c|c|}
\hline DENOMINACIÓN & $\begin{array}{l}\text { PRINCIPALES } \\
\text { VALEDORES }\end{array}$ & DEFINICIÓN \\
\hline competencias & $\begin{array}{c}2006) \\
\text { (Monereo \& } \\
\text { Coll, 2008) } \\
\text { (diSessa, 2001) }\end{array}$ & $\begin{array}{l}\text { accessing, critically interpreting and effectively } \\
\text { using a variety of languages, codes, semiotic } \\
\text { resources and technological affordances as } \\
\text { tools for learning, communication, and sense- } \\
\text { making in situated social practices» (O'Farrill, } \\
2008, \text { p. 167) }\end{array}$ \\
\hline Multialfabetización & $\begin{array}{l}\text { (Cazden et al., } \\
\text { 1996) } \\
\text { (Cope \& } \\
\text { Kalantzis, 1999, } \\
\text { 2009a, 2009b) } \\
\text { (Lankshear \& } \\
\text { knobel, 2008) } \\
\text { (Lonsdale \& } \\
\text { McCurry, 2004) }\end{array}$ & $\begin{array}{l}\text { La multialfabetización «Indica las clases muy } \\
\text { diferentes de alfabetismos que se necesitan } \\
\text { para acceder, interpretar, criticar y participar } \\
\text { en las nuevas formas emergentes de cultura y } \\
\text { sociedad» (Snyder, 2004, p. 240). Estos nuevos } \\
\text { alfabetismos están constituidos tanto por una } \\
\text { sustancia técnica diferente de la de los } \\
\text { alfabetismos tradicionales, como por una } \\
\text { sustancia espiritual distinta (Lankshear \& } \\
\text { knobel, 2008). }\end{array}$ \\
\hline
\end{tabular}

Adaptado de Lonsdale y McCurry (2004)

En la tabla 2.1, presentada más arriba, se puede observar sintética una enumeración de las principales teorías y conceptos sobre alfabetización tratados y otros no tratados hasta el momento.

\subsection{El concepto de multialfabetización. La multialfabetización como marco integrador de las competencias informacionales}

Hasta este momento de la exposición, hemos dejado claro que en el modelo teórico que estamos defendiendo a lo largo del texto proponemos la teoría de la multialfabetización como el marco global en el que se integran las competencias básicas, y entre ellas, la que nos ocupa, que no es otra que las competencias informacionales.

Como ya hemos reflejado más arriba, el primer grupo de autores que introducen el término de multialfabetización es el New London Group (1996), en lo que se viene a 
denominar "pedagogía de la multialfabetización". En un mundo en cambio, en el que el entorno de las comunicaciones también lo hace, la enseñanza y el aprendizaje de las alfabetizaciones debe cambiar (Cope \& Kalantzis, 2009a).

Llegados a este punto, creemos necesario, siguiendo la estructura que defienden Cope y Kalantzis en su discurso, exponer más detenidamente el significado de la multialfabetización a través de un análisis del porqué de esta teoría, a qué se refiere y cómo se desarrolla:

Por qué: El campo de la construcción de significados y de la representación en la vida cotidiana de cada entorno concreto, implica una enseñanza diferente de la alfabetización, no sólo centrada en educar una lengua estándar.

Mientras que el capitalismo antiguo era jerárquico, basado en la disciplina, estático y abogaba por la estandarización y homogeneización social, el sistema capitalista actual es diverso, diferenciado y flexible. No tiene sentido en este nuevo contexto una forma tradicional de alfabetizar, basada en la visión bancaria de la educación, como forma de homogeneización de la población y mantenimiento de las estructuras y estamentos sociales (Freire, 1975).

Por otro lado, la pérdida de poder relativo de los Estados debido a la implantación del neoliberalismo (Castells, 1999b) y la consecuente reducción del estado del bienestar y progresiva privatización de servicios hasta la fecha públicos, pone en tela de juicio el papel actual de la escuela, procedente de la sociedad industrial. Tradicionalmente la escuela estaba considerada como un medio para "enculturizar" a los ciudadanos en la cultura y conocimientos comunes de la sociedad, esto es, un instrumento de homogeneización de los sujetos de un país.

\footnotetext{
«Enseñar a leer, escribir y contar durante muchas décadas fue la razón que justificaba la existencia de la escuela como institución. Por ello, una de las funciones clave de la escolaridad desde hace más de un siglo es precisamente la alfabetización, entendida en un sentido amplio, como la capacidad para decodificar (leer) y codificar (escribir) los símbolos de la cultura» (Area Moreira, 2010b, p. 42)
}

Actualmente, a pesar de que la sociedad es plural, dinámica y diferenciada (en una palabra, glocal), la escuela no ha cambiado en demasía, y parece que sigue teniendo estas antiguas intenciones, hoy en día obsoletas. No se entiende que en un mundo radicalmente distinto al industrial, la educación de la espalda a las nuevas formas culturales de representación, comunicación, difusión y acceso a la información (Area Moreira, 2010b). 
Otro aspecto importante a considerar es cómo ha cambiado la consideración y situación de los propios ciudadanos en la sociedad. De ser considerados en la sociedad industrial como meros espectadores pasivos, como lectores, como audiencia, hemos pasado en la sociedad de la información a considerar a las personas como jugadores, agentes de cambio participantes en las narrativas y dinámicas sociales. Los ciudadanos hoy en día tienen la posibilidad de elegir qué información recibir, cuándo hacerlo y en qué lugar disponer de ella (Majó i Cruzate \& Marqués, 2002; Tubella i Casadevall \& Vilaseca i Requena, 2005). Es más, pueden ser ellos mismos los que transmitan, transformen o decidan cómo recibir esa misma información. La vieja lógica de la alfabetización y de la propia educación está condenada al fracaso en este entorno mediático tan opuesto al existente en la sociedad industrial. El tipo de persona que podrá desenvolverse adecuadamente en este entorno tan sumamente elástico, incluso líquido (Bauman, 2006), será aquella capaz de mantener altos niveles de plasticidad mental (Prensky, 2009), de aprender a aprender, a desaprender y a reaprender (Andrade, 2005) y de ser lo bastante flexible para colaborar en grupos interdisciplinares con otras personas más o menos diferentes que uno mismo (Cope \& Kalantzis, 2009a).

Qué: El mundo es cada vez más multimodal en la presentación de cualquier información. Podríamos decir que Alfabetización con mayúscula existe una (Lankshear \& knobel, 2008) ${ }^{14}$, pero en varios canales (O'Farrill, 2008). Por ello, la enseñanza se debe ampliar a todos estos lenguajes, incluyendo el aprendizaje de la lectura y la escritura de textos multimodales.

La multimodalidad, gracias a la experiencia desde el surgimiento de las TIC y a las actuales posibilidades técnicas, va en aumento. Las posibilidades de representación son, por lo tanto, cada vez más amplias. Cada modalidad tiene una naturaleza distinta, que lo diferencia del resto. Sin embargo, también debemos de tener en cuenta que estas modalidades se presentan interrelacionadas, por lo que tienen elementos paralelos y conexos. Así, además de existir una considerable variedad de alfabetizaciones, podemos afirmar que «las competencias y alfabetizaciones se presentan siempre en la práctica en constelación [...] siempre aplicamos al mismo

\footnotetext{
${ }^{14} \mathrm{El}$ autor, en su obra, diferencia entre Alfabetización, entendida como el sentido que se asigna a las cosas inmersas en el mundo, en la propia vida, y alfabetización, como el proceso concreto de leer, escribir, ver, escuchar, manipular imágenes y sonidos, etc.

Es decir, mientras que el alfabetismo se refiere según el autor al proceso básico y mécánico integrado en la lecto-escritura, el Alfabetismo se refiere al concepto que le asigna la teoría sociocrítica, como un nivel cognitivo superior.
} 
tiempo y en diversos grados de intensidad varios modos y medios de comunicación: lo oral y lo gestual van siempre de la mano, por ejemplo» (Pasadas Ureña, 2010a, p. 27).

Desde la teoría que proponemos (Cazden et al., 1996; Cope \& Kalantzis, 2009a), la multialfabetización está constituida por los siguientes elementos o modos (de ahí las referencias hechas hasta el momento a la multimodalidad inherente a la teoría de la multialfabetización):

- Lengua escrita en todas sus formas

- Lengua oral en todas sus formas

- Representación visual estática o en movimiento.

- Representación audio

- Representación táctil. Tacto, olor y sabor

- Representación gestual. Expresiones, brazos y manos, rostro, ritmo,...

- Representación para uno mismo. Impresiones y emociones.

- Representación espacial. Tipo de paisaje, construcción, proximidad,...

Todos estos modos están diferenciados, ya que tienen un potencial de transmisión de significado muy diferente. Sin embargo, como ya hemos señalado, la información se suele mostrar no de forma aislada, sino entrelazando diferentes modos. Desde esta postura, entendemos que un sistema educativo que restrinja el aprendizaje a un único modo, segregándolo del resto, favorecerá el desarrollo de ciertos tipos de aprendices (Cope \& Kalantzis, 2009b). Es evidente que la alfabetización tradicional, comúnmente integrada en las escuelas, se encarga sólo de la lengua escrita, y de algún modo de la lengua oral.

Así, en este entorno, nos encontramos con que la alfabetización tradicional es monomodal. Este reduccionismo es tremendamente irreal si pensamos en las necesidades de la vida cotidiana de los estudiantes (Cope \& Kalantzis, 2009a).

De hecho, en la sociedad actual el ideal de buen comunicador consiste precisamente en el empleo fusionado y eficiente de todo el conjunto de medios y modos disponible para transmitir además de un mensaje, una visión del mundo o ideología determinada.

Mientras que la multimodalidad nos ofrece la posibilidad de construir significados aparentemente iguales de maneras muy diferentes, en función de la propia ideología que queramos transmitir, la escuela está restringiendo esta variedad y primando un 
tipo de aprendizajes concretos, favoreciendo a un tipo de aprendices sobre otros. Por tanto, podemos inferir la idea de que "la escuela tradicional, hoy por hoy, les propone [a los estudiantes] una definición de alfabetización mientras que la sociedad les empieza a exigir otra» (Ferreiro, 1997, p. 63)

En otro orden de cosas, partimos de la idea de que todas las formas de representación de la información son, más que procesos de reproducción y convenciones sociales, procesos de construcción y transformación de significados, y por tanto son valiosos para la educación. Así, mientras que la vieja alfabetización forma aprendices pasivos que reciben una información uniforme y estática para reproducirla conforme a las convenciones existentes en el entorno geográfico e histórico, estos mismos estudiantes se mueven en el entorno de la multialfabetización, en el que son actores protagonistas en el proceso de construcción de significados. La pedagogía de la multialfabetización (Cazden et al., 1996; Cope \& Kalantzis, 1999, 2009a), por tanto, propone un modelo que va más allá de la simple presentación y reproducción de los diseños y modelos de representación de la realidad disponibles. La pedagogía de la multialfabetización considera que cada ciudadano o grupo social va a producir sus propios significados a partir de los diseños disponibles, y que el aprendizaje sólo se alcanza cuando la persona o personas rediseñan los propios diseños estudiados, construyendo nuevos diseños (Cope \& Kalantzis, 2009a).

En este contexto, las competencias informacionales se postulan de nuevo como una competencia básica para la consecución del objetivo de la multialfabetización, ya que va a permitir a las personas tanto acceder como construir y transformar los significados propuestos a través de los diversos modos y medios.

Cómo: Siguiendo los principios de la alfabetización crítica y liberadora de Freire. Partiendo de la realidad contextual propia de cada grupo de sujetos y promocionando las mentes críticas y la práctica transformadora.

La pedagogía tradicional, como ya hemos ido señalando, trata la alfabetización como un simple proceso mecánico, consistente en aprender la relación entre letras y fonemas para más adelante poder mecanizar la lectura y escritura de palabras, párrafos y textos completos y aprender las reglas esenciales del lenguaje. Desde la perspectiva de la multialfabetización este tipo de enseñanza no tiene sentido, ya que no tiene en cuenta el contexto concreto en el que se enmarcan los grupos sociales ni la construcción personal y grupal de significados que lleva a la transformación de las propias representaciones. 
Así, la pedagogía de la multialfabetización se basa en cuatro preceptos (Cazden et al., 1996; Kalantzis \& Cope, 2005a):

- La práctica situada. Con este concepto nos queremos referir a las propias experiencias en un entorno contextual concreto. Tanto las nuevas experiencias, en las que nos enfrentamos a lo extraño y construimos nuevos significados, como las experiencias ya vividas, sobre las que debemos reflexionar $y$ reelaborar los significados.

- La instrucción abierta o conceptualización, es decir, la propia construcción y diseño de significados a partir de las experiencias. Esta construcción es propia de cada sujeto y no está sujeta a estructuras predefinidas. Cada aprendiz es un constructor de conceptos activo y establece teorías y generalizaciones a partir de lo particular.

- La capacidad crítica o de análisis, que no es otra cosa que ser capaz de juzgar las diversas situaciones, elementos y/o personas empleando un razonamiento lógico que lleve a la extracción de conclusiones sobre la bondad, causas y efectos de esa realidad analizada.

- La práctica transformadora. Además de participar en experiencias contextualizadas y valiosas, es esencial que el sujeto aprenda a intervenir en el mundo, transformar los significados de manera crítica, abierta y creativa.

Estos ejes vertebradores de la educación en el contexto de la pedagogía de la multialfabetización están íntimamente relacionados, como se puede observar, con los criterios defendidos en el primer capítulo al hablar del desarrollo de la cultura del aprendizaje y de la educación para tender puentes entre la sociedad de la información y la sociedad del conocimiento. Se podría señalar que estos ejes son una adaptación de dichos criterios al contexto de la teoría de la alfabetización.

Una vez que hemos analizado desde varias perspectivas las condiciones, causas y consecuencias de lo que se denomina sociedad de la información, estudiando sus efectos en el mundo de la educación, y hemos llevado a cabo una revisión del concepto de alfabetización desde sus inicios hasta llegar al contexto de la sociedad actual, nos encontramos en condiciones de discutir acerca de un elemento central de esta disquisición teórica: ¿podemos considerar el conjunto de conocimientos, habilidades, disposiciones y conductas que capacitan a los individuos para detectar la necesidad de información, buscar la información adecuada, evaluar su idoneidad, interpretarla adecuadamente y darle un uso pertinente como una alfabetización o 
como una competencia? ¿Nos referiremos entonces a la alfabetización informacional o a las competencias informacionales?

De la exposición desarrollada hasta este punto el lector habrá detectado perfectamente nuestra postura. Sin embargo, creemos necesario aportar una explicación de la misma basada en los modelos teóricos adoptados.

La teoría de la multialfabetización, desarrollada por los investigadores del New London Group, y que hemos adoptado en nuestra construcción, señala que la alfabetización se puede considerar hoy en día múltiple como consecuencia de la realidad multimodal. Así, podemos agrupar todos los modos, o campos en los que desarrollar la alfabetización, en los siguientes (Cope \& Kalantzis, 2009b): Lengua escrita en todas sus formas, lengua oral en todas sus formas, representación visual estática o en movimiento, representación audio, representación táctil, representación gestual, representación para uno mismo y representación espacial. Cada uno de estos modos es susceptible de aprendizaje, ya que facilita a los grupos sociales una herramienta de construcción de significados, y por ende, de transformación de la realidad. En la sociedad actual los mensajes se presentan habitualmente de manera multimodal, combinando modos. Así, la elección de una determinada multimodal influirá en el propio mensaje y en el significado que transmite.

Por otro lado, gran cantidad de autores, entre los que nos incluimos, defienden la alfabetización, o más bien multialfabetización, como un «un proceso mediante el cual las personas adquirimos las competencias necesarias para convertirnos en miembros de un grupo que comparte una cultura determinada» (Monereo \& Coll, 2008, p. 331). Así, entendemos que la pedagogía de la multialfabetización se despliega a partir de la adquisición de un mapa de competencias determinado que lleve al dominio y comprensión de los diferentes modos y medios de construcción de significados culturales. $Y$ es dentro de este mapa de competencias en el que se encuentra la que nosotros tratamos en este trabajo, ya que consideramos que como competencia básica realmente permite alcanzar una parte de ese objetivo global.

En suma, como consecuencia del modelo teórico que aquí defendemos, no concebimos el concepto de alfabetización informacional como tal, sino que entendemos que este conjunto de conocimientos, habilidades, disposiciones y conductas forman una competencia básica, concretamente la que hemos venido denominando competencias informacionales. 


\title{
2.4. La formación del profesorado en un contexto multialfabetizado
}

\begin{abstract}
«Los profesores importan para ayudar a mejorar la calidad de la enseñanza que reciben los alumnos [...] el profesorado cuenta. Cuenta para influir en el aprendizaje de los alumnos. Cuenta para mejorar la calidad de la educación que las escuelas e institutos llevan a cabo día a día. Cuenta en definitiva como una profesión necesaria e imprescindible para la sociedad del conocimiento. Y puesto que el profesorado cuenta, necesitamos que nuestros sistemas educativos sean capaces de atraer a los mejores candidatos para convertirse en docentes. Necesitamos buenas políticas para que la formación inicial de estos profesores les asegure las competencias que van a requerir a lo largo de su extensa, flexible y variada trayectoria profesional. Y la sociedad necesita buenos profesores cuya práctica profesional cumpla los estándares profesionales de calidad que asegure el compromiso de respetar el derecho que los alumnos tienen de aprender.» (Marcelo Garcia, 2009, p. 34)
\end{abstract}

Al igual que las metas inherentes a las organizaciones e instituciones educativas han ido cambiando a lo largo de las décadas, desde su nacimiento hasta la actualidad, en lo que respecta a la formación inicial y permanente del profesorado los objetivos, contenidos y perspectivas también han cambiado en buena medida.

La aparición de las primeras instituciones públicas para la formación del profesorado en España se desarrolla a finales del siglo XVIII y principios del XIX. Estas instituciones se configuran como las precursoras de las Escuelas Normales (Escolano Benito, 1982). Es en 1839 cuando se crea la Escuela Central de Maestros, que tiene como finalidad «iniciar la formación del profesorado en nuestro país de forma reglada y formar a las personas encargadas de extender las (escuelas) Normales a todas las capitales de provincia del país» (Anguita Martínez, 1997, p. 98). A pesar del nacimiento de esta escuela para hombres, la Escuela Central de Maestras tarda 20 años más en fundarse (Escolano Benito, 1982).

Desde su nacimiento, hasta su integración definitiva en las universidades, la formación del profesorado propuesta en estas Escuelas sufre varios problemas (Anguita Martínez, 1997):

1. Excesiva politización de las Escuelas. Las reformas de estas instituciones se suceden cada vez que había algún cambio en el signo político del estado. De hecho, como señala Anguita, «maestros y maestras se convirtieron en el eje 
clave del sistema y, por ello, se hizo necesario un control cada vez más directo sobre su formación» (1997, p. 99).

2. A pesar de la atención recibida por el poder político, los medios humanos y materiales de los que disponían las Escuelas Normales para llevar a cabo su labor eran escasos e inadecuados (Escolano Benito, 1982).

3. Excesiva influencia ejercida por la iglesia en la formación del profesorado en este periodo.

4. Formación inferior con respecto a otras profesiones. «El currículum de las Escuelas de Magisterio a lo largo de todo el siglo XIX consistió en poco menos que aprender las destrezas básicas» (Anguita Martínez, 1997, p. 100)).

5. Exceso de formación cultural y falta de formación profesional específica de la profesión. La baja formación exigida para acceder a los estudios de Magisterio provoca que la formación esté más centrada en aportar conocimientos culturales que en enseñar aspectos específicos de la profesión.

La tradición de las Escuelas de Magisterio, que ofrecen una formación desvinculada del ámbito universitario, provoca el desprestigio de la profesión y la inexistencia de un perfil profesional de maestro consistente en España. Esta situación dura hasta bien entrado el siglo XX, cuando la Ley de Educación de 1970 logra que las Escuelas Normales se integren en la Universidad como Escuelas Universitarias (Benejam Arguimbau, 2002).

$Y$ es desde comienzos de los años 80 , cuando la formación del profesorado pasa a formar parte de los aspectos clave de las políticas educativas. De este modo, comienza a expandirse el modelo universitario de formación inicial. Ya en los años 90 comienza a plantearse la necesidad de incluir un tronco de conocimientos teóricos comunes en la formación inicial de maestros y profesores, y se registra una tendencia generalizada a aumentar la extensión de la formación inicial (Vaillant Alcalde, 2009). De hecho, comienzan a aparecer Instituciones internacionales que elaboran normas y estándares al respecto. Es en el siglo XXI cuando, gracias a la tendencia hacia los sistemas de formación basados en competencias, emergentes desde los 90, se comienza a hablar del perfil competencial docente, y se acaba por alcanzar la consideración de la labor del profesor «como una profesión que posee un perfil profesional específico y distinto al de otros profesionales» (Pavié Nova, 2011, p. 68). Así, varios estudiosos han 
localizado la existencia de competencias exclusivamente pertenecientes al ámbito docente.

«Estamos asistiendo, en este inicio del siglo XXI, a un regreso de los profesores al centro de las preocupaciones educativas. Los años 70 estuvieron marcados por la racionalización de la enseñanza, la pedagogía por objetivos, la planificación. Los años 80 por las reformas educativas y por la atención a las cuestiones del currículo. Los años 90 por la organización, administración y gestión de los establecimientos de enseñanza. Ahora parece que hemos vuelto a los tiempos de los profesores.» (Nóvoa, 2009, p. 205)

En el caso de la formación de docentes en la etapa de la Educación Secundaria, la situación es más grave, ya que, desde que fue necesaria la formación de profesorado de esta etapa para cubrir las necesidades mínimas del sistema educativo (años 70), hasta casi la actualidad, ha subsistido un programa tan criticado como el Curso de Adaptación Pedagógica (CAP). «La prolongación de una propuesta formativa tan limitada y reprobada durante tanto tiempo [...] no ha hecho más que aumentar e intensificar su desprestigio y, en cierta manera, incluso desacreditar o, al menos, desconfiar, de las nuevas propuestas» (González Sanmamed, 2009, p. 64).

Este curso, de 300 horas de duración, ha sido el requisito necesario, junto con la titulación de la especialidad correspondiente, para acceder a los diversos cuerpos docentes de secundaria. Así, un docente de Educación Secundaria, Formación Profesional o Bachillerato únicamente ha recibido al final de su proceso de formación inicial 300 horas de formación específica sobre el perfil docente del profesor.

Actualmente, esta situación se está intentando revertir con la implantación del Máster de Formación de Profesorado de Educación Secundaria (ORDEN $\mathrm{ECl} / 3858 / 2007$, de 27 de diciembre ${ }^{15}$ ), en el que se imparten 60 créditos ECTS de formación (alrededor de 1500 horas de trabajo del estudiante). El cambio en los paradigmas educativos y las perspectivas curriculares hacia una formación basada en competencias está facilitando este cambio hacia una mayor profesionalización docente. El enfoque por competencias aplicado a la formación de formadores implica la consideración de la labor del profesor «como una profesión que posee un perfil profesional específico y distinto al de otros profesionales» (Pavié Nova, 2011, p. 68).

\footnotetext{
${ }^{15}$ ORDEN ECI/3858/2007, de 27 de diciembre, por la que se establecen los requisitos para la verificación de los títulos universitarios oficiales que habiliten para el ejercicio de las profesiones de Profesor de Educación Secundaria Obligatoria y Bachillerato, Formación Profesional y Enseñanzas de Idiomas. (BOE 29 de diciembre de 2007).
} 
Sin embargo, la tradición en la formación de profesorado en España, narrada en las anteriores páginas, implica en muchos casos que la opción de ser profesor de educación secundaria sea un "mal menor" ante la dificultad de encontrar empleo para profesionales que se consideran matemáticos, físicos, biólogos, filólogos, etc. Así, mientras que estos profesionales de diferentes ámbitos en ningún momento se consideran parte del ámbito profesional de los profesores, muchos terminan por impartir docencia. Los estudiosos de la formación de profesorado y del perfil profesional del profesor coinciden al señalar que «la identidad profesional contribuye a la percepción de autoeficacia, motivación, compromiso y satisfacción en el trabajo del profesorado y es un factor importante para convertirse en un buen profesor» (Marcelo Garcia, 2009, p. 38). Así, no es de extrañar que la investigación empírica avala un malestar docente endémico en el profesorado de enseñanza secundaria (Touriñán López, Oliveira Oliveira, \& Rodríguez Martínez, 2003).

Lo que es evidente es que un sistema como el CAP, o como un Máster Universitario posterior a la formación especializada, no facilita en absoluto la formación de una identidad profesional propia en el profesorado de Educación Secundaria. «la identidad profesional que predomina en los futuros docentes cuando acceden al Máster de Educación Secundaria suele ser la del científico o profesional que ha realizado estudios de licenciatura en una determinada área de conocimiento» (Marcelo Garcia, 2009, p. 38).

A pesar de estos motivos para el desánimo, también existen aspectos positivos, ya que ante la «prácticamente unánime afirmación de que la formación inicial y el aprendizaje de la profesión docente es, dentro de otros factores, uno de los más decisivos en la mejora de la educación y de los estudiantes [...] La calidad de un sistema educativo no excede la calidad de su profesorado» (Escudero Muñoz, 2009), en la educación secundaria la formación inicial del profesorado está iniciando sus pasos y buscando crear una cultura pedagógica y profesional adecuada. Los teóricos de la formación del profesorado ya están incluyendo reflexiones válidas para que la formación del profesorado de educación secundaria sea más profesionalizante:

«la calidad de un programa de formación no reside en la cantidad de contenidos, sino en su relevancia para el currículo escolar y la enseñanza, en el grado de articulación y coherencia que logre entre los distintos componentes (contenidos, metodologías, teoría y práctica), lo que es bien diferente de la mera acumulación de disciplinas en un currículo fragmentado de formación» (Escudero Muñoz, 2009, p. 87) 
Por otro lado, también se extienden reflexiones acerca de la herencia que deja el CAP y cómo aprovecharla:

«Entendemos que la situación de la formación del profesorado de Secundaria merece no sólo una búsqueda de las razones extrínsecas y coyunturales que la han propiciado y alimentado en estas décadas. Más bien consideramos que esta indagación nos puede permitir profundizar en las cuestiones clave de la formación y la profesionalización docente y aprovechar la exploración de la lógica particular para evocar las cuestiones relevantes de los discursos y las prácticas de la formación docente. Preguntarse por la formación que se ofrece a través del CAP nos servirá para ahondar en los ejes conceptuales, programáticos y de intervención que sustentan y articulan cualquier proyecto de formación y, a través de ellos, observar e indagar en las secuencias y en las rupturas que iremos encontrando.» (González Sanmamed, 2009, p. 64)

A pesar de estas claves señaladas por algunos autores, también nos encontramos con la existencia de dificultades que complican en buena medida la formación del profesorado (Sánchez Asín, Boix Peinado, \& Jurado de los Santos, 2009):

- Excesiva información en los libros de texto.

- Desconocimiento de conocimientos previos del alumno

- No existen palabras clave en los textos escolares.

- Falta de dominio del contenido por parte del profesor.

- Nerviosismo, impaciencia o excesiva velocidad del profesor.

- No reconocimiento de los logros del alumno.

- Rigidez en la gestión de las relaciones grupales e individuales.

- Desmotivación profesional.

- Falta de planificación del proceso de aprendizaje.

- Falta de actualización profesional.

- Utilización aislada de recursos multimedia y experiencias extraescolares.

- Falta de coordinación con compañeros y familias. 
Teniendo en cuenta esto, nos encontramos con grandes desafíos para la formación inicial del profesorado de Educación Secundaria (Terigi, 2009):

1. Formar para nuevas funciones para las que la formación inicial tradicional (academicista) no es suficiente. La atención a la diversidad, la tutorización, la enseñanza individualizada.

2. Adoptar una pedagogía de la formación. Se debe tanto poseer herramientas para la docencia efectiva en la práctica, como ser competente para generalizar las herramientas adquiridas en contextos de práctica reales.

3. Tener en cuenta la cuestión de las TIC. Dentro de la formación de profesorado se deben incluir contenidos relacionados, además de con el estudio de las TIC como un contenido concreto de enseñanza, se debe especialmente fomentar la concepción de las tico como un recurso potencial para el acceso al conocimiento.

Buena parte de estas dificultades y desafíos, tanto en formación inicial como permanente, tienen que ver con el nuevo entorno de la sociedad de la información y el contexto multialfabetizado en el que se desarrollan nuestros alumnos. Los alumnos de hoy en día, gracias a la existencia de las TIC, están inmersos en una cultura totalmente diferente a la existente hace tan solo una o dos décadas. En esta cultura multimedio y multialfabetizada, en la que el ordenador es el centro de información de los alumnos, más que los libros o el propio profesor «ya no les sirve sólo lo que dicen los libros, pues pueden aprender cada vez más, por sí mismos, plantear, planificar estrategias y resolver situaciones en permanente transformación, gracias a su gran accesibilidad a los medios telemáticos» (Sánchez Asín et al., 2009, p. 183). Así, ante esta nueva situación socio-cultural, será necesario pensar en una formación del profesorado radicalmente diferente a la promulgada en el CAP o en las Escuelas de Magisterio.

«El principal problema de los profesores de la generación digital es que la sociedad actual ha cambiado de forma muy rápida y el profesorado se encuentra con una situación complicada: se han producido muy pocos cambios en cuanto a la estructura y la gestión de la escuela mientras que la sociedad ha cambiado de forma rápida y los niños actuales necesitan otro tipo de formación. Los profesores se han formado y se están formando con una cultura y una visión del significado de su profesión que ya ha cambiado.» (Gros Salvat \& Silva Quiroz, 2005, p. 4). 
La formación en TIC y con TIC del profesorado es esencial para adaptar las prácticas educativas a las demandas de la sociedad de la información. Sin embargo la evidencia científica

«parece apuntar que muchos profesionales no han recibido una formación inicial en este sentido y la formación permanente que se les brinda parece insuficiente, excesivamente técnica e instrumental en cuanto a los contenidos abordados y poco orientada hacia aspectos pedagógicos que permitan un cambio metodológico capaz de crear entornos de aprendizaje diferentes» (García-Valcárcel Muñoz-Repiso \& Tejedor Tejedor, 2005, p. 125)

Uno de los campos más destacados en los que se está desarrollando la investigación científica para dar un empujón a la formación del profesorado en estos aspectos, y más concretamente en la del profesorado de educación secundaria, es en la de la conformación de un perfil competencial del docente. Podríamos considerar la competencia docente como la «competencia profesional del docente para desempeñarse en la interacción social, en los diferentes contextos y situaciones cotidianas que implican la práctica social de la profesión» (Guzmán Ibarra \& Marín Uribe, 2011, p. 156). Dado que este campo de conocimientos está aún poco desarrollado en nuestro país, «es necesario generar metodologías y momentos para la identificación de competencias docentes, que se correspondan con prácticas docentes concretas» (Guzmán Ibarra \& Marín Uribe, 2011, p. 160).

Sin embargo, no debemos dejarnos llevar por estándares que normativicen el perfil del profesor, ya que los posibles contextos de docencia posibles son de tal variedad, que más que preparar al futuro profesor para todas y cada una de dichas contingencias, la formación inicial del profesorado debe centrarse en «enseñar al futuro profesor a analizar, con el mayor detalle posible, los múltiples factores que están influyendo en las situaciones de enseñanza en las que desarrolla su actividad docente cotidiana» (Esteve Zarazaga, 2009, p. 20). Así, en la formación de profesorado nos debemos centrar en cuatro tareas esenciales (Esteve Zarazaga, 2009):

- Perfilar la propia identidad profesional. Esto significa especificar el papel o papeles profesionales que el profesor va a asumir, sus objetivos profesionales, su propio estilo docente apropiado a sus cualidades e ideas.

- Entender que el aula es un sistema de interacción y comunicación. Transmitir la idea de que el profesor no es el centro de la verdad absoluta, un conferenciante que espera que la audiencia escuche respetuosa y 
pacientemente. Los alumnos deben responder de algún modo, y su respuesta será adecuada siempre y cuando estén motivados e ilusionados con el tema y hayan podido expresar sus ideas libremente. Hacer esto implica dominar los diversos códigos de comunicación y climas que se encuentran en el aula. En suma, todo profesional de la educación debería analizar e interpretar correctamente las interacciones alumno-alumno y alumno-profesor que se establecen en el aula, tanto a nivel verbal como no verbal.

- Organizar la clase para que funcione con un orden aceptable. El profesor es un guía de un grupo social, y como tal debe organizarle para que funcione de manera efectiva. Así, el docente asume tareas diferentes a la de enseñar, como organizar el trabajo y la estructura del grupo, definir objetivos, sistemas de evaluación, etc. El profesor debe ser capaz de dirigir un grupo con el estilo de dirección que mejor le convenga.

- Adaptar los contenidos a los conocimientos previos de los alumnos. Ponerse al nivel de los alumnos, en su Zona de Desarrollo Próximo (Vygotsky, 1979). Los contenidos deben presentarse organizados y clasificados de manera que los alumnos puedan transformarlos en conocimiento de manera adecuada. El profesor, en este caso, asume el rol de "traductor" especializado para que la audiencia pueda asimilar la información.

Por otro lado, Nóvoa (2009), propone cinco propuestas de trabajo que deben inspirar los programas de formación de profesores, y que se podrían señalar como cinco facetas que definen el buen profesor:

- Conocimiento: Existencia de un componente práctico esencial. Centrado en el aprendizaje de los alumnos y en el estudio de casos concretos, teniendo como referencia el trabajo en el propio centro escolar.

- Cultura profesional: Realización desde el núcleo de la profesión. Eso es, se debe basar en la adquisición de una cultura profesional clara, concediendo a los profesores más expertos un papel central en la formación inicial del profesorado.

- Tacto pedagógico: Atención especial a las dimensiones personales de la profesión docente. Trabajar la capacidad de relación y comunicación que define el desempeño pedagógico. 
- Trabajo en equipo: Valoración del trabajo cooperativo y el ejercicio colectivo de la profesión. Reforzar la importancia de los proyectos educativos comunes de escuela.

- Compromiso social: Desarrollo del principio de responsabilidad social. Promover la comunicación pública y la participación profesional en el espacio público de la educación.

Para que la formación del profesorado incluya todos y cada uno de estos elementos esenciales, y que consiga que todo profesor esté cualificado tanto en los conocimientos básicos, como en la cultura profesional, el tacto pedagógico, la capacidad de trabajo en equipo y el compromiso con la sociedad, se debe fundamentar y orientar hacia un tipo de formación concreta. Así, los grandes ejes de la formación del profesorado se podrían vincular a las 5 áreas siguientes (Terigi, 2009):

- Formación pedagógica general.

- Formación disciplinar básica y de profundización en el área de especialización.

- Formación didáctica específica propia del área de especialización.

- Prácticas docentes progresivas en contextos reales.

- Contenidos de formación cultural (comprensión de cambios socio-culturaleshistóricos) y propedéutica (enseñanzas instrumentales en herramientas para la formación continua).

En este sentido, consideramos que la formación específica del profesorado en competencias informacionales debe ser un aspecto básico de la formación del profesorado de educación secundaria. Además de considerarlo un eje esencial en los conocimientos teóricos que debe poseer todo profesor, la adquisición de competencias informacionales dota al profesorado de unas herramientas didácticas útiles para el desarrollo de metodologías de formación activas y basadas en competencias, además de facilitar la comprensión de los cambios culturales y sociales emergentes con la sociedad de la información y el entendimiento de la cultura presente multialfabetizada. 


\subsection{Resumen}

El objeto principal de este capítulo no ha sido otro que, una vez analizadas de manera pormenorizada las características de lo que hemos denominado sociedad de la información, encontrar un marco teórico en el que comprender cómo se plantean los procesos alfabetizadores en este contexto tan específico y plantear un modelo global sólido y operativo que sirva de guía para plantear el problema de investigación sobre el que se va a indagar en esta Tesis, en concreto sobre las competencias informacionales. Así mismo, se ha hecho un breve recorrido analizando la formación inicial del profesorado, teniendo en cuenta cómo en el nuevo contexto multialfabetizado de la sociedad de la información el perfil profesional del profesorado cambia enormemente.

Hemos comenzado el capítulo analizando los elementos concretos de la sociedad en la que nos encontramos inmersos que consideramos que plantean la exigencia de una reformulación radical del concepto de alfabetización. Así, hemos visto como principales características que nos encontramos en una realidad multidimensional en el que se plantean nuevas condiciones laborales y de empleabilidad en gran parte debido al surgimiento de la "nueva economía. El nuevo modelo económico del capitalismo actual conduce indudablemente a un cambio importante en el modelo tradicional de Estado, que parece estar en crisis. Por otro lado, el nacimiento y la espectacular evolución de las TIC supone también un impacto considerable en las consideraciones sobre la alfabetización; surgen nuevos perfiles laborables exigibles y, sobre todo, aparecen nuevos medios y modos de presentar la información que exigen una formación multimodal y multimedio de los sujetos. Esto, unido a la realidad líquida en la que nos desenvolvemos, provoca a su vez la exigencia de la formación a lo largo de la vida como requisito esencial para todos los ciudadanos actuales.

Todos estos factores indican la apremiante necesidad de la modificación de los modelos más tradicionales de alfabetización, que parece que se perpetúan en las aulas y en los currículos de educación básica.

Una vez establecidos estos criterios y detectadas las necesidades, nos hemos embarcado en el estudio de la evolución del concepto alfabetización desde el surgimiento de la educación alfabetizadora tradicional, pasando por los modelos sociocríticos y liberadores, hasta llegar al actual concepto de multialfabetización. Hemos visto cómo a lo largo de los años se ha pasado de un concepto de alfabetización como dominio de habilidades mecánicas de decodificación y codificación de símbolos 
gráficos a una concepción más global y humanista. Alfabetizar, más que el simple hecho de leer y escribir, se refiere a construir y transformar significados culturales, esto es, una persona alfabetizada es aquella capaz de participar de manera activa, responsable, reflexiva y crítica en las prácticas sociales concretas que se establecen en su contexto particular.

Así se ha introducido el concepto de alfabetización funcional, que rompe con la clásica dicotomía entre alfabetizado y analfabeto, estableciendo una escala continua entre los dos extremos.

Una vez analizada la evolución del término, nos hemos encontrado en condiciones de acercarnos a la construcción de la teoría de la multialfabetización, que adoptamos como modelo de base a partir de la que diseñar todas las acciones posteriores encaminadas a desarrollar las competencias informacionales. Hemos partido básicamente de las propuestas que proponen el New London Group y dos de sus principales investigadores, Cope y Kalantzis, fuentes primigenias y principales valedores de la teoría de la multialfabetización y la realidad multimodal.

Enraizando esta disertación con el tema concreto de la presente Tesis Doctoral, hemos finalizado este apartado señalando cómo las competencias informacionales se integran perfectamente como un elemento dentro del propio modelo de la multialfabetización. Así mismo, hemos aprovechado que ya habíamos desarrollado los elementos teóricos suficientes para señalar y aclarar ciertas disquisiciones de orden terminológico alrededor del término competencias informacionales.

Por último, se ha analizado brevemente la situación de la formación del profesorado en el contexto de la sociedad de la información. A partir de un recorrido histórico de la formación del profesorado de educación básica, se ha observado cómo en España, desde sus inicios, ha ido creando una cultura de la figura del maestro y el profesor como profesionales poco cualificados y con un perfil profesional difuso. Así, en nuestros días, una de las principales preocupaciones de la investigación en este sentido es la de la formación de un perfil profesional docente delimitado, que se desarrolle en un ámbito de conocimientos específico, proveniente en gran medida de la pedagogía y la didáctica. Dentro de estos contenidos propios de la formación docente se incluyen, por supuesto, las competencias informacionales, como una respuesta a la omnipresencia de las TIC en todos los ámbitos sociales. 



\section{Capítulo III}

LA FORMACIÓN BASADA EN

COMPETENCIAS: LAS

COMPETENCIAS

INFORMACIONALES 
Capítulo III

La formación basada en competencias: las competencias informacionales
3.1 Aspectos básicos sobre las competencias

3.2 El modelo de formación basado en competencias

3.3 Las competencias informacionales. Competencias básicas para la sociedad del conocimiento

3.4 Resumen 


\section{La formación basada en competencias: las competencias informacionales}

"La primera forma reglada de aprendizaje, la primera escuela históricamente conocida, las 'casas de tablillas' aparecidas en Sumer hace unos 5000 años, estaba vinculada a la enseñanza del primer sistema de lectoescritura conocido y dio lugar a la primera metáfora cultural del aprendizaje, que aún perdura entre nosotros: la mente del alumno es una tabula rasa en la que se inscribe de forma literal el conocimiento impartido por el maestro, una metáfora todavía vigente, aunque ya escasamente válida [...] Las nuevas tecnologías de la información, unidas a otros cambios sociales y culturales, están dando lugar a una nueva cultura del aprendizaje que trasciende el marco de la cultura impresa y que debe condicionar los fines sociales de la educación y, en especial, las metas de la educación secundaria» (Coll et al., 2010, p. 64)

Hasta ahora hemos visto cómo las circunstancias tecnológicas contextuales propias de la sociedad de la información, junto con la situación de permanente cambio e incertidumbre, han provocado una profunda reforma de las estructuras sociales en todos los campos. Concretamente en el campo educativo estos acontecimientos, junto con la transformación del concepto de alfabetización desde una perspectiva sociocultural, han provocado la exigencia de cambios estructurales de los sistemas formativos en la búsqueda de diseños basados en competencias. Es evidente que los sistemas educativos no pueden quedarse al margen del impacto de las Tecnologías de la Información y la Comunicación (TIC) y de la sociedad que rodea hoy en día a los nuevos ciudadanos, y que esto supone un gran reto al mundo educativo (Alonso García, 2002; Area Moreira, 2001; Bolívar Botía, 2009; Cabero Almenara \& Alonso García, 2007; Majó i Cruzate \& Marqués, 2002; Monereo \& Coll, 2008).

Como señala Gómez Hernández, «La escuela es, tal vez, la institución más eficaz para la enseñanza de la lectoescritura -como lo fue antaño- pero está quedándose atrás hoy en día en la promoción de la nueva alfabetización de la sociedad de la información» (2000, p. 20). No debemos olvidar que la noción de competencia se puede considerar, desde el punto de vista que estamos asumiendo, como una concreción del concepto de alfabetización informacional en el campo educativo.

De hecho, hemos planteado en los dos capítulos anteriores la formación basada en competencias $y$, en concreto, las competencias informacionales, como competencias básicas para cualquier ciudadano del siglo XXI (Area Moreira, 2010a), sin profundizar en las bases teórico-epistemológicas que fundamentan este concepto. A lo largo de este capítulo, por tanto, analizaremos el concepto de competencia a partir de su evolución histórica y del estudio de las aportaciones de los principales autores en este 
campo y profundizaremos en la estructura del modelo de formación basada en competencias para analizar los procesos de desarrollo y evaluación de competencias. Para finalizar, trataremos de estudiar pormenorizadamente el concepto de competencias informacionales, desde su definición y evolución histórica, hasta las dimensiones teóricas que contiene el propio constructo. 


\title{
3.1. Aspectos básicos sobre las competencias
}

\begin{abstract}
«Posiblemente, y al margen de sus virtudes o defectos, nunca ha existido un movimiento educativo tan global como el de la enseñanza por competencias. Las administraciones públicas y privadas de una mayoría de países de los cinco continentes han optado por promover currículos basándose en las competencias en todos sus niveles educativos. Justificar pues su importancia y la necesidad de su estudio parece innecesario.» (Monereo \& Badia, 2012, p. 76)
\end{abstract}

Antes de llevar a cabo un análisis pormenorizado del modelo de formación basado en competencias y del desarrollo y evaluación de las competencias, es esencial estudiar el concepto de competencia desde una perspectiva amplia.

La razón de que consideremos necesario este análisis del propio concepto se debe a varios factores:

- El término competencia es ambiguo, ya que se identifica con multitud de significados en función del área de conocimiento desde el que lo enfoquemos.

- Por ello, no existe un acuerdo entre los estudiosos de la formación basada en competencias en lo que respecta a la definición de competencia. Cada autor define el término desde su perspectiva, teniendo en cuenta factores diferentes.

- El concepto de competencia tiene una íntima relación con varios conceptos de la tradición psicológica y pedagógica (Torres, Marín, Bustamante, Gómez, \& Barrantes, 2002; Zabala \& Arnau, 2007) como:

- El concepto de desempeño comprensivo (Gardner, 1998; Tishman, Perkins, \& Jay, 1994)

- La teoría de la acción mediada (Vygotsky, 1995; Wertsch, 1988)

- El concepto de competencia tiene mucho que ver con el denominado conocimiento práctico (Gimeno Sacristán, 2008; Schön, 1984, 1987)

- La tradición de la Escuela Nueva (Decroly, 1929; Dewey, 1952; Freinet, 1972) ya habla de educar para la vida y de la importancia de una práctica sustentada por la teoría. 
- El concepto competencia procede más del mundo empresarial que de la tradición pedagógica, por lo que las bases en las que se fundamenta son poco firmes. Así, en el proceso de incorporación a los currículos del diseño por competencias en muchos casos «se obvia el debate del conocimiento, de los contenidos culturales que precisamos presentar al alumnado para que pueda entender nuestro pasado, el mundo del presente $y$, por tanto, prepararse [...] para una incorporación más informada y activa en su comunidad, como ciudadanas y ciudadanos que son» (Gimeno Sacristán, 2008, p. 165)

De este modo, la primera parte de este capítulo servirá para mostrar qué entendemos nosotros por competencia basándonos en el desarrollo histórico del concepto, las causas que han llevado a adoptarlo, el análisis crítico del propio concepto y las diferentes concepciones en función del punto de vista de referencia.

\subsubsection{Análisis socio-histórico del concepto competencias}

Ya hemos señalado más arriba que las competencias no son un concepto nuevo, revolucionario y que haya hecho derribar las bases de la pedagogía moderna. Todo lo contrario, el concepto competencia es un concepto ya analizado y formulado en gran cantidad de estudios previos que de alguna manera se habían olvidado (Bustamante et al., 2004). Entonces, ¿por qué renace la formación basada en competencias como un paradigma educativo que parece que va a solucionar todos los problemas formativos que se plantean en la sociedad de la información? Analicémoslo más detenidamente desde una perspectiva socio-histórica.

El nacimiento del concepto los podemos encontrar en la lengua griega, en la obra de Platón. La palabra procede del término "ikano", un derivado de "iknoumai”, cuyo significado es llegar. «El antiguo griego tenía un equivalente para competencia, que es ikanótis (ıkavotns). Se traduce como la cualidad de ser ikanos (capaz), tener la habilidad de conseguir algo, destreza.» (Mulder, Weigel, \& Collings, 2008, p. 2)

En latín, podemos encontrar la palabra en su raíz conocida en nuestro idioma. El término competens se entendía como ser capaz, y competentia entendido como la capacidad y la permisión (Mulder et al., 2008). Ya a partir del siglo XVI, se podía reconocer este concepto en idiomas derivados del latín como el inglés, el francés o el holandés. 
Así pues, está claro que el concepto de competencia no es algo nuevo, sino que es un término con una gran tradición. Sin embargo, "el uso institucionalizado de la competencia en el desarrollo de la formación profesional es un fenómeno reciente que ha aparecido mezclado con otras innovaciones» (Mulder et al., 2008, p. 3).

Volviendo a nuestros días, los primeros pasos en el empleo del concepto de formación basada en competencias los podemos localizar en Estados Unidos a partir de los años 30 del siglo XX. La orientación de esta terminología era en un principio más económica que educativa. Sin embargo, es a partir de los años 70 de este mismo siglo cuando la noción de competencia resurge como un intento de adecuar la educación y capacitación a las necesidades de la industria. A partir de este momento, competencia pasa a designar lo que caracteriza a una persona capaz de realizar una tarea concreta de manera eficiente (Gimeno Sacristán, 2008; Pérez Gómez, 2012; Zabala \& Arnau, 2007).

Esta orientación básicamente económica tiene que ver con el surgimiento de la nueva economía, ya expuesta en el primer capítulo, que supone una reestructuración total del sistema productivo, y conlleva la transformación del trabajo humano. Un nuevo sistema productivo implica una cualificación del trabajador totalmente nueva. En consecuencia, las personas y grupos incapaces de adaptarse a la nueva situación socio-laboral, podrían ser marginados del sistema laboral o devaluados como trabajadores. De hecho, cuanto más evolucionan las tecnologías humanas en las fábricas y oficinas, mayor es la necesidad de empleados autónomos, flexibles y preparados para hacerlas frente (Area Moreira, 2001; Castells, 1999a).

Desde un punto de vista educativo puede ser aceptable la modificación en la organización y la noción misma de los sistemas educativos como consecuencia de los cambios estructurales en los sistemas productivos (Luengo Navas, Luzón Trujillo, \& Torres Sánchez, 2008). No obstante, basar un cambio tan profundo en la concepción de los procesos de enseñanza-aprendizaje únicamente en argumentos económicos parece, a priori, poco fundamentado.

Así, aún estando de acuerdo con que el diseño por competencias se fundamenta en «prepare themselves to respond satisfactorily to the requirements of society and to any new issues, needs or interests that may arise» (Villa Sánchez \& Poblete Ruiz, 2009), no debemos olvidar que existen nuevas necesidades formativas fruto de las nuevas condiciones sociales, y es a estas condiciones sociales principalmente a las que se deben adaptar los sistemas educativos. De hecho, en la sociedad de la información 
las expectativas educativas y las propias necesidades de los niños y adolescentes son radicalmente diferentes a las del siglo XX (Fernández Enguita et al., 2007): por ejemplo, mientras que los sistemas educativos tradicionales se enfrentaban a un mundo estable en el que el conocimiento era duradero y en el que la memoria era un valor muy positivo, ahora existen máquinas que memorizan por nosotros (Bauman, 2007). Entonces, ¿por qué la memoria sigue siendo la capacidad esencial que deben desarrollar los estudiantes en la educación básica? Por tanto, entendemos que los nuevos sistemas formativos deben centrarse en promover la autonomía y en la búsqueda de la elaboración, construcción y reconstrucción de la propia cultura y el conocimiento, y no convertir a los estudiantes «en meros receptores de productos culturales ya acabados» (Coll et al., 2010, p. 65)

Para organizar de manera más metódica todo lo expuesto hasta ahora, podríamos agrupar los principales motivos que sirven como factor detonante del surgimiento de la formación basada en competencias en los siguientes (Cano García, 2008; Zabala \& Arnau, 2007):

- Las características propias de la sociedad de la información. En una sociedad dinámica, en permanente cambio e inundada de información, los diseños por competencias pretenden que las personas desarrollen unas capacidades que les permitan aprender y desaprender durante toda su vida, de manera que puedan adaptarse a la realidad cambiante.

- La función social de la enseñanza y el conocimiento. Dada la complejidad e incertidumbre a la que nos enfrentamos en la sociedad de la información existe, más que una necesidad de formación académica, una necesidad de formación integral en todos los órdenes de la vida. Así, los diseños por competencias favorecen el desarrollo de inteligencias no estrictamente cognitivas «que pueden ayudarnos a dar respuesta a una situación de forma eficiente o a adaptarnos a realidades cambiantes» (Cano García, 2008, p. 3). De hecho, podríamos afirmar que la transformación de una educación basada en contenidos a otra basada en competencias tiene que ver con la metamorfosis que se está desarrollando en lo que respecta a la consideración de los fines de la educación. Desde una concepción de la enseñanza escolar como una preparación para la formación universitaria, hasta una noción de la educación como formación integral para toda la vida, que permita a los ciudadanos el mejor desarrollo de sus diversas posibilidades personales y profesionales (Zabala \& Arnau, 2007). 
- La complejidad del conocimiento. En la misma línea que el anterior factor, podemos concretar en la gran complejidad que ha alcanzado el conocimiento, que se ha hecho más interdisciplinar. Hoy en día no sirve con desarrollar una base de conocimientos fragmentada y disciplinar, sino que es necesario desarrollar un conocimiento integrado. Las competencias, en este aspecto, proponen la movilización combinada de conocimientos en los contextos concretos en los que son requeridos.

- La presión socio-laboral. Este es el factor al que más hemos hecho referencia a lo largo de este apartado. La desconexión entre teoría y práctica y la consecuente incapacidad que se constata en buena parte de la ciudadanía para aplicar conocimientos que se poseen a situaciones reales, ha conducido a la construcción de una fuerte corriente de opinión favorable a la formación por competencias, tanto en el ámbito social como en el laboral.

- El proceso de convergencia europea. Este factor tiene una perspectiva más geográfica, pero su influencia es muy elevada. En el ámbito universitario se ha desarrollado un proceso de cambio motivado por la necesidad de convergencia europea. Este proceso tiene su punto de partida en la Declaración de Bolonia (1999), aunque la referencia explícita a la formación basada en competencias aparece en 2005, en la Declaración de la Conferencia de Ministros de la Unión de Bergen (Gimeno Sacristán, 2008). Aparentemente, este proceso puesto en marcha en los últimos años, sólo pretende promover cambios en el sistema universitario (Rodríguez Conde, 2011). Sin embargo, esta transformación se está haciendo visible no sólo en la Educación Superior sino también en los niveles educativos previos (Buendía Eisman, Olmedo Moreno, \& González Gijón, 2009; Hernández Pina, Rosário, Cuesta Sáez de Tejada, Martínez Clares, \& Ruiz Lara, 2006; Hernández Pina, 2009).

Para terminar de comprender el camino que ha llevado a la situación actual en la que se encuentran los procesos de enseñanza-aprendizaje basados en competencias, creemos conveniente terminar con el análisis, mediante un breve repaso, de la evolución histórica que ha sufrido la organización de los sistemas de formación y enseñanza desde su asentamiento formal. Veamos pues las principales etapas (De Kelete, 2008):

- Primera etapa: Predomino humanista y noción del conocimiento como dominio y reflexión sobre la literatura clásica. Se desarrolla en la edad antigua, la Edad 
Media y en el Renacimiento. La educación consistía en enseñar los textos fundadores de la civilización, en especial las obras cumbre de la literatura griega, romana y árabe. El estudiante debía estudiar estos textos y al mismo tiempo comentarlos críticamente. Así, la facultad de Filosofía y Letras era el centro educativo por excelencia.

- Segunda etapa: Eclosión de las ciencias de la naturaleza. Los conocimientos sobre la naturaleza comienzan a multiplicarse gracias al desarrollo de la observación sistemática y del método científico. Así, comienza un proceso de separación entre la ciencia y la filosofía, y comienzan a surgir disciplinas independientes, que se multiplican y se subdividen en numerosas especialidades. De este modo, se hace imposible para una sola persona, dominar todo el conocimiento existente. En este contexto, se ve necesario el desarrollo de nuevos sistemas educativos que transmitan los nuevos conocimientos adquiridos por la comunidad científica. Ahora el problema era definir el mapa de conocimientos necesarios para las personas. Esta evolución acaba convirtiendo los programas de formación en «inventarios de conocimientos que habían de ser transmitidos en un momento dado» (De Kelete, 2008, p. 3).

- Tercera etapa: El paradigma positivista; Taylorismo, fordismo y Pedagogía por objetivos. Debido al inmenso desarrollo de las ciencias puras y la consecuente devaluación de las Artes y Humanidades, surge un movimiento reformista que trata de aportar más racionalidad en el mundo de la educación. Así, se procede a la construcción de mapas de objetivos operativos y taxonomías, de manera que los resultados esperados se pudieran concretar en comportamientos específicos y observables.

- Cuarta etapa: Formación por competencias: Después de la Segunda Guerra Mundial, y más aún tras la caída del Muro de Berlín, comienza el proceso de internacionalización y globalización de la economía de mercado, de manera que la competitividad alcanza cotas muy altas. Este proceso desencadena que las empresas, preocupadas por la eficiencia y el rendimiento, comiencen a crear sus propios servicios de formación para sus trabajadores. Así compensaban las deficiencias en la formación de base de sus empleados y conseguían un personal más "competente". De este modo comienza a aparecer en el contexto educativo el concepto de competencias. Las empresas, que están destinando grandes recursos a la formación, se comienzan a interesar por 
influir en las escuelas para que transformen sus sistemas de formación y que incluyan el enfoque basado en competencias. Así, comienzan a presionar sobre las propias autoridades para que promulguen sus planes de modificación de las bases que guían la acción educativa. Este hecho desemboca en un sistema educativo más preocupado por la medición del rendimiento cuantitativo de los estudiantes que por la orientación hacia el rendimiento cualitativo. Los grandes organismos internacionales detectan esto y muestran su preocupación mediante varios trabajos, con lo que surge la idea de desarrollar un currículum basado en el aprendizaje de competencias básicas, de vida, con la finalidad de permitir a cada persona vivir en la sociedad de la información. La formación integral se convierte, pues, en la clave de los sistemas educativos.

\subsubsection{Aproximación al concepto de competencias: definiciones de competencia}

Una vez estudiada la procedencia del término competencia, nos podemos enfrentar con alguna garantía al problema de su significación, esto es, al análisis de lo que realmente significa el concepto de competencia. Debido a su naturaleza ambigua y a su empleo en campos diversos, es muy complicado llegar a un acuerdo en la definición de este término. Así, existen diferencias significativas en cuanto a lo que entienden los diversos estudiosos de la materia por competencia.

«Si existiera una conceptualización científica única de las competencias, podríamos intentar confrontarla de forma metódica con las definiciones en uso en los programas escolares que afirman hacer de ellas unos objetivos centrales de la educación básica. Por desgracia, esta referencia a una teoría consensual no es posible. Y aunque lo fuese, esta referencia no tendría ninguna legitimidad particular. Competencias, capacidades, conocimientos, actitudes son términos que pertenecen al sentido común igual que al mundo científico [...] podrían plantearse (estos interrogantes) a todos los sistemas nacionales que orientan su currículo hacia el desarrollo de competencias, más allá de las diferencias de terminología y de conceptualización. Porque si hay diferencias, también hay similitudes y motivos para hacerse unas preguntas que atraviesan las fronteras, incluso si las controversias y las respuestas son nacionales o regionales» (Perrenoud, 2012, pp. 54-55)

Existen múltiples definiciones desde el campo profesional, pero ateniéndonos al objeto de este estudio nos centraremos principalmente al ámbito educativo, en el que el intento de formulación de una definición de competencia estándar ha sido un tema 
muy recurrente. Sin embargo, como señala Perrenoud, "sería absurdo proponer una visión única de las competencias en la medida en que, al pasar de una disciplina a la otra, este concepto se integra en campos conceptuales distintos y se refiere a problemáticas distintas» (2012, p. 57) Así, nosotros construiremos un concepto de competencia que se adapte a nuestra situación contextual concreta y nuestro campo de conocimientos de partida. Veamos por tanto las definiciones más habituales de competencia en el campo educativo:

El Consejo Europeo (2001) define competencia como «la suma de conocimientos, destrezas y características individuales que permiten a una persona realizar acciones».

El Centro de Investigación y Documentación Educativa (CIDE), actualmente denominado Centro Nacional de Innovación e Investigación Educativa, del Ministerio de Educación, Cultura y Deporte, en colaboración con el Eurydice (2002), define competencias como «las capacidades, conocimientos y actitudes que permiten una participación eficaz en la vida política, económica, social y cultural de la sociedad».

A nivel universitario, el Proyecto Tuning define las competencias del siguiente modo (González \& Wagenaar, 2003): «las competencias representan una combinación dinámica de atributos - con respecto al conocimiento y su aplicación, a las actitudes y a las responsabilidades - que describen los resultados del aprendizaje de un determinado programa, o cómo los estudiantes serán capaces de desenvolverse al finalizar el proceso educativo».

Por su parte, en el proyecto DeSeCo (Proyecto de Definición y Selección de Competencias), se define competencia como (OCDE, 2004a):

\footnotetext{
"La habilidad de cumplir con éxito las exigencias complejas, mediante la movilización de los prerrequisitos psicosociales. De modo que se enfatizan los resultados que el individuo consigue a través de la acción, selección o forma de comportarse según las exigencias...cada competencia es la combinación de habilidades prácticas, conocimientos (incluidos conocimientos tácitos), motivación, valores éticos, actitudes, emociones y otros componentes sociales y de comportamiento que pueden movilizarse conjuntamente para que la acción realizada en una situación determinada pueda ser eficaz»
}

Si buscamos las principales definiciones de algunos autores estudiosos del tema de la formación por competencias, podemos mostrar la definición de Perrenoud (2004), que señala que 
"Capacidad de movilizar varios recursos cognitivos para hacer frente a un tipo de situaciones. Esta definición insiste en cuatro aspectos:

1. Las competencias no son en sí mismas conocimientos, habilidades o actitudes, aunque movilizan, integran, orquestan tales recursos.

2. Esta movilización sólo resulta pertinente en situación, y cada situación es única, aunque se la pueda tratar por analogía con otras, ya conocidas.

3. El ejercicio de la competencia pasa por operaciones mentales complejas, sostenidas por esquemas de pensamiento los cuales permiten determinar y realizar una acción relativametne adaptada a la situación.

4. Las competencias profesionales se crean, en formación, pero también a merced de la navegación cotidiana del practicante, de una situación de trabajo a otra» (p. 11)

Por otro lado, Mario de Miguel indica que competencia es la «...capacidad que tiene un estudiante para afrontar con garantías situaciones problemáticas en un contexto académico o profesional determinado» $(2006$, p. 34).

Por último, desde un punto de vista más cercano a la psicología encontramos la definición que aporta Monereo (2005), cuando señala que

«...estrategia y competencia implican repertorios de acciones aprendidas, autorreguladas, contextualizadas y de dominio variable..., mientras que la estrategia es una acción específica para resolver un tipo contextualizado de problemas, la competencia sería el dominio de un amplio repertorio de estrategias en un determinado ámbito o escenario de la actividad humana. Por lo tanto, alguien competente es una persona que sabe leer con gran exactitud qué tipo de problema es el que se le plantea y cuáles son las estrategias que deberá activar para resolverlo»

Así, llevando a cabo un análisis conjunto de todas estas definiciones, podríamos concluir que, aunque todas presentan algunas diferencias que se podrían considerar sustanciales, son similares y complementarias. Las coincidencias se pueden agrupar en lo siguiente (Zabala \& Arnau, 2007):

- La finalidad de las competencias es la realización de tareas eficaces o excelentes.

- Las tareas están relacionadas con un desempeño profesional claramente definido, esto es, en un contexto concreto de aplicación.

- Las competencias implican la movilización de un conjunto de recursos que posee la persona. 
Siguiendo con el análisis de las diferentes definiciones de competencia, podríamos percatarnos de cómo la concepción de la formación basada en competencias se sitúa, en función de unos autores y otros, en un lugar del continuum entre dos polaridades que podemos identificar con el paradigma positivista y el paradigma interpretativo (Boterf, 2001; Cano García, 2008).

Tabla 3.1 Polaridad en la concepción de competencia

\begin{tabular}{|l|l|}
\hline \multicolumn{1}{|c|}{ Paradigma positivista } & \multicolumn{1}{c|}{ Paradigma interpretativo } \\
\hline Concepción técnica & Concepción holística \\
\hline Taylorismo, fordismo. & $\begin{array}{l}\text { Trabajo complejo que no se resuelve con un } \\
\text { algoritmo o protocolo sino que exige iniciativa, } \\
\text { transferencia, innovación. }\end{array}$ \\
\hline $\begin{array}{l}\text { Prescripción cerrada: Ejecución de } \\
\text { tareas simples según estándares } \\
\text { prescritos. }\end{array}$ & Acto complejo \\
\hline $\begin{array}{l}\text { De corte conductual } \\
\text { Ligada a la cualificación profesional y al } \\
\text { desempeño de tareas concretas en } \\
\text { puestos laborales }\end{array}$ & $\begin{array}{l}\text { Ligada al desarrollo profesional y personal más allá } \\
\text { de puestos de trabajo concretos }\end{array}$ \\
\hline $\begin{array}{l}\text { Concebida como conjunto de destrezas } \\
\text { para realizar una función productiva }\end{array}$ & $\begin{array}{l}\text { Concebida como “saber actuar". Demanda reflexión } \\
\text { teórica, tener presente el propósito y las } \\
\text { consecuencias o impactos. }\end{array}$ \\
\hline
\end{tabular}

Como se puede observar en la tabla 3.1, los extremos a los que nos referimos tienen que ver con considerar la competencia como una habilidad que conduce a la conducta mecánica y a la especialización productiva (paradigma positivista) o a verla como un conjunto de capacidades integradas que se combinan para desenvolverse como un ciudadano íntegro en un contexto cultural determinado (paradigma interpretativo).

A pesar de que somos conscientes de que ciertos elementos que caracterizan los procesos de formación basada en competencias en la educación obligatoria apuntan a la perspectiva interpretativa como la más apropiada, realizar una evaluación de competencias objetiva y sistemática desde este paradigma tiene una gran dificultad. Así, la definición que realizaremos de competencias y la estructura a partir de la que trabajaremos con las mismas abarcará una visión ecléctica de estas dos posturas aparentemente enfrentadas. En todo caso, no debemos olvidar algunos hechos que acercan al paradigma interpretativo en la concepción de competencia (Gimeno Sacristán, 2008; Zabala \& Arnau, 2007): 
- Está claro que las competencias se desarrollan a partir de conceptos (saber), procedimientos (saber hacer) y actitudes (saber estar/ser), pero las competencias van más allá. Más allá porque tienen un carácter holístico e integrado. Suponen, además de poseer estos conocimientos, integrarlos y saber generalizarlos de una manera determinada en un momento concreto. Las competencias integran elementos variados y son genéricas, por lo que no deberían ser un sinónimo de habilidades.

- Las competencias, por su misma naturaleza, se vinculan a rasgos de personalidad, pero al mismo tiempo tienen un carácter evolutivo, se aprenden. Se desarrollan a lo largo de la vida a partir de las capacidades innatas de las personas. No podemos decir que la competencia se tiene o no se tiene, ya que podemos ser competentes en un orden de cosas en el presente y no serlo en el futuro, o ser competentes en un contexto determinado y no en otros que requieren la misma acción. En suma, las competencias se desarrollan progresivamente, perfeccionándose y ampliándose o deteriorándose y restringiéndose a lo largo del tiempo.

- A pesar de que se implementa en la acción, la competencia tiene un carácter reflexivo, alejado de lo mecánico. El que las competencias sean un elemento de acción no quiere decir que se muestren conductas mecánicas y repetitivas, sino todo lo contrario. Toda competencia debe ser transferible a diferentes situaciones, las cuales definen el protocolo de actuación más pertinente. «La competencia, por tanto, ha de entenderse como un sistema de reflexión abierta, de investigación y acción» (Gimeno Sacristán, 2008, p. 79).

- Las competencias no son exclusivamente ni hacen referencia únicamente al individuo en cuestión, sino que incluyen y tienen en cuenta la riqueza cultural y/o profesional de cada contexto.

\subsubsection{Análisis crítico de la formación basada en competencias desde una perspectiva pedagógica}

«Lo que está en juego es llegar al fondo del problema: ¿cumple la escuela con su misión? Lo cual remite a una segunda pregunta: ¿cuál es esta misión a día de hoy? En numerosos países, se justifica el énfasis puesto en las competencias por la preocupación de ver la escuela preparar a los jóvenes para la vida que les espera. 
La vida es la esfera de la acción, en oposición a la de los exámenes escolares. Así, se puede entender la insistencia que se le da al uso de los conocimientos, su movilización, en oposición a su simple restitución bajo una forma escolar. Pero, ¿acaso es suficiente? ¿Postular que los conocimientos escolares serán más cercanos a la vida por el simple hecho de que uno aprende en la escuela a manejarlos para llevar a cabo proyectos, tomar decisiones, gestionar situaciones complejas? Las reformas curriculares actuales no cuestionan la pertinencia de los saberes escolares tradicionalmente enseñados. Se limitan a subrayar la necesidad de aprender a usarlos, a aplicarlos en situaciones complejas. Un uso legítimo, pero que se detiene a medio camino» (Perrenoud, 2012, p. 22)

A pesar del aparente consenso que existe entre los pedagogos en lo que respecta a adoptar la formación basada en competencias como el paradigma sobre el que se fundamentan los procesos de enseñanza-aprendizaje actuales, la verdad es que muchos estudiosos del campo de la pedagogía ponen en cuestión tanto las bases epistemológicas como la procedencia e implicaciones de este concepto (Bustamante et al., 2004; Gimeno Sacristán, 2008; Luengo Navas et al., 2008; Mulder et al., 2008; Pérez Gómez, 2012; Torres et al., 2002).

A partir del estudio de los principales autores que critican diferentes aspectos en torno al concepto de formación basada en competencias, podemos resumir las críticas esenciales en las siguientes ideas:

- El empleo del concepto de competencia en los ambientes educativos es relativamente nuevo, y de hecho, la formación basada en competencias no está claramente fundamentada en la tradición de algún paradigma educativo. Como consecuencia de esto, a pesar de que prevalece una tendencia a adoptar este concepto como una verdad incuestionable, no existe consenso alguno entre los autores que lo estudian en cuanto a la definición de competencia. Así, el término competencia se acepta y utiliza desde cualquier perspectiva educativa que se asuma, deformando su significado en función de las necesidades, intereses y perspectivas de la persona o grupo que lo emplee. Podemos resumir esta idea en lo siguiente: la falta de bases firmes y claras que fundamenten la noción de competencia y de formación basada en competencias, conlleva un empleo indiscriminado de este concepto, aportándole significados distintos en función del contexto en el que se emplea. De este modo, el término competencia puede que sea simplemente fruto de una moda pasajera, y que como tal desaparezca sin haber aportado nada positivo o nuevo. 
- Entroncada con la anterior idea, podemos señalar que el término competencia tiene muchas acepciones, en función del campo de conocimiento desde el que nos acerquemos a su significado. Por eso, como hemos señalado previamente es un concepto ambiguo y poco claro, que da pie a diferentes interpretaciones y malentendidos.

- Desde la perspectiva de la empleabilidad, la noción de competencia fue ampliamente empleada en el ámbito de la psicología conductual (McClelland, 1973, 1998; Moreno Olivos, 2009). Las competencias se adquieren a través de la formación y se pueden describir a través de conductas y desempeños medibles, observables y secuenciables (Mulder et al., 2008). Como tal, se corre el riesgo de asumir esta perspectiva y reducir lo que el sujeto aprende a un acto mecánico y repetitivo. Sobra decir que no todos los aprendizajes necesarios en la etapa de formación obligatoria y postobligatoria pueden ser evidenciables en una ejecución concreta y explícita. Así, someter la enseñanza básica, en la que principalmente se busca la formación integral de las personas y la transmisión cultural, a este reduccionismo es desde nuestro punto de vista cuando menos peligroso.

- Los modelos de diseño y desarrollo de competencias muestran un parecido evidente y considerable con las taxonomías de Bloom y la pedagogía por objetivos. Así, existe la percepción de que la asunción de la formación basada en competencias es, en parte, una reforma impuesta por las administraciones en pos de su afán controlador y evaluador de la eficiencia de los sistemas educativos para optimizar la formación de personas productivas en el ámbito laboral. Esta tendencia se concreta claramente en el interés desmesurado que están mostrando toda clase de organismos internacionales en estandarizar y diseñar un mapa de competencias genéricas y en las diferentes áreas de conocimiento. Debemos tener en cuenta que la estandarización de la enseñanza pone en peligro la heterogeneidad cultural y no atiende a las diferencias contextuales que existen en los diversos entornos educativos posibles.

- Conversión mercantilista de la educación con la asunción de la formación basada en competencias. El debate sobre el futuro y la finalidad de la propia educación se sitúa ahora en un terreno económico-laboral, ajeno al mundo de la pedagogía. La educación pasa a entenderse como algo instrumental; se busca 
el perfil más adecuado y adaptado a las necesidades de los empleadores y a la contribución a la productividad económica. La importancia que se asigna a «la eficacia, la racionalidad técnica, la rentabilidad económica y la proyección sociolaboral ha desplazado el interés por el discurso moral y político de la educación y por el interés formativo. El conocimiento deja de ser un valor en sí mismo, deja de ser considerado como proceso en construcción y pasa a ser considerado resultado, como producto» (Gimeno Sacristán, 2008, p. 218).

- En una realidad incierta, en la que la dirección que toman los acontecimientos y la velocidad a la que se producen los cambios son hechos totalmente impredecibles, no se pueden prever las competencias específicas que se requerirán en un empleo o desempeño concreto. Así, es imposible definir con una cierta precisión el mapa de competencias específicas que requerirá cada desempeño profesional, y mucho menos las necesarias en los contextos personales, sociales y culturales futuros. Así, la formación de las personas no se puede resumir en la formación de habilidades específicas ni en la adquisición de conocimientos concretos, sino que se deben fomentar y desarrollar aprendizajes genéricos y críticos que capaciten a las personas para adaptarse adecuadamente a cualquier situación.

- La práctica de una evaluación auténtica e integral de las competencias es un ejercicio muy complejo que conlleva mucho tiempo, más incluso del que disponen los educadores. Por eso, en el intento de reducir costes temporales, muchas veces la evaluación de competencias se reduce a una evaluación, o bien de los conocimientos conceptuales adquiridos, o bien de la ejecución de una tarea específica totalmente contextualizada en el ambiente académico.

Como se puede observar si nos paramos a reflexionar sobre estas críticas, la mayor parte de ellas están relacionadas íntimamente con el punto de vista desde el que nos acercamos a la formación basada en competencias, esto es, con el posicionamiento dentro del continuum de polos paradigma positivista-paradigma interpretativo que mostrábamos más arriba. Para muchos profesionales defensores del paradigma interpretativo, la asunción de la formación basada en competencias como la nueva norma es un paso atrás en lo que respecta a todo lo que se había avanzado hacia una educación más humana, comprensiva, integral y holística.

Nuestro punto de vista es que en lugar de mantener una postura inmovilista y tratar de simplemente mantener las cotas ya alcanzadas a partir de feroces críticas al 
sistema de formación basada en competencias, podemos aprovechar los elementos bondadosos de este concepto para perseguir y continuar acercándonos a los fines deseados.

Así, como se verá en los siguientes apartados del capítulo, nosotros abogamos por un enfoque holístico en la formación basada en competencias y el desarrollo de competencias. Trataremos de desmarcarnos del conductismo propio de las perspectivas más positivistas de la formación basada en competencias y respaldaremos el desarrollo de competencias básicas que capaciten para aprender a lo largo de la vida y ser flexibles para adaptarse a las condiciones contextuales cambiantes e inciertas (Mulder et al., 2008).

En todo caso, a pesar de que la naturaleza de este trabajo requiere que analicemos de manera sistemática y pormenorizada el concepto y la estructura interna de la formación basada en competencias, no podemos terminar este apartado sin hacer referencia a las reveladoras palabras de Gimeno Sacristán:

«En lugar de dejarnos distraer por el artificio de las competencias podríamos comenzar a pensar las pedagogías del siglo XXI, pensar nuevos modos de afrontar los retos del conocimiento científico, intentar entender cómo son las generaciones que llegarán en un futuro a nuestras aulas, diseñar espacios para la autonomía, la creatividad, la comunicación y el intercambio[...], aceptar que la educación y formación no es neutral y que tenemos que asumir valores éticos, que tenemos una responsabilidad social ineludible, no sólo con el entorno inmediato sino con aquellas sociedades que nos necesitan y que, a su vez, desde luego, necesitamos enseñar al alumnado que nuestro mundo es, porque así lo hemos hecho, diverso, complejo y frágil» (Gimeno Sacristán, 2008, p. 203)

\subsubsection{Nuestra definición de competencia}

Una vez realizadas todas estas consideraciones previas que rodean al concepto de competencia, ya estamos en condiciones, con las potencialidades y limitaciones que hemos visto que el empleo de esta terminología acarrea, de acercarnos a una definición de competencia que englobe y ponga de manifiesto nuestra propia perspectiva acerca de la formación basada en competencias.

Siguiendo el modelo propuesto por Zabala y Arnau (2007), cualquier definición de competencia debería atender a varios interrogantes dispuestos en dos ámbitos, el ámbito semántico y el ámbito estructural. Así, el concepto de competencia debe incluir información sobre qué es, para qué sirve, cómo lo hace, dónde se desarrolla (todas 
estas abarcan el ámbito semántico) y por medio de qué se implementa (ámbito estructural).

De este modo, atendiendo a la extensión semántica expresada más arriba, consideramos competencia como la capacidad que se tiene de movilizar un conjunto de recursos cognitivos para afrontar con garantías situaciones problemáticas en contextos académicos o profesionales concretos. Analicémoslo más concretamente:

- Capacidad (qué): Una competencia presupone aptitud para hacer una actividad del orden que sea. Las capacidades son dinámicas, se desarrollan a lo largo de toda la vida de los sujetos.

- Movilizar recursos cognitivos (cómo): Para ser competente no sólo basta con tener capacidad, sino que también es necesario dominar los instrumentos específicos que hay que poner en juego. El sujeto debe ser capaz de generalizar los recursos que ha adquirido en un contexto concreto a distintas situaciones (transferencia de aprendizajes). Estos recursos, que no son más que componentes de la competencia, los podemos dividir en (Delors, 1997; Martínez Clares \& Echeverría Samanes, 2009; Villa Sánchez \& Poblete Ruiz, 2009):

- Saber (aprender a conocer): Conjunto de conocimientos, tanto generales como específicos, tanto teóricos como prácticos.

- Saber hacer (aprender a hacer): Habilidades y destrezas fruto del aprendizaje y la experiencia.

- Saber estar (aprender a vivir juntos): Ser capaz de convivir y participar en el entorno de modo constructivo.

- Saber ser (aprender a ser): Valores y actitudes de la persona.

- Afrontar situaciones problemáticas (para qué): Una competencia sólo existe «si se vincula a un objeto o una situación» (De Miguel Díaz, 2006, p. 35). Si la competencia no se pone en juego en una situación, ésta no es perceptible. Por tanto, deberemos crear situaciones-problema que requieran el empleo de ciertas competencias para su resolución. Así, podremos obtener las evidencias de que la competencia existe y a qué nivel está integrada en el sujeto. 
- En contextos académicos o profesionales concretos (dónde): Toda acción está íntimamente vinculada a un contexto. El dominio de las competencias básicas se vincula a dar respuesta al rango de posibles problemas a los que se pueda enfrentar cualquier persona a lo largo de su vida. Por tanto, la competencia tiene un componente contextual muy importante, que implica no solo la movilización de recursos para la resolución de problemas, sino también la capacidad de identificar y valorar el contexto en el que se presentan de cara a su correcta resolución. El mismo problema presentado en contextos diferentes puede requerir protocolos de actuación distintos por parte de la misma persona.

Por su parte, en cuanto al ámbito estructural, que se refiere a las herramientas concretas que se ponen en marcha para desarrollar las competencias, nos estamos refiriendo a recursos cognitivos, que como se desarrolla más arriba, están divididos en saber, saber hacer, saber estar y saber ser. Si nos centramos más específicamente en la estructura interna de estos recursos cognitivos, podemos señalar los ámbitos que atraviesan transversalmente cada uno de estos componentes de la competencia, que son (Zabala \& Arnau, 2007):

- Ámbito social, que se refiere al compromiso del ciudadano de participar activa y responsablemente en la construcción de una sociedad mejor.

- Ámbito inter-personal, que abarca todo lo que tiene que ver con relacionarse, comunicarse y vivir en armonía con los demás, cooperando y participando en las actividades humanas.

- Ámbito personal, referido a la capacidad de ejercer la autonomía de manera responsable y crítica, y de comportarse con libertad y creatividad «mediante el conocimiento y comprensión de sí mismo, de la sociedad y de la naturaleza» (Zabala \& Arnau, 2007, p. 95)

- Ámbito profesional, que incluye todas las competencias necesarias para poder ejercer una tarea profesional adecuada a las capacidades e intereses de la persona. 
Tabla 3.2 Dimensiones y componentes de la competencia*

\begin{tabular}{|c|c|c|c|c|}
\hline & SABER & SABER HACER & SABER SER & SABER ESTAR \\
\hline $\begin{array}{l}\text { Ámbito } \\
\text { social }\end{array}$ & $\begin{array}{l}\text { Conocimientos } \\
\text { propios de la } \\
\text { sociología, } \\
\text { política, etc. }\end{array}$ & $\begin{array}{l}\text { Saber participar, } \\
\text { comprender, } \\
\text { valorar, } \\
\text { intervenir, etc. }\end{array}$ & $\begin{array}{l}\text { Persona } \\
\text { justa, } \\
\text { solidaria, } \\
\text { democrática, } \\
\text { etc. }\end{array}$ & $\begin{array}{c}\text { Comportamiento } \\
\text { activo, crítico, } \\
\text { respetuoso, etc. }\end{array}$ \\
\hline $\begin{array}{l}\text { Ámbito } \\
\text { inter- } \\
\text { personal }\end{array}$ & $\begin{array}{l}\text { Conocimiento de } \\
\text { habilidades } \\
\text { sociales y de } \\
\text { comunicación, } \\
\text { etc. }\end{array}$ & $\begin{array}{l}\text { Saber cooperar, } \\
\text { comunicarse, } \\
\text { relacionarse, etc. }\end{array}$ & $\begin{array}{c}\text { Persona } \\
\text { participativa, } \\
\text { comprensiva, } \\
\text { etc. }\end{array}$ & $\begin{array}{c}\text { Comportamiento } \\
\text { tolerante, } \\
\text { abierto a la } \\
\text { colaboración. }\end{array}$ \\
\hline $\begin{array}{l}\text { Ámbito } \\
\text { personal }\end{array}$ & $\begin{array}{l}\text { Autoconocimiento } \\
\text { (autorregulación, } \\
\text { autocontrol, etc.) }\end{array}$ & $\begin{array}{c}\text { Saber resolver } \\
\text { problemas } \\
\text { autónomamente. }\end{array}$ & $\begin{array}{l}\text { Persona } \\
\text { libre, } \\
\text { creativa, etc. }\end{array}$ & $\begin{array}{l}\text { Comportamiento } \\
\text { con un alto } \\
\text { grado de } \\
\text { autonomía } \\
\text { personal. }\end{array}$ \\
\hline $\begin{array}{l}\text { Ámbito } \\
\text { profesional }\end{array}$ & $\begin{array}{l}\text { Conocimientos } \\
\text { provenientes de } \\
\text { múltiples } \\
\text { disciplinas } \\
\text { científicas. }\end{array}$ & $\begin{array}{c}\text { Saberes } \\
\text { generales } \\
\text { propios de los } \\
\text { diferentes } \\
\text { ámbitos } \\
\text { profesionales. }\end{array}$ & $\begin{array}{l}\text { Persona } \\
\text { flexible, } \\
\text { reflexiva y } \\
\text { rigurosa. }\end{array}$ & $\begin{array}{c}\text { Comportamiento } \\
\text { responsable y } \\
\text { profesional. }\end{array}$ \\
\hline
\end{tabular}

Adaptado de Zabala y Arnau (2007)

En la tabla 3.2, mostrada más arriba se puede observar cómo se interrelacionan cada uno de los ámbitos de la competencia con los componentes de la misma.

Así pues, podemos concluir en cuanto al ámbito estructural que mientras que toda competencia se puede descomponer en cuatro componentes (saber, saber hacer, saber ser y saber estar), cada competencia colabora en el desarrollo de los cuatro ámbitos expuestos (social, personal, inter-personal y profesional) en mayor o menor medida. Esto no quiere decir que no podamos encontrar competencias que coexistan en varios de estos ámbitos por igual. Lo que queremos expresar es que las competencias más específicas pueden ajustar la mayor parte de su componente a uno de los ámbitos mostradas, sin perjuicio de que algún elemento se adapte mejor a otro u otros ámbitos.

Nos referimos en este apartado a las competencias específicas ya que la estructura de las competencias básicas es ligeramente distinta. Debido a su generalidad, las competencias básicas no se ajustan tan claramente a estos ámbitos, sino que reparten sus componentes entre todos ellos en forma de competencias específicas. 


\subsection{El modelo de formación basada en competencias}

A lo largo del anterior apartado hemos ido adelantando elementos estructurales de las competencias, como las dimensiones y los componentes. Durante este apartado nos centraremos en esto, mostrando el modelo de competencia desde el que partimos, diseccionando la estructura que tienen las competencias y por último señalando los elementos que componen los procesos de aprendizaje basados en competencias.

En primer lugar, por tanto, trataremos de analizar del modo más gráfico y claro posible el modelo propuesto. Dicho modelo se fundamenta y está elaborado principalmente a partir de las ideas de Mario de Miguel (2006), Villa y Poblete (2007, 2009), Zabala y Arnau (2007), Bolívar (2009) y Delors (1997). Se debe de tener en cuenta, no obstante, que la mayor parte de los trabajos que trabajan acerca de la formación basada en competencias provienen del ámbito universitario, por lo que deberemos adaptar estas perspectivas al ámbito en el que nosotros nos situamos de la educación secundaria.

Como señalan Cabero y Alonso (2007, p. 17), «la movilización de estrategias son cada vez más importantes ya que en un mundo repleto de información, y de una información que se transforma en cortos periodos de tiempo, más importante que el qué enseñar será cómo hacerlo». A pesar de que entendemos que no existe una metodología específica para la enseñanza de competencias (Zabala \& Arnau, 2007), pensamos que los entornos de formación por competencias exigen principalmente cambios metodológicos, sobre todo en lo que implica al desarrollo del aprendizaje activo, la capacidad de los alumnos para emitir un juicio crítico y la facultad para saber cómo aprender (Sabán Vera \& Monclús Estella, 2008). Así, consideramos que un buen modelo de formación por competencias nos puede ser útil para centrarnos en el cómo enseñar más que en el qué enseñar, ya que, como añade Peña-López, el desarrollo de competencias «imply changes in teaching, in syllabuses, in learning practices or in organizations» (2010a, p. 27).

La construcción que propone el modelo de formación basada en competencias supone un continente que puede ser apropiado para contener con rigor y estabilidad una enseñanza más centrada en la formación integral y para toda la vida (Zabala \& 
Arnau, 2007). Este recipiente, contenedor de las competencias básicas, aporta las siguientes características a las mismas (Villa Sánchez \& Poblete Ruiz, 2007):

- Las competencias básicas son multifuncionales: Se necesitan en un rango muy amplio de desempeños cotidianos, profesionales y para la vida social.

- Las competencias genéricas son transversales en diferentes campos.

- Las competencias genéricas se refieren a un orden superior de complejidad mental: como tal favorecen el desarrollo de los niveles de pensamiento intelectual de orden superior. Favorecen la autonomía de pensamiento y la capacidad para reflexionar distanciándose de los procesos de socialización.

- Las competencias genéricas son multidimensionales.

A partir de estas premisas, desarrollamos el modelo que se presenta a continuación.

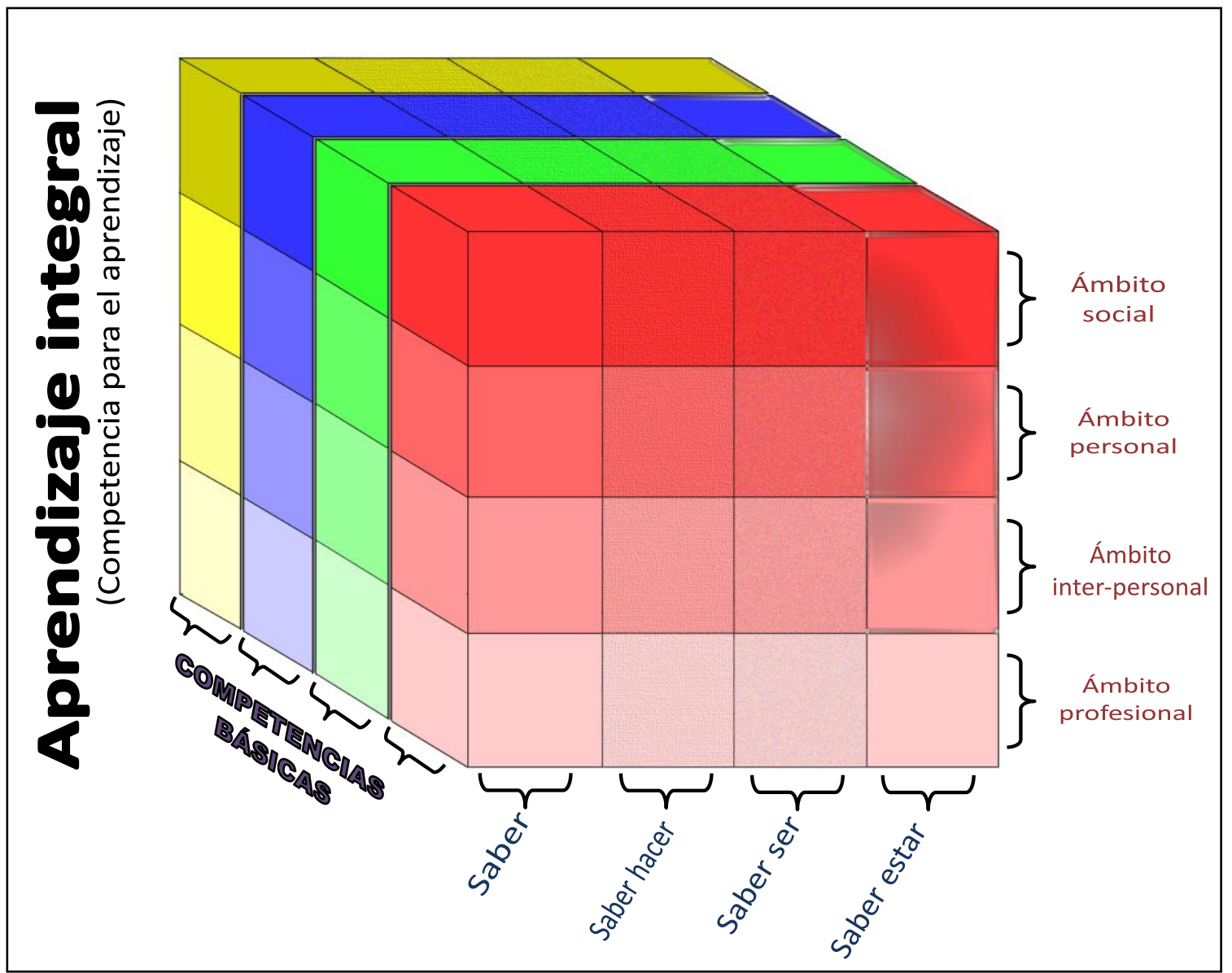

Figura 3.1 Modelo de formación basada en competencias*

* Elaboración propia 
En la figura 3.1 se muestra una representación del modelo que proponemos. Se puede observar cómo consideramos que la naturaleza de las competencias es multidimensional, atendiendo a su ámbito básico de actuación (social, inter-personal, personal y profesional). Por otro lado, se observa cómo la competencia es multifuncional, ya que está dividida en cuatro componentes básicos (saber, saber hacer, saber ser y saber estar). Cada sección de distinto color representa una competencia básica, que como hemos señalado anteriormente, aglutina componentes de todos los ámbitos. Cada competencia básica se puede subdividir en competencias específicas que se incluyen en un solo ámbito, manteniendo los cuatro componentes básicos inherentes a toda competencia.

Por último, se refleja un corte más pronunciado entre cada una de las competencias. Esto se debe a nuestro interés por poner de manifiesto que, frente al sistema tradicional, que hacía un corte por contenidos dispuestos en las diferentes disciplinas, ahora la sección principal se hace de una manera diferente, por competencias básicas, que se desarrollan transversalmente a lo largo de todas las disciplinas académicas.

\subsubsection{Estructura de las competencias}

Una vez analizada la composición y organización interna del continente considerado como competencias, nos queda llenarlo de contenido. Por tanto, llegados a este punto nos parece necesario estudiar el formato o la estructura que adquieren los contenidos académicos cuando se les incluye en los procesos de formación basada en competencias.

Así, principalmente en los ciclos formativos básicos, nos encontramos con una estructura fundamentada en una serie de competencias básicas o competencias clave que como ya hemos expresado comprenden contenidos y desempeños muy genéricos y amplios repartidos a lo largo de las disciplinas del currículo. Estas competencias básicas, a su vez, pueden fragmentarse en un conjunto de sub-competencias más específicas, que aunque conservan su naturaleza transversal, se podrían enmarcar e identificar mejor dentro de una disciplina o actividad concreta. Mientras que una competencia clave es incómoda a nivel operativo (es complejo descomponerla en evidencias concretas y definir claramente el saber, saber hacer, saber estar y saber ser que delimitan), las sub-competencias son más manejables en lo que respecta a su empleo con fines educativos. 
Por lo tanto, bajo nuestro punto de vista, las competencias se implementan bajo una estructura jerárquica bien definida que procedemos a exponer a continuación.

Aceptando que en el nuevo contexto social, económico y laboral es evidente que la educación no puede estar dirigida a la transmisión de conocimientos y de informaciones, sino a desarrollar la capacidad de producirlos y de utilizarlos continuamente (Tedesco, 2007), estaríamos de acuerdo en apuntar hacia la existencia de una competencia esencial que esté por encima del resto de competencias básicas.

Sin embargo, esta misión global de la formación basada en competencias, que se traduce en la misión general de la escuela, parece igual de evidente que de compleja; «Decir que la escuela debe preparar para la vida, es descubrir América: nadie puede oponerse a esta idea [...] Queda por determinar lo que la escuela debe hacer para preparar a los jóvenes para la vida» (Perrenoud, 2012, p. 175). No se puede pretender elaborar un mapa de competencias y planificar un sistema formativo que prepare a todos los sujetos para todos los aspectos de la vida presente y futura.

El propio Perrenoud (2012), señala ocho factores que otorgan una gran complejidad a este objeto:

1. La vida no empieza después de la escuela, por lo que la formación básica no puede limitarse a una preparación para la vida adulta.

2. La vida y los usos sociales evolucionan a tal velocidad que no se puede pretender una formación escolar para toda la vida (Bauman, 2007).

3. No se puede prever lo que espera a los futuros adultos dentro de varios años.

4. A pesar de que pueden existir denominadores comunes en las condiciones de vida de las personas, no se puede estandarizar lo que se entiende como formación para la vida, ya que existe una gran diversidad de historias y condiciones.

5. La escuela no posee el monopolio de la preparación para la vida. Existen otras instituciones de educación informal como las familias, que no dependen del sistema escolar, y que contribuyen a esta formación en gran medida.

6. El currículo oculto produce aprendizajes no planificados ni programados y tienen importancia. 
7. La formación en las escuelas no es integral ni tiene una visión holística: En las etapas de la educación primaria e infantil, a pesar de que se pone énfasis en la transversalidad de las materias, los alumnos tienen experiencias con maestros diferentes con visiones diferenciadas. Lo que es más, a partir de la enseñanza secundaria, se considera el contenido de manera vertical, en compartimentos estanco. Para conseguir los objetivos de esta etapa «no es requerido, y a veces es hasta disfuncional, dejarse guiar por una visión de conjunto del proceso de formación» (Perrenoud, 2012, p. 177).

8. Es utópico pretender formar personas con la totalidad de las competencias y conocimientos para desenvolverse de forma pertinente en todas las situaciones posibles del día de mañana.

Sin embargo, a pesar de que pretender la estandarización de una formación global para la vida parece una meta inalcanzable, sí existen ciertas capacidades que pueden dotar a los individuos de los recursos suficientes para aprender, reaprender y desaprender las competencias necesarias e impredecibles que van a necesitar en un futuro próximo.

Así, nos encontramos con la competencia para el aprendizaje, definida por Bolívar (2009), y que podemos situar en la base de todas las demás.

\footnotetext{
«En esta sociedad la escuela no está llamada a luchar con las otras informaciones que ya recibe la ciudadanía. Por el contrario, el núcleo duro del desarrollo cognitivo y cultural que deba proporcionar se sitúa en capacitar a los ciudadanos con marcos de referencia propios en los que puedan "encajar" y procesar los múltiples y contradictorios mensajes que reciben y, por otra parte, en tener competencias para aprender autónomamente [...] La competencia para el aprendizaje supone preparar a las personas para hacerse cargo de su propio proceso de aprendizaje, que tendrán que llevar a cabo a lo largo de su vida» (Bolívar Botía, 2009, pp. 2-3)
}

La competencia para el aprendizaje supone la meta final de la educación (al menos de la educación básica), el ideal del aprendizaje integral y global que hemos venido demandando insistentemente. Es una competencia íntimamente ligada con la capacidad las personas de autogestionar su propio aprendizaje durante toda la vida, gracias al dominio de la capacidad de aprender a aprender y aprender a desaprender (Alemany, 2003; Andrade, 2005). La importancia de esta competencia cobra más vigencia si consideramos la naturaleza continua de las competencias (De Miguel Díaz, 2006). El contexto líquido, que supone para las personas que conocer no es apropiarse de la verdad, sino saber dialogar con la incertidumbre (Coll et al., 2010; Morin, 2000), 
somete consecuentemente a las competencias a una exigencia de maleabilidad a lo largo del tiempo. De hecho "podemos decir que las competencias del estudiante no son para siempre; actuaciones que fueron apropiadas hace un tiempo, dejaron de ser operativas ayer y son obsoletas hoy» (De Miguel Díaz, 2006, p. 34).

Por lo tanto, consideramos esta competencia como nuclear, que está en el fondo de todas las competencias básicas que se desarrollan a continuación y que conforman el segundo nivel en la jerarquía que forma la estructura de las competencias.

A pesar de que el concepto de competencia para el aprendizaje es valioso en cuanto a que aporta una idea clara de las metas últimas de una educación basada en competencias, debido a su excesivo nivel de generalidad consideramos que no es pertinente incluirlo tal cual en los diseños curriculares, ni implementarlo directamente en proceso educativo alguno.

En este sentido aparece lo que podríamos considerar el siguiente nivel de concreción del contenido de las competencias, las competencias básicas, competencias clave o competencias genéricas. A lo largo de este texto, emplearemos con más insistencia el término competencias básicas, debido a que es el que se emplea en el diseño curricular del sistema educativo español, y más concretamente en la educación secundaria (Boletín Oficial del Estado, 2007a, 2007b).

A pesar de que mantienen un alto nivel de generalidad, las competencias básicas, a diferencia de la competencia para el aprendizaje, ya hacen referencia a capacidades y comportamientos más específicos e identificables en sub-competencias. Por ello, son más idóneos para integrarlos en los documentos planificadores de la enseñanza como primer nivel general de las competencias.

Esta naturaleza de las competencias básicas se ve reflejada en las definiciones de las mismas que los autores proponen. Partiendo de la idea anterior, sirva de ejemplo la siguiente definición, que entronca además con nuestra perspectiva sobre la alfabetización funcional y su vinculación con las competencias: «Las competencias básicas son aquellas que capacitan a los individuos para participar activamente en múltiples contextos o ámbitos sociales» (Gimeno Sacristán, 2008, p. 37). Se observa claramente en esta definición la naturaleza global de las competencias básicas acompañada de una perspectiva supeditada a comportamientos concretos.

Para ejemplificar mejor lo que se considera competencia básica, veamos los modelos propuestos en algunos documentos reguladores de la enseñanza tanto en el 
entorno europeo, con las recomendaciones que eleva sobre competencias básicas, como su concreción en el caso español, a partir del currículo y la ordenación de enseñanzas básicas de la Educación Secundaria Obligatoria.

A nivel europeo nos encontramos un documento bastante revelador de la perspectiva que es asumida, la "Recomendación del Parlamento Europeo y del Consejo de 18 de diciembre de 2006 sobre las competencias clave para el aprendizaje permanente" (Diario oficial de la Unión Europea, 2006). A pesar de que el documento emplea la terminología "competencias clave", nosotros consideraremos este concepto un sinónimo de "competencias básicas".

Las competencias se definen en dicho documento como «una combinación de conocimientos, capacidades y actitudes adecuadas al contexto. Las competencias clave son aquellas que todas las personas precisan para su realización y desarrollo personales, así como para la ciudadanía activa, la inclusión social y el empleo» (p. 13). Se puede observar cómo se aporta a las competencias básicas la capacidad de proporcionar la formación integral de las personas, lo cual entronca con nuestro modelo y con la hipótesis de la competencia para el aprendizaje.

Las ocho competencias clave para el aprendizaje permanente que se señalan en el citado documento son las siguientes:

- Comunicación en la lengua materna;

- comunicación en lenguas extranjeras;

- competencia matemática y competencias básicas en ciencia y tecnología;

- competencia digital;

- aprender a aprender;

- competencias sociales y cívicas;

- sentido de la iniciativa y espíritu de empresa, y

- conciencia y expresión culturales.

Al margen de nuestro grado de acuerdo sobre la selección de estas competencias clave, nos parece especialmente reseñable que se añada aprender a aprender como una competencia, cuando no nos parece que reúna las características de partida para 
ser así considerado (combinación de conocimientos, capacidades y actitudes adecuadas al contexto).

Por otro lado, se observa la inclusión de la competencia digital como competencia clave. La competencia digital hace referencia a «el uso seguro y crítico de las tecnologías de la sociedad de la información [...] Se sustenta en las competencias básicas en materia de TIC: el uso de ordenadores para obtener, evaluar, almacenar, producir, presentar e intercambiar información, y comunicarse y participar en redes de colaboración a través de internet»(p. 16). La definición de esta competencia está íntimamente relacionada con las competencias informacionales, que defendemos como competencias básicas en este estudio. La diferencia fundamental es el empleo del término digital, que limita mucho el propio concepto: mientras que las competencias informacionales se refieren a todo el comportamiento relacionado con el manejo de la información disponible en fuentes tanto digitales como analógicas, la competencia digital se limita a las fuentes digitales.

En el contexto español, podemos analizar dos documentos más centrados en el ámbito concreto que nos ocupa en este estudio, la Enseñanza Secundaria Obligatoria. Aunque ambos documentos están relacionados y coordinados, nos encontramos, por un lado el "Real Decreto 1631/2006, de 29 de diciembre, por el que se establecen las enseñanzas mínimas correspondientes a la Educación Secundaria Obligatoria" (Boletín Oficial del Estado, 2007a), y por otro la Orden ECl/2220/2007, de 12 de julio, por la que se establece el currículo y se regula la ordenación de la Educación Secundaria Obligatoria" (Boletín Oficial del Estado, 2007b).

Dichos documentos reguladores señalan las competencias básicas como aquellas que «permiten identificar aquellos aprendizajes que se consideran imprescindibles desde un planteamiento integrador y orientado a la aplicación de los saberes adquiridos» (p. 678). Continua añadiendo que la adquisición de estas competencias pretende la «realización personal, el ejercicio de la ciudadanía activa, la incorporación satisfactoria a la vida adulta y el desarrollo de un aprendizaje permanente a lo largo de la vida» (p. 678). Se observa cómo esta definición guarda muchas similitudes con la que se señalaba en las recomendaciones del Parlamento Europeo, y sigue estando en consonancia con el modelo de formación basada en competencias y la estructura interna de las competencias que hemos propuesto en este documento. Como diferencia clara entre esta documentación del contexto español y la del europeo, cabe destacar que en ningún momento en los documentos reguladores de las enseñanzas de educación secundaria en España se hace referencia explícitamente a una definición 
de competencia. Dada la ya señalada la ambigüedad y tendencia a múltiples interpretaciones a las que se presta el concepto competencia, identificamos esto como una deficiencia y consideramos que las autoridades competentes en el tema deberían hacer un esfuerzo conjunto en definir claramente qué se entiende por competencia en el ámbito educativo español.

Al margen de esta reflexión, se puede continuar analizando el contenido de los documentos señalados hasta llegar al siguiente punto que nos compete, la lista de las competencias básicas incluidas en el Currículo español de Educación Secundaria. Al igual que en el caso europeo, se definen ocho competencias básicas en el Currículo de Educación Secundaria en España (Boletín Oficial del Estado, 2007b):

- Competencia en comunicación lingüística;

- competencia matemática;

- competencia en el conocimiento y la interacción con el mundo físico;

- tratamiento de la información y competencia digital;

- competencia social y ciudadana;

- competencia cultural y artística;

- competencia para aprender a aprender y

- autonomía e iniciativa personal

Se vuelven a observar similitudes muy claras con la recomendación europea. Por ejemplo, se sigue manteniendo aprender a aprender. En el caso español la inclusión de este constructo como una competencia básica no tiene discusión, ya que no se define previamente lo que es competencia. Por otro lado, se incluye el tratamiento de la información y competencia digital como una sola competencia básica. La perspectiva en este caso parece más general que en el caso europeo, que señalaba nada más la competencia digital. Pero veamos cómo se define esta competencia básica en los documentos españoles. Señala que

«...consiste en disponer de habilidades para buscar, obtener, procesar y comunicar información y para transformarla en conocimiento [...] Está asociada con la búsqueda, selección, registro y tratamiento o análisis de la información, utilizando técnicas y estrategias diversas para acceder a ella según la fuente a la que se acuda 
y el soporte que se utilice (oral, impreso, audiovisual, digital o multimedia)» ( $p$. 688).

Se puede advertir claramente cómo esta perspectiva es mucho más amplia que la europea y se adapta mejor a nuestro concepto de competencias informacionales.

Ya hemos expresado que bajo la perspectiva de nuestro modelo, la estructura interna de las competencias exige que las competencias básicas se desarrollen en subcompetencias, más concretas y operativas. Por ejemplo, las competencias informacionales, que nos ocupará específicamente más adelante, las podemos subdividir en una primera etapa en cuatro apartados: competencia en la búsqueda de información, en la evaluación de información, en el procesamiento de información y en la comunicación y difusión de información. A su vez, cada uno de estos elementos se podría sub-dividir en el siguiente nivel de concreción, que no sería otro que el universo de escenarios de actuación propios de ese preciso campo susceptibles de encontrarnos en algún contexto. Con esto nos estamos refiriendo a las situaciones problemáticas a las que se hacía referencia en la definición de competencia propuesta. Así, como es imposible que una persona se haya enfrentado a todas y cada una de las situaciones posibles, lo importante es el desarrollo de las sub-competencias relativas y la capacidad de generalización de las mismas. Y estas competencias se operativizan en los componentes a los que ya hemos hecho referencia anteriormente: saber, saber hacer, saber ser y saber estar. Toda competencia, evidentemente, debe integrar los 4 componentes, aunque alguno de ellos tenga más peso en función de la naturaleza de la competencia concreta. 


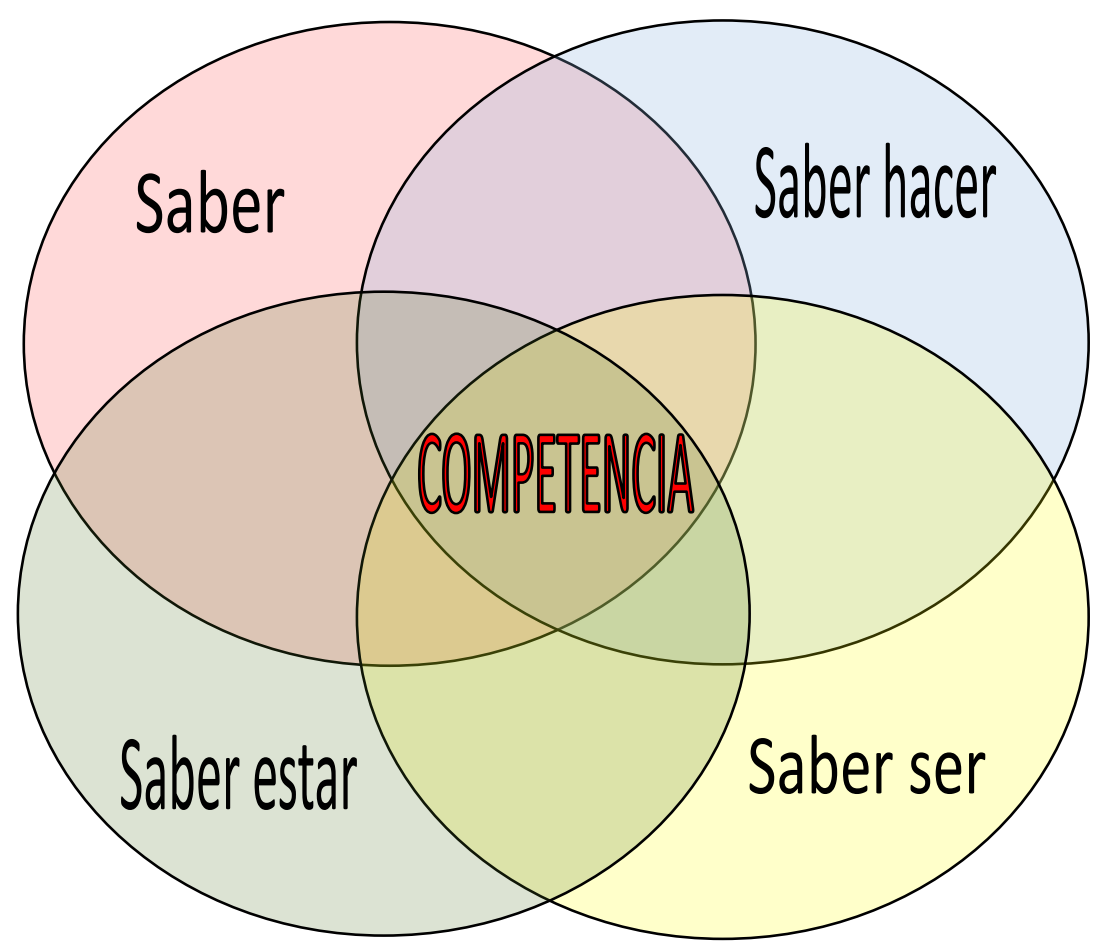

Figura 3.2 Componentes de las competencias

Esto se expresa perfectamente a través del clásico diagrama de Venn (figura 3.2). Se puede observar cómo el desarrollo de la competencia debe integrar todos los saberes.

De nada sirve, por ejemplo, en lo que respecta a la competencia para la búsqueda de información, conocer todas las técnicas de búsqueda de información y todos los recursos de información disponibles (saber), ser capaz de utilizar todos los recursos de información de modo pertinente (saber hacer) y tener la capacidad para trabajar en grupo y comunicarse eficazmente (saber estar), si cuando nos enfrentamos a la tarea que suponga, por ejemplo, encontrar información para desarrollar el cuerpo teórico de un proyecto de investigación creemos que no somos capaces y no tenemos un control adecuado del estrés que nos crea la propia tarea (saber ser).

A pesar de que ya hemos definido de un modo genérico lo que supone cada uno de los 4 componentes de la competencia, vemos necesario hacer un análisis más profundo de los mismos, que aporte pistas sobre a qué elementos concretos de la propia tarea, desempeño o comportamiento se está refiriendo el saber, el saber hacer, el saber ser y el saber estar.

Así, nos encontramos con la excelente conceptualización que realizan Majó y Marqués (2002), que definen perfectamente el elemento cognitivo que está incluido 
dentro de cada uno de los componentes. La tabla 3.3 incluye, por tanto, una descripción pormenorizada de cada uno de los componentes de la competencia.

Tabla 3.3 Descripción de los componentes de la competencia*

\begin{tabular}{|c|c|}
\hline \multicolumn{2}{|r|}{ COMPONENTES DE LA COMPETENCIA } \\
\hline SABER & $\begin{array}{l}\text { Conocimiento de la cultura. Conocimientos, visiones del mundo, } \\
\text { ideas, instrumentos, normas... } \\
\text { Idiomas. } \\
\text { Construir conocimiento. } \\
\text { Informarse. Observar, leer, buscar información relevante... }\end{array}$ \\
\hline SABER HACER & $\begin{array}{l}\text { Iniciativa en la toma de decisiones. } \\
\text { Perseverancia en la acción pese a las dificultades. } \\
\text { Creatividad en la manera de percibir el mundo y modo original de } \\
\text { realizar las tareas cotidianas. } \\
\text { Motivación, estar dispuesto a asumir los riesgos inherentes a la } \\
\text { acción. } \\
\text { Uso eficiente de recursos: información, matemáticas, TIC... Utilizar } \\
\text { con confianza las técnicas y conocimientos. }\end{array}$ \\
\hline SABER SER & $\begin{array}{l}\text { Autoconocimiento y capacidad de autocrítica. } \\
\text { Autoestima. } \\
\text { Adaptación a las diversas situaciones, flexibilidad. Capacidad de } \\
\text { aprender a aprender y desaprender. } \\
\text { Autocontrol de las emociones y el estrés. } \\
\text { Curiosidad. Actitud observadora y crítica. } \\
\text { Interpretar y valorar. Capacidad para emitir juicios de valor. } \\
\text { Pensamiento abierto y crítico. }\end{array}$ \\
\hline SABER ESTAR & $\begin{array}{l}\text { Responsabilidad en el modo de actuar. } \\
\text { Expresarse adecuadamente por medio de diversos lenguajes. } \\
\text { Comunicarse demostrando un buen nivel de comunicación } \\
\text { interpersonal, con capacidad empática, de gestionar conflictos, } \\
\text { discutir, persuadir y negociar. } \\
\text { Respeto a la diversidad cultural, de ideas y de personas. } \\
\text { Saber trabajar cooperativamente, en equipo. } \\
\text { Solidaridad y participación en la vida democrática de la comunidad. }\end{array}$ \\
\hline
\end{tabular}

* Adaptado de Majó y Marqués (2002, págs. 122-124)

«a los pilares del saber y el saber hacer, se añaden otros dos: el saber ser y el saber convivir. En consecuencia, la introducción en la enseñanza del término competencia es resultado de la necesidad de utilizar un concepto que dé respuesta a las necesidades reales de intervención de la persona en todos los ámbitos de la vida» (Zabala \& Arnau, 2007, p. 28) 
No debemos olvidar, a pesar de las dudas que supone y de las críticas recibidas al respecto, las diferencias entre la noción global de competencia y el saber hacer o habilidad. En este sentido, se debería hablar de competencia para hacer referencia al dominio global de una situación, y de habilidad cuando nos referimos al dominio de una operación específica insuficiente para enfrentarse a todos los parámetros de la situación (Perrenoud, 2012).

A partir de estas indicaciones se podría definir un mapa de competencias, subcompetencias y componentes que guíen un proceso educativo inmerso en un contexto concreto.

Llegados a este punto, en el que ya hemos estudiado pormenorizadamente el concepto y los fundamentos estructurales que desde nuestro punto de vista asignamos a las competencias, creemos necesario aportar más generalidad a nuestro discurso y analizar cómo se organizan los procesos de aprendizaje a partir de un modelo de formación basado en competencias.

\subsubsection{El aprendizaje en un modelo basado en competencias}

A la hora de abordar el diseño de planes de estudio basados en competencias, se deben de tener en cuenta una serie de aspectos o elementos esenciales sobre los que hay que realizar una toma de decisiones. Esto supone que en función de la naturaleza de las competencias y sub-competencias que pretendamos desarrollar, del entorno en el que queramos implementar el plan formativo, de las características personales de los aprendices, de los recursos de los que dispongamos, etc., nos inclinaremos por la adopción de un determinado tipo de técnicas.

La toma de decisiones se ha de tomar de manera interrelacionada a partir de 4 ejes fundamentales (De Miguel Díaz, 2006; Villa Sánchez \& Poblete Ruiz, 2007, 2009).

\section{i) Estrategias y metodología de enseñanza-aprendizaje}

Podemos definir este eje como el «diseño de un proceso regulable compuesto por una serie de procedimientos y normas que aseguran una decisión óptima en cada situación, en función de los objetivos perseguidos, incorporando los métodos y técnicas adecuados y ajustándolos a los tiempos previstos» (Villa Sánchez \& Poblete Ruiz, 2007, p. 36). La metodología empleada es la que nos va a permitir dar respuesta a 
la finalidad que perseguimos con el proceso educativo emprendido. Por ello, debemos tener en cuenta dentro de este eje tanto la estrategia general, como los métodos y técnicas específicas empleados, como los recursos (personales, espaciales e instrumentales) y la asignación de tiempos.

Evidentemente, en los procesos de formación basados en competencias es necesaria una metodología variada, que se adapte a las necesidades individuales y/o grupales, y a la diversidad de contenidos y competencias. De hecho, cada competencia, debido a su naturaleza multidimensional, es susceptible de desarrollarse a partir de una gran diversidad de actividades de aprendizaje. (De Miguel Díaz, 2010)

En este aspecto, la labor del profesor se debe dirigir hacia la selección para cada situación didáctica de la estrategia y el método que más se adecúe para lograr la motivación y la actividad orientada al aprendizaje del estudiante.

Existen infinidad de métodos, entre otros, podemos señalar a modo de ejemplo la lección magistral, el estudio de casos, la resolución de ejercicios y problemas, el aprendizaje basado en problemas y orientado a proyectos, el aprendizaje cooperativo o el contrato de aprendizaje (De Miguel Díaz, 2006).

\section{ii) Modalidad}

Podríamos entender la modalidad como la forma general de organizar el proceso de enseñanza-aprendizaje. Una definición más específica la podemos encontrar en la obra de de Miguel (2006), cuando señala que la modalidad de aprendizaje son «los distintos escenarios donde tienen lugar las actividades a realizar por el profesorado y el alumnado a lo largo de un curso, y que se diferencian entre sí en función de los propósitos de la acción didáctica, las tareas a realizar y los recursos necesarios para su ejecución» (p. 41).

Se puede hacer una diferenciación entre la modalidad general de enseñanza (presencial, no presencial y mixta o semi-presencial) y modalidades específicas (clase teórica, trabajo autónomo, clase práctica, seminario, trabajo en grupo, prácticas externas, etc.). A nivel general, un programa educativo se adscribe a una sola modalidad general, mientras que en todo programa de formación basado en competencias el empleo de las modalidades específicas debe ser variado. 
La decisión sobre la adopción de una modalidad u otra depende en buena medida del estilo del profesor y de la intención que éste tiene en lo que respecta a cómo se va a llevar a cabo el proceso de comunicación con los estudiantes.

Se pone de relieve cómo los términos modalidad y metodología pueden llevar a confusiones por su similitud conceptual. Sin embargo, para evitar este desconcierto, podemos afirmar que mientras que la modalidad tiene que ver con el escenario en el que se desenvuelve el acto educativo (contexto), la metodología es el conjunto de técnicas concretas empleadas a lo largo del proceso formativo que persiguen el objetivo de la adquisición de competencias (procedimiento).

\section{iii) Seguimiento del proceso}

El seguimiento del proceso tiene mucho que ver con el concepto de evaluación formativa y continua, ya que su propósito es averiguar si los objetivos que se definían en el diseño están alcanzándose durante la implementación del plan formativo, esto es, si los alumnos están alcanzando los niveles de competencia deseados, y a partir de ello tomar decisiones con respecto a cómo debe seguir desarrollándose el propio proceso educativo.

Desarrollar un buen plan de seguimiento es muy importante, ya que asegura la retroalimentación y mejora continuas del proceso, lo cual facilita la calidad. Por otro lado, a medida que el alumno avanza hasta cursos superiores se va haciendo un proceso de seguimiento menos sistemático y regular, favoreciendo la autonomía personal y la autorregulación del aprendizaje.

\section{iv) Sistema de evaluación}

\footnotetext{
«De entrada, en la evaluación por competencias cambia la óptica, el punto de mira, de lo que se quiere evaluar: si habitualmente se hace mirando al pasado anterior (qué se espera que los estudiantes hayan aprendido); en las competencias, por el contrario, se hace mirando al futuro: con qué grado de éxito pueden poner en práctica lo que han aprendido y aplicar sus conocimientos y habilidades en nuevos contextos [...] De otro lado, hay una oposición entre la evaluación que tiende a cuantificar unos aprendizajes en un momento dado, viendo los conocimientos acumulados, y la evaluación que tiende a documentar un recorrido de formación o de desarrollo» (Bolívar Botía, 2009, p. 18)
}

La evaluación es, bajo nuestro punto de vista el eje más importante que regula el aprendizaje en los procesos de formación por competencias. Su naturaleza variada, 
continua y como agente de retroalimentación le confiere un papel esencial para asegurar la calidad del proceso de formación implementado.

De hecho, desde nuestro punto de vista parece claro que la variedad y la necesidad de que sea procesual, son dos características irrenunciables a tener en cuenta a la hora de planificar y desarrollar los procesos de evaluación en la formación basada en competencias.

En primer lugar, haciendo referencia a la realidad procesual de la evaluación, consideramos que los sistemas de evaluación deben estar planificados e integrados durante la totalidad del proceso de aprendizaje, ya que son «el elemento principal que orienta y motiva el aprendizaje del alumno y la propia enseñanza» (De Miguel Díaz, 2006, p. 52).

En segundo lugar, en cuanto a la necesidad de una evaluación diversa y variada, se puede observar que cada competencia tiene componentes muy heterogéneos que por tanto requerirán de múltiples procedimientos para ser evaluados correctamente. «Cuando el sistema de evaluación [...] se basa en el examen tradicional, se puede afirmar que, en la práctica, no se evalúan competencias y, por tanto, existe un déficit importante en la aplicación del sistema» (Villa Sánchez \& Poblete Ruiz, 2007, p. 40).

A partir de la perspectiva de estos autores (De Miguel Díaz, 2006; de Miguel Díaz, 2010; Villa Sánchez \& Poblete Ruiz, 2007, 2009), señalaremos en la tabla 3.4 las características y funciones renovadas del proceso de evaluación por competencias en contraste con la evaluación tradicional.

Tabla 3.4 Funciones de la evaluación basada en competencias*

\begin{tabular}{|c|c|}
\hline EVALUACIÓN TRADICIONAL & EVALUACIÓN BASADA EN COMPETENCIAS \\
\hline Evaluación limitada & Evaluación auténtica \\
\hline Evaluación conforme a la norma & Evaluación conforme al criterio \\
\hline Profesor único responsable de la evaluación & Responsabilidad compartida de la evaluación \\
\hline Evaluación final y sumativa & Evaluación continua y formativa \\
\hline Evaluación mediante un único procedimiento & Evaluación variada y múltiple \\
\hline
\end{tabular}

* Adaptada de Mario de Miguel (2006) 
Veamos más pormenorizadamente una descripción de cada una de las funciones que cumple le evaluación en los procesos de formación por competencias, enumeradas en la tabla anterior:

- Evaluación auténtica: Si las competencias tienen que ver con las capacidades efectivas para el desempeño personal y/o profesional en la vida, la evaluación de las mismas no puede ser un hecho puntual, sino «un acto planificado, integral y pertinente a las competencias a alcanzar» (De Miguel Díaz, 2006, p. 54). Así, la evaluación auténtica consiste en presentar al alumno situaciones problemáticas que podría encontrarse la vida real en cuya resolución tiene que desplegar un determinado repertorio de competencias y sus sub-componentes.

- Evaluación conforme al criterio: No tiene sentido que las calificaciones de los alumnos estén organizadas en función del rendimiento de los compañeros. Con la formación basada en competencias, cada una de ellas debe tener específicamente establecidos los niveles de desempeño que se consideran adecuados. Estos criterios serán el referente que oriente la calificación del alumno.

- Responsabilidad compartida de la evaluación: Mientras que tradicionalmente era el profesor el que llevaba el peso y la responsabilidad completa de la evaluación, en la formación basada en competencias el aprendizaje del alumno implica un rol activo de éste. Así, cobran especial relevancia estrategias de evaluación (como la evaluación por pares o la autoevaluación) que hacen más responsable y consciente al alumno del desarrollo de su propio aprendizaje y el del grupo.

- Evaluación continua y formativa: En la evaluación tradicional, el objetivo primordial de la evaluación era certificar el nivel del alumno al finalizar una etapa. Mientras que esta función sigue teniendo una gran importancia, aparecen otras utilidades propias a la evaluación, como son la función continua y formativa. Así, se deben integrar dentro del proceso de enseñanzaaprendizaje actividades de evaluación que presten al alumno y al propio proceso el necesario y continuo feed-back sobre los logros y dificultades encontrados. De este modo, una evaluación continuada va orientando a los actores participantes en el proceso (profesor y alumno) en sus decisiones estratégicas. 
- Evaluación variada y múltiple: Tanto las competencias, como sus componentes son muy diversos, y como tal, se les debe acompañar de estrategias y técnicas de evaluación de diferente naturaleza e incluso de manera combinada. Así, durante el proceso formativo se emplearán multitud de procedimientos evaluativos tanto al iniciarse (evaluación de conocimientos previos o inicial), como durante el desarrollo (evaluación continua y formativa o procesual) y al finalizar (evaluación sumativa o final). La elección de las actividades evaluativas debe planificarse de modo conjunto, dando un sentido global a todo el proceso de evaluación.

En suma, podemos concluir este subapartado indicando que, en contraste con la evaluación tradicional, que es más cuantitativa, puntual, resultadista y unidimensional, con la formación basada en competencias se propone una evaluación más comprensiva, continua, variada y multidimensional.

Este hecho, junto con el resto de características y estructuras inherentes a las competencias, todo ello señalado más arriba, fundamenta nuestro punto de vista acerca de la renovación pedagógica que debería suponer la introducción de planes de estudio centrados en competencias. Así mismo, podemos concluir que la propia configuración interna de la formación basada en competencias le confiere un plus de adaptación, en contraste con otros sistemas, al nuevo contexto formativo comandado por la sociedad de la información y caracterizado por la búsqueda de la senda de la sociedad del conocimiento. 


\subsection{Las competencias informacionales. Competencias básicas para la sociedad del conocimiento}

Una vez analizados pormenorizadamente todos los aspectos relevantes que rodean al concepto de competencia, y propuesto un modelo formativo basado en competencias que se adapte a dicho concepto, estamos en condiciones de centrarnos más específicamente en el tema que aquí más nos interesa, que no es otro que las competencias informacionales. Ya hemos puesto de manifiesto previamente el consenso existente sobre considerar esta competencia como básica en la sociedad de la información.

Ya aclaradas estas nociones previas, totalmente necesarias para llegar hasta este punto en condiciones adecuadas, estamos preparados para describir qué es eso de competencias informacionales, cómo y porqué surgen, qué dimensiones se les atribuyen, etc. Procedamos pues a la disección del concepto a analizar.

\subsubsection{Las competencias informacionales, nuevas competencias en la sociedad contemporánea}

El impacto producido por la integración de las TIC en todos los procesos humanos, transforma los modos de proceder y las propias estructuras económicas, sociales y culturales (Castells, 1999a; Majó i Cruzate \& Marqués, 2002).

Concretamente, desde la aparición de estas tecnologías, que fomentan y optimizan la gestión y manejo de la información, la relación e interacción del hombre con la información exige una transformación profunda. Las TIC han roto los esquemas de acceso, búsqueda, uso y publicación de la información, y han generado, además, nuevos canales de comunicación y nuevas fuentes de información (Fernández, Zayas, \& Urra, 2008). E internet es, por méritos propios, la innovación relacionada con las TIC que más importancia tiene en este aspecto, en cuanto a que incrementa la información, la diversifica y promueve una localización distribuida (Hernández Serrano \& Fuentes Agustí, 2011).

"The internet has been the key driver of this paradigm shift because it has made possible the transition from analogue to digital information, and this has affected how knowledge is produced and disseminated through the effect of the internet 
means that this knowledge is more widely accessible than ever before» (Jones \& Goff, 2011, p. 11)

En todo caso, esta concepción actual de una red mundial en la que personas de todo el mundo están interconectadas, pudiendo intercambiar y acceder a información presente en enormes fuentes del conocimiento no es del todo nueva. Podemos encontrar visos de esta idea desde los escritores de ciencia ficción del siglo XIX hasta la actualidad (Miraut Andrés, 2011):

- Julio Verne (1863), en "París en el siglo XX", una de sus primeras novelas, ya describe un futuro muy similar al nuestro en el que existe una red telemática mundial muy similar a lo que hoy entendemos por internet.

- Otro dramaturgo famoso más actual, George Wells, desarrolla durante los años 1936 y 1938 una serie de ensayos conocidos como "World Brain", que desarrolla la idea del autor sobre la posibilidad de elaborar una Enciclopedia Mundial que reuniera, ordenara, clasificara y comparara el conjunto de todos los conocimientos que el ser humano poseyera. Esta enciclopedia se distribuiría entre los estudiantes a través de "microfilms", que reproducirían una copia exacta de cualquier libro o documento. Esta idea de digitalizar los documentos se asemeja a la actual digitalización de la información.

- Otros autores como Murray Leinster (1946), en "Un lógico Ilamado Joe", o Marta Green (1956), en "Ozonis - en algún lugar del Universo" también desarrollan ideas de un futuro en el que existen sistemas a través de los que las personas pueden comunicarse y compartir información a tiempo real a lo largo de todo el planeta.

Sin embargo, como señala el propio Miraut (2011):

«Quizá el escritor de ciencia ficción cuya visión ha descrito con mayor hacierto las posiblidades que pone a nuestra disposición la tecnología es Isaac Asimov. Entre los años 1974 y 1980, publicó una serie de artículos en los que vislumbraba una nueva concepción del trabajo. Las casas, empresas y bibliotecas estarían conectadas a través de fibra óptica; los trabajadores en sus casas podrían supervisar el trabajo de las máquinas ayudados por una interfaz de pantallas; dicha interfaz también les permitiría acceder a cualquier libro, revista, panfleto o documento para referencias rápidas e imprimirlo para referencias más pausadas; e incluso dar conferencias por circuito cerrado con cada participante sentado tranquilamente en su casa.» (p. 245) 
Volviendo la mirada hacia la actualidad, parece como si las ideas más o menos delirantes de estos soñadores se han hecho realidad, o incluso han superado a la propia ficción: El avance de las TIC ha permitido a muchos ciudadanos de todo el mundo tener a su alcance un repositorio con la mayor parte de los conocimientos de la humanidad disponibles, proyectos como la Wikipedia han hecho posible el sueño de Wells de la Enciclopedia Mundial, actualizada día a día, editores gobiernos y empresas a nivel mundial se han lanzado a la digitalización de todos los archivos para hacer más sencilla y fácil su consulta,...

Así, aunque la irrupción de esta realidad no ha pillado a muchos por sorpresa, el hecho es que el mundo de la educación no se ha sabido adaptar a las nuevas necesidades que se estaban gestando desde hace tiempo y que han aparecido en la actualidad, y hoy en día se encuentra con el difícil reto de abarcar las reformas pertinentes para incorporarse efectivamente al nuevo contexto.

Cierto es, que debido a la existencia de gran cantidad de información poco válida y confiable en internet, ha surgido un núcleo de profesores preocupado por desarrollar acciones formativas encaminadas a ayudar a los jóvenes a mejorar sus búsquedas en internet, ya que sus aprendizajes pueden estar basados en informaciones incorrectas (Leguízamo León \& García Carrasco, 2011). Sin embargo, los datos indican que esta preocupación es insuficiente.

La omnipresencia de internet en la vida de nuestros jóvenes es hoy por hoy incuestionable (Amat, 2011), sin embargo, las instituciones educativas no le han dedicado la atención que se merecía, y el aprendizaje en lo que respecta a las habilidades de uso de internet es meramente informal. Las consecuencias pueden ser perversas, ya que, a pesar de la creencia de los políticos, asesorados por las grandes corporaciones proveedoras de material informático, de que la mera exposición a la tecnología logrará desarrollar jóvenes competentes en el manejo de la información, las investigaciones llevadas a cabo hasta la fecha sugieren que el aumento de la información disponible no se traduce automáticamente en mayores conocimientos y en una mejor comprensión del mundo (Amat, 2011; Hernández Serrano \& Fuentes Agustí, 2011; Martí Lahera, 2007; Miraut Andrés, 2011).

Algunas investigaciones que ejemplifican esta afirmación (Hernández Serrano, 2009; Rowlands, 2008), muestran cómo los jóvenes se encuentran con grandes dificultades tanto a la hora de evaluar sus propias necesidades de información, como 
cuando diseñan e implementan estrategias de búsqueda, evaluación y procesamiento de información.

Parece que el dominio de estrategias concretas y la capacidad para diseñar y ejecutar planes estratégicos a la hora de implementar un proceso de manejo y gestión de la información, es un elemento determinante del éxito o fracaso del proceso emprendido. Así, podemos señalar algunas investigaciones al respecto:

- Fuentes y Monereo (2008), presentan una investigación en la que tras el análisis de los perfiles de búsqueda de información en internet de alumnos de ESO, detectan 4 perfiles en función de 2 variables: La primera la capacidad estratégica en función de la tarea y la segunda los conocimientos tecnológicos sobre las diversas fuentes y herramientas relacionadas con la gestión y manejo de la información y su funcionamiento. Se concluye que los mejores buscadores o los buscadores más eficientes son los que dominan conjuntamente las dos variables.

- Hernández Serrano (2011; 2009), demuestra que los alumnos del ámbito universitario que actúan poco estratégicamente son menos eficientes que los que sí lo hacen. Así, se apunta hacia que son necesarios tanto conocimientos tecnológicos como estratégicos. Se observa cómo los conocimientos previos sobre la temática de la tarea propuesta también influyen significativamente en el resultado final o nivel de desempeño obtenido.

De este modo, se vislumbra la evidencia de que es necesario un entrenamiento de los estudiantes en ciertos procedimientos estratégicos, además de proveer formación técnica en herramientas específicas, para ayudarles a que mejoren en sus procesos de gestión y manejo de la información y que, por ende, tengan mejor cubiertas sus propias necesidades informacionales. Los educadores debemos formar en torno a una serie de estrategias que lleven al desarrollo de competencias para «acceder de forma eficiente a la información en línea, lo que permitirá satisfacer de manera coherente las necesidades y propósitos informacionales» (Hernández Serrano \& Fuentes Agustí, 2011, p. 68).

Y todo este conjunto de estrategias vislumbradas por las investigaciones mostradas no son otras que las sub-competencias y elementos que conforman lo que hemos venido a denominar competencias informacionales. Unas competencias en su gran parte novedosas, procedentes muchas veces de las nuevas alfabetizaciones que 
han asaltado y determinan el funcionamiento y la estructura actual de todos los contextos humanos. Unas nuevas competencias que, evidentemente, suponen nuevos contextos culturales que exigen personas que las dominen en respuesta a las necesidades vitales y del mercado laboral (Federighy, 2006). "Las habilidades que se exigen en la era electrónica con de magnitud diferente a las de la época de la imprenta» (Gómez Hernández \& Benito Morales, 2001, p. 55), ahora es necesario tener habilidades en el manejo y gestión de la información que nos permitan utilizar con eficiencia la infinita información disponible. De hecho, en el ámbito laboral las competencias informacionales son parte de un conjunto de competencias básicas y laborales que se espera traiga consigo cada profesional que se integra a una organización concreta.

«Some of the knowledge, skills, abilities, competencies and personal characteristics that were necessary for life in previous centuries have now become irrelevant, while others have become critical» (Markauskaite, 2006)

La existencia de la necesidad de estas nuevas competencias, unido al axioma de la sociedad líquida (Bauman, 2006, 2007), genera entornos formativos volubles en los que las personas necesitan de una formación flexible, dinámica, que permita el aprendizaje, el desaprendizaje y el reaprendizaje (Ruiz, 2005). Entornos que requieren, por tanto, de enseñanzas más instrumentales que conceptuales, que formen a las personas para que puedan aprender a aprender a lo largo de su vida, adaptándose así a los continuos cambios sociales (Area Moreira, 2005; Calderón Rehecho, 2010; Majó i Cruzate \& Marqués, 2002).

En un momento en el que ya disponemos de una gran parte de la población habituada al uso de las tecnologías disponibles, parece que hemos empezado a comprender que la base del crecimiento económico y social se sustenta en la generación, difusión y aplicación del conocimiento (Fernández et al., 2008). Y para ello se necesitan personas con habilidades para trabajar con la información adecuada en el formato en el que se encuentre, que sepan cómo localizar la información que necesitan, qué hacer con ella y cómo generar conocimiento y aplicarlo de forma efectiva.

La definición de estas nuevas competencias en los currículos y planes de estudio tanto de la educación básica como de la educación superior, conlleva una nueva cultura educativa que contrasta con la cultura que se ha venido desarrollando y perpetuando en la época industrial. Se trata de evolucionar desde una cultura del 
contenido hasta una cultura del aprendizaje o cultura informacional (Bolívar Botía, 2009; Martí Lahera, 2007; Monereo \& Coll, 2008; Pozo et al., 2006). Se debe superar la barrera que supone concebir que educar es aprender una cultura (Pozo et al., 2006), más bien lo que se debe fomentar una cultura del aprendizaje acorde con las características de la sociedad de la información, que motive a la persona a aprender constantemente y a participar en los procesos sociales.

Esta nueva cultura informacional, vinculada al desarrollo de competencias informacionales, es la base que apoya y fundamenta el camino desde la sociedad de la información hasta la sociedad del conocimiento (Martí Lahera, 2007; Pinto Molina et al., 2008).

En este contexto, la información pasa de poseer un valor meramente instrumental a ser en sí misma un valor económico que se acrecienta. Esto quiere decir que el concepto de información se modifica radicalmente. Ahora la información no es algo objetivo, externo al propio usuario, estático y tangible, sino que pasa a considerarse que una información puede tomar diferentes sentidos en función del usuario y sus intereses. Así, la información, desde la perspectiva de la cultura para el aprendizaje, pasa a ser considerada como una realidad subjetiva, cognitiva y contextual. En consecuencia:

\footnotetext{
«la idea de que un sistema de información, por definición, es capaz de proporcionar la respuesta más pertinente sin considerar la situación del usuario final es desechada a favor de la idea de que el usuario y su contexto determinan el valor de la información proporcionada por un sistema» (González Teruel, 2011, p. 34)
}

En suma, parece esencial señalar a partir de todo lo comentado en este apartado, que la sociedad está demandando ciudadanos formados en competencias informacionales, y que las propias personas necesitan de estas competencias para desarrollarse de manera íntegra en la sociedad. Así, aceptando la hipótesis de la importancia básica de las competencias informacionales, abogamos por la asunción de una nueva cultura educativa y social que permita el adecuado desarrollo de las mismas.

\subsubsection{Aspectos básicos sobre las competencias informacionales}

Antes de desarrollar una definición de competencias informacionales que aporte una idea más clara sobre el punto de vista desde el que nos enfrentamos al concepto, 
creemos que es necesario analizar ciertos elementos que le rodean. En primer lugar, al igual que otros autores, queremos expresar nuestra preferencia por el término competencias informacionales sobre otros empleados que se analizarán más adelante, tanto por la emergencia y afianzamiento en todos los niveles de la educación del término competencia (Blasco Olivares \& Durban Roca, 2012), como por las implicaciones inherentes al término informacional (Area Moreira \& Guarro, 2012; Area Moreira, 2010a; Bawden, 2001; CRUE-TIC \& REBIUN, 2009).

Así, en primer lugar nos gustaría hacer una aclaración terminológica, que indique el porqué del empleo de los términos "competencia" e "informacional" y no de otros como "alfabetización", "informática", "digital”, etc., muy empleados en la literatura especializada. Analicemos pues, ambos términos por separado.

Competencia: Si observamos el estado de la cuestión en lo que se refiere al tema general de nuestro trabajo, rápidamente nos percatamos de que la acepción empleada más habitualmente en la literatura es "alfabetización" y no "competencia". Este predominio se debe al nacimiento y evolución del propio concepto. La noción de competencias informacionales evolucionó en el seno de estudiosos del ámbito de la Biblioteconomía y las Ciencias de la Información, área alejado de las Ciencias de la Educación. En este contexto, se asumió la acepción "information literates" que empleó el propio Zurkowski (1974), autor al que se le atribuye el nacimiento de este concepto.

El hecho de que nosotros defendamos el empleo del término competencia en lugar del otro tiene su fundamento en razones pedagógicas. Como hemos analizado en el anterior capítulo, nuestra concepción de alfabetización enraíza con la teoría de la pedagogía crítica o pedagogía de la liberación de Paulo Freire $(1974,1975)$, y por lo tanto tiene una dimensión funcional y social, de construcción comunitaria de significados. Las habilidades de manejo y gestión de la información, por su parte, tienen, como hemos señalado anteriormente, una naturaleza instrumental, vinculada a la acción concreta en un contexto determinado.

Por tanto, consideramos que no son realidades comparables, y que las habilidades y estrategias relacionadas con la búsqueda, evaluación, procesamiento y difusión de la información son en sí mismas competencias. Unas competencias, que unidas al desarrollo de otro amplio abanico de ellas, permitirán a la personas estar funcionalmente alfabetizadas en los distintos lenguajes expresivos, dando acceso a éstas a una participación activa y significativa en su contexto cultural concreto. De hecho, podríamos afirmar que «la multialfabetización no es más que una constelación 
clave de competencias para el hoy y para el mañana» (Pasadas Ureña, 2010a, p. 23), y por tanto, la informacional es una competencia clave y no una alfabetización propia del mapa de alfabetizaciones.

Informacional: En cuanto al empleo del término "informacional", el consenso es mayor entre los estudiosos del término. Sin embargo, en este caso ocurre al contrario que en el anterior, ya que mientras esta acepción es aplicada prácticamente por la totalidad de los expertos en Biblioteconomía y Ciencias de la Información, en Ciencias de la Educación, el término que se puede localizar en más ocasiones es "digital". En el ámbito español, esto parece tener un respaldo institucional, ya que se observa cómo tanto en el currículo oficial como en las enseñanzas mínimas (Boletín Oficial del Estado, 2007a, 2007b), mientras que se hace referencia al concepto "competencia digital" como competencia básica, el tratamiento de la información se trata como una habilidad, esquivando en todo momento el considerarlo como competencia.

«la pretensión de que el alfabetismo digital incluye e integra otros alfabetismos como el informacional, visual, etc. no deja de plantear serias dificultades para su aceptación como marco de los demás alfabetismos, puesto que en buena lógica el alfabetismo digital no existiría como tal o existiría referido estrictamente al tipo de soporte utilizado» (Pasadas Ureña, 2008, p. 70)

Bajo nuestro punto de vista, el término digital tiene unas implicaciones más vinculadas al propio objeto que al objetivo que pueden ser un poco perversas. Parece como si siguiéramos pensando en implicar la tecnología como un fin en sí misma y no como un medio para alcanzar los verdaderos objetivos educativos. Como indica Area Moreira, "La información es el contenido; lo digital, su continente [...] La tecnología digital cobra sentido, significación y utilidad social porque nos proporciona experiencias valiosas con la información» (Area Moreira, 2010a, p. 2). Las competencias digitales implican todo lo relacionado con el manejo instrumental de las herramientas informáticas, y las competencias informacionales tienen que ver más con el aspecto de manejo de la información mediado por estas y otras herramientas (Pinto Molina \& Uribe Tirado, 2012).

Por tanto, el concepto digital pone más énfasis en el instrumento, el continente, las TIC, que digitalizan la información. Sin embargo, el concepto informacional pone el punto de mira principalmente en la gestión y tratamiento de la información que se encuentra detrás de estos instrumentos, en el contenido (Monereo \& Coll, 2008). Así, «parece lógico y conveniente que la competencia informacional disponga de una articulación propia que no debe confundirse con la determinada para la competencia 
digital, sin obviar, por supuesto, que ambas comparten una parte importante de su contenido» (Blasco Olivares \& Durban Roca, 2012, p. 106).

La inclusión de la acepción digital, «aplicado acríticamente a casi cualquier cosa sirve para otorgar marchamo de modernidad y excelencia» (Pasadas Ureña, 2008, p. 70). Es evidente, por tanto, que el término tiene implicaciones mercantilistas $y$ comerciales, por lo que se debe desechar e imponer otro más incluyente, que tenga en cuenta varios elementos (Cabero Almenara \& Alonso García, 2007):

- El manejo técnico de las tecnologías.

- El dominio de las competencias para la búsqueda, evaluación, procesamiento y difusión de la información.

- La formación crítica que desarrolle valores y actitudes hacia la tecnología, evitando así la tecnofilia o la tecnofobia.

- La formación para que las personas utilicen las TIC más que como objetos de ocio y consumo, como medios para el conocimiento compartido, la expresión y la comunicación con otras personas.

Por otra parte, existen también otros términos en la literatura que se emplean muchas veces como sinónimos, como son competencia informática, competencia en internet o competencia en medios (Bawden, 2001). Desde nuestro punto de vista, no se pueden igualar los ordenadores o las herramientas informáticas (físicas o no físicas) a lo que es la información, y por tanto estos anteriores términos no pueden ser sinónimos de competencias informacionales. De hecho, podríamos decir que las competencias informáticas, en internet y en medios son condiciones necesarias pero no suficientes para las competencias informacionales (Bawden, 2001). Lo que parece claro es que la situación actual tan interrelacionada nos lleva a pensar que «cuando el individuo pasa de consumidor de información a productor de contenidos, las fronteras entre las distintas alfabetizaciones, informacional, media, digital, informática o tecnológica, se vuelven borrosas» (González Fernández-Villavicencio, 2012, p. 35).

Podríamos acabar esta disertación mostrando, en la figura 3.3, nuestra simple visión sobre la relación existente entre todas estas competencias, que parte de las ideas de David Bawden (2001). 


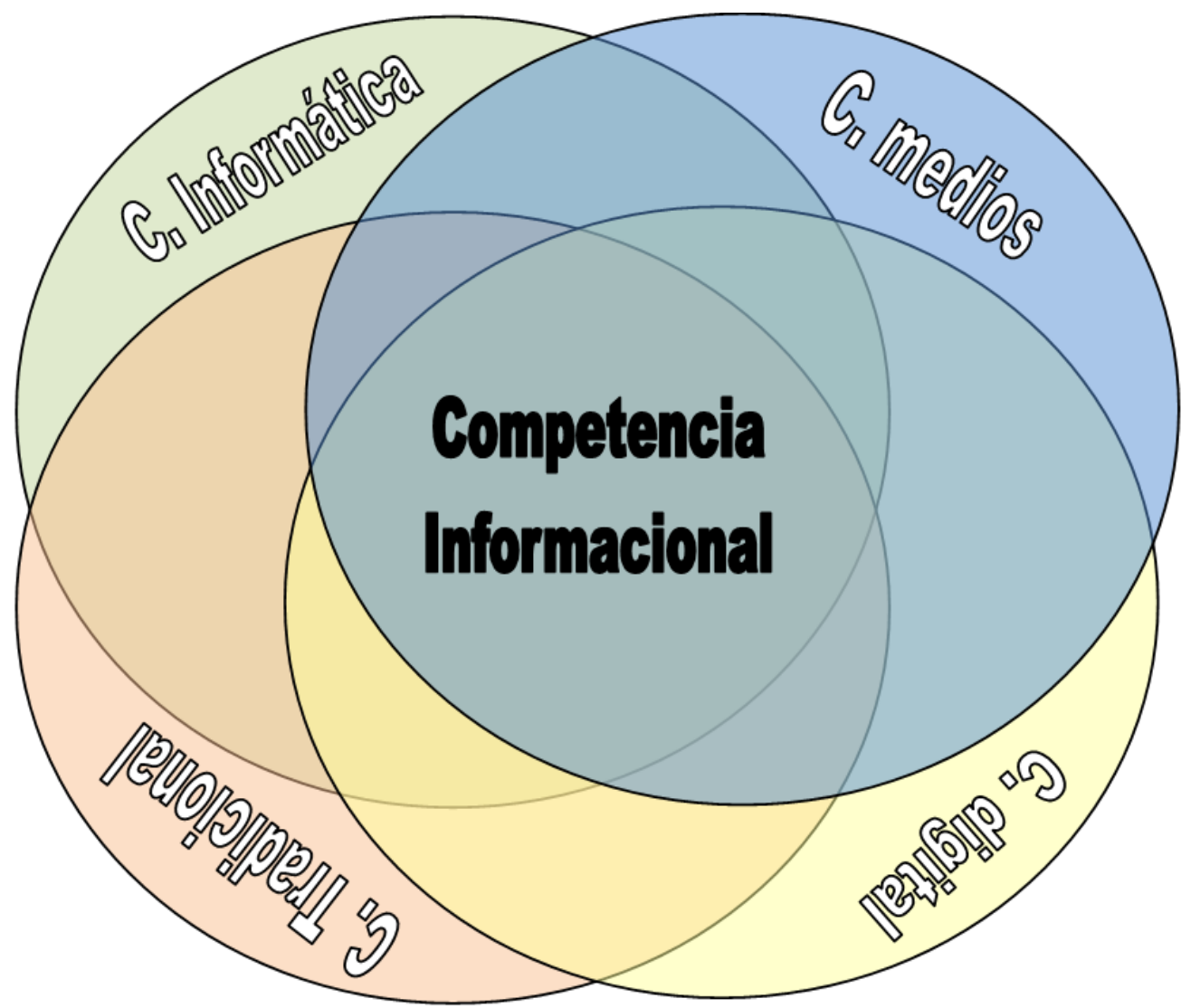

Figura 3.3 Sociedad de la información vs. sociedad del conocimiento

De este modo, las competencias informacionales son unas competencias básicas que aglutinan un buen número de sub-competencias, como son la Competencia Informática, Competencia en Medios, Competencia Digital o Competencia Tradicional, entendida como el conjunto de habilidades relacionadas con la gestión y manejo de la información a través de medios analógicos. Como resume Weiner, las competencias informacionales son «the umbrella term for emerging literacies such as technology literacy, media literacy and health literacy» (2010).

\subsubsection{Definición de competencias informacionales}

Veamos, antes de lanzarnos a la búsqueda de una definición consensuada, una breve referencia histórica sobre el desarrollo del concepto Alfabetización Informacional desde que Paul Zurkowski (1974) lo citara por primera vez hasta la actualidad, en la que decidimos optar por la acepción competencias informacionales.

En un primer momento, como ya hemos señalado, es Paul Zurkowski el primero que habla de Information Literacy, al percatarse de que con el nacimiento del hipertexto, la naturaleza del texto mismo se modifica, perdiendo este su linealidad y modificándose el mismo soporte. Así, la existencia de un nuevo soporte que presenta 
el texto de manera diferente, multimodal, más dinámica e interconectada, supone que las personas deban conocer y estudiar los nuevos mecanismos de organización del conocimiento y en los que se presenta la información (Martí Lahera, 2007).

Adentrándose en la definición del concepto y desde dónde se origina su difusión, la alfabetización en información proviene del término anglosajón "Information literacy" que promociona Paul Zurkowski en 1974, al publicar los resultados de su investigación, en un informe en el que define la information literacy como un tipo de preparación necesaria en los profesionales, una herramienta para la generación de conocimiento a base del manejo de procesos relacionados con la información. En dicha investigación el autor planea que un porcentaje muy pequeño de la población contaba con esa preparación

«People trained in the application of information resources to their work can be called information literates. They haved learned techniques and skills for utilizing the wide range of information tools as well as primary resources in molding information solutions to their problems» (Zurkowski, 1974, p. 6)

La traducción de Information literacy a la conocida Alfabetización Informacional la realiza José Antonio Gómez Hernández en 1998 (Gómez Hernández, 2007) y el acrónimo ALFIN lo propone Benito Morales (1996). La traducción de Gómez Hernández ha sido la más aceptada, sin embargo, el concepto ha sido cuestionado, como se ha comentado en los apartados anteriores, tanto por su denominación al incluir la palabra alfabetización, como también por las implicaciones e incorporación efectiva en el ámbito educacional. La discusión por la denominación del concepto se ha centrado principalmente en la palabra alfabetización por ser un concepto incorporado y aceptado en la conciencia colectiva como aprender a leer y escribir. Hoy en día este conflicto ha cambiado de perspectiva al nacer las alfabetizaciones múltiples o multialfabetizaciones.

Una vez analizados todos los detalles que rodean a las competencias informacionales, podemos acercarnos a una definición más específica, clara y global del término.

La mayoría de autores consultados estudiosos de las competencias informacionales (Andretta, 2007; Koltay, 2009; Pinto Molina et al., 2008; Wen \& Shih, 2008) aluden, al referirse a su significado, a la definición clásica de la American Library 
Association (ALA) (1989): «Recognize when information is needed and have the ability to locate, evaluate and use effectively the needed information» (p. 1).

La práctica totalidad de las definiciones al respecto que surgen a partir de ésta, mantienen los ejes que instaura. Así, por ejemplo, podemos encontrarnos un buen número de autores e instituciones que se acercan a este concepto:

Alex Byrne señala que «es la capacidad de acceder, valorar y utilizar la información de manera eficaz en la vida diaria» $(2005$, p. 15)

Por su parte, Bundy añade que son «an understanding and set of abilities enabling individuals to recognize when information is needed and have the ability to define, locate, evaluate and use effectively the needed information» $(2004$, p. 3).

En la Declaración de Praga (NCLIS, 2003), se señala que «la alfabetización informacional comprende el conocimiento y necesidades de los individuos y la habilidad para identificar, localizar, evaluar, organizar y crear, utilizar y comunicar información eficazmente para enfrentar aspectos o problemas» y añade que "debe ser una parte integral de la educación para todos, lo que puede contribuir en forma crítica al cumplimiento de las Metas de Desarrollo del Milenio de las Naciones Unidas»

Un poco más cerca en el tiempo, en la Declaración de Alejandría (National Forum of Information Literacy, 2005), se observa que la alfabetización informacional «Capacita a la gente de toda clase y condición para buscar, evaluar, utilizar y crear información eficazmente para conseguir sus metas personales, sociales, ocupacionales y educativas.» Así, esta "incluye las competencias para reconocer las necesidades de información y para localizar, evaluar, aplicar y crear información dentro de contextos sociales y culturales» (p. 1).

El presidente de la Sección de Habilidades Informativas de la Federación Internacional de Asociaciones de Bibliotecarios e Instituciones (IFLA), Jesús Lau, junto con Ralph Catts, señalan más recientemente que «es la capacidad de las personas para reconocer sus necesidades de información, localizar y evaluar la calidad de la información, almacenar y recuperar información y aplicar la información para crear y comunicar conocimiento» (2009, p. 8). 
En el ámbito de nuestro país nos encontramos con autores reconocidos como la Catedrática de Información y Documentación de la Universidad de Granada, María Pinto, que define el concepto del siguiente modo:

«la Alfabetización Informacional es, en síntesis, una capacidad de comprender y un conjunto de habilidades y competencias que capacitan a los individuos para reconocer cuándo se necesita información, así como poseer la capacidad de localizar, evaluar y utilizar eficazmente la información requerida» (2008, p. 95).

Pasadas Ureña, por su parte, señala que la Alfabetización Informacional es el "alfabetismo que capacita, en los niveles requeridos para cada estadio educativo, para el acceso, uso y producción de contenidos y significados a través del modo, medio y soporte más adecuado al diseño seleccionado para el mensaje a comunicar, pero dando prioridad a una verdadera alfabetización informacional crítica centrada en la fase de producción de significados por parte de una ciudadanía activa» (2008, p. 59).

Otro destacado estudioso español Félix Benito, aporta una definición que se aparta las anteriores visiones, ya que es presentada desde una perspectiva más educativa $(2008$, p. 161$)$ :

«Es un paradigma teórico orientado a potenciar las buenas prácticas de modelos formativos para aprender, en espacios educativos formales o no formales, como las bibliotecas, desde una triple perspectiva:

- Cognitiva, para que el aprendiz modele un pensamiento crítico para cuestionar razonamientos, hacerse preguntas y buscar respuestas, y adquiera estrategias en el manejo de información, para planificar y supervisar el propio trabajo intelectual.

- Emocional, para que el aprendiz desarrolle hábitos y actitudes que mantengan su inquietud por aprender cuando haya terminado su formación académica.

- Ética, para que el aprendiz comprenda la problemática relacionada con el uso indiscriminado de materiales informativos, con temas como el plagio o la propiedad intelectual, y sea consciente de los peligros de las nuevas formas de comunicación en Internet.»

Por último nos encontramos con la definición desarrollada por la Conferencia de Rectores de Universidades Españolas y la Red de Bibliotecas Universitarias, más actualizada que las anteriores y que más se adapta mejor a nuestros presupuestos 
teóricos y a los objetivos de nuestra investigación. Por lo tanto será la que adoptemos a partir de este momento.

«Las competencias informacionales son el conjunto de conocimientos, habilidades, disposiciones y conductas que capacitan a los individuos para reconocer cuándo necesitan información, dónde localizarla, cómo evaluar su idoneidad y darle el uso adecuado de acuerdo con el problema que se plantea» (CRUE-TIC \& REBIUN, 2009, p. 7)

Desde la perspectiva que presenta esta definición, se pueden señalar las competencias informacionales como la adquisición de las habilidades siguientes:

- El estudiante es capaz de buscar la información que necesita.

- El estudiante es capaz de analizar y evaluar la información de manera crítica y autónoma.

- El estudiante es capaz de organizar la información de manera adecuada.

- El estudiante es capaz de utilizar y comunicar la información eficazmente de forma ética y legal, con el fin de construir conocimiento.

De este modo, después de todo lo expuesto a lo largo de estos primeros apartados, parece claro que el desarrollo de competencias relacionadas con el manejo de información y la generación de conocimiento son aprendizajes claves en el contexto de la sociedad de la información. Clave en dos sentidos: En primer lugar, en el sentido de que las personas que no desarrollen este tipo de competencias tendrán graves dificultades para incorporarse efectivamente a la sociedad de la información, ya que los estudios empíricos han demostrado que el simple hecho de disponer de tecnología no implica la equidad de oportunidades y de competencias en TIC (Castaño-Muñoz, 2010); y en segundo lugar, en el sentido de que el simple desarrollo de competencias técnicas en el manejo de las tecnologías propias de esta sociedad sin tener en cuenta su contenido (Area Moreira, 2010a) y los procesos sociales en los que están inmersas (Hargittai, 2010), no previene de los riesgos que surgen en la misma, como la brecha del conocimiento, la infoxicación o el analfabetismo funcional. 


\subsubsection{Organización de las competencias informacionales. Dimensiones, modelos y normas}

Como hemos ido analizando en la mayor parte de las definiciones mostradas anteriormente, podemos considerar que las competencias informacionales, competencias básicas en la sociedad actual, se desarrollan en sub-competencias repartidas en una serie de dimensiones o campos de acción determinados. De hecho, esta es la razón por la que hacemos referencia a las competencias informacionales en plural, ya que entendemos que engloban una serie de competencias de menor rango, con una organización concreta que vamos a indicar a continuación.

Desde nuestro punto de vista, partiendo de la definición que nos hemos apropiado, y desde la que nos acercamos a las competencias informacionales, podemos considerar que este concepto abarca y se estructura en base a cuatro dimensiones básicas:

- La persona es capaz de buscar la información que necesita. Nos encontramos así con una dimensión que podríamos denominar "búsqueda de información", que no es otra cosa que conocimiento de la terminología específica de la materia que se está estudiando o la realidad que se está abarcando, la capacidad para utilizar fuentes de información de todo tipo (libros y revistas impresas, bases de datos informáticas, catálogos de bibliotecas, etc.), y las habilidades en el empleo de estrategias específicas que ayuden en la labor de la búsqueda de información (empleo de buscadores especializados, búsqueda avanzada, etc.).

- La persona analiza y evalúa la información de manera crítica y autónoma. En esta categoría podríamos agrupar la dimensión "evaluación de información", que incluye competencias tan diversas como saber evaluar la calidad de los recursos encontrados y si estos están o no actualizados, identificar el tipo de documento que se ha encontrado (artículo en revista científica, artículo de divulgación, tesis doctoral, foro de opinión, etc.), 
conocer los autores o instituciones más relevantes en el ámbito de estudio y actuar en consecuencia, o ser capaz de reconocer las principales ideas del autor en el texto.

- La persona tiene capacidad para organizar la información de manera adecuada. Este apartado se refiere a la dimensión que podríamos denominar "procesamiento de información", que no es otra cosa que el desarrollo de competencias para reconocer la estructura propia de un texto, ser capaz de resumirlo y esquematizarlo y saber manejar diferentes herramientas que faciliten la gestión de la información (gestores de bases de datos y de referencias bibliográficas, software para el análisis matemático y estadístico, etc.).

- La persona utiliza y comunica la información eficazmente de forma ética y legal, con el fin de construir conocimiento. A esta última dimensión podría tomar como nombre la "comunicación y difusión de información", haciendo referencia al conjunto de competencias que posibilitan redactar un documento y/o una presentación académica con una estructura y complejidad conforme a las características de los receptores, a la capacidad de comunicar en público tanto en el propio idioma natal como en otros, al conocimiento de la propia legislación sobre el uso de la información y del código ético del ámbito académico/profesional en el que se está inmerso y al domino de herramientas que posibilitan la difusión de la información deseada en diversos medios, sobre todo por internet (webs, blogs, redes sociales, ...).

De esta manera, durante el proceso de recogida, análisis e interpretación de datos que llevemos a cabo a lo largo de esta investigación se tendrán en cuenta estas dimensiones teóricas y se tratarán de validar a través de la aplicación de las técnicas estadísticas que se consideren más oportunas.

Y es dentro de esta organización característica de las competencias informacionales en donde nacen las normas o estándares para las competencias informacionales. Estas normas tratan de aglutinar el conjunto de sub-competencias 
que reúne la competencia básica, desplegándose en indicadores de rendimiento y en resultados observables y evidenciables de su consecución.

De hecho, mientras que algunos autores destacan la importancia de estas normas: «The establishment of standards for information literacy competence plays an important role in elevating teachers' information literacy abilities» (Wen \& Shih, 2008, p. 795), otros las critican por no ser adaptativas a los diversos contextos: «Las personas producen, leen e interpretan textos dentro de comunidades y no de manera individual [...] Por lo tanto, la alfabetización no puede describirse en términos generales como un grupo de habilidades universales y procesos abstractos» (Elborg, 2008, p. 106).

A pesar de este debate, lo cierto es que el esfuerzo de las instituciones que han llevado a cabo mapas completos de las competencias informacionales es innegable, recogiendo todas estas normas «la habilidad para recoger una necesidad de información y la capacidad para localizar, evaluar, almacenar, recuperar y aplicar la información y para comunicar nuevo conocimiento» (Catts \& Lau, 2009, p. 15). Lo que esto quiere decir, es que estas normas se adaptan con bastante fidelidad a las cuatro dimensiones teóricas que nosotros hemos propuesto en nuestro modelo de definición de las competencias informacionales.

El comienzo de la redacción de estas normas se desarrolló a finales de los años 80 del siglo XX en el contexto bibliotecario de Estados Unidos (Catts \& Lau, 2009). De hecho, el primer modelo formal fue elaborado por la American Association of School Libraries (AASL). La AASL en 2007 desarrolla unas normas para los estudiantes del siglo XXI que gozan de bastante reconocimiento (AASL, 2008). En los años siguientes, entre finales de los 80 y principios de los 90, se desarrollan varias normas más en el ámbito estadounidense, así como otras iniciativas más citadas como Big6 (Eisenberg \& Berkowitz, 1990).

Por otro lado, instituciones relacionadas con la educación superior, más adelante, se lanzan a desarrollar estándares para estudiantes universitarios. Así surgen las normas de la Association of College and Research Libraries (ALA/ACRL, 2000), de Society of College, National and University Libraries (SCONUL, 2001) o del Council of 
Australian University Librarians (CAUL, 2001). Este conjunto de normas, similares entre sí, convergen en el proyecto Big Blue (Mackenize, Howard, Makin, \& Ryan, 2002).

Veamos pues, más detenidamente, cada una de las instituciones o investigadores más destacados que han desarrollado modelos de normas en competencias informacionales:

En primer lugar, podemos encontrar la Association of College and Research Libraries (ACRL), una división de la American Library Association (ALA), formada principalmente por bibliotecarios académicos y que se dedica al aumento de la capacidad de las bibliotecas universitarias y de los profesionales de la información para dar respuesta a las necesidades informacionales de la comunidad de la educación superior. Además, trata de mejorar el aprendizaje, la enseñanza y la investigación en la universidad.

Por otro lado, tenemos la Society of College, National and University Libraries (SCONUL), una agrupación de las bibliotecas de todas las universidades del Reino Unido e Irlanda. Su actividad se centra principalmente a la coordinación y el apoyo a las bibliotecas, promoviendo el intercambio y desarrollo de buenas prácticas, influyendo en los responsables políticos y estimulando el debate sobre la importancia de las bibliotecas universitarias y elevando el perfil de la educación superior y de las bibliotecas universitarias.

En el ámbito Australiano, muy importante en el contexto de la Alfabetización Informacional y en el desarrollo de normas al respecto, nos encontramos el Council of Australian University Librarians (CAUL), que trata de agrupar a todas las bibliotecas universitarias de Australia y de mejorar el acceso a los recursos de información necesarios a los estudiantes y el personal docente e investigador de dichas bibliotecas. Así, trata de maximizar el potencial de las bibliotecas como elemento dinamizador del aprendizaje y el desarrollo de conocimiento.

Con otros objetivos un tanto diferentes, pero de gran importancia, nos encontramos el Australian and New Zealand Institute for Information Literacy (ANZIIL), que se encarga específicamente de la promoción y difusión del desarrollo de las 
competencias informacionales, y que colabora con el CAUL en el desarrollo de los principios y normas para el desarrollo de competencias informacionales.

En el ámbito español nos encontramos con la Red de Bibliotecas Universitarias Españolas (REBIUN), que tiene como objetivo básico representar a todas las bibliotecas universitarias españolas para conseguir:

- Elevar el nivel de los servicios y de la infraestructura bibliotecaria mediante la cooperación.

- Llevar a cabo las acciones cooperativas que supongan un beneficio para los usuarios de las bibliotecas universitarias Españolas.

- Representación ante organismos públicos y privados.

- Intercambio y formación del personal bibliotecario y/o universitario.

Alejándonos de asociaciones de educación superior relacionadas con la biblioteconomía nos encontramos proyectos como el Big Blue o el Big Six Skills, ya señalados anteriormente y que más que intentar presentar una serie de normas para el desarrollo de las competencias informacionales, tratan de desarrollar modelos pedagógicos que estructuran y guían el proceso de enseñanza-aprendizaje de este tipo de competencias. Dentro de este grupo, también podemos señalar el modelo Gavilán, desarrollado en el ámbito latinoamericano basándose en los modelos Big Blue y Big Six Skills. En realidad, haciendo un análisis de la literatura existente, podemos observar cómo, a pesar de los esfuerzos realizados en la elaboración de modelos y normas, se encuentra una gran heterogeneidad de propuestas y estrategias para la enseñanza de las competencias informacionales (Blasco Olivares \& Durban Roca, 2012). 
Tabla 3.5 Comparación de los diferentes modelos pedagógicos y normas-estándares de las competencias informacionales*

\begin{tabular}{|c|c|c|c|c|c|}
\hline \multirow{8}{*}{ 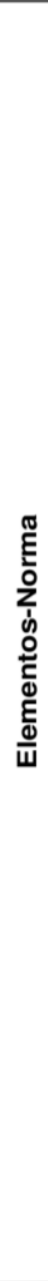 } & DIRECTRICES IFLA & SCONUL, 1999 & BIG BLUE, 2002 & KUHLTHAU, 2001 & BIG SIX SKILLS, 1990 \\
\hline & $\begin{array}{l}\text { Definición y articulación } \\
\text { de la necesidad } \\
\text { informativa }\end{array}$ & $\begin{array}{l}\text { 1. Aptitud para reconocer la necesidad } \\
\text { de información } \\
\text { 2. Aptitud para distinguir entre las } \\
\text { distintas formas de tratamiento de la } \\
\text { necesidad de información reconocida }\end{array}$ & $\begin{array}{l}\text { 1. Reconocer la necesidad de } \\
\text { información }\end{array}$ & $\begin{array}{l}\text { 1. Iniciación: Análisis de la tarea, } \\
\text { problema o proyecto asignado e } \\
\text { identificación de los posibles temas o } \\
\text { preguntas que se plantean } \\
\text { 2. Selección: Seleccionar un tema, } \\
\text { problema o pregunta que lo lleve a } \\
\text { explorar }\end{array}$ & $\begin{array}{l}\text { 1. Definición de la tarea a realizar } \\
\text { 2. Estrategias para Buscar la } \\
\text { Información }\end{array}$ \\
\hline & $\begin{array}{l}\text { Localización de la } \\
\text { información }\end{array}$ & $\begin{array}{l}\text { 3. Aptitud para construir estrategias de } \\
\text { localización de la información } \\
\text { 4. Aptitud para localizar y acceder a la } \\
\text { información }\end{array}$ & $\begin{array}{l}\text { 2. Afrontar la necesidad de información } \\
\text { 3. Obtener información }\end{array}$ & $\begin{array}{l}\text { 3. Exploración: Se encuentra } \\
\text { inconsistencia o incompatibilidad en la } \\
\text { información y las ideas }\end{array}$ & 3. Localización y Acceso \\
\hline & $\begin{array}{l}\text { Valoración de la } \\
\text { información }\end{array}$ & $\begin{array}{l}\text { 5. Aptitud para comparar y evaluar la } \\
\text { información obtenida en diversas } \\
\text { fuentes }\end{array}$ & 4. Evaluar críticamente la información & $\begin{array}{l}\text { 4. Formulación: Conformar una } \\
\text { perspectiva centrada en la información } \\
\text { encontrada }\end{array}$ & \\
\hline & $\begin{array}{l}\text { Organización de la } \\
\text { Información }\end{array}$ & $\begin{array}{l}\text { 6. Aptitud para organizar, aplicar y } \\
\text { comunicar la información a otras } \\
\text { personas y de forma adecuada }\end{array}$ & 6. Organizar la información & $\begin{array}{l}\text { 5. Recolección: Recopilar y documentar } \\
\text { la información sobre el punto central }\end{array}$ & \\
\hline & Uso de la información & $\begin{array}{l}\text { 7. Aptitudes para sintetizar y edificar a } \\
\text { partir de la información existente, } \\
\text { contribuyendo a la creación de nuevo } \\
\text { conocimiento }\end{array}$ & 5. Adaptar la información & & 4. Uso de la Información \\
\hline & $\begin{array}{l}\text { Comunicación y uso ético } \\
\text { de la Información }\end{array}$ & & 7. Comunicar la información & $\begin{array}{l}\text { 6. Presentación: Conectar y ampliar la } \\
\text { perspectiva enfocada para presentarla } \\
\text { ante la comunidad de aprendices }\end{array}$ & 5. Síntesis \\
\hline & & & 8. Revisar todo el proceso & $\begin{array}{l}\text { 7. Evaluación: Reflexionar sobre el } \\
\text { proceso y el contenido del aprendizaje; } \\
\text { sensación de un Proceso de Búsqueda } \\
\text { Personal }\end{array}$ & 6. Evaluación \\
\hline
\end{tabular}




\begin{tabular}{|c|c|c|c|c|c|}
\hline \multirow{8}{*}{ 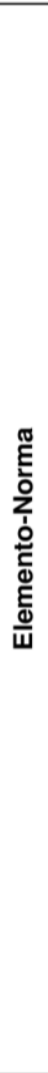 } & DIRECTRICES IFLA & GAVILÁN, 2006 & 8W's LAMB, 1997 & ACRL, 2000 & CAUL, 2000-2001 \\
\hline & $\begin{array}{l}\text { Definición y articulación } \\
\text { de la necesidad } \\
\text { informativa }\end{array}$ & $\begin{array}{l}\text { 1. Definir el problema de información y } \\
\text { qué se necesita indagar para resolverlo }\end{array}$ & $\begin{array}{l}\text { 1. Observar-Explorar } \\
\text { 2. Asombrar-Cuestionar }\end{array}$ & $\begin{array}{l}\text { 1. Determinar la naturaleza y alcance } \\
\text { de la información necesaria }\end{array}$ & $\begin{array}{l}\text { 1. Determinar la naturaleza y alcance } \\
\text { de la información necesaria }\end{array}$ \\
\hline & $\begin{array}{l}\text { Localización de la } \\
\text { información }\end{array}$ & $\begin{array}{l}\text { 2. Buscar y evaluar fuentes de } \\
\text { información }\end{array}$ & 3. Tejer-Buscar & $\begin{array}{l}\text { 2. Acceder a la información requerida } \\
\text { de manera eficaz y eficiente }\end{array}$ & $\begin{array}{l}\text { 2. Acceder a la información requerida } \\
\text { de manera eficaz y eficiente }\end{array}$ \\
\hline & $\begin{array}{l}\text { Valoración de la } \\
\text { información }\end{array}$ & 3. Analizar la información & 4. Actuar-Evaluar & $\begin{array}{l}\text { 3. Evaluar la información y sus fuentes } \\
\text { de forma crítica e incorporar la } \\
\text { información seleccionada a su propia } \\
\text { base de conocimientos y a su sistema } \\
\text { de valores }\end{array}$ & $\begin{array}{l}\text { 3. Evaluar la información y sus fuentes } \\
\text { de forma crítica e incorporar la } \\
\text { información seleccionada a su propia } \\
\text { base de conocimientos y a su sistema } \\
\text { de valores }\end{array}$ \\
\hline & $\begin{array}{l}\text { Organización de la } \\
\text { Información }\end{array}$ & & 5. Organizar-Sintetizar & & $\begin{array}{l}\text { 4. Clasificar, almacenar, manipular y } \\
\text { reelaborar la información reunida o } \\
\text { generada }\end{array}$ \\
\hline & Uso de la información & 4. Sintetizar la información y utilizarla & 6. Desarrollar-Crear & $\begin{array}{l}\text { 4. Utilizar la información eficazmente } \\
\text { para cumplir un propósito específico }\end{array}$ & $\begin{array}{l}\text { 5. Utilizar la información eficazmente } \\
\text { para cumplir un propósito específico } \\
\text { 7. Reconocer que el aprendizaje a lo } \\
\text { largo de toda la vida y la participación } \\
\text { ciudadana requieren alfabetización en } \\
\text { información }\end{array}$ \\
\hline & $\begin{array}{l}\text { Comunicación y uso ético } \\
\text { de la Información }\end{array}$ & & 7. Intercambiar-Comunicar & $\begin{array}{l}\text { 5. Comprender los problemas y } \\
\text { cuestiones económicas, legales y } \\
\text { sociales que rodean el uso de la } \\
\text { información, y acceder y utilizar la } \\
\text { información de forma ética y legal }\end{array}$ & $\begin{array}{l}\text { 6. Comprender los problemas y } \\
\text { cuestiones económicas, legales y } \\
\text { sociales que rodean el uso de la } \\
\text { información, y acceder y utilizar la } \\
\text { información de forma ética y legal }\end{array}$ \\
\hline & & & 8. Autoevaluar-Valorar & & \\
\hline
\end{tabular}




\begin{tabular}{|c|c|c|c|c|c|c|}
\hline & DIRECTRICES IFLA & ANZIL, 2003 & AASL/AECT, 1998 & CIUDAD JUÄREZ, 2002 & WEB-B.I.S. 2004 & BARRY \\
\hline & $\begin{array}{l}\text { Definición y articulación } \\
\text { de la necesidad } \\
\text { informativa }\end{array}$ & $\begin{array}{l}\text { 1. Reconocer la necesidad de } \\
\text { información y determina la } \\
\text { naturaleza y nivel de la } \\
\text { información que necesita }\end{array}$ & $\begin{array}{l}\text { 4. Buscar información referente } \\
\text { a intereses personales }\end{array}$ & $\begin{array}{l}\text { 1. Habilidad para determinar la } \\
\text { naturaleza de una necesidad } \\
\text { informativa }\end{array}$ & 1. Tópico de búsqueda & $\begin{array}{l}\text { 1. Formulación y análisis de } \\
\text { necesidades } \\
\text { 2. Identificación de posibles } \\
\text { fuentes }\end{array}$ \\
\hline & $\begin{array}{l}\text { Localización de la } \\
\text { información }\end{array}$ & $\begin{array}{l}\text { 2. Encontrar la información que } \\
\text { necesita de manera eficaz y } \\
\text { eficiente }\end{array}$ & $\begin{array}{l}\text { 1. Acceder a la información con } \\
\text { eficiencia y efectividad }\end{array}$ & $\begin{array}{l}\text { 2. Habilidad para buscar y } \\
\text { encontrar información } \\
\text { 3. Habilidad para recuperar } \\
\text { información }\end{array}$ & $\begin{array}{l}\text { 2. Tópico y proceso de } \\
\text { búsqueda } \\
\text { 3. Estructura de las } \\
\text { herramientas de búsqueda }\end{array}$ & $\begin{array}{l}\text { 3. Localización de fuentes } \\
\text { individuales } \\
\text { 4. Examen, selección y rechazo } \\
\text { de fuentes }\end{array}$ \\
\hline & $\begin{array}{l}\text { Valoración de la } \\
\text { información }\end{array}$ & $\begin{array}{l}\text { 3. Evaluar la información y el } \\
\text { proceso de búsqueda de } \\
\text { información }\end{array}$ & $\begin{array}{l}\text { 2. Evaluar la información de } \\
\text { forma crítica y competente }\end{array}$ & $\begin{array}{l}\text { 4. Habilidad para evaluar } \\
\text { información }\end{array}$ & 4. Calidad de la Información & 5. Interrogación a las fuentes. \\
\hline & $\begin{array}{l}\text { Organización de la } \\
\text { Información }\end{array}$ & $\begin{array}{l}\text { 4. Gestionar la información } \\
\text { reunida o generada }\end{array}$ & & & & $\begin{array}{l}\text { 6. Registro y almacenamiento } \\
\text { de información. }\end{array}$ \\
\hline 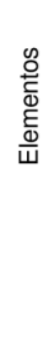 & Uso de la información & $\begin{array}{l}\text { 5. Aplicar la información } \\
\text { anterior y la nueva para } \\
\text { elaborar nuevos conceptos o } \\
\text { crear nueva comprensión }\end{array}$ & $\begin{array}{l}\text { 3. Usar la información de forma } \\
\text { correcta y creativa } \\
\text { 5. Apreciar y disfrutar la } \\
\text { literatura y otras expresiones } \\
\text { creativas de información } \\
\text { 6. Esforzarse al máximo por la } \\
\text { excelencia en la búsqueda de } \\
\text { información y generación de } \\
\text { conocimiento }\end{array}$ & $\begin{array}{l}\text { 5. Habilidad para asimilar y } \\
\text { utilizar la información }\end{array}$ & & $\begin{array}{l}\text { 7. Interpretación, análisis, } \\
\text { síntesis y evaluación de } \\
\text { información }\end{array}$ \\
\hline & $\begin{array}{l}\text { Comunicación y uso } \\
\text { ético de la Información }\end{array}$ & $\begin{array}{l}\text { 6. Utilizar la información con } \\
\text { sensibilidad y reconoce los } \\
\text { problemas y cuestiones } \\
\text { culturales, éticas, económicas, } \\
\text { legales y sociales que rodean el } \\
\text { uso de la información. }\end{array}$ & $\begin{array}{l}\text { 7. Reconocer la importancia de } \\
\text { la información en una sociedad } \\
\text { democrática } \\
\text { 8. Practicar un comportamiento } \\
\text { ético respecto a la información } \\
\text { y a la tecnología de la } \\
\text { información } \\
\begin{array}{l}\text { 9. Participa efectivamente en } \\
\text { grupos para ubicar y generar } \\
\text { información }\end{array}\end{array}$ & $\begin{array}{l}\text { 6. Habilidad para presentar los } \\
\text { resultados de la información } \\
\text { obtenida } \\
\text { 7. Respeto a la propiedad } \\
\text { intelectual y a los derechos de } \\
\text { autor }\end{array}$ & & $\begin{array}{l}\text { 8. Presentación y comunicación } \\
\text { del trabajo resultante. }\end{array}$ \\
\hline & & & & & & 9. Evaluación de los logros. \\
\hline
\end{tabular}

* (Uribe Tirado, 2008, pp. 77-79) 
Siguiendo con este tipo de estudios, podemos encontrarnos con las 8 Ws de Lamb, (Lamb \& And Others, 1997): Los procesos de enseñanza-aprendizaje basados en proyectos de investigación implican preguntarse acerca de un tema (wondering), manejarse a través de la información (wiggling) y construir el conocimiento nuevo de manera conjunta (weaving). Así, existen también pasos intermedios entre estos elementos fundamentales. Las 8 Ws de Lamb, en el siguiente orden, son las siguientes: watching, wondering, webbing, wiggling, weaving, wrapping, waving y wishing.

Por otro lado, entre los autores que han desarrollado modelos para el desarrollo de estas competencias, podemos destacar a Kuhlthau y su Search Process Model (Kuhlthau, 1989, 2002), que define siete etapas por las que pasan los alumnos en el transcurso del proceso de búsqueda de información.

En la tabla 3.5 se puede observar una comparativa entre los modelos y normas presentados por varias de las instituciones e investigadores presentados anteriormente, en función de las directrices que señala la International Federation of Library Associations (IFLA) sobre las dimensiones de las competencias informacionales. Como se observa, estas dimensiones o ejes de desarrollo son muy similares a los que nosotros hemos descrito y adoptado. Vemos cómo la diferencia principal es la inclusión de una dimensión nueva que podríamos denominar "necesidad de información". Las competencias relacionadas con la necesidad de información se refieren a la percepción de las nuevas necesidades, la capacidad para analizar la situación de manera que se detecte la necesidad pertinente en el contexto concreto, la capacidad de observación y exploración, así como la de cuestionamiento de las situaciones, etc. Desde nuestro modelo no abarcamos esta dimensión ya que el contexto personal de nuestra investigación es el alumnado de Educación Secundaria Obligatoria, y consideramos que las habilidades relacionadas con la necesidad de información son de un nivel de complejidad superior a este nivel educativo, que se produce en los procesos de investigación autónomos (Blasco Olivares \& Durban Roca, 2012), más propios de los niveles de bachillerato y enseñanza superior; estos niveles requieren una capacidad crítica que se puede alcanzar en los niveles universitarios e incluso a lo largo de la vida adulta. 
Otros modelos interesantes existentes para el desarrollo de las competencias informacionales no incluidos en el trabajo anterior de Uribe Tirado, son los siguientes:

- Modelo 3.3.3 (Blasco Olivares \& Durban Roca, 2012). Que desarrolla las destrezas generales y básicas de cada una de las tres fases de las competencias informacionales (búsqueda de información, tratamiento de la información y comunicación de conocimiento). La figura 3.4 muestra cómo estas forman un sistema retroalimentado y que cada fase se compone de varias destrezas o desempeños generales y básicos.

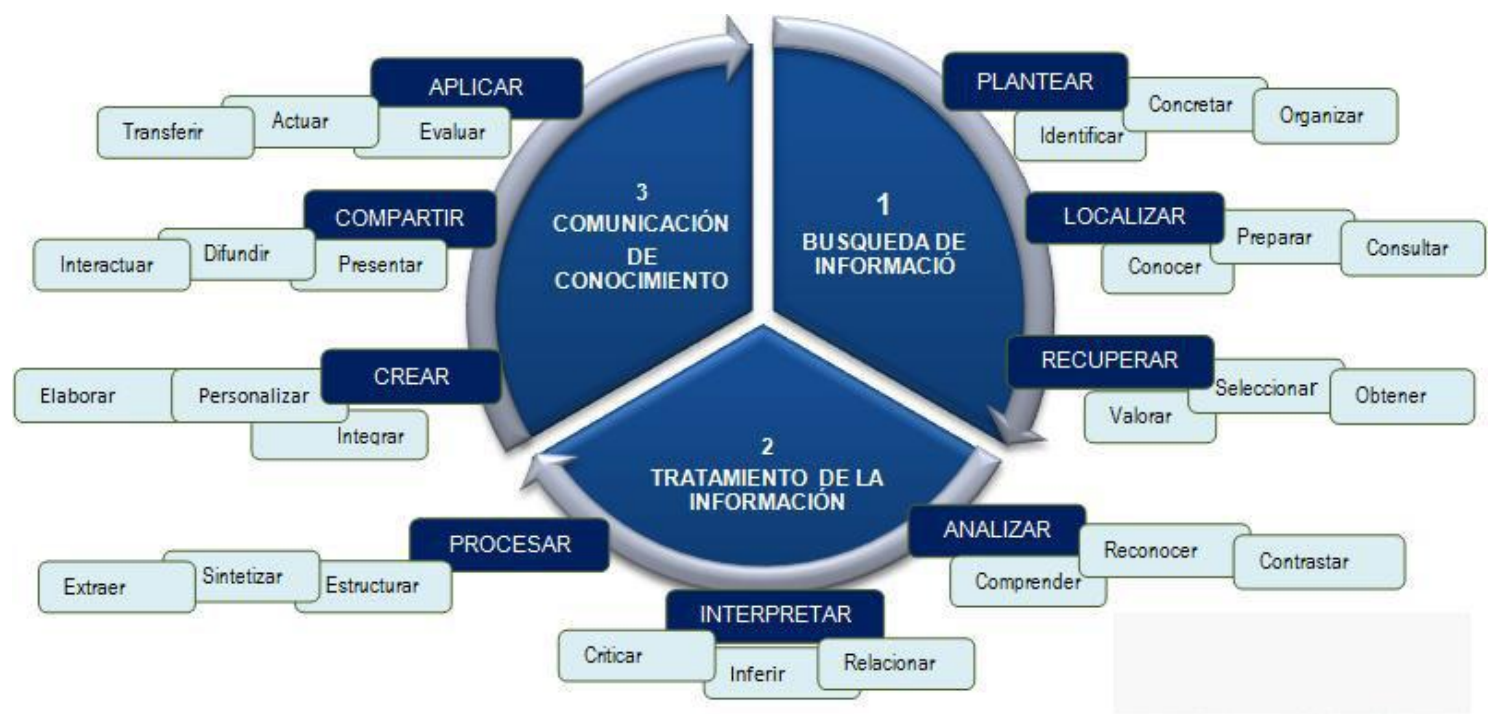

Figura 3.4 Modelo $3 \cdot 3 \cdot 3^{*}$

* (Blasco Olivares \& Durban Roca, 2012, p. 115)

- Las 5As (Jukes, Dosaj, \& Macdonald, 2000): El manejo de la información debe centrarse en 5 elementos básicos: cuestionar (asking), acceder (accessing), analizar (analyzing), aplicar (applying) y evaluar resultados (assessing).

- Siete pilares de la alfabetización informacional (Pasadas Ureña, 2001; SCONUL, 2001, 2004). Modelo que hace énfasis en las relaciones entre el usuario de la información de nivel básico y las competencias para el manejo de la información (figura 3.5). 
MODELO DE APTITUDES PARA LA INFORMACIÓN

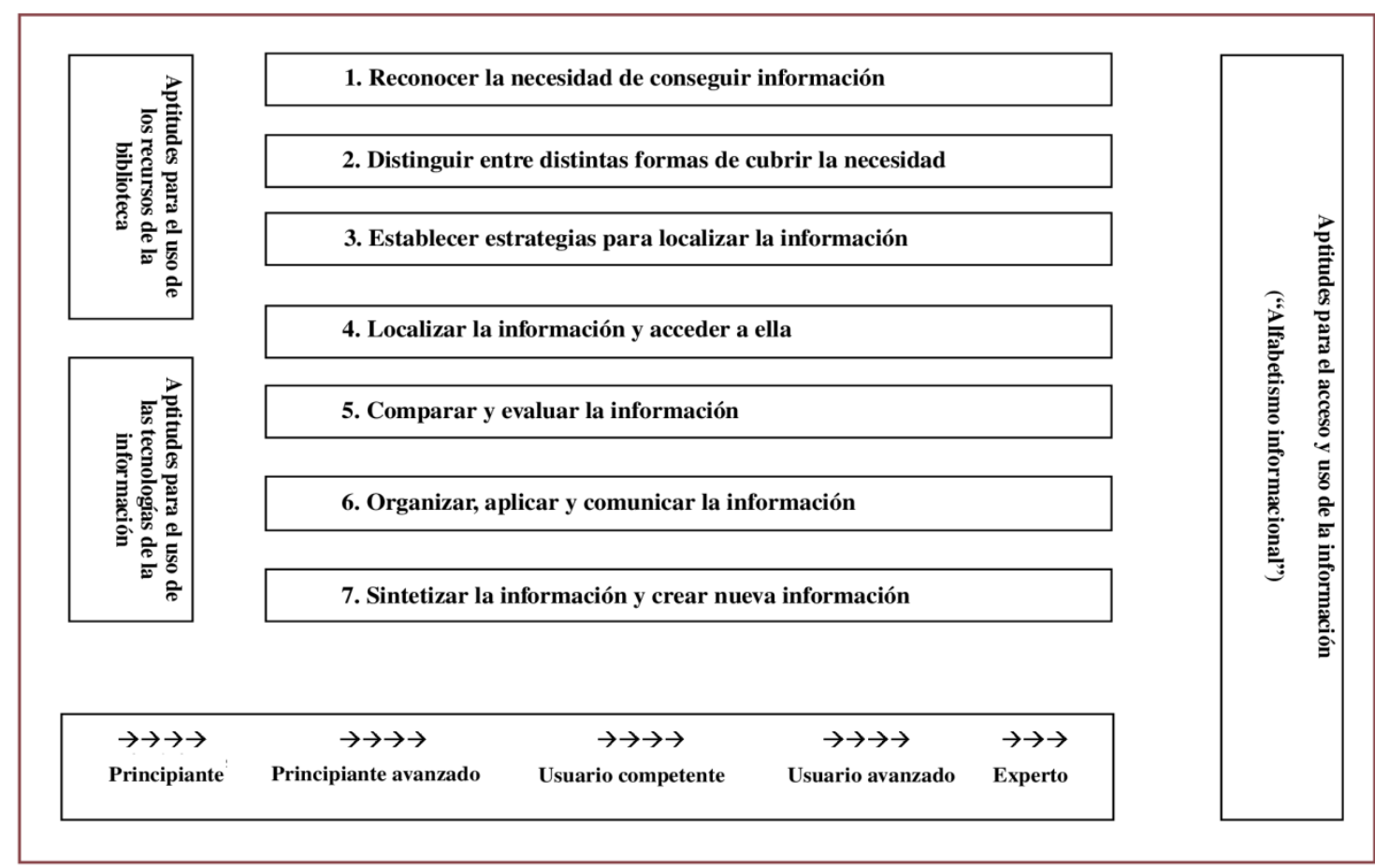

Figura 3.5 Siete pilares de la alfabetización informacional*

* (Pasadas Ureña, 2001, p. 70)

- Modelo de Marland (1981): Modelo clásico, que propone 9 cuestiones que los estudiantes se deben formular ordenadamente cuando se enfrentan a un problema de información: 1. ¿Qué necesito hacer?; 2. ¿Dónde podría ir?;

3. ¿Cómo podría obtener la información?; 4. ¿Qué recursos se podrían usar?; 5. ¿Para qué podría utilizarlos?; 6. ¿Cuáles empleo?; 7. ¿Qué hago con la información que necesito utilizar; 8. ¿Cómo la presento?; 9. ¿Qué he logrado?

- Modelo PLUS (Herring, Tarter, \& Naylor, 2002; Herring, 1996): Modelo en el que se definen 4 categorías para la enseñanza de las competencias informacionales, especialmente en la educación secundaria: propósito (purpose), localización (location), uso (use) y auto-evaluación (selfevaluation). Dentro de cada categoría se desglosa un listado de habilidades explícitas y concretas.

- Modelo Pathways of knowledge (Pappas \& Tepe, 2002): Modelo en el que parten de una visión no lineal del manejo de la información (búsqueda, evaluación, procesamiento y comunicación). Por ello, concluyen que no 
existen fases en el proceso, sino secciones que pueden intercomunicarse. Las secciones son apreciación y disfrute, pre-búsqueda, búsqueda, interpretación, comunicación y evaluación.

- Las siete caras de la alfabetización informacional (Bruce, 1997): Se presenta un modelo a partir de las 7 maneras que la autora identifica para relacionarse con la información. Aporta una visión de las competencias informacionales alejada de los formalismos propuestos por las instituciones de normalización y estandarización de dichas competencias.

- Por su interés para este estudio en concreto, se presenta el programa HEBORI (Habilidades y Estrategias para Buscar, Organizar y Razonar la Información) que propone Benito Morales (1996, 2000). Este modelo, diseñado para el desarrollo de competencias informacionales en las etapas de educación primaria y secundaria se centra, más que en las etapas propias de las competencias informacionales, en las fases que requiere todo proceso de aprendizaje en el que se aprende a manejar la información. Así, se describen 5 módulos emergentes cada uno de una de las fases: crítico-transformacional, cognitivo-lingüístico, documentaltecnológico, estratégico-investigador y creativo-transferencial.

Siguiendo por este ámbito, nos podemos encontrar con propuestas que no podrían ser consideradas explícitamente como modelos, pero sí como guías que organizan y estructuran el contenido propio de las competencias informacionales para su enseñanza. Así, la propuesta más fundamentada en este aspecto son las dimensiones inmersas en la enseñanza de las competencias informacionales, que proponen Area y Guarro (2012). Como se muestra en la figura 3.6, proponen la enseñanza de las competencias informacionales inmersa en cinco dimensiones globales; instrumental, cognitiva, comunicativa, axiológica y emocional.

Esta última aportación es de vital importancia, ya que propone la enseñanza de las competencias informacionales desde diferentes perspectivas y de una manera holística y comprensiva. Por otro lado, la propuesta no es excluyente con los modelos de enseñanza de las competencias informacionales antes señalados. 


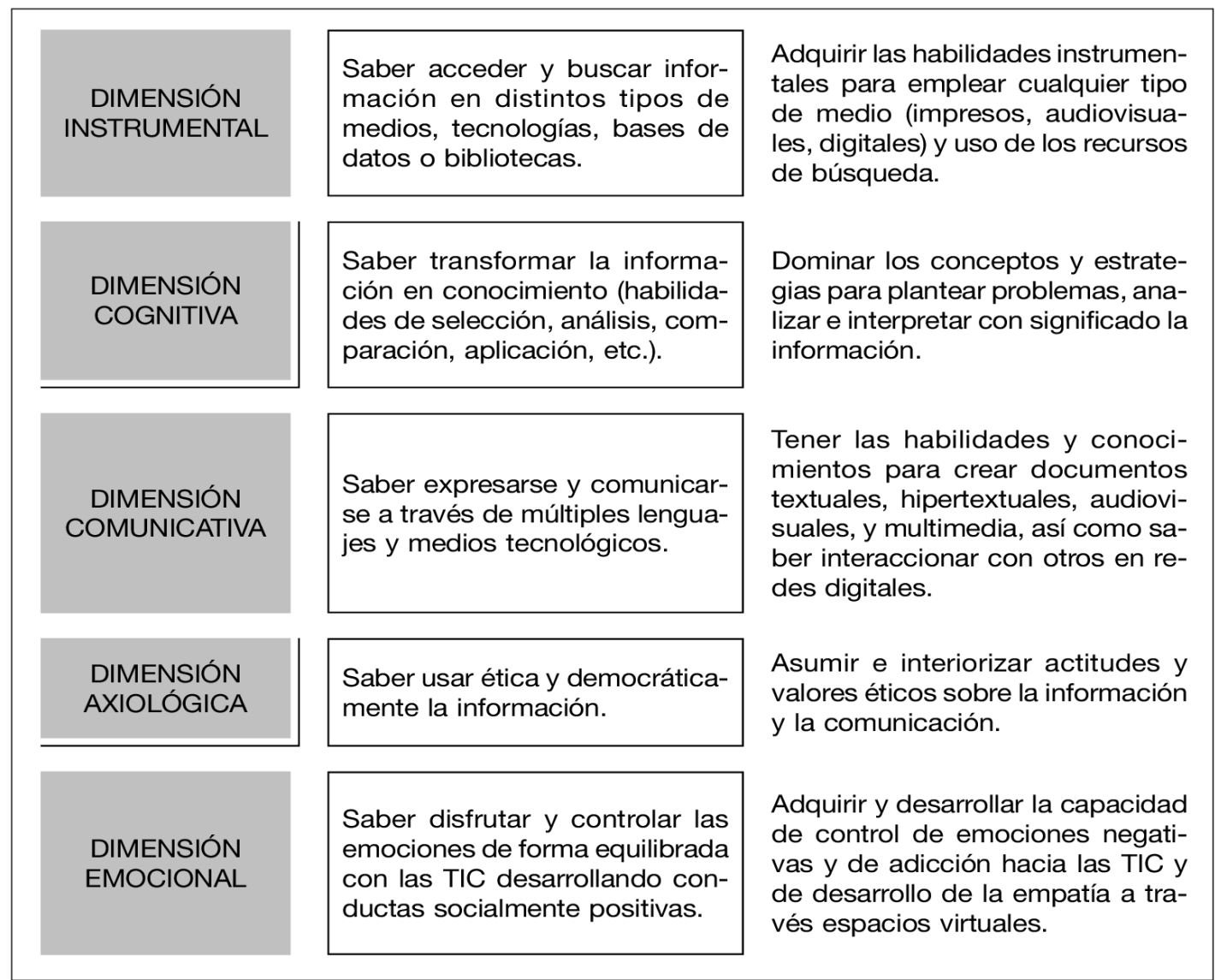

Figura 3.6 Dimensiones globales para la enseñanza de las competencias informacionales*

* (Area Moreira \& Guarro, 2012, p. 66)

\subsubsection{Desempeños específicos inmersos en las competencias informacionales}

A pesar de que en el contexto nacional no se definen unas normas y estándares propios sobre los contenidos de las competencias informacionales sistemáticos y operativos, a lo largo de este sub-apartado vamos a definir, a partir de los documentos de las principales instituciones internacionales, qué desempeños concretos incluimos dentro de cada una de las dimensiones y sub-dimensiones propias de las competencias informacionales.

En este aspecto, nos basaremos en las normas promulgadas por el ALA/ACRL americano (2000), el ANZIIL del continente australiano (2004), el CAUL australiano (2001) y el SCONUL británico (2004).

En primer lugar, podemos observar las primeras normas, promulgadas por la Asociación Americana de Bibliotecarios. Se basa en cinco estándares o sub- 
competencias incluidas dentro de la macro-competencia "competencias informacionales". Cada competencia incluye dentro de sí misma unos indicadores de rendimiento y resultados observables:

1. Ser capaz de determinar la naturaleza y nivel de la necesidad de información.

Indicadores de rendimiento y resultados observables:

a. Ser capaz de definir y articular las necesidades de información. El estudiante competente en el manejo de información:

i. Habla con los profesores y participa en discusiones de clase, en grupos de trabajo y en foros electrónicos para identificar temas de investigación o cualquier otra necesidad de información.

ii. Desarrolla una afirmación y formula preguntas basadas en la necesidad de información.

iii. Puede explorar las fuentes generales de información para aumentar su familiaridad con el tema.

iv. Define o modifica la necesidad de información para lograr un enfoque manejable.

v. Es capaz de identificar los términos y conceptos clave que describen la necesidad de información.

vi. Se da cuenta de que la información existente puede ser combinada con el pensamiento original, la experimentación y/o el análisis para producir nueva información.

b. Ser capaz de identificar una gran variedad de tipos y formatos de fuentes potenciales de información. El estudiante competente en el manejo de información:

i. Sabe cómo se produce, organiza y difunde la información, tanto formal como informalmente.

ii. Se da cuenta de que el conocimiento puede organizarse en torno a disciplinas, lo que influye en la forma de acceso a la información. 
iii. Es capaz de identificar el valor y las diferencias entre recursos potenciales disponibles en una gran diversidad de formatos.

iv. Puede identificar la finalidad y los destinatarios de los recursos potenciales.

v. Es capaz de diferenciar entre fuentes primarias y secundarias y sabe que su uso e importancia varía en las diferentes disciplinas.

vi. Se da cuenta de que puede que sea necesario elaborar la información a partir de datos en bruto sacados de fuentes primarias.

c. Valorar los costes y beneficios de la adquisición de la información necesaria. El estudiante competente en el manejo de información:

i. Establece la disponibilidad de la información requerida y toma decisiones sobre la ampliación del proceso de búsqueda más allá de los recursos locales.

ii. Se plantea la posibilidad de adquirir un nuevo lenguaje o habilidad para poder reunir la información requerida y comprenderla en su contexto.

iii. Diseña un plan global y temporalizado de modo realista para la adquisición de la información requerida.

d. Replantearse la naturaleza y el nivel de la información que se necesita. El estudiante competente en el manejo de información:

i. Revisa la necesidad inicial de información para aclarar, reformar o delimitar más la pregunta.

ii. Describe los criterios utilizados para tomar decisiones y opciones sobre la información

2. Acceder a la información requerida de manera eficiente y eficaz.

Indicadores de rendimiento y resultados observables:

a. Seleccionar los métodos de investigación o los sistemas de recuperación de la información más adecuados para acceder a la 
información que se necesita. El estudiante competente en el manejo de información:

i. Identifica los métodos de investigación más adecuados.

ii. Analiza los beneficios y la posibilidad e aplicación de diversos métodos de investigación.

iii. Investiga la cobertura, contenidos y organización de los sistemas de recuperación de la información.

iv. Selecciona procedimientos eficaces y eficientes para el acceso a la información que necesita de acuerdo con el método de investigación o el sistema de recuperación de la información seleccionado.

b. Construir y poner en práctica estrategias de búsqueda diseñadas eficazmente. El estudiante competente en el manejo de información:

i. Desarrolla un plan de investigación ajustado al método elegido.

ii. Identifica palabras clave, sinónimos y términos relacionados para la información que necesita.

iii. Selecciona un vocabulario controlado apropiado a la disciplina o el sistema de recuperación de información.

iv. Construye una estrategia de búsqueda empleando los comandos apropiados del sistema de recuperación de información elegido.

v. Aplica la estrategia de búsqueda en varios sistemas de recuperación, utilizando diferentes interfaces de usuario y motores de búsqueda, con diferentes lenguajes, protocolos y parámetros de búsqueda.

vi. Aplica la búsqueda empleando protocolos de investigación adecuados a la disciplina.

c. Obtener información en línea o físicamente empleando diversos métodos. El estudiante competente en el manejo de la información: 
i. Utiliza diversos sistemas de búsqueda para recuperar la información en diversos formatos.

ii. Emplea variedad de esquemas de clasificación u otros sistemas para localizar los recursos de información dentro de una biblioteca o para identificar lugares específicos donde poder llevar a cabo una búsqueda.

iii. Utiliza físicamente o en línea los servicios disponibles en la institución para recuperar la información necesaria.

iv. Emplea encuestas, cartas, entrevistas u otras formas de investigación para construir información primaria.

d. Saber afinar más la estrategia de búsqueda si es necesario. El estudiante competente en el manejo de información:

i. Valora la cantidad, calidad y relevancia de los resultados de una búsqueda para decidir sobre la utilización de sistemas de recuperación de información o métodos de investigación alternativos.

ii. Identifica lagunas en la información recuperada y está capacitado para determinar si es necesaria la revisión de la estrategia de búsqueda.

iii. Repite las búsquedas empleando la estrategia revisada según sea necesario.

e. Sabe extraer, registrar y gestionar la información y las fuentes. El estudiante competente en el manejo de información:

i. Selecciona la tecnología más adecuada para extraer la información que necesita.

ii. Crea un sistema de organización de la información.

iii. Sabe diferenciar entre los tipos de fuentes y comprende los elementos y la citación correcta de una cita de cualquier recurso.

iv. Registra la información pertinente de una cita para referirla en un futuro. 
v. Emplea tecnologías para la gestión de la información recogida.

3. Evaluar la información y sus fuentes de forma crítica e incorporar la información seleccionada en el cuerpo de conocimientos propio y el sistema personal de valores.

Indicadores de rendimiento y resultados observables:

a. Ser capaz de resumir las ideas principales a extraer de la información reunida. El estudiante competente en el manejo de información:

i. Lee el texto y selecciona las ideas principales.

ii. Infiere los conceptos del texto, los redacta con sus propias palabras y selecciona los datos con criterio.

iii. Identifica exactamente el material y lo cita adecuadamente de forma literal.

b. Formular y aplicar unos criterios iniciales para evaluar la información y sus fuentes. El estudiante competente en el manejo de información:

i. Examina y compara la información de varias fuentes y evalúa su fiabilidad, validez, corrección, autoridad, oportunidad y objetividad.

ii. Analiza la estructura y lógica de las argumentaciones de un texto.

iii. Reconoce prejuicios, engaño o manipulación.

iv. Reconoce el contexto cultural, físico o de cualquier tipo dentro del que se creó la información y comprende su impacto al interpretarla.

c. Estar capacitado para sintetizar las ideas principales para construir conocimiento. El estudiante competente en el manejo de información:

i. Reconoce la interrelación entre conceptos y los combina en nuevos enunciados potencialmente útiles con razones $y$ evidencias que los apoyen. 
ii. Extiende en la medida de lo posible la síntesis inicial hacia un nivel mayor de abstracción para construir nuevas hipótesis que puedan requerir información adicional.

iii. Emplea ordenadores y otras tecnologías digitales para estudiar la interacción entre las ideas y otros fenómenos.

d. Saber comparar el nuevo conocimiento con los conocimientos previos para definir el valor añadido, las contradicciones $u$ otras características inherentes a la información. El estudiante competente en el manejo de información:

i. Es capaz de determinar si la información satisface las necesidades propias.

ii. Emplea criterios seleccionados conscientemente para establecer si una información contradice o verifica la información lograda en otras fuentes.

iii. Saca conclusiones basadas en la información localizada.

iv. Comprueba las teorías con las técnicas más apropiadas.

v. Determina la exactitud de sus resultados valorando la fuente, las limitaciones de las estrategias y herramientas empleadas y lo razonable de las conclusiones.

vi. Integra las nuevas informaciones con los conocimientos previos.

vii. Selecciona la información que ofrece evidencias sobre el tema en cuestión.

e. Saber determinar si los nuevos conocimientos tienen influencia sobre el sistema de valores propio y tomar las medidas apropiadas para reconciliar las diferencias. El estudiante competente en el manejo de información:

i. Investiga los diferentes puntos de vista existentes en los documentos.

ii. Determina si incorporar o rechazar los puntos de vista localizados. 
f. Comprobar la comprensión e interpretación de la información mediante el contraste de opiniones con diferentes audiencias. El estudiante competente en el manejo de información:

i. Participa activamente en discusiones de clase y de otros tipos.

ii. Participa en foros de discusión online para estimular el debate sobre los temas.

iii. Busca la opinión de expertos por medio de mecanismos variados.

g. Determinar si la formulación de la pregunta inicial debe ser revisada. El estudiante competente en el manejo de información:

i. Puede determinar si la necesidad inicial de información ha sido o no satisfecha.

ii. Revisa la estrategia de búsqueda e incorpora nuevos términos según sea necesario.

iii. Revisa las fuentes empleadas e incluye otras si es necesario.

4. Emplear la información eficazmente para cumplir algún propósito específico, de manera individual o grupal.

Indicadores de rendimiento y resultados observables:

a. Aplicar la información antigua y la nueva para planificar y diseñar un producto o actuación concreta. El estudiante competente en el manejo de información:

i. Organiza el contenido de manera que apoye los fines y formato del producto o actuación.

ii. Articula el conocimiento y las habilidades adquiridas anteriormente en la planificación y creación del producto o actuación.

iii. Integra la información nueva con la antigua, incluyendo citas y paráfrasis, de manera que apoye la finalidad del producto o actuación.

iv. Maneja textos digitales, imágenes y datos según sea necesario, adaptándolos a nuevos contextos. 
b. Revisar el proceso de desarrollo del producto o actuación. El estudiante competente en el manejo de información:

i. Mantiene una guía de actividades relacionadas con el proceso de búsqueda, evaluación y comunicación de información.

ii. Reflexiona sobre los éxitos, fracasos y estrategias alternativas anteriores.

c. Ser capaz de comunicar a los demás con eficacia el producto o actuación. El estudiante competente en el manejo de la información:

i. Elige el medio y formato que mejor apoye los objetivos del producto o actuación y los destinatarios a los que se dirige.

ii. Emplea diversas aplicaciones de las TIC a la hora de crear el producto o la actividad.

iii. Incorpora principios de diseño y comunicación.

iv. Comunica con claridad y un estilo apropiados a la audiencia.

5. Comprender muchos de los problemas y cuestiones económicas, legales y sociales que rodean el uso de información, y acceder y emplear la información de manera ética y legal.

Indicadores de rendimiento y resultados observables:

a. Comprender las cuestiones éticas, legales y sociales que rodean la información y las TIC. El estudiante competente en el manejo de información:

i. Identifica y discute las cuestiones relacionadas con la intimidad y privacidad y la seguridad tanto en el entorno físico como virtual.

ii. Identifica y discute sobre las cuestiones relativas al acceso libre o restringido a la información.

iii. Identifica y discute sobre los problemas relacionados con la censura y la libertad de expresión. 
iv. Comprende los conceptos de la propiedad intelectual, derechos de reproducción y empleo correcto de los documentos con copyright.

b. Respetar las leyes, reglamentos y políticas institucionales así como las normas de cortesía relacionadas con el acceso y uso de los recursos. El estudiante competente en el uso de información:

i. Participa en foros de discusión online siguiendo el protocolo aceptado.

ii. Emplea las claves de acceso apropiadas y demás formas de identificación para el acceso a los recursos.

iii. Cumple con la normativa sobre acceso a los recursos.

iv. Preserva la integridad de los recursos, del equipamiento, de los sistemas y de las instalaciones.

v. Obtiene y guarda legalmente textos, datos, imágenes y sonidos.

vi. Demuestra comprensión sobre el plagio y no presenta como propios trabajos de otros autores.

vii. Comprende las normas de la institución sobre la investigación de temas relativos a los seres humanos.

c. Reconoce las fuentes empleadas al difundir su producto o actuación. El estudiante competente en el uso de información:

i. Selecciona un estilo de presentación adecuado y lo emplea de forma consistente al citar las fuentes.

ii. Envía las notas de autorización que se requieran para materiales registrados con copyright.

Ya se puede observar cómo las sub-competencias o dimensiones incluidas dentro de las competencias informacionales se definen como la necesidad de información, la búsqueda de información, la evaluación de información, el procesamiento de infomación y la comunicación de información.

En segundo lugar, nos encontramos con las normas del ANZIIL y el CAUL, que, al tratarse de instituciones del mismo ámbito geográfico, son muy similares. 
Sin embargo, existen algunas diferencias perceptibles entre ambas. Por un lado, mientras que el ANZIIL propone seis normas básicas para toda persona competente en el manejo de la información, el CAUL toma estas seis y añade una séptima. Por otro lado, el ANZIIL propone cuatro principios generales que se consideran los pilares de las normas después señaladas, y el CAUL no hace referencia a estos principios. Los principios que señala el ANZIIL son los siguientes:

- Se implica en el propio aprendizaje mediante la construcción de nuevos significados, comprensión y conocimientos.

- Obtiene satisfacción y realización personal gracias a un empleo eficaz de la información.

- Busca y emplea la información tanto individual como colectivamente durante el proceso de toma de decisiones y solución de problemas para afrontar las cuestiones personales, profesionales y sociales.

- Demuestra un sentimiento de responsabilidad social mediante el compromiso con el lifelong learning y la participación en comunidades de aprendizaje.

A partir de estos cuatro principios inquebrantables, se definen las seis normas básicas, que se concretan a su vez en unos resultados de aprendizaje concretos. Definiremos a continuación las seis primeras normas propuestas por el ANZIIL, añadiendo la séptima que aparece en los documentos publicados por el CAUL.

1. La persona competente en el manejo de información reconoce la necesidad propia de información y determina la naturaleza y nivel de información que necesita.

Resultados de aprendizaje. La persona competente en el manejo de información:

a. Define y articula la necesidad de información.

b. Entiende la finalidad, alcance y adecuación de gran variedad de fuentes de información.

c. Se replantea en todo momento la naturaleza y el alcance de la información que necesita. 
d. Emplea diversas fuentes de información para la toma de decisiones.

2. La persona competente en el manejo de información localiza la información que necesita eficaz y eficientemente.

Resultados de aprendizaje. La persona competente en el manejo de información:

a. Selecciona los métodos o las herramientas más apropiadas para localizar la información.

b. Construye e implementa estrategias eficaces de búsqueda.

c. Obtiene la información empleando los métodos más apropiados.

d. Se mantiene actualizado respecto de las fuentes de información, las TIC, los instrumentos de acceso a la información y los métodos de investigación.

3. La persona competente en el manejo de información evalúa de manera crítica la información y el proceso de búsqueda de información.

Resultados de aprendizaje. La persona competente en el manejo de información:

a. Valora la utilidad y la relevancia de la información obtenida.

b. Define y aplica criterios operativos para evaluar la información.

c. Reflexiona sobre el propio proceso de búsqueda de información y revisa las estrategias de búsqueda empleadas si es necesario.

4. La persona competente en el manejo de información gestiona la información obtenida y/o elaborada.

Resultados de aprendizaje. La persona competente en el manejo de información:

a. Registra la información y sus fuentes.

b. Organiza la información

5. La persona competente en el manejo de información integra la información antigua con la nueva para elaborar nuevos conceptos o crear una nueva comprensión de la realidad

Resultados de aprendizaje. La persona competente en el manejo de información: 
a. Compara e integra la nueva visión del mundo con los conocimientos previos para establecer el valor añadido, las contradicciones o cualquier otra característica de la información.

b. Comunica los conocimientos y la nueva visión de la realidad de forma eficaz.

6. La persona competente en el manejo de información emplea la información con sensibilidad y reconoce los problemas y cuestiones culturales, éticas, económicas, legales y sociales que rodean al uso de información.

Resultados de aprendizaje. La persona competente en el manejo de información:

a. Reconoce los problemas éticos y socioeconómicos relacionados con el acceso y uso de la información.

b. Es consciente de que la información está íntimamente relacionada con los valores y creencias.

c. Cumple con las normas y el protocolo en relación con el acceso y uso de información.

d. Obtiene, almacena y difunde textos, datos, imágenes o sonidos de manera legal.

7. La persona competente en el manejo de información entiende que el lifelong learning y la participación ciudadana requieren de competencias informacionales.

Resultados de aprendizaje. La persona competente en el manejo de información:

a. Se percata de que las competencias informacionales requieren una implicación constante con el aprendizaje y las TIC para que el lifelong learning sea posible.

b. Decide si la nueva información obtenida tiene implicaciones para las instituciones democráticas y para el sistema de valores propio, y toma las medidas oportunas para reconciliar las diferencias. 
Vemos en el caso de las instituciones del ámbito australiano cómo las subcompetencias incluidas dentro de las competencias informacionales vuelven a situarse como: la necesidad de información, la búsqueda de información, la evaluación de información, la gestión y procesamiento de información y el empleo o comunicación de información. Así, se añade a posteriori una sub-competencia nueva como el aprendizaje a lo largo de la vida y la participación en comunidades de aprendizaje (Jiménez Fernández, García Llamas, Álvarez González, \& Quintanal Díaz, 2012).

Por último, nos encontramos con las normas del SCONUL. Dichas normas surgen a partir de un Grupo de Trabajo establecido por el Comité Ejecutivo de SCONUL en diciembre de 1998, que tiene la finalidad de diseñar las competencias informacionales necesarias para los estudiantes de educación superior. Por fin, se sitúan las competencias informacionales en torno a siete sub-competencias o aptitudes básicas.

1- Competencia para reconocer la necesidad propia de información.

2- Competencia para diferenciar entre las diferentes formas de tratamiento de la información requerida.

a. Conocimiento de los recursos adecuados para cada situación, sea en el formato que sea.

b. Selección de los recursos más ajustados a la necesidad de información y situación concreta.

c. Habilidad para comprender los problemas que afectan a la accesibilidad de las fuentes.

3- Competencia para construir estrategias de búsqueda de información.

a. Articular la necesidad de información para contrastarla con los recursos disponibles.

b. Desarrollar un método sistemático y operativo, adecuado a las necesidades concretas.

c. Comprender los principios de la estructura y producción de las bases de datos.

4- Competencia para buscar y acceder a la información.

a. Desarrollar técnicas adecuadas de búsqueda como la lógica de los operadores booleanos. 
b. Emplear las TIC, incluyendo el acceso a redes internacionales.

c. Emplear los servicios apropiados de indexación y de resúmenes, índices de citas y bases de datos.

d. Emplear los métodos de actualización y servicios de alerta para mantenerse al día.

5- Competencia para comparar y evaluar la información obtenida de los recursos.

a. Tener en cuenta los problemas del sesgo y la autoría.

b. Conocer el método de revisión por pares.

c. Extraer apropiadamente la información en función de las necesidades concretas de información.

6- Competencia para organizar, aplicar y comunicar la información a la audiencia de manera apropiada a la misma.

a. Citar adecuadamente las referencias bibliográficas.

b. Construir un sistema bibliográfico personal.

c. Aplicar la información al problema concreto.

d. Comunicar con eficacia mediante el empleo de un medio adecuado.

e. Comprender y respetar los problemas de derechos de autor y plagio.

7- Competencia para sintetizar y construir conocimiento a partir de la información obtenida.

En el caso de las normas del SCONUL nos encontramos con un contexto menos adecuado a la población diana de la tesis, ya que se vincula más a las competencias informacionales a desarrollar por los estudiantes universitarios. Sin embargo, las subcompetencias que se describen siguen siendo la necesidad de información, la búsqueda de información, la evaluación de información, el procesamiento de información y la comunicación de información. Se añade como una nueva competencia la construcción de conocimiento.

Por último, en España, en un esfuerzo reciente por la formación en Competencias Informáticas e Informacionales ( $\mathrm{Cl} 2)$, la Comisión mixta formada por miembros de la CRUE-TIC y REBIUN publica un manual para la formación en este tipo de competencias 
(2012), como continuación al trabajo iniciado en 2009 con el informe de la misma comisión (CRUE-TIC \& REBIUN, 2009). Este manual es una traducción y adaptación del Handbook for Information Literacy Teaching, publicado por la Universidad de Cardiff en 2009. Así, se proponen una serie de contenidos para la formación en $\mathrm{Cl}$. Entre los contenidos propios de las competencias informacionales se incluyen los siguientes:

1- Proceso de búsqueda de información

a. Identificar la necesidad de información y seleccionar la forma más adecuada de darle respuesta: bibliografía recomendada, obras de consulta, revistas, prensa, artículos, datos, normas, textos legales, patentes, etc.

b. Dónde encontrar información general y por materias.

i. Internet, motores de búsqueda, web social.

ii. El catálogo de la biblioteca, centro de recursos para el aprendizaje y la investigación y catálogos colectivos.

iii. Bases de datos, revistas, portales.

iv. Guías temáticas.

v. Repositorios.

vi. Metabuscadores.

c. Servicios de apoyo.

i. Soporte a la docencia y al aprendizaje.

ii. Puntos de información al estudiante.

2- Evaluación de información.

a. Criterios para evaluar la información: autoría, fuente, actualización, etc.

b. Actitud crítica y reflexiva ante la información.

3- Organización y comunicación de información.

a. Gestores de contenidos: Wordpress, Drupal, etc.

b. Gestores de referencias: Refworks, Mendeley, etc.

c. Herramientas útiles para la redacción. Libros de estilo.

d. Tipos de comunicación: trabajo académico, artículo de investigación, tesis doctoral, comunicación oral, póster, etc. 
e. Cómo citar recursos de información y la utilidad de los gestores de referencias.

f. Uso ético de la información.

i. Propiedad intelectual y derechos de autor.

ii. Los derechos de autor en entornos digitales.

g. Publicación de una obra

i. El depósito legal.

ii. La edición comercial: ISBN, ISSN.

iii. Acceso libre. Los repositorios institucionales.

4- Mantenerse al día y compartir información.

a. Mantenerse al día de la información científica.

i. Sistemas de alerta de las bases de datos.

ii. Fuentes web: RSS, Atom, etc.

iii. Agregadores o lectores de fuentes web.

b. Compartir información:

i. Los blogs.

ii. Las wikis.

iii. Marcadores sociales, herramientas para compartir medias, etc.

iv. Otras herramientas: Google Drive, Dropbox, etc.

Estas recomendaciones sobre los contenidos de las $\mathrm{Cl} 2$ están vinculados al mundo universitario, y en concreto a la labor formativa del bibliotecario de los centros de educación superior.

Así, en nuestro empeño por evaluar y formar en competencias informacionales, nos basaremos a la hora del diseño de los instrumentos y procedimientos en estas normas y estándares señalados.

\subsubsection{Modelo para la enseñanza de las competencias informacionales}

A partir de las normas y modelos señalados con anterioridad, dado que existen algunas discordancias entre nuestro planteamiento de los principios básicos del 
concepto de competencias informacionales y las bases teórico-conceptuales de las que parten la mayoría, parece necesario desarrollar un modelo propio para la enseñanza de las competencias informacionales. Intentaremos, por tanto, mostrar un modelo sencillo y derivado directamente del modelo de formación basada en competencias expuesto más arriba.

Para ello, adaptaremos la propuesta presentada por Zabala y Arnau (2007), en la que identifican cuatro dimensiones implicadas en el aprendizaje de las competencias (social, personal, inter-personal y profesional).

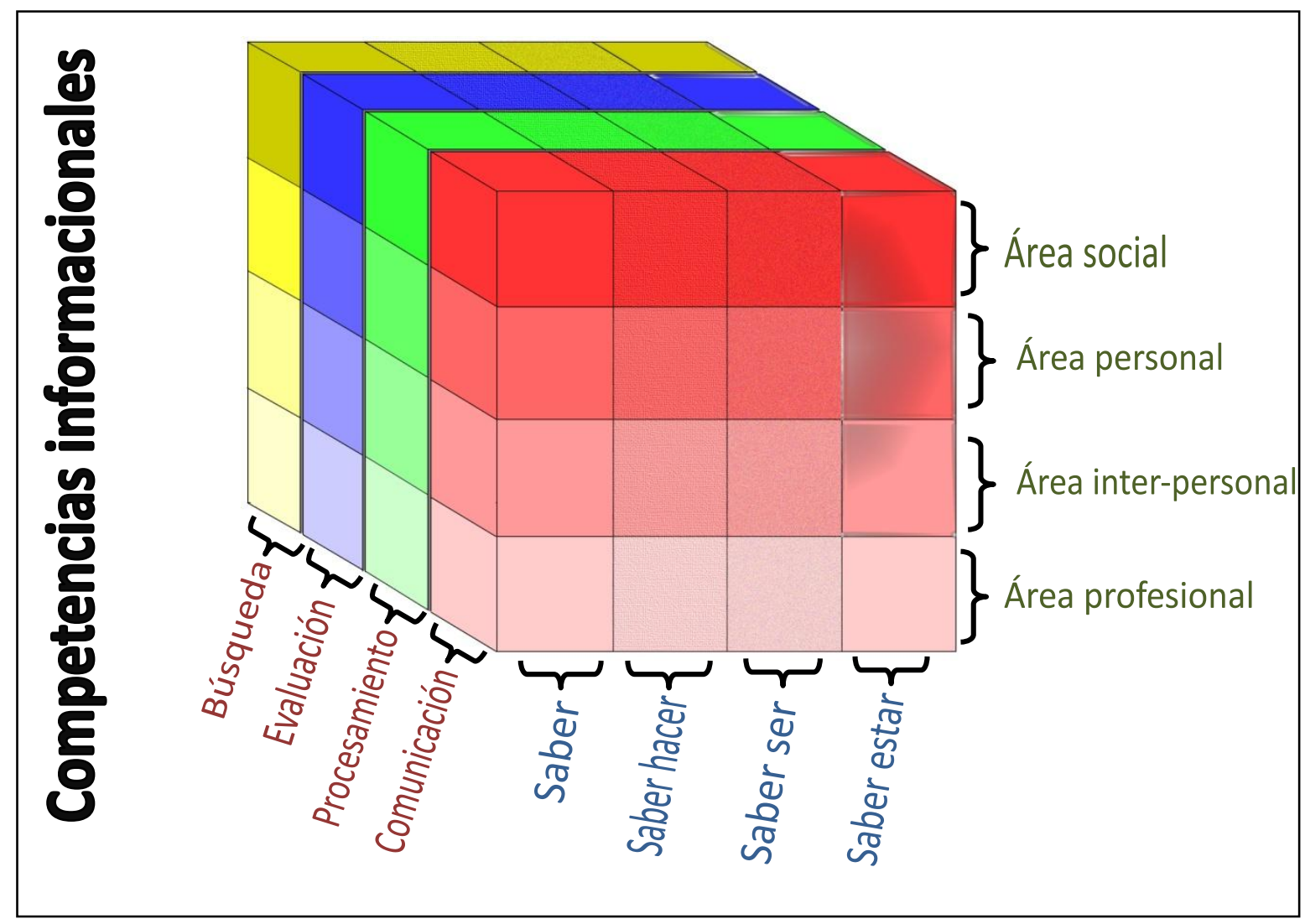

Figura 3.7 Modelo de formación en competencias informacionales*

* Elaboración propia

En primer lugar, es necesario señalar que emplearemos en nuestra presentación, para ser coherentes con el discurso presentado hasta la fecha, una terminología relativamente diferente a la propuesta por los citados autores. Nuestra concepción de dimensión es diferente, considerando como ámbitos o áreas lo que estos autores consideraban dimensiones: 
- Dimensión: En nuestro trabajo consideraremos dimensión a cada una de las agrupaciones o conjuntos que están incluidas en el fenómeno de análisis. En nuestro caso, dado que las competencias informacionales (fenómeno de análisis) conforman una competencia compleja y un constructo en sí mismas, podemos encontrar cinco subcompetencias o dimensiones teóricas incluidas dentro de dicho constructo. Cada una de estas consiste en un conjunto de contenidos relativo a un mismo campo de conocimiento. Las dimensiones propias del constructo competencias informacionales (Catts, 2005) son la necesidad de información, la búsqueda de información, la evaluación de información, el procesamiento de información y la comunicación de información. En nuestro estudio, dado que nos centramos en la educación secundaria, en la que la enseñanza es guiada, la necesidad de información la determina en buena parte el docente que guía las prácticas educativas, y no se incluye dentro de las dimensiones propias de la enseñanza de las competencias informacionales en la educación básica.

- Área o ámbito: En segundo lugar nos encontramos con áreas o ámbitos de aprendizaje. Mientras que las dimensiones son diferentes y específicas para cada competencia (ya que los contenidos propios de cada competencia no son comparables), las áreas son genéricas a todas las competencias. En la enseñanza de cualquier competencia básica, dentro de la que se incluyen las competencias informacionales, está implícito el desarrollo del estudiante en cada uno de los ámbitos implicados. Dentro de estas áreas, se incluyen:

- Ámbito social: Compromiso personal de cada estudiante en la construcción individual y compartida del conocimiento para el desarrollo común de la sociedad.

- Ámbito inter-personal: Capacidad del estudiante para relacionarse, participar y cooperar en las actividades propiamente educativas, especialmente en comunidades de aprendizaje físicas o virtuales.

- Ámbito personal: Modo en el que se ejerce la libertad y responsabilidad personales para el desarrollo de una formación 
autónoma y la participación activa en el propio proceso de aprendizaje.

- Ámbito profesional: Nivel de desempeño en cada una de las competencias necesarias para la práctica de una tarea profesional específica.

- Componentes: En último lugar, nos encontramos con los componentes de la competencia, que se podrían considerar como los diferentes aspectos a trabajar dentro de toda competencia. Mientras que los ámbitos o áreas de aprendizaje se encuentran en un nivel superior a la competencia, o supranivel, los componentes de la competencia son el esqueleto de las propias competencias, están a un nivel inferior o infranivel. Las áreas se comprenden y desarrollan a nivel de persona (las personas deben formarse en el ámbito social, personal, interpersonal y profesional), pero los componentes se desarrollan a nivel de competencia (las competencias se componen de un saber, un saber hacer, un saber ser y un saber estar). Podemos identificar en toda competencia cuatro componentes:

- Saber: Conocimientos necesarios para el dominio de la propia competencia, tanto generales como específicos, tanto teóricos como prácticos. En la resolución de problemas, para poner en práctica de manera eficaz y eficiente las competencias necesarias, será necesario poseer ciertos conocimientos relativos a alguna materia (matemáticas, física, lengua, literatura, historia, geografía, etc.).

- Saber hacer: Habilidades y destrezas instrumentales y/o cognitivas relacionadas con el manejo de medios y recursos necesarios para la puesta en práctica de la competencia. A la hora de enfrentarse a cualquier problema, la planificación y ejecución de las posibles soluciones no se podrá llevar a cabo sin capacidades cognitivas e instrumentales de tipo tanto técnico como metodológico.

- Saber estar: Capacidad para poner en juego la competencia en colaboración con otras personas en proyectos comunes de forma comunicativa y constructiva. Los problemas a los que se enfrentan 
las personas y los grupos requieren en la mayor parte de los casos, además del ejercicio de las competencias adquiridas, de su implementación coordinada de manera grupal.

- Saber ser: Nivel de autonomía y creatividad y capacidad de innovación demostrados en la puesta en práctica de la competencia. Para enfrentarse a problemas novedosos no conocidos hasta la fecha, las personas deben ser capaces de aplicar soluciones creativas partiendo de las competencias ya adquiridas, incorporando así una innovación en su mapa de competencias.

Así, nuestro modelo de formación en competencias informacionales parte de los aspectos más globales de la persona, para centrarse en los elementos más específicos (aunque interrelacionados) de la competencia en sí.

La formación en competencias informacionales parte directamente del concepto de competencia y sus implicaciones. Así, se ponen en marcha los principios de la formación basada en competencias, y se propone una formación contextualizada, activa, centrada en el alumno y en el propio aprendizaje y fundamentada en los resultados de aprendizaje o evidencias programadas. En una palabra, se busca una formación auténtica.

«Una formación auténtica sería aquella que favorece la apropiación de competencias, en nuestro caso informacionales, y cuyo diseño se basa en la selección y emulación de situaciones-problema cuyas condiciones de aplicación guardan una gran fidelidad con las que se producen en sus contextos de desempeño real en los que se precisa localizar y utilizar información apropiada» (Monereo \& Badia, 2012, p. 90)

\subsubsection{La implementación y evaluación de las competencias informacionales en programas educativos}

«Sin evaluación no hay aprendizaje. Sólo por la evaluación, que es reflexión, el aprendizaje adquiere sentido. Por la evaluación la información recogida, cualquiera que sea el recurso, se hace comprensible, se hace transparente, y se hace materia 
de aprendizaje. Sin evaluación, sin reflexión, el aprendizaje se vuelve tarea mecánica, rutinaria, inconsciente, ejercicio de memoria a corto plazo: el que dicta la fecha del control, la fecha del examen. Por tanto, no es comprensible y no parece consistente la postura de quien sostiene que en la escuela, y por extensión, en el sistema educativo, se evalúa mucho. Si acaso, se examina mucho, que es otra cuestión. Por eso se aprende tan poco de las pruebas evaluadoras -lo más correcto sería llamarlas calificadoras- que se llevan a cabo.» (Álvarez Méndez, 2012, p. 141)

Después de llevar a cabo toda la revisión teórica acerca del concepto y estructura de las competencias básicas en general, y de las competencias informacionales en particular, consideramos que estamos en condiciones de considerar cómo se desarrollan los procesos de enseñanza-aprendizaje relacionados con las competencias informacionales.

El primer punto en el que queremos detenernos es en el estudio de cuál es o debe ser, el posicionamiento que se merecen estos contenidos en los propios currículos educativos.

A estas alturas, no ponemos en duda la necesidad imperiosa de que los currículos recojan este contenido como básico a lo largo de toda la educación básica. Podríamos no obstante argumentar esta postura presentando algunos criterios ya tratados a lo largo de las anteriores páginas:

- La producción de conocimiento crece en todas las áreas de manera exponencial, por lo que el ciudadano debería «disponer de los criterios y estrategias intelectuales para encontrar nuevas informaciones que sean valiosas para su ámbito o campo de estudio, de investigación o de actividad profesional» (Area Moreira, 2010a, p. 3)

- Cada vez existen fuentes más numerosas, sobre todo en formato digital, que almacenan, organizan y difunden información.

- Para alcanzar con éxito la implementación de las teorías socioconstructivistas del aprendizaje, es necesario como condición previa que el alumno esté formado en competencias informacionales.

- La realidad es cada vez más multimodal, apareciendo continuamente nuevos lenguajes expresivos que debe dominar el ciudadano para poder acceder, interpretar, comunicar y difundir conocimiento. 
La propia naturaleza del concepto de competencia exige que la formación en competencias informacionales se realice planteando "situaciones contextualizadas a través de preguntas no reproductivas desde una visión global que exija una acción cooperativa, razonada y planificada» (Blasco Olivares \& Durban Roca, 2012, p. 111).

Es más, teniendo en cuenta que nos hemos acercado a la educación desde una perspectiva basada en un modelo sociocrítico, no tiene ningún sentido tratar de formar a los sujetos a partir contenidos descontextualizados, pretendidamente asépticos y no inmersos en la realidad de un contexto y unas prácticas culturales determinadas.
"La ALFIN puede verse desarrollada y expresada por completo solamente dentro de un contexto, y la aplicación de sus conceptos difiere de un campo de conocimiento a otro. En consecuencia, los programas genéricos de ALFIN pueden ofrecer poco valor porque están esencialmente descontextualizados $y$, por tanto, se considera que sólo pueden promover un aprendizaje de bajo nivel» (A. Byrne, 2005, p. 15).

La realidad transversal y poco tangible del día a día del desarrollo de estas competencias también dificulta en buena medida el diseño e implementación de sistemas de evaluación sistemáticos y basados en evidencias. Esta supuesta transversalidad en cada una de las áreas de contenido del currículo es esencial, ya que «el que los profesores, mientras enseñan y evalúan su materia, enseñen y evalúen al mismo tiempo ciertas competencias informacionales, garantizará en mayor medida su aprendizaje» (Monereo \& Badia, 2012, p. 94).

A nivel general, al tratarse de una competencia básica, consideramos que se deben mantener los criterios de evaluación de las competencias básicas que ya se han planteado más arriba: evaluación auténtica, conforme al criterio, desarrollo de la responsabilidad compartida en el proceso de evaluación, continua, formativa, variada y múltiple.

En todo caso, conforme al modelo de competencias propuesto, las competencias informacionales se dividen en sub-competencias, que a su vez pueden ser diseccionadas en constelaciones de componentes de las sub-competencias. Recordemos que estos componentes se pueden clasificar en cuatro tipos bien diferenciados (saber, saber hacer, saber estar y saber ser).

De este modo, nos encontramos con que, a través del desarrollo del razonamiento deductivo, podemos "desmontar" las propias competencias informacionales en un conjunto de conocimientos, habilidades, disposiciones y conductas concretas que son 
evidenciables, y que, como tal, también son evaluables empleando sistemas e instrumentos más o menos objetivos. Sin embargo, no debemos olvidar que las competencias informacionales, a pesar de poder dividirse fácilmente en subdimensiones y múltiples componentes, forman un todo integrado y relacionado, por lo que en el proceso de evaluación deberemos mantener en todo momento una visión global de la propia competencia. Como medida para tratar de evitar la excesiva compartamentalización de los diferentes componentes que forman las competencias informacionales, proponemos, a partir de los componentes que se quieran desarrollar, implementar rúbricas de evaluación que además de facilitar una evaluación objetiva basada en evidencias, colaboren en aportar a la vez una visión holística de la competencia total que se está trabajando (Torres Gordillo \& Perera Rodríguez, 2010). 


\subsection{Resumen}

En este tercer capítulo nos hemos embarcado en el objetivo de crear un marco conceptual válido para situar la competencia y la formación basada en competencias en el entorno descrito a lo largo de los dos capítulos anteriores. Así, se han estudiado de manera pormenorizada todos los elementos relacionados con las competencias en general y con las competencias informacionales en particular. Realmente, lo que se buscaba era aportar un nivel de concreción superior a los capítulos precedentes: mientras que en el primer capítulo hemos llevado a cabo un análisis general de la sociedad actual y en el segundo hemos concretado las consecuencias generales en el mundo de la educación, en este tercer capítulo hemos llegado a un nivel de concreción mucho más específico al terminar focalizando nuestro análisis precisamente en la competencia concreta objeto de este trabajo.

El desarrollo del capítulo se ha iniciado analizando ciertos aspectos y elementos básicos acerca del concepto de competencia. En primer lugar se ha hecho un análisis del propio término desde una perspectiva histórica y epistemológica, con el objeto de entender su procedencia y las bases conceptuales que están detrás del constructo competencia. Una vez clarificados estos elementos básicos, hemos procedido al estudio y análisis de las principales definiciones de competencia vertidas por varios autores desde campos muy diversos. De este modo nos hemos percatado de que existen perspectivas muy diversas a la hora de enfrentarse al término competencia, llegando a considerarse incluso un concepto muy ambiguo y poco concreto.

Por ello, con la intención de discernir lo que realmente nosotros vamos a entender por competencia a lo largo del resto de la investigación, analizamos el propio término desde una perspectiva pedagógica, para terminar construyendo una definición de competencia adaptada a nuestros enfoques. En suma, hemos considerado que competencia se refiere a la capacidad que se tiene de movilizar un conjunto de recursos cognitivos para afrontar con garantías situaciones problemáticas en contextos académicos o profesionales concretos.

Una vez que ya teníamos bien delimitado y concretizado lo que entendemos por competencia, ya estábamos en condiciones de llevar a cabo un estudio más analítico de las estructuras que subyacen a un modelo de formación basada en competencias. Así, hemos continuado la exposición diferenciando los ámbitos de aprendizaje que entran en juego en todo proceso de formación por competencias (social, 
interpersonal, personal y profesional) y los componentes por los que toda competencia está formada (saber, saber hacer, saber ser y saber estar). Profundizando en estas estructuras, hemos construido un modelo de formación basada en competencias, que ha resultado ser multidimensional y con una estructura jerárquica basada en las competencias básicas.

Al haber definido ya el modelo de competencias a partir del que vamos a trabajar en este proyecto, el razonamiento teórico nos ha conducido a preguntarnos acerca de cómo se desarrollan los procesos de enseñanza-aprendizaje y de evaluación en los modelos de formación basados en competencias. Las siguientes líneas del trabajo han ido destinadas a tratar de resolver este interrogante.

Teniendo perfectamente conceptualizado y modelizado el proceso de formación basado en competencias, hemos procedido a concretar más en nuestro discurso profundizando específicamente sobre ciertos elementos acerca de las competencias informacionales. En este caso, hemos comenzado resolviendo la duda sobre el porqué de la necesidad del desarrollo de competencias informacionales en la sociedad actual.

Una vez resueltas estas consideraciones previas, hemos llevado a cabo un análisis de las principales definiciones de competencias informacionales, hasta adoptar la definición que más se adapta a nuestras perspectivas e ideas.

Cuando ya teníamos claro el porqué de las competencias informacionales, y habíamos definido adecuadamente el concepto defendido, hemos considerado pertinente llevar a cabo un estudio de los aspectos básicos que rodean al concepto analizado, teniendo en cuenta la problemática de la terminología, su estructura multidimensional y los componentes por los que está formado.

Después de este estudio genérico de las competencias informacionales, nos hemos dispuesto a descomponerlo en sus dimensiones internas y éstas en desempeños concretos o resultados de aprendizaje. Para ello, nos hemos servido de los diversos documentos institucionales a nivel internacional existentes en torno a las normas y estándares en competencias informacionales. Se pone en evidencia cómo estas normas son coincidentes en casi su totalidad, estando las dimensiones de las competencias informacionales claras y bien delimitadas. Así mismo, nos hemos adentrado en el análisis de alguno de los modelos de formación en competencias más importantes de la actualidad, que no hacen otra cosa que operativizar las normas y estándares de los documentos oficiales a programas formativos concretos. 
A partir del análisis pormenorizado del contenido propio de las competencias informacionales, visto que los modelos existentes son dispersos y poco adaptados a nuestras necesidades e intereses, hemos considerado que era preciso plantear un modelo propio de formación en competencias informacionales extraído directamente del modelo propuesto anteriormente de formación basada en competencias. Así, se definen perfectamente los diversos elementos del modelo, como son las dimensiones de la competencia, ámbitos o áreas de aprendizaje del modelo y los componentes de la competencia. Todos los elementos, a pesar de que conforman realidades diferentes, construyen en conjunto un todo relacionado inseparable, en el que, a través de la práctica organizada basada en los componentes de la competencia se llega al dominio de las dimensiones que conforman las competencias informacionales $y$, en última instancia, al aprendizaje de los diferentes ámbitos que ayudan a construir el 'yo' de la persona y el 'nosotros' de la sociedad.

Por último, la exposición finaliza analizando concretamente ciertos problemas relacionados con la integración de las competencias informacionales en los procesos educativos formales y en los currículos de educación básica y con el diseño, implementación y evaluación de estas competencias en la educación básica. 



\section{Capítulo IV}

ESTUDIO I: Evaluación de competencias informacionales en estudiantes y futuro profesorado de ESO 


\section{Capítulo IV}

\begin{abstract}
Evaluación de las competencias informacionales en estudiantes de educación secundaria (14-16 años) y en futuros profesores de ESO
\end{abstract}

4.1 Introducción al estudio empírico

4.2 Metodología de la investigación

4.3 Resultados en estudiantes de educación secundaria

4.4 Resultados en futuro profesorado de educación secundaria

4.5 Resumen 


\section{ESTUDIO I: Evaluación de las competencias informacionales en estudiantes de educación secundaria (14-16 años) y en futuros profesores de ESO}

\subsection{Introducción al estudio empírico}

En el marco de nuestra labor como investigadores, se entiende la investigación educativa como una actividad científica formal, por lo tanto, sistemática, controlada, empírica y objetiva. Así, esta Tesis Doctoral pretende, como fin último, aportar información valiosa acerca del proceso de evaluación y desarrollo de competencias básicas relacionadas con el acceso a la información y su transformación en conocimiento. Así, se trabaja en colaborar, con los resultados obtenidos, en la creación y desarrollo de un cuerpo de conocimientos estable sobre evaluación y desarrollo de competencias informacionales en educación secundaria.

Partiendo desde este punto de vista, se proponen tres objetivos generales que se irán resolviendo con los empíricos propuestos:

1. Realizar una evaluación diagnóstica del alumnado de Educación Secundaria Obligatoria sobre el nivel de desempeño e importancia percibidos en competencias informacionales, aplicando técnicas estadísticas como los modelos causales de regresión múltiple para conocer la relación entre las competencias informacionales percibidas y ciertas variables antecedentes 0 predictoras.

2. Constatar el nivel percibido en competencias informacionales en el futuro profesorado de Educación Secundaria Obligatoria, aplicando técnicas estadísticas como los modelos causales de regresión múltiple para conocer la relación entre las competencias informacionales percibidas y ciertas variables antecedentes o predictoras.

3. Diseñar, desarrollar y evaluar los resultados de un programa de intervención para la mejora de las competencias informacionales en futuros profesores de Enseñanza Secundaria Obligatoria. 
Los objetivos propuestos demandan, debido a su diversa naturaleza, la implementación de procedimientos metodológicos diferenciados para su correcto tratamiento. Por ello, dentro del estudio empírico fruto de esta Tesis Doctoral se plantean dos procesos metodológicos específicos: uno de ellos ligado a los objetivos evaluativos 1 y 2 y un segundo proceso, que da respuesta al objetivo 3.

En primer lugar, para dar respuesta a los dos primeros objetivos presentados, se plantea un estudio con un diseño de tipo no experimental, englobado dentro de las metodologías ex-post-facto. En el mismo, se plantean estrategias de tipo descriptivocorrelacional, a través de estudios de encuesta (Kerlinger \& Lee, 2002). No pretendemos en este primer estudio presentar un diseño experimental, ya que la meta es explorar y explicar en la medida de lo posible una situación concreta que ocurre de manera natural y que desconocemos de partida. Así, no se modifican las variables, sólo se seleccionan y observan (Arnal, Rincón, \& Latorre, 1992).

Por otro lado, el último objetivo mostrado se abarca a través de un diseño cuasiexperimental de control mínimo, desarrollado en un grupo único con pretest y postest (D. T. Campbell \& Stanley, 1963). En este caso, la variable dependiente (nivel de desarrollo en las diferentes dimensiones de las competencias informacionales) es medida antes y después de administrar el tratamiento (programa de intervención para la mejora de las competencias informacionales) sobre un único grupo de sujetos experimentales, futuros profesores de educación secundaria.

Debido a la distinta naturaleza de los diseños planteados en ambos estudios, el tratamiento de las variables y la formulación de las hipótesis de trabajo se ajusta a las peculiaridades de cada uno.

En el primer estudio, de corte no experimental, no tiene sentido hablar de hipótesis experimentales de modo estricto. Sin embargo, se plantean a lo largo del estudio hipótesis científicas acerca de la autopercepción del nivel de desarrollo sobre competencias informacionales en función de ciertas variables personales y/o sociales. Por otro lado, en cuanto al tratamiento de las variables, al no existir una manipulación ni control previo de las mismas, nos referiremos en todo caso a variables criterio y predictoras. Se entiende como variable predictora aquella variable que colabora en la explicación de un fenómeno concreto. La variable criterio se podría definir como aquel fenómeno que se pretende explicar a partir del estudio de un conjunto de variables predictoras. 
El segundo estudio, más cercano a los diseños experimentales propiamente dichos, se fundamenta a partir del planteamiento de hipótesis experimentales acerca de las diferencias obtenidas en la aplicación de la prueba de manera previa y posterior al tratamiento. En este caso, dado que en el tratamiento se lleva a cabo una manipulación de las variables estudiadas, se puede hablar de variables dependientes e independientes. Asi, variable independiente «Es la característica que el investigador observa o manipula deliberadamente para conocer su relación con la variable dependiente. La VI es la situación antecedente de un efecto; responde a la idea de causa» (Arnal et al., 1992, p. 72). Por su lado, variable dependiente se puede considerar como «la característica que aparece o cambia cuando el investigador aplica, suprime o modifica la variable independiente. Suele denominarse criterio y corresponde a la idea de efecto producido por los cambios de la VI.» (Arnal et al., 1992, p. 73).

Para terminar de introducir este bloque, dado el enfoque cuantitativo de los dos estudios que aquí se presentan, creemos necesario hacer una breve referencia a los criterios de selección de las técnicas más apropiadas para el análisis de datos tanto en uno como en otro estudio.

En el Estudio I, dado que se trata de un estudio ex-post-facto, se aplican técnicas de tipo descriptivo, correlacional y multivariante:

- Como paso previo al análisis de datos más propiamente dicho, se procede al estudio de las propiedades psicométricas de los instrumentos aplicados, con el fin de constatar la valides y fiabilidad de los resultados obtenidos. Así, se procede inicialmente al estudio de la fiabilidad de las escalas mediante la medición de la consistencia interna y del análisis de discriminación de los ítems (la correlación ítem-total corregida). Por otro lado, se validan las propiedades dimensionales de las escalas mediante la aplicación de técnicas de análisis factorial, tanto exploratorio cómo confirmatorio.

- Una vez comprobada la validez y fiabilidad de las escalas, en primer lugar se lleva a cabo un proceso exploratorio de las variables con la finalidad de seleccionar las técnicas descriptivas más adecuadas: Estudio de las funciones de densidad y distribución, momentos respecto al origen y a la media. medidas de posición (cuantiles, percentiles, cuartiles, deciles,...), medidas de tendencia 
central (media, mediana y moda), medidas de dispersión (varianza, desviación típica, rango y coeficiente de variación) y medidas de forma (asimetría y curtosis)

- En segundo lugar, después del proceso exploratorio, a partir del consecuente estudio descriptivo se implementa un estudio de correlación para determinar en qué medida las variables están relacionadas entre sí. Previamente se lleva a cabo un estudio para determinar qué tipo de regresión es la más adecuada para los datos existentes (lineal, exponencial, logarítmica, cuadrática,...). Así, se procede al estudio de las matrices de correlaciones aplicando la medida más oportuna en función de la naturaleza de las variables correlacionadas (coeficiente de Pearson, Spearman, fi, correlación biserial puntual,...).

- Por último, una vez realizado el estudio de correlaciones simples, se procede al estudio de las variaciones conjuntas y covarianzas existentes en los datos mediante la aplicación de técnicas multivariantes. Con el objeto de establecer un modelo causal explicativo del desarrollo de las competencias informacionales, se analizan las variables clave a partir de técnicas de modelos de ecuaciones estructurales. Estas técnicas permiten analizar las relaciones entre variables observadas y latentes, a partir de la matriz de varianzascovarianzas de dichas variables, en el estudio de un fenómeno de interés concreto (Silva Zamora \& Schiattino Lemus, 2008). Dichas relaciones no implican una causalidad inherente a la propia técnica estadística (Pearl, 1995, 2003), sino que son necesarias evidencias teóricas fundamentadas para aceptarla.

Por su parte, en el Estudio II, de naturaleza cuasiexperimental, se aplican principalmente técnicas de tipo inferencial, con el objetivo de generalizar los resultados obtenidos en la muestra representativa a la población diana del estudio:

- Previamente al estudio inferencial (Tejedor Tejedor, 2006) propiamente dicho, se requiere un análisis de la bondad de ajuste de las variables con las que se va a hacer inferencia. Así, se lleva a cabo un estudio de las funciones de densidad de las variables para verificar su ajuste a la distribución normal (distribución 
simétrica y mesocúrtica). Además del estudio previo de la gráfica de la función de densidad, se procede a la aplicación de pruebas que contrastan esta bondad de ajuste: homocedasticidad mediante el test de Levene (Levene, 1960), normalidad mediante el estudio de la asimetría, curtosis, la prueba de Kolmogorov-Smirnov e independencia de las observaciones mediante la prueba de rachas para verificar la aleatoriedad de la muestra.

- Entre las pruebas paramétricas para realizar la inferencia, se programa aplicar:

- Para contrastar la dependencia o independencia de dos variables en una población se procede al análisis de la diferencia de medias para muestras relacionadas, mediante la aplicación del estadístico de contraste t de Student.

- En el caso de que sea necesario llevar a cabo el contraste entre más de dos elementos se aplican técnicas de análisis de varianza (ANOVA) (Tejedor Tejedor, 1999).

- En el caso de que por problemas en la bondad de ajuste se tenga que recurrir a pruebas no paramétricas (Siegel, 1970), se procede a la aplicación de pruebas basadas en el estadístico de contraste Chi-cuadrado, más concretamente la prueba de los signos de Wilcoxon (alternativa a la diferencia de medias para muestras relacionadas, que hace una comparación entre el sumatorio de rangos positivos y negativos) y el contraste de Kruskal-Wallis (alternativa al ANOVA).

A continuación se presenta el primer estudio realizado dentro del marco de la investigación completa. Tras la descripción de todos los aspectos metodológicos que sustentan la investigación desarrollada, se presentan los resultados derivados del estudio.

Como ya se ha señalado con anterioridad, el estudio I se divide en dos subapartados; los resultados obtenidos en la encuesta aplicada a los estudiantes del segundo ciclo de Educación Secundaria Obligatoria (14 -16 años), y los resultados obtenidos en la encuesta aplicada al futuro profesorado de Educación Secundaria Obligatoria, que se encontraba finalizando el Máster Oficial en Profesor de Educación Secundaria Obligatoria, Bachillerato, Formación Profesional y Enseñanzas de Idiomas. En ambos casos, la escala principal aplicada tanto a futuros profesores como a 
alumnos se adapta a partir de la escala IL-HUMASS de Pinto (2009). Sin embargo, como se mostrará más adelante, a pesar de que las dimensiones teóricas de ambos cuestionarios son las mismas, el número de ítems y la formulación final de los mismos no es exactamente igual en ambas escalas.

Así, mientras que el diseño de la investigación y el análisis de datos son comunes dentro del estudio I, la definición de las variables e instrumentos, la descripción de la población y muestra y la exposición de resultados se informan por separado. 


\subsection{Metodología de la investigación. Estudio I}

En las siguientes páginas se presenta el primer estudio realizado dentro del marco de la investigación completa.

Tras la descripción de todos los aspectos metodológicos que sustentan la investigación desarrollada, se presentan los resultados derivados del estudio.

\subsubsection{Antecedentes. Estudio I}

Como ya hemos indicado en el marco teórico de esta investigación, desde que Zurkowski (1974), de una manera visionaria, apunta por primera vez hacia la existencia de una serie de conocimientos básicos para los ciudadanos que conviven día a día con las TIC, hasta nuestros días, el estudio e investigación de las competencias informacionales ha ido reinventándose y desarrollándose.

En un principio, a mediados de los años 70, en los que las ya emergentes tecnologías relacionadas con el intercambio de información y datos se presentaban en diferentes ámbitos de la sociedad, Zurkowski apunta lo siguiente:

\footnotetext{
«People trained in the application of information resources to their work can be called information literates. They have learned techniques and skills for utilizing the wide range of information tools as well as primary range of information tools as well as primary resources in molding information-solutions to their problems» $(1974$, p. 6)
}

A partir de ahí, y hasta la actualidad, las referencias e investigaciones relacionadas con el desarrollo de estas competencias o alfabetizaciones ${ }^{16}$ han ido creciendo progresivamente. Tanto es así que, como muestra la tabla 4.1, en los últimos años se registra la masa de estudios más abultada, que incluso multiplica los registrados tan solo 10 años atrás.

Tabla 4.1 Citaciones en revistas JCR a artículos relacionados con competencias informacionales

\begin{tabular}{cccc|cccc|ccc}
\hline & \multicolumn{3}{c}{ INFORMATION LITERACY } & \multicolumn{3}{c}{ INFORMATION SKILLS } & \multicolumn{3}{c}{ INFORMATION COMPETENCIES } \\
\cline { 2 - 11 } & TOTAL & EDU & $\%$ EDU & TOTAL & EDU & $\%$ EDU & TOTAL & EDU & $\%$ EDU \\
\hline 1978 & 0 & 0 & - & 1 & 1 & $100.00 \%$ & 0 & 0 & - \\
\hline 1979 & 0 & 0 & - & 0 & 0 & - & 0 & 0 & - \\
\hline 1980 & 0 & 0 & - & 1 & 1 & $100.00 \%$ & 0 & 0 & - \\
\hline
\end{tabular}

\footnotetext{
${ }^{16}$ Como ya se señaló en los primeros capítulos teóricos de la tesis doctoral, desde el campo de la Biblioteconomía y las Ciencias de la Información se prefiere el empleo del agregado 'alfabetización' para denominar al tipo de conocimientos al que hacemos referencia.
} 


\begin{tabular}{|c|c|c|c|c|c|c|c|c|c|}
\hline 1981 & 0 & 0 & - & 0 & 0 & - & 0 & 0 & - \\
\hline 1982 & 0 & 0 & - & 1 & 1 & $100.00 \%$ & 0 & 0 & - \\
\hline 1983 & 0 & 0 & - & 0 & 0 & - & 0 & 0 & - \\
\hline 1984 & 0 & 0 & - & 0 & 0 & - & 0 & 0 & - \\
\hline 1985 & 0 & 0 & - & 0 & 0 & - & 0 & 0 & - \\
\hline 1986 & 0 & 0 & - & 2 & 1 & $50.00 \%$ & 0 & 0 & - \\
\hline 1987 & 1 & 1 & $100.00 \%$ & 2 & 0 & $0.00 \%$ & 0 & 0 & - \\
\hline 1988 & 1 & 0 & $0.00 \%$ & 7 & 2 & $28.57 \%$ & 0 & 0 & - \\
\hline 1989 & 0 & 0 & - & 5 & 2 & $40.00 \%$ & 0 & 0 & - \\
\hline 1990 & 0 & 0 & - & 16 & 10 & $62.50 \%$ & 0 & 0 & - \\
\hline 1991 & 3 & 0 & $0.00 \%$ & 24 & 18 & $75.00 \%$ & 0 & 0 & - \\
\hline 1992 & 3 & 1 & $33.33 \%$ & 23 & 19 & $82.61 \%$ & 0 & 0 & - \\
\hline 1993 & 0 & 0 & - & 24 & 23 & $95.83 \%$ & 0 & 0 & - \\
\hline 1994 & 6 & 1 & $16.67 \%$ & 21 & 21 & $100.00 \%$ & 0 & 0 & - \\
\hline 1995 & 8 & 0 & $0.00 \%$ & 39 & 30 & $76.92 \%$ & 0 & 0 & - \\
\hline 1996 & 6 & 1 & $16.67 \%$ & 41 & 29 & $70.73 \%$ & 0 & 0 & - \\
\hline 1997 & 12 & 0 & $0.00 \%$ & 30 & 17 & $56.67 \%$ & 0 & 0 & - \\
\hline 1998 & 27 & 5 & $18.52 \%$ & 36 & 22 & $61.11 \%$ & 0 & 0 & - \\
\hline 1999 & 42 & 4 & $9.52 \%$ & 50 & 25 & $50.00 \%$ & 0 & 0 & - \\
\hline 2000 & 17 & 3 & $17.65 \%$ & 35 & 22 & $62.86 \%$ & 0 & 0 & - \\
\hline 2001 & 67 & 10 & $14.93 \%$ & 42 & 25 & $59.52 \%$ & 2 & 1 & $50.00 \%$ \\
\hline 2002 & 94 & 10 & $10.64 \%$ & 44 & 23 & $52.27 \%$ & 1 & 0 & $0.00 \%$ \\
\hline 2003 & 129 & 20 & $15.50 \%$ & 63 & 29 & $46.03 \%$ & 1 & 0 & $0.00 \%$ \\
\hline 2004 & 106 & 21 & $19.81 \%$ & 60 & 31 & $51.67 \%$ & 2 & 0 & $0.00 \%$ \\
\hline 2005 & 207 & 51 & $24.64 \%$ & 74 & 42 & $56.76 \%$ & 1 & 0 & $0.00 \%$ \\
\hline 2006 & 234 & 32 & $13.68 \%$ & 102 & 38 & $37.25 \%$ & 0 & 0 & - \\
\hline 2007 & 360 & 77 & $21.39 \%$ & 142 & 72 & $50.70 \%$ & 6 & 2 & $33.33 \%$ \\
\hline 2008 & 501 & 138 & $27.54 \%$ & 170 & 86 & $50.59 \%$ & 5 & 4 & $80.00 \%$ \\
\hline 2009 & 590 & 153 & $25.93 \%$ & 150 & 72 & $48.00 \%$ & 7 & 4 & $57.14 \%$ \\
\hline 2010 & 738 & 157 & $21.27 \%$ & 189 & 76 & $40.21 \%$ & 8 & 6 & $75.00 \%$ \\
\hline 2011 & 937 & 224 & $23.91 \%$ & 208 & 83 & $39.90 \%$ & 11 & 8 & $72.73 \%$ \\
\hline 2012 & $581 *$ & $144^{*}$ & $24.78 \%$ & $134^{*}$ & $51^{*}$ & $38.06 \%$ & $5 *$ & $4^{*}$ & $80.00 \%$ \\
\hline Total & 4670 & 1053 & $22.55 \%$ & 1736 & 872 & $50.23 \%$ & 49 & 29 & $59.18 \%$ \\
\hline
\end{tabular}

* Datos correspondientes a 2012 incompletos (Consulta realizada en septiembre de 2012)

En la tabla anterior se puede observar cómo durante la década de los 80 las referencias a artículos de investigación indexados en JCR relacionadas con las competencias informacionales son prácticamente inexistentes, salvo en los últimos años, en los que el término information skills comienza a repuntar. La presencia en el campo de las ciencias de la educación es prácticamente testimonial, ya que sólo se localizan 8 referencias a artículos con esta temática. 


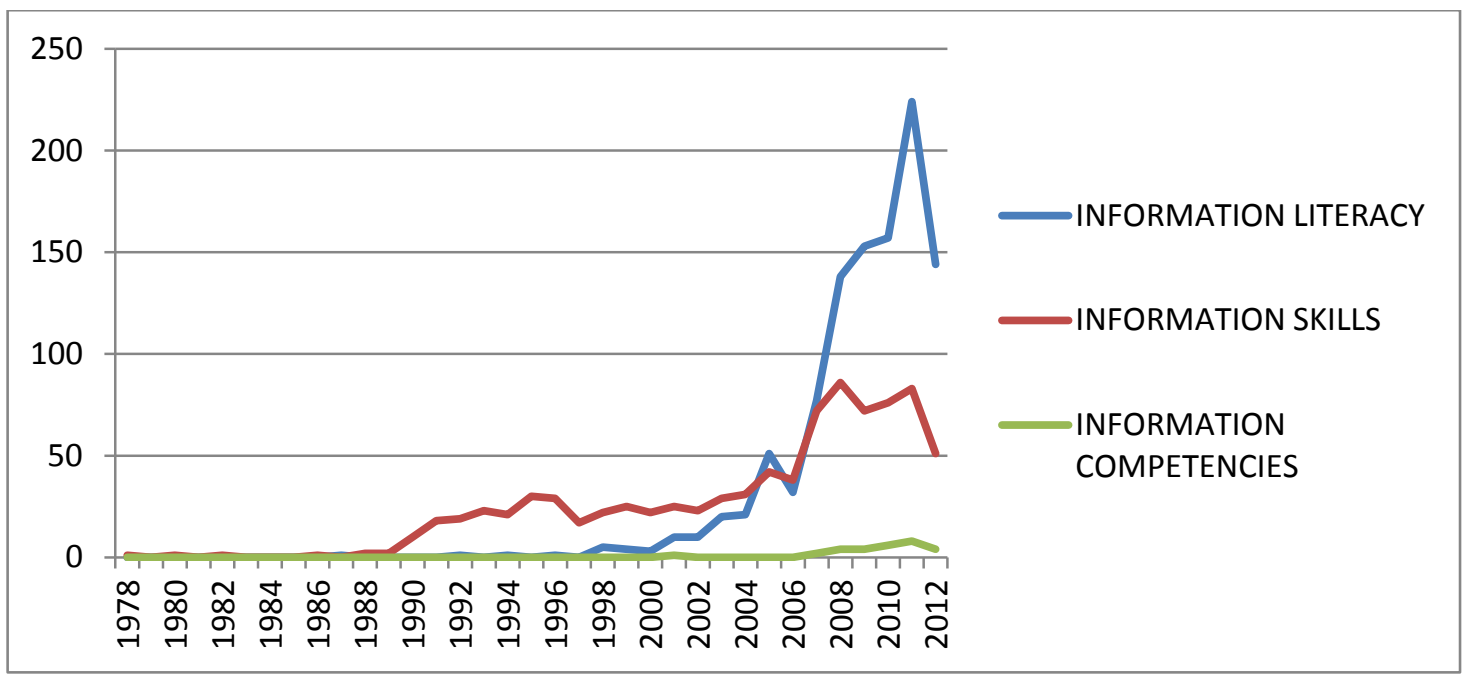

Gráfico 4.1 Citaciones a artículos relacionados con competencias informacionales en Revistas de Ciencias de la Educación

Por su parte, el gráfico 4.1 muestra más claramente esta tendencia ascendente en lo que respecta únicamente a las revistas del ámbito de las Ciencias de la Educación desde inicios de los años 90 en el caso de information skills, y posteriormente en el resto de casos.

Se corrobora, además, lo observado por otros estudios relacionados, que observan cómo information skills va perdiendo presencia a favor del término information literacy (Pinto Molina, Cordón, \& Díaz, 2010; Pinto Molina, Uribe Tirado, Gómez Díaz, \& Cordón, 2011)

Es a partir de los primeros años de la década de los 90, coincidiendo con el empuje que aportan instituciones como la American Library Association (ALA), junto con su división Association of College \& Research Libraries (ACLR) en los Estados Unidos de América o la Society of College, National and University Librarians (SCONUL) en Gran Bretaña al estudio de este tipo de competencias en el campo de las Ciencias de la Información y la Biblioteconomía, cuando germinan multitud de estudios al respecto. En estos años, empujados por el auge de la Informática, la Biblioteconomía y las Ciencias de la Información, los términos más abundantes tienen que ver con la information literacy y las information skills. El término que nosotros empleamos de competencias informacionales aún no se ha extendido en la investigación educativa ni científica en general.

Si bien en los años 90 se comienza a desarrollar un corpus sólido y sistemático de las competencias informacionales gracias a las investigaciones desarrolladas, no es hasta bien entrada la primera década del siglo XXI cuando los estudios relacionados con las competencias informacionales explotan y aumentan exponencialmente. Es en 
este momento, coincidiendo con el impulso dado a la formación basada en competencias, cuando las Ciencias de la Educación se comienzan a interesar por este tipo de competencias relacionadas con el manejo de la información. Así, se observa cómo, mientras entre los años 1990 y 2005 se emplea mayoritariamente en el campo de la investigación educativa el término information skills, a partir de 2006 los estudiosos del ámbito de las Ciencias de la Educación comienzan a asumir otros conceptos más pedagógicos como information literacy e information competences.

El hecho de que information literacy tenga tanto auge entre esta área en concreto en los últimos años tiene que ver con los nuevos postulados sobre las alfabetizaciones múltiples (Cazden et al., 1996; Cope \& Kalantzis, 1999, 2009a; Lankshear \& knobel, 2008), que han alcanzado una gran popularidad dentro del mundo de la educación, y especialmente en el campo de la formación con TIC. Por su parte, el término competencias informacionales, por el que abogamos por razones ya expuestas, comienza su andadura en 2001, y va creciendo hasta la actualidad de manera sostenida.

Ahora, una vez hecho este breve repaso al concepto, la pregunta es: ¿Qué es lo que motiva esta eclosión de los estudios de investigación relacionados con las competencias informacionales cuando tradicionalmente no se implementa ningún estudio al respecto?

Ya hemos señalado en los capítulos teóricos de este documento que el auge de las competencias informacionales está, dada su naturaleza, íntimamente relacionado con la explosión de las TIC en la sociedad y con el surgimiento de la sociedad de la información. Sin embargo, estas tecnologías ya se comenzaron a desarrollar y extender en los años 80 y a generalizar a principios de los 90 . Entonces, ¿por qué esta tardanza en el desarrollo de estas investigaciones?

Todo esto tiene que ver, bajo nuestro punto de vista, con el surgimiento durante los años 90 del 'esqueleto' teórico de este campo de conocimiento. Dada la falta de una base teórica firme y consistente que sostuviera el constructo competencias informacionales, y la falta de referencias sobre los contenidos que incluir dentro de estas competencias, las principales asociaciones de bibliotecas de varios países del mundo se ponen manos a la obra en la generación de estándares y normas que aportan indicadores sobre las competencias, sub-competencias y desempeños concretos incluidos dentro de las competencias informacionales. 
Así, la primera institución que lleva a cabo un esfuerzo en este sentido es la ALA (1989), que publica el informe "American Library Association Presidential Committee on Information Literacy: final report", en el que se comienza la senda de la estandarización y normativización de las competencias. En el informe, se definen cuatro componentes dentro de las competencias informacionales: habilidad para reconocer cuándo se necesita una información, y para localizar, evaluar y usar con eficacia la información requerida. Estos componentes, aunque con matices, han sido mantenidos como subcompetencias de la propia competencia general hasta la actualidad.

Después del informe de la ALA, a finales de la década de los años 90 y principios del siglo XXI, se comienza una carrera para crear un estándar válido de competencias informacionales. Así, varias asociaciones nacionales de bibliotecas lanzan sus normas que, como se indicó en el apartado teórico respectivo, tienen muchos puntos en común. En este ámbito, el ACLR, parte integrante de la ALA, publica un informe sobre estándars y normas (2000). En el ámbito europeo, el SCONUL es el representante principal que publica un manual con los estándares y normas básicas (2001). También en el ámbito europeo se encuentra el Chartered Institute of Library and Information Proffesionals (CILIP), que desarrolla algunas normas agregadas a las anteriores (Abell et al., 2004) En el contexto del continente australiano, con la emergencia de investigadores destacados en este ámbito como Alan Bundy, Christine Bruce o Colin Lankshear, aparece el Australian and New Zealand Institute for Information Literacy (ANZIIL), que publica también sus propios estándares (2004). En los últimos años también se han comenzado a desarrollar normas y estándares en el ámbito de nuestro país. La institución encargada de este tipo de estudios es la Red de Bibliotecas Universitarias Españolas (REBIUN), junto con la Conferencia de Rectores de Universidades Españolas (CRUE), que desarrollan el proyecto de Competencias Informáticas e Informacionales (CI2) en los últimos años (CRUE-TIC \& REBIUN, 2009, 2012).

De este modo, mientras que durante los años 90 se comienza a desarrollar el cuerpo teórico que compone este campo, es a finales de esta década y a principios de la nueva cuando se generaliza un corpus común aceptado globalmente.

En este sentido, las primeras experiencias llevadas a cabo en las que se proponen programas educativos formales diseñados para el desarrollo de las competencias informacionales, basados en estos estándares, tienen también su nacimiento en esta década de los 90. En primer lugar, el principal programa diseñado a inicios de los 90 se 
denomina Big Six (Eisenberg \& Berkowitz, 1990), que consiste en un modelo en el que los estudiantes aprenden la habilidad necesaria para la solución efectiva y eficiente de problemas de información y tiene una gran aceptación. El programa Big Six va seguido de otros intentos como las 8 W's (Lamb \& And Others, 1997), que plantea 8 tópicos o cuestiones sobre las que los usuarios tienen que trabajar. Estas cuestiones son watching (explorar), wondering (cuestionarse), webbing (buscar), wiggling (evaluar la calidad/pertinencia), weaving (sintetizar), wrapping (crear), waving (comunicar) y wishing (evaluar los resultados/proceso). Por último, otro proyecto que ha tenido un gran alcance internacional es el desarrollado en Gran Bretaña, denominado como Big Blue (Mackenize et al., 2002), que tiene como propósito ofrecer a los distintos profesionales implicados en la enseñanza de las competencias informacionales una guía actualizada para la enseñanza de las competencias informacionales, así como identificar y describir las buenas prácticas en este sentido que se desarrollan en el campo de acción del proyecto. A partir de los años siguientes, estos programas pierden pertinencia y actualidad ya que la investigación muestra cómo la enseñanza de este tipo de competencias, que son por naturaleza transversales, tiene sentido contextualizada como herramienta para la enseñanza de contenidos concretos (A. Byrne, 2005; Gómez Hernández \& Benito Morales, 2001). De hecho, dada la transversalidad curricular de las competencias básicas (De Miguel Díaz, 2010; Martínez Clares \& Echeverría Samanes, 2009), en el marco español y europeo estas competencias se desarrollan, a nivel normativo al menos, conjuntamente a lo largo de las diferentes materias del currículo más como una herramienta de trabajo que como un objeto en sí mismo.

Visto cómo se desarrolla el proceso de nacimiento y conformación del campo de la alfabetización informacional, veamos cuál es el proceso que lleva a adoptar desde la investigación educativa estas bases teóricas para llevar a cabo un estudio más pormenorizado del desarrollo, evaluación y formación sobre competencias informacionales.

A pesar de que el tema ya había suscitado cierto interés en el campo educativo, como se ha observado anteriormente, es a partir del inicio del siglo XXI cuando el desarrollo de competencias relacionadas con el manejo de la información, especialmente en redes informáticas, comienza su apogeo. Este 'boom' coincide, no azarosamente, con la integración masiva de los programas de formación basados en competencias. Se puede decir que la formación basada en competencias es un trampolín que favorece a la inclusión en la investigación educativa y en los programas 
formativos nacionales e internacionales de las competencias informacionales como un área concreto.

El modelo de formación basado en competencias se traslada a todos los niveles educativos, tanto en la educación básica como en la educación superior (De Miguel Díaz, 2006; Gaio Alves et al., 2010; Hensen, 2010; Saarinen, 2005). En el caso de la Universidad, el detonante del cambio es la instauración del Proceso de Bolonia y el consiguiente Espacio Europeo de Educación Superior ${ }^{17}$.

Paralelamente a esta transformación de los sistemas educativos de todo el mundo, ya se ha señalado con anterioridad cómo surgen propuestas curriculares tanto a nivel nacional como internacional que incluyen nuevas competencias básicas, entre las que se incorporan las competencias informacionales con diversas denominaciones. Así, en este sentido existen propuestas a nivel internacional (Delors, 1997; UNESCO, 2005), a nivel europeo (Diario oficial de la Unión Europea, 2006; OCDE, 2004b, 2005, 2011) y a nivel nacional (Boletín Oficial del Estado, 2007a, 2007b; CRUE-TIC \& REBIUN, 2009) en las que se comienzan a vislumbrar intentos para llevar a cabo esta integración.

De este modo llegamos a la situación actual, en la que las competencias informacionales se han situado como una competencia básica esencial para los ciudadanos del siglo XXI (Mackey \& Jacobson, 2011; Weiner, 2010; Williamson, 2009). Sin embargo, las evidencias empíricas muestran que los estudiantes actuales no alcanzan un nivel de desarrollo de estas competencias informacionales satisfactorio (Head \& Eisenberg, 2009; Hernández Serrano \& Fuentes Agustí, 2011; Pifarré et al., 2009; Sánchez Burón, Rodríguez, \& Fernández Martín, 2009; Sigalés et al., 2009).

Dada esta situación, las líneas de trabajo por las que está desarrollándose la investigación en el ámbito de las competencias informacionales se pueden definir en cuatro grandes bloques o líneas de investigación.

1. En primer lugar, existe una corriente clásica, encargada de la definición del marco teórico de las competencias informacionales. Dado que este campo es relativamente nuevo, existe un buen número de teóricos encargados de desarrollar las bases que guían las investigaciones empíricas relacionadas con estas competencias. En este sentido, además del esfuerzo realizado por las Instituciones nacionales e internacionales de bibliotecarios durante los años 90 y principios del siglo XXI por elaborar estándares y normas al respecto, en la

\footnotetext{
${ }^{17}$ http://www.educacion.gob.es/boloniaeees/inicio.html
} 
actualidad se sigue desarrollando este campo de manera continua. Así, mientras que por una parte nos encontramos estudios e investigaciones individuales procedentes de diversos puntos geográficos (Bawden, 2001; Bruce, 1997; Bundy, 1998, 2004; Lau \& Cortés, 2009; Markauskaite, 2006; O'Farrill, 2008), por otra aparecen instituciones internacionales preocupadas por el desarrollo de las competencias informacionales que publican estudios sobre el estado actual de las competencias informacionales en diferentes regiones del mundo. Entre estas instituciones, podemos señalar como destacadas la International Federation of Library Associations and Institutions (IFLA), que publica varios informes al respecto (Gwyer, Stubbings, \& Walton, 2012; Lau, 2007) o la United Nations Educational, Scientific and Cultural Organization (UNESCO), que publica también algunos libros relacionados con esta temática (Catts \& Lau, 2009; Horton \& UNESCO, 2008; Sayers \& UNESCO, 2006).

2. Por otro lado, otro campo de investigación, todavía alejado del que en la presente tesis se desarrolla, es el relacionado con el estudio del papel de las bibliotecas y de los profesionales de la biblioteconomía en el desarrollo de las competencias informacionales. Este ámbito de estudio está muy desarrollado en el ámbito de la Biblioteconomía y las Ciencias de la Información, dados sus evidentes vínculos con esta carrera profesional. En los últimos años se han desarrollado un gran número de investigaciones al respecto (Chen \& Lin, 2011; Diehm \& Lupton, 2012; Maitaouthong, Tuamsuk, \& Tachamanee, 2012; Sanderson, 2011; Staley, Branch, \& Hewitt, 2010).

3. En tercer lugar, nos encontramos con un buen número de investigaciones que estudian el perfil de manejo de la información, tratando de establecer qué perfiles de manejo de información existen entre los estudiantes y usuarios de la información (Head \& Eisenberg, 2009; Jansen \& McNeese, 2005; Pifarré et al., 2009; Rowlands, 2008; Savolainen \& Kari, 2006; Sigalés et al., 2009), cuáles son las características comunes que definen estos perfiles (CastañedaPeña, González Niño, Marciales Vivas, Barbosa Chacón, \& Barbosa Herrera, 2010; Fuentes Agusti \& Monereo, 2008; Fuentes, Monereo, \& Sànchez, 2000; Hernández Serrano \& Fuentes Agustí, 2011; Lorigo et al., 2006; Madden, Eaglestone, Ford, \& Whittle, 2006), y cómo promocionar perfiles más apropiados para desarrollar las actividades propias relacionadas con el manejo 
de la información (Guinee, 2004; Henry, 2006; Hernández Serrano, 2009; Wildemuth, 2004).

4. Por último, podemos encontrarnos con otros estudios, en el que se enmarca el que es descrito en la presente investigación, relacionados con el diseño, estudio de las características psicométricas y aplicación de instrumentos de evaluación (estudio I) y la puesta en marcha de propuestas de formación sobre competencias informacionales (estudio II).

En cuanto a la evaluación de las competencias informacionales, podríamos hablar de la evaluación de diferentes realidades. Por una parte, existen estudios que evalúan las competencias informacionales de los alumnos (Ozkul \& Kaya, 2009; Resnis, Gibson, \& Hartsell-Gundy, 2010; Rodríguez Conde, Olmos Migueláñez, Pinto Molina, Martínez Abad, \& García Riaza, 2011) y de los profesores (Bury, 2011; Probert, 2009; Williams \& Coles, 2007; Williams \& Wavell, 2007). En estos casos el instrumento de evaluación empleado suele ser de elaboración propia, o adaptado de otros estudios. La falta de instrumentos de evaluación estandarizados dificulta mucho la comparabilidad entre estudios y regiones geográficas. Por otra parte, también se encuentran varios trabajos que se proponen el análisis de los programas formativos existentes de integración de las competencias informacionales (Emmett \& Emde, 2007; Gratch Lindauer, 2006; Marzal García-Quismondo, 2010), aunque estos últimos no se corresponden con el tópico aquí estudiado.

Volviendo al tema de la evaluación de las competencias informacionales en profesorado y alumnado, surge el problema de su medida. Mientras que en la mayor parte de los casos se emplean herramientas de elaboración propia o adaptadas de otras no estandarizadas (Ferguson, Neely, \& Sullivan, 2006; Probert, 2009; Resnis et al., 2010), tampoco se tiene clara la preferencia entre escalas de autopercepción de la competencia (Kurbanoglu, Akkoyunlu, \& Umay, 2006; Ozkul \& Kaya, 2009; Pinto Molina, 2009; Williams \& Wavell, 2007) o de actitudes hacia la misma (Bury, 2011; Richter, Naumann, \& Groeben, 2000). Lo que queda en evidencia es que no se localizan escalas con un estudio psicométrico sistemático y completo, y las que se encuentran no obtienen los ajustes esperados (Rodríguez Conde, Olmos Migueláñez, \& Martínez Abad, 2012). Por otro lado, no se localizan en la literatura escalas de evaluación de la competencia real, siendo lo más extendido y aceptado las escalas de autoeficacia que, aunque poseen una base que las aporta validez, deben ser interpretadas con las pertinentes reticencias. Este escollo puede ser una gran barrera que dificulte el desarrollo de instrumentos de evaluación adecuados, fiables y válidos. 
Por otro lado, dentro de esta línea de investigación, se localizan estudios que aplican programas formativos a una muestra de alumnos concreta (Freeman \& LyndBalta, 2010; Hernández Hernández, 2010; Mackey \& Ho, 2005; Warschauer, 2007). Dichos estudios suelen tratarse de estudios de caso en los que se aportan evidencias sobre la eficacia del programa en concreto, que suele ser diseñado por el propio equipo de investigación a partir de los estándares aportados por alguna de las Instituciones señaladas más arriba. La evaluación de los programas se realiza con instrumentos no estandarizados de manera generalizada. Así, a pesar de que se atisba una sistematización de los contenidos que se incluyen dentro de las competencias informacionales, la investigación sigue adoleciendo de instrumentos de evaluación de las mismas comparables y con unas cualidades psicométricas aceptables.

Otro aspecto importante a tener en cuenta es el nivel educativo en el que desarrollar las propias competencias informacionales. En este ámbito se localizan principalmente estudios enfocados en la etapa universitaria de los estudiantes (Hernández Serrano \& Fuentes Agustí, 2011; Hernández Serrano, 2009; Ozkul \& Kaya, 2009; Pinto Molina, 2009; Resnis et al., 2010), mientras que los estudios relacionados con las etapas de educación básica, en la que se desarrolla el presente estudio, son menos numerosas y más centradas en desempeños concretos de las competencias informacionales, principalmente la búsqueda de información (Fuentes Agusti \& Monereo, 2008; Head \& Eisenberg, 2009; Pifarré et al., 2009).

Así, nos debemos preguntar por qué tomar, para el estudio del nivel adquirido en competencias informacionales, como referente poblacional a los alumnos del segundo ciclo de educación secundaria (14-16 años) y no de otras etapas de la educación básica.

La figura siguiente, adaptada de Blasco y Durban (2012) muestra cómo se desarrollan los procesos de manejo de la información en la etapa escolar.

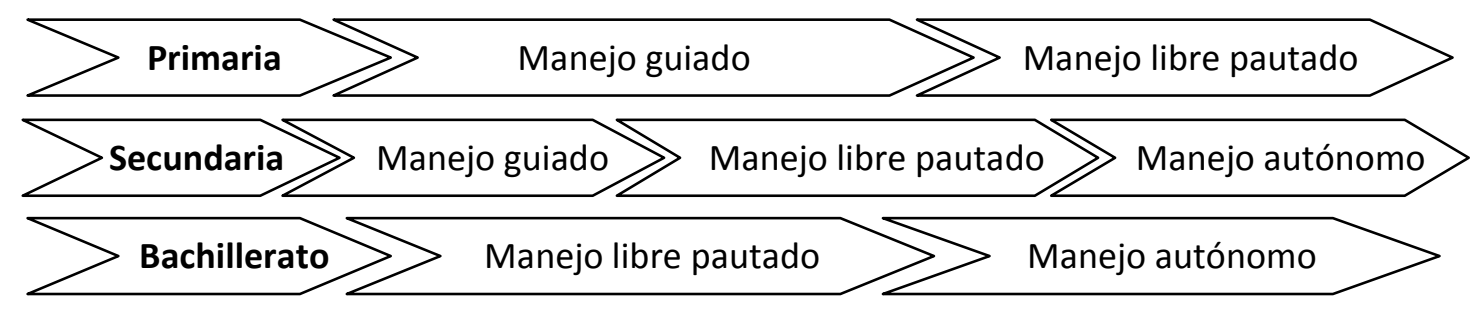

Figura 4.1 Evolución de las competencias informacionales en la etapa escolar

Se indica cómo, en la etapa de la educación primaria, el manejo de la información se desarrolla de una manera guiada por el profesor, dirigida implícita y explícitamente. 
Es en la etapa de la educación secundaria en la que el alumno comienza a tener una capacidad mayor para trabajar de manera autónoma en la búsqueda, evaluación, procesamiento y comunicación de información. Poco a poco, el docente va dando más autonomía al alumno en este tipo de labores implícitas en todo proceso de aprendizaje/investigación. Por tanto, en el segundo ciclo de la educación secundaria es cuando el alumno debe haber alcanzado un nivel de desempeño en competencias informacionales suficiente como para hacerlo explícito de manera autónoma.

A nivel curricular queda claro, pues, cómo la competencia básica para el Tratamiento de la Información y Competencia Digital, presente en los planes de estudio de educación primaria y secundaria, va tomando forma a lo largo de toda la educación primaria e inicios de la secundaria hasta alcanzar un desarrollo mayor en el último ciclo de la educación secundaria.

Por otro lado, a nivel cognitivo, atendiendo a los estadios del desarrollo cognitivo descritos por Jean Piaget $(1973,1975)$, nos encontramos cómo hasta la etapa de las operaciones formales, en la que el adolescente se ve inmerso a partir de los 11 o 12 años, no se desarrolla una capacidad de abstracción sobre los conocimientos concretos que permita la implementación de procesos de razonamiento lógico inductivo y/o deductivo.

Así, parece evidente la consideración acerca de que las primeras evaluaciones diagnósticas sobre el nivel actual de desempeño en competencias informacionales con un nivel de sistematicidad y abstracción considerable tienen sentido sólo a partir de la etapa de educación secundaria, preferentemente en el segundo ciclo. De hecho, es en estas edades, en torno a los 15 años, cuando se aplican las evaluaciones diagnósticas de estudiantes a nivel internacional. Por ejemplo, el proyecto PISA se centra en esta edad para la evaluación de las competencias básicas en Matemáticas, Lenguaje y Ciencias (OCDE, 2012).

Inmersos en este contexto, surgen una serie de interrogantes que motivan el diseño y desarrollo de la presente investigación:

- Una vez definidas las competencias informacionales como constructo, ¿Qué subcompetencias y desempeños concretos lo conforman? ¿Se puede diseñar/adaptar algún instrumento de evaluación adecuado, que contemple estas subcompetencias y las mantenga a nivel empírico? 
- En una etapa clave de desarrollo cognitivo, como la adolescencia ¿Cuál es el nivel de desarrollo en competencias informacionales que posee el alumnado de Educación Secundaria Obligatoria? ¿Y el profesorado? ¿Está el alumnado y el futuro profesorado suficientemente formado en estos aspectos?

- ¿Qué variables influyen de manera más determinante en el desarrollo de las competencias informacionales en el alumnado y futuro profesorado de Educación Secundaria?

- ¿En qué elementos concretos de las competencias informacionales alcanzan ambos grupos unas cotas de desempeño más bajas?

- ¿Está el futuro profesorado capacitado para enseñar a sus alumnos las competencias informacionales? ¿Qué necesidades principales presenta en su formación en estos aspectos?

\subsubsection{Objetivos de la investigación. Estudio I}

Desde nuestro punto de vista, la pertinencia de esta investigación se justifica en la percepción de que los resultados obtenidos se podrán aprovechar para el desarrollo de acciones de mejora relacionadas con la formación en competencias informacionales que puedan contribuir a una mayor calidad de la enseñanza, y por ende, a la mejora del sistema educativo, máxime en un contexto como el de la sociedad de la información, en el que se hacen tan necesarias (Adell, 1997; Area Moreira, 2001, 2010a; Majó i Cruzate \& Marqués, 2002; Monereo \& Coll, 2008; Pozo et al., 2006).

Así, a partir de esta percepción y de los antecedentes descritos, podemos identificar dentro del primer estudio que aquí se presenta los siguientes objetivos:

1. Llevar a cabo una evaluación diagnóstica del alumnado de Educación Secundaria Obligatoria sobre el nivel de desempeño e importancia percibidos en competencias informacionales.

a. Estudio psicométrico de la escala: Determinar las dimensiones básicas intervinientes en el desarrollo de las competencias informacionales y determinar los ítems que las componen.

b. Estudio exploratorio y descriptivo: Analizar y describir el estado de desarrollo de las competencias informacionales entre los alumnos de Educación Secundaria Obligatoria. 
c. Estudio inferencial: Comparar los niveles de autopercepción sobre el desarrollo de competencias informacionales por grupos principales.

d. Estudio correlacional: Diseñar un modelo explicativo del desarrollo de las competencias informacionales en alumnos de Educación Secundaria Obligatoria.

e. Identificar las principales debilidades y fortalezas en la formación de los alumnos de Educación Secundaria Obligatoria en lo que respecta a las competencias informacionales.

Resultados previstos: Caracterización lo más exhaustiva posible del mapa de desarrollo de competencias informacionales entre los alumnos de Educación Secundaria Obligatoria.

2. Evaluación del nivel percibido sobre competencias informacionales en el futuro profesorado de Educación Secundaria Obligatoria.

a. Estudio psicométrico de la escala: Determinar las propiedades métricas de la escala para el futuro profesorado de Educación Secundaria.

b. Estudio exploratorio y descriptivo: Analizar el nivel de desarrollo de las competencias informacionales entre el futuro profesorado de Educación Secundaria Obligatoria.

c. Estudio inferencial: Comparar los niveles de autopercepción sobre el desarrollo de competencias informacionales por grupos principales.

d. Estudio correlacional: Diseñar un modelo explicativo del desarrollo de las competencias informacionales en futuro profesorado de Educación Secundaria Obligatoria.

e. Determinar las áreas dentro de las competencias informacionales en las que el futuro profesorado tiene una formación más deficitaria.

f. Identificar las necesidades formativas concretas del futuro profesorado de Educación Secundaria Obligatoria en cuanto a las competencias informacionales.

Resultados previstos: Definición profunda y sistemática del nivel de desarrollo autopercibido y establecimiento de las áreas prioritarias de las competencias informacionales en las que el futuro profesorado tiene una formación más deficitaria y en las que el alumnado tiene necesidades formativas más substanciales.

Dada la complejidad del estudio I, que, como se verá a continuación, posee dos vertientes, queremos mostrar previamente un esquema general del proceso 
investigador llevado a cabo con la intención de facilitar al lector el seguimiento de las próximas páginas.

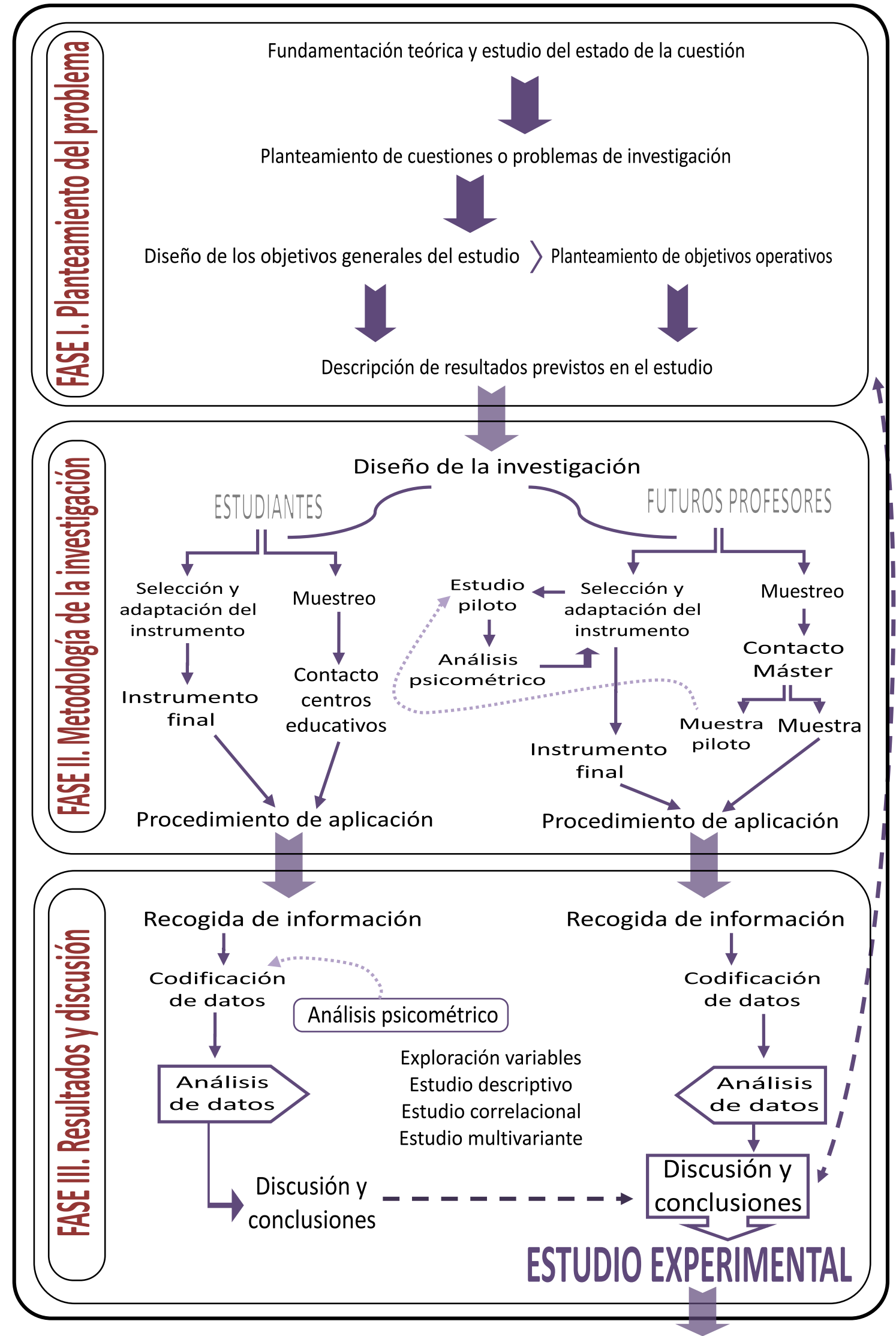

Figura 4.2 Esquema general del proceso de investigación. Estudio I 
Como se puede observar en la figura 4.2, el proceso investigador, que parte de una primera fase, en la que se plantea el problema de investigación desde una perspectiva teórica, se bifurca en dos sub-estudios al llegar a la fase de metodología de la investigación. Estas dos investigaciones paralelas tienen como principal diferencia la muestra sobre la que se lleva a cabo la recogida de información, que es, en el primer caso, de estudiantes de educación secundaria y, en el segundo caso, de futuros profesores. Ambos procesos se desarrollan en paralelo hasta llegar al punto de confluencia en la discusión y conclusiones.

Finalmente, se parte directamente de la información recogida a lo largo de todo el estudio I para el diseño de los materiales y el planteamiento de la investigación del estudio II (experimental), que se presentará más adelante.

\subsubsection{Diseño de la investigación. Estudio I}

El primer estudio basa su diseño en una metodología no experimental, esto es, que no se modifican las variables, sólo se seleccionan y observan (Arnal et al., 1992). Concretamente, está enmarcado en los métodos descriptivo y correlacional, a través de estudios de encuesta (Kerlinger \& Lee, 2002). Así, el estudio se puede situar dentro de las metodologías ex-post-facto ya que no se modifica el objeto de estudio, sino que simplemente se trata de estudiar y explorar las variables y de localizar las posibles relaciones entre las mismas.

\subsubsection{Variables. Estudio I}

La selección de variables se ha llevado a cabo previamente a la construcción de los instrumentos de medida definitivos, conforme a los objetivos planteados. Con la intención de desarrollar del mejor modo el estudio exploratorio, descriptivo, correlacional y multivariante, se definen tanto variables predictoras como variables criterio. Las encuestas diseñadas en un primer momento están compuestas por una gran diversidad de variables, que se muestran en la tabla 4.2 . 
Tabla 4.2 Variables intervinientes en el estudio I

a) Variables en la muestra de alumnos de ESO:

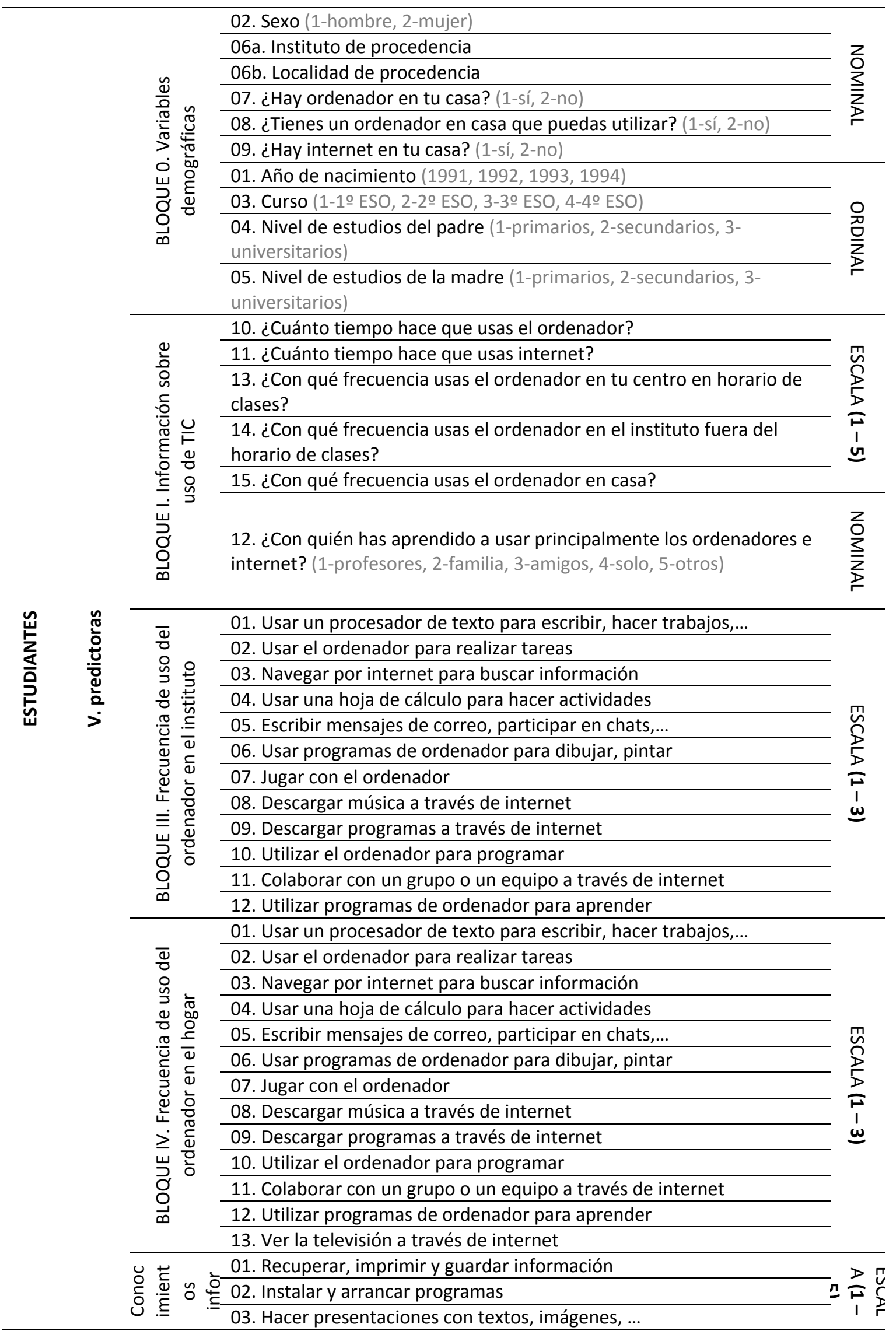


04. Usar hojas de cálculo

05. Encontrar datos en una base

06. Navegar por internet, seleccionar información, guardarla

07. Utilizar buscadores

08. Participar en chats, foros, blogs

09. Ver videos en YouTube

10. Subir videos a YouTube

11. Usar una red social

12. Crear un blog

13. Comentar en un blog

14. Bajar programas de internet

15. Comprar por internet

16. Descargar música de programas

17. Descargar música de un $C D$

18. Grabar un CD

19. Pasar música del ordenador a un MP3

20. Descargar la información de un móvil o una cámara

21. Jugar en red

22. Mandar mensajes con móvil

23. Escuchar un MP3

24. Grabar vídeos con el móvil

25. Usar consolas de videojuegos

26. Usar PDA's

27. Usar una cámara digital

BÚSQUEDA DE INFORMACIÓN

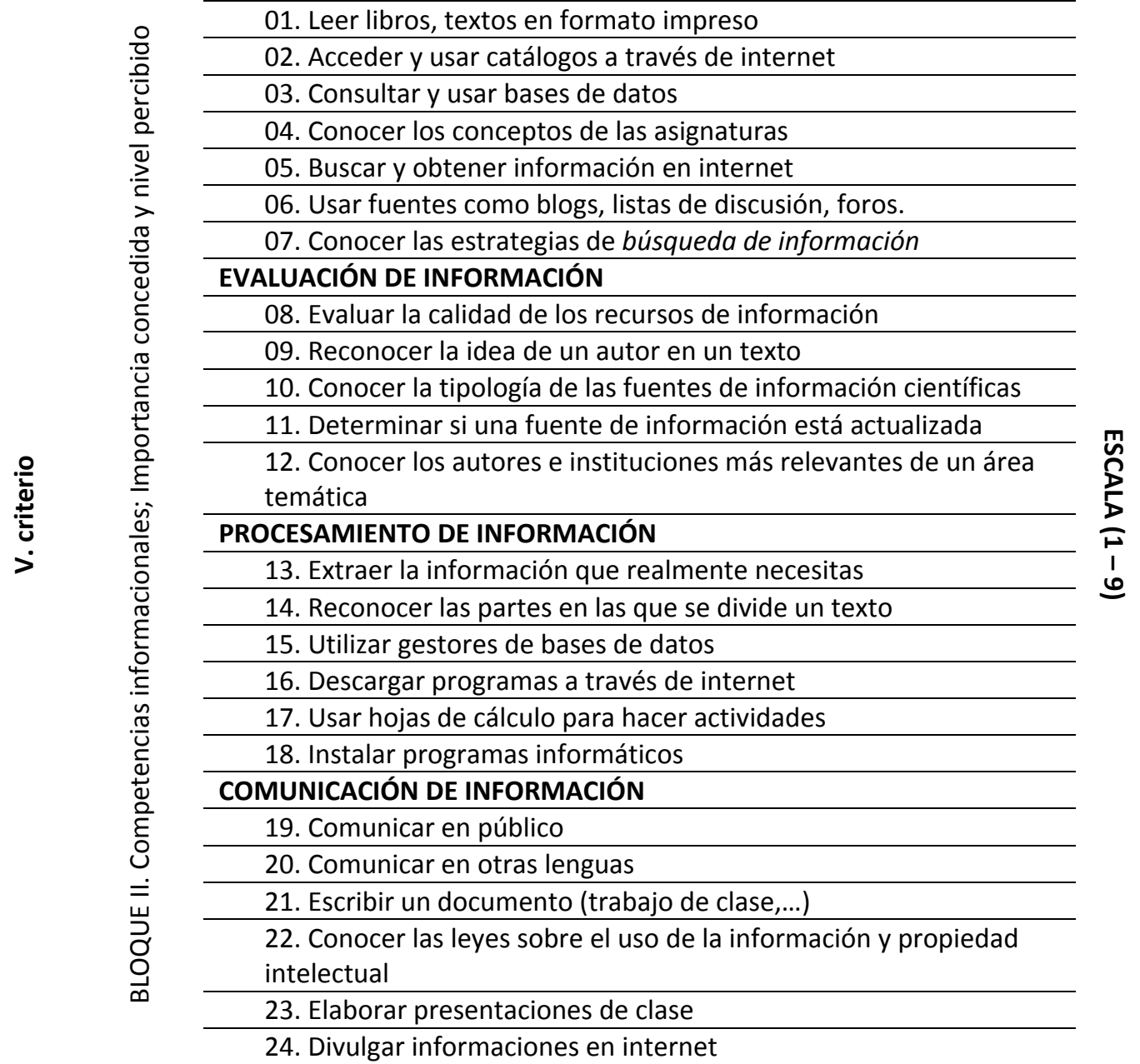


a) Variables en la muestra de futuros profesores de Educación Secundaria:

\begin{tabular}{|c|c|c|c|c|}
\hline & & & 01. Sexo (1-hombre, 2-mujer) & \\
\hline & & & 04. Titulación de procedencia & \\
\hline & & & 05. Universidad de procedencia & $z$ \\
\hline & & 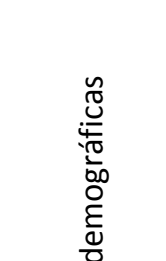 & $\begin{array}{l}\text { 10. ¿Por qué te has apuntado a este Máster? (1-siempre he querido ser } \\
\text { profesor, 2- Es la mejor opción posible para continuar mi formación, 3- } \\
\text { Considero que este Máster tiene la salida profesional más atractiva, 4- } \\
\text { Aumenta mis posibilidades de encontrar empleo, 5-No pude entrar en } \\
\text { otro Máster que elegí en primera opción, 6-No tengo ningún motivo en } \\
\text { especial, 7-Otra (especificar)) }\end{array}$ & $\stackrel{\geqq}{\geqq}$ \\
\hline & & y & 02. Año de nacimiento & \\
\hline & & $\frac{\overline{0}}{\frac{\pi}{\frac{\pi}{\pi}}}$ & $\begin{array}{l}\text { 06. Rendimiento medio en la Universidad (1-Aprobado, 2-Notable, 3- } \\
\text { Sobresaliente, 4-Matrícula de honor) }\end{array}$ & \\
\hline & & $\begin{array}{l}> \\
\dot{m}\end{array}$ & $\begin{array}{l}\text { 07. Nota media de entrada en la universidad (1-Aprobado, 2-Notable, } \\
\text { 3-Sobresaliente, 4-Matrícula de honor) }\end{array}$ & $\begin{array}{l}\text { 윰 } \\
\text { 믁 }\end{array}$ \\
\hline & & ه্] & $\begin{array}{l}\text { 08. Estudios del padre (1-Sin estudios, 2-Primarios, 3-Bach./F.P., 4- } \\
\text { Universitarios) }\end{array}$ & 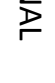 \\
\hline & & & $\begin{array}{l}\text { 09. Estudios de la madre (1-Sin estudios, 2-Primarios, 3-Bach./F.P., 4- } \\
\text { Universitarios) }\end{array}$ & \\
\hline & & & 11. ¿Cuántos años llevas usando el ordenador? & \\
\hline & & & 12. ¿Cuántos años llevas usando internet? & $\cong$ \\
\hline & 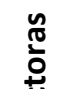 & & $\begin{array}{l}\text { 13. Aproximadamente, ¿Cuántas horas semanales dedicas de media a } \\
\text { navegar por internet? }\end{array}$ & $\stackrel{8}{5}$ \\
\hline$\underset{\sim}{\dddot{\sim}}$ & $\frac{0}{0}$ & & ACTIVIDADES DE OCIO & \\
\hline & 힌 & $\stackrel{0}{\geqq}$ & 01. Comunicarse por internet a través de herramientas síncronas & \\
\hline 岁 & $>$ & $\stackrel{5}{>}$ & 02. Usar el ordenador para jugar & \\
\hline$\frac{\tilde{c}}{a}$ & & $\frac{\stackrel{\circ}{2}}{\frac{0}{\varepsilon}}$ & $\begin{array}{l}\text { 03. Descargar o acceder a contenidos multimedia a través de } \\
\text { internet }\end{array}$ & \\
\hline$\stackrel{\dddot{c}}{\supset}$ & & $\bar{a}$ & 04. Utilizar una red social & \\
\hline 5 & & $\underset{0}{0}$ & 05. Comprar por internet & \\
\hline & & $\frac{\pi}{\frac{\pi}{\sigma}}$ & $\begin{array}{l}\text { 06. Intercambiar información entre el ordenador y accesorios } \\
\text { externos }\end{array}$ & \\
\hline & & $\underset{1}{d}$ & GESTIÓN DE LA INFORMACIÓN EN INTERNET & \\
\hline & & $\frac{\omega}{n}$ & 07. Buscar la información que necesito en buscadores genéricos & $\stackrel{n}{\Omega}$ \\
\hline & & 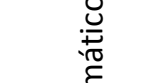 & $\begin{array}{l}\text { 08. Consultar información especializada en metabuscadores y/o } \\
\text { buscadores específicos }\end{array}$ & $\frac{2}{D}$ \\
\hline & & 는 & 09. Manejar el correo electrónico & $\boldsymbol{G}$ \\
\hline & & $\frac{\Xi}{n}$ & 10. Crear, mantener y administrar un espacio en internet & \\
\hline & & $\stackrel{0}{\circ}$ & 11. Colaborar aportando información en webs sociales & \\
\hline & & $\stackrel{\check{d}}{=}$ & 12. Realizar trabajos en grupo a través de herramientas web & \\
\hline & & $\cdot \frac{\varepsilon}{0}$ & MANEJO DEL SOFTWARE & \\
\hline & & 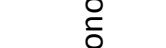 & 13. Diseño y tratamiento de imagen, sonido y vídeo digital & \\
\hline & & U. & 14. Emplear un lenguaje de programación para elaborar recursos & \\
\hline & & $\overline{\bar{\omega}}$ & 15. Mantenimiento del software & \\
\hline & & ఠ̆ & 16. Diseño y manipulación de documentos de texto & \\
\hline & & $\stackrel{\circ}{\underline{m}}$ & 17. Elaboración de presentaciones de diapositivas & \\
\hline & & & 18. Manejo de la hoja de cálculo & \\
\hline & & & BÚSQUEDA DE INFORMACIÓN & \\
\hline & & 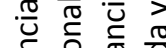 & 01. Saber utilizar fuentes de información impresa & 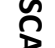 \\
\hline & $\stackrel{ \pm}{ \pm}$ & 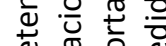 & 02. Saber acceder y usar los catálogos automatizados & 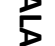 \\
\hline & $\stackrel{\frac{2}{u}}{>}$ & 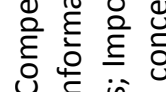 & $\begin{array}{l}\text { 03. Saber consultar y usar fuentes electrónicas de información } \\
\text { primaria }\end{array}$ & 芳 \\
\hline & & & 04. Saber utilizar fuentes electrónicas de información secundaria & \\
\hline
\end{tabular}




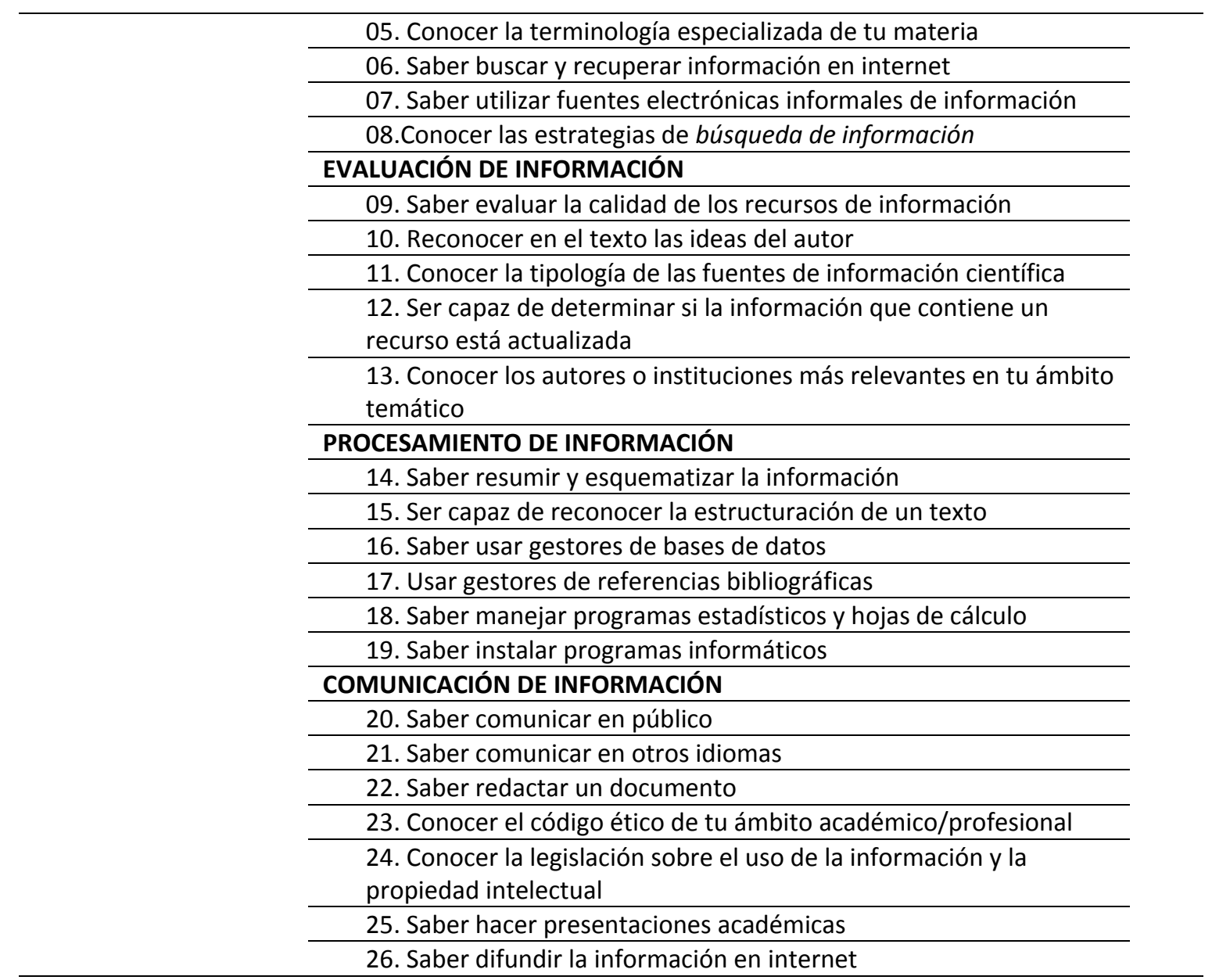

Dentro de las variables predictoras nos encontramos con una serie de variables que se pueden diferenciar en función de su papel previsto en el análisis de datos posterior:

- Las variables demográficas hacen referencia a ciertas características de la muestra que tienen que ver con la identificación de distintos grupos poblacionales (sexo, edad, nivel socio-económico, etc.). Además de permitir la corroboración de que los datos muestrales se ajustan realmente (en términos demográficos) a la población de referencia, a lo largo del estudio, estas variables se tratarán principalmente como variables de agrupación. Esto permitirá el estudio de las diferencias obtenidas en las variables criterio en función del grupo poblacional al que pertenecen los sujetos. Las variables de contexto en el ámbito de la investigación educativa tienen una importancia capital, ya que permiten hacer un análisis más pormenorizado y explicar de una manera más completa los resultados obtenidos (De la Orden Hoz \& Jornet Meliá, 2012; González Barberá, Caso Niebla, Díaz López, \& López Ortega, 2012; Joaristi Olariaga, Lizasoain Hernández, \& Gamboa Ruiz de Eguilaz, 2012; Tiana Ferrer, 2012). 
- El resto de variables criterio incluidas en el estudio, relacionadas en todo caso con los hábitos y usos de herramientas informáticas, se incluyen para formar parte en los estudios de correlación y regresión y multivariantes. Se decide incluir este tipo de variables a partir de los presupuestos teóricos y de la información obtenida en el estudio del estado de la cuestión, que indican que los conocimientos y hábitos informáticos están íntimamente relacionados con el desarrollo y empleo de las competencias informacionales (Bawden, 2001; CRUE-TIC \& REBIUN, 2009, 2012; Pinto Molina \& Uribe Tirado, 2012).

Por otro lado, nos encontramos las variables criterio, que son las que tienen que ver directamente con la definición y conformación del constructo competencias informacionales, es decir, las variables que manifiestan la característica objeto de este estudio. Dentro de las competencias informacionales se definen cuatro dimensiones teóricas:

- Búsqueda de información: la persona es capaz de buscar la información que realmente necesita. No es otra cosa que el conocimiento de la terminología específica de la materia que se está estudiando, la capacidad para utilizar fuentes de información de todo tipo (libros y revistas impresas, bases de datos informáticas, catálogos de bibliotecas, etc.), y las habilidades en el empleo de estrategias específicas que ayuden en la labor de la búsqueda de información (empleo de buscadores especializados, búsqueda avanzada, etc.)

- Evaluación de información: La persona analiza y selecciona la información de manera eficiente. Incluye desempeños tan diversos como saber evaluar la calidad de los recursos encontrados y si estos están o no actualizados, identificar el tipo de documento que se ha encontrado (artículo en revista científica, artículo de divulgación, libro, tesis doctoral, foro de discusión, etc.), conocer los autores o instituciones más relevantes en el ámbito de conocimiento estudiado y actuar en consecuencia, o ser capaz de reconocer las principales ideas del autor en el texto.

- Procesamiento de información: La persona tiene capacidad para organizar y tratar la información de manera adecuada. Dentro de esta dimensión podríamos incluir todos aquellos conocimientos, procedimientos y actitudes que permiten reconocer la estructura propia de un texto, aportan capacidad para resumir y esquematizar la información y aportan la capacidad para el empleo de herramientas que facilitan la gestión de la información (gestores de 
bases de datos y de referencias bibliográficas, software para el análisis matemático y estadístico, etc.).

- Comunicación y difusión de información: La persona utiliza y comunica la información eficazmente, de forma legal y ética y con el fin de construir conocimiento. Nos encontramos aquí con la capacidad para redactar un documento y/o una presentación académica con una estructura y complejidad adecuada a las características de los receptores, para comunicar en público tanto en el idioma natal como en otros, el conocimiento de la propia legislación sobre el uso de la información y del código ético del ámbito académico/profesional en el que se está inmerso y al dominio de herramientas que posibilitan la difusión de la información en diversos medios, sobre todo por internet (webs, blogs, redes sociales, ...).

Evidentemente, estas variables criterio son las que se comportan como dependientes en las pruebas estadísticas que se aplican y que así lo requieren (contrastes de hipótesis, regresión y modelos de ecuaciones estructurales).

\subsubsection{Instrumento: diseño y análisis psicométrico. Estudio I}

Dados los objetivos del estudio I, se decide adaptar un instrumento para evaluar las distintas dimensiones que conforman competencias informacionales a partir de la propuesta de Pinto (2009). El instrumento de recogida de datos resultante, de naturaleza cuantitativa, incorpora el uso de escalas tipo Likert (Likert, 1932, 1974; Morales Vallejo, Urosa, \& Blanco, 2003).

En el estudio de investigaciones anexas, se corrobora que en la medida de actitudes los cuestionarios basados en escalas son la técnica de recogida de datos más empleada (Hernández Pina, 2009), debido a que es el método más estudiado, fundamentado y contrastado (Morales Vallejo, 2000; Tejedor Tejedor, GarcíaValcarcel, \& Prada, 2009).

En el caso de la escala de valoración del nivel autopercibido y de la importancia concedida sobre las competencias informacionales, los ítems poseen puntuaciones que abarcan entre 1 (poco competente/poco importante) y 9 (muy competente/muy importante). Los encuestados deben responder a los distintos ítems puntuando en función del grado de competencia autopercibida y la importancia concedida en cada 
uno. Por otro lado, el estudio se completa, además de la información demográfica de identificación solicitada, se incluyen otras escalas de frecuencia sobre los hábitos y usos en relación con las herramientas informáticas.

En lo que se refiere a la valoración del nivel autopercibido, no debemos olvidar que se trata de una escala de evaluación de autoeficacia en las competencias informacionales, considerando autoeficacia como "el conjunto de juicios de cada individuo sobre las capacidades propias para organizar y ejecutar las acciones requeridas en el manejo de posibles situaciones específicas" (Blanco Blanco, 2010, pp. 1-2). Cuando se pretende valorar una competencia compleja expost-facto, en una muestra representativa, como en este caso, en un intervalo corto de tiempo, el valor de la medida de la "autopercepción de competencia", a través de un instrumento de autoinforme, ha sido avalada por numerosas investigaciones (Bandura \& Locke, 2003; Eastman \& Marzillier, 1984; Vancouver, 2005). La evidencia empírica aporta un sólido soporte al valor predictivo de la autoeficacia en el campo de las Ciencias Sociales (Lent, 1994; Robbins et al., 2004; Rottinghaus, Larson, \& Borgen, 2003; Valentine, Dubois, \& Cooper, 2004).

Como ya se ha señalado anteriormente, y se verá más adelante, las dos muestras del estudio I proceden de poblaciones muy diferentes. Así, las encuestas aplicadas a ambas muestras para evaluar las competencias informacionales autopercibidas, aunque están adaptadas a partir del mismo instrumento (Pinto Molina, 2009), poseen algunas diferencias. Del mismo modo, el resto de variables descritas en el epígrafe previo son diferentes en ambas encuestas. Procederemos a exponer, pues, ambos cuestionarios por separado.

\subsubsection{Cuestionario para alumnos de Educación Secundaria Obligatoria}

\section{a) Diseño del cuestionario}

En este caso, se adapta y diseña una encuesta que recoge información de todo tipo acerca de los tópicos anteriormente descritos. El instrumento definitivo se presenta en las siguientes figuras que se mostrarán a continuación 


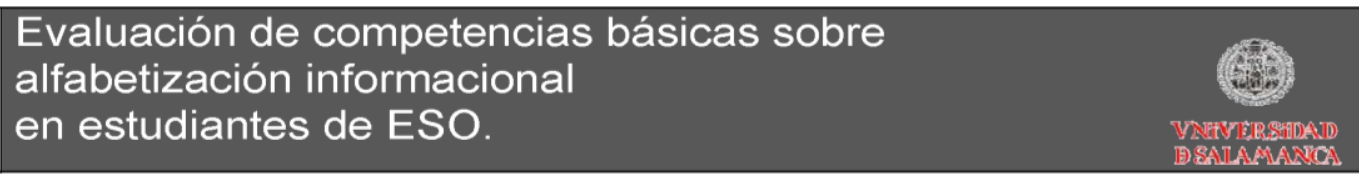

Presentación:

En la sociedad actual, Sociedad de la Información y la Comunicación, es importante acceder, analizar y utilizar la información adecuadamente. Para que esto se pueda realizar, son necesarias una serie de habilidades y capacidades relacionadas con destrezas de razonamiento, generación y transmisión de información. El presente instrumento nos permitirá conocer tu percepción respecto a las competencias que tienes.

Instrucciones:

Responde por favor a las cuestiones que se plantean a continuación, marcando con un círculo la opción correspondiente.

\begin{tabular}{|c|c|c|c|c|c|}
\hline 1. Año de nacimiento & 1991 & 1992 & 1993 & 1994 & Otro \\
\hline 2. Sexo & $\begin{array}{c}1 . \\
\text { Hombre }\end{array}$ & $\begin{array}{c}2 . \\
\text { Mujer }\end{array}$ & & & \\
\hline 3. Curso & $1^{\circ} \mathrm{ESO}$ & $2^{\circ} \mathrm{ESO}$ & $3^{\circ} \mathrm{ESO}$ & $4^{\circ} \mathrm{ESO}$ & \\
\hline 4. Nivel de estudios del padre & $\begin{array}{c}1 . \\
\text { Primarios }\end{array}$ & $\begin{array}{c}2 . \\
\text { Secundarios }\end{array}$ & $\begin{array}{c}3 . \\
\text { Universitarios }\end{array}$ & & \\
\hline 5. Nivel de estudios de la madre & $\begin{array}{c}1 . \\
\text { Primarios }\end{array}$ & $\begin{array}{l}2 . \\
\text { Secundarios }\end{array}$ & $\begin{array}{c}3 . \\
\text { Universitarios }\end{array}$ & & \\
\hline
\end{tabular}

\author{
6. Instituto \\ 7. Localidad
}

\begin{tabular}{|r|r|l|l|}
\hline 1. Información sobre uso de nuevas tecnologías & \\
\hline 7. ¿Hay ordenador en tu casa? & 1. Si & 2. No & \\
\hline 8. ¿Tienes un ordenador en casa que puedas & 1. Si & 2. No & \\
\hline utilizar? & 1. ¿Hay Internet en tu casa? & 2. No & \\
\hline
\end{tabular}

\begin{tabular}{|c|c|c|c|c|c|}
\hline $\begin{array}{l}\text { 10. ¿Cuánto tiempo hace que usas el } \\
\text { ordenador? }\end{array}$ & No lo utilizo & $\begin{array}{l}\text { 2. Entre } 1 \\
\text { y } 3 \\
\text { años }\end{array}$ & $\begin{array}{l}\text { 3. Menos } \\
\text { de } 1 \\
\text { año }\end{array}$ & $\begin{array}{l}\text { 4. Entre } 3 \\
\text { y } 5 \\
\text { años }\end{array}$ & $\begin{array}{l}5 . \\
\text { Más de } 5 \text { años }\end{array}$ \\
\hline $\begin{array}{l}\text { 11. ¿Cuánto tiempo hace que usas } \\
\text { Internet? }\end{array}$ & No lo utilizo & $\begin{array}{l}\text { 2. Entre } 1 \\
\text { y } 3 \text { años }\end{array}$ & $\begin{array}{l}\text { 3. Menos } \\
\text { de } 1 \text { año }\end{array}$ & $\begin{array}{l}\text { 4. Entre } 3 \\
\text { y } 5 \text { años }\end{array}$ & Más de 5 años \\
\hline $\begin{array}{l}\text { 12. ¿Con quién han aprendido a usar } \\
\text { principalmente los ordenadores e } \\
\text { Internet? Marca sólo una de las } \\
\text { siguientes opciones }\end{array}$ & $\begin{array}{l}\text { 1. Con los } \\
\text { profesores }\end{array}$ & $\begin{array}{l}2 . \\
\text { Con la familia }\end{array}$ & $\begin{array}{c}3 . \\
\text { Con los amigos }\end{array}$ & $\begin{array}{l}4 . \\
\text { Solo }\end{array}$ & $\begin{array}{l}5 . \\
\text { Otros }\end{array}$ \\
\hline $\begin{array}{l}\text { 13. ¿Con qué frecuencia usas el } \\
\text { ordenador en tu centro en horario de } \\
\text { clases? }\end{array}$ & $\begin{array}{l}1 . \\
\text { Nunca }\end{array}$ & $\begin{array}{l}\text { 2. Menos de } \\
\text { una } \\
\text { vez al mes }\end{array}$ & $\begin{array}{c}3 . \\
\text { Una o dos } \\
\text { veces al mes }\end{array}$ & $\begin{array}{c}4 . \\
\text { Varias veces a } \\
\text { la semana }\end{array}$ & $\begin{array}{l}5 . \\
\text { Casi todos los } \\
\text { dias }\end{array}$ \\
\hline $\begin{array}{r}\text { 14. ¿Con qué frecuencia usas el } \\
\text { ordenador en el instituto fuera del } \\
\text { horario de clases? }\end{array}$ & $\begin{array}{c}1 . \\
\text { Nunca }\end{array}$ & $\begin{array}{l}\text { 2. Menos de } \\
\text { una vez al } \\
\text { mes }\end{array}$ & $\begin{array}{l}\text { 3. Entre una } \\
\text { vez a la } \\
\text { semana y una } \\
\text { vez al mes }\end{array}$ & $\begin{array}{l}4 . \\
\text { Varias veces a } \\
\text { la semana }\end{array}$ & $\begin{array}{l}5 . \\
\text { Casi todos los } \\
\text { dias }\end{array}$ \\
\hline $\begin{array}{l}\text { 15. ¿Con qué frecuencia usas el } \\
\text { ordenador en casa? }\end{array}$ & $\begin{array}{c}1 . \\
\text { Nunca }\end{array}$ & $\begin{array}{l}\text { 2. Menos de } \\
\text { una vez al } \\
\text { mes }\end{array}$ & $\begin{array}{l}\text { 3. Entre una } \\
\text { vez a la } \\
\text { semana y una } \\
\text { vez al mes }\end{array}$ & $\begin{array}{l}4 . \\
\text { Varias veces a } \\
\text { la semana }\end{array}$ & $\begin{array}{l}5 . \\
\text { Casi todos los } \\
\text { dias }\end{array}$ \\
\hline
\end{tabular}

Proyecto I+D "Modelo de evaluación y desarrollo de competencias implícitas en la ESO: TIC, Lectura y Convivencia Escolar (E-TELECO)". Referencia: SEJ2006-10700, dirigido por Dra. María José Rodríguez-Conde. Proyecto en desarrollo. mjrconde@usal.es

Figura 4.3 Cuestionario para alumnos de Educación Secundaria I

En la Figura 4.3 se puede observar la primera cara del cuestionario para los estudiantes, en la que se incluye una breve presentación del cuestionario, con las instrucciones pertinentes. Por otro lado, este apartado incluye los dos primeros subbloques del cuestionario (datos demográficos e información sobre uso de nuevas tecnologías), referidas a información contextual. 


\begin{tabular}{|c|c|c|c|c|c|c|c|c|c|c|c|c|c|c|c|c|c|}
\hline \multicolumn{18}{|c|}{$\begin{array}{l}\text { Este cuestionario consta de tres partes: En la primera, queremos conocer el nivel de importancia que concedes a cada una de las capacidades que } \\
\text { aparecen a la izquierda. En la segunda (columna central) el nivel de conocimiento que crees que tienes respecto a cada una de ellas. Valora para } \\
\text { los dos partes en la escala del "1" al " } 9 \text { ", siendo " } 1 \text { " lo más bajo y " } 9 \text { " lo más alto, teniendo niveles intermedios. En la tercera columna responde a la } \\
\text { pregunta ¿Dónde los has aprendido? Puede ser en: "Clase", "Cursos fuera del instituto" "Bibliotecas" de forma "Autodidacta" u "Otros". En cada } \\
\text { columna marca sólo una opción de tal forma que cada competencia tenga tres marcas. }\end{array}$} \\
\hline \multirow{2}{*}{$\begin{array}{l}\text { En referencia a ... } \\
\text { Ser capaz de... } \\
\qquad \text { 1. Leer libros, textos en formato impreso }\end{array}$} & \multicolumn{8}{|c|}{$\begin{array}{c}\text { Importancia que concedes a } \\
\ldots\end{array}$} & \multicolumn{9}{|c|}{$\begin{array}{c}\text { Nivel de conocimiento } \\
\text { sobre }\end{array}$} \\
\hline & 12 & 3 & 4 & 5 & 6 & 7 & 8 & & 1 & 2 & 3 & 4 & 5 & 6 & 7 & 8 & 9 \\
\hline 2. Acceder y usar catálogos a través de Internet & 12 & 3 & 4 & & 6 & 7 & 8 & & 1 & 2 & 3 & 4 & 5 & 6 & 7 & 8 & 9 \\
\hline 3. Consular y usar bases de datos & 12 & 3 & 4 & 5 & 6 & 7 & 8 & & 1 & 2 & 3 & 4 & 5 & 6 & 7 & 8 & 9 \\
\hline 4. Conocer los conceptos de las asignaturas & 12 & & 4 & & 6 & 7 & 8 & & 1 & 2 & 3 & 4 & 5 & 6 & 7 & 8 & 9 \\
\hline 5. Buscar y obtener información en internet & 12 & 3 & 4 & 5 & 6 & 7 & 8 & & 1 & 2 & 3 & 4 & 5 & 6 & 7 & 8 & 9 \\
\hline $\begin{array}{r}\text { 6. Usar fuentes como blogs, listas de discusión, } \\
\text { foros }\end{array}$ & 12 & & 4 & & 6 & 7 & 8 & & 1 & 2 & 3 & 4 & 5 & 6 & 7 & 8 & 9 \\
\hline $\begin{array}{l}\text { 7. Conocer las estrategias de búsqueda } \\
\text { de información }\end{array}$ & 12 & 3 & 4 & 5 & 6 & 7 & 8 & & 1 & 2 & 3 & 4 & 5 & 6 & 7 & 8 & 9 \\
\hline 8. Evaluar la calidad de los recursos de información & 12 & 3 & 4 & 5 & 6 & 7 & 8 & & 1 & 2 & 3 & 4 & 5 & 6 & 7 & 8 & 9 \\
\hline 9. Reconocer la idea de un autor en un texto. & 12 & 3 & 4 & 5 & 6 & 7 & 8 & & 1 & 2 & 3 & 4 & 5 & 6 & 7 & 8 & 9 \\
\hline $\begin{array}{l}\text { 10. Conocer la tipologia de las fuentes de } \\
\text { información científicas }\end{array}$ & 12 & 3 & 4 & 5 & 6 & 7 & 8 & 9 & 1 & 2 & 3 & 4 & 5 & 6 & 7 & 8 & 9 \\
\hline $\begin{array}{r}\text { 11. Determinar si una fuente de información } \\
\text { está actualizada }\end{array}$ & 12 & 3 & 4 & 5 & 6 & 7 & 8 & & 1 & 2 & 3 & 4 & 5 & 6 & 7 & 8 & 9 \\
\hline $\begin{array}{l}\text { 12. Conocer los autores e instituciones más } \\
\text { relevantes de un área temática. }\end{array}$ & 12 & 3 & 4 & 5 & 6 & 7 & 8 & 9 & 1 & 2 & 3 & 4 & 5 & 6 & 7 & 8 & 9 \\
\hline $\begin{array}{r}\text { 13. Extraer la información que realmente } \\
\text { necesitas }\end{array}$ & 12 & 3 & 4 & 5 & 6 & 7 & 8 & & 1 & 2 & 3 & 4 & 5 & 6 & 7 & 8 & 9 \\
\hline $\begin{array}{r}\text { 14. Reconocer las partes en las que se se divide un } \\
\text { texto }\end{array}$ & 12 & 3 & 4 & 5 & 6 & 7 & 8 & & 1 & 2 & 3 & 4 & 5 & 6 & 7 & 8 & 9 \\
\hline 15. Utilizar gestores de bases de datos & 12 & 3 & 4 & 5 & 6 & 7 & 8 & & 1 & 2 & 3 & 4 & 5 & 6 & 7 & 8 & 9 \\
\hline $\begin{array}{r}\text { 16. Descargar programas a través de } \\
\text { Internet }\end{array}$ & 12 & 3 & 4 & 5 & 6 & 7 & 8 & & 1 & 2 & 3 & 4 & 5 & 6 & 7 & 8 & 9 \\
\hline 17. Usar hojas de cálculo para hacer actividades & 12 & 3 & 4 & 5 & 6 & 7 & 8 & 9 & 1 & 2 & 3 & 4 & 5 & 6 & 7 & 8 & 9 \\
\hline 18. Instalar programas informáticos & 12 & 3 & 4 & 5 & 6 & 7 & 8 & 9 & 1 & 2 & 3 & 4 & 5 & 6 & 7 & 8 & 9 \\
\hline 19. Comunicar en público & 12 & 3 & 4 & 5 & 6 & 7 & $8 \leq$ & 9 & 1 & 2 & 3 & 4 & 5 & 6 & 7 & 8 & 9 \\
\hline $\begin{array}{r}\text { 20. Comunicar en otras lenguas } \\
\text { (inglés...) }\end{array}$ & 12 & 3 & 4 & 5 & 6 & 7 & 85 & & 1 & 2 & 3 & 4 & 5 & 6 & 7 & 8 & 9 \\
\hline 21. Escribir un documento (trabajo de clase, ...) & 12 & 3 & 4 & 5 & 6 & 7 & $8 \cong$ & 9 & 1 & 2 & 3 & 4 & 5 & 6 & 7 & 8 & 9 \\
\hline $\begin{array}{r}\text { 22. Conocer las leyes sobre el uso de información } \\
\text { y propiedad intelectual }\end{array}$ & 12 & 3 & 4 & 5 & 6 & 7 & 8 & & 1 & 2 & 3 & 4 & 5 & 6 & 7 & 8 & 9 \\
\hline $\begin{array}{l}\text { 23. Elaborar presentaciones de clase } \\
\text { (power point) }\end{array}$ & 12 & 3 & 4 & 5 & 6 & 7 & 8 & & 1 & 2 & 3 & 4 & 5 & 6 & 7 & 8 & 9 \\
\hline $\begin{array}{r}\text { 24. Divulgar informaciones en internet } \\
\text { (webs, blogs, ...) }\end{array}$ & 12 & 3 & 4 & 5 & 6 & 7 & $8 \leq$ & & 1 & 2 & 3 & 4 & 5 & 6 & 7 & 8 & 9 \\
\hline
\end{tabular}

Figura 4.4 Cuestionario para alumnos de Educación Secundaria II

En la segunda cara del cuestionario se incluyen los ítems sobre las competencias informacionales, a partir de las que los sujetos deben responder tanto sobre la importancia que les conceden a los ítems, como sobre el nivel de conocimientos autopercibidos. Dicha encuesta es una adaptación de la diseñada y validada por Pinto (2009). Se muestra en la anterior Figura 4.4. 


\begin{tabular}{|c|c|c|c|}
\hline & $\begin{array}{l}\text { Nula: } \\
\text { menos de una vez al } \\
\text { mes o nunca }\end{array}$ & $\begin{array}{c}\text { Media: } \\
\text { entre una vez a la semana } \\
\text { y una vez al mes }\end{array}$ & $\begin{array}{l}\text { Alta: } \\
\text { casi todos los dias o varias } \\
\text { veces a la semana }\end{array}$ \\
\hline $\begin{array}{r}\text { 1. Usar un procesador de texto para escribir, hacer } \\
\text { trabajos... }\end{array}$ & 1 & 2 & 3 \\
\hline 2. Usar el ordenador para realizar tareas & 1 & 2 & 3 \\
\hline 3. Navegar por Internet para buscar información & 1 & 2 & 3 \\
\hline 4. Usar una hoja de cálculo para hacer actividades & 1 & 2 & 3 \\
\hline 5. Escribir mensajes de correo, participar en chats, & 1 & 2 & 3 \\
\hline $\begin{array}{r}\text { 6. Usar programas de ordenador para dibujar, } \\
\text { pintar }\end{array}$ & 1 & 2 & 3 \\
\hline 7. Jugar con el ordenador & 1 & 2 & 3 \\
\hline 8. Descargar música a través de Internet & 1 & 2 & 3 \\
\hline 9. Descargar programas a través de Internet & 1 & 2 & 3 \\
\hline 10. Utilizar el ordenador para programar & 1 & 2 & 3 \\
\hline $\begin{array}{r}\text { 11. Colaborar con un grupo o un equipo a través } \\
\text { de Internet }\end{array}$ & 1 & 2 & 3 \\
\hline 12. Utilizar programas de ordenador para aprender & 1 & 2 & 3 \\
\hline
\end{tabular}

\begin{tabular}{|c|c|c|c|}
\hline & $\begin{array}{l}\text { Nula: } \\
\text { menos de una vez al } \\
\text { mes o nunca }\end{array}$ & $\begin{array}{c}\text { Media: } \\
\text { entre una vez a la semana } \\
\text { y una vez al mes }\end{array}$ & $\begin{array}{l}\text { Alta: } \\
\text { casi todos los dias o varias } \\
\text { veces a la semana }\end{array}$ \\
\hline $\begin{array}{r}\text { 1. Usar un procesador de texto para escribir, hacer } \\
\text { trabajos... }\end{array}$ & 1 & 2 & 3 \\
\hline 2. Usar el ordenador para realizar tareas & 1 & 2 & 3 \\
\hline 3. Navegar por Internet para buscar información & 1 & 2 & 3 \\
\hline 4. Usar una hoja de cálculo para hacer actividades & 1 & 2 & 3 \\
\hline 5. Escribir mensajes de correo, participar en chats, & 1 & 2 & 3 \\
\hline $\begin{array}{r}\text { 6. Usar programas de ordenador para dibujar, } \\
\text { pintar }\end{array}$ & 1 & 2 & 3 \\
\hline 7. Jugar con el ordenador & 1 & 2 & 3 \\
\hline 8. Descargar música a través de interne & 1 & 2 & 3 \\
\hline 9. Descargar programas a través de Internet & 1 & 2 & 3 \\
\hline 10. Utilizar el ordenador para programar & 1 & 2 & 3 \\
\hline $\begin{array}{r}\text { 11. Colaborar con un grupo o un equipo a través } \\
\text { de Internet }\end{array}$ & 1 & 2 & 3 \\
\hline 12. Utilizar programas de ordenador para aprender & 1 & 2 & 3 \\
\hline 13. Ver la televisión a través de Internet & 1 & 2 & 3 \\
\hline
\end{tabular}

\begin{tabular}{|l|}
\hline $\begin{array}{l}\text { 5. Cuéntanos brevemente alguna actividad de clase en la que hayas utilizado algún tipo de } \\
\text { tecnologías }\end{array}$ \\
\hline \\
\hline \\
\hline
\end{tabular}

Figura 4.5 Cuestionario para alumnos de Educación Secundaria III

La tercera cara del cuestionario (Figura 4.5) incluye dos sub-bloques, que se encuentran dentro del bloque de hábitos y usos de herramientas informáticas. Se trata de nuevo de información contextual. Recogen información concretamente sobre la frecuencia de uso de herramientas informáticas tanto en el centro educativo (en el aula) como fuera del contexto del centro educativo (en el hogar). Como se puede observar, para facilitar la discriminación a los encuestados, la escala en este caso es de 
1 a 3 , siendo 1 una frecuencia de menos de una vez al mes y alta una frecuencia de al menos varias veces por semana.

\begin{tabular}{|c|c|c|c|c|c|}
\hline & Nada & & Algo & & Mucho \\
\hline 1.Recuperar, imprimir y guardar información & 1 & 2 & 3 & 4 & 5 \\
\hline 2. Instalar y arrancar programas & 1 & 2 & 3 & 4 & 5 \\
\hline 3. Hacer presentaciones con textos, imágenes... & 1 & 2 & 3 & 4 & 5 \\
\hline 4. Usar hojas de cálculo & 1 & 2 & 3 & 4 & 5 \\
\hline 5. Encontrar datos en un base & 1 & 2 & 3 & 4 & 5 \\
\hline 6. Navegar por Internet, seleccionar información, guardarla & 1 & 2 & 3 & 4 & 5 \\
\hline 7. Utilizar buscadores & 1 & 2 & 3 & 4 & 5 \\
\hline 8. Participar en chats, foros, blogs & 1 & 2 & 3 & 4 & 5 \\
\hline 9. Ver videos en YouTube & 1 & 2 & 3 & 4 & 5 \\
\hline 10. Subir videos a YouTube & 1 & 2 & 3 & 4 & 5 \\
\hline 11. Usar una red social (como Tuenti, Facebook) & 1 & 2 & 3 & 4 & 5 \\
\hline 12. Crear un blog & 1 & 2 & 3 & 4 & 5 \\
\hline 13. Comentar en un blog & 1 & 2 & 3 & 4 & 5 \\
\hline 14. Bajar programas de Internet & 1 & 2 & 3 & 4 & 5 \\
\hline 15. Comprar por Internet & 1 & 2 & 3 & 4 & 5 \\
\hline 16. Descargar música de programas & 1 & 2 & 3 & 4 & 5 \\
\hline 17. Descargar música de un $C D$ & 1 & 2 & 3 & 4 & 5 \\
\hline 18. Grabar un CD & 1 & 2 & 3 & 4 & 5 \\
\hline 19. Pasar música del ordenador a un MP3 & 1 & 2 & 3 & 4 & 5 \\
\hline 20. Descargar la información de un móvil o una cámara & 1 & 2 & 3 & 4 & 5 \\
\hline 21. Jugar en red con & 1 & 2 & 3 & 4 & 5 \\
\hline
\end{tabular}

7. ¿Sabes...?
\begin{tabular}{r|c|c|c|c|c|c|} 
Mada & \multicolumn{2}{c|}{ Algo } \\
\hline \\
Mandar mensajes por móvil & 1 & 2 & 3 & 4 & 5 \\
\hline Escuchar un MP3 & 1 & 2 & 3 & 4 & 5 \\
\hline Grabar videos con el móvil & 1 & 2 & 3 & 4 & 5 \\
\hline Usar consolas de videojuegos & 1 & 2 & 3 & 4 & 5 \\
\hline Usar PDA's & 1 & 2 & 3 & 4 & 5 \\
\hline Usar una cámara digital & 1 & 2 & 3 & 4 & 5 \\
\hline
\end{tabular}

8. ¿Qué otras cosas sabes hacer con los ordenadores u otro tipo de aparato tecnológico?

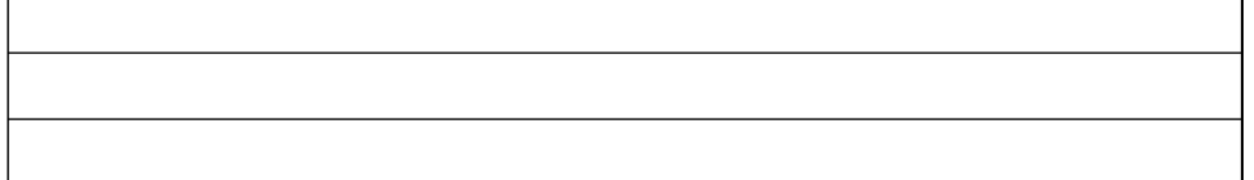

9. ¿Qué es lo que más te divierte de todo lo que puedes hacer con la tecnología?

Muchas gracias por tu colaboración.

Figura 4.6 Cuestionario para alumnos de Educación Secundaria IV

Por último, como se puede observar en la Figura 4.6, la cuarta cara del cuestionario muestra el resto de sub-bloques del bloque de hábitos y usos de herramientas informáticas. En concreto, se refiere a la habilidad o competencia en la realización de determinadas tareas relacionadas con el manejo de software 
informático y de internet. La escala en este caso, para favorecer la variabilidad de las respuestas $y$, por ende, una mayor discriminación de los ítems, se desarrolla de 1 a 5 puntos, correspondiéndose 1 con no tener nada de habilidad en el ítem y 5 con tener mucha habilidad.

Así, la estructura básica de la información recogida en los diferentes bloques de contenido y sub-bloques del cuestionario es la siguiente:

- Variables demográficas

○ Datos puramente demográficos

- Información sobre disponibilidad de nuevas tecnologías

- Hábitos y usos de herramientas informáticas

- Información sobre uso de nuevas tecnologías

- Frecuencia en el empleo del ordenador e internet en el instituto para diversas tareas

- Frecuencia en el empleo del ordenador e internet fuera del instituto para diversas tareas

- Conocimientos en la realización de diversas tareas con el ordenador e internet

- Conocimientos en la realización de diversas tareas con tecnologías digitales anexas al ordenador (MP3, cámara digital, teléfono móvil, etc.)

- Competencias informacionales

- Conocimiento autopercibido

- Importancia concedida

\section{b) Análisis psicométrico del cuestionario}

Una vez descritos con detalle todos los elementos del cuestionario, podemos pasar al análisis psicométrico del cuestionario y las consecuentes pruebas de fiabilidad y validez de las diversas escalas y dimensiones. Cuando se construye un instrumento 
de medida, como un cuestionario, debemos tener en cuenta dos factores determinantes en el éxito de los resultados que obtengamos del mismo, la validez y fiabilidad; puesto que constituyen características primordiales en las pruebas de evaluación de rendimiento. Ambos términos, a pesar de tener significados diferentes, están ampliamente relacionados; de tal forma que para que podamos concluir que una prueba es válida, es necesario que sea fiable.

En cuanto a lo que entendemos por fiabilidad y validez, podemos señalar lo siguiente:

- Fiabilidad. También conocida como estabilidad de las puntuaciones, es una de las características propias de todo instrumento de medida. Entenderemos fiabilidad de aquí en adelante como la consistencia del instrumento respecto a su aplicación en diversos lugares y/o tiempos. Por lo tanto, la obtención de buenos índices de fiabilidad indicaría que el instrumento de medida es preciso y que, por consiguiente, devuelve resultados consistentes en sus diversas aplicaciones (Abad, 2011; Osterlind, 2010)

- Validez. Es un aspecto muy difícil de definir y estudiar. A nivel teórico, podríamos considerar la validez como un atributo de la prueba que indica el grado en el que dicha prueba mide realmente los constructos para los que ha sido construida, y no otra cosa. Podemos distinguir entre la validez referida al criterio, la validez de constructo y la validez de contenido (Abad, 2011; Osterlind, 2010).

La validez referida al criterio se refiere a las relaciones entre las puntuaciones que obtiene nuestra prueba y las que se registran en otras pruebas que miden el mismo constructo. La validez de constructo cumple la función de determinar si el instrumento de medida creado mide el constructo teórico que se trata de estudiar. Por su parte, la validez de contenido se refiere a que el contenido del instrumento sea representativo del constructo que se trata de evaluar, es decir, que el conjunto de ítems del cuestionario sea representativo del universo de conductas del constructo o constructos estudiados. En el contexto de nuestra investigación se tendrá en cuenta tanto la validez de constructo como la validez de contenido.

Las escalas que se pretenden medir son las que se corresponden con las variables predictoras del instrumento, y se corresponden con las competencias autopercibidas en las dimensiones definidas para las competencias informacionales: 
- Búsqueda de información

- Evaluación de información

- Procesamiento de información

- Comunicación y difusión de información

En primer lugar, analizando la fiabilidad de estas escalas, las tablas 4.3, 4.4, 4.5 y 4.6 muestran en primer lugar la relación de estadísticos total-elemento, que aportan información acerca de la relación de cada uno de los ítems con el conjunto de la escala. Antes de llevar a cabo el estudio de las propiedades de las escalas exploraremos los índices de discriminación de cada uno de los ítems de las diferentes escalas con respecto al total, con la finalidad de percibir la contribución de cada uno de ellos a la explicación de la variabilidad total. Se aceptarán como tolerables valores de correlación ítem-total superiores a .4 (Morales Vallejo et al., 2003).

Tabla 4.3 Estadísticos total-elemento para estudiantes. Búsqueda de información

\begin{tabular}{|c|c|c|c|c|c|}
\hline Estadísticos total-elemento & $\begin{array}{c}\text { Media sin } \\
\text { el } \\
\text { elemento }\end{array}$ & $\begin{array}{l}\text { Var. sin el } \\
\text { elemento }\end{array}$ & $\begin{array}{c}\text { Correlac. } \\
\text { elem- } \\
\text { total } \\
\text { corregida }\end{array}$ & $\begin{array}{c}\text { Correlac. } \\
\text { múltiple } \\
\text { al } \\
\text { cuadrado }\end{array}$ & $\begin{array}{c}\alpha \text { de } \\
\text { Cronbach } \\
\text { sin el } \\
\text { elemento }\end{array}$ \\
\hline $\begin{array}{l}\text { 1. Leer libros, artículos en } \\
\text { formato impreso }\end{array}$ & 38.74 & 70.187 & .412 & .202 & .595 \\
\hline $\begin{array}{l}\text { 2. Acceder y usar catálogos } \\
\text { a través de internet }\end{array}$ & 39.48 & 64.957 & .468 & .275 & .573 \\
\hline $\begin{array}{l}\text { 3. Consular y usar bases de } \\
\text { datos }\end{array}$ & 39.64 & 67.397 & .406 & .246 & .592 \\
\hline $\begin{array}{l}\text { 4. Conocer los conceptos de } \\
\text { las asignaturas }\end{array}$ & 38.61 & 67.850 & .207 & .066 & .669 \\
\hline $\begin{array}{l}\text { 5. Buscar y obtener } \\
\text { información en internet }\end{array}$ & 37.31 & 73.702 & .456 & .268 & .598 \\
\hline $\begin{array}{l}\text { 6. Usar fuentes como blogs, } \\
\text { listas de discusión, foros }\end{array}$ & 38.60 & 62.432 & .265 & .130 & .658 \\
\hline $\begin{array}{l}\text { 7. Conocer las estrategias de } \\
\text { búsqueda de información }\end{array}$ & 38.78 & 67.911 & .516 & .301 & .571 \\
\hline
\end{tabular}

En el primer caso, la tabla 4.3 nos muestra unos índices de correlación elementototal no aceptables en los ítems 4, Conocer los conceptos de las asignaturas; y 6, Usar fuentes como blogs, listas de discusión, foros... Analizando el contenido de cada uno de los ítems, se decide eliminar el ítem 6 al considerar que no debe formar parte de un 
proceso integrante en la búsqueda de información para tareas académicas en la Educación Secundaria Obligatoria. No olvidemos que la escala ha sido diseñada originariamente para la población de estudiantes universitarios, y se ha extrapolado a la población de estudiantes de educación secundaria.

Tabla 4.4 Estadísticos total-elemento para estudiantes. Evaluación de información

\begin{tabular}{|c|c|c|c|c|c|}
\hline Estadísticos total-elemento & $\begin{array}{l}\text { Media sin } \\
\text { el } \\
\text { elemento }\end{array}$ & $\begin{array}{l}\text { Var. sin el } \\
\text { elemento }\end{array}$ & $\begin{array}{l}\text { Correlac. } \\
\text { elem- } \\
\text { total } \\
\text { corregida }\end{array}$ & $\begin{array}{l}\text { Correlac. } \\
\text { múltiple } \\
\quad \text { al } \\
\text { cuadrado }\end{array}$ & $\begin{array}{c}\alpha \text { de } \\
\text { Cronbach } \\
\text { sin el } \\
\text { elemento }\end{array}$ \\
\hline $\begin{array}{l}\text { 8. Evaluar la calidad de } \\
\text { recursos de información }\end{array}$ & 22.07 & 38.138 & .502 & .253 & .725 \\
\hline $\begin{array}{l}\text { 9. Reconocer la idea de un } \\
\text { autor en un texto. }\end{array}$ & 22.24 & 38.084 & .512 & .284 & .722 \\
\hline $\begin{array}{l}\text { 10. Conocer la tipología de } \\
\text { las fuentes de información } \\
\text { científicas }\end{array}$ & 22.78 & 35.653 & .533 & .289 & .716 \\
\hline $\begin{array}{l}\text { 11. Determinar si una fuente } \\
\text { de información está } \\
\text { actualizada }\end{array}$ & 22.09 & 37.610 & .500 & .255 & .727 \\
\hline $\begin{array}{l}\text { 12. Conocer los autores e } \\
\text { instituciones más relevantes } \\
\text { de tu área temática. }\end{array}$ & 22.55 & 36.743 & .596 & .365 & .693 \\
\hline
\end{tabular}

En el caso de la segunda subescala, como se puede observar en la tabla 4.4, se obtienen en todos los casos índices de correlación elemento-total satisfactorios. Por lo tanto, los ítems de la escala se mantienen intactos para la valoración de la subcompetencia en la evaluación de información en estudiantes de Educación Secundaria Obligatoria.

Tabla 4.5 Estadísticos total-elemento para estudiantes. Procesamiento de información

\begin{tabular}{lc|c|c|c|c}
\hline Estadísticos total-elemento & $\begin{array}{c}\text { Media } \text { sin } \\
\text { el } \\
\text { elemento }\end{array}$ & Var. sin el & $\begin{array}{c}\text { Correlac. } \\
\text { elemento } \\
\text { total } \\
\text { corregida }\end{array}$ & $\begin{array}{c}\text { Correlac. } \\
\text { múltiple } \\
\text { al } \\
\text { cuadrado }\end{array}$ & $\begin{array}{c}\alpha \text { de } \\
\text { Cronbach } \\
\text { sin el } \\
\text { elemento }\end{array}$ \\
\hline $\begin{array}{l}\text { 13. Extraer la información } \\
\text { que realmente necesitas }\end{array}$ & 31.32 & 50.489 & .448 & .272 & .709 \\
\hline $\begin{array}{l}\text { 14. Reconocer las partes en } \\
\text { las que se divide un texto }\end{array}$ & 31.98 & 49.564 & .434 & .253 & .712 \\
\hline $\begin{array}{l}\text { 15. Utilizar gestores de } \\
\text { bases de datos }\end{array}$ & 33.42 & 45.276 & .473 & .266 & .701 \\
\hline \begin{tabular}{l} 
16. Descargar programas a \\
\hline
\end{tabular} & 31.17 & 45.664 & .532 & .363 & .684 \\
\hline
\end{tabular}




\begin{tabular}{|c|c|c|c|c|c|}
\hline través de internet & & & & & \\
\hline $\begin{array}{l}\text { 17. Usar hojas de cálculo } \\
\text { para hacer actividades }\end{array}$ & 32.52 & 45.557 & .467 & .253 & .703 \\
\hline $\begin{array}{l}\text { 18. Instalar programas } \\
\text { informáticos }\end{array}$ & 31.83 & 44.611 & .498 & .336 & .694 \\
\hline
\end{tabular}

En la tabla 4.5, que muestra los estadísticos total-elemento para la escala de medida del procesamiento de información, se vuelven a obtener índices de correlación elemento-total aceptables en todos los casos. Así, no se modifican los ítems iniciales de la escala.

Tabla 4.6 Estadísticos total-elemento para estudiantes. Comunicación de información

\begin{tabular}{|c|c|c|c|c|c|}
\hline Estadísticos total-elemento & $\begin{array}{l}\text { Media sin } \\
\text { el } \\
\text { elemento }\end{array}$ & $\begin{array}{l}\text { Var. sin el } \\
\text { elemento }\end{array}$ & $\begin{array}{c}\text { Correlac. } \\
\text { elem- } \\
\text { total } \\
\text { corregida }\end{array}$ & $\begin{array}{c}\text { Correlac. } \\
\text { múltiple } \\
\text { al } \\
\text { cuadrado }\end{array}$ & $\begin{array}{c}\alpha \text { de } \\
\text { Cronbach } \\
\text { sin el } \\
\text { elemento }\end{array}$ \\
\hline 19. Comunicar en público & 31.72 & 47.016 & .538 & .324 & .679 \\
\hline $\begin{array}{l}\text { 20. Comunicar en otras } \\
\text { lenguas (inglés...) }\end{array}$ & 31.94 & 47.385 & .473 & .268 & .698 \\
\hline $\begin{array}{l}\text { 21. Escribir un documento } \\
\text { (trabajo de clase, ...) }\end{array}$ & 30.56 & 50.762 & .544 & .338 & .684 \\
\hline $\begin{array}{l}\text { 22. Conocer las leyes sobre } \\
\text { el uso de información y } \\
\text { propiedad intelectual }\end{array}$ & 32.51 & 51.555 & .359 & .129 & .730 \\
\hline $\begin{array}{l}\text { 23. Elaborar presentaciones } \\
\text { académicas (power point) }\end{array}$ & 30.82 & 48.880 & .493 & .307 & .692 \\
\hline $\begin{array}{l}\text { 24. Divulgar informaciones } \\
\text { en internet (webs, blogs, ...) }\end{array}$ & 31.33 & 47.815 & .449 & .234 & .706 \\
\hline
\end{tabular}

En la tabla 4.6, que muestra los estadísticos total-elemento para la escala de medida de la comunicación y difusión de información, se vuelven a obtener índices de correlación elemento-total aceptables en todos los casos. Así, no se modifican los ítems iniciales de la escala.

Tabla $4.7 \alpha$ de Cronbach para las sub-escalas en alumnos. Competencias informacionales autopercibidas

\begin{tabular}{lc|c|c}
\hline \multicolumn{1}{c|}{ Fiabiildad de las subescalas } & $\begin{array}{c}\alpha \text { de } \\
\text { Cronbach }\end{array}$ & $\begin{array}{c}\alpha \text { de Cronbach } \\
\text { basado en los } \\
\text { elementos tip. }\end{array}$ & $\begin{array}{c}\boldsymbol{N} \text { de } \\
\text { elementos }\end{array}$ \\
\hline Búsqueda de información & .658 & .693 & 6 \\
\hline Evaluación de información & .821 & .822 & 5 \\
\hline Procesamiento de información & .763 & .765 & 6 \\
\hline
\end{tabular}


Los estadísticos obtenidos para el $\alpha$ de Cronbach, en la tabla 4.7, muestran en todos los casos valores por encima de 0.65 . Por lo tanto, y teniendo en cuenta que el valor mínimo de la $\alpha$ de Cronbach lo podemos poner en torno a 0.7 (Morales Vallejo et al., 2003), estamos en condiciones de afirmar que nuestras escalas tienen fiabilidades de aceptables. Esto quiere decir que los ítems propuestos son precisos en su medición, y que miden adecuadamente los constructos.

Valoremos a continuación la validez de las sub-escalas estudiadas.

En cuanto a la validez de contenido, se puede señalar a nivel general que el instrumento original a partir del que se deriva el trabajo (IL-HUMASS Survey on Information Literacy in Higher Education) es un cuestionario elaborado por un grupo de expertos internacionales en Ciencias de la Información, con el objetivo de descubrir los principales conceptos, categorías y dimensiones que están implicadas en las competencias informacionales en el ámbito universitario de las Ciencias Sociales y las Humanidades (Pinto Molina, 2009). Su versión inicial fue desarrollada a partir de un estudio de caso, basado en las opiniones de expertos, y el cuestionario definitivo surge a través de un proceso de depuración llevado a cabo a partir de 6 grupos de trabajo: Opinión de los propios estudiantes de universitarios; entrevistas estructuradas con bibliotecarios; informes académicos; programas internacionales en el campo de las competencias informacionales; principios de lo que es una buena práctica; y la información al respecto recogida en los Libros Blancos. La versión definitiva consta de 26 ítems repartidos en 4 dimensiones. Fruto del proceso de adaptación del cuestionario a la población diana de este estudio, la versión adaptada consta de 24 ítems repartidos en las 4 dimensiones teóricas originarias. Así, podemos afirmar antes de llevar a cabo los análisis pertinentes, que la validez de contenido del propio cuestionario está confirmada de antemano gracias al proceso de construcción por expertos y de depuración (Pinto Molina, 2009), explicados más arriba.

Por otro lado, en lo que respecta a la validez de constructo, procederemos a la aplicación de la técnica del análisis factorial, que nos permite analizar las interrelaciones que existen entre las distintas variables. En primer lugar se realizará un análisis exploratorio, para observar el comportamiento general de cada una de las escalas, y en segundo lugar confirmatorio, para tratar de confirmar los resultados obtenidos. Dada la complejidad y amplitud de actividades que se pueden considerar dentro de las competencias informacionales, se considera que dicha competencia está 
formada por sub-competencias muy dispersas que podrían ser consideradas como constructos separados. Así, se realizarán los análisis en dos fases:

1. Primera fase: Se procederá a un análisis factorial de primer orden con la prueba de unidimensionalidad de las sub-escalas de las competencias informacionales a través del análisis factorial exploratorio y confirmatorio.

2. Segunda fase: Se emplearán las puntuaciones factoriales de cada factor para hacer un análisis factorial de segundo orden en el que se comprobará la unidimensionalidad de la escala completa.

En la figura 4.7 se muestra la estructura factorial que se pretende confirmar.

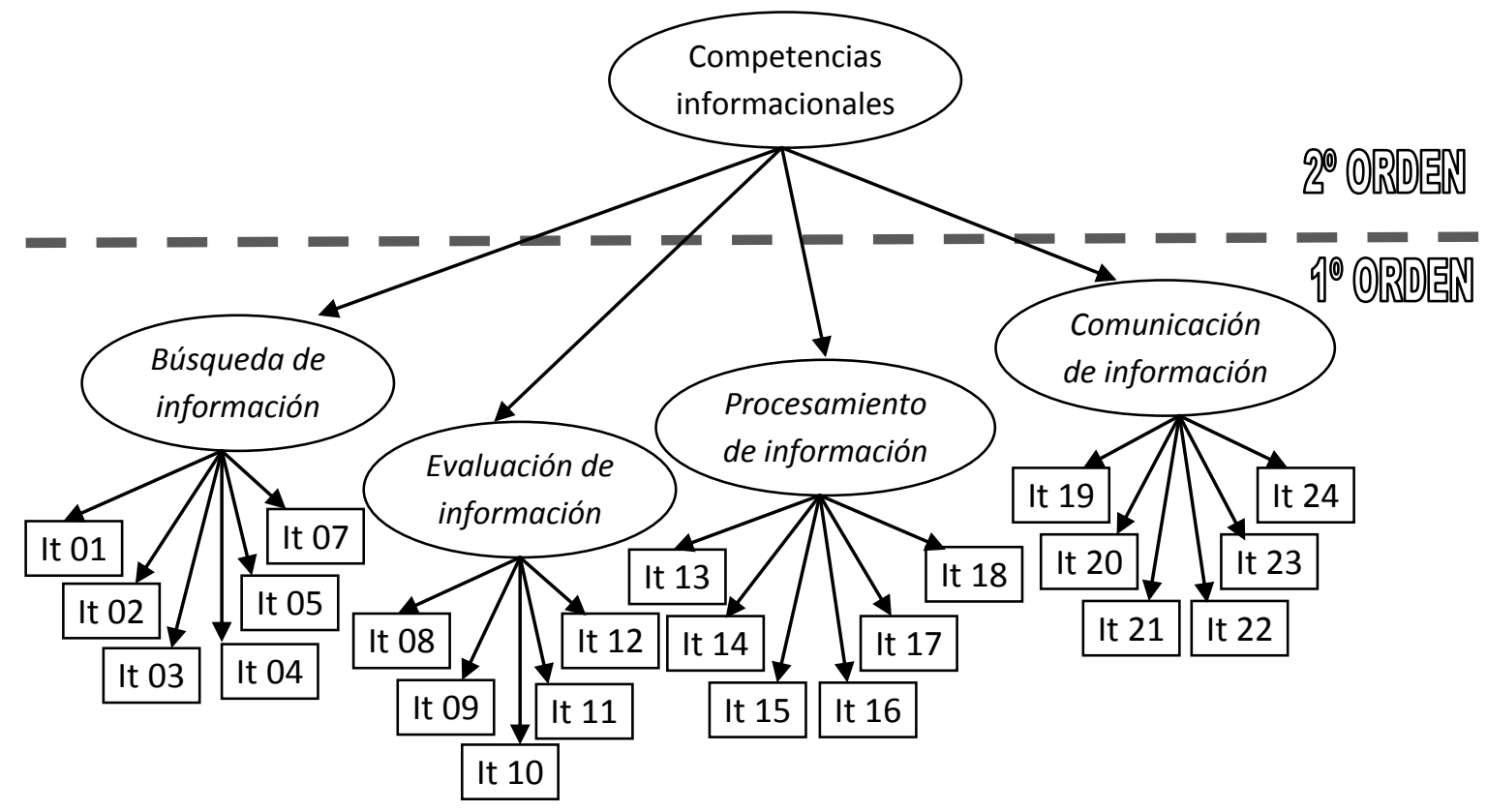

Figura 4.7 Estructura factorial de la escala de competencias informacionales para alumnado

Para comprobar que la técnica de análisis factorial se va a aplicar en unas condiciones mínimas, debemos llevar a cabo un proceso dividido en varias fases:

En primer lugar, es necesario comprobar si la escala cumple las condiciones necesarias para aplicar el análisis factorial (García Jiménez, Gil Flores, \& Rodríguez Gómez, 2000; Guttman, 1954). En segundo lugar, tratamos los factores extraídos inicialmente en el análisis y la rotación de componentes en orden a facilitar la interpretación de los mismos. En tercer lugar, procedemos al análisis conceptual de los distintos factores obtenidos.

1. Cumplimiento de las condiciones necesarias, idoneidad de los datos para aplicar el análisis factorial. 
En relación a la adecuación de los datos para la aplicación del análisis factorial, a continuación, se especifican las condiciones que ineludiblemente deben darse:

a) En primera instancia, se deben analizar los valores de las correlaciones entre las diferentes variables integrantes en el análisis. Se comprobará que los determinantes de las matrices de correlaciones sean diferentes a 0 .

b) En segundo lugar, la prueba de Bartlett para probar la hipótesis de que la matriz de correlaciones es una matriz de identidad. Es necesario rechazar dicha hipótesis para considerar la muestra adecuada para la factorización

c) En tercer lugar, la prueba de Medidas de adecuación muestral -KMO- de Kaiser-Meyer-Olkin. El KMO es un índice que permite comparar las magnitudes de los coeficientes de correlación obtenidos con las magnitudes de los coeficientes de correlación parcial. Debemos obtener valores de KMO altos (KMO > 0.7) para considerar adecuado continuar con el análisis factorial.

d) La última prueba para determinar la idoneidad de los datos para el análisis factorial es observar los valores de la diagonal principal de la matriz de correlaciones anti-imagen. Cuanto más cercanos sean estos valores a 1 , más adecuados serán los datos. Para interpretar los valores de este coeficiente, Kaiser (1974) propone como "maravilloso" un valor cercano a .9, como "meritorio" el cercano a .8, el cercano a .7 "mediano", el que se aproxima a .6 "mediocre" y por debajo de .5 "inaceptable".

Aunque no se ha justificado aún la muestra utilizada en el estudio (se presentará en el siguiente apartado), veremos a continuación los resultados obtenidos en cada una de estas pruebas para contrastar la adecuación muestral, a partir de una muestra representativa de estudiantes de segundo ciclo de Educación Secundaria Obligatoria (14-16 años) de 13 centros públicos y privados concertados de Castilla y León.

Tabla 4.8 Matriz de correlaciones escala búsqueda de información en alumnos*

\begin{tabular}{c|c|c|c|c|c|c}
\hline & It 1 & It 2 & It 3 & It 4 & It 5 & It 7 \\
\hline It 1 & 1.000 & .318 & .293 & .215 & .327 & .273 \\
\hline It 2 & .318 & 1.000 & .401 & .148 & .352 & .351 \\
\hline It 3 & .293 & .401 & 1.000 & .156 & .227 & .373 \\
\hline It 4 & .215 & .148 & .156 & 1.000 & .091 & .172 \\
\hline It 5 & .327 & .352 & .227 & .091 & 1.000 & .401 \\
\hline
\end{tabular}




\begin{tabular}{c|c|c|c|c|c|c}
\hline It 7 & .273 & .351 & .373 & .172 & .401 & 1.000 \\
\hline
\end{tabular}

Tabla 4.9 Matriz de correlaciones escala evaluación de información en alumnos*

\begin{tabular}{c|c|c|c|c|c}
\hline & It 8 & It 9 & It 10 & It 11 & It 12 \\
\hline It 8 & 1.000 & .362 & .377 & .368 & .383 \\
\hline It 9 & .362 & 1.000 & .360 & .322 & .476 \\
\hline It 10 & .377 & .360 & 1.000 & .381 & .450 \\
\hline It 11 & .368 & .322 & .381 & 1.000 & .412 \\
\hline It 12 & .383 & .476 & .450 & .412 & 1.000 \\
\hline
\end{tabular}

* Determinante $=0.343$

Tabla 4.10 Matriz de correlaciones escala procesamiento de información en alumnos*

\begin{tabular}{c|c|c|c|c|c|c}
\hline & It 13 & It 14 & It 15 & It 16 & It 17 & It 18 \\
\hline It 13 & 1.000 & .411 & .202 & .405 & .225 & .310 \\
\hline It 14 & .411 & 1.000 & .324 & .272 & .315 & .187 \\
\hline It 15 & .202 & .324 & 1.000 & .290 & .437 & .325 \\
\hline It 16 & .405 & .272 & .290 & 1.000 & .275 & .534 \\
\hline It 17 & .225 & .315 & .437 & .275 & 1.000 & .310 \\
\hline It 18 & .310 & .187 & .325 & .534 & .310 & 1.000 \\
\hline
\end{tabular}

* Determinante $=0.293$

Tabla 4.11 Matriz de correlaciones escala comunicación de información en alumnos*

\begin{tabular}{c|c|c|c|c|c|c}
\hline & It 19 & It 20 & It 21 & It 22 & It 23 & It 24 \\
\hline It 19 & 1.000 & .453 & .398 & .264 & .290 & .381 \\
\hline It 20 & .453 & 1.000 & .382 & .248 & .291 & .242 \\
\hline It 21 & .398 & .382 & 1.000 & .262 & .485 & .294 \\
\hline It 22 & .264 & .248 & .262 & 1.000 & .243 & .237 \\
\hline It 23 & .290 & .291 & .485 & .243 & 1.000 & .379 \\
\hline It 24 & .381 & .242 & .294 & .237 & .379 & 1.000 \\
\hline
\end{tabular}

$*$ Determinante $=0.317$

En las tablas 4.8, 4.9, 4.10 y 4.11 se pueden verificar los coeficientes de correlación entre las variables de las 4 dimensiones que se van a probar. Los índices son en general aceptables, y el valor del determinante en los cuatro casos es diferente de cero.

A continuación, se muestran los valores del test de esfericidad de Barlett, y el índice KMO para cada una de las dimensiones.

Tabla 4.12 Test de Barlett y KMO para las cuatro dimensiones teóricas en alumnos

\begin{tabular}{lcc}
\hline & Test de esfericidad de Barlett & KMO \\
\hline Búsqueda de información & $971.929(\mathrm{p}<.001)$ & .768 \\
\hline
\end{tabular}




\begin{tabular}{llc}
\hline Evaluación de información & $1132.829(\mathrm{p}<.001)$ & .811 \\
\hline Procesamiento de información & $1309.749(\mathrm{p}<.001)$ & .745 \\
\hline Comunicación de información & $1250.307(\mathrm{p}<.001)$ & .780 \\
\hline
\end{tabular}

Así, según los datos mostrados en la tabla 4.12, en todos los casos se rechaza la hipótesis de que la matriz de correlaciones es una matriz identidad y se considera que existe una buena adecuación muestral para continuar con el análisis factorial.

Tabla 4.13 Matriz de correlaciones anti-imagen. Búsqueda de información en alumnos*

\begin{tabular}{c|c|c|c|c|c|c}
\hline & It 1 & It 2 & It 3 & It 4 & It 5 & It 7 \\
\hline It 1 & .797 & -.140 & -.139 & -.153 & -.200 & -.059 \\
\hline It 2 & -.140 & .782 & -.268 & -.043 & -.195 & -.132 \\
\hline It 3 & -.139 & -.268 & .757 & -.051 & .013 & -.233 \\
\hline It 4 & -.153 & -.043 & -.051 & .778 & .031 & -.090 \\
\hline It 5 & -.200 & -.195 & .013 & .031 & .739 & -.283 \\
\hline It 7 & -.059 & -.132 & -.233 & -.090 & -.283 & .763 \\
\hline
\end{tabular}

* Valores de la diagonal principal $>0.7$

Tabla 4.14 Matriz de correlaciones anti-imagen. Evaluación de información en alumnos*

\begin{tabular}{c|c|c|c|c|c}
\hline & It 8 & It 9 & It 10 & It 11 & It 12 \\
\hline It 8 & .834 & -.165 & -.176 & -.185 & -.134 \\
\hline It 9 & -.165 & .805 & -.120 & -.084 & -.307 \\
\hline It 10 & -.176 & -.120 & .820 & -.177 & -.242 \\
\hline It 11 & -.185 & -.084 & -.177 & .830 & -.202 \\
\hline It 12 & -.134 & -.307 & -.242 & -.202 & .779 \\
\hline
\end{tabular}

* Valores de la diagonal principal $>0.7$

Tabla 4.15 Matriz de correlaciones anti-imagen. Procesamiento de información en alumnos*

\begin{tabular}{c|c|c|c|c|c|c}
\hline & It 13 & It 14 & It 15 & It 16 & It 17 & It 18 \\
\hline It 13 & .749 & -.322 & .025 & -.242 & -.031 & -.106 \\
\hline It 14 & -.322 & .737 & -.186 & -.071 & -.158 & .060 \\
\hline It 15 & .025 & -.186 & .763 & -.073 & -.316 & -.151 \\
\hline It 16 & -.242 & -.071 & -.073 & .731 & -.050 & -.424 \\
\hline It 17 & -.031 & -.158 & -.316 & -.050 & .779 & -.130 \\
\hline It 18 & -.106 & .060 & -.151 & -.424 & -.130 & .725 \\
\hline
\end{tabular}

* Valores de la diagonal principal $>0.7$

Tabla 4.16 Matriz de correlaciones anti-imagen. Comunicación de información en alumnos*

\begin{tabular}{c|c|c|c|c|c|c}
\hline & It 19 & It 20 & It 21 & It 22 & It 23 & It 24 \\
\hline It 19 & .764 & -.315 & -.190 & -.095 & .000 & -.246 \\
\hline It 20 & -.315 & .792 & -.177 & -.099 & -.077 & -.011 \\
\hline
\end{tabular}




\begin{tabular}{c|c|c|c|c|c|c}
\hline It 21 & -.190 & -.177 & .771 & -.089 & -.359 & -.032 \\
\hline It 22 & -.095 & -.099 & -.089 & .879 & -.081 & -.099 \\
\hline It 23 & .000 & -.077 & -.359 & -.081 & .749 & -.248 \\
\hline It 24 & -.246 & -.011 & -.032 & -.099 & -.248 & .787 \\
\hline
\end{tabular}

* Valores de la diagonal principal $>0.7$

Por último, en la prueba del cumplimiento de las condiciones previas para la aplicación del análisis factorial, se observa cómo los índices de las diagonales principales de las matrices anti-imagen se sitúan en todos los casos en valores que se pueden considerar aceptables (valores superiores a 0.7).

Así, visto el cumplimiento de todas las condiciones propuestas, estamos en condiciones de proceder con la segunda fase del análisis.

2. Extracción de factores sobre el nivel percibido en cada dimensión de las competencias informacionales.

Como se tratará de comprobar la unidimensionalidad de las escalas, se procederá en todos los casos a la aplicación del análisis factorial exploratorio a partir del método de extracción de componentes principales (García Jiménez et al., 2000), basado en autovalores mayores que 1.

Tabla 4.17 Comunalidades. Búsqueda de información. Alumnos

\begin{tabular}{r|c}
\hline & Comunalidades \\
\hline 1. Leer libros, artículos en formato impreso & .475 \\
\hline 2. Acceder y usar catálogos a través de internet & .495 \\
\hline 3. Consular y usar bases de datos & .518 \\
\hline 4. Conocer los conceptos de las asignaturas & .473 \\
\hline 5. Buscar y obtener información en internet & .598 \\
\hline 7. Conocer las estrategias de búsqueda de información & .475 \\
\hline
\end{tabular}

Podemos observar en la tabla 4.17 que la varianza explicada para cada una de las variables por el factor búsqueda de información se sitúa en torno al 0.5.

Tabla 4.18 Varianza total explicada. Búsqueda de información. Alumnos*

\begin{tabular}{cc|c|c|c|c|c}
\hline \multirow{2}{*}{ Componente } & \multicolumn{3}{c|}{ Autovalores iniciales } & \multicolumn{3}{c}{ Sumas de las saturaciones al cuadrado de la } \\
\cline { 2 - 7 } & Total & $\begin{array}{c}\text { \% de la } \\
\text { varianza }\end{array}$ & \% acumul. & Total & $\begin{array}{c}\text { \% de la } \\
\text { varianza }\end{array}$ & \% acumul. \\
\hline $\mathbf{1}$ & 2.416 & 40.269 & 40.269 & 2.416 & 40.269 & 40.269 \\
\hline $\mathbf{2}$ & 0.949 & 15.811 & 56.080 & & & \\
\hline $\mathbf{3}$ & 0.788 & 13.139 & 69.218 & & & \\
\hline
\end{tabular}




\begin{tabular}{cc|c|c|c|c|c}
\hline $\mathbf{4}$ & 0.719 & 11.986 & 81.204 & & & \\
\hline $\mathbf{5}$ & 0.618 & 10.300 & 91.504 & & & \\
\hline $\mathbf{6}$ & 0.510 & 8.496 & 100.000 & & & \\
\hline
\end{tabular}

* Método de extracción: Análisis de componentes principales

Como muestra la tabla 4.18, el porcentaje de varianza total explicada para el factor búsqueda de información resulta ser del 40.27\%, con un autovalor superior a 2 puntos.

Tabla 4.19 Matriz de componentes. Búsqueda de información. Alumnos

\begin{tabular}{r|c}
\hline & Componente \\
\hline 2. Acceder y usar catálogos a través de internet & .708 \\
\hline 7. Conocer las estrategias de búsqueda de información & .705 \\
\hline 3. Consular y usar bases de datos & .665 \\
\hline 5. Buscar y obtener información en internet & .654 \\
\hline 1. Leer libros, artículos en formato impreso & .640 \\
\hline 4. Conocer los conceptos de las asignaturas & .372 \\
\hline
\end{tabular}

La matriz de componentes mostrada en la tabla 4.19 indica la aportación de cada variable al factor común. Queda patente cómo tienen más peso en el factor aquellas variables que tienen que ver con la búsqueda de información en redes informáticas, quedando relegados al último lugar aquellos ítems menos relacionados con este ámbito.

Tabla 4.20 Comunalidades. Evaluación de información. Alumnos

\begin{tabular}{r|c}
\hline & Comunalidades \\
\hline 8. Evaluar la calidad de recursos de información & .475 \\
\hline 9. Reconocer la idea de un autor en un texto. & .495 \\
\hline 10. Conocer la tipología de las fuentes de información cientificas & .518 \\
\hline 11. Determinar si una fuente de información está actualizada & .473 \\
\hline 12. Conocer los autores e instituciones más relevantes de tu área temática. & .598 \\
\hline
\end{tabular}

En el caso de la escala evaluación de información nos encontramos comunalidades que rondan también el valor 0.5 (tabla 4.20).

Tabla 4.21 Varianza total explicada. Evaluación de información. Alumnos *

\begin{tabular}{|c|c|c|c|c|c|c|}
\hline \multirow{2}{*}{ Componente } & \multicolumn{3}{|c|}{ Autovalores iniciales } & \multicolumn{3}{|c|}{$\begin{array}{l}\text { Sumas de las saturaciones al cuadrado de lc } \\
\text { extracción }\end{array}$} \\
\hline & Total & $\begin{array}{c}\% \text { de la } \\
\text { varianza }\end{array}$ & \% acumul. & Total & $\begin{array}{c}\% \text { de la } \\
\text { varianza }\end{array}$ & \% acumul. \\
\hline 1 & 2.560 & 51.204 & 51.204 & 2.560 & 51.204 & 51.204 \\
\hline 2 & 0.695 & 13.894 & 65.097 & & & \\
\hline
\end{tabular}




\begin{tabular}{cc|c|c|c|c|c}
\hline $\mathbf{3}$ & 0.642 & 12.842 & 77.940 & & & \\
\hline $\mathbf{4}$ & 0.611 & 12.225 & 90.165 & & & \\
\hline $\mathbf{5}$ & 0.492 & 9.835 & 100.000 & & & \\
\hline
\end{tabular}

* Método de extracción: Análisis de componentes principales

El porcentaje de varianza total explicada para el factor evaluación de información, mostrado en la tabla 4.21, es del 51.2\%, con un autovalor superior a 2 puntos.

Tabla 4.22 Matriz de componentes. Evaluación de información. Alumnos

\begin{tabular}{r|c}
\hline & Componente \\
\hline 12. Conocer los autores e instituciones más relevantes de tu área temática. & .773 \\
\hline 10. Conocer la tipología de las fuentes de información científicas & .720 \\
\hline 9. Reconocer la idea de un autor en un texto. & .704 \\
\hline 8. Evaluar la calidad de recursos de información & .689 \\
\hline 11. Determinar si una fuente de información está actualizada & .688 \\
\hline
\end{tabular}

En cuanto a la matriz de componentes, en la tabla 4.22 se pueden observar ponderaciones similares en la aportación que cada variable hace al factor. Así, parece que el peso que tiene cada una de las variables en el factor común es bastante equilibrada.

Tabla 4.23 Comunalidades. Procesamiento de información. Alumnos

\begin{tabular}{r|c}
\hline & Comunalidades \\
\hline 13. Extraer la información que realmente necesitas & .411 \\
\hline 14. Reconocer las partes en las que se divide un texto & .384 \\
\hline 15. Utilizar gestores de bases de datos & .417 \\
\hline 16. Descargar programas a través de internet & .517 \\
\hline 17. Usar hojas de cálculo para hacer actividades & .410 \\
\hline 18. Instalar programas informáticos & .472 \\
\hline
\end{tabular}

La varianza explicada por el factor procesamiento de información para las variables incluidas en el análisis se sitúa en valores más bajos en este caso, sober todo en lo que se refiere al ítem 14, Reconocer las partes en las que se divide un texto.

Tabla 4.24 Varianza total explicada. Procesamiento de información. Alumnos *

\begin{tabular}{cc|c|c|c|c|c}
\hline \multirow{2}{*}{ Componente } & \multicolumn{3}{c|}{ Autovalores iniciales } & \multicolumn{2}{c}{ Sumas de las saturaciones al cuadrado de la } \\
\cline { 2 - 7 } & Total & $\begin{array}{c}\text { \% de la } \\
\text { varianza }\end{array}$ & \% acumul. & Total & $\begin{array}{c}\text { \% de la } \\
\text { varianza }\end{array}$ & \% acumul. \\
\hline $\mathbf{1}$ & 2.611 & 43.521 & 43.521 & 2.611 & 43.521 & 43.521 \\
\hline $\mathbf{2}$ & 0.958 & 15.973 & 59.494 & & & \\
\hline $\mathbf{3}$ & 0.905 & 15.080 & 74.574 & & & \\
\hline
\end{tabular}




\begin{tabular}{cl|l|l|l|l|l}
\hline $\mathbf{4}$ & 0.570 & 9.497 & 84.071 & & & \\
\hline 5 & 0.509 & 8.480 & 92.550 & & & \\
\hline $\mathbf{6}$ & 0.447 & 7.450 & 100.000 & & & \\
\hline
\end{tabular}

* Método de extracción: Análisis de componentes principales

Como muestra la tabla 4.24, el porcentaje de varianza total explicada para el factor procesamiento de información se sitúa en un $43.52 \%$, con un autovalor superior a 2 puntos.

Tabla 4.25 Matriz de componentes. Procesamiento de información. Alumnos

\begin{tabular}{r|c}
\hline & Componente \\
\hline 16. Descargar programas a través de internet & .719 \\
\hline 18. Instalar programas informáticos & .687 \\
\hline 15. Utilizar gestores de bases de datos & .646 \\
\hline 13. Extraer la información que realmente necesitas & .641 \\
\hline 17. Usar hojas de cálculo para hacer actividades & .640 \\
\hline 14. Reconocer las partes en las que se divide un texto & .620 \\
\hline
\end{tabular}

La matriz de componentes del factor procesamiento de información, mostrado en la tabla 4.25, indica que la aportación de las variables es bastante equitativa. Se corrobora también la tendencia percibida a partir del valor de la comunalidad en el ítem 14. El peso de la citada variable en el factor es el más bajo de todas, aunque con valores aceptables no muy distantes del resto de variables que conforman el factor.

Tabla 4.26 Comunalidades. Comunicación de información. Alumnos

\begin{tabular}{r|c}
\hline & Comunalidades \\
\hline 19. Comunicar en público & .512 \\
\hline 20. Comunicar en otras lenguas (inglés...) & .441 \\
\hline 21. Escribir un documento (trabajo de clase, ...) & .534 \\
\hline 22. Conocer las leyes sobre el uso de información y propiedad intelectual & .277 \\
\hline 23. Elaborar presentaciones académicas (power point) & .471 \\
\hline 24. Divulgar informaciones en internet (webs, blogs, ...) & .399 \\
\hline
\end{tabular}

Las comunalidades de las variables que conforman la escala comunicación de información, mostradas en la tabla 4.26 indican valores diversos. De hecho, la varianza explicada por el factor para el ítem 22, Conocer las leyes sobre el uso de información y propiedad intelectual, es baja. 


\begin{tabular}{cc|c|c|c|c|c}
\hline \multirow{2}{*}{ Componente } & \multicolumn{3}{c|}{ Autovalores iniciales } & \multicolumn{3}{c}{ Sumas de las saturaciones al cuadrado de la } \\
& Total & $\begin{array}{c}\text { \% de la } \\
\text { varianza }\end{array}$ & \% acumul. & Total & $\begin{array}{c}\text { \% de la } \\
\text { varianza }\end{array}$ & \% acumul. \\
\cline { 2 - 8 } & 2.635 & 43.912 & 43.912 & 2.635 & 43.912 & 43.912 \\
\hline $\mathbf{1}$ & 0.827 & 13.780 & 57.692 & & & \\
\hline $\mathbf{3}$ & 0.807 & 13.454 & 71.146 & & & \\
\hline $\mathbf{4}$ & 0.744 & 12.402 & 83.548 & & & \\
\hline $\mathbf{5}$ & 0.534 & 8.899 & 92.447 & & & \\
\hline $\mathbf{6}$ & 0.453 & 7.553 & 100.000 & & & \\
\hline
\end{tabular}

* Método de extracción: Análisis de componentes principales

El porcentaje de varianza total explicada para el factor comunicación de información es del 43.91\%, con un autovalor superior a 2 puntos (tabla 4.27).

Tabla 4.28 Matriz de componentes. Comunicación de información. Alumnos

\begin{tabular}{r|c}
\hline & Componente \\
\hline 21. Escribir un documento (trabajo de clase, ...) & .731 \\
\hline 19. Comunicar en público & .716 \\
\hline 23. Elaborar presentaciones académicas (power point) & .686 \\
\hline 20. Comunicar en otras lenguas (inglés...) & .664 \\
\hline 24. Divulgar informaciones en internet (webs, blogs, ...) & .632 \\
\hline 22. Conocer las leyes sobre el uso de información y propiedad intelectual & .527 \\
\hline
\end{tabular}

En la matriz de componentes para la escala de comunicación de información (tabla 4.28) se observan valores similares en las 5 primeras variables. Como se apuntaba en los valores de comunalidad, el ítem 22 hace una aportación notablemente inferior que el resto de ítems al factor.

Una vez llevado a cabo el análisis factorial exploratorio para cada una de las subescalas, veamos si estos resultados se corroboran aplicando la prueba del análisis factorial confirmatorio.

Tabla 4.29 Índices análisis factorial confirmatorio. Dimensiones teóricas. Alumnos

\begin{tabular}{lcccc|cccc}
\hline & \multicolumn{4}{c|}{ Ajuste global } & \multicolumn{3}{c}{ Ajuste incremental } \\
\cline { 2 - 9 } & $\chi^{2}$ & $g . l$ & $p$. & $R M S E A$ & CFI & NFI & IFI \\
\hline Búsqueda de información & 70.910 & 9 & $<.001$ & .077 & .939 & .932 & .940 \\
\hline Evaluación de información & 13.256 & 5 & .021 & .038 & .993 & .989 & .993 \\
\hline Procesamiento de información & 255.789 & 9 & $<.001$ & .153 & .817 & .814 & .819 \\
\hline Comunicación de información & 109.866 & 9 & $<.001$ & .098 & .920 & .915 & .921 \\
\hline
\end{tabular}


En cuanto al ajuste absoluto del modelo, como se observa en la tabla 4.29, el estadístico Chi cuadrado $\left(\chi^{2}\right)$ resulta significativo $(p<.001)$ en las cuatro dimensiones para un nivel de significación del .05, por lo que el modelo podría considerarse no adecuado. No obstante, este resultado podría ser esperable, dado que $\chi^{2}$ es muy sensible a la falta de normalidad de alguna de las variables observables (Tejedor Tejedor et al., 2009). Así, en estos casos debemos observar el comportamiento de otros indicadores como la ratio $\chi^{2} /$ grados de libertad, o el índice del error de aproximación cuadrático medio (RMSEA) (Schreiber, Nora, Stage, Barlow, \& King, 2006). En este caso, se pueden observar valores del estadístico RMSEA aceptables $(<0.08)$ en las dimensiones de búsqueda y de evaluación de información. Por su parte, en la comunicación de información los valores son cercanos a lo aceptable y en el procesamiento el valor es excesivamente elevado.

En lo que respecta al ajuste incremental del modelo se han calculado varios índices. El índice de ajuste comparado (CFI), que es uno de los indicadores de ajuste más empleados para contrastar la validez de un modelo dado, ya que compara varios coeficientes de ajuste (Alonso, Martínez Galindo, \& Moreno, 2006), adopta valores adecuados ( $>0.9$ ) en tres de las escalas comprobadas (búsqueda, evaluación y comunicación de información), e inferiores a lo considerado aceptable en el procesamiento. Por otro lado, los índices de ajuste normalizado (NFI) y de ajuste incremental (IFI) indican valores aceptables en las tres escalas antes citadas (>0.9). Por otro lado, se repiten valores no aceptables en el procesamiento de información. El índice IFI es más consistente que el CFI, ya que tiene en cuenta en sus cálculos los grados de libertad del modelo (Schmidt, Barreyro, \& Maglio, 2010).

Analizando con detenimiento los ítems de la escala de procesamiento de información, se pueden comprender estos resultados negativos, ya que esta dimensión teórica contiene ítems muy diversos en su naturaleza. Por una parte, incluye ítems que hacen referencia a la comprensión lectora (13. Extraer la información que realmente necesitas; 14. Reconocer las partes en las que se divide un texto). Por otra, también incorpora ítems relacionados con las habilidades informáticas tanto en lo que se refiere al manejo de algún software concreto (15. Utilizar gestores de bases de datos; 17. Usar hojas de cálculo para hacer actividades), como a habilidades genéricas de gestión de un sistema operativo (16. Descargar programas a través de internet; 18. Instalar programas informáticos). Esta heterogeneidad en la naturaleza o el contenido de los ítems que incluyen la escala nos lleva a obtener resultados que indican que no están midiendo un solo constructo o dimensión. 
Así, a pesar de que en adelante se considerarán estas dimensiones teóricas como válidas para los análisis que se llevarán a cabo, debemos ser cautos con los análisis e interpretaciones derivados de ellos, sobre todo en la dimensión procesamiento de información.

3. Extracción de factores de segundo orden, sobre el nivel percibido en cada dimensión de las competencias informacionales

Una vez aplicados los análisis factoriales de primer orden, y mostrado cómo cada grupo de ítems que conforma las dimensiones teóricas pueden componer una escala válida e independiente, pasaremos al análisis de segundo orden, en el que se pretende comprobar si estas escalas o dimensiones pueden ser sub-escalas relacionadas entre sí que conforman un constructo más amplio denominado competencias informacionales.

Para ello, se aplicará la prueba del análisis factorial exploratorio sobre las cuatro variables latentes a partir de las puntuaciones factoriales de cada una de las dimensiones analizadas en la primera fase.

Tabla 4.30 Matriz de correlaciones escala competencias informacionales. Alumnos *

\begin{tabular}{c|c|c|c|c}
\hline & Búsqueda & Evaluación & Procesamiento & Comunicación \\
\hline Búsqueda & 1.000 & .620 & .688 & .645 \\
\hline Evaluación & .620 & 1.000 & .599 & .576 \\
\hline Procesamiento & .688 & .599 & 1.000 & .710 \\
\hline Comunicación & .645 & .576 & .710 & 1.000 \\
\hline
\end{tabular}

$*$ Determinante $=0.128$

En el estudio de las condiciones previas, en primer lugar, la matriz de correlaciones mostrada en la tabla 4.30 devuelve valores altos en todas las variables, y el determinante de la matriz es diferente de 0.

Tabla 4.31 Matriz anti-imagen. Competencias informacionales. Alumnos *

\begin{tabular}{c|c|c|c|c}
\hline & Búsqueda & Evaluación & Procesamiento & Comunicación \\
\hline Búsqueda & .829 & -.302 & -.342 & -.233 \\
\hline Evaluación & -.302 & .871 & -.193 & -.177 \\
\hline Procesamiento & -.342 & -.193 & .798 & -.430 \\
\hline Comunicación & -.233 & -.177 & -.430 & .822 \\
\hline
\end{tabular}

$*$ Valores de la diagonal principal $>0.8$

En cuanto a los valores de la diagonal principal de la matriz de correlaciones antiimagen, como se puede observar en la tabla 4.31, se obtienen valores muy cercanos o superiores a 0.8. Estos valores se pueden considerar meritorios (Kaiser, 1974). 
Tabla 4.32 Test de Barlett y KMO. Competencias informacionales. Alumnos

Test de esfericidad de Barlett

KMO

Competencias informacionales

$1900.363(p<.001)$

.827

Por último, las pruebas de esfericidad de Barlett y el KMO (tabla 4.32), indican valores aceptables en ambos casos. Así, dados estos resultados, podremos continuar con el análisis factorial exploratorio de 20 orden propuesto.

Tabla 4.33 Comunalidades. Competencias informacionales. Alumnos

\begin{tabular}{r|c}
\hline & Comunalidades \\
\hline Dimensión I. Búsqueda de información & .749 \\
\hline Dimensión II. Evaluación de información & .659 \\
\hline Dimensión III. Procesamiento de información & .775 \\
\hline Dimensión IV. Comunicación de información & .738 \\
\hline
\end{tabular}

Los índices obtenidos en las comunalidades muestran que la varianza explicada por el factor común para todas las variables es alta en todos los casos y bastante equilibrada.

Tabla 4.34 Varianza total explicada. Competencias informacionales. Alumnos *

\begin{tabular}{|c|c|c|c|c|c|c|}
\hline \multirow{2}{*}{ Componente } & \multicolumn{3}{|c|}{ Autovalores iniciales } & \multicolumn{3}{|c|}{$\begin{array}{l}\text { Sumas de las saturaciones al cuadrado } \\
\text { de la extracción }\end{array}$} \\
\hline & Total & $\begin{array}{c}\text { \% de la } \\
\text { varianza }\end{array}$ & \% acumul. & Total & $\begin{array}{c}\text { \% de la } \\
\text { varianza }\end{array}$ & \% acumul. \\
\hline 1 & 2.635 & 43.912 & 43.912 & 2.635 & 43.912 & 43.912 \\
\hline 2 & 0.827 & 13.780 & 57.692 & & & \\
\hline 3 & 0.807 & 13.454 & 71.146 & & & \\
\hline 4 & 0.744 & 12.402 & 83.548 & & & \\
\hline
\end{tabular}

* Método de extracción: Análisis de componentes principales

Como muestran los resultados de la tabla 4.34, en la aplicación de la técnica del análisis factorial explicatorio para las cuatro variables obtenidas a partir de las puntuaciones factoriales de las cuatro dimensionse teóricas definidas en la primera fase, existe un solo factor y el porcentaje de varianza total explicada para el constructo competencias informacionales es del $43.91 \%$, con un autovalor de 2.635 .

Tabla 4.35 Matriz de componentes. Competencias informacionales. Alumnos

\begin{tabular}{r|c}
\hline & Componente \\
\hline Dimensión I. Búsqueda de información & .866 \\
\hline Dimensión II. Evaluación de información & .812 \\
\hline
\end{tabular}




\begin{tabular}{c|c}
\hline Dimensión III. Procesamiento de información & .881 \\
\hline Dimensión IV. Comunicación de información & .859 \\
\hline
\end{tabular}

En la matriz de componentes para la escala global competencias informacionales (tabla 4.35) se observan valores elevados similares en todas las variables incluidas en el factor.

Veamos ahora si estos datos obtenidos en el análisis exploratorio se corroboran a partir de los indicadores del análisis confirmatorio. Para ello, pondremos a prueba dos modelos. En primer lugar comprobaremos únicamente el análisis factorial de 2 o orden llevado a cabo, incluyendo en el análisis como variables observadas las puntuaciones factoriales obtenidas en los análisis de primer orden llevados a cabo. En segundo lugar, se planteará el modelo completo directamente a partir de los 24 ítems de la escala, con un primer nivel que incluye las cuatro variables latentes o dimensiones teóricas con las que se ha trabajado hasta el momento, y un segundo nivel en el que estas cuatro dimensiones conforman una nueva variable latente, las competencias informacionales.

Tabla 4.36 Índices análisis factorial confirmatorio. Competencias informacionales. Alumnos

\begin{tabular}{lcccc|cccc}
\hline & \multicolumn{4}{c}{ Ajuste global } & \multicolumn{3}{c}{ Ajuste incremental } \\
\cline { 2 - 9 } & $\chi^{2}$ & g.I & p. & RMSEA & CFI & NFI & IFI \\
\hline $\begin{array}{l}\text { Modelo con puntuaciones } \\
\text { factoriales }\end{array}$ & 14.487 & 2 & .001 & .073 & .994 & .993 & .994 \\
\hline Modelo completo & 2017.563 & 226 & $<.001$ & .082 & .788 & .769 & .789 \\
\hline
\end{tabular}

Los resultados obtenidos en los índices principales del análisis factorial exploratorio, como se puede observar en la tabla 4.36, nos muestran valores que indican un ajuste global e incremental adecuado en la primera prueba, y ajustes poco adecuados en la segunda, cuando procedemos a la realización del modelo completo.

Estos resultados de la segunda prueba son comprensibles teniendo en cuenta que en las pruebas llevadas a cabo anteriormente el ajuste de la dimensión procesamiento de información era poco adecuado. Así, este factor empuja al modelo hacia indicadores de ajuste poco aceptables. Sin embargo, en el caso de la confirmación a partir de las puntuaciones factoriales de cada una de las escalas, esta causa se elimina, ya que los ítems individuales de cada una de las sub-escalas dejan de estar presentes en el modelo puesto a prueba. 


\subsubsection{Cuestionario para futuros profesores de Educación Secundaria}

\section{a) Diseño del cuestionario}

La encuesta diseñada para futuros profesores recoge de manera más fiel la encuesta original de Pinto (2009) a partir de la que se adaptó el cuestionario definitivo. Esto se debe a que el instrumento original se diseñó para la población de estudiantes universitarios, y la población del presente estudio eran los futuros profesores de Educación Secundaria Obligatoria, que en la actualidad estaban estudiando el Máster Oficial en Profesor de Educación Secundaria Obligatoria y Bachillerato, Formación Profesional y Enseñanzas de Idiomas.

Así, queda un cuestionario compuesto en primer lugar por un bloque en el que se recogen datos demográficos de los sujetos, y algún otro relacionado con la experiencia y costumbres en el uso de las nuevas tecnologías. Por otro lado, el segundo bloque presenta los ítems relativos a las variables criterio del estudio, esto es, la escala de nivel e importancia autopercibidos acerca de las diferentes dimensiones que conforman el constructo competencias informacionales. Por último, el cuestionario incluye un bloque sobre la frecuencia de uso y el nivel autopercibido en actividades informáticas de ocio, relacionadas con la gestión de la información en internet y referentes al manejo de diferente software informático relacionado principalmente con el procesamiento y la comunicación de información.

Esta escala final fue diseñada originalmente a partir de los conocimientos teóricoprácticos obtenidos en el proceso de planificación, estudio teórico, análisis de datos y establecimiento de conclusiones del ESTUDIO I. A partir de la información obtenida con la muestra de estudiantes de educación secundaria, se infirieron los conocimientos informáticos más íntimamente correlacionados con el desarrollo de las competencias informacionales, y se dispusieron de manera que los sujetos tuvieran que reflejar tanto la frecuencia con la que se manejan en cada uno de ellos, y el nivel que creen poseer.

En las figuras que se irán mostrando a continuación se puede observar el formato en el que recibían los sujetos de la muestra la escala. Incluye una presentación amplia del cuestionario y de los objetivos de la investigación, junto con unas instrucciones básicas para su cumplimentación. Cabe recordar en este momento que la encuesta es aplicada en el propio aula en el que se encuentra el futuro profesorado, durante el curso académico 2010/2011. 


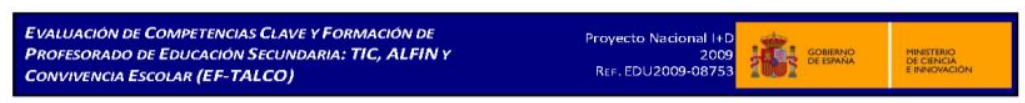

\section{CUESTIONARIO \\ PARA PROFESORES EN FORMACIÓN INICIAL: COMPETENCIAS EN ALFABETIZACIÓN INFORMACIONAL}

En el marco de la Sociedad de la Información surgen nuevas necesidades educativas relacionadas con el manejo, la gestión y la construcción de datos, información y conocimiento. El desarrollo de las Tecnologias de la Información y la Comunicación tiene mucho que ver en la emergencia de estas exigencias.

En este contexto se define un nuevo concepto que hace referencia a este conjunto de competencias: Alfabetización Informacional.

Mientras que en los ambientes teóricos universitarios se sugiere desde hace tiempo la necesidad de implementar una verdadera revolución educativa que renueve las pedagogías existentes para adaptarse a los nuevos tiempos, la realidad en la práctica es que la mayoría de los docentes de todos los niveles educativos mantienen sus prácticas tradicionales prácticamente intactas.

Esta investigación surge con el interés de conocer la situación formativa en la que se encuentran los futuros profesores y profesoras de Educación Secundaria Obligatoria, Bachillerato y Formación Profesional, para, a partir de la definición y análisis de la realidad, detectar las posibles lagunas en este aspecto y diseñar una propuesta curricular realista para fomentar una mejor adaptación de los futuros profesares al contexto informacional circundante.

Es un cuestionario totalmente anónimo, por lo que te pedimos que respondas con la máxima sinceridad posible.

TU OPINIÓN ES IMPORTANTE

NOVIEMBRE, 2010

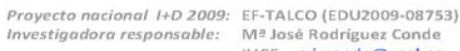

HCE - mirconde consal.es

Figura 4.8 Cuestionario para el futuro profesorado de Educación Secundaria I

Esta primera cara del cuestionario, como se ha señalado más arriba, que se muestra en la figura 4.8, aporta simplemente al encuestado información acerca de la propia encuesta, de los objetivos de la investigación en la que está inmersa, y del investigador principal y el proyecto a partir del que se deriva.

Desde un primer momento se valoró en gran medida que los sujetos de esta muestra en particular tuvieran una información amplia sobre lo que se estaba investigando. Esto se debe tanto a que la temática es de alto interés para personas que están formándose para ser profesores de Educación Secundaria Obligatoria, como a que al tratarse de una escala de nivel autopercibido, se creía esencial crear algún tipo de vínculo con los sujetos de la muestra para asegurar en mayor medida la veracidad de las respuestas allí vertidas. 


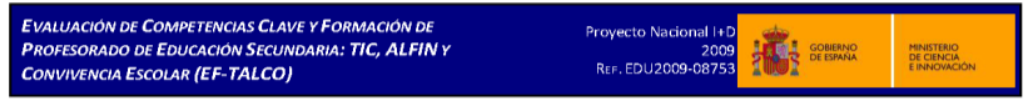

\section{CUESTIONARIO}

INFORMACIÓN SOBRE DATOS DEMOGRÁFICOS

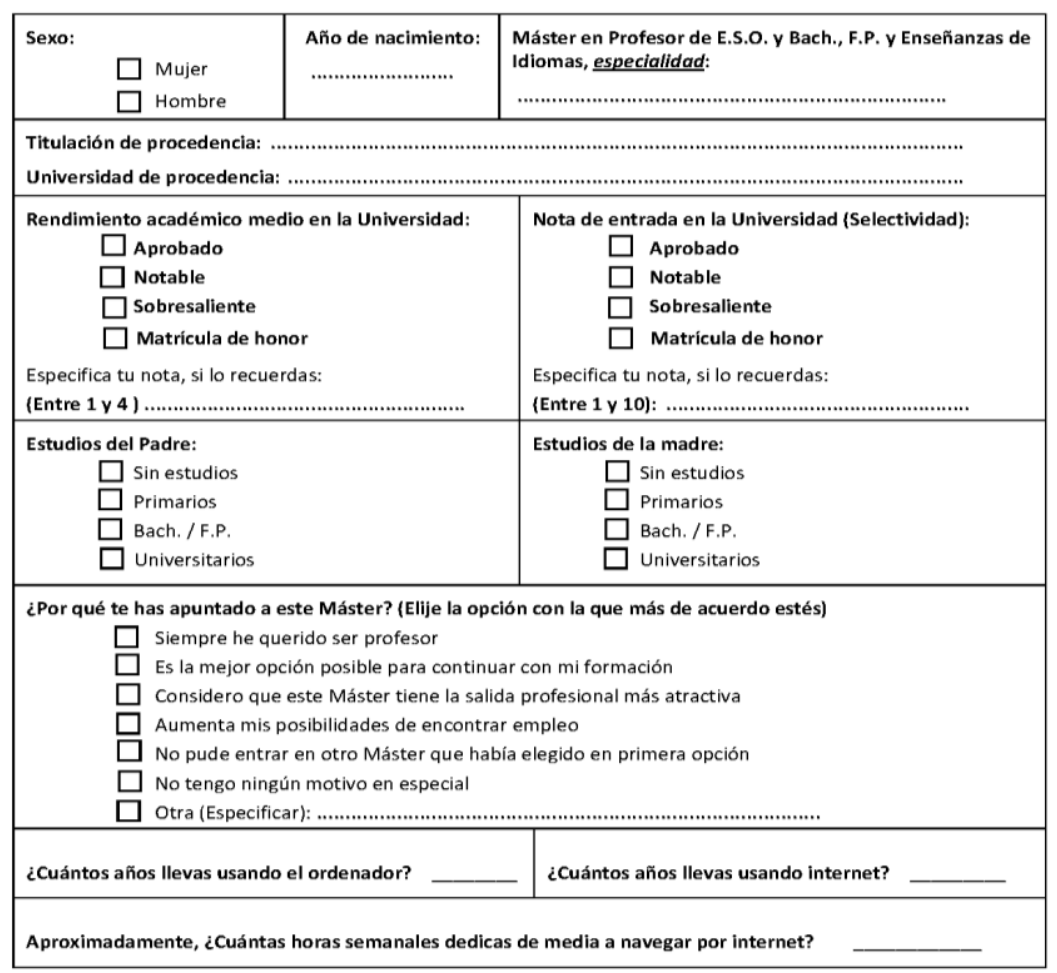

Proyecto nacional 1+D 2009: EF-TALCO (EDU2009-08753)

Investigadora responsable: Mã José Rodriguez Conde

IUCE-mirconde@usal.es

Figura 4.9 Cuestionario para el futuro profesorado de Educación Secundaria II

En esta segunda cara del cuestionario, como muestra la figura 4.9, se presenta el bloque de preguntas para la obtención de información demográfica y algo de información genérica acerca del empleo de tecnologías digitales. 
EVALUACION DE COMPETENCIAS CLAVE Y FormaCION DE

PROFESORADO DE EDUCACION SECUNDARIA: TIC, ALFIN Y

CONVIVENCIA ESCOLAR (EF-TALCO)

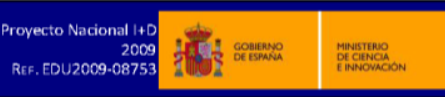

En la actual Sociedad de la Información es importante acceder, analizar y utilizar la información de forma adecuada. Para ello, como figura en los postulados del Espacio Europeo de Educación Superior (EEES), son necesarias una serie de competencias relacionadas con la búsqueda, evaluación, gestión, uso y difusión de la información. Este grupo de preguntas están concebidas con el fin de conocer tu opinión sobre tus propias competencias y habilidades en el manejo y uso de la información. Por favor, señala cómo evalúas las siguientes competencias mediante la selección del número que mejor exprese tu opinión, correspondiendo 1 a una baja competencia y 9 a una competencia excelente. Evalúa cada competencia en relación con las tres variables (motivación-compromiso, auto-eficacia y una fuente de aprendizaje) que se describen a continuación:

Motivación/compromiso: Valora la importancia que tienen las siguientes competencias para tu desarrollo académico Auto-eficacia: Valora tu grado de destreza en las siguientes competencias

Ayúdanos a mejorar; en tu viaje formativo -

\begin{tabular}{|c|c|c|}
\hline En relación con.... & $\begin{array}{c}\text { Motivación / } \\
\text { Compromiso }\end{array}$ & $\begin{array}{c}\text { Auto-eficacia } \\
\text { COMPETENCIAS en ALFABETIZACIÓN INFORMACIONAL (1) }\end{array}$ \\
\hline Bajo AAlto & Bajo Alto \\
1234567899 & 123456789 \\
\hline
\end{tabular}

Búsqueda de la información

01. Saber utilizar fuentes de informacínimpesa

02 . Saber acceder y usar los catálogos automatizado

03. Saber consultar y usar fuentes electrónicas de información primaria ( ej. revistas, ...)

04. Saber utilizar fuentes electrónicas de información secundaria (ej. bases de datos,...)

05 . Conocer la terminologia especializada de tu materia

06. Saber buscar y recuperar información en Internet (ej. búsquedas avanzadas, directorios,

portales, ...)

07. Saber utilizar fuentes electrónicas informales de información (ej. blogs, listas de distribución,

08. Conocer las estrategias de búsqueda de información (descriptores, operadores booleanos, ...

Selección de la información

09. Saber evaluar la calidad de los recursos de información

10. Reconocer en el texto las ideas del autor

11. Conocer la tipología de las fuentes de información cientifica (ej. tesis doctorales, actas de

congresos, ...)

12. Ser capaz de determinar si la información que contiene un recurso está actualizada

13. Conocer los autores o instituciones más relevantes en tu ámbito temático

Procesamiento de la información

14. Saber resumir y esquematizar la información

15. Ser capaz de reconocer la estructuración de un texto

16. Saber usar gestores de bases de datos (ej. Access, MySQL

17. Usar gestores de referencias bibliográficas (ej. End Myste Reference Manager, Zotero)

18. Saber manejar programas estadisticos y hojas de cálculo (ej. SPSS, Excel, ...)

19. Saber instalar programas informáticos

Comunicación de la información

20. Saber comunicar en público

21. Saber comunicar en otros idiomas

22. Saber redactar un documento (ej. informe, trabajo acadent

23. Conocer el código ético de tu ámbito académico/profesional

24. Conocer la legislación sobre el uso de la información y de la prop

25. Saber hacer presentaciones académicas (ej. Powerpoint, ...)

26. Saber difundir la información en Internet (ej. webs, blogs, ...)

(1) Traducido de Pinto, M. (2008)

Señala algunas necesidades que consideres relevantes en tu formación para obtener una mejor competencia informaciona:

Proyecto nacional 1+D 2009: EF-TALCO (EDU2009-08753)

Investigadora responsable: $\mathrm{M}^{a}$ José Rodriguez Conde

IUCE - mirconde@usal.es

Figura 4.10 Cuestionario para el futuro profesorado de Educación Secundaria III

El segundo bloque de recogida de información del cuestionario (Figura 4.10) es el más importante, ya que es en dónde los sujetos informan acerca del nivel y la importancia autopercibidos sobre las diferentes sub-escalas y los diversos grupos de ítems que conforman las competencias informacionales. 
EVALUACION DE COMPETENCIAS CLAVE Y FoRMACION DE

PROFESORADO DE EDUCACION SECUNDARIA: TIC, ALFIN Y

CONVIVENCIA ESCOLAR (EF-TALCO)

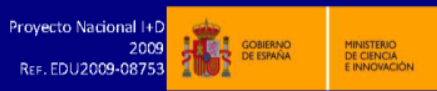

CONOCIMIENTOS INFORMÁTICOS

Ya hemos comentado en la introducción que el impulso de las Tecnologías de la Información y la Comunicación tiene una importancia esencial en el desarrollo de competencias relacionadas con la Alfabetización Informacional. Por ello, con esta última escala queremos conocer tanto con qué frecuencia desarrollas cada una de las tareas que se te presentan a continuación, como qué nivel de desempeño crees que tienes al respecto.

De cada una de las siguientes actividades señala lo siguiente (Marca con una $\mathrm{X}$ la opción que elijas)

- FRECUENCIA con la que realizas la tarea

( $1=$ Nunca; $2=$ Casi nunca; $3=A$ veces; $4=$ =Frecuentemente; $5=$ Casi todos los días)

- NIVEL de conocimientos que crees que posees en la tarea

(1=Sin conocimientos; 2=Bajos conocimientos; 3=Nivel medio; 4=Conocimientos elevados; 5=Experto)

\begin{tabular}{|c|c|c|c|c|c|c|c|c|c|c|}
\hline & \multicolumn{5}{|c|}{ FRECUENCIA DE USO } & \multicolumn{5}{|c|}{ NIVEL (Auto-eficacia) } \\
\hline \multicolumn{11}{|l|}{ Actividades de ocio } \\
\hline $\begin{array}{l}\text { 01. Comunicarse por internet a través de herramientas sincronas } \\
\text { (chat, webcam,...) }\end{array}$ & 1 & 2 & 3 & 4 & 5 & 1 & 2 & 3 & 4 & 5 \\
\hline 02. Usar el ordenador para jugar (Videojuegos, juegos en red,...) & 1 & 2 & 3 & 4 & 5 & 1 & 2 & 3 & 4 & 5 \\
\hline $\begin{array}{l}\text { 03. Descargar o acceder a contenidos multimedia a través de internet } \\
\text { (música, peliculas, fotografías, videos,...) }\end{array}$ & 1 & 2 & 3 & 4 & 5 & 1 & 2 & 3 & 4 & 5 \\
\hline 04. Utilizar una red social & 1 & 2 & 3 & 4 & 5 & 1 & 2 & 3 & 4 & 5 \\
\hline 05. Comprar por internet & 1 & 2 & 3 & 4 & 5 & 1 & 2 & 3 & 4 & 5 \\
\hline $\begin{array}{l}\text { 06. Intercambiar información entre el ordenador y accesorios } \\
\text { externos (Cámara, teléfono móvil, mp3,...) }\end{array}$ & 1 & 2 & 3 & 4 & 5 & 1 & 2 & 3 & 4 & 5 \\
\hline
\end{tabular}

\begin{tabular}{|c|c|c|c|c|c|c|c|c|c|c|}
\hline \multicolumn{11}{|l|}{ Gestión de la información en internet } \\
\hline $\begin{array}{l}\text { 07. Buscar la información que necesito en buscadores genéricos } \\
\text { (Google, Yahoo, Wikipedia, ...) }\end{array}$ & 1 & 2 & 3 & 4 & 5 & 1 & 2 & 3 & 4 & 5 \\
\hline $\begin{array}{l}\text { 08. Consultar información especializada en metabuscadores y/o } \\
\text { buscadores especificos (bibliotecas, bases de datos,...) }\end{array}$ & 1 & 2 & 3 & 4 & 5 & 1 & 2 & 3 & 4 & 5 \\
\hline 09. Manejar el correo electrónico (Contactos, agenda, bandejas,...) & 1 & 2 & 3 & 4 & 5 & 1 & 2 & 3 & 4 & 5 \\
\hline $\begin{array}{l}\text { 10. Crear, mantener y administrar un espacio en internet }(B \mid \text { og, } \\
\text { página web,...) }\end{array}$ & 1 & 2 & 3 & 4 & 5 & 1 & 2 & 3 & 4 & 5 \\
\hline $\begin{array}{l}\text { 11. Colaborar aportando información en webs sociales (Wikipedia, } \\
\text { Yahoo Answers, Youtube, Flickr, Booking,...) }\end{array}$ & 1 & 2 & 3 & 4 & 5 & 1 & 2 & 3 & 4 & 5 \\
\hline $\begin{array}{l}\text { 12. Realizar trabajos en grupo a través de herramientas web (Google } \\
\text { docs, foros, wikis,...) }\end{array}$ & 1 & 2 & 3 & 4 & 5 & 1 & 2 & 3 & 4 & 5 \\
\hline \multicolumn{11}{|l|}{ Manejo del software } \\
\hline $\begin{array}{l}\text { 13. Diseño y tratamiento de imagen, sonido y video digital } \\
\text { (Photoshop, Audacity, Pinnacle,...) }\end{array}$ & 1 & 2 & 3 & 4 & 5 & 1 & 2 & 3 & 4 & 5 \\
\hline $\begin{array}{l}\text { 14. Emplear un lenguaje de programación para elaborar recursos } \\
\text { (C++, Basic, Html,...) }\end{array}$ & 1 & 2 & 3 & 4 & 5 & 1 & 2 & 3 & 4 & 5 \\
\hline $\begin{array}{l}\text { 15. Mantenimiento del software (Actualizaciones, antivirus, } \\
\text { antispyware, limpieza del registro,...) }\end{array}$ & 1 & 2 & 3 & 4 & 5 & 1 & 2 & 3 & 4 & 5 \\
\hline $\begin{array}{l}\text { 16. Diseño y manipulación de documentos de texto (Procesador de } \\
\text { texto y archivos en formato pdf) }\end{array}$ & 1 & 2 & 3 & 4 & 5 & 1 & 2 & 3 & 4 & 5 \\
\hline $\begin{array}{l}\text { 17. Elaboración de presentaciones de diapositivas (Powerpoint, } \\
\text { Impress,...) }\end{array}$ & 1 & 2 & 3 & 4 & 5 & 1 & 2 & 3 & 4 & 5 \\
\hline 18. Manejo de la hoja de cálculo (Excel, Calc,...) & 1 & 2 & 3 & 4 & 5 & 1 & 2 & 3 & 4 & 5 \\
\hline
\end{tabular}

GRACIAS POR TU COLABORACIÓN

Si quieres conocer los resultados del proyecto, señálanos tu e-mail:

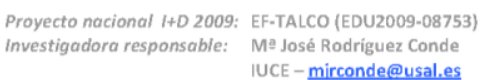

IUCE-mirconde@usal.es

Figura 4.11 Cuestionario para el futuro profesorado de Educación Secundaria VI

Por último, como se puede observar en la figura 4.11, el bloque final del cuestionario es el que recoge información acerca de los hábitos de manejo y el nivel autopercibido en lo que tiene que ver con las competencias informáticas. 
Así, la estructura básica de la información recogida en los diferentes bloques de contenido y sub-bloques del cuestionario es la siguiente:

- Variables demográficas

- Datos puramente demográficos

- Información genérica sobre hábitos en el consumo de tecnologías digitales

- Competencias informacionales

○ Conocimiento autopercibido

- Importancia concedida

- Hábitos y nivel en el manejo de herramientas informáticas

- Frecuencia de uso y nivel en actividades de ocio

○ Frecuencia de uso y nivel en gestión de la información en internet

- Frecuencia de uso y nivel en manejo del software

\section{b) Análisis psicométrico del cuestionario}

Aunque aún no se haya justificado en este momento la muestra empleada (se especificará en el apartado posterior) esta validación empírica se efectúa a partir de una muestra piloto de futuros profesores del Máster Universitario en Profesor de Educación Secundaria Obligatoria y Bachillerato, formación Profesional y Enseñanzas de Idiomas tomada en el curso 2009/2010, constituyendo finalmente un total de 192 sujetos.

Veamos a continuación los resultados obtenidos en las pruebas de fiabilidad y validez aplicadas sobre el cuestionario.

En cuanto a las escalas que se pondrán a prueba, nos centraremos, al igual que en el caso de los alumnos de educación secundaria, en las variables predictoras principales del estudio. Así, se estudiarán las propiedades métricas de las diferentes sub-escalas acerca del nivel autopercibido en competencias informacionales:

- Búsqueda de información 
- Evaluación de información

- Procesamiento de información

- Comunicación y difusión de información

En lo que respecta a la fiabilidad de las escalas, podemos observar, en primer lugar, la correlación entre cada uno de los ítems y el total de las escalas. En las tablas $4.37,4.38,4.394 .40,4.41$ y 4.42 se muestran todo tipo de estadísticos total-elemento que nos aportan pistas acerca de la importancia de cada uno de los ítems dentro de las sub-escalas analizadas.

Tabla 4.37 Estadísticos total-elemento para futuros profesores. Búsqueda de información

\begin{tabular}{|c|c|c|c|c|c|}
\hline Estadísticos total-elemento & $\begin{array}{l}\text { Media sin } \\
\text { el } \\
\text { elemento }\end{array}$ & $\begin{array}{l}\text { Var. sin el } \\
\text { elemento }\end{array}$ & $\begin{array}{l}\text { Correlac. } \\
\text { elem- } \\
\text { total } \\
\text { corregida }\end{array}$ & $\begin{array}{l}\text { Correlac. } \\
\text { múltiple } \\
\quad \text { al } \\
\text { cuadrado }\end{array}$ & $\begin{array}{c}\alpha \text { de } \\
\text { Cronbach } \\
\text { sin el } \\
\text { elemento }\end{array}$ \\
\hline $\begin{array}{l}\text { 01. Saber utilizar fuentes de } \\
\text { información impresa (ej. } \\
\text { libros, ...) }\end{array}$ & 47.30 & 65.510 & .512 & .414 & .820 \\
\hline $\begin{array}{l}\text { 02. Saber acceder y usar los } \\
\text { catálogos automatizados }\end{array}$ & 48.22 & 59.595 & .560 & .347 & .812 \\
\hline $\begin{array}{l}\text { 03. Saber consultar y usar } \\
\text { fuentes electrónicas de } \\
\text { información primaria ( ej. } \\
\text { revistas, ...) }\end{array}$ & 47.44 & 62.048 & .622 & .457 & .807 \\
\hline $\begin{array}{l}\text { 04. Saber utilizar fuentes } \\
\text { electrónicas de información } \\
\text { secundaria (ej. bases de } \\
\text { datos, ...) }\end{array}$ & 48.31 & 56.784 & .636 & .480 & .802 \\
\hline $\begin{array}{l}\text { 05. Conocer la terminología } \\
\text { especializada de tu materia }\end{array}$ & 47.23 & 67.210 & .449 & .249 & .826 \\
\hline $\begin{array}{l}\text { 06. Saber buscar y recuperar } \\
\text { información en internet (ej. } \\
\text { búsquedas avanzadas, } \\
\text { directorios, portales, ...) }\end{array}$ & 47.22 & 59.640 & .671 & .530 & .799 \\
\hline $\begin{array}{l}\text { 07. Saber utilizar fuentes } \\
\text { electrónicas informales de } \\
\text { información (ej. blogs, listas } \\
\text { de distribución, ...) }\end{array}$ & 47.97 & 58.010 & .603 & .423 & .806 \\
\hline
\end{tabular}




\begin{tabular}{|c|c|c|c|c|c|}
\hline $\begin{array}{l}\text { 08. Conocer las estrategias } \\
\text { de búsqueda de información } \\
\text { (descriptores, operadores } \\
\text { booleanos, ...) }\end{array}$ & 49.49 & 53.396 & .538 & .381 & .827 \\
\hline
\end{tabular}

En el primer caso, en la tabla 4.37 podemos apreciar índices de correlación ítemtotal aceptables en todos los ítems de la escala. Encontramos un valor inferior a .5 en el ítem 5. Conocer la terminología especializada de tu materia. Sin embargo, consideramos que este ítem debe mantenerse en la dimensión. A pesar de que no hace directamente referencia a las destrezas para la búsqueda de información, es de vital importancia, como así se ha reflejado a nivel teórico, manejar los conceptos de las materias sobre las que se está trabajando para manejarse adecuadamente con los operadores booleanos y las bases de datos en las búsquedas de información.

Tabla 4.38 Estadísticos total-elemento para futuros profesores. Evaluación de información

\begin{tabular}{|c|c|c|c|c|c|}
\hline Estadísticos total-elemento & $\begin{array}{l}\text { Media sin } \\
\text { el } \\
\text { elemento }\end{array}$ & $\begin{array}{l}\text { Var. sin el } \\
\text { elemento }\end{array}$ & $\begin{array}{l}\text { Correlac. } \\
\text { elem- } \\
\text { total } \\
\text { corregida }\end{array}$ & $\begin{array}{l}\text { Correlac. } \\
\text { múltiple } \\
\text { al } \\
\text { cuadrado }\end{array}$ & $\begin{array}{c}\alpha \text { de } \\
\text { Cronbach } \\
\text { sin el } \\
\text { elemento }\end{array}$ \\
\hline $\begin{array}{l}\text { 09. Saber evaluar la calidad } \\
\text { de los recursos de } \\
\text { información }\end{array}$ & 27.56 & 22.036 & .467 & .255 & .706 \\
\hline $\begin{array}{l}\text { 10. Reconocer en el texto las } \\
\text { ideas del autor }\end{array}$ & 27.08 & 21.238 & .564 & .349 & .678 \\
\hline $\begin{array}{l}\text { 11. Conocer la tipología de } \\
\text { las fuentes de información } \\
\text { científica (ej. tesis } \\
\text { doctorales, actas de } \\
\text { congresos, ...) }\end{array}$ & 28.53 & 17.339 & .518 & .276 & .690 \\
\hline $\begin{array}{l}\text { 12. Ser capaz de determinar } \\
\text { si la información que } \\
\text { contiene un recurso está } \\
\text { actualizada }\end{array}$ & 27.83 & 18.706 & .534 & 290 & .677 \\
\hline $\begin{array}{l}\text { 13. Conocer los autores o } \\
\text { instituciones más relevantes } \\
\text { en tu ámbito temático }\end{array}$ & 27.96 & 19.376 & .469 & 267 & .704 \\
\hline
\end{tabular}

En el caso de la segunda subescala, como se puede observar en la tabla 4.38, se obtienen índices de correlación dentro de lo aceptable en todos los casos. Así, se considera que esta escala, que en el caso del cuestionario para los alumnos de educación secundaria tenía el mejor ajuste, es adecuada. 
En cuanto a la dimensión procesamiento de información, si se analizan los ítems, nos podemos percatar rápidamente de que existen dos grupos diferenciados, los que se refieren al procesamiento informático de datos y los que están relacionados con el procesamiento cognitivo de la información, así, se considerarán por separado en el cálculo de las correlaciones y estadísticos inter-ítem.

Tabla 4. 39 Estadísticos total-elemento para futuros profesores. Procesamiento cognitivo

\begin{tabular}{lc|c|c|c}
\hline \multicolumn{1}{c|}{ Estadísticos total-elemento } & $\begin{array}{c}\text { Media sin el } \\
\text { elemento }\end{array}$ & $\begin{array}{c}\text { Var. sin el } \\
\text { elemento }\end{array}$ & $\begin{array}{c}\text { Correlac. } \\
\text { elem-total } \\
\text { corregida }\end{array}$ & $\begin{array}{c}\text { Correlac. } \\
\text { múltiple al } \\
\text { cuadrado }\end{array}$ \\
\hline $\begin{array}{l}\text { 14. Saber resumir y esquematizar } \\
\text { la información }\end{array}$ & 7.66 & 1.507 & .564 & .319 \\
\hline $\begin{array}{l}\text { 15. Ser capaz de reconocer la } \\
\text { estructuración de un texto }\end{array}$ & 7.76 & 1.317 & .564 & .319 \\
\hline
\end{tabular}

La tabla 4.39, que muestra los estadísticos total-elemento para la subescala de medida del procesamiento cognitivo de la información, existen sólo dos ítems, e indican un buen índice de correlación entre ambos.

Tabla 4.40 Estadísticos total-elemento para futuros profesores. Procesamiento informático

\begin{tabular}{|c|c|c|c|c|c|}
\hline Estadísticos total-elemento & $\begin{array}{c}\text { Media sin } \\
\text { el } \\
\text { elemento }\end{array}$ & $\begin{array}{l}\text { Var. sin el } \\
\text { elemento }\end{array}$ & $\begin{array}{l}\text { Correlac. } \\
\text { elem- } \\
\text { total } \\
\text { corregida }\end{array}$ & $\begin{array}{l}\text { Correlac. } \\
\text { múltiple } \\
\text { al } \\
\text { cuadrado }\end{array}$ & $\begin{array}{c}\alpha \text { de } \\
\text { Cronbach } \\
\text { sin el } \\
\text { elemento }\end{array}$ \\
\hline $\begin{array}{l}\text { 16. Saber usar gestores de } \\
\text { bases de datos (ej. Access, } \\
\text { MySQL, ...) }\end{array}$ & 16.61 & 28.898 & .752 & .597 & .675 \\
\hline $\begin{array}{l}\text { 17. Usar gestores de } \\
\text { referencias bibliográficas (ej. } \\
\text { Endnote, Reference } \\
\text { Manager, Zotero) }\end{array}$ & 17.64 & 33.021 & .547 & .388 & .780 \\
\hline $\begin{array}{l}\text { 18. Saber manejar } \\
\text { programas estadísticos y } \\
\text { hojas de cálculo (ej. SPSS, } \\
\text { Excel, ...) }\end{array}$ & 16.27 & 29.824 & .741 & .576 & .684 \\
\hline $\begin{array}{l}\text { 19. Saber instalar programas } \\
\text { informáticos }\end{array}$ & 15.44 & 36.787 & .429 & .243 & .831 \\
\hline
\end{tabular}

La anterior tabla 4.40 señala los estadísticos total-elemento para la subescala de medida del procesamiento informático de la información. Se pueden observar índices de correlación total-elemento adecuados en general. 
Para finalizar, la escala de Comunicación de información también se divide en dos agrupaciones. La primera hace referencia a habilidades y destrezas cognitivas relacionadas con la comunicación. La segunda hace más referencia a las habilidades informáticas para la comunicación.

Tabla 4.41 Estadísticos total-elemento para futuros profesores. Habilidades comunicativas.

\begin{tabular}{|c|c|c|c|c|c|}
\hline Estadísticos total-elemento & $\begin{array}{l}\text { Media sin } \\
\text { el } \\
\text { elemento }\end{array}$ & $\begin{array}{l}\text { Var. sin el } \\
\text { elemento }\end{array}$ & $\begin{array}{l}\text { Correlac. } \\
\text { elem- } \\
\text { total } \\
\text { corregida }\end{array}$ & $\begin{array}{c}\text { Correlac. } \\
\text { múltiple } \\
\text { al } \\
\text { cuadrado }\end{array}$ & $\begin{array}{c}\alpha \text { de } \\
\text { Cronbach } \\
\text { sin el } \\
\text { elemento }\end{array}$ \\
\hline $\begin{array}{l}\text { 20. Saber comunicar en } \\
\text { público }\end{array}$ & 25.57 & 27.832 & .475 & .263 & .649 \\
\hline $\begin{array}{l}\text { 21. Saber comunicar en } \\
\text { otros idiomas }\end{array}$ & 26.85 & 22.588 & .427 & .201 & .684 \\
\hline $\begin{array}{l}\text { 22. Saber redactar un } \\
\text { documento (ej. informe, } \\
\text { trabajo académico, ...) }\end{array}$ & 24.99 & 29.027 & .515 & .293 & .645 \\
\hline $\begin{array}{l}\text { 23. Conocer el código ético } \\
\text { de tu ámbito } \\
\text { académico/profesional }\end{array}$ & 25.55 & 26.664 & .516 & .274 & .631 \\
\hline $\begin{array}{l}\text { 24. Conocer la legislación } \\
\text { sobre el uso de la } \\
\text { información y de la } \\
\text { propiedad intelectual }\end{array}$ & 26.69 & 24.256 & .454 & .235 & .656 \\
\hline
\end{tabular}

La primera sub-escala de la dimensión de comunicación de información, referida a habilidades y destrezas cognitivas, muestra índices de correlación (tabla 4.41), aunque bajos, aceptables.

Tabla 4.42 Estadísticos total-elemento para futuros profesores. Informática para la comunicación.

\begin{tabular}{lc|c|c|c}
\hline Estadísticos total-elemento & $\begin{array}{c}\text { Media sin el } \\
\text { elemento }\end{array}$ & $\begin{array}{c}\text { Var. sin el } \\
\text { elemento }\end{array}$ & $\begin{array}{c}\text { Correlac. } \\
\text { elem-total } \\
\text { corregida }\end{array}$ & $\begin{array}{c}\text { Correlac. } \\
\text { múltiple al } \\
\text { cuadrado }\end{array}$ \\
\hline $\begin{array}{l}\text { 25. Saber hacer presentaciones } \\
\text { académicas (ej. Powerpoint, ...) }\end{array}$ & 6.65 & 3.187 & .576 & .332 \\
\hline $\begin{array}{l}\text { 26. Saber difundir la información } \\
\text { en internet (ej. webs, blogs, ...) }\end{array}$ & 7.51 & 2.411 & .576 & .332 \\
\hline
\end{tabular}

Por último, podemos ver en la tabla 4.42 los índices que hacen referencia a los ítems de la sub-escala de habilidades informáticas para la comunicación de información. El coeficiente de correlación entre ambos ítems es adecuado. 
Tabla 4.43 $\alpha$ de Cronbach para las sub-escalas en profesores. Competencias informacionales autopercibidas

\begin{tabular}{lc|c|c}
\hline \multicolumn{1}{c|}{ Fiabiildad de las subescalas } & $\begin{array}{c}\alpha \text { de } \\
\text { Cronbach }\end{array}$ & $\begin{array}{c}\alpha \text { de Cronbach } \\
\text { basado en los } \\
\text { elementos tip. }\end{array}$ & $\begin{array}{c}\boldsymbol{N} \text { de } \\
\text { elementos }\end{array}$ \\
\hline Búsqueda de información & .832 & .843 & 8 \\
\hline Evaluación de información & .737 & .749 & 5 \\
\hline Procesamiento de información & .721 & .722 & 2 \\
\hline Procesamiento cognitivo & .799 & .798 & 4 \\
\hline Procesamiento informático & .701 & .726 & 5 \\
\hline Comunicación de información & .727 & .731 & 2 \\
\hline Destrezas cognitivas
\end{tabular}

Los valores obtenidos para el $\alpha$ de Cronbach, en la tabla 4.43, muestran en todos los casos valores por encima de 0.7. Teniendo en cuenta el valor mínimo de la $\alpha$ de Cronbach (Morales Vallejo et al., 2003), estamos en condiciones de afirmar que las escalas tienen fiabilidades de aceptables para el profesorado.

Una vez comprobada la fiabilidad de las escalas y sub-escalas, procederemos al estudio de la validez de las mismas.

En cuanto a la validez de contenido, como ya se ha señalado anteriormente, el presente cuestionario se deriva de un instrumento original (IL-HUMASS Survey on Information Literacy in Higher Education) desarrollado por investigadores expertos en Ciencias de la Información (Pinto Molina, 2009). Mientras que en el caso de la muestra de alumnos el cuestionario se simplificó y adaptó a la población diana a la que iba destinado, en el caso de la muestra de futuros profesores, al tratarse de estudiantes universitarios, la escala se mantuvo intacta. Así, la validez de contenido asegurada en el estudio original sigue vigente en este estudio, ya que no se ha modificado ni el contenido de la propia encuesta ni la población a la que va destinada.

Para la validez de constructo, con el objeto de analizar las interrelaciones existentes entre las variables, procederemos a la aplicación de la técnica del análisis factorial. Seguiremos el mismo proceso que en la muestra de alumnos. Así, se realizarán en primer lugar los análisis factoriales exploratorios que indiquen las estructuras factoriales de las escalas, para acabar con los análisis confirmatorios que corroboren la bondad de ajuste de las escalas. De nuevo, para el análisis factorial exploratorio, al considerar las competencias informacionales como un constructo 
complejo formado por varios sub-constructos, se procederá a la aplicación de dos fases.

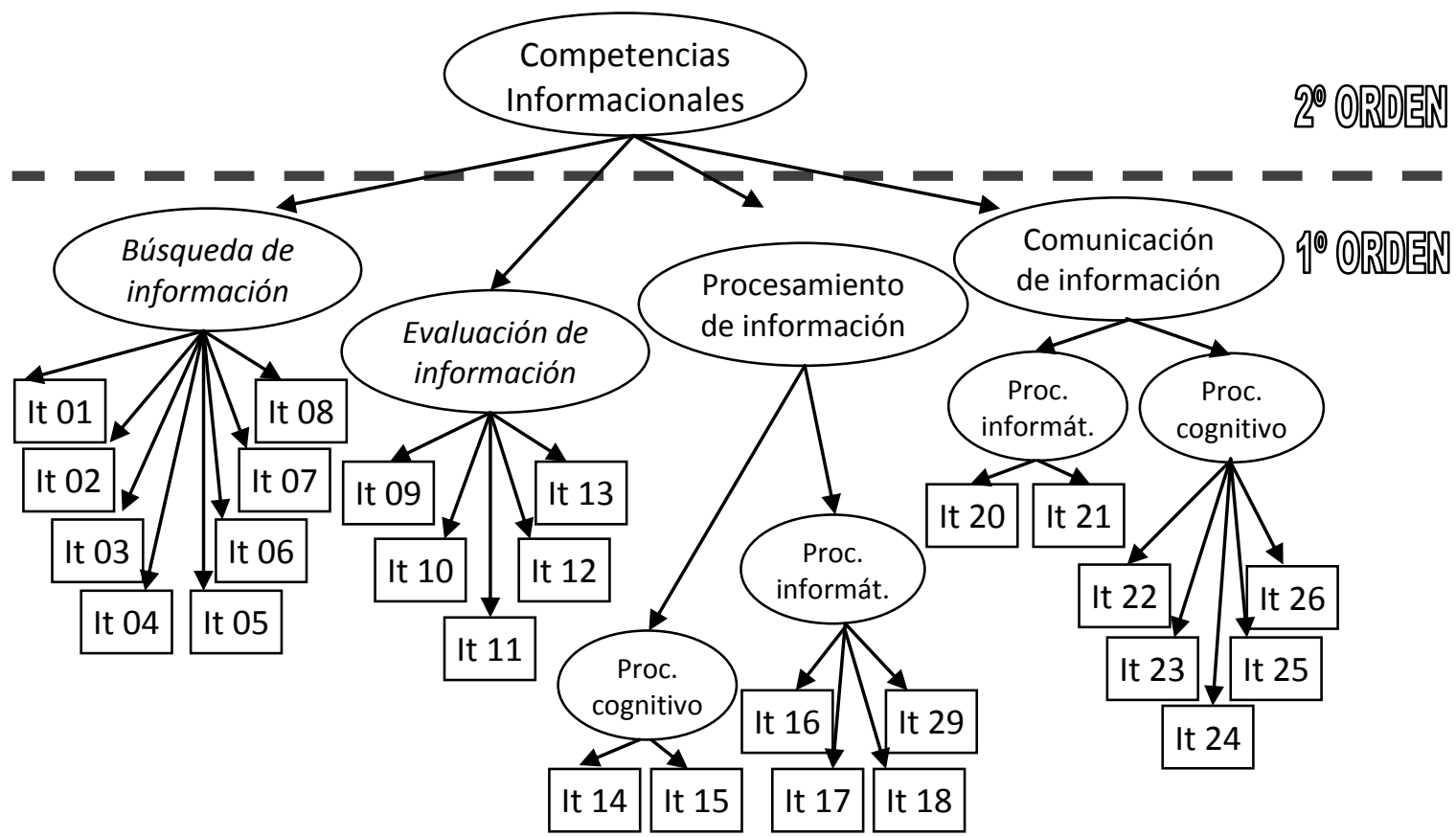

Figura 4.12 Estructura factorial de la escala de competencias informacionales para profesores

En la figura 4.12 se muestra la estructura factorial que se pretende confirmar.

\section{Cumplimiento de las condiciones necesarias, idoneidad de los datos para aplicar el análisis factorial.}

Previamente a la aplicación de las técnicas de análisis factorial, comprobaremos las condiciones previas para su adecuado estudio.

Tabla 4.44 Matriz de correlaciones escala búsqueda de información en profesores *

\begin{tabular}{c|c|c|c|c|c|c|c|c}
\hline & It 1 & It 2 & It 3 & It 4 & It 5 & It 6 & It 7 & It 8 \\
\hline It 1 & 1.000 & .441 & .466 & .277 & .407 & .548 & .330 & .199 \\
\hline It 2 & .441 & 1.000 & .410 & .408 & .267 & .462 & .350 & .407 \\
\hline It 3 & .466 & .410 & 1.000 & .563 & .349 & .525 & .408 & .340 \\
\hline It 4 & .277 & .408 & .563 & 1.000 & .354 & .424 & .447 & .532 \\
\hline It 5 & .407 & .267 & .349 & .354 & 1.000 & .397 & .311 & .232 \\
\hline It 6 & .548 & .462 & .525 & .424 & .397 & 1.000 & .576 & .369 \\
\hline It 7 & .330 & .350 & .408 & .447 & .311 & .576 & 1.000 & .469 \\
\hline It 8 & .199 & .407 & .340 & .532 & .232 & .369 & .469 & 1.000 \\
\hline
\end{tabular}

* Determinante $=0.061$ 
Tabla 4.45 Matriz de correlaciones escala evaluación de información en profesores *

\begin{tabular}{c|c|c|c|c|c}
\hline & It 9 & It 10 & It 11 & It 12 & It 13 \\
\hline It 9 & 1.000 & .423 & .367 & .367 & .237 \\
\hline It 10 & .423 & 1.000 & .354 & .396 & .463 \\
\hline It 11 & .367 & .354 & 1.000 & .433 & .346 \\
\hline It 12 & .367 & .396 & .433 & 1.000 & .346 \\
\hline It 13 & .237 & .463 & .346 & .346 & 1.000 \\
\hline
\end{tabular}

* Determinante $=0.356$

Tabla 4.46 Matriz de correlaciones escala procesamiento de información en profesores *

\begin{tabular}{c|c|c|c|c|c|c}
\hline & It 14 & It 15 & It 16 & It 17 & It 18 & It 19 \\
\hline It 14 & 1.000 & .564 & .176 & .154 & .230 & .097 \\
\hline It 15 & .564 & 1.000 & .258 & .237 & .254 & .123 \\
\hline It 16 & .176 & .258 & 1.000 & .594 & .726 & .434 \\
\hline It 17 & .154 & .237 & .594 & 1.000 & .547 & .220 \\
\hline It 18 & .230 & .254 & .726 & .547 & 1.000 & .462 \\
\hline It 19 & .097 & .123 & .434 & .220 & .462 & 1.000 \\
\hline
\end{tabular}

* Determinante $=0.136$

Tabla 4.47 Matriz de correlaciones escala comunicación de información en profesores *

\begin{tabular}{c|c|c|c|c|c|c|c}
\hline & It 20 & It 21 & It 22 & It 23 & It 24 & It 25 & It 26 \\
\hline It 20 & 1.000 & .274 & .432 & .321 & .366 & .320 & .210 \\
\hline It 21 & .274 & 1.000 & .367 & .349 & .267 & .168 & .201 \\
\hline It 22 & .432 & .367 & 1.000 & .384 & .293 & .418 & .279 \\
\hline It 23 & .321 & .349 & .384 & 1.000 & .398 & .127 & .143 \\
\hline It 24 & .366 & .267 & .293 & .398 & 1.000 & .335 & .377 \\
\hline It 25 & .320 & .168 & .418 & .127 & .335 & 1.000 & .576 \\
\hline It 26 & .210 & .201 & .279 & .143 & .377 & .576 & 1.000 \\
\hline
\end{tabular}

* Determinante $=0.194$

En las tablas $4.44,4.45,4.46$ y 4.47 se muestran las matrices de correlaciones de las escalas correspondientes a las cuatro dimensiones teóricas principales. En general, se pueden observar coeficientes de correlación aceptables. En el caso de las dimensiones de procesamiento y comunicación, se puede observar cómo los ítems $14 / 15$ y $25 / 26$, respectivamente, obtienen índices de correlación con el resto de ítems que tienden a ser más bajos que el resto. Esto se debe, evidentemente, a los aspectos que se señalaron anteriormente en lo que respecta al contenido que tratan. Por otra parte, el valor del determinante de las matrices en los cuatro casos es diferente de cero.

A continuación, se muestran los valores del test de esfericidad de Barlett, y el índice KMO para cada una de las dimensiones. 
Tabla 4.48 Test de Barlett y KMO para las cuatro dimensiones teóricas en profesores

\begin{tabular}{lcc}
\hline & Test de esfericidad de Barlett & KMO \\
\hline Búsqueda de información & $492.749(\mathrm{p}<.001)$ & .847 \\
\hline Evaluación de información & $183.249(\mathrm{p}<.001)$ & .776 \\
\hline Procesamiento de información & $356.831(\mathrm{p}<.001)$ & .725 \\
\hline Comunicación de información & $301.441(\mathrm{p}<.001)$ & .755 \\
\hline
\end{tabular}

A los datos mostrados en la tabla 4.48, en todos los casos se rechaza la hipótesis de que la matriz de correlaciones es una matriz identidad y se considera que existe una buena adecuación muestral para continuar con el análisis factorial.

Tabla 4.49 Matriz de correlaciones anti-imagen. Búsqueda de información en profesores *

\begin{tabular}{c|c|c|c|c|c|c|c|c}
\hline & It 1 & It 2 & It 3 & It 4 & It 5 & It 6 & It 7 & It 8 \\
\hline It 1 & .815 & -.234 & -.213 & .097 & -.223 & -.291 & .004 & .078 \\
\hline It 2 & -.234 & .891 & -.068 & -.110 & .018 & -.143 & .009 & -.208 \\
\hline It 3 & -.213 & -.068 & .858 & -.376 & -.034 & -.186 & -.037 & .029 \\
\hline It 4 & .097 & -.110 & -.376 & .814 & -.155 & -.012 & -.109 & -.330 \\
\hline It 5 & -.223 & .018 & -.034 & -.155 & .899 & -.107 & -.049 & -.001 \\
\hline It 6 & -.291 & -.143 & -.186 & -.012 & -.107 & .847 & -.368 & -.031 \\
\hline It 7 & .004 & .009 & -.037 & -.109 & -.049 & -.368 & .854 & -.247 \\
\hline It 8 & .078 & -.208 & .029 & -.330 & -.001 & -.031 & -.247 & .821 \\
\hline
\end{tabular}

* Valores de la diagonal principal $>0.8$

Tabla 4.50 Matriz de correlaciones anti-imagen. Evaluación de información en profesores *

\begin{tabular}{c|c|c|c|c|c}
\hline & It 9 & It 10 & It 11 & It 12 & It 13 \\
\hline It 9 & .777 & -.279 & -.193 & -.170 & .029 \\
\hline It 10 & -.279 & .749 & -.085 & -.162 & -.339 \\
\hline It 11 & -.193 & -.085 & .798 & -.267 & -.167 \\
\hline It 12 & -.170 & -.162 & -.267 & .804 & -.139 \\
\hline It 13 & .029 & -.339 & -.167 & -.139 & .758 \\
\hline
\end{tabular}

* Valores de la diagonal principal $>0.7$

Tabla 4.51 Matriz de correlaciones anti-imagen. Procesamiento de información en profesores *

\begin{tabular}{c|c|c|c|c|c|c}
\hline & It 14 & It 15 & It 16 & It 17 & It 18 & It 19 \\
\hline It 14 & .587 & -.539 & .043 & .019 & -.116 & .010 \\
\hline It 15 & -.539 & .631 & -.085 & -.084 & -.003 & -.003 \\
\hline It 16 & .043 & -.085 & .734 & -.345 & -.510 & -.188 \\
\hline It 17 & .019 & -.084 & -.345 & .808 & -.220 & .106 \\
\hline It 18 & -.116 & -.003 & -.510 & -.220 & .750 & -.252 \\
\hline It 19 & .010 & -.003 & -.188 & .106 & -.252 & .811 \\
\hline
\end{tabular}


* Valores de la diagonal principal $>0.58$

Tabla 4.52 Matriz de correlaciones anti-imagen. Comunicación de información en profesores *

\begin{tabular}{c|c|c|c|c|c|c|c}
\hline & It 20 & It 21 & It 22 & It 23 & It 24 & It 25 & It 26 \\
\hline It 20 & .829 & -.078 & -.241 & -.104 & -.193 & -.133 & .049 \\
\hline It 21 & -.078 & .826 & -.208 & -.187 & -.069 & .053 & -.087 \\
\hline It 22 & -.241 & -.208 & .775 & -.233 & .029 & -.279 & -.004 \\
\hline It 23 & -.104 & -.187 & -.233 & .744 & -.285 & .112 & .020 \\
\hline It 24 & -.193 & -.069 & .029 & -.285 & .794 & -.099 & -.219 \\
\hline It 25 & -.133 & .053 & -.279 & .112 & -.099 & .681 & -.487 \\
\hline It 26 & .049 & -.087 & -.004 & .020 & -.219 & -.487 & .690 \\
\hline
\end{tabular}

* Valores de la diagonal principal $>0.68$

Por último, en la prueba del cumplimiento de las condiciones previas para la aplicación del análisis factorial, como se puede observar en las tablas 4.49, 4.50, 4.51 y 4.52 , todos los valores de la diagonal principal de las matrices anti-imagen de las dimensiones de búsqueda y evaluación están por encima de 0.7. En la dimensión de procesamiento, debido a la existencia de sub-dimensiones asociadas, encontramos un valor cercano a 0.6. Por último, en la dimensión de comunicación, aunque la mayor parte de valores están por encima de 0.7 , encontramos dos índices ligeramente por debajo de este valor.

2. Extracción de factores sobre el nivel percibido en cada dimensión de las competencias informacionales.

Así, visto el cumplimiento de todas las condiciones propuestas, estamos en condiciones de proceder con la extracción de factores para cada dimensión teórica. En las dos primeras dimensiones (búsqueda y evaluación), debido a que se busca probar la unidimensionalidad, se aplicará el análisis factorial exploratorio a partir del método de extracción de componentes principales (García Jiménez et al., 2000), por otro lado en la aplicación del análisis para las dimensiones de procesamiento y comunicación de información, al definir a nivel teórico sub-escalas relacionadas entre sí dentro de la dimensión principal, el método empleado será el de ejes principales con rotación oblimin con el criterio de Kaiser-Guttman (Kaiser, 1960).

Tabla 4.53 Comunalidades. Búsqueda de información. Profesores

\begin{tabular}{|c|c|}
\hline & Comunalidades \\
\hline 01. Saber utilizar fuentes de información impresa (ej. libros, ...) & .435 \\
\hline 02. Saber acceder y usar los catálogos automatizados & .456 \\
\hline $\begin{array}{r}\text { 03. Saber consultar y usar fuentes electrónicas de información primaria ( ej. } \\
\text { revistas, ...) }\end{array}$ & .555 \\
\hline
\end{tabular}




\begin{tabular}{|c|c|}
\hline $\begin{array}{r}\text { 04. Saber utilizar fuentes electrónicas de información secundaria (ej. bases } \\
\text { de datos, ...) }\end{array}$ & .531 \\
\hline 05. Conocer la terminología especializada de tu materia & .336 \\
\hline $\begin{array}{r}\text { 06. Saber buscar y recuperar información en internet (ej. búsquedas } \\
\text { avanzadas, directorios, portales, ...) }\end{array}$ & .624 \\
\hline $\begin{array}{r}\text { 07. Saber utilizar fuentes electrónicas informales de información (ej. blogs, } \\
\text { listas de distribución, ...) }\end{array}$ & .503 \\
\hline $\begin{array}{r}\text { 08. Conocer las estrategias de búsqueda de información (descriptores, } \\
\text { operadores booleanos, ...) }\end{array}$ & .404 \\
\hline
\end{tabular}

Podemos observar en la tabla 4.53 que la varianza explicada para cada una de las variables por el factor búsqueda de información se sitúa en torno al 0.5, a excepción del ítem 5. Buscar y obtener información en internet, que está por debajo de 0.4.

Tabla 4.54 Varianza total explicada. Búsqueda de información. Profesores *

\begin{tabular}{cc|c|c|c|c|c}
\hline \multirow{2}{*}{ Componente } & \multicolumn{3}{c|}{ Autovalores iniciales } & \multicolumn{3}{c}{ Sumas de las saturaciones al cuadrado } \\
& Total & $\begin{array}{c}\text { \% de la } \\
\text { varianza }\end{array}$ & \% acumul. & Total & $\begin{array}{c}\text { \% de la } \\
\text { varianza }\end{array}$ & \% acumul. \\
\cline { 2 - 7 } & 3.844 & 48.048 & 48.048 & 3.844 & 48.048 & 48.048 \\
\hline $\mathbf{1}$ & 1.000 & 12.497 & 60.545 & & & \\
\hline $\mathbf{3}$ & 0.733 & 9.163 & 69.708 & & & \\
\hline $\mathbf{4}$ & 0.677 & 8.464 & 78.172 & & & \\
\hline $\mathbf{5}$ & 0.622 & 7.774 & 85.946 & & & \\
\hline $\mathbf{6}$ & 0.434 & 5.426 & 91.372 & & & \\
\hline $\mathbf{8}$ & 0.351 & 4.385 & 95.757 & & & \\
\hline
\end{tabular}

Como muestra la tabla 4.54, el porcentaje de varianza total explicada para el factor búsqueda de información resulta ser del $48.27 \%$, con un autovalor cercano a los 4 puntos.

Tabla 4.55 Matriz de componentes. Búsqueda de información. Profesores

\begin{tabular}{|c|c|}
\hline & Componente \\
\hline $\begin{array}{r}\text { 06. Saber buscar y recuperar información en internet (ej. búsquedas } \\
\text { avanzadas, directorios, portales, ...) }\end{array}$ & .790 \\
\hline $\begin{array}{r}\text { 03. Saber consultar y usar fuentes electrónicas de información primaria ( ej. } \\
\text { revistas, ...) }\end{array}$ & .745 \\
\hline $\begin{array}{r}\text { 04. Saber utilizar fuentes electrónicas de información secundaria (ej. bases } \\
\text { de datos, ...) }\end{array}$ & .729 \\
\hline $\begin{array}{r}\text { 07. Saber utilizar fuentes electrónicas informales de información (ej. blogs, } \\
\text { listas de distribución, ...) }\end{array}$ & .709 \\
\hline
\end{tabular}




\begin{tabular}{r|c}
\hline 02. Saber acceder y usar los catálogos automatizados & .675 \\
\hline 01. Saber utilizar fuentes de información impresa (ej. libros, ...) & .660 \\
\hline 08. Conocer las estrategias de búsqueda de información (descriptores, & .635 \\
operadores booleanos, ...) & .580 \\
\hline 05. Conocer la terminología especializada de tu materia & \\
\hline
\end{tabular}

La matriz de componentes mostrada en la tabla 4.55, que indica la aportación de cada variable al factor común, muestra cómo tienen más peso aquellas variables que tienen que ver con la búsqueda de información en redes informáticas. Nótese que esta tendencia también se percibía en el caso de la muestra de alumnos (a pesar de que los ítems no eran exactamente los mismos).

Tabla 4.56 Comunalidades. Evaluación de información. Profesores

\begin{tabular}{|c|c|}
\hline & Comunalidades \\
\hline 09. Saber evaluar la calidad de los recursos de información & .450 \\
\hline 10. Reconocer en el texto las ideas del autor & .572 \\
\hline $\begin{array}{r}\text { 11. Conocer la tipología de las fuentes de información científica (ej. tesis } \\
\text { doctorales, actas de congresos, ...) }\end{array}$ & .501 \\
\hline $\begin{array}{r}\text { 12. Ser capaz de determinar si la información que contiene un recurso está } \\
\text { actualizada }\end{array}$ & .524 \\
\hline 13. Conocer los autores o instituciones más relevantes en tu ámbito temático & .450 \\
\hline
\end{tabular}

En el caso de la evaluación de información, nos encontramos comunalidades que rondan el valor 0.5 (tabla 4.56).

Tabla 4.57 Varianza total explicada. Evaluación de información. Profesores *

\begin{tabular}{cc|c|c|c|c|c}
\hline & \multicolumn{4}{c|}{ Autovalores iniciales } & \multicolumn{3}{c}{$\begin{array}{c}\text { Sumas de las saturaciones al cuadrado } \\
\text { Compone la extracción }\end{array}$} \\
\cline { 2 - 8 } & Total & $\begin{array}{c}\text { \% de la } \\
\text { varianza }\end{array}$ & \% acumul. & Total & $\begin{array}{c}\text { \% de la } \\
\text { varianza }\end{array}$ & \% acumul. \\
\hline $\mathbf{1}$ & 2.498 & 49.951 & 49.951 & 2.498 & 49.951 & 49.951 \\
\hline $\mathbf{2}$ & 0.776 & 15.522 & 65.473 & & & \\
\hline $\mathbf{3}$ & 0.687 & 13.749 & 79.221 & & & \\
\hline $\mathbf{4}$ & 0.570 & 11.400 & 90.622 & & & \\
\hline $\mathbf{5}$ & 0.469 & 9.378 & 100.00 & & & \\
\hline
\end{tabular}

* Método de extracción: Análisis de componentes principales

El porcentaje de varianza total explicada para el factor evaluación de información, mostrado en la tabla 4.57, es del 49.951\%, con un autovalor superior a 2 puntos.

Tabla 4.58 Matriz de componentes. Evaluación de información. Profesores 


\begin{tabular}{|c|c|}
\hline 10. Reconocer en el texto las ideas del autor & .756 \\
\hline $\begin{array}{r}\text { 12. Ser capaz de determinar si la información que contiene un recurso está } \\
\text { actualizada }\end{array}$ & .724 \\
\hline $\begin{array}{r}\text { 11. Conocer la tipología de las fuentes de información científica (ej. tesis } \\
\text { doctorales, actas de congresos, ...) }\end{array}$ & .708 \\
\hline 09. Saber evaluar la calidad de los recursos de información & .671 \\
\hline 13. Conocer los autores o instituciones más relevantes en tu ámbito temático & .671 \\
\hline
\end{tabular}

En cuanto a la matriz de componentes, en la tabla 4.58 se pueden observar ponderaciones similares en la aportación que cada variable hace al factor. Todos los componentes del factor, pues, tienen una aportación similar al factor.

Tabla 4.59 Comunalidades. Procesamiento de información. Profesores

\begin{tabular}{|c|c|c|}
\hline Comunalidades & Inicial & Extracción \\
\hline 14. Saber resumir y esquematizar la información & .329 & .549 \\
\hline 15. Ser capaz de reconocer la estructuración de un texto & .349 & .583 \\
\hline 16. Saber usar gestores de bases de datos (ej. Access, MySQL, ...) & 600 & .785 \\
\hline $\begin{array}{r}\text { 17. Usar gestores de referencias bibliográficas (ej. Endnote, Reference } \\
\text { Manager, Zotero) }\end{array}$ & 393 & .399 \\
\hline $\begin{array}{l}\text { 18. Saber manejar programas estadísticos y hojas de cálculo (ej. SPSS, } \\
\text { Excel, ...) }\end{array}$ & .585 & 732 \\
\hline 19. Saber instalar programas informáticos & 243 & .232 \\
\hline
\end{tabular}

En la tabla 4.59 podemos observar las comunalidades en cuanto al procesamiento de información.

Tabla 4.60 Varianza total explicada. Procesamiento de información. Profesores*

\begin{tabular}{|c|c|c|c|c|c|c|c|}
\hline \multirow{2}{*}{ Comp. } & \multicolumn{3}{|c|}{ Autovalores iniciales } & \multicolumn{3}{|c|}{$\begin{array}{l}\text { Sumas de las saturaciones al } \\
\text { cuadrado de la extracción }\end{array}$} & \multirow{2}{*}{$\begin{array}{c}\text { Sumas de las saturaciones } \\
\begin{array}{c}\text { al cuadrado de la } \\
\text { rotación }\end{array}\end{array}$} \\
\hline & Total & Total & $\begin{array}{c}\text { \% de la } \\
\text { varianza }\end{array}$ & \% acumul. & $\begin{array}{c}\text { \% de la } \\
\text { varianza }\end{array}$ & $\begin{array}{c}\% \\
\text { acumul. }\end{array}$ & \\
\hline 1 & 2.782 & 46.372 & 46.372 & 2.392 & 39.869 & 39.869 & 2.286 \\
\hline 2 & 1.321 & 22.012 & 68.384 & 0.889 & 14.812 & 54.681 & 1.399 \\
\hline 3 & 0.788 & 13.131 & 81.515 & & & & \\
\hline 4 & 0.442 & 7.372 & 88.886 & & & & \\
\hline 5 & 0.401 & 6.685 & 95.572 & & & & \\
\hline 6 & 0.266 & 4.428 & 100.00 & & & & \\
\hline
\end{tabular}


En este caso, como muestra la tabla 4.60, nos encontramos con dos factores dentro de la escala de procesamiento de información. Así, el porcentaje de varianza explicada con los autovalores iniciales se encuentra, incluyendo los dos factores, en el $68.384 \%$. En la solución rotada, que es la que analizaremos, nos encontramos con un $54.681 \%$ de la varianza explicada.

Tabla 4.61 Matriz rotada de configuración. Procesamiento de información. Profesores

\begin{tabular}{|c|c|c|}
\hline & \multicolumn{2}{|c|}{ Factor } \\
\hline & 1 & 2 \\
\hline 16. Saber usar gestores de bases de datos (ej. Access, MySQL, ...) & .894 & -.024 \\
\hline $\begin{array}{r}\text { 18. Saber manejar programas estadísticos y hojas de cálculo (ej. } \\
\text { SPSS, Excel, ...) }\end{array}$ & .847 & .025 \\
\hline $\begin{array}{r}\text { 17. Usar gestores de referencias bibliográficas (ej. Endnote, } \\
\text { Reference Manager, Zotero) }\end{array}$ & .614 & .046 \\
\hline 19. Saber instalar programas informáticos & .491 & -.029 \\
\hline 14. Saber resumir y esquematizar la información & -.033 & .752 \\
\hline 15. Ser capaz de reconocer la estructuración de un texto & .042 & .748 \\
\hline
\end{tabular}

* Método de rotación: Oblimin con Kaiser.

La matriz de componentes rotados del factor procesamiento de información, mostrado en la tabla 4.61, confirma las impresiones teóricas que se señalaban anteriormente. Existe un primer factor, el más explicativo de la escala principal, que tiene que ver con el procesamiento informático de datos. Por otro lado, la segunda dimensión encontrada tiene que ver con el procesamiento cognitivo de datos, ya que las dos únicas variables que tienen un peso significativo en la misma son el 14 y 15 (Saber resumir y esquematizar la información; Ser capaz de reconocer la estructuración de un texto).

Tabla 4.62 Comunalidades. Comunicación de información. Profesores

\begin{tabular}{r|c|c}
\hline Comunalidades & Inicial & Extracción \\
\hline 20. Saber comunicar en público & .275 & .333 \\
\hline 21. Saber comunicar en otros idiomas & .206 & .275 \\
\hline 22. Saber redactar un documento (ej. informe, trabajo académico, ...) & .366 & .423 \\
\hline 23. Conocer el código ético de tu ámbito académico/profesional & .287 & .471 \\
\hline 24. Conocer la legislación sobre el uso de la información y de la & .312 & .347 \\
\hline propiedad intelectual & & .777 \\
\hline 25. Saber hacer presentaciones académicas (ej. Powerpoint, ...) & .428 & .437 \\
\hline 26. Saber difundir la información en internet (ej. webs, blogs, ...) & .376 & \multicolumn{2}{|c|}{.376} \\
\hline
\end{tabular}

Las comunalidades de las variables que conforman la escala comunicación de información se muestran en la tabla 4.62. 
Tabla 4.63 Varianza total explicada. Comunicación de información. Profesores*

\begin{tabular}{|c|c|c|c|c|c|c|c|}
\hline \multirow{2}{*}{ Comp. } & \multicolumn{3}{|c|}{ Autovalores iniciales } & \multicolumn{3}{|c|}{$\begin{array}{l}\text { Sumas de las saturaciones al } \\
\text { cuadrado de la extracción }\end{array}$} & \multirow{2}{*}{$\begin{array}{c}\text { Sumas de las saturaciones a } \\
\text { cuadrado de la rotación** } \\
\text { Total }\end{array}$} \\
\hline & Total & Total & $\begin{array}{c}\% \text { de la } \\
\text { varianza }\end{array}$ & \% acumul. & $\begin{array}{c}\% \text { de la } \\
\text { varianza }\end{array}$ & $\begin{array}{c}\% \\
\text { acumul. }\end{array}$ & \\
\hline 1 & 2.901 & 41.437 & 41.437 & 2.356 & 33.651 & 33.651 & 2.019 \\
\hline 2 & 1.168 & 16.685 & 58.121 & 0.709 & 10.122 & 43.773 & 1.776 \\
\hline 3 & 0.770 & 11.003 & 69.124 & & & & \\
\hline 4 & 0.740 & 10.575 & 79.698 & & & & \\
\hline 5 & 0.596 & 8.516 & 88.214 & & & & \\
\hline 6 & 0.453 & 6.468 & 94.682 & & & & \\
\hline 7 & 0.372 & 5.318 & 100.00 & & & & \\
\hline
\end{tabular}

El porcentaje de varianza total explicada para los autovalores iniciales en cuanto a la comunicación de información, si incluimos los dos factores incluidos en el análisis, es del 58.121\% (tabla 4.63).

Tabla 4.64 Matriz rotada de configuración. Comunicación de información. Profesores

\begin{tabular}{|c|c|c|}
\hline & \multicolumn{2}{|c|}{ Factor } \\
\hline & 1 & 2 \\
\hline 23. Conocer el código ético de tu ámbito académico/profesional & .748 & .179 \\
\hline $\begin{array}{r}\text { 22. Saber redactar un documento (ej. informe, trabajo } \\
\text { académico,...) }\end{array}$ & .540 & -.194 \\
\hline 21. Saber comunicar en otros idiomas & .533 & .020 \\
\hline 20. Saber comunicar en público & .508 & -.129 \\
\hline $\begin{array}{r}\text { 24. Conocer la legislación sobre el uso de la información y de la } \\
\text { propiedad intelectual }\end{array}$ & .465 & -.209 \\
\hline 25. Saber hacer presentaciones académicas (ej. Powerpoint, ...) & -.014 & -.887 \\
\hline 26. Saber difundir la información en internet (ej. webs, blogs, ...) & .070 & -.626 \\
\hline
\end{tabular}

* Método de rotación: Oblimin con Kaiser.

Nuevamente, en la matriz de componentes rotados (tabla 4.64) para la escala comunicación de información, nos encontramos dos factores que se corresponden con las sub-dimensiones teóricas que habíamos planteado previamente. En primer lugar, nos encontramos con todos los ítems que tienen que ver con las destrezas cognitivas relacionadas con la comunicación de información. Por otro lado, el segundo factor, menos explicativo al conjunto de la escala, está compuesto principalmente por los ítems 25 (Saber hacer presentaciones académicas) y 26 (Saber difundir la información en internet), que tienen que ver con el empleo de herramientas informáticas como vehículo para comunicar la información. 
3. Extracción de factores de segundo orden, sobre el nivel percibido en cada dimensión de las competencias informacionales.

Una vez llevado a cabo el análisis factorial exploratorio para las cuatro dimensiones teóricas, veamos si estos resultados se corroboran aplicando el análisis factorial confirmatorio.

Tabla 4.65 Índices análisis factorial confirmatorio. Dimensiones teóricas. Profesores

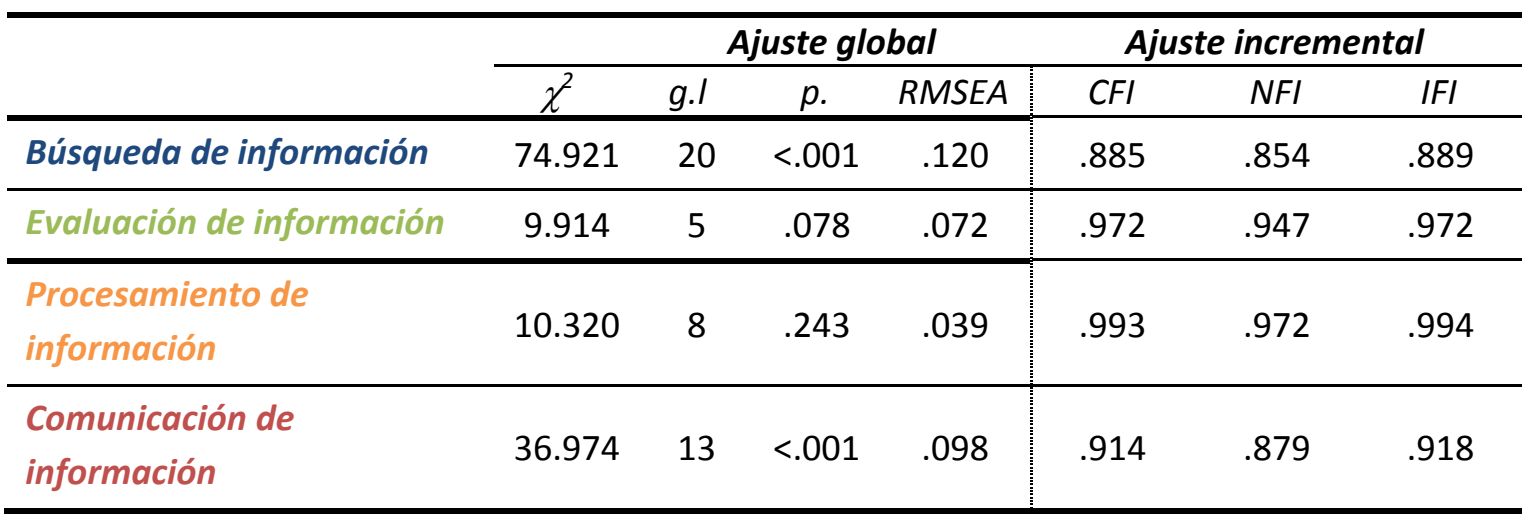

En la tabla 4.65, que muestra el ajuste de las escalas, nos encontramos ajustes adecuados en todos los indicadores para las dimensiones de evaluación de información y procesamiento de información. Por otro lado, la dimensión de comunicación de información devuelve ajustes adecuados en algunos indicadores de ajuste incremental y no aceptables en cuanto al ajuste global. Por último, la primera dimensión teórica, la búsqueda de información, indica un ajuste poco aceptable.

Analizando más detenidamente la escala de búsqueda de información, se observan ítems bastante heterogéneos, ya que contiene por un lado ítems que se refieren directamente a habilidades informáticas que facilitan la búsqueda de información, y por otro ítems relacionados con habilidades cognitivas que facilitan la búsqueda de información (como conocer la terminología de la materia que se está estudiando).

Así, a pesar de que en los análisis consiguientes se considerarán estas dimensiones teóricas como válidas, debemos ser cautos con los análisis e interpretaciones derivados que se lleven a cabo, sobre todo en la dimensión búsqueda de información.

Una vez mostrado cómo cada grupo de ítems que conforma las dimensiones teóricas pueden componer una escala válida e independiente, pasaremos al análisis de segundo orden para comprobar si estas escalas o dimensiones pueden ser sub-escalas relacionadas entre sí que conforman un constructo más amplio denominado competencias informacionales. 
Dada los distintos niveles de las puntuaciones factoriales resultantes de los análisis anteriores, consideramos poco adecuado aplicar un análisis factorial exploratorio, así que aplicaremos directamente el análisis factorial confirmatorio en primer lugar a partir de los ítems del cuestionario y en segundo lugar a partir de las puntuaciones factoriales obtenidas anteriormente.

Tabla 4.66 Índices análisis factorial confirmatorio. Competencias informacionales. Profesores

\begin{tabular}{lcccc|cccc}
\hline & \multicolumn{4}{c|}{ Ajuste global } & \multicolumn{3}{c}{ Ajuste incremental } \\
\cline { 2 - 8 } & $\chi^{2}$ & g.I & p. & RMSEA & CFI & NFI & IFI \\
\hline $\begin{array}{l}\text { Modelo con puntuaciones } \\
\text { factoriales }\end{array}$ & 42.394 & 7 & $<.001$ & .163 & .907 & .894 & .910 \\
\hline \begin{tabular}{l} 
Modelo completo \\
\hline
\end{tabular} & 666.537 & 267 & $<.001$ & .089 & .799 & .688 & .786 \\
\hline
\end{tabular}

Los resultados obtenidos en los índices principales del análisis factorial exploratorio, como se puede observar en la tabla 4.66, nos muestran valores que indican ajustes no adecuados en ambos modelos.

Esto indica que las escalas de búsqueda, evaluación, procesamiento y comunicación no forman parte de una escala común, por lo que en los análisis llevados a cabo a partir de la encuesta no se considerará una dimensión común llamada competencias informacionales, sino que cada una de las dimensiones teóricas deberán ser analizadas como escalas independientes.

\subsubsection{Población y muestra. Estudio I}

La calidad de la información generada mediante la encuesta por muestreo, es decisiva, pues condiciona la eficacia de la inferencia; la sofisticación de los procedimientos estadísticos utilizados para generalizar los datos de la muestra a la población, resultan inútiles si la información que otorga la muestra es sesgada y no representativa (Tejedor Tejedor, 2006).

Por otra parte, sin lugar a la duda, la representatividad es una propiedad que debe caracterizar a toda muestra; como sabemos, es una cualidad de las muestras que permite reproducir a escala los atributos de la población y, en lógica consecuencia, permitirnos inferir a la población origen de la muestra. Sin embargo, siendo precisos en la explicación, no existe una definición formal de qué es lo que se entiende por representatividad y tampoco cómo se puede establecer con exactitud cuándo una muestra es representativa y en qué momento o situación deja de serlo. La práctica enseña que es muy difícil que una muestra reproduzca exactamente los atributos de la 
población; se asume, no obstante, que la muestra es representativa cuando reproduce parcialmente la distribución de frecuencias de ciertas variables seleccionadas ad hoc, sobre todo en aquellas variables que a priori puedan provocar mayor variabilidad en la caracterización de la variable dependiente o de estudio.

Por lo tanto, las generalizaciones deben tomarse con prudencia, siendo una buena práctica asumir que la representatividad total en una muestra seleccionada al azar no puede ser conocida. Esto es, el azar no garantiza la representatividad (Vivanco, 2005).

Ahora bien, el azar es la piedra angular de la inferencia estadística. Según los axiomas en los que se fundamenta el azar, los sesgos se anularán mutuamente cuando se selecciona aleatoriamente un número grande de elementos independientes. En definitiva, aunque nada garantiza que una muestra sea representativa, el azar permite tener esperanza, con un nivel de confianza determinado, en que esta eventualidad ocurra.

A continuación se describirán los procesos de muestreo llevado a cabo para cada una de las dos poblaciones seleccionadas.

\subsubsection{Muestreo para alumnos de Educación Secundaria}

A partir de la población de referencia, el estudio I requiere llevar a cabo un muestreo en los centros de enseñanza no universitaria donde cursan estudios los alumnos del 2o ciclo de la ESO. Es decir, a priori, se cumplen adecuadamente los requisitos para seleccionar conglomerados. Sin embargo, esta estrategia de selección muestral sólo es una suposición teórica, debido a que los sujetos que forman la población están distribuidos en centros educativos, a los que aplicamos de inmediato el concepto conglomerado. En todo caso, ello no supone que, en principio, nos otorgue base científica alguna para elegir esta técnica de selección muestral, por lo que habrá que demostrar la pertinencia.

El muestreo por conglomerados es un diseño efectivo para obtener una cantidad determinada de información, a un coste mínimo, bajo las siguientes condiciones (Mendenhall, Scheaffer, \& Ott, 2006):

- No se encuentra disponible, o es muy costoso, obtener un buen marco que liste los elementos (alumnos) de la población, mientras que se puede obtener fácilmente el marco con el listado de los conglomerados (centros). 
- El coste de observaciones se incrementa con la distancia que separa los elementos ${ }^{18}$. Procede comentar que cuando, como en nuestro caso, el objetivo es el diseño en la aplicación de encuestas, el muestreo por conglomerados proporciona, en ocasiones, más información que cualquier otro de los diseños aleatorios, aunque también implica asumir otras deficiencias.

Un muestreo por conglomerados no es más que una selección de los sujetos a través de diferentes conjuntos. Con ello, se simplifican de inmediato las operaciones de construcción del marco de referencia. En el caso de esta investigación, resultaría muy difícil disponer de todo un listado de alumnos de Castilla y León que estudiaran en el nivel referido; sin embargo, resulta muy simple obtener el listado de todos los Centros donde se cursa ese nivel educativo. Además, las unidades a las que se aplica el instrumento elegido, están físicamente cerca una de otras.

Si bien las ventajas aparecen claras y manifiestas, tiene el inconveniente de que aumenta el error muestral respecto al muestreo aleatorio simple, $y$, en consecuencia, suele necesitar de un tamaño mayor de elementos que han de conformar la muestra.

Entrando en materia con el muestreo llevado a cabo, en primer lugar se debe realizar la especificación de los conglomerados. Para ello, se parte de la clasificación de centros en lo que se imparte el 2 o ciclo de la ESO en la Comunidad de Castilla y León que se muestra en la tabla 4.67.

Tabla 4.67 Distribución de centros de Castilla y León*

\begin{tabular}{cc|c|c}
\hline \multirow{2}{*}{ CENTROS } & Modalidad & N & \% \\
\hline \multirow{3}{*}{ Urbanos } & Público & 76 & 18.8 \\
\cline { 2 - 4 } & Concertado-privado & 125 & 30.9 \\
\cline { 2 - 4 } & Privado estrictamente & 11 & 2.7 \\
\hline \multirow{3}{*}{ Rurales } & Público & 134 & 33.2 \\
\cline { 2 - 4 } & Concertado-privado & 46 & 11.4 \\
\cline { 2 - 4 } & Privado estrictamente & 12 & 3.0 \\
\hline \multirow{2}{*}{ TOTAL } & $\mathbf{4 0 4}$ & $\mathbf{1 0 0 . 0}$ \\
\hline
\end{tabular}

* FUENTE: Instituto Nacional de Estadística. Centros docentes de régimen general

\footnotetext{
${ }^{18}$ En este aspecto, se aprovecha la ventaja de disponer, para el muestreo y recogida de información, de una financiación y apoyo oficiales provenientes del Proyecto de Investigación Nacional I+D de la convocatoria de 2006 Modelo de evaluación y desarrollo de competencias clave implícitas en la ESO: TIC, Lectura y Convivencia Escolar (E-TELECO). Referencia SEJ2006-10700.
} 
Disponemos de un listado de todos los centros de Castilla y León, y ese ámbito es el que se considera como totalidad de conglomerados de la población. Para llevar a cabo el muestreo, se contempla toda la población conjuntamente bajo el calificativo de "centros financiados con fondos públicos en la Comunidad de Castilla y León, en el curso académico 2008-2009". Bajo esta denominación se agrupa prácticamente la totalidad de la estructura poblacional que existe en la actualidad. Ello nos llevaría a excluir los centros estrictamente privados que, como observamos en la muestra, representan únicamente el $5.7 \%$ del total de Centros, con la característica añadida de ser centros con peculiaridades específicas que no se acomodan fácilmente a la población general a estudiar.

Estimando los criterios de selección que hemos mencionado, procede mostrar en la tabla 4.68 la totalidad de conglomerados/centros que constituyen el tamaño poblacional.

Tabla 4.68 Conglomerados/Centros que constituyen el tamaño poblacional

\begin{tabular}{cc|c|c}
\hline CENTROS & Modalidad & N & \% \\
\hline \multirow{2}{*}{ Urbanos } & Público & 76 & 19.9 \\
\cline { 2 - 4 } & Privado (concertado) & 125 & 32.8 \\
\hline \multirow{2}{*}{ Rurales } & Público & 134 & 35.2 \\
\cline { 2 - 4 } & Privado (concertado) & 46 & 12.1 \\
\hline \multirow{2}{*}{ TOTAL } & $\mathbf{3 8 1}$ & $\mathbf{1 0 0 . 0}$ \\
\hline
\end{tabular}

Una vez que disponemos de la relación y número de conglomerados a través de la información propiciada por la página web de la administración correspondiente, se solicita a cada centro a través del correo electrónico dirigida a la dirección de cada uno y de forma voluntaria, información sobre el número de alumnos matriculados en el nivel educativo de referencia (tercero y cuarto de educación secundaria obligatoria), produciéndose el $45.7 \%$ de respuestas. Este alto índice de respuesta permite realizar una estimación poblacional muy precisa, efectuando los cálculos e inferencias por estratos según tipos de centros, tanto privados (financiados con fondos públicos), como públicos, así como rurales y urbanos. Por fin, la estimación del tamaño poblacional de alumnos que cursan el 2 ㅇcㅇo de la ESO en Castilla y León en el curso 2008/2009 es de 43273 sujetos, siendo la media de cada conglomerado de $111.8 \cong$ 112 alumnos, partiendo, naturalmente, del desigual tamaño entre conglomerados.

Tras el cálculo del tamaño de muestra para poblaciones finitas, con un nivel de significación $\alpha=.05$ y con un error definido de $\pm \pm 3 \%$, se obtiene que es necesaria una 
muestra de 1.087 sujetos, lo que equivaldría a la selección aleatoria de 10 conglomerados elegidos aleatoriamente el total de los 381 centros de Castilla y León donde se imparte el nivel educativo en el que se centra el estudio I.

Finalmente, las encuestas se recogieron durante los meses de mayo y junio de 2009 en 13 centros educativos de toda Castilla y León, como indica la tabla 4.69, mostrada a continuación.

Tabla 4.69 Muestra obtenida por centro educativo

\begin{tabular}{rcc}
\hline Curso & N & $\%$ \\
\hline Paula Montal, Astorga (León) & 73 & 6.2 \\
\hline Claudio Sánchez Albornoz, León (León) & 47 & 4.0 \\
\hline Maristas, Palencia (Palencia) & 86 & 7.3 \\
\hline Maestro Ávila, Salamanca (Salamanca) & 115 & 9.8 \\
\hline Epostolado del Sagrado Corazón, Valladolid (Valladolid) & 160 & 13.6 \\
\hline Vela Zanetti, Aranda de Duero (Burgos) & 176 & 15.0 \\
\hline Santa Catalina, Burgo de Osma (Soria) & 101 & 4.3 \\
\hline Gredos, Piedrahita (Ávila) & 38 & 8.6 \\
\hline González Allende, Toro (Zamora) & 65 & 3.2 \\
\hline Parquesol, Valladolid (Valladolid) & 60 & 5.5 \\
\hline San Estanislao de Kostka, Salamanca (Salamanca) & 101 & 5.1 \\
\hline Camarro, Fuente de San Esteban (Salamanca) & 103 & 8.6 \\
\hline & $\mathbf{8 1 7 5}$ & $\mathbf{1 0 0 . 0}$ \\
\hline
\end{tabular}

Como se puede observar, el número total de encuestas recogidas fue de 1175 , superando los 1087 sujetos necesarios para la obtención de la muestra representativa. Por otro lado, se puede observar cómo, de los 13 centros educativos seleccionados, 7 están situados en zonas urbanas (capitales de provincia) y 6 en otras localidades.

\subsubsection{Muestreo para futuros profesores de Educación Secundaria}

En el caso del futuro profesorado de Educación Secundaria Obligatoria, la población a partir de la que se extrae la muestra es la compuesta por los sujetos que estudian a lo largo del curso 2009/2010 el Máster Máster Oficial Universitario en Profesor de Educación Secundaria Obligatoria y Bachillerato, Formación Profesional y Enseñanzas de Idiomas en la comunidad autónoma de Castilla y León. Así, podríamos 
definir de un modo más operativo la población diana del estudio como el futuro profesorado de Educación Secundaria Obligatoria.

El citado Máster oficial, se oferta dentro de Castilla y León en las universidades de León, Burgos, Salamanca, Valladolid y Pontificia de Salamanca.

Considerando los sujetos que estudian el Máster en estas universidades como conglomerados, se decide aplicar las encuestas directamente sobre el conglomerado de la Universidad de Salamanca, en la idea de que dicho conglomerado es representativo de la población de referencia. En este caso, por tanto, se aplica un muestreo incidental.

En el curso 2009/2010, las universidades de Castilla/León ofertaron 1100 plazas distribuidas de la siguiente manera:

- Universidad de León: 220 plazas.

- Universidad de Burgos: 120 plazas.

- Universidad de Salamanca: 300 plazas.

- Universidad de Valladolid: 400 plazas.

- Universidad Pontificia de Salamanca 60 plazas.

A pesar de que la demanda no llegó a los niveles de oferta, hemos partido de una población de 1100 plazas para calcular el tamaño muestral. Así, mediante la aplicación de la correspondiente fórmula para el cálculo del tamaño de muestra para poblaciones finitas (Arnal et al., 1992, p. 81),

$$
n=\frac{Z_{\alpha}^{2} p q N}{e^{2}(N-1)+Z_{\alpha}^{2} p q}
$$

con un nivel de significación $\alpha=.05$, heterogeneidad máxima ( $p=q=0.5=y$ con error definido de $\pm \pm 5 \%$, se obtiene que es necesaria una muestra de,

$$
n=\frac{1.65^{2} * 0.5 * 0.5 * 1100}{0.05^{2} *(1100-1)+1.65^{2} * 0.5 * 0.5}
$$

218 sujetos, Definitivamente, la muestra obtenida está compuesta por 212 sujetos, algo menos que el tamaño de muestra requerido. Al haber hecho una 
consideración al alza del tamaño poblacional, consideramos este tamaño de muestra suficiente para poder proceder con los análisis estadísticos pertinentes. A pesar de que la muestra obtenida es en su totalidad de la Universidad de Salamanca, si atendemos a la especialidad en la que se cursa el Máster Oficial, esto es, a la materia/s que podrán impartir los futuros profesores, la distribución está muy repartida.

Tabla 4.70 Encuestas obtenidas en futuro profesorado por especialidad cursada

\begin{tabular}{|c|c|c|}
\hline Especialidad & Frecuencia & $\%$ \\
\hline Física y Química & 8 & $3.8 \%$ \\
\hline Biología y Geología & 16 & $7.7 \%$ \\
\hline Matemáticas & 7 & $3.3 \%$ \\
\hline Lengua Española y Literatura & 13 & $6.2 \%$ \\
\hline Latín & 2 & $1.0 \%$ \\
\hline Griego & 1 & $0.5 \%$ \\
\hline Inglés & 28 & $13.4 \%$ \\
\hline Francés & 5 & $2.4 \%$ \\
\hline Italiano & 4 & $1.9 \%$ \\
\hline Alemán & 5 & $2.4 \%$ \\
\hline Portugués & 4 & $1.9 \%$ \\
\hline Geografía e Historia & 17 & $8.1 \%$ \\
\hline Filosofía & 7 & $3.3 \%$ \\
\hline Organización y Gestión Comercial & 11 & $5.3 \%$ \\
\hline Formación y Orientación Laboral & 9 & $4.3 \%$ \\
\hline Dibujo & 23 & $11.0 \%$ \\
\hline Música & 9 & $4.3 \%$ \\
\hline Educación Física & 9 & $4.3 \%$ \\
\hline Tecnología & 10 & $4.8 \%$ \\
\hline Técnicas y Procedimientos de Imagen y Sonido & 3 & $1.4 \%$ \\
\hline Procesos sanitarios & 1 & $.5 \%$ \\
\hline Orientación Educativa & 17 & $8.1 \%$ \\
\hline Total & 209 & $100.0 \%$ \\
\hline Perdidos & 3 & \\
\hline
\end{tabular}

En la tabla 4.70 se observa cómo dentro de la muestra se incluyen sujetos de todo tipo de especialidades, lo cual nos indica que la muestra carece de sesgos relacionados con el área de conocimiento preferente del futuro profesorado de educación secundaria. 


\subsubsection{Procedimiento. Estudio I}

Una vez diseñados los instrumentos y llevado a cabo el análisis psicométrico pertinente, se aplica a las muestras definidas anteriormente. La aplicación de las encuestas fue, en función de la muestra de referencia, como se describe a continuación.

\subsubsection{Aplicación de la encuesta entre el alumnado de educación secundaria}

En el caso de la recogida de información en la muestra de alumnos y alumnas de educación secundaria, las encuestas fueron aplicadas por investigadores vinculados al proyecto I+D $+\mathrm{i}^{19}$ en el que está inmersa esta Tesis Doctoral. De este modo, al tratarse de personas expertas en la aplicación de este tipo de cuestionarios, que exponían claramente tanto los objetivos del trabajo como las instrucciones para su correcta cumplimentación, se tratan de evitar en la medida de lo posible algunos sesgos de información debidos al individuo (deseabilidad social, obsequiosidad o atención) y debidos al entrevistador, que con su actitud condicione la respuesta (Martínez Ramos \& Alvira Martín, 1985).

La encuesta es aplicada sobre los conglomerados o centros educativos seleccionados en el proceso de muestreo durante los meses de mayo y junio de 2009. Las fechas en las que se recogen las encuestas a lo largo de los diferentes centros educativos incluidos es la que se muestra en la tabla 4.71 .

Tabla 4.71 Fechas de encuestación en alumnos por centro educativo

\begin{tabular}{rc}
\hline Centro educativo & Fecha \\
\hline Paula Montal, Astorga (León) & $27 / 05 / 09$ \\
\hline Claudio Sánchez Albornoz, León (León) & $26 / 05 / 09$ \\
\hline Maristas, Palencia (Palencia) & $04 / 06 / 09$ \\
\hline Maestro Ávila, Salamanca (Salamanca) & $15 / 06 / 09$ \\
\hline Apostolado del Sagrado Corazón, Valladolid (Valladolid) & $26 / 05 / 09$ \\
\hline Vela Zanetti, Aranda de Duero (Burgos) & $03 / 06 / 09$ \\
\hline Ezequiel González, Segovia (Segovia) & $20 / 05 / 09$ \\
\hline Santa Catalina, Burgo de Osma (Soria) & $28 / 05 / 09$ \\
\hline Gredos, Piedrahita (Ávila) & $05 / 06 / 09$ \\
\hline
\end{tabular}

\footnotetext{
19 Proyecto Nacional I+D+i, convocatoria 2009: Evaluación de Competencias Clave y Formación de Profesorado de Educación Secundaria: TIC, ALFIN Y Convivencia Escolar (EF-TALCO). Ref.: EDU2009-08753.
} 


\begin{tabular}{rr}
\hline González Allende, Toro (Zamora) & $22 / 05 / 09$ \\
\hline Parquesol, Valladolid (Valladolid) & $20 / 05 / 09$ \\
\hline San Estanislao de Kostka, Salamanca (Salamanca) & $19 / 06 / 09$ \\
\hline Campo Charro, Fuente de San Esteban (Salamanca) & $02 / 06 / 09$ \\
\hline
\end{tabular}

\subsubsection{Aplicación de la encuesta entre el futuro profesorado de educación secundaria}

En cuanto a la muestra de futuros profesores que están cursando el Máster Oficial de Profesor de Educación Secundaria Obligatoria, Bachillerato, Formación Profesional y Enseñanzas de Idiomas, para evitar la introducción de elementos extraños en el propio contexto del aula, la encuesta es aplicada por el profesorado habitual de cada grupo. Expertos vinculados al presente estudio exponen al profesorado los objetivos y el procedimiento de cumplimentación de la encuesta, y estos la aplican a sus alumnos.

Todas las encuestas son aplicadas entre el 22 y el 26 de noviembre de 2010, y la distribución en función del grupo de docencia se presenta en la tabla 4.72.

Tabla 4.72 Encuestas obtenidas en futuro profesorado por grupo de docencia

\begin{tabular}{rrr}
\hline Grupo de docencia & Frecuencia & $\%$ \\
\hline Artes y tecnología & 36 & $16.98 \%$ \\
\hline Orientación educativa & 33 & $15.57 \%$ \\
\hline Enseñanza de idiomas & 47 & $22.17 \%$ \\
\hline Ciencias e ingeniería & 31 & $14.62 \%$ \\
\hline Literatura, geografía e historia & 33 & $15.57 \%$ \\
\hline Otras especialidades & 32 & $15.09 \%$ \\
\hline
\end{tabular}

Con respecto a las especialidades de procedencia de los sujetos encuestados, que se han señalado anteriormente, se distribuyen entre los grupos de docencia del modo que se expresa en la tabla 4.73 .

Tabla 4.73 Encuestas obtenidas en futuro profesorado por especialidad

\begin{tabular}{|c|c|c|c|}
\hline Grupo & Especialidad & Frecuencia & $\%$ \\
\hline \multirow{3}{*}{$\begin{array}{r}\text { Artes y } \\
\text { tecnología }\end{array}$} & Dibujo & 23 & $10.85 \%$ \\
\hline & Tecnología & 10 & $4.72 \%$ \\
\hline & Técnicas y procedimientos de imagen y sonido & 3 & $1.41 \%$ \\
\hline Orientación & Formación y orientación laboral & 9 & $4.25 \%$ \\
\hline
\end{tabular}




\begin{tabular}{|c|c|c|c|}
\hline educativa & Orientación educativa & 17 & $8.02 \%$ \\
\hline & Filosofía & 7 & $3.30 \%$ \\
\hline \multirow{5}{*}{$\begin{array}{r}\text { Enseñanza de } \\
\text { idiomas }\end{array}$} & Inglés & 28 & $13.21 \%$ \\
\hline & Francés & 5 & $2.36 \%$ \\
\hline & Italiano & 4 & $1.89 \%$ \\
\hline & Alemán & 5 & $2.36 \%$ \\
\hline & Portugués & 4 & $1.89 \%$ \\
\hline \multirow{3}{*}{$\begin{array}{l}\text { Ciencias e } \\
\text { ingeniería }\end{array}$} & Física y química & 8 & $3.77 \%$ \\
\hline & Biología y Geología & 16 & $7.55 \%$ \\
\hline & Matemáticas & 7 & $3.30 \%$ \\
\hline \multirow{4}{*}{$\begin{array}{r}\text { Literatura, } \\
\text { geografía e } \\
\text { historia }\end{array}$} & Lengua española y literatura & 13 & $6.13 \%$ \\
\hline & Geografía e historia & 17 & $8.02 \%$ \\
\hline & Latín & 2 & $0.94 \%$ \\
\hline & Griego & 1 & $0.47 \%$ \\
\hline \multirow{5}{*}{$\begin{array}{r}\text { Otras } \\
\text { especialidades }\end{array}$} & Organización y gestión comercial & 11 & $5.19 \%$ \\
\hline & Música & 9 & $4.25 \%$ \\
\hline & Educación física & 9 & $4.25 \%$ \\
\hline & Procesos sanitarios & 1 & $0.47 \%$ \\
\hline & Casos perdidos & 3 & $1.41 \%$ \\
\hline Total & & 212 & $100.0 \%$ \\
\hline
\end{tabular}

Se puede observar cómo la muestra está repartida ponderadamente en los grupos, siendo más numeroso el número de encuestas obtenidas en los grupos más amplios.

\subsubsection{Análisis de datos. Estudio I}

En cuanto al análisis de datos llevado a cabo, dada la naturaleza del estudio, que se desarrolla a partir un diseño ex-post-facto (Arnal et al., 1992; L. Cohen \& Manion, 2002; Green, Calimy, \& Elmore, 2006; Kerlinger \& Lee, 1999), y los objetivos descritos, se centra en la mera exploración de las variables y sus relaciones conjuntas. Más concretamente, en la mayor parte de los análisis del estudio I se aplican técnicas propias de la estadística descriptiva, correlacional y multivariante.

- En primer lugar se lleva a cabo un proceso exploratorio de las variables con la finalidad de depurar el archivo y seleccionar las técnicas descriptivas más adecuadas (Etxeberría Murgiondo, 2005; Vargas Sabadías, 1995): Estudio de las funciones de densidad y distribución, momentos respecto al origen y a la media, medidas de posición, medidas de tendencia central 
(media, mediana y moda), medidas de dispersión (varianza, desviación típica, rango y coeficiente de variación) y medidas de forma (asimetría y curtosis). Esta exploración previa va seguida del estudio descriptivo, que se puede disgregar en varias etapas

- Estudio de variabilidad individual de las variables

- Estudio de las diferencias por grupos principales determinados por las variables predictoras.

- Estudio de las diferencias entre las diferentes escalas de las variables criterio.

- En segundo lugar, después del proceso exploratorio, a partir del consecuente estudio descriptivo de cada una de las variables, se implementa un estudio de correlación (Etxeberria Murgiondo, 2004; Glass, Stanley, Galvis Gómez, \& Guzmán, 1986; López González, Miranda Páez, \& Galante Guille, 1993) para determinar en qué medida las variables están relacionadas entre sí. Previamente se lleva a cabo un análisis previo para determinar qué tipo de regresión es la más adecuada para los datos existentes (lineal, exponencial, logarítmica, cuadrática,...). Así, se procede al estudio de las matrices de correlaciones aplicando la medida más oportuna en función de la naturaleza de las variables correlacionadas (coeficiente de Pearson, Spearman, fi, correlación biserial puntual,...).

- Por último, una vez realizado el estudio de correlaciones simples, se procede al estudio de las variaciones conjuntas y covarianzas existentes en los datos mediante la aplicación de técnicas multivariantes (Cea D'Ancona, 2002; Hawkins, 1982; Joaristi Olariaga \& Lizasoain Hernández, 1999; Lizasoain Hernández \& Joaristi Olariaga, 2000). Entre estas técnicas, se llevan a cabo tanto análisis de dependencias para explicar la relación de las variables dependientes con las independientes, como un análisis de interdependencia, para descubrir las interrelaciones y la estructura subyacente existente entre todas las variables. Así, entre las técnicas de análisis de dependencia, se procede en un primer momento a la aplicación de la regresión múltiple con el objetivo de la construcción de modelos de regresión que aporten ecuaciones de regresión con valores del coeficiente de determinación $\left(R^{2}\right)$ aceptables. A partir de estos estudios previos, se 
procede al análisis de las variables a partir de las técnicas de modelos de ecuaciones estructurales (Batista-Foguet \& Coenders, 2000; Bollen, 1989; M. Castro \& Lizasoain Hernández, 2012; Kline, 2005; Schreiber et al., 2006), con el fin de observar y determinar la bondad de ajuste de los propios modelos obtenidos en los análisis de regresión múltiple. En cuanto al análisis de interdependencia se prevé aplicar principalmente técnicas de análisis factorial exploratorio por componentes principales, ejes principales o máxima verosimilitud con rotación ortogonal u oblicua, en función de la naturaleza de los datos.

- Dentro de las técnicas de modelos de ecuaciones estructurales, se analizan por último las diferencias entre grupos principales en lo que respecta al ajuste y los valores obtenidos en las relaciones directas e indirectas existentes en modelo propuesto.

En el análisis de datos se emplean diversos paquetes estadísticos, en función de las necesidades concretas y la potencialidad del paquete con respecto a la técnica que se va a aplicar. Así, se emplea generalmente para los análisis estadísticos el paquete IBM SPSS Statistics V.19 con su complemento para el diseño de modelos de ecuaciones estructurales AMOS 19. Por otro lado, para los análisis gráficos se emplea comúnmente el software $\mathrm{R}$, principalmente a partir de los paquetes estadísticos "MASS" y "rgl". 


\subsection{Resultados en estudiantes de educación secundaria}

Dadas las diferencias existentes tanto en objetivos como en los resultados previstos para cada una de las dos partes de las que se compone el estudio I, analizaremos ambos apartados de manera independiente.

En primer lugar, es necesario llevar a cabo una exposición detallada de los resultados obtenidos en la muestra de estudiantes de educación secundaria con el fin de obtener una caracterización lo más exhaustiva posible de las variables estudiadas en la propia muestra, y por ende, en la población de referencia. Dicha caracterización de la importancia concedida y el nivel autopercibido en competencias informacionales y de las variables relacionadas incluidas en el cuestionario nos permitirá hacer un análisis minucioso de las principales deficiencias formativas localizadas en los estudiantes de educación secundaria.

La exposición de resultados que se muestra a continuación comienza con la descripción general de las variables demográficas de agrupación incluidas en el estudio, para continuar haciendo un análisis descriptivo profundo de las variables criterio y predictivas.

\subsubsection{Información demográfica en estudiantes}

A lo largo de esta primera parte, los resultados que describimos a continuación, constituyen un conjunto de indicadores relacionados con la información general o de identificación y clasificación de los alumnos que han respondido a los cuestionarios aplicados. Para ello, se ha solicitado en la encuesta información relativa al año de nacimiento, sexo, curso actual y niveles de estudios del padre y de la madre.

\subsubsection{Sexo}

Tabla 4.74 Distribución de la muestra global de alumnos por sexo

\begin{tabular}{|c|c|c|c|}
\hline Sexo & $N$ & $\%$ & \% válido \\
\hline Varón & 583 & 49.6 & 50.5 \\
\hline Mujer & 572 & 48.7 & 49.5 \\
\hline Perdidos & 20 & 1.7 & \\
\hline TOTAL & 1175 & 100.0 & 100.0 \\
\hline
\end{tabular}


La tabla 4.74 indica la distribución de la muestra en relación a la variable sexo. Se puede observar que los porcentajes de las variables están muy equilibrados, siendo ligeramente superior la participación de los varones. Estas diferencias son normales, teniendo en cuenta que, según el estudio de Enseñanzas anteriores a la Universidad (2007), desarrollado por el Ministerio de Educación y Ciencia (MEC) ${ }^{20}$, en el curso 2006/2007, del total de 1.834 .685 alumnos que cursaban la ESO, un 51.36\% (942.263 sujetos) eran varones, mientras que el $48.64 \%$ (892.422) restante correspondía a mujeres. Si analizamos la proporción podemos apreciar un porcentaje de distribución de género similar en los porcentajes obtenidos en esta encuesta, pertenecientes a alumnos ubicados en centros educativos de Castilla y León. Tal tendencia, indica que los resultados se ajustan a la distribución de frecuencias de población y no al interés particular por la realización de la actividad centrado en el sexo.

\subsubsection{Año de nacimiento}

Tabla 4.75 Distribución de la muestra global de alumnos por año de nacimiento*

\begin{tabular}{lccc}
\hline Año de nacimiento & $\boldsymbol{N}$ & $\%$ & \% válido \\
\hline 1991 & 67 & 5.7 & 5.8 \\
\hline 1992 & 154 & 13.1 & 13.4 \\
\hline 1993 & 488 & 41.5 & 42.4 \\
\hline 1994 & 442 & 37.6 & 38.4 \\
\hline Perdidos & 24 & 2.0 & \\
\hline TOTAL & $\mathbf{1 1 7 5}$ & $\mathbf{1 0 0 . 0}$ & $\mathbf{1 0 0 . 0}$ \\
\hline
\end{tabular}

* Información recogida entre los meses de mayo y junio de 2009

Al analizar el año de nacimiento de los sujetos que contestaron a la encuesta, como se puede observar en la tabla 4.75, nos encontramos con que la mayor parte de la muestra, un 80.8\%, ha nacido entre 1993 y 1994, siendo muy inferior el porcentaje de sujetos que ha nacido entre 1991 y 1992 (19.2\%).

\footnotetext{
${ }^{20}$ Fuente: Instituto Nacional de Estadística (INE). $\underline{\text { www.ine.es }}$
} 


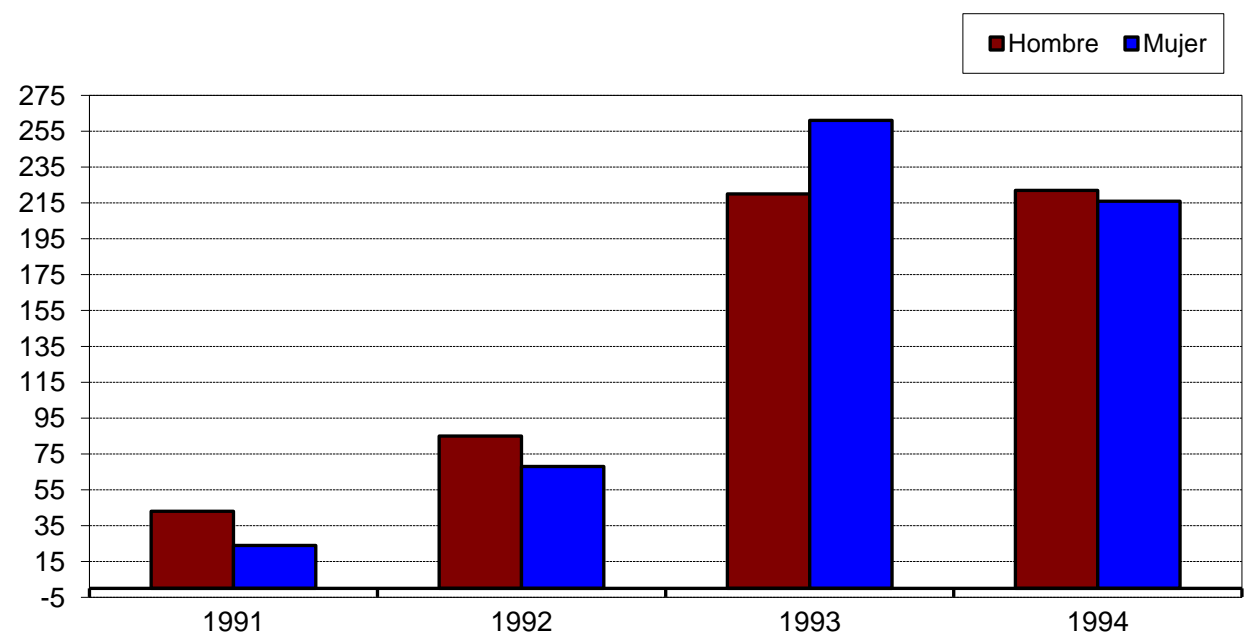

Gráfico 4.2 Distribución de la muestra global, por edad y por sexo

Como podemos apreciar en el gráfico 4.2, sobre las variables sexo y edad, el porcentaje de hombres, tal y como hemos analizado anteriormente, es ligeramente superior en la mayor parte de los tramos, siendo inferior solamente en la muestra de sujetos nacidos en 1993. Cabe destacar que en los años de nacimiento 1991 y 1992 la diferencia entre número de hombres y mujeres, a favor de los hombres, es mayor. Así, de entre los sujetos nacidos en 1991 (67 sujetos), casi el doble, 43 (64.18\%), son hombres, mientras que sólo se han recogido 24 encuestas de mujeres (35.82\%). Estas mayores diferencias se podrían explicar en parte por el hecho de que la mayor parte de los alumnos nacidos en 1991 y 1992 son repetidores (por año de nacimiento deberían estar en un nivel superior al de ESO); según el estudio anteriormente mencionado de Enseñanzas Anteriores a la Universidad (MEC, 2007), en el curso 2006/2007, de los 295.982 alumnos de ESO repetidores, un $58.73 \%$ (173.818 alumnos) son varones, mientras que el $41.27 \%$ restante (122.164 sujetos), son mujeres.

\subsubsection{Curso}

En la tabla 4.76 se observa cómo, en función del curso en el que están titulados los sujetos de la muestra, los porcentajes entre 3 ㅇ y 4 을 están bastante repartidos, siendo ligeramente superior el número de alumnos de la muestra que cursan 3o de la ESO.

Tabla 4.76 Distribución de la muestra global por curso

\begin{tabular}{lcccc}
\hline & curso & N & \% & \% válido \\
\hline 3을SO & 627 & 53.4 & 54.0 \\
\hline 4을S & 535 & 45.5 & 46.0 \\
\hline Perdidos & 13 & 1.1 & \\
\hline TOTAL & $\mathbf{1 1 7 5}$ & $\mathbf{1 0 0 . 0}$ & $\mathbf{1 0 0 . 0}$ \\
\hline
\end{tabular}


Estas ligeras diferencias no nos sorprenden, ya que según la Estadística de Enseñanzas no universitarias (MEC, 2009), en el curso 2006/2007, de los 44.307 alumnos que cursaban el segundo ciclo de ESO en Castilla y León, 23.566 (53.2\%) cursaban 30 de la ESO y los 20.741 restantes (46.8\%) cursaban 40 de la ESO. Por otro lado, cuando analizamos los datos obtenidos a nivel nacional en este mismo estudio, se corrobora que de los 841.256 alumnos que cursaban el segundo ciclo de la ESO en el curso 2006/2007, 452.031 (53.7\%) lo hacían en el nivel de 3ㅇ de la ESO, mientras que 389.225 (46.3\%) alumnos cursaban 3ㅇ de la ESO.

Estos datos son muy similares a los obtenidos en la muestra que nosotros hemos estudiado, y por tanto, podemos afirmar que tal tendencia indica que los resultados se ajustan a la distribución de frecuencias de población y no al interés particular por la realización de la actividad centrado en el curso.

\subsubsection{Nivel de estudios de los padres}

Como podemos observar en las tablas 4.77 y 4.78 , los niveles de estudios del padre y de la madre de los sujetos encuestados se distribuyen sin grandes diferencias en su mayor parte entre los secundarios y los universitarios, siendo el grupo más numeroso el de estudios secundarios. Estos datos se validan comparándolos con los reflejados en los "Indicadores Sociales" (2008) del Instituto Nacional de Estadística (INE), que en 2007 encontró que el 20.82\% de la población mayor de 16 años había completado estudios primarios, mientras que el $44.72 \%$ lo había llegado a los estudios secundarios. En cuanto al nivel educativo en función del sexo, el estudio del INE tampoco encuentra grandes diferencias, encontrándose un $19.95 \%$ de varones con estudios primarios por un $21.66 \%$ de mujeres y un $47.28 \%$ de varones con estudios secundarios por un $42.26 \%$ de mujeres.

Tabla 4.77 Distribución de la muestra global por nivel de estudios del padre

\begin{tabular}{lccc}
\hline Nivel de estudios del padre & $\mathbf{N}$ & $\mathbf{\%}$ & \% válido \\
\hline Primarios & 195 & 16.6 & 17.6 \\
\hline Secundarios & 518 & 44.1 & 46.7 \\
\hline Universitarios & 397 & 33.8 & 35.8 \\
\hline Perdidos & 65 & 5.5 & \\
\hline TOTAL & $\mathbf{1 1 7 5}$ & $\mathbf{1 0 0 . 0}$ & $\mathbf{1 0 0 . 0}$ \\
\hline
\end{tabular}


Tabla 4.78 Distribución de la muestra global por nivel de estudios de la madre

\begin{tabular}{lccc}
\hline Nivel de estudios de la madre & $\boldsymbol{N}$ & \% & \% válido \\
\hline Primarios & 161 & 13.7 & 14.4 \\
\hline Secundarios & 542 & 46.1 & 48.4 \\
\hline Universitarios & 416 & 35.4 & 37.2 \\
\hline Perdidos & 56 & 4.8 & \\
\hline TOTAL & $\mathbf{1 1 7 5}$ & $\mathbf{1 0 0 . 0}$ & $\mathbf{1 0 0 . 0}$ \\
\hline
\end{tabular}

El gráfico 4.3 muestra el nivel de estudios del padre con respecto a los estudios de la madre (y viceversa). Se observa claramente cómo existe la tendencia a que los niveles de estudios de los cónyuges sean iguales. Esta "endogamia" con respecto al nivel de estudios, se encuentra en el $68.82 \%$ en el total de los casos, mientras que es de un $56.98 \%$ en los sujetos con estudios primarios, de un $70.05 \%$ en los sujetos con estudios secundarios y de un $72.39 \%$ en los sujetos con estudios universitarios.

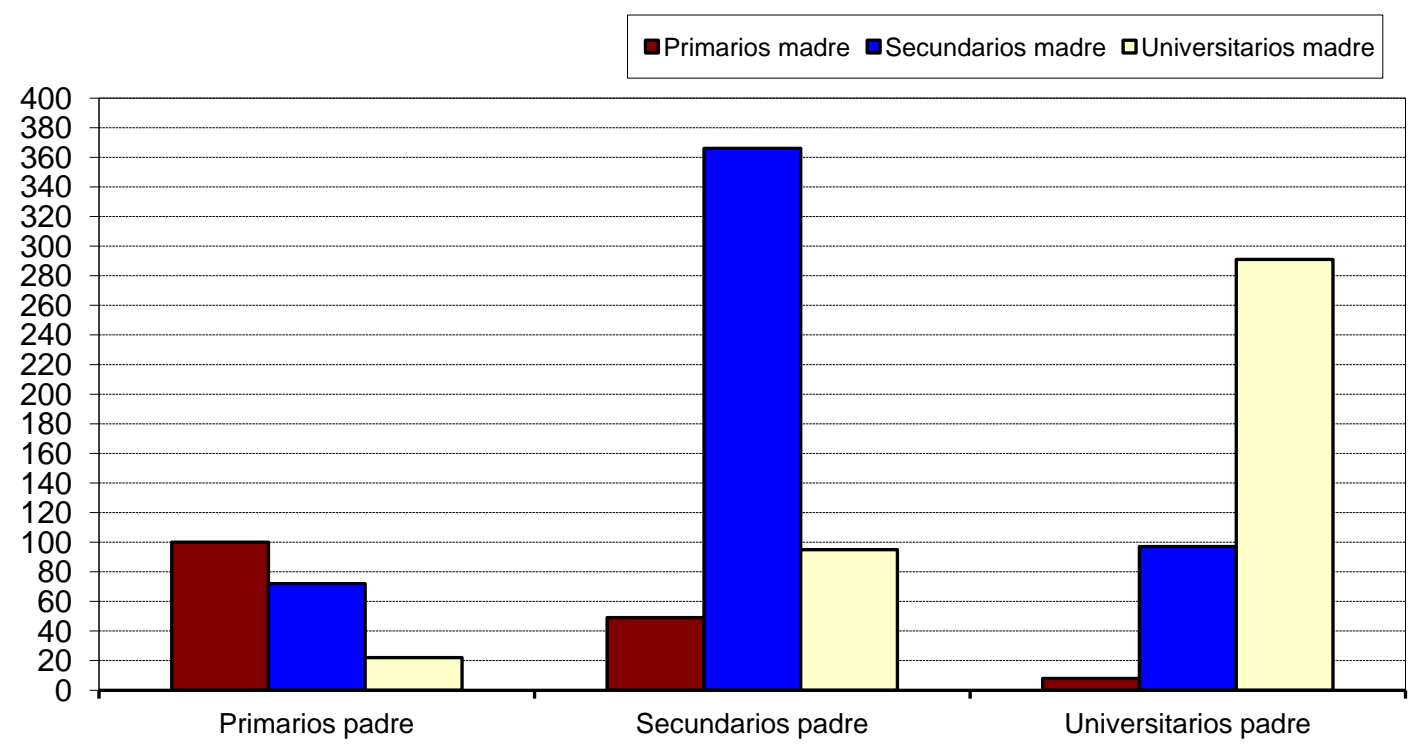

Gráfico 4.3 Distribución de la muestra global, por estudios del padre y de la madre

Por tanto, la evidencia obtenida parece indicar que, en cuanto a los datos de información demográfica obtenidos en la muestra, hemos visto cómo existe una estrecha relación entre la información que se ha obtenido en el presente estudio y los datos de otras muestras y estudios más amplios (INE, 2008; MEC, 2007, 2009; Sigalés \& Mominó, 2004). Por tanto, se tienen indicios sólidos que revelan que no existen sesgos de selección y que, por tanto, los estadísticos obtenidos se aproximan a los parámetros poblacionales. 


\subsubsection{Información general sobre el uso del ordenador}

Como complemento a la información obtenida anteriormente, hemos querido conocer de este grupo de alumnos y alumnas, algunas cuestiones relativas a los niveles generales de disponibilidad y empleo del ordenador en el centro educativo y en el hogar durante el curso 2008/2009, que formarán parte del grupo de variables predictoras en el estudio de regresión posterior.

En este apartado, por tanto, el alumnado debe responder sobre si dispone de ordenador y/o de internet en casa, cuánto tiempo lleva utilizándolos, cuál ha sido la principal fuente de la que ha aprendido a utilizarlos, y sobre la frecuencia de empleo del ordenador dentro y fuera del centro educativo. Estas variables poseen interés educativo por cuanto son indicadores de impacto de las TIC sobre la población de referencia ${ }^{21}$.

\subsubsection{Infraestructura: Existencia de ordenadores en el hogar}

Este sub-apartado, además de cuestionar acerca de la existencia o no de ordenadores e internet en los hogares del alumnado, se pretende conocer qué alumnos tienen disponibilidad para utilizarlo en casa con cierta libertad.

Como se refleja en la tabla 4.79 , el $98 \%$ del alumnado afirma que en su hogar existe al menos un ordenador. Estos datos se asemejan a los derivados del estudio de Isabel Gutiérrez Porlán (2007) en una encuesta aplicada a alumnos de Educación Secundaria Obligatoria; en dicha investigación, resulta que el 91.5\% de los alumnos dispone de ordenador en su residencia habitual.

Tabla 4.79 Distribución de la muestra global, por existencia o no de computadora en el hogar

\begin{tabular}{lccc}
\hline Existencia de ordenador en casa & $\boldsymbol{N}$ & \% & \% válido \\
\hline Sí & 1147 & 97.6 & 98.0 \\
\hline No & 24 & 2.0 & 2.0 \\
\hline Perdidos & 4 & 0.3 & \\
\hline TOTAL & $\mathbf{1 1 7 5}$ & $\mathbf{1 0 0 . 0}$ & $\mathbf{1 0 0 . 0}$ \\
\hline
\end{tabular}

\footnotetext{
${ }^{21}$ En España se pueden consultar los indicadores apuntados por el Ministerio de Industria, Energía y Turismo como los principales para evaluar el impacto de las TIC en hogares y empresas (http://www.ontsi.red.es/ontsi/es/indicadores), o las variables empleadas en informes sobre el estado de la sociedad de la información (http://sociedadinformacion.fundacion.telefonica.com/DYC/SHI/InformesSI/)
} 
Por otro lado, en la tabla 4.80 se puede constatar que la mayor parte de los alumnos y alumnas que tienen ordenador en casa, pueden disponer de él (97.2\% de los sujetos frente al $98 \%$ que tenían ordenador en casa).

Tabla 4.80 Distribución de la muestra global, por disponibilidad o no de computadora en el hogar

\begin{tabular}{lccc}
\hline $\begin{array}{c}\text { Disponibilidad de ordenador en } \\
\text { casa }\end{array}$ & N & \% & \% válido \\
\hline Sí & 1136 & 96.7 & 97.2 \\
\hline No & 33 & 2.8 & 2.8 \\
\hline Perdidos & 6 & 0.5 & \\
\hline TOTAL & $\mathbf{1 1 7 5}$ & $\mathbf{1 0 0 . 0}$ & $\mathbf{1 0 0 . 0}$ \\
\hline
\end{tabular}

Como se puede observar en la Tabla 4.81, el porcentaje de discentes con acceso a internet en sus hogares es muy alto, llegando el $85.3 \%$. Estos datos difieren moderadamente de los reflejados en el informe anteriormente señalado (Gutiérrez Porlán, 2007), en el que se señala que el $67.8 \%$ de los sujetos encuestados tenía internet en casa. Estas diferencias se pueden deber, en parte, a que dicho informe corresponde a información obtenida en 2006, tres años antes de la obtenida en el presente estudio.

Así mismo, los datos desprendidos de la "Encuesta sobre equipamiento y uso de tecnologías de la información y comunicación en los hogares" (INE, 2009), señalan que el $54 \%$ de los hogares españoles disponen de acceso a internet. Sin embargo, también señala que el $60.49 \%$ de los hogares de 3 miembros dispone de conexión a internet, así como el $72.02 \%$ de los hogares de 4 miembros y el $68.77 \%$ de los de 5 o más miembros.

Parece, pues, que el hecho de que un componente del hogar sea un estudiante del 2 o ciclo de ESO está relacionado con una mayor disponibilidad de acceso a internet en el mismo.

Tabla 4.81 Distribución de la muestra global, por existencia o no de internet en el hogar

\begin{tabular}{lccc}
\hline Existencia de internet en casa & $\boldsymbol{N}$ & $\boldsymbol{\%}$ & \% válido \\
\hline Sí & 998 & 84.9 & 85.3 \\
\hline No & 172 & 14.6 & 14.7 \\
\hline Perdidos & 5 & 0.4 & \\
\hline TOTAL & $\mathbf{1 1 7 5}$ & $\mathbf{1 0 0 . 0}$ & $\mathbf{1 0 0 . 0}$ \\
\hline
\end{tabular}


La tabla 4.82 muestra como dato destacable, el porcentaje de sujetos que dispone de ordenador con conexión a internet en casa. Así, la mayor parte de sujetos que declaran tener ordenador en casa, señalan que también disponen de conexión a internet

Tabla 4.82 Tabla de contingencia, porcentaje por disponibilidad de ordenador y de internet.

\begin{tabular}{cccc|c}
\hline & & \multicolumn{2}{c|}{$\begin{array}{c}\text { Disponibilidad de } \\
\text { internet en casa }\end{array}$} & \\
\hline & & Sí & No & Total \\
\hline \multirow{2}{*}{$\begin{array}{c}\text { Disponibilidad de } \\
\text { ordenador en casa }\end{array}$} & Sí & $\mathbf{8 4 . 9 \%}$ & $12.2 \%$ & $\mathbf{9 7 . 2 \%}$ \\
\cline { 2 - 5 } TOTAL & & $0.3 \%$ & $2.5 \%$ & $\mathbf{2 . 8 \%}$ \\
\hline No & $\mathbf{8 5 . 3 \%}$ & $\mathbf{1 4 . 7 \%}$ & $\mathbf{1 0 0 . 0 \%}$ \\
\hline
\end{tabular}

En conclusión, podemos afirmar que la mayor parte de los alumnos del segundo ciclo de educación secundaria en la comunidad de Castilla y León dispone de ordenador en casa. De entre estos alumnos que tienen acceso a un ordenador en el hogar, la mayor parte (más de 5/6) afirma disponer también de conexión a internet.

\subsubsection{Frecuencia en el manejo general del ordenador}

Con este grupo de ítems se pretende observar a nivel genérico qué experiencia tienen los sujetos en el manejo del ordenador e internet, y con qué frecuencia las emplean.

Sobre cada uno de los ítems se pide a los alumnos que señalen, qué frecuencia de uso y qué experiencia tienen aproximadamente en su empleo.

Tabla 4.83 Descriptivos básicos sobre la experiencia en el manejo del ordenador

\begin{tabular}{l|ccccc|c}
\hline Experiencia en el manejo del ordenador & $\begin{array}{c}\text { (\%) } \\
\text { Nolo } \\
\text { utiliza }\end{array}$ & $\begin{array}{c}\text { Menos 1 } \\
\text { año }\end{array}$ & $\begin{array}{c}\text { (\%) } \\
\mathbf{1} \text { a 3 } \\
\text { años }\end{array}$ & $\begin{array}{c}\text { (\%) } \\
\mathbf{3} \text { a 5 } \\
\text { años }\end{array}$ & $\begin{array}{c}\text { (\%) } \\
\text { Más 5 } \\
\text { años }\end{array}$ & $\boldsymbol{N}$ \\
\hline Tiempo utilizando el ordenador & 1.6 & 4.7 & 17.1 & 34.1 & 42.4 & 1157 \\
\hline Tiempo utilizando internet & 4.9 & 10.2 & 34.5 & 34 & 16.4 & 1165 \\
\hline
\end{tabular}

* Media y desviación típica obtenidas de escala entre 1 y 5 (1=No lo utilizo; 2=Menos de 1 año; $3=$ Entre 1 y 3 años; 4=Entre

3 y 5 años; $5=$ Más de 5 años)

Según la tabla 4.83, podemos afirmar que los alumnos llevan más de 3 años empleando tanto los ordenadores como internet, y que, evidentemente, tuvieron sus primeras experiencias antes en el manejo de ordenadores que en el de internet. Éstos datos coinciden en buena medida con otro estudio (Sigalés et al., 2009) elaborado por el grupo de investigación IN3 (Internet Interdisciplinary Institute), en el que se afirma 
que el $57.7 \%$ de los alumnos procedentes de Educación Primaria y Secundaria llevaban más de 3 años manejando internet. También podemos hacer referencia, por su similitud, a otro estudio (Sánchez Burón et al., 2009) desarrollado sobre alumnos de Educación Secundaria Obligatoria en España, que encuentra que el 10.9\% llevan menos de 1 año empleando internet, el 42.6\% entre 2 y 3 años, y el $46.5 \%$ restante más de 3 años.

Como muestra el gráfico 4.4, las principales fuentes de aprendizaje que señalan los alumnos cuando se les cuestiona sobre dónde aprenden lo que saben sobre TIC, son el auto-aprendizaje (48.4\%) y la familia (26.6\%). Por otro lado, solamente el $7 \%$ de los encuestados afirma que los profesores son la principal fuente de aprendizaje. Estos datos no son sorprendentes cuando observamos en la tabla 4.83 que la frecuencia de manejo del ordenador en el hogar es mucho mayor que en el aula (4.51 de media frente a 2.96). Estos datos también son muy cercanos a los obtenidos por el estudio señalado anteriormente, (Sigalés et al., 2009), ya que señala que el $40.4 \%$ de los encuestados afirma haber adquirido habilidades informáticas principalmente de manera autodidácta, y el $28.8 \%$ con ayuda de la familia.

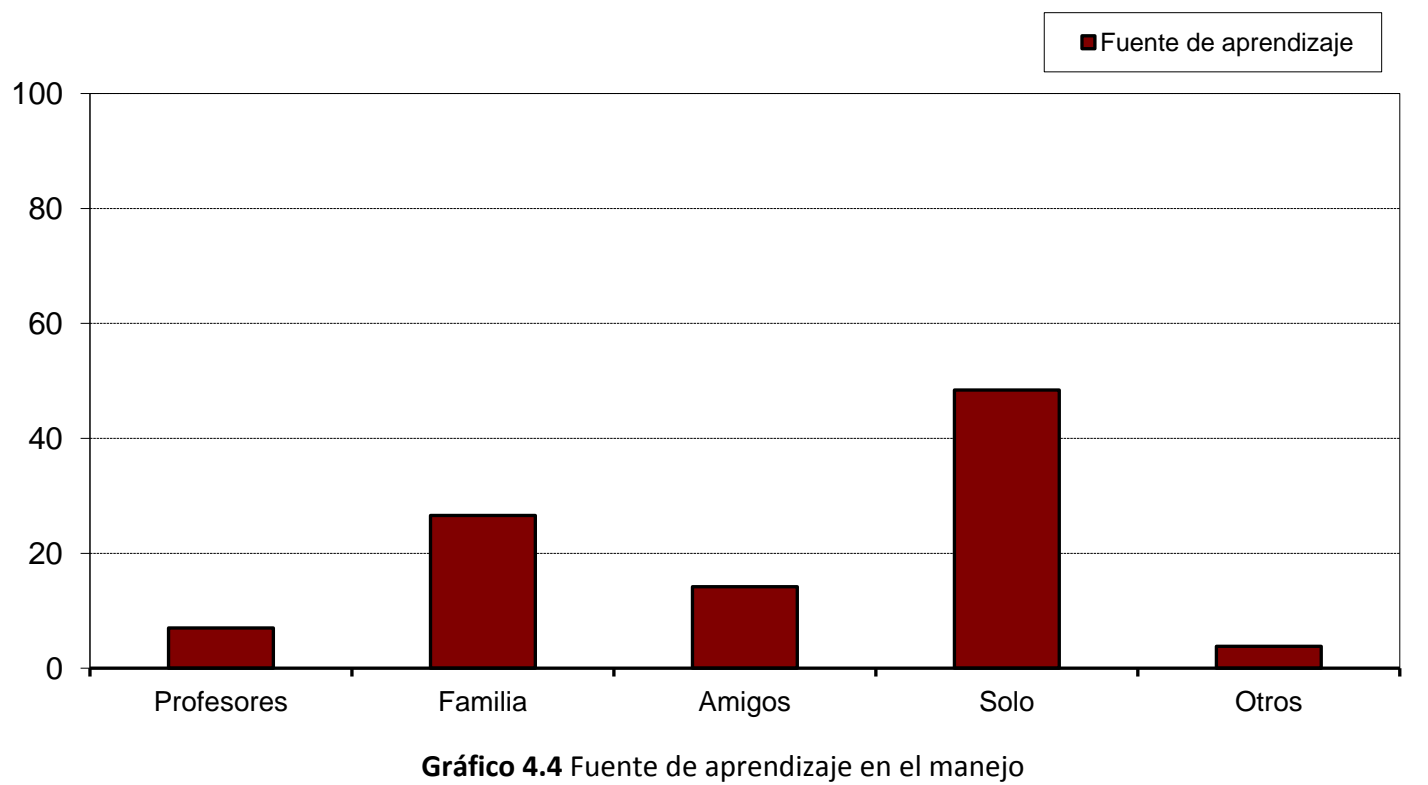

Como se observa en la tabla 4.84, Una gran mayoría de los encuestados (65.9\%) afirma emplear el ordenador casi todos los días en su casa, mientras que en el aula ese porcentaje es solamente del $4 \%$. Estos resultados concuerdan con el informe anteriormente citado (Sigalés et al., 2009). 
Tabla 4.84 Estadísticos básicos sobre la frecuencia en el manejo del ordenador

\begin{tabular}{|c|c|c|c|c|c|c|}
\hline Frecuencia en el manejo del ordenador & $\begin{array}{l}1(\%) \\
\text { Nunca }\end{array}$ & $\begin{array}{l}2(\%) \\
\text { Menos } 1 \\
\text { mes }\end{array}$ & $\begin{array}{c}3(\%) \\
7-30 \text { días }\end{array}$ & $\begin{array}{l}4(\%) \\
\text { Varias } \\
\text { seman }\end{array}$ & $\begin{array}{l}5(\%) \\
\text { Todos } \\
\text { dias }\end{array}$ & $N$ \\
\hline Frecuencia de uso en el hogar & 2.4 & 1.4 & 5.3 & 25 & 65.9 & 1150 \\
\hline $\begin{array}{l}\text { Frecuencia de empleo en horario de } \\
\text { clases }\end{array}$ & 15.7 & 17 & 27.1 & 36.1 & 4 & 1157 \\
\hline $\begin{array}{l}\text { Frecuencia de uso en la escuela fuera del } \\
\text { aula }\end{array}$ & 71.9 & 8.1 & 3.5 & 6.8 & 9.7 & 1166 \\
\hline
\end{tabular}

* Media y desviación típica obtenidas de escala entre 1 y 5 ( $1=$ Nunca; $2=$ Menos de una vez al mes; 3=Entre una vez a la semana y una vez al mes; $4=$ Varias veces a la semana; $5=$ Casi todos los días)

Como conclusión al presente apartado, cabe destacar, en primer lugar que, evidentemente, los alumnos declaran haber comenzado a emplear el ordenador antes que internet. Por otro lado, es recalcable el hecho de que los alumnos declaran emplear mucho más frecuentemente el ordenador en el hogar que en el aula o en el propio instituto fuera del horario de clases.

\subsubsection{Empleo de herramientas informáticas en estudiantes}

Como ya se ha señalado anteriormente, dentro del cuestionario completo se incluyen una serie de escalas para valorar tanto la frecuencia como el nivel en el empleo de herramientas informáticas. Además de esta medida, se tienen en cuenta las diferencias entre el empleo en el hogar y el empleo en el propio instituto en el horario de clases.

\subsubsection{Conocimientos informáticos}

En este apartado se describen los niveles de conocimientos básicos que declaran poseer los encuestados en relación con actividades informáticas concretas que a priori desempeñan en su vida cotidiana. Se organiza en torno a una escala de 1 a 5 puntos, siendo 1 un conocimiento nulo y 5 muy alto.

Tabla 4.85 Descriptivos básicos sobre el nivel de conocimientos en aplicaciones para el ordenador

\begin{tabular}{l|cc|ccccc|c}
\hline \multicolumn{1}{c|}{$\begin{array}{c}\text { Nivel de conocimientos } \\
\text { informáticos (Ordenador) }\end{array}$} & $\bar{X}$ & $S_{x}$ & $\begin{array}{l}1(\%) \\
\text { Nada }\end{array}$ & $2(\%)$ & $\begin{array}{l}3(\%) \\
\text { Algo }\end{array}$ & $4(\%)$ & $\begin{array}{c}5(\%) \\
\text { Mucho }\end{array}$ & $N$ \\
\hline $\begin{array}{l}\text { 19. Pasar música del ordenador a } \\
\text { un MP3 }\end{array}$ & 4.71 & .756 & 1.5 & 1.5 & 5.0 & 9.0 & 83.1 & 1159 \\
\hline $\begin{array}{l}\text { 9. Ver videos en YouTube } \\
\text { 6. Navegar por internet, } \\
\text { seleccionar información, }\end{array}$ & 4.65 & .816 & 1.8 & 2.1 & 4.8 & 11.3 & 79.9 & 1155 \\
\hline
\end{tabular}




\begin{tabular}{|c|c|c|c|c|c|c|c|c|}
\hline guardarla & & & & & & & & \\
\hline $\begin{array}{l}\text { 20. Descargar la información de } \\
\text { un móvil o una cámara }\end{array}$ & 4.51 & .989 & 3.5 & 2.9 & 6.6 & 13.6 & 73.5 & 1157 \\
\hline $\begin{array}{l}\text { 11. Usar una red social (como } \\
\text { Tuenti, Facebook) }\end{array}$ & 4.47 & 1.091 & 5.3 & 3.1 & 6.0 & 10.1 & 75.5 & 1156 \\
\hline 18. Grabar un $C D$ & 4.42 & 1.012 & 3.0 & 4.0 & 8.9 & 16.3 & 67.8 & 1158 \\
\hline $\begin{array}{l}\text { 1. Recuperar, imprimir y guardar } \\
\text { información }\end{array}$ & 4.41 & .838 & 1.1 & 1.4 & 12.1 & 26.4 & 59.0 & 1157 \\
\hline 7. Utilizar buscadores & 4.37 & .936 & 1.7 & 3.6 & 10.8 & 23.6 & 60.2 & 1154 \\
\hline $\begin{array}{l}\text { 16. Descargar música de } \\
\text { programas }\end{array}$ & 4.28 & 1.148 & 5.0 & 5.2 & 10.0 & 16.0 & 63.8 & 1155 \\
\hline 17. Descargar música de un $C D$ & 4.26 & 1.148 & 5.1 & 4.9 & 10.8 & 17.1 & 62.0 & 1156 \\
\hline 14. Bajar programas de internet & 4.15 & 1.917 & 6.3 & 5.4 & 12.7 & 22.8 & 52.7 & 1154 \\
\hline $\begin{array}{l}\text { 3. Hacer presentaciones con } \\
\text { textos, imágenes... }\end{array}$ & 4.14 & .960 & 1.6 & 4.6 & 16.5 & 32.5 & 44.8 & 1143 \\
\hline 8. Parcitipar en chats, foros, blogs & 4.08 & 1.192 & 5.5 & 7.2 & 12.9 & 22.9 & 51.5 & 1152 \\
\hline 2. Instalar y arrancar programas & 4.03 & 1.055 & 2.8 & 6.1 & 18.9 & 29.2 & 43.0 & 1156 \\
\hline 21. Jugar en red con... & 3.90 & 1.299 & 8.0 & 8.4 & 16.5 & 19.5 & 47.6 & 1155 \\
\hline 13. Comentar en un blog & 3.85 & 1.316 & 9.4 & 8.4 & 13.9 & 24.7 & 43.7 & 1154 \\
\hline 12. Crear un blog & 3.47 & 1.390 & 13.7 & 11.3 & 21.0 & 22.4 & 31.5 & 1157 \\
\hline 10. Subir videos a YouTube & 3.37 & 1.527 & 19.2 & 12.0 & 17.0 & 16.5 & 35.4 & 1154 \\
\hline 5. Encontrar datos en una base & 3.31 & 1.238 & 9.4 & 16.8 & 28.2 & 24.7 & 20.8 & 1147 \\
\hline 4. Usar hojas de cálculo & 3.21 & 1.222 & 9.8 & 18.6 & 30.9 & 22.3 & 18.4 & 1155 \\
\hline 15. Comprar por internet & 2.89 & 1.513 & 28.1 & 14.0 & 20.0 & 16.0 & 21.8 & 1149 \\
\hline
\end{tabular}

*Media y desviación típica obtenidas de escala entre 1 y 5 (1=Nada; 3=Algo; 5=Mucho)

Si relacionamos estos datos con otros estudios, podemos ver, por ejemplo, cómo según el ya mencionado de la Universidad Camilo José Cela (Sánchez Burón et al., 2009), las acciones más realizadas por los jóvenes estudiantes de ESO en la red, son las relacionadas con el acceso a redes sociales, al Messenger y las descargas de contenidos multimedia, hace unos pocos años. Por otro lado, según el informe desarrollado por el mencionado IAB, sobre el empleo de las redes sociales en España, (Elogia Ipsofacto, 2009), una de las redes sociales más conocida, superada sólo por Facebook, es Youtube, con un 84\% de integración.

Tabla 4.86 Estadísticos básicos sobre el nivel de manejo de aparatos digitales diferentes del ordenador

\begin{tabular}{c|ccc|ccccc|c}
\hline $\begin{array}{c}\text { Nivel de conocimientos } \\
\text { informáticos (Ajenos al } \\
\text { ordenador) }\end{array}$ & $\bar{X}$ & $S_{x}$ & $\begin{array}{c}\mathbf{1}(\%) \\
\text { Nada }\end{array}$ & $\mathbf{2 ( \% )}$ & $\begin{array}{c}3(\%) \\
\text { Algo }\end{array}$ & $\begin{array}{c}4(\%) \\
5(\%) \\
\text { Mucho }\end{array}$ & $N$ \\
\hline Sabes escuchar un mp3 & 4.88 & .513 & .7 & .7 & 1.7 & 3.5 & 93.4 & 1159 \\
\hline
\end{tabular}




\begin{tabular}{l|cc|ccccc|c}
\hline $\begin{array}{l}\text { Sabes mandar mensajes por } \\
\text { móvil }\end{array}$ & 4.85 & .563 & .9 & .6 & 2.5 & 4.6 & 91.5 & 1159 \\
\hline Sabes grabar videos con el móvil & 4.79 & .683 & 1.3 & 1.4 & 3.2 & 4.8 & 89.3 & 1158 \\
\hline Sabes usar una cámara digital & 4.76 & .695 & 1.2 & 1.4 & 3.6 & 7.7 & 86.1 & 1159 \\
\hline $\begin{array}{l}\text { Sabes usar consolas de } \\
\text { videojuegos }\end{array}$ & 4.60 & .886 & 2.2 & 2.3 & 7.2 & 10.3 & 78.0 & 1156 \\
\hline Sabes usar PDA`s & 3.75 & 1.396 & 12.2 & 7.5 & 17.0 & 19.4 & 43.9 & 1154 \\
\hline
\end{tabular}

*Media y desviación típica obtenidas de escala entre 1 y 5 (1=Nada; 3=Algo; 5=Mucho)

La tabla 4.86 aporta información acerca del nivel de uso que alcanzan los alumnos y alumnas en el manejo de otras tecnologías digitales, como puede ser un teléfono móvil o una cámara digital. Los resultados son en todos los casos altos, exceptuando el conocimiento en el empleo de la PDA, que alcanza unos valores moderados, debido, en gran parte, a su pobre cuota de mercado, que en 2009 alcanzaba a un 5.5\% de los hogares (INE, 2009).

\subsubsection{Frecuencia en el empleo de herramientas informáticas}

La finalidad de este apartado no es otra que contrastar las diferencias existentes entre el empleo de las herramientas informáticas que realizan los alumnos de Educación Secundaria dentro y fuera del instituto. Para ello se aplican 12 ítems que expresan actividades concretas en el manejo del ordenador. Los sujetos de la muestra responden acerca de la frecuencia con la que las realizaban tanto dentro como fuera del centro escolar. La escala empleada en esta ocasión, para facilitar la elección a los encuestados, se mueve entre 1 y 3 , correspondiendo 1 a un empleo nulo o casi inexistente, 2 a un empleo moderado (semanalmente, más de una vez al mes) y 3 alto (casi todos los días o varias veces por semana).

La tabla 4.87 nos muestra la frecuencia en el manejo del ordenador dentro del instituto. Ésta es en general muy baja, rondando la media entre 1 y 2. Comparando estos datos con los obtenidos en otros estudios, podemos observar que existen coincidencias; según el informe del IN3 (Sigalés et al., 2009), un 41.1\% de los alumnos afirma manejar el ordenador en el aula nunca u ocasionalmente, un 53.9\% entre mensual y semanalmente y sólo un $4.9 \%$ afirma hacerlo diariamente.

Tabla 4.87 Estadísticos básicos sobre la frecuencia en el manejo del ordenador dentro del instituto

\begin{tabular}{l|c|c|ccc|c}
\hline $\begin{array}{l}\text { Frecuencia en el manejo del ordenador en } \\
\text { el centro }\end{array}$ & $\bar{X}$ & $\boldsymbol{S}_{\boldsymbol{x}}$ & $\begin{array}{c}\mathbf{1}(\%) \\
\text { Nula }\end{array}$ & $\begin{array}{c}\mathbf{2} \text { (\%) } \\
\text { Media }\end{array}$ & $\begin{array}{c}3 \mathbf{3}(\%) \\
\text { alta }\end{array}$ & $\boldsymbol{N}$ \\
\hline $\begin{array}{l}\text { 3. Navegar por internet para buscar } \\
\text { información }\end{array}$ & 1.98 & .810 & 33.9 & 34.4 & 31.7 & 1160 \\
\hline
\end{tabular}




\begin{tabular}{|c|c|c|c|c|c|c|}
\hline $\begin{array}{l}\text { 12. Utilizar programas de ordenador para } \\
\text { aprender }\end{array}$ & 1.94 & .771 & 32.8 & 40.2 & 27.0 & 1164 \\
\hline 2. Usar el ordenador para realizar tareas & 1.86 & .772 & 37.4 & 38.7 & 23.9 & 1168 \\
\hline $\begin{array}{l}\text { 1. Usar un procesador de texto para escribir, } \\
\text { hacer trabajos... }\end{array}$ & 1.85 & .755 & 37.1 & 40.8 & 22.0 & 1166 \\
\hline $\begin{array}{l}\text { 4. Usar una hoja de cálculo para hacer } \\
\text { actividades }\end{array}$ & 1.54 & .694 & 57.6 & 30.7 & 11.6 & 1152 \\
\hline 10. Utilizar el ordenador para programar & 1.48 & .665 & 61.7 & 28.7 & 9.6 & 1158 \\
\hline $\begin{array}{l}\text { 5. Escribir mensajes de correo, participar en } \\
\text { chats, ... }\end{array}$ & 1.46 & .748 & 69.3 & 15.2 & 15.5 & 1160 \\
\hline 7. Jugar con el ordenador & 1.46 & .706 & 66.7 & 20.8 & 12.5 & 1162 \\
\hline 9. Descargar programas a través de internet & 1.45 & .714 & 67.7 & 19.2 & 13.0 & 1165 \\
\hline $\begin{array}{l}\text { 6. Usar programas de ordenador para } \\
\text { dibujar pintar }\end{array}$ & 1.44 & .661 & 65.8 & 24.6 & 9.5 & 1165 \\
\hline 8. Descargar música a través de internet & 1.39 & .724 & 75.7 & 10.0 & 14.3 & 1165 \\
\hline $\begin{array}{l}\text { 11. Colaborar con un grupo o un equipo a } \\
\text { través de internet }\end{array}$ & 1.35 & .605 & 72.3 & 20.8 & 7.0 & 1165 \\
\hline
\end{tabular}

*Media y desviación típica obtenidas de escala entre 1 y 3 (1=Nula; 2=Media; 3=Alta)

En cuanto a los resultados concretos, este mismo informe del IN3 también nos aporta datos interesantes, como que el $85.5 \%$ de los encuestados afirma haber empleado el ordenador en el aula para realizar búsquedas, lo cual concuerda con el dato de que "navegar por internet para buscar información" es el ítem con una mayor media, o como que sólo el $34.4 \%$ afirma haber empleado internet para trabajar colaborativamente, lo cual casa también con nuestro dato de que "colaborar con un grupo o un equipo a través de internet" es el ítem con una menor media.

Tabla 4.88 Estadísticos básicos sobre la frecuencia en el manejo del ordenador fuera del instituto

\begin{tabular}{|c|c|c|c|c|c|c|}
\hline $\begin{array}{l}\text { Frecuencia en el manejo del ordenador } \\
\text { fuera del centro }\end{array}$ & $\bar{X}$ & $s_{x}$ & $\begin{array}{l}1(\%) \\
\text { Nula }\end{array}$ & $\begin{array}{l}2(\%) \\
\text { Media }\end{array}$ & $\begin{array}{l}3(\%) \\
\text { alta }\end{array}$ & $N$ \\
\hline $\begin{array}{l}\text { 3. Navegar por internet para buscar } \\
\text { información }\end{array}$ & 2.59 & .621 & 7.2 & 26.2 & 66.6 & 1165 \\
\hline 8. Descargar música a través de internet & 2.55 & .702 & 12.3 & 20.2 & 67.5 & 1164 \\
\hline $\begin{array}{l}\text { 5. Escribir mensajes de correo, participar en } \\
\text { chats,... }\end{array}$ & 2.49 & .721 & 13.5 & 24.0 & 62.5 & 1158 \\
\hline 9. Descargar programas a través de internet & 2.36 & .762 & 17.5 & 28.7 & 53.8 & 1156 \\
\hline 7. Jugar con el ordenador & 2.25 & .775 & 20.5 & 33.5 & 46.0 & 1165 \\
\hline 2. Usar el ordenador para realizar tareas & 2.21 & .708 & 16.7 & 45.6 & 37.7 & 1165 \\
\hline $\begin{array}{l}\text { 1. Usar un procesador de texto para escribir, } \\
\text { hacer trabajos... }\end{array}$ & 2.19 & .659 & 13.9 & 53.0 & 33.2 & 1167 \\
\hline 12. Utilizar programas de ordenador para & 1.83 & .756 & 38.2 & 40.2 & 21.6 & 1161 \\
\hline
\end{tabular}




\begin{tabular}{|c|c|c|c|c|c|c|}
\hline aprender & & & & & & \\
\hline 10. Utilizar el ordenador para programar & 1.81 & .769 & 41.2 & 37.1 & 21.7 & 1146 \\
\hline $\begin{array}{l}\text { 6. Usar programas de ordenador para } \\
\text { dibujar pintar }\end{array}$ & 1.76 & .778 & 45.2 & 33.8 & 21.0 & 1164 \\
\hline $\begin{array}{l}\text { 11. Colaborar con un grupo o un equipo a } \\
\text { través de internet }\end{array}$ & 1.60 & .758 & 56.4 & 26.9 & 16.7 & 1155 \\
\hline $\begin{array}{l}\text { 4. Usar una hoja de cálculo para hacer } \\
\text { actividades }\end{array}$ & 1.55 & 699 & 56.8 & 31.2 & 12.0 & 1164 \\
\hline
\end{tabular}

*Media y desviación típica obtenidas de escala entre 1 y 3 (1=Nula; 2=Media; 3=Alta)

Como se puede observar en la tabla 4.88, los alumnos emplean el ordenador en el hogar frecuentemente para ciertas actividades como son buscar información, descargar música y programas, escribir mensajes y jugar. Nuevamente las similitudes son palpables con el informe referido anteriormente (Sigalés et al., 2009). Según dicha investigación, las tres actividades que más habitualmente realizan los alumnos con el ordenador fuera del aula son "Comunicar con los amigos y la familia", "Descargar música, películas, juegos u otros programas" y "Buscar información sobre temas que me interesan".

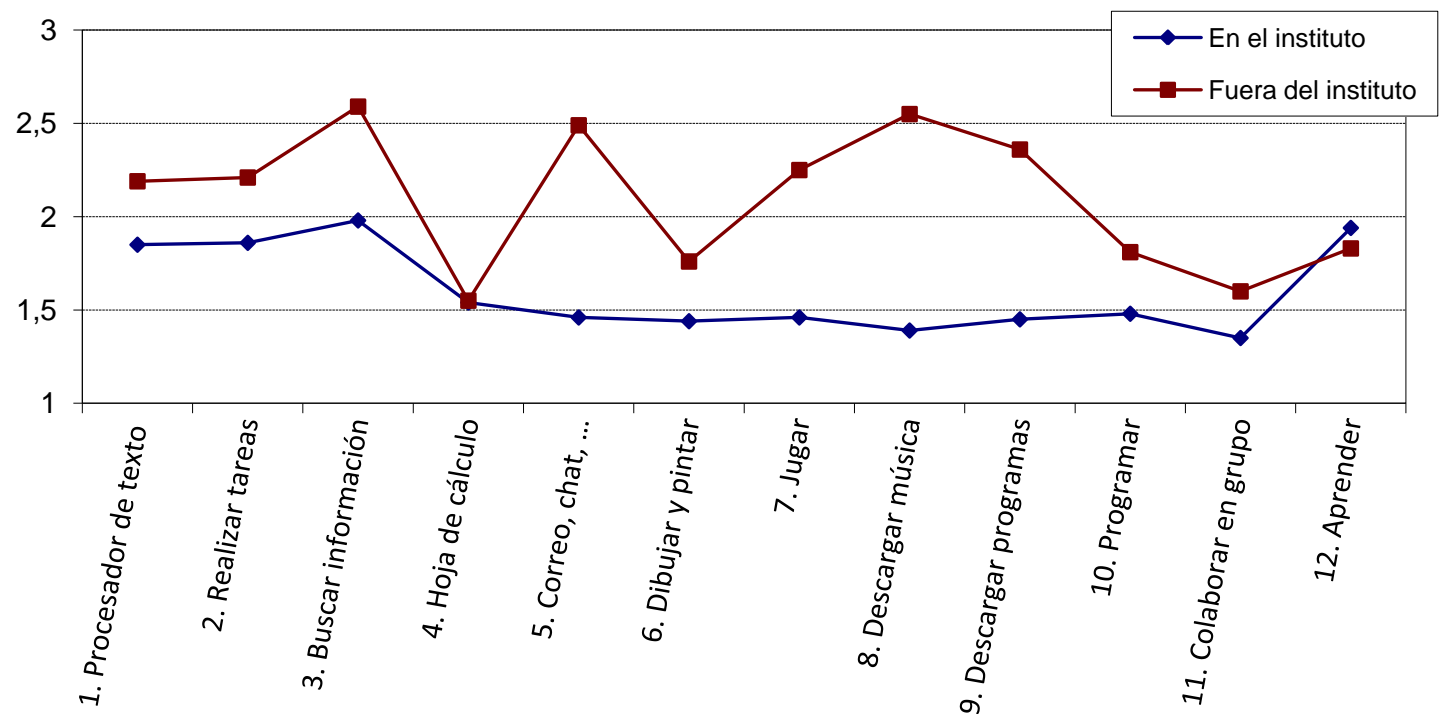

*Media y desviación típica obtenidas de escala entre 1 y 3 (1=Nula; 2=Media; 3=Alta)

Gráfico 4.5 Diferencias entre el empleo del ordenador dentro y fuera del aula

En el gráfico 4.5 podemos observar las diferencias anteriormente comentadas, que son en general bastante amplias, con excepción de actividades específicas y técnicas, como emplear una hoja de cálculo. Así, las diferencias obtenidas en 2009 son menores en actividades que podríamos denominar como más académicas, que en las actividades de ocio, aunque siguen favoreciendo al uso fuera del instituto. Mientras 
que las mayores diferencias se registran en actividades como descargar música y programas, utilizar el chat o jugar, en otras menos vinculadas al ocio como colaborar en grupo, programar, usar un procesador de textos, realizar tareas o buscar información estas diferencias se acercan, tanto por la disminución de su frecuencia en casa como por el aumento (aunque muy ligero) de su empleo en el instituto.

Esta tendencia no sorprende si hacemos caso al hecho de que la frecuencia en el empleo del ordenador y de actividades relacionadas con internet era mucho mayor en el propio hogar que en el instituto ya fuera dentro del propio aula o fuera del horario escolar.

Si procedemos al cálculo de los intervalos poblacionales para cada uno de los ítems tanto en casa como en el instituto, como se indica en la tabla 4.89, se pueden observar para la mayor parte de ítems diferencias significativas favorables al empleo en el hogar.

Tabla 4.89 Intervalos poblacionales para el manejo del ordenador en el aula y en el hogar

\begin{tabular}{|c|c|c|c|c|c|c|c|c|}
\hline $\begin{array}{l}\text { Frecuencia en el manejo del } \\
\text { ordenador }\end{array}$ & $\begin{array}{c}\bar{X} \\
\text { aula }\end{array}$ & $\begin{array}{c}\bar{X} \\
\text { hogar }\end{array}$ & \multicolumn{2}{|c|}{ Intervalo aula } & \multicolumn{2}{|c|}{ Intervalo hogar } & $t$ & p. \\
\hline $\begin{array}{l}\text { 1. Usar un procesador de texto } \\
\text { para escribir, hacer trabajos... }\end{array}$ & 1.85 & 2.19 & 1.79 & 1.91 & 2.14 & 2.24 & -12.9 & $<.001$ \\
\hline $\begin{array}{l}\text { 2. Usar el ordenador para realizar } \\
\text { tareas }\end{array}$ & 1.86 & 2.21 & 1.81 & 1.92 & 2.16 & 2.26 & -12.7 & $<.001$ \\
\hline $\begin{array}{l}\text { 3. Navegar por internet para } \\
\text { buscar información }\end{array}$ & 1.98 & 2.59 & 1.92 & 2.04 & 2.55 & 2.64 & -21.3 & $<.001$ \\
\hline $\begin{array}{l}\text { 4. Usar una hoja de cálculo para } \\
\text { hacer actividades }\end{array}$ & 1.54 & 1.55 & 1.49 & 1.59 & 1.50 & 1.61 & -0.39 & .699 \\
\hline $\begin{array}{l}\text { 5. Escribir mensajes de correo, } \\
\text { participar en chats, ... }\end{array}$ & 1.46 & 2.49 & 1.41 & 1.52 & 2.44 & 2.55 & -34.3 & $<.001$ \\
\hline $\begin{array}{l}\text { 6. Usar programas de ordenador } \\
\text { para dibujar pintar }\end{array}$ & 1.44 & 1.76 & 1.39 & 1.49 & 1.70 & 1.82 & -13.3 & $<.001$ \\
\hline 7. Jugar con el ordenador & 1.46 & 2.25 & 1.40 & 1.51 & 2.20 & 2.31 & -29.7 & $<.001$ \\
\hline $\begin{array}{l}\text { 8. Descargar música a través de } \\
\text { internet }\end{array}$ & 1.39 & 2.55 & 1.33 & 1.44 & 2.50 & 2.61 & -39.6 & $<.001$ \\
\hline $\begin{array}{l}\text { 9. Descargar programas a través } \\
\text { de internet }\end{array}$ & 1.45 & 2.36 & 1.40 & 1.51 & 2.31 & 2.42 & -32.6 & $<.001$ \\
\hline $\begin{array}{l}\text { 10. Utilizar el ordenador para } \\
\text { programar }\end{array}$ & 1.48 & 1.81 & 1.43 & 1.53 & 1.75 & 1.86 & -12.3 & $<.001$ \\
\hline $\begin{array}{l}\text { 11. Colaborar con un grupo o un } \\
\text { equipo a través de internet }\end{array}$ & 1.35 & 1.60 & 1.30 & 1.39 & 1.55 & 1.66 & -10.6 & $<.001$ \\
\hline 12. Utilizar programas de & 1.94 & 1.83 & 1.89 & 2.00 & 1.78 & 1.88 & 3.7 & $<.001$ \\
\hline
\end{tabular}




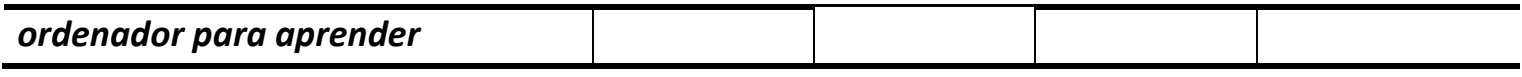

$*$ Nivel de significación $\alpha=.01$

Existe pues, un ítem en el que no existen diferencias significativas. Sin embargo, se refiere a actividades académicas, más propias del ámbito del aula. En otros casos, en actividades también vinculadas con actividades propias del instituto como emplear el procesador de textos, usar el ordenador para realizar tareas, navegar por internet para buscar información o colaborar con un grupo o equipo a través de internet, sí se observan diferencias significativas, aunque son favorables al hogar. El único ítem en el que se registran diferencias favorables al aula es en Utilizar programas de ordenador para aprender. A pesar de la clara alusión a la finalidad educativa del empleo del ordenador, vemos cómo los intervalos de confianza de las medias de ambas variables son muy cercanos entre sí, por lo que las diferencias son pequeñas.

\subsubsection{Competencias informacionales en estudiantes}

En este apartado se desarrolla la parte principal del estudio, consistente en analizar qué competencias relacionadas con el manejo y gestión de la información dominan los alumnos, en qué nivel, qué cota de importancia conceden a su dominio, y cuál ha sido la principal fuente de aprendizaje de las mismas. El instrumento empleado para la recogida de datos es la adaptación a la muestra de una encuesta elaborada por María Pinto (2009).

\subsubsection{Importancia y nivel de conocimientos percibidos sobre las competencias informacionales}

En este apartado se les pregunta a los discentes sobre 24 ítems relacionados con las competencias informacionales. Los sujetos responden a cada ítem, en una escala de 1 a 9 (siendo 1 muy baja y 9 muy alta), sobre el nivel de importancia que creen que tiene para su proceso de formación y el nivel de conocimiento que declaran poseer en estos momentos acerca del mismo.

Los resultados se muestran en las tablas 4.90 (Importancia que conceden los alumnos a las competencias informacionales) y 4.91 (Nivel de conocimientos que poseen los alumnos acerca de las competencias informacionales). Los ítems se reparten a lo largo de cada una de las 4 dimensiones teóricas confirmadas en el análisis factorial del siguiente modo: 
- Búsqueda de información: ítems del 1 al 7. Se debe de tener en cuenta que en cuanto a los ítems relacionados con la Búsqueda de información, tras el análisis individual de las cualidades psicométricas de los mismos, se decidió eliminar el ítem 6.

- Evaluación de información: ítems del 8 al 12.

- Procesamiento de información: ítems del 13 al 18.

- Comunicación y difusión de información: ítems del 19 al 24.

Los ítems se han ordenado en las tablas en función de la media de cada uno, estando en primer lugar los ítems con una media mayor, y en último lugar los que tienen una media menor. 
Tabla 4.90 Descriptivos básicos sobre la importancia que conceden los alumnos a las competencias informacionales. Alumnos

\begin{tabular}{|c|c|c|c|c|c|c|c|c|c|c|c|c|}
\hline Competencias informacionales (Importancia concedida) & $\bar{X}$ & $S_{x}$ & $1(\%)$ & $2(\%)$ & $3(\%)$ & $4(\%)$ & $5(\%)$ & $6(\%)$ & $7(\%)$ & $8(\%)$ & $9(\%)$ & $N$ \\
\hline 5. Buscar y obtener información en internet & 7.84 & 1.468 & 0.5 & 0.4 & 0.9 & 1.8 & 4.8 & 6.5 & 12.7 & 30.1 & 42.1 & 1161 \\
\hline 13. Extraer la información que realmente necesitas & 7.50 & 1.665 & 0.9 & 0.7 & 1.5 & 3.3 & 5.9 & 10.1 & 16.2 & 26.4 & 35.1 & 1152 \\
\hline 16. Descargar programas a través de internet & 7.31 & 1.805 & 1.3 & 1.2 & 2.4 & 3.2 & 6.8 & 10.3 & 19.2 & 23.2 & 32.4 & 1153 \\
\hline 21. Escribir un documento (trabajo de clase, ...) & 7.21 & 1.766 & 1.2 & 1.0 & 1.8 & 4.3 & 7.8 & 11.1 & 20.5 & 24.0 & 28.3 & 1163 \\
\hline 18. Instalar programas informáticos & 7.06 & 1.940 & 1.8 & 2.1 & 2.6 & 4.5 & 7.9 & 11.6 & 18.6 & 23.0 & 27.9 & 1159 \\
\hline 4. Conocer los conceptos de las asignaturas & 6.84 & 1.938 & 2.4 & 1.4 & 3.2 & 4.0 & 11.3 & 13.7 & 19.3 & 22.8 & 21.9 & 1159 \\
\hline 23. Elaborar presentaciones académicas (power point) & 6.81 & 1.984 & 2.8 & 1.6 & 3.0 & 4.8 & 9.8 & 13.7 & 20.7 & 21.1 & 22.4 & 1159 \\
\hline 7. Conocer las estrategias de búsqueda de información & 6.74 & 1.819 & 1.5 & 1.7 & 2.8 & 4.7 & 11.3 & 16.5 & 23.1 & 20.5 & 17.9 & 1159 \\
\hline 20. Comunicar en otras lenguas (inglés...) & 6.73 & 2.370 & 5.4 & 2.8 & 4.1 & 5.4 & 9.1 & 9.3 & 14.4 & 18.7 & 30.7 & 1161 \\
\hline 19. Comunicar en público & 6.53 & 2.036 & 3.3 & 1.8 & 3.0 & 6.9 & 12.9 & 15.8 & 19.8 & 17.2 & 19.4 & 1147 \\
\hline 24. Divulgar informaciones en internet (webs, blogs, ...) & 6.43 & 2.142 & 4.1 & 2.5 & 4.3 & 5.9 & 11.5 & 16.7 & 18.8 & 17.0 & 19.2 & 1150 \\
\hline 14. Reconocer las partes en las que se divide un texto & 6.38 & 1.985 & 2.5 & 1.9 & 4.9 & 7.2 & 14.7 & 14.8 & 20.3 & 19.2 & 14.4 & 1157 \\
\hline 11. Determinar si una fuente de información está actualizada & 6.19 & 2.157 & 4.9 & 3.1 & 4.6 & 7.1 & 12.9 & 16.5 & 19.4 & 17.8 & 13.7 & 1145 \\
\hline 8. Evaluar la calidad de recursos de información & 6.17 & 1.925 & 2.8 & 2.5 & 4.1 & 7.6 & 16.3 & 18.8 & 22.3 & 14.6 & 11.0 & 1138 \\
\hline 1. Leer libros, artículos en formato impreso & 6.14 & 2.097 & 3.6 & 3.2 & 5.0 & 8.3 & 16.1 & 15.5 & 19.2 & 14.9 & 14.3 & 1171 \\
\hline 9. Reconocer la idea de un autor en un texto. & 5.97 & 2.154 & 4.8 & 4.1 & 4.6 & 9.1 & 15.2 & 16.5 & 19.0 & 14.9 & 11.8 & 1159 \\
\hline 17. Usar hojas de cálculo para hacer actividades & 5.95 & 2.189 & 5.9 & 3.0 & 6.8 & 7.4 & 13.0 & 17.2 & 19.8 & 16.3 & 10.6 & 1150 \\
\hline 3. Consular y usar bases de datos & 5.89 & 2.073 & 4.4 & 2.9 & 6.5 & 8.4 & 17.9 & 15.6 & 20.4 & 14.4 & 9.4 & 1155 \\
\hline 22. Conocer las leyes sobre el uso de información y propiedad intelectual & 5.89 & 2.198 & 6.4 & 3.2 & 5.3 & 7.6 & 17.2 & 15.2 & 20.0 & 13.5 & 11.5 & 1138 \\
\hline 12. Conocer los autores e instituciones más relevantes de tu área temática. & 5.78 & 2.088 & 5.5 & 3.6 & 4.3 & 10.3 & 17.6 & 17.5 & 19.7 & 13.2 & 8.4 & 1144 \\
\hline 10. Conocer la tipología de las fuentes de información científicas & 5.63 & 2.104 & 6.5 & 3.2 & 6.5 & 9.4 & 18.0 & 17.3 & 20.2 & 12.5 & 6.5 & 1131 \\
\hline 15. Utilizar gestores de bases de datos & 5.56 & 2.120 & 6.9 & 3.8 & 6.3 & 8.6 & 19.3 & 18.8 & 18.8 & 10.5 & 7.1 & 1119 \\
\hline 2. Acceder y usar catálogos a través de internet & 5.40 & 2.139 & 6.8 & 4.8 & 7.7 & 10.7 & 18.0 & 19.2 & 16.7 & 9.0 & 7.0 & 1164 \\
\hline
\end{tabular}

* Media y desviación típica obtenidas de escala entre 1 y 9 (1=Muy baja; 3=Baja; 5=Media; 7=Alta; 9=Muy alta) 
Como se puede observar en la tabla 4.90, los sujetos conceden una importancia media-alta a todas las competencias informacionales presentadas, considerando las más importantes $(\bar{X}>7)$ las relacionadas principalmente con habilidades genéricas de manejo de herramientas informáticas que los alumnos y alumnas, a priori, utilizan más frecuentemente (saber buscar información relevante en internet, descargar e instalar programas y escribir un documento). Es en parte lógico que la competencia "Buscar y obtener información de internet" sea la valorada como más importante, teniendo en cuenta que según un estudio de la Universidad de Washington (Head \& Eisenberg, 2009), cuando a los alumnos se les presentan en su vida diaria problemas que les exigen buscar información, más de un $90 \%$ de los sujetos suele acudir a Google y Wikipedia; por otro lado, cuando estos problemas son académicos, estos porcentajes siguen estando entre el 85 y el $95 \%$.

Por otro lado, los alumnos conceden la menor importancia $(\bar{X}<6)$ a competencias más específicas relacionadas con conocimientos informáticos especializados (empleo de hojas de cálculo, bases de datos y gestores de bases de datos, acceso a catálogos, conocimiento de las fuentes más relevantes en un área temática y tener en cuenta la tipología de la fuente de información). Así mismo, se puede observar una tendencia a valorar más bajo la importancia de las sub-competencias relacionadas con la categoría "Evaluación de información", y algo más altas las sub-competencias relacionadas con el "Procesamiento de información".

Estos resultados nos sugieren que quizás los sujetos asignen una mayor importancia a las competencias que mejor dominan, y que el hecho de considerar menos importantes otras, se debe más al propio desconocimiento de lo relacionado con la competencia (Por ejemplo, qué es una base de datos y para qué se puede utilizar) que al convencimiento personal de su escasa importancia formativa.

Por otro lado, en la tabla 4.91 se presentan los resultados sobre el nivel de competencias informacionales que afirman alcanzar los alumnos y alumnas. Al tratarse de un nivel autopercibido, debemos ser cautelosos en las afirmaciones y generalizaciones vertidas. 
Tabla 4.91 Estadísticos básicos sobre el nivel de conocimientos autopercibidos en competencias informacionales. Alumnos

\begin{tabular}{|c|c|c|c|c|c|c|c|c|c|c|c|c|}
\hline Competencias informacionales (nivel autopercibido) & $\overline{\boldsymbol{X}}$ & $S_{x}$ & 1 (\%) & $2(\%)$ & $3(\%)$ & $4(\%)$ & $5(\%)$ & $6(\%)$ & $7(\%)$ & $8(\%)$ & $9(\%)$ & $N$ \\
\hline 5. Buscar y obtener información en internet & 7.84 & 1.483 & 0.5 & 0.4 & 1.0 & 2.1 & 4.1 & 6.7 & 14.3 & 26.8 & 44.0 & 1152 \\
\hline 16. Descargar programas a través de internet & 7.25 & 2.028 & 2.8 & 1.7 & 2.2 & 3.6 & 7.9 & 9.0 & 14.9 & 21.5 & 36.5 & 1146 \\
\hline 21. Escribir un documento (trabajo de clase, ...) & 7.20 & 1.711 & 1.0 & 0.9 & 1.7 & 2.9 & 10.1 & 12.0 & 19.0 & 26.3 & 26.1 & 1154 \\
\hline 13. Extraer la información que realmente necesitas & 7.13 & 1.683 & 0.7 & 1.0 & 1.9 & 3.7 & 9.6 & 12.4 & 22.4 & 24.0 & 24.3 & 1145 \\
\hline 23. Elaborar presentaciones académicas (power point) & 6.94 & 2.019 & 2.9 & 1.6 & 3.0 & 3.8 & 10.1 & 11.2 & 19.7 & 20.6 & 27.1 & 1158 \\
\hline 18. Instalar programas informáticos & 6.59 & 2.217 & 3.6 & 2.8 & 4.8 & 6.6 & 10.6 & 13.1 & 15.9 & 18.0 & 24.7 & 1154 \\
\hline 4. Conocer los conceptos de las asignaturas & 6.56 & 2.948 & 1.8 & 1.4 & 2.3 & 3.9 & 15.6 & 19.4 & 26.4 & 19.3 & 9.7 & 1142 \\
\hline 14. Reconocer las partes en las que se divide un texto & 6.47 & 1.843 & 1.2 & 2.1 & 4.2 & 5.7 & 15.2 & 17.5 & 21.3 & 18.9 & 13.9 & 1148 \\
\hline 1. Leer libros, artículos en formato impreso & 6.44 & 1.904 & 2.0 & 2.3 & 3.4 & 5.8 & 15.8 & 16.9 & 21.7 & 17.0 & 15.1 & 1158 \\
\hline 24. Divulgar informaciones en internet (webs, blogs, ...) & 6.42 & 2.275 & 5.0 & 3.0 & 4.2 & 7.3 & 11.6 & 12.3 & 17.8 & 16.9 & 22.0 & 1149 \\
\hline 7. Conocer las estrategias de búsqueda de información & 6.38 & 1.865 & 1.6 & 2.1 & 4.3 & 6.6 & 15.7 & 16.5 & 23.9 & 15.7 & 13.6 & 1150 \\
\hline 19. Comunicar en público & 6.04 & 2.099 & 3.8 & 3.4 & 5.5 & 8.1 & 15.9 & 17.7 & 18.8 & 13.4 & 13.4 & 1137 \\
\hline 17. Usar hojas de cálculo para hacer actividades & 5.91 & 2.200 & 5.4 & 3.5 & 6.5 & 8.6 & 14.6 & 16.7 & 18.2 & 14.1 & 12.4 & 1147 \\
\hline 8. Evaluar la calidad de recursos de información & 5.85 & 2.027 & 2.7 & 2.9 & 4.4 & 9.7 & 21.2 & 21.0 & 21.4 & 10.2 & 6.3 & 1122 \\
\hline 11. Determinar si una fuente de información está actualizada & 5.83 & 2.091 & 4.7 & 4.1 & 5.6 & 8.5 & 15.3 & 21.2 & 17.9 & 13.2 & 9.4 & 1139 \\
\hline 20. Comunicar en otras lenguas (inglés...) & 5.82 & 2.236 & 6.4 & 4.0 & 5.5 & 9.1 & 15.7 & 15.4 & 18.2 & 14.5 & 11.1 & 1150 \\
\hline 2. Acceder y usar catálogos a través de internet & 5.70 & 2.257 & 6.7 & 4.5 & 7.7 & 8.1 & 14.8 & 16.8 & 17.5 & 14.0 & 9.9 & 1153 \\
\hline 9. Reconocer la idea de un autor en un texto. & 5.68 & 2.020 & 4.3 & 3.2 & 8.1 & 9.2 & 18.4 & 20.0 & 18.0 & 11.1 & 7.7 & 1149 \\
\hline 3. Consular y usar bases de datos & 5.54 & 2.208 & 7.6 & 3.6 & 7.4 & 10.4 & 16.3 & 16.9 & 17.5 & 12.7 & 7.5 & 1141 \\
\hline 12. Conocer los autores e instituciones más relevantes de tu área temática. & 5.37 & 1.980 & 5.1 & 5.3 & 6.5 & 11.7 & 21.5 & 19.9 & 16.6 & 8.9 & 4.5 & 1135 \\
\hline 22. Conocer las leyes sobre el uso de información y propiedad intelectual & 5.25 & 2.111 & 7.7 & 4.3 & 8.2 & 11.2 & 21.3 & 18.2 & 15.4 & 7.7 & 6.0 & 1127 \\
\hline 10. Conocer la tipología de las fuentes de información científicas & 5.14 & 2.230 & 7.5 & 5.4 & 7.7 & 11.8 & 22.8 & 19.6 & 14.8 & 6.1 & 4.3 & 1123 \\
\hline 15. Utilizar gestores de bases de datos & 5.04 & 2.190 & 9.4 & 5.7 & 9.4 & 11.9 & 21.0 & 16.0 & 13.2 & 7.9 & 5.6 & 1112 \\
\hline
\end{tabular}

* Media y desviación típica obtenidas de escala entre 1 y 9 (1=Muy baja; 3=Baja; 5=Media; 7=Alta; 9=Muy alta) 
Los sujetos consideran tener un nivel de conocimientos medio-alto en todas las competencias informacionales presentadas. Así mismo, declaran tener unos conocimientos elevados $(\bar{X}>7)$ en prácticamente las mismas competencias en las que señalaban que tenían una importancia alta (saber buscar información relevante en internet, descargar programas y escribir un documento). Además, son los ítems de respuesta más homogénea.

Por otro lado, también coinciden en buena medida las competencias a las que los alumnos conceden la menor importancia con las que afirman dominar menos. Por ejemplo, podemos encontrar en este grupo "Utilizar gestores de bases de datos" $(\bar{X}=5.04)$, "Conocer la tipología de las fuentes de información científicas" ( $\bar{X}=5.14)$, "Consultar y usar bases de datos" ( $\bar{X}=5.54)$ o "Conocer los autores e instituciones más relevantes de tu área temática" ( $\bar{X}=5.37)$.

Estas coincidencias en los resultados siguen alimentando la tesis de que las competencias que mejor dominan los sujetos son las que consideran, por lógica, más importantes, ya que conocen qué beneficios puede reportarles dicha competencia. Sin embargo, es complicado entender las ventajas que puede ofrecer el dominio de competencias que desconocen, o que conocen en menor medida. Nuevamente se puede observar cómo los alumnos afirman que las competencias que menos dominan son las relacionadas con la evaluación de información.

Podemos complementar estos datos con los obtenidos en otro estudio (Sigalés et al., 2009), en el cual se indica que la mayor parte de los alumnos es capaz de crear un documento de texto (78.8\%) y de instalar/desinstalar programas (71\%), mientras que sólo aproximadamente un tercio de los encuestados (32.2\%) se reconoció capaz de crear una base de datos. Por otro lado, existen otros datos que aportan coherencia a los resultados obtenidos, como son los relativos a las habilidades del alumnado en el uso de internet; mientras que los alumnos encuestados en el citado informe afirman tener altas habilidades en la búsqueda de información (91.8\%) y en la descarga de archivos (77.5\%), señalan también tener una habilidad más baja en lo que se refiere a publicar contenidos en internet (36.9\%).

El gráfico 4.6, mostrado a continuación, hace un análisis comparativo de las medias de cada uno de los ítems en función de la importancia asignada y el nivel autopercibido en cuanto a las competencias informacionales. 


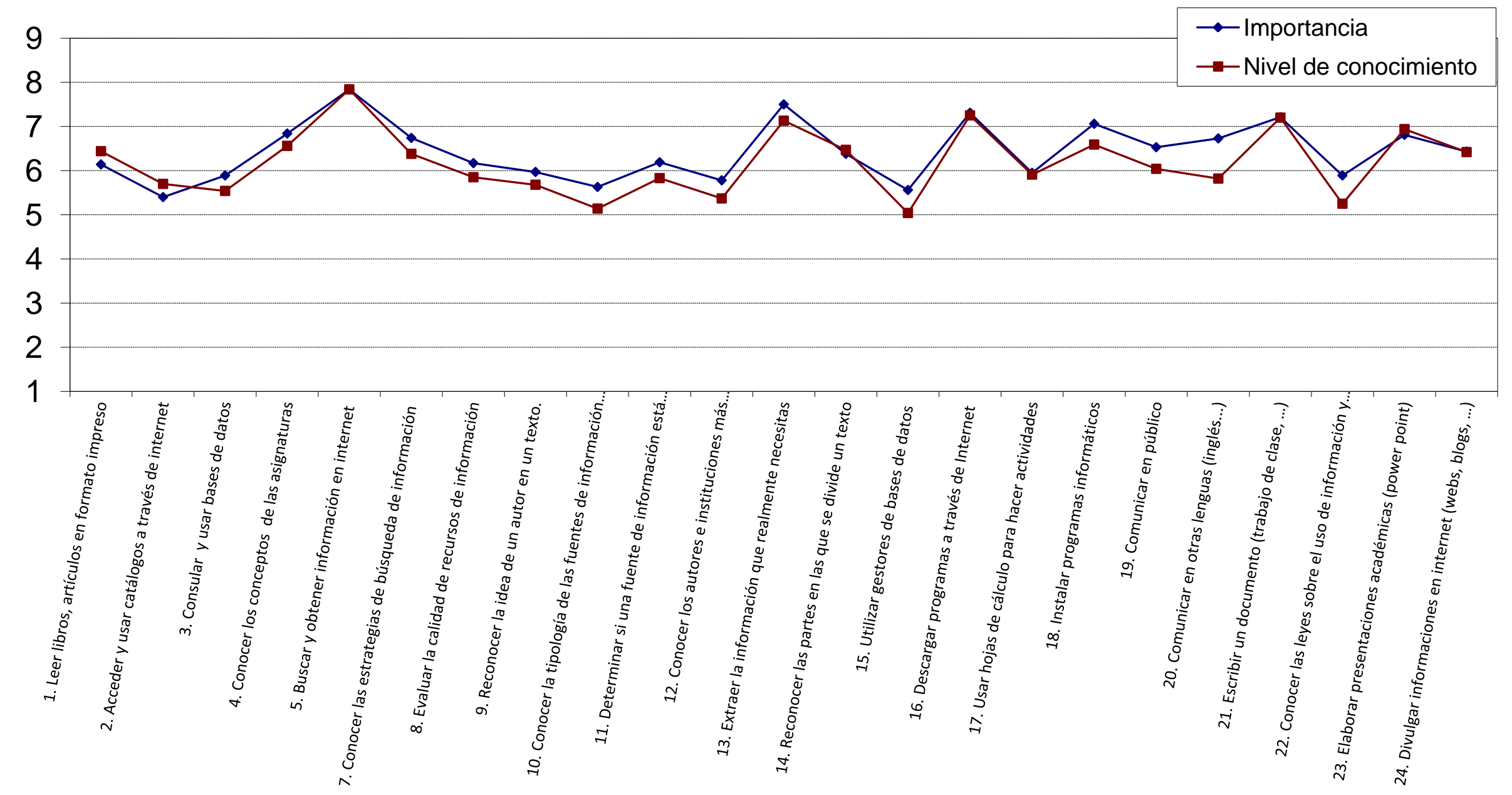

* Media y desviación típica obtenidas de escala entre 1 y 9 (1=Muy baja; 3=Baja; 5=Media; 7=Alta; 9=Muy alta)

Gráfico 4.6 Diferencias en la percepción de la importancia y el nivel de conocimientos de las competencias informacionales. Alumnos 
Analizando las diferencias entre el nivel de conocimientos y la importancia asignada a las competencias informacionales (gráfico 4.6), se puede observar cómo éstas son en casi todos los ítems mínimas, y que, en la mayoría de los casos, el valor de la media de la importancia asignada es ligeramente superior al valor de la media del nivel de conocimientos. Estos resultados coinciden con los obtenidos en otros estudios similares (Pinto Molina \& Puertas Valdeiglesias, 2012). Los resultados sugieren que los sujetos encuestados consideran que deberían tener un nivel de conocimientos superior en lo que respecta a las cuatro dimensiones básicas de las que se componen las competencias informacionales.

Si analizamos algún caso en concreto, se puede señalar que la mayor diferencia registrada se encuentra en el ítem "Comunicar en otras lenguas" ( $\bar{X}_{1}-\bar{X}_{2}=0.91$ ). Esto se podría interpretar en el sentido de que los alumnos son conscientes de su bajo nivel en cuanto al dominio de los idiomas, a pesar de su importancia para el futuro profesional.

\subsubsection{Competencias informacionales: análisis de dimensiones}

Una vez analizados los ítems por separado, podemos llevar a cabo el estudio de las dimensiones del cuestionario tanto en lo que se refiere a la importancia asignada a las competencias informacionales, como en lo que respecta al nivel autopercibido en las mismas.

Estas dimensiones serán las que ejercerán de variables criterio (latentes) en adelante. Así, se estudiará su comportamiento en función de algunos grupos principales que actuarán de variables predictoras, como pueden ser el sexo, el tipo de centro, el nivel en el manejo de herramientas informáticas o el nivel de estudios de los padres. Por ello, con la intención de definir el empleo de las técnicas más adecuadas (paramétricas o no paraméticas), comenzaremos con una exploración de las características de sus funciones de densidad.

\section{a) Importancia concedida a las dimensiones}

En primer lugar, podemos observar a continuación las gráficas que muestran las cuatro funciones de densidad de la importancia asignada a cada una de las dimensiones de las competencias informacionales.

En los cuatro casos se aprecian curvas asimétricas, en las que existe una tendencia al alza en las puntuaciones. Por otro lado, se aprecia de manera más leve cómo el 
grueso de las puntuaciones está acumulado en un rango de valores bajo. Así, analizando simplemente las gráficas, estaríamos en condiciones de afirmar que las variables analizadas van a devolver valores con una asimetría negativa y una ligera curtosis leptocúrtica.

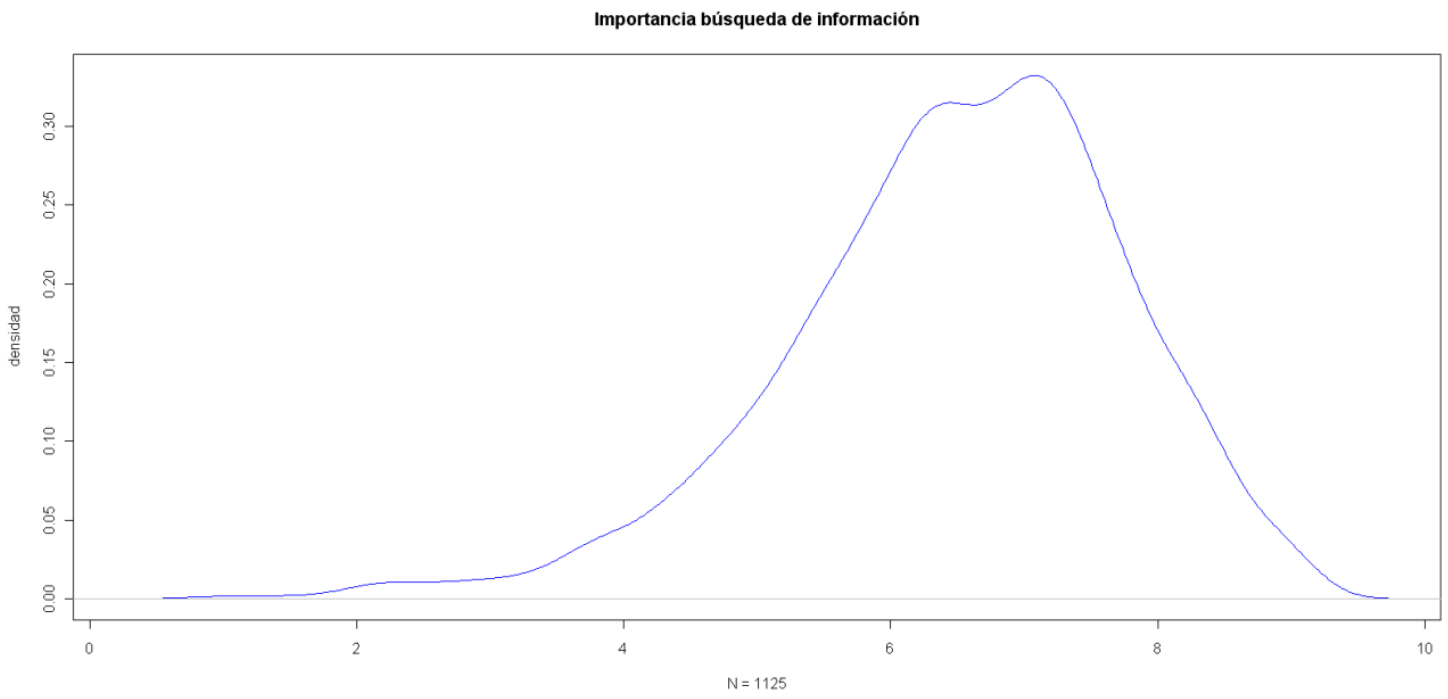

Gráfico 4.7 Función de densidad de la importancia asignada a la búsqueda de información. Alumnos

El gráfico 4.7 muestra la función de densidad de la dimensión de importancia asignada a la búsqueda de información. Como se señalaba anteriormente, se observa claramente una tendencia hacia puntuaciones altas, ya que la cola de la función es más prolongada hacia la izquierda de la escala que hacia la derecha.

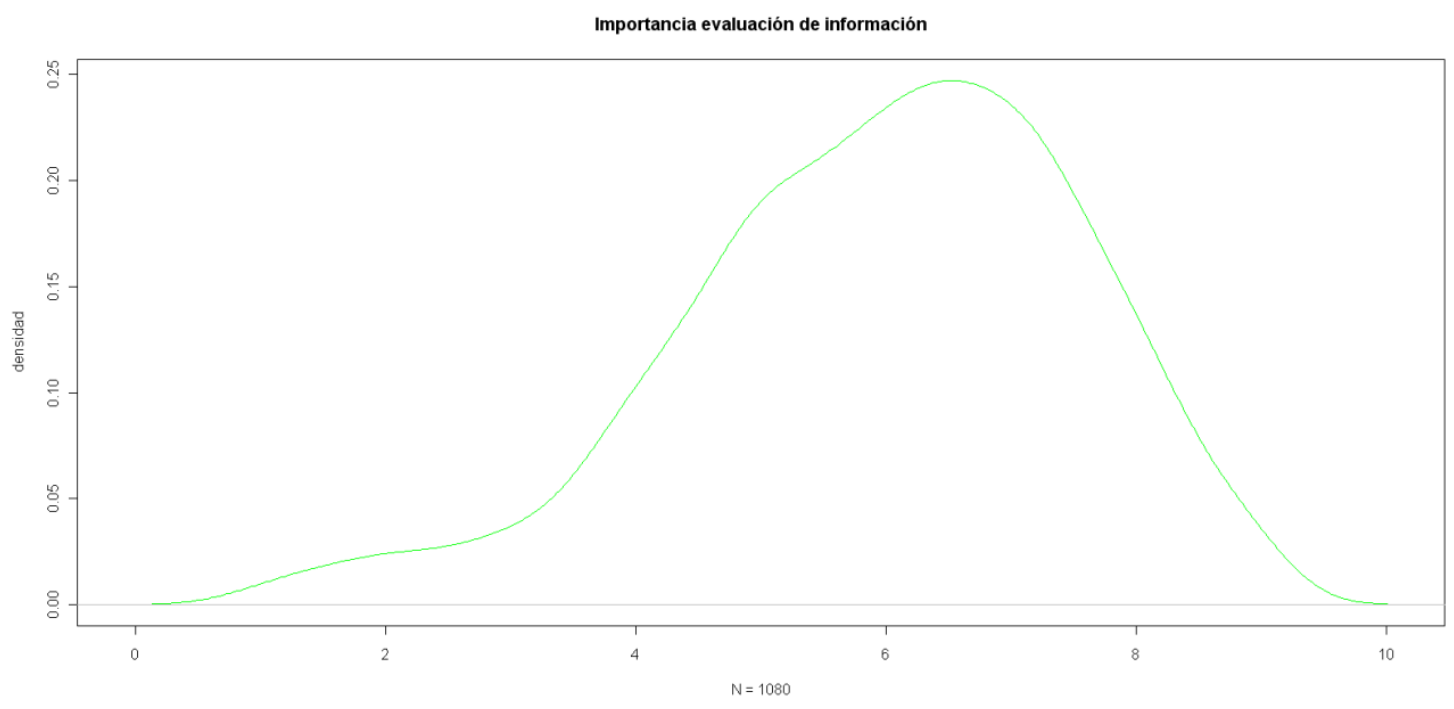

Gráfico 4.8 Función de densidad de la importancia asignada a la evaluación de información. Alumnos 
El gráfico 4.8 indica una tendencia algo más moderada que la anterior; aunque se sigue percibiendo que los valores de la media son ligeramente superiores a los de la moda y, por ende, que exista una asimetría negativa, esta tendencia es más moderada.

Así mismo, la curtosis, que en la gráfica de la importancia asignada a la búsqueda de información parecía claramente leptocúrtica, parece ahora menos elevada. Esto se corrobora observando los valores máximos que se alcanzan en la densidad (eje de ordenadas), que es en el caso de la búsqueda de más de 0.30 y en el caso de la evaluación no llega a 0.25 .

Importancia procesamiento de información

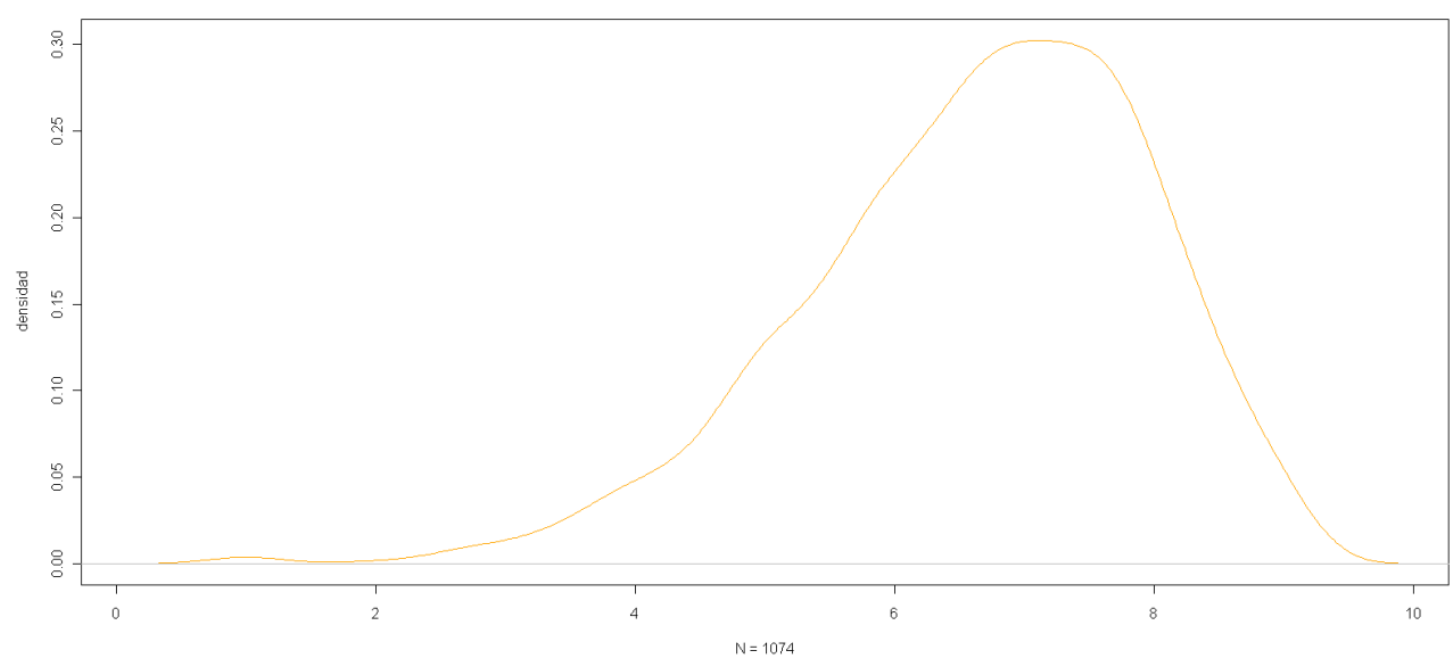

Gráfico 4.9 Función de densidad de la importancia asignada al procesamiento de información. Alumnos

En tercer lugar, el gráfico 4.9, muy similar a los anteriores, vuelve a devolver resultados que indican que la asimetría es negativa y la curtosis leptocúrtica.

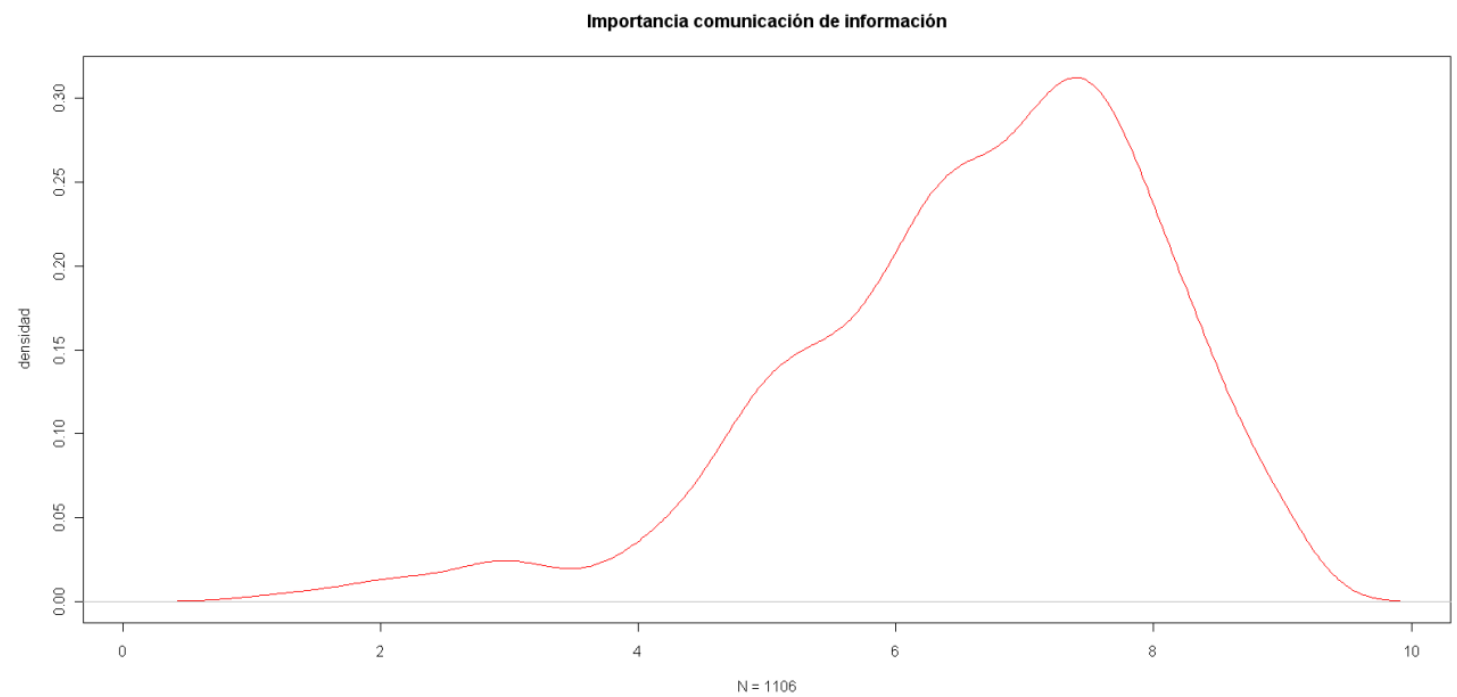

Gráfico 4.10 Función de densidad de la importancia asignada a la comunicación de información. Alumnos 
Por último, el gráfico 4.10 sigue siendo muy similar al resto, con una tendencia, si cabe, más intensa hacia la asimetría negativa y la curtosis leptocúrtica.

Observando estas gráficas, dado el elevado tamaño de muestra, consideramos probable que la prueba de normalidad indique que estos resultados provienen de variables que no se ajustan a nivel poblacional a una distribución normal.

En lo que respecta al estudio de la variabilidad y las medidas de posición básicas de las variables, podemos observar los diagramas de cajas resultantes.

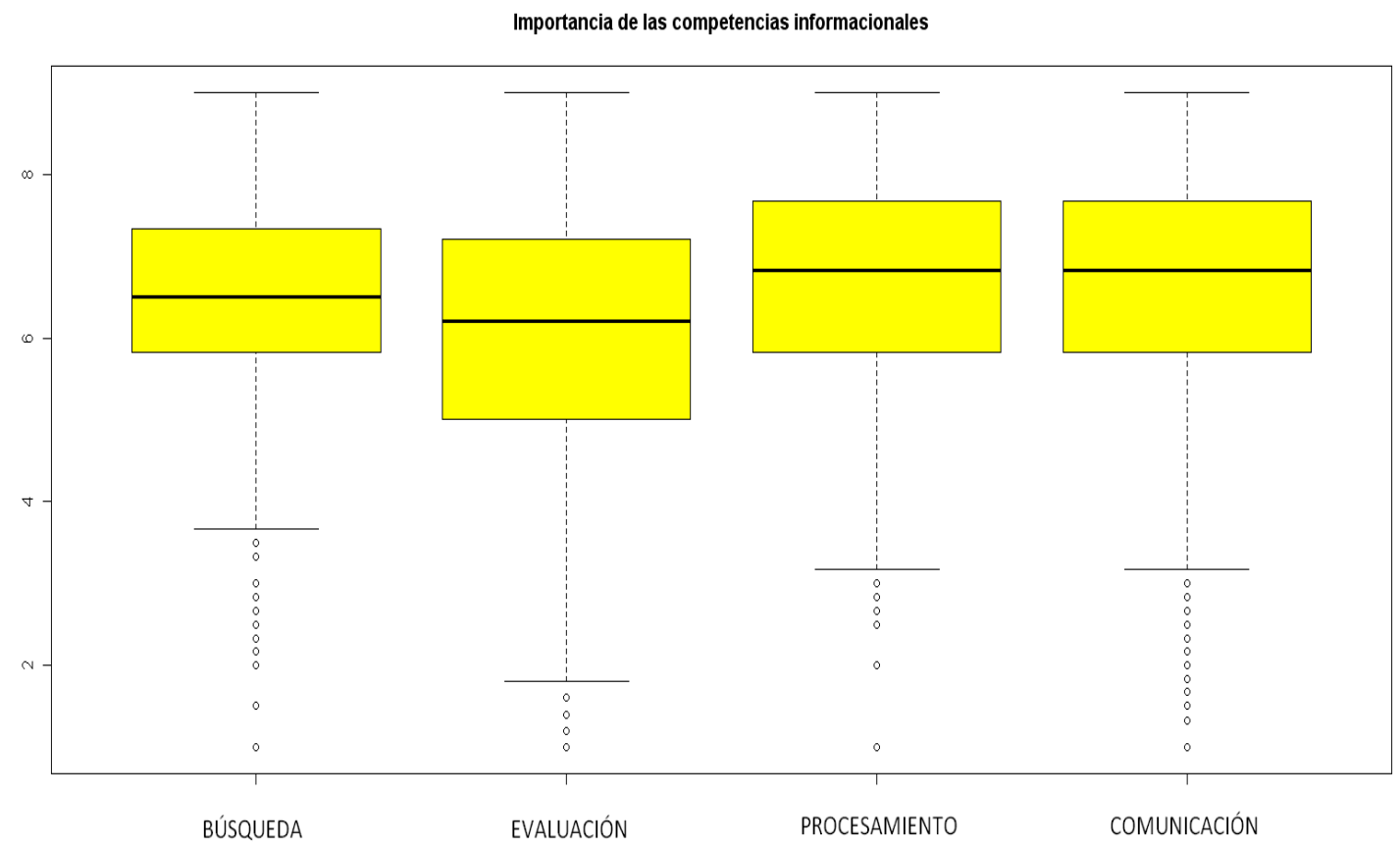

Gráfico 4.11 Diagramas de cajas importancia percibida sobre competencias informacionales. Alumnos

En los diagramas de cajas mostrados en el gráfico 4.11, que se refieren a la importancia asignada a las competencias informacionales para cada una de las cuatro dimensiones definidas, se observa en general una amplitud intercuartílica baja, a excepción de la variable evaluación de información, en la que parece que las puntuaciones están más dispersas.

Se puede percibir también, en los citados diagramas de cajas, que los valores atípicos se agrupan únicamente en las puntuaciones bajas. En primer lugar, esto se debe al hecho de que la asimetría es negativa; como se podía observar en las gráficas de las funciones de densidad, las colas de las funciones eran más alargadas en la zona de puntuaciones bajas. Por otro lado, al tener rangos de puntuaciones intercuartílicos pequeños, la cantidad de valores atípicos es grande. 
Por tanto, nuevamente, los diagramas de cajas nos vuelven a indicar que quizás los datos no se distribuyan normalmente, y que las variables procedan de distribuciones diferentes a la normal.

Una vez llevados a cabo estos análisis gráficos, vamos a proceder a explorar los valores de los indicadores principales de las variables. La tabla 4.92 muestra los valores del coeficiente de variación, la mediana y la amplitud intercuartílica y los coeficientes de asimetría y curtosis de las cuatros variables en las que se divide la importancia asignada a las competencias informacionales.

Tabla 4.92 Exploración de las dimensiones de la importancia de las competencias informacionales. Alumnos

\begin{tabular}{l|c|cc|ccc|cc}
\hline \multicolumn{1}{c|}{ Importancia asignada } & CV & Mdn & $\begin{array}{c}\text { Amp. } \\
\text { Interc. }\end{array}$ & \multicolumn{2}{c}{ Asimetría } & \multicolumn{3}{c}{ Curtosis } \\
\hline Búsqueda de información & $18.77 \%$ & 6.67 & 1.50 & -0.676 & .082 & 0.861 & .163 \\
\hline Evaluación de información & $26.63 \%$ & 6.20 & 2.20 & -0.627 & .082 & 0.267 & .163 \\
\hline Procesamiento de información & $19.88 \%$ & 6.83 & 1.83 & -0.801 & .082 & 0.945 & .163 \\
\hline $\begin{array}{l}\text { Comunicación y difusión de } \\
\text { información }\end{array}$ & $21.62 \%$ & 6.83 & 1.83 & -0.937 & .082 & 1.179 & .163 \\
\hline
\end{tabular}

Analizando los valores obtenidos en la exploración de las dimensiones de la importancia asignada podemos encontrarnos, en primer lugar, con valores del coeficiente de variación satisfactorios (<30\%) en todos los casos. Este resultado nos indica que podemos emplear en adelante la media como un estimador adecuado de la tendencia central de los datos.

Por otro lado, se muestran los valores de la mediana y la amplitud intercuartil. Estos valores se corresponden con los resultados analizados en los gráficos anteriores, por lo que no se volverán a interpretar en este momento.

Por último, los valores de asimetría y curtosis confirman las observaciones llevadas a cabo a partir de los gráficos de las funciones de densidad. En todos los casos se obtienen valores que indican asimetrías negativas, e índices de curtosis que muestran una distribución conforme a una curtosis leptocúrtica. Si se analizan estos valores conjuntamente con los errores típicos obtenidos, se puede concluir que a nivel poblacional, a un nivel de significación $\alpha=.01$ ( $z=2.5758$ ) las variables no se comportan conforme a la distribución normal. La única variable en la que sí se puede aceptar una distribución normal en cuanto al índice de curtosis es la evaluación de información, variable en la que se obtienen valores que podrían indicar una curtosis mesocúrtica, 
Curt $=0.267 ;$ Error típ $=0.163 \rightarrow I=0.267 \pm 0.163 * 2.5758=(0.6868,-0.1528)$

en este caso, el intervalo de confianza incluye el valor 0 , por lo que se puede aceptar que a nivel poblacional la curtosis sea mesocúrtica.

Finalmente, en esta exploración, trataremos de confirmar estas interpretaciones sobre la distribución de las variables a través de la exploración de gráficos Q-Q normales y de la aplicación de las pruebas de normalidad de Kolmogorov-Smirnov.

El gráfico 4.12 muestra cómo, mientras que los valores empíricos que ocupan las posiciones centrales se ajustan de manera más o menos adecuada a la distribución normal, en los valores más extremos, el ajuste es mucho peor.

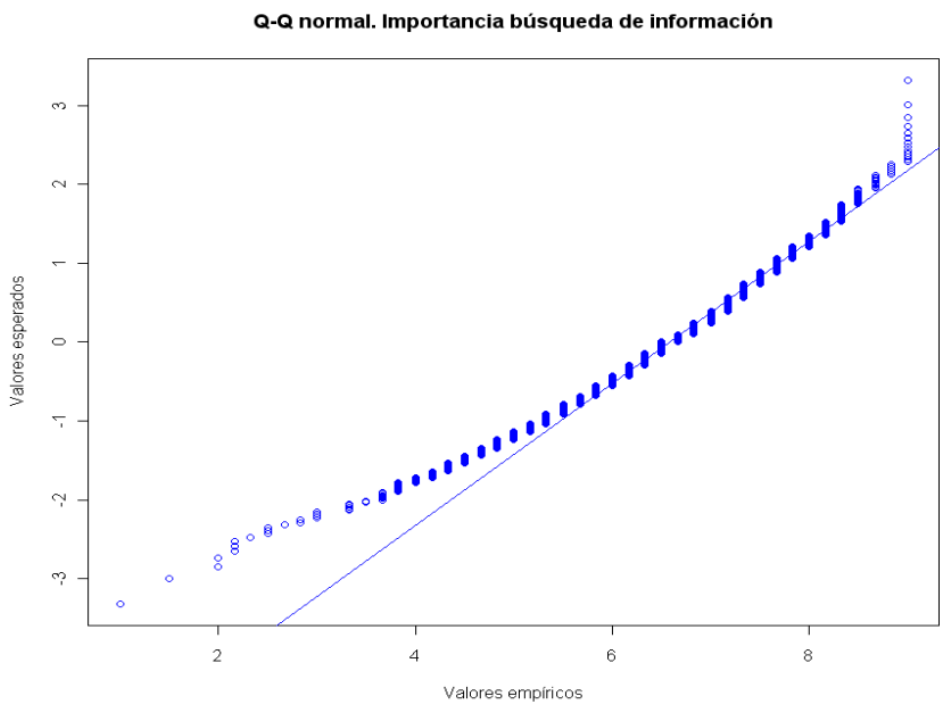

Gráfico 4.12 Q-Q normal para la importancia en la búsqueda de información. Alumnos

En el gráfico 4.13, correspondiente a la importancia asignada a la evaluación de información, se vuelven a observar ajustes poco adecuados en los valores más extremos, aunque con una tendencia más ajustada que en el caso de la importancia asignada a la búsqueda.

Esta tendencia será común en todos los gráficos $Q-Q$ normales que se irán señalando en adelante para cada una de las dimensiones.

El bajo ajuste es más evidente en los valores bajos. Estos resultados son lógicos a tenor de los gráficos analizados anteriormente ya que, como se mostraba en los diagramas de cajas, casi la totalidad de los valores atípicos extremos se encontraba en el rango de puntuaciones bajas. 


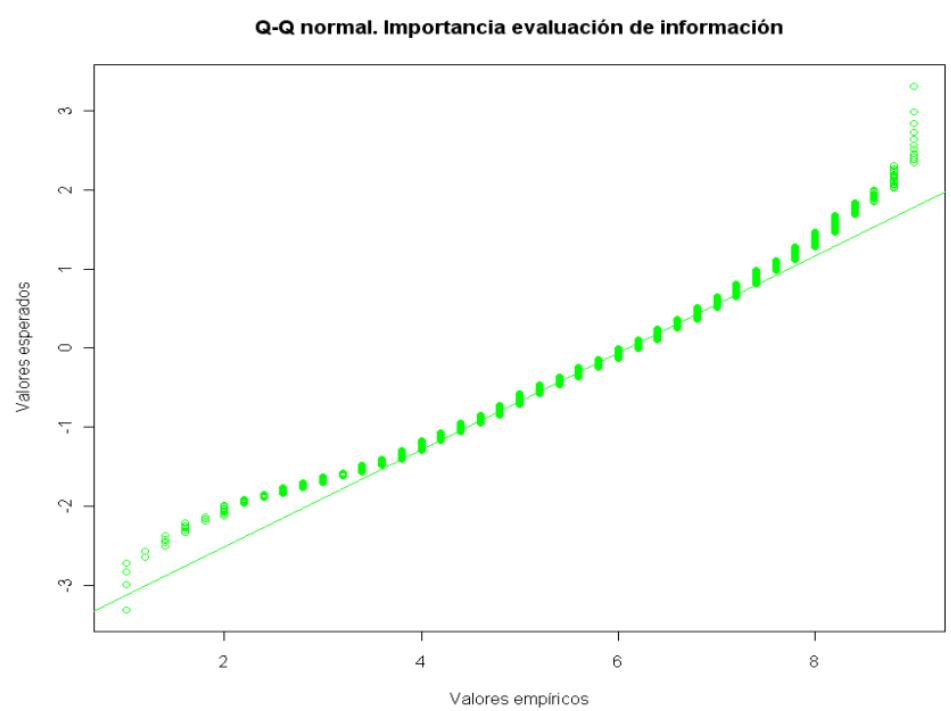

Gráfico 4.13 Q-Q normal para la importancia en la evaluación de información. Alumnos

El gráfico 4.14, referido a la importancia asignada al procesamiento de información, vuelve a indicar lo observado anteriormente.

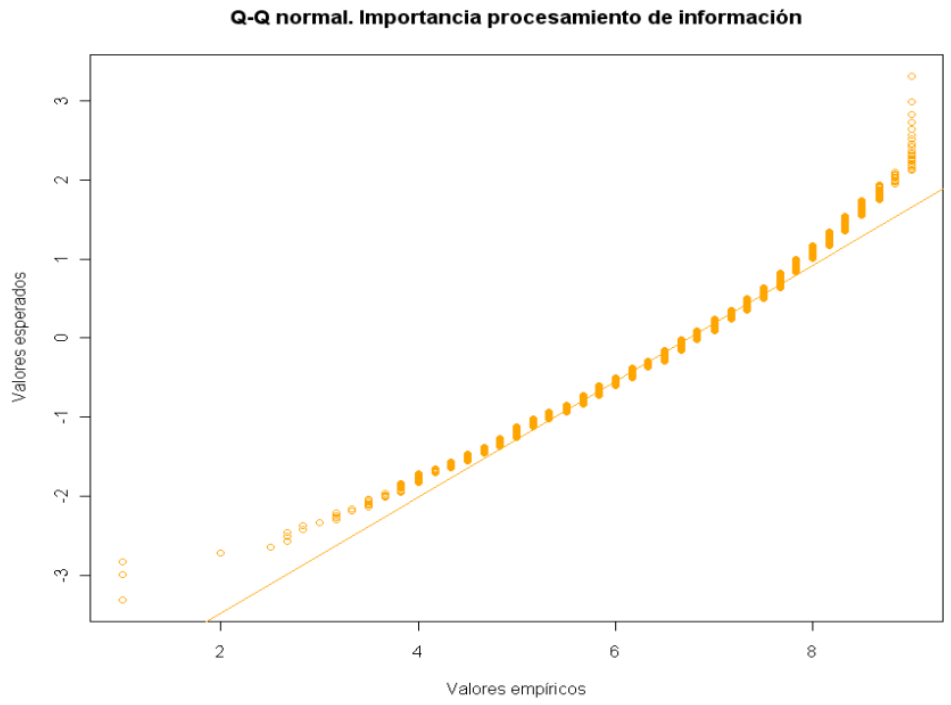

Gráfico 4.14 Q-Q normal para la importancia en el procesamiento de información. Alumnos

Por último, el gráfico 4.15 muestra el ajuste a la distribución normal de la variable de la importancia asignada a la comunicación de información. Se vuelve a observar un ajuste poco adecuado. De hecho, en este caso los valores inferiores de la variable muestran un ajuste muy lejano a la distribución normal, más incluso que en el resto de variables analizadas. Esto es lógico teniendo en cuenta que esta variable indicaba los valores más altos (en términos absolutos) en los índices de asimetría y de curtosis. 


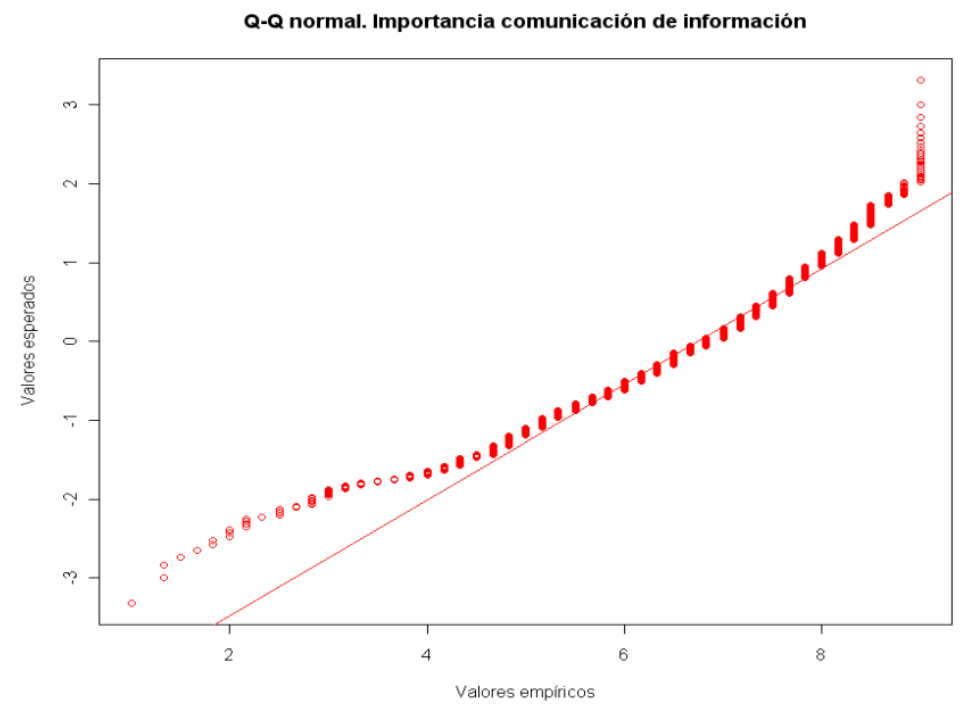

Gráfico 4.15 Q-Q normal para la importancia en la comunicación de información. Alumnos

Veamos por último los resultados de la prueba de Kolmogorov-Smirnov, mostrados en la tabla 4.93 .

Tabla 4.93 Prueba de normalidad de Kolmogorov-Smirnov para la importancia concedida. Alumnos

\begin{tabular}{l|cc|c}
\hline \multicolumn{1}{c|}{ Importancia asignada } & $\boldsymbol{D}^{*}$ & $\boldsymbol{z}(\boldsymbol{K}-\boldsymbol{S})$ & $\boldsymbol{p}$. \\
\hline Búsqueda de información & .069 & 2.320 & $<.001$ \\
\hline Evaluación de información & .067 & 2.213 & $<.001$ \\
\hline Procesamiento de información & .074 & 2.415 & $<.001$ \\
\hline Comunicación y difusión de información & .089 & 2.970 & $<.001$ \\
\hline
\end{tabular}

*Diferencia absoluta más alta entre la frecuencia acumulada teórica y la observada

Según la prueba de normalidad efectuada se rechaza la $\mathrm{H}_{0}$ de que las variables se ajustan a una distribución normal, por lo que podemos afirmar que las variables analizadas no se ajustan a dicha distribución (n.s.=.01).

Una vez llevada a cabo la exploración pertinente, podemos concluir que las variables no se ajustan a la distribución normal y que, por tanto, deberemos proceder a la aplicación de técnicas no paramétricas en el caso de querer llevar a cabo algún análisis comparativo-inferencial.

Veamos a continuación la exploración de las dimensiones que tienen que ver con las competencias informacionales autopercibidas.

\section{b) Competencia autopercibida en las dimensiones}


En primer lugar, el análisis de las funciones de densidad vuelve a indicar asimetría negativa y curtosis leptocúrtica.

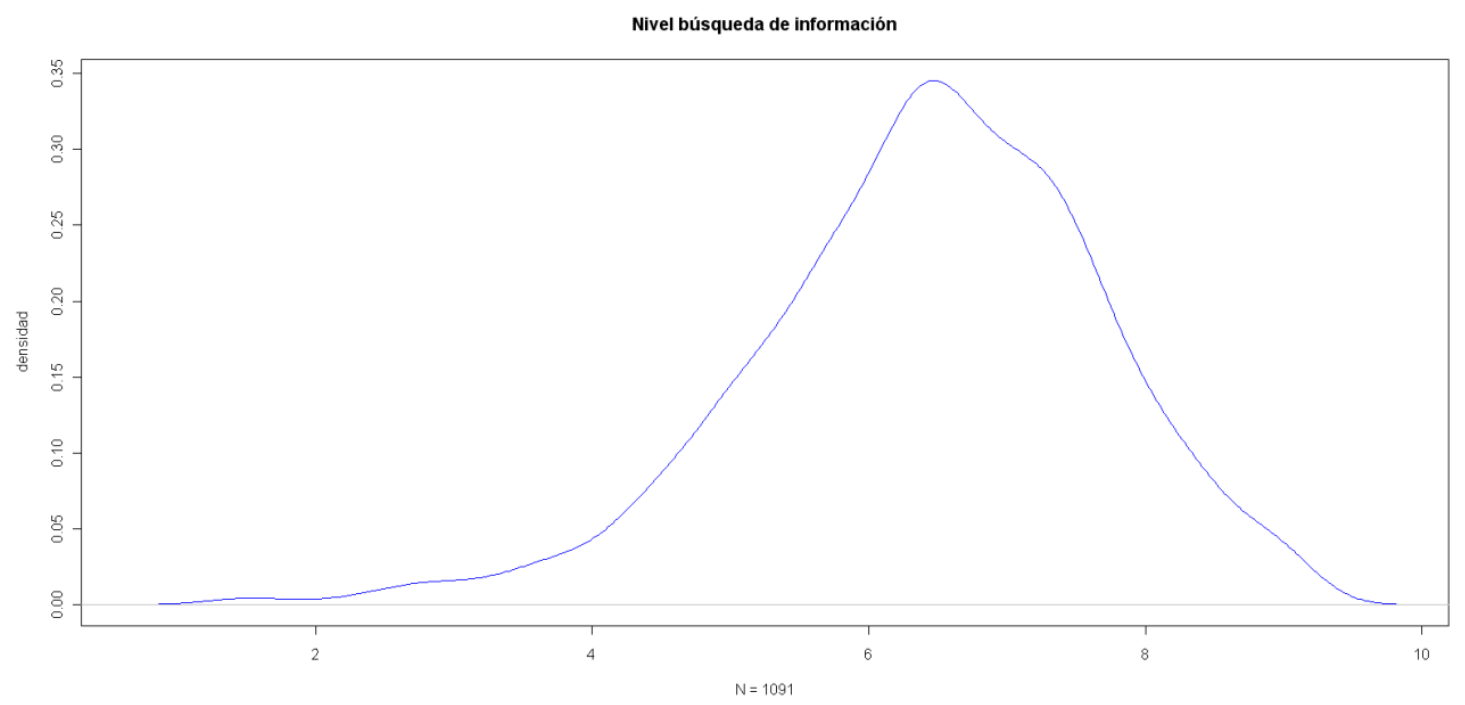

Gráfico 4.16 Función de densidad del nivel autopercibido en la búsqueda de información. Alumnos

El gráfico 4.16 muestra la función de densidad de la dimensión de competencia autopercibidia en la búsqueda de información. Se observa cómo en los puntos más elevados de la curva la densidad es alta, por lo que la curtosis será probablemente marcadamente leptocúrtica. Por otro lado, la curva es claramente asimétrica negativa.

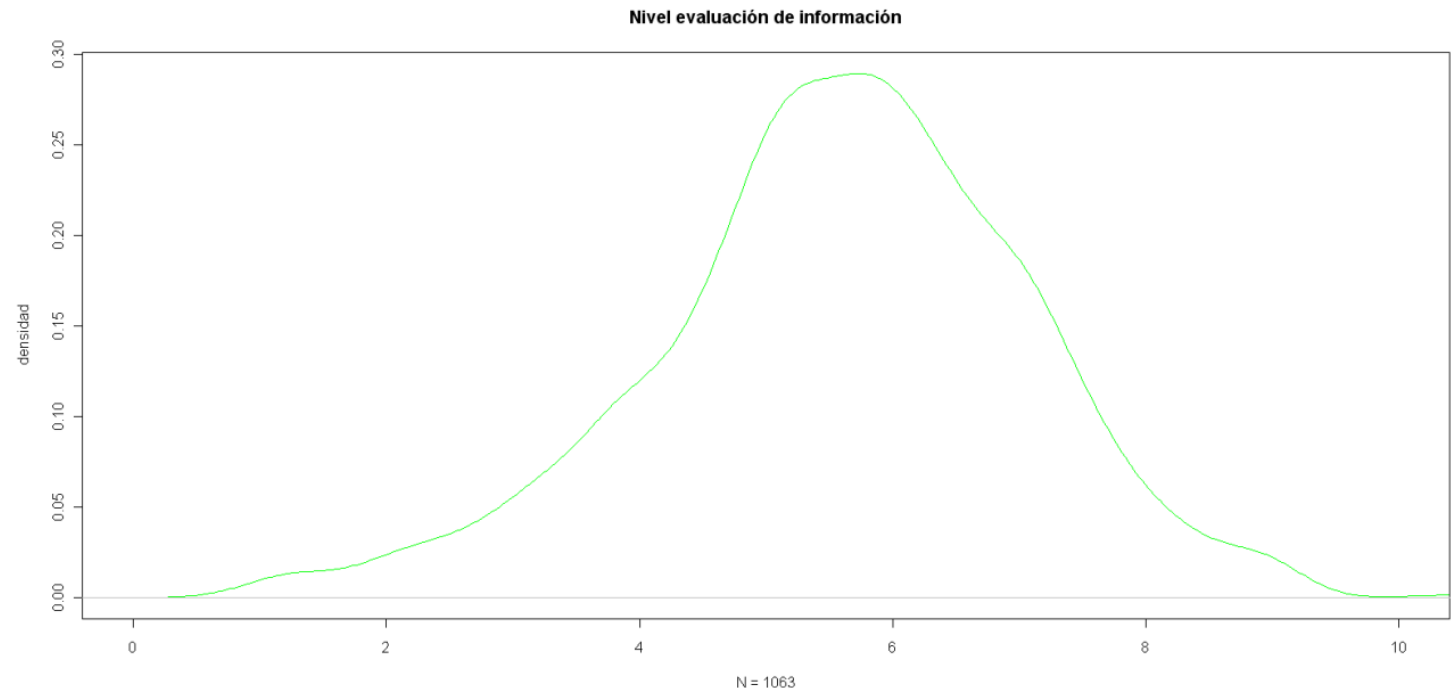

Gráfico 4.17 Función de densidad del nivel autopercibido en la evaluación de información. Alumnos

El gráfico 4.17, al igual que ocurría en el análisis de la importancia percibida, indica una tendencia algo más moderada que la anterior; aunque la curva sigue mostrando una densidad alta en los puntos más elevados. En este caso, la curva, aunque sigue siendo asimétrica negativa, parece más simétrica que el resto. 


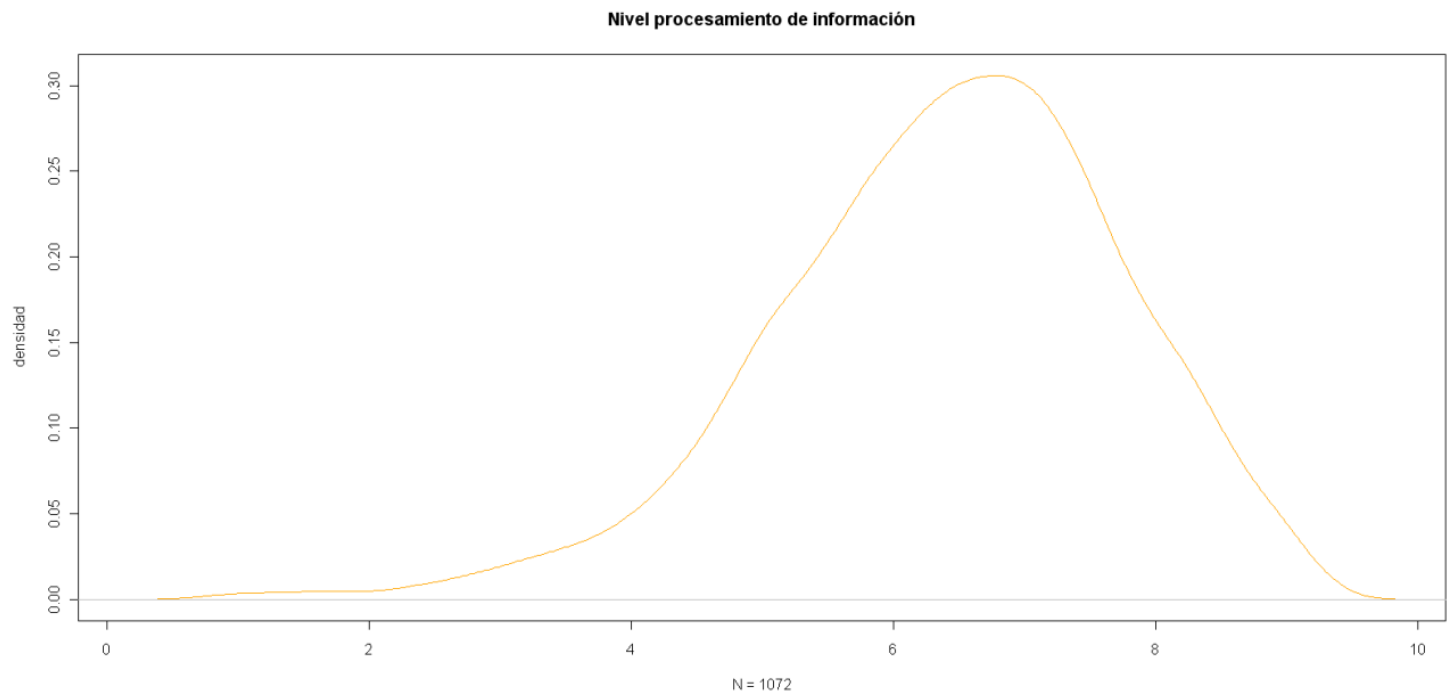

Gráfico 4.18 Función de densidad del nivel autopercibido en el procesamiento de información. Alumnos

En tercer lugar, el gráfico 4.18, similar al obtenido en el análisis del nivel autopercibido en la búsqueda de información, vuelve a devolver resultados que indican que la asimetría es negativa y la curtosis leptocúrtica.

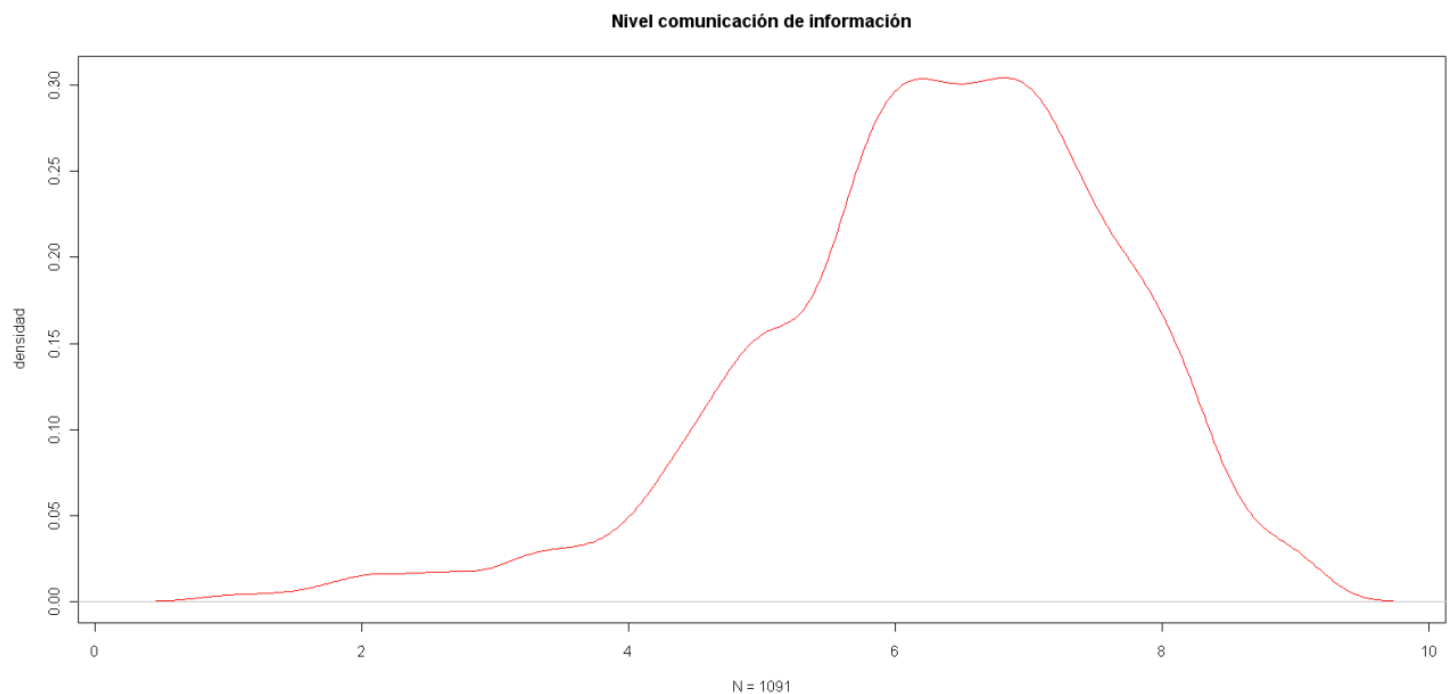

Gráfico 4.19 Función de densidad del nivel autopercibido en la comunciación de información. Alumnos

El gráfico 4.19, por último, muestra la función de densidad del nivel autopercibido en la comunicación de información. Vuelve a ser similar al resto, con una tendencia clara hacia la asimetría negativa y la curtosis leptocúrtica.

Nuevamente, analizando críticamente las anteriores funciones de densidad, existen altas probabilidades de que los resultados provengan de variables que no se ajustan a distribuciones poblacionales $\mathrm{N}(0.1)$. 
Estudiemos a continuación la variabilidad y los indicadores de las medidas de posición a través del estudio de los diagramas de cajas de las variables de nivel autopercibido.

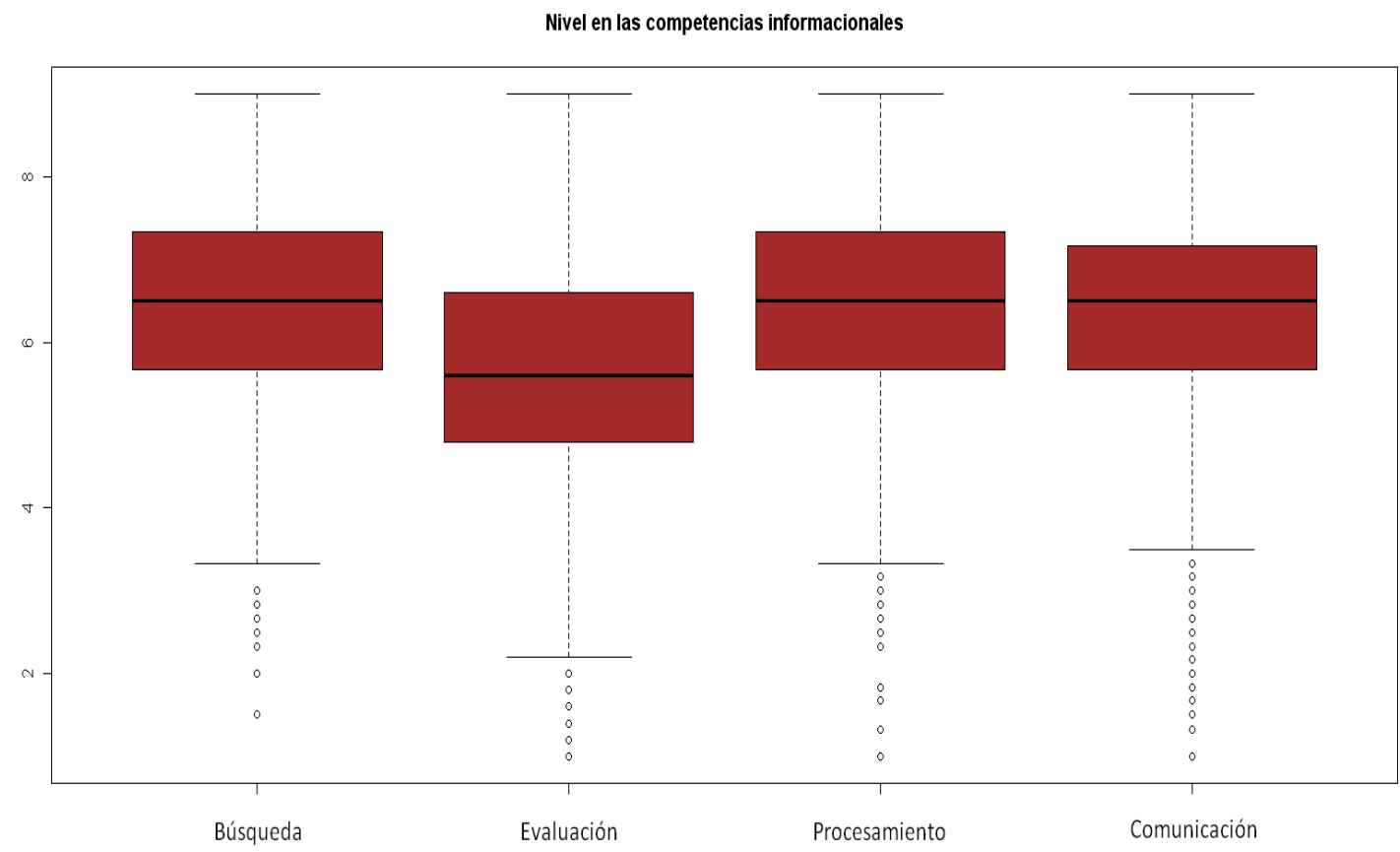

Gráfico 4.20 Diagramas de cajas nivel autopercibido sobre competencias informacionales. Alumnos

Los diagramas de caja y bigotes que se presentan en el gráfico 4.20, muestran los valores de las variables referidas al nivel percibido en las cuatro dimensiones. Se muestran rangos de la amplitud intercuartil pequeños y, como en los diagramas de la importancia asignada, valores atípicos únicamente en las puntuaciones bajas de la escala.

Tabla 4.94 Exploración de las dimensiones del nivel autopercibido en competencias informacionales. Alumnos

\begin{tabular}{l|c|cc|cc|cc}
\hline \multicolumn{1}{c|}{ Importancia asignada } & CV & Mdn & $\begin{array}{c}\text { Amp. } \\
\text { Interc. }\end{array}$ & \multicolumn{2}{c|}{ Asimetría } & \multicolumn{3}{c}{ Curtosis } \\
& & & Valor & E. típ. & Valor & E. típ. \\
\hline Búsqueda de información & $20.73 \%$ & 6.5 & 1.67 & -0.606 & .082 & 0.863 & .163 \\
\hline Evaluación de información & $26.51 \%$ & 5.6 & 1.80 & -0.328 & .082 & 0.447 & .163 \\
\hline Procesamiento de información & $20.81 \%$ & 6.5 & 1.67 & -0.656 & .082 & 0.890 & .163 \\
\hline $\begin{array}{l}\text { Comunicación y difusión de } \\
\text { información }\end{array}$ & $21.63 \%$ & 6.5 & 1.67 & -0.789 & .082 & 1.144 & .163 \\
\hline
\end{tabular}

Si analizamos los valores concretos mostrados en la tabla 4.94, obtenidos para la exploración de las dimensiones sobre el nivel autopercibido, nos encontramos, en 
primer lugar, valores del coeficiente de variación satisfactorios $(<30 \%)$ en todos los casos. Así, la media se empleará en adelante como estimador de la tendencia central.

La mediana y la amplitud intercuartílica son muy similares en las cuatro variables, lo cual indica que los valores de las principales medidas de dispersión serán muy cercanos, y que la dispersión de los datos será similar en las variables.

Al igual que en los análisis sobre las dimensiones de la importancia concedida, los valores de curtosis y asimetría nos indican en todos los casos curtosis leptocúrtica y asimetría negativa. Analizados estos valores conjuntamente con los errores típicos, nos encontramos en todos los casos con intervalos de confianza $(\alpha=.01)$ que indican que las variables poblacionales se distribuyen de manera asimétrica y con curtosis leptocúrtica.

Por último, al igual que anteriormente, vamos a tratar de confirmar las observaciones iniciales a través del análisis de los gráficos $Q-Q$ normales y de la aplicación de las pruebas de normalidad de Kolmogorov-Smirnov.

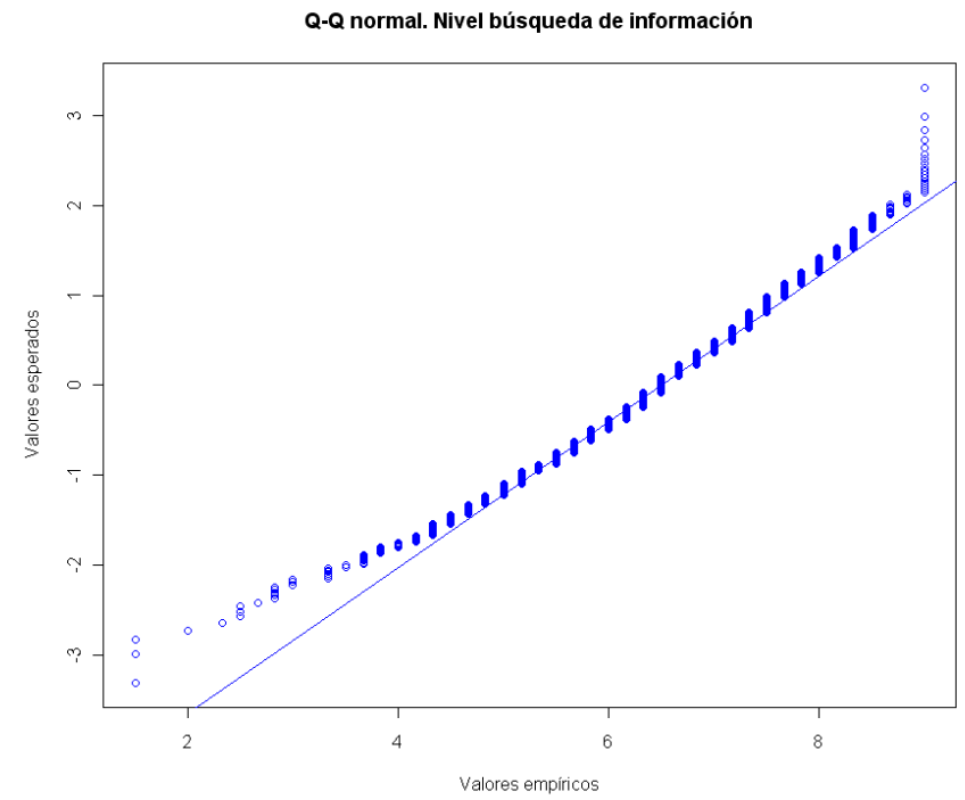

Gráfico 4.21 Q-Q normal para el nivel autopercibido en la búsqueda de información. Alumnos

En primer lugar, el gráfico 4.21, que muestra el Q-Q normal para el nivel autopercibido en la búsqueda de información, vuelve a mostrar valores ajustados a nivel general, a excepción de los que se encuentran en puntuaciones bajas, que se alejan del ajuste perfecto. 
Estos resultados se repiten con características similares en adelante, como se podrá observar en el gráfico 4.22, mostrado a continuación, y en los siguientes

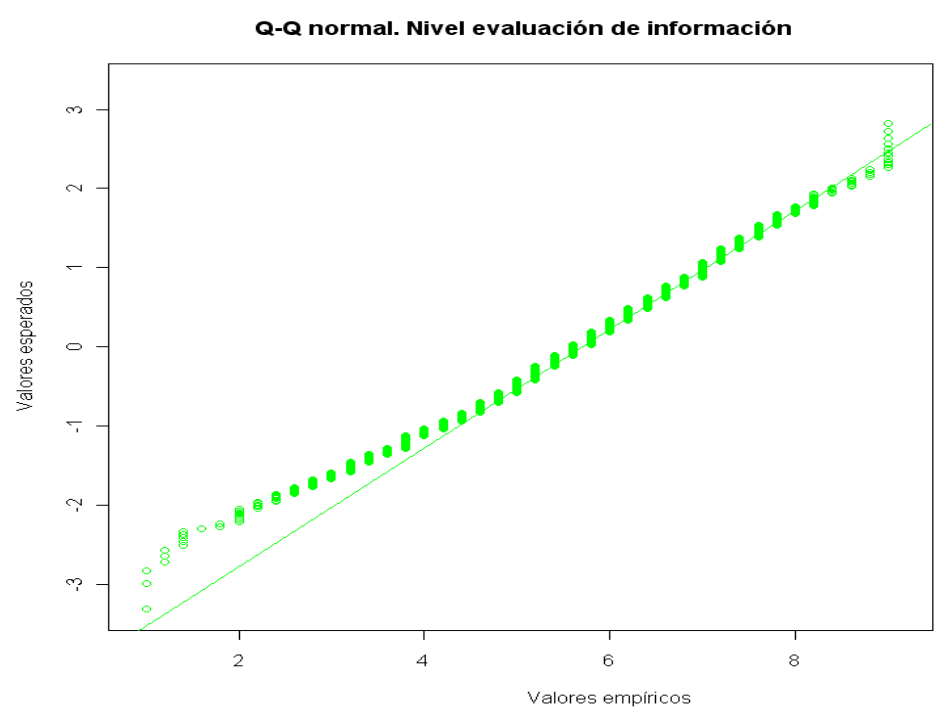

Gráfico 4.22 Q-Q normal para el nivel autopercibido en la evaluación de información. Alumnos

El gráfico 4.23 se refiere al ajuste de la variable de procesamiento de información, y vuelve a mostrar ajustes pobres.

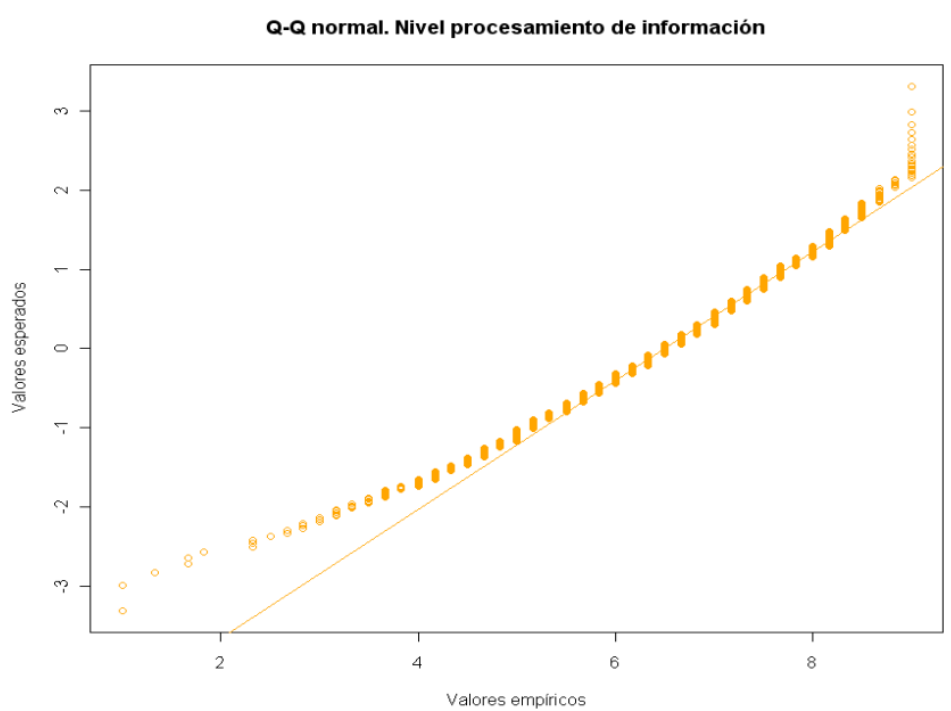

Gráfico 4.23 Q-Q normal para el nivel autopercibido en el procesamiento de información. Alumnos

En último lugar, el gráfico 4.24, que muestra el ajuste a la distribución normal de la variable del nivel autopercibido en la comunicación de información, se muestran peores ajustes que en el resto de variables. 


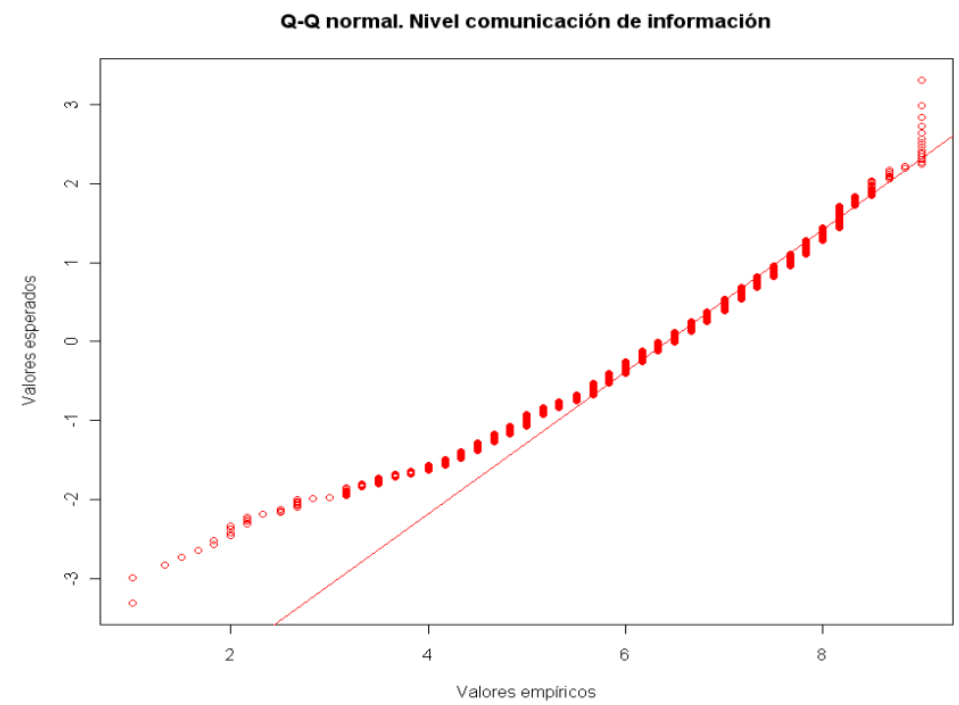

Gráfico 4.24 Q-Q normal para el nivel autopercibido en la comunicación de información. Alumnos

A nivel general, por tanto, dados los resultados obtenidos en las funciones de densidad, los diagramas de cajas, los valores de asimetría y curtosis, y las gráficas $Q-Q$ normales, junto con el elevado tamaño de muestra del que disponemos, es de esperar que la prueba de Kolmogorov-Smirnov indique malos ajustes que nos lleven a rechazar la $\mathrm{H}_{0}$. Así, la tabla 4.95 nos muestra los valores de la citada prueba que llevan, en todos los casos, al rechazo de la hipótesis de adaptación de los datos a una distribución poblacional normal.

Tabla 4.95 Prueba de normalidad de Kolmogorov-Smirnov para el nivel autopercibido. Alumnos

\begin{tabular}{l|cc|c}
\hline \multicolumn{1}{c|}{ Nivel autopercibido } & $\boldsymbol{D}^{*}$ & $\boldsymbol{z}(\boldsymbol{K}-\boldsymbol{S})$ & $\boldsymbol{p}$. \\
\hline Búsqueda de información & .068 & 2.252 & $<.001$ \\
\hline Evaluación de información & .065 & 2.112 & $<.001$ \\
\hline Procesamiento de información & .063 & 2.054 & $<.001$ \\
\hline Comunicación y difusión de información & .074 & 2.431 & $<.001$ \\
\hline
\end{tabular}

*Diferencia absoluta más alta entre la frecuencia acumulada teórica y la observada

De nuevo, una vez realizada exploración oportuna, se concluye que las variables no se ajustan a la distribución normal y que, por tanto, se debe proceder a la aplicación de técnicas no paramétricas en el caso de querer llevar a cabo algún análisis comparativo-inferencial para las dimensiones relacionadas con el nivel autopercibido de las competencias informacionales.

c) Diferencias entre el nivel y la importancia declarados en las dimensiones 
Continuaremos, dentro del análisis de las variables generadas a partir de las dimensiones teóricas de las competencias informacionales, comparando las medias de las citadas variables. Para ello, en primer lugar observaremos a nivel descriptivo los grupos de dimensiones, para, en segundo lugar, llevar a cabo tanto un análisis gráfico como estadístico para la comparación de variables. En los análisis estadísticos, dados los resultados obtenidos en las anteriores pruebas de ajuste a la distribución normal de los datos, se deberán llevar a cabo análisis no paramétricos. En concreto, para la diferencia de medias para dos grupos relacionados, se empleará la prueba de los rangos con signo de Wilcoxon, que compara el valor del sumatorio de los rangos positivos y de los rangos negativos obtenidos a partir del cálculo de la diferencia entre cada pareja de valores. Así, la hipótesis de igualdad de las variables se realiza a partir de la mediana y no a partir de la media como lo hacen las pruebas paramétricas.

En primer lugar, en la tabla 4.96 se pueden observar las diferencias registradas en la importancia asignada a las cuatro dimensiones. Se observa cómo la categoría evaluación de información es la que más diferencias registra a mucha distancia del resto, que tienen diferencias poco apreciables. Como parecían indicar los datos observados en el análisis individual de los estadísticos descriptivos básicos de los ítems, en la dimensión evaluación de información los sujetos perciben una menor importancia sobre el resto. Por su parte, el procesamiento de información es la dimensión en la que los alumnos declaran tener una mayor competencia, aunque seguida muy de cerca por la búsqueda y la comunicación.

Tabla 4.96 Estadísticos básicos. Importancia de las competencias informacionales por dimensiones. Alumnos

\begin{tabular}{l|ll|l}
\hline \multicolumn{1}{c|}{$\begin{array}{c}\text { Importancia de las competencias } \\
\text { informacionales }\end{array}$} & $\overline{\boldsymbol{X}}$ & $\boldsymbol{S}_{\boldsymbol{x}}$ & $\boldsymbol{N}$ \\
\hline Búsqueda de información & 6.48 & 1.216 & 1116 \\
\hline Evaluación de información & 5.96 & 1.587 & 1080 \\
\hline Procesamiento de información & 6.63 & 1.318 & 1074 \\
\hline Comunicación y difusión de información & 6.61 & 1.429 & 1106 \\
\hline
\end{tabular}

En la tabla 4.97 se observan las diferencias registradas en cuanto al nivel autopercibido en las 4 dimensiones. En este caso, la categoría evaluación de información sigue siendo la que obtiene una media más baja a mucha distancia del resto, que tienen diferencias poco apreciables en las medias. Sin embargo, en esta ocasión la categoría con una media más alta cambia con respecto al nivel de importancia que señalaban los sujetos que han contestado la encuesta; mientras que para los estudiantes las categorías más importantes son las competencias relacionadas 
con el procesamiento de información, cuando se les pregunta por sus conocimientos al respecto, indican que son más competentes en la búsqueda de información.

Tabla 4.97 Estadísticos básicos sobre el nivel de competencias informacionales por dimensiones. Alumnos

\begin{tabular}{l|ccc|c}
\hline $\begin{array}{c}\text { Nivel autopercibido en competencias } \\
\text { informacionales }\end{array}$ & $\overline{\boldsymbol{X}}$ & $\boldsymbol{S}_{\boldsymbol{x}}$ & $\boldsymbol{N}$ \\
\hline Búsqueda de información & 6.43 & 1.333 & 1079 \\
\hline Evaluación de información & 5.59 & 1.482 & 1063 \\
\hline Procesamiento de información & 6.41 & 1.334 & 1072 \\
\hline Comunicación y difusión de información & 6.30 & 1.363 & 1091 \\
\hline
\end{tabular}

Así, comparando las medias obtenidas en las muestras, los resultados indican que los sujetos consideran en todas las parejas de variables que la importancia es superior al nivel percibido. La única variable en la que existen diferencias mínimas es en la búsqueda de información, en la que sólo existen 0.05 puntos de diferencia.

Estos datos nos indican que los alumnos de la muestra están demandando una mayor formación en lo que respecta a las competencias relacionadas con la evaluación, el procesamiento y la comunicación y difusión de información.

Volviendo a un análisis más visual de los resultados, podemos mostrar gráficos bidimensionales que nos muestren las distribuciones conjuntas de la importancia y el nivel percibidos para cada una de las dimensiones.

El gráfico 4.25 muestra la distribución de densidad conjunta de la importancia y el nivel de adquisición autopercibidos en la dimensión de búsqueda de información. 


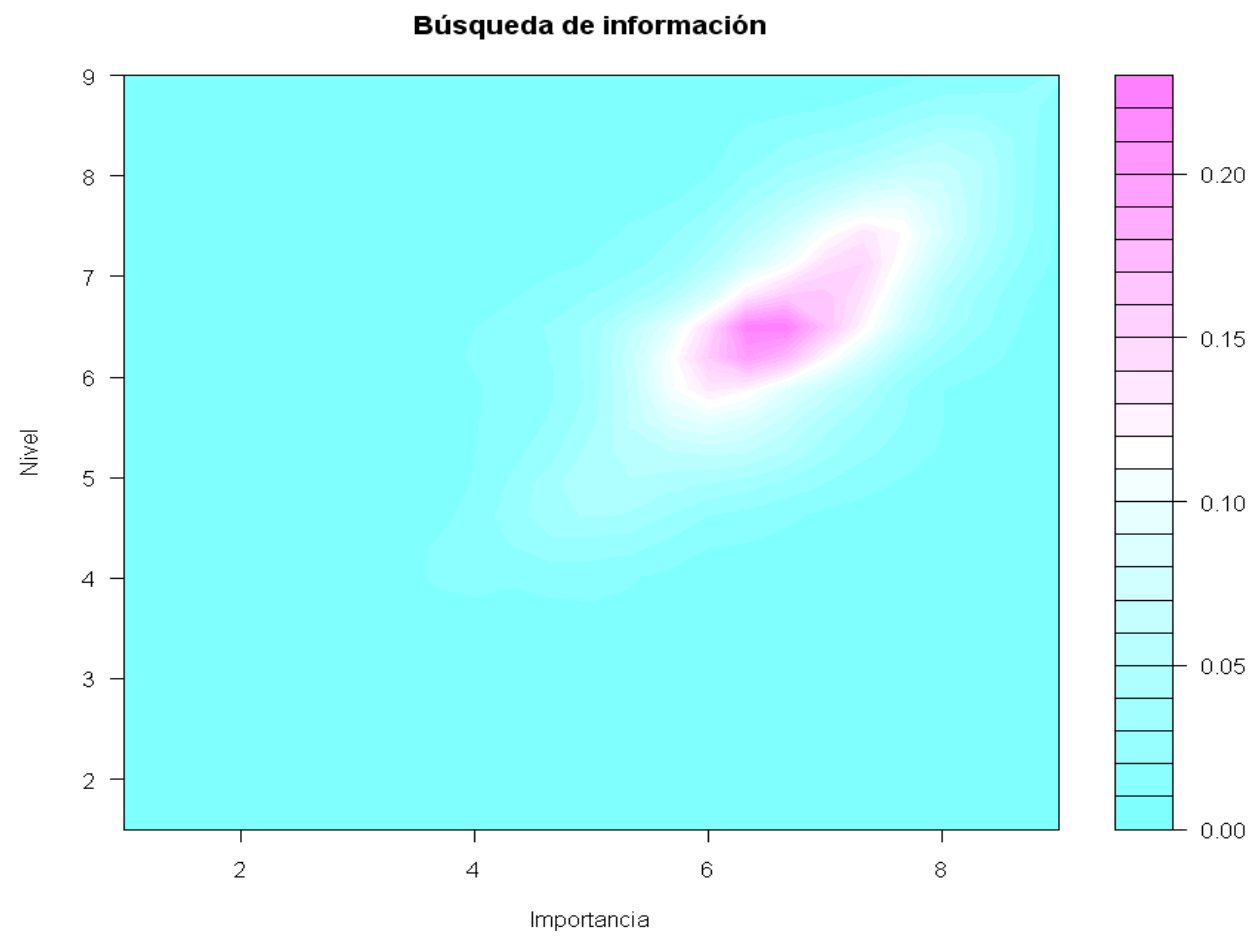

Gráfico 4.25 Distribución de densidad conjunta para el nivel y la importancia en la búsqueda. Alumnos

Comparando los valores de importancia y nivel en el gráfico anterior, se puede observar cómo las diferencias en las puntuaciones asignadas a ambas variables son poco perceptibles. Sin embargo, se observa cómo en la importancia los valores tienden a ser ligeramente más elevados. En todo caso, la elevada curtosis leptocúrtica de ambas variables dificulta el análisis gráfico de las mismas en la curva de densidad conjunta.

En cuanto al gráfico 4.26, referido a la distribución de la función de densidad conjunta de la importancia asignada y el nivel autopercibido para la evaluación de información, se vuelven a obtener resultados similares. Se observa cómo un mayor número de casos se sitúan en los valores altos de la importancia asignada, mientras que en el caso del nivel estos valores tienden a ser medios-altos. 


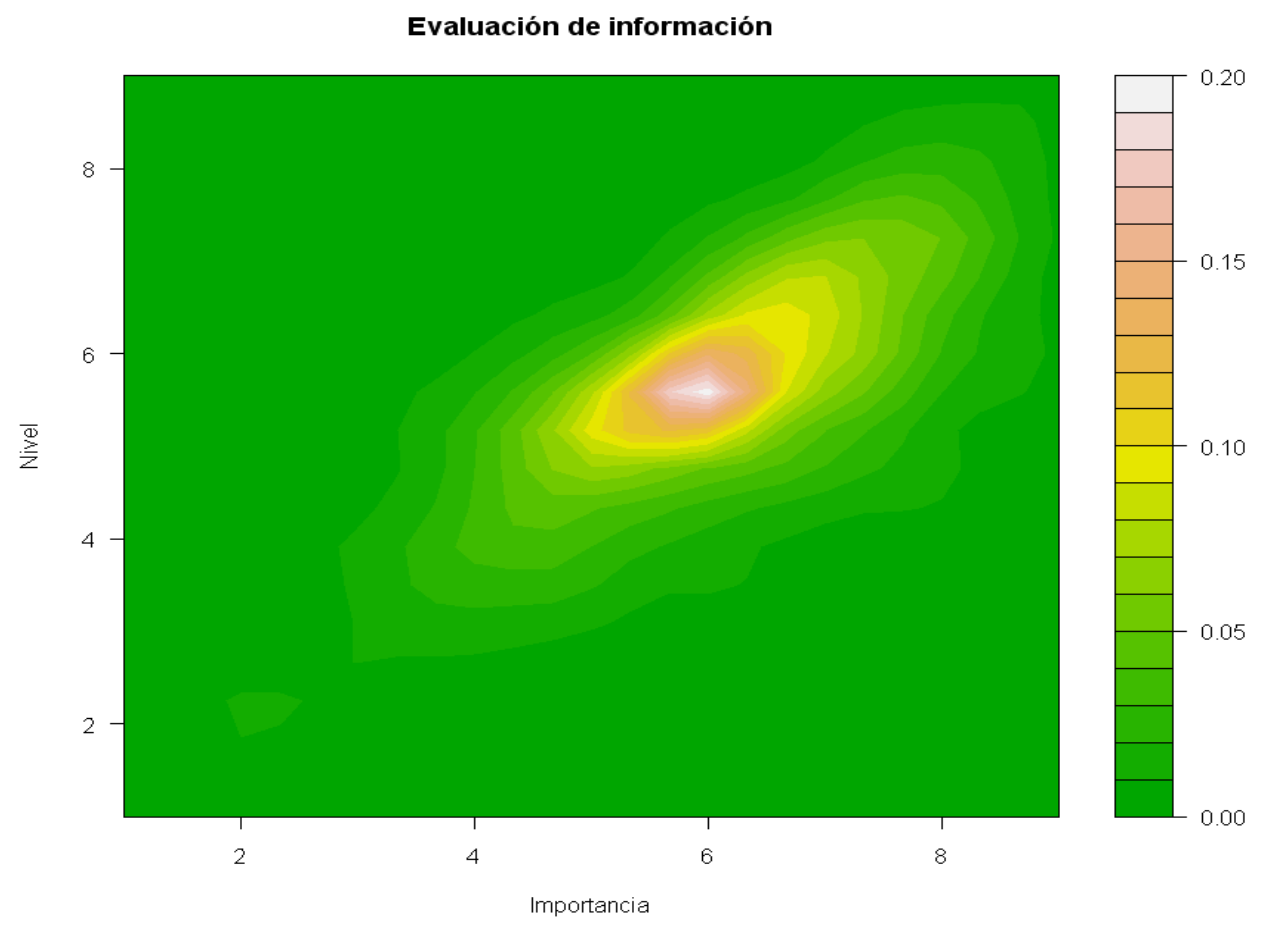

Gráfico 4.26 Distribución de densidad conjunta para el nivel y la importancia en la evaluación. Alumnos

En el gráfico 4.27 se repita, aunque moderadamente, la tendencia antes señalada.

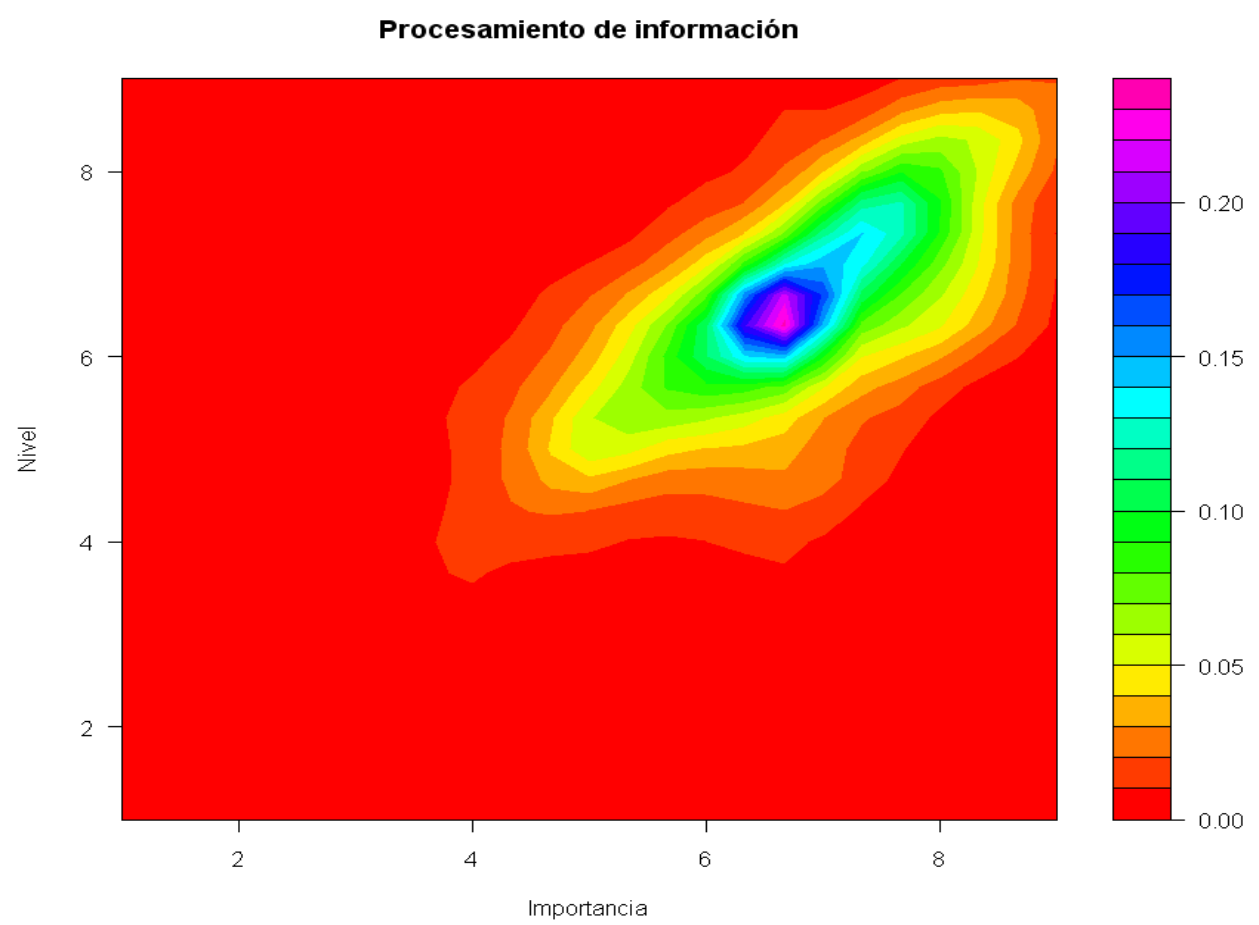

Gráfico 4.27 Distribución de densidad conjunta para el nivel y la importancia en el procesamiento. Alumnos

Por último, el gráfico 4.28, referido a la comunicación de información, vuelve a indicar lo mismo. 


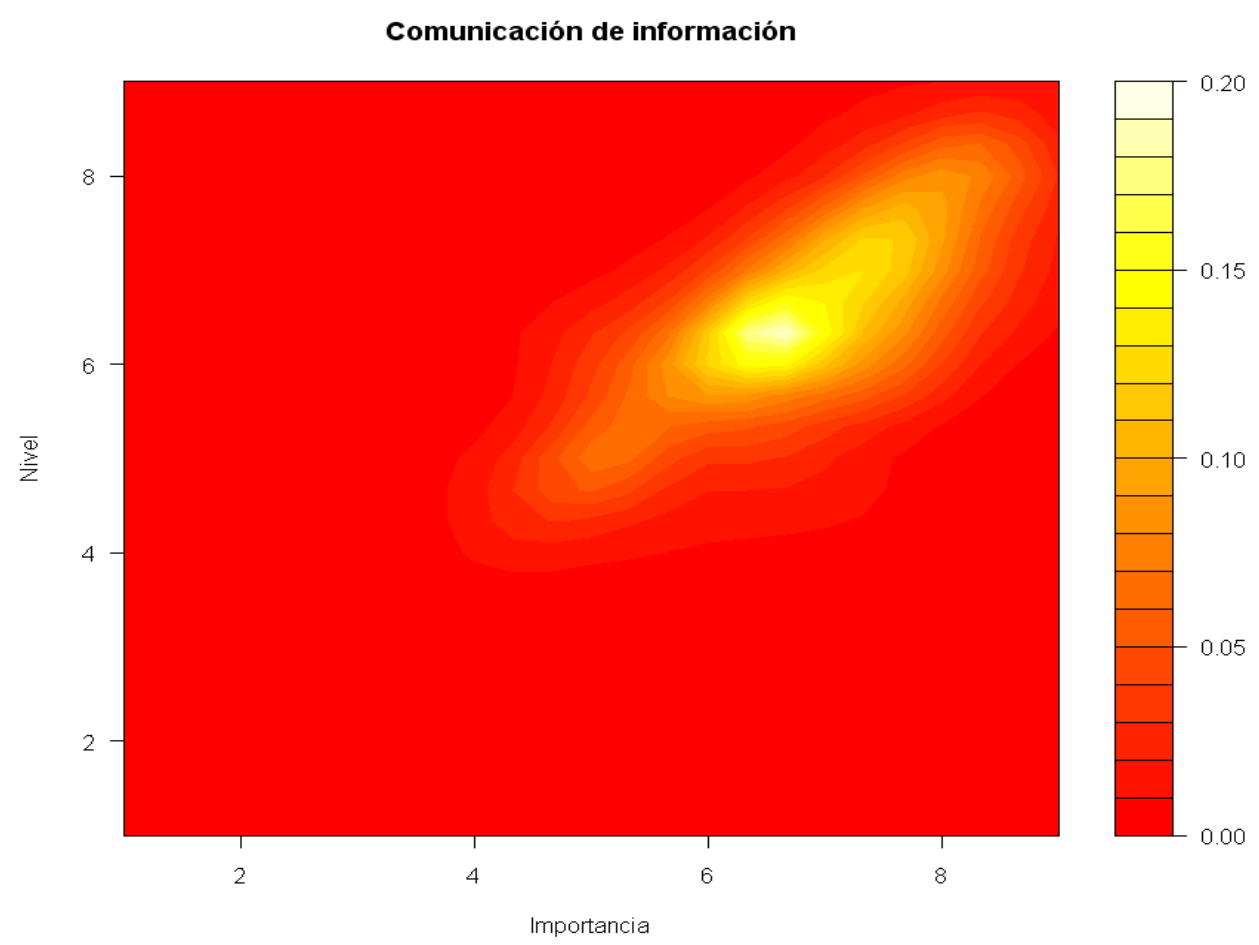

Gráfico 4.28 Distribución de densidad conjunta para el nivel y la importancia en la comunicación. Alumnos

En cuanto a la prueba de los rangos con signo de Wilcoxon, se procede a analizar los resultados obtenidos en la tabla 4.98. Como se puede observar en la citada tabla, después del cálculo de los rangos promedio provenientes de los valores de la diferencia positivos y negativos respectivamente, y del sumatorio de estos rangos positivos y negativos, los valores obtenidos para la $z$ arrojan valores que en todo caso están por encima, en términos absolutos, del $Z_{.99}$ establecido $\left(|z|>Z_{.99}=2.5758\right)$.

Tabla 4.98 Prueba de los rangos con signo de Wilcoxon. Importancia y nivel percibidos en competencias informacionales. Alumnos

\begin{tabular}{l|cc|ccc|cc}
\hline $\begin{array}{c}\text { Competencias } \\
\text { informacionales }\end{array}$ & $\overline{\boldsymbol{R}}_{+}$ & $\overline{\boldsymbol{R}}_{-}$ & $\sum \boldsymbol{R}_{+}$ & $\sum \boldsymbol{R}_{-}$ & $\boldsymbol{z}$ & $\boldsymbol{p}$. \\
\hline $\begin{array}{l}\text { Búsqueda de información } \\
\text { Evaluación de información }\end{array}$ & 364.62 & 486.59 & 193282.00 & 261299.00 & -4.010 & $<.001$ \\
\hline Procesamiento de información & 391.02 & 471.79 & 139201.50 & 245801.50 & -7.116 & $<.001$ \\
\hline $\begin{array}{l}\text { Comunicación y difusión de } \\
\text { información }\end{array}$ & 394.75 & 476.38 & 120794.00 & 281062.00 & -10.357 & $<.001$ \\
\hline
\end{tabular}

Rechazamos la $\mathrm{H}_{0}$ sobre la igualdad de rangos y estamos en condiciones de afirmar, que los estudiantes del segundo ciclo de ESO en Castilla y León perciben que su formación es inferior a la importancia que conceden a las diferentes dimensiones que conforman las competencias informacionales. 
Así, a nivel general, el alumnado del segundo ciclo de ESO de la Comunidad de Castilla y León declara que tiene un nivel de conocimientos sobre competencias informacionales medio-alto, levemente inferior al nivel de importancia que las concede. Estas cifras son normales teniendo en cuenta otros estudios, como el titulado "La escuela en la sociedad red" (Sigalés \& Mominó, 2004), que destaca que cuando los alumnos tienen que valorar sus conocimientos sobre el dominio de internet, El $15.6 \%$ afirma tener conocimientos muy altos, el $36.6 \%$ altos, el $30.4 \%$ medios, y el $17.1 \%$ restante entre bajos o muy bajos.

\subsubsection{Estudio comparado de competencias informacionales, por grupos principales}

A lo largo de este apartado se definirán las diferencias localizadas agrupando a los sujetos de la muestra por grupos principales. Los principales grupos seleccionados se basan, como se describió en los datos demográficos de este informe de resultados, en el sexo, el curso académico en el que está matriculado el sujeto, y los estudios de los padres.

Así, se irá analizando para cada uno de estos grupos su comportamiento comparado en la importancia asignada y el nivel autopercibido en las diferentes dimensiones constitutivas de las competencias informacionales.

Como las variables criterio se comportan conforme a distribuciones diferentes de la normal, a lo largo de los análisis se aplicarán las técnicas no paramétricas más apropiadas.

\subsubsection{Estudio comparado por sexo}

En los últimos años, en la literatura científica del ámbito de la investigación educativa se detecta una cierta tendencia hacia los estudios de género (Gargallo Castel, Esteban Salvador, \& Pérez Sanz, 2010; Gargallo López, Suárez, \& Belloch, 2003; Mullola et al., 2011; Ohland et al., 2011), que tratan de localizar algunas diferencias culturales existentes entre hombres y mujeres que tengan algún tipo de efecto sobre las condiciones en las que se desarrollan ciertas competencias. Este tipo de investigaciones es especialmente recurrente en trabajos relacionados con los hábitos de manejo de las TIC y la competencia digital, y la evidencia científica muestra que existen diferencias de género significativas en lo que respecta a los hábitos y 
habilidades en el manejo de estas tecnologías (Iglesias Fernández, Llorente Heras, \& Dueñas Fernández, 2010; Ruiz Palomero \& Sánchez Rodríguez, 2010).

Así, dada la estrecha relación existente entre las TIC y las competencias informacionales, soportada por una amplia literatura (Bundy, 2004; Jarson, 2010; O’Farrill, 2008; Pifarré et al., 2009; Pinto Molina, 2009), cabe plantearse si la importancia y el nivel autopercibidos sobre las competencias informacionales estará mediatizada en algún aspecto por el sexo.

Veamos en primer lugar cómo se comportan los descriptivos básicos por sexo. En la tabla 4.99 se indica cómo, en función del sexo, las mujeres tienden a atribuir una mayor importancia a todas las dimensiones de las competencias informacionales.

Tabla 4.99 Estadísticos descriptivos. Importancia por sexo. Alumnos

\begin{tabular}{l|cc|cc|cc}
\hline \multicolumn{1}{c|}{ Importancia asignada } & $\overline{\boldsymbol{X}}_{\boldsymbol{h}}$ & $\boldsymbol{S}_{\boldsymbol{h}}$ & $\overline{\boldsymbol{X}}_{\boldsymbol{m}}$ & $\boldsymbol{S}_{\boldsymbol{m}}$ & $\boldsymbol{n}_{\boldsymbol{h}}$ & $\boldsymbol{n}_{\boldsymbol{m}}$ \\
\hline Búsqueda de información & 6.41 & 1.33 & 6.56 & 1.18 & 562 & 546 \\
\hline Evaluación de información & 5.87 & 1.60 & 6.05 & 1.57 & 541 & 524 \\
\hline Procesamiento de información & 6.60 & 1.31 & 6.66 & 1.33 & 538 & 519 \\
\hline Comunicación y difusión de información & 6.40 & 1.52 & 6.83 & 1.29 & 554 & 535 \\
\hline
\end{tabular}

Estos datos nos indican, por tanto, que en la muestra son las mujeres las que valoran más positivamente la importancia de las competencias informacionales.

En la tabla 4.100 se muestra la prueba de la $U$ de Mann-Whitney para la importancia en cada una de las dimensiones asignadas. Tomando un nivel de significación $\alpha=.01$, estamos en condiciones de rechazar la $H_{0}$ en las diferencias obtenidas para la importancia asignada en la comunicación y difusión de información $(z=4.834 ; p<.001)$. Así, se puede afirmar que existen diferencias significativas en función del sexo en lo que respecta a la importancia asignada en la comunicación y difusión de información

Tabla 4.100 Prueba Prueba U de Mann-Whitney. Importancia por sexo. Alumnos

\begin{tabular}{l|cc|c|cr}
\hline \multicolumn{1}{c|}{ Importancia asignada } & $\sum \boldsymbol{R}_{\boldsymbol{h}}$ & $\sum \boldsymbol{R}_{\boldsymbol{m}}$ & $\boldsymbol{U}$ & $\boldsymbol{z}$ & $\boldsymbol{p}$. \\
\hline Búsqueda de información & 301131.00 & 313255.00 & 142928.000 & -1.973 & .048 \\
\hline Evaluación de información & 278164.50 & 289480.50 & 131553.500 & -2.032 & .042 \\
\hline Procesamiento de información & 280419.00 & 278734.00 & 135428.000 & -0.844 & .399 \\
\hline $\begin{array}{l}\text { Comunicación y difusión de } \\
\text { información }\end{array}$ & $\mathbf{2 7 6 8 6 7 . 0 0}$ & $\mathbf{3 1 6 6 3 8 . 0 0}$ & $\mathbf{1 2 3 1 3 2 . 0 0 0}$ & $\mathbf{- 4 . 8 3 4}$ & $<.001$ \\
\hline
\end{tabular}


En cuanto al nivel autopercibido, en la tabla 4.101, que indica los estadísticos descriptivos en función del sexo, se muestra que existen diferencias en la muestra favorables a los hombres en las tres primeras dimensiones y a las mujeres en la última, comunicación y difusión de información.

Tabla 4.101 Estadísticos descriptivos. Nivel por sexo. Alumnos

\begin{tabular}{l|cc|cc|cc}
\hline \multicolumn{1}{c|}{ Nivel autopercibido } & $\overline{\boldsymbol{X}}_{\boldsymbol{h}}$ & $\boldsymbol{S}_{\boldsymbol{h}}$ & $\overline{\boldsymbol{X}}_{\boldsymbol{m}}$ & $\boldsymbol{S}_{\boldsymbol{m}}$ & $\boldsymbol{n}_{\boldsymbol{h}}$ & $\boldsymbol{n}_{\boldsymbol{m}}$ \\
\hline Búsqueda de información & 6.49 & 1.28 & 6.35 & 1.20 & 547 & 529 \\
\hline Evaluación de información & 5.65 & 1.51 & 5.51 & 1.44 & 535 & 513 \\
\hline Procesamiento de información & 6.53 & 1.33 & 6.27 & 1.31 & 545 & 510 \\
\hline Comunicación y difusión de información & 6.19 & 1.42 & 6.41 & 1.29 & 544 & 530 \\
\hline
\end{tabular}

Por otra parte, midiendo la significación de estas diferencias, en la tabla 4.102 se aplica la prueba para comparar las medianas en función del sexo. Como se puede observar, se obtienen valores significativos tanto en el procesamiento como en la comunicación. Así, existen diferencias significativas en función del sexo en las medianas de ambas variables. Estas diferencias son, en el caso del procesamiento de información, favorables a los hombres, y en el caso de la comunicación de información, favorables a las mujeres.

Tabla 4.102 Prueba Prueba U de Mann-Whitney. Nivel por sexo. Alumnos

\begin{tabular}{l|cc|c|cc}
\hline \multicolumn{1}{c|}{ Nivel autopercibido } & $\sum \boldsymbol{R}_{\boldsymbol{h}}$ & $\sum \boldsymbol{R}_{\boldsymbol{m}}$ & $\boldsymbol{U}$ & $\boldsymbol{z}$ & $\boldsymbol{p}$. \\
\hline Búsqueda de información & 303886.50 & 275539.50 & 135354.500 & -1.832 & .067 \\
\hline Evaluación de información & 287063.00 & 262613.00 & 130772.000 & -1.319 & .187 \\
\hline Procesamiento de información & $\mathbf{3 0 3 4 2 0 . 5 0}$ & $\mathbf{2 5 3 6 1 9 . 5 0}$ & $\mathbf{1 2 3 3 1 4 . 5 0 0}$ & $\mathbf{- 3 . 1 6 9}$ & $\mathbf{. 0 0 2}$ \\
\hline $\begin{array}{l}\text { Comunicación y difusión de } \\
\text { información }\end{array}$ & $\mathbf{2 7 6 9 4 9 . 0 0}$ & $\mathbf{3 0 0 3 2 6 . 0 0}$ & $\mathbf{1 2 8 7 0 9 . 0 0 0}$ & $\mathbf{- 3 . 0 4 3}$ & $\mathbf{. 0 0 2}$ \\
\hline
\end{tabular}

* Nivel de significación $\alpha=.01$

Así, haciendo un análisis más profundo de estos resultados podemos interpretar, a nivel general, que mientras que el grupo de las mujeres de nuestra muestra tiende a valorar de un modo más alto la importancia de las competencias informacionales, son los hombres los que afirman tener un nivel más alto. Así, conforme a las deducciones que realizábamos con anterioridad, en este caso podemos señalar que es el grupo de mujeres el que está indicando que necesita una formación más amplia en estos aspectos. Por su parte, en el caso de los hombres, aunque mantienen unas 
puntuaciones mayores en la importancia que en el nivel autopercibido, estas diferencias son menores.

A nivel más específico, podemos observar cómo las alumnas de segundo ciclo de ESO de Castilla y León consideran más importante la dimensión de comunicación de información y se sienten más formadas en la misma. En cambio, los hombres se sienten más formados que las mujeres en las competencias relacionadas con el procesamiento de información.

\subsubsection{Estudio comparado por curso}

Dado que 30 y 4 o de la ESO se encuentran situados en el mismo ciclo educativo, y que existe solamente diferencia de un año entre cursar uno u otro nivel, la hipótesis de partida es que no existen diferencias significativas entre los alumnos de 30 y 4 o de ESO en lo que respecta a la importancia concedida y el nivel autopercibido sobre las dimensiones que componen las competencias informacionales.

En primer lugar, si analizamos los estadísticos descriptivos básicos a nivel muestral, como se indica en la tabla 4.103, se puede observar una ligera tendencia de los alumnos de la muestra de 4 o curso a valorar por encima la importancia de las subcompetencias derivadas de las competencias informacionales.

Tabla 4.103 Estadísticos descriptivos. Importancia por curso

\begin{tabular}{|c|c|c|c|c|c|c|}
\hline Importancia asignada & $\bar{X}_{30}$ & $S_{30}$ & $\bar{X}_{4}$ & $S_{4 o}$ & $n_{30}$ & $n_{4}$ \\
\hline Búsqueda de información & 6.42 & 1.38 & 6.57 & 1.11 & 599 & 515 \\
\hline Evaluación de información & 5.90 & 1.67 & 6.03 & 1.49 & 579 & 491 \\
\hline Procesamiento de información & 6.60 & 1.38 & 6.67 & 1.25 & 574 & 491 \\
\hline Comunicación y difusión de información & 6.54 & 1.50 & 6.70 & 1.35 & 590 & 505 \\
\hline
\end{tabular}

Para comprobar la significatividad de las diferencias en cuanto a la importancia concedida a nivel poblacional, como se muestra en la tabla 4.104, se aplica la prueba $U$ de Mann-Whitney. Se observa cómo todos los índices del estadístico de contraste se encuentran dentro de la zona de aceptación (aceptamos $\mathrm{H}_{0}$ en todos los contrastes) a un nivel de significación $\alpha=.01$. Así, no existen diferencias entre los alumnos de 3으 y 4 으 de educación secundaria en cuanto a la importancia concedida. 
Tabla 4.104 Prueba Prueba U de Mann-Whitney. Importancia por curso

\begin{tabular}{l|cc|c|cc}
\hline \multicolumn{1}{c|}{ Importancia asignada } & $\sum_{\boldsymbol{R}^{\circ}}$ & $\sum \boldsymbol{R}_{\mathbf{4}^{\circ}}$ & $\boldsymbol{U}$ & $\boldsymbol{z}$ & $\boldsymbol{p}$. \\
\hline Búsqueda de información & 330359.00 & 290696.00 & 150659.00 & -0.670 & .503 \\
\hline Evaluación de información & 305215.00 & 267770.00 & 137305.00 & -0.962 & .336 \\
\hline Procesamiento de información & 303711.00 & 263934.00 & 138686.00 & -0.446 & .655 \\
\hline $\begin{array}{l}\text { Comunicación y difusión de } \\
\text { información }\end{array}$ & 315585.50 & 284474.50 & 141240.50 & -1.484 & .138 \\
\hline
\end{tabular}

$*$ Nivel de significación $\alpha=.01$

En lo que respecta al nivel autopercibido sobre competencias informacionales en función del curso se muestra la tabla 4.105, que analiza las diferencias en los estadísticos descriptivos básicos. Se pone en evidencia que, en la muestra, las diferencias son, de nuevo, ligeramente favorables a los sujetos de 4ㅇ de la ESO.

Tabla 4.105 Estadísticos descriptivos. Importancia por curso

\begin{tabular}{l|cc|cc|cc}
\hline \multicolumn{1}{c|}{ Nivel autopercibido } & $\overline{\boldsymbol{X}}_{\mathbf{3 0}}$ & $\boldsymbol{S}_{\mathbf{3 0}}$ & $\overline{\boldsymbol{X}}_{\mathbf{4 0}}$ & $\boldsymbol{S}_{\mathbf{4} \boldsymbol{0}}$ & $\boldsymbol{n}_{\mathbf{3 0}}$ & $\boldsymbol{n}_{\mathbf{4 0}}$ \\
\hline Búsqueda de información & 6.39 & 1.35 & 6.45 & 1.13 & 578 & 503 \\
\hline Evaluación de información & 5.57 & 1.57 & 5.61 & 1.39 & 568 & 485 \\
\hline Procesamiento de información & 6.35 & 1.43 & 6.48 & 1.21 & 576 & 486 \\
\hline Comunicación y difusión de información & 6.23 & 1.45 & 6.38 & 1.24 & 585 & 495 \\
\hline
\end{tabular}

* Nivel de significación $\alpha=.01$

Por último, la tabla 4.106 indica la prueba de contraste de hipótesis. De nuevo volvemos a no encontrar diferencias significativas (n.s.=.01) en caso alguno.

Tabla 4.106 Prueba Prueba U de Mann-Whitney. Nivel por curso

\begin{tabular}{l|cc|c|cc}
\hline \multicolumn{1}{c|}{ Nivel autopercibido } & $\sum \boldsymbol{R}_{\boldsymbol{h}}$ & $\sum \boldsymbol{R}_{m}$ & $\boldsymbol{U}$ & $\boldsymbol{z}$ & $\boldsymbol{p}$. \\
\hline Búsqueda de información & 310591.00 & 274230.00 & 143260.000 & -0.412 & .680 \\
\hline Evaluación de información & 297121.50 & 257809.50 & 135525.500 & -0.451 & .652 \\
\hline Procesamiento de información & 300202.00 & 264251.00 & 134026.000 & -1.194 & .232 \\
\hline $\begin{array}{l}\text { Comunicación y difusión de } \\
\text { información }\end{array}$ & 309038.00 & 274702.00 & 137633.000 & -1.402 & .161 \\
\hline
\end{tabular}

* Nivel de significación $\alpha=.01$

En todo caso, podemos finalizar señalando que por curso académico no existen diferencias entre los sujetos. Esto quiere decir que la variable curso no tiene influencia sobre la importancia asignada y el nivel autopercibido en las dimensiones constitutivas 
de las competencias informacionales. Las diferencias localizadas son únicamente a nivel muestral, y su tamaño es prácticamente imperceptible.

\subsubsection{Estudio comparado por nivel de estudios de los padres}

El estudio del estatus socio-económico y cultural de las familias es un tema muy recurrido en la investigación educativa (Doussoulin, 2005; Fernández Fernández, 2005; Gil Flores, 2011; Joaristi Olariaga et al., 2012; Lizasoain Hernández \& Joaristi Olariaga, 2010; Mora Corral, 2010; Peralta, 1997). De hecho, las investigaciones llevadas a cabo al respecto suelen confirmar que el nivel socio-económico y cultural de las familias están relacionados con el rendimiento académico y el estilo cognitivo de los hijos e influyen en su desarrollo (Gil Flores, 2011; Lizasoain Hernández \& Joaristi Olariaga, 2010; Peralta, 1997). Así, a lo largo de este sub-epígrafe trataremos de estudiar el comportamiento del alumnado del segundo ciclo de educación secundaria en cuanto a la percepción de importancia y nivel de las competencias informacionales en función del nivel de estudios de los padres.

Para llevar a cabo el contraste de hipótesis en esta ocasión, al tratarse de variables de agrupación con más de dos categorías, y de variables criterio con distribuciones diferentes de la normal, se aplicará la prueba de la $\mathrm{H}$ de Kruskal-Wallis, que se basa en cálculos a partir de los rangos de cada uno de los grupos conformados por las categorías de la variable independiente.

En primer lugar, analizaremos las diferencias localizadas en la muestra a partir de la comparación de los descriptivos básicos de las variables. La tabla 4.107 muestra estos estadísticos. Analizándolos, vemos cómo la tendencia en la muestra es hacia valorar más positivamente las competencias relacionadas con el manejo de la información a medida que los padres tienen estudios más avanzados. Así, las diferencias, como se puede observar en la tabla, se reflejan entre los sujetos de la muestra de padres con estudios primarios y los alumnos de padres con estudios universitarios, quedando los estudiantes de padres con estudios secundarios en todos los casos en una posición intermedia, más cercana al grupo de padres con estudios primarios. 
Tabla 4.107 Estadísticos descriptivos. Importancia por estudios del padre

\begin{tabular}{l|cc|cc|cc}
\hline \multicolumn{1}{c|}{ Importancia asignada } & $\overline{\boldsymbol{X}}_{\text {Prim }}$ & $\boldsymbol{S}_{\text {Prim }}$ & $\overline{\boldsymbol{X}}_{\text {Sec }}$ & $\boldsymbol{S}_{\text {Sec }}$ & $\overline{\boldsymbol{X}}_{\text {Univ }}$ & $\boldsymbol{S}_{\text {Univ }}$ \\
\hline Búsqueda de información & 6.19 & 1.36 & 6.48 & 1.24 & 6.72 & 1.13 \\
\hline Evaluación de información & 5.82 & 1.57 & 5.97 & 1.54 & 6.13 & 1.58 \\
\hline Procesamiento de información & 6.41 & 1.45 & 6.63 & 1.25 & 6.81 & 1.22 \\
\hline Comunicación y difusión de información & 6.35 & 1.50 & 6.52 & 1.42 & 6.91 & 1.30 \\
\hline
\end{tabular}

Una vez analizadas las tendencias de la muestra a partir de los descriptivos básicos, se presenta la tabla 4.108, que aplica el contraste de hipótesis para la importancia declarada en función de los estudios del padre.

Tabla 4.108 Prueba Prueba H de Kruskal-Wallis. Importancia por estudios del padre

\begin{tabular}{|c|c|c|c|c|c|}
\hline Importancia asignada & $\sum \boldsymbol{R}_{\text {Prim }}$ & $\sum \boldsymbol{R}_{S e c}$ & $\sum R_{U n i v}$ & $x^{2}$ & p. \\
\hline Búsqueda de información & 85441.50 & 260560.50 & 223776.00 & 20.391 & $<.001$ \\
\hline Evaluación de información & 83074.00 & 243345.00 & 199406.00 & 7.259 & .027 \\
\hline Procesamiento de información & 80696.00 & 236922.00 & 200035.00 & 10.374 & .006 \\
\hline $\begin{array}{l}\text { Comunicación y difusión de } \\
\text { información }\end{array}$ & 81644.50 & 244684.50 & 224396.00 & 26.884 & $<.001$ \\
\hline
\end{tabular}

En cuanto a las diferencias localizadas en función de los estudios del padre, nos encontramos, para un nivel de significación $\alpha=.01$, con diferencias significativas en la importancia asignada a la búsqueda, el procesamiento y la comunicación de información.

A continuación se analizan las diferencias para el nivel autopercibido en función de los estudios del padre. En la tabla 4.109 se muestran los descriptivos básicos en función de la variable de agrupación.

Tabla 4.109 Estadísticos descriptivos. Nivel por estudios del padre

\begin{tabular}{l|cc|cc|cc}
\hline \multicolumn{1}{c|}{ Nivel autopercibido } & $\overline{\boldsymbol{X}}_{\text {Prim }}$ & $\boldsymbol{S}_{\text {Prim }}$ & $\overline{\boldsymbol{X}}_{\text {Sec }}$ & $\boldsymbol{S}_{\text {Sec }}$ & $\overline{\boldsymbol{X}}_{\text {Univ }}$ & $\boldsymbol{S}_{\text {Univ }}$ \\
\hline Búsqueda de información & 6.20 & 1.34 & 6.36 & 1.21 & 6.67 & 1.15 \\
\hline Evaluación de información & 5.44 & 1.44 & 5.62 & 1.46 & 5.70 & 1.46 \\
\hline Procesamiento de información & 6.27 & 1.43 & 6.35 & 1.30 & 6.59 & 1.24 \\
\hline Comunicación y difusión de información & 6.03 & 1.42 & 6.15 & 1.35 & 6.67 & 1.20 \\
\hline
\end{tabular}


En este caso, se vuelve a constatar una tendencia en la muestra a percibir un nivel personal más alto en competencias informacionales si el padre posee estudios universitarios.

Si analizamos el nivel de significatividad de estas diferencias, indicado en la tabla 4.110, nos encontramos diferencias significativas en la búsqueda y la comunicación de información.

Tabla 4.110 Prueba Prueba H de Kruskal-Wallis. Nivel por estudios del padre

\begin{tabular}{l|ccc|cc}
\hline \multicolumn{1}{c|}{ Nivel autopercibido } & $\sum_{\boldsymbol{R}_{\text {Prim }}}$ & $\sum_{\boldsymbol{R}_{\text {Sec }}}$ & $\sum \boldsymbol{R}_{\text {Univ }}$ & $\chi^{2}$ & $\boldsymbol{p}$. \\
\hline Búsqueda de información & $\mathbf{8 2 7 5 4 . 5 0}$ & $\mathbf{2 3 7 5 4 3 . 5 0}$ & $\mathbf{2 1 5 8 3 2 . 0 0}$ & $\mathbf{2 2 . 0 0 3}$ & $<.001$ \\
\hline Evaluación de información & 81999.00 & 239877.00 & 187669.00 & 4.077 & .130 \\
\hline Procesamiento de información & 82944.00 & 234084.00 & 198592.00 & 8.990 & .011 \\
\hline $\begin{array}{l}\text { Comunicación y difusión de } \\
\text { información }\end{array}$ & $\mathbf{7 9 6 8 6 . 0 0}$ & $\mathbf{2 3 3 1 3 7 . 0 0}$ & $\mathbf{2 2 2 2 7 2 . 0 0}$ & $\mathbf{4 2 . 5 6 4}$ & $<.001$ \\
\hline
\end{tabular}

Nuevamente, se observa una ligera tendencia de los estudiantes de padres con estudios inferiores a puntuar de manera más baja su percepción de competencia en cada una de las dimensiones. En este caso, las diferencias son entre los estudiantes de padres con estudios universitarios y los otros dos grupos, siempre a favor de los estudiantes de padres con estudios superiores.

En conclusión, podemos afirmar que el nivel de estudios de los padres tiene influencia sobre la importancia asignada y el nivel autopercibido de los estudiantes de educación secundaria de la comunidad de Castilla y León. Además, se puede señalar que a medida que los padres tienen un nivel educativo superior, los hijos tienden a valorar más positivamente tanto la importancia como el nivel autopercibido en las competencias informacionales.

Veamos a continuación la influencia de los estudios de la madre sobre las dimensiones de las competencias informacionales.

En primer lugar, se estudia la influencia sobre la importancia asignada a la búsqueda, evaluación, procesamiento y comunicación de información. Veamos, a partir de los datos mostrados en la tabla 4.111, entre qué grupos de la muestra se encuentran estas diferencias. Los descriptivos básicos indican, a nivel general, una tendencia similar a la localizada en el estudio comparativo por estudios del padre. Esta tendencia consiste en que, a medida que las madres tienen un mayor nivel de 
estudios, la importancia que asignan los sujetos de la muestra a las competencias informacionales es mayor.

Tabla 4.111 Estadísticos descriptivos. Importancia por estudios de la madre

\begin{tabular}{l|cc|cc|cc}
\hline \multicolumn{1}{c|}{ Importancia asignada } & $\overline{\boldsymbol{X}}_{\text {Prim }}$ & $\boldsymbol{S}_{\text {Prim }}$ & $\overline{\boldsymbol{X}}_{\text {Sec }}$ & $\boldsymbol{S}_{\text {Sec }}$ & $\overline{\boldsymbol{X}}_{\text {Univ }}$ & $\boldsymbol{S}_{\text {Univ }}$ \\
\hline Búsqueda de información & 6.14 & 1.43 & 6.47 & 1.23 & 6.77 & 1.14 \\
\hline Evaluación de información & 5.76 & 1.55 & 5.94 & 1.59 & 6.19 & 1.53 \\
\hline Procesamiento de información & 6.30 & 1.51 & 6.66 & 1.26 & 6.83 & 1.21 \\
\hline Comunicación y difusión de información & 6.36 & 1.67 & 6.49 & 1.40 & 6.95 & 1.28 \\
\hline
\end{tabular}

Además, se observa cómo estas diferencias de asignación no son escalonadas, sino que dan un salto principalmente entre los estudios secundarios y los universitarios. Así, mientras que la importancia asignada en la muestra por los estudiantes con madres que han cursado estudios primarios y secundarios es similar, la de los estudiantes con madres con titulación universitaria es superior al resto.

En este caso, como muestra la tabla 4.112, se localizan diferencias significativas en todas las variables estudiadas. Además, el valor del estadístico de contraste Chi Cuadrado es en todos los casos mayor que en la prueba llevada a cabo para los estudios de los padres.

Tabla 4.112 Prueba Prueba H de Kruskal-Wallis. Importancia por estudios de la madre

\begin{tabular}{l|ccc|cc}
\hline \multicolumn{1}{c|}{ Importancia asignada } & $\sum R_{\text {Prim }}$ & $\sum R_{\text {Sec }}$ & $\sum R_{\text {Univ }}$ & $\chi^{2}$ & $p$. \\
\hline Búsqueda de información & 68697.00 & 272253.00 & 238476.00 & 28.475 & $<.001$ \\
\hline Evaluación de información & 66042.50 & 256895.00 & 211123.50 & 11.844 & .003 \\
\hline Procesamiento de información & 62105.00 & 252911.50 & 209783.50 & 16.082 & $<.001$ \\
\hline $\begin{array}{l}\text { Comunicación y difusión de } \\
\text { información }\end{array}$ & 68547.50 & 254686.00 & 236977.50 & 32.319 & $<.001$ \\
\hline
\end{tabular}

En lo que respecta a las diferencias localizadas para el nivel autopercibido, en la tabla 4.113 se muestra el análisis de los estadísticos descriptivos en función de los estudios de la madre. Las tendencias son similares a las percibidas en los análisis anteriores llevados a cabo con los estudios del padre como variable de agrupación. Si cabe, las diferencias obtenidas en la muestra son en este caso más importantes. 
Tabla 4.113 Estadísticos descriptivos. Nivel por estudios de la madre

\begin{tabular}{l|cc|cc|cc}
\hline \multicolumn{1}{c|}{ Nivel autopercibido } & $\overline{\boldsymbol{X}}_{\text {Prim }}$ & $\boldsymbol{S}_{\text {Prim }}$ & $\overline{\boldsymbol{X}}_{\text {Sec }}$ & $\boldsymbol{S}_{\text {Sec }}$ & $\overline{\boldsymbol{X}}_{\text {Univ }}$ & $\boldsymbol{S}_{\text {Univ }}$ \\
\hline Búsqueda de información & 6.11 & 1.29 & 6.39 & 1.19 & 6.68 & 1.21 \\
\hline Evaluación de información & 5.43 & 1.35 & 5.58 & 1.45 & 5.77 & 1.53 \\
\hline Procesamiento de información & 6.08 & 1.35 & 6.40 & 1.33 & 6.60 & 1.26 \\
\hline Comunicación y difusión de información & 6.02 & 1.38 & 6.18 & 1.35 & 6.64 & 1.25 \\
\hline
\end{tabular}

Por otro lado, como se observa en la tabla 4.114, volvemos a encontrarnos valores significativos del estadístico de contraste en la búsqueda, procesamiento y comunicación de información, estando la evaluación de información en valores muy cercanos a la zona de rechazo para un nivel de significación $\alpha=.01$, y dentro de la zona de rechazo para un nivel de significación $\alpha=.05$.

Tabla 4.114 Prueba Prueba H de Kruskal-Wallis. Nivel por estudios de la madre

\begin{tabular}{l|ccc|cc}
\hline \multicolumn{1}{c|}{ Nivel auto-pecibido } & $\sum_{\boldsymbol{R}_{\text {Prim }}}$ & $\sum_{\boldsymbol{R}_{\text {Sec }}}$ & $\sum \boldsymbol{R}_{\text {Univ }}$ & $\chi^{2}$ & $\boldsymbol{p}$. \\
\hline Búsqueda de información & $\mathbf{6 2 1 9 4 . 5}$ & $\mathbf{2 5 5 7 5 7 . 5}$ & $\mathbf{2 2 6 4 9 4}$ & $\mathbf{2 6 . 9 5 9}$ & $<.001$ \\
\hline Evaluación de información & 65719.5 & 249627.5 & 202306 & 8.617 & .013 \\
\hline Procesamiento de información & 60742.5 & 254159 & 209898.5 & 16.418 & $<.001$ \\
\hline $\begin{array}{l}\text { Comunicación y difusión de } \\
\text { información }\end{array}$ & 63793 & 247802 & 230766 & 37.201 & $<.001$ \\
\hline
\end{tabular}

Estos resultados nos indican que los estudios de la madre influyen de manera significativa sobre el nivel autopercibido en competencias informacionales. Además, se puede observar cómo se localizan diferencias significativas principalmente entre el grupo de madres con estudios primarios y el de estudios universitarios. Por otro lado, como ocurría con el análisis de la importancia asignada, el grupo de estudiantes con madres con estudios secundarios, está más cerca de los estudiantes con madres con estudios básicos en su nivel percibido para cada una de las dimensiones de las competencias informacionales.

En conclusión, podemos afirmar que el nivel de estudios de las madres tiene influencia sobre la importancia asignada y el nivel autopercibido de los estudiantes de educación secundaria de la comunidad de Castilla y León. Además, esta influencia parece ser más importante en el caso de los estudios de la madre, que en el caso de los de los padres. 


\subsubsection{Estudio correlacional y multivariante en estudiantes}

Por lo argumentado anteriormente a lo largo del desarrollo teórico y el estudio empírico, parece clara la importancia de las TIC como elemento esencial que promociona el surgimiento y dinamiza el desarrollo de la sociedad de la información (Castells, 1999a; Valimaa \& Hoffman, 2008). Lo que es más, centrándose en el ámbito educativo, parece también evidente la implicación de la tecnología sobre los currículos nacionales y programas formativos (Diario oficial de la Unión Europea, 2006; OCDE, 2011), desde su surgimiento, hasta la actualidad (Cabero Almenara \& Alonso García, 2007).

Esta relevancia asignada a las TIC desde todos los sectores, especialmente el educativo, parece haber sido el principal detonante de la emergencia de determinadas competencias (García, Gros, \& Noguera, 2010), especialmente las competencias informacionales, consideradas en la actualidad como competencias básicas indispensables para alcanzar el objetivo de la sociedad del conocimiento (Area Moreira, 2010a; Weiner, 2010). Así, en la amplia literatura existente referente al tópico, se puede observar la estrecha relación que los autores atribuyen a las TIC y las competencias informacionales (Markauskaite, 2006; O'Farrill, 2008), no teniendo sentido estas últimas sin la existencia de las primeras. Sin embargo, aunque ya se ha apuntado previamente, cabe también destacar que las competencias informacionales comprenden un rango de contenidos, habilidades y actitudes mucho más amplio que el simple manejo de las TIC (Bawden, 2001; CRUE-TIC \& REBIUN, 2012).

Para finalizar estas consideraciones iniciales, enlazando los razonamientos aportados con la investigación que se presenta, el propósito de esta porción del estudio no es otro que comprobar a nivel empírico si estos postulados teóricos se cumplen. En suma, se pone a prueba si la importancia fundamental que se asigna a las TIC en lo que se refiere al desarrollo de competencias informacionales es real, esto es, si el empleo de las TIC influye en la construcción de las competencias informacionales, fomentando y promocionando su desarrollo.

Así, a nivel operativo, nos planteamos contrastar la siguiente hipótesis de trabajo: la frecuencia y el nivel en el empleo de diferentes herramientas y aplicaciones informáticas ejerce un efecto directo positivo sobre la percepción de auto-eficacia en el 
conjunto de tareas que integran las competencias informacionales en alumnos de Educación Secundaria de Castilla y León.

En primer lugar, se llevará un estudio previo de las relaciones lineales entre las variables estudiadas, para establecer qué relaciones son significativas y cuáles no. A continuación, se procederá al planteamiento de un modelo causal explicativo del desarrollo de las competencias informacionales a partir de la frecuencia y habilidad en el empleo de herramientas informáticas. Por último, se llevará a cabo un estudio de las diferentes evoluciones de este modelo en función de los grupos principales.

\subsubsection{Relación lineal entre variables}

En el presente apartado se estudia la relación entre las variables relacionadas con el manejo de herramientas informáticas y las variables relacionadas con las competencias informacionales autopercibidas.

En primer lugar, se va a proceder a definir las variables relacionadas con el manejo de herramientas informáticas. El resto de variables, las relacionadas con las competencias informacionales autopercibidas, ya se han señalado previamente, por lo que no se definirán para este estudio.

Las variables relacionadas con el manejo de herramientas informáticas, recodificadas a partir de la suma de los ítems seleccionados a partir del cuestionario original, son las siguientes:

1. Frecuencia de manejo del ordenador en casa para actividades académicas

a. Usar un procesador de texto para escribir, hacer trabajos...

b. Usar el ordenador para hacer tareas

c. Navegar por internet para buscar información

d. Usar una hoja de cálculo para hacer actividades

e. Utilizar el ordenador para programar

f. Colaborar con un grupo o equipo a través de internet

g. Utilizar programas de ordenador para aprender

2. Frecuencia de manejo del ordenador en el aula para actividades académicas ${ }^{22}$

3. Frecuencia de manejo del ordenador en casa para actividades de ocio

\footnotetext{
${ }^{22}$ Compuesta de los mismos ítems que la frecuencia de manejo en casa para actividades académicas
} 

a. Escribir mensajes de correo, participar en chats,...
b. Usar programas de ordenador para dibujar, pintar,...
c. Jugar con el ordenador
d. Descargar música a través de internet
e. Descargar programas a través de internet

4. Frecuencia de manejo del ordenador en el aula para actividades de ocio ${ }^{23}$

5. Competencias informáticas multimedia
a. Grabar un CD
b. Descargar música de un CD
c. Descargar música de programas
d. Pasar música del ordenador a un MP3
e. Descargar la información de un móvil o una cámara
f. Bajar programas de internet

6. Competencias informáticas con herramientas portátiles
a. Saber escuchar un $\mathrm{mp3}$
b. Saber grabar vídeos con el móvil
c. Saber mandar mensajes por móvil
d. Saber usar una cámara digital

7. Competencias informáticas de comunicación y colaboración online: Web 2.0
a. Crear un blog
b. Comentar en un blog
c. Participar en chats, foros, blogs,...
d. Usar una red social
e. Subir vídeos a youtube

8. Competencias informáticas del ámbito académico
a. Usar hojas de cálculo
b. Encontrar datos en una base
c. Hacer presentaciones con textos, imágenes...
d. Recuperar, imprimir y guardar información

${ }^{23}$ Compuesta de los mismos ítems que frecuencia de manejo en casa para actividades de ocio. 
e. Instalar y arrancar programas

9. Competencias básicas en internet
a. Navegar por internet
b. Ver vídeos en Youtube
c. Utilizar buscadores

10. Competencias informáticas de ocio personal
a. Saber usar consolas de videojuegos
b. Jugar en red
c. Saber usar una PDA
d. Comprar por internet

Esta agrupación de ítems se realiza a partir del análisis factorial previo de las grandes dimensiones "frecuencia de empleo en el aula", "frecuencia de empleo en casa" y "Competencias informáticas".

En cuanto a las frecuencias de empleo tanto en el aula como en casa, se aplicó un análisis factorial para cada grupo de ítems, resultando de estos escalas unidimensionales en todos los análisis.

En el caso de las competencias informáticas, se aplicó un análisis factorial a la escala completa, siendo los resultados los que se muestran a continuación.

La tabla 4.115 muestra los resultados obtenidos en el análisis factorial exploratorio llevado a cabo a partir de los 27 ítems de la escala de competencias informáticas autopercibidas. El método de aplicación ha sido el de componentes principales, con rotación varimax.

Tabla 4.115 Análisis factorial exploratorio para las competencias informáticas. Alumnos

\begin{tabular}{cc|c|c|c|c|c|c|c|c}
\hline & \multicolumn{4}{c|}{ Autovalores iniciales } & \multicolumn{3}{c|}{$\begin{array}{c}\text { Sumas de las saturaciones al } \\
\text { cuadrado de la extracción }\end{array}$} & \multicolumn{3}{|c}{$\begin{array}{c}\text { Suma de las saturaciones } \\
\text { al cuadrado de la rotación }\end{array}$} \\
\cline { 2 - 12 } & Total & $\begin{array}{c}\text { \% de la } \\
\text { varianza }\end{array}$ & \% acumul. & Total & $\begin{array}{c}\text { \% de la } \\
\text { varianza }\end{array}$ & $\begin{array}{c}\text { \% } \\
\text { acumul. }\end{array}$ & Total & $\begin{array}{c}\text { \% de la } \\
\text { varianza }\end{array}$ & $\begin{array}{c}\text { \% } \\
\text { acumul. }\end{array}$ \\
\hline $\mathbf{1}$ & 9.145 & 33.871 & 33.871 & 9.145 & 33.871 & 33.871 & 3.493 & 12.94 & 12.94 \\
\hline $\mathbf{2}$ & 2.431 & 9.003 & 42.874 & 2.431 & 9.003 & 42.874 & 3.320 & 12.30 & 25.24 \\
\hline $\mathbf{3}$ & 1.646 & 6.097 & 48.971 & 1.646 & 6.097 & 48.971 & 3.126 & 11.58 & 36.81 \\
\hline $\mathbf{4}$ & 1.457 & 5.397 & 54.367 & 1.457 & 5.397 & 54.367 & 2.697 & 9.990 & 46.80 \\
\hline $\mathbf{5}$ & 1.191 & 4.410 & 58.777 & 1.191 & 4.410 & 58.777 & 2.262 & 8.379 & 55.18 \\
\hline
\end{tabular}




\begin{tabular}{|c|c|c|c|c|c|c|c|c|c|}
\hline 6 & 1.012 & 3.749 & 62.527 & 1.012 & 3.749 & 62.527 & 1.983 & 7.344 & 62.53 \\
\hline 7 & 0.804 & 2.977 & 65.504 & & & & & & \\
\hline 8 & 0.720 & 2.665 & 68.169 & & & & & & \\
\hline 9 & 0.693 & 2.567 & 70.736 & & & & & & \\
\hline 10 & 0.673 & 2.494 & 73.230 & & & & & & \\
\hline 11 & 0.612 & 2.266 & 75.496 & & & & & & \\
\hline 12 & 0.587 & 2.175 & 77.671 & & & & & & \\
\hline 13 & 0.561 & 2.078 & 79.749 & & & & & & \\
\hline 14 & 0.548 & 2.029 & 81.778 & & & & & & \\
\hline 15 & 0.510 & 1.888 & 83.666 & & & & & & \\
\hline 16 & 0.484 & 1.793 & 85.459 & & & & & & \\
\hline 17 & 0.474 & 1.755 & 87.213 & & & & & & \\
\hline 18 & 0.452 & 1.675 & 88.889 & & & & & & \\
\hline 19 & 0.427 & 1.580 & 90.469 & & & & & & \\
\hline 20 & 0.414 & 1.532 & 92.001 & & & & & & \\
\hline 21 & 0.391 & 1.448 & 93.449 & & & & & & \\
\hline 22 & 0.363 & 1.346 & 94.795 & & & & & & \\
\hline 23 & 0.346 & 1.280 & 96.076 & & & & & & \\
\hline 24 & 0.319 & 1.183 & 97.259 & & & & & & \\
\hline 25 & 0.299 & 1.106 & 98.365 & & & & & & \\
\hline 26 & 0.253 & 0.938 & 99.302 & & & & & & \\
\hline 27 & 0.188 & 0.698 & 100.000 & & & & & & \\
\hline
\end{tabular}

* Método de extracción: Análisis de componentes principales

Se puede observar que se obtienen 6 factores, que se corresponden con las variables expuestas más arriba, relacionadas con las competencias informáticas.

En la tabla 4.116, por su parte, se puede observar la solución rotada del análisis factorial. Para facilitar la lectura de los datos, se han ordenado por valores y se han eliminado los pesos factoriales inferiores a 0.46 . Se puede observar cómo todas las dimensiones están compuestas por al menos un factor con un peso superior a 0.7.

Tabla 4.116 Solución rotada AFAC. Competencias informáticas. Alumnos

\begin{tabular}{l|c|c|c|c|c|c}
\hline & \multicolumn{7}{|c}{ Componente } \\
\cline { 2 - 7 } & 1 & 2 & 3 & 4 & 5 & 6 \\
\hline 18. Grabar un CD & .763 & & & & & \\
\hline 17. Descargar música de un CD & .744 & & & & & \\
\hline 16. Descargar música de programas & .651 & & & & & \\
\hline 19. Pasar música del ordenador a un MP3 & .602 & & & & & \\
\hline $\begin{array}{l}\text { 20. Descargar la información de un móvil o una } \\
\text { cámara }\end{array}$ & .580 & & & & & \\
\hline
\end{tabular}




\begin{tabular}{l|l|l|l|l|l|l}
\hline 14. Bajar programas de internet & .512 & & & & & \\
\hline 23. Sabes escuchar un mp3 & & .804 & & & & \\
\hline 24. Sabes grabar videos con el móvil & .795 & & & & \\
\hline 22. Sabes mandar mensajes por móvil & & .793 & & & & \\
\hline 27. Sabes usar una cámara digital & & .736 & & & & \\
\hline 12. Crear un blog & & & .830 & & & \\
\hline 13. Comentar en un blog & & & .810 & & & \\
\hline 8. Parcitipar en chats, foros, blogs & & & .633 & & & \\
\hline 11. Usar una red social (como Tuenti, Facebook) & & & .575 & & & \\
\hline 10. Subir videos a YouTube & & & .550 & & & \\
\hline 4. Usar hojas de cálculo & & & & .797 & & \\
\hline 5. Encontrar datos en un base & & & & .735 & & \\
\hline 3. Hacer presentaciones con textos, imágenes... & & & & .630 & & \\
\hline 1. Recuperar, imprimir y guardar información & & & & .555 & & \\
\hline 2. Instalar y arrancar programas & & & & .494 & & \\
\hline $\begin{array}{l}\text { 6. Navegar por internet, seleccionar información, } \\
\text { guardarla }\end{array}$ & & & & & .702 & \\
\hline 9. Ver videos en YouTube & & & & & .631 & \\
\hline 7. Utilizar buscadores & & & & & .592 & \\
\hline 25. Sabes usar consolas de videojuegos & & & & & & .732 \\
\hline 21. Jugar en red con... & & & & & & .579 \\
\hline 26. Sabes usar PDA `s & & & & & & .462 \\
\hline 15. Comprar por internet & & & & & .463 \\
\hline
\end{tabular}

Método de extracción: Análisis de componentes principales.

Método de rotación: Normalización Varimax con Kaiser

La rotación ha convergido en 9 iteraciones

Una vez expuestas las variables que se incluyen en el estudio, vamos a observar la correlación entre las mismas. En la tabla 4.117 se muestra la matriz de correlaciones correspondiente que incluye todas las variables definidas más arriba. Se puede observar cómo la mayor parte de correlaciones son significativas a un nivel de significación $\alpha=.01$, a excepción de buena parte de las relacionadas con la frecuencia de manejo de herramientas informáticas en el aula, en donde se alcanzan valores cercanos a 0. 
Tabla 4.117 Matriz de correlaciones frecuencia de empleo y nivel de manejo en herramientas informáticas. Alumnos

\begin{tabular}{|c|c|c|c|c|c|c|c|c|c|c|}
\hline & $\begin{array}{c}\text { Frec. } \\
\text { casa } \\
\text { acad. }\end{array}$ & $\begin{array}{l}\text { Frec. } \\
\text { casa } \\
\text { ocio }\end{array}$ & $\begin{array}{l}\text { Frec. } \\
\text { aula } \\
\text { ocio }\end{array}$ & $\begin{array}{l}\text { Frec. } \\
\text { aula } \\
\text { acad. }\end{array}$ & $\begin{array}{c}\text { Inf. } \\
\text { multim. }\end{array}$ & $\begin{array}{l}\text { Inf. } \\
\text { portát. }\end{array}$ & $\begin{array}{c}\text { Inf. } \\
\text { Web } 2.0\end{array}$ & $\begin{array}{l}\text { Inf. } \\
\text { acad. }\end{array}$ & $\begin{array}{c}\text { Inf. } \\
\text { internet }\end{array}$ & Inf. ocio \\
\hline $\begin{array}{l}\text { Frec. casa } \\
\text { acad. }\end{array}$ & 1 & $.471 *$ & $.196 *$ & $.254^{*}$ & $.316^{*}$ & $.134 *$ & $.310^{*}$ & $.459 *$ & $.212^{*}$ & $.328 *$ \\
\hline $\begin{array}{l}\text { Frec. casa } \\
\text { ocio }\end{array}$ & & 1 & $.135 *$ & $.086^{*}$ & $.470^{*}$ & $.207 *$ & $.465 *$ & $.343^{*}$ & $.388^{*}$ & $.417 *$ \\
\hline $\begin{array}{l}\text { Frec. aula } \\
\text { ocio }\end{array}$ & & & 1 & $.559 *$ & .037 & -.052 & .060 & $.090 *$ & -.049 & $.105^{*}$ \\
\hline $\begin{array}{l}\text { Frec. aula } \\
\text { acad. }\end{array}$ & & & & 1 & .037 & -.015 & .062 & $.144^{*}$ & -.038 & .071 \\
\hline Inf.multim. & & & & & 1 & $.402 *$ & $.580 *$ & $.537 *$ & $.584 *$ & $.527 *$ \\
\hline Inf. Portát. & & & & & & 1 & $.332 *$ & $.256^{*}$ & $.378^{*}$ & $.409 *$ \\
\hline $\begin{array}{c}\text { Inf.Web } \\
2.0\end{array}$ & & & & & & & 1 & $.457 *$ & $.573^{*}$ & $.592 *$ \\
\hline $\begin{array}{l}\text { Inf. gestión } \\
\text { info. }\end{array}$ & & & & & & & & 1 & $.491 *$ & $.504^{*}$ \\
\hline Inf.internet & & & & & & & & & 1 & $.467^{*}$ \\
\hline Inf. Ocio & & & & & & & & & & 1 \\
\hline
\end{tabular}

* Correlación significativa a un nivel de significación ( $\alpha=.01$

Las correlaciones marcadas con negrita (>.4) son las que se han considerado aceptables para valorar el estudio. Los resultados muestran correlaciones aceptables entre la mayor parte de los ítems relacionados con las competencias informáticas, a excepción de las que tienen que ver con el manejo de dispositivos portátiles. El ítem de competencias informáticas básicas relacionadas con internet no alcanza correlaciones aceptables en ningún caso con las frecuencias de empleo de herramientas informáticas.

Por otro lado, la frecuencia de empleo en el aula para actividades relacionadas con el ocio, además de mantener correlaciones insignificantes, tiene poca relación con lo que se desea estudiar en la presente investigación.

Así, en esta primera exploración, siguiendo criterios teóricos y empíricos, se decide eliminar las siguientes variables:

- Competencias informáticas con herramientas portátiles

- Competencias básicas de manejo de internet

- Frecuencia de manejo en el aula de herramientas de ocio 
- Frecuencia de manejo en el aula para actividades académicas

Analicemos a continuación la correlación de las variables que se siguen incluyendo con las cuatro dimensiones que conforman las competencias informacionales. La tabla 4.118 muestra las correlaciones que existen entre las variables de frecuencia de empleo y nivel autopercibido en actividades con herramientas informáticas y las cuatro dimensiones de las competencias informacionales.

Tabla 4.118 Correlación competencias y hábitos informáticos con competencias informacionales. Alumnos

\begin{tabular}{l|cc|cccc}
\hline \multicolumn{1}{c|}{ Nivel auto-pecibido } & $\begin{array}{c}\text { Frec. } \\
\text { casa } \\
\text { acad. }\end{array}$ & $\begin{array}{c}\text { Frec. } \\
\text { aula } \\
\text { acad. }\end{array}$ & $\begin{array}{c}\text { Inf. } \\
\text { multim }\end{array}$ & $\begin{array}{c}\text { Inf. Web } \\
\mathbf{2 . 0}\end{array}$ & $\begin{array}{c}\text { Inf. } \\
\text { acad. }\end{array}$ & Inf. ocio \\
\hline Búsqueda de información & $.338^{*}$ & $.086^{*}$ & $.336^{*}$ & $.310^{*}$ & $.419^{*}$ & $.351^{*}$ \\
\hline Evaluación de información & $.316^{*}$ & $.129^{*}$ & $.229^{*}$ & $.276^{*}$ & $.323^{*}$ & $.262^{*}$ \\
\hline Procesamiento de información & $.365^{*}$ & $.121^{*}$ & $.446 *$ & $.351^{*}$ & $.496 *$ & $.370^{*}$ \\
\hline $\begin{array}{l}\text { Comunicación y difusión de } \\
\text { información }\end{array}$ & $.345^{*}$ & $.127^{*}$ & $.391^{*}$ & $.415^{*}$ &. $\mathbf{4 1 2 *}$ & $.305^{*}$ \\
\hline
\end{tabular}

* Correlación significativa a un nivel de significación $\alpha=.01$

En este caso, nos encontramos con todas las correlaciones significativas (nivel de significación $\alpha=.01)$. Sin embargo, el número de correlaciones que están por encima de 4 es bastante escaso. Con la intención de llevar a cabo un modelo parsimonioso, se decide mantener el mínimo número de variables posible. De este modo, debido a que nuestro estudio se mantiene inmerso en el ámbito académico de la enseñanza formal, y vista la tendencia que muestran las correlaciones entre las variables, se plantea mantener únicamente las variables que tengan una relación directa con el ámbito académico.

Por fin, las variables relacionadas con las herramientas y aplicaciones informáticas que serán incluidas son las siguientes:

- Frecuencia de manejo del ordenador en casa para actividades académicas

- Frecuencia de manejo del ordenador en el aula para actividades académicas

- Competencias informáticas del ámbito académico

\subsubsection{Modelo de ecuaciones estructurales}

A continuación, dada la importancia fundamental que se asigna a las TIC en lo que se refiere al desarrollo de competencias informacionales, se procederá a comprobar si 
el empleo de las TIC en contextos de educación formal y de ocio fomenta y promociona el desarrollo de competencias informacionales.

Se considera que la técnica estadística más adecuada para comprobar las relaciones entre un buen número de variables es, en este caso, la técnica multivariante de los modelos de ecuaciones estructurales (Batista-Foguet \& Coenders, 2000; Bollen, 1989; B. Byrne, 2001; Kline, 2005; Silva Zamora \& Schiattino Lemus, 2008).

Conforme a la hipótesis planteada, la principal variable estudiada, latente y endógena, se puede definir como el nivel de percepción de autoeficacia en todas aquellas tareas que constituyen las competencias informacionales en alumnos de segundo ciclo de educación secundaria de Castilla y León.

Por otro lado, las variables exógenas del estudio las podríamos concretar como la frecuencia y el nivel en el empleo académico de herramientas y aplicaciones informáticas.

Analicemos a continuación los aspectos más relevantes del modelo descrito.

\section{a) Estructura del modelo teórico}

A partir de los objetivos de la presente investigación y del estudio teórico de la cuestión, se diseña el modelo hipotético que se desea contrastar. Como se puede observar en la figura 4.13, se diseña un modelo parsimonioso que pone a prueba si el nivel autopercibido sobre competencias informacionales $\left(\eta_{1}\right)$, variable latente medida a partir de 4 subescalas, puede explicarse en parte por la frecuencia y el nivel en el manejo de determinadas herramientas informáticas básicas. 


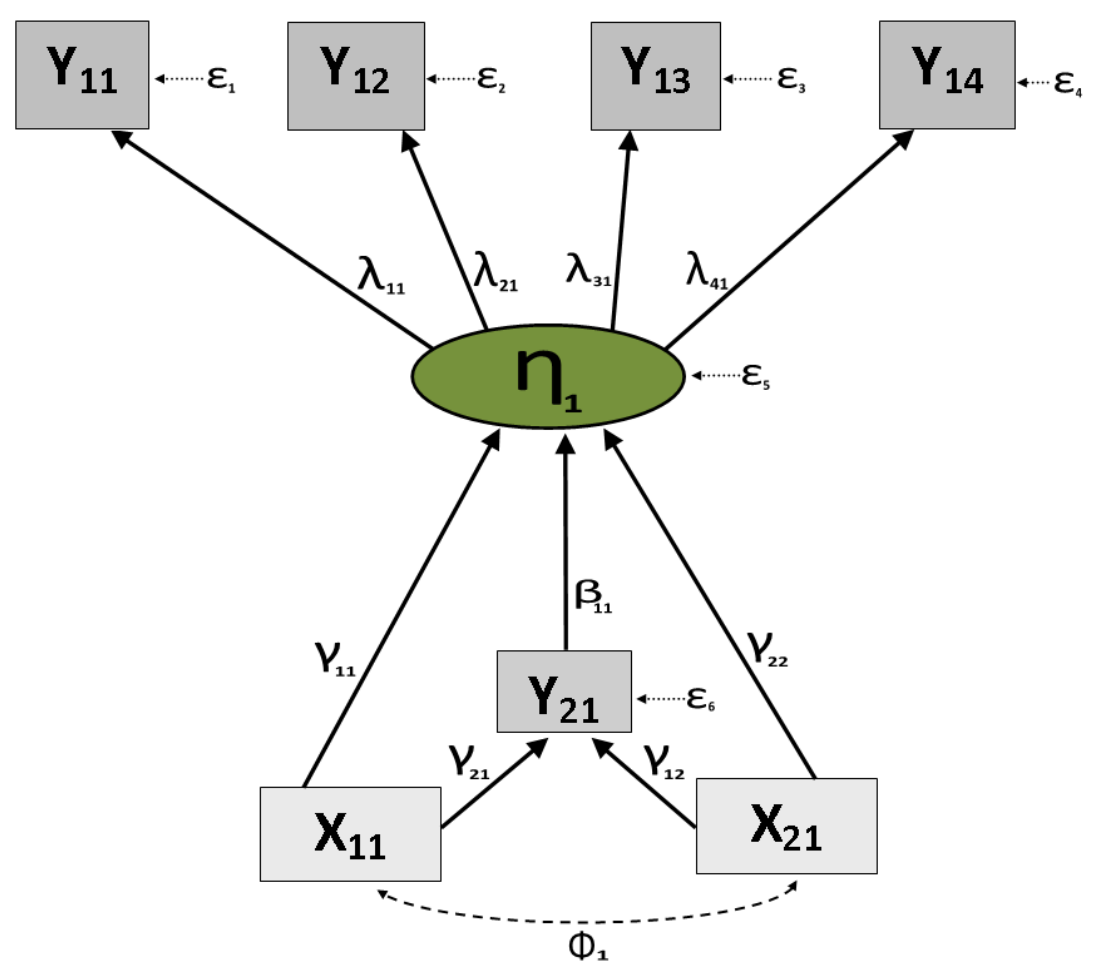

Figura 4.13 Diseño del modelo de ecuaciones estructurales teórico. Alumnos

Las variables observadas que explican la puntuación global obtenida en las competencias informacionales son las siguientes:

- Frecuencia en el manejo de herramientas informáticas del ámbito académico en casa $\left(\mathrm{X}_{11}\right)$ : Se refiere a situaciones ajenas al ámbito académico de la escuela.

- Frecuencia en el manejo de herramientas informáticas del ámbito académico en la escuela $\left(\mathrm{X}_{21}\right)$ : Se refiere a todas las situaciones formativas que se pueden dar en la escuela.

- Nivel en el manejo de herramientas informáticas $\left(\mathrm{Y}_{21}\right)$ : Se refiere al nivel autopercibido en el manejo de herramientas informáticas básicas de tipo académico. Esta escala se obtiene de la suma de las puntuaciones obtenidas en el nivel autopercibido en cada una de las herramientas incluidas en la escala inicial

Por otro lado, las variables que se corresponden con las dimensiones que componen el constructo competencias informacionales se forman a partir de las puntuaciones factoriales obtenidas en el análisis factorial llevado a cabo previamente, 
y confirmadas en otros estudios previos (Rodríguez Conde et al., 2012). Son las siguientes:

- Búsqueda de información $\left(\mathrm{Y}_{11}\right)$

- Evaluación de información $\left(\mathrm{Y}_{12}\right)$

- Procesamiento de información $\left(\mathrm{Y}_{13}\right)$

- Comunicación y difusión de información $\left(\mathrm{Y}_{14}\right)$

\section{b) Contraste de los supuestos previos al análisis}

Como paso previo a la aplicación de las técnicas de ecuaciones estructurales, se pone a prueba el cumplimiento de los supuestos subyacentes a las mismas. En primer lugar, la prueba de normalidad consiste en el análisis de los valores de asimetría y curtosis de las variables observadas incluidas en el modelo (tabla 4.119). Ya se había estudiado previamente la falta de normalidad de las distribuciones de las dimensiones que componen las competencias informacionales. Sin embargo, ahora se vuelve hacer este análisis para comprobar el comportamiento de las distribuciones conjuntas de todas las variables incluidas en el estudio.

Tabla 4.119 Test de normalidad para las variables incluidas en el modelo. Alumnos

\begin{tabular}{lcc|cc}
\hline \multicolumn{1}{c|}{ Variables } & Asimetría & $\boldsymbol{t}$ & Curtosis & $\boldsymbol{t}$ \\
\hline $\begin{array}{l}\text { 1. Frecuencia en el manejo de herramientas } \\
\text { informáticas en la escuela }\end{array}$ & 0.21 & 2.40 & -0.88 & $-5.05^{*}$ \\
$\begin{array}{l}\text { 2. Frecuencia en el manejo de herramientas } \\
\text { informáticas en casa }\end{array}$ & 0.26 & $3.03^{*}$ & -0.36 & -2.08 \\
$\begin{array}{l}\text { 3. Habilidades en el manejo de herramientas } \\
\text { informáticas }\end{array}$ & -1.33 & $-15.19^{*}$ & 1.92 & $10.98^{*}$ \\
4. Búsqueda de información & -0.80 & $-9.15^{*}$ & 1.23 & $7.03^{*}$ \\
5. Evaluación de información & -0.46 & $-5.24^{*}$ & 0.59 & $3.40^{*}$ \\
6. Procesamiento de información & -0.36 & $-4.16^{*}$ & 0.22 & $1.29^{*}$ \\
7. Comunicación y difusión de información & -0.53 & $-6.05^{*}$ & 0.43 & 2.47 \\
\hline COEFICIENTE DE MARDIA & & & 10.41 & 12.99 \\
\hline * $\alpha=.01$. & & & &
\end{tabular}

Se observa cómo para la asimetría se obtienen valores que indican una ligera asimetría positiva en las variables Frecuencia en el manejo de herramientas informáticas en la escuela y Frecuencia en el manejo de herramientas informáticas en casa. Por otro lado, se obtiene una clara tendencia a la asimetría negativa en el resto 
de variables. Si se analizan los valores del estadístico de contraste obtenidos para la asimetría, se observan en la mayoría de los casos variables cuya función de densidad no se ajusta a una distribución normal $(\alpha=.01)$ en este aspecto. En cuanto a la curtosis, el valor obtenido a partir del coeficiente de Mardia indica que no existe normalidad multivariada (Bollen, 1989).

Por tanto, al no cumplirse el supuesto de normalidad, teniendo en cuenta que el tamaño de la muestra en el presente estudio es mayor a 1000 sujetos (Muthén \& Kaplan, 1985), se decide aplicar un método de estimación no paramétrica asintóticamente libre de distribución (Browne, 1984; Hawkins, 1982).

En cuanto a la identificación del modelo, se verifica la condición de orden (11 grados de libertad), la condición de rango (determinante de la matriz de covarianzas $\neq$ 0) y la inexistencia de varianzas/covarianzas del error negativas, errores estándar excesivamente elevados o correlaciones entre los coeficientes estimados muy elevadas (superiores a .80).

\section{c) Comprobación del ajuste del modelo}

En la comprobación del ajuste del modelo, que determina el grado en que el modelo predice la matriz de covarianzas observadas, se tienen en cuenta tanto medidas de ajuste absoluto como de ajuste incremental. Por último, se introducen medidas de ajuste de parsimonia que ofrecen información acerca de la simplicidad del modelo.

Es necesario indicar que la aplicación de técnicas no paramétricas en la estimación de parámetros son menos eficientes que otras técnicas paramétricas (Chandler \& Scott, 2011), más aún si las muestras son muy grandes. Así, es probable que esto afecte al modelo aquí propuesto.

En cuanto al ajuste global del modelo, en la tabla 4.120 se pueden observar valores del estadístico de contraste Chi cuadrado que indican una falta de ajuste global ( $p$ <.001). No obstante, este resultado es esperable, dada la sensibilidad de este estadístico cuando los tamaños de muestra son muy elevados (Tejedor Tejedor et al., 2009). Así, calculando el índice de bondad de ajuste GFI, que no depende en el cálculo del tamaño de la muestra (Kline, 2005), se obtiene un valor que indica que el ajuste global es bueno (GFI=.987). Así mismo, el valor del Error de Aproximación Cuadrático Medio alcanza un valor aceptable aceptable (RMSEA=.045). Otro índice que aproxima 
la bondad de ajuste global en estos casos es la ratio $\chi^{2} /$ grados de libertad $(3.43$ puntos).

Por otro lado, analizando el nivel de ajuste incremental y de parsimonia a partir del índice GFI ajustado, obtenemos valores de ajuste incremental (AGFI=.967), y de ajuste de parsimonia ( $\mathrm{PCFI}=.491)$ que se encuentran dentro de los niveles habitualmente aceptables ( $\mathrm{Wu}, 2011)$. Otros valores de ajuste incremental, que se pueden observar en la tabla 4.120 son el $\mathrm{CFI}$, IFI y $\mathrm{NFI}$, todos ellos con ajustes aceptables.

Tabla 4.120 Indicadores de ajuste del modelo causal. Alumnos

\begin{tabular}{lccccc|cccc}
\hline & \multicolumn{4}{c}{ Ajuste global } & \multicolumn{4}{c}{ Ajuste incremental } \\
\cline { 2 - 10 } & $\chi^{2}$ & g.I & p. & RMSEA & GFI & CFI & NFI & IFI & AGFI \\
\hline Modelo propuesto & 37.694 & 11 & $<.001$ & .045 & .987 & .938 & .916 & .939 & .967 \\
\hline
\end{tabular}

Por último, es reseñable indicar cómo el modelo explica el $28.5 \%$ de la varianza de la variable endógena competencias informacionales.

\section{d) Evaluación de las relaciones individuales planteadas}

Si se lleva a cabo un análisis individual de los coeficientes de regresión para cada vía propuesta en el modelo (Figura 4.14), se pueden observar relaciones significativas y no significativas a un nivel de significación $\alpha=.01$.

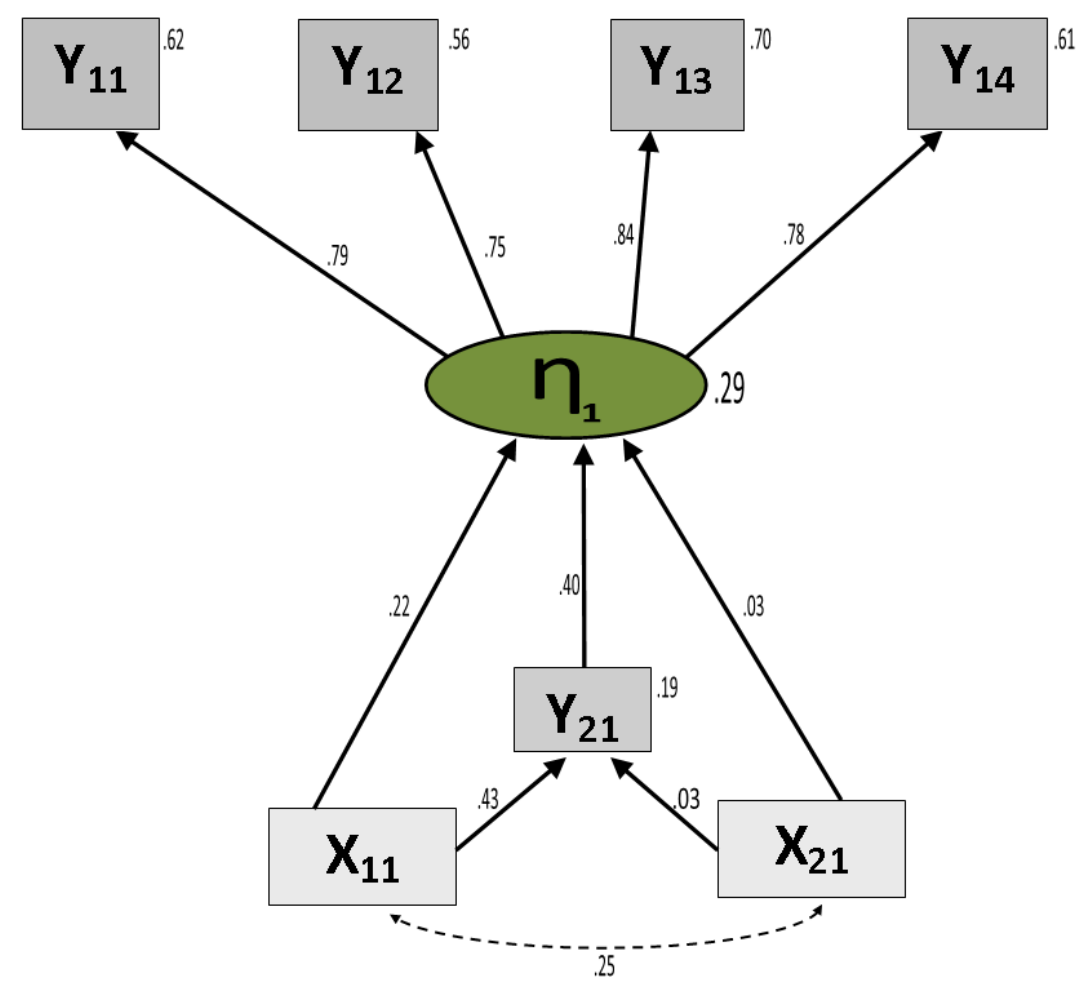


Figura 4.14 Solución estandarizada del modelo planteado. Alumnos

Esto se observa mejor analizando los efectos directos, indirectos y totales existentes en el modelo (tabla 4.121).

Tabla 4.121 Efectos directos, indirectos y totales estandarizados entre las variables del modelo

\begin{tabular}{ccccc}
\hline & & $\begin{array}{c}\text { Frecuencia uso } \\
\text { casa }\end{array}$ & $\begin{array}{c}\text { Frecuencia uso } \\
\text { escuela }\end{array}$ & $\begin{array}{c}\text { Habilidades } \\
\text { informáticas }\end{array}$ \\
\hline \multirow{2}{*}{$\begin{array}{c}\text { Habilidades } \\
\text { informáticas }\end{array}$} & Directos & $0.431^{*}$ & 0.033 & 0.000 \\
& Indirectos & 0.000 & 0.000 & 0.000 \\
\cline { 2 - 5 } & Totales & $\mathbf{0 . 4 3 1 ^ { * }}$ & $\mathbf{0 . 0 3 3}$ & $\mathbf{0 . 0 0 0}$ \\
\hline \multirow{2}{*}{$\begin{array}{c}\text { Competencias } \\
\text { informacionales }\end{array}$} & Directos & $0.217^{*}$ & 0.026 & $0.395^{*}$ \\
\cline { 2 - 5 } & Indirectos & $0.170^{*}$ & 0.013 & 0.000 \\
\cline { 2 - 5 } & Totales & $\mathbf{0 . 3 8 7 ^ { * }}$ & $\mathbf{0 . 0 3 9}$ & $\mathbf{0 . 3 9 5 *}$ \\
\hline
\end{tabular}

$* \alpha=.01$

Principalmente se pone de manifiesto cómo, mientras que la frecuencia en el manejo de herramientas informáticas en casa $\left(\mathrm{X}_{11}\right)$ tiene un efecto tanto directo (.217) como indirecto (.170) significativo sobre el nivel autopercibido en competencias informacionales $\left(\eta_{1}\right)$, la frecuencia en el manejo de herramientas informáticas en la escuela $\left(\mathrm{X}_{21}\right)$ tiene efectos no significativos tanto directos (.026) como indirectos (.013). Por otro lado, se repite este patrón en lo que respecta a los efectos de estas dos variables sobre las habilidades informáticas autopercibidas $\left(\mathrm{Y}_{21}\right)$. Mientras que la frecuencia en el manejo de herramientas informáticas en casa $\left(X_{11}\right)$ tiene un efecto directo significativo (.431) sobre las habilidades informáticas, la frecuencia en el manejo de herramientas informáticas en la escuela $\left(X_{21}\right)$ tiene efectos directos insignificantes (.033) sobre esta misma variable.

\subsubsection{Diferencias por grupos principales}

Llegados a este punto, en el que hemos desarrollado un modelo causal que aparentemente indica buenos coeficientes de ajuste global, incremental y de parsimonia, surge una cuestión importante:

- ¿Se comportará de igual manera el modelo en función de los grupos principales definidos?

Nuestra hipótesis de partida, en función de los resultados cosechados hasta este punto, es que, en función del sexo y los estudios de la madre el modelo se comportará 
de manera diferente, y que, en función del curso académico no existirán diferencias en el modelo.

Veamos, pues, cómo se comporta el modelo en estas situaciones.

\section{a) Diferencias por sexo}

En primer lugar, en cuanto a las diferencias por sexo, una vez aplicado el modelo, podemos ver la bondad de ajuste global en la tabla 4.122 .

Tabla 4.122 Indicadores de ajuste del modelo causal por sexo.

\begin{tabular}{lccccc|cccc}
\hline & \multicolumn{4}{c}{ Ajuste global } & \multicolumn{4}{c}{ Ajuste incremental } \\
\cline { 2 - 11 } & $\chi^{2}$ & g.I & p. & RMSEA & GFI & CFI & NFI & IFI & AGFI \\
\hline Hombres & 32.715 & 11 & .001 & .058 & .979 & .902 & .865 & .906 & .946 \\
\hline Mujeres & 33.019 & 11 & .001 & .059 & .978 & .899 & .861 & .903 & .945 \\
\hline Multi-grupo & 65.734 & 22 & $<.001$ & .042 & .979 & .900 & .863 & .905 & .946 \\
\hline
\end{tabular}

En función de los resultados podemos observar cómo las escalas funcionan aceptablemente tanto en la población de hombres como en la de mujeres.

En lo que hace referencia a las relaciones individuales planteadas en ambos modelos (figura 4.15), los datos muestran valores similares en el peso de cada una de las dimensiones sobre las competencias informacionales (búsqueda, evaluación, procesamiento y comunicación). En cuanto a las vías que se plantean como explicativas del constructo, se observa una tendencia favorable a los hombres en cuanto a la aportación de la frecuencia de empleo en el hogar, y una tendencia favorable a las mujeres en cuanto a la aportación de las competencias informáticas generales.

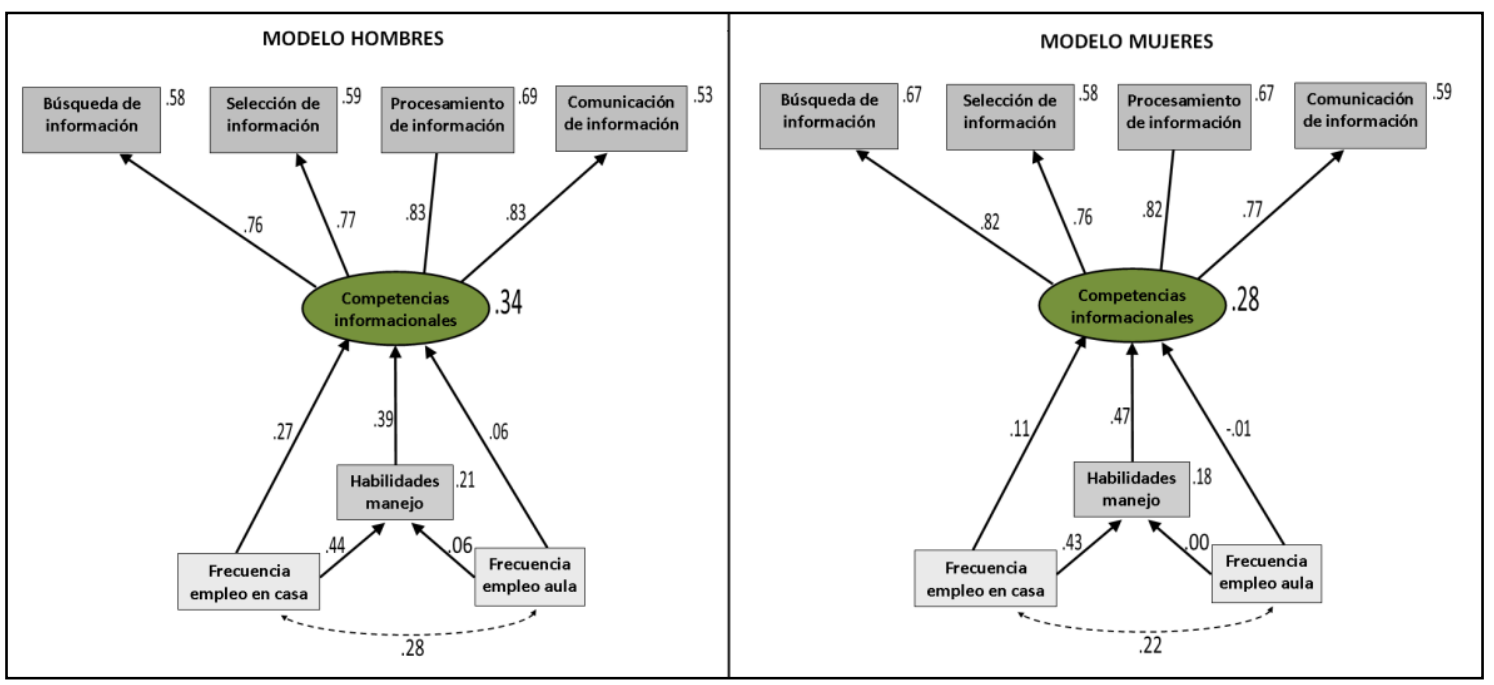


Figura 4.15 Solución estandarizada del modelo por sexo

Es también reseñable, si cabe que la varianza total de las competencias informacionales explicada por el modelo $\left(R^{2}\right)$ es en el caso de los hombres del $34 \%$ y en el de las mujeres del $28 \%$. De ahí que los valores de ajuste global señalados en la tabla anterior sean ligeramente favorables a los hombres.

A continuación, en la tabla 4.123, se muestran los valores de z para las diferencias localizadas entre hombres y mujeres para cada una de las vías. Se observan diferencias significativas en la vía correspondiente a los efectos de la frecuencia de empleo de herramientas informáticas en casa sobre las competencias informacionales. En cuanto a la dirección de las diferencias, como se puede observar en el modelo, es favorable a los hombres.

Tabla 4.123 Contraste de las vías planteadas por sexo

\begin{tabular}{ccccc}
\hline & $\begin{array}{c}\text { Habilidades } \\
\text { informáticas }\end{array}$ & $\begin{array}{c}\text { Uso en centro } \\
\text { educativo }\end{array}$ & $\begin{array}{c}\text { Uso en el } \\
\text { hogar }\end{array}$ & $\begin{array}{c}\text { Competencias } \\
\text { informacionales }\end{array}$ \\
\hline $\begin{array}{c}\text { Habilidades } \\
\text { informáticas }\end{array}$ & 0.000 & & & \\
\hline $\begin{array}{c}\text { Uso en centro } \\
\text { educativo }\end{array}$ & -1.021 & 0.000 & & \\
\hline $\begin{array}{c}\text { Uso en el } \\
\text { hogar }\end{array}$ & 0.724 & - & 0.000 & 0.000 \\
\hline $\begin{array}{c}\text { Competencias } \\
\text { informacionales }\end{array}$ & 1.115 & -1.099 & $-\mathbf{2 . 0 7 0 *}$ & \\
\hline
\end{tabular}

* Valor de $\mathrm{z}$ significativo a un nivel $\alpha=.05$

Una vez observadas estas diferencias, nos podemos plantear si existen diferencias significativas entre la frecuencia en empleo en el hogar de las herramientas informáticas. Si aplicamos el estadístico de contraste adecuado ( $U$ de Mann-Whitney), obtenemos una $U=1444234.00$ con un valor $z=-1.487(p=.137)$. Este valor indica que no existen diferencias significativas en esa variable entre hombres y mujeres.

\section{b) Diferencias por curso}

En lo que respecta al modelo por curso, como indica la tabla 4.124, podemos encontrarnos de nuevo buenos índices de ajuste tanto global como incremental en los alumnos de tercero y cuarto curso. 
Tabla 4.124 Indicadores de ajuste del modelo causal por curso.

\begin{tabular}{lccccc|cccc}
\hline & \multicolumn{4}{c}{ Ajuste global } & \multicolumn{4}{c}{ Ajuste incremental } \\
\cline { 2 - 10 } & $\chi^{2}$ & g.I & $p$. & RMSEA & GFI & CFI & NFI & IFI & AGFI \\
\hline Tercer curso & 21.420 & 11 & .029 & .039 & .985 & .957 & .918 & .959 & .962 \\
\hline Cuarto curso & 28.816 & 11 & .002 & .055 & .981 & .921 & .884 & .925 & .952 \\
\hline Multi-grupo & 50.237 & 22 & .001 & .033 & .983 & .940 & .901 & .942 & .957 \\
\hline
\end{tabular}

En este caso obtenemos valores del estadístico Chi cuadrado aceptables en el caso de los alumnos de tercer curso. El hecho de que la muestra se reduzca en el análisis de cada grupo concreto facilita que los valores de este índice se acerque a lo aceptable (Kline, 2005).

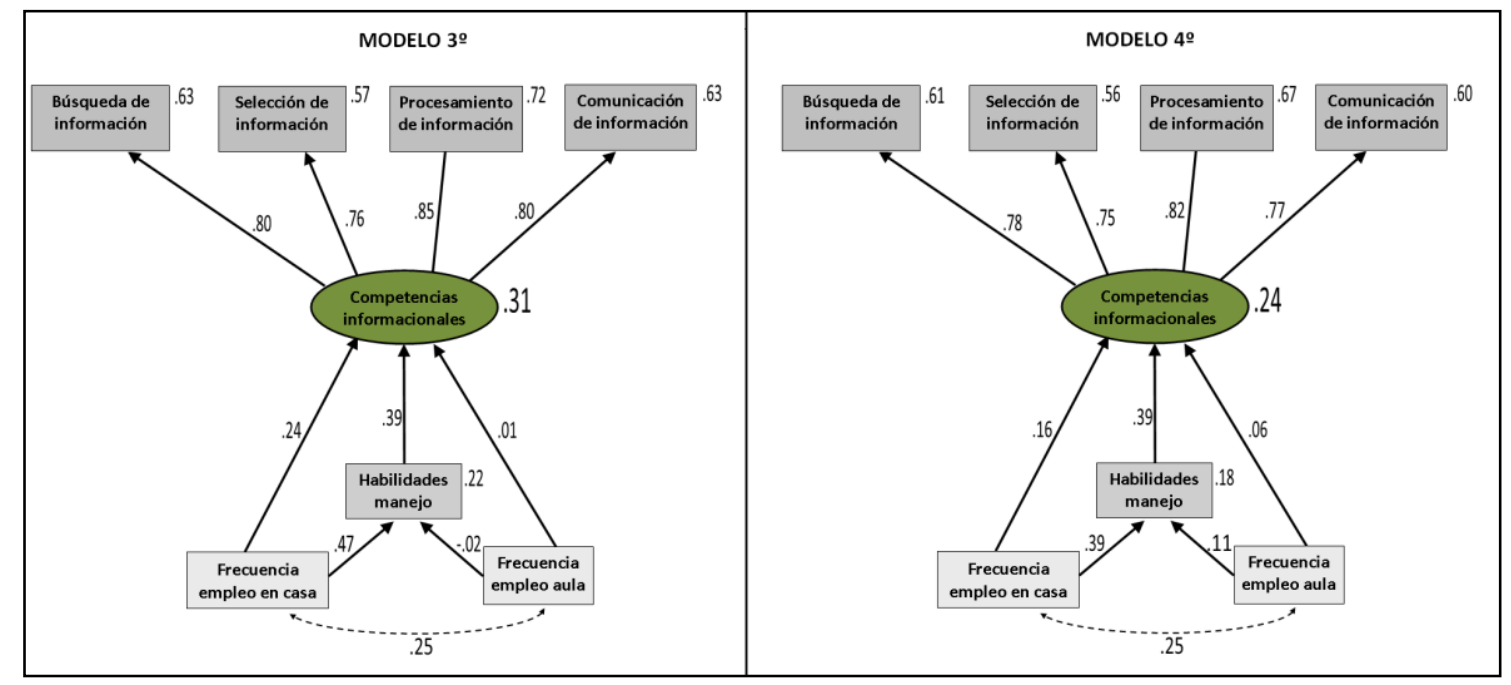

Figura 4.16 Solución estandarizada del modelo por curso

Si se analizan las diferencias en las relaciones individuales, mostradas en la figura 4.16, se pueden observar algunas diferencias en lo que respecta a la aportación de la frecuencia en el empleo de herramientas informáticas en casa y en el aula sobre otras variables. Mientras en que los alumnos de 3 o existen unos efectos mayores del empleo en casa, en los alumnos de 4으 se perciben efectos mayores del empleo en el aula.

Tabla 4.125 Contraste de las vías planteadas por curso

\begin{tabular}{ccccc}
\hline & $\begin{array}{c}\text { Habilidades } \\
\text { informáticas }\end{array}$ & $\begin{array}{c}\text { Uso en centro } \\
\text { educativo }\end{array}$ & $\begin{array}{c}\text { Uso en el } \\
\text { hogar }\end{array}$ & $\begin{array}{c}\text { Competencias } \\
\text { informacionales }\end{array}$ \\
\hline $\begin{array}{c}\text { Habilidades } \\
\text { informáticas }\end{array}$ & 0.000 & & \\
\hline $\begin{array}{c}\text { Uso en centro } \\
\text { educativo }\end{array}$ & $\mathbf{2 . 4 7 3 ^ { * }}$ & 0.000 & \\
\hline Uso en el & -1.417 & - & 0.000 \\
\hline
\end{tabular}




\begin{tabular}{ccccc}
\hline hogar & & & & \\
\hline $\begin{array}{c}\text { Competencias } \\
\text { informacionales }\end{array}$ & -0.735 & 0.550 & -1.623 & 0.000 \\
\hline
\end{tabular}

* Valor de z significativo a un nivel $\alpha=.05$

De hecho, como se señala en la tabla 4.125, existen diferencias significativas en los efectos del uso de herramientas informáticas en el centro educativo sobre las propias habilidades informáticas. Si analizamos las diferencias en la variable frecuencia en el uso de herramientas informáticas en el centro educativo en función del curso, encontramos una $U=123928.50$, con una $z=-5.697$ ( $p<.001)$. Así, los alumnos de 4o curso declaran que emplean más frecuentemente las herramientas informáticas del ámbito académico en el aula, y este hecho es el que está afectando de una manera más directa sobre las diferencias observadas en esta vía.

\section{c) Diferencias por estudios de la madre}

En lo que respecta a los modelos obtenidos en función de los estudios de la madre, en la tabla 4.126 se puede observar el ajuste de los modelos planteados. Se observan, en general, buenos ajustes globales y ajustes incrementales un poco más pobres en algunos indicadores.

En todo caso, en lo que respecta a los índices de bondad de ajuste multi-grupo, nos encontramos en general ajustes aceptables, por lo que continuaremos con el contraste de las diferencias obtenidas.

Tabla 4.126 Indicadores de ajuste del modelo causal por Estudios de la madre.

\begin{tabular}{lccccc|cccc}
\hline & \multicolumn{4}{c}{ Ajuste global } & \multicolumn{4}{c}{ Ajuste incremental } \\
\cline { 2 - 11 } & $\chi^{2}$ & g.I & p. & RMSEA & GFI & CFI & NFI & IFI & AGFI \\
\hline Estudios primarios & 15.527 & 11 & .160 & .051 & .966 & .917 & .795 & .930 & .914 \\
\hline Estudios secund. & 26.624 & 11 & .005 & .051 & .982 & .934 & .896 & .936 & .954 \\
\hline Estudios univers. & 38.487 & 11 & $<.001$ & .078 & .970 & .839 & .799 & .848 & .839 \\
\hline Multi-grupo & 80.659 & 33 & $<.001$ & 0.036 & .975 & .897 & .846 & .903 & .936 \\
\hline
\end{tabular}

En la figura 4.17 se muestran las soluciones estandarizadas para cada uno de los grupos, que luego serán contrastadas individualmente.

En primer lugar, se puede observar cómo la varianza explicada de las competencias informacionales por el modelo es moderadamente más alta en el modelo para los sujetos de la muestra con madres con estudios universitarios (37\%) 
que para los sujetos con madres con estudios secundarios (28\%) y con estudios primarios (23\%).

Por otro lado, en cuanto a las vías generadas desde la frecuencia de uso tanto en casa como en el aula sobre otras variables, parece que los efectos son similares. Sin embargo, se localizan diferencias importantes en los efectos generados en la variable de habilidades en el manejo de herramientas informáticas sobre las competencias informacionales.

Una vez observadas estas diferencias a nivel muestral, analizaremos si existen diferencias significativas a nivel poblacional.

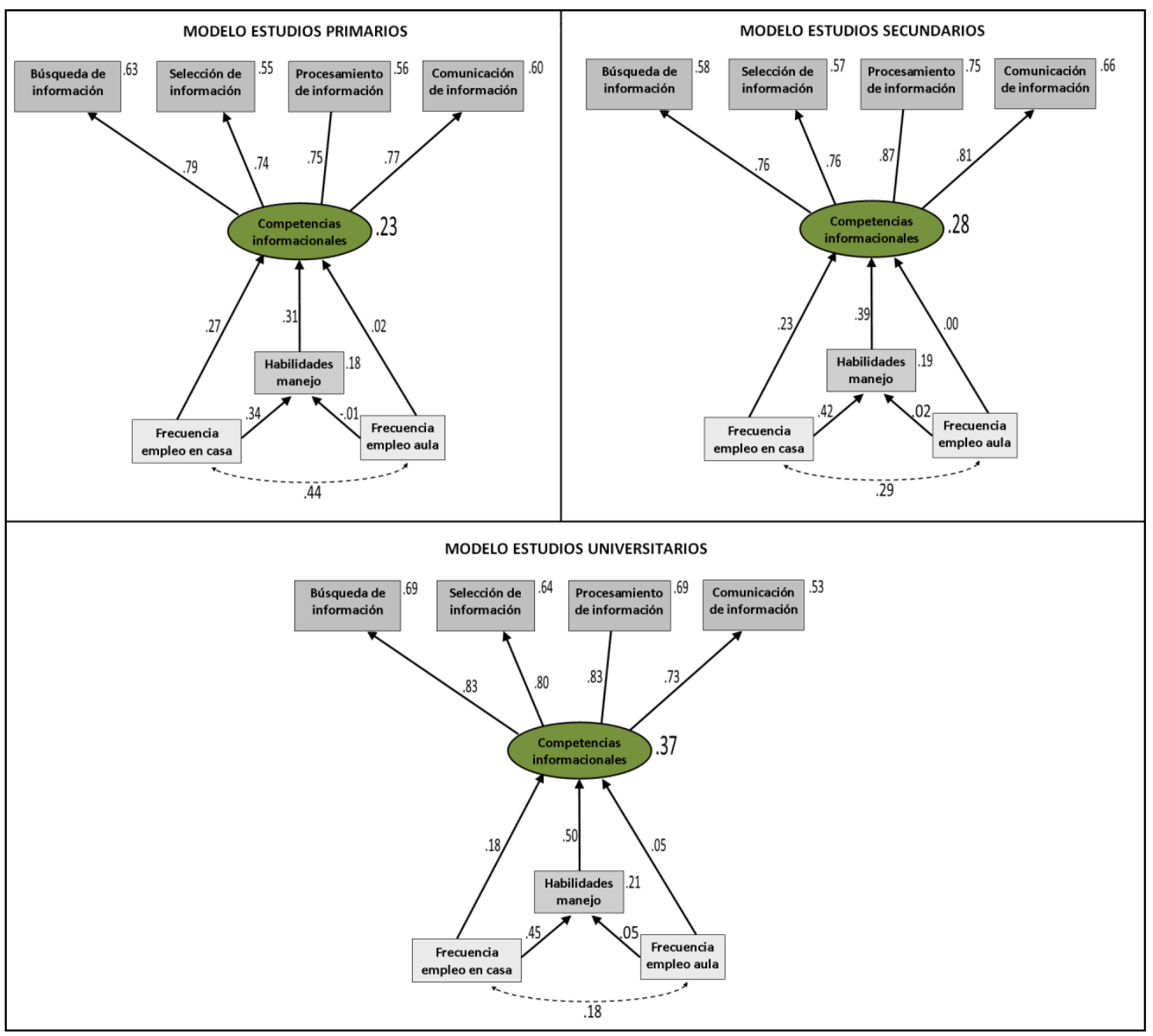

Figura 4.17 Solución estandarizada del modelo por estudios de la madre

La tabla 4.127 muestra la significatividad de las diferencias observadas anteriormente. Entre todos los contrastes llevados a cabo, encontramos un valor significativo del estadístico de contraste en la vía que indica los efectos de la 
frecuencia en el manejo de herramientas informáticas sobre la variable latente competencias informacionales.

Las diferencias se localizan entre los grupos de estudios secundarios y universitarios y es favorable, como se ha observado anteriormente, al grupo de los sujetos con madres que han finalizado los estudios universitarios.

Al igual que se ha ido realizando hasta el momento, veamos si estas diferencias pueden explicarse con las diferencias obtenidas entre ambos grupos en el comportamiento de la propia variable de habilidades en el manejo de herramientas informáticas. Llevada a cabo la prueba estadística no paramétrica de la $U$ de MannWhitney, nos encontramos con un valor de $U=30044.50$, con una $z=-0.392(p=.695)$. Así, podemos afirmar que no existen diferencias significativas entre los sujetos con madres con estudios secundarios y universitarios en lo que respecta a las habilidades en el manejo de herramientas informáticas para labores académicas.

Tabla 4.127 Contraste de las vías planteadas por estudios de la madre

\begin{tabular}{|c|c|c|c|c|}
\hline \begin{tabular}{|l|} 
Primarios \\
Secundarios \\
\end{tabular} & $\begin{array}{c}\text { Habilidades } \\
\text { informáticas }\end{array}$ & $\begin{array}{c}\text { Uso en centro } \\
\text { educativo }\end{array}$ & $\begin{array}{c}\text { Uso en el } \\
\text { hogar }\end{array}$ & $\begin{array}{c}\text { Competencias } \\
\text { informacionales }\end{array}$ \\
\hline $\begin{array}{l}\text { Habilidades } \\
\text { informáticas }\end{array}$ & 0.000 & & & \\
\hline $\begin{array}{c}\text { Uso en centro } \\
\text { educativo }\end{array}$ & 0.479 & 0.000 & & \\
\hline $\begin{array}{l}\text { Uso en el } \\
\text { hogar }\end{array}$ & 0.690 & - & 0.000 & \\
\hline $\begin{array}{l}\text { Competencias } \\
\text { informacionales }\end{array}$ & 0.379 & -0.192 & -0.872 & 0.000 \\
\hline \begin{tabular}{|c|} 
Primarios \\
Universit \\
\end{tabular} & $\begin{array}{c}\text { Habilidades } \\
\text { informáticas }\end{array}$ & $\begin{array}{c}\text { Uso en centro } \\
\text { educativo }\end{array}$ & $\begin{array}{c}\text { Uso en el } \\
\text { hogar }\end{array}$ & $\begin{array}{c}\text { Competencias } \\
\text { informacionales }\end{array}$ \\
\hline $\begin{array}{l}\text { Habilidades } \\
\text { informáticas }\end{array}$ & 0.000 & & & \\
\hline $\begin{array}{c}\text { Uso en centro } \\
\text { educativo }\end{array}$ & 0.730 & 0.000 & & \\
\hline $\begin{array}{c}\text { Uso en el } \\
\text { hogar }\end{array}$ & 0.811 & - & 0.000 & \\
\hline $\begin{array}{l}\text { Competencias } \\
\text { informacionales }\end{array}$ & 1.880 & 0.397 & -1.045 & 0.000 \\
\hline \begin{tabular}{|c|} 
Secundarios \\
Universit. \\
\end{tabular} & $\begin{array}{c}\text { Habilidades } \\
\text { informáticas }\end{array}$ & $\begin{array}{c}\text { Uso en centro } \\
\text { educativo }\end{array}$ & $\begin{array}{c}\text { Uso en el } \\
\text { hogar }\end{array}$ & $\begin{array}{c}\text { Competencias } \\
\text { informacionales }\end{array}$ \\
\hline $\begin{array}{c}\text { Habilidades } \\
\text { informáticas }\end{array}$ & 0.000 & & & \\
\hline $\begin{array}{c}\text { Uso en centro } \\
\text { educativo }\end{array}$ & 0.398 & 0.000 & & \\
\hline $\begin{array}{l}\text { Uso en el } \\
\text { hogar }\end{array}$ & 0.222 & - & 0.000 & \\
\hline
\end{tabular}




\begin{tabular}{|c|c|c|c|c|}
\hline $\begin{array}{c}\text { Competencias } \\
\text { informacionales }\end{array}$ & $2.026^{*}$ & 0.905 & -0.299 & 0.000 \\
\hline
\end{tabular}

* Valor de $z$ significativo a un nivel $\alpha=.05$

Por lo tanto, se puede afirmar que las diferencias localizadas entre los sujetos de madres con estudios universitarios y con estudios secundarios no responden a las diferencias existentes en la valoración de las habilidades informáticas, sino a las diferencias existentes en la adquisición de las propias competencias informacionales. 


\subsection{Resultados en futuro profesorado de educación secundaria}

Una vez observados y analizados pormenorizadamente los resultados obtenidos en la muestra de estudiantes de educación secundaria de Castilla y León (curso 2008/2009), y detectadas las principales deficiencias formativas de los mismos, procederemos a la exposición de los resultados de la segunda parte del estudio I.

Se llevará a cabo un estudio exploratorio, descriptivo, inferencial y correlacional con el fin de determinar cómo se percibe el futuro profesorado en el campo de las competencias informacionales (curso 2010/2011). Así, mediante la puesta en relación de estos resultados y los cosechados en la primera parte del estudio, se persigue la meta última de identificar las principales necesidades formativas del futuro profesorado de educación secundaria en este sentido

A continuación se muestra una exposición de resultados que comienza con la descripción general de las variables demográficas de agrupación incluidas en el estudio, y continua con un análisis descriptivo en profundidad de las variables criterio y predictivas definidas en la metodología.

\subsubsection{Información demográfica en futuro profesorado}

A lo largo de este epígrafe, se describirán los indicadores relacionados con la información de identificación y clasificación de los sujetos de la muestra seleccionada. Se tiene en cuenta el sexo, la edad de los sujetos y los estudios del padre y la madre.

\subsubsection{Sexo}

Como se puede observar en la tabla 4.128, en cuanto a la distribución de la muestra por sexo, encontramos un porcentaje superior de mujeres, de aproximadamente las dos terceras partes del total.

Estas diferencias eran esperables, teniendo en cuenta que es tradicional la existencia de una mayor proporción de alumnado femenino que masculino en todas las titulaciones relacionadas con la educación básica. 
Tabla 4.128 Distribución de la muestra global de futuros profesores por sexo

\begin{tabular}{lcccc}
\hline & Sexo & $\boldsymbol{n}_{\boldsymbol{i}}$ & $\boldsymbol{\%}$ & \% válido \\
\hline Varón & 70 & 33.0 & 33.0 \\
\hline Mujer & 142 & 67.0 & 67.0 \\
\hline Perdidos & 0 & 0.0 & \\
\hline TOTAL & $\mathbf{1 9 2}$ & $\mathbf{1 0 0 . 0}$ & $\mathbf{1 0 0 . 0}$ \\
\hline
\end{tabular}

De hecho, en la investigación que se lleva a cabo sobre muestras de futuro profesorado de educación secundaria (Pérez Sánchez, Gilar Corbí, \& González Gómez, 2007) estos porcentajes son prácticamente idénticos, así como en muestras de estudios llevados a cabo sobre profesorado de educación secundaria en activo (Alvarez Martino, Alvarez Hernández, Castro Pañeda, Campo Mon, \& Fueyo Gutiérrez, 2008; González-Vallinas Alvarez, Oterino, \& San Fabián Maroto, 2007).

\subsubsection{Edad}

En lo que respecta a la edad, nos encontramos con una distribución muy dispersa (Tabla 4.129).

Tabla 4.129 Distribución de la muestra global del futuro profesorado por edad

\begin{tabular}{ccccc}
\hline Edad & $\boldsymbol{n}_{\boldsymbol{i}}$ & $\boldsymbol{\%}$ & \% válido & \% ac. \\
\hline 21 años & 2 & 0.9 & 1.0 & 1.0 \\
\hline 22 años & 23 & 10.8 & 11.0 & 12.0 \\
\hline 23 años & 66 & 31.1 & 31.6 & 43.5 \\
\hline 24 años & 39 & 18.4 & 18.7 & 62.2 \\
\hline 25 años & 20 & 9.4 & 9.6 & 71.8 \\
\hline 26 años & 17 & 8.0 & 8.1 & 79.9 \\
\hline 27 años & 7 & 3.3 & 3.3 & 83.3 \\
\hline 28 años & 5 & 2.4 & 2.4 & 85.6 \\
\hline 29 años & 7 & 3.3 & 3.3 & 89.0 \\
\hline 30 años & 4 & 1.9 & 1.9 & 90.9 \\
\hline 31 años & 3 & 1.4 & 1.4 & 92.3 \\
\hline 32 años & 2 & 0.9 & 1.0 & 93.3 \\
\hline 33 años & 2 & 0.9 & 1.0 & 94.3 \\
\hline 34 años & 2 & 0.9 & 1.0 & 95.2 \\
\hline 35 años & 2 & 0.9 & 1.0 & 96.2 \\
\hline 36 años & 1 & 0.5 & 0.5 & 96.7 \\
\hline 37 años & 1 & 0.5 & 0.5 & 97.1 \\
\hline
\end{tabular}




\begin{tabular}{lllll}
\hline 38 años & 1 & 0.5 & 0.5 & 97.6 \\
\hline 39 años & 1 & 0.5 & 0.5 & 98.1 \\
\hline 40 años & 1 & 0.5 & 0.5 & 98.6 \\
\hline 41 años & 1 & 0.5 & 0.5 & 99.0 \\
\hline 45 años & 1 & 0.5 & 0.5 & 99.5 \\
\hline 48 años & 1 & 0.5 & 0.5 & 100.0 \\
\hline Perdidos & 3 & 1.4 & & \\
\hline TOTAL & $\mathbf{2 1 2}$ & $\mathbf{1 0 0 . 0}$ & $\mathbf{1 0 0 . 0}$ & \\
\hline
\end{tabular}

Al analizar las frecuencias absolutas, nos percatamos de que la mayor parte de la distribución de sujetos, un total de 165, está agrupada en años de nacimiento comprendidos entre 1984 y 1988 (77.83\%).

Esto se puede observar de manera más clara en el gráfico 4.29, mostrado a continuación.

\section{Edad}

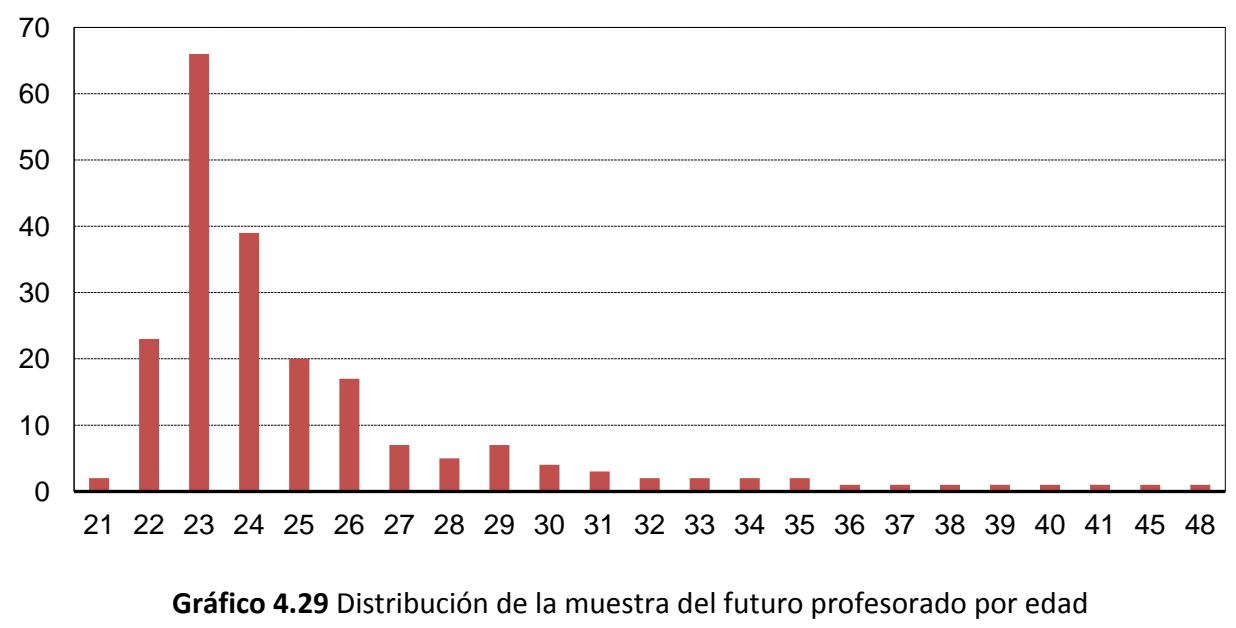

Estos resultados no nos sorprenden teniendo en cuenta que, la mayor parte de los futuros profesores de educación secundaria que estudian el Máster profesionalizante, lo hacen inmediatamente después a la obtención de la titulación universitaria correspondiente.

\subsubsection{Nivel de estudios de los padres}

En cuanto al nivel de estudios de los padres, podemos observar en las tablas 4.130 y 4.131 cómo se sigue una distribución acorde con lo señalado previamente en el estudio para estudiantes de educación secundaria. 
Tabla 4.130 Distribución de la muestra de futuros profesores por nivel de estudios del padre

\begin{tabular}{lccc}
\hline Nivel de estudios del padre & $\boldsymbol{n}_{\boldsymbol{i}}$ & $\boldsymbol{\%}$ & $\boldsymbol{\%}$ válido \\
\hline Sin estudios & 8 & 3.8 & 3.8 \\
\hline Primarios & 80 & 37.7 & 38.3 \\
\hline Bach./F.P. & 51 & 24.1 & 24.4 \\
\hline Universitarios & 70 & 33.0 & 33.5 \\
\hline Perdidos & 3 & 1.4 & \\
\hline TOTAL & $\mathbf{2 1 2}$ & $\mathbf{1 0 0 . 0}$ & $\mathbf{1 0 0 . 0}$ \\
\hline
\end{tabular}

Tabla 4.131 Distribución de la muestra de futuros profesores por nivel de estudios de la madre

\begin{tabular}{lccc}
\hline Nivel de estudios de la madre & $\boldsymbol{n}_{\boldsymbol{i}}$ & $\boldsymbol{\%}$ & $\mathbf{\%}$ válido \\
\hline Sin estudios & 2 & 0.9 & 1.0 \\
\hline Primarios & 75 & 35.4 & 36.2 \\
\hline Bach./F.P. & 67 & 31.6 & 32.4 \\
\hline Universitarios & 63 & 29.7 & 30.4 \\
\hline Perdidos & 5 & 2.4 & \\
\hline TOTAL & $\mathbf{2 1 2}$ & $\mathbf{1 0 0 . 0}$ & $\mathbf{1 0 0 . 0}$ \\
\hline
\end{tabular}

No existen grandes diferencias, pues, entre las proporciones obtenidas en padres y madres. De hecho, si se observa la gráfica 4.30, queda patente cómo existe una cierta tendencia hacia la endogamia en los estudios de ambos cónyuges.

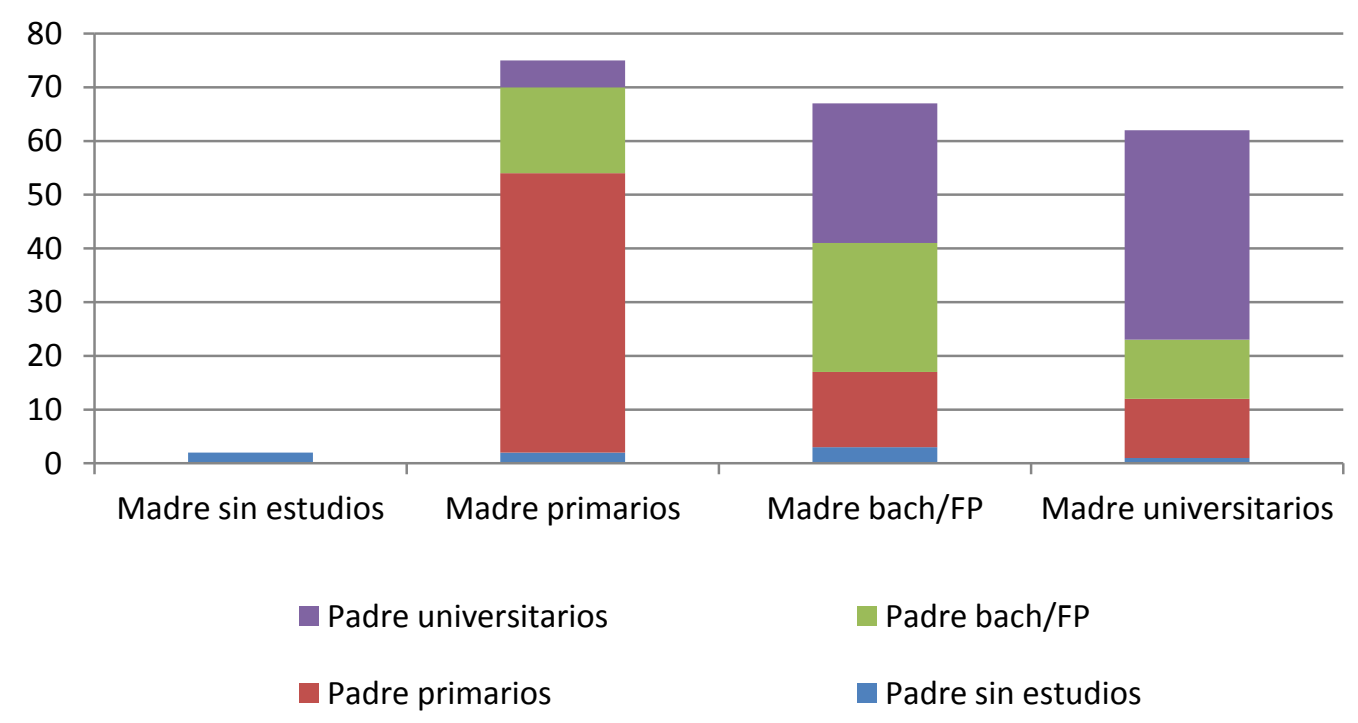

Gráfico 4.30 Distribución de la muestra del futuro profesorado por estudios del padre y de la madre 
Esta endogamia es, exactamente, del $25 \%$ en el caso de las familias de padres sin estudios, del $67.5 \%$ en el de los estudios primarios, del $47.1 \%$ en el de los estudios secundarios y del $55.7 \%$ en el de los estudios universitarios.

\subsubsection{Motivación hacia la docencia}

Se planteó a los futuros profesores una cuestión acerca de sus motivaciones hacia su futura labor como profesores vinculada con la elección del actual Máster. Los resultados se muestran en la tabla 4.132.

Tabla 4.132 Distribución de la muestra de futuros profesores por motivación hacia el Máster

\begin{tabular}{lccc}
\hline \multicolumn{1}{c}{ Elección del Máster } & $\boldsymbol{n}_{\boldsymbol{i}}$ & $\%$ & $\begin{array}{c}\% \\
\text { válido }\end{array}$ \\
\hline Siempre he querido ser profesor & 52 & 24.5 & 25.0 \\
\hline Es la mejor opción posible para continuar con mi formación & 41 & 19.3 & 19.7 \\
\hline $\begin{array}{l}\text { Considero que este Máster tiene la salida profesional más } \\
\text { atractiva }\end{array}$ & 29 & 13.7 & 13.9 \\
\hline Aumenta mis posibilidades de encontrar empleo & 49 & 23.1 & 23.6 \\
\hline $\begin{array}{l}\text { No pude entrar en otro Máster que había elegido en primera } \\
\text { opción }\end{array}$ & 3 & 1.4 & 1.4 \\
\hline No tengo ningún motivo en especial & 6 & 2.8 & 2.9 \\
\hline Realizar oposiciones & 17 & 8.0 & 8.2 \\
\hline Otra & 11 & 5.2 & 5.3 \\
\hline NS/NC & 4 & 1.9 & $\mathbf{1 0 0 . 0}$ \\
\hline Total & $\mathbf{2 1 2}$ & $\mathbf{1 0 0 . 0}$ \\
\hline
\end{tabular}

La principal razón por la que los alumnos del curso 2010/2011 eligieron el Máster es el deseo de ser profesores (25\%) seguida de cerca por la percepción de que aumenta las posibilidades de encontrar empleo (23.6\%). Un buen número de sujetos también creen que es la mejor opción para encontrar empleo (19.7\%).

Las tres primeras opciones mostradas, que se relacionan con una motivación intrínseca hacia la docencia, reúnen el 58.6\% de los casos.

\subsubsection{Empleo de herramientas informáticas en futuro profesorado}

El instrumento incluye una serie de escalas para valorar tanto la frecuencia como el nivel en el empleo de herramientas informáticas. Se introducen 2 
subapartados. En primer lugar se recoge información acerca unos parámetros generales en cuanto a la frecuencia en el empleo de este tipo de herramientas. Por otro lado, se incluye una escala sobre la frecuencia y nivel autopercibidos en el manejo de herramientas informáticas concretas para la gestión de la información, las actividades de ocio y el manejo específico de determinado software.

\subsubsection{Frecuencia en el manejo general del ordenador}

Con este grupo de ítems se pretende observar a nivel genérico qué experiencia tienen los sujetos en el manejo del ordenador e internet, y con qué frecuencia las emplean.

Sobre cada uno de los ítems se pide a los alumnos que señalen, qué frecuencia de uso y qué experiencia tienen aproximadamente en su empleo.

Tabla 4.133 Frecuencia en manejo general del ordenador en futuro profesorado

\begin{tabular}{l|c|cc}
\hline \multicolumn{1}{c|}{ Experiencia en el manejo del ordenador } & $\boldsymbol{N}$ & $\overline{\boldsymbol{X}}$ & $\boldsymbol{S}_{\boldsymbol{x}}$ \\
\hline No de años empleando el ordenador & 210 & 11.15 & 3.54 \\
\hline No de años empleando internet & 210 & 7.92 & 2.73 \\
\hline $\begin{array}{l}\text { No de horas semanales navegando por } \\
\text { internet }\end{array}$ & 210 & 13.96 & 9.78 \\
\hline
\end{tabular}

En función de lo señalado en la tabla 4.133, podemos afirmar que el futuro profesorado de educación secundaria lleva más de 11 años de media empleando los ordenadores y casi 8 haciendo uso de internet. Por otro lado, en cuanto al número medio de horas navegando por internet, la cifra se acerca a 14 horas, lo cual hace alrededor de 2 horas diarias empleadas a la tarea.

El alto nivel de empleo diario de internet nos inclinaría a pensar, a priori, que la muestra declarará tener unas habilidades elevadas en cuanto a las diferentes tareas que componen las competencias informacionales. De hecho, existen evidencias empíricas que muestran que existe esta correlación (Mackey \& Ho, 2005). Por otro lado, el relacionar íntimamente, o incluso considerar sinónimos, el desarrollo de competencias informacionales con el manejo de herramientas informáticas es algo muy común entre profesionales de la educación y personas "novatas" en el estudio de estas competencias (Williams \& Wavell, 2007). Así, otros estudios llevados a cabo al respecto indican que ésta relación entre manejo de herramientas informáticas y competencias informacionales adquiridas no es necesariamente causal (Head \& Eisenberg, 2009; Pifarré et al., 2009). A nivel más teórico, lo que parece que puede 
estar ocurriendo es que los conocimientos y habilidades en el manejo de herramientas informáticas forman parte del acervo de sub-competencias intervinientes en la conformación del constructo competencias informacionales (Bawden, 2001; Bruce, 1997) .

\subsubsection{Empleo de herramientas informáticas}

Como ya se ha señalado anteriormente, dentro del cuestionario completo (ver anexo II) se incluyen una serie de escalas para valorar tanto la frecuencia como el nivel en el empleo de herramientas informáticas.

Tabla 4.134 Descriptivos básicos sobre la frecuencia en el manejo de herramientas informáticas

\begin{tabular}{|c|c|c|c|c|c|c|c|c|}
\hline $\begin{array}{l}\text { Frecuencia manejo herramientas } \\
\text { informáticas }\end{array}$ & $\bar{X}$ & $S_{x}$ & $\begin{array}{l}1 \\
(\%)\end{array}$ & $\begin{array}{c}2 \\
(\%)\end{array}$ & $\begin{array}{c}3 \\
(\%)\end{array}$ & $\begin{array}{c}4 \\
(\%)\end{array}$ & $\begin{array}{l}5 \\
(\%)\end{array}$ & $N$ \\
\hline \multicolumn{9}{|l|}{ Actividades de ocio } \\
\hline $\begin{array}{l}\text { 01. Comunicarse por internet a través } \\
\text { de herramientas síncronas }\end{array}$ & 3.74 & 1.222 & 5.7 & 11.8 & 21.7 & 25.0 & 35.8 & 212 \\
\hline 02. Usar el ordenador para jugar & 2.17 & 1.263 & 40.6 & 26.9 & 13.2 & 13.2 & 6.1 & 212 \\
\hline $\begin{array}{l}\text { 03. Descargar o acceder a contenidos } \\
\text { multimedia a través de internet }\end{array}$ & 3.92 & 1.041 & 2.8 & 6.6 & 21.7 & 34.0 & 34.9 & 212 \\
\hline 04. Utilizar una red social & 3.93 & 1.350 & 10.5 & 5.7 & 13.9 & 19.6 & 50.2 & 209 \\
\hline 05. Comprar por internet & 2.28 & 1.137 & 32.9 & 23.8 & 29.5 & 10.0 & 3.8 & 210 \\
\hline $\begin{array}{l}\text { 06. Intercambiar información entre el } \\
\text { ordenador y accesorios externos }\end{array}$ & 3.39 & 1.209 & 9.0 & 13.2 & 28.8 & 28.3 & 20.8 & 212 \\
\hline \multicolumn{9}{|c|}{ Gestión de la información en internet } \\
\hline $\begin{array}{l}\text { 07. Buscar la información que necesito } \\
\text { en buscadores genéricos }\end{array}$ & 4.49 & 0.664 & 0.5 & 0.5 & 5.2 & 37.3 & 56.6 & 212 \\
\hline $\begin{array}{l}\text { 08. Consultar información en } \\
\text { metabuscadores o buscadores }\end{array}$ & 3.32 & 0.981 & 2.8 & 17.5 & 35.1 & 33.6 & 10.9 & 211 \\
\hline 09. Manejar el correo electrónico & 4.60 & 0.677 & 0.5 & 0.5 & 6.6 & 23.1 & 69.3 & 212 \\
\hline $\begin{array}{l}\text { 10. Crear, mantener y administrar un } \\
\text { espacio en internet }\end{array}$ & 2.41 & 1.300 & 33.2 & 23.2 & 20.9 & 14.7 & 8.1 & 211 \\
\hline $\begin{array}{l}\text { 11. Colaborar aportando información } \\
\text { en webs sociales }\end{array}$ & 1.90 & 1.149 & 51.0 & 24.3 & 13.8 & 6.2 & 4.8 & 210 \\
\hline $\begin{array}{l}\text { 12. Realizar trabajos en grupo a través } \\
\text { de herramientas web }\end{array}$ & 2.51 & 1.259 & 27.0 & 26.5 & 23.2 & 15.2 & 8.1 & 211 \\
\hline \multicolumn{9}{|l|}{ Manejo del software } \\
\hline $\begin{array}{l}\text { 13. Diseño y tratamiento de imagen, } \\
\text { sonido y vídeo digital }\end{array}$ & 2.51 & 1.241 & 25.9 & 26.9 & 25.0 & 14.2 & 8.0 & 212 \\
\hline $\begin{array}{l}\text { 14. Emplear un lenguaje de } \\
\text { programación para elaborar recursos }\end{array}$ & 1.72 & 1.022 & 58.5 & 19.8 & 15.1 & 4.2 & 2.4 & 212 \\
\hline
\end{tabular}




\begin{tabular}{l|lll|llllll}
\hline 15. Mantenimiento del software & 2.92 & 1.184 & 14.2 & 21.7 & 32.1 & 22.2 & 9.9 & 212 \\
\hline $\begin{array}{l}\text { 16. Diseño y manipulación de } \\
\text { documentos de texto }\end{array}$ & 3.79 & 1.064 & 3.8 & 8.0 & 22.2 & 37.3 & 28.8 & 212 \\
\hline $\begin{array}{l}\text { 17. Elaboración de presentaciones de } \\
\text { diapositivas }\end{array}$ & 3.52 & 1.077 & 4.7 & 11.3 & 30.7 & 33.5 & 19.8 & 212 \\
\hline \begin{tabular}{l} 
18. Manejo de la hoja de cálculo \\
\hline
\end{tabular} & 2.57 & 1.249 & 22.3 & 32.2 & 21.3 & 14.7 & 9.5 & 211 \\
\hline
\end{tabular}

*Media y desviación típica obtenidas de escala entre 1 y 5 (1=Nunca; $2=$ Casi nunca; 3=A veces; 4=Frecuentemente; 5=Casi todos los días)

Como se indica en la tabla 4.134, que señala la frecuencia en el manejo de ciertas aplicaciones relacionadas con las herramientas informáticas, la muestra de futuros profesores de educación secundaria declara, a nivel general, emplear más frecuentemente las herramientas informáticas para actividades relacionadas con el ocio, tales como comunicarse en chats, el empleo de redes sociales, o la descarga de contenidos. Por otra parte, mientras que el empleo de software específico para el manejo de la información parece quedar en segundo lugar, las labores relacionadas con la gestión de la información no están muy bien definidas: Mientras que las labores de búsqueda de información y manejo del correo electrónico parecen muy frecuentes, las relacionadas con la generación de comunidades de aprendizaje y colaboración en el intercambio de información en internet tienen menos peso.

Tabla 4.135 Descriptivos básicos sobre el nivel en el manejo de herramientas informáticas

\begin{tabular}{|c|c|c|c|c|c|c|c|c|}
\hline $\begin{array}{l}\text { Nivel de conocimientos manejo } \\
\text { herramientas informáticas }\end{array}$ & $\bar{X}$ & $S_{x}$ & $\begin{array}{c}1 \\
(\%)\end{array}$ & $\begin{array}{c}2 \\
(\%)\end{array}$ & $\begin{array}{l}3 \\
(\%)\end{array}$ & $\begin{array}{c}4 \\
(\%)\end{array}$ & $\begin{array}{c}5 \\
(\%)\end{array}$ & $N$ \\
\hline \multicolumn{9}{|l|}{ Actividades de ocio } \\
\hline $\begin{array}{l}\text { 01. Comunicarse por internet a través } \\
\text { de herramientas síncronas }\end{array}$ & 3.87 & 0.965 & 0.9 & 8.5 & 22.3 & 38.9 & 29.4 & 211 \\
\hline 02. Usar el ordenador para jugar & 2.77 & 1.301 & 22.4 & 21.0 & 24.8 & 21.4 & 10.5 & 210 \\
\hline $\begin{array}{l}\text { 03. Descargar o acceder a contenidos } \\
\text { multimedia a través de internet }\end{array}$ & 3.73 & 1.068 & 2.4 & 9.6 & 31.1 & 26.8 & 30.1 & 209 \\
\hline 04. Utilizar una red social & 3.80 & 1.195 & 7.6 & 5.7 & 20.4 & 31.8 & 34.6 & 211 \\
\hline 05. Comprar por internet & 2.97 & 1.359 & 22.3 & 11.7 & 28.2 & 22.8 & 15.0 & 206 \\
\hline $\begin{array}{l}\text { 06. Intercambiar información entre el } \\
\text { ordenador y accesorios externos }\end{array}$ & 3.56 & 1.205 & 7.6 & 11.4 & 23.8 & 31.4 & 25.7 & 210 \\
\hline \multicolumn{9}{|c|}{ Gestión de la información en internet } \\
\hline $\begin{array}{l}\text { 07. Buscar la información que } \\
\text { necesito en buscadores genéricos }\end{array}$ & 4.18 & 0.749 & 0.0 & 0.5 & 19.0 & 42.4 & 38.1 & 210 \\
\hline $\begin{array}{l}\text { 08. Consultar información en } \\
\text { metabuscadores o buscadores }\end{array}$ & 3.31 & 0.972 & 3.3 & 15.2 & 39.0 & 31.4 & 11.0 & 210 \\
\hline 09. Manejar el correo electrónico & 4.36 & 0.777 & 0.0 & 1.4 & 14.3 & 31.4 & 52.9 & 210 \\
\hline
\end{tabular}




\begin{tabular}{l|ll|llllll|l}
\hline $\begin{array}{l}\text { 10. Crear, mantener y administrar un } \\
\text { espacio en internet }\end{array}$ & 2.70 & 1.356 & 25.7 & 21.0 & 24.8 & 15.2 & 13.3 & 210 \\
\hline $\begin{array}{l}\text { 11. Colaborar aportando información } \\
\text { en webs sociales }\end{array}$ & 2.31 & 1.298 & 35.9 & 26.3 & 17.7 & 11.5 & 8.6 & 209 \\
\hline $\begin{array}{l}\text { 12. Realizar trabajos en grupo } \\
\text { través de herramientas web }\end{array}$ & 2.76 & 1.302 & 23.0 & 19.1 & 28.7 & 17.7 & 11.5 & 209 \\
\hline
\end{tabular}

Manejo del software

\begin{tabular}{|c|c|c|c|c|c|c|c|c|}
\hline $\begin{array}{l}\text { 13. Diseño y tratamiento de imagen, } \\
\text { sonido y vídeo digital }\end{array}$ & 2.53 & 1.307 & 28.4 & 24.0 & 24.5 & 12.5 & 10.6 & 208 \\
\hline $\begin{array}{l}\text { 14. Emplear un lenguaje de } \\
\text { programación para elaborar recursos }\end{array}$ & 1.81 & 1.128 & 55.7 & 21.4 & 12.9 & 5.7 & 4.3 & 210 \\
\hline 15. Mantenimiento del software & 2.81 & 1.295 & 19.0 & 23.3 & 29.5 & 13.8 & 14.3 & 210 \\
\hline $\begin{array}{l}\text { 16. Diseño y manipulación de } \\
\text { documentos de texto }\end{array}$ & 3.66 & 1.076 & 3.8 & 9.6 & 28.7 & 32.5 & 25.4 & 209 \\
\hline $\begin{array}{l}\text { 17. Elaboración de presentaciones de } \\
\text { diapositivas }\end{array}$ & 3.68 & 1.075 & 2.9 & 11.5 & 26.4 & 32.7 & 26.4 & 208 \\
\hline 18. Manejo de la hoja de cálculo & 2.75 & 1.217 & 17.3 & 25.5 & 33.2 & 12.5 & 11.5 & 208 \\
\hline
\end{tabular}

*Media y desviación típica obtenidas de escala entre 1 y 5 (1=Nunca; $2=$ Casi nunca; 3=A veces; 4=Frecuentemente; 5=Casi todos los días)

En cuanto al nivel autopercibido en lo que respecta al manejo de aplicaciones informáticas, se observa una tendencia similar a lo señalado en la frecuencia de empleo. Las tareas relacionadas con el manejo de las herramientas informáticas para actividades de ocio son en las que la muestra declara tener un nivel más alto. La muestra también declara poseer un nivel alto en cuanto a las labores de búsqueda de información en internet. Por su lado, en cuanto al manejo de software específico y las actividades de gestión de la información para compartir y generar aprendizajes, los sujetos de la muestra señalan un nivel de desempeño medio-bajo.

Complementando la información obtenida aquí con los datos que indicaban un número de horas semanales elevado dedicadas a navegar por internet, parece que sería más explicable que la muestra no dispusiera de un elevado desarrollo de las competencias informacionales. Las causas de esta reflexión se deben a que la muestra emplea internet básicamente para comunicarse con herramientas síncronas y asíncronas, para acceder a redes sociales, y para buscar y descargar contenidos de interés. Por otra parte, las labores más relacionadas con la participación en comunidades de aprendizaje y el manejo de software específico para la gestión de la información tienen una frecuencia y nivel de uso moderados. 
En aras de hacer una primera comparación del nivel y la frecuencia de empleo declarados, se muestra el gráfico 4.31, en el que se puede observar cómo a nivel general no se localizan diferencias reseñables.

A nivel más específico, se localizan algunos ítems en los que la muestra declara poseer un nivel más alto que la frecuencia con la que se hace uso de sus posibilidades. En concreto, se localizan estas diferencias en las actividades de ocio Jugar con el ordenador y Comprar a través de internet. Por otra parte, también se localizan importantes diferencias favorables al nivel autopercibido en las actividades relacionadas con la participación en comunidades de aprendizaje y el intercambio de información en la red.

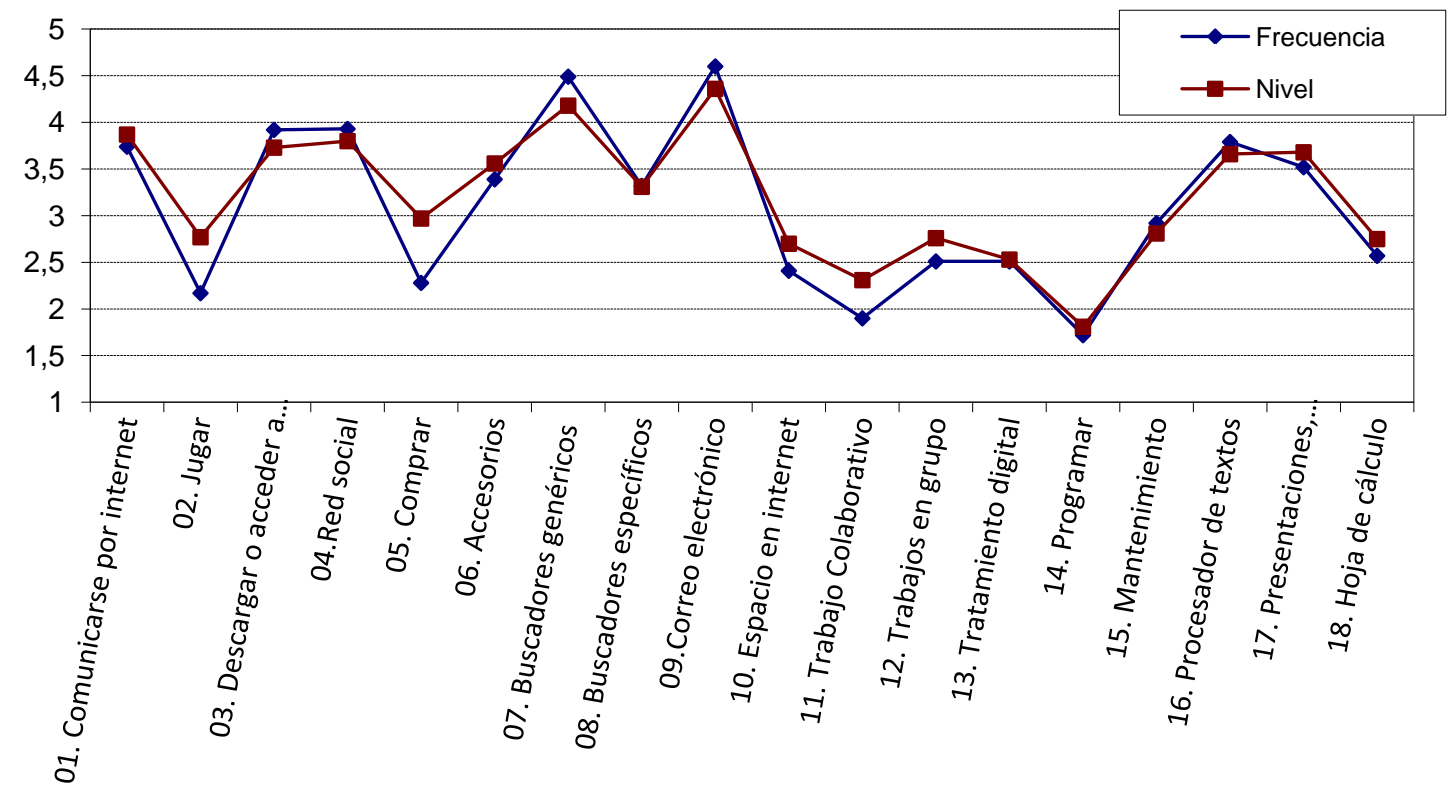

Gráfico 4.31 Diferencias entre la frecuencia y nivel declarados en el manejo de herramientas

Si procedemos al cálculo de los intervalos poblacionales para cada uno de los ítems tanto en la frecuencia de empleo como en el nivel autopercibido, como se indica en la tabla 4.136, se pueden observar para la mayor parte de ítems diferencias no significativas.

Tabla 4.136 Intervalos poblacionales para la frecuencia y el nivel en el manejo de aplicaciones informáticas

\begin{tabular}{|c|c|c|c|c|c|c|}
\hline Manejo de aplicaciones informáticas & $\begin{array}{c}\bar{X} \\
\text { frecuencia }\end{array}$ & $\begin{array}{c}\bar{X} \\
\text { nivel }\end{array}$ & & $\begin{array}{l}\text { valo } \\
\text { ncia }\end{array}$ & \multicolumn{2}{|c|}{ Intervalo nivel } \\
\hline \multicolumn{7}{|l|}{ Actividades de ocio } \\
\hline $\begin{array}{l}\text { 01. Comunicarse por internet a través de } \\
\text { herramientas síncronas }\end{array}$ & 3.736 & 3.872 & 3.57 & 3.90 & 3.74 & 4.00 \\
\hline 02. Usar el ordenador para jugar & 2.175 & 2.767 & 2.00 & 2.35 & 2.59 & 2.94 \\
\hline
\end{tabular}




\begin{tabular}{|c|c|c|c|c|c|c|}
\hline $\begin{array}{l}\text { 03. Descargar o acceder a contenidos } \\
\text { multimedia a través de internet }\end{array}$ & 3.915 & 3.727 & 3.77 & 4.06 & 3.58 & 3.87 \\
\hline 04. Utilizar una red social & 3.933 & 3.801 & 3.75 & 4.12 & 3.64 & 3.96 \\
\hline 05. Comprar por internet & 2.281 & 2.966 & 2.13 & 2.44 & 2.78 & 3.15 \\
\hline $\begin{array}{l}\text { 06. Intercambiar información entre el } \\
\text { ordenador y accesorios externos }\end{array}$ & 3.387 & 3.562 & 3.22 & 3.55 & 3.40 & 3.73 \\
\hline \multicolumn{7}{|l|}{ Gestión de la información en internet } \\
\hline $\begin{array}{l}\text { 07. Buscar la información que necesito en } \\
\text { buscadores genéricos }\end{array}$ & 4.491 & 4.181 & 4.40 & 4.58 & 4.08 & 4.28 \\
\hline $\begin{array}{l}\text { 08. Consultar información en } \\
\text { metabuscadores o buscadores }\end{array}$ & 3.322 & 3.314 & 3.19 & 3.46 & 3.18 & 3.45 \\
\hline 09. Manejar el correo electrónico & 4.604 & 4.357 & 4.51 & 4.70 & 4.25 & 4.46 \\
\hline $\begin{array}{l}\text { 10. Crear, mantener y administrar un } \\
\text { espacio en internet }\end{array}$ & 2.412 & 2.695 & 2.24 & 2.59 & 2.51 & 2.88 \\
\hline $\begin{array}{l}\text { 11. Colaborar aportando información en } \\
\text { webs sociales }\end{array}$ & 1.895 & 2.306 & 1.74 & 2.05 & 2.13 & 2.48 \\
\hline $\begin{array}{l}\text { 12. Realizar trabajos en grupo a través de } \\
\text { herramientas web }\end{array}$ & 2.507 & 2.756 & 2.34 & 2.68 & 2.58 & 2.93 \\
\hline \multicolumn{7}{|l|}{ Manejo del software } \\
\hline $\begin{array}{l}\text { 13. Diseño y tratamiento de imagen, } \\
\text { sonido y vídeo digital }\end{array}$ & 2.514 & 2.529 & 2.35 & 2.68 & 2.35 & 2.71 \\
\hline $\begin{array}{l}\text { 14. Emplear un lenguaje de programación } \\
\text { para elaborar recursos }\end{array}$ & 1.722 & 1.814 & 1.58 & 1.86 & 1.66 & 1.97 \\
\hline 15. Mantenimiento del software & 2.920 & 2.810 & 2.76 & 3.08 & 2.63 & 2.99 \\
\hline $\begin{array}{l}\text { 16. Diseño y manipulación de documentos } \\
\text { de texto }\end{array}$ & 3.792 & 3.660 & 3.65 & 3.94 & 3.51 & 3.81 \\
\hline $\begin{array}{l}\text { 17. Elaboración de presentaciones de } \\
\text { diapositivas }\end{array}$ & 3.524 & 3.683 & 3.38 & 3.67 & 3.54 & 3.83 \\
\hline 18. Manejo de la hoja de cálculo & 2.569 & 2.755 & 2.40 & 2.74 & 2.59 & 2.92 \\
\hline
\end{tabular}

* Nivel de significación $\alpha=.05$

En cuanto a las diferencias localizadas, se observa cómo para los ítems en los que se obtienen medias más bajas de frecuencia y nivel declarados (Usar el ordenador para jugar, Comprar por internet, Colaborar aportando información en redes sociales) se obtienen niveles de manejo significativamente más altos que frecuencias de empleo. Mientras, cuando las medias son altas (Buscar información en buscadores genéricos, Manejar el correo electrónico), las diferencias se obtienen favorables a las frecuencias de empleo. 
Así, podemos interpretar que cuanto mayor nivel tienen los usuarios en el manejo de una herramienta concreta, más conscientes son de las deficiencias de formación que poseen al respecto.

\subsubsection{Competencias informacionales en futuro profesorado}

En este apartado se desarrolla la parte principal del estudio, consistente en analizar las competencias relacionadas con el manejo y gestión de la información el futuro profesorado, en qué nivel se encuentran y qué cota de importancia conceden a su dominio. El instrumento empleado para la recogida de datos es la traducción de una encuesta elaborada por María Pinto (2009).

\subsubsection{Importancia y nivel de conocimientos percibidos sobre las competencias informacionales}

En este apartado se les pregunta a los docentes sobre 26 ítems relacionados con las competencias informacionales. Los sujetos responden a cada ítem, en una escala de 1 a 9 (siendo 1 muy baja y 9 muy alta), sobre el nivel de importancia que creen que tiene para su proceso de formación y el nivel de conocimiento que declaran poseer en estos momentos acerca del mismo.

Los resultados se muestran en las tablas 4.137 (importancia que conceden los alumnos a las competencias informacionales) y 4.138 (nivel de conocimientos que poseen los alumnos acerca de las competencias informacionales). Los ítems se reparten a lo largo de cada una de las 4 dimensiones teóricas ya definidas y expuestas con anterioridad:

- Búsqueda de información: ítems del 1 al 8.

- Evaluación de información: ítems del 9 al 13.

- Procesamiento de información: ítems del 14 al 19.

- Comunicación y difusión de información: ítems del 20 al 26.

Los ítems se han ordenado en las tablas en función de la media de cada uno, estando en primer lugar los ítems con una media mayor, y en último lugar los que tienen una media menor. 
Tabla 4.137 Descriptivos básicos sobre la importancia asignada a las competencias informacionales. Futuro profesorado

\begin{tabular}{|c|c|c|c|c|c|c|c|c|c|c|c|c|}
\hline Competencias informacionales (Importancia concedida) & $\bar{X}$ & $s_{x}$ & $1(\%)$ & $2(\%)$ & $3(\%)$ & $4(\%)$ & $5(\%)$ & $6(\%)$ & $7(\%)$ & $8(\%)$ & $9(\%)$ & $N$ \\
\hline 14. Saber resumir y esquematizar la información & 8.1 & 1.2 & 0.0 & 0.5 & 0.5 & 0.5 & 2.4 & 5.2 & 13.3 & 29.5 & 48.1 & 210 \\
\hline 22. Saber redactar un documento (ej. informe, trabajo académico,...) & 8.0 & 1.3 & 0.0 & 0.5 & 1.0 & 1.0 & 1.4 & 7.1 & 15.7 & 23.8 & 49.5 & 210 \\
\hline 05. Conocer la terminología especializada de tu materia & 8.0 & 1.1 & 0.0 & 0.0 & 0.0 & 0.5 & 1.4 & 9.5 & 18.6 & 30.5 & 39.5 & 210 \\
\hline 15. Ser capaz de reconocer la estructuración de un texto & 7.9 & 1.3 & 0.0 & 0.5 & 0.5 & 0.5 & 3.8 & 5.7 & 21.0 & 25.7 & 42.4 & 210 \\
\hline 10. Reconocer en el texto las ideas del autor & 7.9 & 1.3 & 0.0 & 0.0 & 1.0 & 1.4 & 3.8 & 6.7 & 19.1 & 26.3 & 41.6 & 209 \\
\hline 20. Saber comunicar en público & 7.8 & 1.6 & 1.0 & 0.5 & 1.0 & 2.4 & 5.7 & 6.7 & 14.3 & 22.9 & 45.7 & 210 \\
\hline 25. Saber hacer presentaciones académicas & 7.6 & 1.6 & 1.4 & 0.0 & 1.0 & 2.4 & 5.7 & 6.2 & 19.1 & 30.1 & 34.0 & 209 \\
\hline 06. Saber buscar y recuperar información en internet & 7.6 & 1.5 & 1.4 & 0.0 & 0.5 & 2.4 & 3.8 & 4.8 & 30.6 & 27.3 & 29.2 & 209 \\
\hline 13. Conocer los autores o instituciones más relevantes en tu ámbito & 7.5 & 1.6 & 0.5 & 1.0 & 1.9 & 1.4 & 7.2 & 10.6 & 20.2 & 21.6 & 35.6 & 208 \\
\hline 01. Saber utilizar fuentes de información impresa (ej. libros, ...) & 7.5 & 1.5 & 0.5 & 1.0 & 2.4 & 2.9 & 9.6 & 12.4 & 30.6 & 23.4 & 17.2 & 210 \\
\hline 23. Conocer el código ético de tu ámbito académico/profesional & 7.4 & 1.5 & 0.0 & 0.0 & 1.0 & 1.5 & 10.7 & 11.2 & 25.2 & 17.5 & 33.0 & 206 \\
\hline 09. Saber evaluar la calidad de los recursos de información & 7.4 & 1.5 & 0.0 & 0.0 & 1.4 & 1.0 & 10.1 & 12.5 & 22.6 & 21.6 & 30.8 & 208 \\
\hline 21. Saber comunicar en otros idiomas & 7.3 & 2.1 & 2.9 & 1.4 & 2.4 & 2.4 & 11.0 & 7.6 & 11.0 & 22.4 & 39.0 & 210 \\
\hline 12. Determinar si la información que contiene un recurso está actualizada & 7.1 & 1.6 & 0.0 & 1.0 & 2.9 & 1.9 & 11.0 & 12.0 & 21.5 & 28.7 & 21.1 & 209 \\
\hline 03. Saber consultar y usar fuentes electrónicas de información primaria & 7.0 & 1.6 & 0.0 & 0.0 & 0.0 & 0.5 & 1.4 & 9.5 & 18.6 & 30.5 & 39.5 & 209 \\
\hline 26. Saber difundir la información en internet & 6.9 & 1.8 & 2.4 & 1.0 & 3.4 & 2.4 & 8.2 & 12.5 & 30.3 & 22.1 & 17.8 & 208 \\
\hline 07. Saber utilizar fuentes electrónicas informales de información & 6.7 & 1.9 & 2.9 & 0.5 & 1.4 & 6.2 & 11.5 & 15.3 & 23.9 & 19.6 & 18.7 & 209 \\
\hline 24. Legislación sobre el uso de la información y de la propiedad intelectual & 6.7 & 1.9 & 2.4 & 1.4 & 3.9 & 2.9 & 10.6 & 19.8 & 19.8 & 22.2 & 16.9 & 207 \\
\hline 04. Saber utilizar fuentes electrónicas de información secundaria & 6.7 & 1.8 & 1.4 & 0.0 & 0.5 & 2.4 & 3.8 & 4.8 & 30.6 & 27.3 & 29.2 & 210 \\
\hline 02. Saber acceder y usar los catálogos automatizados & 6.6 & 1.9 & 2.9 & 1.0 & 1.9 & 3.3 & 13.8 & 16.2 & 22.4 & 24.8 & 13.8 & 209 \\
\hline 11. Conocer la tipología de las fuentes de información científica & 6.5 & 1.8 & 1.4 & 1.9 & 4.3 & 3.4 & 13.0 & 20.2 & 22.6 & 20.7 & 12.5 & 208 \\
\hline 19. Saber instalar programas informáticos & 6.3 & 2.4 & 8.6 & 3.8 & 1.9 & 3.3 & 12.4 & 14.8 & 17.2 & 17.7 & 20.1 & 209 \\
\hline 16. Saber usar gestores de bases de datos & 6.3 & 2.2 & 4.8 & 4.8 & 3.3 & 5.7 & 9.6 & 12.4 & 26.8 & 19.1 & 12.9 & 209 \\
\hline 18. Saber manejar programas estadísticos y hojas de cálculo & 6.0 & 2.3 & 8.6 & 3.8 & 3.8 & 5.7 & 11.0 & 11.5 & 27.3 & 15.3 & 12.9 & 209 \\
\hline 08. Conocer las estrategias de búsqueda de información & 5.9 & 2.2 & 8.7 & 1.5 & 3.1 & 7.2 & 17.9 & 14.9 & 24.1 & 10.8 & 11.8 & 195 \\
\hline 17. Usar gestores de referencias bibliográficas & 5.3 & 2.5 & 13.5 & 6.5 & 5.5 & 8.0 & 10.0 & 14.5 & 23.0 & 10.0 & 8.5 & 200 \\
\hline
\end{tabular}

* Media y desviación típica obtenidas de escala entre 1 y 9 (1=Muy baja; 3=Baja; 5=Media; 7=Alta; 9=Muy alta) 
Como se puede observar en la tabla 4.137, los sujetos conceden una importancia media-alta a todas las competencias informacionales presentadas, considerando las más importantes $(\bar{X}>7)$ las habilidades genéricas no relacionadas con el manejo de herramientas informáticas (Saber resumir y esquematizar la información, Saber redactar un documento, Conocer la terminología especializada de una materia, reconocer la estructura de un texto, reconocer en un texto las ideas del autor y saber comunicar en público). Todas estas sub-competencias o desempeños concretos tienen que ver con herramientas cognitivas pertenecientes a las diferentes dimensiones de las competencias informacionales, esenciales para el correcto desarrollo y manejo de las competencias informacionales.

Por otra parte, las competencias a las que los sujetos conceden la menor importancia son aquellas relacionadas con el procesamiento de información con herramientas informáticas (Saber instalar programas informáticos, Saber usar gestores de bases de datos, Saber manejar programas estadísticos y hojas de cálculo o Usar gestores de referencias bibliográficas).

Queda patente pues, que el futuro profesorado asigna una mayor importancia a aquellas habilidades cognitivas que facilitan el desarrollo de las competencias informacionales que a aquellas habilidades más relacionadas con el aspecto instrumental de manejo de aplicaciones informáticas determinadas.

Estos resultados nos sugieren que quizá los sujetos asignen una mayor importancia a las competencias que mejor dominan, y que el hecho de considerar menos importantes otras se debe más al propio desconocimiento de lo relacionado con la competencia (por ejemplo, qué es una base de datos y para qué se puede utilizar) que al convencimiento personal de su escasa importancia formativa.

Por otro lado, en la tabla 4.138 se presentan los resultados sobre el nivel de competencias informacionales que afirman alcanzar los futuros profesores de educación secundaria incluidos en el estudio. Al tratarse de un nivel autopercibido, debemos ser cautelosos en las afirmaciones y generalizaciones vertidas en adelante, ya que no se trata de una medida sobre el nivel real de los sujetos. 
Tabla 4.138 Estadísticos básicos sobre el nivel de conocimientos autopercibidos en competencias informacionales. Futuro profesorado

\begin{tabular}{|c|c|c|c|c|c|c|c|c|c|c|c|c|}
\hline Competencias informacionales (nivel autopercibido) & $\bar{X}$ & $s_{x}$ & $1(\%)$ & $2(\%)$ & $3(\%)$ & $4(\%)$ & $5(\%)$ & $6(\%)$ & $7(\%)$ & $8(\%)$ & $9(\%)$ & $N$ \\
\hline 14. Saber resumir y esquematizar la información & 7.70 & 1.231 & 1.0 & 0.0 & 1.9 & 2.9 & 9.1 & 17.3 & 31.7 & 19.2 & 16.8 & 210 \\
\hline 10. Reconocer en el texto las ideas del autor & 7.56 & 1.172 & 0.0 & 0.0 & 0.5 & 0.5 & 4.3 & 11.0 & 29.7 & 29.7 & 24.4 & 209 \\
\hline 15. Ser capaz de reconocer la estructuración de un texto & 7.53 & 1.298 & 0.5 & 0.0 & 0.0 & 1.4 & 6.2 & 8.6 & 28.1 & 29.5 & 25.7 & 210 \\
\hline 05. Conocer la terminología especializada de tu materia & 7.51 & 1.171 & 0.0 & 0.0 & 0.5 & 1.0 & 4.8 & 10.0 & 29.5 & 33.3 & 21.0 & 210 \\
\hline 22. Saber redactar un documento (ej. informe, trabajo académico, ...) & 7.43 & 1.337 & 0.0 & 0.5 & 1.0 & 0.5 & 6.7 & 12.9 & 26.2 & 28.1 & 24.3 & 210 \\
\hline 01. Saber utilizar fuentes de información impresa (ej. libros, ...) & 7.28 & 1.264 & 0.0 & 0.5 & 0.0 & 1.9 & 5.3 & 16.7 & 30.1 & 27.3 & 18.2 & 209 \\
\hline 25. Saber hacer presentaciones académicas (ej. Powerpoint, ...) & 7.28 & 1.626 & 1.0 & 0.5 & 1.9 & 2.4 & 9.6 & 8.1 & 22.5 & 30.1 & 23.9 & 209 \\
\hline 06. Saber buscar y recuperar información en internet & 7.14 & 1.607 & 1.4 & 0.0 & 1.4 & 3.8 & 8.1 & 12.0 & 23.9 & 30.6 & 18.7 & 209 \\
\hline 13. Conocer los autores o instituciones más relevantes en tu ámbito & 6.96 & 1.490 & 1.0 & 1.9 & 2.9 & 9.1 & 17.3 & 31.7 & 19.2 & 16.8 & 0 & 208 \\
\hline 09. Saber evaluar la calidad de los recursos de información & 6.89 & 1.329 & 0.0 & 0.5 & 1.0 & 1.9 & 12.4 & 17.2 & 35.9 & 19.6 & 11.5 & 209 \\
\hline 03. Saber consultar y usar fuentes electrónicas de información primaria & 6.78 & 1.513 & 0.5 & 1.0 & 1.0 & 4.8 & 12.0 & 16.7 & 31.6 & 20.6 & 12.0 & 209 \\
\hline 20. Saber comunicar en público & 6.71 & 1.629 & 1.0 & 1.4 & 1.4 & 4.3 & 11.9 & 20.5 & 25.2 & 21.4 & 12.9 & 210 \\
\hline 23. Conocer el código ético de tu ámbito académico/profesional & 6.60 & 1.634 & 1.0 & 1.5 & 2.4 & 2.4 & 15.5 & 20.9 & 26.2 & 18.0 & 12.1 & 206 \\
\hline 07. Saber utilizar fuentes electrónicas informales de información & 6.50 & 1.800 & 2.4 & 0.5 & 1.4 & 7.2 & 17.7 & 16.3 & 23.0 & 17.2 & 14.4 & 209 \\
\hline 12. Determinar si la información que contiene un recurso está actualizada & 6.46 & 1.519 & 0.5 & 1.4 & 1.4 & 4.3 & 20.1 & 17.2 & 30.1 & 17.7 & 7.2 & 209 \\
\hline 02. Saber acceder y usar los catálogos automatizados & 6.14 & 1.816 & 2.9 & 1.9 & 1.4 & 7.7 & 23.0 & 17.2 & 21.1 & 16.7 & 8.1 & 209 \\
\hline 04. Saber utilizar fuentes electrónicas de información secundaria & 6.10 & 1.850 & 2.4 & 2.4 & 4.8 & 5.3 & 20.2 & 20.7 & 20.7 & 14.9 & 8.7 & 208 \\
\hline 21. Saber comunicar en otros idiomas & 6.09 & 2.194 & 3.8 & 3.3 & 7.1 & 6.2 & 15.7 & 14.3 & 18.6 & 16.7 & 13.8 & 210 \\
\hline 11. Conocer la tipología de las fuentes de información científica & 6.01 & 1.860 & 0.5 & 1.4 & 1.4 & 4.3 & 20.1 & 17.2 & 30.1 & 17.7 & 7.2 & 208 \\
\hline 26. Saber difundir la información en internet (ej. webs, blogs, ...) & 6.01 & 2.209 & 6.7 & 1.9 & 5.8 & 6.7 & 14.4 & 16.8 & 20.7 & 13.9 & 13.0 & 208 \\
\hline 19. Saber instalar programas informáticos & 5.91 & 2.628 & 12.0 & 4.3 & 1.9 & 8.6 & 13.9 & 8.6 & 16.3 & 14.4 & 20.1 & 209 \\
\hline 24. Legislación sobre el uso de la información y de la propiedad intelectual & 5.48 & 2.106 & 6.3 & 4.8 & 6.3 & 9.7 & 20.8 & 18.8 & 15.5 & 11.6 & 6.3 & 207 \\
\hline 16. Saber usar gestores de bases de datos (ej. Access, MySQL, ...) & 5.24 & 2.333 & 8.6 & 8.1 & 6.2 & 10.0 & 17.2 & 15.8 & 16.3 & 9.6 & 7.7 & 209 \\
\hline 18. Saber manejar programas estadísticos y hojas de cálculo & 5.22 & 2.449 & 12.4 & 6.7 & 5.7 & 8.6 & 18.2 & 13.4 & 14.8 & 12.0 & 8.1 & 209 \\
\hline 08. Conocer las estrategias de búsqueda de información & 4.96 & 2.309 & 12.4 & 6.2 & 7.2 & 10.3 & 23.2 & 12.4 & 13.9 & 8.8 & 5.7 & 194 \\
\hline 17. Usar gestores de referencias bibliográficas & 4.14 & 2.283 & 21.0 & 8.0 & 9.0 & 13.5 & 17.5 & 13.0 & 11.5 & 4.5 & 1.5 & 200 \\
\hline
\end{tabular}

* Media y desviación típica obtenidas de escala entre 1 y 9 (1=Muy baja; 3=Baja; 5=Media; 7=Alta; 9=Muy alta) 
Los sujetos consideran tener un nivel de conocimientos medio en la mayor parte de las competencias informacionales presentadas y medio-bajo en algunas otras. Así mismo, declaran tener unos conocimientos elevados $(\bar{X}>7)$ en prácticamente las mismas competencias en las que señalaban que tenían una importancia alta (Saber resumir y esquematizar la información, Reconocer en el texto las ideas del autor, Reconocer la estructura de un texto, Conocer la terminología especializada de una materia o Saber redactar un documento). Por otro lado, también coinciden en buena medida las competencias a las que los futuros profesores conceden la menor importancia con las que afirman dominar menos. Por ejemplo, podemos encontrar en este grupo "Usar gestores de referencias bibliográficas" ( $\bar{X}=4.14)$, "Conocer las estrategias de búsqueda de información" ( $\bar{X}=4.96)$, "Saber manejar programas estadísticos y hojas de cálculo" ( $\bar{X}=5.22)$ o "Saber usar gestores de bases de datos" $(\bar{X}=5.24)$.

Estas coincidencias en los resultados sugieren, como complemento a lo señalado anteriormente, que las competencias que mejor dominan los sujetos son las que consideran, por lógica, más importantes, ya que conocen qué beneficios puede reportarles dicha competencia. Sin embargo, es complicado entender las ventajas que puede ofrecer el dominio de competencias que desconocen, o que conocen en menor medida los sujetos de la muestra. De nuevo se vuelve a observar cómo los futuros profesores señalan que las estrategias que menos dominan son las relacionadas con el procesamiento de información a partir del manejo y gestión de herramientas informáticas como hojas de cálculo, paquetes estadísticos o gestores de bases de datos y de referencias bibliográficas.

Para llevar a cabo un análisis y comparación más sistemáticos de los resultados obtenidos en todos y cada uno de los ítems tanto en la importancia designada como en el nivel autopercibido, se muestra a continuación el gráfico 4.32. Éste hace un análisis comparativo de las medias de cada uno de los ítems en función de la importancia asignada y el nivel autopercibido en cuanto a las competencias informacionales. 


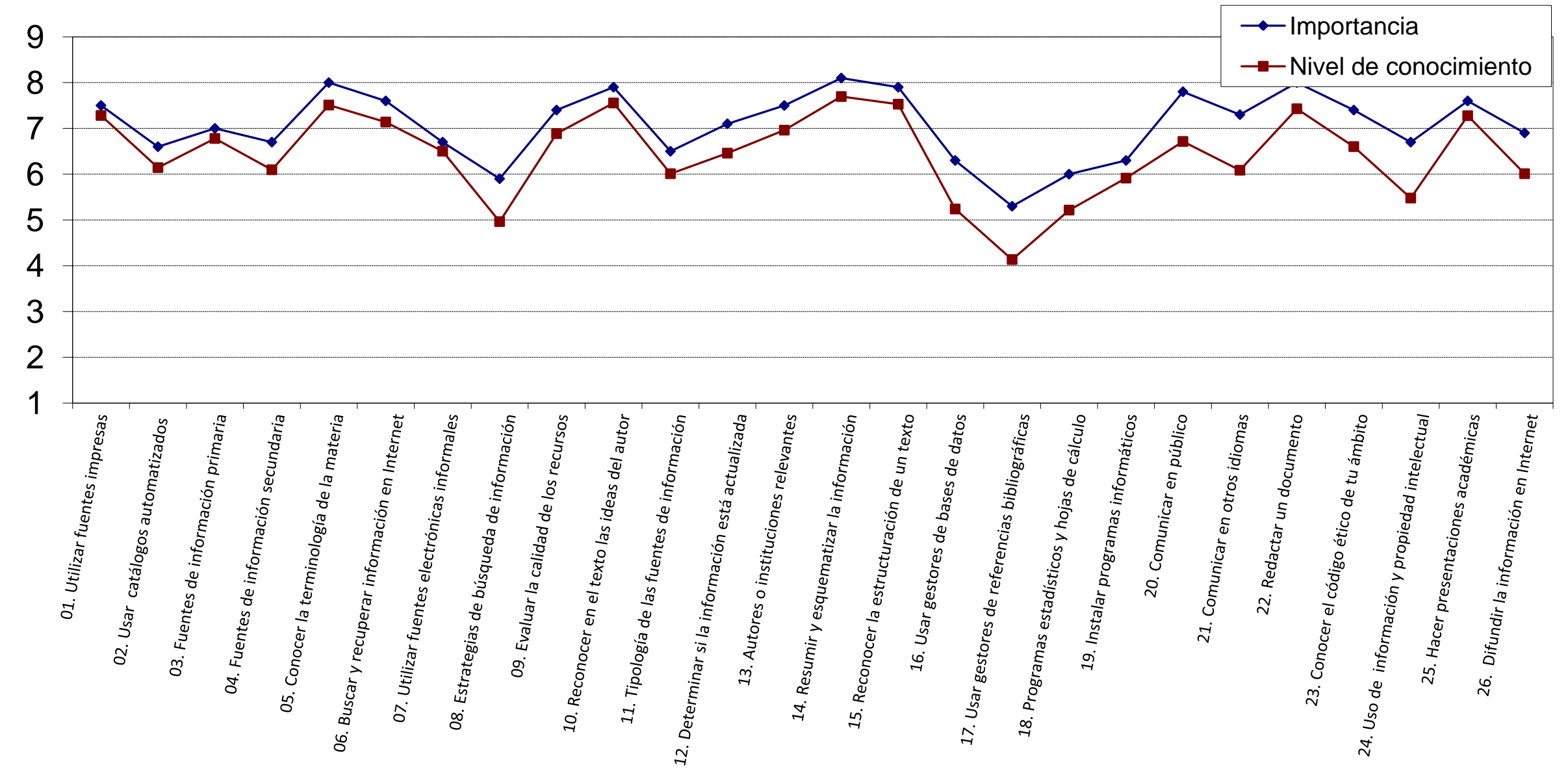

* Media y desviación típica obtenidas de escala entre 1 y 9 (1=Muy baja; 3=Baja; 5=Media; 7=Alta; 9=Muy alta)

Gráfico 4.32 Diferencias en la percepción de la importancia y el nivel de conocimientos de las competencias informacionales. Futuro profesorado 

Analizando las diferencias entre el nivel de conocimientos y la importancia asignada a las competencias informacionales (gráfico 4.32), se puede observar cómo de manera generalizada la importancia asignada es superior al valor de la media del nivel de conocimientos. Estos resultados sugieren que los sujetos encuestados consideran que deberían tener un nivel de conocimientos superior en lo que respecta a las cuatro dimensiones básicas de las que se compone las competencias informacionales.

Si analizamos algún caso en concreto, se puede señalar que la mayor diferencia registrada se encuentra en los ítems 24 "Conocer las normas de uso de la información y de la propiedad intelectual" $\left(\bar{X}_{1}-\bar{X}_{2}=1.22\right)$ y 21 "Comunicar en otros idiomas" $\left(\bar{X}_{1}-\bar{X}_{2}\right.$ $=1.21$ ). Esto se podría interpretar en el sentido de que los futuros profesores son conscientes de su bajo nivel en cuanto al dominio de los idiomas y al conocimiento de las leyes para el manejo de la información propia y ajena, a pesar de su importancia para sus futuros profesionales.

\subsubsection{Competencias informacionales: análisis de dimensiones en futuros profesores de Secundaria}

Una vez analizados los ítems por separado, procedamos al estudio de las dimensiones del cuestionario tanto en lo que se refiere a la importancia asignada a las competencias informacionales, como en lo que respecta al nivel autopercibido en las mismas.

Al igual que se hizo con la muestra de estudiantes, estas dimensiones serán las que ejercerán de variables criterio en adelante. Así, se estudiará su comportamiento en función de algunos grupos principales que actuarán de variables predictoras. Por ello, con la intención de definir el empleo de las técnicas de contraste de hipótesis más adecuadas (paramétricas o no paraméticas), se explorarán en primer lugar las características de las funciones de densidad de cada una de las variables.

\section{a) Análisis sobre la importancia concedida a las dimensiones: análisis de normalidad}

Vamos a proceder, por tanto, a analizar las gráficas que muestran las funciones de densidad en cuanto a la importancia asignada a cada una de las dimensiones de las competencias informacionales. 
En todas las dimensiones de la importancia designada nos encontramos con curvas de densidad con una tendencia hacia la asimetría negativa. En cuanto a la curtosis, aunque a simple vista no se aprecia una tendencia clara, se puede señalar una muy ligera variación de las curvas con respecto a la N(0.1), hacia la acumulación de los sujetos en un rango de puntuaciones pequeño.

Importancia búsqueda de información

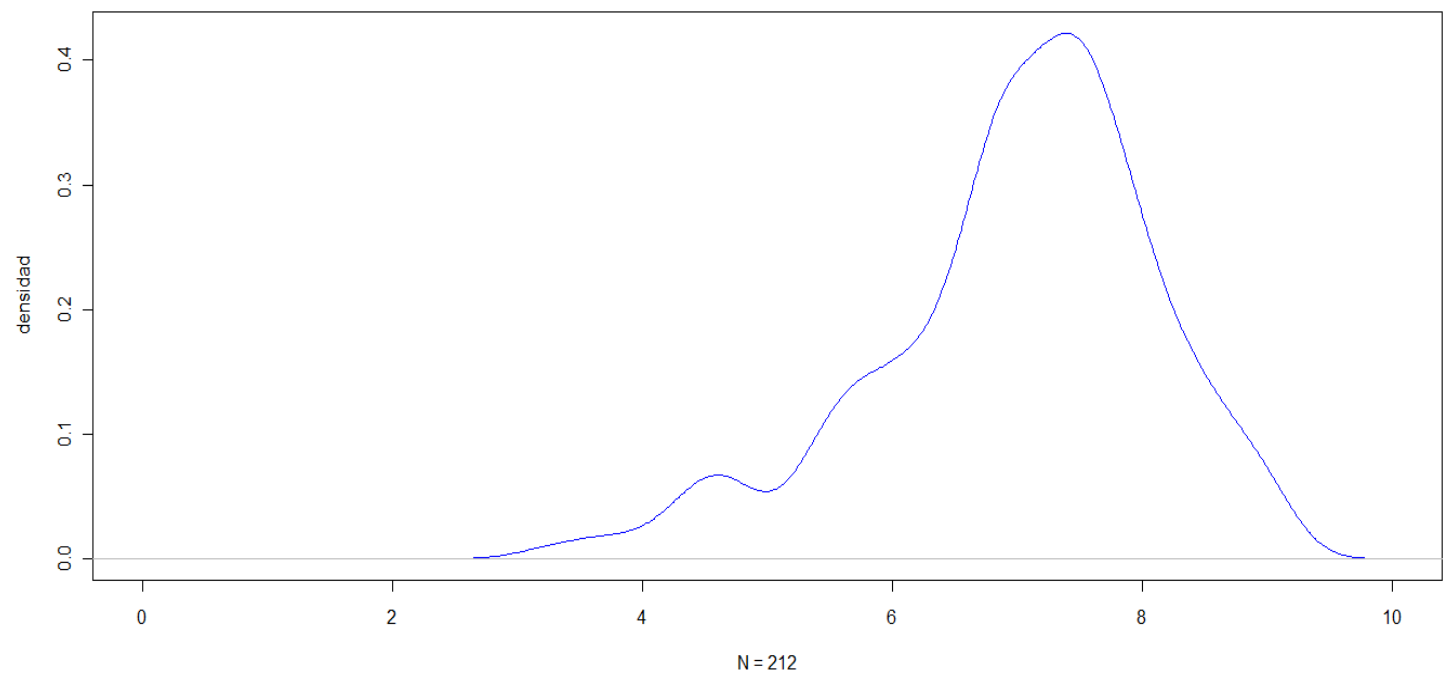

Gráfico 4.33 Función de densidad de la importancia asignada a la búsqueda de información. Futuro profesorado

El gráfico 4.33 muestra la función de densidad de la dimensión de importancia asignada a la búsqueda de información. Como se señalaba anteriormente, se observa claramente una tendencia hacia puntuaciones altas, ya que la cola de la función es más prolongada hacia la izquierda de la escala que hacia la derecha. Además, en este caso sí que se observa una clara tendencia a la curtosis leptocúrtica

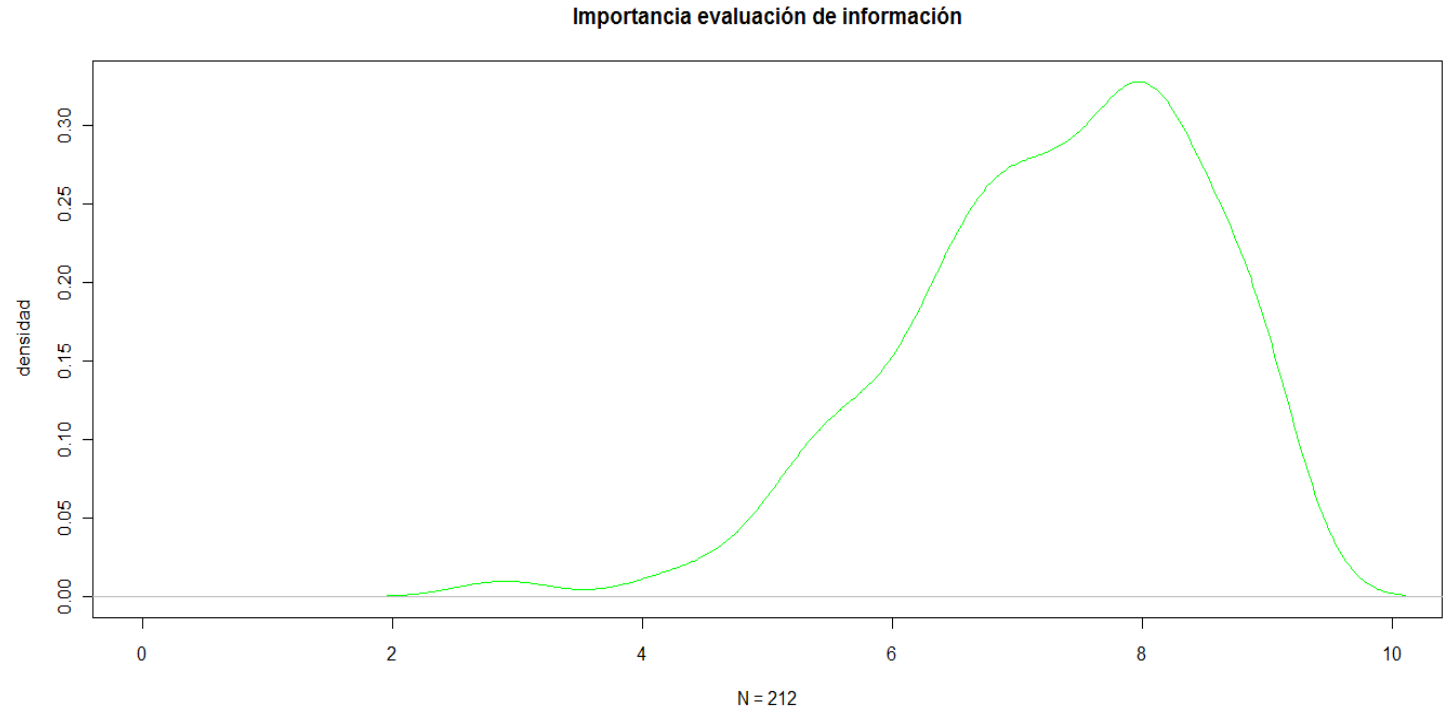

Gráfico 4.34 Función de densidad de la importancia asignada a la evaluación de información. Futuro profesorado 
El gráfico 4.34 indica una tendencia que sigue indicando que los valores de la media son ligeramente superiores a los de la moda y, por ende, existe una asimetría negativa. La tendencia a la curtosis leptocúrtica parece seguir existiendo.

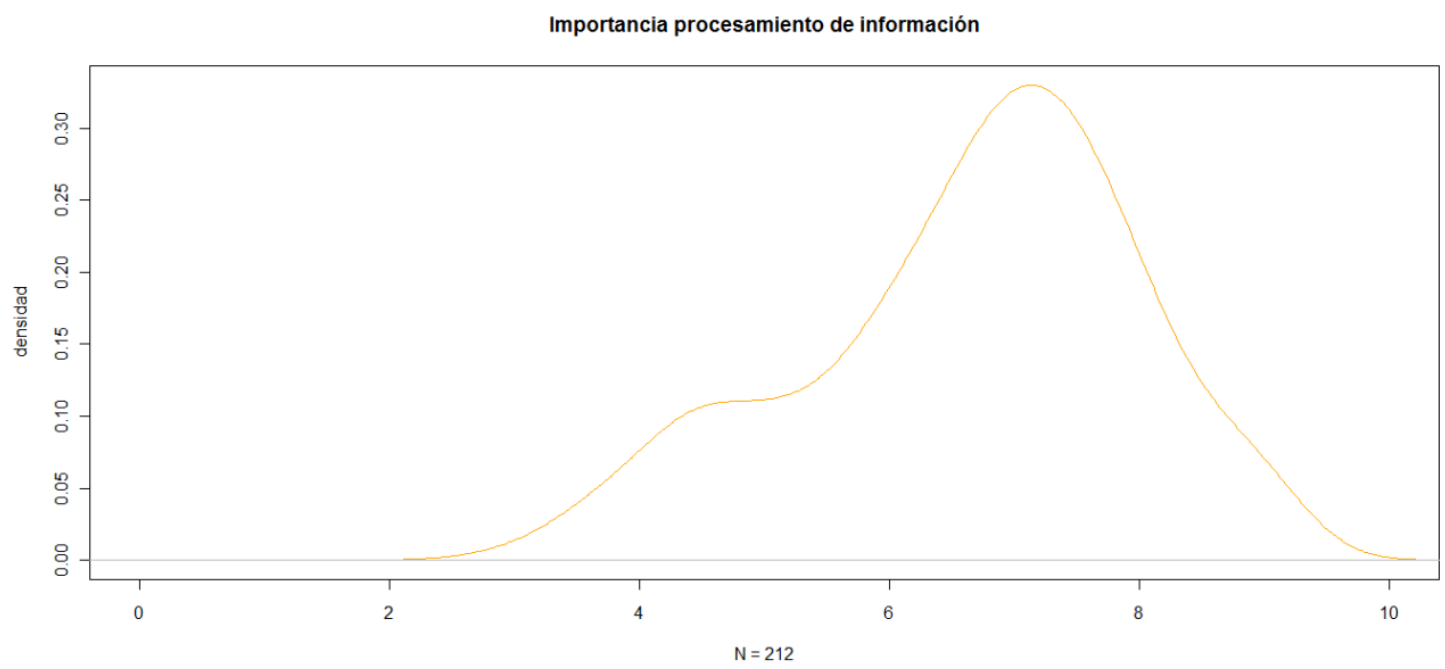

Gráfico 4.35 Función de densidad de la importancia asignada al procesamiento de información. Futuro profesorado

El gráfico 4.35, referido a la importancia asignada al procesamiento de información, sigue indicando una distribución asimétrica negativa. La elevación de la curva en la citada función parece menor en este caso, por lo que podríamos estar acercándonos a la curtosis mesocúrtica.

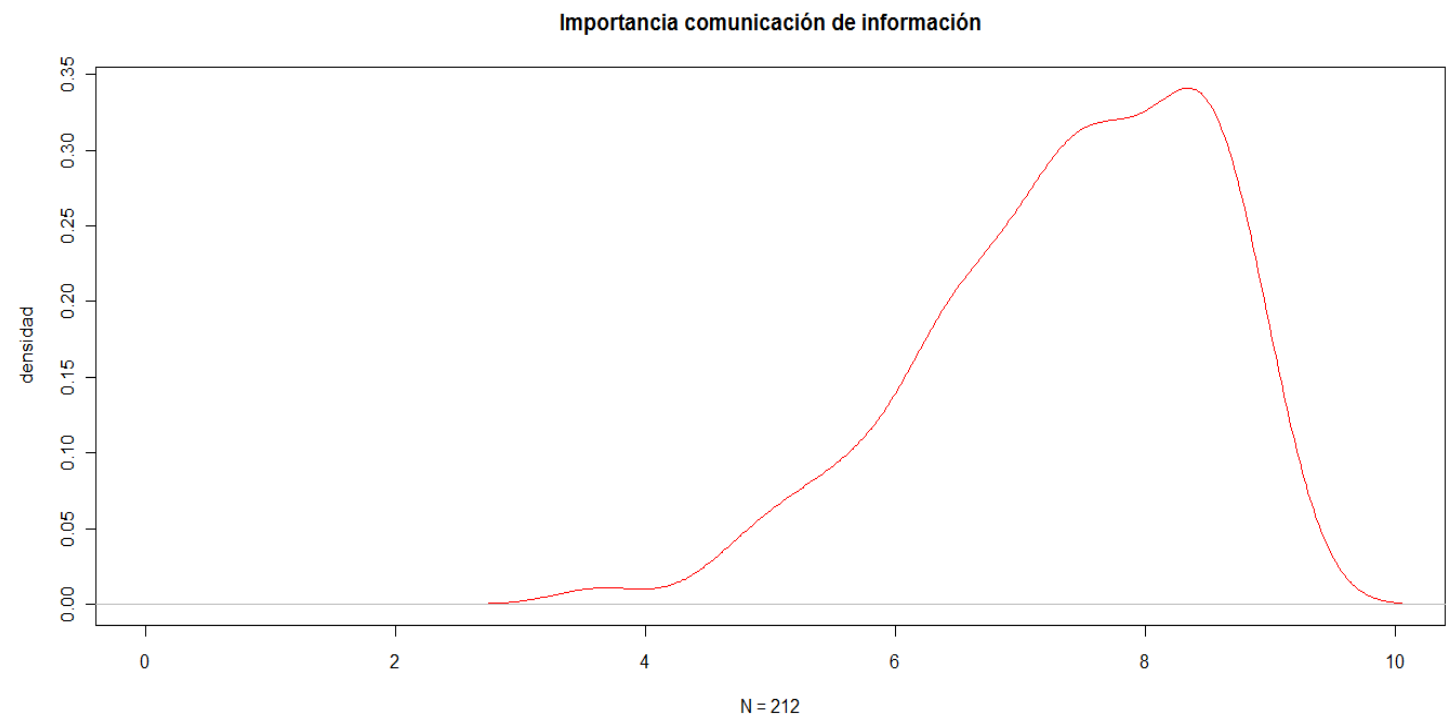

Gráfico 4.36 Función de densidad de la importancia asignada a la comunicación de información. Futuro profesorado

Por último, el gráfico 4.36, que indica la función de densidad de la importancia declarada de la comunicación de información, presenta cualidades similares a las expresadas anteriormente. 
Dada la tendencia observada en las funciones de densidad de las variables, será necesario continuar con otras pruebas de normalidad más sistemáticas para determinar si las variables se ajustan a una distribución normal o no.

En lo que respecta al estudio de la variabilidad y las medidas de posición básicas de las variables, podemos observar los diagramas de caja y bigotes resultantes.

Importancia de las competencias informacionales

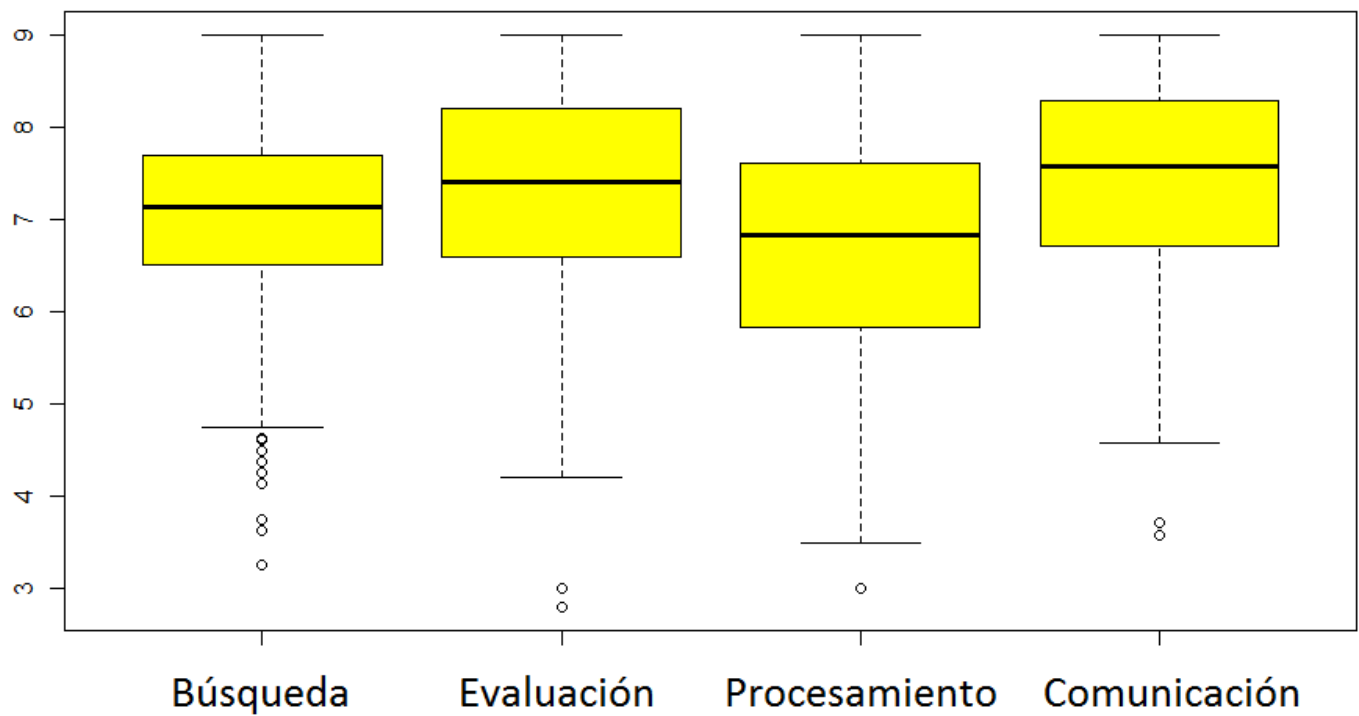

Gráfico 4.37 Diagramas de cajas importancia percibida sobre competencias informacionales. Futuro profesorado

Los diagramas de cajas, mostrados en el gráfico 4.37, se refieren a la importancia asignada a las competencias informacionales en la muestra de futuros profesores de educación secundaria para cada una de las cuatro dimensiones definidas. Se observa en el caso de la búsqueda de información una amplitud intercuartílica baja, y en el resto moderada.

Se puede percibir también cómo los valores atípicos se presentan principalmente en la variable de importancia asignada a la búsqueda de información y se agrupan únicamente en las puntuaciones bajas. En primer lugar, esto se debe al hecho de que la asimetría es negativa; como se podía observar en las gráficas de las funciones de densidad, las colas de las funciones eran más alargadas en la zona de puntuaciones bajas. En segundo lugar, al tener rangos de puntuaciones intercuartílicos pequeños, la cantidad de valores atípicos aumenta considerablemente. 
Así, de nuevo la exploración de los datos, basada ahora en el análisis de diagramas de cajas, sigue manteniéndonos con la duda de si los datos se distribuyen normalmente o si las variables proceden de distribuciones diferentes a la normal.

Confirmemos por tanto estas primeras impresiones gráficas a través de los estadísticos que nos indiquen la forma de la distribución de las variables.

Tabla 4.139 Exploración de las dimensiones de la importancia de las competencias informacionales. Futuro profesorado

\begin{tabular}{l|c|cc|ccc|cc}
\hline \multicolumn{1}{c|}{ Importancia asignada } & \multirow{2}{*}{$\boldsymbol{C V}$} & Mdn & $\begin{array}{c}\text { Amp. } \\
\text { Interc. }\end{array}$ & \multicolumn{2}{c|}{ Asimetría } & \multicolumn{2}{c}{ Curtosis } \\
& & & & Valor & E. típ. & Valor & E. típ. \\
\hline Búsqueda de información & $16.14 \%$ & 7.13 & 1.22 & -0.771 & .167 & 0.600 & .333 \\
\hline Evaluación de información & $16.42 \%$ & 7.40 & 1.60 & -0.781 & .167 & 0.691 & .333 \\
\hline Procesamiento de información & $20.08 \%$ & 6.83 & 1.80 & -0.511 & .167 & -0.290 & .333 \\
\hline $\begin{array}{l}\text { Comunicación y difusión de } \\
\text { información }\end{array}$ & $15.44 \%$ & 7.57 & 1.57 & -0.751 & .167 & 0.173 & .333 \\
\hline
\end{tabular}

La tabla 4.139 muestra los principales estadísticos para valorar las distribuciones de densidad de las muestras. Analizando los valores obtenidos podemos encontrarnos, en primer lugar, con valores del coeficiente de variación satisfactorios (<30\%) en todos los casos. Este resultado nos indica que podemos emplear en adelante la media como un estimador adecuado de la tendencia central de los datos.

Los valores de asimetría confirman las observaciones llevadas a cabo a partir de los gráficos de las funciones de densidad, ya que en todos los casos se obtienen valores que indican asimetrías negativas. Por otra parte, los índices de curtosis muestran que se podría considerar mesocúrtica, aunque con las debidas reticencias, en las cuatro variables.

Tabla 4.140 Exploración de las dimensiones de la importancia de las competencias informacionales. Futuro profesorado

\begin{tabular}{l|ll|cc}
\hline \multicolumn{1}{c|}{ Importancia asignada } & \multicolumn{2}{c|}{ Int. asimetría } & \multicolumn{2}{c}{ Int. curtosis } \\
\hline Búsqueda de información & -1.10 & -0.44 & -0.05 & 1.25 \\
\hline Evaluación de información & -1.11 & -0.45 & 0.04 & 1.34 \\
\hline Procesamiento de información & -0.84 & -0.18 & -0.94 & 0.36 \\
\hline Comunicación y difusión de información & -1.10 & -0.42 & -0.48 & 0.83 \\
\hline
\end{tabular}

Por último, puesto que aún tenemos algunas dudas sobre la procedencia de las funciones de densidad de las variables, vamos a proceder a la confirmación de los 
estadísticos anteriores a través de la exploración de los gráficos $Q-Q$ normales y la aplicación de la prueba de normalidad de Kolmogorov-Smirnov.

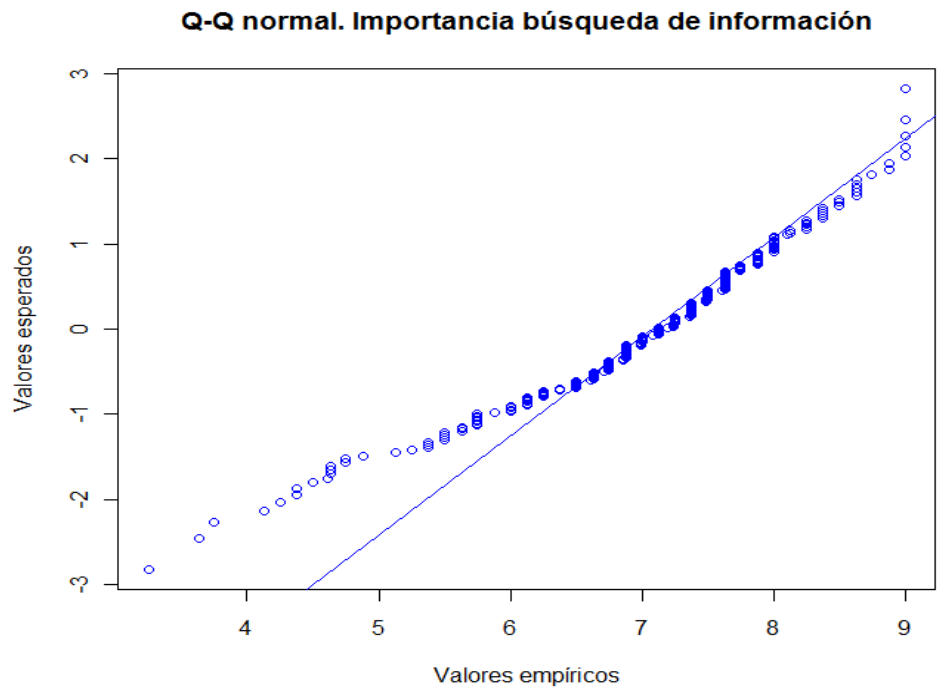

Gráfico 4.38 Q-Q normal para la importancia en la búsqueda de información. Futuro profesorado

En el gráfico 4.38 se puede observar cómo el ajuste a la distribución normal de la variable de importancia asignada a la búsqueda de información se aleja en el extremo inferior de las puntuaciones. En el diagrama de cajas mostrado con anterioridad ya se apreciaba un alto índice de valores atípicos.

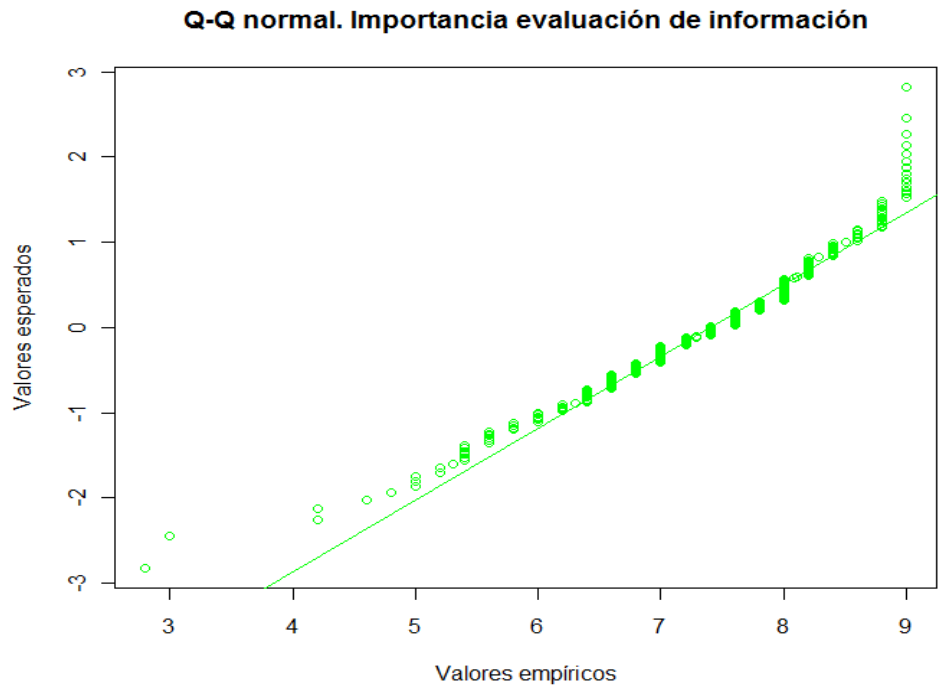

Gráfico 4.39 Q-Q normal para la importancia en la evaluación de información. Futuro profesorado

En cuanto a la importancia asignada a la evaluación de información (gráfico 4.39), se observa cómo los extremos vuelven a registrar valores poco ajustados. 
Los altos índices de asimetría negativa de estas variables también quedan patentes, al observarse la mayor densidad de sujetos en las puntuaciones altas de los valores empíricos.

Q-Q normal. Importancia procesamiento de informaciór

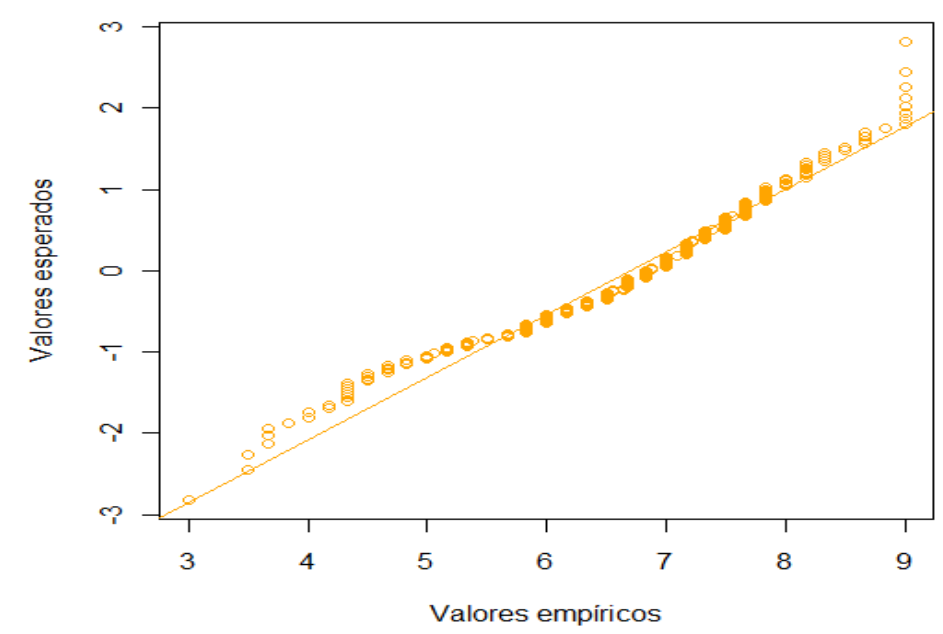

Gráfico 4.40 Q-Q normal para la importancia en el procesamiento de información. Futuro profesorado

Por su parte, el gráfico 4.40 muestra cómo la importancia asignada al procesamiento de información muestra un ajuste a la distribución normal más ajustado que en los anteriores casos, a excepción de los valores altos, en los que existen varios casos atípicos.

Q-Q normal. Importancia comunicación de información

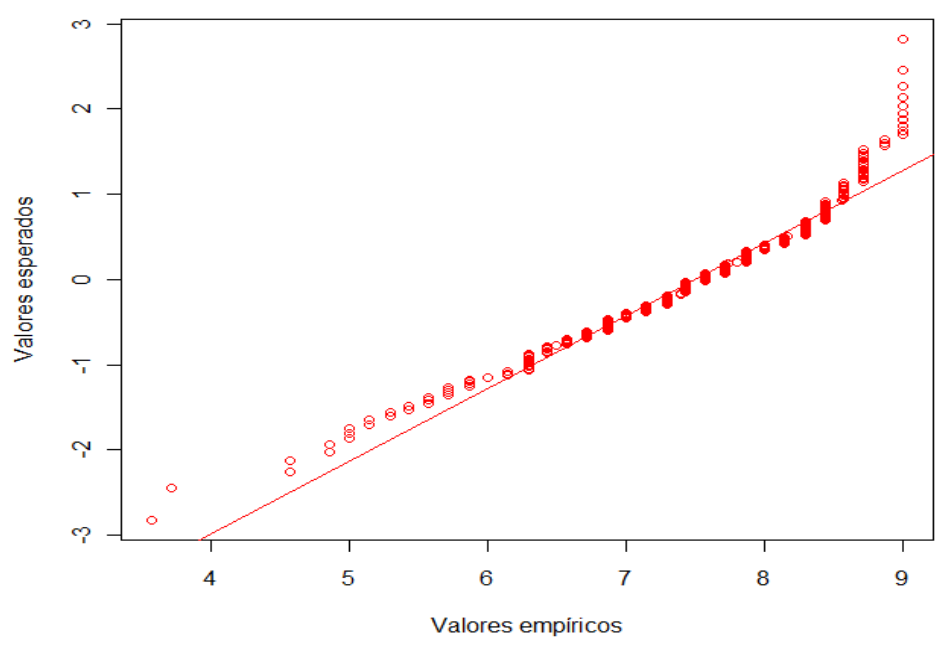

Gráfico 4.41 Q-Q normal para la importancia en la comunicación de información. Futuro profesorado

Por último, el gráfico 4.41 muestra el ajuste a la distribución normal de la variable de la importancia asignada a la comunicación de información. Se vuelve a observar un 
ajuste poco adecuado en los sujetos con puntuaciones más altas. La asimetría negativa también queda patente.

Veamos por último los resultados de la prueba de Kolmogorov-Smirnov, mostrados en la tabla 4.141.

Tabla 4.141 Prueba de normalidad de Kolmogorov-Smirnov para la importancia concedida. Futuro profesorado

\begin{tabular}{l|cc|c}
\hline \multicolumn{1}{c|}{ Importancia asignada } & $\boldsymbol{D} *$ & $\boldsymbol{z}(\boldsymbol{K}-\boldsymbol{S})$ & $\boldsymbol{p}$ \\
\hline Búsqueda de información & .105 & 1.523 & .019 \\
\hline Evaluación de información & .100 & 1.463 & .028 \\
\hline Procesamiento de información & .096 & 1.397 & .040 \\
\hline Comunicación y difusión de información & .086 & 1.250 & .088 \\
\hline
\end{tabular}

*Diferencia absoluta más alta entre la frecuencia acumulada teórica y la observada

La prueba efectuada indica que las variables de importancia concedida a la búsqueda, evaluación y procesamiento de información no se ajustan a una distribución normal ( $\alpha=.05$ ). Por otro lado, la variable de comunicación y difusión de información sí que se ajusta a los parámetros exigidos por la prueba.

Los datos obtenidos indican los desajustes pequeños, por lo que podemos concluir que las variables no se ajustan a la distribución normal y que, por tanto, deberemos proceder a la aplicación de técnicas no paramétricas en el caso de llevar a cabo algún análisis comparativo-inferencial con las anteriores variables.

\section{b) Análisis sobre la competencia autopercibida a las dimensiones: análisis de normalidad}

En todo caso, las principales variables del estudio, consideradas a nivel general como criterio, son las que tienen que ver con las competencias informacionales percibidas. Así, la decisión sobre la aplicación de pruebas paramétricas o no paramétricas en futuros análisis dependerá en gran parte de los resultados que se deriven de estos mismos análisis con las variables que indican el nivel autopercibido para cada una de las dimensiones analizadas.

En primer lugar, procediendo al análisis de las curvas de densidad, observamos distribuciones menos asimétricas y con una tendencia menor a la curtosis leptocúrtica que las indicadas anteriormente. 


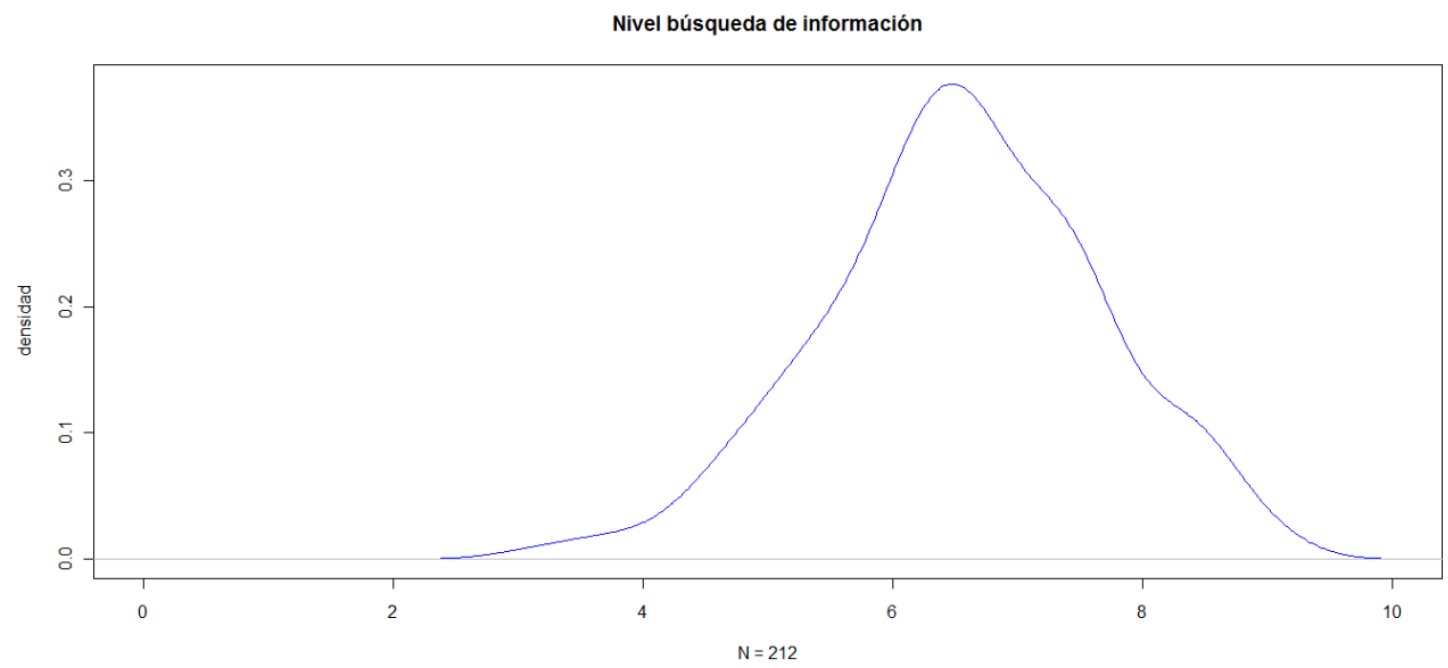

Gráfico 4.42 Función de densidad del nivel autopercibido en la búsqueda de información. Futuro profesorado

El gráfico 4.42 muestra la función de densidad de la dimensión de competencia auto-percibidia en la búsqueda de información. A priori, parece una distribución ligeramente asimétrica negativa y con una curtosis leptocúrtica muy ligera.

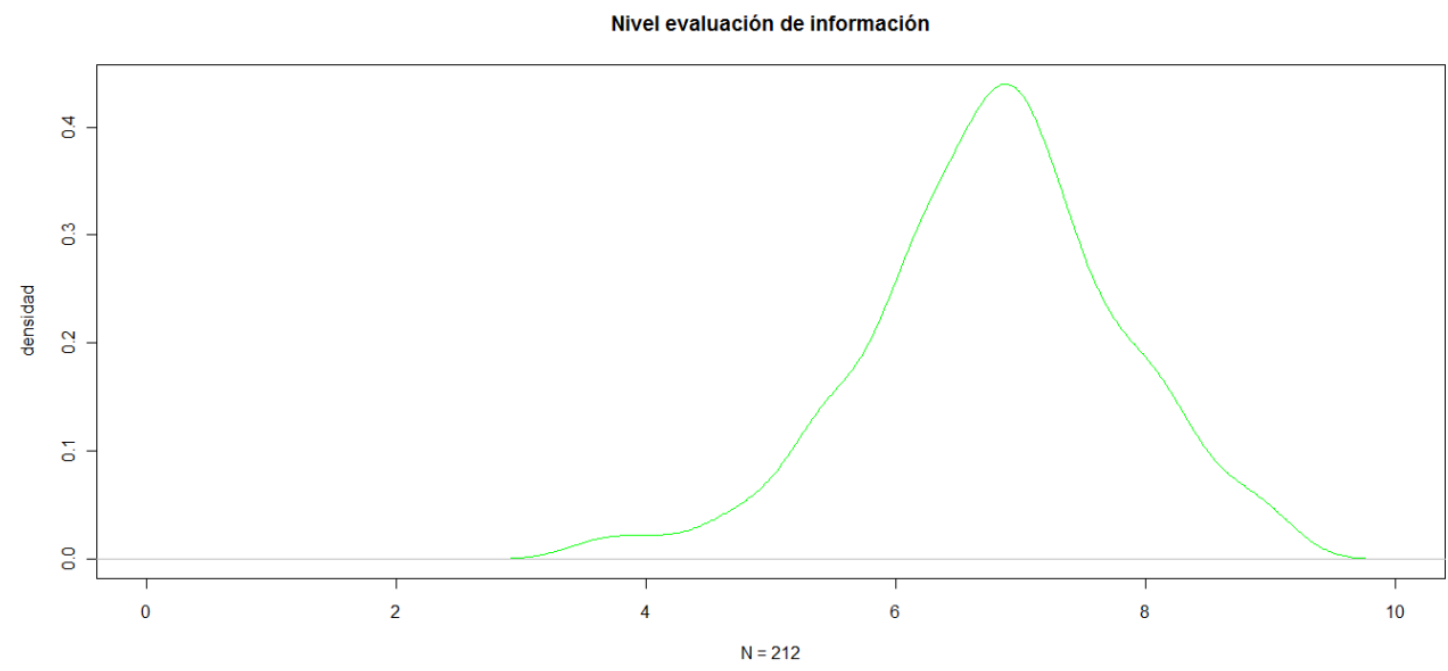

Gráfico 4.43 Función de densidad del nivel autopercibido en la evaluación de información. Futuro profesorado

El gráfico 4.43, muestra que las puntuaciones en cuanto al nivel autopercibido en la evaluación de información se tienden a agrupar en un pequeño rango de valores. En cuanto a la simetría de la curva, al no existir puntuaciones por debajo de 3 puntos, se mantiene prácticamente simétrica.

Esta tendencia parece repetirse en las cuatro dimensiones analizadas en este apartado del estudio. 


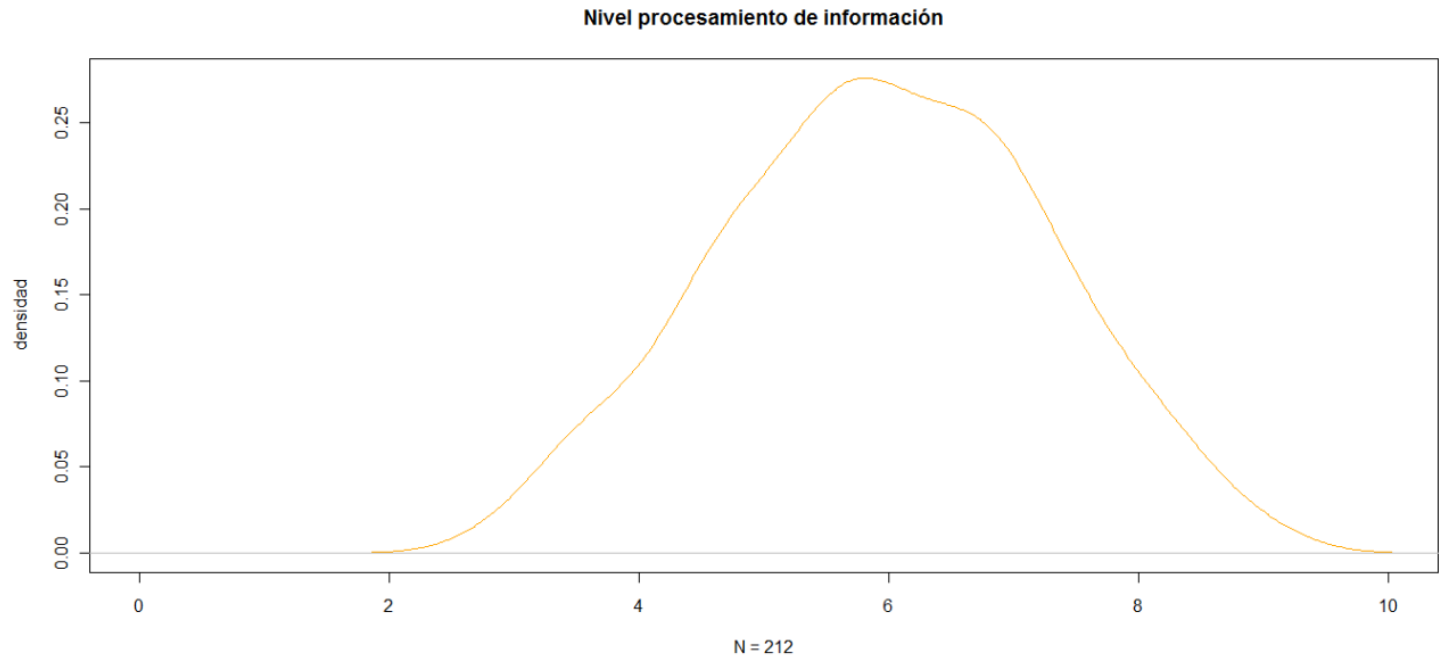

Gráfico 4.44 Función de densidad del nivel autopercibido en el procesamiento de información. Futuro profesorado

El gráfico 4.44, referido al procesamiento de información, es el que parece ajustarse mejor a la distribución normal, con una asimetría casi inapreciable y una distribución de los valores a lo largo de la curva bastante uniforme.

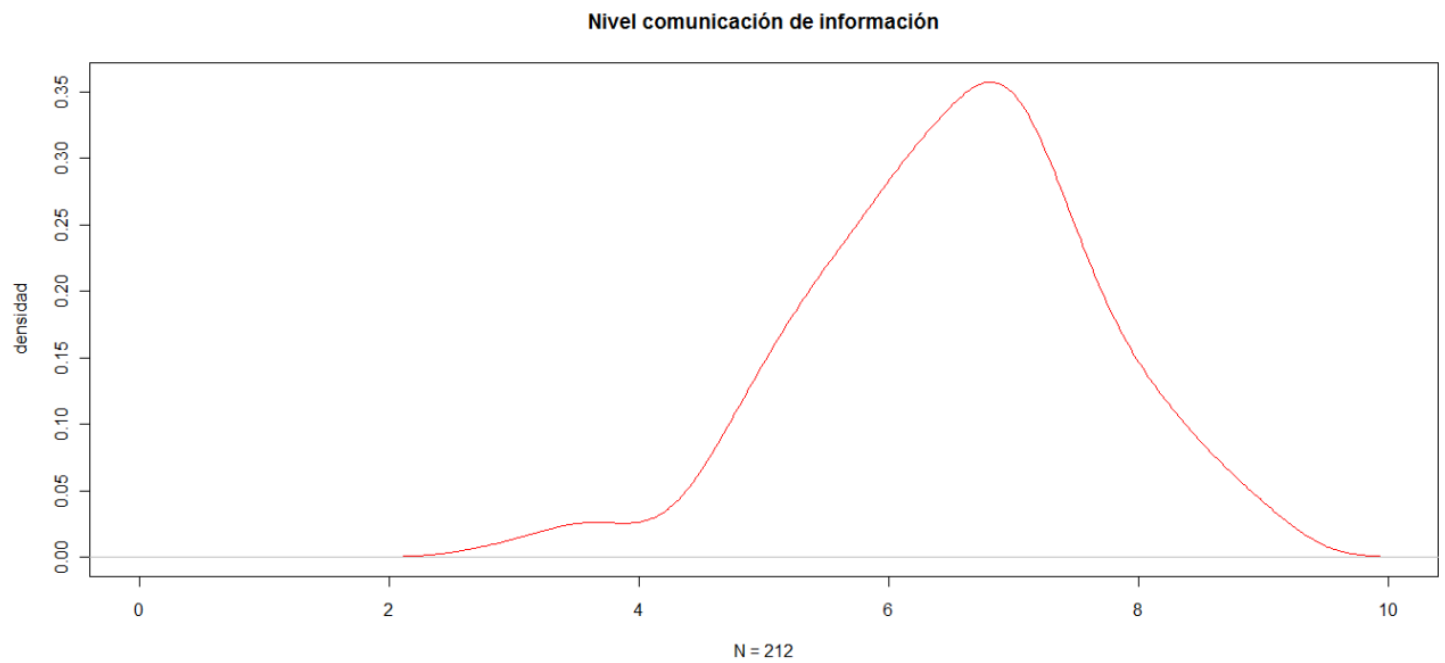

Gráfico 4.45 Función de densidad del nivel autopercibido en la comunciación de información. Futuro profesorado

En último lugar, el nivel percibido en la comunicación de información (gráfico 4.45), por último, muestra de nuevo una ligera tendencia a la asimetría negativa y a la curtosis leptocúrtica.

Analizando los anteriores resultados de manera global, parece que las distribuciones, con ligeras perturbaciones, probablemente se ajusten a una distribución normal. 
Para continuar acercándonos al comportamiento de las variables estudiadas, analicemos los diagramas de cajas de las mismas.

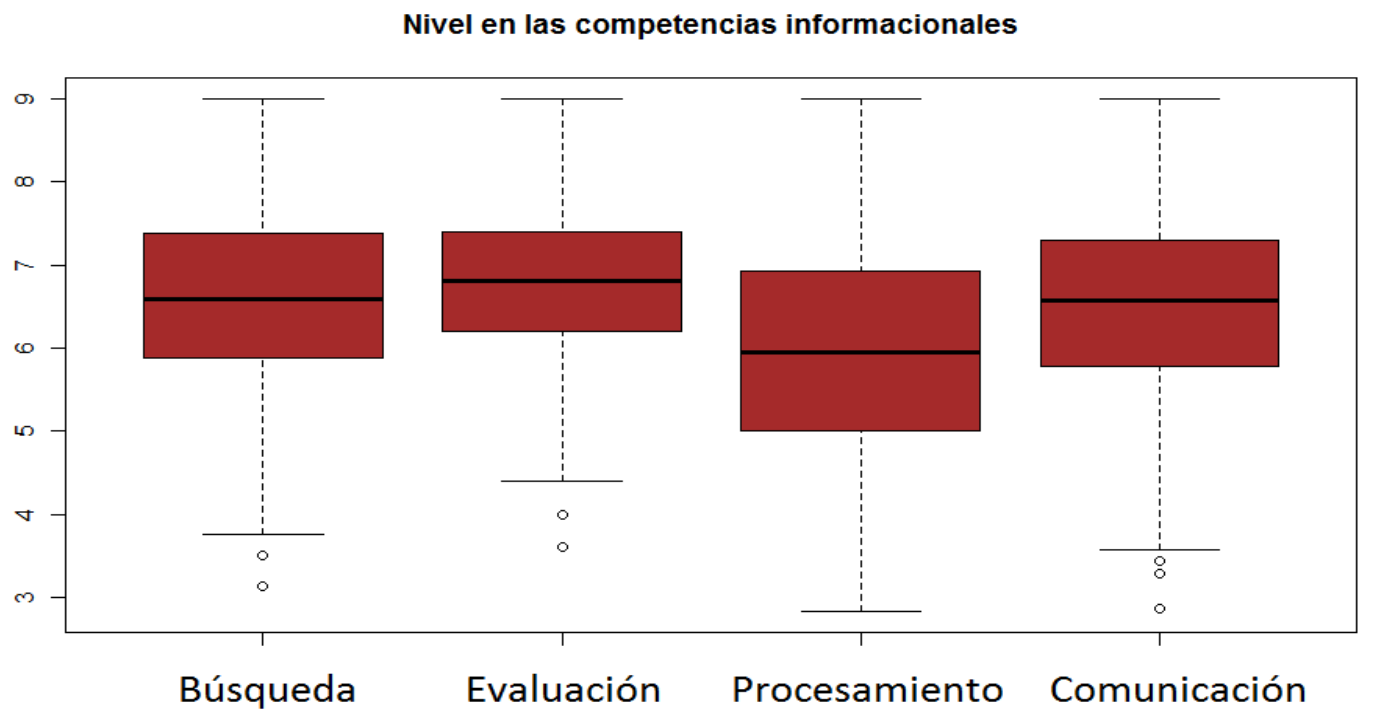

Gráfico 4.46 Diagramas de cajas nivel autopercibido sobre competencias informacionales. Futuro profesorado

A nivel general, el gráfico 4.46 muestra cómo nos encontramos pocos valores atípicos y con distribuciones bastante simétricas. En algunos casos se observa una tendencia a la curtosis leptocúrtica, pero no excesivamente marcada.

Tabla 4.142 Exploración de las dimensiones del nivel autopercibido en competencias informacionales. Futuro profesorado

\begin{tabular}{l|c|cc|ccc|cc}
\hline \multicolumn{1}{c|}{ Importancia asignada } & CV & Mdn & $\begin{array}{c}\text { Amp. } \\
\text { Interc. }\end{array}$ & \multicolumn{2}{c|}{ Asimetría } & \multicolumn{2}{c}{ Curtosis } \\
\hline Búsqueda de información & $16.92 \%$ & 6.55 & 1.5 & -0.211 & .167 & 0.054 & .333 \\
\hline Evaluación de información & $15.13 \%$ & 6.80 & 1.2 & -0.339 & .167 & 0.458 & .333 \\
\hline $\begin{array}{l}\text { Procesamiento de información } \\
\text { Comunicación y difusión de }\end{array}$ & $22.01 \%$ & 5.95 & 1.96 & -0.043 & .167 & -0.497 & .333 \\
\hline \begin{tabular}{l} 
información \\
\hline
\end{tabular} & $17.62 \%$ & 6.51 & 1.54 & -0.322 & .167 & 0.262 & .333 \\
\hline
\end{tabular}

Los valores mostrados en la tabla 4.142, muestran índices del coeficiente de variación satisfactorios en todas las variables, valores de asimetría generalizadamente negativos pero bastante moderados, e índices de curtosis variables pero también moderados.

A priori, parece que se comienzan a confirmar las primeras impresiones, y probablemente nos encontremos con variables distribuidas normalmente. 
Llegados a este punto, procederemos a observar los gráficos Q-Q normales de las variables centro de análisis.

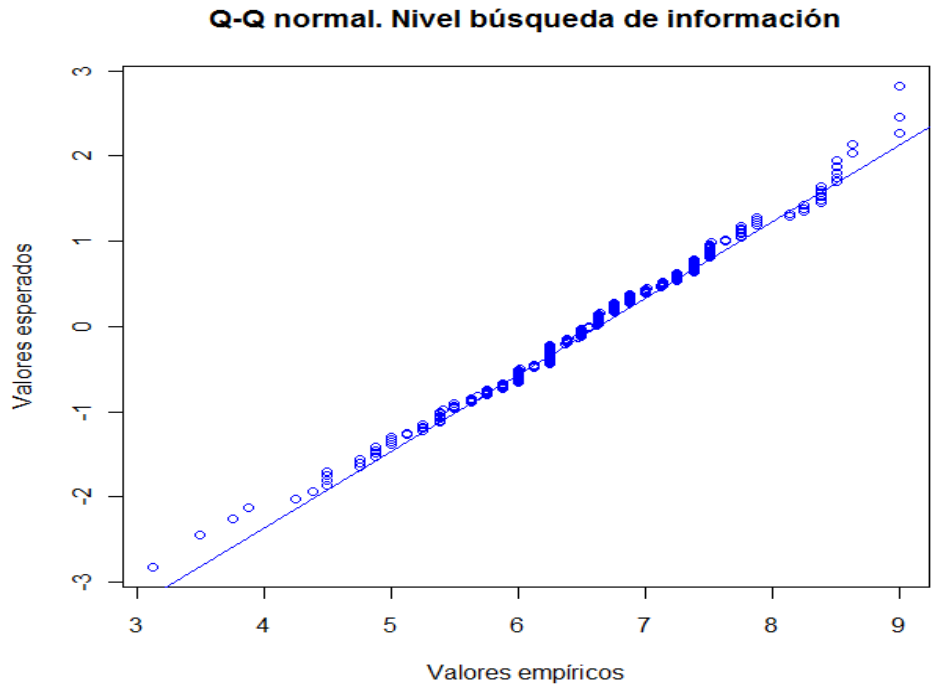

Gráfico 4.47 Q-Q normal para el nivel autopercibido en la búsqueda de información. Futuro profesorado

El gráfico 4.47, referido a la primera variable sobre la búsqueda de información, indica valores muy ajustados a lo largo de toda la curva. En los extremos aparecen algunos sujetos con un ajuste menos adecuado, pero no excesivamente alejado.

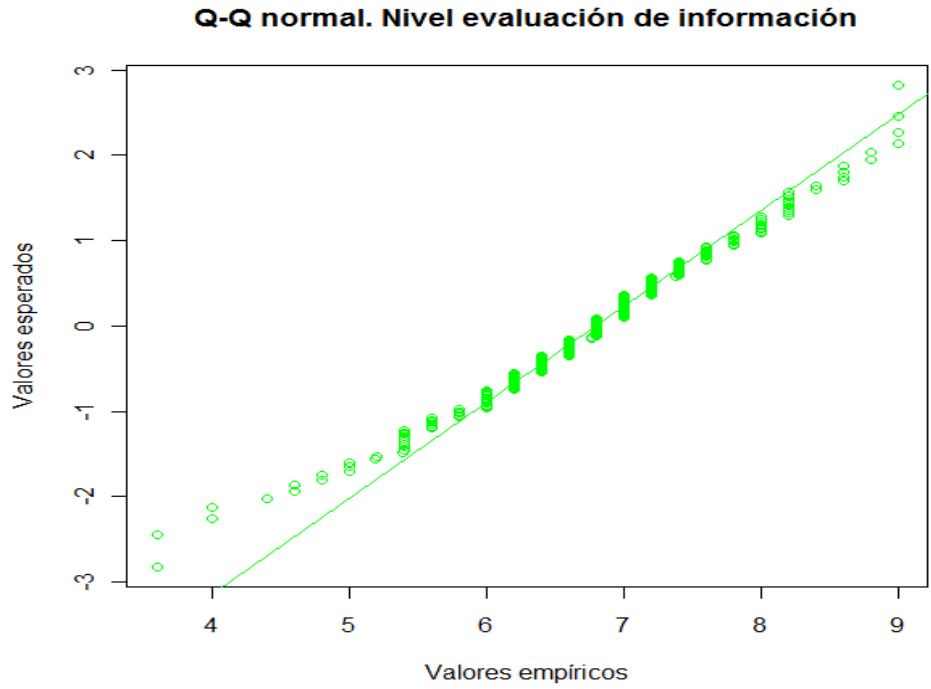

Gráfico 4.48 Q-Q normal para el nivel autopercibido en la evaluación de información. Futuro profesorado

En cuanto a la evaluación de información (gráfico 4.48), se observan resultados con un ajuste bueno, aunque ligeramente peor que anteriormente. 


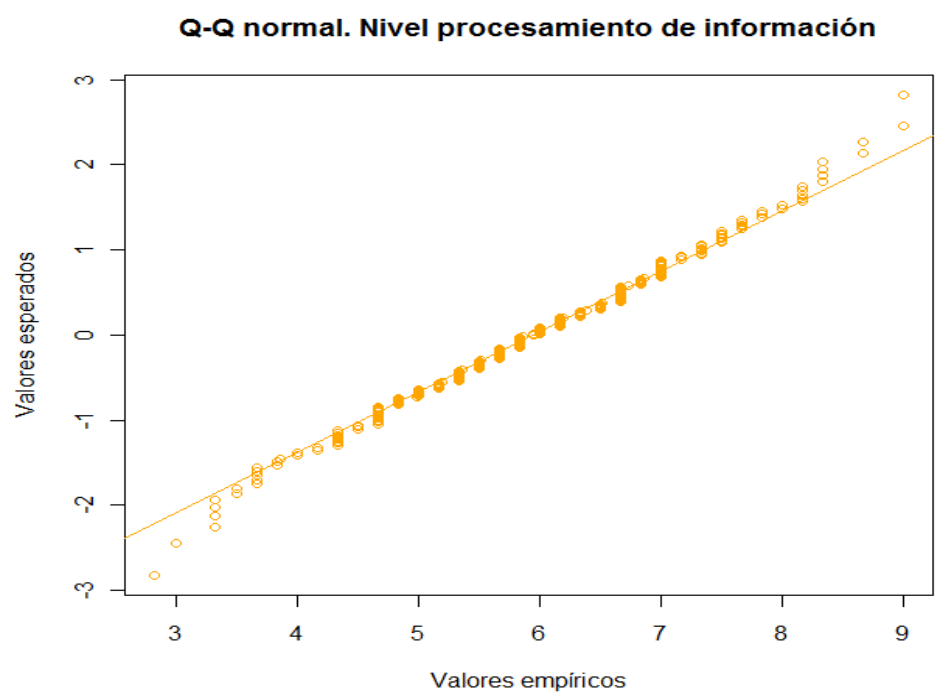

Gráfico 4.49 Q-Q normal para el nivel autopercibido en el procesamiento de información. Futuro profesorado

El nivel autopercibido en el procesamiento de información (gráfico 4.49) muestra por su parte un ajuste muy adecuado a lo largo de toda la distribución.

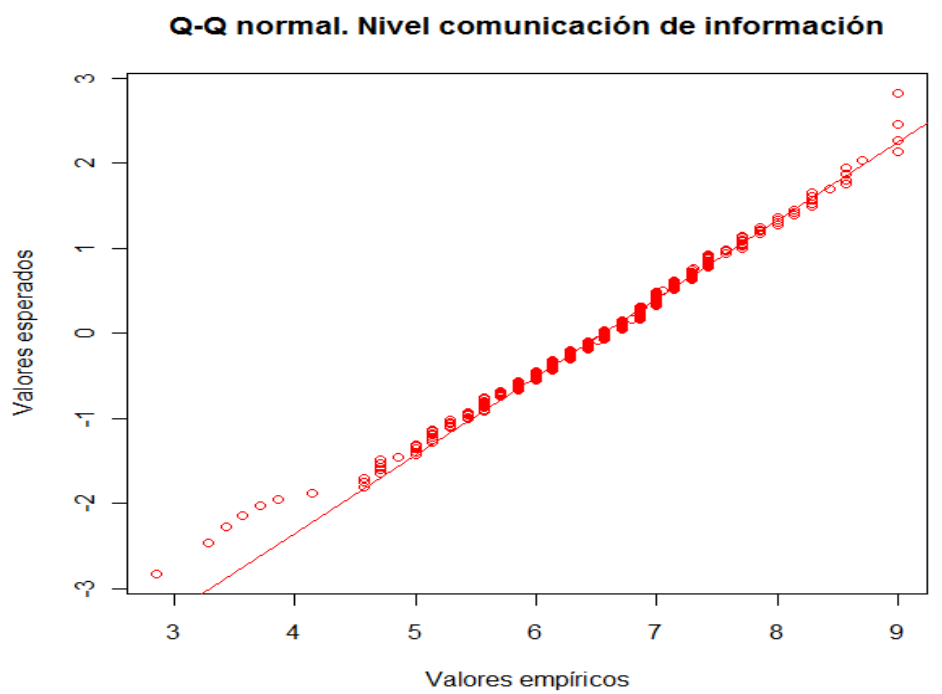

Gráfico 4.50 Q-Q normal para el nivel autopercibido en la comunicación de información. Futuro profesorado

Por último, el gráfico 4.50 muestra que el nivel autopercibido en la comunicación de información se ajusta también correctamente.

A nivel general, por tanto, dados los resultados obtenidos en las funciones de densidad, los diagramas de cajas, los valores de asimetría y curtosis, y las gráficas Q-Q normales, y teniendo en cuenta el tamaño de muestra existente, es de esperar que la prueba de Kolmogorov-Smirnov indique buenos ajustes que nos lleven a no rechazar la $\mathrm{H}_{0}$ y considerar que las variables estudiadas proceden de una distribución normal. 
Tabla 4.143 Prueba de normalidad de Kolmogorov-Smirnov para el nivel autopercibido. Futuro profesorado

\begin{tabular}{l|cc|c}
\hline \multicolumn{1}{c|}{ Nivel autopercibido } & $\boldsymbol{D}^{*}$ & $\boldsymbol{z}(\boldsymbol{K}-\boldsymbol{S})$ & $\boldsymbol{p}$. \\
\hline Búsqueda de información & .061 & 0.412 & .412 \\
\hline Evaluación de información & .069 & 0.260 & .260 \\
\hline Procesamiento de información & .056 & 0.528 & .528 \\
\hline Comunicación y difusión de información & .052 & 0.626 & .626 \\
\hline
\end{tabular}

*Diferencia absoluta más alta entre la frecuencia acumulada teórica y la observada

Llevada a cabo la prueba de Kolmogorov-Smirnov (tabla 4.143), en ningún caso podemos rechazar la $\mathrm{H}_{0}$ de ajuste a la distribución normal, y por tanto podemos señalar que las cuatro variables estudiadas sobre las competencias informacionales autopercibidas se ajustan a una distribución normal.

\section{c) Análisis comparativo entre 'importancia' y 'nivel autopercibido'}

A continuación, vamos a proceder al estudio de las diferencias obtenidas entre las variables referidas a la importancia y las referidas al nivel autopercibido. A partir de un estudio descriptivo previo de las mismas, procederemos a la comparación de las variables a nivel inferencial

En primer lugar, en la tabla 4.144 se pueden observar los descriptivos básicos en la importancia asignada a las cuatro dimensiones. Se observa cómo la categoría evaluación de información y comunicación y difusión de información obtienen unas medias más altas que el resto de variables.

Tabla 4.144 Estadísticos básicos. Importancia de las competencias informacionales por dimensiones. Futuro profesorado

\begin{tabular}{l|ll|c}
\hline \multicolumn{1}{c|}{$\begin{array}{c}\text { Importancia de las competencias } \\
\text { informacionales }\end{array}$} & $\overline{\boldsymbol{X}}$ & $\boldsymbol{S}_{\boldsymbol{x}}$ & $\boldsymbol{N}$ \\
\hline Búsqueda de información & 6.99 & 1.13 & 212 \\
\hline Evaluación de información & 7.29 & 1.20 & 212 \\
\hline Procesamiento de información & 6.65 & 1.34 & 212 \\
\hline Comunicación y difusión de información & 7.39 & 1.14 & 212 \\
\hline
\end{tabular}

En la tabla 4.145 se observan los descriptivos básicos obtenidos en cuanto al nivel autopercibido en las 4 dimensiones. Se observan medias generalizadamente más bajas que en el caso de la importancia asignada, y con menos diferencias entre sí. El 
procesamiento de información sigue siendo la variable menos valorada, pero en el caso de la búsqueda de información se obtienen valores de la media que se acercan a las otras dos variables incluidas en el estudio.

Tabla 4.145 Estadísticos básicos sobre el nivel de competencias informacionales por dimensiones. Futuro profesorado

\begin{tabular}{l|ccc|c}
\hline $\begin{array}{c}\text { Nivel autopercibido en competencias } \\
\text { informacionales }\end{array}$ & $\overline{\boldsymbol{X}}$ & $\boldsymbol{S}_{\boldsymbol{x}}$ & $\boldsymbol{N}$ \\
\hline Búsqueda de información & 6.55 & 1.11 & 212 \\
\hline Evaluación de información & 6.77 & 1.02 & 212 \\
\hline Procesamiento de información & 5.95 & 1.31 & 212 \\
\hline Comunicación y difusión de información & 6.51 & 1.15 & 212 \\
\hline
\end{tabular}

Estos datos nos indican, al igual que en el caso de los alumnos, que el futuro profesorado demanda una mayor formación en lo que respecta a las competencias informacionales.

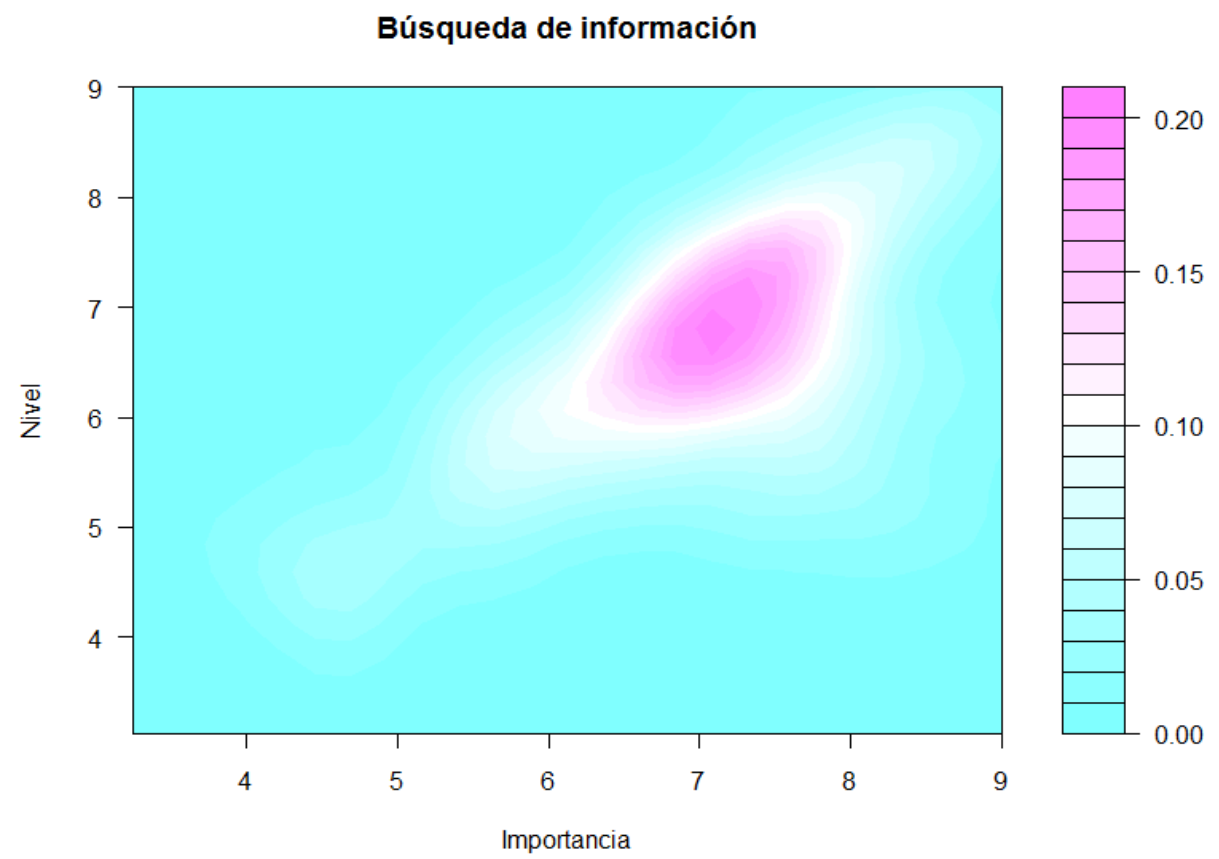

Gráfico 4.51 Distribución de densidad conjunta para el nivel y la importancia en la búsqueda. Futuro profesorado

Comparando los valores de importancia y nivel en la búsqueda de información (gráfico 4.51), se puede observar cómo en la importancia los valores tienden a ser levemente más elevados. 


\section{Evaluación de información}

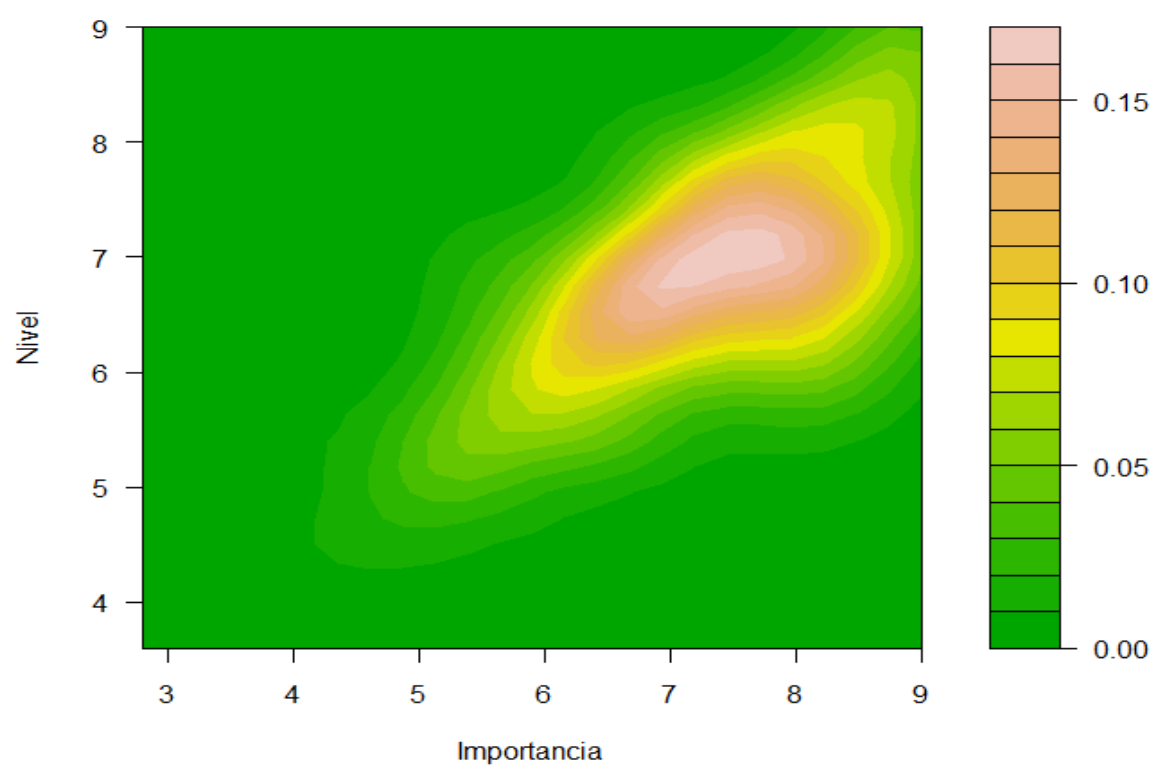

Gráfico 4.52 Distribución de densidad conjunta para el nivel y la importancia en la evaluación. Futuro profesorado

En cuanto al gráfico 4.52, que lleva a cabo la comparación para la evaluación de información, se observa claramente la tendencia de la muestra a valorar más positivamente la importancia que el nivel asignado.

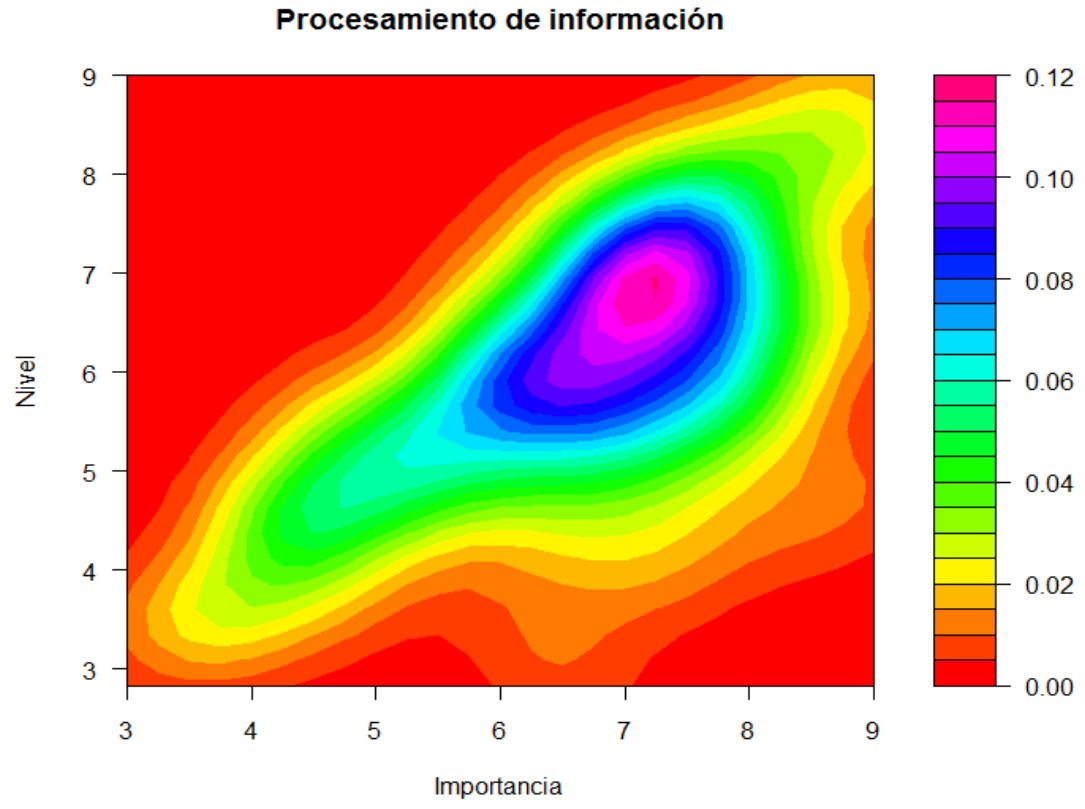

Gráfico 4.53 Distribución de densidad conjunta para el nivel y la importancia en el procesamiento. Futuro profesorado

En el gráfico 4.53, referido al procesamiento de información, se observa esta misma tendencia de manera más ligera y dispersa. 


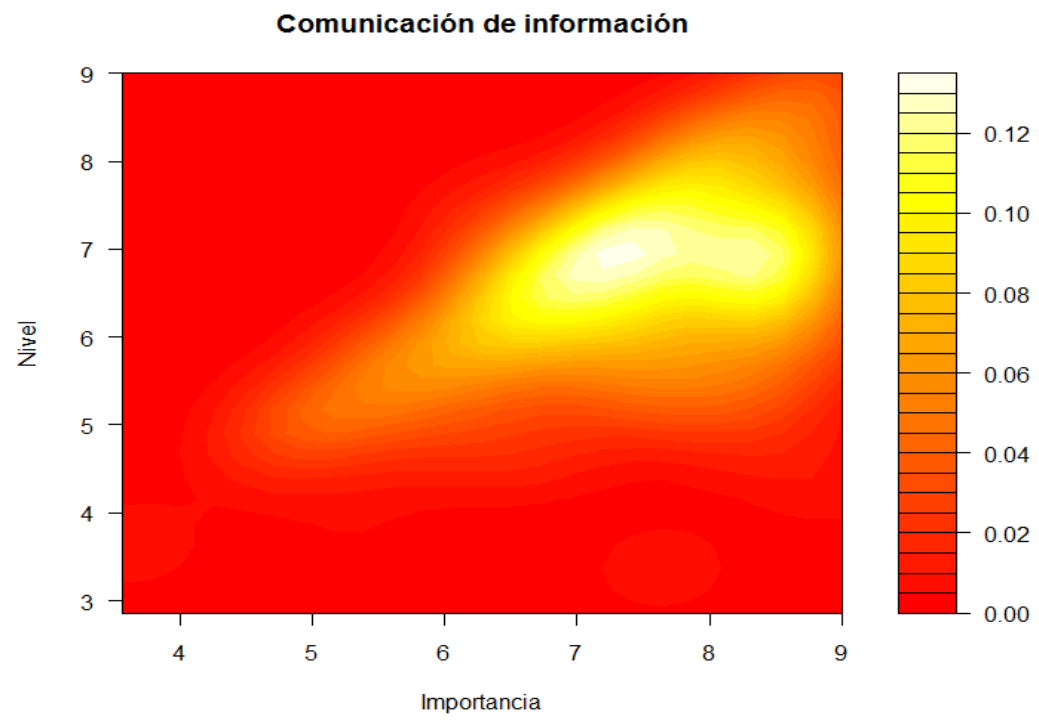

Gráfico 4.54 Distribución de densidad conjunta para el nivel y la importancia en la comunicación. Futuro profesorado

Por último, en el gráfico 4.54 se vuelve a observar esta tendencia para las variables de comunicación de información. Aquí se observa claramente una tendencia mucho más marcada a la asimetría negativa en el caso de la importancia que en el caso del nivel.

Para llevar a cabo los análisis inferenciales, al no comportarse las variables relacionadas con la importancia asignada conforme a una distribución normal, se decide aplicar la prueba no paramétrica de los rangos con signo de Wilcoxon, más robusta en estos casos.

Tabla 4.146 Prueba de los rangos con signo de Wilcoxon. Importancia y nivel percibidos en competencias informacionales. Futuro profesorado

\begin{tabular}{l|cc|cc|cc}
\hline \multicolumn{1}{c|}{$\begin{array}{c}\text { Competencias } \\
\text { informacionales }\end{array}$} & $\overline{\boldsymbol{R}}_{+}$ & $\overline{\boldsymbol{R}}_{-}$ & $\sum \boldsymbol{R}_{+}$ & $\sum \boldsymbol{R}_{-}$ & $\boldsymbol{z}$ & $\boldsymbol{p}$. \\
\hline Búsqueda de información & 67.64 & 92.96 & 3179.00 & 11527.00 & -6.443 & $<.001$ \\
\hline Evaluación de información & 57.16 & 90.14 & 2172.00 & 11358.00 & -7.556 & $<.001$ \\
\hline Procesamiento de información & 44.82 & 94.59 & 1658.50 & 12202.50 & -8.508 & $<.001$ \\
\hline $\begin{array}{l}\text { Comunicación y difusión de } \\
\text { información }\end{array}$ & 32.20 & 94.51 & 869.50 & 13326.50 & -9.872 & $<.001$ \\
\hline
\end{tabular}

En los resultados descritos en la tabla 4.146 se indica cómo en todos los casos se rechaza $\mathrm{H}_{0}$, lo cual indica que existen diferencias significativas entre las variables contrastadas $(\alpha=.05)$. 
Así, estamos en condiciones de afirmar, que el futuro profesorado de educación secundaria de Castilla y León considera que posee una formación inferior a la importancia que concede a las diferentes dimensiones que conforman las competencias informacionales.

\subsubsection{Diferencias por grupos principales en futuro profesorado}

A continuación se describirán las principales diferencias localizadas sobre la importancia otorgada y el nivel autopercibido en competencias informacionales en función de agrupaciones principales. Dichas agrupaciones serán las siguientes:

a. Sexo: Diferencias de género.

b. Edad: Agrupando las edades de los sujetos en las siguientes categorías:

i. Primer grupo que comprende a los sujetos de 23 o menos años.

ii. Segundo grupo que incluye a los sujetos de entre 24 y 26 años.

iii. Último grupo en el que se añaden los sujetos de 27 años o más.

c. Especialidad: Realizando tres agrupaciones por afinidad de los estudios previos a comenzar el Máster de profesor en educación secundaria:

i. Ciencias sociales y jurídicas

ii. Humanidades y artes

iii. Ciencias, ciencias de la salud e ingenierías

Como las variables criterio se comportan conforme a distribuciones diferenciadas, en el caso de los análisis para la importancia asignada se aplicarán técnicas no paramétricas y para el nivel declarado paramétricas.

\subsubsection{Diferencias localizadas por sexo}

Veamos en primer lugar cómo se comportan los descriptivos básicos por sexo. En la tabla 4.147 se indica cómo, en función del sexo, las mujeres de la muestra tienden a atribuir una mayor importancia a todas las dimensiones de las competencias informacionales. 
Tabla 4.147 Estadísticos descriptivos. Importancia por sexo. Futuro profesorado

\begin{tabular}{l|cc|cc|cc}
\hline \multicolumn{1}{c|}{ Importancia asignada } & $\overline{\boldsymbol{X}}_{\boldsymbol{h}}$ & $\boldsymbol{S}_{\boldsymbol{h}}$ & $\overline{\boldsymbol{X}}_{\boldsymbol{m}}$ & $\boldsymbol{S}_{\boldsymbol{m}}$ & $\boldsymbol{n}_{\boldsymbol{h}}$ & $\boldsymbol{n}_{\boldsymbol{m}}$ \\
\hline Búsqueda de información & 6.89 & 1.02 & 7.04 & 1.18 & 70 & 142 \\
\hline Evaluación de información & 6.97 & 1.33 & 7.45 & 1.10 & 70 & 142 \\
\hline Procesamiento de información & 6.61 & 1.14 & 6.67 & 1.43 & 70 & 142 \\
\hline Comunicación y difusión de información & 7.19 & 1.09 & 7.49 & 1.15 & 70 & 142 \\
\hline
\end{tabular}

Estos datos nos indican, por tanto, que en la muestra son las futuras profesoras las que valoran más positivamente la importancia de las competencias informacionales.

En la tabla 4.148 se muestra la prueba de la $U$ de Mann-Whitney para la importancia en cada una de las dimensiones asignadas. Tomando un nivel de significación $\alpha=.05$, estamos en condiciones de rechazar la $H_{0}$ en las diferencias obtenidas para la importancia asignada en la evaluación de información y la comunicación y difusión de información. El tamaño del efecto de las diferencias basado en $r$, calculado conforme a la formulación mostrada a continuación (Corder \& Foreman, 2009),

$$
r=\frac{z}{\sqrt{n}}
$$

, es de .17 en el caso de la evaluación y de .15 en la comunicación. Son valores que se pueden situar entre bajos y medios (J. Cohen, 1969).

Tabla 4.148 Prueba Prueba U de Mann-Whitney. Importancia por sexo. Futuro profesorado

\begin{tabular}{l|cc|c|cr}
\hline \multicolumn{1}{c|}{ Importancia asignada } & $\sum \boldsymbol{R}_{\boldsymbol{h}}$ & $\sum \boldsymbol{R}_{\boldsymbol{m}}$ & $\boldsymbol{U}$ & $\boldsymbol{Z}$ & $\boldsymbol{p}$. \\
\hline Búsqueda de información & 6951.00 & 15627.00 & 4466.00 & -1.201 & .230 \\
\hline Evaluación de información & $\mathbf{6 4 1 6 . 5 0}$ & $\mathbf{1 6 1 6 1 . 5 0}$ & $\mathbf{3 9 3 1 . 5 0}$ & $\mathbf{- 2 . 4 7 6}$ & $\mathbf{. 0 1 3}$ \\
\hline Procesamiento de información & 7104.50 & 15473.50 & 4619.50 & -0.835 & .404 \\
\hline $\begin{array}{l}\text { Comunicación y difusión de } \\
\text { información }\end{array}$ & $\mathbf{6 5 6 8 . 0 0}$ & $\mathbf{1 6 0 1 0 . 0 0}$ & $\mathbf{4 0 8 3 . 0 0}$ & $\mathbf{- 2 . 1 1 4}$ & $\mathbf{0 3 5}$ \\
\hline
\end{tabular}

En cuanto al nivel autopercibido, en la tabla 4.149, que indica los estadísticos descriptivos en función del sexo, las diferencias son más moderadas que en cuanto a la importancia asignada. En algún caso son ligeramente favorables a los hombres y en otro a las mujeres. 
Tabla 4.149 Estadísticos descriptivos. Nivel por sexo. Futuro profesorado

\begin{tabular}{l|cc|cc|cc}
\hline \multicolumn{1}{c|}{ Nivel autopercibido } & $\overline{\boldsymbol{X}}_{\boldsymbol{h}}$ & $\boldsymbol{S}_{\boldsymbol{h}}$ & $\overline{\boldsymbol{X}}_{\boldsymbol{m}}$ & $\boldsymbol{S}_{\boldsymbol{m}}$ & $\boldsymbol{n}_{\boldsymbol{h}}$ & $\boldsymbol{n}_{\boldsymbol{m}}$ \\
\hline Búsqueda de información & 6.67 & 1.14 & 6.49 & 1.09 & 70 & 142 \\
\hline Evaluación de información & 6.72 & 1.10 & 6.80 & 0.99 & 70 & 142 \\
\hline Procesamiento de información & 6.05 & 1.38 & 5.91 & 1.28 & 70 & 142 \\
\hline Comunicación y difusión de información & 6.41 & 1.26 & 6.57 & 1.09 & 70 & 142 \\
\hline
\end{tabular}

Por otra parte, midiendo la significación de estas diferencias, en la tabla 4.150 se aplica la prueba para comparar las medias en función del sexo. Como se puede observar, no se obtienen en ningún caso valores significativos. Así, no estamos en condiciones de rechazar $\mathrm{H}_{0}$ y no podemos afirmar que existan diferencias significativas a nivel poblacional entre hombres $y$ mujeres en el nivel en competencias informacionales a un nivel de significación $\alpha=.05$.

Tabla 4.150 Prueba de t para muestras independientes. Nivel por sexo. Futuro profesorado

\begin{tabular}{l|c|cc|cc}
\hline \multicolumn{1}{c|}{ Nivel autopercibido } & $\overline{\boldsymbol{X}_{\mathbf{1}}}-\overline{\boldsymbol{X}_{\mathbf{2}}}$ & $\boldsymbol{T}$ & $\boldsymbol{p .}$ & \multicolumn{2}{|c}{ Interv. (95\%) } \\
\hline Búsqueda de información & 0.176 & 1.087 & .278 & -0.14 & 0.49 \\
\hline Evaluación de información & -0.077 & -0.517 & .606 & -0.37 & 0.22 \\
\hline Procesamiento de información & 0.144 & 0.750 & .454 & -0.23 & 0.52 \\
\hline Comunicación y difusión de información & -0.162 & -0.965 & .336 & -0.49 & 0.17 \\
\hline
\end{tabular}

* Nivel de significación $\alpha=.05$

Así, podemos concluir que, mientras que el grupo de las mujeres muestra una tendencia clara a valorar más positivamente la importancia de las competencias informacionales, sobre todo las que tienen que ver con la evaluación y la comunicación y difusión de información, en cuanto al nivel autopercibido no se localizan diferencias apreciables

\subsubsection{Diferencias localizadas por edad}

Una vez categorizada la muestra en las tres agrupaciones de edad descritas anteriormente, los sujetos quedan distribuidos de la siguiente forma: de los 212 sujetos que componen la muestra 91 (43.5\%) posee 23 años o menos, 76 (36.4\%) está entre 24 y 26 años y 42 (20.1\%) más de 26. Por su parte nos encontramos con 3 casos perdidos. 
Tabla 4.151 Estadísticos descriptivos. Importancia por edad del futuro profesorado

\begin{tabular}{l|cc|cc|cc}
\hline \multicolumn{1}{c|}{ Importancia asignada } & $\overline{\boldsymbol{X}}_{\mathbf{1}}$ & $\boldsymbol{S}_{\mathbf{1}}$ & $\overline{\boldsymbol{X}}_{\mathbf{2}}$ & $\boldsymbol{S}_{\mathbf{2}}$ & $\overline{\boldsymbol{X}}_{\mathbf{3}}$ & $\boldsymbol{S}_{\mathbf{3}}$ \\
\hline Búsqueda de información & 7.00 & 1.18 & 6.92 & 1.13 & 7.19 & 0.99 \\
\hline Evaluación de información & 7.48 & 1.26 & 7.14 & 1.17 & 7.27 & 1.00 \\
\hline Procesamiento de información & 6.67 & 1.40 & 6.67 & 1.30 & 6.66 & 1.24 \\
\hline Comunicación y difusión de información & 7.53 & 1.05 & 7.34 & 1.26 & 7.30 & 0.98 \\
\hline
\end{tabular}

En la tabla 4.151 se observa cómo las diferencias entre grupos son pequeñas y además no parece existir una tendencia clara hacia que alguno de los grupos valore de manera más positiva la importancia de cada una de las dimensiones de las que están compuestas las competencias informacionales. Contrastemos, pues, estas primeras impresiones con la prueba de hipótesis correspondiente, que en este caso debe ser no paramétrica.

Tabla 4.152 Prueba Prueba H de Kruskal-Wallis. Importancia por edad del futuro profesorado

\begin{tabular}{l|ccc|cc}
\hline \multicolumn{1}{c|}{ Importancia asignada } & $\sum_{\boldsymbol{R}_{\mathbf{1}}}$ & $\sum_{\boldsymbol{R}_{2}}$ & $\sum_{\boldsymbol{R}_{3}}$ & $\boldsymbol{\chi}^{2}$ & $\boldsymbol{p}$. \\
\hline Búsqueda de información & 106.14 & 99.76 & 112.01 & 1.170 & .557 \\
\hline Evaluación de información & 115.36 & 95.25 & 100.20 & 4.925 & .085 \\
\hline Procesamiento de información & 105.66 & 104.69 & 104.12 & 0.022 & .989 \\
\hline $\begin{array}{l}\text { Comunicación y difusión de } \\
\text { información }\end{array}$ & 110.80 & 103.62 & 94.94 & 2.042 & .360 \\
\hline
\end{tabular}

Como indica la tabla 4.152, los datos indican que no existen diferencias significativas en la importancia asignada a las competencias informacionales en función de la edad del futuro profesorado de educación secundaria.

Tabla 4.153 Estadísticos descriptivos. Nivel por edad del futuro profesorado

\begin{tabular}{l|cc|cc|cc}
\hline \multicolumn{1}{c|}{ Nivel autopercibido } & $\overline{\boldsymbol{X}}_{\mathbf{1}}$ & $\boldsymbol{S}_{\mathbf{1}}$ & $\overline{\boldsymbol{X}}_{\mathbf{2}}$ & $\boldsymbol{S}_{\mathbf{2}}$ & $\overline{\boldsymbol{X}}_{\mathbf{3}}$ & $\boldsymbol{S}_{\mathbf{3}}$ \\
\hline Búsqueda de información & 6.48 & 1.08 & 6.48 & 1.13 & 6.91 & 1.10 \\
\hline Evaluación de información & 6.85 & 0.99 & 6.61 & 1.07 & 6.99 & 0.93 \\
\hline Procesamiento de información & 5.78 & 1.30 & 5.97 & 1.28 & 6.28 & 1.32 \\
\hline Comunicación y difusión de información & 6.54 & 1.16 & 6.43 & 1.17 & 6.66 & 1.07 \\
\hline
\end{tabular}

Entrando a analizar el nivel autopercibido, nos encontramos con los datos mostrados en la tabla 4.153. En este caso se aprecia una ligera tendencia en la muestra a declarar un nivel autopercibido mayor a medida que se alcanza una mayor edad. 
Contrastemos la significatividad de estas diferencias a través de la prueba de análisis de varianza.

Previamente a la aplicación de la prueba, aceptado el ajuste de las variables a la distribución normal, se debe contrastar la homogeneidad de varianzas (Tejedor Tejedor, 1999). Llevada a cabo esta prueba a través del test de Levene, no se rechaza $\mathrm{H}_{0}$ en ninguno de los casos: para la búsqueda de información $\mathrm{p}=.110$; para la evaluación de información $\mathrm{p}=.530$; para el procesamiento de información $\mathrm{p}=.748$; $\mathrm{y}$ para la comunicación y difusión de información $\mathrm{p}=.053$.

Comprobados los supuestos previos, se puede proceder a la aplicación del análisis de varianza, que se presenta en la tabla 4.154.

Tabla 4.154 Tabla ANOVA. Nivel por edad del futuro profesorado

\begin{tabular}{|c|c|c|c|c|c|c|}
\hline \multicolumn{2}{|l|}{ Nivel autopercibido } & S.C & g.l. & C.M. & $\boldsymbol{F}$ & $p$. \\
\hline \multirow{3}{*}{ Búsqueda de información } & Intergrupo & 6.44 & 2 & 3.22 & \multirow{3}{*}{2.653} & \multirow{3}{*}{.073} \\
\hline & Intragrupo & 249.89 & 206 & 1.21 & & \\
\hline & Total & 256.33 & 208 & & & \\
\hline \multirow{3}{*}{ Evaluación de información } & Intergrupo & 4.50 & 2 & 2.25 & \multirow{3}{*}{2.20} & \multirow{3}{*}{.113} \\
\hline & Intragrupo & 210.52 & 206 & 1.02 & & \\
\hline & Total & 215.02 & 208 & & & \\
\hline \multirow{3}{*}{ Procesamiento de información } & Intergrupo & 7.04 & 2 & 3.52 & \multirow{3}{*}{2.10} & \multirow{3}{*}{.126} \\
\hline & Intragrupo & 347.12 & 206 & 1.69 & & \\
\hline & Total & 354.17 & 208 & & & \\
\hline \multirow{3}{*}{$\begin{array}{l}\text { Comunicación y difusión de } \\
\text { información }\end{array}$} & Intergrupo & 1.42 & 2 & 0.71 & \multirow{3}{*}{0.54} & \multirow{3}{*}{.583} \\
\hline & Intragrupo & 270.87 & 206 & 1.32 & & \\
\hline & Total & 272.29 & 208 & & & \\
\hline
\end{tabular}

La tabla 4.155 muestra, por tanto, cómo tampoco se registran diferencias significativas en el nivel autopercibido para cada una de las dimensiones de las competencias informacionales en función de la edad del futuro profesorado.

De hecho, podemos observar otro estadístico como el porcentaje de la varianza total que se debe a las diferencias entre los grupos incluidos en el análisis para cada una de las variables. Interpretando esta medida como un valor del tamaño del efecto de las diferencias entre los grupos, se verifica que se obtienen índices en todo caso pequeños: 
- $R_{\text {busq }}^{2}=\frac{6.44}{256.33} * 100=2.5 \%$

- $R_{\text {eval }}^{2}=\frac{4.50}{215.02} * 100=2.1 \%$

- $R_{\text {proc }}^{2}=\frac{7.04}{354.17} * 100=2 \%$

- $R_{\text {comun }}^{2}=\frac{1.42}{272.29} * 100=0.5 \%$

Bajo estas condiciones, no se puede afirmar que existan diferencias significativas en función de la edad del profesorado de educación secundaria en lo que respecta al nivel autopercibido sobre competencias informacionales.

\subsubsection{Diferencias localizadas por especialidad}

Veamos por último las diferencias localizadas a partir de los datos obtenidos en función de la especialidad o titulación de licenciatura o de Grado previa al Máster. En este caso nos encontramos con 49 sujetos (23.4\%) que proceden del área de ciencias sociales y de la salud, 118 (56.5\%) de humanidades y 42 (20.1\%) de ciencias e ingenierías. Nos encontramos así mismo con 3 casos perdidos en la muestra.

Tabla 4.155 Estadísticos descriptivos. Importancia por especialidad del futuro profesorado

\begin{tabular}{l|cc|cc|cc}
\hline \multicolumn{1}{c|}{ Importancia asignada } & $\overline{\boldsymbol{X}}_{\text {csoc }}$ & $\boldsymbol{S}_{\text {csoc }}$ & $\overline{\boldsymbol{X}}_{\text {hum }}$ & $\boldsymbol{S}_{\text {hum }}$ & $\overline{\boldsymbol{X}}_{\text {ccing }}$ & $\boldsymbol{S}_{\text {ccing }}$ \\
\hline Búsqueda de información & 6.83 & 1.04 & 7.04 & 1.14 & 7.05 & 1.16 \\
\hline Evaluación de información & 7.17 & 1.02 & 7.60 & 1.10 & 6.65 & 1.25 \\
\hline Procesamiento de información & 6.87 & 1.17 & 6.52 & 1.47 & 6.74 & 1.14 \\
\hline Comunicación y difusión de información & 7.39 & 1.0 & 7.48 & 1.20 & 7.10 & 1.11 \\
\hline
\end{tabular}

En la tabla 4.155 se observan las diferencias en las medias de cada uno de los grupos en la importancia asignada. Se puede apreciar cómo el grupo de sujetos de humanidades tiende a valorar de una manera más alta la importancia de las habilidades relacionadas con la evaluación y comunicación de información.

Tabla 4.156 Prueba H de Kruskal-Wallis. Importancia por especialidad del futuro profesorado

\begin{tabular}{l|ccc|cc}
\hline \multicolumn{1}{c|}{ Importancia asignada } & $\sum_{\boldsymbol{R}_{\text {csoc }}}$ & $\sum_{\boldsymbol{R}_{\text {hum }}}$ & $\sum \boldsymbol{R}_{\text {ccing }}$ & $\chi^{2}$ & $\boldsymbol{p}$. \\
\hline Búsqueda de información & 94.62 & 108.96 & 105.99 & 1.962 & .375 \\
\hline Evaluación de información & $\mathbf{9 3 . 8 0}$ & $\mathbf{1 2 1 . 4 2}$ & $\mathbf{7 1 . 9 5}$ & $\mathbf{2 2 . 9 9 1}$ & $<.001$ \\
\hline Procesamiento de información & 114.20 & 101.54 & 103.99 & 1.536 & .464 \\
\hline Comunicación y difusión de & 102.57 & 112.08 & 87.95 & 5.041 & .080 \\
\hline
\end{tabular}


información

Si se aplica el contraste de hipótesis, como indica la tabla 4.156, se puede observar cómo se obtienen diferencias significativas en la importancia asignada al conjunto de actividades que tienen que ver con la evaluación de información. En este caso, los sujetos del área de humanidades valoran más positivamente la importancia de ese tipo de competencias. El tamaño del efecto de la diferencia en la importancia asignada a la evaluación en la pareja humanidades-ciencias e ingenierías, basada en el valor de la z de la prueba $U$ de Mann-Whitney da un resultado de 0.36 , lo cual implica un tamaño del efecto medio-alto (J. Cohen, 1969; Corder \& Foreman, 2009).

Tabla 4.157 Estadísticos descriptivos. Nivel por especialidad del futuro profesorado

\begin{tabular}{l|cc|cc|cc}
\hline \multicolumn{1}{c|}{ Nivel autopercibido } & $\overline{\boldsymbol{X}}_{\text {csoc }}$ & $\boldsymbol{S}_{\text {csoc }}$ & $\overline{\boldsymbol{X}}_{\text {hum }}$ & $\boldsymbol{S}_{\text {hum }}$ & $\overline{\boldsymbol{X}}_{\text {ccing }}$ & $\boldsymbol{S}_{\text {ccing }}$ \\
\hline Búsqueda de información & 6.43 & 0.96 & 6.47 & 1.08 & 6.95 & 1.26 \\
\hline Evaluación de información & 6.71 & 0.81 & 6.88 & 1.07 & 6.59 & 1.01 \\
\hline Procesamiento de información & 6.39 & 1.08 & 5.61 & 1.27 & 6.39 & 1.42 \\
\hline Comunicación y difusión de información & 6.68 & 0.98 & 6.49 & 1.10 & 6.42 & 1.35 \\
\hline
\end{tabular}

Si se analiza el nivel autopercibido, nos encontramos con pequeñas diferencias. Sin embargo, los datos no parecen indicar una tendencia clara que señale que los sujetos de alguno de los grupos tienda a auto-valorar su propio nivel como mayor. Una vez confirmada la homocedasticidad, procedamos a comprobar si estas diferencias pueden considerarse significativas a nivel poblacional o no.

Tabla 4.158 Tabla ANOVA. Nivel por especialidad del futuro profesorado

\begin{tabular}{|c|c|c|c|c|c|c|}
\hline \multicolumn{2}{|l|}{ Nivel autopercibido } & S.C & g.l. & C.M. & $\boldsymbol{F}$ & p. \\
\hline \multirow{3}{*}{ Búsqueda de información } & Intergrupo & 8.28 & 2 & 4.14 & & \\
\hline & Intragrupo & 244.96 & 206 & 1.19 & 3.48 & .033 \\
\hline & Total & 253.23 & 208 & & & \\
\hline \multirow{3}{*}{ Evaluación de información } & Intergrupo & 2.80 & 2 & 1.40 & & \\
\hline & Intragrupo & 208.02 & 206 & 1.01 & 1.39 & .252 \\
\hline & Total & 210.83 & 208 & & & \\
\hline \multirow{3}{*}{ Procesamiento de información } & Intergrupo & 31.50 & 2 & 15.75 & & \\
\hline & Intragrupo & 326.67 & 206 & 1.59 & 9.93 & $<.001$ \\
\hline & Total & 358.17 & 208 & & & \\
\hline \multirow{3}{*}{$\begin{array}{l}\text { Comunicación y difusión de } \\
\text { información }\end{array}$} & Intergrupo & 1.77 & 2 & 0.88 & & \\
\hline & Intragrupo & 263.27 & 206 & 1.28 & 0.69 & .502 \\
\hline & Total & 265.04 & 208 & & & \\
\hline
\end{tabular}


En la tabla 4.158, en la que se muestran los resultados del ANOVA llevado a cabo, se puede observar cómo se obtienen diferencias significativas en el nivel autopercibido en la búsqueda y el procesamiento de información. En cuanto a la búsqueda, los sujetos de ciencias e ingenierías se sienten más capacitados, y en lo que hace referencia al procesamiento, los sujetos de humanidades se sienten menos capacitados que el resto.

Podemos hacer un análisis más certero calculando el tamaño del efecto de estas diferencias a través del coeficiente de determinación del porcentaje de varianza total que se explica por las diferencias intergrupo:

- $\quad \eta_{b u s q}^{2}=\frac{8.28}{253.23} * 100=3.27 \%$

- $\quad \eta_{\text {proc }}^{2}=\frac{31.50}{358.17} * 100=8.79 \%$

Dado que el tamaño del efecto de la significación es bajo en ambos casos, no nos detendremos a analizar las pruebas post-hoc.

\subsubsection{Estudio correlacional-multivariante: Modelo causal}

Dado que el modelo causal diseñado para la muestra de estudiantes de Educación Secundaria Obligatoria en Castilla y León registraba resultados que indicaban un ajuste adecuado, nos planteamos generar un modelo lo más cercano al mismo. De este modo, el objetivo es contrastar si el desarrollo de competencias informacionales mediado por los conocimientos y frecuencia en el empleo de herramientas informáticas se comporta de modo similar en los alumnos de Secundaria y en los futuros profesores de este nivel.

Así, nos encontramos con la principal variable endógena del estudio, que no es otra que el nivel de percepción de autoeficacia en todas aquellas tareas que constituyen las competencias informacionales en futuro profesorado de educación secundaria.

Por otro lado, otras variables incluidas en el modelo las podríamos concretar como la frecuencia y el nivel en el empleo de herramientas y aplicaciones informáticas. La frecuencia es una variable latente exógena, compuesta por tres variables observadas, y el nivel es una variable endógena y latente, ya que se entiende que el nivel en el empleo de herramientas informáticas está mediado por la frecuencia en el empleo de las mismas. 


\subsubsection{Estructura del modelo teórico}

En cuanto al diseño del propio modelo, como se puede observar en la figura 4.18, se propone un modelo parsimonioso que pone a prueba básicamente si el nivel autopercibido sobre competencias informacionales $\left(\eta_{2}\right)$, variable latente medida a partir de 4 subescalas, puede explicarse en parte por la frecuencia $\left(\xi_{1}\right)$ y el nivel $\left(\eta_{1}\right)$ en el manejo de determinadas herramientas informáticas.

Se añade una relación entre la frecuencia en el empleo y el nivel autopercibido en relación a las herramientas informáticas, ya que, al igual que en el modelo diseñado para los alumnos de educación secundaria, se entiende que la frecuencia en el empleo de herramientas informáticas es una variable causal del propio nivel en el manejo de esas mismas herramientas. Del mismo modo, se entiende que estos hábitos que se corresponden con frecuencia de empleo también tendrán cierta incidencia en el nivel autopercibido en competencias informacionales.

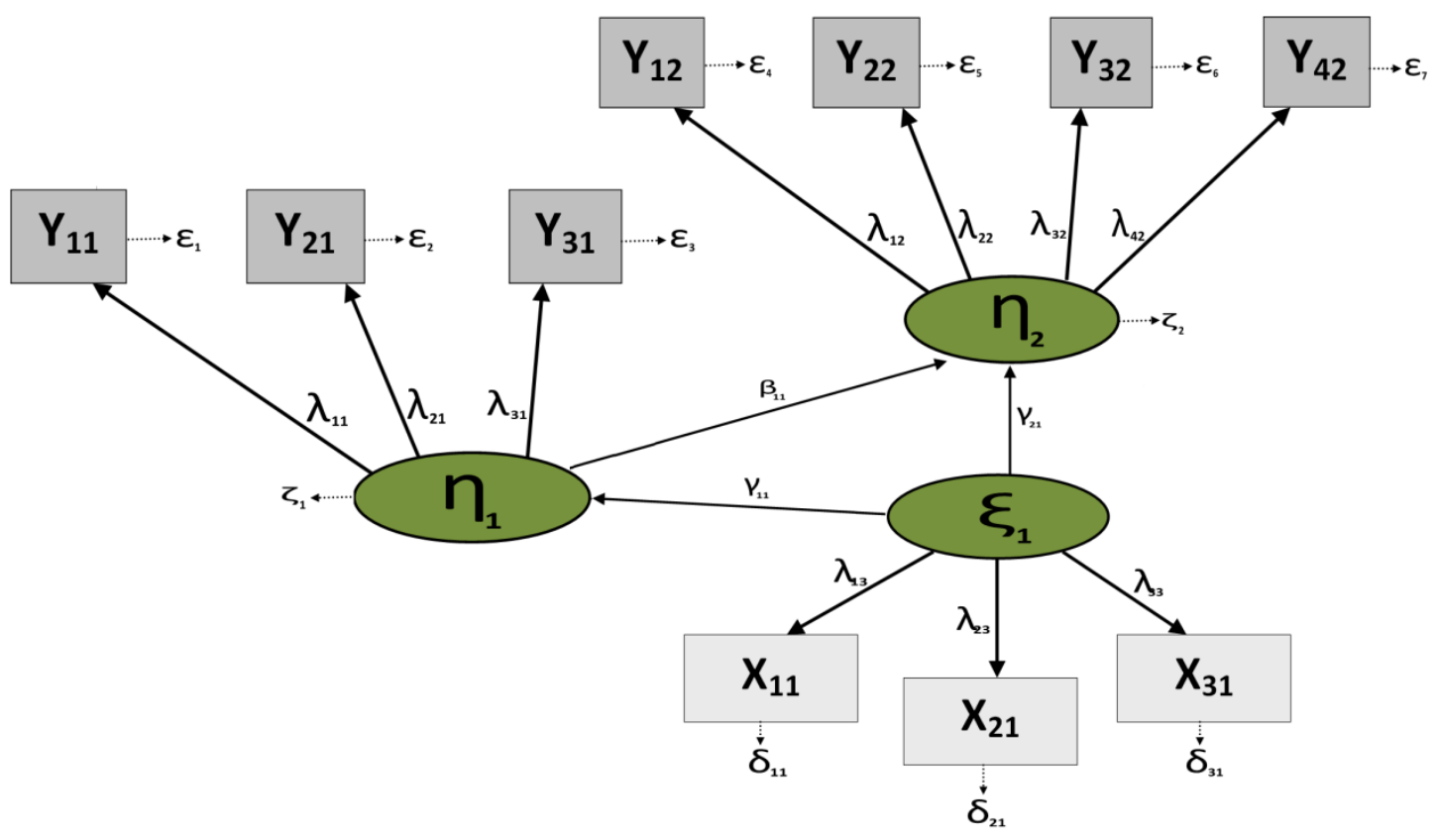

Figura 4.18 Diseño del modelo de ecuaciones estructurales teórico. Futuro profesorado

Las variables incluidas en el modelo son las siguientes:

- Frecuencia en el manejo de herramientas informáticas $\left(\xi_{1}\right)$ : Variable latente exógena que incluye a su vez 3 variables observadas.

- Herramientas de ocio $\left(\mathrm{X}_{11}\right)$ 
- Herramientas para la gestión de la información $\left(\mathrm{X}_{21}\right)$

- Software informático de ámbito académico $\left(\mathrm{X}_{31}\right)$

- Nivel autopercibido en el manejo de herramientas informáticas $\left(\eta_{1}\right)$ : Variable latente y endógena compuesta por 3 variables observadas.

- Herramientas de ocio $\left(\mathrm{Y}_{11}\right)$

- Herramientas para la gestión de la información $\left(\mathrm{Y}_{21}\right)$

- Software informático de ámbito académico $\left(\mathrm{Y}_{31}\right)$

- Nivel autopercibido sobre competencias informacionales $\left(\eta_{2}\right)$ : Variable latente exógena cuya puntuación se deriva de las 4 variables que componen las competencias informacionales.

- Búsqueda de información $\left(\mathrm{Y}_{12}\right)$

- Evaluación de información $\left(\mathrm{Y}_{22}\right)$

- Procesamiento de información $\left(\mathrm{Y}_{32}\right)$

- Comunicación y difusión de información $\left(\mathrm{Y}_{42}\right)$

\subsubsection{Supuestos previos al análisis}

Como paso previo a la aplicación de las técnicas de ecuaciones estructurales, se pone a prueba el cumplimiento de los supuestos subyacentes a las mismas. En primer lugar, la prueba de normalidad consiste en el análisis de los valores de asimetría y curtosis de las variables observadas incluidas en el modelo (tabla 4.159). En el caso de las variables relacionadas con las competencias informacionales ya se había estudiado previamente y aceptado la normalidad de las distribuciones. Sin embargo, ahora se vuelve hacer este análisis para comprobar el comportamiento univariante del resto de variables incluidas y multivariante de todas juntas.

Tabla 4.159 Test de normalidad para las variables incluidas en el modelo. Futuro profesorado.

\begin{tabular}{lcc|cc}
\hline \multicolumn{1}{c|}{ Variables } & Asimetría & $\boldsymbol{t}$ & Curtosis & $\boldsymbol{t}$ \\
\hline $\begin{array}{l}\text { 1. Frecuencia en el manejo de herramientas } \\
\text { informáticas de ocio }\end{array}$ & -0.118 & -0.700 & -0.235 & -0.700 \\
$\begin{array}{l}\text { 2. Frecuencia en el manejo de herramientas } \\
\text { informáticas para la gestión de información }\end{array}$ & 0.645 & $3.835^{*}$ & 0.162 & 0.480
\end{tabular}




\begin{tabular}{lcc:|cc} 
3. Frecuencia en el manejo de software académico & 0.181 & 1.076 & -0.556 & -1.651 \\
$\begin{array}{l}\text { 4. Nivel en el manejo de herramientas informáticas de } \\
\text { ocio }\end{array}$ & -0.102 & -0.609 & -0.448 & -1.449 \\
$\begin{array}{l}\text { 5. Nivel en el manejo de herramientas informáticas } \\
\text { para la gestión de información }\end{array}$ & 0.351 & $2.086^{*}$ & -0.444 & -1.321 \\
6. Nivel en el manejo de software académico & 0.320 & 1.904 & -0.444 & -1.320 \\
7. Búsqueda de información & -0.210 & -1.248 & 0.025 & 0.073 \\
8. Evaluación de información & -0.337 & $-2.002^{*}$ & 0.419 & 1.245 \\
9. Procesamiento de información & -0.043 & -0.256 & -0.513 & -1.526 \\
10. Comunicación y Difusión de información & -0.319 & -1.898 & 0.227 & 0.676 \\
\hline COEFICIENTE DE MARDIA & & & 22.030 & 10.353 \\
\hline
\end{tabular}

${ }^{*} \alpha=05$.

A pesar de que en algunas variables se encuentran desviaciones en la prueba de simetría, en todos los casos parecen moderadas. Así, si atendemos al coeficiente de Mardia (Bollen, 1989) observamos una normalidad multivariante más que aceptable, ya que el valor del coeficiente es muy inferior al límite $p(p+2)$ (Almeida et al., 2011).

Por lo tanto, consideramos que se cumple el supuesto de normalidad, y se decide aplicar el método de estimación de máxima verosimilitud.

En cuanto a la identificación del modelo, se verifica la condición de orden (29 grados de libertad), la condición de rango (determinante de la matriz de covarianzas $\neq$ 0) y la inexistencia de varianzas/covarianzas del error negativas, errores estándar excesivamente elevados o correlaciones entre los coeficientes estimados muy elevadas (superiores a .80).

\subsubsection{Comprobación del ajuste del modelo}

Es necesario indicar que el estadístico Chi Cuadrado es muy sensible a la falta de normalidad de alguna de las variables incluidas en el modelo (Tejedor Tejedor et al., 2009), por lo que es probable que los resultados en la prueba de ajuste global realizada con este estadístico de contraste se vea afectada, y que haya que recurrir al análisis de otros estadísticos.

En la tabla 4.160 se pueden observar valores del estadístico de contraste Chi cuadrado que indican una falta de ajuste global $(p<.001)$. Por otro lado, analizando el índice de bondad de ajuste GFI, que no depende en el cálculo del tamaño de la muestra (Kline, 2005), se obtiene un valor cercano al mínimo exigible para considerarlo aceptable (GFI $\approx 9$ ). Otros estadísticos, como el valor del Error de Aproximación 
Cuadrático Medio alcanza un valores no aceptables (RMSEA=.131) que nos hacen pensar que el modelo no se ajusta adecuadamente a nivel global.

En cambio, a nivel incremental parece que el modelo obtiene índices aceptables, como el CFI, el IFI y el NFI. Por último, el ajuste de parsimonia parece adecuado, ya que se alcanzan valores del PNFI y PCFI cercanos a .6.

Tabla 4.160 Indicadores de ajuste del modelo causal. Futuro profesorado

\begin{tabular}{lccccc|cccc}
\hline & \multicolumn{4}{c}{ Ajuste global } & \multicolumn{4}{c}{ Ajuste incremental } \\
\cline { 2 - 10 } & $\chi^{2}$ & g.I & p. & RMSEA & GFI & CFI & NFI & IFI & AGFI \\
\hline Modelo propuesto & 133.62 & 29 & $<.001$ & .131 & .895 & .924 & .907 & .925 & .801 \\
\hline
\end{tabular}

Por último, es reseñable indicar cómo el modelo explica el $40 \%$ de la varianza de la variable endógena competencias informacionales.

\subsubsection{Relaciones individuales planteadas}

A pesar de que hemos obtenido valores de ajuste que hacen tener reticencias acerca del buen comportamiento del modelo, sigue pareciendo de interés el analizar las relaciones individuales que se plantean en cada una de las vías establecidas en el modelo.

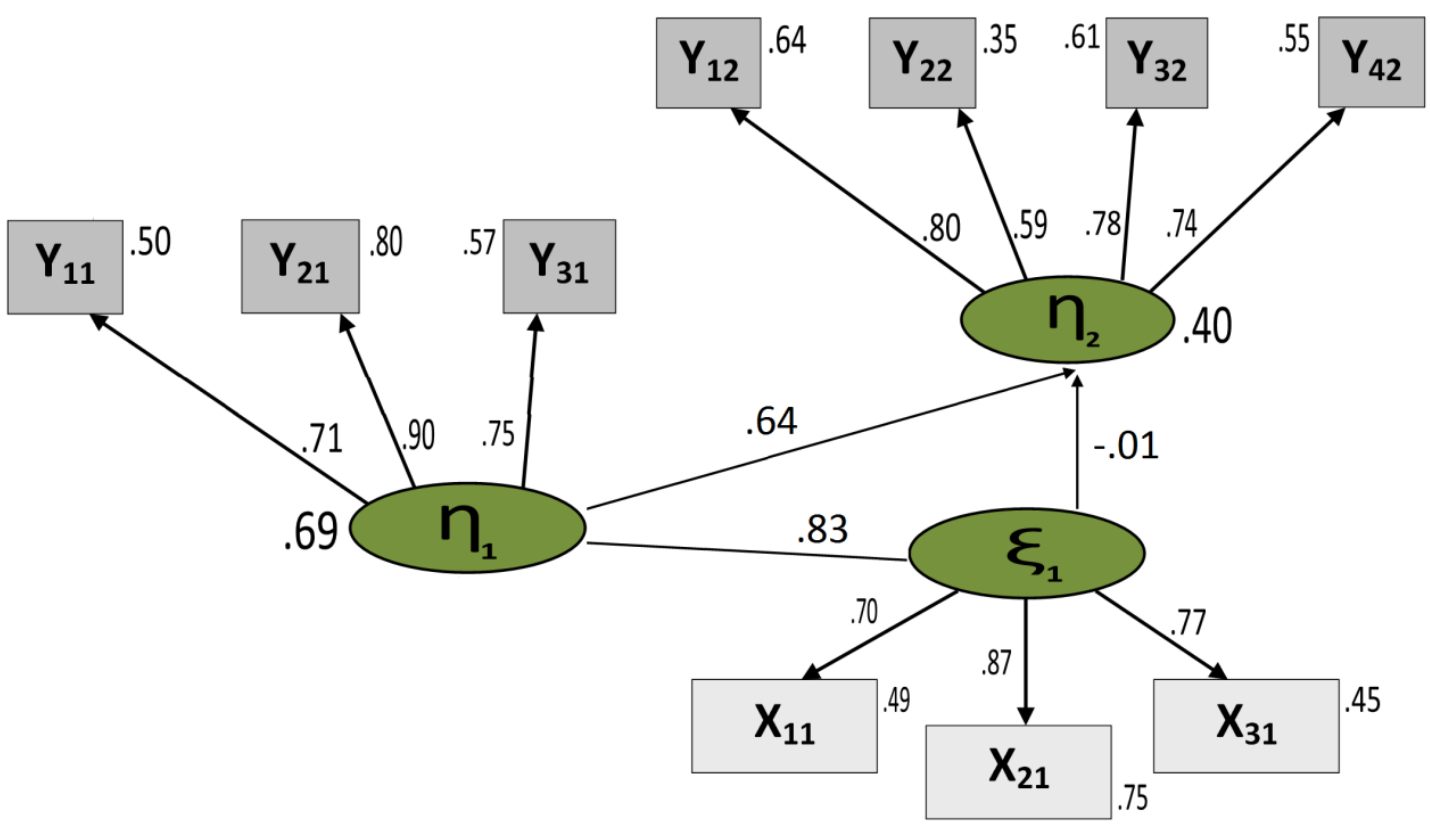

Figura 4.19 Solución estandarizada del modelo planteado. Futuro profesorado

La figura 4.19 muestra los principales valores obtenidos. En primer lugar, el peso de las variables que conforman los diferentes factores parece suficiente en todos los 
casos. Por otro lado, analizando las vías planteadas entre las variables latentes del modelo, los datos muestran que, en primer lugar, existe un efecto claramente significativo (.83) de la frecuencia en el empleo de herramientas informáticas sobre el nivel autopercibido. Sin embargo, la frecuencia en el empleo de estas herramientas no tiene ningún efecto directo (-.01) sobre el nivel autopercibido en competencias informacionales. Por su parte, el nivel autopercibido en el manejo de herramientas informáticas sí que tiene un efecto considerable (.64) sobre el nivel considerado en competencias informacionales.

Los datos parecen indicar, por tanto, que la frecuencia con la que el futuro profesorado emplea las herramientas informáticas no es relevante en la explicación de la variabilidad del nivel autopercibido en competencias informacionales. Cabe reseñar, no obstante, que mientras que los efectos directos de la frecuencia sobre las competencias informacionales son inapreciables (-.01), los efectos indirectos obtenidos (efectos mediados por el nivel en el manejo de estas herramientas) son altos (.534). 


\subsection{Resumen}

A lo largo del siguiente capítulo, el más extenso de la Tesis Doctoral, se ha ido describiendo tanto el proceso metodológico como los resultados obtenidos en el estudio I, consistente en la evaluación diagnóstica del estado autopercibido en la formación en competencias informacionales tanto de estudiantes del segundo ciclo de ESO, como de futuro profesorado de esta etapa educativa.

En primer lugar, previamente al desarrollo del capítulo propiamente dicho, se ha comenzado con una introducción general a los estudios empíricos. Dada la complejidad estructural de los estudios realizados en general y, en particular, del estudio I, se ha añadido esta introducción, que señala cómo se han desarrollado los estudios. El fin de este apartado es aportar al lector una visión general de la estructura de los dos siguientes capítulos, y mostrar la lógica del proceso seguido durante la investigación, que acaba desembocando en dos estudios diferenciados pero interdependientes.

Después de esta introducción aclaratoria, se comienza con la descripción de la metodología de investigación del primer estudio. Tras un estudio de antecedentes que sirven como punto de partida desde el que se afronta la investigación, el capítulo profundiza en los aspectos metodológicos, como son los objetivos, el diseño de la investigación, la definición de variables e instrumentos o la población y muestra.

A lo largo de la descripción de la metodología de investigación del estudio I, es necesario en ocasiones hacer una separación entre la evaluación diagnóstica de los estudiantes de educación secundaria y la del futuro profesorado. Asi, principalmente, se implementan análisis diferenciados en la definición y estudio de los instrumentos. Evidentemente, el análisis psicométrico de las escalas es diferenciado, al tener que trabajar con poblaciones de partida distintas. Derivado de este razonamiento, se observa cómo el proceso de muestreo también se afronta de manera diferenciada en uno y otro caso. El análisis psicométrico muestra cómo las escalas se comportan de una manera algo distinta en ambas poblaciones, dadas las diferentes situaciones de partida sobre las que afrontan ambas muestras las competencias informacionales.

Por el contrario, otros aspectos metodológicos como el diseño de la investigación, la definición de variables o el análisis de datos, se exponen de manera conjunta, dado que son más los puntos comunes que los unen que diferenciados que los separan. 
Una vez finalizada la descripción detallada de la metodología de la investigación, se exponen en primer lugar los resultados cosechados en la muestra de estudiantes de educación secundaria. Se comienza con un análisis descriptivo de las variables incluidas en el estudio para, poco a poco ir centrándose más en análisis correlacionales e inferenciales.

En lo que respecta a los análisis inferenciales, se llevan a cabo comparaciones por grupos principales definidos en la información demográfica recogida. Así, se obtienen algunas diferencias reseñables entre hombres y mujeres y haciendo un análisis en función del nivel de estudios de los padres (principalmente de la madre).

En cuanto a los análisis correlacionales, después de un estudio de la relación lineal entre las variables seleccionadas como clave, se aplica un modelo de ecuaciones estructurales con la intención de modelizar la relación entre las competencias informacionales y las relacionadas con el manejo de herramientas informáticas. La prueba del modelo teórico en el contexto empírico devuelve índices de bondad de ajuste adecuados, por lo que es aceptable. Por último, se combina la metodología correlacional y multivariante con la inferencial mediante la comparación del modelo causal construido por grupos principales. Se obtienen diferencias en este caso nuevamente por sexo y por estudios de la madre.

Tras la exposición de los resultados obtenidos en los estudiantes, se procede a mostrar los resultados obtenidos en los futuros profesores de educación secundaria. En este caso, el procedimiento es prácticamente igual que en la exposición de resultados de los estudiantes.

Se comienzan analizando los resultados descriptivos obtenidos, para pasar a mostrar un estudio inferencial en el que se comparan los grupos principales, y terminar diseñando y aplicando un modelo teórico con la metodología de modelos de ecuaciones estructurales. En este caso, dado que no se obtienen diferencias reseñables en el estudio inferecial comparativo, no se lleva a cabo un estudio comparativo del modelo por grupos principales. 


\title{
Capítulo V
}

\author{
ESTUDIO II: Formación en \\ competencias informacionales \\ para el futuro profesorado
}




\section{Capítulo V}

Formación en competencias informacionales para el futuro profesorado
5.1 Metodología de la investigación. Estudio experimental

5.2 Resultados del estudio experimental

5.3 Resumen 


\section{ESTUDIO II: Formación en competencias informacionales para el futuro profesorado}

Una vez desarrollados los objetivos planteados en el primer estudio, procederemos a la descripción del proceso metodológico y los resultados obtenidos en el estudio II.

Como se ha venido señalando anteriormente, el estudio II, de corte experimental, fruto de los resultados obtenidos a partir del primer estudio, consiste en el diseño, desarrollo y evaluación de un programa formativo en competencias informacionales para una muestra de futuros profesores de educación secundaria.

Para el diseño de dicho programa se parte, en primer lugar, del estudio teórico de las dimensiones y contenidos propios de las competencias informacionales. En segundo lugar, se tienen en cuenta las áreas formativas más relevantes para el futuro profesorado de educación secundaria y aquellas que se han localizado como deficitarias en el estudio anterior. Los contenidos de estas áreas serán tratados en mayor profundidad e insistencia.

Paralelamente al diseño del propio programa, se diseña una batería de instrumentos de evaluación de los conocimientos adquiridos por los propios participantes en el curso. Dichos instrumentos, que consisten en la aplicación de varias escalas a partir de un modelo pretest-postest, son validados previamente por jueces expertos en diferentes ámbitos relacionados con las competencias informacionales y la formación de profesorado.

El análisis de datos y la exposición de resultados sobre la eficacia del programa tiene que ver, por tanto, más con las técnicas inferenciales que con las descriptivas o multivariantes. 


\subsection{Metodología de la investigación. Estudio experimental}

El proceso investigador tiene las fases que se muestran a continuación:

\section{ESTUDIOI I}

Estudio de antecedentes de la investigación

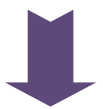

Diseño de los objetivos generales del estudio > Planteamiento de objetivos operativos

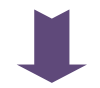

Formulación de la hipótesis de investigación

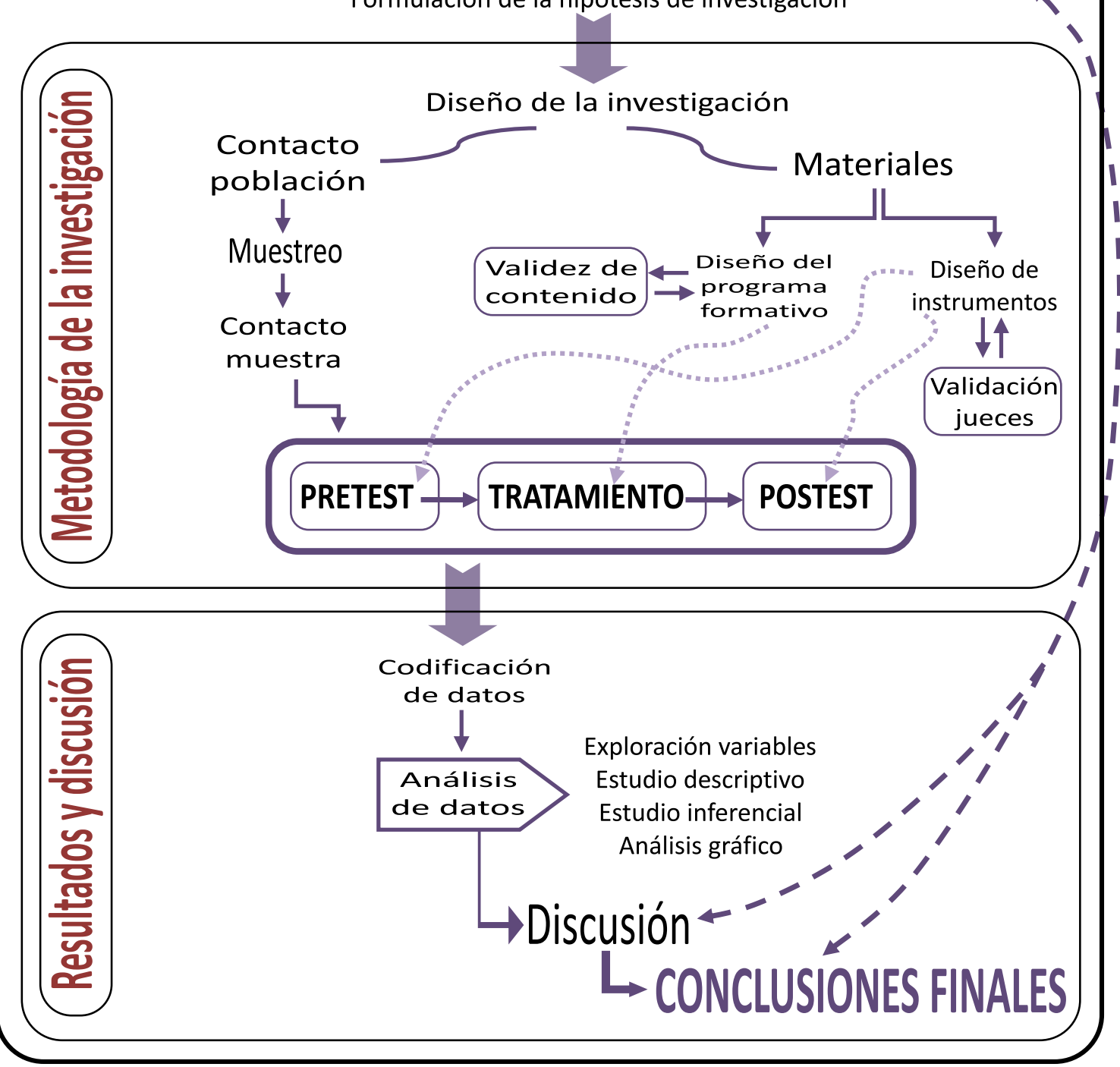

Figura 5.1 Esquema general del proceso de investigación. Estudio experimental.

En la figura 5.1 se muestran las principales fases que se desarrollan para implementar el estudio experimental. 
A partir de los antecedentes de la investigación, entre los que se incluye tanto el análisis del estado de la cuestión, como los resultados obtenidos en el estudio I, se diseña la metodología de investigación, en la que se diseñan y validan los instrumentos de recogida de información y los materiales empleados para el programa formativo, y se lleva a cabo un muestreo para asegurar la representatividad del estudio.

Por último, se lleva a cabo el análisis de datos basado principalmente en técnicas inferenciales y análisis gráficos, y se finaliza con una discusión y enunciación de conclusiones finales, emparentadas directamente tanto con los resultados obtenidos como con el estudio de antecedentes desarrollado previamente.

Una vez vista la estructuración general del estudio experimental, se comenzará con la especificación de los aspectos metodológicos básicos que han guiado el presente estudio para justificar la pertinencia del mismo y de la posterior exposición de resultados y derivación de conclusiones llevada a cabo.

\subsubsection{Antecedentes. Estudio experimental}

Dado que ya nos hemos centrado en el estudio I sobre los aspectos básicos de la investigación científica desarrollada en relación con las competencias informacionales en general, en este apartado nos centraremos únicamente en los esfuerzos llevados a cabo para implementar procesos formativos y evaluarlos empíricamente.

En este aspecto, a pesar de las reticencias que existen actualmente, ya señaladas, acerca de la puesta en marcha de programas de formación en competencias informacionales descontextualizados, cuyo objeto es simplemente la propia competencia básica, salvo escasas excepciones que sumergen el programa dentro de algún contenido curricular propiamente dicho (Beishuizen \& Stoutjesdijk, 1999; Kuiper, Volman, \& Terwel, 2009), el resto de investigaciones localizadas se limita a desarrollar el programa directamente (Appleton, 2005; Grant \& Brettle, 2006; Oliver \& Perzylo, 1994; Rangachari \& Rangachari, 2007; Saito \& Miwa, 2007).

En primer lugar, a pesar de que, como señalábamos anteriormente, el periodo básico de formación del corpus teórico de este campo se desarrolla en los años 90, se mantienen en la literatura actual estudios teóricos que indican los principales tópicos que se deben tratar a la hora de llevar a cabo cualquier acción formativa que pretenda formar en competencias informacionales (Forrest \& Simpson, 2007; Johnston \& Webber, 2003; Spring, 2010). Este tipo de investigaciones, que suelen consistir en 
revisiones de la literatura existente, han proliferado mucho en la primera década del siglo XXI y aún hoy en día siguen teniendo vigencia (Diehm \& Lupton, 2012; González Teruel, 2011; Leguízamo León \& García Carrasco, 2011; Mackey \& Jacobson, 2011)

En lo que respecta a los estudios empíricos propiamente dichos, se detecta en la literatura un buen número de investigaciones que trabajan únicamente con alguna de las subdimensiones incluidas en las competencias informacionales. Esta disgregación se debe, en gran parte a que, a pesar de que las competencias informacionales se han definido como un constructo (Van Helvoort, 2010), la evidencia mostrada en el ESTUDIO I indica que es de tal complejidad que en ocasiones es preferible hacer un análisis más atomizado que holístico:

- Búsqueda de información: En esta dimensión se pueden encontrar investigaciones tanto desde el campo de la Biblioteconomía y Ciencias de la Información, como de la Informática y de la Educación. Las principales experiencias formativas localizadas al respecto tienen una buena fundamentación teórica. Así, las principales evidencias indican que para llevar a cabo un buen aprendizaje en búsqueda de información es necesario programar acciones formativas que propongan ayudas continuas 0 feedback (Puustinen \& Rouet, 2009) y que permitan la consecuente reflexión en la acción y sobre la propia acción (Saito \& Miwa, 2007). Por otro lado, parece que es de vital importancia el papel de la formulación previa de preguntas o tópicos principales de la búsqueda (Kuiper et al., 2009), y que éstos sean específicos y bien centrados en el objetivo concreto. Estos estudios suelen incorporar en los programas formativos algunos módulos relacionados con la evaluación de información, ya que es un campo más limitado e íntimamente relacionado con la búsqueda.

- Procesamiento de información: Otro campo habitual en lo que respecta a los estudios científicos es del procesamiento de información, sobre todo aquello que tiene que ver con la comprensión de textos y dificultades de aprendizaje relacionadas (Acuña Castillo, García Rodicio, \& Sánchez Miguel, 2011; Beishuizen \& Stoutjesdijk, 1999; Oliver \& Perzylo, 1994; Rosales, Sánchez Miguel, \& Pérez, 2004; Sánchez Miguel, Rosales, \& Cañedo, 1998). Dada la importante tradición sobre investigaciones al respecto, los estudios desarrollados tienen niveles de experimentalidad altos. Lo que no se localiza son investigaciones de este tipo que se vinculen explícitamente con 
las competencias informacionales, hasta el punto de parecer una rama ajena a estas mismas.

- Comunicación y difusión de información: En lo que respecta a la comunicación de información, cabe destacar el avance que en los últimos años están tomando los estudios sobre alfabetización mediática (Appel, 2012; Austin, Pinkleton, Austin, \& Van de Vord, 2012; Camps Cervera, 2009; González Fernández-Villavicencio, 2012; Grizzle, Wilson, \& UNESCO, 2011; Jeong, Cho, \& Hwang, 2012; Kesten, 2012; Pérez Tornero, 2008), que se está configurando como un área de investigación prolífica y en muchos casos disgregada (aunque íntimamente relacionada) de las competencias informacionales.

Además de sucederse estudios que analizan específicamente la realidad de alguna de las subcompetencias de las que están compuestas las competencias informacionales, también existen intentos globales de desarrollar programas formativos para la enseñanza de las competencias informacionales (Appleton, 2005; Grant \& Brettle, 2006; Rangachari \& Rangachari, 2007). En este sentido, los estudios localizados adolecen de una definición teórica de las competencias amplia que aporte una buena base al propio programa formativo desarrollado, que en todos los casos es de elaboración propia. En cuanto a la evaluación de la eficacia de estos programas, se lleva a cabo con escalas diseñadas 'ad hoc' en unos casos y sin una validación previa (Appleton, 2005; Grant \& Brettle, 2006) y extraídas de otros estudios, aunque de autopercepción en otros (Rangachari \& Rangachari, 2007). En todos los casos, los resultados y conclusiones encontradas indican que estos programas favorecen el desarrollo de conductas más adecuadas y efectivas en el empleo de las competencias informacionales, y en algunos incluso se observa una tendencia a una mejora del rendimiento académico en los sujetos con un buen desempeño adquirido en competencias informacionales (Appleton, 2005).

Así, al igual que encontrábamos en el estudio I, en cuanto a la investigación relacionada con el diseño, implementación y evaluación de la eficacia de programas formativos relacionados con el desarrollo de las competencias informacionales, mientras que nos encontramos con estudios específicos que alcanzan un nivel de experimentalidad alto, los estudios más genéricos plantean diseños preexperimentales, o en el mejor de los casos cuasiexperimentales. Por otro lado, los estudios genéricos, dentro de los que se enmarca el que se presenta en este documento, suelen fundamentarse en un pilar teórico menos consistente y claro. $A$ 
nivel general, los instrumentos de evaluación empleados son mejorables tanto en la fiabilidad como en la validez de sus mediciones.

Así, llegamos hasta este punto de la investigación, en el que nos planteamos los siguientes interrogantes:

- ¿El diseño de un programa dedicado específicamente a contenidos relacionados con competencias informacionales optimizará el aprendizaje de éstas por parte del futuro profesorado? ¿Cómo se puede evaluar de una manera auténtica y objetiva el nivel alcanzado en las competencias informacionales?

- ¿Se producirá una mejora más patente en los aprendizajes adquiridos en las áreas prioritarias y deficitarias localizadas que en el resto de contenidos?

- ¿Variará la importancia que asigna el futuro profesorado a las competencias informacionales una vez desarrollado el curso? ¿Hacia qué dirección?

\subsubsection{Objetivos de la investigación e hipótesis de validación}

El diseño y desarrollo de la presente investigación se justifica simplemente por la intención de que los resultados que se deriven puedan ser aprovechados para la ampliación de los conocimientos adquiridos sobre el desarrollo de competencias informacionales en los procesos de formación de profesorado. Se trata de aportar datos teóricos y empíricos que ayuden en la ampliación del corpus de conocimientos de esta área en cuestión.

Partiendo de esta premisa, se pueden identificar como objetivo principal el diseño, desarrollo y evaluación de un programa de intervención para la mejora de las competencias informacionales en futuros profesores de educación secundaria obligatoria. Partiendo de esta meta global, nos podemos plantear los siguientes objetivos:

1. Diseño de un programa formativo de intervención para la mejora de las competencias informacionales basado en los argumentos teóricos estudiados y que se centre más específicamente en las áreas prioritarias y de formación deficitaria detectadas en el estudio previo (estudio I). 
a. Análisis y estudio en la literatura existente de las dimensiones teóricas y los contenidos que conforman las competencias informacionales.

b. Diseño de los contenidos y actividades del programa en función del estudio teórico y de las áreas prioritarias y de formación deficitaria localizadas

c. Elaboración de un protocolo válido y fiable para la evaluación del programa diseñado.

2. Implementación del programa de intervención para la mejora de las competencias informacionales para la población del futuro profesorado de educación secundaria obligatoria.

a. Selección de una muestra representativa del futuro profesorado de educación secundaria.

b. Seguimiento sistemático del desarrollo del programa diseñado conforme a los criterios organizacionales planteados previamente.

c. Análisis de resultados sobre rendimiento y satisfacción alcanzados en la muestra acerca del programa.

3. Evaluación del impacto del programa en lo que respecta a la mejora de las competencias informacionales en el futuro profesorado de educación secundaria.

a. Diseño de los instrumentos de evaluación del curso y validación por jueces de los mismos.

b. Aplicación de instrumentos de evaluación a la muestra seleccionada como pretest y postest

c. Análisis exploratorio, descriptivo e inferencial de los datos recogidos en la evaluación de los conocimientos adquiridos y valoración de la efectividad del curso para el aprendizaje de las competencias informacionales.

Resultados previstos: Aportación de un programa validado para la mejora en competencias informacionales en el futuro profesorado de enseñanza secundaria de la comunidad de Castilla y León, principalmente en las áreas prioritarias y de formación deficitaria existentes en este colectivo.

A partir de la contextualización teórica y empírica del presente estudio, y los objetivos planteados, nos planteamos la siguiente hipótesis a validar: los futuros profesores de educación secundaria que han realizado el programa de formación diseñado, bajo las 
condiciones establecidas en la investigación, adquieren un nivel de competencias informacionales superior a las inicialmente demostradas.

\subsubsection{Diseño de la investigación. Estudio experimental}

Para la comprobación de la hipótesis planteada, se selecciona un diseño cuasiexperimental de control mínimo, aplicado en un grupo con pretest y postest. Podríamos hablar de algunas limitaciones en el estudio, ya que al no existir un grupo control, algunos autores hablan de un diseño preexperimental pretest-postest de un solo grupo (D. T. Campbell \& Stanley, 1963). Se selecciona este diseño en concreto dada la realidad de la muestra y las dificultades inherentes a la misma para localizar un grupo control participante en el estudio. Somos conscientes que en este tipo de diseños no se tiene control sobre algunas variables externas que puedan sesgar los resultados obtenidos, y eliminar la validez interna del propio estudio (D. T. Campbell \& Stanley, 1973). Sin embargo, dado que los miembros de la muestra pertenecen a diferentes grupos docentes del Máster de Profesor en Educación Secundaria, los acontecimientos académicos que puedan ocurrir durante la aplicación del tratamiento no afectarán por igual a todos los sujetos. Por tanto, no se puede afirmar que los eventos académicos intermedios puedan ser causa de las diferencias globales registradas.

$$
\boldsymbol{O}_{1} \rightarrow X \rightarrow \boldsymbol{O}_{2}
$$

En el caso concreto de la aplicación de este diseño en nuestra investigación, la variable dependiente (nivel de competencia adquirido en las diferentes dimensiones de las competencias informacionales) es medida antes $\left(O_{1}\right)$ y después $\left(O_{2}\right)$ de administrar el tratamiento " $\mathrm{X}$ " (programa de intervención para la mejora de las competencias informacionales).

\subsubsection{Descripción del programa formativo}

El tratamiento en el desarrollo de un programa formativo online.

El curso se desarrolla entre el 9 de enero y el 10 de febrero de 2012, y tiene una duración de 40 horas, repartidas entre las diversas actividades planificadas, que se van implementando de manera cronológica a lo largo del curso. 
El programa de la actividad formativa se resume a continuación (para más información acerca del programa, consultar anexo III):

TíTULO: Educar en el siglo XXI: el desarrollo de competencias informacionales

FECHAS: 40 horas

DURACIÓN: 40 horas

DESTINATARIOS: Curso destinado a los estudiantes que en el curso académico 2011/2012 están matriculados en el Máster Universitario en Profesor de Educación Secundaria Obligatoria y Bachillerato, Formación Profesional y Enseñanzas de Idiomas.

MODALIDAD: Modalidad no presencial (curso online)

OBJETIVOS: Podemos señalar como objetivo general reflexionar acerca de la importancia de las competencias informacionales en la sociedad de la información y formar en el desarrollo de competencias relacionadas con el manejo de la información.

Los objetivos específicos, referidos a los distintos bloques de contenido del curso, son los siguientes:

- Desarrollar conocimientos básicos en torno al concepto competencias informacionales.

- Reflexionar acerca de la importancia del desarrollo de competencias relacionadas con el manejo de información en la sociedad actual.

- Detectar y diferenciar cada una de las dimensiones que conforman las competencias informacionales en el ámbito educativo.

- Dominar técnicas y estrategias concretas inmersas en las diferentes dimensiones de las competencias informacionales.

- Examinar desde una perspectiva crítica la situación y tratamiento de las competencias informacionales a partir del estudio de programas implementados en el contexto de la educación básica.

\section{CONTENIDOS:}

BLOQUE 0: Introducción al concepto competes informacionales 
1. Importancia de las competencias informacionales en la sociedad actual

a. El contexto de la sociedad de la información; concepto y características

b. La educación en la sociedad de la información

c. Las competencias informacionales como elemento esencial de la sociedad de la información

2. ¿Qué son las competencias informacionales?

a. De la alfabetización informacional a las competencias informacionales

b. El concepto de competencias informacionales

3. Elementos esenciales de las competencias informacionales

BLOQUE 1: Desarrollo de competencias informacionales

1. La búsqueda de información
a. Las fuentes de información
b. Estrategias de búsqueda
c. Planificación de la búsqueda
d. Tecnologías concretas para la búsqueda

2. La evaluación de información

a. Criterios para la evaluación de información

b. El proceso de evaluación de información

3. El procesamiento de información
a. Estrategias cognitivas
b. Herramientas informáticas disponibles

4. La comunicación de información
a. La redacción de documentos científicos
b. La web 2.0
c. Legislación en materia de derechos de autor. Comunicación y uso de la información.

BLOQUE 2: Implementación de competencias informacionales

1. Diseño, implementación y evaluación de programas para el desarrollo de competencias informacionales

ACTIVIDADES: Las actividades planteadas, que desarrollan a nivel práctico los contenidos planteados en el curso, son las siguientes (para más información acerca de las actividades, consultar anexo III): 
1. La sociedad de la información. Importancia de las competencias informacionales.

$\begin{array}{ll}\text { TIPO: } & \text { Gran grupo } \\ \text { HERRAMIENTA: } & \text { Foro de debate y discusión } \\ \text { DURACIÓN: } & 2 \text { horas } \\ \text { TEMPORALIZACIÓN: } & \text { Todo el curso }\end{array}$

A lo largo de todo el curso se mantiene abierta esta línea de debate en varios frentes para que los alumnos, guiados por los comentarios del profesor, vayan descubriendo y pensando acerca de la composición de la sociedad actual o sociedad de la información y sobre la importancia de las competencias informacionales en este contexto colindante.

\section{La planificación de la búsqueda documental}

$\begin{array}{ll}\text { TIPO: } & \text { Grupal/Individual } \\ \text { HERRAMIENTA: } & \text { Foro de debate/Tarea } \\ \text { DURACIÓN: } & 4 \text { horas }\end{array}$

TEMPORALIZACIÓN: $\quad 11-22$ de enero

Actividad en la que los alumnos elaboran, en primer lugar de modo grupal, un protocolo para la planificación de la búsqueda documental, y en segundo lugar, de manera individual, dos procesos de planificación de búsqueda de información. La intención es que los alumnos interioricen el proceso de planificación de la búsqueda documental, y que conozcan y sepan aplicar las diferentes fases que se desarrollan en ese proceso.

\section{Operadores booleanos y otras estrategias de búsqueda}

TIPO: Individual

HERRAMIENTA: $\quad$ Cuestionario en línea de Moodle

DURACIÓN: 2 horas

TEMPORALIZACIÓN: $\quad 11-15$ de enero

Los alumnos disponen de material teórico en el que se exponen las diversas estrategias de búsqueda de información en redes: Operadores boolerianos, descriptores, búsqueda avanzada,... 
Después de la atenta lectura del citado documento y de la práctica individual en diversos buscadores y fuentes de información de dichas estrategias, cada alumno procede a la resolución de un test de conocimientos sobre estos temas.

\section{Las fuentes de información y la evaluación de información}

TIPO: Individual

HERRAMIENTA: $\quad$ Tarea en Moodle

DURACIÓN: $\quad 4$ horas

TEMPORALIZACIÓN: $\quad 18-29$ de enero

Los alumnos disponen de material en el que se especifican las principales fuentes de información existentes y se define su utilidad básica. Existe así mismo un documento en el que se exponen algunas técnicas concretas y sencillas para evaluar si la información obtenida es fiable y válida.

Una vez que los alumnos han accedido y revisado el material, se les propone una actividad en la que se les facilitan varios recursos de diverso formato y calidad. Éstos tienen que determinar en cada uno de qué fuente se trata, y en algunos casos llevar a cabo una evaluación de los mismos en función de los criterios señalados en el documento teórico.

\section{Software informático de apoyo al procesamiento de información}

TIPO: Individual

HERRAMIENTA: $\quad$ Software informático Zotero

DURACIÓN: $\quad 3$ horas

TEMPORALIZACIÓN: $\quad$ 18-29 de enero

El objetivo de esta actividad es que los alumnos aprendan a manejar una herramienta informática que presta apoyo al procesamiento de información. Para esto, vamos a disponer del gestor de referencias bibliográficas Zotero (software libre).

Cada alumno lleva a cabo una actividad en este formato, consistente en elaborar un breve documento tipo Word u Open Office en el que se incluyen varias referencias bibliográficas y al final la bibliografía.

\section{Fases internas y estrategias para el procesamiento de información}

TIPO:

Grupal 


$\begin{array}{ll}\text { HERRAMIENTA: } & \text { Wiki en Moodle } \\ \text { DURACIÓN: } & 3 \text { horas } \\ \text { TEMPORALIZACIÓN: } & 18-29 \text { de enero }\end{array}$

En esta actividad, los alumnos, divididos en grupos limitados, buscan la información necesaria para elaborar un documento tipo wiki en el que se exponen, desde la perspectiva del constructivismo social, las fases a través de las que se lleva a cabo el procesamiento de información en el cerebro humano, así como las principales estrategias que facilitan el procesamiento de información (resumen, subrayado, esquematización, etc.)

Los alumnos trabajan colaborativamente para ir elaborando el documento teórico definitivo. Además, disponen de un foro de debate en el que pueden ir compartiendo ideas, información y debatiendo sobre cómo elaborar la propia wiki.

\section{Web 2.0. Legislación en materia de uso y comunicación de información}

$\begin{array}{ll}\text { TIPO: } & \text { Gran Grupo } \\ \text { HERRAMIENTA: } & \text { Documento de texto compartido } \\ \text { DURACIÓN: } & 2 \text { horas } \\ \text { TEMPORALIZACIÓN: } & \text { Todo el curso }\end{array}$

Actividad consistente en elaborar de manera colaborativa entre todos los alumnos un artículo sobre los aspectos básicos de la web 2.0, y por ende, la legislación actual en relación con el uso de información de cualquier tipo que esté publicado en red con diversas licencias.

El profesor facilita un índice que incluye los epígrafes que debe tener el documento final. Los alumnos deben buscar la información pertinente y elaborarla en el documento conjunto.

\section{Comunicar la información. La redacción de textos científicos}

$\begin{array}{ll}\text { TIPO: } & \text { Individual } \\ \text { HERRAMIENTA: } & \text { Tarea en Moodle } \\ \text { DURACIÓN: } & 3 \text { horas } \\ \text { TEMPORALIZACIÓN: } & 24-31 \text { de enero }\end{array}$

El conocimiento del estilo de redacción y de la estructura habitual de los distintos formatos de texto es esencial. En función de la audiencia a la que se destina el 
documento y la fuente en la que se va a insertar, el estilo y la redacción cambian de manera importante. Así, en esta actividad, los alumnos deben ordenar, encontrar los epígrafes adecuados y señalar algunos errores en el estilo de redacción de un texto científico que es presentado.

9. Implementación y evaluación de programas de desarrollo de competencias informacionales

$\begin{array}{ll}\text { TIPO: } & \text { Individual } \\ \text { HERRAMIENTA: } & \text { Rúbrica de evaluación/Formulario } \\ \text { DURACIÓN: } & 5 \text { horas } \\ \text { TEMPORALIZACIÓN: } & 1-7 \text { de febrero }\end{array}$

Después de haber trabajado con la búsqueda, selección, procesamiento y comunicación y difusión de información, los alumnos se disponen a consultar y evaluar un programa real de formación en competencias informacionales diseñado e implementado para alumnos de educación básica. Dicho curso fue desarrollado por el Centro Internacional de Tecnologías Avanzadas, dentro del Proyecto Utilitic, en colaboración con la institución educativa SEK.

Los alumnos deben consultar y evaluar dicho curso a partir de una rúbrica de evaluación que aborda todos los apartados estudiados a lo largo del curso.

Todas estas actividades están acompañadas por su propia ficha, en la que se definen en un primer folio los objetivos como los contenidos de la actividad y en un segundo folio las instrucciones de la misma. Por ejemplo, se han incluido en las figuras 5.2 y 5.3 (para más información acerca de las actividades, consultar anexo III), mostradas a continuación, las instrucciones completas de la actividad 2 "la planificación de la búsqueda documental".

RECURSOS: Se facilitan al alumno diversas fuentes documentales vinculadas con la temática abordada. Debido al contenido del curso, se intenta en todo momento que el alumno tenga que buscar fuentes documentales de diverso tipo en redes informáticas. Por otro lado, para fomentar el trabajo cooperativo entre los alumnos se emplea gran variedad de recursos tecnológicos disponibles en Moodle: Foros, chats, wikis, etc. 


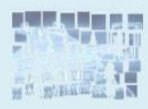

EDUCar en Et HICIO WXI

c1 decamello de Competeneier Informecionales

La planificación de la búsqueda documental

Obietivos:

- Conocer el protocolo para la planificación de la búsqueda documental

- Dominar las estrategias de planificación para iniciar una búsqueda documental

Comprender la importancia de la audiencia en la planificación de la búsqueda documental

\section{Contenidos:}

1. Protocolo para la planificación de la búsqueda

a) Definición del tema de interés

b) Vocabulario especializado de la materia o clave

i) Sinónimos

ii) Antónimos

iii) Conceptos "espúreos"

c) Toma de decisiones sobre operadores booleanos

d) Selección de la fuente de información

e) Ejecución y redefinición de la búsqueda

Figura 5.2 Objetivos y contenidos actividad 2

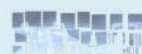

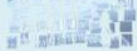

Actividad:

TIPO:

INDIVIDUAL/GRUPAL

HERRAMIENTA:

FORO DE DEBATE/TAREA EN LÍNEA

DURACIÓN:

4 HORAS

FECHAS:

10-22 de ENERO

La actividad se divide en 2 fases:

1. La primera fase es grupal y consiste en la elaboración del protocolo de planificación de la búsqueda. A partir de la consulta del documento "planificación general", los alumnos deben elaborar de manera conjunta, divididos en los grupos que genere automáticamente la plataforma, un protocolo que indique en una extensión de 1 folio los pasos y pautas generales para hacer la planificación. Este documento será una especie de esquema o resumen del documento "planificación general". Este trabajo se debe realizar en a partir del foro de debate grupal titulado "protocolo para la planificación". Dicho foro permitirá compartir documentos para que los alumnos puedan ir haciendo las modificaciones pertinentes hasta llegar a la versión final del mismo.

2. En la segunda fase, de tipo individual, lo primero que se debe hacer es consultar el documento "búsqueda sol". En dicho documento, se plantean dos situaciones problemáticas en las que se necesita emprender un proceso de búsqueda de información. Cada alumno, individualmente, debe elaborar un documento en la tarea en línea titulad "protocolo sol" en el que indique los pasos a seguir a partir del protocolo elaborado en la fase anterior.

El resultado exigible, por tanto, en esta tarea, es tanto un protocolo general para la planificación de una búsqueda, como el desarrollo de dicho protocolo en dos situaciones concretas.

\section{CRITERIOS MÍNIMOS DE EVALUACIÓN}

Participación activa en la primera fase (Actividad grupal) y entrega con un mínimo de calidad de la tarea de la segunda fase.

Figura 5.3 Instrucciones actividad 2

METODOLOGÍA: Modalidad no presencial. 
La metodología que se emplea la podríamos encuadrar dentro del denominado "constructivismo social" (Vygotsky, 1979; Wertsch, 1988), consistente en la combinación de actividades individuales y grupales que permitan la reflexión y generación de ideas personales en un primer momento, y el trasvase de las mismas y debate con los compañeros más tarde. Por tanto, se intenta promover en todo momento una actitud activa por parte del alumno.

En la presentación de los diferentes temas se procuran integrar la propuesta teórica y práctica de cada contenido. El proceso de aprendizaje se aborda a través de la plataforma online Moodle 1.9.

EVALUACIÓN: Los alumnos son evaluados continuamente, en todas las actividades desarrolladas a lo largo de los temas (reflexiones personales, foros, Chat,...). Por lo tanto, se pretende, en este aspecto, atender a una evaluación formativa del alumnado. Por otro lado, también se desarrolla una evaluación sumativa, en el sentido de que el alumno deberá haber superado al menos un $85 \%$ de las actividades para poder aprobar el curso.

Evaluación del curso: A través de un cuestionario de satisfacción, cuyos resultados serán analizados más adelante, se valora si se han logrado los objetivos y se han cumplido las expectativas de los estudiantes.

En cuanto a la evaluación, además de indicar los criterios mínimos de evaluación, se diseñan rúbricas de evaluación adaptadas a las distintas actividades realizadas durante el curso para facilitar al alumno el conocimiento de los criterios de evaluación que se seguirán en la valoración de las propias actividades.

Por una parte, en la figura 5.4 se puede observar la rúbrica de evaluación para el trabajo en foros y chats, y por otro, en la figura 5.5 se puede observar la rúbrica para las actividades en las que se emplee una wiki o directamente la presentación de una tarea concreta.

Como se puede observar, dicha rúbrica especifica tanto los criterios mínimos en cuanto a la calidad del contenido que se elabora, como en cuanto a la forma en la cual se entrega, esto es, la expresión escrita. 
늠ำin

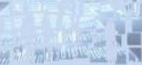

EDUORR En EI HIGIO $\mathrm{m}$

El decamollo de Competeneiar Informacienales

RÚBRICA DE EVALUACIÓN

RÚBRICA DE EVALUACIÓN: chat y foro

\begin{tabular}{|c|c|c|c|c|c|c|}
\hline \multicolumn{2}{|c|}{ INDICADORES } & INSUFICIENTE & ACEPTABLE & BIEN & MUY BIEN & EXCELENTE \\
\hline \multirow[t]{4}{*}{ Contenido } & $\begin{array}{l}\text { Relevancia para } \\
\text { el tema tratado }\end{array}$ & $\begin{array}{l}\text { No aporta nada relevante } \\
\text { al debate }\end{array}$ & $\begin{array}{l}\text { Aporta ideas básicas } \\
\text { que siguen el debate }\end{array}$ & $\begin{array}{l}\text { Aporta ideas } \\
\text { elaboradas que } \\
\text { apoyan el debate }\end{array}$ & $\begin{array}{l}\text { Aporta ideas } \\
\text { elaboradas que dan pie } \\
\text { a nuevos comentarios }\end{array}$ & $\begin{array}{l}\text { Aporta ideas complejas } \\
\text { que dan soluciones o } \\
\text { sugieren nuevas ideas }\end{array}$ \\
\hline & $\begin{array}{l}\text { Adecuación a } \\
\text { los contenidos } \\
\text { teóricos }\end{array}$ & $\begin{array}{l}\text { No se adecua a los } \\
\text { contenidos teóricos en } \\
\text { sus intervenciones }\end{array}$ & $\begin{array}{l}\text { En ocasiones se } \\
\text { adecua a los } \\
\text { contenidos teóricos }\end{array}$ & $\begin{array}{l}\text { Se adecua a los } \\
\text { contenidos } \\
\text { normalmente }\end{array}$ & $\begin{array}{l}\text { Casi siempre se basa } \\
\text { en contenidos teóricos } \\
\text { en sus intervenciones }\end{array}$ & $\begin{array}{l}\text { Siempre se basa en los } \\
\text { contenidos teóricos }\end{array}$ \\
\hline & $\begin{array}{l}\text { Coherencia con } \\
\text { la linea de } \\
\text { debate }\end{array}$ & $\begin{array}{l}\text { Sus aportaciones no } \\
\text { tienen que ver con el } \\
\text { debate seguido }\end{array}$ & $\begin{array}{l}\text { Se basa en el debate, } \\
\text { pero no en lo más } \\
\text { esencial }\end{array}$ & $\begin{array}{l}\text { Sigue la linea de } \\
\text { debate centrándose en } \\
\text { ocasiones en lo } \\
\text { básico }\end{array}$ & $\begin{array}{l}\text { Sigue la linea de } \\
\text { debate centrándose } \\
\text { habitualmente en lo } \\
\text { esencial }\end{array}$ & $\begin{array}{l}\text { Sus aportaciones } \\
\text { siempre tienen que ver } \\
\text { con el núcleo esencial } \\
\text { del debate }\end{array}$ \\
\hline & $\begin{array}{l}\text { Presenta } \\
\text { aportaciones } \\
\text { originales }\end{array}$ & $\begin{array}{l}\text { No tiene ningún grado } \\
\text { de originalidad }\end{array}$ & $\begin{array}{l}\text { Hace aportaciones } \\
\text { nuevas basadas en } \\
\text { otros comentarios }\end{array}$ & $\begin{array}{l}\text { Hace aportaciones } \\
\text { originales adecuadas } \\
\text { sin base cientifica }\end{array}$ & $\begin{array}{l}\text { Hace aportaciones } \\
\text { originales con base } \\
\text { cientifica }\end{array}$ & $\begin{array}{l}\text { Hace aportaciones } \\
\text { originales e innovadoras } \\
\text { con base cientifica }\end{array}$ \\
\hline \multirow[t]{4}{*}{$\begin{array}{l}\text { Expresión } \\
\text { escrita }\end{array}$} & $\begin{array}{l}\text { Adecuación del } \\
\text { lenguaje }\end{array}$ & $\begin{array}{l}\text { Utiliza un lenguaje } \\
\text { totalmente inapropiado }\end{array}$ & $\begin{array}{l}\text { En ocasiones utiliza } \\
\text { un lenguaje } \\
\text { inapropiado }\end{array}$ & $\begin{array}{l}\text { Suele emplear un } \\
\text { lenguaje apropiado, } \\
\text { aunque a veces su } \\
\text { jerga es inadecuada }\end{array}$ & $\begin{array}{l}\text { Utiliza un lenguaje } \\
\text { apropiado para el } \\
\text { lector }\end{array}$ & $\begin{array}{l}\text { Emplea terminología } \\
\text { adecuada y un lenguaje } \\
\text { apropiado }\end{array}$ \\
\hline & $\begin{array}{l}\text { Ortografia y } \\
\text { puntuación }\end{array}$ & $\begin{array}{l}\text { Comete continuos } \\
\text { errores }\end{array}$ & $\begin{array}{l}\text { Apocopa el lenguaje } \\
\text { y comente algunos } \\
\text { errores }\end{array}$ & $\begin{array}{l}\text { Omite algunos } \\
\text { acentos y signos de } \\
\text { puntuación }\end{array}$ & $\begin{array}{l}\text { Ortografia y } \\
\text { puntuación adecuados }\end{array}$ & $\begin{array}{l}\text { Respeto exquisito de la } \\
\text { ortografia y la } \\
\text { puntuación }\end{array}$ \\
\hline & $\begin{array}{l}\text { Coherencia } \\
\text { estructural }\end{array}$ & $\begin{array}{l}\text { Las frases y párrafos no } \\
\text { tienen ninguna } \\
\text { coherencia. Es imposible } \\
\text { determinar la idea } \\
\text { principal }\end{array}$ & $\begin{array}{l}\text { Es necesario releer el } \\
\text { texto para captar la } \\
\text { idea principal. Las } \\
\text { conexiones entre } \\
\text { frases son confusas }\end{array}$ & $\begin{array}{l}\text { Se identifica } \\
\text { fácilmente la idea } \\
\text { principal. En } \\
\text { ocasiones el texto no } \\
\text { tiene coherencia }\end{array}$ & \begin{tabular}{|l|} 
Facilidad para \\
identificar la idea \\
principal. Las \\
secciones guardan una \\
correcta relación \\
\end{tabular} & $\begin{array}{l}\text { Muestra idea principal } \\
\text { relacionada claramente } \\
\text { con las secundarias. } \\
\text { Coherencia y correcta } \\
\text { relación entre frases }\end{array}$ \\
\hline & $\begin{array}{l}\text { Claridad y } \\
\text { concisión }\end{array}$ & $\begin{array}{l}\text { Continuas oraciones mal } \\
\text { construidas y poco } \\
\text { claras }\end{array}$ & $\begin{array}{l}\text { Suelen existir } \\
\text { oraciones claras y } \\
\text { bien construidas }\end{array}$ & $\begin{array}{l}\text { Las oraciones son } \\
\text { fluidas, salvo en } \\
\text { algunos momentos }\end{array}$ & $\begin{array}{l}\text { El texto destaca por su } \\
\text { claridad la mayor } \\
\text { parte del tiempo }\end{array}$ & $\begin{array}{l}\text { Las oraciones fluyen sin } \\
\text { problemas, transmiten el } \\
\text { significado previsto }\end{array}$ \\
\hline
\end{tabular}

Figura 5.4 Objetivos y contenidos actividad 2

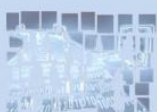

RÚBRICA DE EVALUACIÓN: Wikis y Tareas

\begin{tabular}{|c|c|c|c|c|c|c|}
\hline \multicolumn{2}{|c|}{ INDICADORES } & \multirow{2}{*}{$\begin{array}{l}\text { INSUFICIENTE } \\
\begin{array}{l}\text { No alcanza ningún } \\
\text { grado de cientificidad } \\
\text { en el desarrollo }\end{array} \\
\end{array}$} & \multirow{2}{*}{$\begin{array}{l}\text { ACEPTABLE } \\
\text { Desarrollo serio pero } \\
\text { con cierto grado de } \\
\text { imprecisión }\end{array}$} & \multirow{2}{*}{\begin{tabular}{|l}
\multicolumn{1}{|c}{ BIEN } \\
Alcanza un nivel de \\
desarrollo serio y \\
efectivo
\end{tabular}} & \multirow{2}{*}{\begin{tabular}{|l|c|}
\multicolumn{1}{|c|}{ MUY BIEN } \\
$\begin{array}{l}\text { Desarrolla los } \\
\text { contenidos atendiendo } \\
\text { a criterios científicos }\end{array}$ \\
\end{tabular}} & \multirow{2}{*}{\begin{tabular}{|l|}
\multicolumn{1}{|c|}{ EXCELENTE } \\
$\begin{array}{l}\text { Desarrolla los } \\
\text { contenidos con máxima } \\
\text { precisión }\end{array}$ \\
\end{tabular}} \\
\hline Contenido & $\begin{array}{l}\text { Cientificidad de } \\
\text { los contenidos }\end{array}$ & & & & & \\
\hline & $\begin{array}{l}\text { Adecuación a } \\
\text { los contenidos } \\
\text { teóricos }\end{array}$ & $\begin{array}{l}\text { No se adecua a los } \\
\text { contenidos teóricos en } \\
\text { sus intervenciones }\end{array}$ & $\begin{array}{l}\text { En ocasiones se adecua } \\
\text { a los contenidos } \\
\text { teóricos }\end{array}$ & $\begin{array}{l}\text { Se adecua a los } \\
\text { contenidos } \\
\text { normalmente }\end{array}$ & $\begin{array}{l}\text { Casi siempre se basa en } \\
\text { contenidos teóricos en } \\
\text { el texto }\end{array}$ & $\begin{array}{l}\text { Siempre se basa en los } \\
\text { contenidos teóricos }\end{array}$ \\
\hline & $\begin{array}{l}\text { Presenta } \\
\text { aportaciones } \\
\text { originales }\end{array}$ & $\begin{array}{l}\text { No tiene ningún grado } \\
\text { de originalidad }\end{array}$ & $\begin{array}{l}\text { Hace aportaciones } \\
\text { originales adecuadas } \\
\text { sin base cientifica }\end{array}$ & $\begin{array}{l}\text { Hace aportaciones } \\
\text { originales basadas en } \\
\text { otros documentos }\end{array}$ & $\begin{array}{l}\text { Hace aportaciones } \\
\text { originales elaboradas } \\
\text { con base cientifica }\end{array}$ & $\begin{array}{l}\text { Hace aportaciones } \\
\text { originales e innovadoras } \\
\text { con base cientifica }\end{array}$ \\
\hline & $\begin{array}{l}\text { Sistematicidad } \\
\text { de contenidos }\end{array}$ & $\begin{array}{l}\text { Hace un desarrollo de } \\
\text { contenidos bago e } \\
\text { inconstante }\end{array}$ & $\begin{array}{l}\text { Aporta un grado básico } \\
\text { de persistencia y } \\
\text { constancia en los } \\
\text { contenidos }\end{array}$ & $\begin{array}{l}\text { Desarrolla contenidos } \\
\text { de modo ordenado y } \\
\text { metódico }\end{array}$ & $\begin{array}{l}\text { Alcanza cierto grado de } \\
\text { profundidad en los } \\
\text { contenidos y los trata } \\
\text { con constancia }\end{array}$ & \begin{tabular}{|l|} 
Es metódico y \\
persistente en el \\
desarrollo de contenidos \\
y los analiza en \\
profundidad
\end{tabular} \\
\hline \multirow[t]{4}{*}{$\begin{array}{l}\text { Expresión } \\
\text { escrita }\end{array}$} & $\begin{array}{l}\text { Adecuación } \\
\text { del lenguaje }\end{array}$ & $\begin{array}{l}\text { nguaje } \\
\text { lapropiado }\end{array}$ & un & $\begin{array}{l}\text { Suele emplear un } \\
\text { lenguaje apropiado, } \\
\text { aunque a veces su } \\
\text { jerga es inadecuada } \\
\end{array}$ & $\begin{array}{l}\text { e } \\
\text { lector }\end{array}$ & $\begin{array}{l}\text { Emplea terminologia } \\
\text { adecuada y un lenguaje } \\
\text { apropiado }\end{array}$ \\
\hline & $\begin{array}{l}\text { Ortogrc } \\
\text { puntuac }\end{array}$ & $\begin{array}{l}\text { Comete } \\
\text { errores }\end{array}$ & $\begin{array}{l}\text { Apocopa el lenguaje y } \\
\text { comente algunos } \\
\text { errores }\end{array}$ & $\begin{array}{l}\text { Omite algunos } \\
\text { acentos y signos de } \\
\text { puntuación }\end{array}$ & adecuados & $\begin{array}{l}\text { Respeto exquisito de la } \\
\text { ortografia y la } \\
\text { puntuación }\end{array}$ \\
\hline & $\begin{array}{l}\text { Coherencia } \\
\text { estructural }\end{array}$ & $\begin{array}{l}\text { Las frases y párrafos no } \\
\text { tienen ninguna } \\
\text { coherencia. Es } \\
\text { imposible determinar la } \\
\text { idea principal }\end{array}$ & $\begin{array}{l}\text { Es necesario releer el } \\
\text { texto para captar la } \\
\text { idea principal. Las } \\
\text { conexiones entre frases } \\
\text { son confusas }\end{array}$ & $\begin{array}{l}\text { Se identifica } \\
\text { fácilmente la idea } \\
\text { principal. En } \\
\text { ocasiones el texto no } \\
\text { tiene coherencia }\end{array}$ & $\begin{array}{l}\text { Facilidad para } \\
\text { identificar la idea } \\
\text { principal. Las secciones } \\
\text { guardan una correcta } \\
\text { relación }\end{array}$ & $\begin{array}{l}\text { Muestra idea principal } \\
\text { relacionada claramente } \\
\text { con las secundarias. } \\
\text { Coherencia y correcta } \\
\text { relación entre frases }\end{array}$ \\
\hline & $\begin{array}{l}\text { Claridady } \\
\text { concisión }\end{array}$ & $\begin{array}{l}\text { Continuas oraciones } \\
\text { mal construidas y poco } \\
\text { claras }\end{array}$ & $\begin{array}{l}\text { Suelen existir } \\
\text { oraciones claras y bien } \\
\text { construidas }\end{array}$ & $\begin{array}{l}\text { Las oraciones son } \\
\text { fluidas, salvo en } \\
\text { algunos momentos }\end{array}$ & $\begin{array}{l}\text { El texto destaca por su } \\
\text { claridad la mayor parte } \\
\text { del tiempo }\end{array}$ & $\begin{array}{l}\text { Las oraciones fluyen sin } \\
\text { problemas, transmiten } \\
\text { el significado previsto }\end{array}$ \\
\hline
\end{tabular}

Figura 5.5 Objetivos y contenidos actividad 2

Por último, vamos a exponer la propia interfaz desarrollada en Moodle. 
Como se ha señalado anteriormente, se emplea el Moodle 1.9 para desarrollar la interfaz a partir de la que los alumnos van a interactuar y trabajar.

La interfaz de usuario de un sistema informático es el modo en el que este sistema se comunica con las personas, y como tal debe cumplir unos criterios para que este intercambio de información se optimice (Carvalho Levy, 2005). Por ello, en el diseño de la interfaz se tratan de respetar unos criterios básicos, adaptados a partir de los propuestos por Weis (2001):

1. Escribir el menor texto posible en la pantalla: La legibilidad en una pantalla en peor que en el papel. Los textos deben ser cortos y precisos, utilizando los principios del sistema de hipertexto.

2. Disposición adecuada en la pantalla: Los elementos mostrados deben ser visuales, accesibles a primera vista. La repetición de estructuras facilita mucho los procesos de acceso a los recursos.

3. Utilización de símbolos: El uso de iconos, botones y colores facilita la navegación, ya que aporta una información visual que la dinamiza. Sin embargo, un empleo muy reiterado, con gráficos animados, exceso de colores, etc., puede ser perjudicial en el sentido de que puede despistar más que guiar al usuario.

4. El camino de la navegación: Hay que procurar que el camino que tenga que recorrer cada usuario para llegar a su objetivo sea lo más corto posible.

5. Mecanismo de ventanas: El salto de nuevas ventanas, o la navegación en la misma debe ser algo uniforme.

6. Rendimiento del software: Cuanto más lenta sea la carga de las páginas, menos invitará a abrirlas.

Por otro lado, se ha considerado la consistencia interna como uno de los elementos más importantes en la interfaz de usuario (Nielsen, 1989). Podemos hablar de dos componentes en la consistencia: descriptiva, es decir, hacer el diseño estimando en qué términos específicos debe ser consistente; y evaluativa, esto es, que el diseño de la interfaz sea operativo en relación al uso para el que está destinada, en este caso, un entorno académico-formal. 
Podemos observar cómo están desarrollados los contenidos en el espacio de Moodle a continuación.

\section{Educar en el siglo XXI. El desarrollo de competencias informacionales}

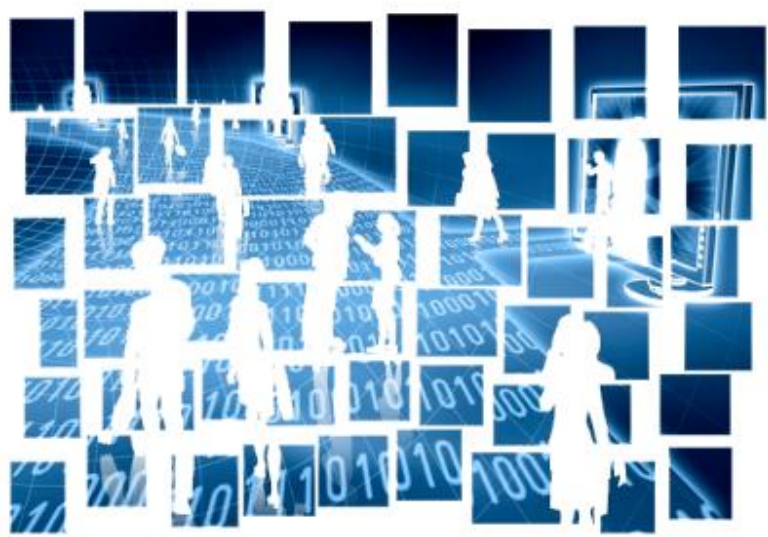

¿ Programa del curso

- Orientaciones para los alumnos

[7. Cronograma del curso y calendario para las actividades

团 Criterios de evaluación

[- Tutorías

\section{Foro de Noticias}

3 Chat de tutorías

Foro de dudas

Presentaciones y comentarios

\section{EVALUACIÓN DE CONOCIMIENTOS PREVIOS. 7-10 de ENERO}

Completa el cuestionario que se facilita a continuación. Te llevará aproximadamente 1 hora.

E. Evaluación de conocimientos previos

Figura 5.6 Portada espacio Moodle curso competencias informacionales

En primer lugar, se observa en la figura 5.6 cómo todos los documentos y elementos básicos se disponen en la primera página, que es la que se puede visualizar directamente al acceder al espacio.

En cuanto a los criterios señalados anteriormente, se puede observar cómo se trata de presentar la menor cantidad de texto posible en esta interfaz principal, se tratan de mostrar los elementos organizados de manera lógica, clara y jerarquizada, se maximiza el empleo de símbolos diferentes para facilitar la visualización y localización de algún elemento concreto, y se trata de que el camino de la navegación sea el más 
corto posible. Así mismo, al hacer clic en cada uno de los enlaces, el recurso se abre en una nueva ventana, con lo que se posibilita un mecanismo de ventanas que facilita la navegación.

\section{BLOQUE 1. Búsqueda de Información \\ La primera etapa en el despliege de las Competencias Informacionales tiene que ver con los conomicmientos y habilidades relacionados con la búsqueda de información. Entre otras cosas, esta etapa hace referencia a la planificación previa del proceso de búsqueda, la tipología de las fuentes de información, o el manejo de operadores booleanos en las sentencias de búsqueda.}

ACTIVIDAD 1.1: La planificación de la búsqueda documental

(11-22 de enero)

a) INSTRUCCIONES Actividad 1.1

저 Listado grupos curso

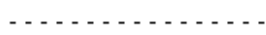

¿- Planificación General

즈 Búsqueda Sol

- . . . . . . . . . . .

Protocolo para la Planificación

10 Protocolo Sol

ACTIVIDAD 1.2: Operadores booleanos y otras estrategias de búsqueda

(11-15 de enero)

[i] INSTRUCCIONES Actividad 1.2

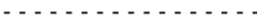

[-] Introducción a los operadores booleanos 1

6. Introducción a los operadores booleanos 2

저 Búsqueda avanzada en Google

6] Operadores booleanos en Google

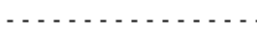

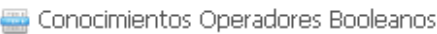

[辶] Solución preguntas actividad

Figura 5.7 Bloque II espacio Moodle curso competencias informacionales

En la figura 5.7 se puede observar cómo se dispone la información de cada uno de los bloques y de las actividades que en ellos se desarrollan. Queda patente cómo se siguen intentando mantener los criterios de interfaz anteriormente señalados en las páginas de cada uno de los bloques.

Por otro lado, con la intención de facilitar el camino de la navegación, cada uno de los bloques está señalizado con colores diferentes, tanto en su presentación como 
en el color de fondo de los documentos de formato .pdf que se adjuntan a cada actividad. Siguiendo con el estilo cromático que se ha seguido a lo largo del estudio I de esta tesis doctoral, cada bloque de actividades va vinculado con los siguientes colores: búsqueda de información en azul, evaluación de información en verde, procesamiento de información en naranja y comunicación y difusión de información en rojo. En cuanto a los otros dos bloques anexos, en la introducción se emplea el color gris y en la parte de diseño, implementación y evaluación de programas de competencias informacionales el marrón.

\subsubsection{Escala de satisfacción}

La escala de satisfacción se diseña integrada en el espacio de Moodle, como un cuestionario autoconfigurable. El formato es el siguiente:

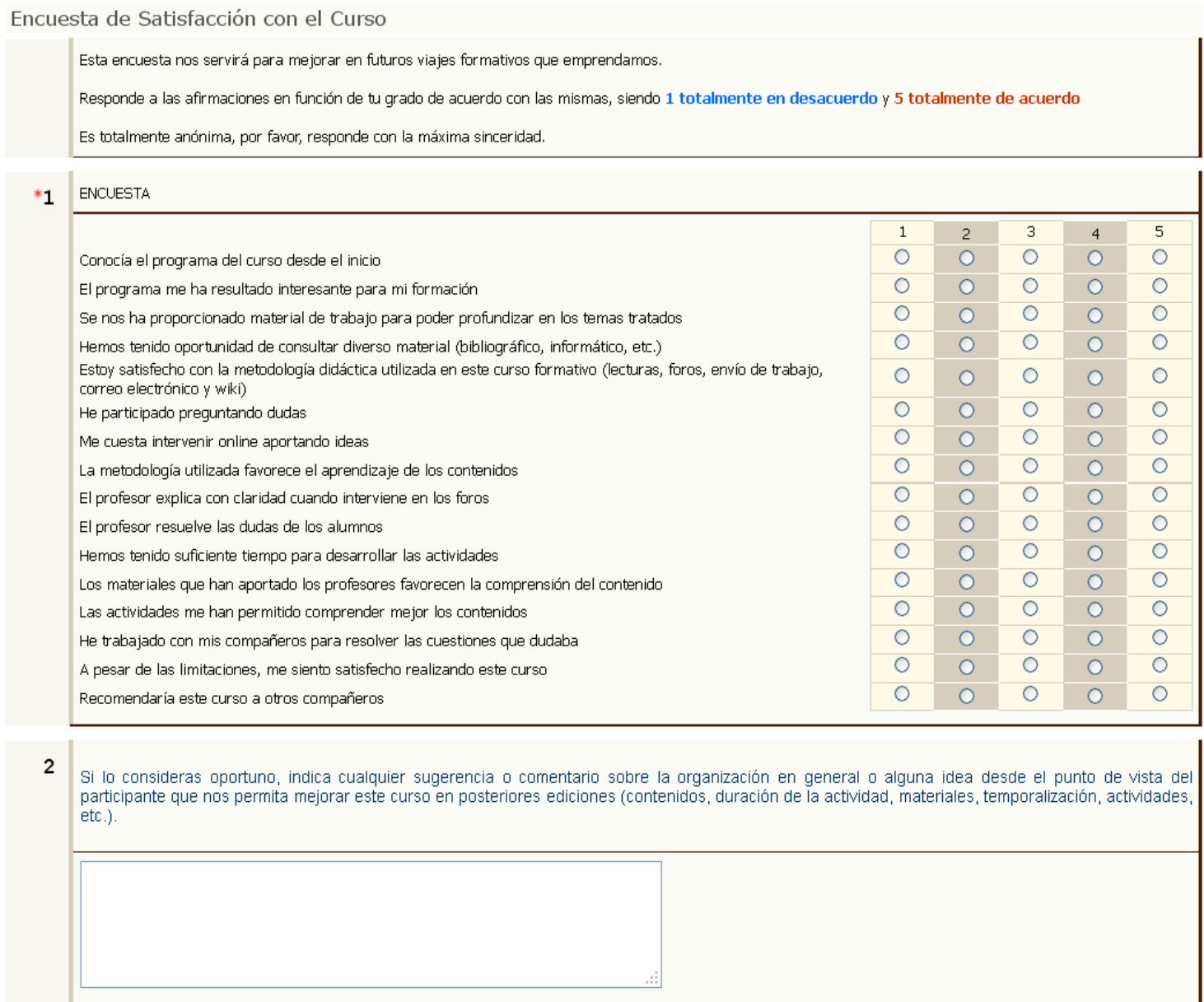

Figura 5.8 Encuesta de satisfacción Moodle curso competencias informacionales

Se observa cómo la encuesta consiste en 16 ítems con escala tipo likert con opciones de respuesta de 1 a 5, siendo 1 totalmente en desacuerdo con la afirmación y 
5 totalmente de acuerdo. Por último, se incorpora una pregunta abierta en la que los alumnos pueden incorporar sugerencias para la mejora del propio curso. La plataforma recoge las respuestas y las devuelve en formato texto, que se exportan en una hoja de cálculo para ser analizadas con un programa estadístico.

\subsubsection{Variables e instrumentos. Estudio experimental}

Dado que nos encontramos con un estudio de corte experimental (aunque con control mínimo), tiene sentido en este caso hacer referencia a variables dependientes e independientes, expresadas en la hipótesis de trabajo. En este estudio concreto, como se indicaba anteriormente, puesto que dada la naturaleza de la muestra seleccionada las variables extrañas se aleatorizan, no se atiende a este tipo de variables intervinientes de manera más específica.

Podemos definir varios grupos de variables intervinientes:

- Debidas al alumno: Conocimientos previos, inteligencia general, tiempo de estudio, motivación, edad, etc.

- Dada la naturaleza del proceso de muestreo, estas variables se aleatorizan, salvo la motivación, que se mantiene constante.

- Debidas al profesor: Estilo docente, experiencia, especialidad, etc.

- Sólo existe un profesor-tutor, que dirige el tratamiento desde principio a fin. Por tanto, esta variable está balanceada.

- Debidas al contexto: Ya se ha expuesto antes que, debido a que los sujetos sobre los que se aplica el tratamiento reciben la docencia del Máster en grupos diferentes, las variables intervinientes en este sentido que nos interesan (de tipo académico o formativo) se aleatorizan. El resto de variables debidas al contexto, como las características del aula o del grupo en el que se desarrolla el aprendizaje, son estables.

La variable independiente, variable que es manipulada intencionalmente para observar su efecto sobre el resto de variables dependientes controladas, es el tratamiento aplicado. Concretamente la variable independiente de este estudio es el programa formativo de intervención para la mejora en competencias informacionales en el futuro profesorado de educación secundaria obligatoria. Dentro de este 
programa formativo se incluyen varios bloques de contenido como se ha mostrado previamente, y se puede consultar más detenidamente en el anexo III:

- BLOQUE 0: Introducción al concepto competencias informacionales

- BLOQUE 1: Desarrollo de competencias informacionales

- La búsqueda de información

- La Evaluación de información

- El procesamiento de información

- La comunicación de información

- La implementación y evaluación de programas para el desarrollo de competencias informacionales

En cuanto a las variables dependientes, se diseñan con la intención de medir la diferencia en el nivel alcanzado en competencias informacionales antes y después de implementar el tratamiento.

En consecuencia, se diseña "ad hoc" un inventario de instrumentos para la evaluación de competencias informacionales en futuros profesores de ESO. Tras el proceso de diseño y validación del inventario, que será descrito en el apartado correspondiente, la estructura del inventario se acaba dividiendo en $\mathbf{4}$ instrumentos diferenciados, y cada uno de ellos desarrolla uno de los 3 componentes de la competencia (Delors, 1997; Martínez Clares \& Echeverría Samanes, 2009; Villa Sánchez \& Poblete Ruiz, 2009):

- Saber (componente 1 de la competencia): Conjunto de conocimientos, tanto generales como específicos, tanto teóricos como prácticos.

- En este bloque se ha diseñado una prueba objetiva (instrumento 1), compuesta por 41 ítems con 4 opciones de respuesta.

- Saber hacer (componente 2 de la competencia): Habilidades y destrezas fruto del aprendizaje y la experiencia. Dada la complejidad existente en la evaluación de este aspecto con una simple aplicación de una prueba, se han elaborado dos escalas diferentes. 
- La primera se trata de una escala ordinal (instrumento 2), en la que el encuestado deberá establecer el orden concreto de 4 opciones en función de la consigna que se establezca en el enunciado del ítem. Esta escala está compuesta por 12 ítems.

- "Píldoras de desempeño" (instrumento 3): Se denomina así a la segunda escala, consistente en pequeñas actividades en las que el encuestado deberá evidenciar algunas habilidades relacionadas con las competencias informacionales. Esta escala está compuesta por 8 ítems, aunque alguno de ellos se subdivide en más tareas.

- Saber ser/estar (componente 3 de la competencia): Valores y actitudes de la persona. Importancia percibida sobre cada uno de los elementos que componen las competencias informacionales.

- Para este tercer componente de la competencia se ha adaptado una escala de actitudes (instrumento 4) de Pinto (2009) ya validada previamente por jueces. Dicho instrumento consta de 26 ítems tipo likert con una escala de 1 a 9 puntos, en la que se cuestiona a los sujetos acerca de la importancia de los desempeños específicos que componen las competencias informacionales. Al estar ya validada previamente, no es necesaria su valoración en este procedimiento.

Dentro del constructo competencias informacionales se ha considerado, además de las 4 dimensiones teóricas estudiadas durante toda la presente investigación, la introducción de un bloque de contenidos inicial denominado "Conceptos básicos sobre las competencias informacionales".

Así, los instrumentos incluidos en los componentes de la competencia descritos más arriba se desarrollan en cada una de las dimensiones señaladas. Por tanto, conforme a los criterios teóricos establecidos, el constructo "competencias informacionales" se divide en $\mathbf{4}$ dimensiones (más un bloque inicial básico). En cada dimensión se sitúan los diferentes componentes de la competencia (saber, saber hacer y saber ser) y los instrumentos a través de los que se evalúa el nivel de desempeño de los sujetos en cada uno de los componentes.

En la tabla 5.1 se puede observar la estructura básica de los instrumentos para la medida de la variable dependiente competencias informacionales. 
Tabla 5.1 Estructura de los instrumentos de evaluación

\begin{tabular}{|c|c|c|c|}
\hline Dimensión & Instrumento & Componente & № de ítems \\
\hline \multirow{2}{*}{$\begin{array}{r}\text { DIMENSIÓN 0: } \\
\text { CONCEPTOS BÁSICOS SOBRE } \\
\text { COMPETENCIAS INFORMACIONALES }\end{array}$} & Prueba objetiva & $S A B E R$ & 5 \\
\hline & $\begin{array}{l}\text { Píldoras de } \\
\text { desempeño }\end{array}$ & SABER HACER & 2 \\
\hline \multirow{4}{*}{$\begin{array}{r}\text { DIMENSIÓN 1: } \\
\text { BÚSQUEDA DE INFORMACIÓN }\end{array}$} & Prueba objetiva & SABER & 13 \\
\hline & Escala Ordinal & SABER HACER & 3 \\
\hline & $\begin{array}{l}\text { Píldoras de } \\
\text { desempeño }\end{array}$ & SABER HACER & $2(1 \times 3+1 \times 3)$ \\
\hline & Escala ordinal & SABER SER & 8 \\
\hline \multirow{4}{*}{$\begin{array}{r}\text { DIMENSIÓN 2: } \\
\text { EVALUACIÓN DE INFORMACIÓN }\end{array}$} & Prueba objetiva & SABER & 6 \\
\hline & Escala Ordinal & SABER HACER & 3 \\
\hline & $\begin{array}{l}\text { Píldoras de } \\
\text { desempeño }\end{array}$ & SABER HACER & $1_{x 6}$ \\
\hline & Escala ordinal & SABER SER & 5 \\
\hline \multirow{4}{*}{$\begin{array}{r}\text { DIMENSIÓN 3: } \\
\text { PROCESAMIENTO DE INFORMACIÓN }\end{array}$} & Prueba objetiva & SABER & 8 \\
\hline & Escala Ordinal & SABER HACER & 3 \\
\hline & $\begin{array}{l}\text { Píldoras de } \\
\text { desempeño }\end{array}$ & SABER HACER & $1_{x 2}$ \\
\hline & Escala ordinal & SABER SER & 6 \\
\hline \multirow{4}{*}{$\begin{array}{r}\text { DIMENSIÓN 4: } \\
\text { COMUNICACIÓN Y DIFUSIÓN DE } \\
\text { INFORMACIÓN }\end{array}$} & Prueba objetiva & SABER & 9 \\
\hline & Escala Ordinal & SABER HACER & 3 \\
\hline & $\begin{array}{l}\text { Píldoras de } \\
\text { desempeño }\end{array}$ & SABER HACER & $2(1+1 \times 4)$ \\
\hline & Escala ordinal & SABER SER & 7 \\
\hline
\end{tabular}

Los ítems que componen cada uno de estos instrumentos de evaluación se muestran completamente en el anexo IV.

\subsubsection{Encuesta de satisfacción}

En el marco del presente estudio, con el objetivo de tener en cuenta la opinión de los alumnos acerca de la calidad del tratamiento recibido, se aplica una breve escala de satisfacción que recoge información sobre el profesor, las metodologías, la participación en el curso, el programa, las actividades desarrolladas, el material facilitado y la satisfacción general con el curso. Los ítems incluidos en el instrumento son los siguientes:

- Programa 1: Conocía el programa del curso desde el inicio. (ITEM_01)

- Programa 2: El programa me ha resultado interesante para mi formación. (ITEM_02) 
- Material 1: Se nos ha proporcionado material de trabajo para poder profundizar en los temas tratados. (ITEM_03)

- Material 2: Hemos tenido oportunidad de consultar diverso material (bibliográfico, informático, etc.). (ITEM_04)

- Material 3: Los materiales que han aportado los profesores favorecen la comprensión del contenido. (ITEM_05)

- Metodología 1: Estoy satisfecho con la metodología didáctica utilizada en este curso formativo (lecturas, foros, envío de trabajo, correo electrónico y wiki). (ITEM_06)

- Metodología 2: La metodología utilizada favorece el aprendizaje de los contenidos. (ITEM_07)

- Participación 1: He participado preguntando dudas. (ITEM_08)

- Participación 2: Me cuesta intervenir online aportando ideas. (ITEM_09). Este ítem está formulado en negativo, por lo que se da la vuelta en el análisis de datos.

- Participación 3: He trabajado con mis compañeros para resolver las cuestiones que dudaba. (ITEM_10)

- Profesor 1: El profesor explica con claridad cuando interviene en los foros. (ITEM_11)

- Profesor 2: El profesor resuelve las dudas de los alumnos. (ITEM_12)

- Actividades 1: Hemos tenido suficiente tiempo para desarrollar las actividades. (ITEM_13)

- Actividades 2: Las actividades me han permitido comprender mejor los contenidos. (ITEM_14)

- General 1: A pesar de las limitaciones, me siento satisfecho realizando este curso. (ITEM_15)

- General 2: Recomendaría este curso a otros compañeros. (ITEM_16) 
- Pregunta abierta: Si lo consideras oportuno, indica cualquier sugerencia o comentario sobre la organización en general o alguna idea desde el punto de vista del participante que nos permita mejorar este curso en posteriores ediciones (contenidos, duración de la actividad, materiales, temporalización, actividades, etc.). (ITEM_17)

\subsubsection{Fiabilidad y validez de los instrumentos del inventario}

En función de los objetivos del estudio II, se decide construir un inventario para la evaluación del nivel real en competencias informacionales, tanto en conocimientos y destrezas, como en actitudes. Como se ha indicado, en el estudio I se analizan competencias autopercibidas tanto en alumnado como en futuro profesorado. Debemos de ser conscientes de que, aunque cuando se pretende valorar una competencia compleja ex-post-facto, la eficacia del instrumento de autoinforme ha sido avalada por numerosas investigaciones (Bandura \& Locke, 2003; Eastman \& Marzillier, 1984; Vancouver, 2005), existe un sesgo inherente a que este tipo de escalas debido a que se nutren del conjunto de juicios de los individuos sobre sus propias capacidades (Blanco Blanco, 2010).

Así, se valora la importancia del diseño de instrumentos de evaluación de la competencia alcanzada en un instante temporal concreto, y se hace necesario el estudio pormenorizado de fiabilidad y validez de los ítems y variables latentes que componen cada instrumento.

\subsubsection{Inventario de evaluación de nivel en competencias informacionales}

\section{a) Diseño del instrumento}

En primer lugar, se diseña el instrumento de evaluación conforme a los criterios teóricos que se infieren del análisis del estado de la cuestión de la formación por competencias y las competencias informacionales en la educación secundaria. Así, se decide que el instrumento debe contemplar a nivel vertical cada una de las dimensiones de las competencias informacionales (búsqueda, evaluación, procesamiento y comunicación y difusión de información) y a nivel horizontal cada uno de los componentes de la competencia (saber, saber hacer y saber ser/estar). 
El instrumento se compone finalmente de 87 ítems, estructurados de la manera que se expone a continuación:

- Conceptos básicos sobre competencias informacionales (7 ítems)

- Saber (prueba objetiva): 5 ítems

- Saber hacer (píldoras de desempeño): 2 ítems

- Búsqueda de información (26 ítems)

○ Saber (prueba objetiva): 13 ítems

- Saber hacer

- Escala ordinal: 3 ítems

- Píldoras de desempeño: 2 ítems

○ Saber ser/estar (escala de actitudes): 8 ítems

- Evaluación de información (15 ítems)

○ Saber (prueba objetiva): 6 ítems

- Saber hacer

- Escala ordinal: 3 ítems

- Píldoras de desempeño: 1 ítem

- Saber ser/estar (escala de actitudes): 5 ítems

- Procesamiento de información (18 ítems)

○ Saber (prueba objetiva): 8 ítems

- Saber hacer

- Escala ordinal: 3 ítems

- Píldoras de desempeño: 1 ítem

O Saber ser/estar (escala de actitudes): 6 ítems 
- Comunicación de información (21 ítems)

- Saber (prueba objetiva): 9 ítems

- Saber hacer

- Escala ordinal: 3 ítems

- Píldoras de desempeño: 2 ítems

- Saber ser/estar (escala de actitudes): 7 ítems

Para la aplicación del inventario se decide emplear herramientas online, en concreto la tecnología gratuita Google Docs, que en su opción "form" o "formulario" permite el diseño de cuestionarios y pruebas on-line de fácil acceso y manejo. El hecho de que en la aplicación los sujetos de la muestra deban aportar su nombre, elimina los problemas de validez de este tipo de herramientas asociados con las respuestas cuando los sujetos son anónimos (Serrano Angulo, 2012).

En cuanto a la presentación de los ítems a los sujetos, se les muestra estructurados por componentes de la competencia. En primer lugar tienen que señalizar los datos de identificación, en segundo lugar deben resolver la prueba objetiva (saber), en tercer lugar las escalas ordinales (saber hacer) y las píldoras de desempeño (saber hacer) y por último la escala de actitudes en la que valoran la importancia de algunos ítems relacionados con las competencias informacionales (saber ser/estar).

En la figura 5.9, mostrada más abajo, se puede observar la pantalla de identificación. Los sujetos deben indicar su nombre, apellidos y DNI para continuar. Estos campos son obligatorios, por lo que todos los sujetos deben rellenarlos para continuar con la evaluación. Gracias a estos datos podemos identificar los sujetos del pretest y del postest y cuadrarlos para llevar a cabo los contrastes de hipótesis adecuados. 


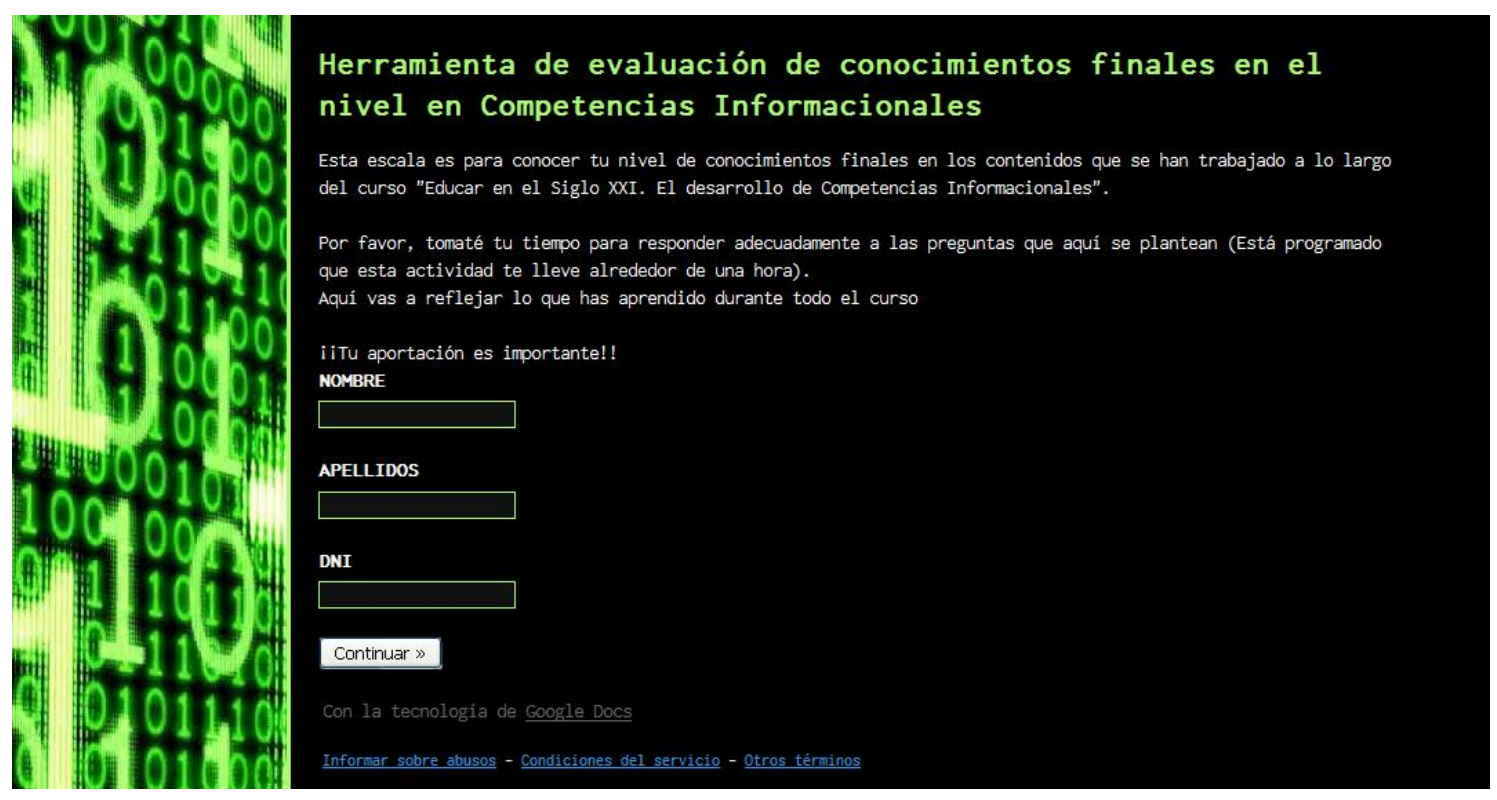

Figura 5.9 Evaluación de nivel en competencias informacionales. Identificación

Como se puede observar, el diseño de la plantilla en la que está incrustado el cuestionario se seleccionó teniendo en cuenta los contenidos trabajados a lo largo del curso. La imagen representa una serie de datos mostrados en código binario, el código habitual de las herramientas informáticas.

Una vez que los alumnos han rellenado los datos de identificación, pasan a la resolución de la prueba objetiva que, como se puede observar en la figura 5.10, y se ha señalado anteriormente, contiene cuatro opciones de respuesta de las cuales sólo una es correcta. 


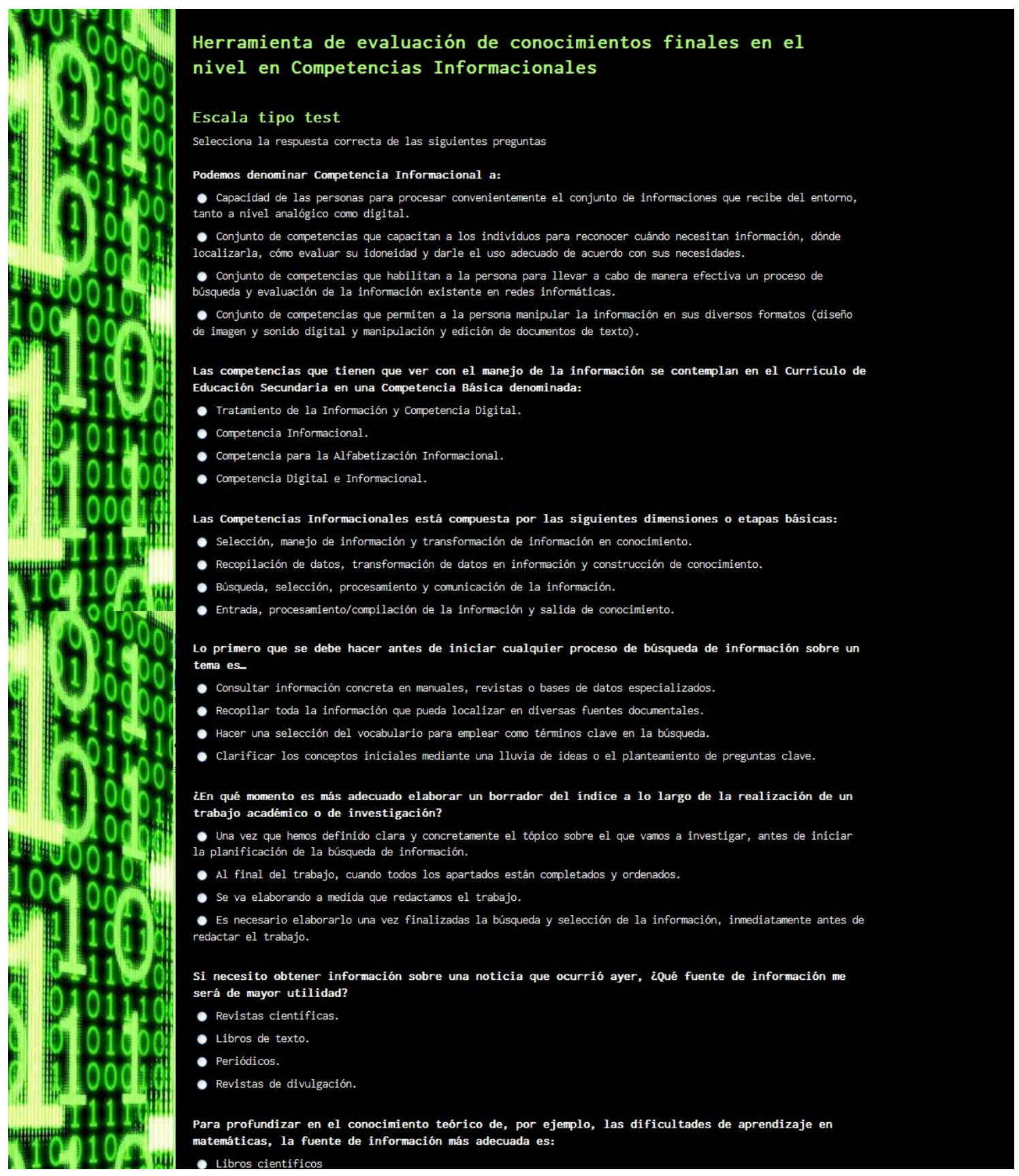

Figura 5.10 Evaluación de nivel en competencias informacionales. Prueba objetiva

Esta prueba objetiva consta de 41 ítems.

Una vez finalizada la prueba objetiva, los sujetos deben resolver las escalas ordinales. La figura 5.11 muestra cómo se presentan de manera desordenada los 4 elementos que los sujetos deben ordenar y mecanografiar en los cuadros de texto habilitados al efecto. 


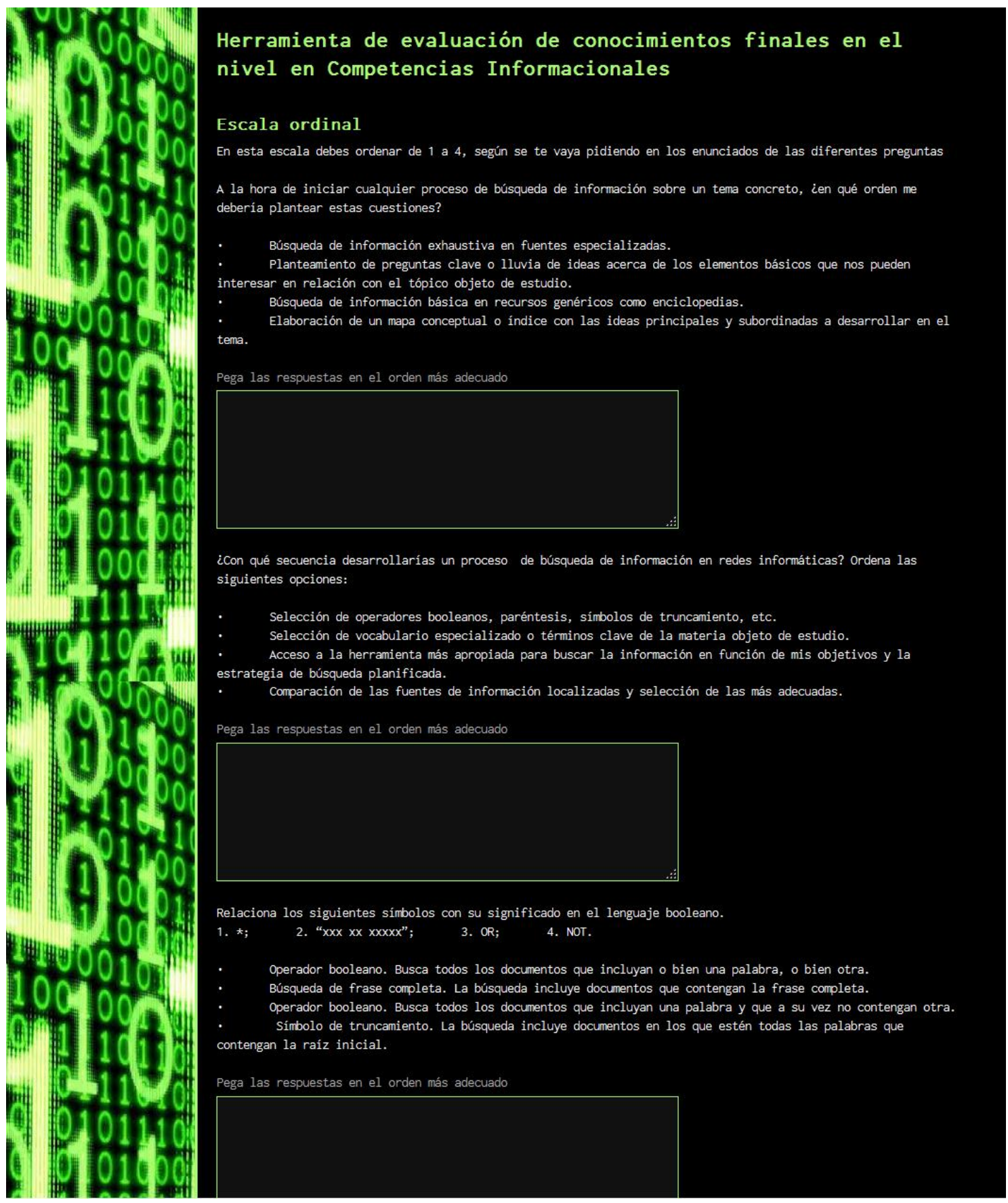

Figura 5.11 Evaluación de nivel en competencias informacionales. Escala ordinal

Como segundo tipo de escalas diseñadas para la evaluación del saber hacer en competencias informacionales, se incorporan las píldoras de desempeño. Para resolverlas se añade un cuadro de texto en el que los sujetos deben añadir su respuesta. Habitualmente, las píldoras de desempeño requieren del evaluando que navegue por internet buscando información, emplee algunas herramientas para realizar tareas, etc., por lo que la realización del inventario permite al usuario emplear todas las aplicaciones del ordenador libremente. 


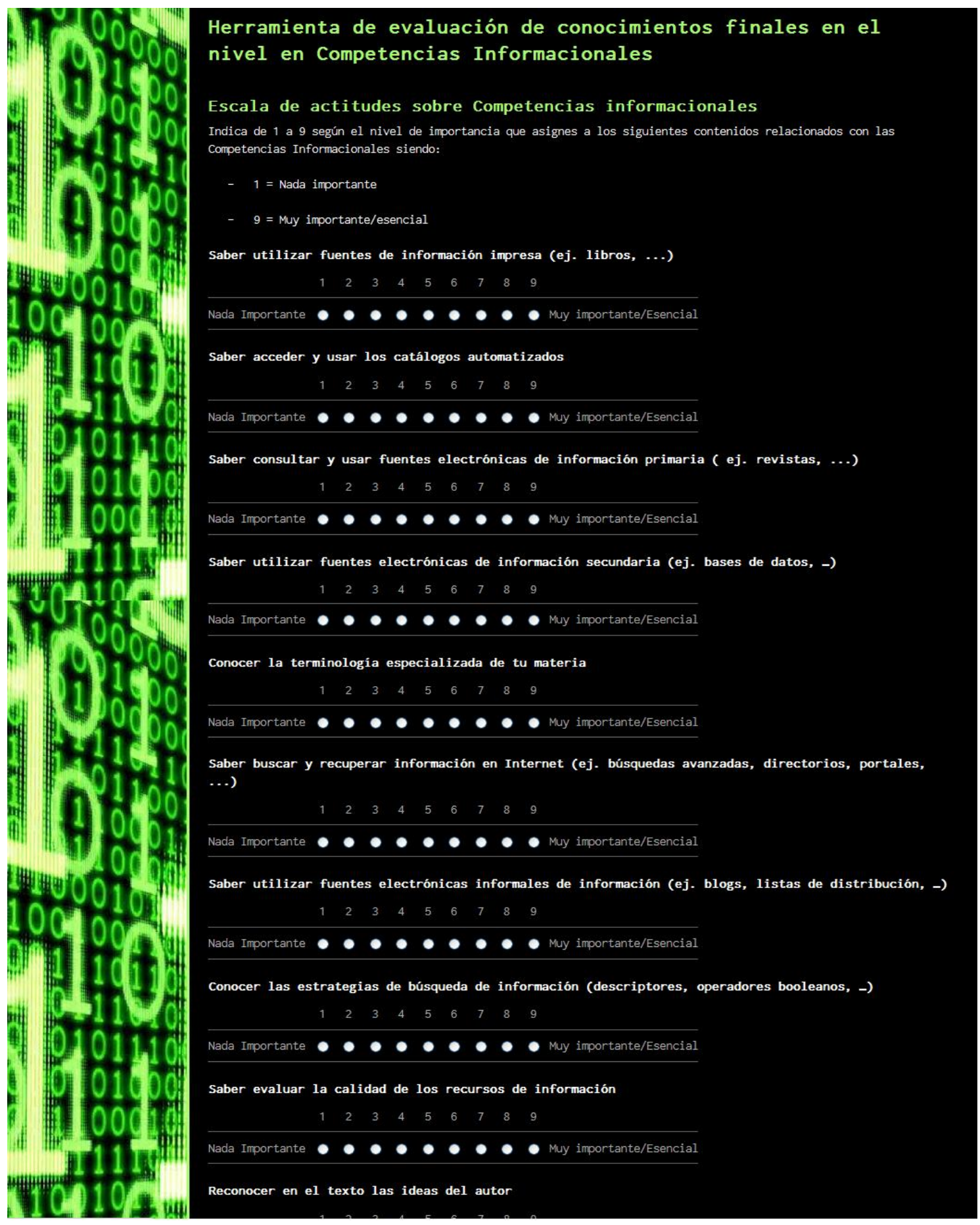

Figura 5.12 Evaluación de nivel en competencias informacionales. Escala de actitudes

Por último, nos encontramos con la escala de actitudes, que, como se muestra en la figura 5.12, contiene 26 ítems provenientes del cuestionario IL-HUMASS (Pinto Molina, 2009). Se extrae la parte del cuestionario que recoge información acerca de la importancia concedida a las competencias informacionales. 


\section{Herramienta de evaluación de conocimientos finales en el nivel en Competencias Informacionales}

Hemos registrado tu respuesta.

Enviar otra respuesta | Crea tu propio formulario.

\section{Google docs}

Figura 5.13 Evaluación de nivel en competencias informacionales. Feedback final

Una vez finalizado el cuestionario, los sujetos reciben un feedback que les indica que se ha enviado correctamente (figura 5.13).

En cuanto a cómo se asignan las puntuaciones para cada una de las escalas, es diferente en función del instrumento diseñado.

- En la prueba objetiva se puntúa con un punto cada acierto y con cero puntos cada no acierto (error o no respuesta). Por otro lado, en el caso de las preguntas erradas, se tiene en cuenta la eliminación de los efectos del azar a partir de la fórmula matemática clásica (A-(E/(K-1)).

O $A=$ =aciertos; $E=$ =errores; $K=N$ No de opciones de respuesta

- En la escala ordinal, dado que a nivel teórico se ha considerado de mayor importancia identificar las fases más relevantes que las que lo son menos, se diseña una escala de 1 a 9 puntos, siendo 1 la puntuación más baja y 9 la más alta. Las puntuaciones que se asignan a cada combinación de puntuaciones se pueden observar más abajo, en la tabla 5.2.

- En cuanto a las píldoras de desempeño, se observa cómo cada una puntúa sobre un máximo de 1 punto. Para evitar la subjetividad asociada a la corrección de esta prueba, que es más cualitativa que cuantitativa, previamente a la aplicación de la misma, se establecen unos criterios de evaluación que objetivan en gran medida las puntuaciones asignadas en estos ítems. Estos criterios se pueden observar en el anexo IV, dónde se enuncian todos los ítems del inventario. 
Tabla 5.2 Plantilla de puntuaciones escala ordinal

\begin{tabular}{c|l}
\hline Valoración & \multicolumn{1}{c}{ Combinaciones } \\
\hline 9 & ABCD \\
\hline 8 & ABDC \\
\hline 7 & ACBD \\
\hline 6 & BACD \\
\hline 5 & ADCB \\
\hline 4 & ADBC, ACDB, CBAD \\
\hline 3 & BCAD, BDCA, DBCA \\
\hline 2 & CABD, CBDA, DBAC, DACB \\
\hline 1 & BADC, BCDA, CADB, CDAB, CDBA, DABC, DCBA, DCAB, BDAC \\
\hline
\end{tabular}

\section{b) Análisis de ítems}

Dada la diferente naturaleza de las escalas (tenemos un conjunto de variables dicotómicas y otras cuantitativas discretas), se deben realizar análisis diferenciados. En primer lugar, se calculará el índice de dificultad y el índice de discriminación de cada ítem de la prueba objetiva y los índices de fiabilidad basados en el cálculo del coeficiente de Kuder-Richardson (Kuder \& Richardson, 1937) de cada una de las dimensiones y del cuestionario completo.

Por otro lado, se analizarán los estadísticos total-elemento para las escalas de actitudes, y sus coeficientes de fiabilidad.

Comencemos, por tanto, con el análisis de la prueba objetiva. Para el cálculo de los estadísticos señalados, se obtienen los datos de la primera muestra, de 48 sujetos en total, que realizan el pretest completo.

Tabla 5.3 Clasificación dificultad de ítems

\begin{tabular}{c|l}
\hline Frecuencia \% & \multicolumn{1}{c}{ Dificultad } \\
\hline $0-15$ & Muy difícil \\
\hline $15-40$ & Difícil \\
\hline $40-60$ & Moderada \\
\hline $60-85$ & Fácil \\
\hline $85-100$ & Muy fácil \\
\hline
\end{tabular}


Para la valoración de los valores del índice de dificultad, entendido como la puntuación media en el ítem, tomaremos la clasificación indicada Por Pomés y Argüelles (1991, p. 50), que se indica en la tabla 5.3.

Una prueba bien diseñada, para ser proporcionada debería tener un buen número de ítems de dificultad moderada, un porcentaje similar de ítems fáciles y difíciles y pocos ítems muy fáciles o muy difíciles.

Tabla 5.4 Índice de dificultad de ítems. Prueba objetiva

\begin{tabular}{|c|c|c|}
\hline Ítem & Índice dificultad \% & Dificultad \\
\hline Ítem 01 & $55.56 \%$ & Moderada \\
\hline Ítem 02 & $72.92 \%$ & Fácil \\
\hline Ítem 03 & $72.22 \%$ & Fácil \\
\hline Ítem 04 & $48.61 \%$ & Moderada \\
\hline Ítem 05 & $66.67 \%$ & Fácil \\
\hline Ítem 06 & $43.75 \%$ & Moderada \\
\hline Ítem 07 & $39.58 \%$ & Difícil \\
\hline Ítem 08 & $95.83 \%$ & Muy fácil \\
\hline Ítem 09 & $52.08 \%$ & Moderada \\
\hline Ítem 10 & $58.33 \%$ & Moderada \\
\hline Ítem 11 & $81.25 \%$ & Fácil \\
\hline Ítem 12 & $33.33 \%$ & Difícil \\
\hline Ítem 13 & $29.17 \%$ & Difícil \\
\hline Ítem 14 & $27.08 \%$ & Difícil \\
\hline Ítem 15 & $62.50 \%$ & Fácil \\
\hline Ítem 16 & $47.92 \%$ & Moderada \\
\hline Ítem 17 & $85.42 \%$ & Muy fácil \\
\hline Ítem 18 & $68.75 \%$ & Fácil \\
\hline Ítem 19 & $58.33 \%$ & Moderada \\
\hline Ítem 20 & $66.67 \%$ & Fácil \\
\hline Ítem 21 & $64.58 \%$ & Fácil \\
\hline Ítem 22 & $39.58 \%$ & Difícil \\
\hline Ítem 23 & $31.25 \%$ & Difícil \\
\hline Ítem 24 & $68.75 \%$ & Fácil \\
\hline Ítem 25 & $60.42 \%$ & Fácil \\
\hline
\end{tabular}




\begin{tabular}{l|l|l}
\hline Ítem 26 & $37.50 \%$ & Difícil \\
\hline Ítem 27 & $79.17 \%$ & Fácil \\
\hline Ítem 28 & $31.25 \%$ & Difícil \\
\hline Ítem 29 & $60.42 \%$ & Moderada \\
\hline Ítem 30 & $70.83 \%$ & Fácil \\
\hline Ítem 31 & $85.42 \%$ & Muy fácil \\
\hline Ítem 32 & $77.08 \%$ & Fácil \\
\hline Ítem 33 & $47.92 \%$ & Moderada \\
\hline Ítem 34 & $56.25 \%$ & Moderada \\
\hline Ítem 35 & $87.50 \%$ & Muy fácil \\
\hline Ítem 36 & $25.00 \%$ & Difícil \\
\hline Ítem 37 & $97.92 \%$ & Muy fácil \\
\hline Ítem 38 & $64.58 \%$ & Fácil \\
\hline Ítem 39 & $75.00 \%$ & Fácil \\
\hline Ítem 40 & $12.50 \%$ & Muy difícil \\
\hline Ítem 41 & $50.00 \%$ & Moderada \\
\hline
\end{tabular}

La tabla 5.4 indica la distribución de nuestros ítems en cuanto al índice de dificultad. Encontramos 5 ítems muy fáciles, 15 fáciles, 11 de dificultad moderada, 9 difíciles y 1 muy difícil. Dada esta clasificación, se observa cómo el test tiene una dificultad moderada.

A continuación, se estudia el índice de discriminación ítem-dimensión a partir del cálculo del índice de correlación biserial-puntual. La valoración de los índices, en función de los valores obtenidos será la que se muestra en la tabla 5.5 (Pomés \& Argüelles, 1991).

Tabla 5.5 Clasificación discriminación de ítems

\begin{tabular}{c|l}
\hline Frecuencia $(\mathbf{p})$ & \multicolumn{1}{c}{ Discriminación } \\
\hline $.0-.14$ & No discrimina \\
\hline $.15-.29$ & Discrimina poco \\
\hline $.30-.49$ & Discrimina bien \\
\hline $.5-1$ & Discrimina muy bien \\
\hline
\end{tabular}

Así, se considerarán candidatos a ser eliminados aquellos ítems que se encuentren en el primer rango de valores, con lo que se entienda que no discriminan. La decisión 
final sobre la eliminación de ítems con índices deficitarios se tomará en función tanto de los criterios estadísticos extraídos de los resultados obtenidos en el cálculo de los índices de discriminación y dificultad, como de criterios teóricos provenientes del estudio del estado de la cuestión.

Tabla 5.6 Índice de discriminación de ítems. Prueba objetiva

\begin{tabular}{|c|c|c|}
\hline Ítem & Índice discriminación & Discriminación \\
\hline Ítem 01 & .173 & Discrimina poco \\
\hline Ítem 02 & .323 & Discrimina bien \\
\hline Ítem 03 & .151 & Discrimina poco \\
\hline Ítem 04 & .032 & No discrimina \\
\hline Ítem 05 & .077 & No discrimina \\
\hline Ítem 06 & .273 & Discrimina poco \\
\hline Ítem 07 & .357 & Discrimina bien \\
\hline Ítem 08 & .252 & Discrimina poco \\
\hline Ítem 09 & .058 & No discrimina \\
\hline Ítem 10 & .323 & Discrimina bien \\
\hline Ítem 11 & .182 & Discrimina poco \\
\hline Ítem 12 & .372 & Discrimina bien \\
\hline Ítem 13 & .356 & Discrimina bien \\
\hline Ítem 14 & .339 & Discrimina bien \\
\hline Ítem 15 & .569 & Discrimina muy bien \\
\hline Ítem 16 & .187 & Discrimina poco \\
\hline Ítem 17 & .468 & Discrimina bien \\
\hline Ítem 18 & .456 & Discrimina bien \\
\hline Ítem 19 & .236 & Discrimina poco \\
\hline Ítem 20 & .535 & Discrimina muy bien \\
\hline Ítem 21 & .475 & Discrimina bien \\
\hline Ítem 22 & .333 & Discrimina bien \\
\hline Ítem 23 & .396 & Discrimina bien \\
\hline Ítem 24 & .571 & Discrimina muy bien \\
\hline Ítem 25 & .322 & Discrimina bien \\
\hline Ítem 26 & .543 & Discrimina muy bien \\
\hline Ítem 27 & .527 & Discrimina muy bien \\
\hline
\end{tabular}




\begin{tabular}{l|l|l}
\hline Ítem 28 & .343 & Discrimina bien \\
\hline Ítem 29 & .353 & Discrimina bien \\
\hline Ítem 30 & .367 & Discrimina bien \\
\hline Ítem 31 & .380 & Discrimina bien \\
\hline Ítem 32 & .296 & Discrimina poco \\
\hline Ítem 33 & .593 & Discrimina muy bien \\
\hline Ítem 34 & .335 & Discrimina bien \\
\hline Ítem 35 & .444 & Discrimina bien \\
\hline Ítem 36 & .450 & Discrimina bien \\
\hline Ítem 37 & .016 & No discrimina \\
\hline Ítem 38 & .567 & Discrimina muy bien \\
\hline Ítem 39 & .536 & Discrimina muy bien \\
\hline Ítem 40 & .182 & Discrimina poco \\
\hline Ítem 41 & .631 & Discrimina muy bien \\
\hline
\end{tabular}

Como se muestra en la tabla 5.6, de los 41 ítems que componen la escala inicial, 9 discriminan poco, 19 discriminan bien y 9 discriminan muy bien. Por su parte, los 4 ítems restantes no discriminan. Estos 4 ítems con índices de discriminación inferiores a lo aceptable son los siguientes:

- $\quad$ 04. El Big 6 consiste en...

- 05 . El método científico general, necesario para el desarrollo de procesos de investigación, consta de las siguientes fases:

- 09. Para profundizar en el conocimiento teórico de, por ejemplo, las dificultades de aprendizaje en matemáticas, la fuente de información más adecuada es...

- 37. En cuanto a la redacción de un informe de cualquier proceso de investigación o trabajo, ¿Qué pautas se siguen generalmente?

Dada la naturaleza de los ítems incluidos entre los que no discriminan, se decide eliminar los cuatro. En primer lugar, el ítem 04 se refiere a un conocimiento teórico sobre un modelo concreto para la enseñanza de competencias informacionales, lo cual no se considera un conocimiento esencial. El ítem 05 se refiere al método científico, por lo que se refiere a conocimientos relacionados con las competencias 
informacionales, pero no esenciales para el dominio de las mismas. Analizando detenidamente el ítem 09, se observa cómo su respuesta se presta a diferentes interpretaciones, no quedando suficientemente claro cuál es la respuesta correcta. Por último, el ítem 37 parece importante a nivel teórico, pero dado el índice de dificultad del mismo del $97.32 \%$, se entiende que es extremadamente simple y que no discrimina en absoluto, por lo que no tiene sentido incluirlo en la escala.

En cuanto a la fiabilidad, dado que los ítems son cualitativos dicotómicos y muestran índices de dificultad o medias diferentes, emplearemos el cálculo del $K R_{20}$ (Kuder \& Richardson, 1937).

Tabla 5.7 Índice de fiabilidad de ítems. Prueba objetiva

\begin{tabular}{l|l}
\hline \multicolumn{1}{c|}{ Escala } & $\mathbf{K R}_{\mathbf{2 0}}$ \\
\hline Búsqueda de información (12 ítems) & .655 \\
\hline Evaluación de información (6 ítems) & .487 \\
\hline $\begin{array}{l}\text { Procesamiento de información (8 ítems) } \\
\text { Comunicación y difusión de información } \\
\text { (8 ítems) }\end{array}$ & .554 \\
\hline Prueba objetiva (37 ítems) & .712 \\
\hline
\end{tabular}

La tabla 5.7 muestra índices de fiabilidad dispares para cada una de las dimensiones. Sin embargo, la fiabilidad de la escala completa es alta (>.70).

En lo que respecta las escalas generadas a partir de las respuestas en las que los sujetos debían ordenar los datos (ordinales) y las píldoras de desempeño, al disponer de pocos ítems por dimensión, se considera poco recomendable llevar a cabo un análisis de ítems de la naturaleza del que aquí se está implementando.

Por último, se analizan los ítems de la escala de actitudes. Al tratarse de dimensiones con escalas continuas, se analizarán los estadísticos inter-ítem y la fiabilidad a partir del estadístico alfa de Cronbach. 
Tabla 5.8 Estadísticos total-elemento búsqueda de información. Escala de actitudes.

\begin{tabular}{lc|c|c|c}
\hline \multicolumn{1}{c|}{ Estadísticos total-elemento } & $\begin{array}{c}\text { Media sin el } \\
\text { elemento }\end{array}$ & $\begin{array}{c}\text { Var. sin el } \\
\text { elemento }\end{array}$ & $\begin{array}{c}\text { Correlac. } \\
\text { elem-total } \\
\text { corregida }\end{array}$ & $\begin{array}{c}\text { Correlac. } \\
\text { múltiple al } \\
\text { cuadrado }\end{array}$ \\
\hline $\begin{array}{l}\text { Utilizar fuentes de información } \\
\text { impresa }\end{array}$ & 54.29 & 64.437 & .462 & .474 \\
\hline $\begin{array}{l}\text { Acceder y usar los catálogos } \\
\text { automatizados }\end{array}$ & 54.22 & 58.268 & .749 & .606 \\
\hline $\begin{array}{l}\text { Usar fuentes electrónicas de } \\
\text { información primaria }\end{array}$ & 53.91 & 62.946 & .677 & .652 \\
\hline $\begin{array}{l}\text { Utilizar fuentes electrónicas de } \\
\text { información secundaria }\end{array}$ & 54.38 & 56.831 & .729 & .605 \\
\hline $\begin{array}{l}\text { Conocer la terminología } \\
\text { especializada de tu materia }\end{array}$ & 54.33 & 56.136 & .713 & .582 \\
\hline $\begin{array}{l}\text { Buscar y recuperar información } \\
\text { en internet }\end{array}$ & 54.20 & 56.391 & .765 & .689 \\
\hline $\begin{array}{l}\text { Utilizar fuentes electrónicas } \\
\text { informales de información }\end{array}$ & 55.42 & 56.477 & .521 & .321 \\
\hline $\begin{array}{l}\text { Conocer las estrategias de } \\
\text { búsqueda de información }\end{array}$ & 54.49 & 52.710 & .687 & .635 \\
\hline
\end{tabular}

En primer lugar, como se señala en la tabla 5.8, nos encontramos con índices de correlación ítem-total aceptables (>.45) en todos los casos (L. Cohen \& Manion, 2002).

Tabla 5.9 Estadísticos total-elemento evaluación de información. Escala de actitudes.

\begin{tabular}{lc|c|c|c}
\hline \multicolumn{1}{c|}{ Estadísticos total-elemento } & $\begin{array}{c}\text { Media sin el } \\
\text { elemento }\end{array}$ & $\begin{array}{c}\text { Var. sin el } \\
\text { elemento }\end{array}$ & $\begin{array}{c}\text { Correlac. } \\
\text { elem-total } \\
\text { corregida }\end{array}$ & $\begin{array}{c}\text { Correlac. } \\
\text { múltiple al } \\
\text { cuadrado }\end{array}$ \\
\hline $\begin{array}{l}\text { Saber evaluar la calidad de los } \\
\text { recursos de información }\end{array}$ & 29.79 & 22.807 & .702 & .514 \\
\hline $\begin{array}{l}\text { Reconocer en el texto las ideas } \\
\text { del autor }\end{array}$ & 30.13 & 25.176 & .530 & .327 \\
\hline $\begin{array}{l}\text { Conocer la tipología de las } \\
\text { fuentes de información }\end{array}$ & 30.88 & 21.048 & .664 & .516 \\
\hline $\begin{array}{l}\text { Determinar si la información } \\
\text { está actualizada }\end{array}$ & 30.17 & 24.057 & .707 & .581 \\
\hline Conocer los autores o & 30.63 & 21.899 & .699 & .514 \\
\hline
\end{tabular}


instituciones más relevantes

En lo que respecta a los índices de correlación ítem-total en la dimensión de evaluación de información (tabla 5.9), nos encontramos también con valores aceptables en todos los casos.

Tabla 5.10 Estadísticos total-elemento procesamiento de información. Escala de actitudes.

\begin{tabular}{lc|c|c|c}
\hline \multicolumn{1}{c|}{ Estadísticos total-elemento } & $\begin{array}{c}\text { Media sin el } \\
\text { elemento }\end{array}$ & $\begin{array}{c}\text { Var. sin el } \\
\text { elemento }\end{array}$ & $\begin{array}{c}\text { Correlac. } \\
\text { elem-total } \\
\text { corregida }\end{array}$ & $\begin{array}{c}\text { Correlac. } \\
\text { múltiple al } \\
\text { cuadrado }\end{array}$ \\
\hline $\begin{array}{l}\text { Resumir y esquematizar la } \\
\text { información }\end{array}$ & 34.98 & 41.152 & .354 & .665 \\
\hline $\begin{array}{l}\text { Reconocer la estructuración de } \\
\text { un texto }\end{array}$ & 35.40 & 40.985 & .333 & .600 \\
\hline $\begin{array}{l}\text { Usar gestores de bases de } \\
\text { datos }\end{array}$ & 36.09 & 32.601 & .586 & .644 \\
\hline $\begin{array}{l}\text { Usar gestores de referencias } \\
\text { bibliográficas }\end{array}$ & 36.23 & 30.879 & .605 & .725 \\
\hline $\begin{array}{l}\text { Manejar programas } \\
\text { estadísticos y hojas de cálculo }\end{array}$ & 36.21 & 29.780 & .688 & .545 \\
\hline \begin{tabular}{l} 
Instalar programas $\begin{array}{l}\text { informáticos } \\
\text { inf }\end{array}$ \\
\hline
\end{tabular}
\end{tabular}

En cuanto a la dimensión de procesamiento de información (tabla 5.10), nos encontramos en el segundo ítem "reconocer la estructuración de un texto" con un valor de discriminación inferior, aunque cercano, al mínimo señalado. Dada la importancia teórica asignada a dicho ítem, no se sopesa la posibilidad de eliminarlo para llevar a cabo los análisis posteriores.

Tabla 5.11 Estadísticos total-elemento comunicación y difusión de información. Escala de actitudes.

\begin{tabular}{lc|c|c|c}
\hline \multicolumn{1}{c}{ Estadísticos total-elemento } & $\begin{array}{c}\text { Media sin el } \\
\text { elemento }\end{array}$ & $\begin{array}{c}\text { Var. sin el } \\
\text { elemento }\end{array}$ & $\begin{array}{c}\text { Correlac. } \\
\text { elem-total } \\
\text { corregida }\end{array}$ & $\begin{array}{c}\text { Correlac. } \\
\text { múltiple al } \\
\text { cuadrado }\end{array}$ \\
\hline Comunicar en público & 46.31 & 38.128 & .559 & .548 \\
\hline Comunicar en otros idiomas & 46.27 & 41.291 & .439 & .388 \\
\hline Redactar un documento & 45.98 & 37.931 & .622 & .592 \\
\hline $\begin{array}{l}\text { Conocer el código ético de tu } \\
\text { ámbito académico/profesional }\end{array}$ & 46.60 & 35.700 & .635 & .589 \\
\hline
\end{tabular}




\begin{tabular}{lc|c|c|c}
\hline $\begin{array}{l}\text { Uso de la información y de la } \\
\text { propiedad intelectual }\end{array}$ & 46.96 & 32.953 & .548 & .536 \\
\hline $\begin{array}{l}\text { Hacer presentaciones } \\
\text { académicas }\end{array}$ & 46.71 & 38.619 & .561 & .363 \\
\hline $\begin{array}{l}\text { Difundir la información en } \\
\text { internet }\end{array}$ & 46.78 & 35.040 & .527 & .439 \\
\hline
\end{tabular}

Por último, la tabla 5.11 muestra los estadísticos total-elemento para la dimensión de comunicación y difusión de información. Nos volvemos a encontrar con valores más que aceptables. Así, se incluyen definitivamente todos los ítems de las 4 dimensiones que abarca la escala de actitudes.

Tabla 5.12 Índice de fiabilidad de ítems. Escala de actitudes

\begin{tabular}{l|c}
\hline \multicolumn{1}{c|}{ Escala } & $\alpha$ de Cronbach \\
\hline Búsqueda de información (8 ítems) & .880 \\
\hline Evaluación de información (5 ítems) & .847 \\
\hline $\begin{array}{l}\text { Procesamiento de información (6 ítems) } \\
\text { Comunicación y difusión de información }\end{array}$ & .783 \\
\hline (7 ítems) & .808 \\
\hline Escala de actitudes (37 ítems) & .941 \\
\hline
\end{tabular}

La tabla 5.12, que indica los valores de fiabilidad de las dimensiones de la escala de actitudes, entendida la fiabilidad como consistencia interna ( $\alpha$ de Cronbach), muestra que en todas las dimensiones se obtiene un valor superior al mínimo exigible (>.7), por lo que nos encontramos con escalas consistentes.

\section{c) Validez de las escalas}

En lo que respecta a la validez, en este caso concreto se trata de asegurar a través de la validez de contenido a través del análisis de contenido llevado a cabo por jueces externos.

Se seleccionan un total de 9 jueces, expertos en distintos campos relacionados afines a la evaluación de competencias informacionales:

- Un profesor titular en el Departamento de Psicología Básica, Evolutiva y de la Educación de la Universidad Autónoma de Barcelona y un ayudante doctor del Departamento de Teoría e Historia de la Educación de la 
Universidad de Salamanca, especialistas en los procesos y perfiles de búsqueda y evaluación de información en educación.

- Un profesor titular en el Departamento de Didáctica, Organización y Métodos de Investigación de la Universidad de Salamanca y un ayudante doctor en el Departamento de Didáctica, Organización y Métodos de Investigación de la Universidad de Salamanca, expertos en evaluación de competencias en educación básica y universitaria.

- Un profesor catedrático de universidad en el Departamento de Biblioteconomía y Documentación de la Universidad de Granada y un Profesor Titular de Universidad en el Departamento de Biblioteconomía y Documentación de la Universidad de Salamanca, expertos en alfabetización informacional y gestión de la información.

- Un profesor titular de universidad en el Departamento de Informática y Automática de la Universidad de Salamanca, experto en redes informáticas y web 2.0.

- Un profesor de filosofía y orientador en un centro educativo de la provincia de Salamanca y un profesor de tecnología en un centro educativo de educación secundaria en Salamanca, expertos en el desarrollo de competencias básicas en Educación Secundaria Obligatoria.

Una vez realizado el contacto con los jueces, se les facilita una herramienta para la evaluación de los ítems y las dimensiones asociadas a los mismos. Dicho proceso de evaluación se desarrolla en 3 etapas, situadas de manera que se facilite el razonamiento inductivo en las valoraciones realizadas. Dado que la escala de actitudes ya está validada previamente, no se incluye dentro de la propia herramienta de validación. Las 3 etapas se desarrollan como se describe a continuación.

1. Valoración de la calidad de cada uno de los ítems de manera independiente. En esta primera etapa, se pide que se valore cada uno de los ítems de los instrumentos conforme a 3 criterios (En una escala de 1 a 5):

a. Pertinencia: Correspondencia entre el contenido del ítem y la dimensión para la cual va a ser utilizado.

b. Relevancia: Grado de importancia del ítem en la explicación de la dimensión. 
c. Claridad: El ítem está redactado de forma clara y precisa, facilitando su comprensión por los sujetos encuestados.

Junto a estos 3 criterios, se incluirá el apartado "Comentarios/formulación alternativa", en el que se permite hacer comentarios, observaciones y plantear modos alternativos de formular los ítems que se consideren inadecuados por su falta de pertinencia, relevancia y/o claridad.

2. Valoración de la calidad de cada una de las dimensiones. La segunda etapa consiste en evaluar cada dimensión en conjunto, esto es, si los ítems de los diferentes instrumentos incluidos en la dimensión ' $x$ ' sirven, en conjunto, para valorar la dimensión global. Así, se incluyen en esta etapa los siguientes criterios:

a. Validez de la dimensión (Escala de 1 a 5): Grado en el que los ítems de la dimensión, en conjunto, explican la dimensión a la que pertenecen.

b. Puntos fuertes/débiles (A nivel de contenido): Aspectos en los que se basa la solidez de la dimensión conformada; deficiencias a subsanar.

c. Observaciones: Espacio reservado para realizar cualquier tipo de comentario acerca de la dimensión en general, de las relaciones entre los ítems, del solapamiento entre contenidos, etc.

3. Valoración de la calidad global de los instrumentos. En la última etapa se indica que se aporte el punto de vista personal experto para valorar la capacidad global de los instrumentos para evaluar el nivel de desarrollo de competencias informacionales. Se incluyen los siguientes criterios:

a. Adecuación (Escala 1 a 5): En qué medida los instrumentos se adaptan al modelo de formación basado en competencias.

b. Relevancia de las dimensiones (Escala 1 a 5): Grado en que cada una de las dimensiones colabora en la explicación de las competencias informacionales.

c. Validez de la herramienta (Escala 1 a 5): Grado en que las dimensiones, en conjunto, ayudan en la explicación del constructo competencias informacionales.

d. Puntos fuertes/débiles (A nivel de contenido): Aspectos en los que se basa la solidez de los instrumentos; deficiencias que deberían ser subsanadas. 
e. Observaciones: Comentarios acerca de los instrumentos, relaciones entre dimensiones, etc.

El conjunto de tablas que deben cumplimentar los jueces para llevar a cabo el proceso de validación de la herramienta se pueden consultar completas en el anexo $\mathrm{V}$.

Una vez llevado a cabo el proceso de validación por los jueces, se procede a la evaluación de los resultados y la modificación de la escala para adaptarla a las indicaciones de los propios expertos. En este aspecto, mientras que a nivel global el instrumento y las dimensiones son valorados muy positivamente, en el análisis ítem por ítem es en el que se llevan a cabo los cambios más profundos.

La claridad es el aspecto en el que se llevan a cabo más modificaciones en los ítems, ya que, a juicio de los expertos, varios de ellos se expresan de manera poco clara y/o tanto la respuesta correcta como los distractores están enunciados en ocasiones de manera intrincada. Estos ítems se ven sometidos únicamente a cambios de forma y no de fondo. Los ítems que sufren cambios en este aspecto por indicaciones de alguno o varios de los expertos son:

- OBJ2, OBJ3, OBJ5, OBJ6, OBJ7, OBJ8, OBJ9, OBJ10, OBJ14, OBJ15, OBJ20, OBJ21, OBJ22, OBJ23, OBJ24, OBJ26, OBJ31, OBJ32, OBJ35, OBJ38, ORD1, ORD2, ORD3, ORD4, ORD9.

Por otro lado, nos encontramos con ítems que son mejorables en cuanto a la relevancia individual en la explicación de la dimensión de referencia. En estos casos, se amplía el enunciado modificando algunos aspectos de contenido y/o se mejoran los distractores y la propia respuesta correcta. Nos encontramos con cambios de este tipo en los siguientes ítems:

- OBJ1, OBJ4, OBJ11, OBJ12, OBJ13, OBJ19, OBJ25, OBJ33, OBJ36, OBJ37, ORD6.

Por último, algunos de los ítems muestras índices bajos de pertinencia, esto es, que indican poca correspondencia entre el ítem y la dimensión a la que pertenecen. En estos casos se plantea o bien la eliminación del ítem o bien la modificación completa del contenido del mismo. Al encontrar indicaciones concretas de los expertos en los dos casos en los que se da esta situación, se procede a la modificación profunda del contenido de los ítems en ambos casos. Los ítems que sufren esta modificación son los siguientes: 
- OBJ27, OBJ28.

\subsubsection{Población y muestra. Estudio experimental}

Partiendo de la población referente, que no es otra que el grupo de alumnos que en el curso 2011-2012 están estudiando el Máster Universitario en Profesor de Educación Secundaria Obligatoria, Bachillerato, Formación Profesional y Enseñanza de Idiomas en la Universidad de Salamanca, nos encontramos con un tamaño poblacional de $\mathrm{N}=244$. Así se puede calcular el tamaño mínimo de muestra a partir del cálculo del tamaño muestral para poblaciones finitas (Arnal et al., 1992),

$$
n=\frac{N * Z_{\alpha}^{2} * p * q}{d^{2} *(N-1)+Z_{\alpha}^{2} * p * q}
$$

en donde:

$\mathrm{N}=$ Total de la población

$\mathrm{Z}_{\alpha}=$ Valor $\mathrm{Z}$ para un nivel de confianza $1-\alpha$

$p=$ proporción esperada del parámetro a estudiar

$q=1-p$

$\mathrm{d}$ = nivel de error máximo admitido

Aplicando esta fórmula, con un nivel de significación $\alpha=.05$, una $p=q=.5$ (ya que no conocemos el valor aproximado del parámetro a estudiar) y un error máximo del 3\%, se obtiene un tamaño muestral mínimo de 198 sujetos.

Dada la naturaleza del presente estudio, de corte experimental con medida pretest-postest mediante la aplicación de un tratamiento, no se dispone de recursos suficientes para atender a un tamaño de muestra tan grande. Así, para asegurar la representatividad de la muestra, en lugar de aplicar el criterio del cálculo del tamaño muestral, se contrasta la hipótesis de correspondencia con la distribución teórica a partir de la prueba de bondad de ajuste (basada en Chi cuadrado). Por otro lado, para contrastar el cumplimiento de la aleatoridad de las variables

La distribución de la población diana por especialidad es la siguiente (tabla 5.13). 
Tabla 5.13 Distribución de la población de alumnos del Máster

\begin{tabular}{r|c|c}
\hline \multicolumn{1}{|c|}{ Especialidad } & Población $\left(\mathbf{f}_{\mathbf{i}}\right)$ & Población (\%) \\
\hline Física y Química & 15 & $6.15 \%$ \\
\hline Biología y Geología & 25 & $10.25 \%$ \\
\hline Idiomas & 59 & $24.18 \%$ \\
\hline Lengua y Literatura & 20 & $8.20 \%$ \\
\hline Matemáticas & 12 & $4.92 \%$ \\
\hline Orientación & 11 & $4.51 \%$ \\
\hline Formación profesional & 29 & $11.89 \%$ \\
\hline Tecnología y Dibujo & 34 & $13.93 \%$ \\
\hline Filosofía y Música & 17 & $6.97 \%$ \\
\hline Geografía e Historia & 22 & $9.02 \%$ \\
\hline TOTAL & $\mathbf{2 4 4}$ & $100 \%$ \\
\hline
\end{tabular}

Teniendo en cuenta que se obtiene una muestra inicial de 50 futuros profesores de los que, por diversas circunstancias, finalizan el curso 36 sujetos, las frecuencias teóricas y empíricas resultantes son las siguientes (tabla 5.14).

Tabla 5.14 Distribución de la muestra de alumnos del Máster

\begin{tabular}{r|c|c|c}
\hline \multicolumn{1}{|c|}{ Especialidad } & $\begin{array}{c}\text { Frecuencia } \\
\text { teórica }\end{array}$ & $\begin{array}{c}\text { Frecuencia } \\
\text { empírica }\end{array}$ & $\frac{\left(\boldsymbol{f}_{\boldsymbol{e}}-\boldsymbol{f}_{\boldsymbol{t}}\right)^{\mathbf{2}}}{\boldsymbol{f}_{\boldsymbol{t}}}$ \\
\hline Física y Química & 2.21 & 3 & 0.28 \\
\hline Biología y Geología & 3.69 & 5 & 0.47 \\
\hline Idiomas & 8.70 & 10 & 0.19 \\
\hline Lengua y Literatura & 2.95 & 3 & 0.00 \\
\hline Matemáticas & 1.77 & 1 & 0.34 \\
\hline Orientación & 1.62 & 2 & 0.09 \\
\hline Formación profesional & 4.28 & 4 & 0.02 \\
\hline Tecnología y Dibujo & 5.02 & 4 & 0.21 \\
\hline Filosofía y Música & 2.51 & 2 & 0.10 \\
\hline Geografía e Historia & 3.25 & 2 & 0.48 \\
\hline TOTAL & $\mathbf{3 6}$ & $\mathbf{3 6}$ & $\mathbf{2 . 1 7}$ \\
\hline
\end{tabular}


Dado que, el valor del estadístico de contraste $\chi_{9 ; .05}^{2}=16.919>\chi^{2}=2.17$, se acepta $\mathrm{H}_{0}$, y no se puede rechazar la hipótesis de que la distribución muestral se ajusta a la poblacional en este caso.

Por último, para asegurar empíricamente la aleatoriedad de la muestra, se procede a la aplicación de la prueba de rachas para cada una de las variables del estudio.

Tabla 5.15 Prueba de rachas para las variables del inventario

\begin{tabular}{|c|c|c|c|c|}
\hline \multirow{2}{*}{ Variable } & \multicolumn{2}{|c|}{ Pretest } & \multicolumn{2}{|c|}{ Postest } \\
\hline & $z$ & p. & $z$ & p. \\
\hline Prueba objetiva básico & 0.455 & .649 & 0.911 & .362 \\
\hline Prueba objetiva búsqueda & 1.618 & .106 & 0.188 & .850 \\
\hline Prueba objetiva evaluación & .089 & .929 & 0.000 & 1.000 \\
\hline Prueba objetiva procesamiento & 0.845 & .398 & -0.829 & .407 \\
\hline Prueba objetiva comunicación & -0.191 & .849 & 0.000 & 1.000 \\
\hline Ordinal búsqueda & -0.169 & .866 & -0.955 & .340 \\
\hline Ordinal evaluación & -0.169 & .866 & 0.169 & .866 \\
\hline Ordinal procesamiento & -0.507 & .612 & -0.169 & .866 \\
\hline Ordinal comunicación & -0.574 & .566 & 0.000 & 1.000 \\
\hline Píldoras básico & -0.845 & .398 & -0.169 & .866 \\
\hline Píldoras búsqueda & 0.327 & .744 & 0.191 & .849 \\
\hline Píldoras evaluación & 0.000 & 1.000 & -1.250 & .211 \\
\hline Píldoras procesamiento & -0.041 & .967 & 0.448 & .654 \\
\hline Píldoras comunicación & -0.095 & .924 & 0.247 & .805 \\
\hline Actitudes búsqueda & 0.000 & 1.000 & 0.696 & .486 \\
\hline Actitudes evaluación & 1.618 & .106 & 0.348 & .728 \\
\hline Actitudes procesamiento & 0.000 & 1.000 & 0.590 & .555 \\
\hline Actitudes comunicación & 0.528 & .598 & 0.590 & .555 \\
\hline Total prueba objetiva & 0.188 & .850 & -0.169 & .866 \\
\hline Total ordinal & 0.169 & .866 & 0.495 & .621 \\
\hline Total píldoras & 0.845 & .398 & -0.829 & .407 \\
\hline Total actitudes & -0.507 & .612 & 1.206 & .228 \\
\hline
\end{tabular}


Como se puede observar en la tabla 5.15, en ninguna de las 44 pruebas hechas para cada una de las variables se rechaza la $H_{0}(\alpha=.05)$, por lo que no se rechaza la hipótesis de independencia en caso alguno.

Así, los resultados empíricos parecen confirmar que la muestra seleccionada es representativa de la población de referencia y cumplen el criterio de independencia de las observaciones. Por tanto, se verifica que la selección de la presente muestra no se debe en ningún caso a intereses partidarios de la investigación en cuestión.

\subsubsection{Procedimiento de aplicación del programa}

En primer lugar, dado que el tratamiento consiste en el diseño, implementación y evaluación de la efectividad de un programa formativo en competencias informacionales, se procede al estudio profundo de las bases conceptuales que están detrás de estas competencias (AASL, 2008; ALA/ACRL, 2000; Andretta, 2005; Brock, 1993; Bundy \& ANZIIL, 2004; Bundy, 1998; Catts \& Lau, 2009; CAUL, 2001, 2002; Cope \& Kalantzis, 2009a; CRUE-TIC \& REBIUN, 2009; Lankshear \& knobel, 2008; SCONUL, 2001). Todo ello con la intención de atender al objetivo general del estudio II, que no es otro que el diseño, desarrollo y evaluación de un programa de intervención para la mejora de las competencias informacionales en futuros profesores de educación secundaria obligatoria.

Una vez definidos operativamente el objetivo general y los específicos, se plantea el diseño de investigación más adecuado para el estudio de la cuestión y se perfilan los instrumentos y variables que serán las líneas maestras que dirijan todo el proceso. Por una parte se encuentra el diseño del propio tratamiento a partir del estudio teórico ya señalado y por la otra el inventario de evaluación que valorará su eficacia. El diseño de estos instrumentos se realiza entre los meses de septiembre y noviembre de 2011, y el inventario es validado por los jueces expertos entre los meses de noviembre y diciembre.

La selección de la población y la muestra sobre la que se aplica el tratamiento se realiza igualmente durante los meses de noviembre y diciembre de 2011, resultando seleccionada una muestra de 50 sujetos, de los que finalmente realizan el pretest, el tratamiento y el postest 36.

Para acceder a la muestra se procedió del siguiente modo: 
En primer lugar, se ofertó un Curso Extraordinario (ofertado por el Centro de Formación Permanente ${ }^{24}$ de la USAL) a todos los estudiantes del Máster de formación de profesorado que asistieron a las clases presenciales entre el 27 de octubre y el 11 de noviembre de 2011. El proceso consistió en la entrega de un tríptico informativo en el que, como puede observarse en el anexo $\mathrm{VI}$, se indicaban las principales características del curso. Así mismo, se facilitó a todos los alumnos un correo electrónico para que, en caso de tener interés en el curso, se pusieran en contacto para formalizar la preinscripción. El plazo de preinscripción se prolongó entre el 27 de octubre y el 12 de noviembre de 2011, de manera que todas las solicitudes recogidas en ese plazo estaban preseleccionadas. En total se recibieron 104 preinscripciones en el plazo indicado y por el procedimiento correcto.

El proceso de selección de matriculados, que se realizó los días 13 y 14 de noviembre de 2011 , se llevó a cabo conforme a los siguientes criterios, sobre los que fueron informados todos los preinscritos (en orden de importancia descendiente):

1․ Equilibrio relativo entre las diferentes especialidades del Máster: Se pretende que la ponderación o peso de cada especialidad sea en el curso similar a la que existe en el propio Máster.

20 Riguroso orden de inscripción: A partir del número de alumnos que se calcule aceptar por especialidad, se procede a la selección de los mismos por riguroso orden de recepción de las solicitudes (se toma como fecha de referencia, el primer correo recibido por el alumno mostrando su interés).

Además de los 50 seleccionados, se asignaron 14 plazas de reserva, teniendo al menos una plaza en reserva para cada especialidad. Los alumnos seleccionados debían enviar en 10 días hábiles un formulario de inscripción y la fotocopia escaneada del impreso de matrícula en el Máster (para asegurar que el sujeto estaba realmente matriculado en el mismo).

Una vez confirmados los estudiantes que ocuparían las 50 plazas, se les convocó a una reunión inicial previa al inicio del curso, para informar a los alumnos en persona sobre los parámetros del curso, la estructura del mismo y cómo se organizarían los contenidos, actividades, evaluación, etc. Dicha reunión se celebró el 20 de diciembre de 2011, y asistió más del 75\% de los alumnos matriculados.

\footnotetext{
${ }^{24}$ Para más información consultar la web del citado Servicio: http://campus.usal.es/ formacionpermanente/index.html
} 
Posteriormente, en los primeros días de enero se aplica el pretest y entre el 9 de enero y el 10 de febrero de 2012 se aplica el tratamiento. El postest se aplica inmediatamente después de finalizar el tratamiento, para evitar la intervención de variables extrañas ajenas al proceso investigador. La escala de satisfacción con el curso recibido se aplica una vez respondido el postest.

\subsubsection{Análisis de datos. Estudio experimental}

Al tratarse el estudio II de una investigación de corte experimental, se aplican en base a los objetivos y a la propia naturaleza de las variables, técnicas de tipo principalmente inferencial (Tejedor Tejedor, 2006). El proceso llevado a cabo durante el análisis de datos es el siguiente:

- En primer lugar, se procede a la construcción de las variables finales que van a ser analizadas. Para cada una de las 4 dimensiones definidas a lo largo del estudio (búsqueda, evaluación, procesamiento y comunicación de comunicación) se obtienen tres medidas diferenciadas, que tienen que ver con el componente de la competencia:

- Saber: Resultados de la prueba objetiva.

- Saber hacer: Ponderación de las escalas ordinales con las píldoras de desempeño. Las ponderaciones son en búsqueda $.5^{*} .5$, en evaluación . $8 * .2$, en procesamiento $.5 * .5$ y en comunicación $.6 * .4$.

- Saber ser: Resultados de la escala de actitudes.

- Previamente al estudio inferencial propiamente dicho, se requiere un análisis exploratorio de las variables, para comprobar el comportamiento de sus distribuciones. En base a los resultados obtenidos se toma la decisión acerca de la aplicación de técnicas paramétricas (Tejedor Tejedor, 1999, 2006) o no paramétricas (Corder \& Foreman, 2009; Siegel, 1970). Dentro de este análisis se lleva a cabo en primer lugar un análisis gráfico de las funciones de densidad de cada una de las variables y de los diagramas de caja y bigotes. Posteriormente se analizan los estadísticos descriptivos básicos de forma, todo ello con el objetivo de chequear la adaptación de las funciones de densidad de cada una de las variables a la distribución normal (distribución simétrica y mesocúrtica). Para asegurar estas primeras impresiones, se lleva a cabo la aplicación del contraste de ajuste a la curva normal y el análisis de gráficas Q-Q normales. 
- En el caso de que las parejas de variables se ajusten a una distribución normal se aplican pruebas paramétricas, y en el caso de que una de las dos variables, ya sea el pretest o el postest, no se ajuste se aplican técnicas no paramétricas.

- En el caso de encontrar valores atípicos extremos en variables ajustadas a la normalidad, se emplea para el cálculo la media recortada al 5\% (Borges del Rosal, Sánchez Bruno, \& Cañadas Osinski, 2000). Esto implica que en estos casos aislados las variables pasan de tener 36 casos a 34 o 32, en función de la asimetría localizada en la variable en cuestión.

- En la aplicación de los contrastes de hipótesis, se emplea para las variables ajustadas a la distribución normal la prueba de $t$ para muestras relacionadas, y para las variables no ajustadas la prueba de los rangos con signo de Wilcoxon (Wilcoxon, 1945). En todos los casos el cálculo de la significación de las diferencias se acompaña del cálculo de la potencia de la prueba y el tamaño del efecto basado en el estadístico g de Hedges para las pruebas de $\mathrm{t}$ y el cálculo de la probabilidad de superioridad (Grissom \& Kim, 2011) y el tamaño del efecto basado en la correlación (Corder \& Foreman, 2009) para los contrastes no paramétricos. La interpretación de las diferencias localizadas entre el pretest y el postest se basa, por tanto, no sólo en los criterios estadísticos que aporta el contraste de hipótesis, sino también en la cantidad de efecto existente en el contraste concreto. Para la aplicación de los contrastes de hipótesis se emplea el software IBM SPSS, para el cálculo del tamaño del efecto se emplea la hoja de cálculo del paquete de Microsoft Office, y para el cómputo de la potencia de la prueba se emplea el software Stata en su versión $11^{25}$.

- Posteriormente a la aplicación de las pruebas paramétricas que confirman la existencia de diferencias significativas entre los resultados de desempeño obtenidos en el pretest y el postest, se procede al estudio gráfico más detallado de las variables en las que se han localizado las diferencias.

- Antes de llevar a cabo este estudio, de tipo eminentemente gráfico, se procede a una transformación lineal de las variables; para

\footnotetext{
${ }^{25}$ Licencias de campus de la Universidad de Salamanca: IBM SPSS v.19; Microsoft Office 2007; Stata 11.
} 
facilitar la comparación entre las puntuaciones obtenidas por los sujetos en el pretest y el postest, se tipifican las variables a puntuaciones $T(50,15)$. Las transformaciones se realizan mediante la programación de hojas de cálculo del paquete de Microsoft Office.

- Una vez tipificadas las variables, estamos en condiciones de analizar las diferencias de medias entre las variables y estudiar el comportamiento de las gráficas de las funciones de distribución conjuntas de las parejas de variables. Mientras que las medias se calculan a partir del paquete IBM SPSS, el diseño de los gráficos se lleva a cabo con el software $\mathrm{R}^{26}$.

- Por último, como parte añadida al estudio, para asegurar la calidad del tratamiento implementado, se procede a la valoración de la escala de satisfacción aplicada a los alumnos mediante la aplicación de técnicas estadísticas descriptivas.

${ }^{26}$ Software libre distribuido bajo licencia GNU GPL, de acceso abierto. 


\subsection{Resultados del estudio experimental}

\subsubsection{Estudio exploratorio de las variables}

Comenzaremos pues el estudio con la exploración de las características de las distribuciones de las variables incluidas en el estudio. Veamos en primer lugar las distribuciones de las variables incluidas en el pretest, según el contenido de la prueba.

\subsubsection{Pretest: Análisis gráfico de distribuciones}
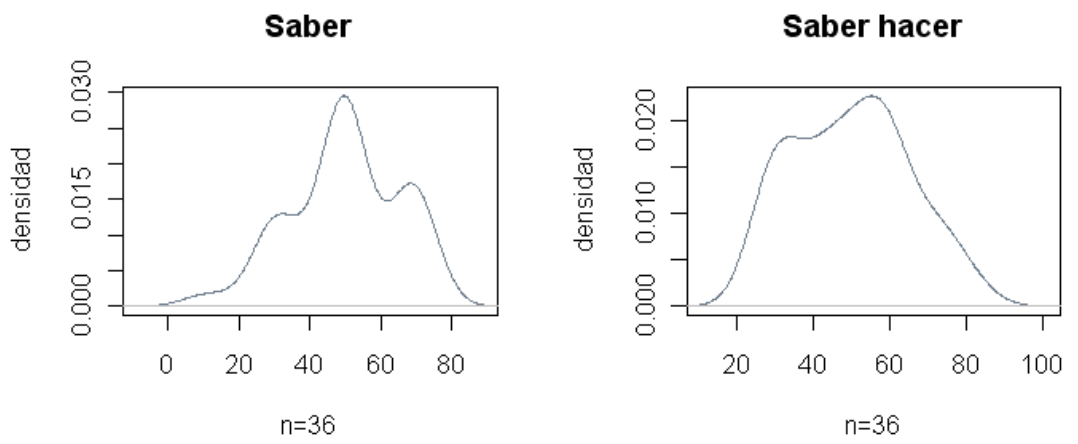

Gráfico 5.1 Funciones de densidad pretest. Aspectos básicos.

En el gráfico 5.1 se pueden observar las funciones de densidad de las variables de conocimientos básicos, transformadas a una escala $\mathrm{T}$, con media 50 y desviación típica 15. Se intuyen distribuciones que en saber tienden a la curtosis leptocúrtica y a la asimetría negativa y en el saber hacer a la curtosis platicúrtica y a la simetría.

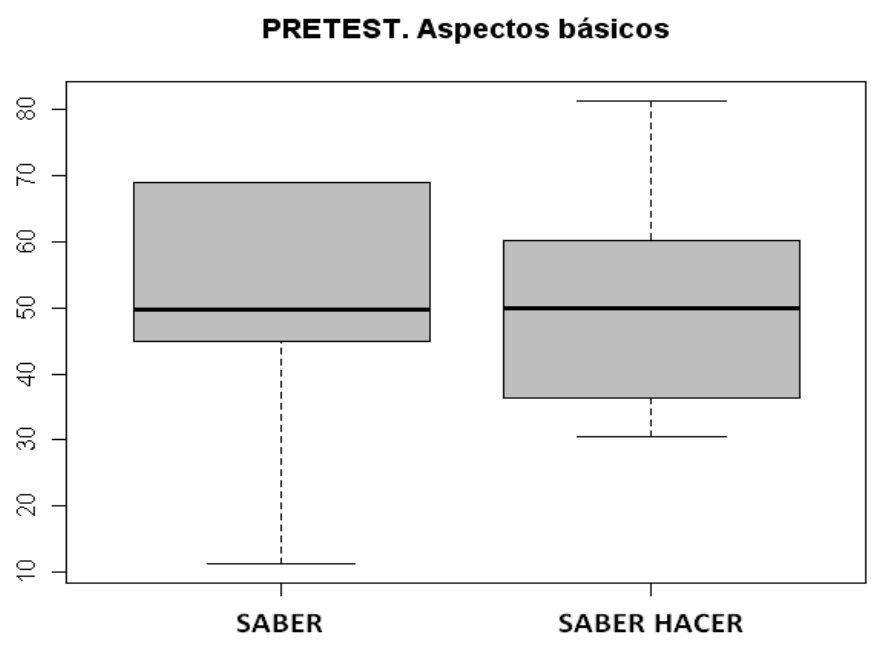

Gráfico 5.2 Diagramas de cajas pretest. Aspectos básicos.

En cuanto al estudio de los diagramas de cajas (gráfico 5.2) se observa claramente lo antes señalado. 
Mientras que la distribución de la variable saber tiende claramente a la asimetría negativa, la variable saber hacer presenta una distribución bastante equilibrada.
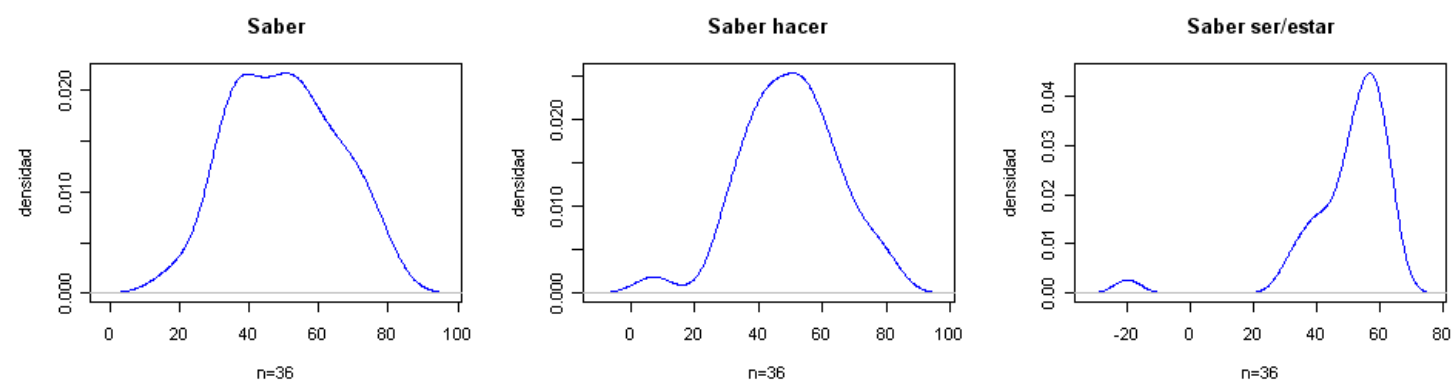

Gráfico 5.3 Funciones de densidad pretest. Búsqueda de información.

En cuanto a la dimensión de búsqueda de información, en el gráfico 5.3, incluido encima, se puede observar una distribución cercana a la normal en el saber y saber hacer, quizás con un poco de apuntamiento en el segundo caso. Por su parte, en la escala de actitudes (saber ser/estar) se observa una clara tendencia a la asimetría negativa, y la curtosis leptocúrtica.

Se observa algún caso extremadamente bajo en la escala de actitudes de la búsqueda de información. Aunque estos casos atípicos son mínimos, dado el reducido tamaño de la muestra, puede que afecten en los resultados obtenidos en las pruebas de normalidad llevadas a cabo.

PRETEST. Búsqueda de información

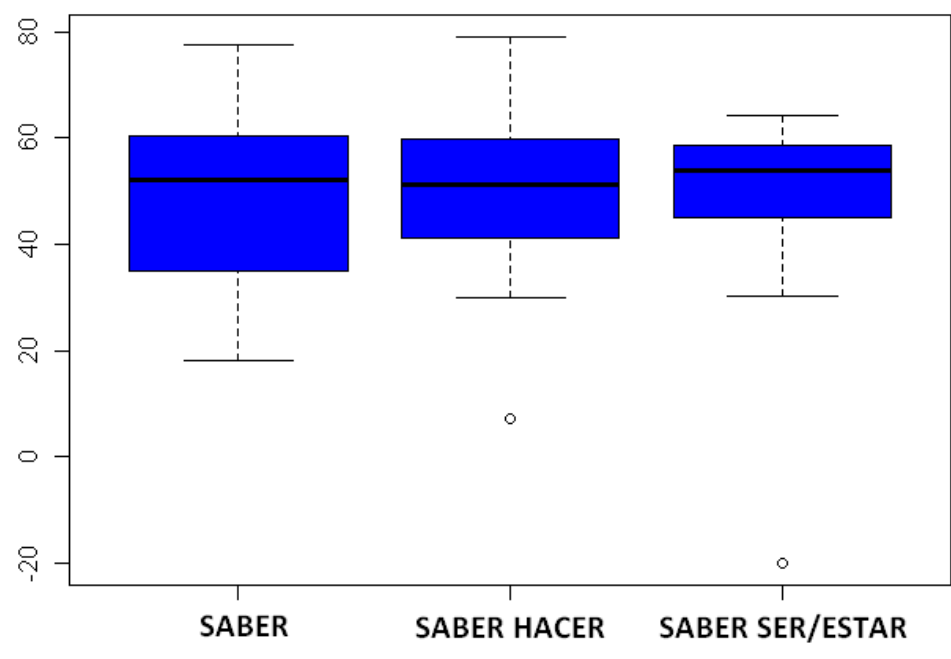

Gráfico 5.4 Diagramas de cajas pretest. Búsqueda de información.

Si analizamos el diagrama de cajas de las variables de esta dimensión (gráfico 5.4), observamos distribuciones similares a excepción de la escala saber ser/estar, en la que, además de encontrar el valor atípico señalado anteriormente, vemos una distribución con poca variabilidad. 
El gráfico 5.5 muestra las funciones de densidad para la dimensión de evaluación de información.
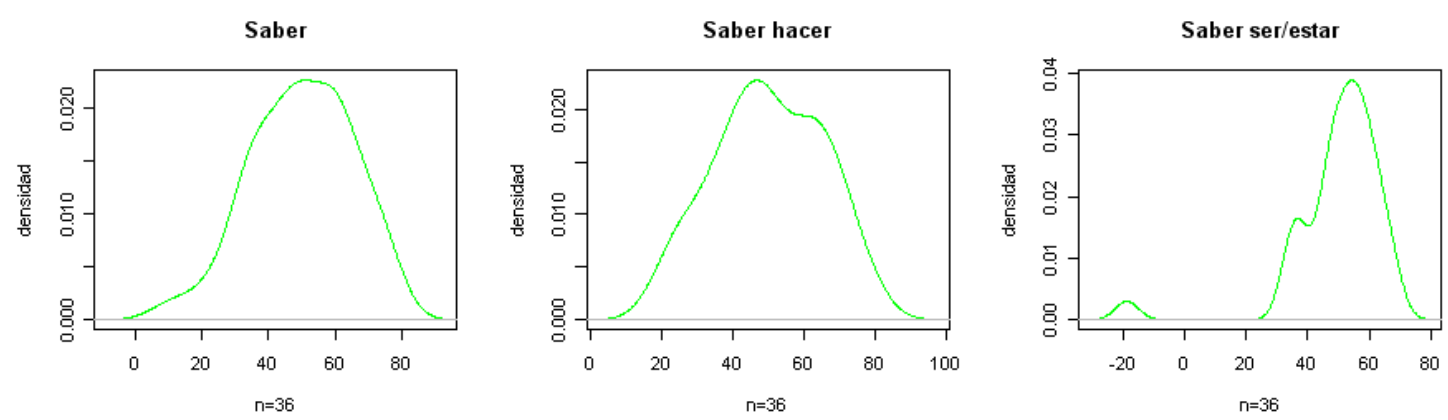

Gráfico 5.5 Funciones de densidad pretest. Evaluación de información.

Se vuelve a observar una tendencia similar a la comentada en la dimensión de búsqueda en lo que respecta a la variable saber y al saber hacer. Por otro lado, en la escala de actitudes se vuelven a obtener casos extremos y una curva muy apuntada, tendiente a la curtosis leptocúrtica.

PRETEST. Evaluación de información

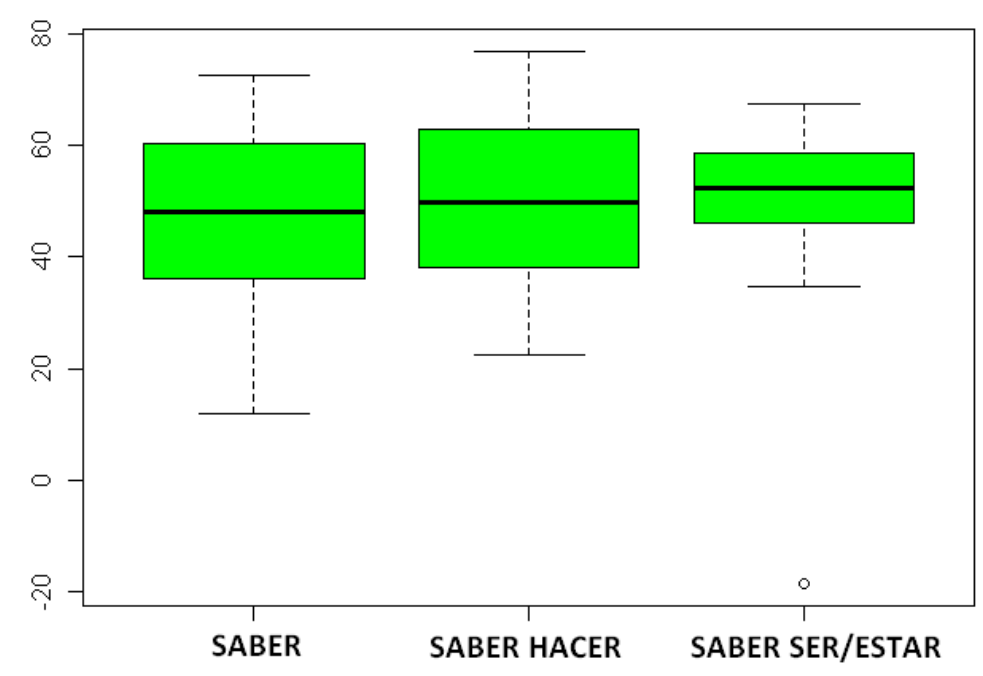

Gráfico 5.6 Diagramas de cajas pretest. Procesamiento de información.

En el gráfico 5.6, por su parte, se pueden observar los diagramas de cajas y bigotes de las variables constituyentes de la dimensión de evaluación de información. Como se indicaba previamente, tanto la prueba objetiva (saber) como la escala de procedimientos (saber hacer) tienen distribuciones que aparentemente tienden a la simetría y con una variabilidad que no parece excesiva.

Sin embargo, si observamos el diagrama de la variable saber ser/estar, nos volvemos a encontrar con un valor atípico extremo, que puede influir en los análisis que se realicen en adelante de la variable en cuestión. 
No obstante, se poseen indicios que indican, a nivel general, que las variables tienden a la normalidad y que la procedencia de las distribuciones es, por tanto, la distribución normal.
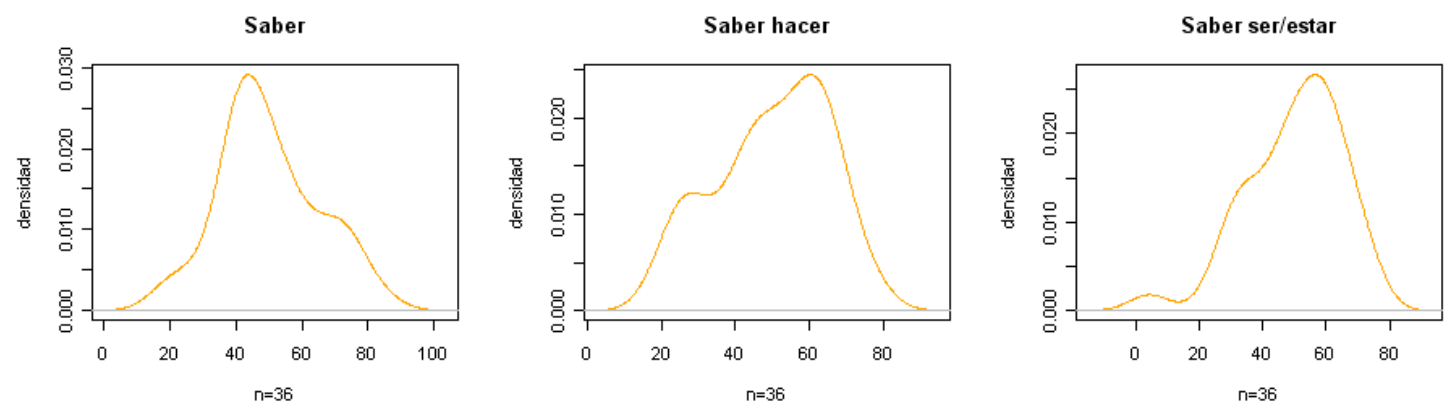

Gráfico 5.7 Funciones de densidad pretest. Procesamiento de información.

Por su parte, el gráfico 5.7, referido a la dimensión de procesamiento de información en el pretest, muestra unas tendencias un poco diferentes a las indicadas anteriormente.

Por un lado, la prueba objetiva tiende ligeramente a la asimetría negativa y se observan indicios de curtosis leptocúrtica. Por otro lado, la variable saber hacer muestra una ligera tendencia a la asimetría negativa y por último la escala de actitudes muestran una tendencia más clara a la asimetría negativa. Parece pues que las distribuciones de las variables saber y saber hacer incluidas en la dimensión de procesamiento de información se alejan algo más de la normalidad, aunque no exageradamente.

Si analizamos estas distribuciones a través de los gráficos de caja y bigotes (gráfico 5.8), vemos funciones de densidad con una variabilidad similar, aunque con algunas pequeñas diferencias. Nuevamente en la escala de actitudes se sigue observando la existencia de un caso atípico. Sin embargo, este caso es menos extremo que los localizados en la variable saber ser/estar de las dimensiones de búsqueda y evaluación de información. 
PRETEST. Procesamiento de información

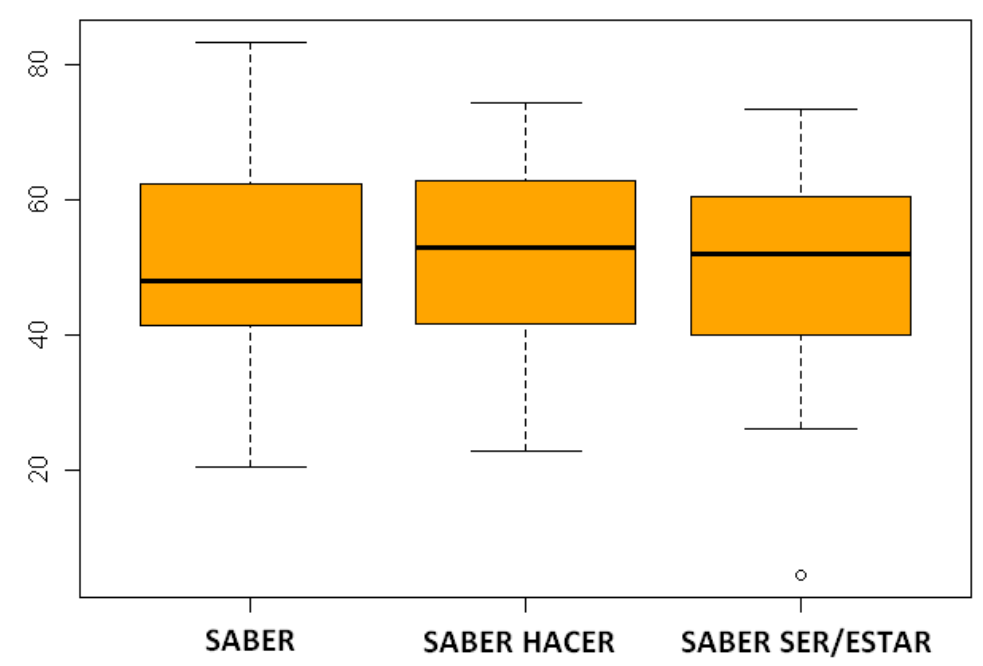

Gráfico 5.8 Diagramas de cajas pretest. Procesamiento de información.

Por último, nos encontramos con las distribuciones de densidad de las variables obtenidas en el pretest incluidas en la dimensión de comunicación y difusión de información (gráfico 5.9).
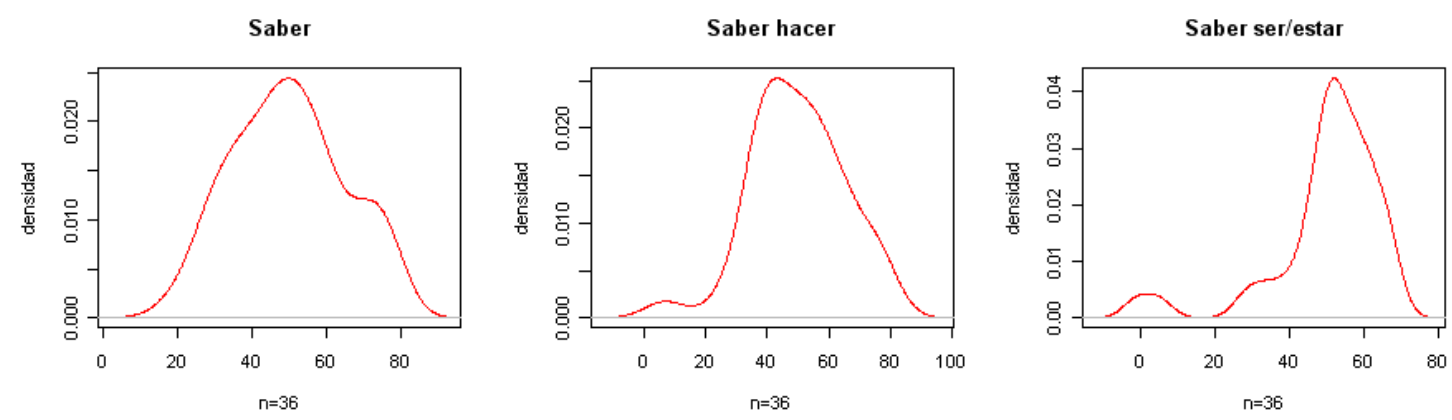

Gráfico 5.9 Funciones de densidad pretest. Comunicación de información.

Por un lado, como se puede observar en el gráfico de más arriba, las variables obtenidas a partir de las escalas de procedimientos y la escala de actitudes muestran distribuciones asimétricas negativas y con una marcada curtosis leptocúrtica. Se sigue observando la existencia de un valor extremo en la variable saber ser/estar. Por otro lado, en el saber, la gráfica de la función de densidad indica que probablemente la variable se ajuste a la distribución normal. 
PRETEST. Comunicación de información

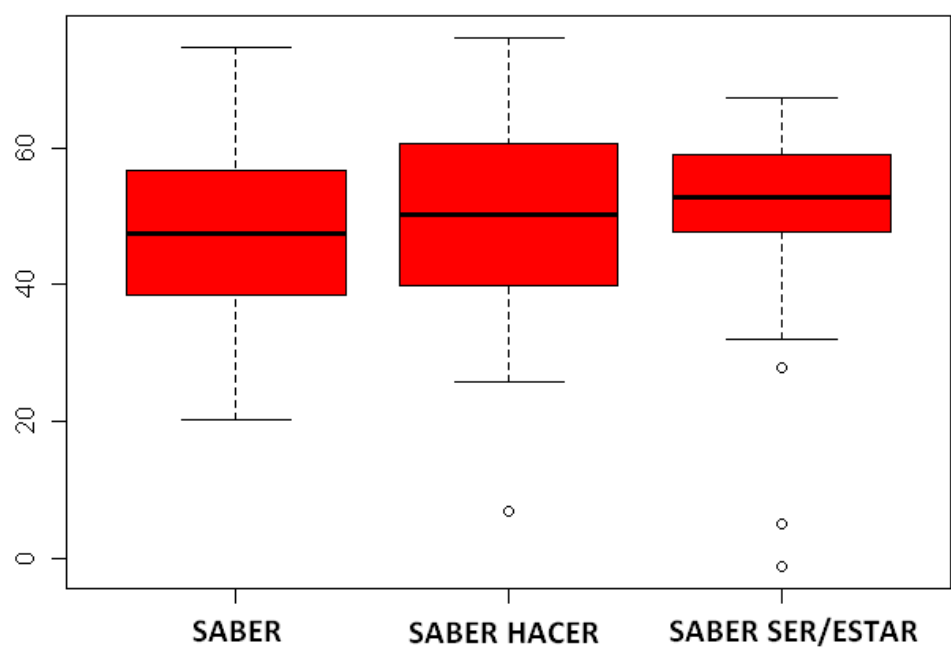

Gráfico 5.10 Diagramas de cajas pretest. Comunicación de información.

Estas consideraciones se pueden apreciar con más detenimiento en los diagramas de cajas y bigotes (gráfico 5.10). A pesar de que nos encontramos con algún valor atípico, las distribuciones parecen tendentes a la simetría y con una variabilidad aceptable, salvo en el caso de la escala de actitudes, que es más baja.

\subsubsection{Pretest: Análisis estadístico básico y contrastes de normalidad}

Una vez llevadas a cabo las primeras consideraciones gráficas, parece clara la necesidad de, en el caso de decidir aplicar un contraste paramétrico en las variables del saber ser/estar, hacerlo a partir de la media recortada al 5\%, para evitar la influencia de los valores atípicos extremos localizados (Borges del Rosal et al., 2000).

En todo caso, previamente a la decisión sobre el empleo de contrastes paramétricos o no paramétricos, procederemos al análisis sistemático de los estadísticos de forma y dispersión más apropiados en este momento. Posteriormente se procederá a la prueba de Kolmogorov-Smirnov para comprobar la normalidad de las distribuciones de procedencia de cada una de las variables que participa en el presente estudio.

Nos encontramos en la tabla 5.16 con los estadísticos de forma básicos, junto con la mediana y el recorrido o amplitud intercuartílica. Los resultados refrendan las observaciones llevadas a cabo anteriormente, sobre todo en lo que respecta a las escalas de actitudes, que tienen en general índices de asimetría negativa y de curtosis leptocúrtica elevados. 
Tabla 5.16 Pretest. Exploración de estadísticos básicos para las puntuaciones T estandarizadas

\begin{tabular}{l|ll|lc|cc}
\hline \multicolumn{1}{c|}{ Pretest } & Mdn & \multicolumn{2}{c|}{ Amp. } & \multicolumn{2}{c}{ Asimetría } & \multicolumn{2}{c}{ Curtosis } \\
& & Interc. & Valor & E. típ. & Valor & E. típ. \\
\hline Básicos. Saber & 49.78 & 26.46 & -0.38 & .39 & -0.20 & .77 \\
\hline Básicos. Saber hacer & 49.87 & 26.80 & 0.19 & .39 & -0.88 & .77 \\
\hline Búsqueda. Saber & 51.98 & 25.47 & 0.09 & .39 & -0.72 & .77 \\
\hline Búsqueda. Saber hacer & 51.11 & 19.61 & -0.28 & .39 & 0.74 & .77 \\
\hline Búsqueda. Saber ser/estar & 53.80 & 15.00 & -3.10 & .39 & 13.16 & .77 \\
\hline Evaluación. Saber & 48.22 & 24.26 & -0.35 & .39 & -0.19 & .77 \\
\hline Evaluación. Saber hacer & 49.83 & 25.18 & -0.10 & .39 & -0.83 & .77 \\
\hline Evaluación. Saber ser/estar & 52.40 & 13.96 & -2.83 & .39 & 12.04 & .77 \\
\hline Procesamiento. Saber & 48.02 & 20.97 & 0.29 & .39 & -0.18 & .77 \\
\hline Procesamiento. Saber hacer & 52.95 & 22.13 & -0.37 & .39 & -0.90 & .77 \\
\hline Procesamiento. Saber ser/estar & 51.92 & 22.17 & -0.83 & .39 & 0.94 & .77 \\
\hline Comunicación. Saber & 47.57 & 18.17 & 0.12 & .39 & -0.74 & .77 \\
\hline Comunicación. Saber hacer & 50.31 & 21.54 & -0.28 & .39 & 0.71 & .77 \\
\hline Comunicación. Saber ser/estar & 52.77 & 11.89 & -1.96 & .39 & 4.59 & .77 \\
\hline
\end{tabular}

A pesar de estos índices, aún no disponemos de datos que refrenden totalmente la hipótesis de no normalidad de las distribuciones de procedencia de las variables. El acercamiento a través de los gráficos $Q-Q$ nos aproximará más a la realidad.
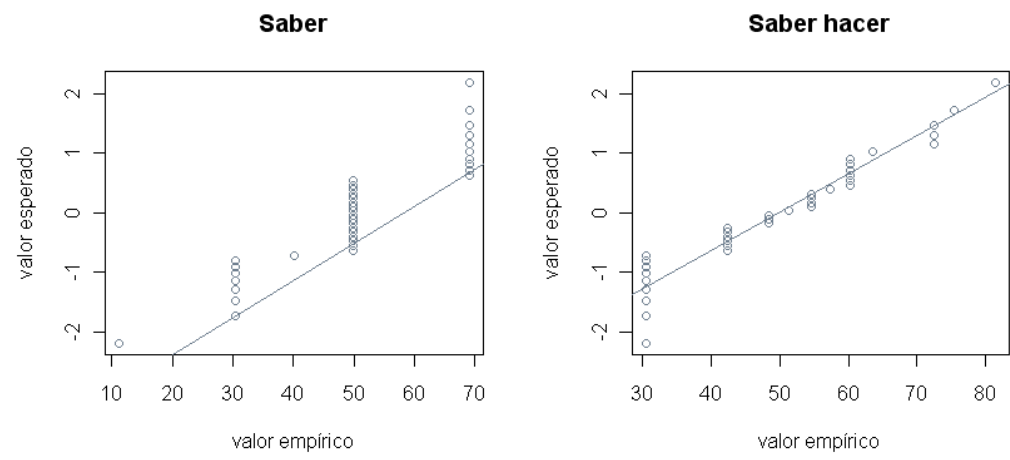

Gráfico 5.11 Gráficos Q-Q normales pretest. Aspectos básicos.

En cuanto a los aspectos básicos (gráfico 5.11), mientras que los datos en la variable saber hacer sí parecen ajustarse bien a los valores esperados para una distribución normal, en la escala de conocimientos se aleja dado su escaso rango de valores. 

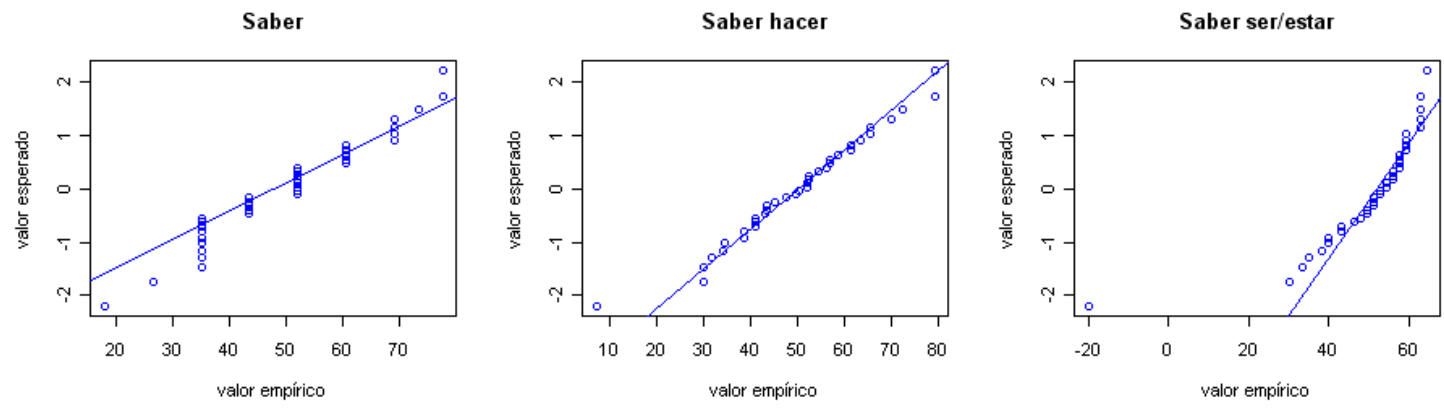

Gráfico 5.12 Gráficos Q-Q normales pretest. Búsqueda de información.

En lo que hace referencia a la búsqueda de información, como se puede observar en el gráfico 5.12, parece que las distribuciones de las variables del pretest se ajustan a la curva normal, con la excepción del caso atípico extremo de la escala de actitudes, que se eliminará en los análisis posteriores.
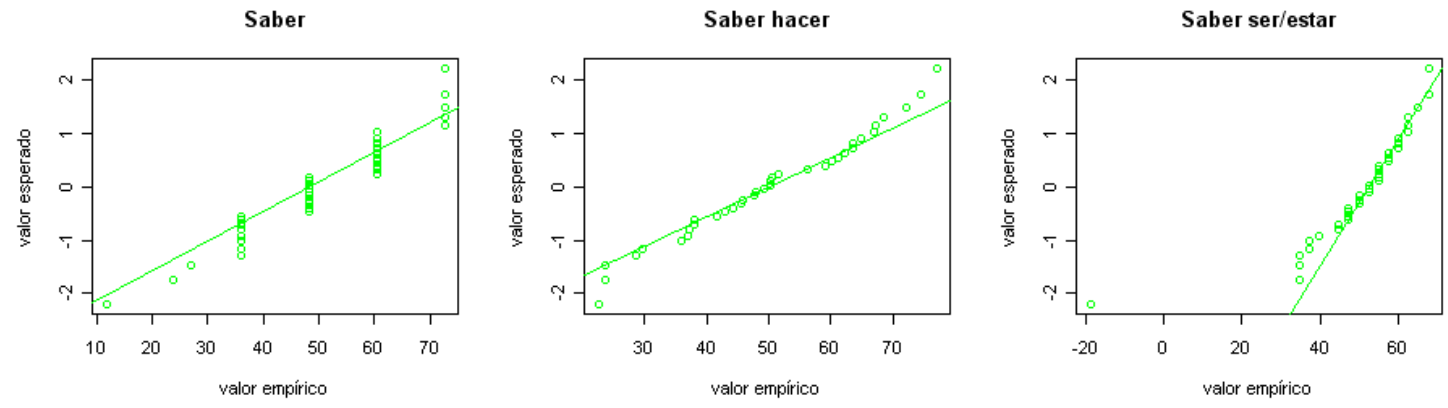

Gráfico 5.13 Gráficos Q-Q normales pretest. Evaluación de información.

Las variables incluidas en la evaluación de información (gráfico 5.13) también aparentan tener ajustes relativamente aceptables. Nuevamente se observa un reducido rango de valores en el saber y un valor extremo en el saber ser/estar.
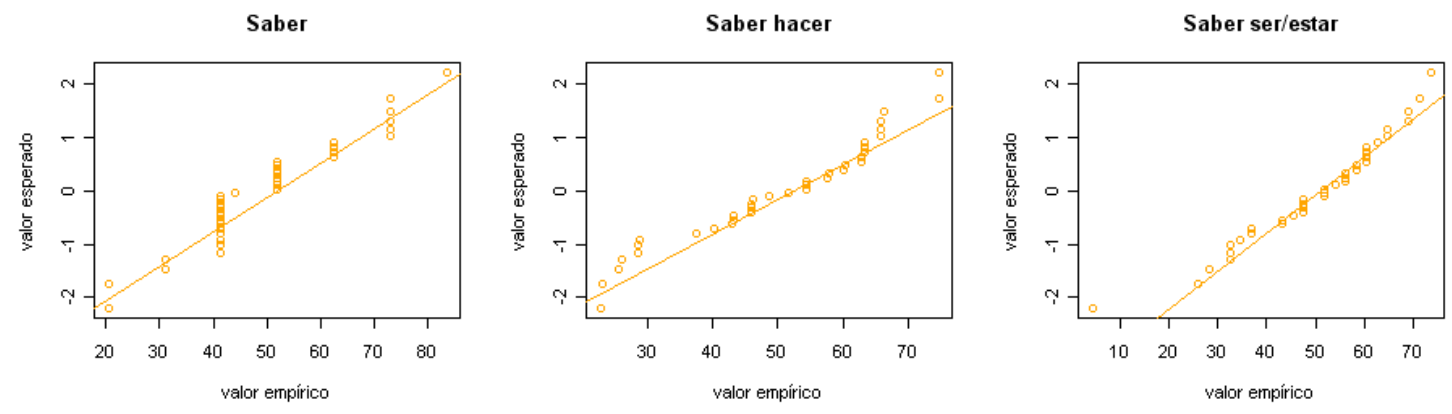

Gráfico 5.14 Gráficos Q-Q normales pretest. Procesamiento de información.

Los gráficos Q-Q normales referidos a las variables sobre el procesamiento de información (gráfico 5.14) también aportan índices que indican un ajuste aceptable. 

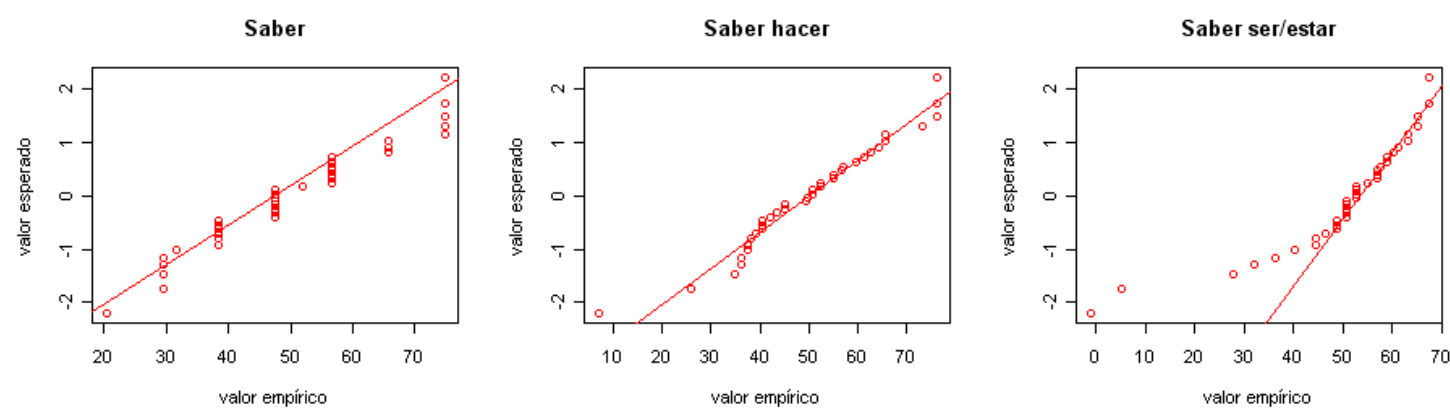

Gráfico 5.15 Gráficos Q-Q normales pretest. Comunicación de información.

Por último, en la dimensión de comunicación y difusión de información (gráfico 5.15), se observan ajustes relativamente adecuados en la escala de la prueba objetiva y en el saber hacer. Sin embargo, la distribución del saber ser/estar está algo más alejada de la distribución normal, sobre todo en los valores inferiores de la escala.

En todas las escalas de actitudes se observa cómo los valores atípicos extremos por la parte baja de la distribución se encuentran muy alejados del valor esperado, por lo que se corrobora la decisión de hacer el cálculo del contraste de hipótesis con la media recortada al 5\% (en el caso de proceder con técnicas de análisis paramétrico). La media se recortará únicamente por la izquierda de las citadas distribuciones a la hora de llevar a cabo las pruebas de diferencia de medias para muestras relacionadas.

Por último, como análisis final del pretest, observemos los valores obtenidos en la prueba de Kolmogorov-Smirnov, que prueba la hipótesis de la bondad de ajuste de las distribuciones del estudio a la distribución normal.

Tabla 5.17 Test de normalidad de Kolmogorov-Smirnov pretest

\begin{tabular}{l|cc|c}
\hline & \multicolumn{1}{|c}{$\boldsymbol{D}^{*}$} & $\boldsymbol{z}$ & $\boldsymbol{p}$. \\
& & & \\
\hline Básicos. Saber & .243 & $\mathbf{1 . 4 5 7}$ & .029 \\
\hline Básicos. Saber hacer & .153 & 0.919 & .367 \\
\hline Búsqueda. Saber & .147 & 0.879 & .422 \\
\hline Búsqueda. Saber hacer & .062 & 0.374 & .999 \\
\hline Búsqueda. Saber ser/estar & .188 & 1.126 & .158 \\
\hline Evaluación. Saber & .172 & 1.030 & .239 \\
\hline Evaluación. Saber hacer & .088 & 0.529 & .943 \\
\hline Evaluación. Saber ser/estar & .179 & 1.075 & .198 \\
\hline Procesamiento. Saber & .187 & 1.123 & .160 \\
\hline Procesamiento. Saber hacer & .115 & 0.690 & .728 \\
\hline
\end{tabular}




\begin{tabular}{l|rr|r}
\hline Procesamiento. Saber ser/estar & .107 & 0.639 & .808 \\
\hline Comunicación. Saber & .121 & 0.724 & .672 \\
\hline Comunicación. Saber hacer & .098 & 0.588 & .879 \\
\hline Comunicación. Saber ser/estar & .213 & 1.280 & .076 \\
\hline
\end{tabular}

*Diferencia absoluta más alta entre la frecuencia acumulada teórica y la observada

Como indica la tabla 5.17, parece que las variables del pretest, a excepción de los aspectos básicos de la prueba objetiva, tienden a una distribución normal. Sin embargo, como hemos señalado anteriormente hay que tener varios elementos en cuenta en el caso de que se apliquen las pruebas paramétricas en los contrastes de hipótesis:

- En primer lugar, se debe recortar la media de las escalas de actitudes del pretest al 5\%, ya que nos encontramos con valores atípicos extremos en todas las variables de la escala (Borges del Rosal et al., 2000).

- Por otro lado, las escalas de las variables de tipo saber tienen un rango de valores limitado, por lo que es recomendable ser cautos en la consideración de esta escala como cuantitativa continua.

\subsubsection{Postest: Análisis gráfico}

Hagamos a continuación un análisis exploratorio de las variables obtenidas en el postest del mismo modo en el que se ha llevado a cabo con las variables recogidas en el pretest.
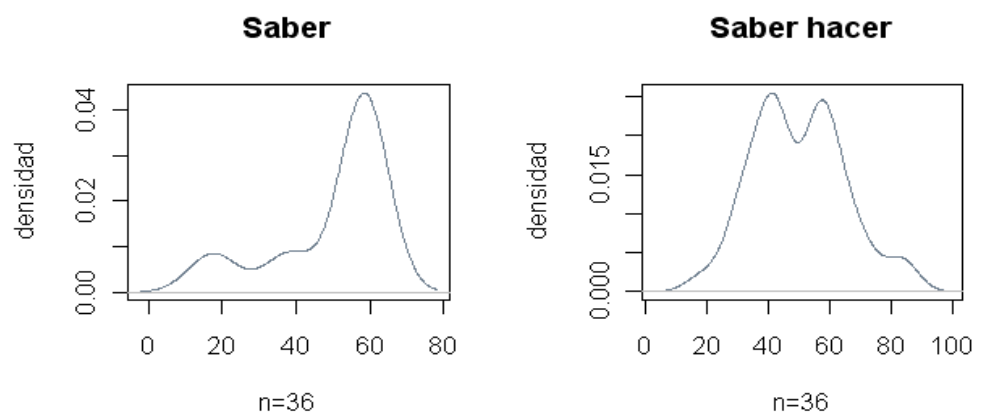

Gráfico 5.16 Funciones de densidad postest. Aspectos básicos.

En el gráfico 5.16 se observan las funciones de densidad de las variables de conocimientos básicos en el postest. Se muestra en primer lugar una distribución claramente leptocúrtica y con asimetría negativa. La segunda función de densidad, 
referida al saber hacer, sí que muestra una distribución que puede ajustarse a la normalidad.

Dado que en el pretest los conocimientos básicos del saber no se distribuían normalmente, es del todo probable que se tengan que aplicar en este caso pruebas no paramétricas.

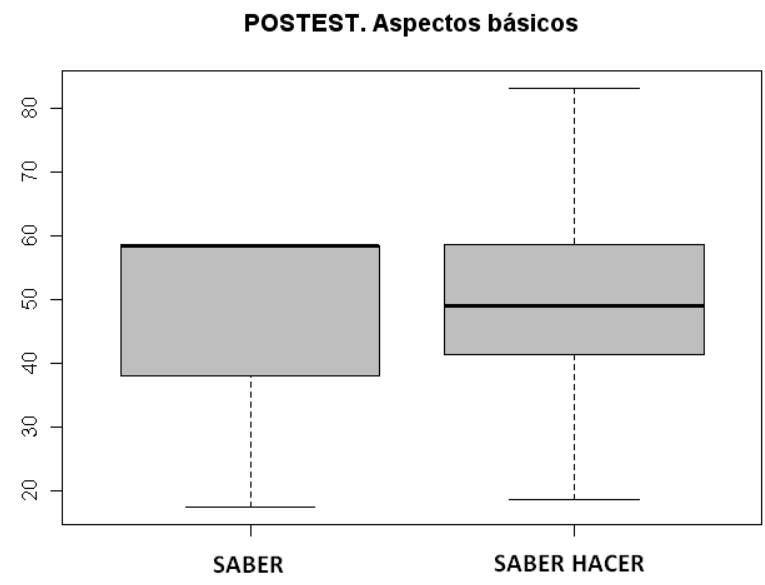

Gráfico 5.17 Diagramas de cajas postest. Aspectos básicos.

Por su parte, el gráfico 5.17 muestra el diagrama de cajas de las mismas distribuciones. Se ve claramente la asimetría negativa de la primera variable. En el caso del saber hacer, se observa una distribución simétrica.
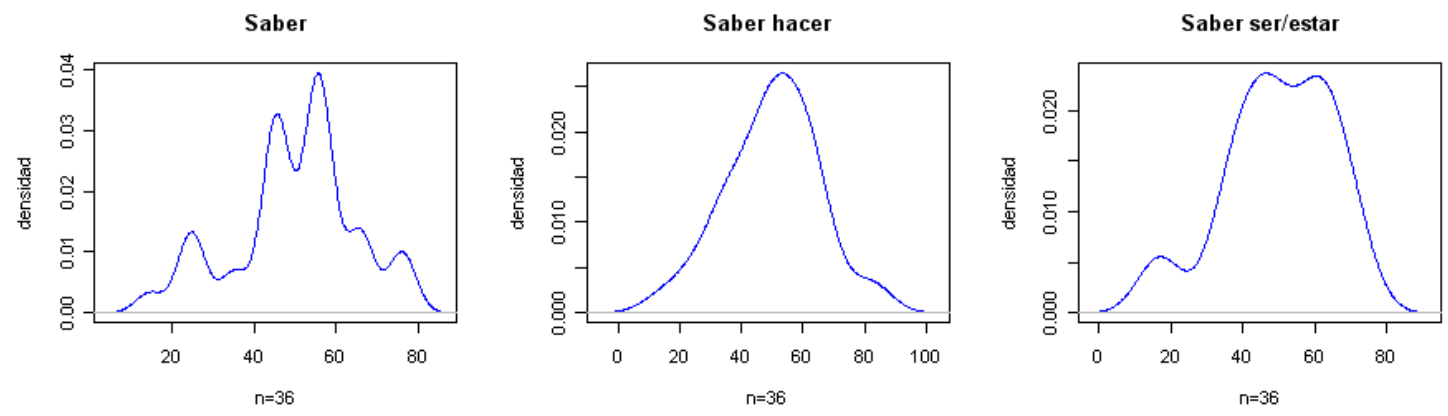

Gráfico 5.18 Funciones de densidad postest. Búsqueda de información.

En cuanto al postest de la dimensión de búsqueda de información, como se puede observar en el gráfico 5.18, se localizan distribuciones con cierta simetría en todos los casos. La función de densidad de la variable saber tiene una forma irregular debido al pequeño número de valores diferentes que se dan en la misma.

En cuanto al diagrama de cajas de las variables de la búsqueda de información (gráfico 5.19), observamos distribuciones similares a excepción de la escala de conocimientos, en la que se pueden encontrar algunos valores atípicos por ambas colas y una distribución claramente asimétrica negativa. 


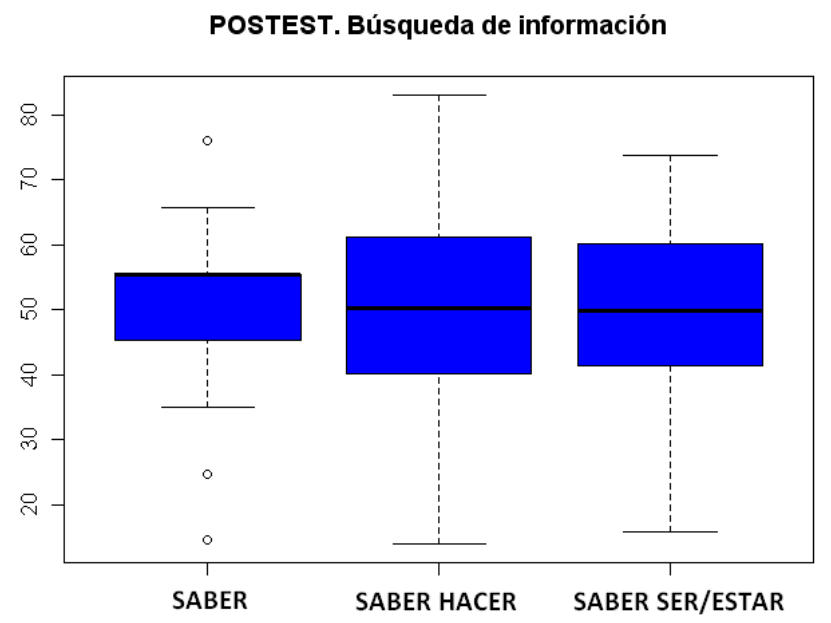

Gráfico 5.19 Diagramas de cajas postest. Búsqueda de información.

Veamos a continuación las funciones de densidad obtenidas para las variables de la dimensión de evaluación de información (gráfico 5.20).
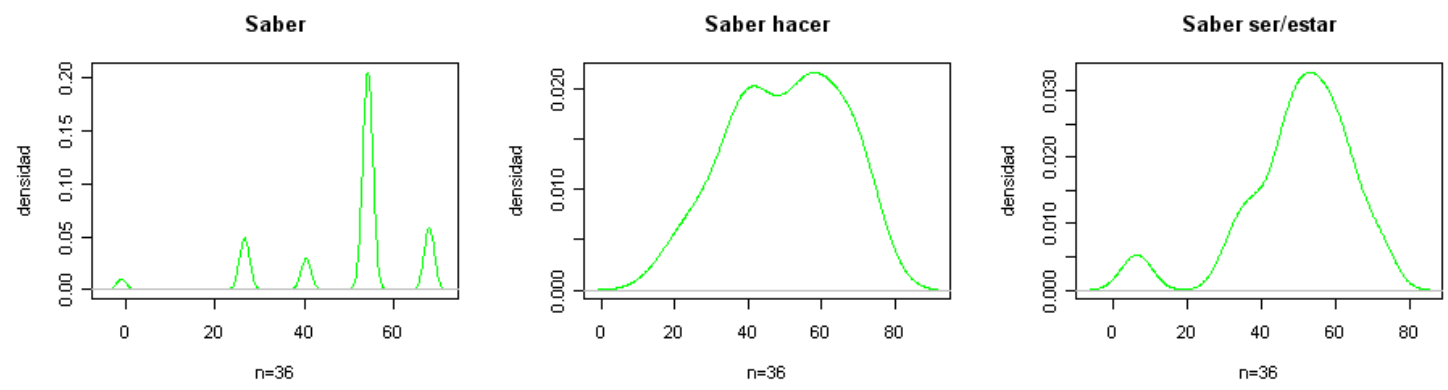

Gráfico 5.20 Funciones de densidad postest. Evaluación de información.

En primer lugar, en cuanto a la variable saber, se observa una distribución aparentemente no continua. De nuevo, estas formas de la función de densidad se deben al limitado número de valores en los que se encuentran los sujetos dentro de la variable en cuestión.

Por su parte, en la variable saber hacer sí que se localiza una distribución con una curtosis aparentemente mesocúrtica y una tendencia casi inapreciable a la asimetría negativa. En cuanto al saber ser/estar se observa una curva con una tendencia más clara a la asimetría negativa y a la curtosis leptocúrtica.

Dado que nos encontramos con valores que podrían ser atípicos tanto en saber como en saber ser/estar, vamos a analizar detenidamente los diagramas de cajas de las variables. 


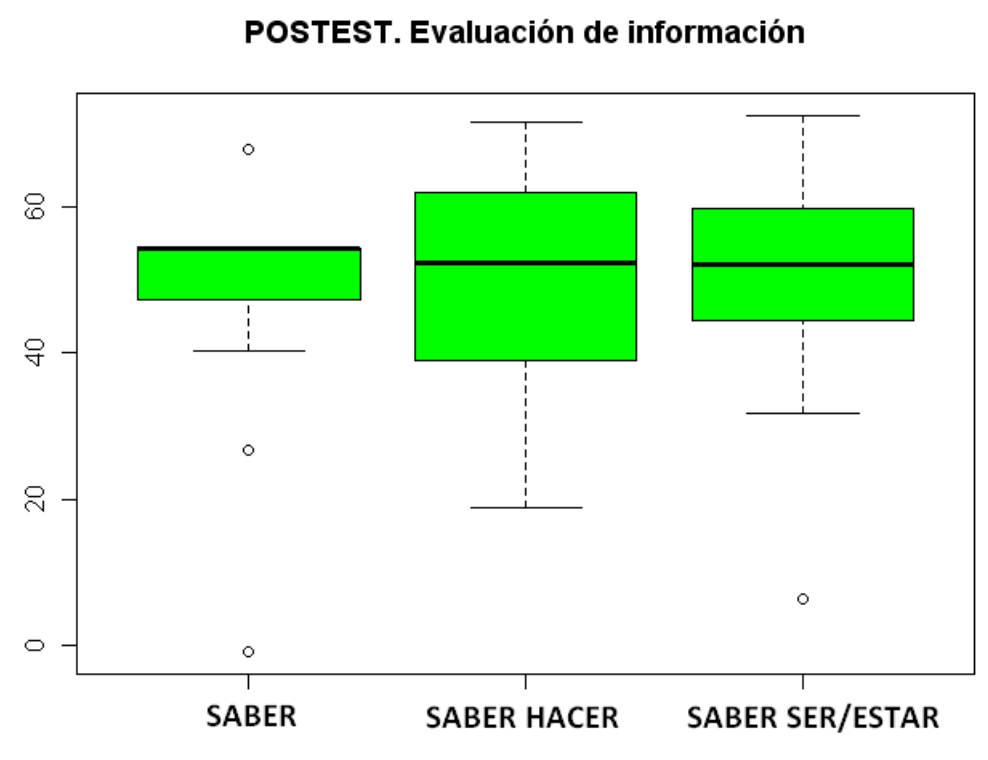

Gráfico 5.21 Diagramas de cajas postest. Procesamiento de información.

En el gráfico 5.21 se indican cómo la distribución de la escala de conocimientos de la dimensión evaluación de información es claramente asimétrica y con valores atípicos y extremos. Estos hechos nos hacen pensar que los contrastes de hipótesis que se deberán realizar con la variable saber de esta dimensión deberán ser de tipo no paramétrico.

En cuanto a las otras dos variables, tanto el saber hacer como el saber ser/estar muestran distribuciones con una dispersión y simetría aceptables. Así, los gráficos nos hacen pensar que estas dos variables tienden a la normalidad, y que la procedencia de las distribuciones es, por tanto, la distribución normal.
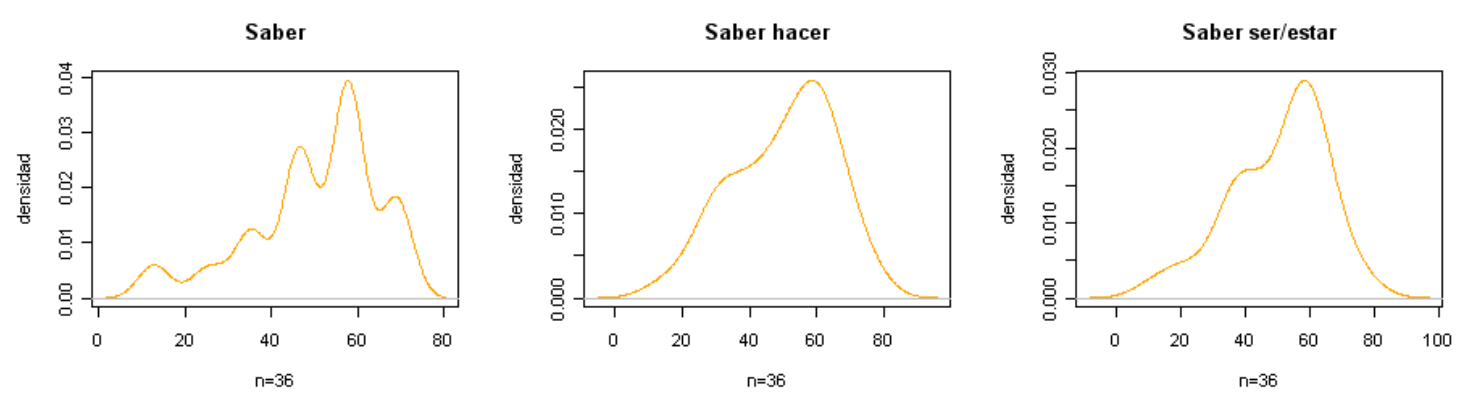

Gráfico 5.22 Funciones de densidad postest. Procesamiento de información.

Por su parte, el gráfico 5.22, referido a la dimensión de procesamiento de información en el postest, muestra tendencias muy similares. En todos los casos se observan curvas tendentes a la asimetría negativa y con cierto apuntamiento. Nuevamente aparece una función de densidad algo irregular en la variable saber, por razones idénticas a las señaladas anteriormente. 
Si analizamos estas distribuciones a través de los gráficos de caja y bigotes (gráfico 5.23), nos encontramos en el caso del saber y saber hacer con diagramas con una variabilidad similar, y con cierta asimetría negativa, aunque no muy apuntada. La escala del saber está claramente menos ajustada a la distribución normal, aunque tendremos que esperar a los resultados obtenidos en las pruebas posteriores para no aceptar la hipótesis de ajuste a la distribución normal.

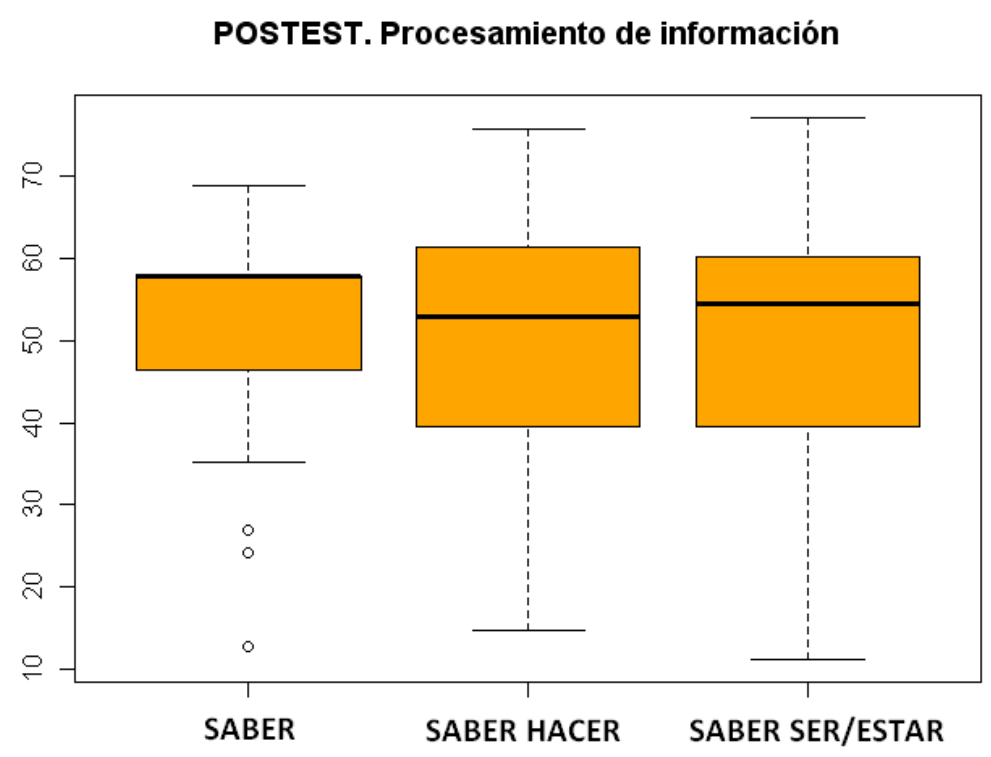

Gráfico 5.23 Diagramas de cajas postest. Procesamiento de información.

Por último, analizaremos las funciones de densidad de las variables obtenidas en el postest para la dimensión de comunicación y difusión de información.
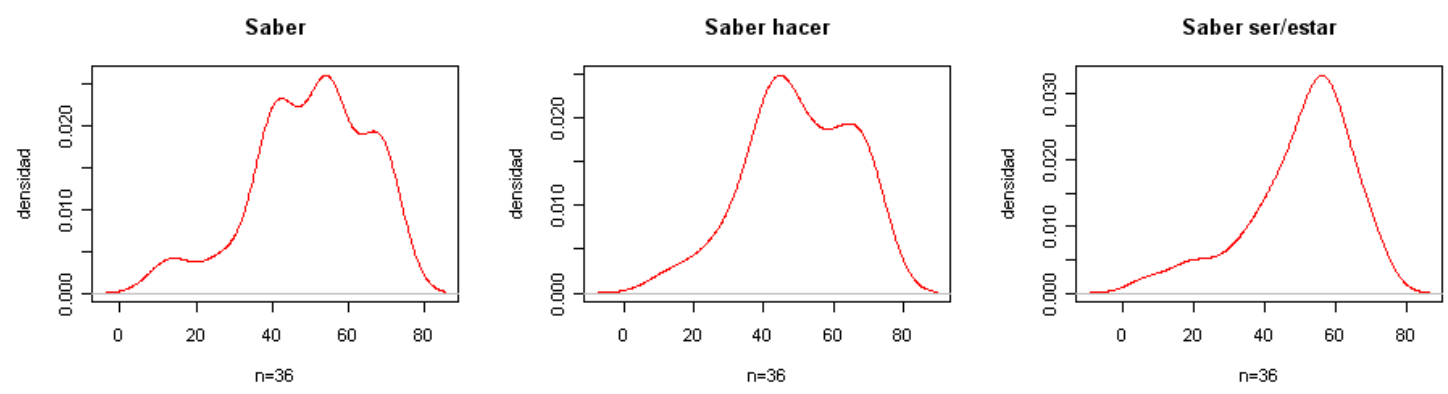

Gráfico 5.24 Funciones de densidad postest. Comunicación de información.

El gráfico 5.24 muestra distribuciones que en todos los casos son asimétricas negativas. En el caso del saber ser/estar, se observa un cierto apuntamiento que indica valores altos de curtosis leptocúrtica. Sin embargo, estas tendencias no son lo suficientemente claras como para adelantar ninguna conclusión. 


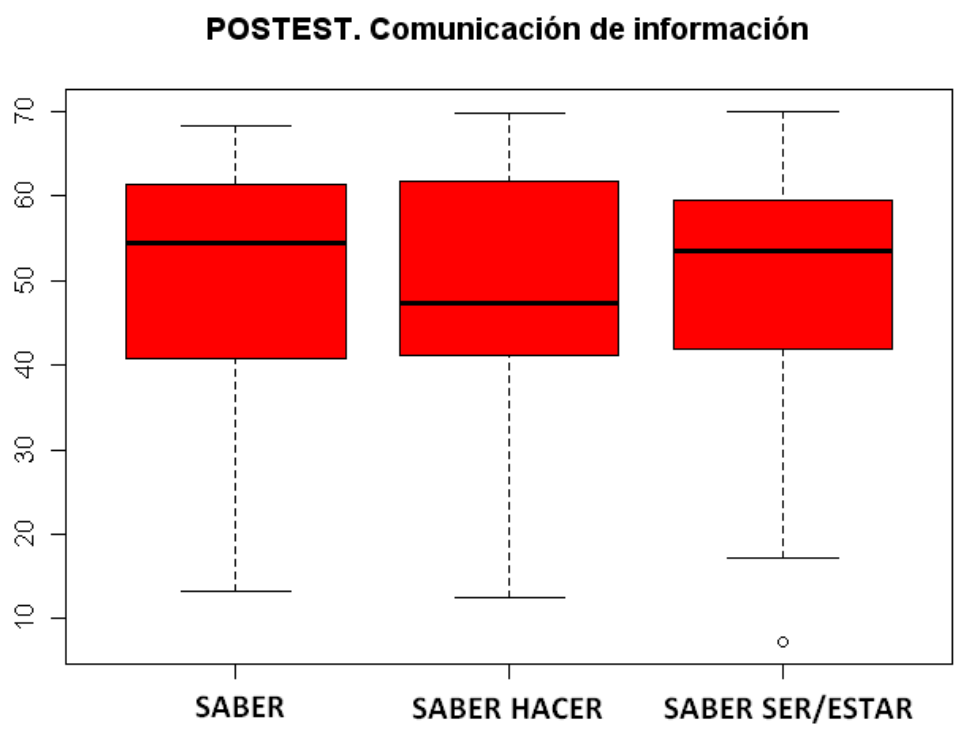

Gráfico 5.25 Diagramas de cajas postest. Comunicación de información.

A pesar de lo indicado anteriormente, si analizamos los diagramas de cajas y bigotes, mostrados en el gráfico 5.25, podemos observar distribuciones similares con distintos niveles de asimetría. Parece, a priori, que buena parte de las distribuciones de las variables incluidas en el postest proviene de una distribución normal. En todo caso, seguiremos adelante con la exploración de las citadas variables para decidir de la manera más acertada posible el tipo de contraste que se llevará a cabo para cada una de ellas. Así, veamos un resumen de los estadísticos de forma y de dispersión más importantes para cada una de las variables analizadas previamente.

\subsubsection{Postest: Análisis estadístico básico y contrastes de normalidad}

Una vez exploradas las distribuciones de las variables incluidas en el estudio II, vamos a hacer un estudio más sistemático observando los principales valores de sus estadísticos básicos de forma y posición y su ajuste a la curva normal.

Tabla 5.18 Postest. Exploración de estadísticos básicos para las puntuaciones T estandarizadas

\begin{tabular}{l|cc|ccc|cr}
\multicolumn{1}{c|}{ Pretest } & Mdn & $\begin{array}{c}\text { Amp. } \\
\text { Interc. }\end{array}$ & \multicolumn{2}{c}{ Asimetría } & \multicolumn{2}{c}{ Curtosis } \\
& & & Valor & E. típ. & Valor & E. típ. \\
\hline Básicos. Saber & 58.54 & 20.44 & -1.47 & .39 & 0.61 & .77 \\
\hline Básicos. Saber hacer & 49.17 & 18.20 & 0.30 & .39 & -0.14 & .77 \\
\hline Búsqueda. Saber & 55.52 & 10.22 & -0.40 & .39 & 0.03 & .77 \\
\hline Búsqueda. Saber hacer & 50.26 & 22.04 & -0.15 & .39 & 0.27 & .77 \\
\hline Búsqueda. Saber ser/estar & 49.90 & 19.60 & -0.62 & .39 & 0.01 & .77 \\
\hline
\end{tabular}




\begin{tabular}{l|cc|cc|cc}
\hline Evaluación. Saber & 54.22 & 10.36 & -1.44 & .39 & 2.62 & .77 \\
\hline Evaluación. Saber hacer & 52.40 & 23.44 & -0.26 & .39 & -0.87 & .77 \\
\hline Evaluación. Saber ser/estar & 52.16 & 17.81 & -1.27 & .39 & 2.35 & .77 \\
\hline Procesamiento. Saber & 57.74 & 11.27 & -0.89 & .39 & 0.45 & .77 \\
\hline Procesamiento. Saber hacer & 52.94 & 23.27 & -0.45 & .39 & -0.57 & .77 \\
\hline Procesamiento. Saber ser/estar & 54.56 & 21.68 & -0.70 & .39 & 0.16 & .77 \\
\hline Comunicación. Saber & 54.45 & 24.06 & -0.68 & .39 & 0.26 & .77 \\
\hline Comunicación. Saber hacer & 47.28 & 20.61 & -0.41 & .39 & -0.25 & .77 \\
\hline Comunicación. Saber ser/estar & 53.51 & 18.71 & -1.09 & .39 & 1.03 & .77 \\
\hline
\end{tabular}

Nos encontramos en la tabla 5.18 con los estadísticos de forma y dispersión básicos de las variables incluidas en el postest. Como ya se había observado previamente en el análisis gráfico llevado a cabo, los resultados obtenidos indican índices de asimetría en casi todos los casos negativa y de curtosis generalizadamente leptocúrtica. Al tratarse de los resultados del postest, estos datos parecen coherentes, ya que a priori en el postest los sujetos son más competentes en todas las dimensiones de las competencias informacionales y tienden a tener un nivel de competencia más homogéneo que lo que ocurría previamente al tratamiento.
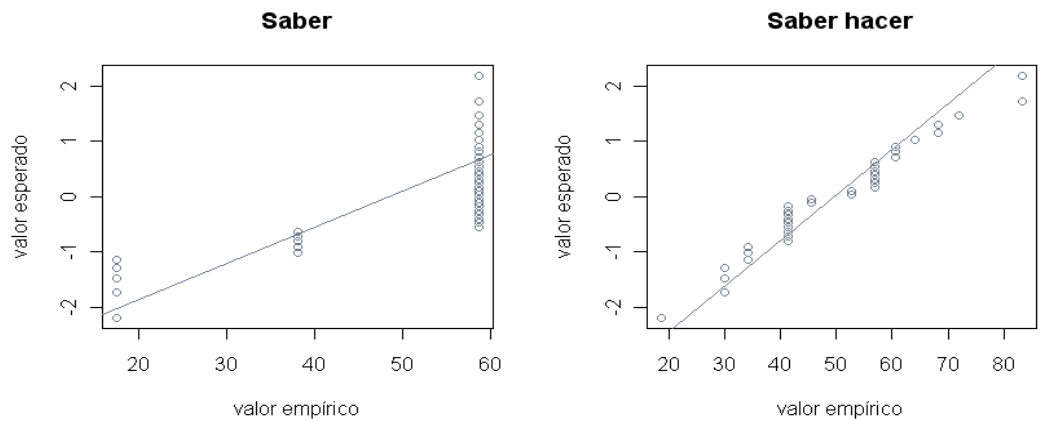

Gráfico 5.26 Gráficos Q-Q normales postest. Aspectos básicos.

En cuanto a los aspectos básicos del postest (gráfico 5.26), mientras que en el saber hacer nos encontramos con una distribución que se ajusta relativamente bien a la curva normal, en el saber nos encontramos solamente con 3 valores diferentes en la variable, lo cual imposibilita el ajuste a la curva normal. 

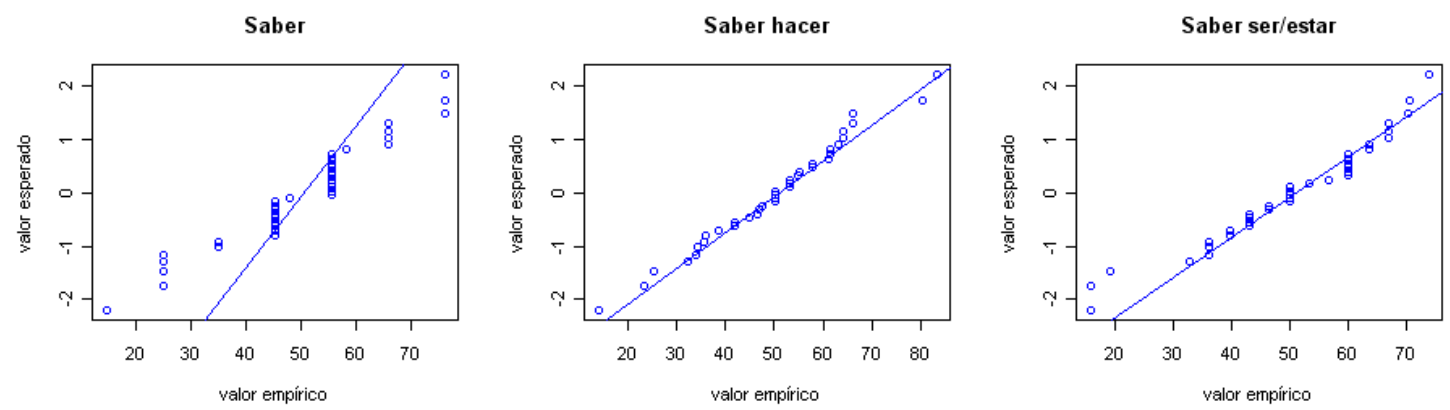

Gráfico 5.27 Gráficos Q-Q normales postest. Búsqueda de información.

En lo que hace referencia a la búsqueda de información, parece que las distribuciones de las variables saber hacer y saber ser/estar del pretest se ajustan claramente a la curva normal. Por su parte, en la variable saber, el ajuste es algo más deficitario, y habrá que contrastar estas observaciones con la prueba de KolmogorovSmirnov que se realizará más adelante.
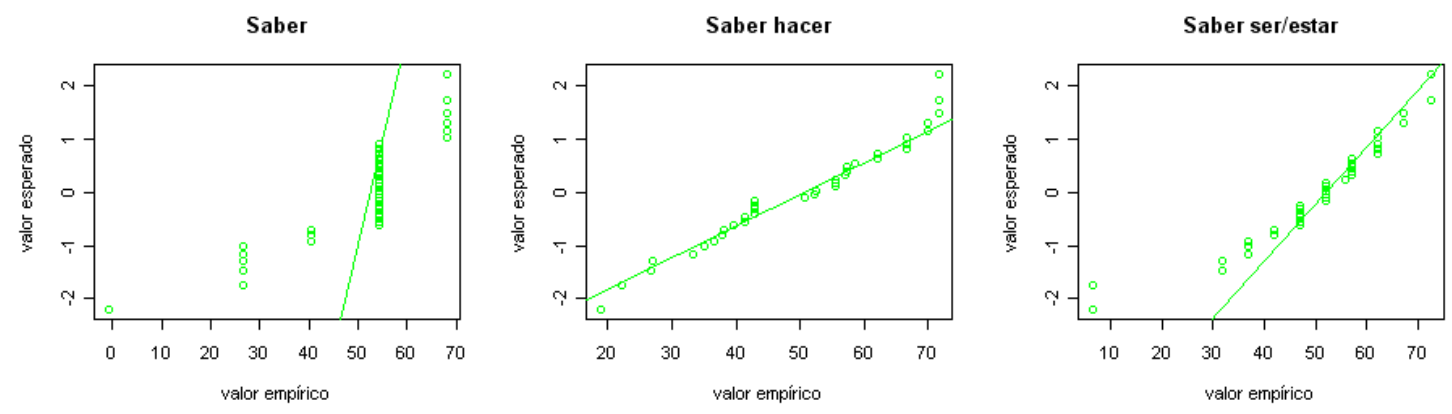

Gráfico 5.28 Gráficos Q-Q normales postest. Evaluación de información.

Las variables incluidas en el postest para la evaluación de información (gráfico 5.28) vuelven a mostrar ajustes aparentemente aceptables en el saber hacer y saber ser/estar. Por otro lado, la distribución de la variable saber sigue dando muestras de no ajustarse a la distribución normal.
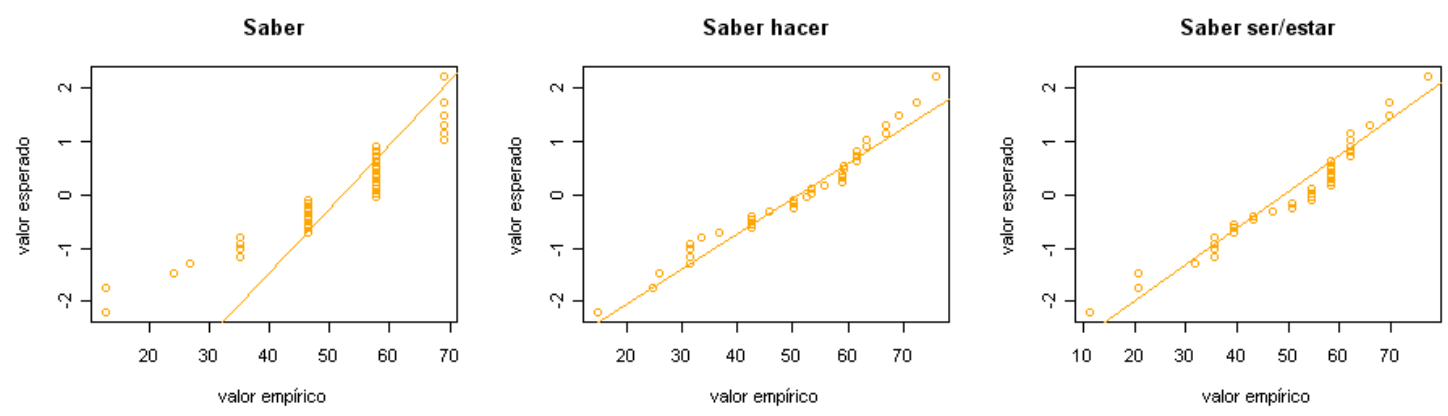

Gráfico 5.29 Gráficos Q-Q normales postest. Procesamiento de información. 
Los gráficos $Q-Q$ normales referidos a las variables que se encuentran dentro de la dimensión de procesamiento de información tienen tendencias muy similares a las analizadas anteriormente; mientras que en saber el ajuste a la curva normal es relativo, dado el bajo número de valores diferentes que contiene la variable, en el saber hacer y saber estar parece que las variables están ajustadas a esta distribución estandarizada.
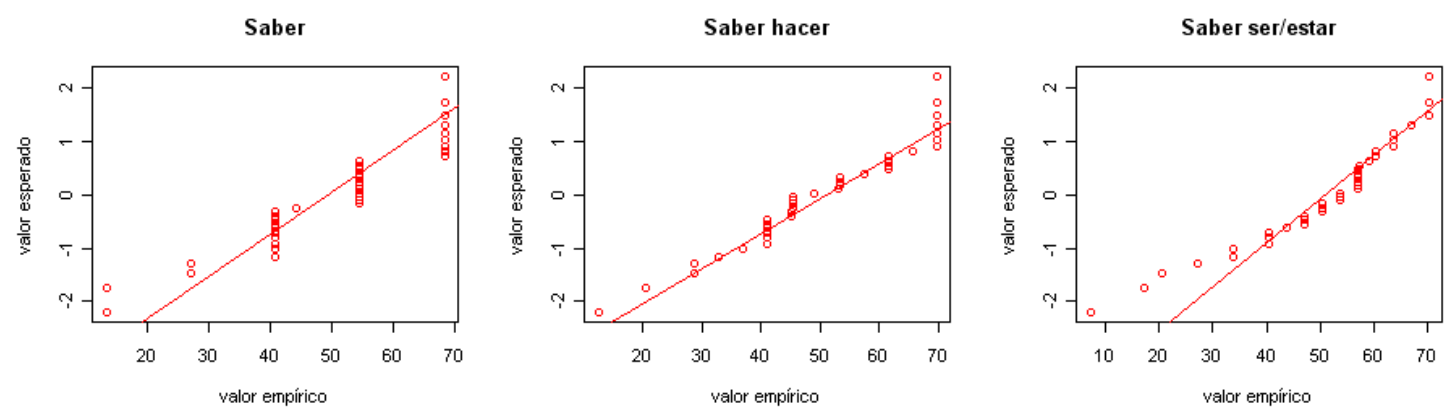

Gráfico 5.30 Gráficos Q-Q normales postest. Procesamiento de información.

Por último, tenemos los resultados obtenidos en el postest de la dimensión comunicación y difusión de información. Los datos parece que se ajustan bien en general a la distribución normal, aunque en el saber nos volvemos a encontrar con la limitación en el número diferente de valores que se obtienen en la variable.

Tabla 5.19 Test de normalidad de Kolmogorov-Smirnov pretest

\begin{tabular}{|c|c|c|c|}
\hline & $D^{*}$ & $z$ & p. \\
\hline Básicos. Saber & .438 & 2.626 & $<.001$ \\
\hline Básicos. Saber hacer & .161 & 0.963 & .312 \\
\hline Búsqueda. Saber & .183 & 1.096 & .181 \\
\hline Búsqueda. Saber hacer & .090 & 0.542 & .931 \\
\hline Búsqueda. Saber ser/estar & .139 & 0.834 & .489 \\
\hline Evaluación. Saber & .361 & 2.164 & $<.001$ \\
\hline Evaluación. Saber hacer & .126 & 0.754 & .621 \\
\hline Evaluación. Saber ser/estar & .173 & 1.035 & .234 \\
\hline Procesamiento. Saber & .225 & 1.348 & .053 \\
\hline Procesamiento. Saber hacer & .144 & 0.865 & .443 \\
\hline Procesamiento. Saber ser/estar & .175 & 1.050 & .221 \\
\hline Comunicación. Saber & .201 & 1.205 & .110 \\
\hline Comunicación. Saber hacer & .119 & 0.716 & .684 \\
\hline Comunicación. Saber ser/estar & .148 & 0.889 & .409 \\
\hline
\end{tabular}


*Diferencia absoluta más alta entre la frecuencia acumulada teórica y la observada

En la tabla 5.19 se pueden observar los estadísticos obtenidos para el contraste de bondad de ajuste a la curva normal de Kolmogorov-Smirnov para cada una de las variables analizadas en el postest. Se acepta la $\mathrm{H}_{0}$ en casi todos los casos, con lo que se acepta la hipótesis de ajuste a la distribución normal. Las dos variables que no cumplen los criterios exigibles son el saber de los aspectos básicos, y el saber de la dimensión de evaluación de información.

Como resultado de todo el estudio estadístico previo de la fase pretest y de la fase postest, se aplicarán tres tipos de contrastes diferentes en función de cómo se comportan las funciones de densidad a las que nos estamos enfrentando:

1. Diferencia de medias para muestras relacionadas (prueba de $\mathrm{t}$ ). Contraste paramétrico a partir de las medias originales de las variables estudiadas. Se aplica este contraste en las variables mostradas a continuación.
a. Aspectos básicos. Saber hacer
b. Búsqueda de información. Saber
c. Búsqueda de información. Saber hacer
d. Evaluación de información. Saber hacer
e. Procesamiento de información. Saber
f. Procesamiento de información. Saber hacer
g. Comunicación de información. Saber
h. Comunicación de información. Saber hacer

2. Diferencia de medias recortadas al $5 \%$ para muestras relacionadas (prueba de t). Contraste paramétrico a partir de las medias recortadas al $5 \%$ por la cola izquierda de las variables en las que se localizan casos atípicos extremos. Las variables son las siguientes.
a. Búsqueda de información. Saber ser/estar
b. Evaluación de información. Saber ser/estar
c. Procesamiento de información. Saber ser/estar
d. Comunicación de información. Saber ser/estar

3. Prueba de los rangos con signo de Wilcoxon. Contraste no paramétrico para las parejas de variables que no se ajustan a la distribución normal. Encontramos en este caso únicamente dos parejas de variables. 


\section{a. Aspectos básicos. Saber \\ b. Evaluación de información. Saber}

Una vez llevados a cabo los procedimientos adecuados para comprobar los supuestos previos a la aplicación de las técnicas inferenciales, podemos proceder con un mayor nivel de confianza al estudio de los contrastes de hipótesis paramétricos y no paramétricos y al cálculo de otros estadísticos anexos que aseguren una interpretación más fiable, como el tamaño del efecto y la potencia de la prueba en cada caso.

\subsubsection{Diferencias pretest-postest. Contraste de hipótesis}

Se procede a continuación a contrastar las diferencias registradas entre el pretest y el postest en las variables analizadas y mediadas por el tratamiento implementado. Para ello, se toman las puntuaciones directas obtenidas por los sujetos en cada una de las variables ${ }^{27}$

En primer lugar, de cara a aportar una visión general de las variables que intervienen en las pruebas llevadas a cabo más adelante, se analizan los estadísticos básicos que participan en los principales contrastes llevados a cabo posteriormente.

Tabla 5.20 Estadísticos básicos y diferencia de medias pretest-postest

\begin{tabular}{|c|c|c|c|c|c|c|c|c|}
\hline & \multirow[b]{2}{*}{$n$} & \multicolumn{3}{|c|}{ Pretest } & \multicolumn{3}{|c|}{ Postest } & \multirow{2}{*}{$\bar{X}_{\text {postest }}-\bar{X}_{\text {pretest }}$} \\
\hline & & $\bar{X}$ & $S_{x}$ & E. típ. & $\bar{X}$ & $S_{x}$ & E. típ. & \\
\hline Básicos. Saber & 36 & $0.56^{* *}$ & 0.35 & - & $0.81 * *$ & 0.33 & - & 0.25 \\
\hline Básicos. Saber hacer & 36 & 0.54 & 0.42 & .07 & 1.02 & 0.33 & .05 & 0.47 \\
\hline Búsqueda. Saber & 36 & 0.42 & 0.20 & .39 & 0.72 & 0.16 & .33 & 0.30 \\
\hline Búsqueda. Saber hacer & 36 & 20.50 & 3.31 & .55 & 22.22 & 2.07 & .34 & 1.72 \\
\hline $\begin{array}{l}\text { Búsqueda. Saber } \\
\text { ser/estar }\end{array}$ & 34 & $7.97^{*}$ & 0.65 & $.11^{*}$ & $8.15^{*}$ & 0.56 & $.10^{*}$ & 0.18 \\
\hline Evaluación. Saber & 36 & $0.37^{* *}$ & 0.27 & - & $0.71^{* *}$ & 0.24 & - & 0.34 \\
\hline Evaluación. Saber hacer & 36 & 19.69 & 3.31 & .55 & 22.08 & 2.52 & .42 & 2.39 \\
\hline
\end{tabular}

\footnotetext{
${ }^{27}$ Debido a que la aplicación de la tipificación a las variables imposibilita los contrastes de hipótesis basados en estadísticos de tendencia central, se aplican las técnicas paramétricas y no paramétricas sobre las puntuaciones directas obtenidas en cada una de las variables. Por el contrario, como los estadísticos de forma y posición permanecen estables, y debido a que la unificación de escalas facilita la interpretación y comparación de las curvas de densidad de las variables, para el análisis gráfico se han empleado las variables tipificadas a una escala $T(50,15)$.
} 


\begin{tabular}{|c|c|c|c|c|c|c|c|c|}
\hline $\begin{array}{l}\text { Evaluación. Saber } \\
\text { ser/estar }\end{array}$ & 34 & $7.81^{*}$ & 0.71 & $.12 *$ & $8.14^{*}$ & 0.51 & $.09 *$ & 0.23 \\
\hline Procesamiento. Saber & 36 & 0.47 & 0.24 & .32 & 0.72 & 0.22 & .30 & 0.25 \\
\hline $\begin{array}{l}\text { Procesamiento. Saber } \\
\text { hacer }\end{array}$ & 36 & 21.03 & 2.64 & .44 & 23.39 & 2.24 & .37 & 2.36 \\
\hline $\begin{array}{l}\text { Procesamiento. Saber } \\
\text { ser/estar }\end{array}$ & 34 & $7.34^{*}$ & 0.96 & $.16^{*}$ & $7.66^{*}$ & 0.64 & $.11 *$ & 0.32 \\
\hline Comunicación. Saber & 36 & 0.38 & 0.28 & 0.37 & 0.61 & 0.18 & 0.24 & 0.23 \\
\hline $\begin{array}{l}\text { Comunicación. Saber } \\
\text { hacer }\end{array}$ & 36 & 21.97 & 3.07 & 0.51 & 24.44 & 2.18 & 0.36 & 2.47 \\
\hline $\begin{array}{l}\text { Comunicación. Saber } \\
\text { ser/estar }\end{array}$ & 34 & $8.00 *$ & 0.65 & $0.11 *$ & $8.13^{*}$ & 0.66 & $0.11^{*}$ & 0.13 \\
\hline
\end{tabular}

* Media recortada al 5\%

** Tomado de variable no ajustada a la curva normal

Los estadísticos descriptivos básicos mostrados en la tabla 5.20 muestran cómo, en todos los casos, la puntuación lograda en el postest supera a la puntuación obtenida en el pretest. Así, se puede afirmar que los sujetos de la muestra han tenido un mejor desempeño en las pruebas realizadas posteriormente a la implementación del tratamiento. Ahora la cuestión que se debe plantear es, ¿el proceso formativo llevado a cabo en el tratamiento mejora las competencias informacionales de la población formada por el futuro profesorado de educación secundaria de Castilla y León?

Tabla 5.21 Contraste de hipótesis. Diferencia de medias-medianas pretest-postest

\begin{tabular}{|c|c|c|c|c|c|c|c|c|c|c|}
\hline & \multirow[b]{2}{*}{$n$} & \multicolumn{4}{|c|}{ A. paramétrico } & \multicolumn{4}{|c|}{ A. no paramétrico } & \multirow{2}{*}{$\begin{array}{c}\text { Potencia } \\
\text { de la } \\
\text { prueba }\end{array}$} \\
\hline & & $t$ & $p$ & $\begin{array}{c}\text { Tam. } \\
g\end{array}$ & $\begin{array}{c}\text { fecto } \\
p .\end{array}$ & $z$ & $p$ & $\begin{array}{c}\text { Tam. } \\
r\end{array}$ & $\begin{array}{l}P S_{d e p} \\
\text { fecto }\end{array}$ & \\
\hline Básicos. Saber & 36 & - & - & - & - & 3.23 & .00 & .54 & .71 & $94.7 \% * *$ \\
\hline Básicos. Saber hacer & 36 & 7.89 & .00 & 1.44 & .93 & - & - & - & - & $100 \%$ \\
\hline Búsqueda. Saber & 36 & 8.92 & .00 & 1.84 & .97 & - & - & - & - & $100 \%$ \\
\hline Búsqueda. Saber hacer & 36 & 3.84 & .00 & 0.83 & .80 & - & - & - & - & $99.9 \%$ \\
\hline $\begin{array}{l}\text { Búsqueda. Saber } \\
\text { ser/estar }\end{array}$ & 34 & $1.76^{*}$ & $.09 *$ & $0.31^{*}$ & $.62 *$ & - & - & - & - & $46.28 \%$ \\
\hline Evaluación. Saber & 36 & - & - & - & - & 4.31 & .00 & .72 & .83 & $95.0 \% * *$ \\
\hline Evaluación. Saber hacer & 36 & 4.58 & .00 & 0.95 & .83 & - & - & - & - & $99.9 \%$ \\
\hline $\begin{array}{l}\text { Evaluación. Saber } \\
\text { ser/estar }\end{array}$ & 34 & $2.92 *$ & $.01^{*}$ & $0.66^{*}$ & $.75^{*}$ & - & - & - & - & $97.7 \%$ \\
\hline Procesamiento. Saber & 36 & 4.76 & .00 & 1.12 & .87 & - & - & - & - & $100 \%$ \\
\hline Procesamiento. Saber & 36 & 5.59 & .00 & 1.05 & .85 & - & - & - & - & $100 \%$ \\
\hline
\end{tabular}




\begin{tabular}{|c|c|c|c|c|c|c|c|c|c|c|}
\hline \multicolumn{11}{|l|}{ hacer } \\
\hline $\begin{array}{l}\text { Procesamiento. Saber } \\
\text { ser/estar }\end{array}$ & 34 & $2.30 *$ & $.03 *$ & 0.49* & $.69 *$ & - & - & - & - & $84.2 \%$ \\
\hline Comunicación. Saber & 36 & 4.45 & .00 & 1.28 & .90 & - & - & - & - & $100 \%$ \\
\hline $\begin{array}{l}\text { Comunicación. Saber } \\
\text { hacer }\end{array}$ & 36 & 5.92 & .00 & 1.13 & .87 & - & - & - & - & $100 \%$ \\
\hline $\begin{array}{l}\text { Comunicación. Saber } \\
\text { ser/estar }\end{array}$ & 34 & $1.22 *$ & $.23^{*}$ & $0.18^{*}$ & $.57^{*}$ & - & - & - & - & $19.9 \%$ \\
\hline
\end{tabular}

* Media recortada al $5 \%$

** $95 \%$ de la potencia paramétrica

La tabla 5.21 muestra las diferencias obtenidas en los contrastes de hipótesis implementados. Se analiza si existen diferencias significativas entre el desempeño de los sujetos en el pretest y el postest para cada una de las variables incluidas en el estudio experimental.

En cuanto a los resultados obtenidos para cada una de las dimensiones de la prueba objetiva (saber), se observan en todos los casos diferencias significativas. Lo mismo ocurre en las escalas de saber hacer para todas las dimensiones. En lo que respecta a las actitudes, esto es, el saber ser/estar, se observan cambios menos intensos en todas las dimensiones, hasta el punto de obtener diferencias no significativas en las actitudes hacia las dimensiones búsqueda de información y comunicación y difusión de información. Precisamente, es hacia estas dos variables hacia las que muestran unas actitudes más altas los sujetos en el pretest. A pesar de mantenerse en el postest con unos índices de saber ser/estar altos, la subida no es tan amplia como en las otras dos dimensiones.

A pesar de las reticencias de algunos estudiosos de la magnitud del efecto sobre hablar de tamaños del efecto grandes, medios y pequeños (Glass, McGaw, \& Smith, 1981), creemos que esta clasificación ayuda a interpretar de una manera más simple estos índices. Así, analizando la magnitud de las diferencias significativas localizadas (tamaños del efecto) a partir de la g de Hedges (1982) y la $r$ (Corder \& Foreman, 2009), nos encontramos en todos los contrastes de las variables de saber y de saber hacer con tamaños grandes ( $\mathrm{g}>0.8 ; \mathrm{r}>.37$ ), de acuerdo a la clasificación propuesta por Cohen (1969). Centrándonos en la propuesta de Hopkins (2000), más exigente que la de Cohen en la interpretación de las magnitudes del efecto, nos encontramos con una clasificación que nos aporta una información más específica sobre la efectividad del tratamiento aplicado sobre la mejora en cada uno de los componentes de la competencia definidos a nivel teórico: 
- Grandes $(g \approx>1.15 ; r \approx>.5)$ : Las variables existentes para cada una de las dimensiones en el saber tienen un tamaño del efecto grande. Esto implica que el tratamiento ha mejorado de una manera muy importante los conocimientos conceptuales de los sujetos sobre competencias informacionales.

- Medios $(\mathrm{g} \approx>0.63 ; \mathrm{r} \approx>.3$ ): En las variables de saber hacer de todas las dimensiones se alcanzan tamaños del efecto medios y medios-altos. Esto implica que el curso ha sido efectivo en lo que respecta al desarrollo del componente procedimental de las competencias informacionales.

- Bajos $(g \approx>0.2 ; r \approx>.1)$ : En este caso, las variables relacionadas con las actitudes, esto es, saber ser/estar, son las que menos mejora han experimentado, ya que se encuentran en tamaños del efecto bajos o medios-bajos.

En lo que respecta a la potencia de las pruebas, es decir, la probabilidad de rechazar $\mathrm{H}_{0}$ cuando $\mathrm{H}_{0}$ es falsa, nos encontramos con que en la mayor parte de pruebas que rechazan $\mathrm{H}_{0}$ se obtienen potencias más que aceptables (>95\%). Por otro lado, cabe señalar que la eficiencia-potencia de la prueba en los contrastes no paramétricos es aproximadamente, en muestras pequeñas, del $95 \%$ de la potencia lograda en la aplicación del contraste paramétrico para las mismas variables y tamaños de muestra (Mood, 1954; Siegel, 1970). Así, para el cálculo de la potencia de la prueba en los contrastes en los que se aplica la prueba de los rangos con signo de Wilcoxon, se aplica este criterio: se obtiene la potencia hipotética de la diferencia de medias para grupos relacionados (t de Student) tomando el mismo par de variables y se calcula el 95\% del valor obtenido.

Así, en todos los aprendizajes relacionados con el saber y el saber hacer se localizan potencias altas. Mientras, la probabilidad de error de tipo II aumenta considerablemente en las variables de saber ser/estar en las que se acepta $\mathrm{H}_{0}$. Así, dado que la probabilidad de un falso negativo es muy elevada, debemos ser cautelosos a la hora de aceptar que no existen diferencias significativas en las actitudes de las variables de búsqueda y comunicación y difusión de información.

\subsubsection{Diferencias pretest-postest. Análisis gráfico}


Una vez confirmado que existen diferencias significativas entre la mayor parte de las variables estudiadas en el pretest y el postest, y que los efectos de las diferencias son en muchos casos altos, cabe preguntarse cómo ha sido el comportamiento exacto de las variables en el desarrollo de este cambio. Para llevar a cabo un análisis de este tipo, parece conveniente llevar a cabo un estudio de las funciones de densidad conjuntas o bidimensionales de las variables incluidas en el pretest y el postest.

Se irá haciendo un análisis de los gráficos por componentes de la competencia. Así, se comenzará analizando las funciones de densidad del saber, posteriormente del saber hacer y finalmente del saber ser/estar. 

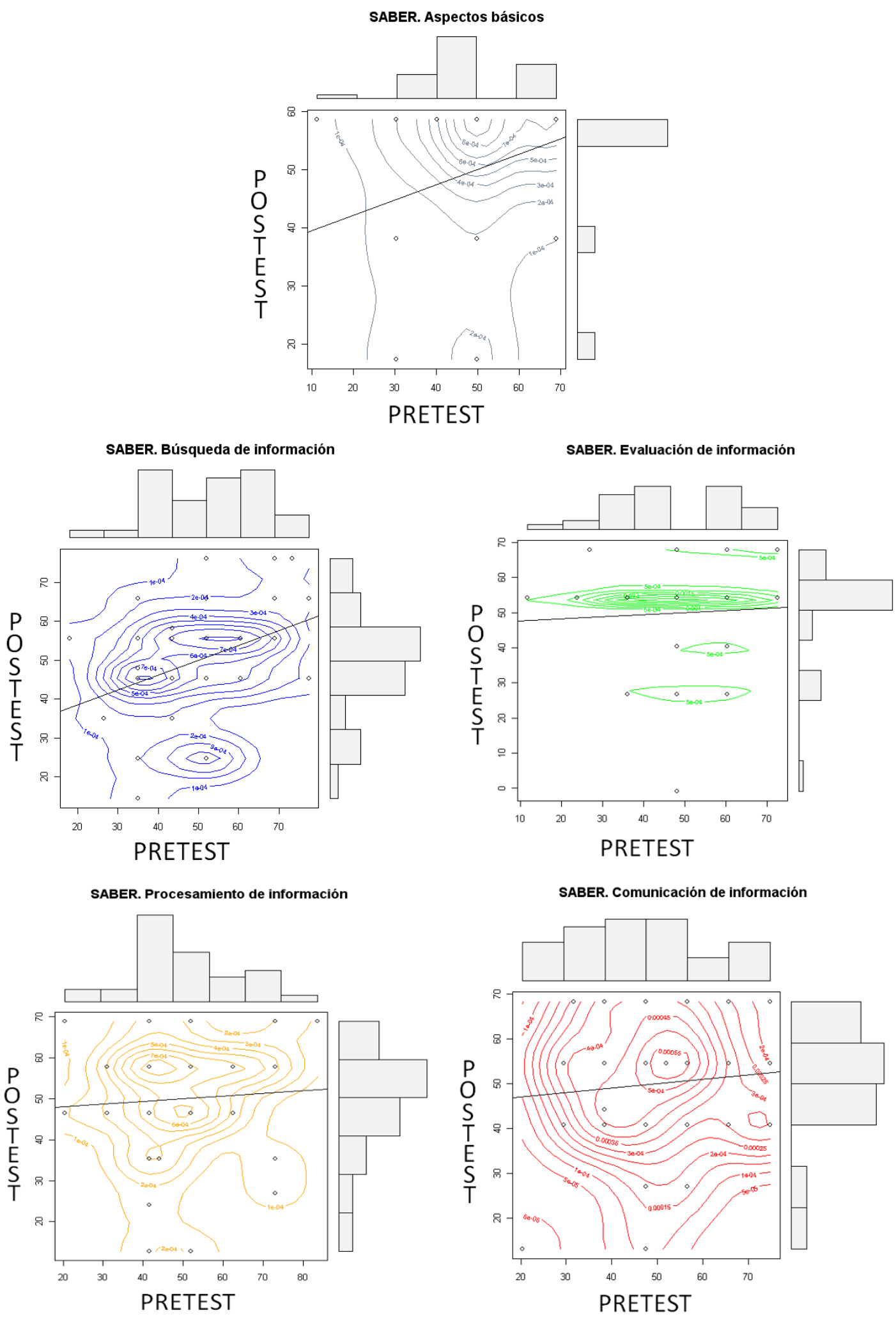

Gráfico 5.31 Diagramas de dispersión e histograma variables bidimensionales. Saber

Más arriba se pueden observar los gráficos de las 5 dimensiones de las que se extrae información acerca del saber (gráfico 5.31). Se puede observar cómo en las curvas de nivel existe una tendencia a una mayor variabilidad en el pretest que en el postest, lo cual indica que los alumnos, tras la aplicación del tratamiento, como es 
previsible, tienen un nivel más homogéneo (y superior, a tenor de los resultados obtenidos en los contrastes de hipótesis).

La tendencia señalada anteriormente se encuentra reflejada especialmente en el caso de la prueba objetiva de la búsqueda de información y del procesamiento, casos en los que se obtenían potencias altas. En el gráfico 5.32 se muestran las funciones de densidad conjuntas de ambas variables bidimensionales. Las puntuaciones en el postest tienden a ser más homogéneas y la asimetría tiende a su vez a ser más negativa en el postest por el predominio de las puntuaciones altas.

SABER. Búsqueda de información

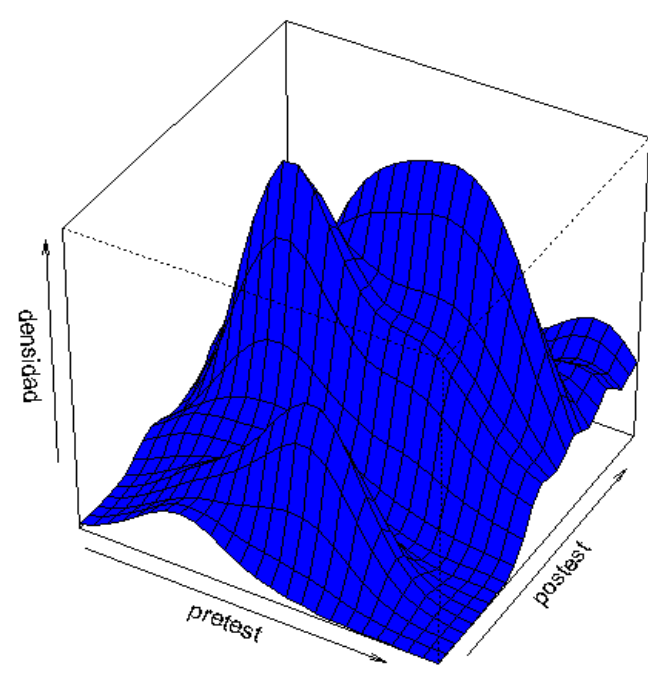

SABER. Procesamiento de información

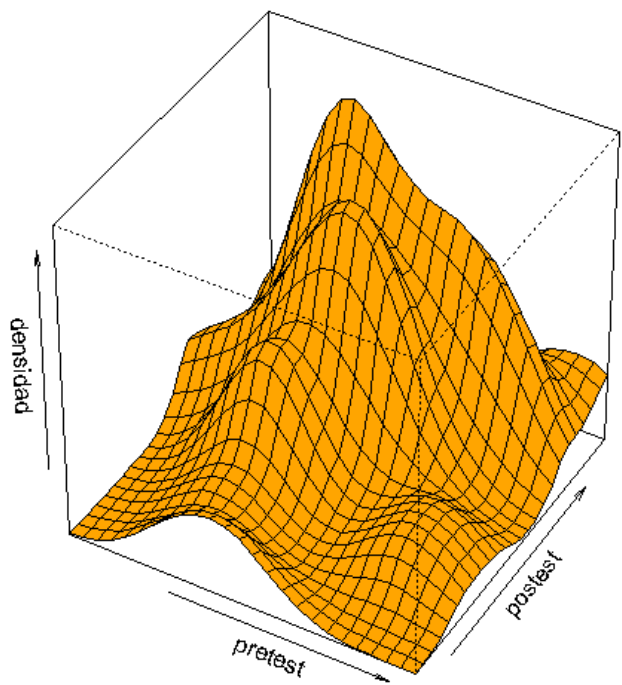

Gráfico 5.32 Funciones de densidad conjuntas búsqueda y procesamiento. Saber

Así, en las variables incluidas dentro del componente de la competencia saber, queda clara la tendencia hacia la homogeneización de las puntuaciones posteriormente a la aplicación del tratamiento y a la existencia de unas diferencias entre los resultados obtenidos en el pretest y el postest muy abultadas.

A continuación se muestran los diagramas de dispersión con las curvas de nivel de las variables pretest y postest de manera conjunta y los histogramas de cada una de las variables.

Como se muestra en el gráfico 5.33, en este caso las distribuciones son más homogéneas y ajustadas a una distribución normal a nivel general. De hecho, la recta de regresión indica que en cuanto a la tendencia de los sujetos en las puntuaciones obtenidas en el pretest y el postest, existe una correlación alta entre obtener una buena puntuación en el pretest y hacerlo en el postest. Lo mismo ocurre viceversa. 

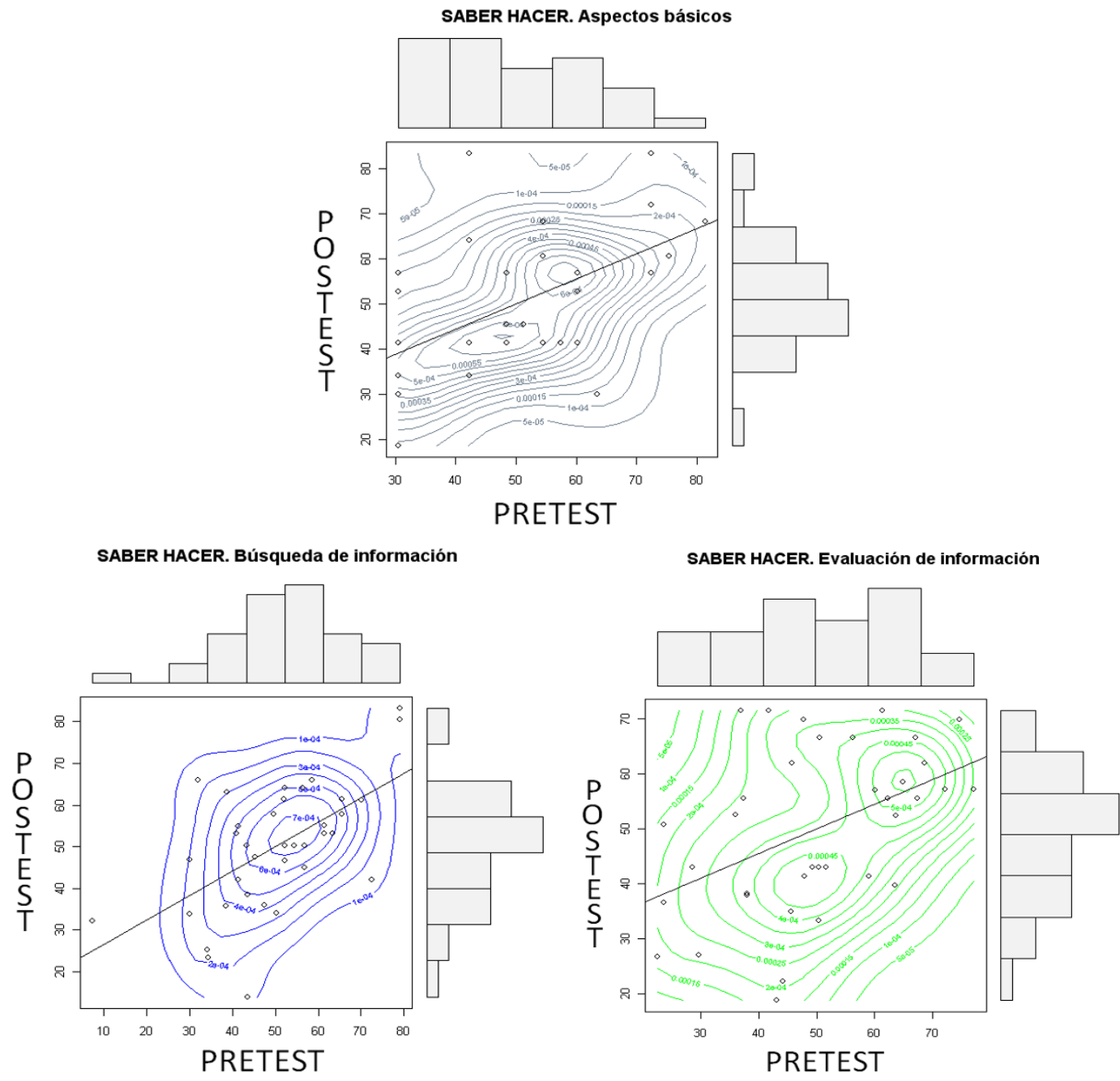

SABER HACER. Procesamiento de información
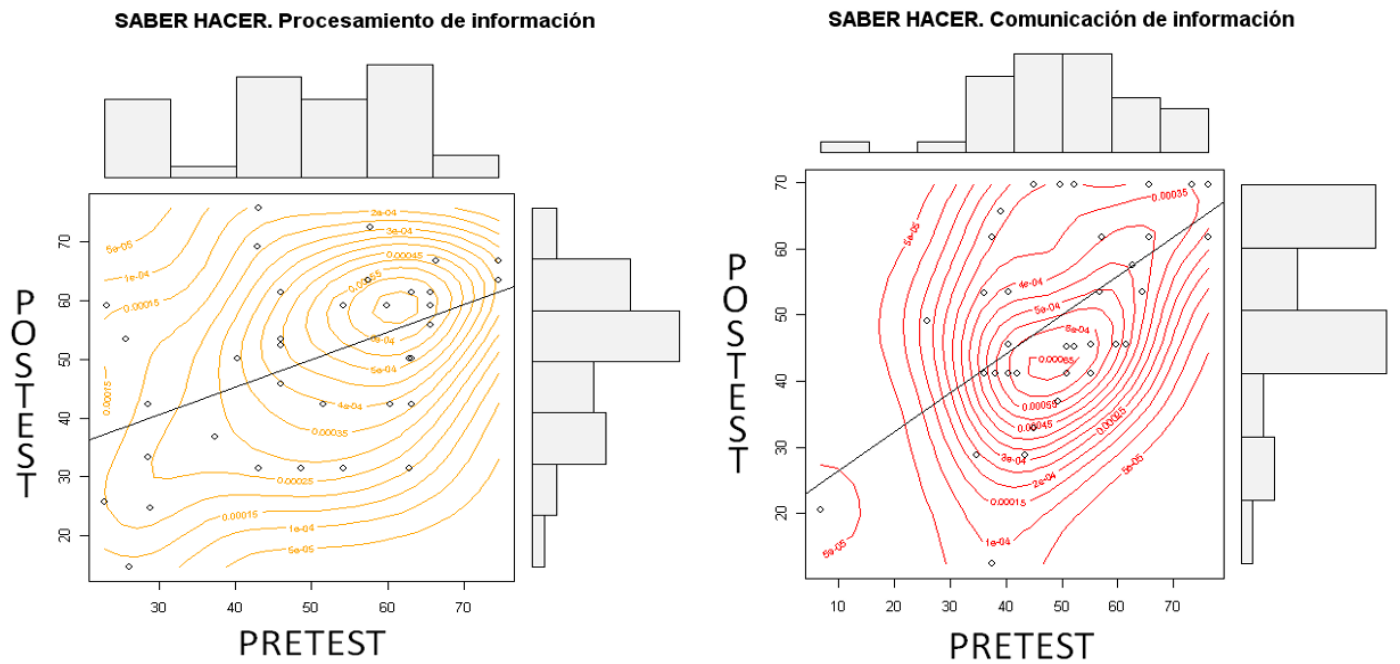

Gráfico 5.33 Diagramas de dispersión e histograma variables bidimensionales. Saber hacer

También se puede observar, aunque de manera menos manifiesta, cómo la variabilidad es ligeramente superior en el pretest que en el postest.

Evidentemente, dado que las puntuaciones en el postest son mejores que en el pretest, se vuelve a recoger la tendencia hacia una mayor asimetría negativa en el 
postest que en el pretest. Veamos esta tendencia más claramente en las funciones de densidad conjuntas de las variables de evaluación y tratamiento de información.

SABER HACER. Evaluación de información

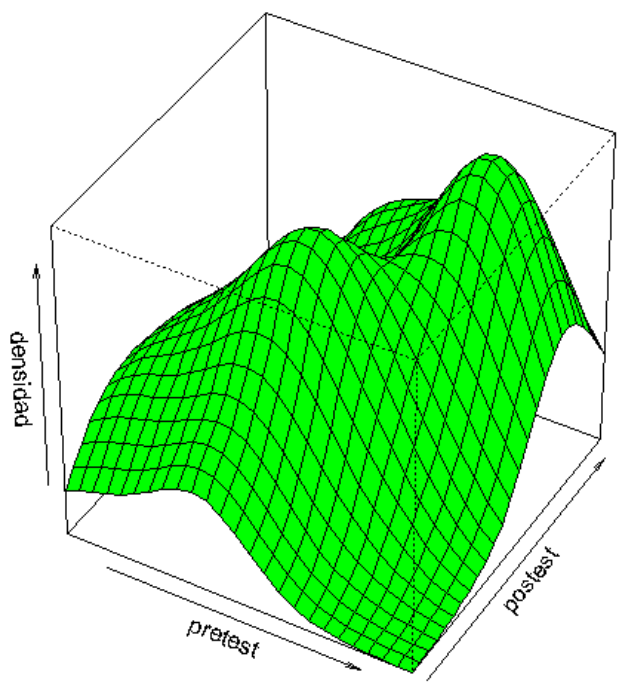

SABER HACER. Procesamiento de información

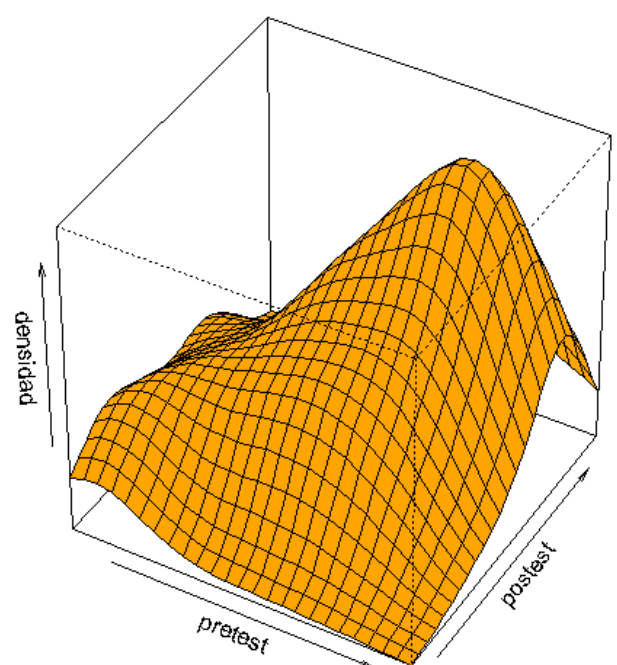

Gráfico 5.34 Funciones de densidad conjuntas evaluación y tratamiento. Saber hacer

En ambos casos, la función de densidad indica una alta correlación positiva entre el pretest y el postest, con una ligera variabilidad mayor en el pretest.

Por último, nos encontramos con las gráficas correspondientes a las diferentes variables de la escala de actitudes hacia las competencias informacionales (gráfico $5.35)$.

Vuelve a destacar en las distribuciones la existencia de casos extremos que en el pretest obtenían puntuaciones muy bajas. En estos casos, se puede observar cómo las puntuaciones en el postest de estos sujetos son cercanas a la mediana. 


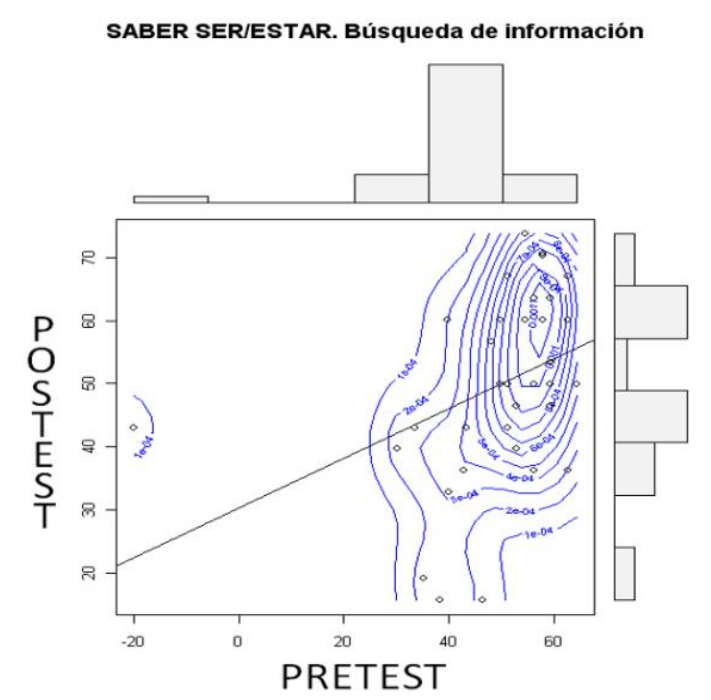

SABER SER/ESTAR. Procesamiento de información

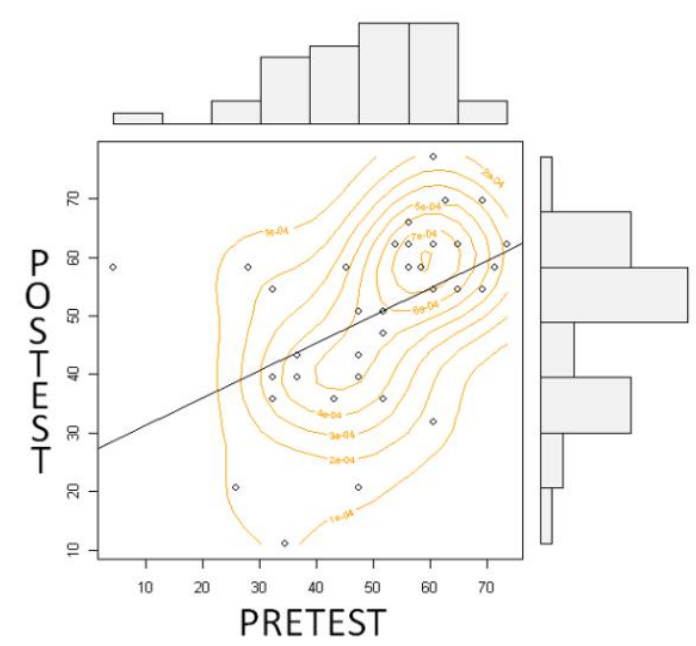

SABER SER/ESTAR. Evaluación de información

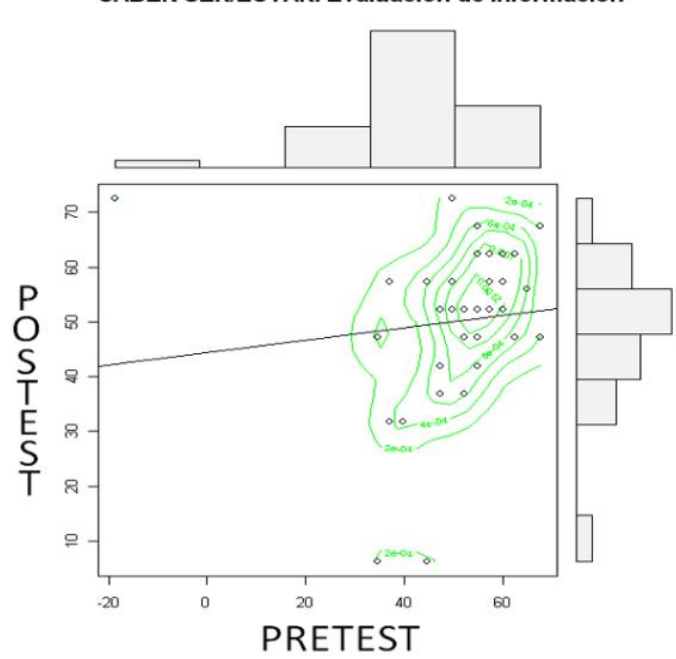

SABER SER/ESTAR. Comunicación de información

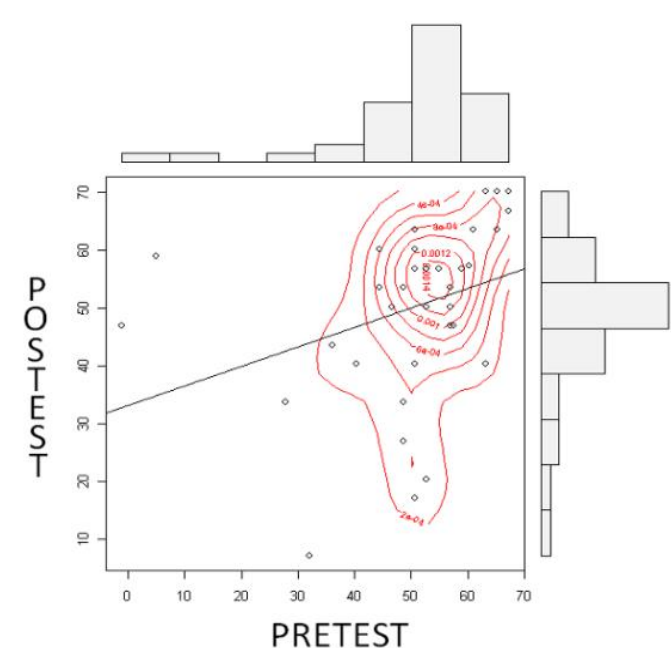

Gráfico 5.35 Diagramas de dispersión e histograma variables bidimensionales. Saber ser/estar

Por otro lado, destaca en estas distribuciones, tanto en el pretest como en el postest, la fuerte tendencia hacia el predomino de puntuaciones altas y la poca variabilidad en el rango de puntuaciones de todas las variables. Especialmente, se puede observar esta tendencia en la evaluación y la comunicación de información, como se muestra en el gráfico 5.36 . 

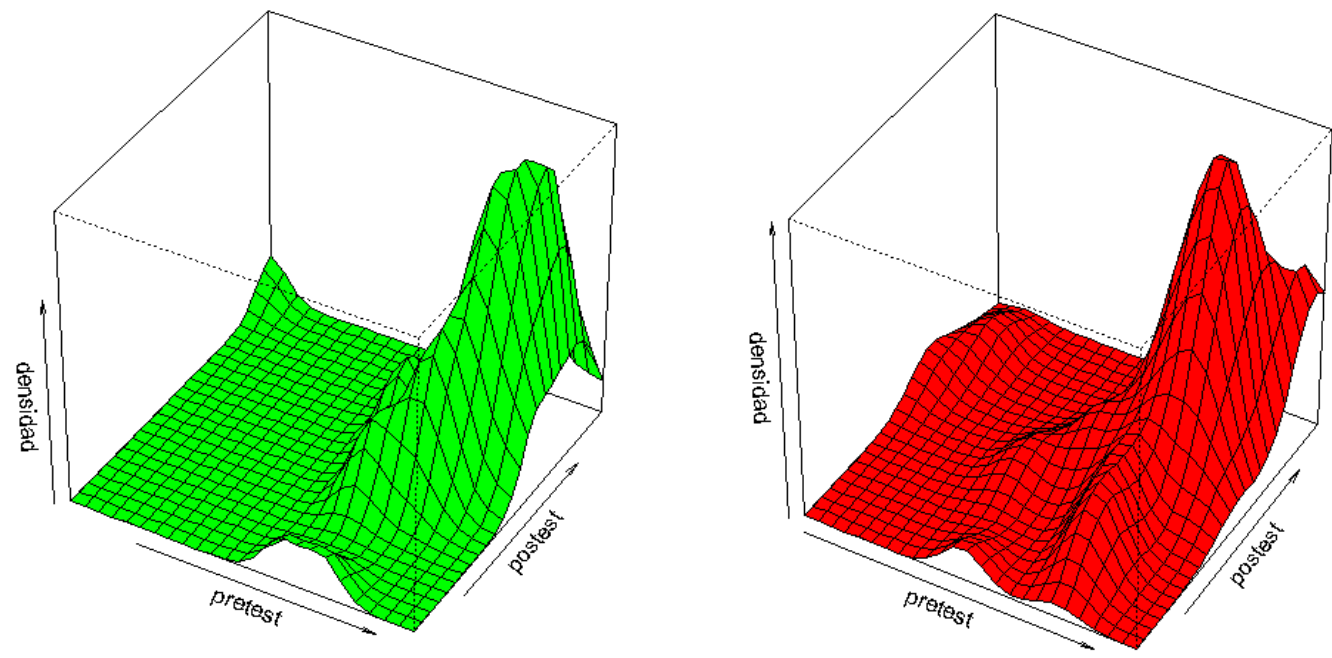

Gráfico 5.36 Funciones de densidad conjuntas evaluación y comunicación. Saber ser/estar

Se observa en dicho gráfico cómo, mientras que los valores extremos obtenidos en el pretest provocan que las distribuciones aparenten una mayor variabilidad en el postest que en el pretest, en realidad no existen grandes diferencias en esta variabilidad. Por otro lado, lo que sí se observa claramente es el apuntamiento de la función de densidad en los valores altos del pretest y el postest. Este hecho es el que nos está indicando que las diferencias registradas en el pretest y el postest, a pesar de ser significativas en algunos casos, poseen tamaños de efecto bajos o medios-bajos.

\subsubsection{Escala de satisfacción}

La escala de satisfacción, tomada a partir de la escala empleada para la evaluación de la satisfacción de varios Cursos Extraordinarios de Verano de la Universidad de Salamanca en el Departamento de Didáctica, Organización y Métodos de Investigación (Área de Métodos de Investigación), consiste, como ya se ha señalado, en 16 ítems de escala tipo likert de 1 a 5 más una pregunta abierta. En cuanto a los ítems de respuesta cerrada, los resultados se pueden observar en la tabla 5.22.

Tabla 5.22 Descriptivos básicos ítems escala de satisfacción

\begin{tabular}{lc|ccccc|ccc}
\hline \multicolumn{1}{c|}{ Escala de satisfacción } & $\boldsymbol{n}$ & $\mathbf{1}(\%)$ & $\mathbf{2}(\%)$ & $\mathbf{3 ~ ( \% )}$ & $\mathbf{4}(\%)$ & $\mathbf{5}(\%)$ & $\overline{\boldsymbol{X}}$ & $\boldsymbol{S}_{\boldsymbol{x}}$ & $\boldsymbol{C V}$ \\
\hline Profesor 2 (ITEM_12) & 29 & 0.0 & 0.0 & 0.0 & 13.8 & 86.2 & 4.86 & 0.35 & $7.22 \%$ \\
\hline Profesor 1 (ITEM_11) & 29 & 0.0 & 0.0 & 3.4 & 24.1 & 72.4 & 4.69 & 0.54 & $11.54 \%$ \\
\hline Material 1 (ITEM_03) & 29 & 0.0 & 0.0 & 10.3 & 34.5 & 55.2 & 4.45 & 0.69 & $15.42 \%$ \\
\hline Material 2 (ITEM_04) & 29 & 0.0 & 0.0 & 3.4 & 48.3 & 48.3 & 4.45 & 0.57 & $12.87 \%$ \\
\hline General 1 (ITEM_15) & 29 & 3.4 & 0.0 & 3.4 & 34.5 & 58.6 & 4.45 & 0.87 & $19.55 \%$ \\
\hline
\end{tabular}




\begin{tabular}{ll|ccccc|ccc}
\hline Actividades 2 (ITEM_14) & 29 & 0.0 & 0.0 & 13.8 & 31.0 & 55.2 & 4.41 & 0.73 & $16.60 \%$ \\
\hline Material 3 (ITEM_05) & 29 & 0.0 & 0.0 & 13.8 & 41.4 & 44.8 & 4.31 & 0.71 & $16.53 \%$ \\
\hline Programa 2 (ITEM_02) & 29 & 3.4 & 0.0 & 10.3 & 37.9 & 48.3 & 4.28 & 0.92 & $21.56 \%$ \\
\hline General 2 (ITEM_16) & 29 & 3.4 & 0.0 & 10.3 & 37.9 & 48.3 & 4.28 & 0.92 & $21.56 \%$ \\
\hline Programa 1 (ITEM_01) & 29 & 6.9 & 6.9 & 6.9 & 17.2 & 62.1 & 4.21 & 1.26 & $30.05 \%$ \\
\hline Metodología 1 (ITEM_06) & 29 & 3.4 & 0.0 & 13.8 & 37.9 & 44.8 & 4.21 & 0.94 & $22.35 \%$ \\
\hline Metodología 2 (ITEM_07) & 29 & 3.4 & 0.0 & 17.2 & 51.7 & 27.6 & 4.00 & 0.89 & $22.16 \%$ \\
\hline Actividades 1 (ITEM_13) & 29 & 6.9 & 10.3 & 17.2 & 31.0 & 34.5 & 3.76 & 1.24 & $33.09 \%$ \\
\hline Participación 3 (ITEM_10) & 29 & 3.4 & 3.4 & 37.9 & 48.3 & 6.9 & 3.52 & 0.83 & $23.57 \%$ \\
\hline Participación 1 (ITEM_08) & 29 & 13.8 & 3.4 & 37.9 & 34.5 & 10.3 & 3.24 & 1.15 & $35.61 \%$ \\
\hline Participación 2 (ITEM_09) & 29 & 13.8 & 17.2 & 27.6 & 17.2 & 24.1 & 3.21 & 1.37 & $42.68 \%$ \\
\hline
\end{tabular}

* Media y desviación típica obtenidas de escala entre 1 y 5 (1=Totalmente en desacuerdo; 5=Totalmente de acuerdo)

Se observa cómo el ítem con una mayor media es el número 12, referido al profesor, "el profesor resuelve las dudas de los alumnos", seguida por el otro ítem referido al profesor, "el profesor explica con claridad cuando interviene en los foros". Ambos ítems tienen una media muy alta $(\bar{X}>4.5)$. Con medias altas $(4<\bar{X}<4.5)$ también se encuentran, en primer lugar, los ítems referidos al material proporcionado en el curso, "se nos ha proporcionado material de trabajo para poder profundizar en los temas tratados", "hemos tenido la oportunidad de consultar diverso material" y "los materiales que han aportado los profesores favorecen la comprensión del contenido". En segundo lugar, con medias altas nos encontramos los ítems de satisfacción general, "a pesar de las limitaciones, me siento satisfecho realizando este curso" y "recomendaría este curso a otros compañeros". Los ítems referidos a la metodología reciben puntuaciones medias-altas, "estoy satisfecho con la metodología didáctica utilizada en este curso formativo" y "la metodología utilizada favorece el aprendizaje de los contenidos". Con puntuaciones bajas se encuentran los ítems referidos a la participación activa de los alumnos durante el curso, "he participado preguntando dudas", "me cuesta intervenir online aportando ideas" y "he trabajado con mis compañeros para resolver las cuestiones que dudaba". A pesar de considerar estas puntuaciones como bajas, todas ellas están por encima de la puntuación media de la escala, 3. En cuanto a los aspectos relacionados con las actividades, la tendencia es menos clara, ya que se observa un ítem en puntuaciones altas, "las actividades me han permitido comprender mejor los contenidos" y medias, "hemos tenido suficiente tiempo para desarrollar las actividades". Esta poca consistencia en las respuestas se debe a la naturaleza de los ítems, que en el caso de la segunda variable se refiere más al tiempo disponible para hacer las actividades que a las propias actividades. 
Estas tendencias se pueden observar mucho mejor si calculamos estos estadísticos para las categorías antes señaladas (tabla 5.23).

Tabla 5.23 Descriptivos básicos categorías escala de satisfacción

\begin{tabular}{lc|ccccc|ccc}
\hline \multicolumn{1}{c|}{ Escala de satisfacción } & $\boldsymbol{n}$ & $\mathbf{1}(\%)$ & $\begin{array}{c}\mathbf{2} \\
\text { (\%) }\end{array}$ & $\mathbf{3}$ (\%) & $\mathbf{4}(\%)$ & $\mathbf{5}(\%)$ & $\bar{X}$ & $\boldsymbol{S}_{\boldsymbol{x}}$ & $\boldsymbol{C V}$ \\
\hline profesor & 29 & 0.00 & 0.00 & 1.72 & 18.97 & 79.31 & 4.78 & 0.39 & $8.20 \%$ \\
\hline Material & 29 & 0.00 & 0.00 & 9.20 & 41.38 & 49.43 & 4.40 & 0.54 & $12.21 \%$ \\
\hline General & 29 & 3.45 & 0.00 & 6.90 & 36.21 & 53.45 & 4.36 & 0.84 & $19.35 \%$ \\
\hline Programa & 29 & 5.17 & 3.45 & 8.62 & 27.59 & 55.17 & 4.24 & 0.91 & $21.51 \%$ \\
\hline Metodología & 29 & 3.45 & 0.00 & 15.52 & 44.83 & 36.21 & 4.10 & 0.85 & $20.69 \%$ \\
\hline Actividades & 29 & 3.45 & 5.17 & 15.52 & 31.03 & 44.83 & 4.09 & 0.79 & $19.37 \%$ \\
\hline Participación & 29 & 13.79 & 8.05 & 34.48 & 33.33 & 10.34 & 3.18 & 0.69 & $21.78 \%$ \\
\hline
\end{tabular}

* Media y desviación típica obtenidas de escala entre 1 y 5 (1=Totalmente en desacuerdo; 5=Totalmente de acuerdo)

Como se podía percibir en los datos descritos anteriormente, la categoría mejor valorada, con diferencia respecto a las anteriores, es la del profesor. Por otra parte, en la parte baja se queda, como era previsible, la categoría participación. El resto de categorías quedan en posiciones intermedias con valores altos de la media y similares entre sí (distanciadas alrededor de 20 centésimas de máximo).

La satisfacción general con el curso es alta, ya que supera con creces los 4 puntos de valoración, quedándose cerca del 4.5, que hemos señalado como muy alto. Así, se puede afirmar que los alumnos declaran una alta satisfacción general hacia el curso, y valoran de manera bastante elevada las categorías específicas.

En cuanto a las valoraciones vertidas en la pregunta abierta, se localizan tanto sugerencias de mejora en algunos aspectos, como de valoración positiva en otros.

El aspecto que más críticas recibe es el tiempo disponible para la realización de las actividades y el solapamiento de las mismas. Algunos comentarios al respecto de los alumnos son los siguientes:

"La duración de las actividades debería ajustarse a las fechas acordadas en un primer momento pues los cambios posteriores generan confusión. Además a veces su duración es breve pues se solapa con otras y no podemos dedicarle el tiempo que quisiéramos." 
"El tiempo para la realización de las actividades me ha parecido correcto, sin embargo, al ser todo con ordenador me parece difícil el cuantificar las horas que se dedican a cada actividad (creo que se echan más de las que en inicio se piensa)."

"Con respecto a las actividades, me gustaría comentar que en ocasiones me agobiaba un poco porque las actividades individuales se solapaban con las grupales y con los foros."

"Habría que dejar más tiempo para realizar las actividades. Es un curso muy intenso."

"Yo particularmente necesitaría más tiempo para realizar bien los ejercicios porque en la mayoría he hecho una lectura superficial que solo me ha valido para la resolución del problema por falta de tiempo..."

Sin embargo, en cuanto al solapamiento de las actividades, también se reconocen aspectos positivos:

"sí que hubiera preferido que las actividades no se solapasen [...] No obstante, tal vez esta capacidad para realizar distintas actividades a la vez, tan características de internet y de las TIC, sea necesaria en todo trabajo online. Por otro lado, hay que reconocer la flexibilidad en cuestión de límites de entrega que se nos ha concedido, permitiéndome así adaptar cada actividad a mi propio ritmo y disponibilidad."

Otro aspecto en el que los alumnos señalan algo de disconformidad es en cuanto a la participación en actividades grupales, ya que consideran que los cursos online, dada su naturaleza, dificultan la realización de este tipo de trabajos. Por ello, consideran que la metodología empleada en las actividades de grupo debería haber sido de otra manera que facilitara más su correcto desempeño:

"Quizá la metodología de los foros pudiera enfocarse mejor a grupos más pequeños de debate"

“...creo que la organización de los grupos debería estar más controlada (o diseñada de otro modo), puesto que prácticamente en las dos actividades grupales ha habido poca participación y una persona, dos o tres no pueden encargarse del trabajo de todas" 
"Yo mejoraría el apartado de hacer un trabajo o tener un foro para hacer algo entre todos los alumnos. Creo que es un poco utópico porque siempre unos hacen y otros no y esto se controlaría mejor por pequeños grupos de trabajo como se ha hecho en otras actividades."

"En las actividades grupales era muy difícil poder intervenir aportando algo nuevo porque las primeras personas que lo hacían no dejaban contenido sin tratar para poder hacerlo."

Parece, pues, que los alumnos perciben que las actividades en grupo deberían haberse realizado con tamaños de los grupos más reducidos. Así se habría facilitado la organización de los mismos y el desempeño de las actividades encomendadas.

En general, los alumnos valoran el resto de aspectos del curso, desde la disponibilidad del profesor implicado en la tutorización el curso, hasta los materiales facilitados y las actividades programadas:

"Sinceramente, me ha sorprendido este curso online, ya que he realizado otros en esta misma universidad y la metodología era muy diferente. Me ha gustado el fomento a la participación continua, tanto individual como colectiva. Enhorabuena."

"Muy positivo el incluir el documento de instrucciones de la actividad porque tienes visible en todo momento lo que vas a trabajar y qué se va a valorar en la tarea final. A lo largo del curso no he echado en falta nada!! implicación del profesor, bibliografía, recursos, contenidos útiles, distintos formatos de trabajo, ... Una valoración totalmente positiva!!"

"...estoy muy contento con el curso. Me ha parecido muy útil, he aprendido muchas cosas nuevas y afianzado otras que creía saber pero que no era así. El profesor me ha parecido accesible [...] Programas como Zotero o la redacción de textos científicos me han parecido de muchísima utilidad. El trabajo en grupo online me ha resultado mucho más fácil de lo que imaginaba"

"...en lo que respecta al curso, estoy muy satisfecha, ienhorabuena! la verdad, es que ha superado mis expectativas."

"...felicitar a los organizadores, pues me ha resultado provechoso y útil." 
"Las explicaciones y el planteamiento del curso han sido perfectas y muy muy interesantes."

Por tanto, las valoraciones cualitativas de los alumnos son acordes con los datos registrados en la escala cuantitativa, ya que valoran muy positivamente la organización y desarrollo general del curso, centrando las críticas en la participación activa de los alumnos en los trabajos en grupo y en el solapamiento y el tiempo disponible para la realización de las actividades. 


\subsection{Resumen}

El capítulo quinto de la presente Tesis Doctoral aborda el estudio II, consistente en el diseño, implementación y evaluación de un programa formativo para la enseñanza de competencias informacionales al futuro profesorado de educación secundaria. Tras el análisis de los resultados obtenidos en la evaluación diagnóstica del estudio I, estamos en condiciones de desarrollar un estudio de este ámbito desde un punto de partida que aporte más garantías de éxito.

Se comienza el estudio II describiendo la metodología de investigación. Tras la exposición de los antecedentes del estudio y los propios objetivos generales y operativos, se muestra cómo nos encontramos con estudio de corte experimental (o cuasi-experimental, dado que se trabaja sin grupo de control) de natrualeza pretestpostest, con un tratamiento intermedio que no es otra cosa que el propio curso de formación.

Tras la descripción de los principales ejes vertebradores que estructuran el programa formativo, se procede a la exposición de las variables e instrumentos aplicados en el estudio. A partir de este punto, se dedica buena parte del apartado de metodología de la investigación a describir la fiabilidad y validez de los instrumentos del inventario diseñado para la evaluación de las competencias informacionales en el pretest y el postest. Asi, se muestra cómo se ha llevado a cabo el proceso de diseño de los instrumentos, y su validación por jueces en un primer lugar, y el análisis de fiabilidad y validez en un segundo lugar.

Se finaliza el apartado de metodología de investigación señalando los principales aspectos sobre el proceso de muestreo llevado a cabo, esquematizando cómo se ha desarrollado el procedimiento de aplicación del programa y de los instrumentos de evaluación y anticipando las técnicas de análisis de datos que se aplicarán durante la exposición de resultados.

El resto del capítulo se dedica al análisis de los resultados obtenidos en el programa. En primer lugar, con la intención de obtener un mayor conocimiento de las características básicas de las funciones de densidad de las variables y de seleccionar las técnicas estadísticas más adecuadas para cada caso, se procede a un estudio exploratorio de las variables del pretest y el postest. Dicho estudio se continúa con un análisis más sistemático de las propias distribuciones de las variables, de cara a 
confirmar en cada caso la pertinencia de emplear técnicas paramétricas, paramétricas con medias recortadas, o no paramétricas.

Una vez llevado a cabo este análisis previo al estudio inferencial propiamente dicho, se lleva a cabo el contraste de hipótesis entre todos los pares de variables con las técnicas seleccionadas. Estos contrastes, junto con los tamaños de efecto obtenidos, muestran cómo el éxito del programa ha sido alto, sobre todo en lo que respecta a la formación en conocimientos teóricos (saber) y, en menor medida, procedimientales (saber hacer). Como técnica anexa a los contrastes de hipótesis aplicados se lleva a cabo un estudio de tipo gráfico de las funciones conjuntas pretestpostest a lo largo de las diversas variables. Los análisis muestran cierta consistencia entre el pretest y el postest $y$, como diferencias más significativas, una tendencia generalizada a una menor variabilidad y una asimetría negativa más pronunciada en el postest.

Por último, se analiza la escala de satisfacción aplicada al finalizar el curso. Los resultados muestran una satisfacción alta, sobre todo con respecto al profesorado del curso y a los materiales facilitados.

En suma, los resultados del estudio II muestran cómo el curso online ha sido exitoso, principalmente en los aspectos que más potencian en este tipo de cursos, como son el aprendizaje de contenidos de tipo teórico y la calidad de los materiales presentados. 



\section{Capítulo VI}

DISCUSIÓN Y CONCLUSIONES 


\section{Capítulo VI}

Discusión y conclusiones

6.1 Discusión: Marco teórico

6.2 Discusión: Estudio I

6.3 Discusión del estudio experimental

6.4 A modo de conclusión 


\section{Discusión y conclusiones}

\subsection{Discusión: Marco teórico}

A lo largo de todo el marco teórico, se ha definido pormenorizadamente el contexto de la sociedad de la información, y se han analizado las consecuencias que la misma implica en la formación de sus ciudadanos.

Se observa cómo en este entorno el concepto de alfabetización sigue evolucionando hacia modelos más comprensivos y multidimensionales, que impliquen una formación más integral, flexible, contínua e implicada con el propio concepto de ciudadano activo.

Dado que los mismos ejes alrededor de los que se fundaron las bases de institución escolar han mutado, es necesario repensar tanto la formación del profesorado, como de los estudiantes. Todo este cambio lleva a modificar los paradigmas educativos que fundamentan las prácticas y los procesos de enseñanzaaprendizaje.

Así, se ha llegado a la situación actual, en la que el modelo de formación basado en competencias se ha impuesto de manera generalizada, y en la que, por ende, surge una competencia básica novedosa, las denominadas competencias informacionales.

Parece que las competencias informacionales forman una parte esencial de los conocimientos, habilidades y actitudes que todo ciudadano de la sociedad de la información debería dominar.

\section{De la sociedad de la información a la sociedad del conocimiento}

El desarrollo de la tecnología humana, principalmente en el campo de las TIC, han provocado una metamorfosis total en la mayoría de los campos y en la manera en la que el hombre se relaciona con el entorno (Castells, 1998, 1999a, 1999b).

El desarrollo exponencial de las TIC, unido con su gran potencial de inserción en todos los ámbitos de la vida humana (Tubella i Casadevall \& Vilaseca i Requena, 2005), ha cambiado el mundo, y lo sigue cambiando a una velocidad hasta hace sólo unos años impensable (Cebrián Herreros, 2009; Majó i Cruzate \& Marqués, 2002). 
De hecho, muchos autores hablan de la revolución informacional o tercera revolución industrial para designar este periodo de cambios relacionados con tecnologías que facilitan y fomentan el uso eficiente de la información (Area Moreira, 2001; Cabero Almenara \& Alonso García, 2007; Castells, 1999a; D. Cohen \& McCuaig, 2008).

Así, ¿cómo denominar este nuevo contexto socio-cultural? En este sentido, existe un controvertido debate entre el concepto sociedad de la información o sociedad del conocimiento (Cassity \& Ang, 2006; Cebrián Herreros, 2009; D. Cohen \& McCuaig, 2008; Sakaiya \& Fields, 1991; Valimaa \& Hoffman, 2008). Partiendo de la idea de que el conocimiento es el conjunto de informaciones filtradas, procesadas, asimiladas e interiorizadas por un sujeto o grupo de sujetos, y que generan riqueza y desarrollo, se entiende que la información simplemente se puede considerar como un conjunto de datos codificados y dispuestos con algún tipo de organización que les confiere legibilidad.

Así, los defensores de la denominación sociedad del conocimiento entienden que el eje de la nueva sociedad es el manejo, intercambio y generación eficiente del conocimiento. Sin embargo, esta terminología está en desuso al entender gran parte de los estudiosos de estos ámbitos que lo que se mueve en nuestra sociedad son flujos de información, que no necesariamente se convierten en conocimientos (Cebrián Herreros, 2009; D. Cohen \& McCuaig, 2008; Majó i Cruzate \& Marqués, 2002). No debemos olvidar los augurios de Campbell en este sentido, cuando indica que "We're drowning in information and starving for knowledge» (1985, p. 10).

Desde nuestro punto de vista, las evidencias localizadas en la literatura consultada nos inclina a pensar en el presente contexto social como la sociedad de la información, lejos de convertirse en lo que algunos denominan como sociedad del conocimiento.

A pesar de estas diferencias palpables en las bases de la identificación del actual entorno, sí que existe un acuerdo general en cuanto a las características que lo guían. Así, podríamos enumerarlas en las siguientes:

- La información es valiosa y se convierte en un bien de consumo.

- Importancia capital de las nuevas tecnologías (Adell, 1997).

- Lógica de la interconexión global (Area Moreira, 2008). 
- Flexibilidad, capacidad de reconfiguración y de permanente cambio de las estructuras sociales (Bauman, 2007; Markauskaite, 2006; Méndez Paz, 2005).

- Especificidad del mercado de trabajo: Por un lado, nos encontramos con la exigencia de formación a lo largo de toda la vida (Federighy, 2006; Fernández Ludeña, 2007; Sabán Vera \& Monclús Estella, 2008), y por otro con la exigencia de perfiles profesionales en los que se integran nuevas exigencias (Lankshear \& knobel, 2008).

- Importancia de la interdisciplinariedad y el trabajo cooperativo en los procesos sociales (Castells, 1999a; Guitert et al., 2007; Monereo, 2005).

- Avance e imposición de la globalización, y nacimiento de la glocalización a nivel local (Franco, 2000; Robertson, 2003).

- Surgimiento de una nueva economía basada en la información y el conocimiento (Castells, 1999a; Picardo Joao, 2002; Tubella i Casadevall \& Vilaseca i Requena, 2005).

Estas anteriores características, diferenciadoras de esta nueva sociedad con las anteriores, implican a su vez que en la literatura especializada se generalicen y expliciten algunas preocupaciones adosadas:

- Brechas de la sociedad de la información: Como brechas se puede entender tanto las posibilidades de acceso a las tecnologías que articulan la sociedad de la información (brecha digital), como las capacidades para el manejo eficiente de dichas tecnologías (brecha del conocimiento). A pesar de la generalización del concepto brecha digital (Cabero Almenara, 2004; Hernández Nanclares et al., 2003; Peña-López, 2010a, 2010b), se discute su pertinencia, al no tener en cuenta todas las dimensiones implicadas en las desigualdades de la sociedad de la información (Castaño-Muñoz, 2010; Cebrián Herreros, 2009; Pimienta, 2008; Selwyn, 2010). En este sentido, para mitigar la brecha que suponen las desigualdades que se relacionan con las posibilidades personales y/o grupales para aprovechar las tecnologías propias de la sociedad de la información, nos encontramos con la formación en competencias informacionales (búsqueda, evaluación, procesamiento y comunicación de información) más que la formación simplemente en competencias tecnológicas o digitales (Cabero Almenara, 2004; Monereo \& Coll, 2008). 
- Inmigrantes y nativos digitales: Como construcción teórica que desarrolla el concepto de las brechas de la sociedad de la información, nos encontramos con la idea de nativos e inmigrantes digitales (Prensky, 2001a, 2001b, 2005). El desfase que supone para los docentes y profesionales actuales haber nacido y crecido en una sociedad industrial, previa a la actual, es explicado con estos conceptos. En todo caso, esta visión de la realidad, que tanto éxito tuvo en su día al simplificarla de un modo excelente, es criticada a partir de la evidencia empírica, que indica que otras variables menos relevantes a priori como el género o el nivel socioeconómico son más explicativas, al menos, del nivel de competencia tecnológica y digital (Hargittai, 2010; Selwyn, 2010; Snyder, 2004). Además, cuando se mide la capacidad para el manejo de la información (competencias informacionales) más que para el manejo de las TIC, los nativos digitales muestran grandes dificultades, incluso más que el grupo definido como inmigrantes digitales (Gómez Hernández, 2010).

- Infoxicación (Cornellá, 2003, 2009): Nos encontramos en una sociedad abarrotada de información que fluye libremente (Cabero Almenara \& Alonso García, 2007; Martí Lahera, 2007; Pablos Pons, 2010; Scardamalia, 2004), ante la que, si no ponemos el remedio adecuado, aparecen síndromes de fatiga informacional (Baker, 2006; Kabachinski, 2004; Zelder, 2009). Este problema tiene remedio con la formación en competencias informacionales, cuyo dominio permite a las personas la selección de la información pertinente y necesaria en cada momento en función de sus necesidades (Andretta, 2005; Bruce, 1997; CRUE-TIC \& REBIUN, 2009, 2012; O’Farrill, 2008).

- La cultura del espectáculo (Ferrés i Prats, 2000): La cultura de masas ha virado completamente en los últimos años de lo ordinario al sensacionalismo, de lo racional a lo emocional, de lo estático a lo dinámico, de lo narrativo a lo analítico y de lo abstracto a lo concreto y físico. Ante este panorama, y la pasividad de las instituciones educativas en relación, la educación impartida por los docentes debe adaptarse rápidamente y asumir nuevos roles (Gisbert Cervera, 2002; Pavié Nova, 2011; Sánchez Asín et al., 2009; Touriñán López et al., 2003).

- La cultura mosaico (Moles, 1975): Las cápsulas informativas que nos ofrecen las tecnologías de la sociedad actual parecen estar inconexas (Cerezo, 2008), y la formación en competencias informacionales nos puede ayudar a organizar, 
integrar y convertir en conocimiento estas piezas (Majó i Cruzate \& Marqués, 2002; Pozo et al., 2006).

- La alfabetización funcional (Fernández Ludeña, 2007): Pasar de entender la alfabetización como la capacidad para descifrar códigos (UNESCO, 1957) a considerarla como la capacidad para desempeñar eficazmente actividades que requieren cualquier tipo de alfabetización, al servicio propio o del grupo (Fernández Ludeña, 2007; Ferreiro, 2002) supone pasar de entender la educación como una herramienta para enseñar a leer y escribir a entenderla como una oportunidad para formar ciudadanos integrados y comprometidos con el mundo y la sociedad (Lankshear \& knobel, 2008; Monereo \& Coll, 2008; Pozo et al., 2006).

- La vida líquida (Bauman, 2006, 2007): El conocimiento, al igual que el mundo que nos rodea, deja de ser estático, verdadero y único para convertirse en algo flexible, relativo e incierto. En este entorno, cobran una importancia capital las competencias que permiten aprender, reaprender y desaprender (Area Moreira, 2001; Majó i Cruzate \& Marqués, 2002; Pinto Molina et al., 2008), entre las que se puede localizar de manera destacada todo lo relacionado con las competencias informacionales (Bauman, 2007; Organización Internacional del Trabajo, 2003).

Como se ha visto, en la búsqueda de la conciliación entre las posturas inclinadas hacia la consideración del entorno actual como sociedad de la información y los estudiosos que lo consideran sociedad del conocimiento, se encuentran estos retos y las soluciones propuestas. En la actualidad nos encontramos en un punto intermedio entre la sociedad de la información y la sociedad del conocimiento (Pozo et al., 2006), ya que, a nivel general, las personas no han desarrollado suficientemente las competencias informacionales necesarias para manejar apropiadamente la información en todos los formatos en los que se le pueden presentar y transformarla en conocimiento después del proceso informacional (Area Moreira \& Guarro, 2012).

\section{La multialfabetización en el desarrollo de competencias informacionales}

Dado que la nueva sociedad ha sufrido cambios radicales en todos los aspectos, no parece descabellado pensar en la necesidad vigente de una transformación en los pilares básicos de la formación escolar. La alfabetización es un fenómeno cultural (Wagner, 1998), y como tal debe ser una herramienta que se adapte a las realidades 
culturales de cada entorno espacial y temporal concreto (González FernándezVillavicencio, 2012; Koltay, 2009).

Así, se desarrollan numerosos estudios que tratan de acotar y adaptar el concepto de alfabetización a la realidad de cada contexto histórico concreto.

Así, gracias principalmente a las revolucionarias ideas e investigaciones de Paulo Freire (Fiori et al., 1973; Freire, 1975, 1984, 1989), el concepto de alfabetización, estático desde el nacimiento de la escuela hasta entonces, sufre una metamorfosis durante los años 70 y 80 desde una concepción bancaria (UNESCO, 1957) hacia una concepción humanista y liberadora (Gee, 2003; Graff, 1979, 1981). La alfabetización pasa a concebirse, gracias a las ideas renovadoras de Freire, a partir de una postura socio-crítica, alejada radicalmente de la perspectiva positivista que reinaba en el concepto de alfabetización.

Desde entonces, hasta nuestros días, no se volvió a reparar en la importancia de repensar el significado que alfabetizar tiene en la sociedad en general. Así, actualmente, debido a los profundos cambios sociales, la noción de alfabetización está inmersa actualmente en otro cambio radical , con la intención de portar al término una mayor flexibilidad, multidimensionalidad y un sentido más permanente a lo largo de la vida de las personas.

Así, los estudios que proliferan al respecto, se apoyan principalmente en 5 factores que fundamentan este necesario cambio de perspectiva:

En primer lugar, nos encontramos con una realidad multidimensional, en la que existe una visión dinámica del mundo y del conocimiento (Lonsdale \& McCurry, 2004). Todos los conocimientos y aprendizajes que hasta ahora parecían absolutos e inamovibles se vuelven volátiles, dinámicos y cambiantes (Bauman, 2006, 2007).

Por otro lado, el nuevo contexto socio-laboral y económico (D. Cohen \& McCuaig, 2008) modifica por completo las necesidades formativas de los trabajadores exigibles por las empresas e industrias (Castells, 1999a). Estos cambios demandan el desarrollo de nuevas competencias (Cano García, 2008; de Kelete, 2008; Sabán Vera \& Monclús Estella, 2008) que requieren, a su vez, repensar el concepto de alfabetización (Cope \& Kalantzis, 1999, 2009a).

En tercer lugar cabe destacar la importancia capital del surgimiento de las TIC. Además del impacto de estas nuevas tecnologías relacionadas con el manejo y flujo de 
información en la sociedad en todos los contextos imaginables, el aspecto definitorio que implica la transformación del concepto de alfabetización es la aparición de nuevos modos y medios de representación de la realidad gracias a las mismas (Cope \& Kalantzis, 2009b; Kellner, 2004; Lankshear \& knobel, 2008; Lucero Fustes, González Gómez, \& Cubo Delgado, 2003). Al igual que en la sociedad industrial, la existencia del lenguaje oral y escrito como medio principal para transmitir e intercambiar información, determinó el concepto de alfabetización, la existencia en la sociedad actual de múltiples medios y modos para representar la realidad debería transformar este concepto de alfabetización.

Como cuarto factor a tener en cuenta, cabe señalar la crisis del modelo de estado tradicional (Castells, 1998, 1999a). Los estados, debido a la globalización capitalista y la lógica de la sociedad red promovida por las TIC, han perdido el control sobre muchos elementos sociales $y$, por ende, el modelo de escuela como entorno enculturizador de los ciudadanos en el espíritu y cultura de la nación deja de tener vigencia (Area Moreira, 2010b).

Por último, nos encontramos con un contexto dinámico, en el que emerge la necesidad de formación permanente, a lo largo de toda la vida (Buendía Eisman et al., 2009; Gaio Alves et al., 2010; Gunasekara \& Collins, 2008; OCDE, 2004b). La literatura e investigación científicas evidencian el poco sentido de presentar el conocimiento en las escuelas como algo estático, cerrado y absoluto (Area Moreira, 2010a; Cabero Almenara \& Alonso García, 2007; Monereo \& Coll, 2008).

Así, dados estos factores, lo que parece claro en la literatura es que nos enfrentamos a un cambio en la comprensión de lo que significa estar alfabetizado, desde una concepción unidimensional y estática de la alfabetización, hasta otra multidimensional y dinámica (Area Moreira \& Ribeiro-Pessoa, 2012; Cope \& Kalantzis, 2009b, 2009b; Ferreiro, 2002; Lankshear \& knobel, 2008; Monereo \& Coll, 2008). Existe por tanto un consenso en la literatura especializada en considerar la necesidad de transformar completamente el concepto de alfabetización en la sociedad actual (Area Moreira, 2010b; Buschman, 2010; Ferreiro, 1997; Levine, 1990; O'Farrill, 2008; Wagner, 1998), adoptando la perspectiva de la multialfabetización en la formación básica de la ciudadanía del siglo XXI (Cazden et al., 1996; Cope \& Kalantzis, 1999, 2009b; Kalantzis \& Cope, 2005b; Lankshear \& knobel, 2008; Pasadas Ureña, 2010a, 2010b). 
Ante esta nueva realidad social, que afecta a las bases mismas de la formación básica y superior, la evidencia empírica parece indicar que el entorno escolar no ha integrado los cambios necesarios (CNICE, 2007; OCDE, 2011; Pifarré et al., 2009; Sigalés et al., 2009; Sigalés \& Mominó, 2004) que faciliten la enseñanza de las diferentes representaciones de la realidad gracias al multimodo y el multimedio (Cope \& Kalantzis, 2009b). Mientras que la alfabetización escolar continúa siendo monomodal y "monomediada", la exigible en el mundo real es eminentemente multimodal y multimedia.

Es a partir de estas nuevas necesidades de alfabetización múltiple a partir de las que toman vigencia las competencias informacionales como competencias esenciales en la educación básica y en la educación superior (Area Moreira \& Ribeiro-Pessoa, 2012; Buschman, 2010). Esta coexistencia entre la teoría de la multialfabetización y el desarrollo de competencias informacionales se refleja claramente en alguno de los puntos principales de las normas y estándares promulgadas por las diversas instituciones nacionales e internacionales al respecto:

Así, en las normas del ALA/ACRL americano (2000), se hace referencia a elementos relacionados con la multialfabetización en varias ocasiones: En primer lugar, dentro de la primera competencia "ser capaz de determinar la naturaleza y nivel de la necesidad de información", incluye el indicador de rendimiento "ser capaz de identificar una gran variedad de tipos y formatos de fuentes potenciales de información". Por otro lado, en la cuarta competencia referida a la comunicación de información, se incluye un primer indicador "aplicar la información antigua y la nueva para planificar y diseñar un producto o actuación concreta", que incluye un resultado observable revelador al respecto, y que implica que el estudiante "maneja textos digitales, imágenes y datos según sea necesario, adaptándolos a nuevos contextos". Dentro de esta misma competencia, incorporado en el indicador "ser capaz de comunicar a los demás con eficacia el producto o actuación", se añade el resultado de aprendizaje "elige el medio y formato que mejor apoye los objetivos del producto o actuación y los destinatarios a los que se dirige".

En segundo lugar, en las normas del CAUL (2001) australiano, también se incluye alguna referencia al respecto. En la norma 2 "la persona con aptitudes para el acceso y uso de la información accede a la información requerida de manera eficaz y eficiente", se incluye el resultado "la persona con aptitudes para al acceso y uso de la información obtiene la información por medio de una gran variedad de métodos", que incorpora a su vez como ejemplo "utiliza varias herramientas de acceso a la información para 
recuperar la información en formatos diferentes". Por su parte, en la norma 5, referida a la generación de conocimientos a partir de la integración de informaciones nuevas con las ya incorporadas en el cerebro, nos encontramos con el resultado 5, "la persona con aptitudes para el acceso y uso de la información es capaz de comunicar a los demás con eficacia el producto", que incorpora el ejemplo "elige el medio y formato de comunicación que mejor apoye la finalidad del producto y la audiencia elegida".

Por último, ateniéndonos a las normas del SCONUL (2004) británico, podemos destacar, dentro de la competencia para diferenciar entre las diferentes formas de tratamiento de la información requerida, la subcompetencia "conocimiento de los recursos adecuados para cada situación, sea en el formato que sea".

Así, la revisión de la literatura muestra cómo la teoría de la multialfabetización está íntimamente relacionada con los contenidos propios de las competencias informacionales, y es un factor clave que articula y dirige el desarrollo de este tipo de competencias.

Por tanto, se observa cómo, a pesar de los esfuerzos llevados a cabo por una parte de la comunidad de estudiosos del ámbito de las Ciencias de la Educación, en concreto sobre la teoría de la multialfabetización y las competencias informacionales, en los procesos de enseñanza-aprendizaje existentes hoy en día en las escuelas se mantiene un concepto de alfabetización clásico, conforme a una educación bancaria y, por consiguiente, no se integran procedimientos efectivos para el desarrollo de competencias informacionales.

$\mathrm{Y}$, dado que, la calidad del propio equipo docente implicado en los procesos formativos es uno de los factores más decisivos en la mejora de la educación y de las competencias de los propios estudiantes (Escudero Muñoz, 2009), nos podemos plantear si una de las causas principales de esta situación es un déficit en la formación inicial y permanente del profesorado.

A nivel general, existe una tendencia generalizada en la literatura especializada a considerar que en el marco español la tradición en la formación inicial del profesorado, desde la creación de las prototípicas Escuelas Normales hasta la situación actual, acarrea una serie de déficits o problemas que siguen marcando los actuales problemas, además de desprestigiar la labor docente (Anguita Martínez, 1997; Benejam Arguimbau, 2002; Escolano Benito, 1982). 
Poco a poco, se observa cómo el cambio que se inicia en los años 70 , en los que se comienza a vislumbrar la integración de la formación de profesorado en el contexto universitario y se aumenta progresivamente la extensión de la formación inicial (Pavié Nova, 2011; Vaillant Alcalde, 2009), va concienciando a la sociedad sobre la necesidad de desarrollar un perfil profesional específico para la labor del profesor. Sin embargo, bajo el punto de vista de los estudiosos de la formación del profesorado, este perfil profesional, a pesar de los esfuerzos realizados en desarrollarlo, está muy lejos de implantarse en la propia cultura docente, mucho más si nos centramos en la formación inicial del profesorado de educación secundaria (González Sanmamed, 2009; Marcelo Garcia, 2009; Touriñán López et al., 2003). La perpetuación del criticado hasta la extenuación CAP desde los años 70 hasta hace tan solo unos pocos años ha socavado la identidad profesional del profesor de educación secundaria, convirtiendo esta labor en un 'mal menor' para matemáticos, físicos, filósofos,...

En este contexto que hemos definido, se observa cómo en los últimos años se están sucediendo estudios para el desarrollo de un mapa de competencias propio a los profesionales de la educación que "estandarice"los diferentes perfiles profesionales de los docentes de las diversas etapas educativas (Esteve Zarazaga, 2009; Gros, 2006; Gros Salvat \& Silva Quiroz, 2005; Nóvoa, 2009; Terigi, 2009).

Así, dentro de las funciones docentes está tanto tener una visión menos academicista y estática del conocimiento (Terigi, 2009), considerando los procesos de enseñanza-aprendizaje como procesos de investigación e intercambio multidireccional (Esteve Zarazaga, 2009; Sánchez Asín et al., 2009), como el dominio de ciertas competencias básicas, entre las que se incluyen, por supuesto, las competencias informacionales (Benito Morales, 2008; Gómez Hernández, 2010).

\section{La formación basada en competencias: las competencias informacionales}

Mientras que algunos autores entienden cómo, la generalización de la formación basada en competencias en todos los niveles educativos y la implantación en la mayor parte de países son una razón inherente suficiente para justificar su importancia (Monereo \& Badia, 2012), existe un acalorado debate que pone en tela de juicio su verdadero interés pedagógico (Bustamante et al., 2004; Gimeno Sacristán, 2008; Luengo Navas et al., 2008; Mulder et al., 2008; Perrenoud, 2012; Torres et al., 2002).

En primer lugar, si llevamos a cabo un análisis desde una perspectiva económica, socio-laboral e histórica, teniendo en cuenta que el concepto de formación basada en 
competencias tiene un nacimiento vinculado estrechamente al ámbito empresarial, que en el mundo laboral se generalizan los mapas de perfiles competenciales de determinadas profesiones, y que las perspectivas competenciales se identifican fácilmente con la eficacia, rentabilidad y eficiencia, se entiende el distanciamiento y escepticismo que algunos pedagogos quieren mantener al respecto (Gimeno Sacristán, 2008).

A esto hay que unirle el empleo de la noción de competencia que se realiza en la psicología conductual, lejano a las tesis constructivistas aceptadas generalmente hoy en día, y el parecido de estos modelos con las taxonomías de Bloom y la pedagogía por objetivos, hoy en día descartadas al menos a nivel ideal.

Así, los autores consultados coinciden en la preocupación por la mercantilización de la educación que podría llegar a desencadenarse si se generaliza el modelo de formación basado en competencias sin tener en cuenta estos aspectos (Gimeno Sacristán, 2008; Luengo Navas et al., 2008; Mulder et al., 2008).

Por el contrario, lo cierto es que, analizando el concepto de competencia desde una perspectiva pedagógica y teniendo en cuenta estos aspectos, parece que el modelo de formación basado en competencias parece responder adecuadamente a los retos que propone la formación en la sociedad de la información (Coll et al., 2010; Fernández Enguita et al., 2007; Villa Sánchez \& Poblete Ruiz, 2009). De hecho, se señalan generalmente varios factores que determinan el éxito actual del modelo de formación basado en competencias (Cano García, 2008; Zabala \& Arnau, 2007):

- Las características inherentes a la sociedad de la información. La formación por competencias se acerca más a una perspectiva interpretativa que positivista (Martínez Clares \& Echeverría Samanes, 2009) y, por tanto, se acerca más a lo que hemos analizado como necesidades educativas en la sociedad de la información.

- La función social del sistema educativo, de la enseñanza y del conocimiento. Las competencias están vinculadas a la acción, y transmiten al estudiante un punto de vista práctico, de agente activo en la propia sociedad (Zabala \& Arnau, 2007).

- La complejidad que alcanza hoy en día el conocimiento. El conocimiento hoy en día es interdisciplinar, complejo y dinámico (Liu et al., 2010; Rubio et al., 2010). El concepto de competencia permite acercarse a los conocimientos 
desde una perspectiva multidimensional y teniendo en cuenta que el conocimiento no es algo estático.

- La presión ejercida desde el sector socio-laboral. La necesidad de profesionales competentes en determinados aspectos es evidente en un mundo cada vez más profesionalizado (Tubella i Casadevall \& Vilaseca i Requena, 2005). No debemos olvidar por tanto la perspectiva profesionalizante que tienen los modelos de formación basados en competencias.

- El proceso de convergencia europea y de globalización planetaria. El concepto de competencia es abierto y adaptable a los diversos contextos (Perrenoud, 2012) en los que se implica. Así, en una sociedad global, el modelo de formación basado en competencias facilita por un lado una visión común e integral de la educación, pero sin impedir el desarrollo específico de las características culturales específicas de cada grupo social.

Una vez justificada adecuadamente la pertinencia y valor pedagógico de los modelos de formación basados en competencias en la sociedad actual, dado el nulo acuerdo sobre una definición del concepto competencia (Gimeno Sacristán, 2008; Perrenoud, 2012), parece necesario consensuar a qué nos referimos cuando estamos hablando de competencias.

Así, dada la propia naturaleza del concepto de competencia, y sus diferentes acepciones en función del contexto de empleo, en lugar de desarrollar una definición pretendidamente cerrada y acabada de competencia, se deberá atender a los puntos en común entre las definiciones estudiadas propias de nuestro ámbito (De Miguel Díaz, 2006; Eurydice-CIDE, 2002; González \& Wagenaar, 2003; Monereo, 2005; OCDE, 2004b; Perrenoud, 2004) y a varios interrogantes que la acoten (Zabala \& Arnau, 2007): qué es, para qué sirve, cómo lo hace, dónde se desarrolla y por medio de qué se implementa.

Atendiendo a todos estos aspectos, se acaba entendiendo la competencia como la capacidad que se tiene de movilizar un conjunto de recursos cognitivos para afrontar con garantías situaciones problemáticas en contextos académicos o profesionales concretos.

Esta definición propia de formación por competencias se adapta perfectamente a la realidad multidimensional e interdisciplinar propia de la sociedad de la información, expuesta hasta el momento. De hecho, se puede desarrollar un modelo de formación 
basado en competencias comprensivo y adaptable a este contexto a partir de las ideas de los principales autores consultados (Bolívar Botía, 2009; de Miguel Díaz, 2006; Delors, 1997; Perrenoud, 2012; Villa Sánchez \& Poblete Ruiz, 2009; Zabala \& Arnau, 2007).

Teniendo como perspectiva y meta global el aprendizaje integral de las personas, esto es, el desarrollo de la competencia para el aprendizaje (Bolívar Botía, 2009), el modelo de formación basado en competencias se estructura desde tres dimensiones:

Los ámbitos de la competencia (Zabala \& Arnau, 2007): entendiendo ámbitos como áreas de desarrollo personal que promociona o puede promocionar cada competencia desarrollada. Entre los ámbitos, podemos definir el ámbito social, el ámbito personal, el ámbito inter-personal y el ámbito profesional.

Los componentes de la competencia (De Miguel Díaz, 2006; Delors, 1997): considerados como los diferentes aspectos a trabajar dentro de toda competencia. Se definen dentro de los componentes el saber, saber hacer, saber ser y saber estar.

Las competencias básicas (Villa Sánchez \& Poblete Ruiz, 2009): Es el primer nivel de concreción del contenido propio de los currículos y/o de los procesos de enseñanzaaprendizaje, haciendo referencia a capacidades y comportamientos concretos e identificables en grupos de sub-competencias. Y como ya se ha reflejado hasta el momento, las competencias informacionales se consideran competencias básicas (Area Moreira \& Ribeiro-Pessoa, 2012; Area Moreira, 2010a; CRUE-TIC \& REBIUN, 2009, 2012).

Partiendo de la premisa de que la formación en la sociedad de la información ha adoptado las competencias informacionales como uno de sus pilares esenciales (Mackey \& Jacobson, 2011; Weiner, 2010; Williamson, 2009), parece razonable considerar que su estudio y desarrollo se debería promover desde las instituciones educativas. De hecho, en materia de política educativa, se han sucedido pasos importantes dirigidos a impulsar el desarrollo de estas competencias.

Tanto a nivel nacional como internacional, se han integrado las competencias informacionales como parte de las competencias básicas o clave que deben haber sido adquiridas por todas las personas que finalizan la educación básica. Esto queda reflejado a nivel europeo en las Recomendaciones del Parlamento Europeo y del Consejo de 18 de diciembre de 2006 sobre las competencias clave para el aprendizaje permanente, que señala la competencia digital como una de las 8 competencias clave 
y la vincula estrechamente con las TIC. El citado texto define las competencias digitales como «el uso de ordenadores para obtener, evaluar, almacenar, producir, presentar e intercambiar información, y comunicarse y participar en redes de colaboración a través de internet» (Diario oficial de la Unión Europea, 2006, p. 15). En un contexto más cercano, a nivel de España, si nos situamos en la etapa educativa de la educación secundaria, en la que se encuentra la población que abarca esta investigación, podemos encontrar la Orden ECl/2220/2007, de 12 de julio, por la que se establece el Currículo y se regula la ordenación de la Educación Secundaria Obligatoria. En dicho documento se plantea como una de las competencias básicas para la etapa de educación secundaria el tratamiento de la información y la competencia digital, que se define como «seleccionar, tratar y utilizar la información y sus fuentes, así como las distintas herramientas tecnológicas» (Boletín Oficial del Estado, 2007b, p. section31690). Se puede observar cómo se vuelven a vincular muy íntimamente las competencias informacionales con el manejo de herramientas informáticas y cómo se considera esta competencia como clave y básica en el currículo oficial.

Parece, por tanto, que a nivel de política educativa se avanzado positivamente en este aspecto, y se verifica a nivel institucional la importancia de este tipo de competencias relacionadas con el manejo de la información para todos los ciudadanos del siglo XXI.

Ahora bien, el campo de acción y la delimitación conceptual del término competencias informacionales han sido temas muy controvertidos; en cuanto a el ámbito en el que se desarrollan las competencias informacionales, parece que se acotó perfectamente con el desarrollo de las normas y estándares a nivel internacional (ALA/ACRL, 2000; Bundy \& ANZIIL, 2004; CAUL, 2001; CRUE-TIC \& REBIUN, 2012; SCONUL, 2004); sin embargo, en lo que respecta a la delimitación conceptual del propio término, existe aún en la actualidad un debate mucho más amplio.

En cuanto al tipo de aprendizaje al que se refiere, desde nuestro punto de vista se ha señalado siempre como competencia. Sin embargo, desde el nacimiento de este concepto (Zurkowski, 1974), hasta casi la actualidad, en el ámbito de la Biblioteconomía y Ciencias de la Información se ha considerado generalizadamente como una alfabetización (Andretta, 2007; Bruce, 1997; Bundy, 1998; Gunasekara \& Collins, 2008; Mackey \& Jacobson, 2011; Pinto Molina, 2009; Weiner, 2010). Sin embargo, en el ámbito de lengua hispana, los recientes documentos marco al respecto (CRUE-TIC \& REBIUN, 2009, 2012) han dado un empujón a la concepción de estas capacidades como competencias (Blasco Olivares \& Durban Roca, 2012; Gómez 
Hernández, 2010; Pinto Molina \& Puertas Valdeiglesias, 2012; Pinto Molina et al., 2011).

Por otro lado, en lo que respecta al término que hace referencia al contenido concreto que incluyen estas competencias, también se ha localizado un desacuerdo en los últimos años, en este caso principalmente en el ámbito de las Ciencias de la Educación. Se discute en torno al empleo del término informacional, digital, informático y/o mediático. A pesar de que, en algunos casos, confunde o solapa la alfabetización o competencia en medios con la digital y con la informacional (González Fernández-Villavicencio, 2012; Gutiérrez Martín \& Tyner, 2012; Wilson, 2012), este tipo de capacidades, a pesar de sus evidentes nexos de unión con las competencias informacionales, se localiza como una competencia diferenciada de las competencias informacionales (Grizzle et al., 2011).

A pesar de la visión integradora que proponen algunos autores en sus disquisiciones teóricas (Bawden, 2001; González Fernández-Villavicencio, 2012), que tratan de aportar luz en medio de este debate, lo cierto es que se han utilizado los términos digital o informática como simples sinónimos o degeneraciones del término informacional (Blasco Olivares \& Durban Roca, 2012; Monereo \& Coll, 2008; Pasadas Ureña, 2008), cuando el empleo del término digital implica consideraciones más mercantilistas, comerciales y eminentemente instrumentales (Cabero Almenara \& Alonso García, 2007).

Sin embargo, gracias al empuje de las instituciones procedentes del ámbito de la Biblioteconomía y las Ciencias de la Información (ALA/ACRL, 2000; Bundy \& ANZIIL, 2004; CRUE-TIC \& REBIUN, 2009; SCONUL, 2004), el empleo del concepto informacional se ha generalizado en la investigación educativa (Area Moreira, 2010a; Buschman, 2010; Castañeda-Peña et al., 2010; Fernández et al., 2008; Monereo \& Badia, 2012; Pinto Molina et al., 2011).

Así, actualmente, al menos en el ámbito español y latinoamericano, se está generalizando el empleo del constructo (Catts, 2005) competencias informacionales para referirse al tópico básico tratado en este trabajo.

Si existe tanta discusión simplemente en cuanto a la manera de nombrar estas competencias, evidentemente cabe pensar que la definición de las mismas es igualmente compleja. De hecho, al tratarse de una competencia compleja y tan amplia, es fácil hacer una definición demasiado ambigua y general. 
Sin embargo, una gran parte de los autores (Andretta, 2007; Koltay, 2009; Pinto Molina et al., 2008; Wen \& Shih, 2008) hacen referencia al respecto a la clásica definición de la ALA (1989). Así, a pesar de que, como se ha visto a lo largo del capítulo correspondiente, existen pequeñas diferencias entre las definiciones personales del concepto competencias informacionales, todas incluyen las cuatro dimensiones básicas de las que se compone (Bundy, 2004; A. Byrne, 2005; Catts \& Lau, 2009; Pinto Molina et al., 2008).

A pesar de que estos contenidos están muy claros y definidos gracias a los estudios realizados tanto a nivel personal como institucional, dada la naturaleza de las competencias informacionales, parece un hecho claro y consensuado el que la enseñanza de este tipo de competencias sólo tiene sentido inmersa como herramienta dentro de procesos de enseñanza-aprendizaje en los que el contenido es otro. Esto es, dada la transversalidad inherente a las competencias básicas (De Miguel Díaz, 2010; Martínez Clares \& Echeverría Samanes, 2009), las competencias informacionales deben enseñarse de forma contextualizada (A. Byrne, 2005; Gómez Hernández \& Benito Morales, 2001) a lo largo y ancho del currículo.

No tiene, por tanto, sentido la enseñanza a los estudiantes de competencias informacionales en un marco diferente al de la formación basada en competencias y de una manera descontextualizada como un contenido concreto del currículo. Cosa muy diferente es el cómo deben integrarse estas competencias dentro de los currículos para la formación inicial del profesorado. 


\subsection{Discusión: Estudio I}

\subsubsection{Discusión de resultados en estudiantes}

Como se ha venido señalando a lo largo de esta investigación, parece claro que el desarrollo de competencias informacionales se ha convertido en un eje esencial de la formación en la sociedad de la información (Mackey \& Jacobson, 2011; Weiner, 2010; Williamson, 2009). Así, se debería impulsar su integración como objeto de estudio y poner énfasis en su importancia como competencia a promover y/o desarrollar desde las instituciones educativas.

Bien es cierto que dicha importancia viene originada por el auge cada vez mayor de las tecnologías de la información y la comunicación. En líneas generales, la Declaración de Alejandría sobre la alfabetización informacional y el aprendizaje a lo largo de la vida considera que la alfabetización informacional «se extiende más allá de las meras tecnologías actuales para cubrir el aprendizaje, el pensamiento crítico y las competencias de interpretación por encima de fronteras profesionales, potenciando a los individuos y comunidades» (National Forum of Information Literacy, 2005, p. 1). Esto se corrobora en documentos específicos en materia educativa, tanto a nivel nacional como internacional, así la Recomendación del Parlamento Europeo y del Consejo de 18 de diciembre de 2006 sobre las competencias clave para el aprendizaje permanente señala que «La competencia digital entraña el uso seguro y crítico de las tecnologías de la sociedad de la información (TSI) para el trabajo, el ocio y la comunicación. Se sustenta en las competencias básicas en materia de TIC: el uso de ordenadores para obtener, evaluar, almacenar, producir, presentar e intercambiar información, y comunicarse y participar en redes de colaboración a través de internet» (Diario oficial de la Unión Europea, 2006, p. 15). Más aún, si nos ceñimos a la etapa de Educación Secundaria Obligatoria en España, la ORDEN ECI/2220/2007, de 12 de julio, por la que se establece el currículo y se regula la ordenación de la Educación secundaria obligatoria señala lo siguiente:

«el tratamiento de la información y la competencia digital implican ser una persona autónoma, eficaz, responsable, crítica y reflexiva al seleccionar, tratar y utilizar la información y sus fuentes, así como las distintas herramientas tecnológicas; también tener una actitud crítica y reflexiva en la valoración de la información disponible, contrastándola cuando es necesario, y respetar las normas de conducta acordadas socialmente para 
regular el uso de la información y sus fuentes en los distintos soportes» (Boletín Oficial del Estado, 2007b, p. section31690)

En consecuencia, a nivel de política educativa se observa que se han sentado las bases teóricas que promuevan estas enseñanzas adaptadas al ciudadano del siglo XXI. No obstante, a nivel pragmático, las evidencias no parecen mostrar lo que teóricamente se proyecta. Prueba de ello son los resultados que ofrecen varios estudios realizados en diversos países (CNICE, 2007; OCDE, 2004b, 2005; Pifarré et al., 2009), que destacan que los alumnos ponen en juego las habilidades relacionadas con el uso académico de las TIC en el aula de manera escasa. De hecho, la evidencia parece demostrar que los estudiantes de educación secundaria utilizan el ordenador para estos fines más en casa que en la escuela (OCDE, 2011; Sigalés et al., 2009).

En este sentido, nuestro estudio confirma estos resultados ya que indica que, si bien los alumnos declaran a nivel general tener acceso a internet y a las herramientas informáticas básicas, su empleo es mucho más frecuente fuera del aula y el instituto, en el ámbito del hogar. A pesar de ello, los estudiantes declaran poseer buenos conocimientos informáticos tanto en lo que respecta a herramientas de ocio y de comunicación interpersonal, como a aplicaciones más vinculadas con el ámbito académico. No se debe olvidar, sin embargo, que los resultados obtenidos se refieren al curso 2008/2009, y que en la actualidad, dada la velocidad que alcanzan los procesos de transformación de los sistemas e instituciones en una sociedad líquida (Bauman, 2006) como la nuestra, estos datos sobre disponibilidad y manejo de las herramientas informáticas hayan cambiado significativamente.

Por otro lado, en lo que respecta a investigaciones relacionadas con el desarrollo de competencias informacionales en alumnos de educación básica obligatoria, las evidencias científicas apuntan que, mientras que los alumnos declaran estar bien formados al respecto (Ozkul \& Kaya, 2009), los profesores son conscientes de que no están colaborando en el desarrollo de estas competencias (Probert, 2009). Además, los estudios sobre el nivel de competencias informacionales reales en estudiantes indican que los alumnos saben manejar la información de manera muy básica (Laxman, 2010; OCDE, 2011).

En nuestro estudio, en cuanto a la importancia declarada y el nivel autopercibido sobre competencias informacionales de los estudiantes de educación secundaria de Castilla y León, parece que se corroboran estas evidencias. Se observa que, a pesar de que los alumnos afirman tener un nivel adecuado en el conjunto de desempeños que 
conforman las competencias informacionales, consideran que su importancia es incluso mayor. Estos resultados, que también se obtienen en otros estudios relativos a esta temática (Pinto Molina \& Puertas Valdeiglesias, 2012), van acompañados de la observación de que cuanto más importancia conceden los alumnos a una competencia más autoeficaces se sienten en ella y viceversa. Esta correlación supone «una retroalimentación positiva en este ciclo de mejora del aprendizaje» (Pinto Molina \& Puertas Valdeiglesias, 2012, p. 12).

Además, aunque los estudiantes se consideran altamente cualificados, a la vez están señalando que deberían alcanzar un nivel de formación mayor, sobre todo en la evaluación, procesamiento y comunicación de información, y no tanto en la búsqueda de información. Al menos, eso es lo que opinan los propios alumnos de ESO.

En otro orden de cosas, mientras que algunos estudios de género llevados a cabo sobre las competencias digitales y de hábitos en el manejo de TIC (Gargallo Castel et al., 2010; Ruiz Palomero \& Sánchez Rodríguez, 2010) confirman que «hombres y mujeres no se relacionan de la misma forma con el empleo de las TIC» (Iglesias Fernández et al., 2010, p. 105), nuestro estudio también muestra cómo alumnos y alumnas no se relacionan de la misma forma con la percepción de importancia y nivel en competencias informacionales. En general, las mujeres de la muestra parecen demandar más intensamente formación en temas relacionados con competencias informacionales. De hecho, en todas las dimensiones las mujeres señalan que poseen una importancia mayor y los hombres autoperciben un nivel personal mayor. Esta relación es especialmente intensa en la comunicación de información, área que las mujeres consideran significativamente más importante y en la que, a su vez, consideran estar significativamente menos formadas que los hombres.

En cuanto a la relación con las familias, es de destacar la importancia que se atribuye en los estudios previos llevados a cabo a la colaboración escuela-hogar para un apropiado desarrollo de las competencias informacionales (Kong \& Li, 2009). Así, se observa en el estudio la estrecha relación existente entre el nivel de estudios de los padres y la autopercepción de importancia y el propio nivel en competencias informacionales. Por otro lado, queda de manifiesto que tienen un mayor efecto sobre el desarrollo de las competencias informacionales los hábitos de empleo de las TIC en el hogar que los hábitos en la propia aula.

Sin embargo, existen estudios que indican que los entornos escolares en los que se emplean las TIC como elementos integrados totalmente en el currículum, de manera 
sistemática y habitual, poseen alumnos con unas competencias informacionales más desarrolladas (Warschauer, 2007).

Así, centrándose en el estudio correlacional por medio de ecuaciones estructurales que se presenta en este estudio, los resultados obtenidos ayudan a verificar la existencia de una estrecha conexión entre las TIC y las competencias informacionales. De hecho, estos datos confirman que el manejo de herramientas informáticas (frecuencia y habilidad) está relacionado con las competencias informacionales, y contribuye de una manera significativa en su desarrollo.

Por otro lado, el análisis específico de las relaciones existentes en el modelo planteado muestra la presencia de diferencias respecto a la frecuencia en el empleo de herramientas informáticas en el hogar (entornos de educación no formal) y en la escuela (entornos de educación formal).

En concreto, las evidencias indican que en el desarrollo de las competencias informacionales es mayor la influencia que tiene el uso de estas herramientas informáticas en el ámbito de la educación no formal. Estos resultados confirman las conclusiones obtenidas en estudios relacionados (Pifarré et al., 2009; Sigalés et al., 2009; Sigalés \& Mominó, 2004), que indican que los alumnos que utilizan el ordenador con mayor frecuencia fuera de la escuela son más competentes en el ámbito académico. Por otro lado, los resultados muestran que la frecuencia en el empleo de herramientas informáticas en el aula, no parece tener un efecto significativo sobre el desarrollo de competencias informacionales.

De este modo, los resultados sugieren que, a pesar del esfuerzo llevado a cabo en materia de política educativa, las escuelas de Castilla y León, en el curso 2008/2009, no estaban afrontando el desarrollo de las competencias relacionadas con el manejo de la información de manera eficaz, en opinión de los propios estudiantes.

El análisis de las diferencias por grupos principales en cuanto al modelo causal de desarrollo de las competencias informacionales vuelve a indicar, en el caso del sexo, que los diferentes hábitos de manejo de herramientas informáticas en casa implican diferentes efectos sobre el desarrollo de competencias informacionales. Por otro lado, parece ser que el empleo de herramientas informáticas en el aula está más extendido en cuarto que en tercer curso, y que esto, evidentemente, tiene un impacto positivo sobre el desarrollo de las citadas competencias. Por último, en cuanto a las diferencias obtenidas en función de los estudios de la madre, parece ser que confirma la 
importancia que tiene la colaboración de la familia (Kong \& Li, 2009) para el desarrollo de las competencias informacionales.

No debemos olvidar, en todo caso, la limitación temporal del presente estudio, que muestra información recogida en 2009. Se haría necesario, de cara a obtener una medida más fiable del estado actual de los estudiantes en este sentido, el estudio del estado de la cuestión más que transversal, longitudinal, que nos aporte una idea de la evolución de los estudiantes en lo que al dominio de las competencias informacionales y en el manejo de herramientas informáticas se refiere.

Finalmente, siendo conscientes de las limitaciones de la presente investigación, y como aspectos a tener en cuenta de cara a futuras investigaciones, se debería abordar el estudio de las competencias informacionales teniendo en cuenta una medida objetiva de las competencias reales y su análisis y valoración a través de la misma desde un enfoque vinculado a diseños más experimentales.

Si con estos estudios se observa una carencia en los sistemas educativos con respecto al desarrollo de competencias digitales e informacionales, sería necesario promover el desarrollo de programas formativos directamente vinculados con las competencias informacionales en educación secundaria obligatoria, tal y como señalan autores como Pifarré (2009) «una de las competencias básicas a fomentar y que debería ser un logro irrenunciable al finalizar la educación secundaria obligatoria es el tratamiento de la información y la competencia digital (competencia TIC)» (p. 32).

\subsubsection{Discusión de resultados en futuro profesorado}

Ya se ha señalado con anterioridad el papel fundamental que el desarrollo de competencias informacionales está adquiriendo dentro de los sistemas educativos inmersos en la Sociedad de la Información (Mackey \& Jacobson, 2011; National Forum of Information Literacy, 2005; Pinto Molina et al., 2008; Rodríguez Conde et al., 2012, 2011; Weiner, 2010). De hecho, se están realizando grandes esfuerzos tanto a nivel nacional como internacional en la dirección de integrar de manera consistente y firme este tipo de competencias dentro de los currículos y enseñanzas oficiales (Boletín Oficial del Estado, 2007b; Diario oficial de la Unión Europea, 2006; OCDE, 2004b, 2005).

Sin embargo, la evidencia empírica parece demostrar que estos esfuerzos en el ámbito de la educación básica del alumnado no se han trasladado al terreno de la 
formación del profesorado (Hernández Martín \& Quintero Gallego, 2009; Prendes Espinosa \& Castañeda Quintero, 2010; Suárez Rodríguez, Almerich, Gargallo López, \& Aliaga, 2010; Wen \& Shih, 2008). De hecho, estas deficiencias se localizan tanto en la formación inicial del futuro profesorado (Dagiene, Zajanckauskiene, \& Zilinskiene, 2008; Prendes Espinosa \& Castañeda Quintero, 2010) como en la formación permanente del profesorado en activo (Almerich et al., 2005; Almerich, Suárez, Jornet, \& Orellana, 2011; Hernández Martín \& Quintero Gallego, 2009; Rivas, 2004; Suárez Rodríguez et al., 2010).

Así, en el estudio aquí desarrollado se confirma cómo el profesorado demanda una formación más amplia en todos los desempeños de las diferentes dimensiones que conforman las competencias informacionales. Esta afirmación se justifica atendiendo a que en todos los ítems del cuestionario la muestra obtiene valores de la media superiores en el nivel de importancia asignada que en el nivel de desempeño autopercibido. Por otro lado, la prueba de contraste llevada a cabo confirma que los futuros profesores valoran significativamente (nivel de significación $\alpha=.05$ ) por encima la importancia de cada una de las cuatro dimensiones de las competencias informacionales que el nivel autopercibido.

Por otro lado, a diferencia de los resultados cosechados en el grupo de adolescentes del segundo ciclo de educación secundaria de Castilla y León, el profesorado nobel es capaz dentro de cada una de las dimensiones de diferenciar entre subcompetencias cognitivas y subcompetencias instrumentales, entendiendo cognitivas como aquellas que implican más la puesta en marcha de procesos mentales superiores (resumir, identificar las ideas principales de un texto, determinar si una información está actualizada, evaluar la calidad de un documento, comunicar en otros idiomas,...) e instrumentales aquellas meramente técnicas, que únicamente consisten en el manejo de determinadas herramientas. De hecho, al igual que indican otros estudios relacionados (Rivas, 2004), el profesorado asigna una mayor importancia a todas estas competencias cognitivas sobre las instrumentales. Este hecho es el que determina que, nuevamente a diferencia del grupo de alumnos, el profesorado aporte más importancia a las competencias de evaluación y comunicación de información, más vinculadas con los procesos cognitivos, que a la búsqueda y procesamiento, con más ítems vinculados a procesos instrumentales.

Profundizando en las diferencias localizadas entre las escalas estudiadas para estudiantes y para futuro profesorado, las evidencias mostradas parecen indicar que la medición de las competencias informacionales debe ser diferente en ambas 
poblaciones. En primer lugar, el estudio de fiabilidad muestra cómo existen varios ítems que se refieren a los contenidos que los alumnos no identifican con el constructo de escala en la que pretenden ponderar. Por otro lado, y como aspecto más destacado, se observa cómo el futuro profesorado es más capaz de discernir entre algunos factores o dimensiones incluidos en las sub-escalas (procesamiento y comunicación de información) que los estudiantes. Así, las escalas para medir el nivel autopercibido tanto en procesamiento como en comunicación y difusión de información tienen estructuras internas más complejas en el caso del profesorado que en el del alumnado.

Esta idea de que el profesorado tiene una capacidad de discernir mejor factores inherentes a las sub-escalas define, a su vez, otra de las diferencias localizadas en las escalas estudiadas: En función de los datos recogidos en la población de estudiantes, existen evidencias empíricas que señalan que se puede construir una escala global para medir competencias informacionales. Sin embargo, en la población del profesorado en formación inicial, una hipotética escala de estas características no alcanza unos niveles de ajuste aceptables, haciéndose necesario el estudio en escalas separadas de cada una de las sub-competencias de las que están compuestas las competencias informacionales. Dado que las competencias informacionales se han definido a lo largo de todo el presente documento como una serie de desempeños muy amplios y de diversa naturaleza, y a pesar de los intentos de definirlas como un constructo unitario (Catts \& Lau, 2009; Catts, 2005), la evidencia indica aquí cómo es más apropiado medir como escalas independientes cada una de las subcompetencias o dimensiones teóricas por las que están compuestas las competencias informacionales.

Por tanto, a pesar de que podría existir una escala global para medir el nivel de adquisición autopercibido en competencias informacionales para una población de estudiantes del segundo ciclo de educación secundaria, en adelante no se considerará la escala global, y se considerarán por separado las sub-escalas búsqueda, evaluación, procesamiento y comunicación y difusión de la información.

En lo que respecta más específicamente a las áreas prioritarias de formación detectadas, investigaciones relacionadas hacían pensar que una de las principales necesidades se encuentra en lo que respecta a la gestión del trabajo cooperativo y en grupo a través de herramientas informáticas (y sin ellas), a la propia comunicación efectiva de la información y la evaluación de los recursos de información (Almerich et al., 2011, 2011; Prendes Espinosa \& Castañeda Quintero, 2010). El presente estudio encuentra un déficit formativo principalmente en el desarrollo de actividades de 
grupo a través de internet y el empleo de software de trabajo colaborativo. En cuanto a la evaluación de los recursos, se observa cómo el profesorado declara estar razonablemente formado, aunque sigue demandando mayor formación. La preocupación por este déficit formativo es razonable dada la estrecha correlación positiva demostrada entre tener un bajo nivel competencial en el manejo instrumental de algunas herramientas y el registro de una menor integración de ese tipo de tecnologías en el aula (O’Dwyer, Russell, \& Bebell, 2005; Tearle, 2003). Llama la atención el hecho de que, mientras que los futuros profesores se declaran altamente capacitados para el empleo de las redes sociales, afirman que necesitan una formación mucho más amplia en lo que tiene que ver con el desarrollo de trabajo colaborativo a través de herramientas informáticas.

En cuanto a las diferencias registradas por grupos principales, nos encontramos en primer lugar que, por sexo, las mujeres tienen a considerar más importantes todos aquellos desempeños más relacionados con las habilidades cognitivas implicadas en las competencias informacionales. Así, las mujeres valoran de manera significativamente más alta la importancia de la evaluación y la comunicación de información. Por su parte, los hombres de la muestra se consideran ligeramente más capacitados en las dimensiones de búsqueda y procesamiento de información, dimensiones más vinculadas con las habilidades instrumentales. Estos datos inclinan a pensar que los hombres, aunque mínimamente, declaran estar más capacitados en aquellas competencias más instrumentales relacionadas con el manejo de herramientas informáticas. Sin embargo, al contrario que lo localizado en el estudio de Almerich et al. (2005), en el que se localizan diferencias de género muy grandes en lo que respecta a las capacidades de empleo de las TIC, en nuestro estudio, si atendemos a las diferencias por sexo localizadas en los conocimientos informáticos, no se localizan diferencias significativas. Esto se puede justificar por la relación entre el sexo y la edad, ya que en el citado estudio las diferencias de nivel por sexo se hacían más grandes a medida que la edad de los sujetos aumentaba. Cabe recordar que en nuestra muestra la edad media de los sujetos es de 25.3 años.

De hecho, mientras que estudios llevados a cabo (Gargallo Castel et al., 2010; Ruiz Palomero \& Sánchez Rodríguez, 2010) indican claramente que la relación con las tecnologías de la sociedad de la información es diferente en hombres que en mujeres (Iglesias Fernández et al., 2010), la evidencia no ha demostrado que el hecho de ser hombre, mediado por determinadas variables culturales, implique una mayor facilidad para alcanzar un nivel de conocimientos informáticos superior a las mujeres. Así, 
nuestro estudio tampoco descubre diferencias autopercibidas por los sujetos en este sentido.

En cuanto a las diferencias localizadas por edad, una vez categorizada la edad en tres grupos más o menos homogéneos en tamaño, las pruebas llevadas a cabo inclinan a pensar que no existen diferencias en las competencias informacionales por edad en el grupo de futuros profesores de educación secundaria de Castilla y León. A pesar de las discrepancias localizadas entre estos resultados y otros estudios (Almerich et al., 2005), que indican que sí que son significativas estas diferencias, no son sorprendentes, ya que la muestra con la que trabajan estos estudios suele ser de profesorado en activo, que posee un rango de edad mucho mayor que nuestra muestra. Así, estos estudios localizan claras diferencias entre el profesorado de mayor edad, muy lejano a la realidad digital que se ha gestado en los últimos años, y el más joven, más cercano a la muestra completa con la que nosotros contamos.

Por su parte, atendiendo a la especialidad de procedencia del futuro profesorado, parece que los sujetos de humanidades tienden a valorar la importancia de las competencias que tienen que ver con la evaluación de información más positivamente. Además, el efecto de esta relación es medio, o incluso medio-alto, ya que se alcanzan valores importantes del tamaño del efecto. En cuanto al nivel percibido, los sujetos de ciencias e ingenierías los que se consideran más formados en la búsqueda y procesamiento de información, precisamente las dimensiones que tienen más relación con las habilidades instrumentales que se señalaban con anterioridad.

Por último, el modelo de ecuaciones estructurales desarrollado a partir del modelo teórico propuesto y ya implementado en el grupo de estudiantes de educación secundaria, aporta índices de bondad de ajuste relativamente deficitarios, por lo que se debe ser cauteloso con las interpretaciones y conclusiones vertidas. Sin embargo, sí se observa claramente cómo el empleo frecuente de herramientas informáticas no es una causa explicativa de las competencias informacionales. La frecuencia en el empleo de este tipo de tecnologías tiene un efecto indirecto significativo, pero directo inexistente. Estas evidencias nos inclinan a pensar que el simple uso de herramientas informáticas no facilita el desarrollo de las competencias informacionales. Es necesario el desarrollo de estrategias formativas no solamente centradas en los aspectos instrumentales, sino especialmente dirigidas hacia los aspectos cognitivos de las competencias informacionales. 


\subsection{Discusión del estudio experimental}

Ya se puso en evidencia en el anterior estudio cómo en los sistemas educativos, tanto a nivel nacional como internacional, se está promoviendo y generalizando el desarrollo de aprendizajes relacionados con el desarrollo de competencias informacionales (Mackey \& Jacobson, 2011; National Forum of Information Literacy, 2005; Pinto Molina et al., 2008; Rodríguez Conde et al., 2012, 2011; Weiner, 2010). Prueba de ello, son los esfuerzos realizados en la integración dentro de los currículos nacionales y los documentos guía internacionales de este tipo de competencias (Boletín Oficial del Estado, 2007b; Diario oficial de la Unión Europea, 2006; OCDE, 2004b, 2005).

La emergencia de este tipo de aprendizajes no se corresponde finalmente con la importancia asignada a la formación del profesorado, ya sea inicial (Dagiene et al., 2008; Prendes Espinosa \& Castañeda Quintero, 2010) o permanente (Almerich et al., 2005, 2011; Hernández Martín \& Quintero Gallego, 2009; Rivas, 2004; Suárez Rodríguez et al., 2010).

En el campo que nos atañe, el de la formación inicial, ya localizamos en el estudio I las áreas deficitarias de formación que declaraba tener el futuro profesorado. Así, se localizaban estas necesidades en todas las áreas estudiadas, y principalmente en las áreas más relacionadas con habilidades cognitivas y no meramente instrumentales de manejo de herramientas informáticas. Estas áreas se encontraban inmersas dentro de las dimensiones de evaluación y de comunicación y difusión de información.

Sin embargo, la labor para una formación inicial y/o permanente del profesorado es titánica:

\footnotetext{
«¿Quién enseña al profesor qué debe enseñar? ¿Quién le prepara? ¿Es que el profesor debe ser autodidacta? [...]El profesor de hoy es el profesional que más desventajas tiene para enfrentarse a los "nuevos tiempos": pocos recursos materiales, económicos, de tiempo, de aceptación social, de respeto de los padres y de sus alumnos, las leyes educativas no les favorecen [...] Para los profesores en formación inicial, la tarea puede ser más fácil, posible, pero igualmente de gran reto.» (Alonso García, 2002, pp. 74-75)
}

A pesar de que el Espacio Europeo ha creado un clima muy favorable al desarrollo de competencias informacionales al reconocerla como un tema transversal en documentos oficiales como los libros blancos y en los planes de estudio de las nuevas titulaciones (Gómez Hernández, 2010), no parece que a nivel de formación de 
profesorado se haya previsto una formación específica más especializada para los futuros docentes.

A la luz de los estudiosos de las competencias informacionales más vinculados al pensamiento sociocrítico unido con el concepto de alfabetización desarrollado por Paolo Freire (Andretta, 2005; Elborg, 2008; Markauskaite, 2006), no tienen ningún sentido tratar de formar a los sujetos a partir de contenidos descontextualizados, pretendidamente asépticos y no inmersos en la realidad de un contexto y unas prácticas culturales determinadas (Fiori et al., 1973; Freire, 1975, 1984, 1989).

\footnotetext{
«La ALFIN puede verse desarrollada y expresada por completo solamente dentro de un contexto, y la aplicación de sus conceptos difiere de un campo de conocimiento a otro. En consecuencia, los programas genéricos de ALFIN pueden ofrecer poco valor porque están esencialmente descontextualizados y, por tanto, se considera que sólo pueden promover un aprendizaje de bajo nivel» (A. Byrne, 2005, p. 15).
}

Sin embargo, a pesar de que estamos de acuerdo con el hecho de que las competencias informacionales deben enseñarse inmersas en los procesos educativos formales de manera transversal, defendemos el que se implementen cursos formativos específicos de educación inicial y permanente para el profesorado de la educación obligatoria. Esta formación explícita permite una enseñanza sistemática y consciente del contenido de aprendizaje en sí. Posteriormente, es el docente, como profesional experto en el desarrollo de procesos de enseñanza-aprendizaje, el que debe ser capaz de contextualizar este tipo de aprendizajes en un marco vivencial y significativo concreto.

Este razonamiento se fundamenta en los resultados obtenidos en el presente estudio, que muestran en general que el programa ha sido exitoso al haber demostrado cumplir con el objetivo general propuesto, que no era otro que el diseño, desarrollo y evaluación de un programa de intervención para la mejora de las competencias informacionales en futuros profesores de educación secundaria obligatoria. A lo largo del proceso descrito, se ha diseñado un programa con criterios pedagógicos y desde una perspectiva científica, se ha implementado el programa sobre una muestra de futuros profesores de educación secundaria obligatoria y se ha demostrado su eficacia a través del proceso de evaluación y de aplicación de las oportunas pruebas de análisis estadístico.

A pesar de esta evidencia, no debemos olvidar que las competencias informacionales son competencias, y que como tal están compuestas de saber, saber 
hacer y saber ser/estar (Martínez Clares \& Echeverría Samanes, 2009; Villa Sánchez \& Poblete Ruiz, 2009; Zabala \& Arnau, 2007). Evidentemente, todos estos componentes deben ser tenidos en cuenta en toda acción formativa destinada a desarrollar estas competencias y deben ser evaluados por igual con los criterios de evaluación de las competencias básicas: evaluación auténtica, conforme al criterio, desarrollo de la responsabilidad compartida en el proceso de evaluación, continua, formativa, variada y múltiple (De Miguel Díaz, 2006).

El hecho de dividir las competencias en sus partes constituyentes puede facilitar la evaluación del estado actual de las mismas. Sin embargo, en necesario mantener la perspectiva acerca de que las competencias (informacionales), aunque pueden dividirse fácilmente en sus múltiples sub-dimensiones y componentes, conforman en última instancia un todo integrado y relacionado. Así, en todo proceso de evaluación se debe mantener la perspectiva global de la propia competencia. Para evitar la compartamentalización excesiva de los componentes de la competencia, manteniendo la necesaria objetividad y evaluación basada en evidencias, se han desarrollado e implementado para el presente estudio instrumentos de evaluación holísticos como, principalmente, las rúbricas de evaluación (Torres Gordillo \& Perera Rodríguez, 2010).

Partiendo de que a nivel global los resultados son satisfactorios, y que se puede afirmar que los sujetos participantes en el programa formativo han mejorado significativamente en su nivel de adquisición de las competencias informacionales, podemos entrar en un análisis más específico del desarrollo o aprendizaje de los diferentes componentes de la competencia. De hecho, en estos elementos localizamos diferencias reseñables.

Se observa cómo en cuanto a los contenidos conceptuales, es decir, el componente saber de la competencia, el grupo que participa en el curso experimenta un aprendizaje alto. Este es el componente en el que se percibe un cambio más alto comparando el pretest con el postest. No parecen descabellados estos resultados si atendemos a la lógica de los ambientes escépticos y críticos hacia el elearning que, a pesar de reconocer el potencial de las herramientas propias de la formación virtual para fomentar una formación más activa y centrada en el propio alumno, «se tiende a pensar que la enseñanza virtual se limita a imitar las clases presenciales» (Martínez Caro, 2008, p. 154), más vinculadas a la tradicional sesión magistral de conocimientos que a otra cosa. 
De hecho, la idea de que la formación online facilita en mayor medida el aprendizaje de contenidos vinculados con el saber es sostenida por la evidencia científica. Por ejemplo, Juanes y Ruíz-Canela (2008), en un estudio en el que se lleva a cabo un meta-análisis de más de 200 artículos científicos en los que se evalúan las competencias adquiridas por sujetos participantes en cursos online en comparación con otros sujetos que no reciben formación alguna o que reciben formación presencial, encuentran que los efectos de la formación online son más importantes sobre el aprendizaje de contenidos teóricos que de habilidades, destrezas y en mayor medida actitudes. La producción científica muestra, pues, que las actividades formativas online tienen un mayor impacto sobre el saber que sobre el saber hacer y el saber estar/ser.

Extendiendo esta idea, son incluso los propios alumnos cuando son preguntados los que consideran que el elearning es más propicio que la enseñanza presencial en materias teóricas y que las materias más prácticas deben enseñarse de manera presencial (Martínez Caro, 2008).

En cuanto a los contenidos aprendidos en relación con el saber hacer, se observa una mejora media o media/alta en todas las dimensiones incluidas en las competencias informacionales. Estos efectos significativos se dan por buenos dada la dificultad ya señalada para trabajar contenidos procedimientales a través de cursos online.

El componente en el que se registran unos efectos del tratamiento menos importantes es en el saber ser/estar. En este caso, a pesar de que se encuentran diferencias favorables al postest, estas tienen un tamaño del efecto bajo o medio/bajo.

A pesar de que en muchos casos se considera este componente de la competencia como el menos importante, no debemos olvidar que "attitude has great impacts on improving information literacy competence» (Wen \& Shih, 2008, p. 796), y que estas actitudes positivas en el profesorado y alumnado promocionan la integración efectiva de las competencias informacionales en los procesos formativos implementados en el aula (Álvarez Álvarez et al., 2011; Tejedor Tejedor \& García-Valcarcel, 2006).

En todo caso, se debe de tener en cuenta el hecho de que las distribuciones de las variables implicadas en las actitudes hacia las competencias informacionales en el pretest tienden a las puntuaciones altas y a la poca variabilidad, con grandes índices de asimetría negativa y curtosis leptocúrtica (como se puede consultar en los gráficos y tablas mostrados anteriormente). Esta tendencia de las variables implica que los 
sujetos tienen poco margen de mejora en cuanto al saber ser/estar, lo cual ha podido provocar que la mejora en las actitudes de los sujetos haya sido moderada.

Acercándonos más a la calidad inherente de la acción formativa implementada en el tratamiento, podemos tener en cuenta los resultados obtenidos en la escala de satisfacción del curso, que indican una satisfacción muy elevada por parte de los alumnos. Estos altos índices de satisfacción se localizan principalmente hacia el desempeño del profesor y los materiales facilitados.

Como aspectos mejorables, se plantean posibles modificaciones en futuros cursos desarrollados al respecto en cuanto a la organización temporal del propio curso, tanto en número absoluto de horas como en extensión a lo largo del tiempo, y en cuanto a la metodología desarrollada en las actividades de grupo, principalmente en las que se han desarrollado con el grupo completo. En estos casos de actividades con grupos numerosos las actividades han resultado a los alumnos en ocasiones poco organizadas y dirigidas por parte del profesorado. De hecho, la experiencia en cursos de formación completamente online muestra a la comunidad científica que necesitan de una organización y estructuración de los contenidos y actividades más sistemática por parte del profesorado que la ejercida en los cursos presenciales: «aunque la enseñanza en red se realiza en el ciberespacio, ello no significa que no exista una estructura organizativa; es más, ésta llega a ser más compleja» (Cabero Almenara, 2006, p. 7).

En otro orden de cosas, con la intención de acercarnos a una interpretación más global de los resultados, incluiremos en el análisis las principales necesidades formativas registradas en el estudio I con relación a los resultados formativos obtenidos en el estudio II. En relación con las áreas prioritarias de formación localizadas en el primer estudio, se ponía en evidencia cómo el futuro profesorado de educación básica indicaba como de mayor importancia las de ámbito más cognitivo, dejando en un segundo plano las de tipo instrumental relacionadas con el manejo de herramientas informáticas.

El hecho de que el curso de formación se llevara a cabo de forma virtual, supone también un hándicap en este aspecto, ya que la evidencia científica parece confirmar que los cursos de este tipo promueven un mayor impacto en el aprendizaje de habilidades instrumentales que de tipo más aplicado o sistémico (Colás Bravo \& Jiménez Cortés, 2008). De hecho, los cursos online cuyos contenidos son afines a la enseñanza técnica de habilidades instrumentales de manejo de determinadas 
herramientas informáticas tienen una eficacia probada (Baño Egea, Leal Hernández, Sánchez Marín, Ruiz Merino, \& Serna Mármol, 2012).

Volviendo a nuestro estudio, en lo que respecta al desarrollo de habilidades cognitivas (evaluación y comunicación de información) se han obtenido resultados positivos. Por un lado, en la dimensión de comunicación y difusión de información se obtienen tamaños del efecto del tratamiento altos tanto en el saber como en el saber hacer, y bajos, además de no registrar diferencias significativas, en el saber ser/estar. Por otro, en la dimensión de evaluación de información, se obtienen tamaños del efecto moderados tanto en el saber hacer como en el saber ser/estar y tamaños altos en el saber.

Por tanto, a pesar de que las habilidades instrumentales, más relacionadas con el aprendizaje de mecanismos automáticos y la memorización de contenidos conceptuales, se adquiere más fácilmente en la enseñanza online, los efectos del tratamiento en el desarrollo de habilidades más aplicadas y sistémicas son satisfactorios.

Por último, no se puede finalizar este apartado sin hacer referencia a las limitaciones del propio estudio. En este caso se debe de tener en cuenta que se están evaluando los conocimientos que adquiere el futuro profesorado en relación con las competencias informacionales, y no la capacidad adquirida para poner en práctica en el aula estos conocimientos. De hecho, esta limitación abre importantes líneas de investigación futuras como en qué medida un mayor conocimiento de los contenidos relacionados con las competencias informacionales por parte del profesor fomenta tanto la integración de estas competencias en los propios procesos de enseñanzaaprendizaje como una mayor calidad en su implantación. En este sentido, aunque es complicado encontrar estudios que trabajen directamente en el ámbito de los procesos de enseñanza-aprendizaje implementados en las escuelas, se pueden localizar investigaciones interesantes (Colás Bravo \& Jiménez Cortés, 2008; Gutiérrez Martín, Palacios Picos, \& Torrego Egido, 2010; Medina Moya, Jarauta Borrasca, \& Urquizu Sánchez, 2005).

Por tanto, si bien no carece de interés la formación del futuro profesorado en las competencias informacionales propiamente dichas, se mantiene la duda de si esta formación es suficiente para la integración efectiva de estas competencias básicas en el currículo o si es necesaria una formación más aplicada, vinculada a los aspectos 
didácticos que deben regir la enseñanza de las competencias informacionales en la formación básica. 


\subsection{A modo de conclusión}

Este último apartado de la Tesis Doctoral es el resultado de un importante esfuerzo de síntesis, con la intención de condensar los principales logros alcanzados. Se trata de evidenciar las luces y sombras que aporta esta investigacióneducativa y mostrar, a nivel general, el impacto que supone para el área de conocimiento en el que se inscribe, la metodología de investigación en educación. Tanto los resultados obtenidos, como los puntos débiles explicitados acerca del propio proyecto, suponen para la comunidad científica el mantenimiento y apertura de algunas líneas de investigación futuras, como por ejemplo, las que se indican y otras que se pasan por alto, las cuales el lector especializado podrá valorar.

\subsubsection{Conclusiones a nivel teórico y empírico}

En primer lugar, fruto del minucioso estudio teórico realizado, se pueden extraer varias conclusiones generales:

- Parece claro que el desarrollo, evolución y perfeccionamiento de las tecnologías relacionadas con la electrónica y la informática han cambiado de manera radical la manera en la que el hombre se relaciona con el mundo. Así, fruto de esta revolución tecnológica propiciada por las TIC, surge una sociedad con unas características propias totalmente diferenciadas de las existentes en los modelos previos de sociedad.

- La sociedad actual, en la que se suceden incesantes e infinitos flujos de datos e información de forma ubicua, sustituye el modelo tradicional productivo basado en lo material, debido al alto valor que alcanza lo inmaterial, el conocimiento. Así, realmente nos encontramos inmersos en una sociedad de la información, en la que la capacidad de crear conocimientos nuevos se convierte en el principal medio para la generación de riqueza. $\mathrm{Y}$ las competencias informacionales se sitúan en el punto intermedio entre la información y el conocimiento.

- Las transformaciones sociales implican cambios profundos en el propio concepto de educación y en los sistemas e instituciones educativas. Por tanto, la noción de 'estar alfabetizado', como fenómeno cultural que es, vinculado a unas determinadas características espacio-temporales, también se transforma. En este entorno "líquido", incierto y voluble, se puede considerar la 
alfabetización tradicional como algo "sólido", estático y unidimensional. Se adopta, pues, la actual perspectiva de la multialfabetización en contextos multimedia y multimodo.

- En una realidad educativa nueva, la apropiada formación del profesorado es un factor determinante del éxito de la adaptación a la misma. Se hace necesaria la definición de un perfil profesional docente que, por un lado, dignifique y aporte sentido a la labor de los propios docentes (especialmente, de la educación secundaria) y, por otro lado, siente las bases para la construcción de una identidad profesional clara y sólida del profesorado. Parece claro que las competencias informacionales son clave dentro de este perfil profesional docente.

- A pesar de las reticencias que implican algunas características inherentes a su naturaleza, el modelo de formación basada en competencias da respuesta a los retos que supone la educación en la sociedad de la información. La flexibilidad del concepto competencia, la adaptabilidad al afrontamiento de la educación desde un paradigma positivista o interpretativo, la perspectiva centrada en el estudiante, la visión dinámica y multidimensional de la realidad que permite o la facilidad de adaptación a las necesidades y exigencias cambiantes de la sociedad, hacen del modelo de formación basada en competencias un sistema pertinente para la educación en la sociedad actual.

- La implementación de procesos de enseñanza-aprendizaje relacionados con el manejo de información suponen alfabetizar (o más bien multialfabetizar). Sin embargo, su contenido no conforma en sí mismo un tipo de alfabetización. En cambio, las competencias informacionales son un grupo de competencias que forman parte del mapa de competencias básicas que se requieren para alcanzar la meta de la multialfabetización en la sociedad de la información. Por otro lado, cabe señalar que las competencias informacionales se refieren a todo lo relacionado con el manejo de cualquier tipo de información, independientemente del modo y/o medio en el que se presente.

- La enseñanza de competencias informacionales en la educación obligatoria sólo tiene sentido inmersa en un contexto concreto, como continente para desarrollar procesos de enseñanza-aprendizaje sobre algún contenido particular. Las competencias informacionales son, por tanto, un elemento 
transversal del currículo, y deben estar presentes en todas las áreas de conocimiento del mismo.

Debido a que, en parte, se puede afirmar que existe una relación causal entre las conclusiones teóricas y las empíricas, una vez se han explicitado las principales conclusiones a nivel teórico, se señalarán las conclusiones extraídas de los estudios empíricos implementados en la Tesis Doctoral. A nivel general, se pueden indicar las siguientes conclusiones tanto en la población de alumnos como de futuros profesores del estudio I:

- En cuanto a la escala para medir las competencias informacionales autopercibidas, se pone de manifiesto cómo, a pesar de que los resultados obtenidos en el alumnado de educación secundaria (14-16 años) sugieren que se podría construir una escala global para medir las competencias informacionales, es más conveniente el estudio separado de cada una de las subcompetencias que componen las competencias informacionales (búsqueda, evaluación, procesamiento y comunicación y difusión de información). El análisis psicométrico de las escalas muestra, al considerar las competencias informacionales como un constructo, unos índices de bondad de ajuste pobres.

- A medida que los sujetos implicados en los procesos de enseñanza-aprendizaje en la educación secundaria afirman tener un mayor nivel en competencias informacionales, asignan a esas mismas competencias una mayor importancia. Esta relación se puede afirmar también viceversa. Además, se observa cómo existe una tendencia a considerar cada uno de los desempeños con una mayor importancia que el nivel autopercibido. Así, se muestra una clara demanda de formación en todos los ámbitos relacionados con las competencias informacionales, sobre todo en lo que se refiere a la evaluación y comunicación de información. En este aspecto, aparecen algunas diferencias entre las dos muestras del estudio I (alumnos de secundaria y futuros profesores).

- Mientras que los futuros profesores asignan una mayor importancia al conjunto de sub-competencias relacionadas con los aspectos cognitivos, el grupo de alumnos de educación secundaria no muestra esta tendencia de manera tan clara, dándole una importancia similar a habilidades cognitivas e instrumentales. 
- En el caso de los alumnos, existe una correlación positiva entre la formación de base de los padres y la autopercepción de una mayor formación e importancia de cada una de las sub-competencias de las competencias informacionales.

- En este mismo orden de cosas, en cuanto al género, se observa una clara tendencia de las mujeres a considerar las competencias informacionales como más importantes y una ligera predisposición a sentirse menos competentes en las mismas. Así, las mujeres están demandando indirectamente una mayor formación que los hombres en estos aspectos. En cuanto a la importancia percibida, esta tendencia se observa especialmente en lo que tiene que ver con las competencias relacionadas con la comunicación y difusión de información, y más ligeramente en la evaluación de información.

- A pesar de que se observa correlación positiva entre las competencias informacionales y el nivel en el manejo de TIC, lo cual sugiere que el manejo de herramientas de este tipo puede contribuir en el desarrollo de competencias relacionadas con el manejo de la información, se pone de manifiesto que el simple empleo frecuente de las TIC no facilita el desarrollo de las competencias informacionales de manera significativa.

- En el caso de los alumnos de secundaria, se pone en evidencia cómo la frecuencia en el manejo de las TIC en el aula no es causa del nivel autopercibido en competencias informacionales. Además, la frecuencia en el empleo de las TIC de los alumnos es mucho mayor en el hogar que en las escuelas, en el momento de aplicación de la encuesta (curso 2008/2009).

- En el caso del futuro profesorado también se observa cómo, a pesar de que el nivel en el manejo de TIC sí que implica un mayor nivel autopercibido en competencias informacionales, la frecuencia de empleo de este tipo de herramientas no tiene una relación causal significativa con las propias competencias informacionales.

- Aunque no se puede demostrar que el género determine unas capacidades diferentes para el aprendizaje de las competencias informacionales, sí se observa cómo hombres y mujeres se relacionan de una manera diferente con Ias TIC. Y estos diferentes hábitos de manejo de las TIC en entornos de ocio y 
de aprendizaje informal implican diferentes efectos sobre el propio desarrollo de las competencias informacionales.

- Como aspecto global a señalar del estudio I, en el contexto regional analizado, se puede concluir que, a pesar de los esfuerzos que la administración ha llevado a cabo en esta materia, no se están afrontando actualmente (2009-2010) procesos de enseñanza-aprendizaje adecuados para el desarrollo eficaz de las competencias informacionales, ni en las escuelas ni en los ámbitos de formación inicial del profesorado.

En lo que respecta a las conclusiones extraídas del estudio experimental, se puede señalar brevemente lo siguiente:

- A pesar de que está demostrado que el nivel autopercibido correlaciona con el nivel real o nivel observado empíricamente, es procedente y viable el diseño $y$ aplicación de protocolos de evaluación de la competencia real u observada, en concreto en el campo de las competencias informacionales.

- Es posible afrontar el diseño e implementación de un programa formativo online para el desarrollo de competencias informacionales, sobre el futuro profesorado de educación secundaria, con criterios pedagógicos y desde una perspectiva científica, asegurando la eficacia del mismo.

- Los cursos de formación online ponen el énfasis más sobre los conocimientos teóricos que sobre los prácticos y actitudinales. El presente programa, además de demostrar la previsible eficacia en las aptitudes relacionadas con el saber, ha demostrado un alto nivel de eficacia en el desarrollo y perfeccionamiento de las habilidades relacionadas con el saber hacer.

- A pesar de que la formación online parece fomentar en mayor medida las habilidades instrumentales que las cognitivas, aspecto refrendado en el presente estudio, el desarrollo de las habilidades más relacionadas con aspectos cognitivos también ha alcanzado niveles satisfactorios.

- Dada la alta demanda de formación existente entre el futuro profesorado de educación secundaria, el desarrollo de acciones formativas de calidad relacionadas con las competencias informacionales implican altos niveles de satisfacción por el desarrollo del perfil docente en estos aspectos. 


\subsubsection{Propuestas de mejora del estudio empírico}

Desde un planteamiento metodológico, creemos que resulta necesaria una cierta reflexión crítica sobre el trabajo realizado, con el fin de aprender para futuros estudios, en similares circunstancias. A lo largo del estudio teórico y del desarrollo de la investigación empírica propiamente dicha, se han ido localizando ciertos puntos débiles que, si bien se han tratado de corregir paulatinamente, en algunos casos no se han logrado solucionar completamente, ya sea por las propias limitaciones materiales, temporales o personales de la investigación, o por no detectarlos en el momento adecuado.

En primer lugar, se presenta una limitación que nos ha ido acompañando a lo largo del estudio, que tiene que ver con la perspectiva desde la que se aborda. Se decide implementar un estudio empírico desde un punto de vista puramente cuantitativo para dar respuesta a los objetivos del estudio. Sin embargo, surgen algunas consideraciones teóricas que parecen entrar en contradicción con el empleo de esta metodología, como, por ejemplo: el acercamiento al concepto competencia desde una perspectiva interpretativa; la aceptación de las competencias informacionales como materia transversal a lo largo de todo el currículo; o la consideración de la evaluación de competencias auténtica, formativa, continua y conforme a la práctica. En algunos casos, se puede observar cierta inconsistencia entre las construcciones teóricas y el diseño e implementación de la metodología de investigación. Para el equipo implicado en el desarrollo del presente trabajo suponía un reto conjugar una visión interpretativa y holística de la realidad, y de la educación en concreto, con el desarrollo de metodologías cuantitativas, más apropiadas para estudios analíticos y positivistas. Somos conscientes de que no se han logrado conjugar estas dos posturas de un modo completamente satisfactorio. Sin embargo, gracias al empleo de esta metodología puramente cuantitativa, hemos podido realizar un estudio exploratorio y comparativo de las competencias informacionales extensivo $y$, hasta cierto punto, analítico, no aplicado hasta el momento en el ámbito de la educación secundaria. Y no hemos finalizado el estudio con estas conclusiones de tipo descriptivo exploratorio, sino que hemos realizado un segundo estudio con el objetivo de comprobar la eficacia de un programa de intervención para la formación en competencias informacionales en el futuro profesorado de educación secundaria.

Cabe señalar también, desde este mismo razonamiento que, el hecho de abordar el estudio de un conjunto de competencias, tan amplio como las competencias 
informacionales, con un instrumento concreto y limitado, nos conduce a mantener ciertas reservas acerca de su validez interna. Cabe plantearse si es apropiado el estudio global de las competencias informacionales como una competencia básica, o si es más válido para el tipo de metodología empleada el desarrollo de estudios concretos y/o relacionados de las sub-competencias que las competencias informacionales comportan: búsqueda, evaluación, procesamiento y comunicación y difusión de información. De hecho, como se puede comprobar en el estudio II, estas consideraciones nos condujeron a valorar cada una de las dimensiones teóricas de las cometencias informacionales como escalas independientes, lo cual ha tenido implicaciones positivas en las posibilidades de interpretación de los resultados obtenidos.

Por otro lado, cabe señalar cómo el estudio descriptivo implementado es transversal y ceñido a datos obtenidos entre los años 2009 y 2010 en el estudio I, base del posterior estudio experimental. En una sociedad líquida como la actual, en la que especialmente el ámbito de las TIC avanza a una velocidad desmesurada, tanto aspectos concretos de las competencias básicas relacionados con estas tecnologías, como el propio nivel de competencia desarrollada por estudiantes y por futuro profesorado, cambian rápidamente. Por ello, de cara a tener una visión más ajustada sobre el estado actual en el desarrollo de competencias informacionales tanto del futuro profesorado como de los estudiantes, se puede considerar la implementación de estudios de más largo alcance. El logro alcanzado en el diseño y mejora de un instrumento para la evaluación de competencias informacionales validado puede facilitar este tipo de investigaciones.

También se observan algunas deficiencias en el estudio experimental, en lo que respecta al diseño e implementación del programa formativo. Se decide, por cuestiones de accesibilidad de la muestra y disponibilidad de recursos, desarrollar un proceso de enseñanza-aprendizaje de las competencias informacionales como contenido propio de estudio. Mientras, se observa cómo buena parte de estudiosos de las competencias informacionales señalan que éstas deben integrarse dentro de las metodologías cotidianas de los procesos de enseñanza aprendizaje, no como un contenido en sí mismo. Cabe la duda de si, al tratarse de futuro profesorado y no de alumnado propiamente dicho, es adecuado enseñar estos contenidos directamente, 0 si, al igual que en el caso de los estudiantes, es más apropiado su implicación dentro de los procesos de enseñanza-aprendizaje, más como un continente o contenido transversal, que como un contenido independiente. El hecho de que la muestra 
estuviera compuesta por estudiantes del Máster de Profesorado de Educación Secundaria o futuros profesores, nos ha imposibilitado comprobar el impacto sobre unos estudiantes particulares, de la enseñanza de este tipo de competencias.

Por último, se puede señalar la limitación propia del programa formativo en general y del protocolo de evaluación de competencias implementado en particular. En lo que respecta al programa formativo, existe la limitación en primer lugar de que se trata de un curso online, en el que, como ya se ha indicado, parece una modalidad más adecuada para la enseñanza-aprendizaje de contenidos conceptuales y de desempeños instrumentales. En segundo lugar, nos encontramos con que se desarrolla un curso con una extensión reducida ( 40 horas) y que se desarrolla a lo largo de únicamente un mes. De este modo, no se pretende que el futuro profesorado alcance un nivel aceptable en competencias informacionales y que aprenda estrategias para implementarlas en la práctica educativa cotidiana con una acción formativa tan puntual. En realidad, el programa formativo ha sido una introducción al tema para el profesorado, como bien queda demostrado en las valoraciones altamente positivas que el mismo profesorado hace del programa en la pregunta abierta de la escala de satisfacción. $Y$ en lo que hace referencia al inventario de evaluación diseñado e implementado, se vuelven a observar ciertas dificultades de adaptación con los supuestos teóricos acerca del modelo de formación basado en competencias y su evaluación. El inventario de evaluación adolece, por los motivos antes expuestos, de recogida de información sobre las competencias adquiridas por el profesorado en relación a la integración o transferencia de las competencias informacionales desarrolladas en la práctica educativa concreta.

En suma, a pesar de que los aspectos mejorables de la investigación son importantes y suponen un toque de atención para la comunidad educativa de cara a futuros estudios vinculados a la evaluación y formación en competencias básicas, la presente Tesis Doctoral despeja el camino para estas investigaciones venideras, ya que aporta conocimientos significativos y sólidos sobre aspectos clave como la estructura interna del constructo 'competencias informacionales', la evaluación de competencias básicas, el estado actual de desarrollo de competencias informacionales en estudiantes y futuro profesorado de educación secundaria, el proceso de desarrollo de las competencias informacionales en función de grupos de interés, las relaciones entre TIC y competencias informacionales o cómo diseñar e implementar programas formativos en competencias informacionales. 


\subsubsection{Líneas de investigación futuras}

Tanto el estudio del estado de la cuestión, como la reflexión sobre las conclusiones y limitaciones del estudio empírico desarrollado en la presente Tesis Doctoral, ponen de relieve ciertas líneas futuras de investigación que, o están abiertas y siendo estudiadas actualmente, o las consideramos relevantes a pesar de que permanezcan inexploradas hasta este momento. Esta prospectiva se puede considerar como una continuación de la reflexión acerca de las mejoras susceptibles de introducir en los estudios relacionados con la evaluación y formación de competencias informacionales que se desarrollen de aquí en adelante.

- Se ha señalado cómo, de cara a facilitar la existencia de una identidad docente vinculada a un perfil concreto, se está estudiando el mapa de competencias propio de las diferentes categorías docentes. En este aspecto, se considera de interés el estudio de los contenidos propios de las competencias informacionales que deben incorporarse al perfil profesional docente de cada uno de los diferentes niveles educativos.

- Dada la complejidad y dinamismo inherentes a la sociedad de la información, parece que se hace necesario el desarrollo de estudios, más que transversales, longitudinales, que actualicen continuamente la situación en cuanto al desarrollo de las competencias informacionales tanto en estudiantes como en el profesorado. En un contexto como la sociedad líquida los estudios transversales pueden quedar obsoletos en poco tiempo, y aportan una visión de la realidad parcial y menos completa que los estudios longitudinales.

- Dado el punto de vista teórico desde el que se afronta generalmente la formación basada en competencias, es exigible la combinación en estudios empíricos futuros de metodologías cuantitativas, más objetivas y consistentes, con metodologías cualitativas, que facilitan el estudio de las competencias desde una perspectiva más integradora e interpretativa.

- En lo que respecta a la complejidad y amplitud del constructo competencias informacionales se hace necesario, bien, diseñar instrumentos de evaluación más amplios que, además de contener toda la realidad de la que están compuestas estas competencias, tengan en cuenta su perspectiva global, o bien, afrontar su estudio de manera fragmentada, por cada una de las subcompetencias de las que se compone. 
- Las escalas empleadas para medir las competencias informacionales se deben adaptar por tanto a esta complejidad, teniendo en cuenta, por ejemplo, de una manera más explícita la diferenciación entre los aspectos cognitivos e instrumentales de cada sub-competencia.

- Dado que se ha interpretado indirectamente que tanto estudiantes como futuro profesorado demandan una formación mayor en lo que respecta al desarrollo de competencias informacionales, cabe el diseño de estudios que midan directamente la demanda que existe al respecto tanto por parte de los estudiantes como del futuro profesorado y profesorado en activo, de una manera independiente al nivel de formación actual, ya sea real o autopercibido. A este respecto, los resultados obtenidos en esta investigación apuntan algunas tendencias que deberían confirmarse. ¿En realidad las mujeres demandan más formación que los hombres en los aspectos relacionados con las competencias informacionales?, ¿será porque se sienten menos formadas, porque tienen una mayor motivación hacia el aprendizaje y/o la docencia, o es que éstas están realmente menos formadas que los hombres?

- Dado que se verifica que el simple manejo de las TIC no facilita el desarrollo de competencias informacionales, ¿qué estrategias son las más adecuadas para que la integración de las TIC en el aula colabore en el desarrollo de estas competencias? Se consideran apropiados estudios que traten de arrojar un poco de luz al respecto.

- En este sentido, dado que parece que hombres y mujeres no se relacionan de la misma forma con las TIC, caben estudios que valoren los diferentes perfiles de manejo de las TIC en función del género y que aporten pistas sobre qué perfil, o más bien qué elementos de cada perfil, facilita en mayor medida el desarrollo de las competencias informacionales.

- Si bien la integración de las competencias informacionales en el currículum de los programas de formación del futuro profesorado es una cuestión que se nos escapa, cabe promover entre tanto acciones formativas alternativas tanto en formación inicial como continua, con una extensión más amplia que la que aquí se ha implementado. En este sentido, es relevante analizar tanto la satisfacción del profesorado con el programa formativo, como el nivel de aprendizaje alcanzado con instrumentos de evaluación que tengan más en cuenta el 
paradigma interpretativo de base y una visión holística de la realidad. Además, puede suscitar un mayor interés continuar con la formación de profesorado y futuro profesorado, más que en el contenido propio de las competencias informacionales, en estrategias para el desarrollo de procesos de enseñanzaaprendizaje en los que están inmersas las competencias informacionales.

- Todo ello con el fin último de estudiar el impacto sobre los estudiantes de la enseñanza de competencias informacionales en el profesorado en activo y futuro profesorado; ¿qué huella deja en el alumnado la formación por parte del profesorado, centrada principalmente en las competencias informacionales como contenido? ¿es diferente que si se centra más en los aspectos didácticos de su enseñanza? Así, de cara a facilitar el proceso y la mejora y retroalimentación continuas de dichos programas formativos, se tiene en consideración el diseño de instrumentos de evaluación que recojan información válida y fiable sobre las competencias que ha adquirido el profesorado para una correcta integración de las competencias informacionales en la práctica educativa cotidiana del aula. 


\subsection{Publicaciones vinculadas a la Tesis Doctoral}

Durante toda la etapa en la que se ha desarrollado la Tesis Doctoral, se han ido difundiendo los resultados parciales de la misma a través de diversas publicaciones, como artículos en revistas científicas, capítulos de libro en obras colectivas o congresos y simposios de carácter tanto nacional como internacional. Por otro lado, el presente proyecto de Tesis Doctoral se ha implementado inmerso en varios proyectos de investigación Nacionales de los que ha ido disfrutando de manera continuada y progresiva tanto el doctorando como el equipo de investigación que lo ha acogido.

Veamos, por tanto, a continuación, las principales publicaciones realizadas que tienen un estrecho vínculo con la Tesis Doctoral y que han servido para su difusión tanto nacional como internacional:

\subsubsection{Artículos en revistas científicas}

Martínez Abad, F.; Rodríguez Conde, M.J. \& Olmos Migueláñez, S. (aceptado, en prensa). Evaluación de competencias informacionales en educación secundaria: propuesta de modelo causal desde una perspectiva de género. Bordón. Revista de pedagogía.

Rodríguez Conde, M.J.; Martínez Abad, F. \& Olmos Migueláñez, S. (aceptado, en prensa). Evaluación de competencias informacionales autopercibidas en Educación Secundaria Obligatoria: un modelo causal. Cultura \& Educación. Revista de teoría, investigación y práctica.

Rodríguez Conde, M.J.; Olmos Migueláñez, S. \& Martínez Abad, F. (2012). Propiedades métricas y estructura dimensional de la adaptación española de una escala de evaluación de competencia informacional autopercibida (IL-HUMASS). Revista de Investigación Educativa. 30(2). 347-365

Rodríguez Conde, M.J.; Olmos Migueláñez, S.; Pinto Molina, M.; Martínez Abad, F. \& García Riaza, B. (2011). Informational Literacy and Information and Communication Technologies use by Secondary Education students in Spain: a descriptive study. Contemporary Issues in Education Research. 4(4). 1-12 


\subsubsection{Capítulos de libro en obras colectivas}

Hernández Ramos, J.P.; Martínez Abad, F. \& Olmos Migueláñez, S. (2011). Diseño de una Escala de Actitudes para valorar la Pizarra Digital Interactiva (PDI) como herramienta educativa en la universidad. En Albuquerque, F. \& Viana, J. (Coords.) I encontró Internacional TIC e Educaçao. Inovaçao curricular com TIC. (pp. 27-28). Lisboa: Instituto de Educaçao da Universidade deLisboa.

Martínez Abad, F.; Hernández Ramos, J.P. \& Olmos Migueláñez, S. (2010). Evaluación del empleo de la Wiki como herramienta formativa en entornos virtuales: estudio de caso. En Maquilón Sánchez, J.; García Sanz, M. \& Belmonte Almagro, M.L. (Coords.) Innovación educativa en la enseñanza formal (pp. 313-320). Murcia: Edit.um.

Hernández Ramos, J.P.; Martínez Abad, F. \& Olmos Migueláñez, S. (2009). Una nueva pedagogía en la sociedad de la información y la comunicación: nuevas competencias, nuevas metodologías y nuevas formas de evaluación. En Nieto López, E. \& Callejas Albiñana, A.L. (Coords.) Las Competencias Básicas. Reflexiones y Experiencias (pp. 106-120). Albacete: Ediciones de la Universidad de Castilla-La Mancha.

\subsubsection{Contribuciones a congresos}

González Rogado, A.B.; Rodríguez Conde, M.J.; Herrera García, M.E. \& Martínez Abad, F. (2012). E-evaluacion en Ingeniería Informática en Sistemas de Información. Presentado en IV Foro Internacional sobre Innovación Universitaria. Las universidades como generadoras de la innovación: Investigación, iniciativa y responsabilidad social. San José (Costa Rica), 5-7 diciembre.

Martínez Abad, F. \& Hernández Ramos, J.P. (2012). Formación del futuro profesorado de educación básica en competencias informacionales. Presentado en XII Congreso Internacional de Formación del Profesorado. Valladolid, 22-24 noviembre.

Hernández Ramos, J.P.; Martínez Abad, F.; García Peñalvo, F.J.; Herrera García, M.E. \& Rodríguez-Conde, M.J. (2012). Escala de actitud hacia el uso de las TIC por parte del profesorado. Estudio de fiabilidad y validez. Presentado en XIV Simposio 
Internacional de Informática Educativa (SIIE 2012). Andorra la Vella (Andorra), 29-31 octubre.

Hernández Ramos, J.P.; Martínez Abad, F.; García Peñalvo, F.J.; Herrera García, M.E. \& Rodríguez Conde, M.J. (2012). Teacher attitude scale regarding the use of ICT. Reliability and validity study. Presentado en XIV Simposio Internacional de Informática Educativa (SIIE 2012). Andorra la Vella (Andorra), 29-31 octubre.

Martínez Abad, F.; Olmos Migueláñez, S.; Rodríguez Conde, M.J. \& Hernández Ramos, J.P. (2012). Design and implementation of an evaluation scale of Information Skills for Secondary Education teachers in Spain. Presentado en the European Conference on Educational Research 2012 (ECER 2012). Cádiz, 18-21 septiembre.

Martínez Abad, F.; Rodríguez Conde, M.J. \& Olmos Migueláñez, S. (2012). Hacia un modelo causal sobre competencias informacionales en educación secundaria desde una perspectiva de género. Presentado en $X V$ Congreso Nacional y $V$ Iberoamericano de Pedagogía. Entre generaciones: Educación, Herencia y Profesas. Burgos, 4-7 julio.

Martínez Abad, F.; Herrera García, M.E.; García Riaza, B. \& Hernández Ramos, J.P. (2011). Basic dimensions in perceived informational competence of future Secondary Education teachers in Spain. Presentado en the European Conference on Educational Research 2011 (ECER 2011). Berlin (Alemania), 13-16 septiembre.

Martínez Abad, F.; Rodríguez Conde, M.J.; Olmos Migueláñez, S. \& Hernández Ramos, J.P. (2011). Evaluación de la importancia asignada a competencias informacionales: análisis comparado entre estudiantes de ESO y profesores en formación inicial. Presentado en XV Congreso Nacional y I Internacional de Modelos de Investigación Educativa. Investigación y educación en un mundo en red. (AIDIPE). Madrid, 21-23 septiembre.

Martínez Abad, F.; Hernández Ramos, J.P.; Olmos Migueláñez, S. \& Herrera García, M.E. (2011). Adaptación de una escala de evaluación de competencias informacionales auto percibidas y su aplicación al futuro profesorado de Educación Secundaria Obligatoria. Presentado en Evaluar para aprender en la Universidad: Experiencias Innovadoras (EVALtrends 2011). Cádiz, 9-11 marzo. 
Rodríguez Conde, M.J.; Olmos Migueláñez, S.; Pinto Molina, M.; Martínez Abad, F. \& García Riaza, B. (2010). Informational Literacy and Information and Communication Technologies use by Secondary Education students in Spain: a descriptive study. Presentado en the 2010 College Teaching \& Learning Conference (TLC). Dublín (Irlanda), 7-10 junio 2010.

Martínez Abad, F.; Hernández Ramos, J.P. \& Revuelta Domínguez, F.I. (2009). Desarrollo y evaluación de competencias en la Universidad de Salamanca a través de un sistema Learning Management System (LMS). Presentado en XIV Congreso Nacional de Modelos de Investigación Educativa. Educación, investigación y desarrollo social. (AIDIPE). Huelva, 24-26 junio.

\subsubsection{Participación en proyectos de investigación}

Rodríguez Conde, M.J. (Investigadora principal). Evaluación, formación e innovación sobre competencias clave en Educación Secundaria: TIC, competencia informacional y resolución de conflictos (EFI-CINCO). Proyecto nacional $1+D$ (Ministerio de Economía y Competitividad). Duración: 01/01/2013-31/12/2015. Referencia: EDU2012-34000. Financiación: 18500€.

Rodríguez Conde, M.J. (Investigadora principal). Evaluación de competencias clave y formación de profesorado en educación secundaria: TIC, ALFIN y convivencia escolar (EF-TALCO). Proyecto nacional I+D (Ministerio de Ciencia e Innovación). Duración: 01/01/2009-31/12/2012. Referencia: EDU2009-08753. Financiación: $117370 €$.

Rodríguez Conde, M.J. (Investigadora principal). Modelo de evaluación y desarrollo de competencias clave implícitas en la ESO: TIC, Lectura y Convivencia Escolar (ETELECO). Proyecto nacional I+D (Ministerio de Ciencia e Innovación). Duración: 01/01/2006-30/09/2009. Referencia: SEJ2006-10700. Financiación: 15000€. 

BIBLIOGRAFÍA 



\section{Bibliografía}

AASL. (2008). Standards for the 21st-century. Learner in Action. Amer Library Assn.

Abad, F. J. (2011). Medición en ciencias sociales y de la salud. Madrid: Síntesis.

Abell, A., Armstrong, C., Boden, D., Town, J. S., Webber, S., \& Woolley, M. (2004).

Alfabetización en información: la definición de CILIP (UK). Boletín de la Asociación Andaluza de Bibliotecarios, (77), 79-84.

Acuña Castillo, S. R., García Rodicio, H., \& Sánchez Miguel, E. (2011). Fostering active processing of instructional explanations of learners with high and low prior knowledge. European journal of psychology of education, 26(4), 435-452.

Adell, J. (1997). Tendencias en educación en la Sociedad de las tecnologías de la información. Edutec. Revista Electrónica de Tecnología Educativa, 7.

Aguiar Perera, M. V., Farray Cuevas, J. I., \& Brito Santana, J. (2002). Cultura y educación en la sociedad de la información (1a. ed.). A Coruña: Netbiblo.

ALA/ACRL. (2000). Information literacy competency standards for higher education. Chicago IL: ACRL.

Alemany, C. (2003). 14 aprendizajes vitales. Bilbao: Desclée De Brouwer.

Almeida, L. S., Prieto, M. D., Ferreira, A., Ferrando, M., Ferrandiz, C., Bermejo, R., \& Hernández, D. (2011). Structural invariance of multiple intelligences, based on the level of execution. Psicothema, 23(4), 832-838.

Almerich, G., Suárez, J. M., Jornet, J. M., \& Orellana, M. N. (2011). Las competencias y el uso de las Tecnologías de Información y Comunicación (TIC) por el profesorado: estructura dimensional. Revista electrónica de investigación educativa, 13(1), 28-42. 
Almerich, G., Suárez, J. M., Orellana, N., Belloch, C., Bo, R., \& Gastaldo, I. (2005).

Diferencias en los conocimientos de los recursos tecnológicos en profesores a partir del género, edad y tipo de centro. Revista Electrónica de Investigación y Evaluación Educativa, 11(2), 127-146.

Alonso García, C. M. (2002). Nueva cultura, nuevo sujeto: los retos del siglo XXI. En M. V. Aguiar Perera, J. I. Farray Cuevas, \& J. Brito Santana (eds.), Cultura y educación en la sociedad de la información (pp. 73-76). A Coruña: Netbiblo.

Alonso, N., Martínez Galindo, C., \& Moreno, J. A. (2006). Análisis factorial confirmatorio del «Cuestionario de Percepción de Igualdad-Discriminación de Educación Física» en alumnos adolescentes de Educación Física. En M. A. González, J. A. Sánchez, \& A. Areces (eds.), IV Congreso de la Asociación Española de Ciencias del Deporte (pp. 693-696). A Coruña: Xunta de Galicia. Recuperado a partir de gicom.umh.es/publicaciones/veraiii.pdf

Álvarez Álvarez, S., Cuéllar Lázaro, M. del C., López Arroyo, B., Adrada Rafael, C., Anguiano Pérez, R., Bueno García, A., ... Gómez Martínez, S. (2011). Actitudes de los profesores ante la integración de las tic en la práctica docente: Estudio de un grupo de la Universidad de Valladolid. Edutec. Revista electrónica de tecnología educativa, (35), 9-28.

Alvarez Martino, E., Alvarez Hernández, M., Castro Pañeda, P., Campo Mon, M. Á., \& Fueyo Gutiérrez, E. (2008). Funcionamiento de la integración en la Enseñanza Secundaria Obligatoria según la percepción del profesorado. Psicothema, 20(1), $56-61$.

Álvarez Méndez, J. M. (2012). Pensar la evaluación como recurso de aprendizaje. En B. Jarauta Borrasca, F. Imbernón, \& J. M. Álvarez Méndez (eds.), Pensando en el 
futuro de la educación: una nueva escuela para el siglo XXII (pp. 139-158). Barcelona: Graó.

Amat, F. (2011). Usando la web 2.0 para informarse e informar. Una experiencia en educación superior. Teoría de la Educación: Educación y Cultura en la Sociedad de la Información, 12(1), 145-166.

American Library Association. (1989). American Library Association Presidential Committee on Information Literacy: final report. Chicago: American Library Association.

Andrade, R. (2005). Hacia una gnoseología del desaprendizaje dialógico cognoconsciente: Principios para desaprender en el contexto de la complejidad. REDIE: Revista Electrónica de Investigación Educativa, 7(2). Recuperado a partir de http://dialnet.unirioja.es/servlet/articulo?codigo=1301683

Andretta, S. (2005). Information literacy: a practitioner's guide. Oxford: Chandos Pub.

Andretta, S. (2007). Phenomenography: a conceptual framework for information literacy education. Aslib Proceedings, 59(2), 152-168.

Anguita Martínez, R. (1997). Algunas claves de la historia de la Formación del Profesorado en España para comprender el presente. Revista interuniversitaria de formación del profesorado, (30), 97-109.

Antunes, F. (2008). globalização e individualização: educação ao longo da vida entre a economia do conhecimento e a coesão social. En F. Antunes (ed.), A nova ordem educacional. Espaço Europeu de Educaçao e aprendizagem ao longo da vida (pp. 133-175). Coimbra (Portugal): Almedina.

Appel, M. (2012). Are heavy users of computer games and social media more computer literate? Computers \& Education, 59(4), 1339-1349. 
Appleton, L. (2005). Examination of the impact of information-skills training on the academic work of health-studies students: a single case study. Health Information and Libraries Journal, 22(3), 164-172.

Area Moreira, M. (2001). Educar en la sociedad de la información. Bilbao: Desclée De Brouwer.

Area Moreira, M. (2005). Nuevas tecnologías, globalización y migraciones: los retos de la institución educativa. Barcelona: Octaedro.

Area Moreira, M. (2008). Innovación pedagógica con TIC y el desarrollo de las competencias informacionales y digitales. Investigación en la escuela, 64, 5-18.

Area Moreira, M. (2010a). ¿Por qué formar en competencias informacionales y digitales en la educación superior? Revista de Universidad y Sociedad del Conocimiento, $7(2), 2-5$.

Area Moreira, M. (2010b). Tecnologías digitales, multialfabetización y bibliotecas en la escuela del siglo XXI. Boletín de la asociación andaluza de bibliotecarios, (9899), 39-52.

Area Moreira, M., \& Guarro, A. (2012). La alfabetización informacional y digital: fundamentos pedagógicos para la enseñanza y el aprendizaje competente. Revista española de Documentación Científica, ( ${ }^{\circ}$ Monográfico), 46-74.

Area Moreira, M., \& Ribeiro-Pessoa, M. T. (2012). De lo sólido a lo líquido: Las nuevas alfabetizaciones ante los cambios culturales de la Web 2.0. Comunicar, 19(38), $13-20$.

Arnal, J., Rincón, D. del, \& Latorre, A. (1992). Investigación educativa: fundamentos y metodologías (1a. ed.). Barcelona: Labor. 
Askenazy, P. (2002). La Croissance moderne: organisations innovantes du travail. Economica.

Austin, E. W., Pinkleton, B. E., Austin, B. W., \& Van de Vord, R. (2012). The relationships of information efficacy and media literacy skills to knowledge and self-efficacy for health-related decision making. Journal of American college health, 60(8).

Baker, E. (2006). Managing in the information age: preventing «electronic fatigue syndrome». Journal of Public Health Management and Practice, 12(3), 298-300.

Bandura, A., \& Locke, E. A. (2003). Negative self-efficacy and goal effects revisited. The Journal of Applied Psychology, 88(1), 87-99.

Baño Egea, J. J., Leal Hernández, M., Sánchez Marín, F. J., Ruiz Merino, G., \& Serna Mármol, J. P. (2012). Impacto de curso on-line sobre el grado de conocimiento del programa OMI-AP para médicos. Semergen: revista española de medicina de familia, (3), 145-150.

Batista-Foguet, J. M., \& Coenders, G. (2000). Modelos de ecuaciones estructurales: modelos para el análisis de relaciones causales. Madrid: La Muralla.

Bauman, Z. (2006). Vida líquida. Barcelona [etc.]: Paidós.

Bauman, Z. (2007). Los retos de la educación en la modernidad líquida. Barcelona: Gedisa.

Bawden, D. (2001). Information and digital literacies: a review of concepts. Journal of Documentation, 57(2), 218-59.

Beishuizen, J. J., \& Stoutjesdijk, E. T. (1999). Study strategies in a computer assisted study environment. Learning and Instruction, 9(3), 281-301.

Bell, D. (1976). The coming of post-industrial society: a venture in social forecasting. New York: Basic Books. 
Benejam Arguimbau, P. (2002). Las Escuelas Normales en tiempos de la transición.

Historia de la educación: Revista interuniversitaria, (21), 81-90.

Benito Morales, F. (1996). Del dominio de la información a la mejora de la inteligencia.

Diseño, aplicación y evaluación del programa HEBORI (Tesis doctoral).

Universidad de Murcia, España.

Benito Morales, F. (2000). Nuevas necesidades, nuevas habilidades. Fundamentos de la alfabetización en información. En J. A. Gómez Hernández (ed.), Estrategias y modelos para enseñar a usar la información: guía para docentes, bibliotecarios $y$ archiveros (pp. 9-75). Murcia: KR.

Benito Morales, F. (2008). Desarrollo de la alfabetización informacional en la educación obligatoria. En J. A. Gómez Hernández, A. Calderón Rehecho, \& J. A. Magán Wals (eds.), Brecha digital y nuevas alfabetizaciones. El papel de la biblioteca (pp. 149-161). Madrid: Universidad Complutense de Madrid.

Blanco Blanco, Á. (2010). Creencias de autoeficacia de estudiantes universitarios: un estudio empírico sobre la especificidad del constructo. Revista Electrónica de Investigación y Evaluación Educativa, 16(1), 1-28.

Blasco Olivares, A., \& Durban Roca, G. (2012). La competencia informacional en la enseñanza obligatoria a partir de la articulación de un modelo específico. Revista española de Documentación Científica, ( $N^{\circ}$ Monográfico), 100-135.

Boletín Oficial del Estado. REAL DECRETO 1631/2006, de 29 de diciembre, por el que se establecen las enseñanzas mínimas correspondientes a la Educación Secundaria Obligatoria. , BOE núm. 5 677-773 (2007). 
Boletín Oficial del Estado. ORDEN ECI/2220/2007, de 12 de julio, por la que se establece el currículo y se regula la ordenación de la Educación secundaria obligatoria. , BOE núm. 174 31680-31828 (2007).

Bolívar Botía, A. (2001). Globalización e identidades: des-territorialización de la cultura. Revista de Educación, Número extraordinario, 265-288.

Bolívar Botía, A. (2009). Aprender a aprender a lo largo de la vida. Multiárea: revista de didáctica, 4, 87-144.

Bollen, K. A. (1989). Structural equations with latent variables. New York: WileyInterscience.

Borg, C. (2005). The EU memorandum on lifelong learning. Old wine in new bottles? Globalisation, Societies and Education, 3(2), 203-225.

Borges del Rosal, A., Sánchez Bruno, J. A., \& Cañadas Osinski, I. (2000). El contraste de medias recortadas ante la violación de los supuestos paramétricos. Psicothema, 12(2), 506-508.

Boterf, G. le. (2001). Ingenieria de las competencias. Barcelona: Gestion 2000.

Brinkley, I., \& Lee, N. (2006). The knowledge economy in Europe a report prepared for the 2007 EU Spring Council. London: The Work Foundation.

Brock, P. (1993). Literacy and literacy standards. Australian Style, 2(1). Recuperado a partir de http://www.ling.mq.edu.au/centres/sc/dec1993.htm

Browne, M. (1984). Asymptotically distribution-free methods for the analysis of covariance structures. The British journal of mathematical and statistical psychology, 37, 62-83.

Bruce, C. (1997). The seven faces of information literacy. Adelaide: Auslib Press. 
Buendía Eisman, L., Olmedo Moreno, E. M., \& González Gijón, G. (2009). Lifelong learning: diferentes contextos, diferentes situaciones. Revista de Investigación Educativa, 27(1), 185-202.

Bundy, A. (1998). Information literacy: the key competency for the 21sr century. En Annual Conference of the International Association of Technological University Libraries (p. 16). Presentado en Annual Conference of the International Association of Technological University Libraries, Pretoria, South Africa.

Bundy, A. (2004). One essential direction: information literacy, information technology fluency. Journal of eLiteracy, 1, 7-22.

Bundy, A., \& ANZIIL. (2004). Australian and New Zealand information literacy framework principles, standards and practice. Adelaide (Australia): Australian and New Zealand Institute for Information Literacy. Recuperado a partir de http://www.anziil.org/resources/Info\%20lit\%202nd\%20edition.pdf

Burbules, N., \& Torres, C. A. (2001). Globalización y educación. Revista de Educación, Número extraordinario, 13-29.

Bury, S. (2011). Faculty attitudes, perceptions and experiences of information literacy: a study across multiple disciplines at York University, Canada. Journal of Information Literacy, 5(1), 44-64.

Buschman, J. (2010). Alfabetización informacional, nuevas alfabetizaciones y alfabetización. Boletín de la asociación andaluza de bibliotecarios, (98-99), 155183.

Bustamante, G., De Zubiría, S., Bacarat, M. P., Graziano, N. A., Marín, L. F., Gómez, J. H., \& Serrano, E. (2004). El concepto de competencia: una mirada interdisciplinar II. Bogotá: Sociedad Colombiana de Pedagogía. 
Byrne, A. (2005). La alfabetización informacional desde una perspectiva global: eldesastre agudiza nuestras mentes. Anales de Documentación, 8, 7-20.

Byrne, B. (2001). Structural equation modeling with amos: basic concepts, applications, and programming. Oxford: Routledge.

Cabero Almenara, J. (1996). Nuevas tecnologías, comunicación y educación. Edutec. Revista Electrónica de Tecnología Educativa, 1.

Cabero Almenara, J. (2001). Tecnología educativa: diseño y utilización de medios en la enseñanza. Barcelona: Paidós.

Cabero Almenara, J. (2004). Reflexiones sobre la brecha digital y la educación. En F. J. Soto \& J. Rodríguez (eds.), Tecnología, educación y diversidad: retos y realidades de la inclusión digital (pp. 23-42). Murcia: Consejería de Educación y Cultura.

Cabero Almenara, J. (2006). Bases pedagógicas del e-learning. Revista de Universidad y Sociedad del Conocimiento, 3(1), 1-10.

Cabero Almenara, J., \& Alonso García, C. M. (2007). Nuevas tecnologías aplicadas a La educación. Madrid: McGraw Hill.

Calderón Rehecho, A. (2010). Informe APEI sobre alfabetización informacional. Gijón: APEI.

Calvo Bernardino, A., \& Mingorance Arnáiz, C. (2010). Evaluación continua de conocimientos vs de competencias: Resultados de la aplicación de dos métodos valorativos diferentes. Revista de Investigación Educativa, 28(2), 361-383.

Campbell, C. (1985, febrero 25). Torrent of print strains the fabric of libraries. The New York Times. New York. 
Campbell, D. T., \& Stanley, J. (1963). Experimental and quasi-experimental designs for research. Chicago: Wadsworth Publishing.

Campbell, D. T., \& Stanley, J. (1973). Diseños experimentales y cuasiexperimentales en la investigación social. Buenos Aires: Amorrortu.

Camps Cervera, M. V. (2009). La educación en medios, más allá de la escuela. Comunicar, (32), 139-145.

Cano García, M. E. (2008). La evaluación por competencias en la educación superior. Profesorado, Revista de Currículum y formación del Profesorado, 13(3). Recuperado a partir de http://www.ugr.es/local/recfpro/rev123COL1.pdf

Carvalho Levy, D. P. (2005). La interfaz ante la cultura y el comportamiento del usuario. Universitat de les Illes Balears. Recuperado a partir de http://dialnet.unirioja.es/servlet/tesis?codigo=7904

Cassity, E., \& Ang, I. (2006). Industry partnerships and the «Knowledge Society»: the australian experience. Minerva: A Review of Science, Learning and Policy, 44(1), 47-63.

Castañeda-Peña, H., González Niño, L., Marciales Vivas, G., Barbosa Chacón, J. W., \& Barbosa Herrera, J. C. (2010). Recolectores, verificadores y reflexivos: perfiles de la competencia informacional en estudiantes universitarios de primer semestre. Revista Interamericana de Bibliotecología, 33(1), 187-209.

Castaño-Muñoz, J. (2010). Digital inequality amon university students in developed countries and its relation to academic performance. Revista de Universidad y Sociedad del Conocimiento, 7(1), 43-51.

Castells, M. (1998). La Era de la información: economía, sociedad y cultura. El Poder de la Identidad (Vol. 2). Madrid: Alianza. 
Castells, M. (1999a). La Era de la información: economía, sociedad y cultura. La sociedad Red (Vol. 1). Madrid: Alianza Editorial.

Castells, M. (1999b). La Era de la información: economía, sociedad y cultura. Fin de milenio (Vol. 3). Madrid: Alianza.

Castro, M., \& Lizasoain Hernández, L. (2012). Las técnicas de modelización estadística en la investigación educativa: minería de datos, modelos de ecuaciones estructurales y modelos jerárquicos lineales. Revista española de pedagogía, 70(251), 131-148.

Castro, R. (2006). Adult education. New routes in a new landscape. Braga: University of Minho.

Catts, R. (2005). Confirming the relational model of information literacy. International Information and Library Review, 37(1), 19-24.

Catts, R., \& Lau, J. (2009). Hacia unos indicadores de alfabetización informacional. Madrid: Ministerio de Cultura.

CAUL. (2001). Information literacy standards. Canberra: University of South Australia. CAUL. (2002). Normas sobre alfabetización en información ( $1^{\mathrm{a}}$ Edición). Boletín de la asociación andaluza de bibliotecarios, 68, 67-90.

Cazden, C., Cope, B., Fairclough, N., Gee, J., Kalantzis, M., Kress, G., ... Nakata, M. (1996). A pedagogy of multiliteracies: designing social futures. Harvard Educational Review, 66(1). Recuperado a partir de http://wwwstatic.kern.org/filer/blogWrite44ManilaWebsite/paul/articles/A_Pe dagogy_of_Multiliteracies_Designing_Social_Futures.htm

Cea D’Ancona, M. Á. (2002). Análisis multivariable: teoría y práctica en la investigación social. Madrid: Síntesis. 
Cebrián Herreros, M. (2009). La sociedad de la informacion y del conocimiento en los paises nordicos. Barcelona: Gedisa.

Cerezo, J. M. (2008). Hacia un nuevo paradigma: la era de la información fragmentada. Revista Telos, (76). Recuperado a partir de http://sociedadinformacion.fundacion.telefonica.com/telos/articulocuaderno.a sp@idarticulo=6\&rev=76.htm

CNICE. (2007). Las TIC en la educación: panorama internacional y situación española. Madrid: Santillana. Recuperado a partir de http://www.oei.es/tic/DocumentoBasico.pdf

Cohen, D. (2007). Tres lecciones sobre la sociedad postindustrial. Madrid: Katz.

Cohen, D., \& McCuaig, W. (2008). Three lectures on post-industrial society. MIT Press.

Cohen, J. (1969). Statistical power analysis for the behavioral sciences. New York: Academic Press.

Cohen, L., \& Manion, L. (2002). Métodos de investigación educativa. Madrid: La Muralla.

Colás Bravo, M. P. S., \& Jiménez Cortés, R. (2008). Evaluación del impacto de la formación (online) en TIC en el profesorado: una perspectiva sociocultural. Revista de educación, (346), 187-215.

Coll, C., Bustos, A., Córdoba, F., Del Rey, R., Engel, A., Escaño, J., \& Gil, M. (2010). Desarrollo, aprendizaje y enseñanza en la educación secundaria. Barcelona: Graó.

Commission of the European Communities. (2000). A memorandum on lifelong learning. MECD. Recuperado a partir de 
http://ec.europa.eu/education/lifelonglearning-

policy/doc/policy/memo_es.pdf

Consejo Europeo. (2001). Common European framework of reference for languages:

learning, teaching, assessment. Cambridge: Cambridge University Press.

Cope, B., \& Kalantzis, M. (1999). Multiliteracies Literacy Learning and the Design of Social Futures. London: Taylor \& Francis.

Cope, B., \& Kalantzis, M. (2009a). Multiliteracies: new literacies, new learning. Pedagogies: An International Journal, 4(3), 164-195.

Cope, B., \& Kalantzis, M. (2009b). A grammar of multimodality. International Journal of Learning, 16(2), 361-426.

Corder, G. W., \& Foreman, D. I. (2009). Nonparametric statistics for non-statisticians: a step-by-step approach. San Francisco: Wiley.

Cornellá, A. (1997). La cultura de la información como institución previa a la sociedad de la información. Recuperado a partir de http://www1.hcdn.gov.ar/dependencias/agora/biblioteca/aprats.pdf.pdf

Cornellá, A. (2003). KNewton: buscando un orden en la información. Barcelona: Infonomía.

Cornellá, A. (2009). Infoxicación: buscando un orden en la información. Barcelona: Infonomía.

CRUE-TIC, \& REBIUN. (2009). Competencias informáticas e informacionales en los estudios de grado. Recuperado a partir de http://cruetic.uji.es/index.php?option=com_remository\&Itemid=28\&func=startdown\&id= 226 
CRUE-TIC, \& REBIUN. (2012). Manual para la formación en competencias informáticas e informacionales (CI2). Madrid: CRUE.

Chandler, R., \& Scott, M. (2011). Statistical methods for trend detection and analysis in the environmental sciences. San Francisco: Wiley-Blackwell.

Chen, K., \& Lin, P. (2011). Information literacy in university library user education. Aslib Proceedings, 63(4), 399-418.

Dagiene, V., Zajanckauskiene, L., \& Zilinskiene, I. (2008). Distance learning course for training teachers' ICT competence. En R. T. Mittermeir \& M. M. Syslo (eds.), Informatics Education - Supporting Computational Thinking (Vol. 5090, pp. 282292). Berlin: Springer-Verlag Berlin.

David, P., \& Foray, D. (2002). Una introducción a la economía y a la sociedad del saber. Revista Internacional de Ciencias Sociales, (171).

De Kelete, J.-M. (2008). Enfoque socio-histórico de las competencias en la enseñanza. Profesorado, Revista de Currículum y formación del Profesorado, 12(3). Recuperado a partir de http://www.ugr.es/local/recfpro/rev123ART1.pdf

De la Orden Hoz, A., \& Jornet Meliá, J. M. (2012). La utilidad de las evaluaciones de sistemas educativos: el valor de la consideración del contexto. Bordón. Revista de pedagogía, 64(2), 69-88.

De Miguel Díaz, M. (2006). Modalidades de enseñanza centradas en el desarrollo de competencias: orientaciones para promover el cambio metodológico en el Espacio Europeo de Educación Superior. Oviedo: Universidad de Oviedo.

De Miguel Díaz, M. (2010). La renovación del sistema educativo a partir de las competencias básicas. Organización y Gestión Educativa: Revista del Fórum Europeo de Administradores de la Educación, 18(4), 394-402. 
De Miguel Sánchez, C. (2005). Criterios de innovación para la integración curricular de las Tecnologías de la Información y la Comunicación en el aula. Revista Electrónica Iberoamericana sobre Calidad, Eficacia y Cambio en Educación, 3(1), 750-763.

Decroly, O. (1929). Problemas de psicología y de pedagogía. Madrid: Francisco Beltrán. Delors, J. (1997). La educación encierra un tesoro: informe a la UNESCO de la Comisión Internacional de la Educación para el Siglo XXI. Madrid: UNESCO.

Dewey, J. (1952). La busca de la certeza: un estudio de la relación entre el conocimiento y la acción. México, D.F: Fondo de Cultura Económica.

Diario oficial de la Unión Europea. (2006). Recomendación del Parlamento Europeo y del Consejo de 18 de diciembre de 2006 sobre las competencias clave para el aprendizaje permanente. Bruselas: Parlamento Europeo y Consejo de la Unión europea. Recuperado a partir de http://eurlex.europa.eu/LexUriServ/site/es/oj/2006/I394/I 39420061230es00100018.pdf

Diehm, R.-A., \& Lupton, M. (2012). Approaches to learning information literacy: a phenomenographic study. Journal of Academic Librarianship, 38(4), 217-225.

Digital Opportunities Task Force. (2002). Digital opportunities for all. Canadá: Sommet Kananaskis Summit.

diSessa, A. (2001). Changing minds: computers, learning, and literacy. Massachusetts: The MIT Press.

Doussoulin, A. (2005). Influencia del nivel socioeconómico sobre los distintos factores que involucra la estimulación ambiental en preescolares. Revista iberoamericana de psicomotricidad y técnicas corporales, (18), 105-114. 
Eastman, C., \& Marzillier, J. S. (1984). Theoretical and methodological difficulties in Bandura's self-efficacy theory. Cognitive Therapy and Research, 8(3), 213-229.

Echeverría, J. (2012). La escuela continua y el trabajo en el espacio-tiempo electrónico.

En B. Jarauta Borrasca, F. Imbernón, \& J. M. Álvarez Méndez (eds.), Pensando en el futuro de la educación: una nueva escuela para el siglo XXII (pp. 37-49). Barcelona: Graó.

Eisenberg, M. B., \& Berkowitz, R. E. (1990). Information problem solving: the Big Six Skills approach to library \& information skills instruction. New York: Ablex Publishing Corporation. Recuperado a partir de http://www.eric.ed.gov/ERICWebPortal/detail?accno=ED330364

Elborg, J. (2008). Alfabetización informacional crítica: Implicaciones para la práctica educativa. Boletín de la asociación andaluza de bibliotecarios, 92-93, 103-121.

Elogia Ipsofacto. (2009). Estudio sobre redes sociales en internet. IAB Spain Research.

Emmett, A., \& Emde, J. (2007). Assessing information literacy skills using the ACRL standards as a guide. Reference Services Review, 35(2), 210-229.

Entreculturas. (2007). Alfabetización puerta del conocimiento. Madrid: Entreculturas. Escalante Estrada, L. E. (2006). Los estilos de aprendizaje de los alumnos del CEPCSAEGRO. Revista Iberoamericana de Educación, 41(1). Recuperado a partir de http://www.rieoei.org/deloslectores/1428Escalante.pdf

Escolano Benito, A. (1982). Las escuelas normales, siglo y medio de perspectiva histórica. Revista de educación, (269), 55-76.

Escudero Muñoz, J. M. (2009). La formación del profesorado de Educación Secundaria: contenidos y aprendizajes docentes. Revista de educación, (350), 79-103. 
Esteve Zarazaga, J. M. (2009). La formación de profesores: bases teóricas para el desarrollo de programas de formación inicial. Revista de educación, (350), 1530.

Etxeberria Murgiondo, J. (2004). Estadística aplicada: análisis de datos. País Vasco: Universidad del País Vasco.

Etxeberría Murgiondo, J. (2005). Análisis descriptivo de datos en educación. Madrid: La Muralla.

Eurydice-CIDE. (2002). Las competencias clave. Un concepto en expansión dentro de la educación general obligatoria. Madrid: Eurydice.

Federighy, P. (2006). Ensayos e Informes - La educacion y la formacion en Europa tras el 2010. Revista de Educación, (339), 801-826.

Ferguson, J., Neely, T., \& Sullivan, K. (2006). A Baseline Information Literacy assessment of biology students. Reference \& user services quarterly, 46(2), 6171.

Fernández Enguita, M., Souto González, X. M., \& Rodríguez Rávena, R. (2007). La Sociedad del conocimiento: democracia y cultura, los retos de la institución educativa. Barcelona: Octaedro.

Fernández Fernández, J. A. (2005). Relación del desarrollo corporal en el alumno de la e.s.o. con su nivel socioeconómico. Revista Internacional de Medicina y Ciencias de la Actividad Física y del Deporte, (19), 2-.

Fernández Ludeña, A. (2007). Alfabetización: puerta del conocimiento. Madrid: Entreculturas.

Fernández, M., Zayas, R., \& Urra, P. (2008). Normas de competencias informacionales para el Sistema Nacional de Información en Salud. Acimed, 17(4), 1-17. 
Ferreiro, E. (1997). Alfabetización: peoría y práctica. México: Siglo XXI.

Ferreiro, E. (2002). Pasado y presente de los verbos leer y escribir. México: Fondo de cultura económica.

Ferrés i Prats, J. (2000). Educar en una cultura del espectáculo. Barcelona: Paidós.

Fiori, E., Fiori, J. L., \& Freire, P. (1973). Educación liberadora. Algorta (Vizcaya): Zero.

Forrest, M. E. S., \& Simpson, A. E. (2007). Teachability: creating accessible learning and teaching in information skills. Health Information \& Libraries Journal, 24(1), 6971.

Franco, A. de. (2000). ¿Porqué precisamos de un desarrollo local integrado y sostenible? Instituciones y desarrollo, 6.

Freeman, E., \& Lynd-Balta, E. (2010). Developing information literacy skills early in an undergraduate curriculum. College Teaching, 58(3), 109-115.

Freinet, C. (1972). Las invariantes pedagógicas: guía práctica de la escuela moderna. Barcelona: Laia.

Freire, P. (1974). La educación como práctica de la libertad. Madrid [etc.]: Siglo XXI.

Freire, P. (1975). Pedagogía del oprimido. Madrid: Siglo veintiuno de España.

Freire, P. (1984). La importancia de leer y el proceso de liberación. Madrid: Siglo XXI de España.

Freire, P. (1989). Alfabetización: lectura de la palabra y lectura de la realidad. Barcelona [etc.]: Paidós.

Fuentes Agusti, M., \& Monereo, C. (2008). Como buscan informacion en Internet los adolescentes. Investigación en la escuela, (64), 45-58. 
Fuentes, M., Monereo, C., \& Sànchez, S. (2000). Internet search and navigation strategies used by experts and beginners. Interactive Educational Multimedia, (1), 24-34.

Gaio Alves, M., Neves, C., \& Gomes, E. X. (2010). Lifelong learning: Conceptualizations in European educational policy documents. European Educational Research Journal, 9(3), 332-344.

García Carrasco, J. (2009). Las formas de alfabetización cultural en la sociedad de la información. Teoría de la Educación: Educación y Cultura en la Sociedad de la Información, 10(1), 49-75.

García, I., Gros, B., \& Noguera, I. (2010). La relacion entre las prestaciones tecnologicas y el diseno de las actividades de aprendizaje para la construccion colaborativa del conocimiento. Cultura y Educación, 22(4), 395-417.

García Jiménez, E., Gil Flores, J., \& Rodríguez Gómez, G. (2000). Análisis factorial. Madrid: La Muralla.

García-Valcárcel Muñoz-Repiso, A., \& Tejedor Tejedor, F. J. (2005). Condicionantes (actitudes, conocimientos, usos, intereses, necesidades formativas) a tener en cuenta en la formación del profesorado no universitario en TIC. Enseñanza \& Teaching: Revista interuniversitaria de didáctica, (23), 115-142.

Gardner, H. E. (1998). Extraordinary minds: portraits of 4 exceptional individuals and an examination of our own extraordinariness. Basic Books.

Gargallo Castel, A., Esteban Salvador, L., \& Pérez Sanz, J. (2010). Impact of gender in adopting and using ICTs in Spain. Journal of Technology Management \& Innovation, 5(3), 120-128. 
Gargallo López, B., Suárez, J. M., \& Belloch, C. (2003). La división digital en el proceso de integración de las NTIC en la educación. Diferencias de género entre alumnos de E.S.O. de la comunidad valenciana. Teoría de la Educación: Educación y Cultura en la Sociedad de la Información, 4(1).

Gee, J. P. (2003). La ideología en los discursos: lingüística social y alfabetizaciones. Madrid: Fundación Paideia.

Gil Flores, J. (2011). Estatus socioeconómico de las familias y resultados educativos logrados por el alumnado. Cultura y Educación, 23(1), 141-154.

Gimeno Sacristán, J. (2008). Educar por competencias: ¿qué hay de nuevo? Madrid: Ediciones Morata.

Gisbert Cervera, M. (2002). El nuevo rol del profesor en entornos tecnológicos. Acción Pedagógica, 11(1), 48-59.

Glass, G. V., McGaw, B., \& Smith, M. L. (1981). Meta-analysis in social research. London: Sage Publications, Inc.

Glass, G. V., Stanley, J. C., Galvis Gómez, E., \& Guzmán, E. (1986). Métodos estadísticos aplicados a las ciencias sociales. México: Prentice-Hall Hispanoamericana.

Gómez Hernández, J. A. (2000). Estrategias y modelos para enseñar a usar la información: guía para docentes, bibliotecarios y archiveros (1a ed.). Murcia: Editorial KR.

Gómez Hernández, J. A. (2007). Alfabetización Informacional: cuestiones báscas. Anuario ThinkEPI, 43-50.

Gómez Hernández, J. A. (2010). Las bibliotecas universitarias y el desarrollo de las competencias informacionales en los profesores y los estudiantes. Revista de Universidad y Sociedad del Conocimiento, 7(2), 39-49. 
Gómez Hernández, J. A., \& Benito Morales, F. (2001). De la formación de usuarios a la alfabetización internacional: Propuestas para enseñar las habilidades de información. Scire: Representación y organización del conocimiento, 7(2), 5384.

González Barberá, C., Caso Niebla, J., Díaz López, K., \& López Ortega, M. (2012). Rendimiento académico y factores asociados: aportaciones de algunas evaluaciones a gran escala. Bordón. Revista de pedagogía, 64(2), 51-68.

González Fernández-Villavicencio, N. (2012). Alfabetización para una cultura social, digital, mediática y en red. Revista española de Documentación Científica, $\left(\mathrm{N}^{\circ}\right.$ Monográfico), 17-45.

González, J., \& Wagenaar, R. (2003). Tuning educational structures in Europe. Bilbao: Universidad de Deusto.

González Mariño, J. C. (2008). TIC y la transformación de la práctica educativa en el contexto de las sociedades del conocimiento. Revista de Universidad y Sociedad del Conocimiento, 5(2). Recuperado a partir de http://www.uoc.edu/rusc/5/2/dt/esp/gonzalez.html

González Sanmamed, M. (2009). Una nueva oportunidad para la formación inicial del profesorado de Educación Secundaria. Revista de educación, (350), 57-78.

González Teruel, A. (2011). La perspectiva del usuario y del sistema en la investigación sobre el comportamiento informacional. Teoría de la Educación: Educación y Cultura en la Sociedad de la Información, 12(1), 28-46.

González-Vallinas Alvarez, P., Oterino, D., \& San Fabián Maroto, J. L. (2007). Factores asociados a la formación permanente del profesorado de Educación Secundaria 
en Asturias. Profesorado: Revista de curriculum y formación del profesorado, 11(1), 1-.

Goody, J. (1963). The consequences of literacy. Indianapolis: Bobbs-Merrill.

Goody, J. (1977). The domestication of the savage mind. Cambridge: Cambridge University Press.

Goody, J. (2005). Democracy, Values and Modes of Representation. Diogenes, 52(2), 718.

Graff, H. (1979). The literacy myth: literacy and social structure in the nineteenthcentury city. New York: Academic Press.

Graff, H. (1981). Literacy in history: an interdisciplinary research bibliography. New York: Garland Pub.

Grant, M. J., \& Brettle, A. J. (2006). Developing and evaluating an interactive information skills tutorial. Health Information and Libraries Journal, 23(2), 7986.

Gratch Lindauer, B. (2006). Los tres ámbitos de evaluación de la alfabetización informacional. Anales de Documentación, 9, 69-81.

Green, J., Calimy, G., \& Elmore, P. (2006). Complementary methods in education research. Mahwah New Jersey: L. erlbaum.

Grissom, R. J., \& Kim, J. J. (2011). Effect sizes for research: univariate and multivariate applications. Routledge Academic.

Grizzle, A., Wilson, C., \& UNESCO. (2011). Media and information literacy curriculum for teachers. Paris: UNESCO. Recuperado a partir de http://www.unesco.org/new/fileadmin/MULTIMEDIA/HQ/Cl/Cl/pdf/publicatio 
ns/Media\%20and\%20information\%20literacy\%20curriculum\%20for\%20teacher s.pdf

Gros, B. (2006). ¿Qué debe saber el profesorado? Cuadernos de pedagogía, (363), 58-

65.

Gros Salvat, B., \& Silva Quiroz, J. (2005). La formación del profesorado como docente en los espacios virtuales de aprendizaje. Revista Iberoamericana de Educación, 36(1), 3-17.

Guinee, K. (2004). Internet searching by K-12 students: a research-based process model. En Association for Educational Communications and Technology. Recuperado a partir de http://www.eric.ed.gov/ERICWebPortal/detail?accno=ED485138

Guitert, M., Romeu, T., \& Pérez-Mateo, M. (2007). Competencias TIC y trabajo en equipo en entornos virtuales. Revista de Universidad y Sociedad del Conocimiento, 4(1), 1-12.

Gunasekara, C., \& Collins, S. (2008). Information Literacy as a framework to foster lifelong learning. Presentado en Lifelong Learning: Reflecting on success and framing futures: 5th Internacional Lifelong Learning Conference, Yeppoon, Central Queensland. Recuperado a partir de http://acquire.cqu.edu.au:8080/vital/access/manager/Repository/cqu:2929

Gutiérrez Martín, A., Palacios Picos, A., \& Torrego Egido, L. (2010). La formación de los futuros maestros y la integración de las TIC en la educación: anatomía de un desencuentro. Revista de educación, (353), 267-293.

Gutiérrez Martín, A., \& Tyner, K. (2012). Educación para los medios, alfabetización mediática y competencia digital. Comunicar, (38), 31-39. 
Gutiérrez Porlán, I. (2007). Finalidad del uso de las Nuevas Tecnologías por parte de los alumnos de segundo Curso de Enseñanza Secundaría Obligatoria en España. Murcia: Universidad de Murcia.

Guttman, L. (1954). Some necessary conditions for common-factor analysis. Psychometrika, 19(2), 149-161.

Guzmán Ibarra, I., \& Marín Uribe, R. (2011). La competencia y las competencias docentes: reflexiones sobre el concepto y la evaluación. Revista electrónica interuniversitaria de formación del profesorado, 14(1), 151-163.

Gwyer, R., Stubbings, R., \& Walton, G. (2012). The road to information literacy: librarians as facilitators of learning. The Hague: De Gruyter.

Hargittai, E. (2010). Digital na(t)ives? variation in internet skills and uses among members of the net generation. Sociological Inquiry, 80(1), 92-113.

Hawkins, D. (1982). Topics in applied multivariate analysis. Cambridge [etc.]: Cambridge University Press.

Head, A. J., \& Eisenberg, M. (2009). How college students seek information in the digital age. Washington D.C.: University of Washington.

Hedges, L. (1982). Statistical methodology in meta-analysis. Princeton N.J.: ERIC.

Henry, L. A. (2006). SEARCHing for an answer: the critical role of new literacies while reading on the Internet. Reading Teacher, 59(7), 614-627.

Hensen, P. (2010). The «Bologna Process» in European Higher Education: impact of bachelor's and master's degrees on german medical education. Teaching and learning in medicine, 22(2), 142-147.

Hernández Hernández, C. J. (2010). Un plan de formación en competencias de información a través de aulas virtuales: análisis de una experiencia con 
alumnado universitario. Revista de Universidad y Sociedad del Conocimiento, $7(2), 50-62$.

Hernández Martín, A., \& Quintero Gallego, A. (2009). La integración de las TIC en el currículo: necesidades formativas e interés del profesorado. Revista electrónica interuniversitaria de formación del profesorado, 12(2), 103-119.

Hernández Nanclares, N., Blanco Vaca, C., \& Lera López, F. (2003). La «brecha digital» un reto para el desarrollo de la sociedad del conocimiento. Revista de economía mundial, 8, 119-142.

Hernández Pina, F. (2009). Aprendizaje y competencia. Una nueva mirada. Revista Española de Orientación y Psicopedagogía, 20(3), 312-319.

Hernández Pina, F., Rosário, P., Cuesta Sáez de Tejada, J. D., Martínez Clares, P., \& Ruiz Lara, E. (2006). Promoción del aprendizaje estratégico y competencias de aprendizaje en estudiantes de primero de universidad: Evaluación de una intervención. Revista de Investigación Educativa, 24(2), 615-631.

Hernández Serrano, M. J. (2009). Estrategias de búsqueda de información para la generación de conocimiento en red. Salamanca: Ediciones Universidad de Salamanca.

Hernández Serrano, M. J., \& Fuentes Agustí, M. (2011). Aprender a informarse en la red: ¿son los estudiantes eficientes buscando y seleccionando la información? Teoría de la Educación: Educación y Cultura en la Sociedad de la Información, 12(1), 47-78.

Herring, J. E. (1996). Teaching information skills in schools. London: Library Association. 
Herring, J. E., Tarter, A.-M., \& Naylor, S. (2002). An evaluation of the use of the PLUS model to develop pupils' information skills in a secondary school. School Libraries Worldwide, 8(1), 1-24.

Hopkins, W. G. (2000). A new view of statistics. A new view of statistics. Recuperado a partir de http://www.sportsci.org/resource/stats/

Horton, F. W., \& UNESCO. (2008). Understanding information literacy a primer. Francia: UNESCO. Recuperado a partir de http://unesdoc.unesco.org/images/0015/001570/157020e.pdf i2010 High Level Group. (2009). Benchmarking digtal Europe 2011-2015. A conceptual framework. Visby (Sweden): European Comission.

Iglesias Fernández, C., Llorente Heras, R., \& Dueñas Fernández, D. (2010). Diferencias de género en el empleo TIC. Cuadernos de Economía, 33(92), 105-137.

INE. (2008). Indicadores sociales. Instituto Nacional de Estadística. Recuperado a partir de http://www.ine.es/jaxi/menu.do?type=pcaxis\&path=\%2Ft25\%2Fp444\&file=ine base $\& L=0$

INE. (2009). Encuesta sobre equipamiento y uso de tecnologías de la información y comunicación en los hogares. Instituto Nacional de Estadística.

Jansen, B. J., \& McNeese, M. D. (2005). Evaluating the effectiveness of and patterns of interactions with automated searching assistance: Research Articles. Journal of the American Society for Information Science and Technology, 56(14), 14801503.

Jarson, J. (2010). Information literacy and higher education. College and Research Libraries News, 71(10), 534-538. 
Jeong, S.-H., Cho, H., \& Hwang, Y. (2012). Media literacy interventions: a meta-analytic review. Journal of Communication, 62(3).

Jiménez Fernández, C., García Llamas, J. L., Álvarez González, B., \& Quintanal Díaz, J. (2012). investigación y educación en un mundo en red. Madrid: McGraw Hill. Joaristi Olariaga, L., \& Lizasoain Hernández, L. (1999). Análisis de correspondencias. Madrid: La Muralla.

Joaristi Olariaga, L., Lizasoain Hernández, L., \& Gamboa Ruiz de Eguilaz, E. (2012). Construcción y validación de un instrumento de medida del Nivel Socioeconómico y Cultural (NSE) de estudiantes de educación primaria y secundaria. Bordón. Revista de pedagogía, 64(2), 151-172.

Johnson, D. W., Johnson, R. T., \& Holubec, E. J. (1999). El aprendizaje cooperativo en el aula. Buenos Aires: Paidos Argentina.

Johnston, B., \& Webber, S. (2003). Information literacy in higher education: a review and case study. Studies in Higher Education, 28(3), 335-352.

Jones, B., \& Goff, M. (2011). Learning to live with data deluge and what that means for educators. Teoría de la Educación: Educación y Cultura en la Sociedad de la Información, 12(1), 9-27.

Juanes de Toledo, B., \& Ruiz-Canela Cáceres, J. (2008). ¿Es tan efectivo el aprendizaje por Internet como el aprendizaje presencial? Evidencias en pediatría, 4(4), 1215.

Jukes, I., Dosaj, A., \& Macdonald, B. (2000). NetSavvy: building information literacy in the classroom. Cambridge: Corwin Press.

Kabachinski, J. (2004). Coping with information fatigue syndrome. Biomed Instrum Technol, 38(3), 209-12. 
Kaiser, H. F. (1960). The application of electronic computers to factor analysis. Educational and Psychological Measurement, 20(1), 141-151.

Kaiser, H. F. (1974). An index of factorial simplicity. Psychometrika, 39(1), 31-36.

Kalantzis, M., \& Cope, B. (2005a). Learning by design. Melbourne Aus.: Victorian Schools Innovation Commisstion.

Kalantzis, M., \& Cope, B. (2005b). Learning by design. Melbourne: Victorian Schools Innovation Commisstion.

Kellner, D. (2004). Technological transformation, multiple literacies, and the revisioning of education. E-Learning, 1(1), 9-37.

Kerlinger, F., \& Lee, H. (1999). Foundations of behavioral research (004 ed.). Wadsworth Publishing.

Kerlinger, F., \& Lee, H. (2002). Investigación del comportamiento, métodos de investigación en Ciencias Sociales. México: McGrawHill.

Kesten, A. (2012). Difficulties of teaching media literacy course for a social studies teacher: A case study. Energy Education Science and Technology Part B-Social and Educational Studies, 4(2), 1131-1142.

Kline, R. (2005). Principles and practice of structural equation modeling. New York: Guilford Press.

Koltay, T. (2009). Abstracting: information literacy on a professional level. Journal of Documentation, 65(5), 841-855.

Kong, S. C., \& Li, K. M. (2009). Collaboration between school and parents to foster information literacy: Learning in the information society. Computers \& Education, 52(2), 275-282. 
Kuder, G., \& Richardson, M. (1937). The theory of the estimation of test reliability. Psychometrika, 2(3), 151-160.

Kuhlthau, C. (1989). Facilitating information seeking through cognitive modeling of the search process. A library studies research project. New Jersey: Rutgers.

Kuhlthau, C. (2002). Teaching the library research process. Lanham (Maryland): Scarecrow Press.

Kuiper, E., Volman, M., \& Terwel, J. (2009). Developing Web literacy in collaborative inquiry activities. Computers \& Education, 52(3), 668-680.

Kurbanoglu, S. S., Akkoyunlu, B., \& Umay, A. (2006). Developing the information literacy self-efficacy scale. Journal of Documentation, 62(6), 730-743.

Lamb, A., \& And Others. (1997). Wondering, wiggling, and weaving: A new model for project and community-based learning on the web. Learning \& Leading with Technology, 24(7), 6-13.

Lankshear, C., \& knobel, A. (2008). Nuevos alfabetismos su práctica cotidiana y el aprendizaje en el aula. Madrid: Morata.

Lau, J. (2007). Directrices sobre desarrollo de habilidades informativas para el aprendizaje permanente. México: IFLA. Recuperado a partir de http://www.ifla.org/files/assets/information-literacy/publications/iflaguidelines-es.pdf

Lau, J., \& Cortés, J. (2009). Habilidades informativas: convergencia entre ciencias de información y comunicación. Comunicar, 16, 21-30.

Laxman, K. (2010). A conceptual framework mapping the application of information search strategies to well and ill-structured problem solving. Computers \& Education, 55(2), 513-526. 
Leguízamo León, A. V., \& García Carrasco, J. (2011). Semántica de las búsquedas de información en entornos virtuales de formación. Teoría de la Educación: Educación y Cultura en la Sociedad de la Información, 12(1), 80-97.

Lent, R. W. (1994). Toward a unifying social cognitive theory of career and academic interest, choice, and performance. Journal of Vocational Behavior, 45(1), 79122.

Levene, H. (1960). Robust tests for equality of variances. En I. Olkin, S. G. Ghurye, W. Hoeffding, W. G. Madow, \& H. B. Mann (eds.), Contributions to Porbability and Statistics: Essays in Honor of Harold Hotelling (pp. 278-292). Standford, California: Standford University Press.

Levine, K. (1990). Futuro de la alfabetización y alfabetizaciones del futuro. Barcelona: Oficina Internacional de Educación, Centre UNESCO de Catalunya.

Likert, R. (1932). A technique for the measurement of attitudes. Archives of Psychology, 22(140), 1-55.

Likert, R. (1974). A method of constructing an attitude scale. En G. M. Maranell (ed.), Scaling; A Sourcebook for Behavioral Scientists (pp. 233-243). Chicago: Aldine. Liu, X., Liu, H., Bao, Z., Ju, B., \& Wang, Z. (2010). A web-based self-testing system with some features of Web 2.0: Design and primary implementation. Computers \& Education, 55(1), 265-275.

Lizasoain Hernández, L., \& Joaristi Olariaga, L. (2000). El análisis de datos en la evaluación de programas educativos. Revista de investigación educativa, 18(2), $357-380$.

Lizasoain Hernández, L., \& Joaristi Olariaga, L. (2010). Estudio diferencial del rendimiento académico en lengua española de estudiantes de Educación 
Secundaria de Baja California (México). Revista Iberoamericana de Evaluación Educativa, 3(3), 115-134.

Lonsdale, M., \& McCurry, D. (2004). Literacy in the new millennium. Adelaide: NCVER. López González, E., Miranda Páez, J., \& Galante Guille, R. (1993). Análisis de datos en ciencias del comportamiento y educación. Málaga: Universidad de Málaga.

Lorigo, L., Pan, B., Hembrooke, H., Joachims, T., Granka, L., \& Gay, G. (2006). The influence of task and gender on search and evaluation behavior using Google. Information Processing and Management, 42(4), 1123-1131.

Lucero Fustes, F. M., González Gómez, J. J., \& Cubo Delgado, S. (2003). Perspectiva pedagógica de los multimedia. Revista Española de Pedagogía, 61(225), 309336.

Luengo Navas, J. J., Luzón Trujillo, A., \& Torres Sánchez, M. (2008). Las reformas educativas basadas en el enfoque por competencias: una visión comparada. Editorial. Profesorado, Revista de Currículum y formación del Profesorado, 12(3). Recuperado a partir de http://www.ugr.es/local/recfpro/rev123ed.pdf Mackenize, A., Howard, H., Makin, L., \& Ryan, C. (2002). The Big Blue. Information skills for students. Final Report. Leeds: JISC Project, Manchester Metropolitan University, University of Leeds. Recuperado a partir de http://www.library.mmu.ac.uk/bigblue/pdf/finalreportful.pdf

Mackey, T., \& Ho, J. (2005). Implementing a convergent model for information literacy: combining research and web literacy. Journal of Information Science, 31(6), 541-555.

Mackey, T., \& Jacobson, T. E. (2011). Reframing information literacy as a metaliteracy. College \& Research Libraries, 72(1), 62 -78. 
Madden, A. D., Eaglestone, B., Ford, N. J., \& Whittle, M. (2006). Search engines a first step to finding information: preliminary findings from a study of observed searches. Information Research, 12(2). Recuperado a partir de http://informationr.net/ir/12-2/paper294.html

Maitaouthong, T., Tuamsuk, K., \& Tachamanee, Y. (2012). The roles of university libraries in supporting the integration of information literacy in the course instruction. Malaysian Journal of Library \& Information Science, 17(1), 51-64.

Majó i Cruzate, J., \& Marqués, P. (2002). La revolución educativa en la era internet. Barcelona: CissPraxis.

Marcelo Garcia, C. (2009). Formalidad e informalidad en el proceso de aprender a enseñar. Revista de educación, (350), 31-55.

Markauskaite, L. (2006). Towards an integrated analytical framework of information and communications technology literacy: from intended to implemented and achieved dimensions. Information Research, 11(3). Recuperado a partir de http://informationr.net/ir/11-3/paper252.html

Marland, M., British Library, \& Schools Council (Great Britain). (1981). Information skills in the secondary curriculum: the recommendations of a working group. London: Methuen Educational.

Martí Lahera, Y. (2007). Alfabetización informacional: análisis y gestión. Buenos Aires: Alfagrama.

Martínez Bonafé, J. (2012). En las escuela, el futuro ya no es el pasado, o sí. Nuevos currículos, nuevos materiales. En B. Jarauta Borrasca, F. Imbernón, \& J. M. Álvarez Méndez (eds.), Pensando en el futuro de la educación: una nueva escuela para el siglo XXII (pp. 101-112). Barcelona: Graó. 
Martínez Caro, E. (2008). E-learning: un análisis desde el punto de vista del alumno.

RIED: revista iberoamericana de educación a distancia, 11(2), 151-168.

Martínez Clares, P., \& Echeverría Samanes, B. (2009). Formación basada en competencias. Revista de Investigación Educativa, 27(1), 125-147.

Martínez Ramos, M., \& Alvira Martín, F. R. (1985). El efecto de los entrevistadores sobre las respuestas de los entrevistados en encuestas de opinión. Reis: Revista española de investigaciones sociológicas, (29), 219-258.

Marzal García-Quismondo, M. Á. (2010). La evaluación de los programas de alfabetización en información en la educación superiro: estrategias e instrumentos. Revista de Universidad y Sociedad del Conocimiento, 7(2), 28-38.

McClelland, D. C. (1973). Testing for competence rather than for «intelligence». American Psychologist American Psychologist, 28(1), 1-14.

McClelland, D. C. (1998). Identifying competencies with behavioural-event interviews. Psychological Science, 9(5), 331-339.

McLuhan, M. (1967). The medium is the massage. New York: Bantam Books.

McLuhan, M. (1969). La compresión de los medios como las extensiones del hombre. México, D.F: Diana.

McLuhan, M. (1987). Understanding media: the extensions of man. London: Routledge. MEC. (2007). Estudio de enseñanzas anteriores a la universidad. MEC.

MEC. (2009). Estadísticas de las enseñanzas no universitarias. Recuperado a partir de http://www.educacion.es/mecd/jsp/plantilla.jsp?id=310\&area=estadisticas\&co ntenido=/estadisticas/educativas/eenu/avances/Curso08-09/avances.html 
Medina Moya, J. L., Jarauta Borrasca, B., \& Urquizu Sánchez, C. (2005). Evaluación del impacto de la formación del profesorado universitario novel: un estudio cualitativo. Revista de Investigación Educativa, 23(1), 205-238.

Mendenhall, W., Scheaffer, R. L., \& Ott, R. L. (2006). Elementos de muestreo. Barcelona: Paraninfo.

Méndez Paz, C. (2005). La implantación del sistema de créditos europeo como una oportunidad para la innovación y mejora de los procedimientos de enseñanza/aprendizaje en la universidad. Revista Española de Pedagogía, 63(230), 43-62.

Miraut Andrés, D. (2011). El sueño de Isaac y la transformación de los sistemas educativos en la sociedad de la información. Teoría de la Educación: Educación y Cultura en la Sociedad de la Información, 12(1), 240-266.

Moles, A. A. (1975). La comunicación y los mass media: las ideas, las obras, los hombres. Bilbao: Mensajero.

Monereo, C. (2005). Internet y competencias básicas: aprender a colaborar, a comunicarse, a participar, a aprender. Barcelona: Graó.

Monereo, C., \& Badia, A. (2012). La competencia informacional desde una perspectiva psicoeducativa: enseñanza basada en la resoluciónd e problemas prototípicos y emergentes. Revista española de Documentación Científica, ( ${ }^{\circ}$ Monográfico), 75-99.

Monereo, C., \& Coll, C. (2008). Psicología de la educación virtual. Madrid: Morata. Mood, A. (1954). On the asymptotic efficiency of certain non-parametric two-sample tests. The Annals of Mathematical Statistics, 25, 514-522. 
Mora Corral, A. J. (2010). Determinantes del abandono escolar en Cataluña: más allá del nivel socioeconómico de las familias. Revista de educación, (1), 171-190.

Morales Vallejo, P. (2000). Medición De actitudes En psicología y educación:

construcción de escalas y problemas metodológicos. Madrid: Universidad Pontificia Comillas.

Morales Vallejo, P., Urosa, S., \& Blanco, A. (2003). Construcción de escalas de actitudes tipo likert: una guía práctica. Madrid: La Muralla.

Moreno Olivos, T. (2009). Competencias en educación superior: un alto en el camino para revisar la ruta de viaje. Perfiles educativos, 31(124), 69-92.

Morin, E. (2000). La mente bien ordenada: repensar la reforma, reformar el pensamiento. Barcelona: Seix Barral.

Mulder, M., Weigel, T., \& Collings, K. (2008). El concepto de competencia en el desarrollo de la educación y formación profesional en algunos Estados miembros de la UE: un análisis crítico. Profesorado, Revista de Currículum y formación del Profesorado, 12(3). Recuperado a partir de www.ugr.es/local/recfpro/rev123ART6.pdf

Mullola, S., Jokela, M., Ravaja, N., Lipsanen, J., Hintsanen, M., Alatupa, S., \& Keltikangas-Jarvinen, L. (2011). Associations of student temperament and educational competence with academic achievement: The role of teacher age and teacher and student gender. Teaching and Teacher Education, 27(5), 942951.

Muthén, B., \& Kaplan, D. (1985). A comparison of some methodologies for the factor analysis of non-normal Likert variables. British Journal of Mathematical and Statistical Psychology, 38(2), 171-189. 
National Forum of Information Literacy. (2005). Faros para la sociedad de la información, declaración de Alejandría sobre la alfabetización informacional y el aprendizaje a lo largo de la vida. Alejandría: UNESCO.

NCLIS. (2003). Declaración de Praga: hacia una sociedad alfabetizada en información. Praga: NCLIS.

Nielsen, J. (1989). Coordinating user interfaces for consistency. Morgan Kaufmann.

Nóvoa, A. (2009). Para una formación de profesores construida dentro de la profesión. Revista de educación, (350), 203-218.

O’Dwyer, L. M., Russell, M., \& Bebell, D. J. (2005). Identifying teacher, school and district characteristics associated with elementary teachers' use of technology: a multilevel perspective. J. Educational Computing Research, 33(4), 369-393.

O'Farrill, R. (2008). Information Literacy and knowledge management: preparations for an arranged marriage. Libri, 58(3), 155-171.

OCDE. (2004a). Marcos teóricos de PISA 2003. Conocimientos y destrezas en Matemáticas, Lectura, Ciencias y Solución de problemas. Madrid: Ministerio de Educación y Ciencia.

OCDE. (2004b). Completing the foundation for lifelong learning. An OECD survey of upper secondary schools. Centre For Educational Research And Innovation. Recuperado a partir de http://www.openisbn.com/preview/9789264103726/ OCDE. (2005). Are students ready for a technology-rich world?: what PISA studies tell us (programme for international student assessment). Paris: OECD. Recuperado a partir de http://www.google.es/url?sa=t\&rct=j\&q=\&esrc=s\&source=web\&cd=6\&cts=133 1301010086\&ved=0CFkQFjAF\&url=http\%3A\%2F\%2Fdialnet.unirioja.es\%2Fservl 
et\%2Ffichero_articulo\%3Fcodigo\%3D2793217\&ei=vwlaT9GFO-KP0AWz4-

HPDQ\&usg=AFQjCNGOOq8zREVxvhysENT6kIZf-

h_NNg\&sig2=lhvvwP8XSzM7TGRSTlueCA

OCDE. (2011). PISA 2009 results students on line: digital technologies and performance.

Paris: OECD,. Recuperado a partir de

http://dx.doi.org/10.1787/9789264112995-en

OCDE. (2012). PISA 2009 technical report. Paris: OECD Publishing. Recuperado a partir

de

http://proxy.library.carleton.ca/login?url=http://dx.doi.org/10.1787/97892641

67872-en

Ohland, M., Brawner, C., Camacho, M., Layton, R., Long, R., Lord, S., \& Wasburn, M.

(2011). Race, gender, and measures of success in engineering education.

Journal of engineering education, 100(2), 225-252.

Oliver, R., \& Perzylo, L. (1994). Childrens information skills. making effective use of multimedia sources. Educational \& Training Technology International, 31(3), 219-230.

Ong, W. J. (1982). Orality and literacy: the technologizing of the word. London:

Routledge.

Organización Internacional del Trabajo. (2003). Aprender y formarse para trabajar en la sociedad del conocimiento. Recuperado febrero 2, 2010, a partir de http://www.oit.org/public/spanish/employment/skills/hrdr/report/rep_toc.ht

$\mathrm{m}$

Osterlind, S. J. (2010). Modern measurement: theory, principles, and applications of mental appraisal. Boston; Madrid [etc.]: Pearson. 
Ozkul, H., \& Kaya, H. (2009). The views of nursing students about their own information literacy. New Educational Review, 19(3-4), 45-57.

Pablos Pons, J. de. (2010). Universidad y sociedad del conocimiento. Las competencias infomacionales y digitales. Revista de Universidad y Sociedad del Conocimiento, 7(2), 6-16.

Pahl, K., \& Rowsell, J. (Eds.). (2006). Travel notes from the new literacy studies: instances of practice. Bristol: Multilingual Matters.

Pappas, M., \& Tepe, A. E. (2002). Pathways to knowledge and inquiry learning. Greenwood Village: Libraries Unlimited.

Pasadas Ureña, C. (2001). Aptitudes para el acceso y uso de la información en la enseñanza superior: la postura de Sconul. Boletín de la Asociación Andaluza de Bibliotecarios, 16(62), 63-77.

Pasadas Ureña, C. (2008). Multialfabetismo y alfabetización informamional crítica: marco de referencia para la función educativa de la biblioteca. En J. A. Gómez Hernández, A. Calderón Rehecho, \& J. A. Magán Wals (eds.), Brecha digital y nuevas alfabetizaciones. El papel de la biblioteca (pp. 59-86). Madrid: Universidad Complutense de Madrid.

Pasadas Ureña, C. (2010a). Multialfabetización y redes sociales en la universidad. Revista de Universidad y Sociedad del Conocimiento, 7(2), 17-27.

Pasadas Ureña, C. (2010b). Multialfabetización, aprendizaje a lo largo de la vida y bibliotecas. Boletín de la asociación andaluza de bibliotecarios, (98-99), 11-38.

Pavié Nova, A. (2011). Formación docente: hacia una definición del concepto de competencia profesional docente. Revista electrónica interuniversitaria de formación del profesorado, 14(1), 67-80. 
Pearl, J. (1995). Causal inference from indirect experiments. Artificial Intelligence in Medicine Artificial Intelligence in Medicine, 7(6), 561-582.

Pearl, J. (2003). Statistics and causal inference: a review. Test, 12(2), 281-345.

Peña-López, I. (2010a). From laptops to competences: bringing the digital divide in education. Revista de Universidad y Sociedad del Conocimiento, 7(1), 21-32.

Peña-López, I. (2010b). Framing the digital divide in higher education. Revista de Universidad y Sociedad del Conocimiento, 7(1), 2-5.

Peralta, O. A. (1997). Estilos de interacción cognitiva materno-infantil en una situación de resolución de problemas en función del nivel socioeconómico y de la edad del niño. Infancia y Aprendizaje, (80), 85-98.

Pérez Gómez, Á. I. (2012). Educarse en la era digital. Madrid: Morata.

Pérez Sánchez, A. M., Gilar Corbí, R., \& González Gómez, C. (2007). Pensamiento y formación del profesorado de Educación Secundaria. Electronic journal of research in educational psychology, 5(12), 307-324.

Pérez Tornero, J. M. (2008). La sociedad multipantallas: retos para la alfabetización mediática. Comunicar, (31), 15-25.

Perrenoud, P. (2004). Diez nuevas competencias para enseñar: invitación al viaje. Barcelona: Graó.

Perrenoud, P. (2012). Cuando la escuela pretende preparar para la vida: ¿desarrollar competencias o enseñar otros saberes? Barcelona: Graó.

Pesquero Franco, E., Sánchez Martín, M. E., González Ballesteros, M., Martín del Pozo, R., Guardia González, S., Cervelló Collazos, J., ... Varela Nieto, M. P. (2008). Las competencias profesionales de los maestros de Primaria. Revista Española de Pedagogía, 66(241), 447-466. 
Piaget, J. (1973). Estudios de psicología genética. Buenos: Emecé Editores.

Piaget, J. (1975). Seis estudios de psicología. Barcelona; México: Seix Barral.

Picardo Joao, O. (2002). Pedagogía informacional. Edutec. Revista Electrónica de Tecnología Educativa, (15).

Pifarré, M., Sanuy, J., Vendrell, C., \& Gòdia, S. (2009). Internet en la educación secundaria: pensar, buscar y construir conocimiento en la red. Lleida: Milenio.

Pimienta, D. (2008). Brecha digital, brecha social, brecha paradigmática. En J. A. Gómez Hernández, A. Calderón Rehecho, \& J. A. Magán Wals (eds.), Brecha digital y nuevas alfabetizaciones. El papel de la biblioteca (pp. 11-21). Madrid: Biblioteca de la Universidad Complutense de Madrid.

Pinto Molina, M. (2009). Design of the IL-HUMASS survey on information literacy in higher education: A self-assessment approach. Journal of Information Science, 36(1), 86-103.

Pinto Molina, M., Cordón, J. A., \& Díaz, R. G. (2010). Thirty years of information literacy (1977-2007): A terminological, conceptual and statistical analysis. Journal of Librarianship and Information Science, 17.

Pinto Molina, M., \& Puertas Valdeiglesias, S. (2012). Autoevaluación de la competencia informacional en los estudios de psicología desde la percepción del estudiante. Anales de Documentación, 15(2), 1-15.

Pinto Molina, M., Sales, D., \& Osorio, P. (2008). Biblioteca universitaria, CRAI y alfabetización informacional. Gijón: Trea.

Pinto Molina, M., \& Uribe Tirado, A. (2012). Las bibliotecas públicas híbridas en el marco de la Alfabetización Informacional. Revista española de Documentación Científica, ( $\mathrm{N}^{\circ}$ Monográfico), 136-168. 
Pinto Molina, M., Uribe Tirado, A., Gómez Díaz, R., \& Cordón, J. A. (2011). La producción científica internacional sobre competencias informacionales e informáticas: tendencias e interrelaciones. Información, cultura y sociedad, (25), 29-62.

Pomés, J., \& Argüelles, B. (1991). Análisis de ítems de opción múltiple. Zaragoza: Universidad de Zaragoza.

Pozo, J. I., Scheuer, N., Puy Pérez, M., Mateos, M., Martín, E., \& Cruz, M. (2006). Nuevas formas de pensar la enseñanza y el aprendizaje: las concepciones de profesores y alumnos. Barcelona: Graó.

Prendes Espinosa, M. P., \& Castañeda Quintero, L. (2010). Competencias para el uso de TIC de los futuros maestros. Comunicar, 18(35), 175-182.

Prensky, M. (2001a). Digital natives, digital immigrants part 1. On The Horizon - The Strategic Planning Resource for Education Professionals, 9(5), 1-6.

Prensky, M. (2001b). Digital natives, digital immigrants part 2: do they really think differently? On The Horizon - The Strategic Planning Resource for Education Professionals, 9(6), 1-6.

Prensky, M. (2005). Listen to the natives. Educational Leadership, 63(4), 8-13.

Prensky, M. (2009). Homo sapiens digital: from digital immigrants and digital natives to digital wisdom. Innovate: Journal of Online Education, 5(3).

Probert, E. (2009). Information literacy skills: Teacher understandings and practice. Computers \& Education, 53(1), 24-33.

Puustinen, M., \& Rouet, J.-F. (2009). Learning with new technologies: Help seeking and information searching revisited. Computers \& Education, 53(4), 1014-1019.

Quintanilla, M. A. (1992). Tecnología: un enfoque filosófico. Madrid: Fundesco. 
Rangachari, P. K., \& Rangachari, U. (2007). Information literacy in an inquiry course for first-year science undergraduates: a simplified 3C approach. Advances in Physiology Education, 31(2), 176-179.

Resnis, E., Gibson, K., \& Hartsell-Gundy, A. (2010). Information literacy assessment: a case study at Miami University. New Library World, 111(7/8), 287-301.

Richter, T., Naumann, J., \& Groeben, N. (2000). Attitudes toward the computer: construct validation of an instrument with scales differentiated by content. Computers in Human Behavior, 16(5), 473-491.

Rivas, M. R. (2004). ¿Es necesaria la formación técnica y didáctica sobre tecnologías de la información y la comunicación? Argumentos del profesorado de la Universidad de Vigo. Pixel-Bit. Revista de Medios y Educación, (24), 43-58.

Robbins, S. B., Lauver, K., Le, H., Davis, D., Langley, R., \& Carlstrom, A. (2004). Do psychosocial and study skill factors predict college outcomes? a metaanalysis. Psychological Bulletin, 130(2), 261-288.

Robertson, R. (2003). Glocalización: tiempo-espacio y homogeneidad-heterogeneidad. En J. C. Monedero (ed.), Cansancio del leviatán: problemas políticos de la mundialización. (pp. 261-284). Madrid: Trotta.

Rodríguez Conde, M. J. (2011). La garantía de la calidad, base de la movilidad. REDU: Revista de Docencia Universitaria, 9(3), 99-117.

Rodríguez Conde, M. J., Olmos Migueláñez, S., \& Martínez Abad, F. (2012).

Propiedades métricas y estructura dimensional de la adaptación española de una escala de evaluación de competencia informacional autopercibida (ILHUMASS). Revista de Investigación Educativa, 30(2), 347-365. 
Rodríguez Conde, M. J., Olmos Migueláñez, S., Pinto Molina, M., Martínez Abad, F., \& García Riaza, B. (2011). Informational literacy and information and communication technologies use by secondary education students in spain: a descriptive study. Contemporary Issues in Education Research (CIER), 4(4), 1-12.

Rosales, J., Sánchez Miguel, E., \& Pérez, J. R. G. (2004). Interacción profesor-alumno y comprensión de textos: el papel del profesor en la organizaciónde la responsabilidad conjunta. Revista de educación, (334), 347-360.

Rottinghaus, P. J., Larson, L. M., \& Borgen, F. H. (2003). The relation of self-efficacy and interests: a meta-analysis of 60 samples. Journal of Vocational Behavior, 62(2), 221-236.

Rowlands, I. (2008). The Google generation: the information behaviour of the researcher of the future. Aslib Proceedings, 60(4), 290-310.

Rubio, R., Martín, S., \& Morán, S. (2010). Collaborative web learning tools: Wikis and blogs. Computer Applications in Engineering Education, 18(3), 502-511.

Ruiz, J. (2005). Dirección, administración y organización de proyectos de e-learning. Revista de Universidad y Sociedad del Conocimiento, 2(1), 32-43.

Ruiz Palomero, J., \& Sánchez Rodríguez, J. (2010). El género como factor influyente en la estrategia para integrar las TIC en la práctica docente. Pixel-Bit. Revista de Medios y Educación, 37, 67-76.

Saarinen, T. (2005). "Quality» in the Bologna Process: from «competitive edge» to quality assurance techniques. European Journal of Education, 40(2), 189-204.

Sabán Vera, C., \& Monclús Estella, A. (2008). La enseñanza en competencias en el marco de la educación a lo largo de la vida y la sociedad del conocimiento. Revista Iberoamericana de Educación, (47), 24. 
Saito, H., \& Miwa, K. (2007). Construction of a learning environment supporting learners' reflection: A case of information seeking on the Web. Computers \& Education, 49(2), 214-229.

Sakaiya, T., \& Fields, G. (1991). The knowledge-value revolution or a history of the future. New York: Kodansha America.

Sánchez Asín, A., Boix Peinado, J. L., \& Jurado de los Santos, P. (2009). La sociedad del conocimiento y las TICs: una inmejorable oportunidad para el cambio docente. Pixel-Bit: Revista de medios y educación, (34), 179-204.

Sánchez Burón, A., Rodríguez, L., \& Fernández Martín, M. P. (2009). Los adolescentes en la red. Estudio sobre los hábitos de los adolescentes en el uso de internet y redes sociales. Madrid: Universidad Camilo José Cela.

Sánchez Miguel, E., Rosales, J., \& Cañedo, I. (1998). El discurso expositivo en el aula: ¿Realmente comprenden los alumnos lo que sus profesores creen? Infancia y Aprendizaje: Journal for the Study of Education and Development, (81), 65-81.

Sanderson, H. (2011). Using learning styles in information literacy: critical considerations for librarians. Journal of Academic Librarianship, 37(5), 376-385.

Savolainen, R., \& Kari, J. (2006). Facing and bridging gaps in Web searching. Information Processing and Management, 42(2), 519-537.

Sayers, R., \& UNESCO. (2006). Principles of awareness-raising for information literacy: a case study. Bangkok: UNESCO.

Scardamalia, M. (2004). Reflections on the transformation of education for the knowledge age. Teoría de la Educación: Educación y Cultura en la Sociedad de la Información, 5. 
SCONUL. (2001). Information skills in higher education: a SCONUL position paper. London: SCONUL.

SCONUL. (2004). Learning outcomes and information literacy. U.K.: SCONUL.

Schmidt, V., Barreyro, J. P., \& Maglio, A. L. (2010). Escala de evaluación del funcionamiento familiar FACES III: ¿Modelo de dos o tres factores? Escritos de Psicología, 3(2), 30-36.

Schön, D. A. (1984). The reflective practitioner: how professionals think in action (1. ${ }^{a}$ ed.). Basic Books.

Schön, D. A. (1987). La formación de profesionales reflexivos: hacia un nuevo diseño de la enseñanza y el aprendizaje en las profesiones. Barcelona: Paidós.

Schreiber, J. B., Nora, A., Stage, F. K., Barlow, E. A., \& King, J. (2006). Reporting structural equation modeling and confirmatory factor analysis results: a review. Journal of Educational Research, 99(6), 323-337.

Selwyn, N. (2010). Degrees of digital division: reconsidering digital inequalities an contemporary higher education. Revista de Universidad y Sociedad del Conocimiento, 7(1), 33-42.

Serrano Angulo, J. (2012). Aplicación on-line y tratamiento informático de cuestionarios. Revista española de pedagogía, 70(251), 61-76.

Siegel, S. (1970). Estadística no paramétrica: aplicada a las ciencias de la conducta. México: Trillas.

Sigalés, C., \& Mominó, J. M. (2004). La escuela en la sociedad red. Internet en el ámbito educativo no universitario. Barcelona: Generalitat de Catalunya. 
Sigalés, C., Mominó, J. M., Meneses, J., \& Badia, A. (2009). La integración de Internet en la educación escolar española: situación actual y perspectivas de futuro. Barcelona: Planeta.

Silva Zamora, C., \& Schiattino Lemus, I. (2008). Modelos de ecuaciones estructurales ¿Qué es eso? Ciencia \& Trabajo, 29, 106-110.

Snyder, I. (2004). Alfabetismos digitales: comunicación, innovación y educación en la era electrónica. Málaga: Ediciones Aljibe.

Spring, H. (2010). Health professionals of the future: teaching information skills to the Google generation. Health Information \& Libraries Journal, 27(2), 158-162.

Staley, S., Branch, N. A., \& Hewitt, T. L. (2010). Standardised library instruction assessment: An institution-specific approach. Information Research, 15(3). Recuperado a partir de http://informationr.net/ir/15-3/paper436.html

Suárez Rodríguez, J. M., Almerich, G., Gargallo López, B., \& Aliaga, F. M. (2010). Las competencias en TIC del profesorado y su relación con el uso de los recursos tecnológicos. Archivos Analíticos de Políticas Educativas, 18, 1-33.

Tapscott, D. (1998). Growing up digital: the rise of the net generation. New York: McGraw-Hill.

Tearle, P. (2003). ICT implementation: what makes the difference? British Journal of Educational Technology, 34(5), 567-583.

Tedesco, J. C. (2007). Los pilares de la educación del futuro. Revista Iberoamericana de Educación, 43(5). Recuperado a partir de http://oei.es/noticias/spip.php?article521 
Tedesco, J. C. (2012). Escuela y sociedad en el siglo XXII. En B. Jarauta Borrasca, F. Imbernón, \& J. M. Álvarez Méndez (eds.), Pensando en el futuro de la educación: una nueva escuela para el siglo XXII (pp. 23-36). Barcelona: Graó.

Tejedor Tejedor, F. J. (1999). Análisis de varianza: introducción conceptual y diseños básicos. Madrid: La Muralla.

Tejedor Tejedor, F. J. (2006). Análisis inferencial de datos en educación. Madrid: La Muralla.

Tejedor Tejedor, F. J., \& García-Valcarcel, A. (2006). Competencias de los profesores para el uso de las TIC en la ensenanza. Análisis de sus conocimientos y actitudes. Revista Española de Pedagogía, 64(233), 21-43.

Tejedor Tejedor, F. J., García-Valcarcel, A., \& Prada, S. (2009). Medida de actitudes del profesorado universitario hacia la integración de las TIC. Comunicar, (33), 115124.

Terigi, F. (2009). La formación inicial de profesores de Educación Secundaria: necesidades de mejora, reconocimiento de sus límites. Revista de educación, (350), 123-144.

Thomas, S. (1998). Information fatigue syndrome. Is there an epidemic? Issues in mental health nursing, 19(6), 523-524.

Tiana Ferrer, A. (2012). Analizar el contexto para obtener el máximo beneficio de la evaluación. Bordón. Revista de pedagogía, 64(2), 13-28.

Tishman, S., Perkins, D. N., \& Jay, E. (1994). The thinking classroom: learning and teaching in a culture of thinking. Boston: Allyn \& Bacon. 
Tonucci, F. (2012). El alumnado en la escuela del mañana. En B. Jarauta Borrasca, F. Imbernón, \& J. M. Álvarez Méndez (eds.), Pensando en el futuro de la educación: una nueva escuela para el siglo XXII (pp. 63-82). Barcelona: Graó.

Torres, E., Marín, L. F., Bustamante, G., Gómez, J. H., \& Barrantes, E. (2002). El concepto de competencia:una mirada interdisciplinar I. Bogotá: Sociedad Colombiana de Pedagogía.

Torres Gordillo, J. J., \& Perera Rodríguez, V. H. (2010). La rúbrica como instrumento pedagógico para la tutorización y evaluación de los aprendizajes en el foro online en educación superior. Pixel-Bit: Revista de medios y educación, (36), 141-149.

Touriñán López, J. M., Oliveira Oliveira, M. E., \& Rodríguez Martínez, A. (2003). La sociedad de la información y las nuevas exigencias en la formación del profesorado. Aula abierta, (81), 57-74.

Traus Boix, A. (2007). Estudio de las prejubilaciones en las empresas. Recuperado a partir de http://www.recercat.net/bitstream/2072/5185/1/TFC-TRAUS2007.pdf

Tubella i Casadevall, I., \& Vilaseca i Requena, J. (2005). Sociedad del conocimiento. Cómo cambia el mundo ante nuestros ojos. Barcelona: Editorial UOC.

UNESCO. (1957). Records of the General Conference. Nueva Delhi: UNESCO. UNESCO. (1976). Recommendation on the development of adult education: adopted by the General Conference at its nineteenth session, Nairobi, 26 November 1976. Paris: UNESCO.

UNESCO. (2001). Latin America and the Caribbean regional report. Panamá: UNESCO. UNESCO. (2005). Towards knowledge societies. Paris: UNESCO. 
UNESCO. (2009). Global report on adult learning and education. Hamburg Germany: UNESCO. Recuperado a partir de http://www.unesco.org/fileadmin/MULTIMEDIA/INSTITUTES/UIL/confintea/pdf /GRALE/grale_en.pdf

Uppenberg, K. (2010). The knowledge economy in Europe. A review of the 2009 EIB Conference in Economics and Finance. Luxembourg: Eupoean Investment Bank.

Uribe Tirado, A. (2008). Diseño, implementación y evaluación de una propuesta formativa en alfabetización informacional mediante un ambiente virtual de aprendizaje a nivel universitario: caso Escuela Interamericana. Universidad de Antioquía, Colombia.

Vaillant Alcalde, D. E. (2009). Formación de profesores de Educación Secundaria: realidades y discursos. Revista de educación, (350), 105-122.

Valentine, J. C., Dubois, D. L., \& Cooper, H. (2004). The relation between self-beliefs and academic achievement: a meta-analytic review. Educational Psychologist, 39(2), 111-133.

Valimaa, J., \& Hoffman, D. (2008). Knowledge society discourse and higher education. Higher Education: The International Journal of Higher Education and Educational Planning, 56(3), 265-285.

Van Helvoort, A. A. J. (Jos). (2010). Impact of recent trends in information and communication technology on the validity of the construct information literacy in higher education. En S. Kurbanoglu, U. Al, P. L. Erdogan, Y. Tonta, \& N. Ucak (eds.), Technological Convergence and Social Networks in Information Management (pp. 61-73). Berlin: Springer-Verlag. 
Vancouver, J. B. (2005). The depth of history and explanation as benefit and bane for psychological control theories. The Journal of Applied Psychology, 90(1), 38-52.

Vargas Sabadías, A. (1995). Estadística descriptiva e inferencial. Cuenca: Universidad de Castilla-La Mancha.

Velasco Juez, M. V. I. (2006). Consecuencias personales en la ruptura de la vida laboral. El caso de Telefónica. Revista de Antropología Iberoamericana, 1(3), 457-478.

Verne, J. (1863). París en el siglo XX. Santiago de Chile (Chile): Andres Bello.

Villa Sánchez, A., \& Poblete Ruiz, M. (2007). Aprendizaje basado en competencias: una propuesta para la evaluación de las competencias genéricas. Bilbao: Universidad de Deusto.

Villa Sánchez, A., \& Poblete Ruiz, M. (2009). Competence-based learning: a proposal for the assessment of generic competences. Bilbao: University of Deusto.

Vivanco, M. (2005). Muestreo estadistico. Diseño y aplicaciones. Editorial Universitaria.

Vygotsky, L. S. (1973). Pensamiento y lenguaje: teoria del desarrollo cultural de las funciones psiquicas. Buenos Aires: La Pleyade.

Vygotsky, L. S. (1979). El desarrollo de los procesos psicológicos superiores. Barcelona: Crítica.

Vygotsky, L. S. (1995). Obras escogidas. Madrid: Visor.

Wagner, D. A. (1998). Alfabetización: construir el futuro. Paris: UNESCO.

Warschauer, M. (2007). Information literacy in the laptop classroom. Teachers College Record, 109(11), 2511-2540.

Weiner, S. A. (2010). Information Literacy: A neglected core competency. Educase Quarterly, 33(1). Recuperado a partir de 
http://www.educause.edu/EDUCAUSE+Quarterly/EDUCAUSEQuarterlyMagazin eVolum/InformationLiteracyANeglectedC/199382

Weis, U. (2001). Aspectos lingüísticos y comunicativos del interfaz de usuario de un software basado en la tecnología de la Web. Tonos digital: Revista electrónica de estudios filológicos, (2). Recuperado a partir de http://dialnet.unirioja.es/servlet/articulo?codigo=1031464

Wen, J. R., \& Shih, W. L. (2008). Exploring the information literacy competence standards for elementary and high school teachers. Computers \& Education, $50(3), 787-806$.

Wertsch, J. V. (1988). Vygotsky and the social formation of mind. Harvard: Harvard University Press.

Wilcoxon, F. (1945). Individual comparisons by ranking methods. Biometrics Bulletin, 1(6), 80-83.

Wildemuth, B. M. (2004). The effects of domain knowledge on search tactic formulation. Journal of the American Society for Information Science and Technology, 55(3), 246-258.

Wilson, C. (2012). Alfabetización mediática e informacional: Proyecciones didácticas. Comunicar, (39), 15-24.

Williams, D., \& Coles, L. (2007). Teachers' approaches to finding and using research evidence: an information literacy perspective. Educational Research, 49(2), 185-206.

Williams, D., \& Wavell, C. (2007). Secondary school teachers' conceptions of student information literacy. Journal of Librarianship and Information Science, 39(4), 199-212. 
Williamson, K. (2009). Information behavior of people in the fourth age: Implications for the conceptualization of information literacy. Library \& information science research., 31(2), 76-83.

Wu, Y. (Ed.). (2011). Advances in computer, communication, control and automation. Berlín: Springer.

Zabala, A., \& Arnau, L. (2007). 11 ideas clave: cómo aprender y enseñar competencias. Barcelona: Graó.

Zelder, N. (2009). Infoglut: Its the disease of the new millennium. How do we treat it? IEEE Spectrum, 46(10), 30-32 52.

Zurkowski, P. (1974). The information service environment: relationships and priorities. Washington D.C.: National Commission on Libraries and Information Science. 
ANEXOS 



\section{ANEXOS}

Anexo I Cuestionario aplicado a los estudiantes de educación secundaria (estudio I)

Anexo II Cuestionario aplicado al futuro profesorado de educación secundaria (estudio I)

Anexo III Programa formativo aplicado en el estudio experimental (estudio II)

Anexo IV Ítems del inventario de evaluación de competencias informacionales (estudio II)

Anexo V Herramienta para la validación del inventario de evaluación (estudio II)

Anexo VI Informes de resultados sobre evaluación de competencias informacionales enviados a las escuelas

Anexo VII Matriz de datos de estudiantes (estudio I)

Anexo VIII Matriz de datos de futuro profesorado (estudio I)

Anexo IX Matriz de datos resultados pretest-postest (estudio II)

Anexo X Matriz de datos encuesta de satisfacción programa formativo (estudio II) 